\title{
DROBIEMS IN BIOLOGY
}

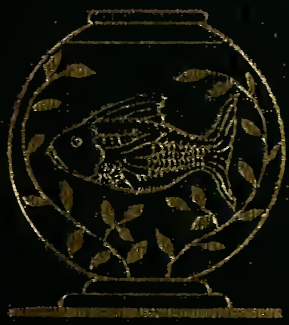

HUNTER 
BOOK $570 . \mathrm{H9} 17$ c. 1

HUNTER \# PROBLEMS IN BIOLOGY

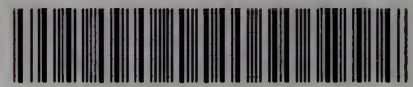

39153001373655 


$$
\text { T: s v? pav }
$$





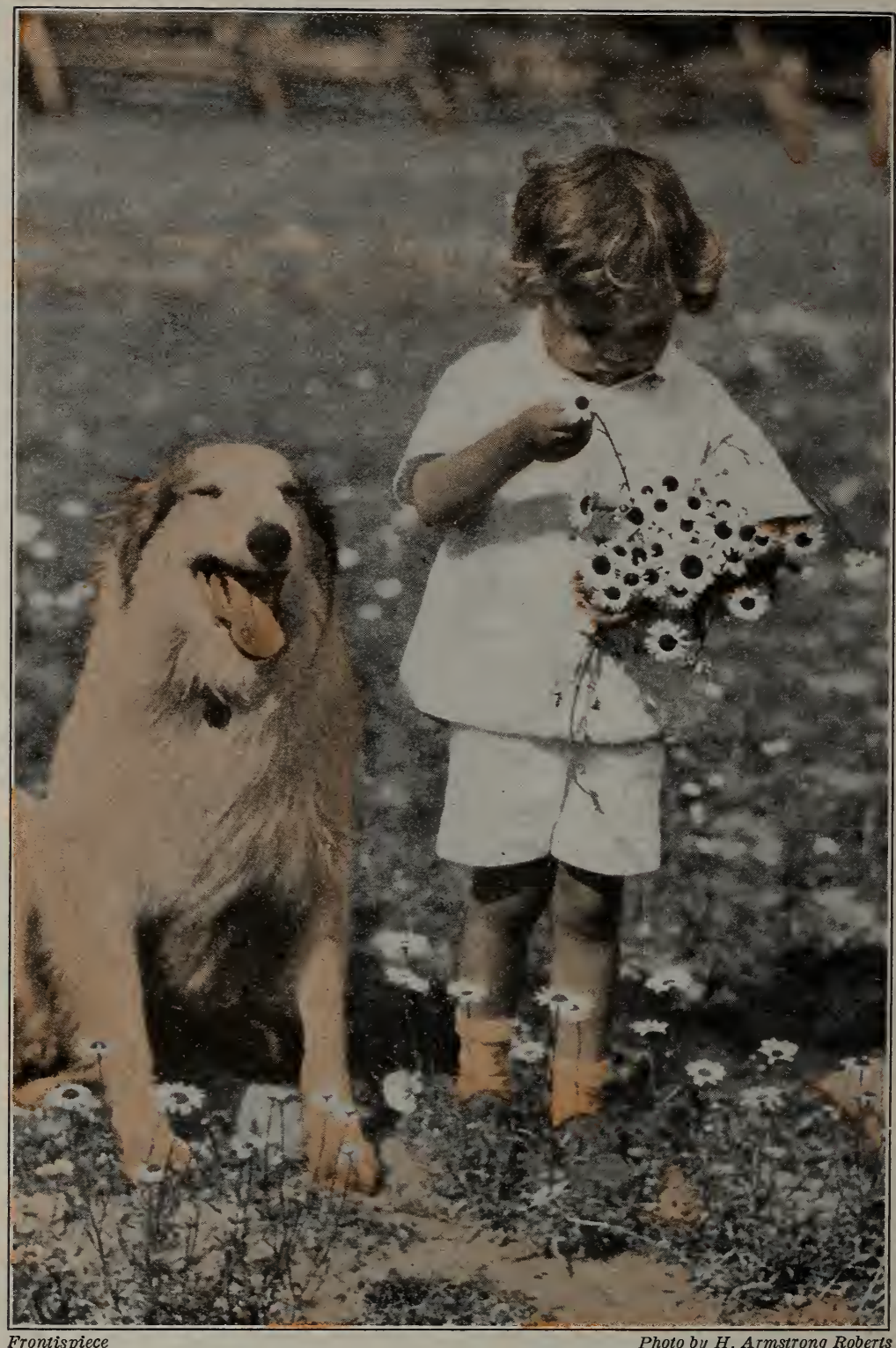

Photo by H. Armstrong Roberts

Biology is the study of plants, animals, and human beings. The out-of-doors is the best classroom and, although the school laboratory has to be used for class work, one can go to nature to confirm the truths that are learned from books and experiments. 


\section{PROBLEMS IN BIOLOGY}

BY

GEORGE W. HUNTER, PH.D.

Lecturer in Methods of Education in Science Claremont Colleges and University of Southern California

Los Angeles, California

Formerly Head of the Department of Biology

Dewitt Clinton High School, New York

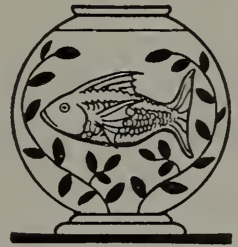

AMERICAN BOOK COMPANY NEW YORK CINCINNATI 


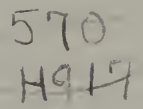

Copyright, 1931, By AMERICAN BOOK COMPANY

All rights reserved

H. BIO.

W. P. 10 


\section{PREFACE}

The modern textbook in elementary science must do several things. First of all, it must contain enough subject matter to permit a rather wide choice of material ; this because of differences in the environment in which the book is used. Obviously every teacher of biology would like a text that interprets the particular environment in which the teaching is done, but since this is an impossibility the solution of the problem is a wide choice of topics. This text gives a large selection of informational material.

Second, the modern text must give to the teacher a variety of problems, demonstrations, projects, and exercises for the workbook in order that the need of the individual student may be adequately met. Nothing is more difficult for the overloaded teacher than to attempt to adjust the work to the individual needs of a large number of pupils. This book, with its many exercises and questions, graded to the needs of a heterogeneous group, squarely meets the problem of individual variation. Projects, demonstrations, and reports are suggested also in sufficient numbers to fill the time of a widely diverging group.

Another thing the modern text should do is to give the student adequate help in testing his own factual knowledge and his own organizing ability. Self-testing devices are useful toward this end. All of the units included in the text have such devices. Formal summaries are purposely omitted. Instead, outline summaries, to be completed by the pupil, are used.

This book follows the approved unit structure, and each unit is built on a general plan which has been tested and found to give satisfactory results. The unit is introduced by a number of survey questions intended to interest the group in the work which follows and to give the teacher an opportunity to find out what " apperceptive mass " exists in the minds of the pupils. This device may 
be used to organize the work of superior students who have a basic knowledge of the material of the unit and who may therefore be allowed to organize some project as their share of the class work. The preview follows, giving a brief introduction to the problems of the unit, and is both an organizing and a motivating device. Next come the problems, many of which are introduced by laboratory exercises or demonstrations, with opportunity for individual work where it is practical. Numerous exercises and problem questions give opportunity for individual pupil assignments and reports. The organization of the unit by the pupil is provided for in the outline summaries, in the attainment tests, in individual check-up on the answers to the survey questions, and in the self-testing exercises. In these ways the teacher has an opportunity for individual work with students. The recitation period may consist of individual reports on rather large blocks of the unit, interspersed with rapid-fire questions where it is obvious that the student organization of the topic has left unexplained some vital point.

The author wishes to thank the following for their critical reading of the manuscript in its entirety or in part or who have made valuable suggestions: Charles W. Finley, State Teachers College, Upper Montclair, New Jersey; Frank M. Wheat, Head of Department of Biology, George Washington High School, New York; Paul B. Mann, Evander Childs High School, New York; Ada L. Weckel, Head of Department of Science, High School, Oak Park, Illinois; Annah P. Hazen, Head of Department of Biology, Eastern District High School, Brooklyn, New York; and George W. Hunter III. Thanks are also due Loran W. Kitch, Herbert Hoover High School, Glendale, California ; Roy Knapp, Burbank Junior High School, Miss Beatrice Cayo, Elsinore High School, Elsinore, California ; Mrs. Karyn B. Sanders, Downey Union High School, Downey, California; and Wright Pierce, Claremont, California, who have read the proof and given suggestions on teaching devices. 


\section{TABLE OF CONTENTS}

WHY AND HOW WE STUDY BIOLOGY • • • • . 1

\section{PART I}

\section{LIVING THINGS IN RELATION TO EACH OTHER} AND THEIR SURROUNDINGS

UNIT I. THE WORLD WE LIVE IN AND WHAT WE TAKE FROM IT

PROBLEM

I. What Does a Tree Take from Its Surroundings? . .

II. What Are the Building Materials of the World and How Are They Used? . . . . . . . . . 23

III. What Are Foods and How Are They Used? . . . 30

IV. How Does Man Control His Environment? . . . 32

UNIT II. WHAT IS BEING ALIVE? THE FUNCTIONS OF LIVING THINGS

I. What Do We Mean bx Reactions to Stimuli? . . . 39

II. How Are Living Things Alike and How Do They Differ? 43

III. What Are Cells and How Do They Produce Others? . 46

IV. What Do We Mean by Adaptation? . . . . . 49

UNIT III. HOW ARE PLANTS AND ANIMALS MUTUALLY DEPENDENT?

I. What Are the Inter-relationships of Plants and Animals?

II. To Know Something of the Structure and Life History OF THE GR,ASSHOPPER

III. To Know Something about the Structure and Life

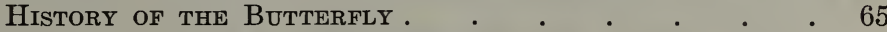

IV. What Do We Mean by Communal Life and Division OF LABOR? .

V. What Are the Characteristics of Other Groups of Insects? 75

VI. Why Are Insects So Numerous? . . . . . . 80

VII. Of What Use Are Flowers to Plants? . . . . . 83

VIII. How Are Fruits Formed? . . . . . . . . . 86

IX. What Are Some Adaptations in Insects for Carrying Pollen?

X. What Are Some Specific Examples of Cross Pollination? 91 vii 
UNIT IV. HOW AND WHY DO SEED PLANTS SUCCEED IN LIFE?

PROBLEM

I. What Are Weeds and What Do They Do? - • 101

II. Why aNd How Should Weeds Be Eradicated? • • . 105

III. How Are Fruits and Seeds Scattered? . . . . 108

PART II

\section{GREEN PLANTS MAKE THE FOOD OF THE WORLD}

\section{UNIT V. WHY DO SEEDS GERMINATE?}

I. Where Are Baby Plants Found? . . . . . 116

II. What Are the Tests for the Organic Nutrients? . . 118

III. What Factors Are Necessary to Awaken the Embryo WITHIN THE SEed?

IV. What Becomes of the Parts of the Embryo during Its

Growth into a Young Plant? . . . . . . 122

V. What Makes a Young Plant Grow? . . . . . 123

VI. Where Is the Food Supply of Different Seeds? . . 125

VII. How Does the Corn Grain Make Use of Stored Food? 128

UNIT VI. GREEN PLANTS AS FOOD MAKERS AND FOOD USERS

I. What Do Plants Take from the Soll? . . . . 137

II. What Factors Influence the Growth of Roots? . 140

III. How Does the Structure of a Root Fit It for Its Work? 143

IV. How Do Root Hairs Take in Water and Soll Salts? • 147

V. What Purposes Do Roots Serve? . . . . . 150

VI. Where Does the Green Plant Mandfacture Food? . 151

VII. What Raw Materials and Conditions Are Needed to

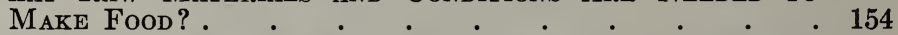

VIII. What Are the Products and Results in Food MandFACTURE? $. . \quad . \quad . \quad . \quad . \quad . \quad . \quad . \quad .160$

IX. How Is Food Circulated in the Plant? . . . . 166

X. Why Are Plants Modified? . . . . . . . 172

PART III

RELATIONSHIPS AND INTER-RELATIONSHIPS OF LIVING THINGS

UNIT VII. THE PLANT WORLD AND HOW IT AFFECTS MANKIND

I. How Do We Classify Plants? . . . . . 179

II. What Are Bacteria and Where Are They Found? . • 181 
PROBLEM

III. What Are Some Usefol Things That Bacteria Do? . 186

IV. What Are Yeasts and What Do They Do? . . 190

V. To Learn abodt Some Destrdctive Fungi . • . . 193

VI. What Are Molds? What Do They Do? . • . . 198

VII. What Are Some Examples of Common Algae? . . . 200

VIII. What Is the Life History of a Moss Plant? • • . 202

IX. What Is the Life History of a Fern Plant? • • . 204

X. What Are Some Examples of Spermatophytes? . . 205

UNIT VIII. HOW DO WE CLASSIFY THE ANIMALS?

I. What Are the Characteristics of One-celled Animals? 217

II. What Are the Characteristics of Some Simpler InverteBRATES? .

III. What Are the Characteristics of the Arthropods? . 232

IV. What Are the Characteristics of the Mollusks? • . 240

V. What Are the Characteristics of the Fishes? . . . 242

VI. What Are the Characteristics of Amphibians? • . 250

VII. What Are Characteristics of the Reptiles? • . . 256

VIII. What Are the Characteristics of Birds? . . . . 260

IX. What Are the Characteristics of Mammals? . . . 268

X. What Story Is Told by the Fossils? . . . . . 271

XI. What Is Man's Place in Nature? . . . . . 274

UNIT IX. WHAT EFFECTS HAVE THE SURROUNDINGS ON THE LIVES OF PLANTS AND ANIMALS?

I. What General Biological Relations Exist between Plants and Animals?. . . . . . . . . 282

II. What Do We Mean by the Nitrogen, Oxygen, and Carbon Cycles in Nature? .

III. What Is Symbiosis and How Does It Differ from Parasitism? . . $.4 . \quad . \quad . \quad . \quad . \quad . \quad .287$

IV. How Does Man Disturb the Balance of Nature? . . 289

V. How Do the Factors of the Environment AFFECT Ecological Relationships? . . . . . . 290

VI. Why Do Plants and Animals Form Communities? • . 298

VII. What Is an Ecological Succession? . . . . 300

viII. What Do We Mean by Geographic Distribution of Living Things? 


\section{PART IV \\ THE BIOLOGY OF MAN}

UNIT X. HOW DOES THE HUMAN MACHINE DO ITS WORK?

PROBLEM

I. What Is the General Structure of the Human Body? 314

II. What Is the Structure of the Skin? . . . . . 316

III. What Is the Relation of Muscles to Bones? . $\quad . \quad 318$

UNIT XI. HOW DOES MAN DETERMINE THE

VALUES OF FOODS?

I. What Do Foods Do For Us? . . . . . . 327

II. What Do Vitamins Do For Us? . $\quad . \quad . \quad . \quad . \quad .333$

III. What Is the Relation of Work, Environment, Age,

Sex, and Digestibility of Foods to Diet? . .

IV. What Is the Best Proportion of Nutrients for Our

DAILY Diet? . . . . . . . . . 340

V. What Is the Daily Calorie Requirement? . . . 343

VI. How Can the Relative Cheapness of Foods Be DeterMINED? : . . . . . . . . . . . .

VII. What Is Adulteration? . . . . . . . . . . $\quad . \quad 348$

VIII. What Is the Truth about Stimulants and Narcotics? . 350

IX. How Does the Pure Food and Drugs Act Work? . 355

UNIT XII. HOW IS FOOD PREPARED FOR BODY USES?

I. What Is a Gland and How Does It Do Its Work? . . 361

II. What Is the Structure and Work of the Mouth Cavity? 363

III. What Are the Parts of the Digestive Tract?. . . 367

IV. What Digestive Changes Take Place in the Stomach? . 369

V. What Work Is Done by the Pancreas? . . . . 373

VI. What Are the Functions of the Liver? . . . . 375

VII. How Are Foods Absorbed and How Do They Get into THE BLOOD? . $. \quad . \quad . \quad . \quad . \quad . \quad . \quad . \quad 376$

UNIT XIII. HOW ARE FOODS CIRCULATED AND USED IN THE BODY?

I. What Is the Composition and What Are the Uses of Different Parts of the Blood? . . . .

II. What Are the Functions of Some of the Endocrine Glands?

III. How Does the Blood Circulate through the Body?

IV. What Is Respiration? . . . . . . . . 403

V. What Are the Mechanics of Breathing? . . . . 406 
PROBLEM

PAGE

VI. What Are the Reasons for, and the Best Methods of VeNTILATION?

VII. What Are the Organs of Excretion and How Do Thex FUNCTION?

UNIT XIV. HOW HAS MAN BECOME THE CONQUEROR OF THE WORLD?

I. What Are the Chief Responses of Plants and Animals? 422

II. How Do Simple Plants and Animals Respond to Stimuli? 424

III. What Are Sense Organs and What Do They Do? . . 427

IV. How Is MaN's Body Controlled? . . . . . . 429

V. What Part Do the Sense Organs Play in the Control OF THE Body? . . . . . . . . . . 435

VI. What Behaviors Are Instinctive? . . . . . 441

VII. How Are Habits Formed? . . . . . . . . 443

VIII. What Are Some Good Health Habits? • • . . . 447

IX. What Are Some Effects of the Drink Habit? . . . 449

\section{PART V}

\section{MAN'S INTER-RELATIONSHIP WITH OTHER LIVING THINGS}

UNIT XV. HOW DOES MAN CONTROL HIS ENVIRONMENT FOR HEALTH?

I. How May We Control the Growth of Bacteria? • . 457

II. How Do Bacteria Cause Disease? . . . . . 461

III. How Do We Get Bacterial Diseases? . . . . . 463

IV. Why Is Quarantine Necessary? . . . . . . . 471

V. What Is Immunity? . . . . . . . . . . . 474

VI. What Are the Differences between Active and Passive IMMUNTTY . . . . . . . . . . . . . 476

VII. How Is Malaria Caused and Transmitted? . . . 482

VIII. How Was the Cause and Control of Yellow Fever Discovered? .

IX. What are Other Disease Carriers and What Diseases

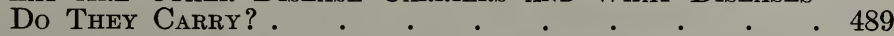

X. What Diseases Are Caused by Worms and How May We Fight Them? .

XI. How May We Improve Conditions at Home?

XII. How May We Improve Conditions at School? . . . 501

XIII. How May We Help Improve Conditions in OUR ComMUNITY? . . . . . . . . . . . . 503

XIV. What Protective Health Agencies Should Exist in a Community? . 
UNIT XVI. HOW DOES MAN CONTROL HIS ENVIRONMENT FOR WEALTH?

PROBLEM

I. How Are Plants Used as Food? . . . . . . 520

II. What Are Other Economic Values of Plants?. . . 528

III. What Is the Value of Animals as Food for Man? . 530

IV. What Are Other Economic Values of Animals? . . 537

V. What Harm Is Done by Animals? . . . . . 544

VI. What Is the Economic Importance of Birds? . . . 547

VII. How Can We Recognize Some Common Birds? . . . 551

VIII. What Is the Economic Importance of Insects? . $\quad .560$

UNIT XVII. HOW DOES MAN CONSERVE HIS NATURAL RESOURCES?

I. What Are the Values of Trees? . . . . . 574

II. Why Is the Conservation of Forests Necessary? - . 579

III. What Is Being Done for the Conservation of Fish and

Other Aquatic Animals? . . . . . . . 587

IV. What Is Being Done for the Conservation of Birds? 594

V. What Is Being Done for the Conservation of Mammals? 598

VI. How Is Conservation Applied to MaN? . • . . 599

UNIT XVIII. HOW DOES MAN CONTROL THE IMPROVEMENT OF LIVING THINGS?

I. How May Environment Affect Plants and Animals? . 608

II. How Do Living Things Reproduce and Develop? . . 611

III. What Are the Laws of Heredity? . . . . . 620

IV. What Determines Heredity? . . . . . . 626

V. How Are New Varieties of Plants and Animals ProDUCED? . . . . . . . . . . . . . 631

VI. How Do the Laws of Heredity Apply to Man? . . 636

UNIT XIX. HOW MAY BIOLOGY AID IN MY OWN IMPROVEMENT?

I. How Can I Choose a Vocation? . . . . . . 646

II. For What Vocations May Biology Help Prepare Me? 649

UNIT XX. WHO ARE SOME OF THE MAKERS OF BIOLOGY?

I. Who Were Some Early Workers in Biology? . . . 657

II. Who Were Some of the Conquerors of Disease? . . 659

III. What Are Some Great Names in the Study of ProgresSive Development? . . . . . . • • • . 665

IV. What Are Some Great Names in Natural History? . 668

V. What Are Some Great Names Connected with Plant and Animal Breeding? . 


\section{WHY AND HOW WE STUDY BIOLOGY}

The study of biology. The word biology comes from two Greek words, bios (life) and logos (word or study). Biology, then, is the study of things that are alive, both plants and animals. Man lives in a world filled with living things. Some are his friends and some are his enemies. It is essential, if he is to be master of this world, that he should understand the living things that are around him. His mastery is due to his understanding of the processes of life in nature. There are many ways in which this conquest is achieved.

Biology in relation to health. It is most important that we control the living things that harm our health. We live in a world that is filled with tiny enemies - some in the water, some in the ground, some living on plants, some living on animals. We call them parasites because they take nourishment from a living organism and give nothing in return.

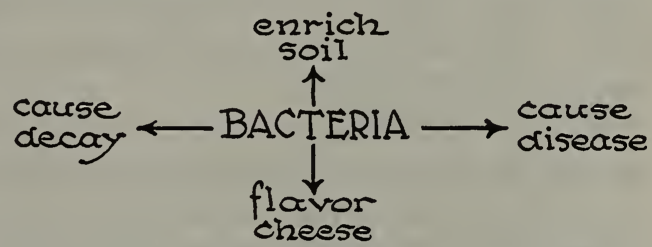

Some of the work done by bacteria. Can you add any others not given in the diagram?

The smallest and yet most widespread of these parasites are the tiny bacteria or germs existing almost everywhere about us, in water, soil, food, and air. They play a tremendous part in shaping the destiny of man. They help him in that they act as scavengers, causing things to decay; they give flavor to cheese and butter; they assist the tanner; and they are invaluable aids to the farmer. But, on the other hand, they cause the decay of meat, fish, vegetables, and fruits; they sour milk and sometimes spoil canned goods; more than this, they cause diseases such as diphtheria, tuberculosis, and typhoid fever.

Hundreds of scientists are devoting their lives to the study of germs and their control, which makes up that subdivision of biology known as bacteriology. A great bacteriologist, Louis Pasteur, 
once said, "It is within the power of man to cause all parasitic diseases to disappear from the world." This prophecy is gradually being fulfilled. It is estimated that from 75 to 90 per cent of all sickness is preventable and that the economic loss in the United States each year from disease and death is about $\$ 3,000,000,000$. This loss could be largely prevented if we were willing to use the knowledge we now have in the methods of controlling and exterminating disease. It may be the lot of some boys and girls who read this book to do their share to bring about this condition of affairs.

The economic values of biology. There are other reasons why we should know something about biology. Plants and animals can live together on the earth only because food is supplied by green plants. Probably many of us do not realize that if all the green plants were gone from the earth there would be no animals. We shall see later why this is true. We all know that man's food supply is determined very largely by his ability to grow and develop plants that produce food for him and for the animals which he eats.

Plants and animals are useful to man in other ways than for food. He uses, for clothing and ornaments, animal products such as wool, fur, leather, hides, ivory, coral, and mother-of-pearl. Plants also provide him with many kinds of building materials. Much of his clothing, and the thread with which he sews it, come from plant fibers. In hundreds of ways plants are made use of in the arts and trades. It is the duty of every boy and girl to know something of these uses.

The conservation of our natural resources. Still another reason why we should study biology is that we may work intelligently for the conservation of our natural resources, especially our forests. The forest, aside from its beauty and its health-giving properties, holds water in the earth. It keeps the water from evaporating from the soil on hot days and from running off the surface on rainy days. Regions that have been deforested, such as parts of China, Italy, and France, are now subject to floods, and are in many places barren. Our supply of timber and to a large extent our future water power depend on the forests. 
Vocational knowledge. Sooner or later the boys and girls who read this book must think of the kind of work they are going to do. Selecting a vocation is one of the most important decisions that one will ever have to make. Through a study of biology you will learn something about such professions as medicine, nursing, forestry, agriculture, or the teaching of science which might appeal to you as worth-while vocations. Your teacher may give you the inspiration which will determine your future career. Many years ago, a professor in college inspired me to become a teacher of biology and I have never regretted my choice. Perhaps you will be as fortunate.

Use of leisure time. It is a wonderful world we live in, but not many of us know how to enjoy it fully. Many boys and girls of today think that they are getting all there is out of life if they go regularly to the "movies" or meet with their crowd at games or parties. But no one has really got very much out of this world until he or she has learned, among the other things, the fun of hiking, of collecting, of observing nature, of taking trips to the shore, to the canyon, and up a mountain with an end in view. The interest that comes in observing and collecting insects or flowers makes life much more worth while. A study of biology will give one the information and incentive for such excursions.

Reading values of biology. The papers and magazines of today contain many discussions and stories which deal with biological subject matter. The daily paper has its column of health hints, its stories of animal doings, and its statistics about animal and plant products. The average person with no biological training reads without being able to judge of the truth contained in these statements. The study of biology ought to give us some knowledge and should certainly show us where to go for accurate information so that we can tell whether our newspaper " science" is true or false. It will also open to us a wealth of books which are accurate and fascinating to read. The names of such books are given from time to time in the pages which follow.

Open-mindedness a by-product. There is no doubt that in spite of living in an age which is noted for its products of scientific thinking, many people are satisfied to have others do their 
thinking for them. They believe almost anything they are told without taking the trouble to investigate the truth of it. Politicians are able to lead the public around by the nose, because people are too indolent to find out the truth for themselves. The study of science ought to make young people disgusted with such lack of thinking. After one has experimented, observed, and read about scientific findings and facts he is not so easily fooled and he wants to be shown, not told. This open-mindedness should come through the study of science. A boy or girl who has learned to think straight will be more likely to live straight and be just that much more worthy a citizen of tomorrow.

Biology in its relation to society. The study of biology should be part of the education of every boy and girl, because society itself is founded upon the principles which biology teaches. Plants and animals are living things, each taking what it can from its surroundings; they enter into competition with one another, and those which are the best fitted for life outstrip the others. Health and strength of body and of mind are factors in man which tell in winning. The strong may hand down to their offspring the characteristics which make them the winners. An understanding of the laws of heredity ought to make each one of us better able to assume the duties of parenthood, duties which all too often are not understood by the boy and girl of today.

Biology should develop character. Finally, if one studies biology with earnest purpose he cannot help but gain in moral and ethical character through the unfolding of truth and the knowledge gained of the working of the laws of nature in the everyday world around us. As Shakespeare once said, a seeker in the great out-ofdoors :

"Finds tongues in trees, books in the running brooks, Sermons in stones, and good in everything."

Where we should study biology. In a modern high school a good deal of time is spent by boys and girls in outside activities athletics, dramatics, debating, and the like; but too little emphasis has been placed on some outside interest that might come directly from the study of biology. Although we must be in the schoolroom much of the time, the ideal place to study biology is out-of-doors, 
for as one biologist once said, "The place where a plant or animal lives is just as important as the plant or the animal itself." One of the most interesting lessons I ever saw taught was given in a vacant lot near a high school in the city of Chicago - a place that seemed to have little in it except weeds and piles of refuse. But the teacher knew the possibilities of that lot, and the pupils were having a wonderful time studying the living things which they found there.

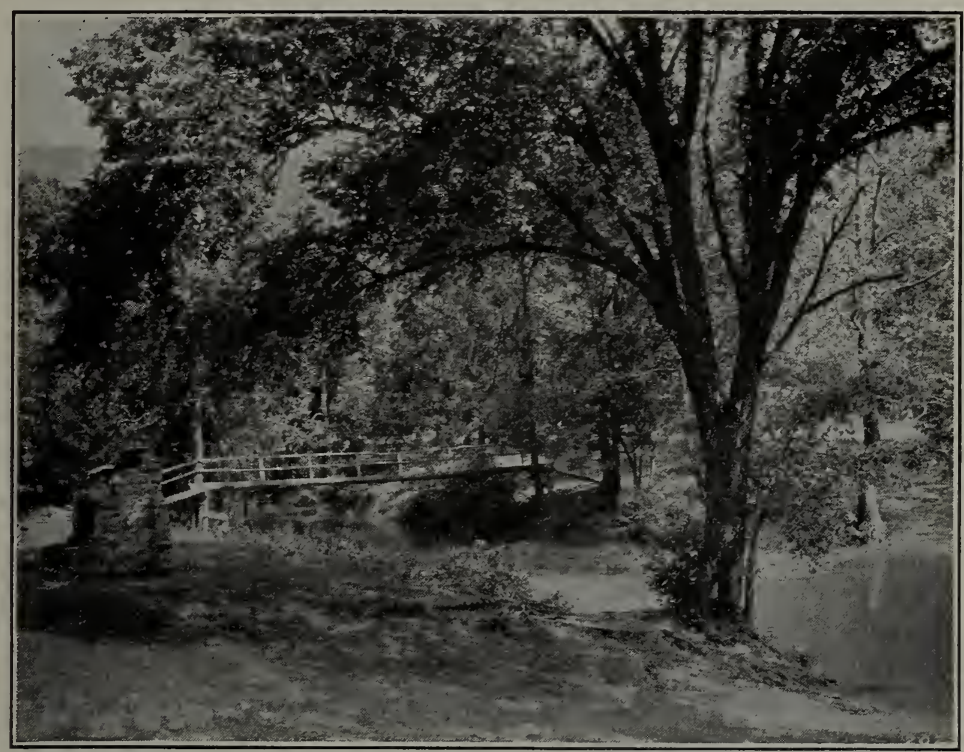

Photo by Shipp-U. S. Forest Service

These surroundings make an ideal outdoor laboratory. Why?

Some were watching the activities of an ant colony, while others were watching to see how a spider built a geometrical web. Every boy and girl in the group had a problem that was most interesting to him or her. But how much more interesting might be a trip to a canyon or a meadow brook or a sea beach! For some of us this might be possible at almost any time.

But if we cannot go to the field for study, then we can bring the field to the laboratory or schoolroom. If each member of the class would bring in some small living things and would arrange to care H. $\mathrm{BIO}-2$ 
for them, the schoolroom would soon be a place much like the out of doors. A balanced aquarium may be started and observations can be made on the life developing there. One can grow plants and learn how to take care of them. One might bring in all sorts of living things and keep them in a vivarium. The laboratory becomes a place for studying nature at first hand, and that is what makes biology interesting.

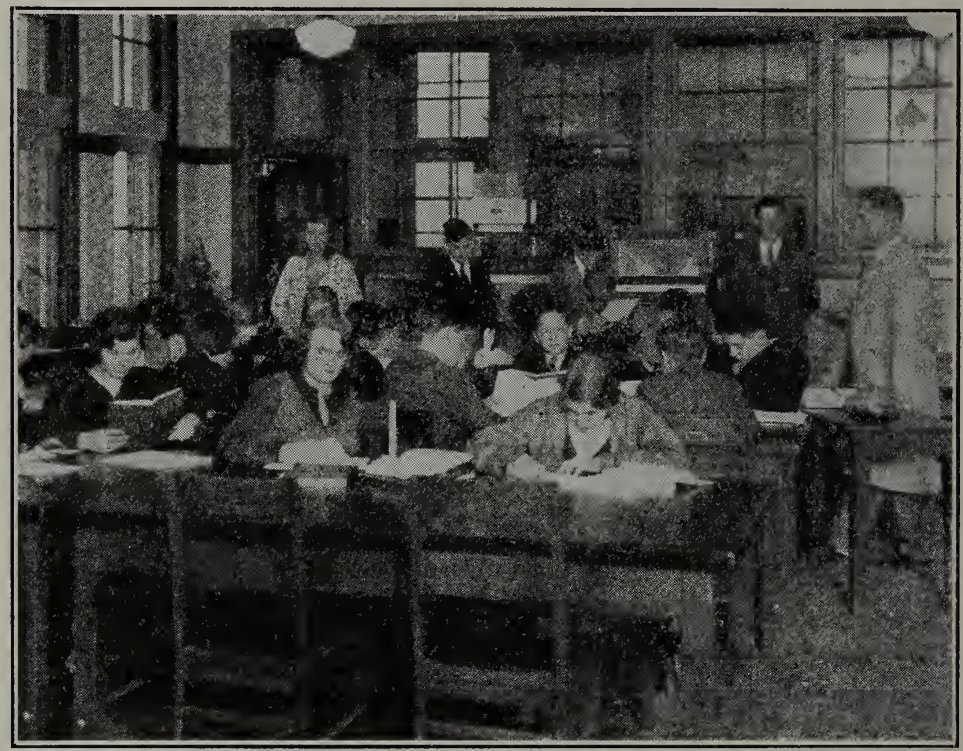

Students at work in an indoor laboratory. What are some of the good features in this laboratory?

In some communities it is possible to have a plot of ground near the school which can be kept as an experimental garden. Here much can be learned about plants, their care, and their insect friends and enemies.

Some interesting activities. Another way to maintain interest in biology is to form a hiking and collecting club. There are so many interesting things to do in the field. One can make collections of local plants, flowers, or insects. A school museum can be started, and one can always have a good deal of fun trying to 
identify new forms. Trips to various localities will help us understand why some animals and plants thrive there while others are found in different places, and to know what kinds of living things to expect in different places - under stones, under the barks of trees, in the water, and in galls on leaves. All these places and many more harbor animals, usually insects.

Another interesting experience that some can have is that of collecting fossils, which are the evidence of life in times past. Many parts of the country have fossil remains, and it is very easy to get some local expert in geology to help you label your findings. Start a collecting club and exchange specimens with boys and girls in other localities. Thus you can do a good piece of constructive work for your school by adding to the school museum. You will be surprised to find many people who are willing to help you in this work.

Have you a biology club in your school? If not, then organize one at once, using 10 to 20 of the most interested members of your classes as a nucleus. This organization will help keep interest in the work and will later in the year be of much help in presenting demonstrations and projects, in planning exhibits and in helping in the care of the living things in the laboratory. Such a club can take charge of the school collections, help classify them, and add to them when possible.

How to prepare for a field trip. The boy or girl who will go afield must do several things to prepare for the trip. Chief among these is to get or prepare collecting nets, insect killing bottles, collecting boxes, and spreading boards. Field trips will be of most value if materials are found and brought back for later study in the school laboratory.

How to make an insect net. An insect net can easily be made in the following way: Cut a 36-inch piece of stout wire (\#12 spring brass wire is good), bend it into a loop nine to twelve inches in diameter, and then twist the ends and bend them so that they will lie in two shallow grooves which have been made in an old broom handle. Fasten the wire in place with fine wire twisted tightly around the end of the broom handle at the place where the two heavy wires lie along the grooves. Make a net of cheesecloth 
or bobbinet, which should be 18 inches deep and large enough to go over the loop. Such a net can be used for catching flying insects, for dredging or scraping insects out of long grass, and for dipping

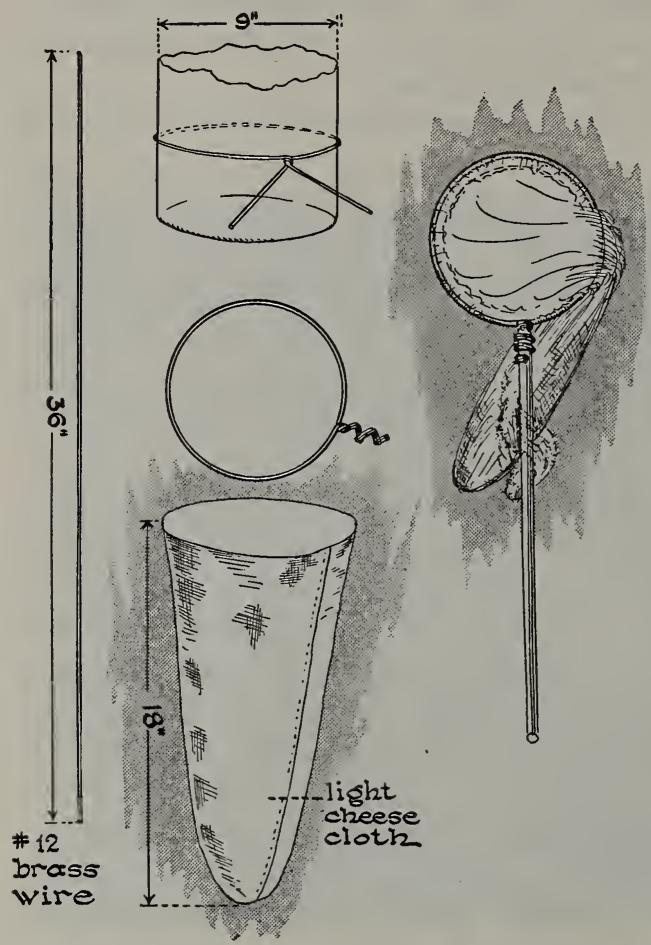

Read your text and then explain the figure. Can you suggest any other ways to make an insect net? insects or other small animals out of shallow ponds or brooks.

The cyanide bottle. Cyanide of potassium fumes are best for killing an insect quickly. Since. these fumes are deadly to man as well as other animals, such a bottle must be handled very carefully. To make a cyanide bottle, take a widemouthed bottle of about 6 to 8 ounces capacity, and place in it two or three pieces of cyanide of potassium the size of a chestnut. Do not breathe the fumes! Cover at once with sawdust and pour in liquid plaster of Paris to a depth of about one inch. The plaster will harden quickly. Cork the bottle tightly and keep it closed except when placing insects inside. Label the bottle like that in the diagram so that you will know it contains a poison.

Collecting water forms. Some of the members of the party should have quart jars so that living water animals may be captured and brought back alive. Be sure to collect with the fish, frogs, or water insects a small amount of some of the green plants growing under water so that you may have living plants to start a balanced aquarium. 
Collecting boxes. After killing in the cyanide bottle, the insects, if butterflies or moths, may be wrapped in little pieces of stiff paper which are folded in triangular form so as to fit the shape of the wings. But a collecting box should be made to hold some of the specimens. A cigar box, with a sheet of quarterinch cork glued in the bottom, and a supply of insect pins are all that is necessary.

Spreading insects. To prepare winged insects for mounting it is necessary to spread their wings out. While the specimen is still flexible, pin it down on a thin board of soft pine or cigar box wood by placing insect pins close to the sides of the body, not through it, then pull the wings out flat and hold them

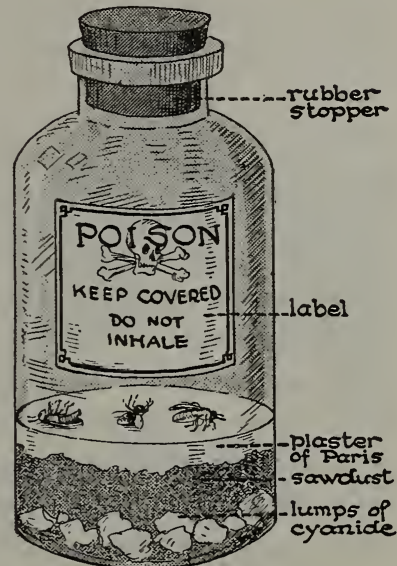

Why do we cover the cyanide with plaster of Paris? down to the board with pieces of glass until they are dry. Place a small piece of pith between the legs so as to keep them in a natural position. When the insect is dry, you can mount it on a pin, and place it on cork in a case not over an inch or so in depth. Boxes

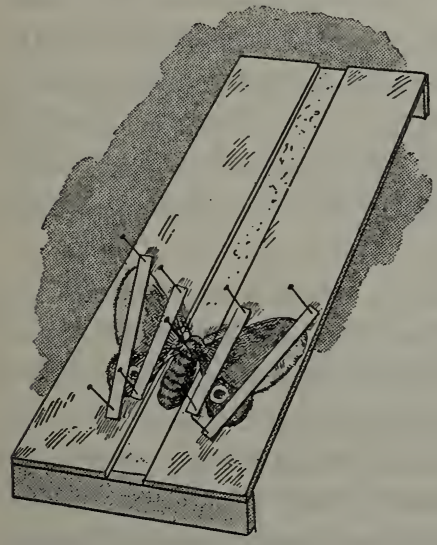

A spreading board. Explain, after reading your text, the use of this board. having glass tops, in which certain brands of chewing gum come, may be obtained for this purpose or boxes may be made in the manual training department of the school.

The art of preparing caterpillars by blowing is described in Hodge's Nature Study and Life or in any good book on entomology. Why not try this as a future project?

Mounting your insects. After the trip is over, the insects may be dried carefully and then placed in Riker mounts if such are available, but homemade mounts are not difficult 
to make. Get two plates of glass of the same size, $4 \times 5$ inch negatives will do. Cut thin strips of wood, not thicker than the largest specimen you wish to mount, glue to one piece of glass, then fasten your insect in place on the glass with a tiny drop of glue, using, if possible, a bit of the dried plant upon which it was feeding as a part of your mount. The other glass may then be placed on the wooden sides and the whole thing permanently sealed by binding around the edges with bicycle tape or passe partout paper. Life histories of insects can be worked out in such cases and can be handled readily, which makes them very useful in class work.

An ants' nest. An ant colony makes a fascinating study for the schoolroom. To make a suitable nest take a piece of roofing slate or a flat tile, glue to it pieces of wood about a quarter inch high so as to make an oblong area six by eight inches or larger, with two little openings between the wood strips; get a piece of window glass to fit over it and then place the slate in a shallow tray which will hold water and will make a moat around your colony of ants, which may easily be found under flat stones. Take a small trowel and, when the colony is found, scrape up as many of the eggs, larvae, and ants as possible. Be sure to get one or more of the winged queens by digging down into the nest. Take your colony home in a well-corked bottle, dump the contents into your prepared nest, smooth down the earth, and place the glass over the top. Cover it with a black cloth or some opaque object so as to exclude the light. Within a day or two the life of the colony will be quite normal and you can study the ants at leisure. Feed them from time to time by placing sugar or crumbs of bread just outside the wood strips.

An insect cage. Frequently we wish to bring living insects into the laboratory in order to study their feeding or other habits. For this purpose an insect cage may be made by taking a shallow flower pot in which earth and some green plant has been placed. Cover this with a lamp chimney having a bit of cheesecloth placed over the top. If the plant within the pot is a food plant and is kept watered, it will be possible to keep the captured insects alive for a considerable period of time. 
Practical Exercise. What insects found in your locality might be kept in the lamp chimney cage?

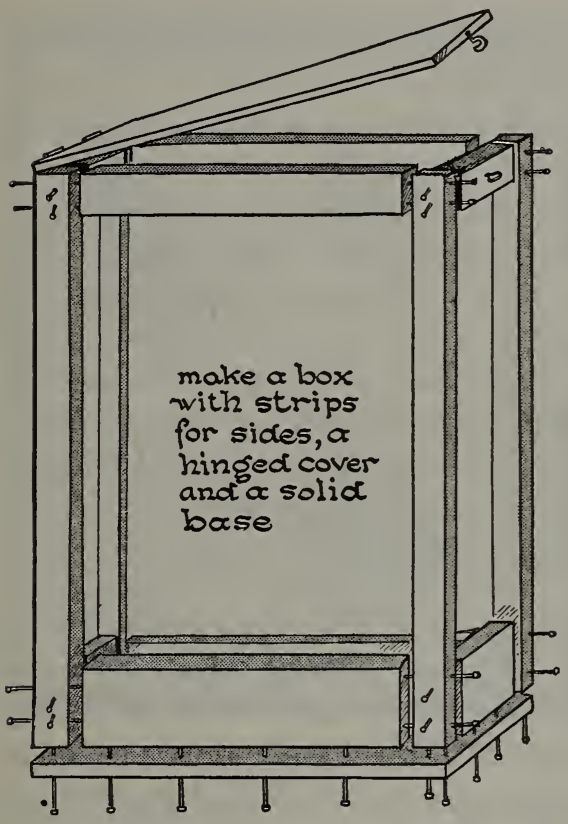

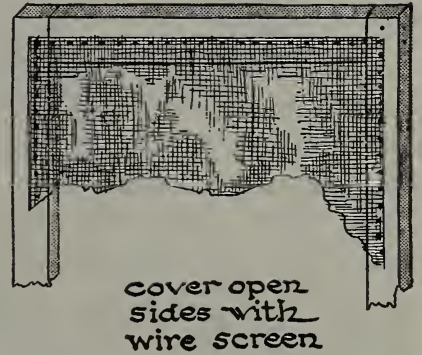

A homemade insect cage. Make the uprights about 24 inches and the sides of the cage 18 inches wide. Place a shallow pan in the bottom, fll it with earth, and put in plants on which the insects may feed.

A balanced aquarium. Frequently, trips may be made to a stream or pond. In such an event, collect snails and other small mollusks by scraping the muddy bottom of the stream with your dip net. Catch any fish that you can with insect larvae, small water beetles, water striders, or other forms of insect life. Be sure to collect several kinds of water plants, especially those with green leaves under water.

Use as your aquarium a large clear glass jar of any shape, and cover the bottom with smooth pebbles. Fasten the water plants down by tying small weights to the base of their stems. Use pond water for the aquarium, transferring the fish and other living things directly into it from the jars you brought them home in. Place the aquarium in a well-lighted part of the room, moving it away from the direct sunlight if the growth of the green plants 
becomes too rapid. Add more snails if the sides of the aquarium become covered with a green growth. In this way, your aquarium will be kept in balance, which means that the plant life supplies the animals with food in sufficient quantity while the animals give the plants enough wastes to allow them to make food in the sunlight. The interesting story of how plants do this will be told later.

Other interesting problems. Out of the field trips and the collecting of insects and other animals will come many other instructive problems. Some pupils may become interested in the classification of animals, others in making a survey of the locality to see where different animals are most plentiful, and others in the various ways in which animals protect themselves or are protected by their surroundings. In fact, there are so many problems that it will be almost impossible for us to note them all here. Let us now turn to some plant problems or projects that will come out of a fall field trip.

Plant studies in the field. The fall of the year usually finds a good many plants in blossom, although most of these have composite blossoms. But flowers are not the only things to collect. A leaf collection can easily be made in the fall and mounted in the way suggested for insects, except that no wood need be used between the plates of glass. Interesting mounts of skeleton leaves may be prepared by placing collected leaves in trays of water until the leaf tissue has rotted away, leaving the skeleton of veins and ribs as a delicate tracing. These make valuable aids in the laboratory study of leaves. Another interesting and easy method of obtaining good leaf illustrations for your notebook is to make blue prints of them. Weed and flower collections may be mounted in a similar manner.

Some members of the class may become interested in making a collection of weeds, and some may wish to make a survey of weeds found in their locality. Weed eradication may be studied as well, thanks to the various government pamphlets which are easily obtainable. Many of us do not even know the trees common to our neighborhood. A survey of trees might be conducted to determine where different types may be found and then sug- 
gestions might be made as to where trees could advantageously be planted in a town. Such a survey might result in real civic better-

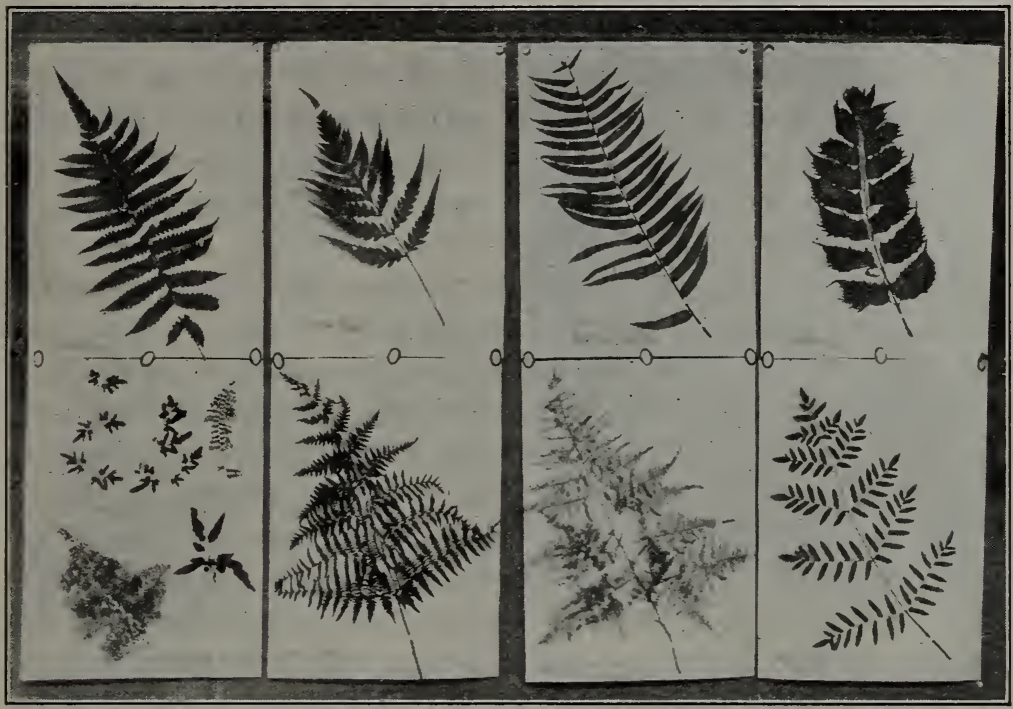

A collection of fern leaves made by high school pupils.

ment. A survey of forest trees would be another interesting project. Planting and raising seedling trees is certainly another worth-while activity.

Other outdoor activities. Birds are most plentiful in the spring and should then be studied out of doors. But birds can always be attracted to your own home by means of nesting boxes, drinking fountains, and by feeding stations. Photographing wild birds is a pleasure worth working for. A census of the number and kinds of birds that frequent your neighborhood and the kind of nests they build are interesting projects. Through bird trapping and banding much can be learned about the migrating and nesting of birds.

Gardening. Gardening and the study of the life of some common garden plants will interest some of us. Others may want to make a study of certain garden or other plant pests and how to eradicate them. Still another study might be that of the plants which do damage to crops or trees of our neighborhood. In short, 
these pages have only begun to suggest some of the activities that will grow out of our study of biology. Most of these are things we can do out of school hours and they certainly are worth while from every viewpoint.

The value of city surveys. Not all of the outdoor work is collecting, nor is the country the only place to make a field trip. We have spoken of studies in vacant lots and tree surveys in a city. Of still more practical importance are sanitary surveys which tell us of the sanitary conditions of our neighborhood. What are the conditions in the meat stores? Are the goods there kept under sanitary conditions? Are the streets of your city well watered and cleaned? Are the garbage and ash collections regular and sufficient? Are the schools well lighted, properly heated, and effectively swept? Are there efficient and well-kept playgrounds, baths, and parks? All these and more can be worked out in the field by a group of pupils of biology, thus proving that biology has a part in citizenship. A group of young people have more than once rid a town of mosquitoes or flies, just by making a survey, discovering the sources of these pests, and then proceeding to eradicate them by the methods which they learned in biology class:

Practical Exercise. How many of the above-mentioned things can be done by the members of your biology class? Give reasons why they can or cannot be done.

The use of the laboratory. It is said that on one occasion, John Hunter, a well-known Scottish physician, who was a teacher of Jenner, and lived from 1728 to 1793 , was present at a discussion concerning the digestive system of birds. The meeting broke up without any decision and at the next meeting several persons brought quotations from the works of such old philosophers as Aristotle, Hippocrates, and Galen to prove their previous statements. But John Hunter brought in a dissected bird and showed the organs in their natural position. This naturally settled all arguments.

Unfortunately we cannot do all of our work out of doors. We must use the laboratory, and of course we must take the authority of books. It goes without saying that if we were to spend our 
time in rediscovering the hundreds of thousands of facts already known about plants and animals, we would not get very far with any new discoveries. So we rely on texts and reference books because they have been written by specialists, and in this way we may make an earlier start toward discoveries of our own.

Biology, more than any subject you are now studying, ought to prepare you to think logically. The method of the experiment is much like the steps of an act of real thinking. In our attempt to solve a problem through an experiment we use four steps: first, we state our problem; second, we do certain things to try to find out

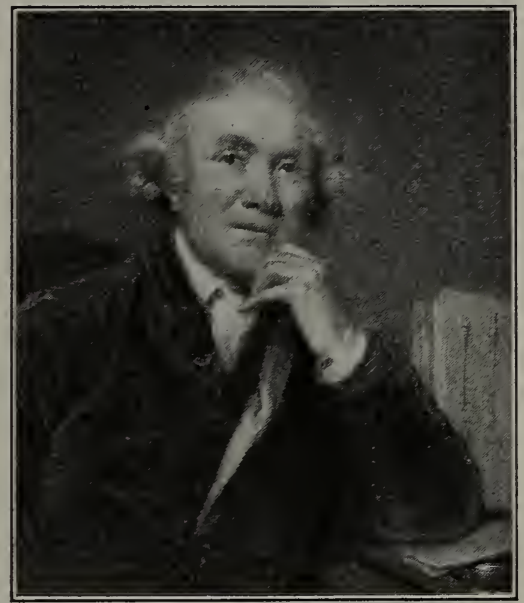

John Hunter, a physiologist and surgeon, carried on much biological research. He always sought the truth through observations and experiments on lower animals.

something about it; third, we observe and analyze what we have done; and fourth, we draw a conclusion as the result of what we have seen. These are the steps taken by any one who really accomplishes anything in the way of constructive work. But in an experiment, if we really want to prove our point, it is necessary to establish a control. For example, suppose we want to know what effect exercise has on the rate of our heart beat. We can first take the pulse rate when quietly sitting at our desk or when lying down, and then we can take a definite amount of exercise and again take the pulse rate. In this way we establish a contrast between the heart beat when we are at rest and when we have had exercise. The rate of the pulse when we are at rest is known as the control. Which of the two rates of the pulse just obtained would be of real value in giving us correct information about our normal heart beat? Experiments and projects with the proper controls will give us the techniques we need to be thinkers and doers in this world. 
Clear thinking should come from science study. Psychologists, the people who study the science of the mind, tell us that those of us who like and understand our work and make its ideals our own ideals get much more general value from its study than those who do not. If, for example, in science we consciously try to see why each step of an experiment is performed and actually practice the method of the experiment in other similar cases, we may carry over this method of thought to other subjects and even apply it in our daily life. The scientific method of thinking has resulted in new inventions, in discoveries, and in straight thinking the world over. Why not try consciously to apply our method of doing and thinking in science to other kinds of doing and thinking in daily life? This would give us the greatest values from biology that we could hope to get.

Method of use of this book. In the pages that follow, a regular procedure will be used which has been shown by actual experiment in schools to be one of the best ways to study introductory science. In the first place, our work is divided into units, each of which has some practical or definite relation to our own lives. Nothing has been included in the text that does not directly or indirectly influence the lives of each one of us.

Each unit is introduced by a series of survey questions which are intended to find out what you already know about the subject matter of the unit. This is followed by a brief preview, or introduction to the work of the unit, which will give you a bird's-eye view of the subject matter of the unit. It might be said to be a "selling" device by which each of you may become interested in the work of the particular section or unit. The preview is followed by a series of problems which explain the unit. Each problem usually includes demonstration or laboratory work, and enough text is given so that this laboratory work is explained. The references given at the ends of the units should be used when available. The problems will be largely your work, and your understanding of biology will depend largely upon your thoroughness in the laboratory or field or library. At the end of each problem and at the end of the unit are certain self-testing devices which will help you to know whether you have mastered the 
contents of the unit. When you have tested yourself, check back on the survey questions to see if you have any corrections to make there. After this is done you are ready to make your report to the class on the unit or such part of it as your teacher may assign to you. To prepare for this recitation make an outline summary for your workbook. This will help you to organize the material in the unit in the best possible way, and thus come to a complete understanding of the material contained therein. If you understand this plan of the book, you will be able to get better results in its use.

The last unit in the book gives short and interesting stories about a few scientists who, by much work and perseverance, made remarkable discoveries that have so largely contributed to our knowledge of biology. The lives of these men may be studied in relation to the unit in which their work is discussed or they may be studied at the completion of the other units.

\section{UsEFul REFERENCES}

Apgar, E. A., Trees of the Northern United States. (American Book Company, New York)

Bailey, F. A., Handbook of Birds of the Western United States. (Houghton, Mifflin Co., Boston. 1921)

Boulenger, E. G., Aquarium Book. (D. Appleton \& Co., New York. 1926)

Clements, E. G., Flowers of Mountain and Plain. (H. W. Wilson Co., New York. 1920)

Comstock, J. H., and Comstock, A., How to Know the Butterflies. (Comstock Publishing Co., Ithaca, N. Y. 1920)

Downing, E. R., Our Living World. (Longmans, Green \& Co., New York. 1924)

Georgia, A. E., Manual of Weeds. (The Maomillan Co., New York. 1914)

Hodge, C. F., Nature Study and Life. (Ginn \& Co., Boston)

Hornaday, W. T., American Natural History. (Charles Scribner's Sons, New York)

Lutz, F. E., Field Book of Insects. (G. P. Putnam's Sons, New York. 1921)

Needham, J. G., and Lloyd, J. T., Life of Inland Waters. (Comstock Publishing Co. 1923)

Palmer, E. L., Field Book of Nature Study. (Comstock Publishing Co. 1927)

Thomson, J. A., Outline of Science. (G. P. Putnam's Sons. 1922)

Waters, H. J., Essentials of the New Agriculture. (Ginn \& Co. 1924) 


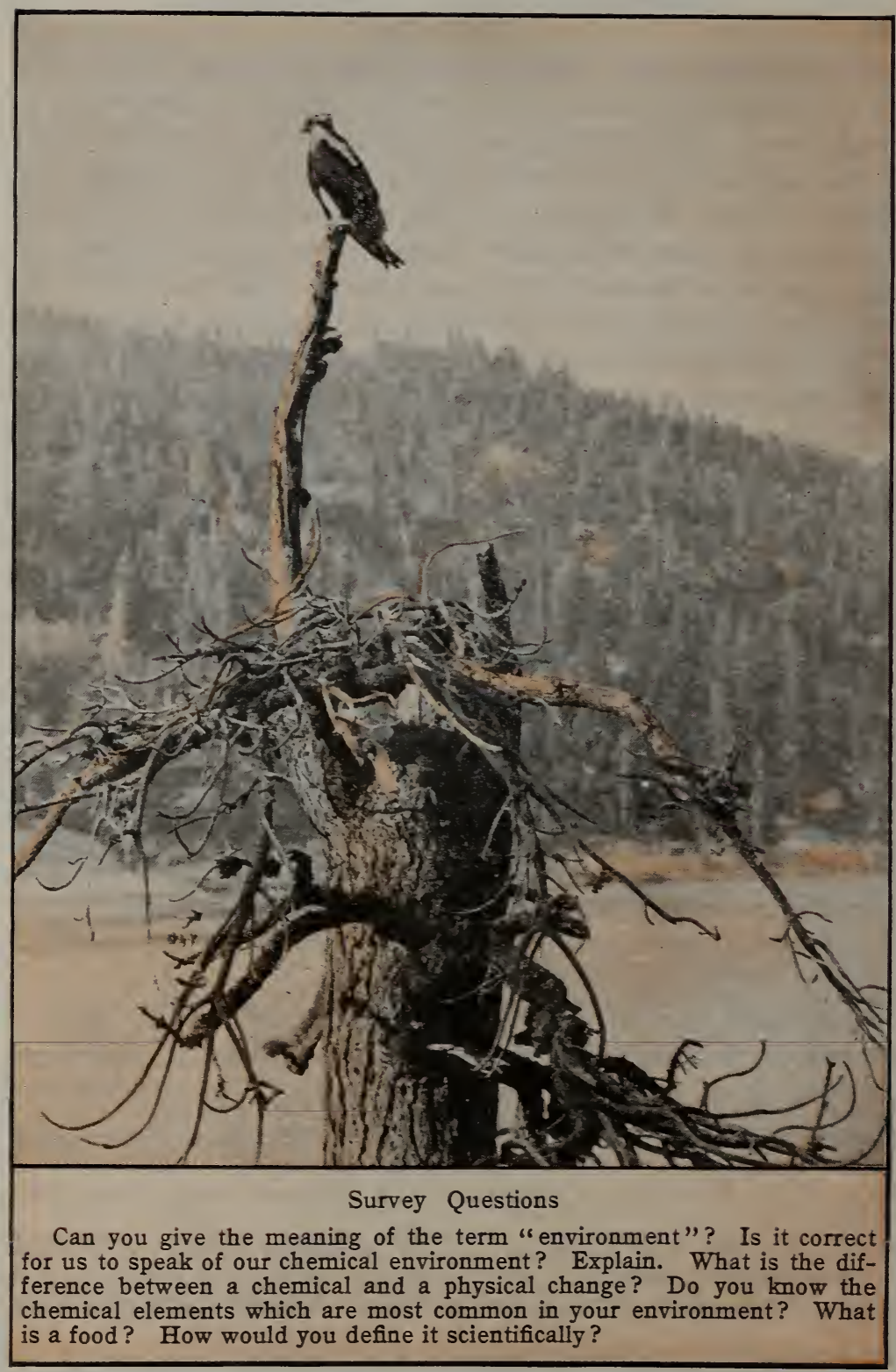




\section{PART I. LIVING THINGS IN RELATION TO THEIR ENVIRONMENT AND TO EACH OTHER}

\section{UNIT I \\ THE WORLD WE LIVE IN AND WHAT WE TAKE FROM IT}

Preview. In our previous experience with science in the elementary and junior high schools we have learned something about our environment and what we get out of it. We know a little about the air and how we use it, about water and how it serves us, of fire, of the weather, and many other useful facts that help us in our daily living. But now we are ready to learn something more about this environment from a different angle.

Biologists realize more than ever before that living things are dependent upon their environment and that they are composed of many of the chemical substances that are found in that environment. Thus, our knowledge of biology depends upon an understanding of the chemists' and physicists' conception of the world about us. This unit will help us to understand some of these important facts about our surroundings. The physicist calls anything that occupies space matter. The chemist in his turn reduces all matter into over ninety simple substances called chemical elements, substances that cannot be broken into more simple substances. These elements are given symbols by the chemist, such as $\mathrm{O}$ for oxygen, $\mathrm{H}$ for hydrogen, $\mathrm{N}$ for nitrogen, and $\mathrm{C}$ for carbon. The soil and other things in nature are composed largely of combinations of elements known as chemical compounds. A few of these compounds, such as water, iron rust, 
and table salt, are simple, inasmuch as they contain only two or three elements; but the greater number of compounds found in nature are very complex. The chemist uses several symbols to designate the binding together of elements into compounds. Several symbols together are known as a formula. For example, $\mathrm{H}_{2} \mathrm{O}$ is the formula for water and indicates that two parts of hydrogen combine with oxygen in a definite proportion by volume.

in sea water

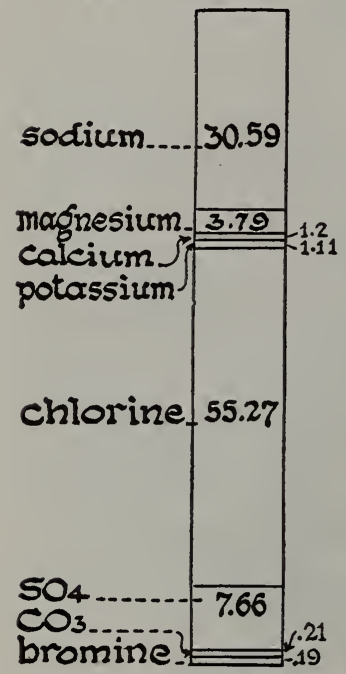

in blood serum

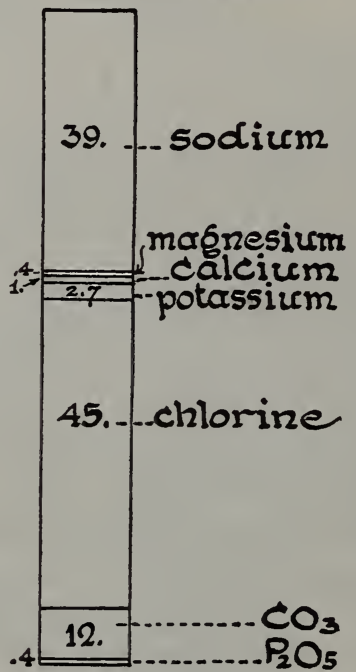

According to analysis, scientists have found that the percentages of chemical substances in sea water are quite similar to those found in the blood serum (after Osborne).

A chemical compound is a combination of two or more elements in which each of the elements loses the characteristics which distinguished it. For example, if fine iron filings and flowers of sulphur are mixed, each element will retain its own peculiar properties, can still be recognized, and can be easily separated by means of a magnet which will attract the iron. But, if the mixture is heated in a test tube, several important changes in the mixture will take place. A solid black substance is obtained which is not attracted by a magnet. The elements can no longer be separated by mechanical means. This black substance is a compound called iron sulphide. It has several properties quite different from those of either the iron or the sulphur. Rocks, humus, organic food substances, and the bodies of plants and animals are all composed of chemical compounds.

Professor H. F. Osborne of Columbia University has pointed out that the chemical substances found in sea water correspond 
very nearly with those in the human blood. There are other facts also which prove that some of the same chemical elements found in the environment somehow or other become organized into the tremendously complex material of which we find living plants and animals composed.

\section{PROBLEM I. HOW IS A TREE FITTED TO LIVE IN ITS NATURAL SURROUNDINGS?}

Field Exercise. Observe a tree in its natural environment. Bring in all the information you can to class concerning where a given tree grows, its form, size, characteristics, etc. The findings of the class can be tabulated on the board, and from this a general statement can be made concerning the characteristics of all trees.

As Joyce Kilmer well said, there is no poem as lovely as a tree. Trees are so commonplace that we are not likely to consider what life would be without them. They grow straight and tall, even in cities where life for them must be very difficult. The problem before us is, "How do they do it?" How can a tree (or any other green plant for that matter) develop into the great bulk that they have? They cannot make something out of nothing. It takes several acorns to weigh an ounce, but an oak tree weighs several tons. Where does this increase come from? Evidently the young tree must take something from its surroundings in order to grow. What are the substances it uses? And how does it do this?

The skeleton. Let us take a typical tree, such as the maple or elm. We notice in winter it is a skeleton, a straight trunk or main stem and many branching limbs which spread out into ever smaller and smaller branches. These are covered with buds which in spring will produce leaves or flowers or both. Under the ground we know there are roots, which, in the same manner as the branches, spread out widely and continually branch so that in many trees there is almost as much of the tree below ground as above it. Evidently the roots anchor the tree in the ground, while the branches place the buds and leaves in the most favorable position possible.

Leaves. In the summer the tree is covered with green leaves. These, we notice, are set as far out as possible on the branches. Evidently sunlight influences them, for a bird's-eye view of the н. вIо -3 
tree shows that the leaves are placed so that they shade each other but little, and present their flat surfaces at right angles to the sun's rays. The leares, as we shall later see, are food factories

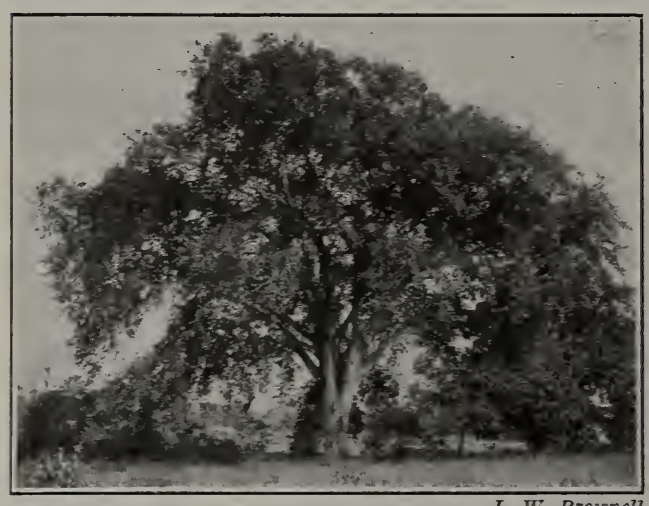

An American elm in summer.

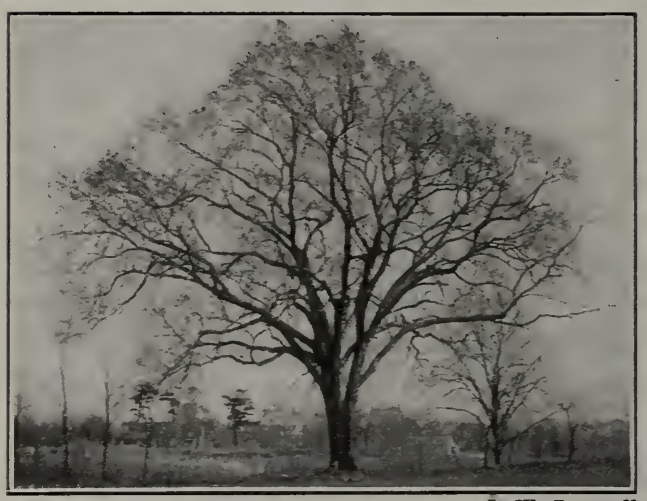

The same tree, as above, during the winter. and do their work by energy received from the sun's rays.

Roots. If we were to examine the roots, we would find here evidences that they take in water, besides anchoring the tree and giving it firm support. Trees growing near irrigating ditches or sewers often fill them with masses of fine roots which have sought out the water. The smaller rootlets are covered with tiny absorbing organs called root hairs.

However, the tree must take other materials than water from its surroundings in order to grow, for no thing can live and grow on water alone. Our problem now becomes more difficult, and we cannot answer it completely. But we do know that the green plant, taking substances from the air and soil surrounding it, manufactures the material we call organic food, and uses this food to make its living material.

To discover just what a tree takes from its surroundings involves the knowledge of some chemistry. Most of us have had some 
of this knowledge from a course in general science, but we must now review some of the elementary facts in order to answer the problems which follow.

\section{Self-Testing Exercise}

A tree has $\ldots \ldots .(1), \ldots \ldots(2), \ldots \ldots$ (3), and green (4). The ....... (5) serve to anchor the tree in the ground and take in .......(6). The stem holds to the light the (7), which are the ...... (8) ...... (9). The tree takes .......(10) materials from its environment and makes them into .........(11) and .......(12) matter.

\section{PROBLEM II. WHAT ARE THE BUILDING MATERIALS OF THE WORLD AND HOW ARE THEY USED?}

Matter. Matter and energy are the fundamental things in the world. Matter is anything which has weight or occupies space. The tree is made of matter, as is the surrounding soil, the water, and even the air which it uses. Matter is usually present in one of three forms, a gas, a solid, or a liquid ; and, as we know, is capable of being changed from one form to another. For example, a liquid, water, may be changed into a vapor, steam, by heating, or into a solid, ice, by freezing. In biology, matter is usually thought of as being of two sorts, organic, or that which comes from living things, and inorganic, or the material that never has been alive.

Energy. When a tree grows, or the roots push their way through the soil, or take in water, energy is being exerted. Energy means the power or ability to do work. There are five kinds of energy: mechanical, electrical, chemical, heat, and light energy. To perform its work the tree uses light energy, chemical energy, and heat energy, which it may change into mechanical energy. Any one form of energy may be changed into another form. We may observe such a change when we strike a nail with a hammer and discover that the nail becomes hot. Our mechanical energy has turned into heat energy.

Demonstration 1. Show some elements, as carbon, iron, phosphorus, and sulphur. 
Forms of matter. Both living and non-living things are made up of chemical elements. There are over ninety elements. The

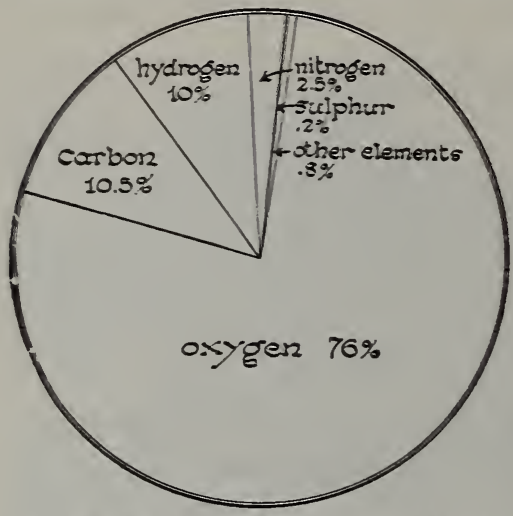

The percentage of difierent chemical elements that are found in the human body. How do you account for such a large proportion of the gas oxygen? common ones that are found in a tree are oxygen, carbon, nitrogen, and hydrogen; while a number of others, less common, such as sulphur, potassium, iron, and phosphorus, are also found in the composition of most plants and animals. Many of these same elements are found in soil, in air, and in water. Some elements are gases, such as oxygen and nitrogen. Some are solids, such as carbon and sulphur, and two which are not found in the composition of the tree are liquids, mercury and bromine. Elements are simple substances. For example, iron, so far as we know, has nothing but iron in it ; and oxygen nothing but oxygen in it. It is easy to separate some elements from their compounds and not so easy to get others. Carbon, for example, in its pure state is obtained when we collect on a sheet of white paper the black substance from the smoke of a candle. Soot is almost pure carbon. The yellow sulphur that we buy at the drug store is an element. It is not so easy to obtain oxygen in a pure state. This element is often combined in nature with other elements to form substances called compounds. A simple compound containing oxygen is water.

Demonstration 2. The separation of water into its elements. If by means of the apparatus shown in the diagram an electric current is passed through water to which a little sulphuric acid has been added, we find that the water separates into two gases. In one tube the gas present occupies just half as much space as in the other tube. The gas present in the smaller quantity proves upon test to be oxygen as it causes a glowing splinter to burst into flame. The other gas, colorless, tasteless, and odorless like the oxygen, differs from it by igniting with a slight explosion when a burning match or splinter is introduced 
into the tube. As the gas burns, drops of water are formed, showing that it is passing back to its original condition, that is, it is uniting with oxygen to form water. This gas is hydrogen. Elements always unite in definite proportions to form compounds, as in water the proportion by volume is always two parts of hydrogen to one part of oxygen.

Oxygen, when carefully prepared, is found to be colorless, odorless, and tasteless. Combined with other substances, it forms a very large part of the composition of water, rocks, minerals, and the bodies of plants and animals.

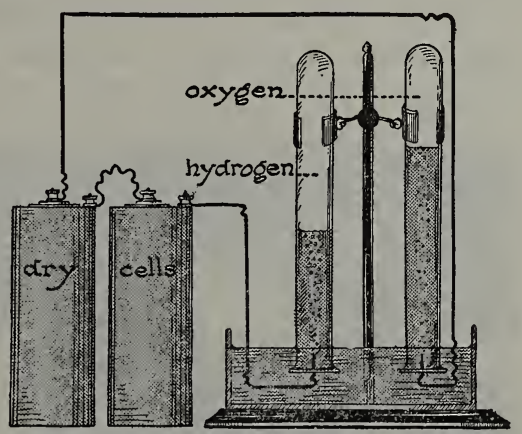

Oxygen has the very important property of uniting with many other substances. The chemical union of oxygen with another substance is called oxidation. When a candle burns, the oxygen in the air unites with the carbon in the candle and forms a gas, called carbon dioxide, which puts out a flame. This gas may be tested for as follows :

Demonstration 3. Burn a candle in a closed jar. After the candle goes out, remove it carefully (the gas in the jar is heavier than air). Add a spoonful of limewater - screw down the top of the jar and shake

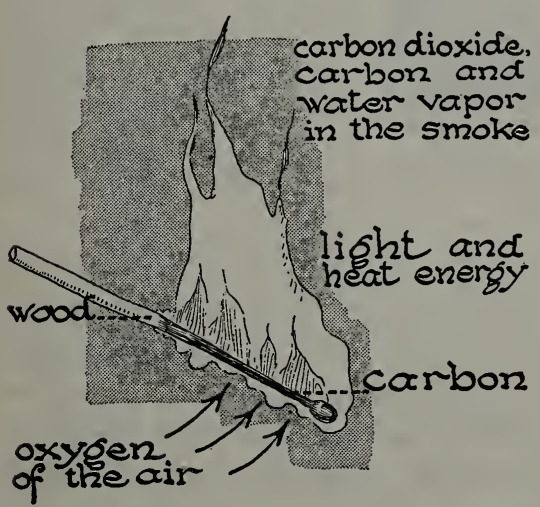

Why is the burning of a match an example of oxidation? so as to mix the gas in the jar with the limewater. What happens to the limewater? This test with limewater shows that carbon has been oxidized, forming carbon dioxide.

Practical Exercise 1. Burn a number of different substances in closed jars and test in each case for carbon dioxide. How many of the substances produce carbon dioxide when burned?

\section{Oxidation. Oxidation may} take place slowly, as in the rusting of an iron nail, which is caused by oxygen uniting 
with the element iron. Slow oxidation of chemical compounds is constantly taking place in nature and is a part of the process of decay and of breaking down of complex materials into simpler forms.

One of the most important effects of oxidation lies in the fact that, when anything is oxidized, heat is produced. This heat may be of the greatest use. Coal, in being oxidized, gives off

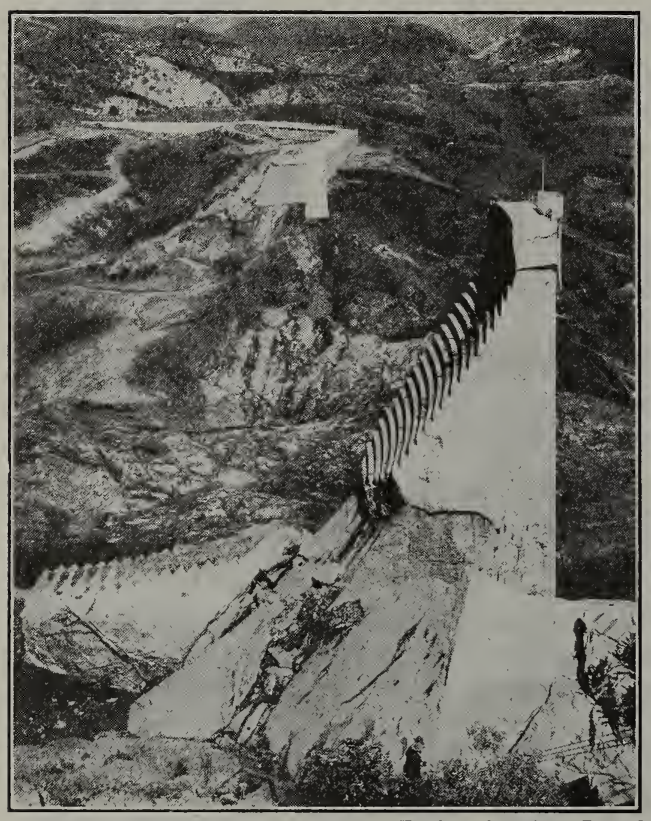

Engineering News-Record

The energy held in the water in this dam was sufficient to uproot trees, sweep buildings from their foundations, and dislodge rocks, when a wall of the dam broke. heat; this heat boils the water in the tubes of a boiler; steam is generated, wheels of an engine are turned, and work is performed. The energy released by the burning of coal has been transformed into work or power. We shall find later that the oxidation of certain materials in the bodies of plants or animals releases energy which is used to perform work. The heat of the human body is maintained by the constant slow oxidation of food materials within the body.

Forms of energy. Energy has been shown to be the power to do work. The energy locked in the coal before it is released by the process of burning is known as potential or stored energy. The energy released by the burning process is kinetic or active energy. The potential energy held in the water of the San Francisquito dam became kinetic energy when the dam gave way and let the great volume of water rush down the fertile Santa Clara valley, bringing death and destruction to its inhabitants. 
Conservation of energy. Physical science teaches us that energy, such as that released so disastrously in that California valley, may never be lost, created, or destroyed. It always is, and always has been. The great force, released when the flood rushed down the valley, dug deep channels in the soil, moved huge rocks, smashed houses, and left countless other ruins in its ruthless path. If the water could have been harnessed to a turbine, it might have turned a dynamo, produced electricity, lighted a city, or turned the wheels of factories. Energy may be changed from one form to another, but it can never be created or destroyed; it is everlasting!

Practical Exercise 2. Give three examples of transformation of energy that helps to make life more comfortable for you.

Water in living things. Water forms an important part of the substance of plants and animals. This is seen when a number of green leaves are weighed, placed in a hot oven for a few moments. and then reweighed. The same experiment made with a softbodied animal, as the oyster, would show the presence of a greater percentage of water than was found in leaves. Some jellyfish are over 90 per cent water. Over 65 per cent of the human body is water.

Mineral matter in living things. If a piece of wood is burned in a very hot fire, the carbon in it will all be consumed, and eventually nothing will be left except a grayish ash. This ash consists of mineral matter which the plant has taken up from the soil dissolved in water, and which has been stored in the wood or leaves. All living things contain small quantities of mineral substances.

Practical Exercise 3. Weigh several different substances such as soil, apple, meat, dried beans, celery, etc. Dry out each substance in an oven under slow heat (do not char). After several hours reweigh and determine percentages of water lost by each substance. Then try to burn out all organic material. The gray residue is the ash or mineral content. What per cent of the original weight is the ash?

Gases present in living things. Some gases are found in a free state in the bodies of plants or animals. Oxygen is of course present wherever oxidation of organic matter is taking place, as is carbon dioxide. Other gases may be present in minute quantities. 
Materials found in tree. Our experiments have shown us that elements may be separated from compounds, and elements may be built up into compounds. In a living tree similar processes are continually going on. Compounds containing the elements sulphur, potassium, iron, etc., are taken from the earth, dissolved in water. Nitrogen, which is an absolute necessity for building living material, is taken from the earth in the form of very complicated compounds which usually come from the decaying bodies of plants and animals and are found in the black soil we call humus. Oxygen comes from the air and is taken into the plant through breathing holes in the leaves. All together, the tree is a wonderful laboratory, for out of these raw materials it builds foods and from these foods it builds its own wonderful structure. The leaves not only make food in the sunlight, but they digest and circulate it to all parts of the plant. This may be done in darkness as well as in light.

The table on the opposite page gives us the characteristics of the most common elements that are found in the tree and its environment. It will also tell us how to identify each of these elements by testing for those properties by which they are known, where they are found, and what use they have in nature.

\section{Self-Testing Exercise}

Matter is anything that has ....... (1) or occupies ....... (2). It may be in the form of a ...... (3), a ...... (4), or a ...... (5). Energy is ....... (6) to do ....... (7). One form of energy may be ....... (8) into another, as is seen in making ....... (9) by means of water power. Energy may be stored in a substance as ........(10) energy, but when released to do work, it is .......(11) energy. Both ........(12) and ........(13) things are made up of ....... (14) elements. There are over .......(15) in all. The commonest ones found in living things are ........(16), (17), ....... (18), and .......(19). Elements combine in .......(20) proportions to form ........(21), as two parts of .......(22) and one part of ....... (23) form water. When anything ....... (24) with oxygen, we say .......(25) is taking place. If an organic substance is ....... (26) or oxidized, it gives off ...... (27) ...... (28). If ....... (29) turns .......(30), when used as a test for this gas we know that .......(31) ........(32) is present. 


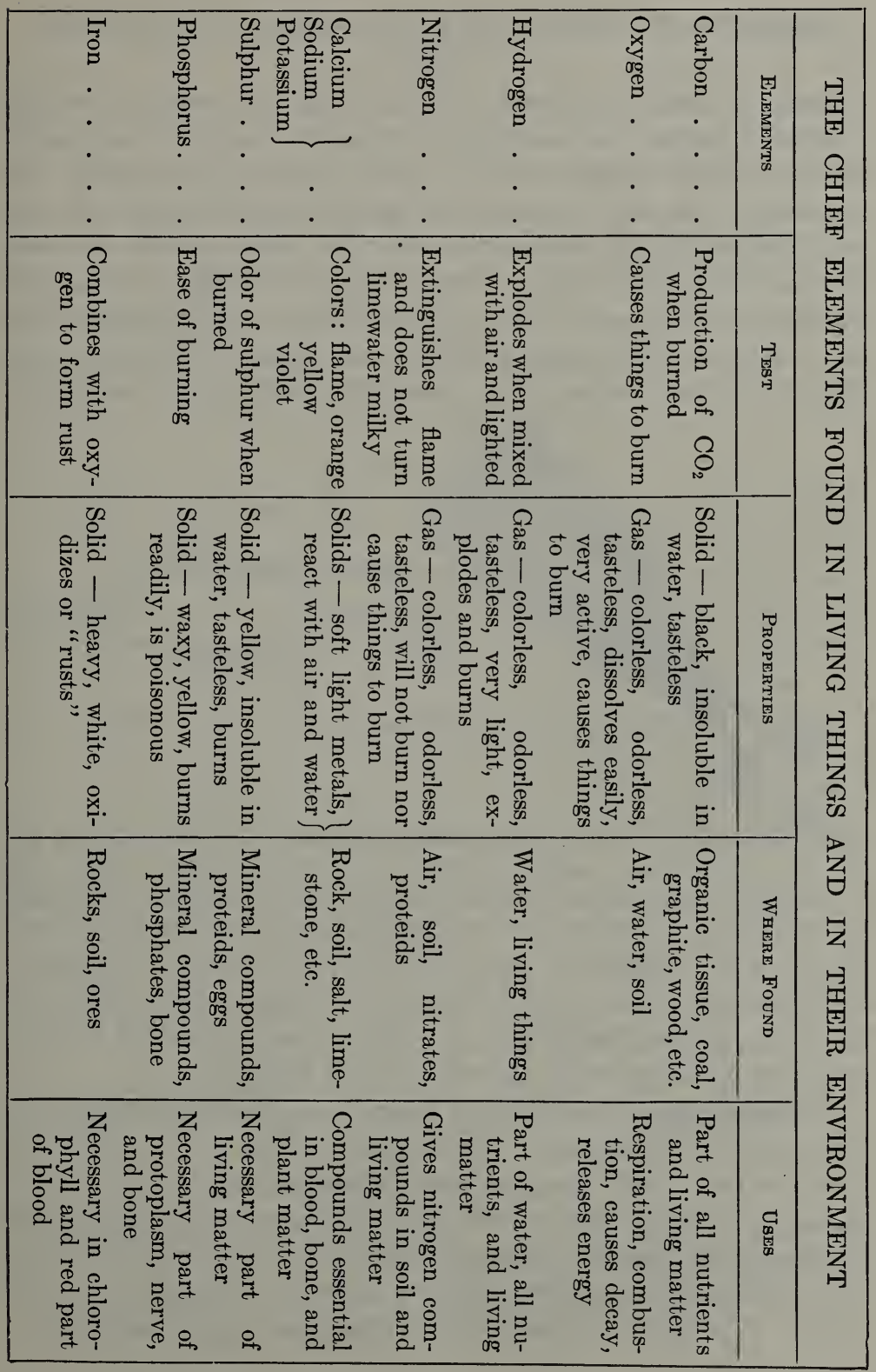




\section{PROBLEM III. WHAT ARE FOODS AND HOW ARE THEY USED?}

Foods. What is a food? We know that if we eat a suitable amount of proper foods at regular times, we shall be able to go on doing a certain amount of work, both physical and mental. We know, too, that day by day, if our general health is good, we may be adding weight to our bodies, and that added weight comes as the result of eating food. A similar statement may be made with reference to plants and foods. If food is supplied in proper quantity and proportion, plants will live and grow; if their food supply is cut off, or even greatly reduced, they will suffer and may die.

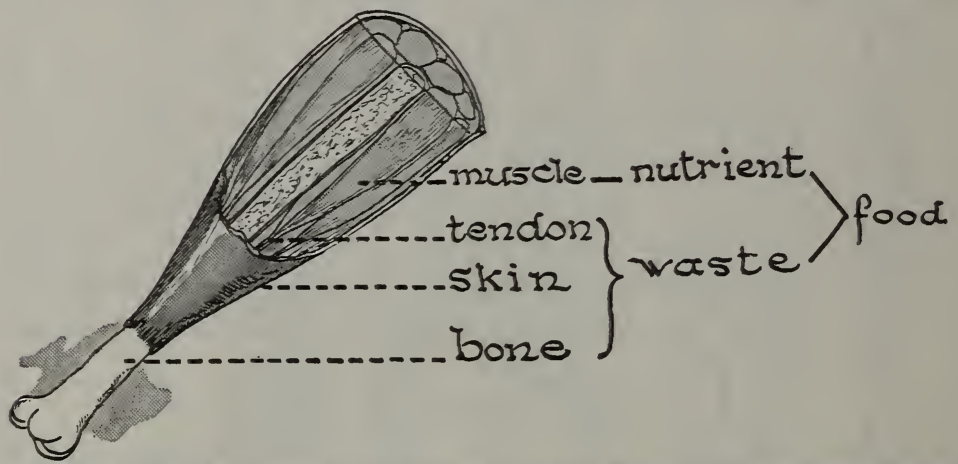

Compare this turkey leg with other materials used as food, by making similar analysis of them.

However, only a small part of a food, as potatoes, can be used by the body. For a food is made up of a combination of wastes as water in vegetables, skins of fruits, and tendons in meatand nutrients which repair or build up the body or, when oxidized in the body, furnish it with energy. The organic nutrients found in foods are carbohydrates, fats or oils, and proteins.

Carbohydrates. Starch and sugar are common examples of this group of substances. The former we find in our cereals and most of our vegetables. Several kinds of sugar, such as cane sugar, beet sugar, and glucose or grape sugar, are commonly used as food. Glucose, the natural sugar of grapes, honey, and fruits, is manufactured commercially from starch by the action of dilute acids. It is used as an adulterant in sirups, honey, and candy. 
Fats and oils. Fats and oils form a part of the composition of plants and animals. Examples of food containing fat are: butter and cream, oils from nuts and olives, and fat from animals.

Proteins. Proteins contain the element nitrogen in addition to carbon, hydrogen, and oxygen of the carbohydrates and fats and oils. They include some of the most complex substances known to the chemist, and, as we shall see, have a chemical composition very similar to that of living matter. Proteins occur in different substances. White of egg, lean meat, beans, and peas are examples of substances composed largely of proteins.

Vitamins. Vitamins, substances the composition of which is practically unknown as yet, are also necessary parts of a diet. We shall learn more about them in Unit XI.

Inorganic nutrients. Water and various salts, some of which, as calcium found in drinking water, form important parts of the diet of plants and animals. Later we shall see that green plants, although they use precisely the same nutrients (carbohydrates, oils, and proteins) as we do, take into their bodies the chemical elements from which these are formed. From these raw food materials organic foods are manufactured in the body of the plant.

The tree. Foods in a fluid form are circulated to all parts of a tree. It grows by elongating its roots and its branches, and by putting on a thin layer of living matter on all parts of its body. This layer grows more in summer than in winter. If we should cut down a tree, we can see the concentric rings in its trunk which mark its yearly growth. How did the tree do this? Here again the chemical laboratory is at work. The organic foods which were made consist of the same elements that are found in the living stuff of the tree. These foods were used, not only to supply energy so that the tree may do work, but they give it the materials out of which to build its living material.

\section{Self-Testing Exercise}

A nutrient is anything that supplies ...... (1), and ...... (2) or ........ (3) up the ....... (4) of living things. Foods are made up of (5) and ........ (6). The organic nutrients are ...... (7), (8) or ....... (9), and....... (10). 


\section{PROBLEM IV. HOW DOES MAN CONTROL HIS ENVIRONMENT?}

Natural environment. Besides the chemical elements in our surroundings, temperature, absence or presence of water, the kind of earth surface, the presence of different salts in the soil or water, all may play a part in determining what kind of life will be present in a given locality. Mountain, plain, desert, lake, woods, tropical jungle, each has its own inhabitants and these inhabitants are limited to life in that particular part of the world.

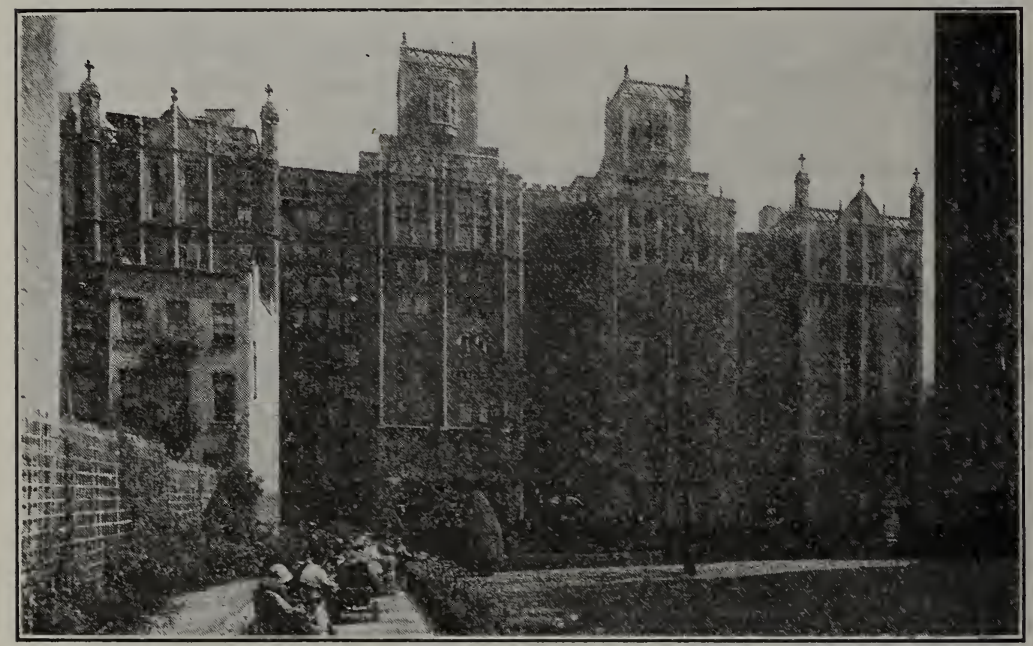

Photo by Douglas-Nesmith \& Associates

A city apartment house. Why do we consider this a favorable artificial environment?

Man, while he is like other animals in requiring heat, light, water, and food, differs from them in that he has come to live in a more or less artificial environment. Men who lived on the earth thousands of years ago did not wear clothes or have elaborate homes of wood, brick, or stone. They did not use fire, nor did they eat cooked foods. But, by slow degrees, man has come to live in an environment changed from that of other animals. He has learned to build houses and to use fire. The living together of men in communities has caused certain needs to develop. Many things can be supplied in common, as water, milk, and fuel. Wastes 
of all kinds in a town or city have to be disposed of. Homes are now placed close together, or built one on top of another, as in modern apartment buildings. Fields and trees, in fact most aspects of country outdoor life, have virtually disappeared in a large city. City-dwelling man has come to live in an artificial environment.

Care and improvement of the environment. Man can modify or change his surroundings by making this artificial environment favorable to live in. He can heat his dwellings in winter and cool

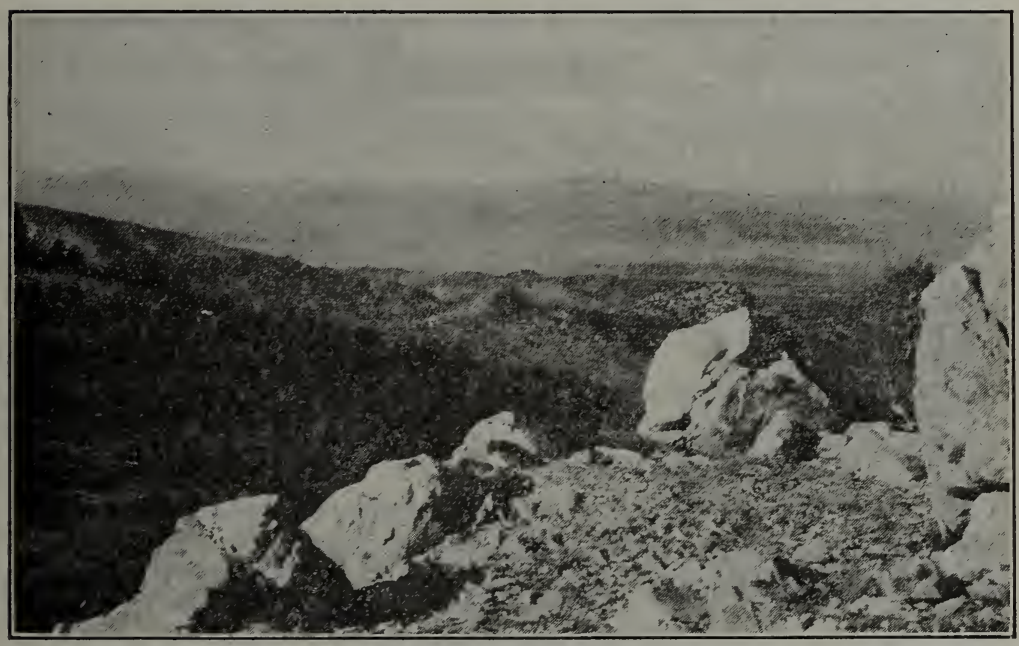

Why do we call this an unfavorable natural environment?

Wright Pierce

them in summer so as to maintain a moderate and nearly constant temperature. He can have windows in his dwellings to let light and air pass in and out. He can have light at night and shade from intense light by day. He can have pure water in his home, and drains or sewers to carry away his wastes. He can plan parks and playgrounds so that the city people may have breathing spaces, as do people in the smaller towns. He can see to it that people ill with communicable diseases are isolated or quarantined from others. Best of all, he is slowly learning to control the tiny parasites, plant and animal, that cause and spread 
diseases. This care of the artificial environment is known as sanitation, while the care of the individual for himself is known as hygiene.

\section{Self-Testing Exercise}

The environment is our ....... (1). With man much of this environment is ....... (2). He can ....... (3) his environment while other living things $\ldots \ldots \ldots(4)$ do this. The $\ldots \ldots \ldots$ (5) of the artificial environment is called .......(6), the care of the individual for himself without considering his ...... (7) is ...... (8).

Organization of work. In each unit there are certain fundamental things that we must learn and do. Everything in a unit is not of equal importance. It, therefore, is necessary for you to decide on the most important material from which you will make your recitation. To make this organization, a summary outline which you can use as a guide is helpful, as:

The tree a living thing

What does it use in its environment?

How does it get it?

Matter - what is it?

Elements and compounds

Oxygen and oxidation

Elements found in living things
Energy - forms of Conservation of

Foods and nutrients Kinds of each

Control of environment by man

In all except the first two or three units, there will be no summary outline and you will be expected to make one for your notebook. You should also test your knowledge of the unit in the following ways: (1) answer and check all of the survey questions ; (2) perform all assigned exercises or laboratory work ; and (3) check with your teacher the various self-testing exercises, including the final test on fundamental concepts and the attainment test.

\section{Test on Fundamental Concepts}

Make in your notebook two vertical columns, one headed CORRECT and the other INCORRECT. In the first column place the number of the statements you think are right, in the second the ones you think are wrong. Your grade $=$ number right $\times 4$.

I. The environment (1) contains the same chemical elements as do the living things in it ; (2) has the same chemical composition as living things; (3) is everything that surrounds us; (4) can be controlled by man; (5) determines the kind of plants or animals living in it. 
II. Matter (6) is anything that has meight; ( 7 ) is easily destroyed; (8) is material in the form of gas, liquid, or solid; (9) can be changed from one form to another; (10) is organic or inorganic.

III. Energy (11) can be either gaseous or liquid ; (12) is power to do work; (13) may be released by oxidation; (14) is potential or kinetic ; (15) is stored in the foods we eat.

IV. Foods (16) contain waste material; (17) are all obtained in their final state from the soil ; (18) contain nutrients; (19) are used by plants and animals to release energy and to build and repair tissue; (20) are made by green plants.

V. Man (21) can control his environment; (22) needs green plants to make food; (23) is not able to oxidize food to release energy; (2t) is composed of the same chemical elements as his environment; (25) is the only living thing that can change his environment.

\section{Achievement Test}

1. How can you make oxygen?

2. How do you test for carbon dioxide?

3. What chemical and physical happenings take place when you burn a match?

4. What are the chemist's symbols for oxygen, nitrogen, carbon, hydrogen, and carbon dioxide?

5. What is meant by the term "conservation of energy"? How could you perform a demonstration to prove it?

6. How can you distinguish between the natural and artificial factors of your environment?

\section{Practical Problems}

1. List the ways in which a tree and man use their environments. List the natural and artificial factors of your environment.

2. Take some factor of the environment in your community that you think is poor and make definite suggestions for its improvement.

3. Show some example of conservation of energy taken from your own home environment; from the country in which you live.

\section{USEFul ReFERENCES}

Downing, Our Living World, pp. 309-350. (Longmans, Green, \& Co., New York, 1924.)

Hunter, G. W., and Whitman, W. G., Problems in General Science. "Control of Environment," pp. 15-34. (American Book Company.) Pack, Trees as Good Citizens, pp. 17-26. (American Tree Association, Washington, D.C., 1922.) 


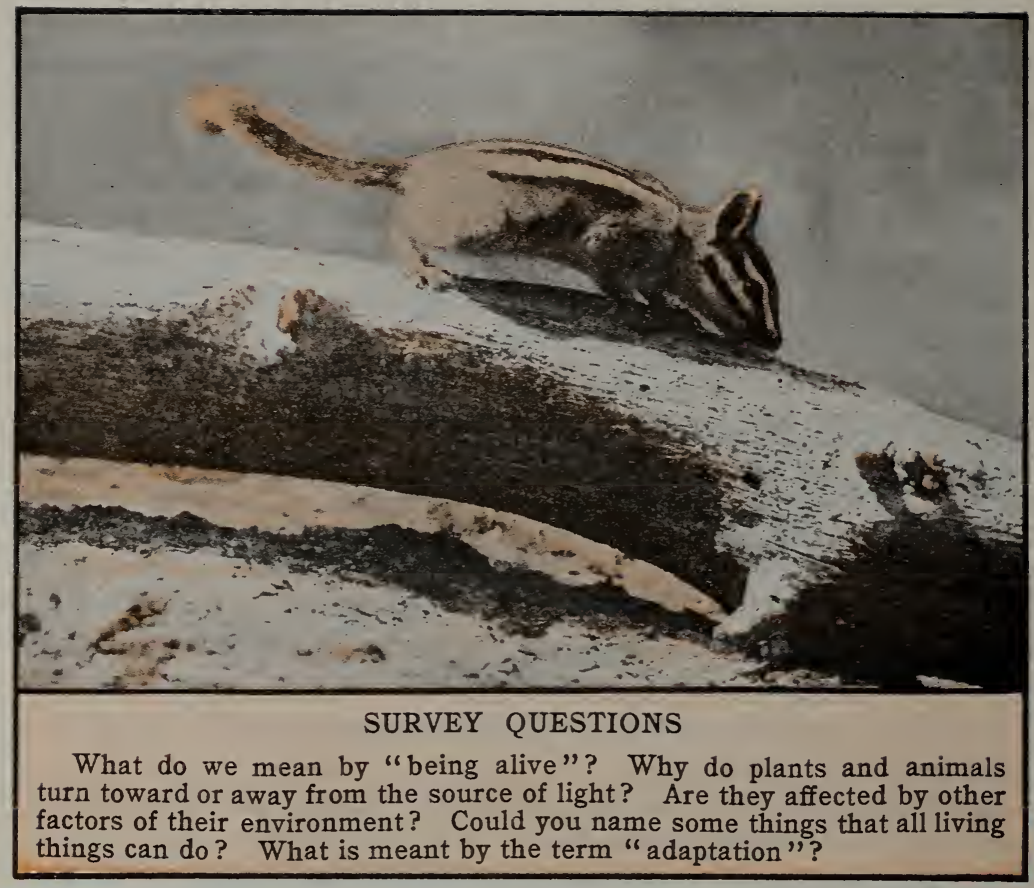

UNIT II

\section{WHAT IS BEING ALIVE? THE FUNCTIONS OF LIVING THINGS}

Preview. We have seen in our study of elementary science, several differences between living and non-living matter. Water, for example, when cooled sufficiently, becomes ice, or, if heated to the boiling point, becomes vapor. In order to be changed it has to be acted upon by outside forces. But when a plant or an animal grows, or moves, or in some other way manifests energy, that energy is released by the living thing itself.

We think of things as being alive when they do something. Yet water may turn a wheel and generate electricity which has a force capable of "doing something." Such a force may set off a blast 
of dynamite. Or electricity, in the form of a flash of lightning, may destroy a tree.

It is not easy to tell exactly what it is to be alive, any more than it is easy to tell what electricity is or what radioactivity is. Electricity is a servant of man, but the greatest expert cannot tell what the force actually is. Life is a manifestation of forces, like a flame or electricity. Every living thing, as we shall see later, is like a steam engine or any other machine, in that it is a medium used for the transformation of energy. So to understand the meaning of life we had better start by trying to see how living things act in their normal environment when outside forces influence them.

One of the world's great biologists, Jacques Loeb (zhảk lōb), some years before his death attempted to prove that all living things are more or less automatically controlled by the factors of their environment. He assumed that all living matter is sensitive and that it responds or reacts to the forces of its environment, in very definite ways. These forces we call stimuli (sing. stimulus); the response which is made to such a stimulus we call a tropism. Loeb and his followers have shown quite conclusively that living matter responds very definitely to temperature, touch, chemical substances, electricity, and various other factors of the environment. The behavior of plants and animals in response to these various stimuli is one indication of being alive.

Response to stimuli is evidenced by activity or movement. Movement in living things is brought about by changes within the living material of which the organism is composed, while the movement of non-living things, as an engine, is brought about by the force of burning coal or exploding gasoline. This activity is due to the fact that living things are like engines in another respect: while the engine oxidizes fuel to release energy, they oxidize the food taken into their bodies and release energy in the form of motion or other kinds of work.

Any living thing, plant or animal, must get food and digest it, must circulate this digested food to various parts of its body, must assimilate or make the prepared food into a part of itself, must excrete or get rid of wastes, and must reproduce or form new ‥ $\mathrm{BIO}-4$ 
plants or animals. Adaptability is also a characteristic of living things. We say that a plant or animal adapts itself to its surroundings, meaning that some structure of the animal or plant has made it possible for the organism to live under the conditions in which it is placed.

A little over two hundred years ago, a Dutchman, Anton van Leeuwenhoek (lā'věn-hơk), became interested in lenses. $\mathrm{He}$

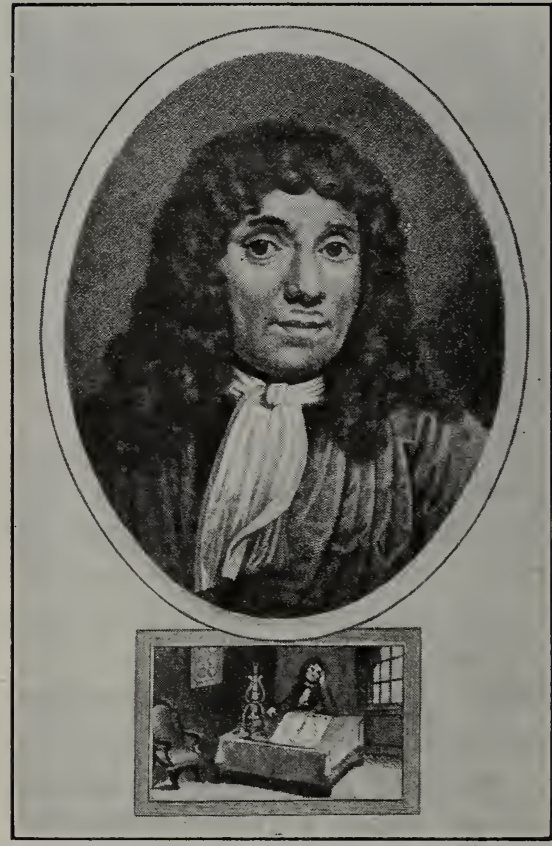

Culoer Service

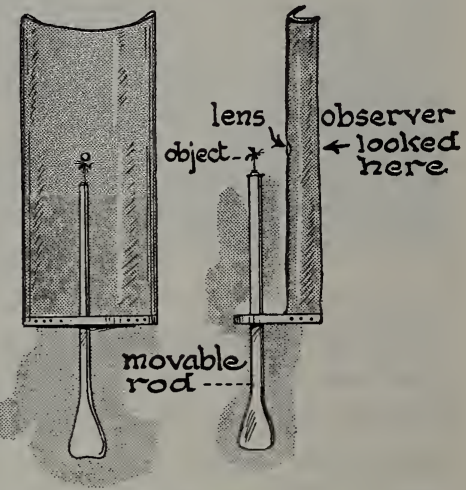

Anton van Leeuwenhoek was at first only interested in grinding lenses and making crude microscopes so that he could see things bigger than the naked eye could see them. But later he became interested in observing minute animals that could not be seen with the naked eye. Through his discoveries and observation, incentive was given to the study of bacteria.

ground hundreds of them, and used them in various combinations to magnify tiny plants and animals. With these improved lenses he was able to see tiny organisms swimming in drops of pond water, and it is even thought that he probably saw living bacteria. An English doctor, Robert Hooke (1635-1703), examined a small section of cork, which is the bark of an oak tree, and found it was made up of tiny compartments, like rooms, which he called cells, a term which is now universally used for the unit of structure in living things. 
The name cell is not very descriptive. Hooke saw the dead walls around the spaces that during the life of the plant contained living matter. But it was not until more recent times that biologists found that the contents of the cell is the important living substance. This living material has been named protoplasm (Gr. protos, first; plasma, formative material). While we rarely see it or feel it, nevertheless observation has shown it to be always present where there is life. It is a sticky, semi-fluid substance, somewhat like the white of an egg in consistency. Its chemical composition is very difficult to discover and it is probable that there are a number of different kinds of protoplasms in the bodies of plants and animals. Under the microscope it seems to be either granular, or made of tiny bubbles floating in a more fluid medium, or it sometimes appears to be made up of delicate fibers or threads, forming a network of infinite complexity. The cell is always found in the structure of living things, just as bricks make up the structure of a wall or a house.

\section{PROBLEM I. WHAT DO WE MEAN BY REACTION TO STIMULI?}

Demonstrations. 1. Reaction to water. Plant some bean seeds in sawdust in a box with glass front. Water the seeds in one end of the box only. How do the roots grow?

2. Reaction to light. Put oxalis or other plant in a place where it will receive light on one side only. Put some earthworms in a pan covered at one end. What happens in each case?

3. Reaction to gravity. Place a pocket garden (see page 142), in which radish seeds are germinating, on end and then turn it two or three times at intervals of 24 hours. What happens?

4. Reaction to chemical stimuli. Make observations on young seedlings growing in solutions containing a lack of certain chemical elements necessary for growth (see page 609). What do you find?

5. Reaction to temperature. Put some beans in moist sawdust in vessels. Put one vessel in the ice-box, another in a moderately warm room, and the third in an oven where the temperature is over $160^{\circ} \mathrm{F}$. Observe what happens.

Water. It is a well-known fact that living things need water, in order to sustain life. The roots of green plants grow toward a source of water. Some animals appear to be stimulated to move toward water, whereas others move away from moisture. Water is of so much importance to man that from the time of the Caesars 
until now he has spent enormous sums of money to bring pure water to his cities.

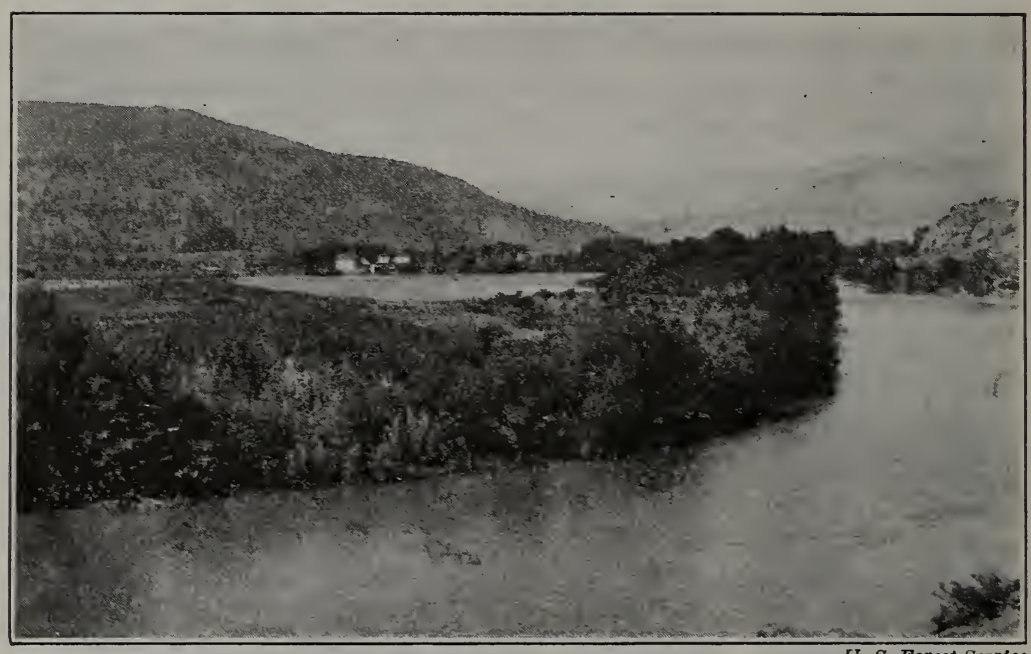

An irrigated ranch. Why is the vegetation unusually thick along the water edge?

Light. Light is another important factor of the environment. A study of the leaves on any green plant growing near a window will convince one that the stems of such plants grow toward the light, and that the leaves grow in positions to get a maximum amount of sunlight. All green plants are thus influenced by the sun. We say an organism is positively influenced by a stimulus when it turns or moves toward that stimulus, and that it is negatively responsive when it turns or moves away from the stimulus. Other plants which are not green seem either indifferent or negatively influenced by the stimulus of light. The direction, as well as the intensity of light, is an important factor. Animals may or may not be attracted by light. A moth, for example, will fly toward a flame; an earthworm will move away from light. Some animals prefer a moderate or weak intensity of light and live in shady forests or jungles, prowling about at night. Others seem to need strong light. Man himself is most comfortable and works most efficiently in a moderate intensity of light. 
Gravity. Another factor influencing both plants and animals is gravity. The main or top roots of plants, for example, tend to grow downward. Lateral roots, on the other hand, grow in an approximately horizontal direction. Careful experiments in which other forces are substituted for the pull of gravity have proven that gravity is the attractive force. The stem, on the other hand, grows upward. This seems to be a negative response to gravity. Many animals show this response to gravity in very definite ways. The maintenance of one's equilibrium is undoubtedly a response to gravity, as has been proved in some of the lower animals, such as shrimps and fishes.

Food or chemical substances. Plants are greatly influenced by the presence or absence of chemical substances in the soil. You have probably noticed the differences between plants that grow near the sea, where salt is found in the soil, and those growing inland. No one who has traveled in a country where the soil is impregnated with alkali can fail to see the differences between vegetation there

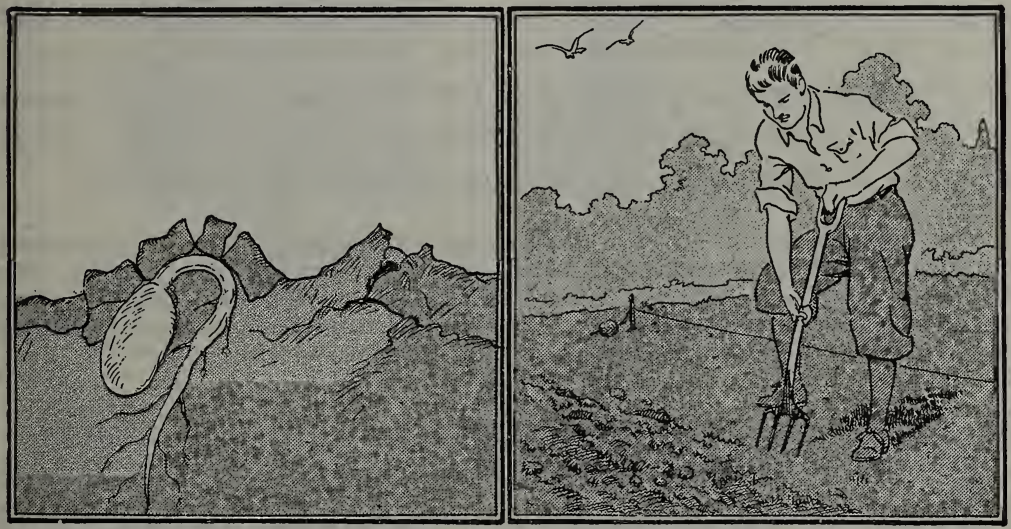

How does the seedling show energy? How does the man?

and in other regions where no alkali exists but where similar conditions of temperature and moisture are found. Since the mineral salts of the soil are absorbed by the plant and later built into it, we can easily see that responses of this sort are of the utmost importance.

Temperature. Living things are affected by heat or cold. Animals and small plants that are able to move in the water fre- 
quently go away from a temperature that becomes unfavorable to their existence. In cold weather, green plants either die or temporarily suspend their life activities. They become dormant. Likewise, small animals, such as insects, which might be killed by cold, usually hibernate under stones or boards. Their life activities are slowed down until the coming of warm weather. Bears and some other large animals go to sleep during the winter and awake, thin and hungry, on the approach of warm weather. Animals and plants used to certain temperatures frequently die if they are put in a colder or hotter climate. Even man, one of the most adaptable of all animals, cannot stand great changes without discomfort and sometimes death. He heats his houses in winter and sometimes cools them in summer, so as to have the amount of heat most favorable to his health ; namely, about $68^{\circ} \mathrm{Fahrenheit.}$

The value of tropisms. A study of hundreds of experiments with plants and animals shows us that their instinctive resporises or tropisms are of the greatest use to them. Response to a favorable stimulus results in placing the living plant or animal where it can get food, light, or more moisture and thus better succeed in the world. In general, tropisms bring the plants or animals into adjustment with their environment so that they may obtain what they need in order to succeed in the surroundings in which they must live.

Practical Exercise. Make a list of as many responses to stimuli in the plant world as you can find and classify them under the headings given above. Do the same thing for animals. Then make a list of your own responses and classify them in the same manner. Do you differ markedly in your responses from plants? From lower animals? If so, how?

\section{Self-Testing Exercise}

Tropisms are the $\ldots \ldots \ldots$ (1) .......(2) of plants and animals to certain .......(3) in their ....... (4). Roots of plants react .(5) to gravity while the stems react .......(6). Roots grow toward ........(7), and leaves usually turn toward the ....... (8). Earthworms will move .......(9) the light. Tropisms help bring plants and animals into $\ldots \ldots \ldots(10)$ with their $\ldots \ldots \ldots$ (11), so that they can .......(12) there. Plants are affected by the .......(13) .......(14) found in the soil. Living things are affected by $\ldots \ldots$ (15) and $\ldots . . .(16)$. 


\section{PROBLEM II. HOW ARE LIVING THINGS ALIKE AND HOW DO THEY DIFFER?}

Laboratory Exercise. Compare a living plant and a living animal, with reference to life functions. Use living grasshoppers under glass tumblers placed over a bean seedling, a small living weed or a grass plant. Use the text of the problem which follows as a laboratory guide.

If we attempt to compare an insect with the plant on which it feeds, we see several points of likeness and difference at once. Both plant and insect are made up of parts, each of which, as the stem of the plant or the leg of the insect, appears to be distinct, but, which is a part of the whole living plant or animal. Each part of the living plant or animal which has a separate work to do is called an organ. Plants and animals, therefore, are spoken of as organisms.

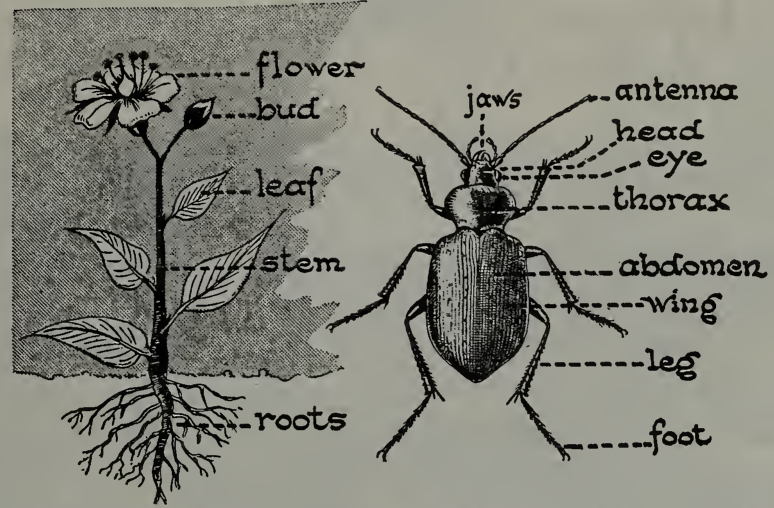

Read your text carefully and compare the uses of the parts of the plant and the insect given in the diagram.

In spite of the apparent differences between a green plant, such as a tree, and an animal, like the grasshopper, the life functions or processes are very similar, as we shall see in the paragraphs that follow.

Sensation and motion. We have already shown that all living things respond to various stimuli. The stem of a green plant turns toward the light, an earthworm shuns the sun's rays. Plants, as well as animals, move, as is observed in the movements of roots toward a source of water, or the movements of fish in a stream so that they head up against the current. 
Food taking. It is not so easy to prove at this time that all living things take food. We know animals will die without a food

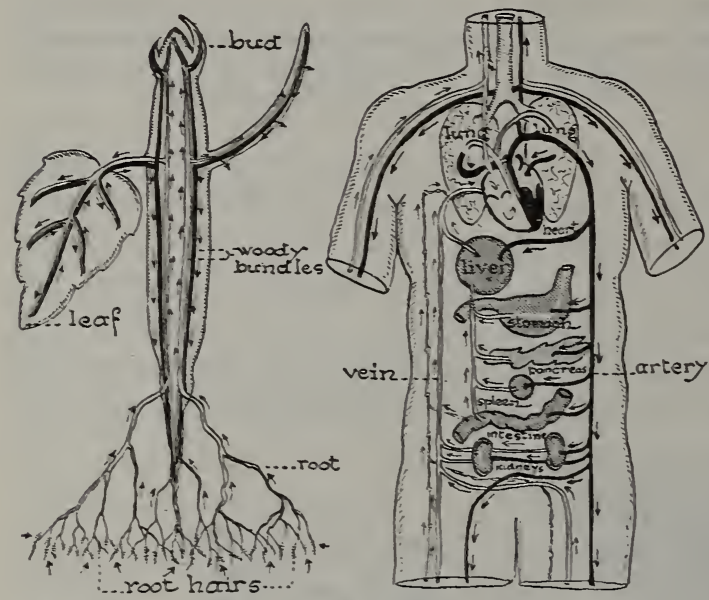

In what ways are the circulations of a plant and an animal alike? In what ways do they differ? supply. We also know that some plants, like molds or mildews, grow on food substances. But green plants live in soil apparently without food if they have a moderate water supply. This is possible because green plants make organic food substances out of the materials obtained from the soil, of water, and a part of the air. Both plants and animals use organic food substances in exactly the same way, that is, they get energy out of them to do work, and they build up their bodily material out of the food they use.

Respiration. Respiration is the process by which oxygen is supplied to the body and carbon dioxide is removed. As a result food is oxidized and energy is released. The processes are the same in both plants and animals as will be shown in detail later. Plants release enough energy to force their way through the compact earth; animals release their energy in the activity we associate with running, swimming, flying, etc.

Nutrition. The foods of plants and animals must be made liquid so that they may pass freely to various parts of the organism to be used there. In order to do this they must be digested, or changed to a form that will enable it to be taken in by the smallest units of body structure, the cells. The way this is done will form the basis of an important problem later on in our course. Then these foods must be absorbed or taken into the organs of circulation, 
which are woody tubes in plants and blood vessels in animals. Then this digested food must finally become part of the living organism by assimilation.

Excretion. Wastes, such as water, carbon dioxide, and urea, are formed in the body by oxidation and other changes. If these wastes are not eliminated at once, they interfere with the normal working of the body. Therefore excretion is a necessary body function.

Reproduction. Reproduction, or the formation of new organisms, is the outcome of all the nutritive processes. Plants and animals have various methods of giving rise to new plants and animals. But the result is the same in both cases; that mysterious something we call life is started again as a seed, an egg, or a baby animal to become in time a parent of another generation of life. Some of the material in the following units deal with this life function.

Practical Exercise. List for comparison the evidences of life processes (mentioned in preceding paragraphs) in a common plant and in an animal.

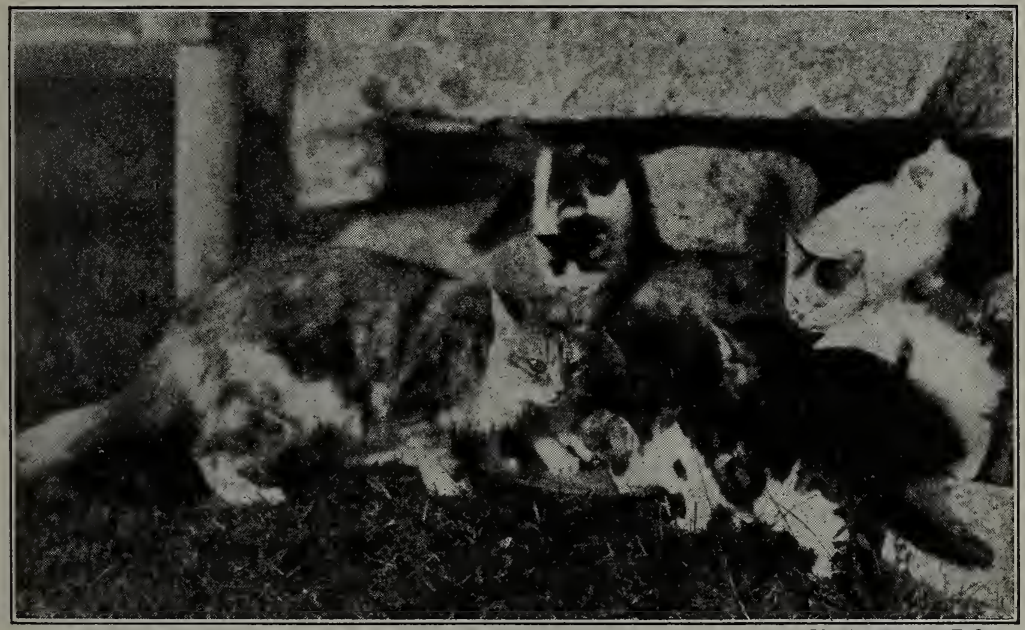

H. Armstrong Roberts

Animals and plants give rise to new organisms. These offspring resemble their parents and each other. Yet, very seldom do we find two individuals exactly alike.

\section{Self-Testing Exercise}

Living things, because they are .......(1) of . . . . (2) are called organisms. Both plants and animals have similar .......(3). 
They both respond to $\ldots \ldots \ldots$ (4), use $\ldots \ldots$. (5) to grow or release ....... (6), and respire. Nutrition is the process by which living things $\ldots \ldots$...(8),$\ldots \ldots$ (9),$\ldots \ldots$ (10) and .......(11) food.

\section{PROBLEM III. WHAT ARE CELLS AND HOW DO THEY PRODUCE OTHERS?}

Laboratory Exercise. Put a drop of impure water on a slide. Cover with a cover slide and observe it under a compound microscope. Adjust the lenses until the particles in the water can be plainly seen.

Now scrape, with a sterilized toothpick, the inside of the cheek. Place a small bit of the material in a drop of pure water on a glass slide and

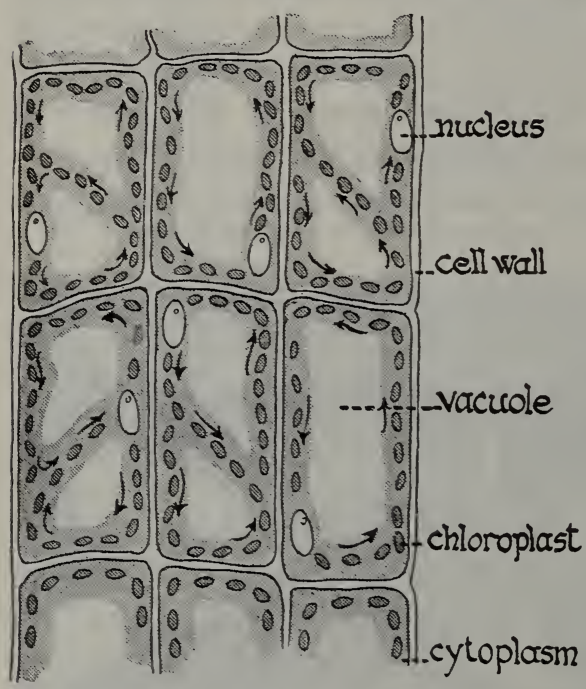

What are the characteristics of a plant cell? How does Elodea differ from animal cells? stain it with a small drop of diluted fountain pen ink or methylene blue. Notice the irregular blue structures or cells. Find a deeper blue body inside the cell. This is the nucleus. The outer faint blue line marking the edge of the cell is the cell membrane.

Peel the skin from one of the fleshy leaves forming an onion bulb, mount a small bit of it in water to which is added a drop of dilute tincture of iodine. Examine it under a microscope. Note the cells. Plant cells differ from animal cells in that they have a delicate wood wall outside the membrane. Draw two or three animal and plant cells in your notebook. Make each cell at least one inch in diameter. Label all parts.

An examination of the delicate leaves of the Elodea, a water plant used in aquariums, shows cells with many large spaces or vacuoles, which are filled with a non-living fluid instead of protoplasm. Forming a part of the protoplasm are many small ovoid bodies, most of which are green in color. These are the chloroplasts (klō'rò-plăsts) or chlorophyll (klō'rof-fül) bodies (Gr. chloros, green ; phyllon, leaf). We shall see later that they are of the utmost importance to each one of us, as it is by means of the action of the sun upon them that food is manufactured in the green parts of plants. 
In living Elodea, an interesting phenomenon may be observed. The protoplasm in the cell body is seen to be constantly in motion, flowing slowly in the direction of the arrows shown in the diagram. This streaming of protoplasm is one of the manifestations of life within the cell. In many cells this movement may be observed, and we have reason to believe that the protoplasm in most living cells is in motion, thus affording a circulation of the cell contents.

Tissues and organs. The cells which form certain parts of the veins, the flat

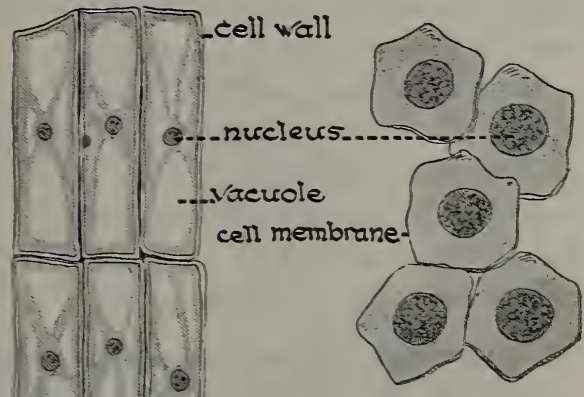
blade, or other portions of a leaf, are found in groups or aggregations, and are more or less alike in size and shape. Such a collection of cells is called a tissue. Examples of tissues in ani-

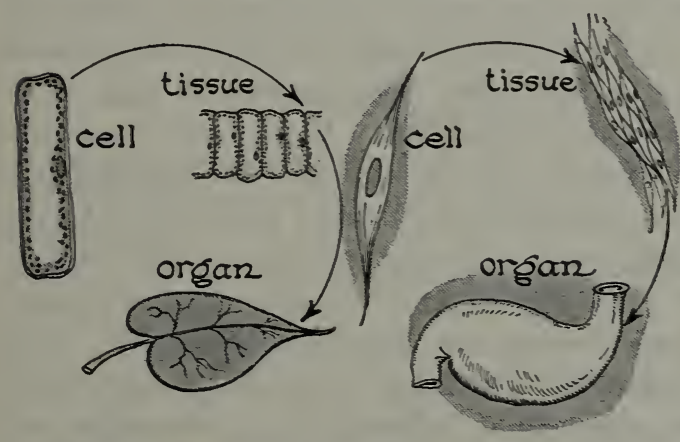

Cells, tissues, and organs in plants and animals. Explain this illustration. mals are the cells covering the outside of the body, forming the skin or epidermal tissue; muscle tissue, which produces movement; and bony tissue, which forms the framework to which the muscles are attached. Tissue cells of ten differ greatly in size and shape. A large plant or animal is ordinarily made up of more, not larger, cells than a smaller organism.

Collections of tissues which act together in the performance of 
work form organs. Such an organ is a leaf, made of supporting cells, green cells, spongy cells, etc.; or the human arm, with its bony supporting tissue, its nerves and muscles, its blood vessels and connective tissue.

How cells form others. Cells can grow only to a certain size. When this limit is reached, the cell splits, forming two cells. In this process, which is of very great importance in the growth of both plants and animals, the nucleus elongates and divides; the halves separate and go to opposite ends of the cell. Then the rest of the protoplasm divides equally and two cells are formed, each
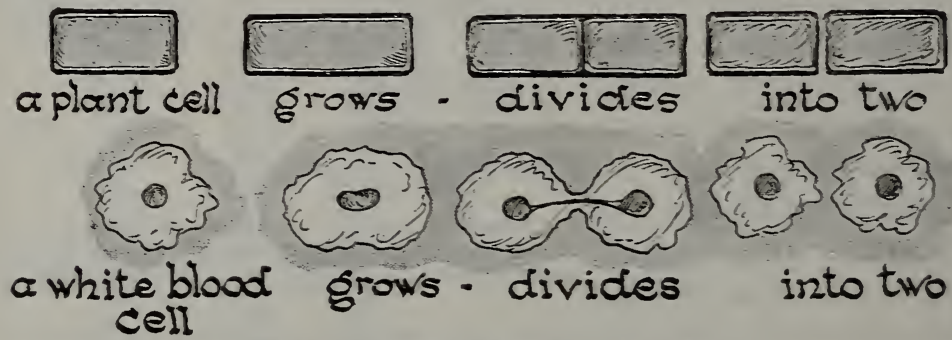

Plant and animal cells multiply by division.

containing a nucleus. Each cell will have exactly the same characteristics possessed by the original cell. This process is known as direct cell division. Usually a more complicated process of division known as mitosis occurs in most cells. See diagram on page 49 .

The chromosomes and their functions. If we now examine a specially prepared and stained cell, for example, the egg cell of a worm or a frog, we shall find that the nucleus, when stained with certain dyes, shows numerous small deeply stained bodies within it. These structures are called chromosomes (krō'mö-sōmz; Gr. chroma, color; soma, body), or color-bearing bodies. The number of these chromosomes in each body cell of a given kind of plant or animal is always the same. For example, forty-eight are found in man, four in a certain worm, and eight in one kind of lily. In plants and animals there are two distinct kinds of cells, one group called the somatic or body cells, which form the bulk of the body, and the sex cells which pass on the heredity qualities to the next generation. The sex cells are able to do this by means of 
the chromosomes, which are believed to be the bearers of the hereditary qualities which can be handed down from parent to offspring.

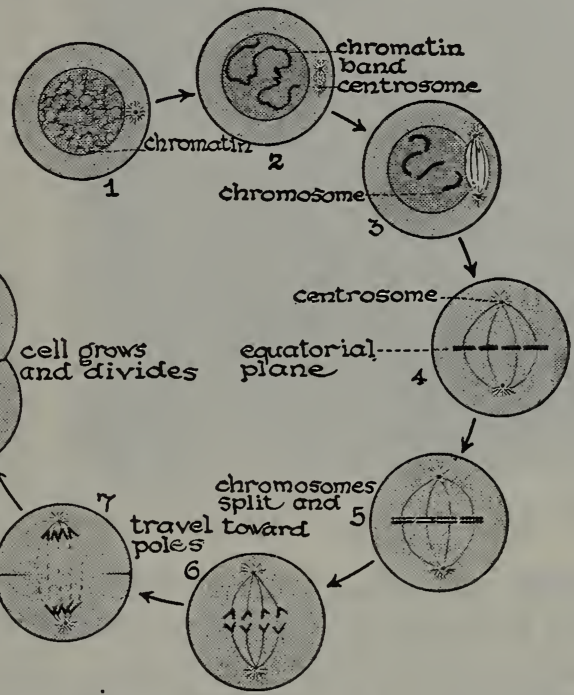

An animal cell showing mitotic division. During this division the chromatin granules form a coiled thread which finally breaks up into chromosomes. Each chromosome splits into two similar parts which go to the opposite ends of the cell, where they become a part of two new nuclei. At the same time a small structure, the centrosome, separates into two parts. A wall forms midway between the two nuclei, and the cell divides, forming two cells.

\section{Self-Testing Exercise}

Cells are the units of .......(1) of plants and animals. A plant cell differs from an animal cell by having a ...... (2) ...... (3) and containing ........ (4). All cells contain a ....... (5). Cells grow by .......(6). Hereditary qualities are handed down from one generation to another by means of the ....... (7) in the ....... (8) .......(9). A collection of like cells is called a ........(10). An organ is made up of a .......(11) of .......(12) acting together to do ........(13).

\section{PROBLEM IV. WHAT DO WE MEAN BY ADAPTATION?}

Demonstration 6. Show by means of charts, pictures, and actual examples, a number of adaptations such as bills and legs of birds ; wings of insects; teeth of carnivorous animals. Protective coloring in insects, and adaptations in plants, especially in cactus, pitcher plant, 


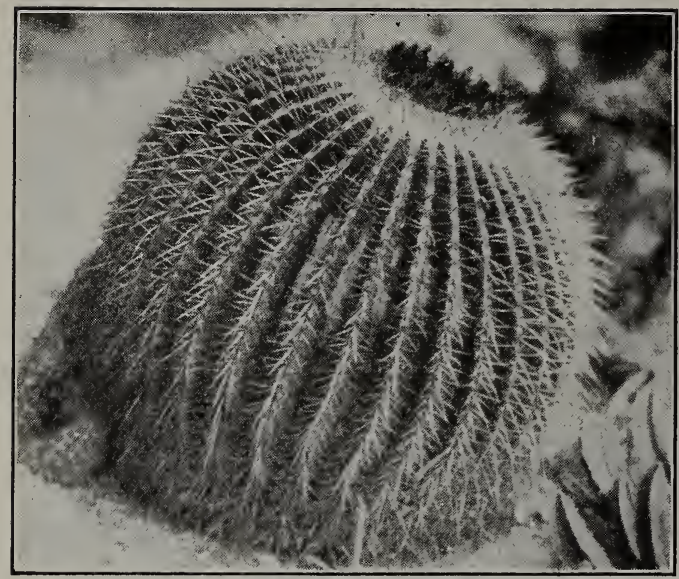

Wright Pierce
Mention several ways in which this cactus is fitted to live in the desert. and thistle, are striking examples. Opportunity should be given for all members of the group to go, if possible, to a good museum where such material is on display.

Practical Exercise. List as many different examples of plant and animal adaptations as you can. Be prepared to explain them before the class. If possible, bring to class examples or diagrams of the animals or the plants which show these adaptations.

Adaptability, a function of living things. Not only are plants and animals fitted to live under certain conditions, but each part of their bodies may be fitted to do certain work. I notice that as I write the fingers of my right hand grasp the pen firmly and the hand and arm execute some very complicated movements. This

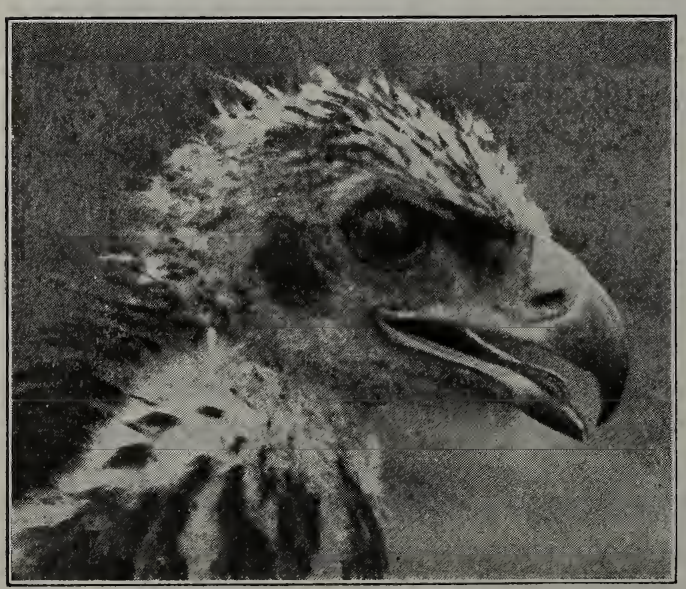

Wright Pierce

How does the beak of the eagle fit it for catching and using its food? they are able to do because of the movement made possible by the arrangement of the delicate bones of the arm, a complex system of muscles which move the bones, and a directing nervous system which plans the work. Because of the peculiar fitness in the structure of the hand for this work we say it is adapted to its 
function of grasping objects. A structure which is useful to an organism in some special way is called an adaptation.

Each part of a plant or animal is usually suited for some particular work. The root of a green plant, for example, is able to take in water by having tiny absorbing root hairs grow-

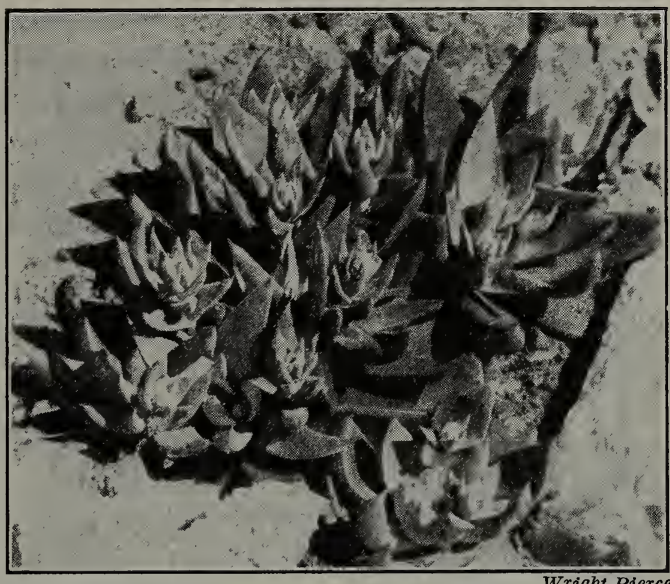

How is this low plant with large succulent leaves fitted to live in a desert?

ing from it. The stems have tubes to convey liquids up and down from roots to leaves, and are strong enough to support the leafy part of the plant. The thin, flat leaves are arranged to receive a very large amount of sunlight and to act as solar engines, that is, using energy from the sun. Each part of a plant does work, and is fitted, by means of certain structures, to do that work. The lungs of a land animal are able to take oxygen from the air, while the gills of a fish can take their supply of oxygen only from the water; that is, from the air that is dissolved in water. It is because of such adaptations that organisms are able to live within

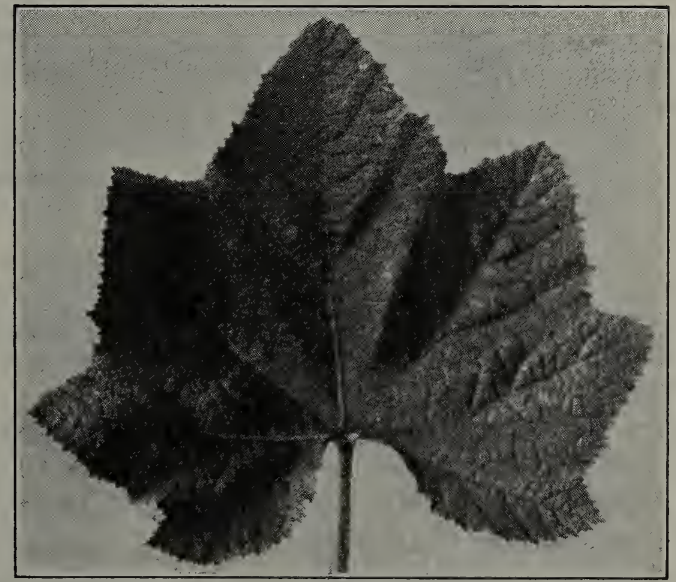

Wright Pierce

What might be the advantages of a large flat leaf to a plant? 
their particular environments. Some adaptations are protective, as the bark of trees, the spines or thorns on some plants, the shells of turtles, the feathers of birds, the heavy hairy coats of a dog or a cat, the strong teeth of a tiger. The trunk of the elephant, the long neck of the giraffe, the pouch of the kangaroo, the flipper of the whale, or the web on the wing of the bat are all adaptations for various purposes.

Practical Exercise. Classify the above adaptations according to their specific uses. Make a table giving at least five kinds of adaptations found in plants, and five kinds found in animals.

\section{Self-Testing Exercise}

An adaptation is a .......(1) that is ......(2) to an orga -1 ism in some .......(3). By means of .......(4), .....(5) and (6) are enabled to .......(7) in various environments. Without adaptations ....... (8) would be impossible.

\section{Review Summary}

Test your knowledge of the unit by: (1) Answering and rechecking the survey questions; (2) performing the assigned exercises; (3) checking with the teacher your scores on the various tests, and if you do not have a perfect score, try again the parts you missed; (4) doing as much of the optional work as has been assigned to you; and finally filling in the following outline as fully as possible for your notebook.

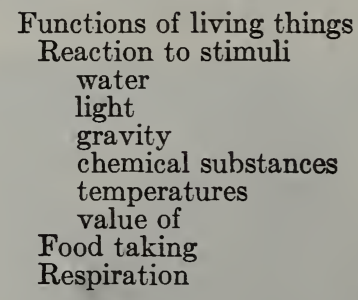

Nutrition

Excretion

Reproduction

Cell unit of structure parts functions of formation of

Adaptations of living things

\section{Test on Fundamental Concepts}

Make two columns on your notebook. Head one CORRECT, the other INCORRECT. Place in these columns the numbers of the sentences you think are right and those you think are wrong. Your grade will be the number correct $\times 4$.

I. Tropisms (1) are reactions to the various stimuli in the environment; (2) are structures which cause reactions to stimuli ; (3) make it possible for green plants to live without the sun; (4) are brought about by food, water, light, heat, chemical substances, and other factors of the environment; (5) bring the organism into adjustment with its environment. 
II. Both plants and animals (6) are made up of cells; (7) react to stimuli; (8) have the same life processes ; sensation, motion, respiration, nutrition, excretion, and reproduction; (9) make food; (10) release energy from their food in order to do work.

III. Cells (11) are made of living material ; (12) are always green in color; (13) all contain nuclei; (14) in both plants and animals are exactly alike; (15) are units of building material in living things.

IV. Growth in organisms takes place (16) by increase in the size of the cells; (17) by increase in the number of the cells ; (18) by increase in the number of chromosomes in the cells ; (19) when cells composing them divide; (20) when the living matter takes in more food.

V. A living thing (21) is adapted to live in a given environment when it has structures which fit it for that life ; $(22)$ is adapted to do a given piece of work when it has structures that fit it for that work ; (23) may adapt itself to any environment; (24) reacts to stimuli ; (25) will die if taken from its original environment.

\section{Achievement Test}

1. How do plants or animals react to stimuli?

2. How would you perform at least one experiment to show tropism?

3. How can you distinguish between living and non-living things?

4. Have you seen a cell? Name the parts and uses of each part.

5. How can you make a classification of adaptations and show slearly just what you mean by this classification?

\section{Practical Problems}

1. Show specifically how man has made use of the fact that certain plants or animals react to the stimulus of light.

2. Prove how some tropism is of value to a plant; to an animal.

3. Explain fully how your leg is adapted to its uses.

\section{USEFul REFERENCES}

Burlingame and others, General Biology. (Henry Holt \& Co. 1928.) Caldwell, Skinner, Tietz, Biological Foundations of Education. (Ginn \& Co. 1931.)

Eikenberry and Waldron, Educational Biology. (Ginn \& Co. 1930.) Loeb, Forced Movements, Tropisms and Animal Conduct. (J. B. Lippincott Co. 1918.)

Plunkett, Outlines of Modern Biology. (Henry Holt \& Co. 1930.) Shumway, General Biology. (John Wiley \& Sons. 1931.)

Thomson, The Outline of Science. (G. P. Putnam's Sons. 1922.)

Transeau, General Botany. (World Book Company. 1923.)

Wiggam, Fruit of the Family Tree. (Bobbs-Merrill Co. 1924.)

$$
\text { в. В10 }-5
$$




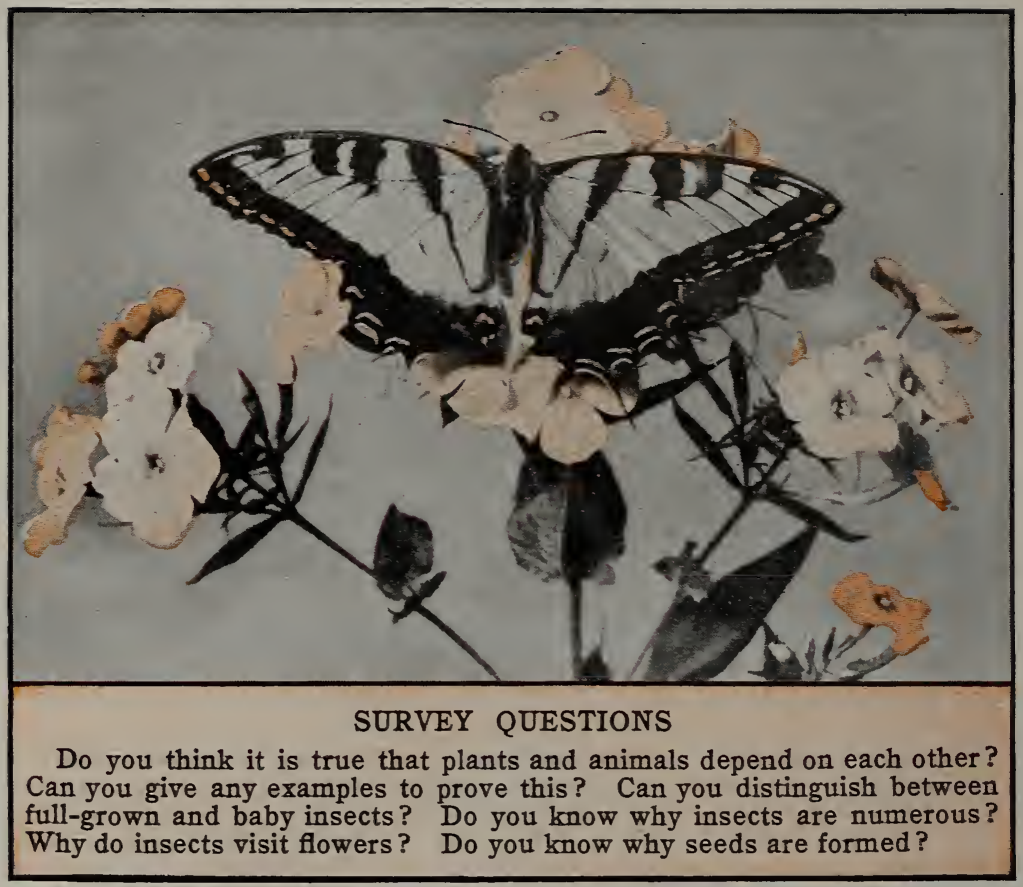

UNIT III

\section{HOW ARE ANIMALS AND PLANTS MUTUALLY DEPENDENT?}

Preview. Anyone who has been in the field cannot help thinking that insects have something to do with flowers and green plants. Grasshoppers eat the green leaves, beetles crawl over the goldenrods, butterflies light on flowers or deposit their eggs on some plant that their young will use as food. Almost everywhere honeybees can be seen busily at work among the flowers. What are they all doing? Is it something that we can discover for ourselves?

If we were to take a single tree for observation, we might find birds nesting in the branches; perhaps a squirrel or two has a home there ; insects of many kinds may be found on its leaves, or under 
its bark; while an examination of the soil around its roots would show us many other living forms such as the pupae and nymphs of insects. Perhaps our tree might have queer looking growths called galls on the leaves or stems. These, if examined, would be found to be the homes of tiny insects and bacteria. If the tree had flowers we should be sure to see numerous insects on them.

Each insect has its own favorite food plant or plants, and in many cases the eggs are laid on the plant so that the young may have food close at hand. Some insects like the rotted wood of trees. An American zoölogist, Packard, has listed 462 species of insects that live upon oak trees alone. Everywhere insects are engaged in taking their nourishment from plants, and millions of dollars of damage is done every year to gardens, fruits, and cereal crops by these animals. Insects in turn are the food of birds; cats and dogs may kill birds ; lions and tigers live on large defenseless animals such as deer or cattle; and finally, man eats the bodies of both plants and animals. But if we reduce this search for food to its final limit, we see that green plants provide all the food for animals. For the lion or tiger eats the deer which feeds upon grass or green shoots of young trees, and the cat eats the bird that lives on weed seeds or on insects that eat plants. Green plants supply the food of the world.

On a field trip no one can fail to observe that plants often give animals a home. The grass shelters grasshoppers and smaller insects. Some insects, such as the tent caterpillar, build their homes in the trees or bushes on which they feed, while others tunnel through the wood, making homes there. Spiders build webs on plants, often using the leaves for shelter. Birds nest in trees, and many wild animals use the forest as their home. Man has learned to use many kinds of plant products to aid him in making his home, wood and various fibers being the most important of these products.

So far it has seemed as if green plants benefited animals and received nothing in return. We shall see later that plants and animals together form a balance of life on the earth and that each is necessary for the other. Certain substances found in the body wastes of animals are necessary to the life of a green plant. 
One of the most interesting relationships for study are those that exist between insects and flowers. Flowering plants, as we know, produce seeds and fruits, and from these come new generations of plants. Not all of us realize, however, the very close dependence of these plants on the insects that visit them. If it were not for these insect visits, many plants would not produce seeds.

In the latter part of the eighteenth century a German named Christian Konrad Sprengel worked out the facts that the structure of certain flowers seemed to be adapted to the visits of insects. Certain facilities were offered to an insect in the way of easy foothold, sweet odor, and food in the shape of pollen and nectar, the latter a sweet-tasting substance manufactured by certain parts of the flower known as the nectar glands. Sprengel further discovered the fact that pollen could be and was carried by insect visitors from the anthers or pollen-bearing organ of the flower to the top of the part that produced the seeds. It was not until the middle of the nineteenth century, however, that an Englishman, Charles Darwin, worked out further the relation of insects to flowers by his investigations on the cross-pollination of flowers. By this we mean the transfer of pollen from the pollen-producing organ of one flower to the seed-producing organ of another flower of the same kind.

Many species of flowers are self-pollinated, but Charles Darwin found that some flowers which were self-pollinated did not produce as many seeds, and that the plants which grew from their seeds were smaller and weaker than plants from seeds produced by cross-pollinated flowers of the same kind. He also found that plants grown from cross-pollinated seeds tended to vary more than those grown from self-pollinated seeds. This has an important bearing, as we shall see later, in the production of new varieties of plants. Darwin studied for many years the pollination of flowers, and discovered in almost every case that showy, șweetscented, or otherwise attractive flowers were most likely to be cross-pollinated by insects. He also found that, in the case of flowers that were inconspicuous in appearance, often a compensation appeared in the odor which apparently rendered them attrac- 
tive to certain insects. The so-called carrion flowers, pollinated by flies, are good examples, their odor being like that of decayed flesh. Other flowers, which open at night, are white and provided with a powerful scent so as to attract night-flying moths and other insects. All these and many other interesting facts about insects and flowers and their interrelationships will be found in the pages that follow.

\section{PROBLEM I. WHAT ARE SOME OF THE INTERRELATIONS BETWEEN PLANTS AND ANIMALS?}

Field Exercise. To determine whether conditions of mutual aid exist between insects and flowering plants.

Materials. An insect net, cigar boxes containing sheets of cork, insect pins, and a cyanide bottle are useful. (Caution: Do not smell the cyanide; the fumes are deadly poison.)

Object of trip. The object of this trip is threefold:

1. To find out some of the relations of mutual help existing between plants and animals.

2. To learn to know a few common insects, and to collect them for later study.

3 . To have such an enjoyable time that you will wish to go again by yourself.

Method. Your trip should include fields and waste lots covered with weeds and trees. Look for six-legged animals (insects) on plants. Do they receive any protection from such plants? Shelter? Food? Give examples under each of these headings. Do you find any insects laying their eggs upon plants? Why do you think they do this?

Follow a bee until it alights on a flower. Try to find out exactly what it gets from the flower and how it does it. Now observe where it goes next. Do bees visit flowers of the same kind in succession?

Look for other flying insects that are on flowers. (Extra credit may be given for the working out of the relation between a butterfly and a flower.)

Carefully observe the goldenrod blossoms for yellow and black beetles (locust borer) about an inch long. What are they doing? Observe grasshoppers or other insects on stalks of grass. What are they doing there?

Strip the bark from fallen trees. Look carefully for any signs of living things. Collect any living animals you may see. If a small stream or pond is available, scrape or dredge through the aquatic plants near the shore and see what animals you can find. What are they doing there?

Dig into rich soil near the roots of grain or other plants and note what living animals may be there. Ask help from your instructor in their identification. 
Laboratory Exercise. How to identify an insect. If possible, use a living bee from an observation hive, although some observation may be made in the field and reported to the class.

Examine its body carefully. Notice that it has three regions : a front part or head; a middle part, the thorax, divided into three portions or segments; and a hind portion, segmented ${ }^{1}$ and hairy, the abdomen.

How many pairs of legs does it have? The legs, jointed and provided with tiny hooks at the end, are attached to the thorax. Two pairs of delicate wings are attached to the upper or dorsal side of the thorax. To which segments of the thorax are they attached? The entire body has a tough covering or exoskeleton composed of chitin (kitin), a substance chemically much like a cow's horn. This exoskeleton in the bee is partly covered with tiny hairs which form a vesture ${ }^{2}$ over the body. The muscles, which provide for movement, are fastened to the interior of the exoskeleton, for there is no internal skeleton.

Is there any movement of the abdomen of a living bee? The animal breathes through tiny openings called spiracles ( $\left.\operatorname{spur}^{\prime} \dot{a}-k^{\prime} l\right)$, which are found on each segment of the abdomen and lead into branching air tubes. Bees have compound eyes composed of numerous units called ommitidia. Simple eyes or ocelli are usually also present. Bees are provided with a pair of jointed feelers called antennae. Wings are not found on all insects, nor is a vesture; but the other structures just given are characteristics of the great group of animals we call insects.

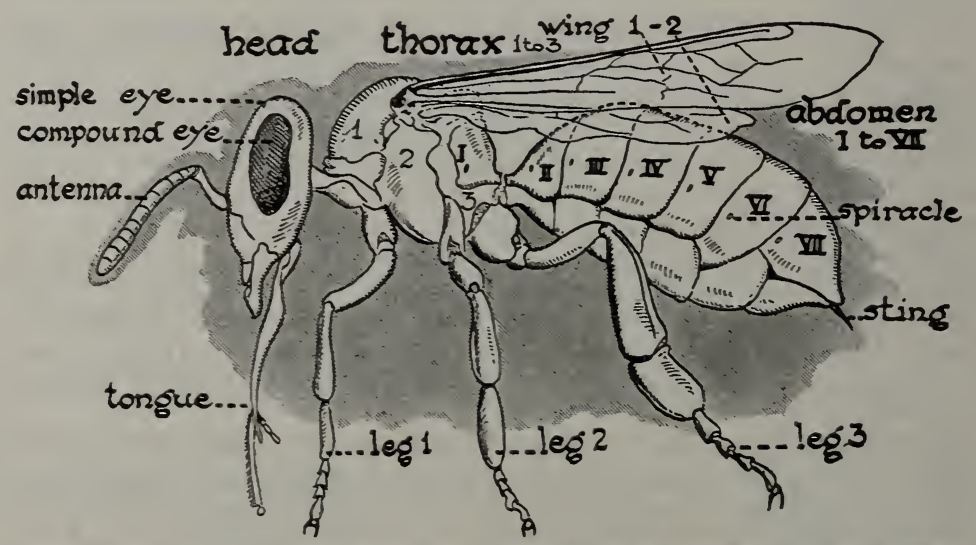

The honeybee. How many of the parts labeled here can you find on your specimen?

Common forms of insects. Inasmuch as there are more than 450,000 different kinds of insects, it is evident that it would be a hopeless task for us even to attempt to recognize all of them.

1 Segmented (sĕg'měnt-ěd) : separated into sections or parts.

2 Yesture (věs'tứr) : a covering. 
But we can learn to distinguish a few examples of the common forms that might be seen on a field trip. In the fields, on grass, or on flowering plants we may find members from at least six of the twenty orders of insects. These may be known by the following characters :

The order Hymenoptera (hī-mĕn-ŏp'tẽr- $\dot{a}$, membrane wings), to which the bees, wasps, and ants belong, is the only insect order of which some of the members are provided with true stings. This sting is placed in a sheath at the extreme hind end of the abdomen. All structures which the honey bee has are possessed by this group of insects.

Butterflies and moths will be found hovering over flowers. They belong to the order Lepidoptera (lěp-ı̆-dŏp'tẽr- $\dot{a}$, scaled wings) (see p. 68). This name is given to them because their wings are covered with tiny scales, which fit into little sockets much as shingles are placed on a roof. The wings are always large and usually brightly colored; the legs are small, and one pair of them is often inconspicuous. These insects take liquid food through a long tubelike organ, called the proboscis (prö-bŏs'ĩs).

Grasshoppers, found almost everywhere, katydids, and crickets, black grasshopper-like insects often found under stones, belong to the order Orthoptera (ŏr-thŏp'tẽr-ä, straight wings). Members of this group may usually be distinguished by their strong, jumping hind legs, by their chewing or biting mouth parts, and by the fact that the hind wings are folded up under the somewhat stiffer front wings.

Another group of insects sometimes found on flowers in the fall are flies. They belong to the order Diptera (dǐp'terr- $\dot{a}$, two wings). These insects are usually rather small and have a single pair of gauzy wings. Some of man's worst enemies are found in this group of insects, which includes the house fly, mosquitoes, stable fly, and botfly.

Bugs, members of the order Hemiptera (hè-mǐp'terr- $\dot{a}$, half wing), have mouth parts that are fitted for piercing and sucking. They are usually small and many of them have a pair of delicate membranous wings covered with outer wings which are somewhat thickened. 


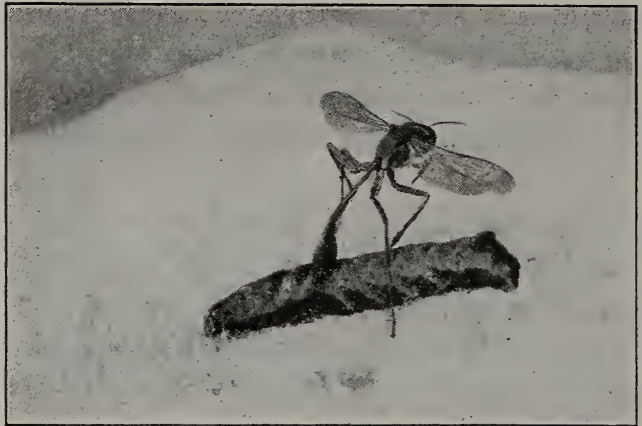

C. Clarke

A wasp stinging a caterpillar. Why is the wasp a member of Hymenoptera?
The cicadas, aphids, and scale insects belong to the order Homoptera (hô-mŏp'ter- $\dot{a}$, similar wings). Their mouthparts are formed for sucking.

The beetles belong to the order Coleoptera (kŏl-ẽ-ŏp'tẽr- $\dot{a}$, sheath wings), and are often called "bugs" by the uninformed. Any beetle will show the following characteristics: The body is usually heavy and broad. Its exoskeleton is hard and tough. This chitinous body covering is better developed in the beetles than in any other of the insects. The three pairs of legs are

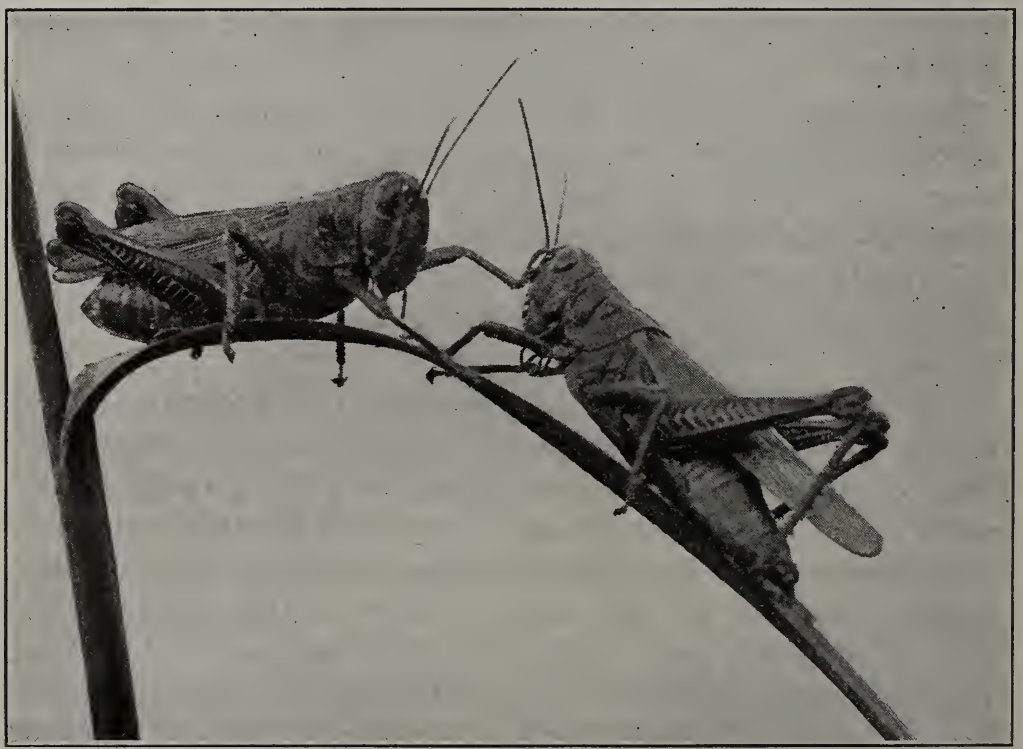

C. Clarke

Two grasshoppers having an argument as to which one is to occupy that blade of grass. 
stout and rather short. The outer wings are hard and fit like a shield over the under wings, which are efficient organs of flight. The mouth parts, provided with an upper and lower lip, are fitted for biting. They consist of heavy curved pincher-shaped mandibles (măn-dǐ-b'll), which

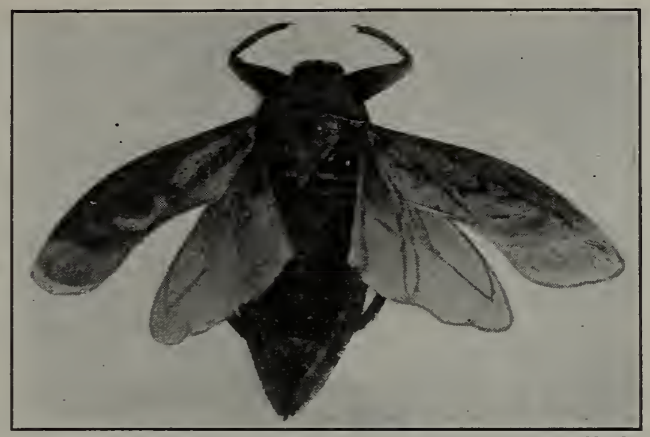

C. Clarke

A water scorpion. Why is it classified as a member of Hemiptera? are provided with palpi (păl'pī), organs of taste and smell.

Practical Exercise 1. Look up in a reference book the names of other orders of insects than those that have already been given. Give examples of insects in each of these orders.

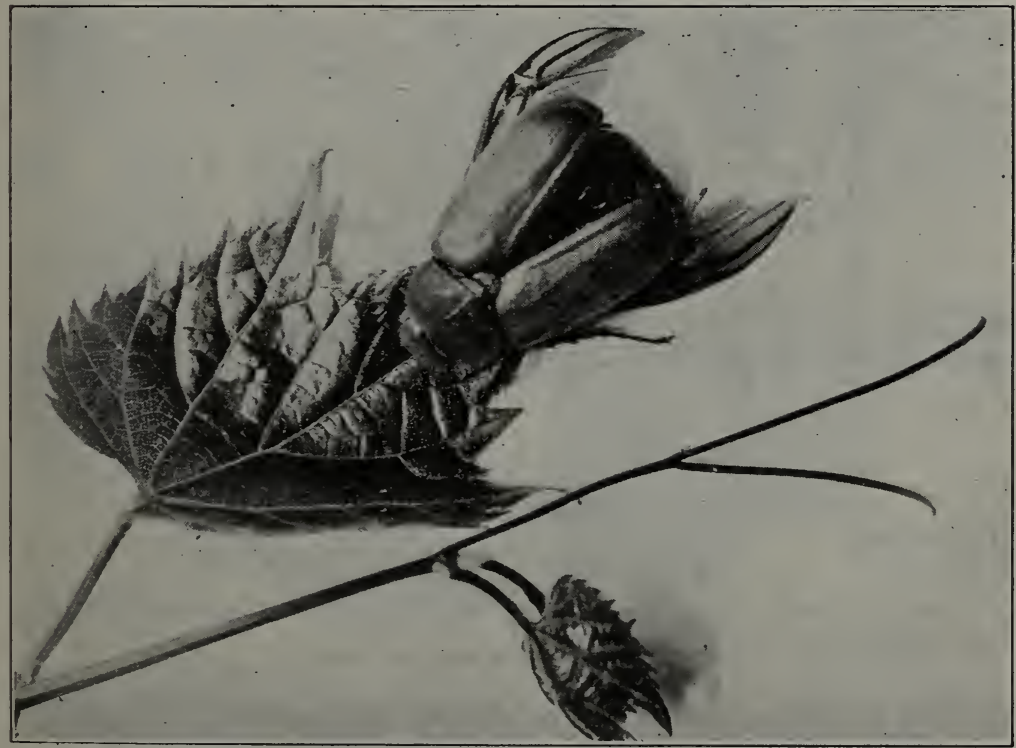

C. Clarke

A June beetle lighting on a grape leaf and folding his wings under his brown wing covers. 


\section{Self-Testing Exercise}

Everywhere in nature we find .......(1) .......(2) on plants or using them for ....... (3). Insects also are seen to visit ....... (4). ....... (5) are the most numerous of all .......(6). An insect has ........ (7) body parts; ....... (8) pairs of legs; an exoskeleton composed of ......(9) and breathes through ......(10). The eyes are ....... (11). The parts of the insect's body are called the $\ldots \ldots$ (12), .......(13), and ......(14). Bugs have mouth parts fitted for ....... (15) and ....... (16). Beetles have...... (17) pairs of wings, the outer acting as a ....... (18) for the delicate inner pair. Grasshoppers .......(19) their food. Some of man's worst enemies are members of the order .......(20). Bees and wasps are able to ........(21).

\section{PROBLEM II. TO KNOW SOMETHING OF THE STRUCTURE} AND LIFE HISTORY OF THE GRASSHOPPER

Laboratory Exercise. Use living red-legged grasshoppers if possible. Find the three parts: head, thorax, and abdomen. Is there an exoskeleton?

Find the three segments in the thorax? They are called from anterior to posterior, prothorax, mesothorax, and metathorax. Which bear legs? Which bear wings? The membrane-like wings, outgrowths of the body, lie straight along the back when at rest.

Study the hind leg carefully. Compare it with the diagram. Can you find all these parts? Move the leg. How is it used? Can

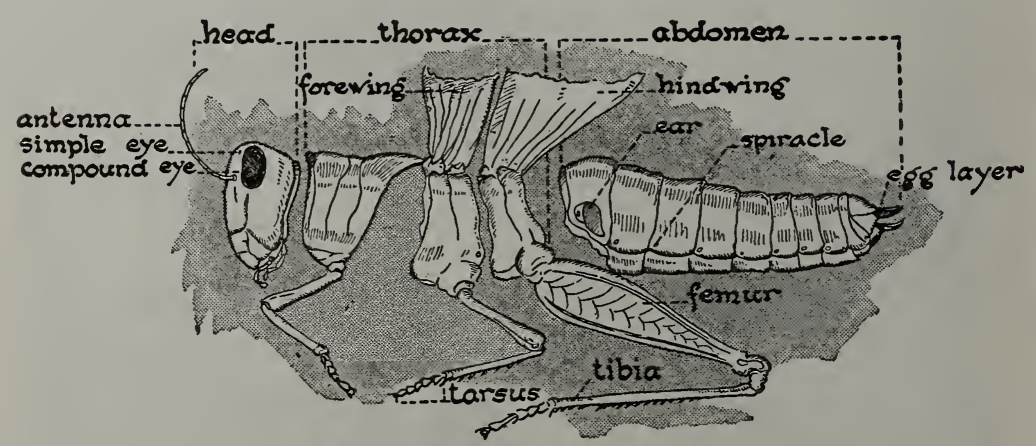

Identify these parts in your specimen.

you find any adaptations? How are the wings placed when not in use? When flying? Are there any differences in the two pairs of wings? - Into how many segments is the abdomen divided? Are all 
of them complete? The end of the abdomen is modified in the female into an ovipositor or egg layer (see diagram).

On each side of the abdomen in eight of the segments (in the redlegged grasshopper) are found tiny openings called spiracles. There are also two pairs of spiracles on the thorax. These spiracles open into little tubes called tracheae (trā'kê-ē). The tracheae divide and subdivide like the branches of a tree, so that all parts of the body cavity are reached by their fine endings. Is there any movement of the abdomen of the living grasshopper? Describe this movement. Air is drawn in by the expansion of the abdomen and forced out when it contracts. By means of the tracheae, air is brought in contact with the blood.

Muscular activity. Insects have the most powerful muscles of any animals of their size. Relatively, an enormous amount of energy is released during jumping or flying. The tracheae pass directly into the muscles and other tissues so that a supply of oxygen is directly at the place where energy is being released.

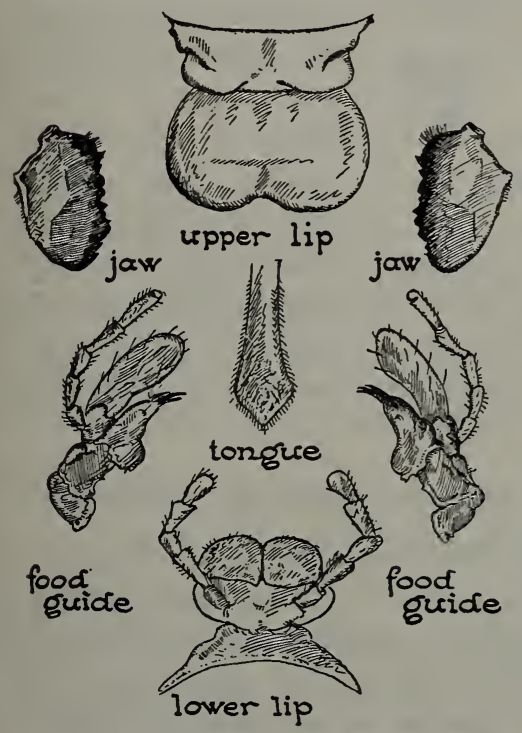

Find the knife and fork of the grasshopper.

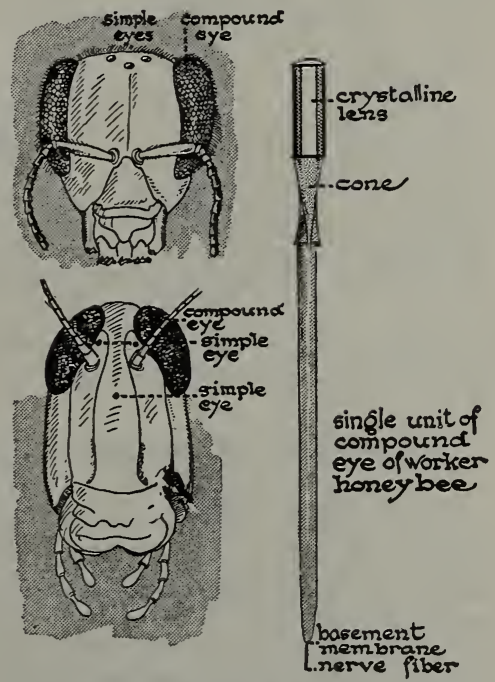

What two insect heads are shown here? Read your text carefully.

Food taking. The grasshopper is provided with two pairs of jaws, a fork-like pair, the maxillae (măk-šl' $\bar{e}$ ), and a pair of hard toothed jaws, the mandibles. These parts when not in use are 
covered by two flaps, the upper and lower lips. The leaf upon which the grasshopper feeds is held in place in the mouth by means of the maxillae, while it is cut into small pieces by the mandibles.

Eyes. An examination of the compound eye of a grasshopper with a lens shows the whole surface to be composed of tiny sixsided lenses called facets (făs'ĕts). Each facet marks the surface

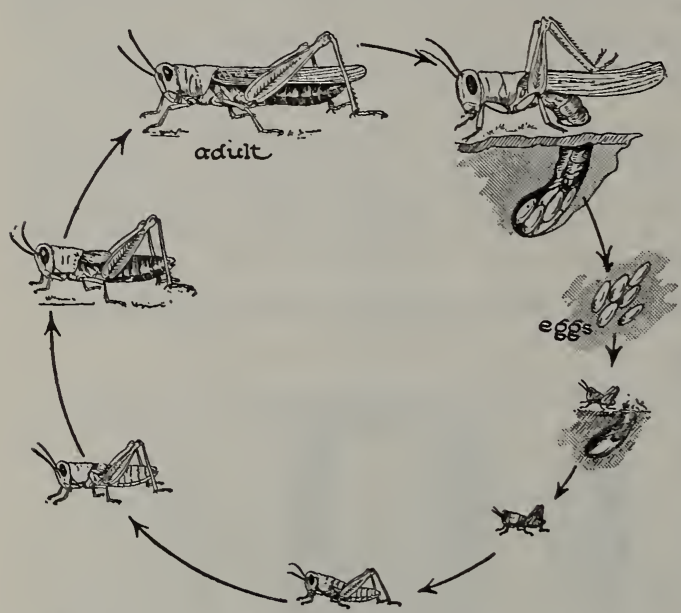

Life history of a grasshoppe:. Explain what is meant by a life cycle; a metamorphosis.

of a unit (ommatidium) of the compound eye. Each unit probably gives a separate impression of light and color. Since each unit is separated from its neighbor by a layer of pigment, a compound eye is most favorable for perceiving the movement of objects. The grasshopper also has three simple eyes, or ocelli, on the front of the head. The simple eyes probably are able only to perceive light and darkness.

Practical Exercise 2. Explain why an insect easily perceives a moving object.

Other sense organs. The segmented feelers, or antennae, have to do with the sense of touch and smell. The auditory organ or ear of the grasshopper is found under the wing on the first segment of the abdomen. Covering the body and on the appendages are found sensory hairs which make the insect sensitive to touch. Thus the armor-covered animal is put in touch with its surroundings.

Life history. In the fall of the year the female grasshopper digs a hole in the ground. She thrusts her abdomen into the hole and lays from twenty to thirty eggs in small oval or bean shaped 
puckets. These hatch out in the spring as tiny wingless grasshoppers called nymphs. The young insects molt or cast off their hard exoskeleton several times. At each shedding of the "skin" the grasshopper gets larger. Since this molting results in a series of changes in form from the young rymph to an adult with wings, the whole process is called a metamorphosis or change of form. The grasshopper is said to have an incomplete metamorphosis because the changes in form are not great. The nymphs can be recognized in the earliest stages as grasshoppers.

In the fall most of the adults die, only a few surviving the winter. In the South and West, some grasshoppers have more than one brood in a summer, which makes them more numerous and therefore more of a pest to the farmers.

Relatives of the grasshoppers. Among the near relatives of the grasshopper are the brown and black crickets, cockroaches, "waterbugs," katydids, praying mantis, and many others.

\section{Self-Testing Exercise}

Grasshoppers belong to the order ........(1) because they have wings placed ........(2) along the back. The mouth parts are fitted for ....... (3). The organs of touch in insects are called ....... (4), the organ of hearing, the ......(5), is usually found under the $\ldots \ldots$ (6). Insects which pass through a series of $\ldots \ldots \ldots$ (7) before they .......(8) adults are said to undergo a ....... (9). Insects have to ....... (10) in order to grow larger.

\section{PROBLEM III. HOW TO KNOW SOMETHING ABOUT THE STRUCTURE AND LIFE HISTORY OF A BUTTERFLY}

Laboratory Exercise. Examine a butterfly carefully with a magnifying glass. What do you find covering the body and wings? Note that the legs are smaller and weaker than those of the grasshopper. How many pairs do they have? Are they all the same size? Examine a small portion of a wing under a compound microscope. Draw a scale showing how it fits into the membranous wing. What name is given to this order of insects? Why? The mouth parts of the butterfly are modified into a long proboscis, a sucking tube through which the insect sucks nectar from the flowers.

Practical Exercise 3. Prepare the life histories of several different butterflies. If possible, use material that you have collected and mounted. 


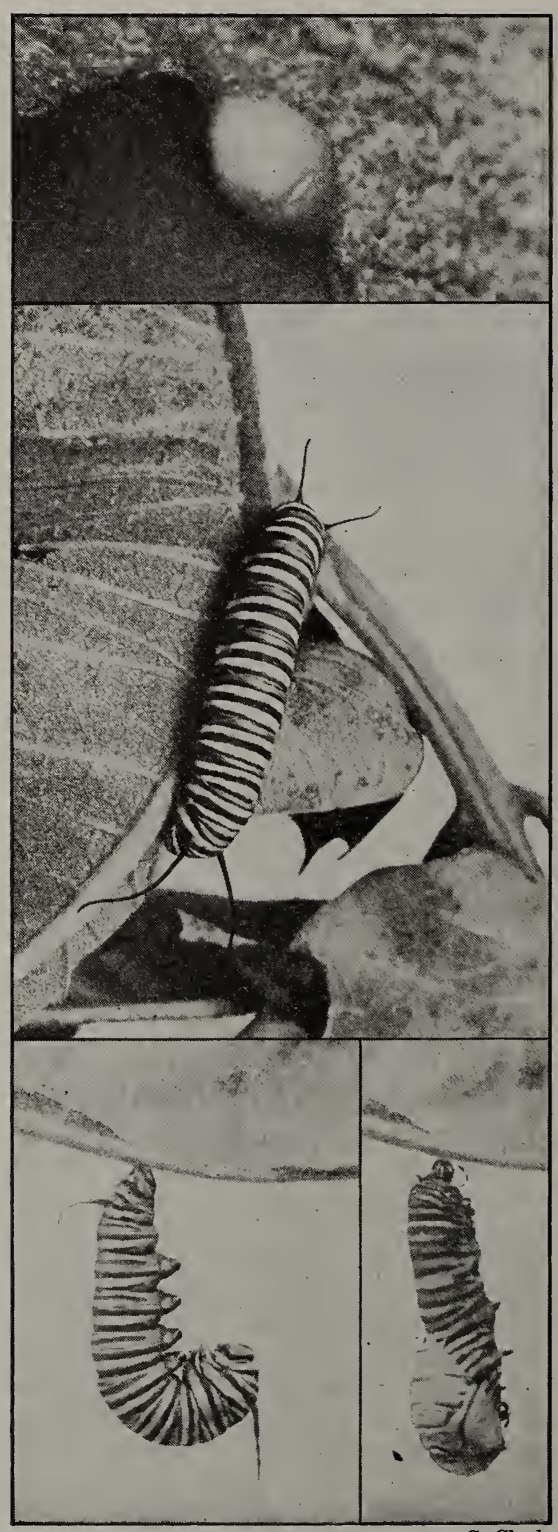

C. Clarke
The life history of the monarch butterfly. If it is possible to find some milkweed on our trip, we are quite likely to find hovering near it a golden brown and black butterfly, the monarch or milkweed butterfly. The female frequents the milkweed in order to lay eggs; she may be found doing this at almost any time from June until September.

Egg and larva. The eggs, tiny mound-shaped dots, a twentieth of an inch in length, are fastened singly to the under side of milkweed leaves. Some instinct leads this butterfly to deposit her eggs on the milkweed, for the young feed upon this plant. The eggs hatch out in four or five days into caterpillars. Each caterpillar will shed its skin several times before it is full grown. These caterpillars possess, in addition to the three pairs of true legs, four pairs of prolegs which are fleshy structures found on

The female monarch butterfly lays her eggs on the edge of the milkweed leaf. The egg hatches and the green, black, and white caterpillar feeds on the milkweed. Later the caterpillar fastens itself to the midrib of a leaf. 
the abdominal segments. The animal at this stage is known as a larva.

Formation of pupa. After a life of a few weeks at most, the caterpillar stops eating and begins to spin a tiny mat of silk upon a leaf or stem. It attaches itself to this web, head downward, and sheds its skin again. After this molt, it is without legs or mouth parts. It hangs to the stem in a dormant stage and is known as the chrysalis (krǐs-a-lĭs) or pupa. During this stage many changes take place and the caterpillar gradually changes into a butterfly.

The adult. After some weeks of inactivity in the pupa state, the pupa case splits along the back, and the adult butterfly emerges. At first the wings are soft and much smaller than in the adult. Within fifteen minutes to half an hour after the butterfly emerges, however, the wings expand and dry, and the insect is ready to fly

The skin splits and a light green chrysalis emerges, which gradually changes its shape. After a time the butterfly comes out of its chrysalid shell. It clings to the shell, spreading and stretching his wings until they are dried and strengthened.

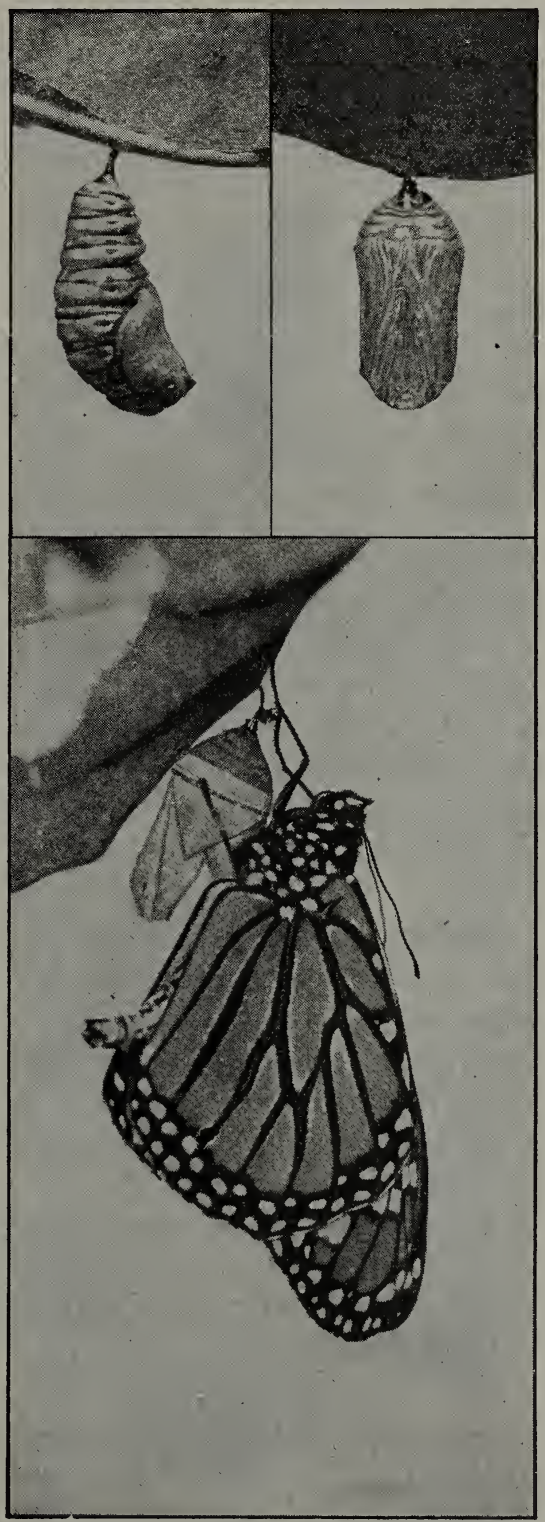

C. Clarke 

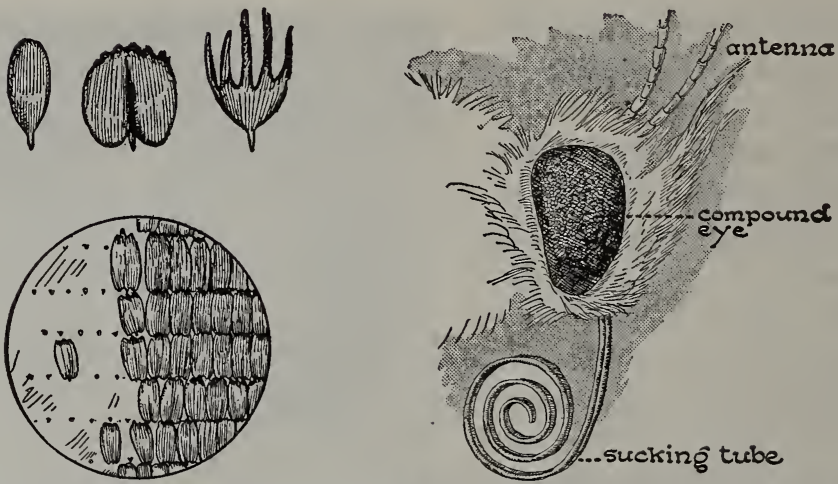

How do the structures you found in your specimen compare with these in the diagram?

away. The female insect, after her marriage flight, deposits her eggs on a milkweed plant.

Since this butterfly in most parts of the United States has at least two broods a year and since the young feed on the milkweed and dogbane, both common weeds, we see some cause for its wide distribution and great numbers. The metamorphosis of the butterfly is said to be complete because it passes through several distinct changes of form.

Moths. Moths are familiar to most of us, but they can usually be seen only at night because of their night-flying habits. Certain differences between them and butterflies are noted in the following table:

\section{Butterfly}

Antennae threadlike, usually knobbed at tip.

Fly in daytime.

Wings held vertically when at rest.

Pupa naked.

\section{Moth}

Antennae feathery or threadlike, never knobbed.

Usually fly at night.

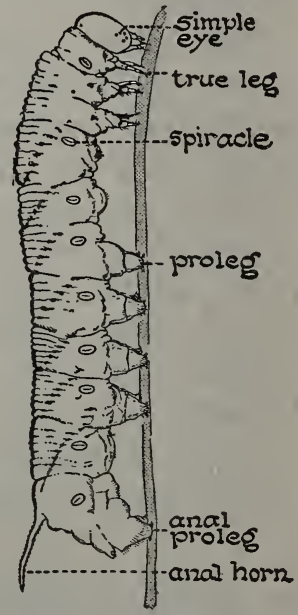

Caterpillar of moth. Find the parts of the adult insect here. Does this agree with your definition of an insect? 
Wings held horizontally or folded over the body when at rest. Pupa usually covered by a cocoon or case.

The Promethea moth, the Polyphemus or American silkworm inoth, and the Cecropia moth are among the largest and most commonly collected.

\section{Self-Testing Exercise}

Butterflies are called ....... (1) because of the .......(2) on the wings. The adults lay their ........ (3) on plants which the ....... (4) will feed upon. This stage is followed by the .......(5) stage. In this stage the chrysalis is usually attached by a $\ldots . . .(6)$ ....... (7) to the ....... (8) plant.

\section{PROBLEM IV. WHAT DO WE MEAN BY COMMUNAL LIFE AND DIVISION OF LABOR?}

Individual Projects. Give a report on the life habits of a solitary wasp. Work out with diagrams the life history of some communal insect.

Keep a hive of bees and report to the class on their habits.

Make an ants' nest and keep a colony of ants in it.

Solitary wasps. Some bees and wasps lead a solitary existence, the digger wasps being an example. Each female wasp burrows in the ground or in wood and constructs a nest in which she lays her eggs. The nest is provisioned with spiders and insects which are not killed but are stung into insensibility. The nest is closed up after food is supplied. When the young hatches it finds plenty of food near at hand to nourish it during its growth.

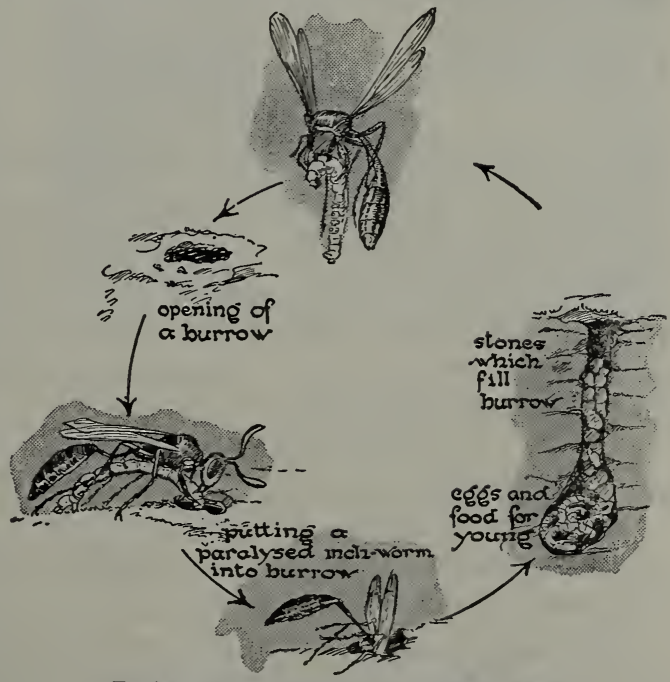

Explain this life history of a solitary wasD.

H. $\mathrm{BIO}-6$ 
Bumblebees. In the life history of the bumblebee we see the beginning of the instinct to live together. Some of the female bees (known as queens) burrow into the ground in the fall and sleep all winter. They lay their eggs the following spring in masses of

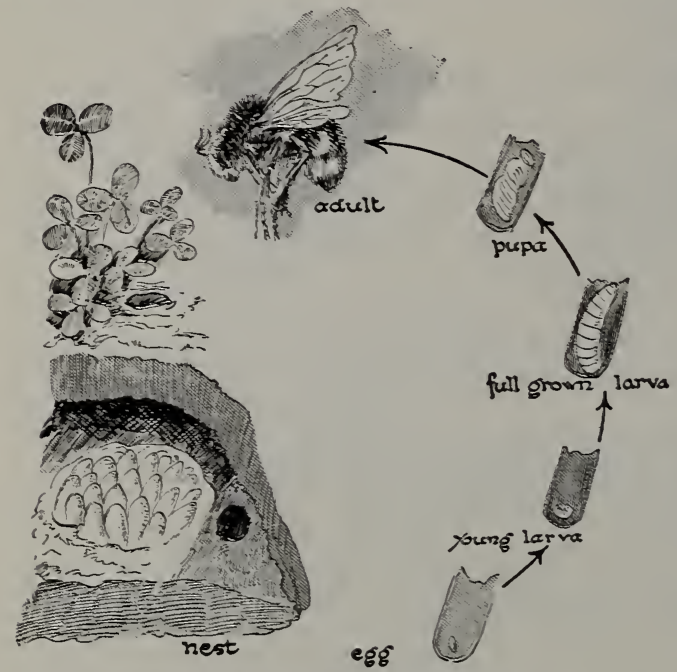

Compare the life history of the bumblebee with that of the solitary wasp. How does it differ? pollen, which they gather and place in holes in the ground, often in a deserted mouse hole. The young hatch as larvae, then pupate, and finally become workers (imperfect females) in which the egg-laying apparatus, or ovipositor, is modified to be used as a sting. The workers bring in pollen to the queen, in which she lays her eggs. Several broods of workers are raised during a summer. In the early fall a brood of males and egg-laying females or queens are produced instead of workers. The males leave the hive as soon as they are able to fly, and never return. They mate with the queens and then die. They live in all about three or four weeks. The young queens also leave the hive, although they occasionally return. By means of these queens the brood is started the following year.

Practical Exercise 4. Report on the life story of some South American wasps. Read Howe's Insect Behavior, Chapters ii and iv-xii inclusive.

The Honeybee. The most wonderful communal life has been developed among the honeybees. ${ }^{1}$

1 Their daily life may be easily watched in the schoolroom, by means of one of the many good and cheap observation hives now made to be placed in a window frame. Directions for making a small observation hive for school work can be found in 
The colony in a hive usually consists of a queen, a few hundred drones, or males, and several thousand imperfect females known as workers. A prosperous colony may have 50,000 to 75,000 members. The division of labor is seen best in a hive in which the bees have been living for some weeks. The queen, a virtual prisoner, does nothing except lay eggs, sometimes as many as fifteen hundred a day, and keeps this up, during the warm weather, for from two to five years. Most of the eggs are fertilized by the sperm cells of a male and develop into workers; the unfertilized eggs develop into males or drones. After a short existence in the hive the drones are usually driven out by the workers.

The cells of the comb are built by the workers out of wax secreted from the under surface of their bodies. The wax is cut off in thin plates by means of the wax shears between the two last joints of the hind legs. The cells of the comb are made in two layers, back to back, opening on opposite sides. They are hexagonal in cross section and are of different sizes, the smaller cells being used for honey storage and for the development of the workers, the larger cells for housing the drones. The queen lays one egg in each cell, and the young are hatched after three days, to begin life as white footless grubs. For a few days they

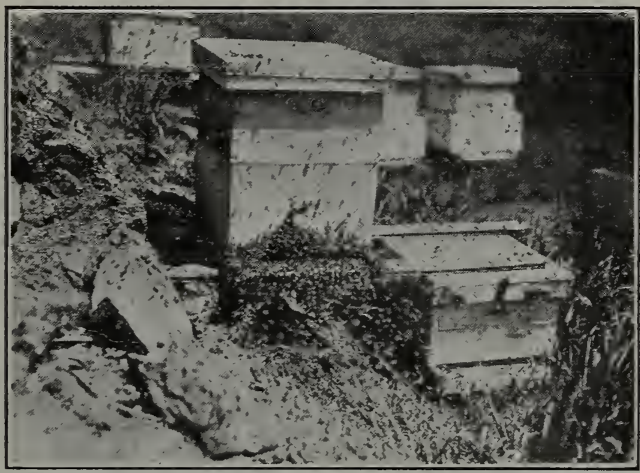

Nature Magazine

Young queen bees sometimes rebel against the old queen, and leave the hive, followed by a large portion of the colony. In this picture, some of the "striking" bees are shown returning to their original home. are fed on partly digested food called bee jelly, regurgitated ${ }^{1}$ from the stomach of the. youngest workers or nurses. Later they receive pollen and Hodge, Nature Study and Life, Chapter xiv. Bulletin No. 1, U. S. Department of Agriculture, entitled The Honey Bee, by Frank Benton, and Farmers' Bulletin 447 on Bees, by E. F. Phillips, give useful information to the bee keeper.

${ }^{1}$ Regurgitate (rè-gûr'jì-tăt) : to cast out again from the stomach. 


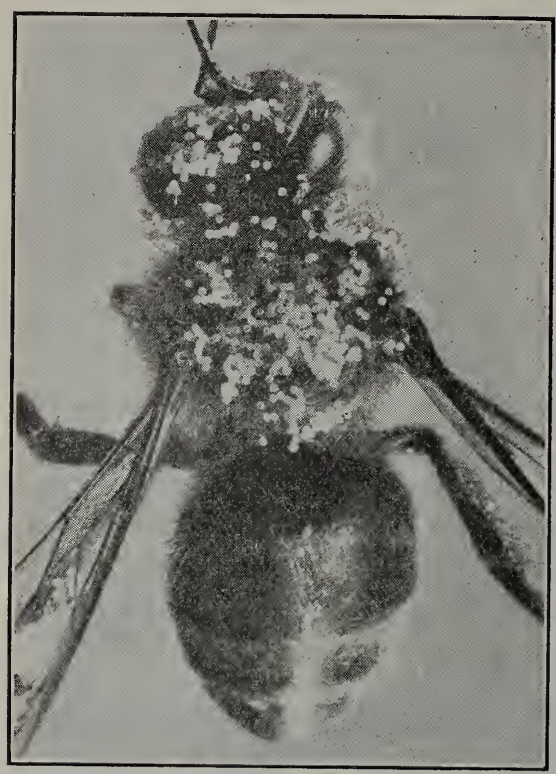

C. Clarke

A honeybee, in search for nectar, has become covered with grains of hollyhock pollen.

honey to eat. A little of this mixture, known as bee bread, is put into the cells, and the lids covered with wax by the working bees, and the young larvae allowed to pupate. After about two weeks of quiescence in the pupal state, it changes into a fully developed adult and chews its way out of the cell. It takes its place in the hive, first caring for the young as a nurse, later making excursions to the open air after food as an adult worker.

If a new queen is to be produced, several of the cell walls are broken down by the workers, making a large ovoid ${ }^{1}$ cell in which one egg is left. The young bee in this cell is fed during its whole larval life upon royal jelly, and grows into a bee of much larger size than an ordinary worker. When a young queen appears, great excitement pervades the community; the bees appear to take sides; some remain with the young queen in the hive, while others follow the old queen out into the world. This is called swarming. They usually settle around the queen, often hanging to the limb of a tree. While the bees are swarming, certain of the workers, acting as scouts, determine on a site for their new home; and, if undisturbed, the bees soon go there and construct their new hive. This instinct is of vital importance to the bees, as it provides them with a means of forming a new colony. A swarm of domesticated bees may be easily hived in new quarters.

Division of labor in the hive. The work of the hive is divided among the various kinds of bees in a most interesting manner. 
We have seen that the queen lays all the eggs, acting as a sort of tribal mother. The eggs are all fertilized by one drone, who places the sperm cells within the body of the queen on her nuptial flight. The young workers feed the larvae and act as nurses. The older bees take turns in a number of duties; some attend to the queen and drones, some act as sanitary police, keeping the hive clean of dirt and bodies of dead bees, others ventilate the hive by buzzing with their wings, while many others work in the field gathering pollen and nectar from flowers.

The nectar is swallowed and kept in the crop, or honey stomach, until after the bee returns to the hive, where it is regurgitated into the cells of the comb. It is now thinner than what we call honey. To thicken it, the bees swarm over the open cells, moving their wings very rapidly, thus evaporating some of the water in the honey. A hive of bees has been known to make over thirtyone pounds of honey in a single day, although the average is very much less than this.

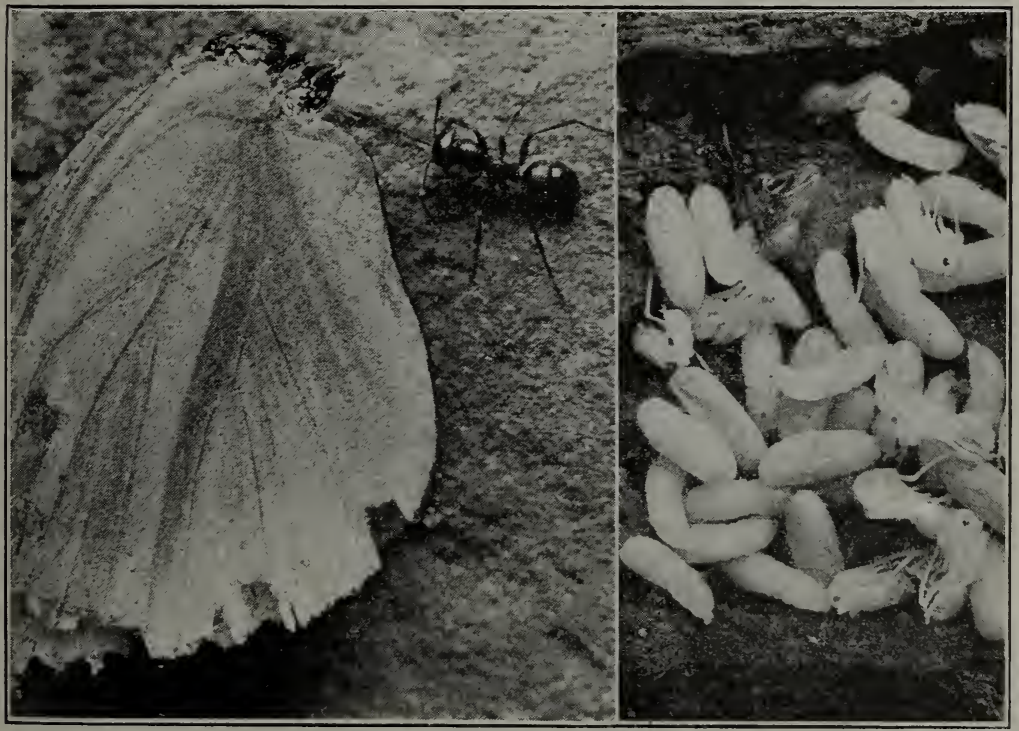

C. Clarke

A tiny ant drags home a cabbage butterfly, to add to its store of food, which is needed for the young. 


\section{HOW ARE ANIMALS AND PLANTS DEPENDENT?}

Ants. Ants are the most truly communal of all the insects. Their life history and habits are not so well known as those of the bee, but what is known shows even more wonderful specialization.

The nest of a colony consists of underground galleries with enlarged storerooms, nurseries, etc. The inhabitants of a nest may consist of winged males and females, and wingless workers, which act as gatherers of food, nurses, and protectors. We may find ant nests almost anywhere in our yards or gardens. Many nests are found under large flat stones, chiefly because stones hold the heat of the sun and keep the nest from cooling too rapidly at night.

The entire communal life of the ants might be said to be based upon the perception of odor. If an ant, although one of the same species, is put into a colony to which it does not belong, it will be set upon and either driven out or killed. Ants never really lose their community odor; those absent for a long time, on returning, apparently will be easily distinguished by their odor, and eagerly welcomed by the other members of the nest. The communication of ants, as seen when they stop each other, away from the nest, is evidently a process of smelling, for they caress each other with the antennae, the organs with which odors are perceived.

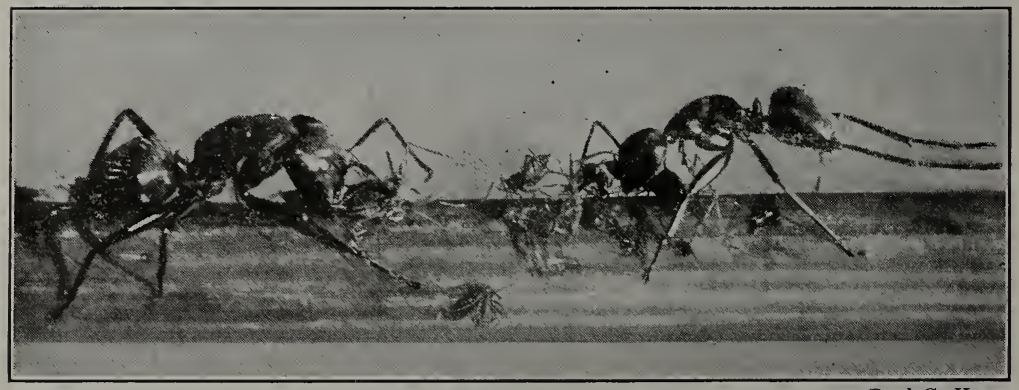

Paul G. Howes

Some ants live on a sweet fluid which is given off by aphids or plant lice. They induce the aphids to exude this fluid by stroking them with their antennae. Such aphids are carefully watched and cared for by the ants.

Ant larvae are called grubs. They are absolutely helpless and are taken care of by nurses. The pupae may often be seen as they are being carried in the mouths of the nurse ants, who bring them to the surface for sun and air. They are wrongly called ants' eggs in this stage. 
Some species of ants are among the most warlike of any insects. In the case of the robber ants, which live entirely by war and pillage, the workers have become modified in structure, and can no longer work, but only fight. Some species go further and make slaves of the ants preyed upon. These slaves do all the work for their captors, even to making additions to the nest and acting as nurses to their young.

Practical Exercise 5. Report on the life in an ant colony in South America as described in Beebe's Jungle Days, or the life of the army ants, Chapter xiv, in Howe's Insect Behavior.

\section{Self-Testing Exercise}

Some wasps lead ........ (1) lives but most ....... (2), ..... (3), and wasps show ........(4) life. In the case of the honeybees we have a ......(5) with a single fully-developed ......(6) or . (7), several hundred .......(8) or ....... (9) and many thousands of .......(10). The latter have many duties such as gathering $\ldots \ldots \ldots$ (11) and ........(12) from flowers, ....... (13) the young, ....... (14) and ....... (15) the hive. They also make ........(16), which they store in cells made of .......(17). Ants also have a complicated communal life, some acting as ........(18), others as .......(19), and still others as ....... (20). The communal life of ants is dependent upon ........ (21). Each colony seems to have its own peculiar ........ (22). Bees, ants, and wasps belong to the order ....... (23).

\section{PROBLEM V. WHAT ARE THE CHARACTERISTICS OF OTHER GROUPS OF INSECTS?}

The Flies. There is an order of insects called Diptera, which is characterized by having only two gauzy wings. The members of this group of insects frequently found on a field trip are mosquitoes, gnats, botflies, and the house fly.

The head of the common fly is freely movable and is provided with mouth parts for sucking and lapping. The foot shows wonderful adaptation for clinging to smooth surfaces, as it is provided with sticky pads bearing tubelike hairs.

The second pair of wings is changed into a pair of small knobs, called balancers. This name suggests their use, for if they are removed, the fly is unable to balance itself.

The development of the fly is extremely rapid. A female may 


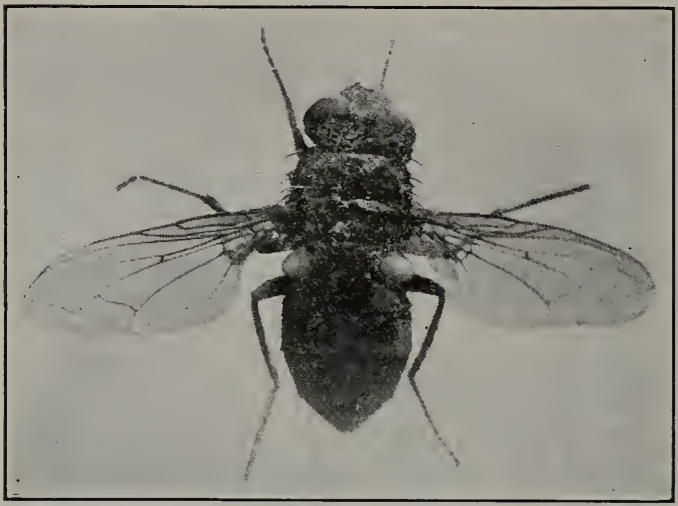

C. Clarke

Why does the house fly belong to the order of insects known as Diptera?

lay from one hundred to two hundred eggs. These are usually deposited in garbage or manure. In warm weather, within a day after the eggs are laid, the young maggots, as the larvae are called, hatch. After about one week of active feeding, these wormlike maggots become quiet and go into the pupal stage, whence under favorable conditions they emerge within less than another week as adult flies. The adults breed at once, and in a short summer there may be over ten generations of flies. This accounts for the great number of flies in late summer. Fortunately few flies survive the winter.

Practical Exercise 6. Discuss the fly problem as it exists in your community. What steps might you take to abate the fly nuisance?

The life history of a beetle. The May beetle or June bug and potato beetle are examples of beetles. Many beetles lay their eggs in the ground, where they hatch into cream-colored grubs. A grub differs from the maggot or larva of the fly in possessing three pairs of legs. These grubs live in burrows in the ground, where they feed on the roots of grass and garden plants. The larval compare the life history of the fly with that of the bumblebee.

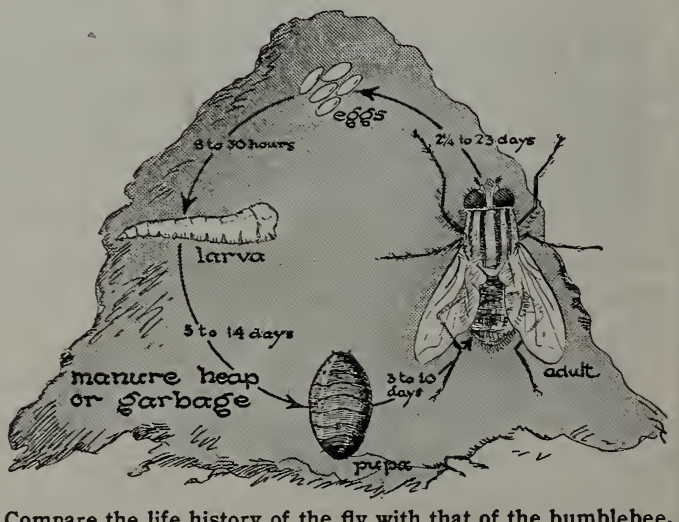


form remains underground from two to three years, the latter part of this time as an inactive pupa. During the latter stage it lies dormant in an ovoid area excavated by it. Eventually the wings (which are budlike in the pupa) grow larger, and the adult beetle emerges fitted for its life in the open air.

This group of insects include some of man's best friends, as the ladybird beetle, and some of his worst enemies, as the potato beetle.

\section{Life history of the ci-} cada. The seventeen-year cicada lays her eggs in slits which she makes in the twigs of trees. Immediately after hatching, the young drop to the ground and bury themselves in the earth. They stay there for seventeen years. In the

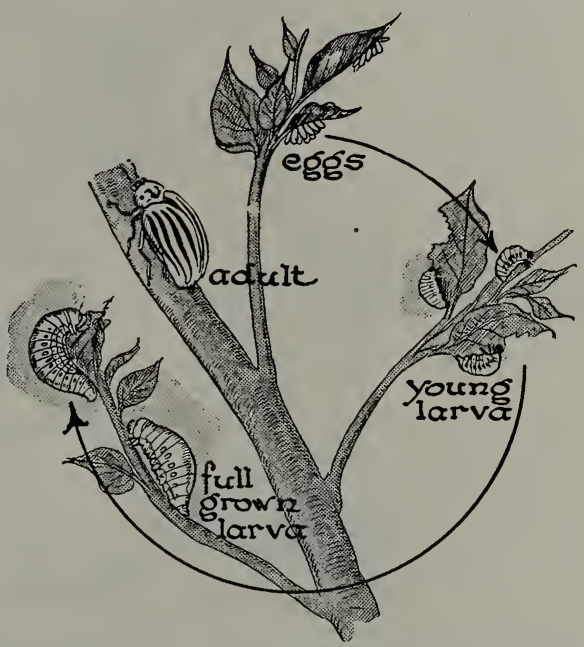

The full grown larva of the Colorado potato beetle drops to the ground and burrows in the soil, forming a pupa.

South these insects live only thirteen years underground. They obtain their food by sucking the juices from the roots of plants. During this stage they somewhat resemble the grub of the beetle (June bug) in habits and appearance. When they are about to molt into an adult, they climb above the ground, and fasten themselves to some firm object, as a wooden fence or a tree trunk. The skin then splits along the back and the adult cicada emerges.

Aphids. The aphids are among the most interesting of the Homoptera. They are familiar to all as tiny green lice seen swarming on the stems and leaves of the rose and other cultivated plants. They suck the juices from stem and leaf. Plant lice have a remarkable life history. Early in the year the eggs develop into wingless females which produce living young, all females. These in turn reproduce in a similar manner, until the plant on which 
they live becomes overcrowded and the food supply runs short. Then a generation of winged aphids is produced. These fly away

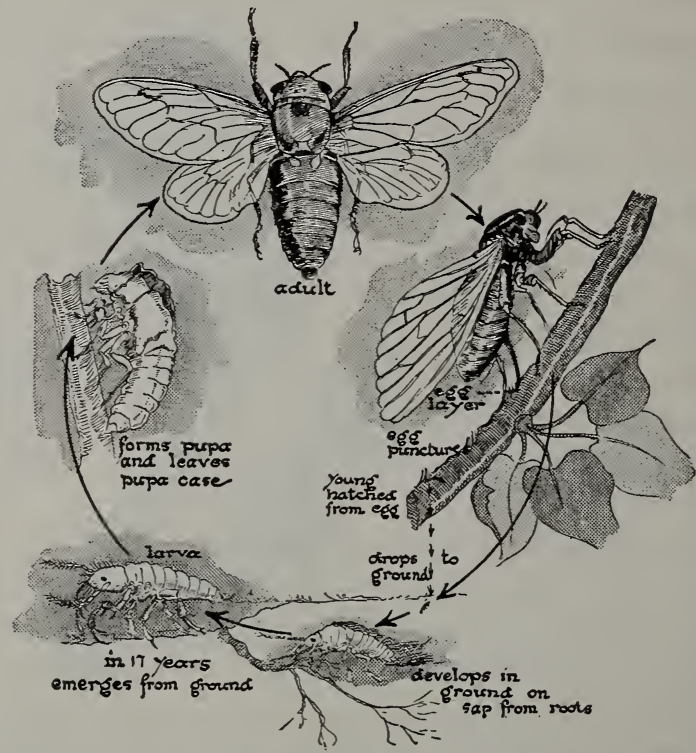

Life history of the seventeen-year cicada. What a: $\in$ the chief differences between this life history and the others shown?

to other plants, and reproduction goes on as before until the approach of cold weather, when males and females appear. Fertilized eggs are then produced which give rise to young the following season.

Dragon flies and their relatives. The dragon fly receives its name from the fact that it preys on insects. The adult eats mosquitoes and other insects which it captures while flying. Its four large, lacelike wings give it power of very rapid flight, while its long, narrow body is admirably adapted for the same purpose. The large compound eyes placed at the sides of the head give keen sight. It possesses powerful jaws (almost covered by the upper and lower lips).

These insects deposit their eggs in the water, and the fact that they may be often seen with the end of the abdomen curved down 
under the surface of the water in the act of depositing the eggs has given rise to the belief that they were then engaged in stinging something. The egg hatches into a form called a nymph, which in the dragon fly is characterized by a greatly developed lower lip. When the animal is at rest, the lower lip covers the large biting jaws, which can be extended to grasp and hold its prey. It may live as a nymph from one summer to as long as two years in the water. It then crawls out on a stick, molts by splitting the skin down the back, and comes out as an adult.

A closely related form is the damsel fly. This may be distinguished from the dragon fly by the fact that when at rest the wings are carried close to the abdomen, while in the dragon fly they are held in a horizontal position.

Another near relative of the dragon fly is the May fly. These insects in the adult stage have lost the power to take food. Most of their life is passed in the larval stage in the water. The adults sometimes live only a few hours, just long enough to mate and deposit their eggs. These insects belong to the order Odonata.

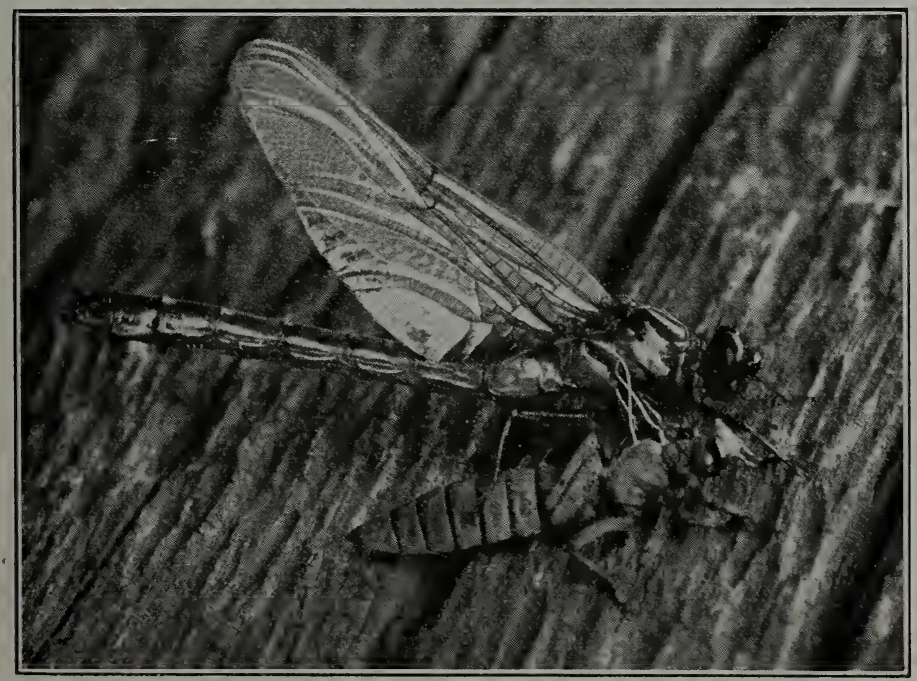

A dragon fly that has just emerged from the nymph. 


\section{Self-Testing Exercise}

The hind wings of the flies are for $\ldots \ldots \ldots$ (1). The $\ldots \ldots$. (2) of a fly is a maggot. The beetle has a larval stage called a ........ (3), which has ........ (4) pairs of ....... (5). A dragon fly in the larval stage is called a .......(6). Aphids ........(7) their food and do much harm in the .......(8) stage.

\section{PROBLEM VI. WHY ARE INSECTS SO NUMEROUS?}

There are over 450,000 different known species of insects, or almost three times as many as all other animals put together. From the standpoint of numbers they are a successful group. Why is this so? Several reasons can be given. Scores, often hundreds, of eggs are laid by a single mother, and sometimes before a month has passed each little female insect that has hatched is ready to lay eggs in its turn. This life cycle may be repeated several times during a season. They grow rapidly, they are often adapted to use food that other animals will not use, as witness the

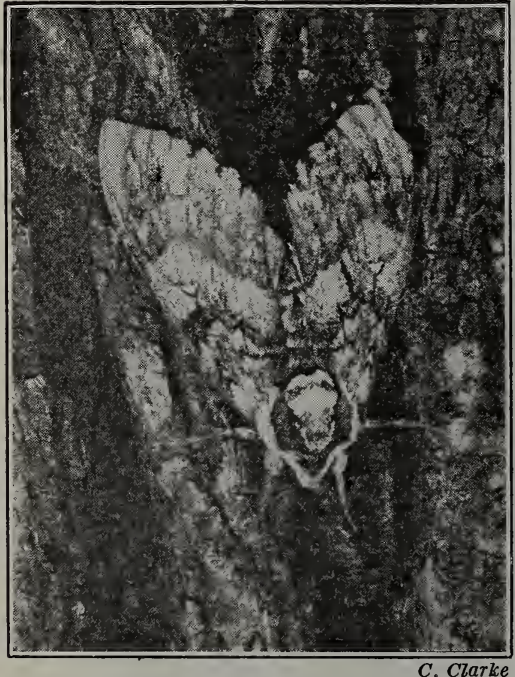

The moth clinging to the trunk of an elm tree is so similar in coloring to the bark that it is not noticeable at a distance.

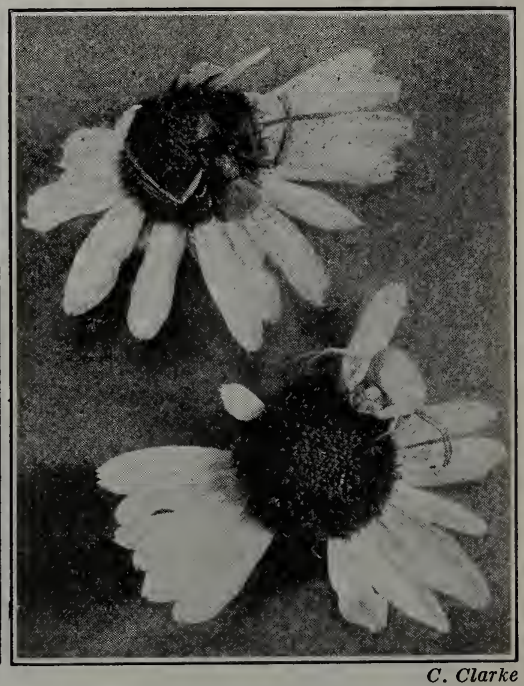

The yellow crab spider on the yellow center of the flower and the white crab spider against the background of white petals are inconspicuous as they lie in wait for some visiting insects. 
hundreds of forms that live on weeds and decayed food, and they have numerous ways of escaping their enemies. Such is the house fly. On the other hand, such insects have many enemies so that few forms become over abundant. Many can fly and thus have an easy way of escaping their enemies. Then many species are very tiny, thus escaping detection. The fact that many species pass through a metamorphosis is an undoubted advantage, for often there is a long quiescent stage either passed out of sight in the ground or under bark of trees or stones. The pupae of many insects are covered, so that birds or their ene-
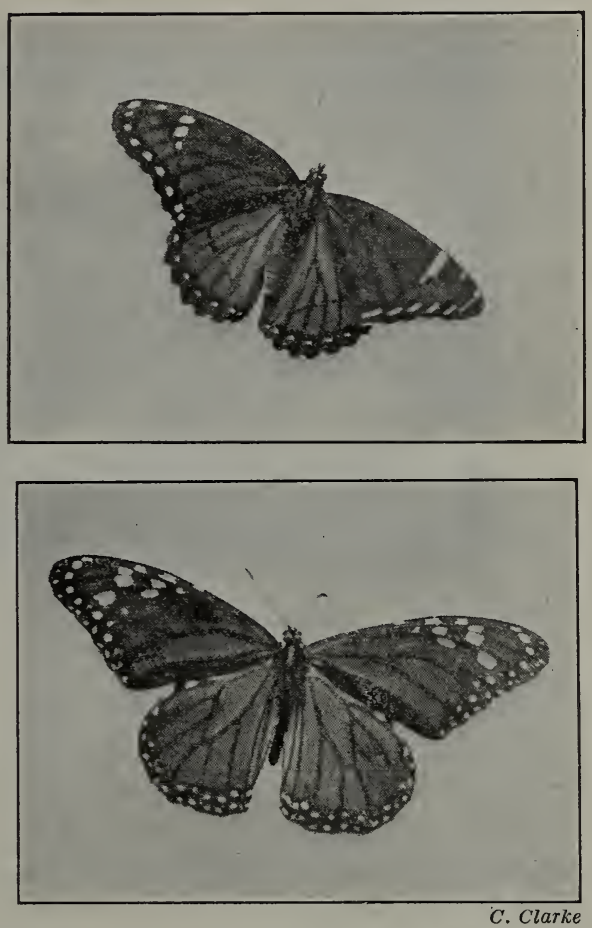

The viceroy butterfly (above) mimics the monarch butterfly, which is distasteful to birds, and thus gains protection from its enemies.

mies would not notice them. Many adults have either a hard body covering or are covered with hairs. In addition many have odor or taste disagreeable to birds, which are their chief enemies.

If we examine insects in their native haunts, we find that many of them have interesting means of protection. The grasshopper is colored like the grass on which it lives. The katydid, with its green body and wings, can scarcely be distinguished from the leaves on which it rests. The walking stick, which resembles the twigs on which it is found, and the walking-leaf insect of the tropics are other examples. This is called protective resemblance.

Some insects are provided with means of defense, such as poison hairs or stings. Those animals which are harmful are sometimes 


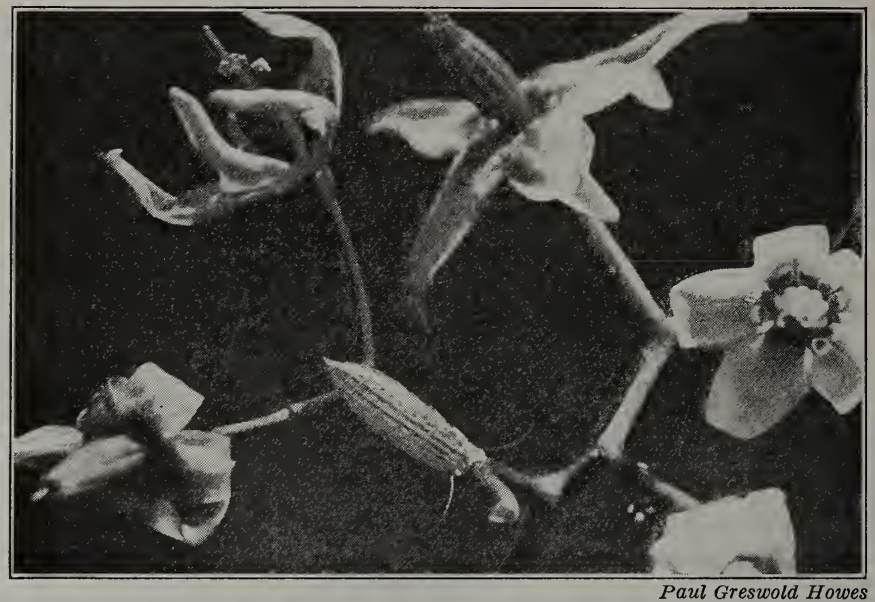

A leaf hopper mimics the central part of the flowers upon which it was found. Find the insect.

brightly colored or marked as if to warn animals to keep off or to take the consequences. They are said to show warning coloration. Examples of such insects may be seen in many varieties of beetles, especially the spotted ladybirds and potato beetles. Wasps show yellow bands, while many forms of caterpillars are conspicuously marked or colored.

Larvae of insects, such as caterpillars, which are harmless, are brightly colored and protrude horns, or pretend to sting when threatened with attack. These animals appear to mimic animals similar in appearance, which really are protected by a sting or by poison. Some butterflies which birds eat look like those that are avoided by them and, therefore, must be distasteful. Such imitation is particularly well shown by the monarch and the viceroy butterflies. Some harmless flies imitate bees, and thus seem to receive a certain protection. When a harmless insect resembles a harmful one, we call it mimicry.

Practical Exercise 7. Write a paragraph giving reasons why insects are more numerous than other forms of animals.

Field Exercise. Find, mount, and exhibit to the class different examples of insects/showing protective resemblance, warning coloration, and mimicry. 


\section{Self-Testing Exercise}

Protective coloring or resemblance is seen in the $\ldots . . .(1)$ (2) and .......(3). Protective mimicry. is seen in the (4) and .......(5) butterflies. Insects are a ......(6) group. Many insects .......(7), and thus escape their enemies. The .......(8) stage is a help, because it provides a long quiescent . (9) during which the insects are hidden from sight. Many insects are .......(10) colored.

\section{PROBLEM VII. OF WHAT USE ARE FLOWERS TO PLANTS?}

Laboratory Exercise. The structure of a simple flower.

The floral envelope. Examine a simple flower, such as a lily. The expanded portion of the flower stalk, which holds the parts of the flower, is called the receptacle. The green leaflike parts covering the unopened flower, when taken together, are called the calyx. Each of these parts is a sepal. How many petals does your specimen have? What use do they seem to have? The more brightly colored structures are the petals. How many do you find? When joined together, the petals form a corolla. The corolla is of importance in making the flower conspicuous. Of what value would this be? Frequently the petals or corolla have bright marks or dots which lead down to the base of the cup of the flower, where a sweet fluid called nectar is secreted by nectar glands. It is principally this food substance, later made into honey by bees, that makes flowers attractive to insects.

The essential organs of the flower consist of the stamens and pistil (or pistils), the latter being in the center of the flower. How many stamens do you find in your specimen? Cut crosswise through the swollen part of the pistil. How many divisions do you find? Are the parts of the flower in multiples of each other? In a single stamen the boxlike part at the end is the anther; the stalk which holds the anther is called the filament. The anther is in reality a hollow box which produces a large number of little grains called pollen. Each pistil is composed of a rather stout base called the ovary, which contains the ovule or future seeds, and a more or less lengthened portion rising from the ovary called the style. The upper end of the style is called the stigma.

Practical Exercise 8. Draw a longitudinal section of the flower and label all parts. Show the essential organs in color.

Pollen. Pollen grains of various flowers, as seen under the microscope, differ greatly in form and appearance. Some are relatively large, some small, some rough, others smooth, some spherical, and others angular. They all are alike, however, in having a thick wall, with a thin membrane under it, the whole inclosing a mass of pro- 
toplasm. At an early stage the pollen grain is a single cell, but at the time of pollination it contains two or three cells.

Germination of pollen grains. Pollen grains will germinate if they fall on the stigma of a flower of the same kind of plant. The stigma secretes a sticky fluid containing sugar and certain acids, which the pollen absorbs and grows by sending out a thread-
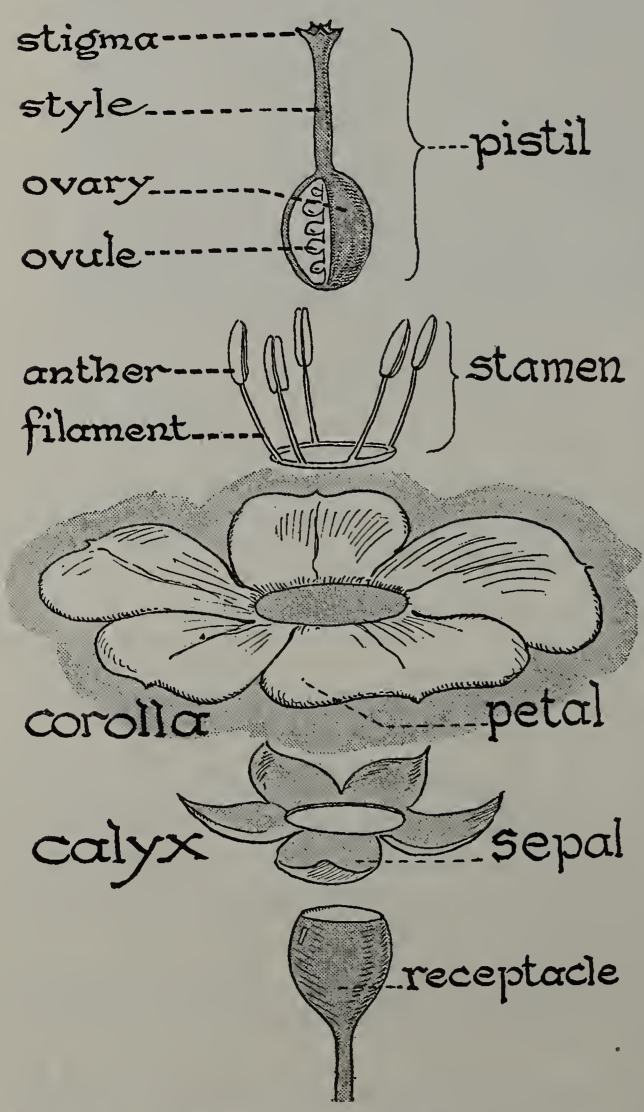

Parts of a complete flower. A flower is called perfect if it contains the essential organs.

like tube which causes the growth of the structure. During this growth, two nuclei are found in the tube. One of them, the tube nucleus, disappears after a time. The second, or germinative nucleus, divides to form two sperm nuclei.

Fertilization. If we cut the pistil of a large flower (as a lily) lengthwise, we notice that the style appears to be composed of rather spongy material in the interior; the ovary is hollow and is seen to contain a number of rounded structures which appear to grow out from the wall of the ovary. These are the ovules. The ovules, under certain conditions, become seeds. The central part of the style is found to be either hollow or composed of a soft tissue through which the pollen tube can easily grow. In germinating, 
the pollen grain sends out a pollen tube which grows downward through the spongy center of the style, following the path of least resistance, to the space within the ovary, and there enters an ovule through a tiny opening in the ovary wall, the micropyle (mì'crò-pil).

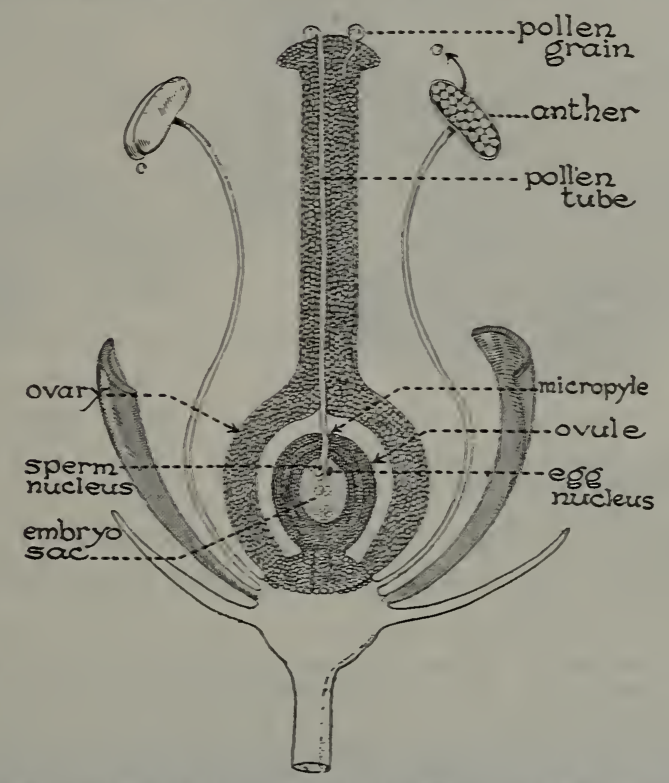

Read carefully the paragraph on fertilization and then explain this diagram in your workbook.

During the growth of the pollen tube the sperm nucleus passes down the elongating tube. When the tube reaches a clear area of protoplasm, known as the embryo sac, its tip is ruptured and the sperm nucleus passes out into this sac. The embryo sac is an oroid space, microscopic in size, filled with semifluid protoplasm containing several nuclei. One of the nuclei, with the protoplasm immediately surrounding it, is called the egg cell. It is toward this cell that the sperm nucleus of the pollen tube grows. Ultimately the sperm nucleus reaches the egg cell and unites with it. The union of the sperm nucleus with the nucleus of the egg cell in the ovule is known as fertilization. The union of the sperm nucleus and the egg cell results in a fertilized egg. This egg, by constant divisions of the cells, H. BIO -7 


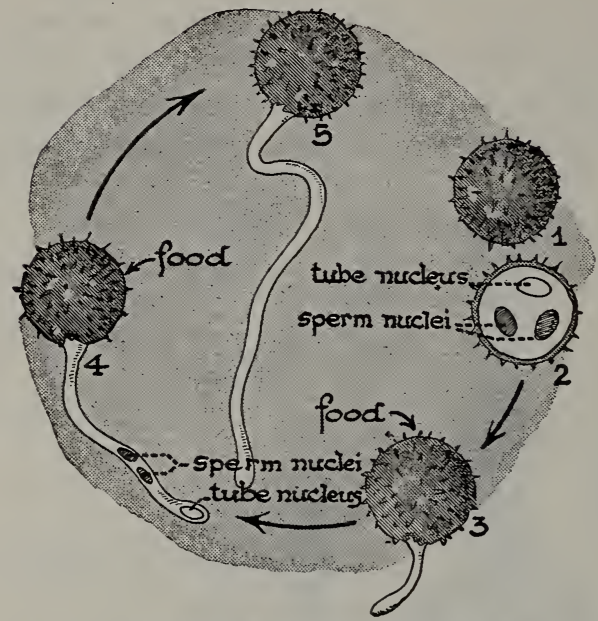

Explain, with reference to your text, the stages in the germination of a pollen grain.

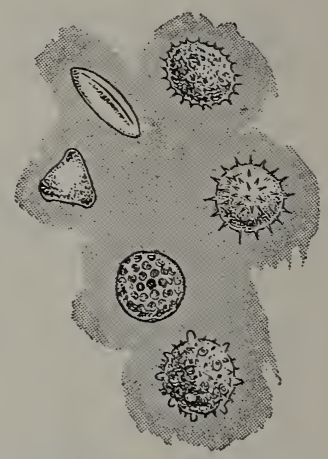

Pollen grains may take various forms. What might be the value of the spinelike structures on the pollen grains?

forms an embryo or baby plant. This is contained in the seed and, as we know, will develop into an adult plant if given proper environmental conditions.

Practical Exercise 9. Make a series of diagrams to show just how the sperm nucleus reaches the egg cell in order to bring about fertilization.

Make an enlarged diagram to show how fertilization takes place.

\section{Self-Testing Exercise}

The parts of a flower are $\ldots \ldots \ldots(1), \ldots \ldots$ (2), ...... (3), $\ldots \ldots \ldots(4)$, and ........ (5). Essential organs are the ....... (6) and the ....... (7). Pollen is produced in the ...... (8). Egg cells are found in the ....... (9). Fertilization of the .......(10) by a $\ldots \ldots .(11)$ nucleus from the pollen .......(12) causes an $\ldots \ldots$. (13) or ....... (14) plant to be formed.

\section{PROBLEM VIII. HOW ARE FRUITS FORMED?}

Laboratory Exercise. Examine an unopened pea or bean pod. Compare it with a pea or bean flower or with drawing. Find the parts of the flower in the fruit. What becomes of the petals and sepals? What happens to the pistil? Where do the seeds grow?

The pod of a bean, pea, or locust illustrates well the growth from the flower. The flower stalk, the ovary, and the remains of the style, the stigma, and the calyx, can be found on most 

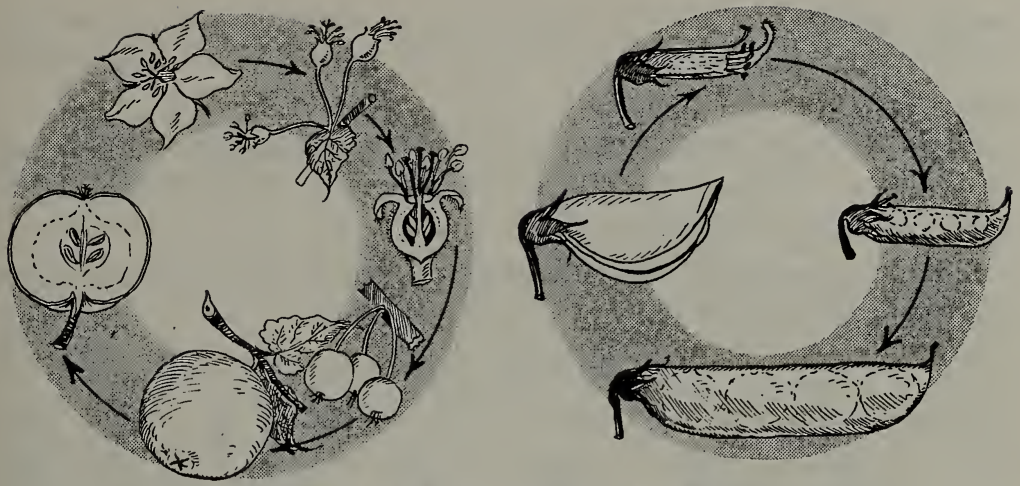

Can you find all parts of the flower in the ripened fruit?

unopened pods. If the pod is opened, the seeds will be found fastened to the ovary wall each by a little stalk called the funiculus (fü-nŭk' the placenta (pla-sěn't $\dot{a}$ ). The walls of the pod are called valves.

The pod, which is in reality a ripened ovary with other parts of the flower attached to it, is considered a fruit. By definition, a fruit is a ripened ovary together with any parts of the flower that

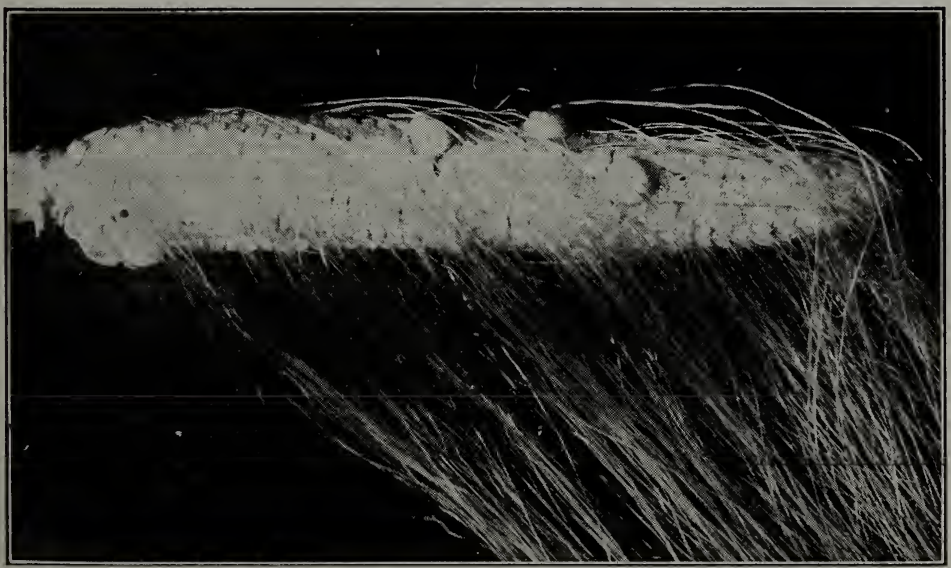

U. S. Department of Agriculture

Why have so few grains appeared in this ear of corn? Remember the corn cob bears pistillate flowers; the "silks" are the long styles with stigmas at the tips. 
may be attached to it. The chief use of the fruit is to hold and to protect the seeds ; it may ultimately distribute them where they can reproduce young plants.

Each seed has been formed as a direct result of the fertilization of the egg cell (contained in the embryo sac of the ovule) by a sperm nucleus of the pollen tube.

Practical Exercise 10. Describe with the aid of diagrams the growth into a fruit of some flower, not given in the text.

\section{Self-Testing Exercise}

In a pod, the seed is fastened to the ovary wall by the $\ldots . . .$. (1). The .......(2) is the part of the wall of pod that bears the $\ldots . \ldots$ (3). The pod is a ....... (4) ......(5) and is called a $\ldots \ldots \ldots$ (6). The chief use of the .......(7) is to protect the $\ldots . \ldots$. (8). Seeds are formed as a direct result of the ....... (9) of the .......(10) cell in the embryo sac by the ....... (11) nucleus in the .......(12) tube.

\section{PROBLEM IX. WHAT ARE SOME ADAPTATIONS IN INSECTS FOR CARRYING POLLEN?}

Insects as pollinating agents. Insects often visit flowers to obtain pollen as well as nectar. In so doing they may transfer some of the pollen from one flower to another of the same kind. This transfer of pollen, called cross-pollination, is of the greatest use to the plant, as we shall see later. Sir John Lubbock observed bees and wasps to learn how many trips they made daily from their homes to the flowers, and found that a wasp went out on 116 visits during a working day of 16 hours, while a bee made almost as many visits and worked almost as long as the wasp. It is evident that in the course of so many trips to the fields a bee must light on hundreds of flowers.

Nectar and nectar glands. The bee is attracted to a flower for food. This food may consist of pollen or nectar. Nectar is a sugary solution that is formed in the flower by little collections of cells called the nectar glands. The nectar glands are usually so placed that to reach them the insect must first brush the stamens and pistil of the flower. Frequently the location of the nectaries (nectar glands) is made conspicuous by brightly colored markings 
on the corolla of the flower. The row of dots in the tiger lily is an example.

Practical Exercise 11. Study a dead bee, to discover adaptations for carrying pollen. Use diagram in text to help. Hand lenses are essential and a compound microscope will be found useful.

Adaptations in a bee. If we look closely at a bee, we find the body and legs more or less covered with tiny hairs, many of them branched. The joints in the legs of the bee adapt it for complicated movements; the arrangement of stiff hairs along the edge of a concavity in one of the joints of the hindmost pair forms a structure called the pollen basket, adapted to hold pollen. Bees collect pollen and force it into this concavity by means of a pollen press (usually called the wax shears), located between the two large joints of the hind pair of legs. Pollen obtained by the bee in this way is taken to
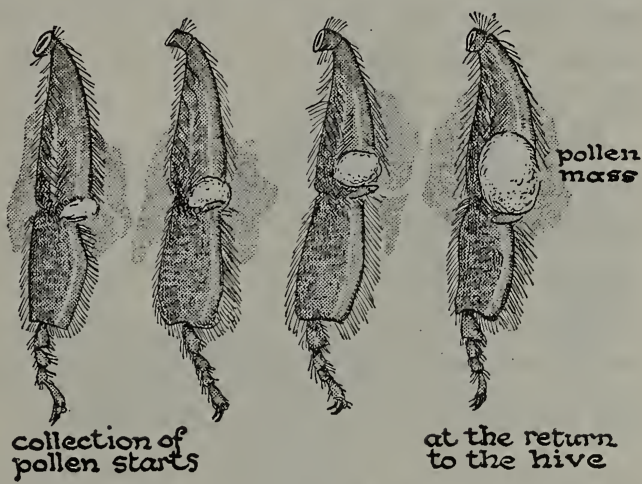

at the return to the hive

What part of the leg holds pollen? Why?

the hive to be used as food. But while the insect is gathering pollen for itself, some is caught on the hairs and other projections on the body or legs and is carried from flower to flower (see page 72).

Field Exercise. In any locality where flowers are abundant; try to answer the following questions: How many bees visit the locality in ten minutes? How many other insects alight on the flowers? Do bees visit flowers of the same kind in succession, or fly from one flower on a given plant to another on a plant of a different kind? If the bee alights on a flower cluster, does it visit more than one flower in the same cluster? How does a bee alight? Exactly what does the bee do when it alights? Try to decide whether color or odor has the most effect in attracting bees to flowers.

The cross-pollination of flowers is not planned by the bee ; it is simply an incident in the course of the food gathering. The bee visits a large number of flowers of the same species during the 
course of a single trip from the hive, and it is then that crosspollination takes place.

Other flower visitors. Other insects besides the bee are pollenizing agents for flowers. Among the most useful are moths and butterflies. Both of these insects feed only on nectar, which they suck through a long tubelike proboscis. The heads and bodies of these insects are more or less thickly covered with hairs, and the wings are thatched with tiny hairlike scales. All these structures are of some use to the flower because they collect and carry pollen; but the palp, a fluffy structure projecting from each side of the head of a butterfly, collects a large amount of pollen, which is deposited upon the stigmas of other flowers when the butterfly pushes its head down into the flower tube after nectar.

Flies and a few other insects are agents in cross-pollination. Humming birds are also active in pollinating some flowers. Snails are said in rare instances to carry pollen. Man and animals may pollinate a few flowers in brushing past them through the fields.

Practical Exercise 12. Devise an experiment to determine if a given insect is attracted to a given flower by color or by odor.

List in a table the plants in your neighborhood that are pollinated by butterflies, bees, beetles, flies, bugs, or other insects.

\begin{tabular}{|l|c|c|c|c|c|}
\hline Butterfies & Bees & Beetles & Flies & Begs & Other Insects \\
\hline & & & & \\
\hline & & & & \\
\hline
\end{tabular}

\section{Self-Testing Exercise}

.......(1) is accomplished by the insect visitors to flowers. The chief adaptations in the bee for carrying pollen are the ....... (2) on the legs and body. The bee uses pollen for ....... (3) and carries it to the hive in ........ (4) ...... (5), concavities on the ...... (6) pair of legs.

$(7), \ldots \ldots$ (8), ......(9),

....... (11), and other animals may aid in cross-pollinating flowers.

These animals visit flowers for ...... (12) and not to ...... (13) them. 


\section{PROBLEM $X$. WHAT ARE SOME SPECIFIC EXAMPLES OF CROSS-POLLINATION?}

Demonstration. Some of the material in the following paragraphs will be available for study. If possible, supplement the text with charts which can be used as a basis for discussion. Snapdragon may be substituted for butter-and-eggs.

Butter-and-eggs. From July to October in the East, the very abundant weed called " butter-and-eggs " may be found, especially along roadsides and in sunny fields. It bears a tall and conspicuous cluster of yellow and orange flowers known to botanists as a spike, the flowers being arranged so that they come out directly on main stalk.

The corolla projects into a spur on the lower side; an upper two-parted lip shuts down upon a lower three-parted lip. The four stamens are in pairs, two long and two short.

Certain parts of the

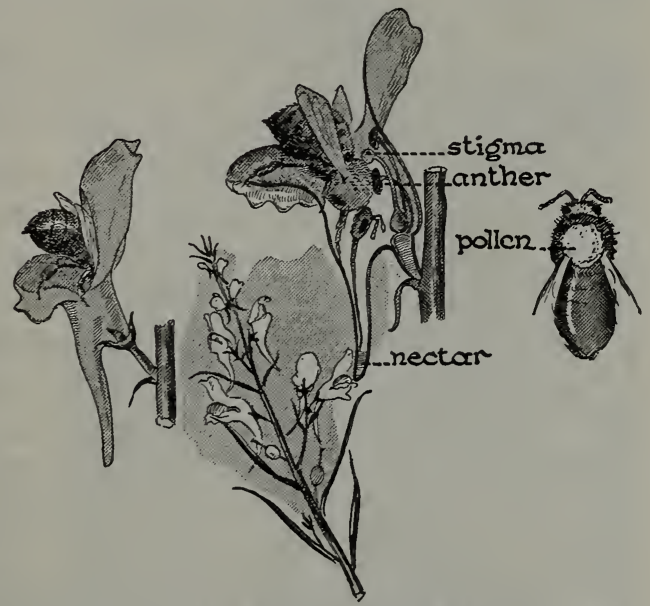

By means of the text and diagram explain how the bee transfers pollen from one flower to another of " butter-andeggs."

corolla are more brightly colored than the rest of the flower. Butter-and-eggs is visited by bumblebees, which apparently are guided by the orange lip to alight just where they can push their way into the flower. The bee, seeking the nectar secreted in the spur, brushes its head and thorax against the stamens. It may then, as it pushes down after nectar, leave some pollen upon the pistil, thus effecting self-pollination. Later in visiting another flower of the same kind, the bee may leave some of the pollen of the first flower on the pistil of the second flower, thus causing cross-pollination. 
Cross-pollination of clover. In a clover head, which is a closely massed cluster of little flowers, cross-pollination is usually effected

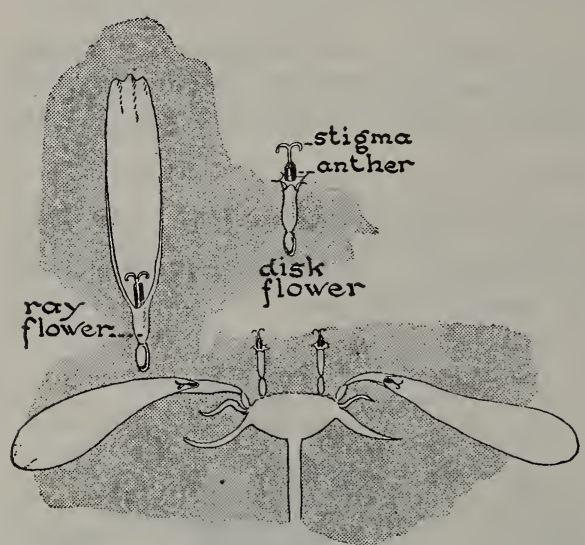

How does pollination take place in a daisy?

by bumblebees which work rapidly from one flower to another in the same group, inserting their tongues deep into the flower cups.

Cross-pollination of a composite head. The daisy, aster, and sunflower are examples of a composite head. The flower cluster has an outer circle of green parts which look like sepals, but in reality are a circle of leaflike parts. Taken together these form an involucre ( $\mathrm{nn}^{\prime}$ vô-lū-kẽr). Inside the involucre is a whorl of brightly colored, irregular flowers called the ray flowers. They appear to act, in some instances at least, as an attraction to insects by showing a definite color (see the common yellow daisy). The flowers occupying the center of the cluster are the disk flowers. Pollen is carried easily from one flower to another even by an insect which crawls.

Devices to secure cross-pollination. There are many other examples of adaptations to secure crosspollination by means
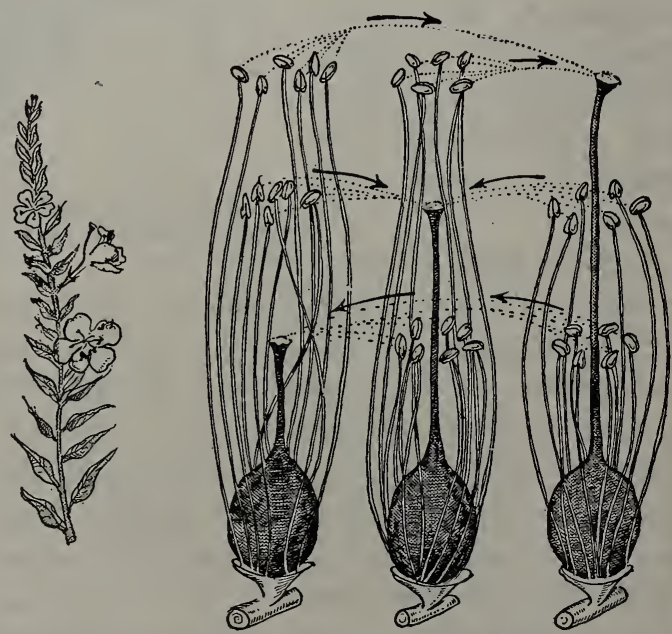

The length of the filaments and height of the stigma may make the self-pollination of loose-strife impossible. Why? 
of the visits of insects. The mountain laurel shows a remarkable adaptation in having the anthers of the stamens caught in little pockets of the corolla. The weight of the visiting insect on the corolla releases the anther from the pocket in which it rests so that it springs up, dusting the body of the visitor with pollen.

In some plants, selfpollination is prevented by certain devices, as in the primroses, in which the stamens and pistils are of different lengths in different flowers. Short styles and long filaments with high-placed anthers are found in some flowers, and long styles and short filaments with low-placed anthers in others. Pollination is most likely to be effected by some of the pollen from a low-placed anther reaching the stigma of a short-styled flower, or by the pollen from a high anther being placed upon a long-styled pistil. There are, as in the case of the spiked loose-strife, flowers

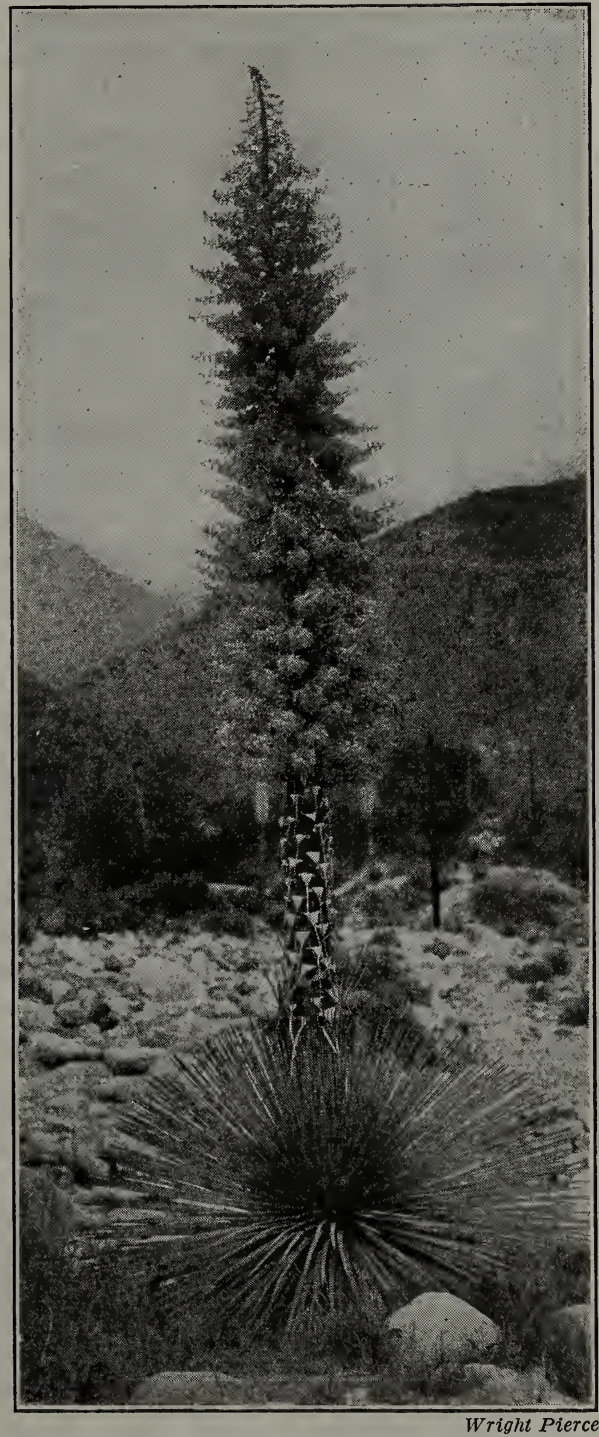

A species of yucca found in the Southwest. It is almost stemless, and has a stout flower stalk 12 to $x_{5}$ feet high carrying a cluster of fragrant, creamy white, bell-shaped flowers. 
having pistils and stamens of three lengths. Pollen grows best on pistils of the same length as the stamens from which it came.

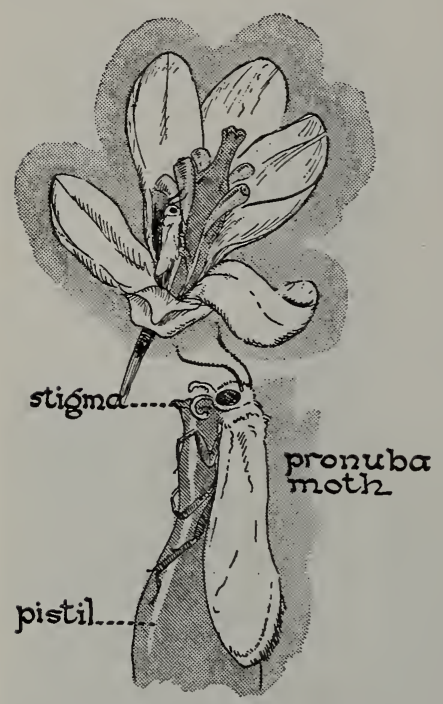

The pollination of yucca. What is the moth doing in the lower figure?

The stamens and pistil ripen at different times in some flowers. The "Lady Washington" geranium, a common house plant, shows this condition.

Pollination of the yucca. A very remarkable instance of insect help is found in the pollination of yucca, a semitropical lily which lives in the washes and semi-desert regions in our Southwest. The anthers of this flower reach nowhere near the stigma, and the plant has to depend upon insects for fertilization. The insect which accomplishes this is the pronuba (prō'nü-bä) moth. The female moth gathers pollen from the anthers of these blossoms and shapes it into a pellet. She flies to another flower, and inserts her ovipositor into the ovary of the flowers and lays her eggs among the ovules. She then thrusts the pollen ball into the opening which extends the length of the style. When the egg hatches, the caterpillar feeds on some of the young seeds which have developed along with the larva. Later it bores its way out of the seed pod and escapes to the ground, leaving the plant to develop the remaining seeds without further molestation.

How the fig is pollinated. The pollination of the fig is another wonderful example of adaptation. The fig is not a fruit but a cluster of fruits, growing inside the inturned ends of a fleshy flower stalk. There may be three kinds of flowers in the clusters, some bearing only stamens, some with only pistils with long styles, and others, pistils with short styles. Some fig flower clusters have long-styled pistillate flowers only, others contain both short-styled and staminate flowers, the latter above the 
pistillate flowers. All of these flowers are visited by a little wasp (Blastophaga grossorum). When it visits the short-styled and staminate fig, it lays its eggs in the ovary, which it can easily reach with its egg-depositing organ (the ovipositor). The females which hatch work their way out and in doing so brush against the staminate flowers, thus collecting pollen on their bodies. They then seek other figs in order to lay their eggs. If a wasp reaches another short-styled flower cluster, the eggs are laid and development takes place as before. But if it flies to a long-styled cluster, it cannot reach the ovary to deposit its eggs. In both cases, however, the wasp has carried pollen to the stigma and pollination takes place with the subsequent development of seeds. The figs we eat are developed from the long-styled pistillate flowers. By importing the wasps to California it is possible to grow figs where for years it was believed that the climate prevented them from ripening.

Pollination by the wind. Not all flowers are dependent upon insects for cross-pollination. Many of the earliest spring flowers appear almost before the insects do. In many trees, such as the oak, poplar, and maple, the flowers open before the leaves come out. Such flowers are usually dependent upon the wind to carry the pollen from the stamens of one flower to the pistil of another.

Among the adaptations that a wind-pollinated flower shows are: (1) The development of many pollen grains to each ovule. In flowers which are pollinated by the wind, a large number of the pollen

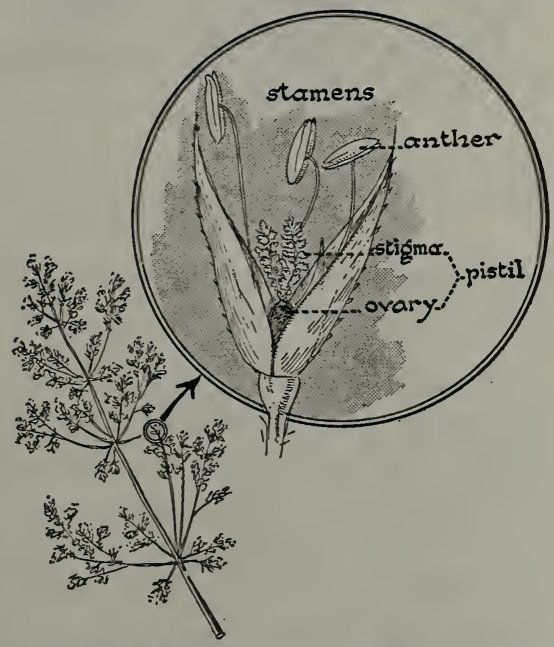

A wind-pollinated flower. What devices are shown that aid in cross-pollination? grains never reach their destination and are wasted. Therefore thousands of pollen grains must be formed to every ovule produced. 
(2) The anthers are usually held high and exposed to the wind when ripe. The common plantain and timothy grass are excellent examples.

(3) The pistil of the flower is peculiarly fitted to retain the pollen by having feathery projections along the sides which increase the

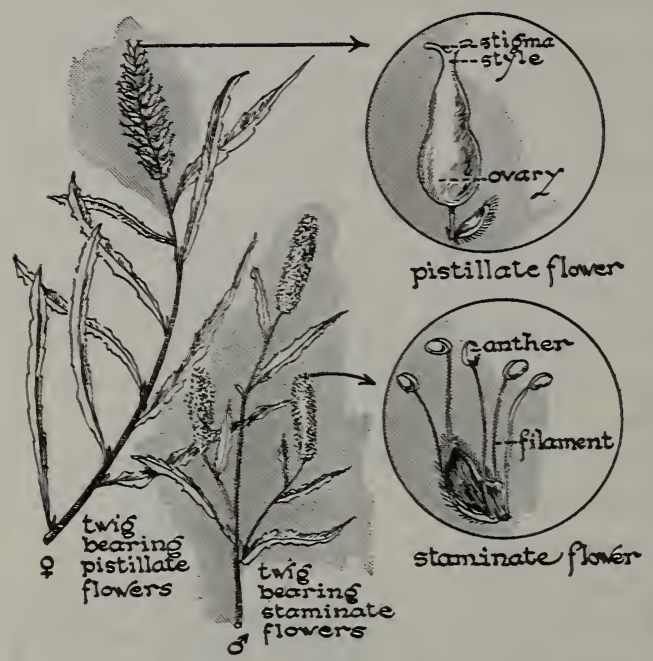

Why are the flowers of the willow imperfect? Explain how cross-pollination might take place. surface of the stigma. All our grains, wheat, rye, oats, and others, have the typical feathery pistil of the wild grasses from which they have been developed.

(4) The corolla is often entirely lacking. It would only be in the way in flowers that are dependent upon the wind to carry pollen.

Practical Exercise 13. Name five plants that have a large proportion of pollen grains to each flower. Study a diagram of a grass flower. Why is pollination easily accomplished by the wind? What is the "silk" of Indian corn? Name a flower that has no corolla. (Look up in a good botany.)

Imperfect flowers. Some flowers, the wind-pollinated ones in particular, are imperfect; that is, they lack either stamens or pistils. In such flowers, cross-pollination must of necessity be depended upon. In some trees, as the willow, staminate flowers (those which contain only stamens) are developed on one plant, and pistillate flowers (those which bear only pistils) on another. Other species have staminate and pistillate flowers on the same plant. The oak, hickory, beech, birch, walnut, and chestnut are familiar examples.

Practical Exercise 14. Show by means of diagram how pollination might take place in the willow. 


\section{SElf-Testing Exercise}

Certain flowers, as butter-and-eggs, are especially fitted to receive .(1), which cause both ........ (2) and ........ (3) pollination. A composite head is composed of .......(4) and ........ (5) flowers. Some flowers, as the yucca, are only pollinated when certain insects .......(6) their .......(7) in them and the seeds are ....... (8) by the young parasites which hatch out. Self-pollination is usually impossible in flowers which have the ......(9) and . (10) maturing at ....... (11) times or placed on ........ (12) flowers. Some plants have only ....... (13) or ....... (14) flowers and are pollinated by the ........(15).

\section{Review Summary}

Check your knowledge of the unit by (1) answering all survey questions; (2) performing all assigned exercises; (3) checking with your teacher on all the tests and making up all incorrect work; and finally (4) making an outline of the unit, for your notebook.

\section{Test on Fundamental Concepts}

Make two vertical columns in your notebook, one headed CORRECT and the other INCORRECT. In one column write the numbers of the statements you believe to be true. In the other the statements you think are false. Your grade = correct answers times 2.

I. All insects (1) have two pairs of wings; (2) have three body parts ; (3) have mouth parts adapted to chewing; (4) have three pairs of legs; (5) have an external skeleton of chitin.

II. All insects breathe (6) through their wings; (7) by taking air out of the water they drink; (8) through holes in the head; (9) by pumping air into their trachea; (10) by swallowing air.

III. Insects may feed by (11) sucking through a proboscis, as the butterfly; (12) chewing by means of the mandibles, as the grasshopper; (13) sucking through a beak, as the cicada; (14) lapping liquid food, as the beetle; (15) piercing and sucking, as the bugs.

IV. The life history of an insect may (16) have four different stages; (17) be passed entirely underground as in the beetle; (18) show an incomplete metamorphosis as in the grasshopper; (19) show a complete metamorphosis as in the house fly; (20) last for thirty or more years.

V. Insects are very numerous because (21) they produce many young in a season; (22) they may be colored like their surroundings 
and thus avoid capture ; (23) they all taste badly to birds ; (24) many have a long quiescent period during metamorphosis; (25) they have few enemies.

VI. Insects when they visit flowers may (26) go there to lay their eggs; (27) carry pollen from one flower to another of a different kind; (28) pierce holes in the flowers in order to steal nectar; (29) transfer pollen from the anthers of one flower to the pistil of another flower of a different species, thus causing self-pollination; (30) carry pollen away without intending it, and thus cross-pollinate flowers.

VII. Fertilization of a flower takes place when (31) a pollen tube is formed; (32) an insect visits a flower ; (33) the sperm nucleus unites with the egg cell; (34) pollen germinates on the stigma and grows a pollen tube; (35) any two cells meet.

VIII. Flowers have (36) essential organs called calyx and corolla; (37) stamens, pistil, petals, and sepals; (38) structures called anthers, which produce pollen; (39) organs called ovaries, which hold the egg cells; (40) the possibility of producing seeds if they are pollinated.

IX. Effective adaptations in insects for bringing about cross-pollination are: (41) hairs on the legs and body; (42) a long piercing beak; (43) fluffy palps, as in the butterfly; (44) smooth bodies, as in the ant; (45) pollen baskets, as in the bee.

$\mathrm{X}$. The flowers most effectively adapted for bringing about crosspollination are : (46) flowers with only stamens or pistils; (47) flowers with essential organs of different lengths; (48) flowers having the stamens and pistils ripen at different times; (49) showy flowers without essential organs; (50) flowers which prevent insect visitors from reaching the pollen.

\section{Achievement Test}

1. How can you tell an insect from other animals?

2. Where would you look for the different orders of insects? From how many of the orders of insects have you been able to find and collect representatives?

3. How many kinds of larvae and pupae in each of the above orders of insects can you name?

4. Have you ever studied an observation hive of bees? Describe it.

5. How could you make an artificial ant's nest and study the life of the colony? 
6. What are some examples of protective coloration or resemblance and warning coloration?

7. What are the parts of a flower and the uses of each part?

8. How would you germinate pollen grains in order to see a pollen tube?

9. How would you make a diagram for your notebook that would describe fertilization in a flower?

10. How can you show that a flower like the pea or apple blossom will form a fruit? (Diagram for notebook.)

11. What are all the adaptations in a bee for carrying pollen? In a butterfly?

12. How can you distinguish between self-pollination and crosspollination?

13. How can you show by diagram the way in which a bee pollinates butter-and-eggs, clover, a daisy? (Draw diagrams in notebook.)

14. How does cross-pollination in the yucca or the fig take place?

15. How can you show that pollination takes place in $(a)$ a chestnut or oak, (b) pine cone, (c) timothy grass?

\section{Practical Problems}

1. Make a collection of insects and classify them according to the information given on pages 59-61.

2. What insects are most abundant in your locality? How can you account for this?

3. Select some flower and find out exactly how it is pollinated. Make diagrams to illustrate and explain your answer.

\section{UsEFul Books OF REFERENCE}

Coulter, Barnes, and Cowles, Botany. Volume Three, pp. 825-878. (American Book Company.)

Downing, Our Living World. Chapters ii, iii, and vi. (Longmans, Green \& Co. 1924.)

Gager, General Botany. (P. Blakiston's Son \& Co. 1926.) Lutz, Field Book of Insects. (G. P. Putnam's Sons. 1921.)

Palmer, Field Book of Nature Study. (Comstock Publishing Co. 1927.)

Transeau, General Botany. (World Book Co. 1923.) 


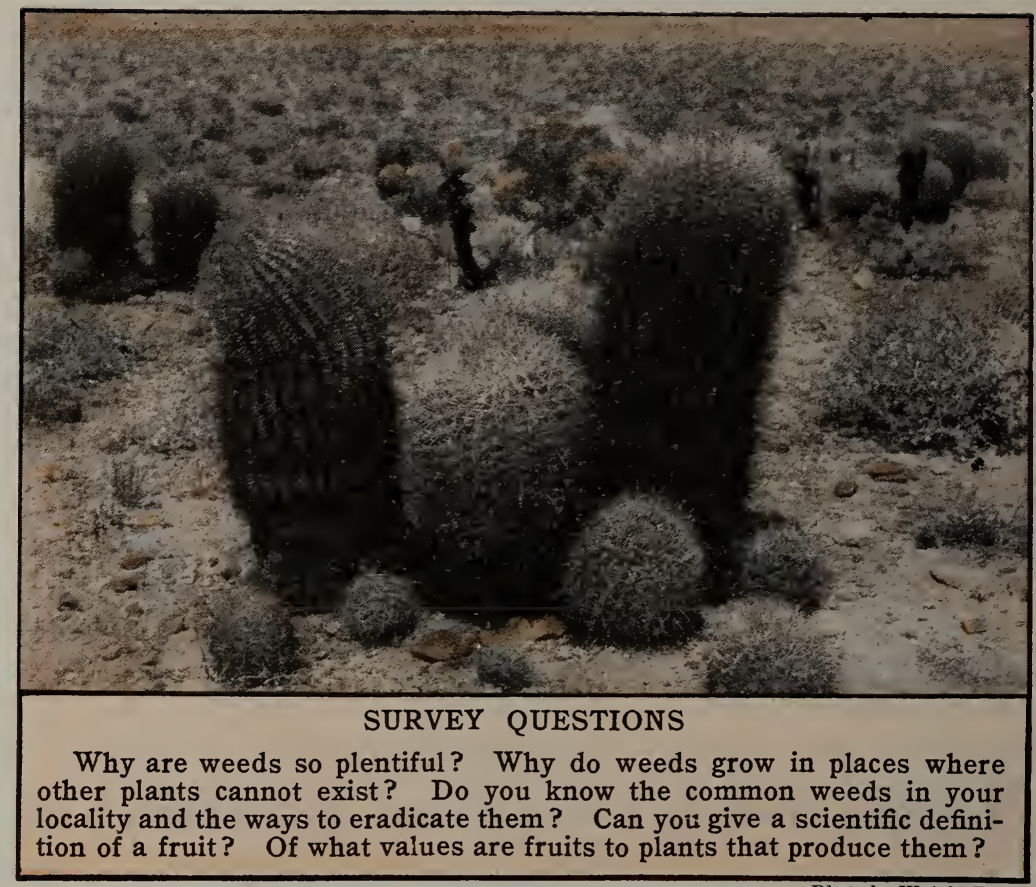

Photo by Wright Pierce

\section{UNIT IV}

\section{HOW AND WHY DO SEED PLANTS SUCCEED IN LIFE?}

Preview. Our study will now be directed to two main problems ; first, what plants are most successful in their battle of life and, second, what fits them for this success.

If you will go out any fall afternoon into the fields, a city park, or even a vacant lot, you can hardly escape seeing how seeds are scattered by the parent plants and trees. Several hundred little seedling trees may be counted under the shade of a single maple or oak tree. But nearly all these young trees are doomed to die, because of crowding and lack of sun. Plants, like animals, are dependent upon their surroundings for food and air. They need light even more than animals need it, because the soil directly 
under the shade of a tree gives raw food material to the plants, and they must have sunlight in order to make it into food. Overcrowding is often seen in the garden where young beet or lettuce plants are growing. The gardener assists nature by thinning out the young plants so that they may not be handicapped in their battle for life by an insufficient supply of air, light, and food.

It is evidently of considerable advantage to a plant to be able to place its progeny ${ }^{1}$ at a considerable distance from itself, in order that the young plants may be provided with sufficient space to get nourishment and foothold. Some plants accomplish this, particularly weeds, more completely than others, and thus they are the more successful ones in the battle of life. Besides depriving other plants of soil salts and water, weeds do much harm. Some are poisonous to cattle and sheep, as the loco-weed, hemlock, and laurel. Other weeds, as the wild onion or garlic, may be eaten by cows, and the milk produced will be ruined in flavor. Some weeds are hosts to injurious parasitic insects or fungi; witness the Hessian fly, which lives in some wild grasses, and the wheat rust, which lives in the barberry. The pollen of the ragweed and of other weeds undoubtedly cause some people to have "hay fever."

Weeds are introduced often into lawns and fields because their seeds are mixed with the good seeds which are sown there. We should use every method possible to prevent weeds from producing seeds. Poisons are used in some cases; sheep, which seem to prefer some weeds to grass, are also a great aid in keeping down these pests ; and birds that eat weed seeds are the most valuable of all.

\section{PROBLEM I. WHAT ARE WEEDS AND WHAT DO THEY DO?}

Weeds are plants that grow in places where they are not wanted. They are generally stronger and faster growing than other plants and therefore they rob crops of food, moisture, and sunlight. Any vacant lot near the school will make a good laboratory for the study of weeds. In such an area we shall find numerous plants, many alike, and all growing closely together in soil that not infrequently appears so dry and stony that it hardly seems possible

1 Progeny (prŏj'ê-ň) : offspring.

в. BIO -8 


\section{HOW DO SEED PLANTS SUCCEED IN LIFE?}

that plants could grow there. But weeds do grow and flourish under what seem impossible conditions for other plants. Let us see some reasons why.

Laboratory Exercise. Visit a roadside, vacant lot, or meadow and observe the weeds growing there. Collect and, with the aid of one of the references given at the end of the unit, try to classify the various weeds growing in this area. Take one weed and study it carefully to determine why it is successful in surviving. Estimate the number of seeds produced, ways of scattering seeds, protection of seeds, and other adaptation of the plant to its environment, etc.

Weeds produce many seeds. One fact readily observed is that many seeds are produced by weeds, be they daisies, dandelions, tumbleweeds, or ragweed. The table that follows shows approximately the number of seeds produced by an average sized plant. In your project on weeds, determine as accurately as possible the number of seeds produced by a plant and check the result against this table.

\begin{tabular}{|c|c|c|c|c|c|c|}
\hline & SEED & $s$ Pro & JCED BY A & TGLE Average-SIzEd & WEED & \\
\hline Dandelion . & & & 1,700 & Burdock & & 24,500 \\
\hline Cocklebur. & . & . & 9,700 & Russian thistle & . & 25,000 \\
\hline Oxeyed daisy & . & 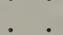 & 9,750 & Purslane. & 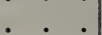 & 69,000 \\
\hline Prickly lettuc & . & . & 10,000 & Crab grass & . & 89,600 \\
\hline Beggar ticks & . & . & 10,500 & Willow foxtail & . & 113,600 \\
\hline Tumbleweed & . & . & 14,000 & Tumble mustard & . & $1,500,000$ \\
\hline Ragweed . & . & & 23,000 & Worm seed & . & $26,000,000$ \\
\hline
\end{tabular}

Individual Project. Make a collection of weed seeds, showing kinds and means of dispersal.

Weeds have good methods of seed dispersal. We have all seen a dandelion or a thistle and know the feathery parachutes by which their seeds travel. Many of us have spent much time and energy in picking beggar-ticks or burdock burs from our clothes after a scramble through a weed-infested lot. Weed seeds or fruits may have hooks, prickles, fluffy outgrowths, or other appendages, which are used for carriage; they may roll along the ground as the Russian thistle, or tumbleweed; or they may have fruit that bursts when ripe, scattering their seeds. Some seeds have 
cork-like coverings and float long distances in streams. Birds eat some seeds and scatter them undigested, far from the parent plants. A study by some school children showed that common weeds given a start in one place might within three years, under average conditions, spread from an area four acres to over three hundred acres in extent around the point where they first came up. Why not make a study in your home locality to determine the rate of spread of some weed?

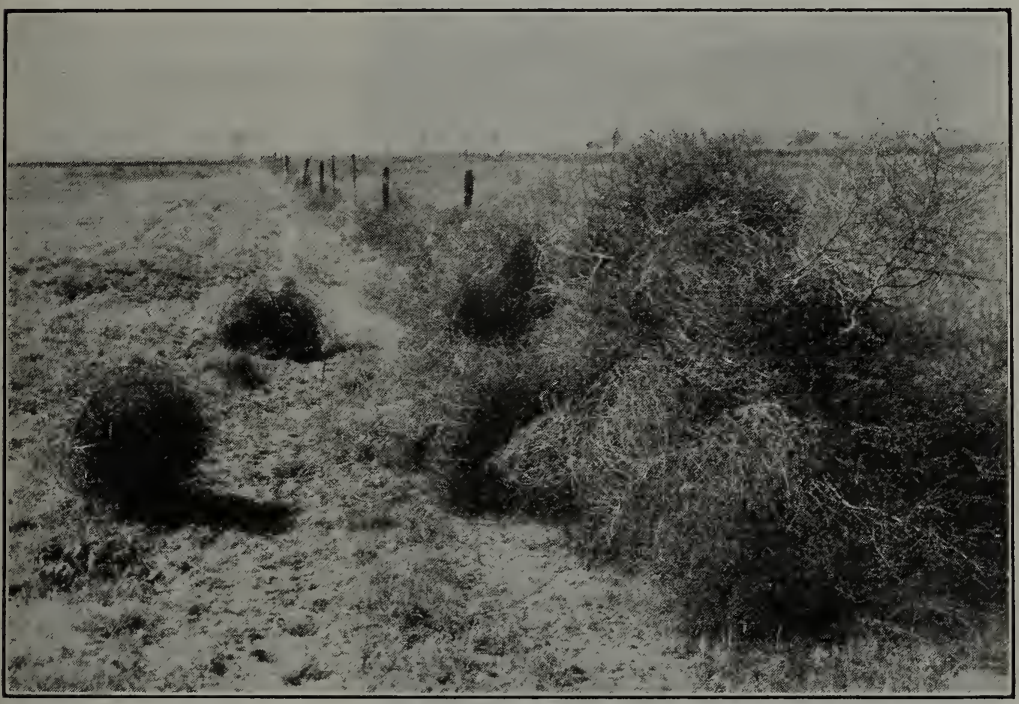

Wright Pierce

The Russian thistle, a tumbleweed, breaks loose when dry and is blown about by the wind, scattering its seeds as it rolls along.

Laboratory Exercise. Select a common weed in your community, and bring it into the laboratory. Thrash out the seeds. Collect and count the seeds and estimate a possible total number of seeds which may be scattered over a given area by several hundred weeds.

Weeds have great vitality. Those of us who have tried to get rid of weeds from a garden or from the lawn know some of the devices these pests have to maintain themselves: long and tough roots and stems; roots which develop wherever the stem touches the ground; leaves protected by thorns or hairs; roots which 


\section{HOW DO SEED PLANTS SUCCEED IN LIFE?}

store food which help the plant to get a better start in the spring; the ability to stand excessive heat and cold; and the ability to maintain themselves in wet or dry conditions. They often grow luxuriously under conditions that would kill an ordinary plant and grow so rapidly that they choke out their less favored competitors. Particularly, their seeds have great vitality, and may

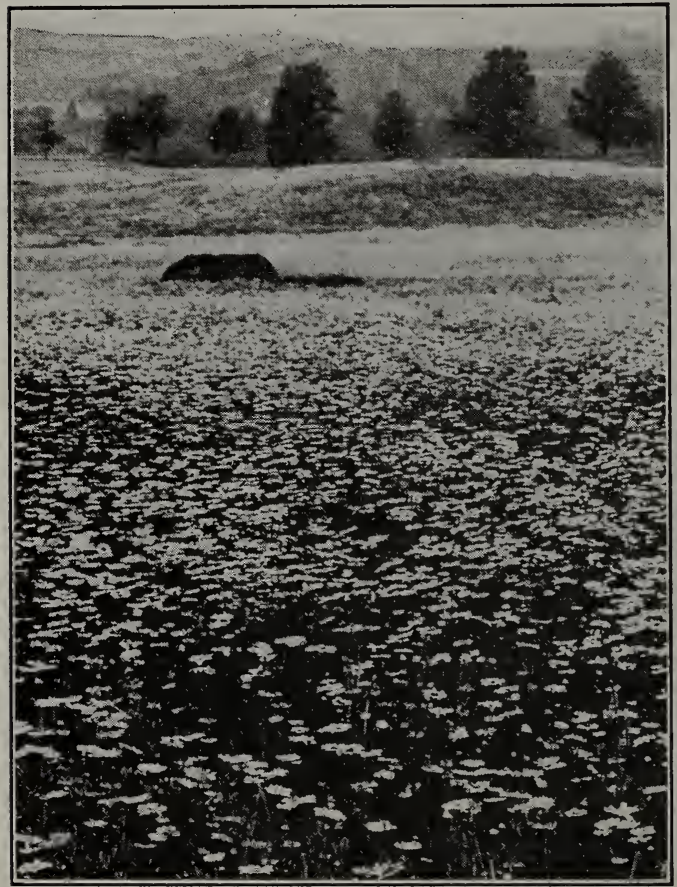

U. S. Department of Agriculture

The field daisies are able to grow in poor soil and they are thus able to smother the useful plants. stay alive in the soil as long as twentyfive years after dispersal from the parent plant.

Practical Exercise 1. Find a number of different ways in which weeds in your locality show vitality.

Weeds have good methods of selfprotection. Some structures by which weeds protect themselves have already been noted, such as the hairs of the mullein or the prickly stem and the leaf of the thistle. Many grow low to the ground, as the dandelion. Some are distasteful to animals and others have a disagreeable odor, as the wild onion, tansy, or yarrow. Most weeds have the ability to resist disease and some, such as the dodder, are parasites and get their living from host plants, giving nothing in return.

Individual Project. Collect and bring to class twenty-five common weeds. Mount them in passe-partout frames under glass. The collection will be of much value in weed identification. 
Weeds grow where other plants cannot live. Many weeds, because of long roots and small leaf surface, are fitted to live where there is little water supply, or even in drought or desert conditions. Such are the Russian thistle, some of the true thistles, the poisonous loco weed, and our common ragweed. Many, at least when young, can get along in the shade of competing plants, their rapid growth enabling them to get into the sunlight later on. Such are the mustards which often color entire fields yellow with their tiny four-petaled flowers. Still other weeds seem to thrive under conditions of soil not suitable for other plants. Such are some of our desert and alkali-loving plants.

\section{Self-Testing Exercise}

Weeds are plants that ....... (1) where they are not ........ (2). They are usually .......(3) and ....... (4) faster than agricultural plants. They rob crops of ....... (5), ...... (6), and ...... (7). Weeds produce many ........(8). Weeds are plentiful because they have good methods of .......(9) ......(10), have great ........(11) and .......(12) where other plants cannot.

\section{PROBLEM II. WHY AND HOW SHOULD WEEDS BE ERADICATED?}

Harmful weeds. Weeds do harm in a number of ways. They reduce the farmer's crops tremendously. We have already seen that they force slower growing plants out. Think of the amount of productive labor lost through keeping weeds out of gardens and fields. Weeds are often introduced into fields through the mixing of their seeds with those of grains, or other crops bought for planting. We can learn to identify such seeds under the microscope, and some farmers have such a test made to see if the seed they buy is pure. Weeds take the minerals and water from the soil much faster than the competing crops because they grow so quickly. Poisonous weeds, such as the loco weed, may kill or injure cattle. Some parasitic weeds like dodder, in the far West, kill great numbers of other plants. Another weed, the tall barberry, harbors another much more dangerous parasite, the wheat rust. Some wild grasses are inhabited by the pupae of the Hes- 


\section{HOW DO SEED PLANTS SUCCEED IN LIFE?}

sian fly, an enemy of the wheat plant. Ragweed and many others scatter pollen which causes hay fever to some people.

Individual Project. Make a survey of your community or town for the tall barberry that harbors wheat rust. Destroy the barberry by using either kerosene or rock salt on the ground over the roots.

Poisonous weeds. Poison ivy, poison oak, and poison sumach cause very painful blisters to most people who touch them. Iron chloride is an excellent preventative, and in potassium permanga-
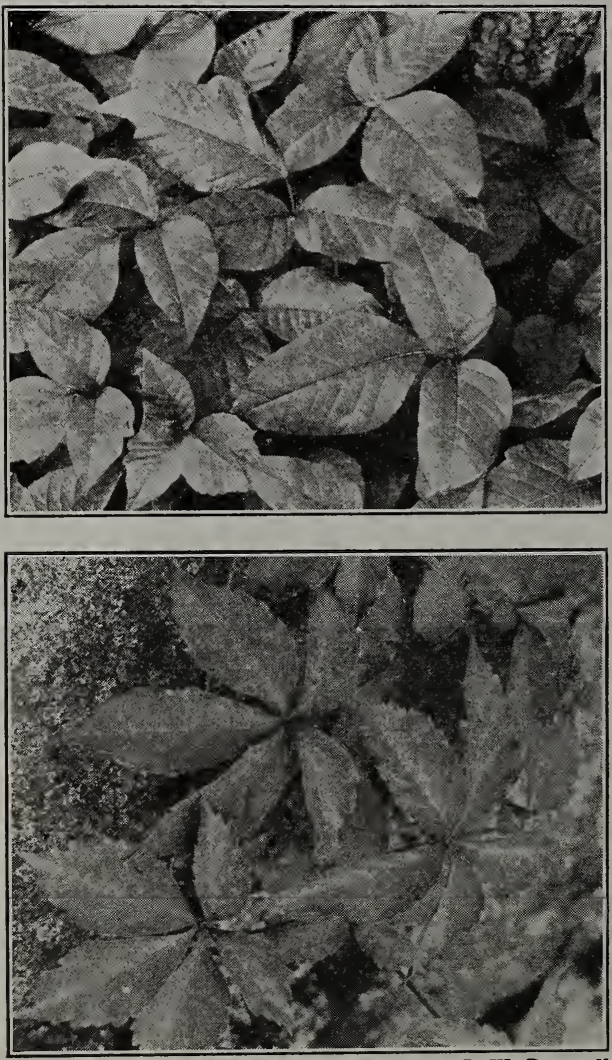

L. W. Brownell

Above, poison ivy leaves. Below, leaves of Virginia creeper. How do they differ? nate dissolved in water is a standard relief agent.

Poison ivy is an example of a weed that is extremely poisonous to touch. It is a climbing plant which attaches itself to trees or walls by means of tiny air roots which grow out from the stem. It has leaves divided in three parts, which aid in distinguishing it from its harmless climbing neighbor, the Virginia creeper, which has leaves divided in five parts. Every boy and girl should know how poison ivy looks in order to avoid it.

Numerous other poisonous common plants are found, one of which deserves special notice because of its presence in vacant city lots. The Jimson weed is a bushy 
plant, from two to five feet high, bearing large leaves. It has white or purplish flowers, and later bears a four-valved seed pod containing many hundred seeds. These plants contain a powerful poison, and children, through ignorance, are sometimes made seriously ill by eating the seeds or other parts.

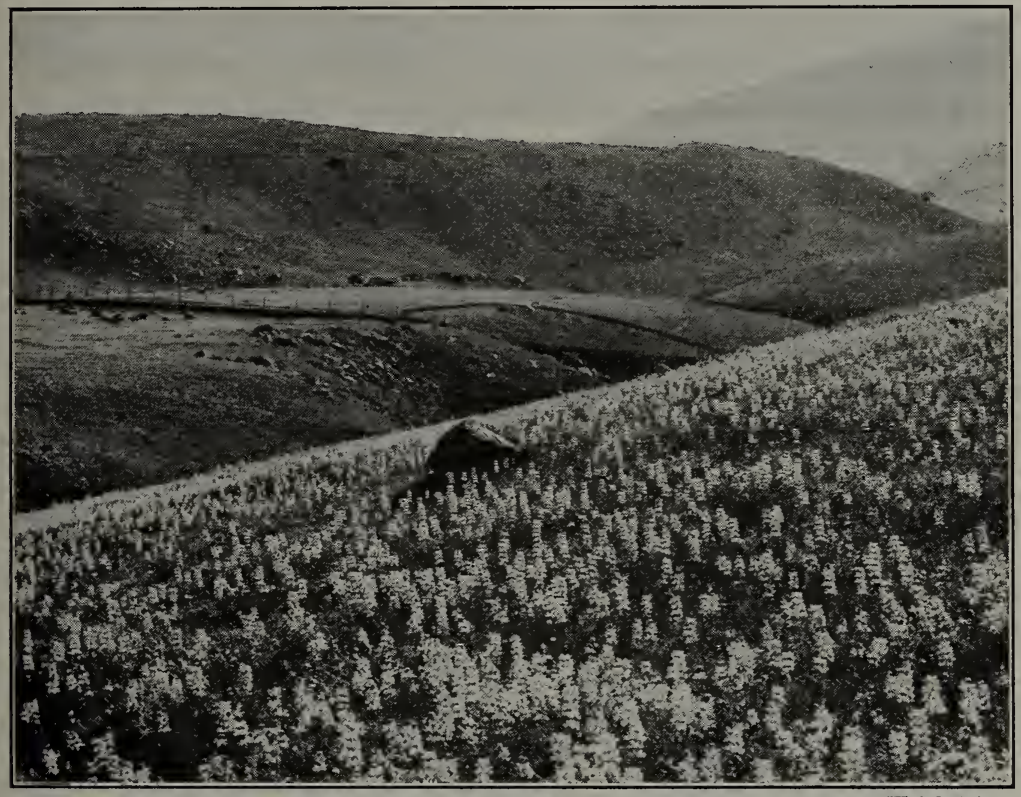

Wright Pierce

A field of lupines. These are useful plants, as they give nitrogen to the soil.

Useful weeds. Some weeds are not harmful, but are beautiful or useful in some ways. The daisy in New York, and the filaree in California, are dear to those who love flowers. Water cress, dandelion, and some other weeds are used as food, and certain weeds are used for medicinal purposes. Plowed under they may act as fertilizer, and in some places they form a protective covering over the soil, thus preventing it from being washed away.

Practical Exercise 2. Discuss the different methods of weed control used in your community. 
How may we eradicate weeds? We have seen the harm that weeds do. How can we get rid of them? The best way would be by not letting them get started. In the fall, burn over all lots that contain weeds. Prevent as many weeds as possible from producing seeds, especially those near gardens or fields of grain. This can be done by cutting the weeds before the seeds mature. Keep weeds out of roadside areas by early cutting. Since sheep like some kinds of weeds better than grass, they can be used in some localities to keep down the weeds. But in the main, destroying the weeds before they get a start seems to be the most effective means of ridding a place of them.

\section{Self-Testing Exercise}

Weeds are injurious to man because they ........ (1) his crops. Some weeds may .......(2) cattle. Weeds harbor dangerous ....... (3). Hay fever is caused by the pollen of .......(4). Wheat rust is a ......(5). Farmers often ......(6) weed seeds with .......(7). Weeds may be eradicated by .......(8), and $\ldots \ldots \ldots$ (9) them before their seeds ....... (10). Some weeds are $\ldots \ldots \ldots$ (11) to ....... (12), and some for .......(13). Poison ivy differs from Virginia creeper by having a leaf divided into ....... (14) ....... (15). Some poisonous weeds are ....... (16) $\ldots \ldots(17)$ and $\ldots \ldots$ (18) $\ldots \ldots$ (19).

\section{PROBLEM III. HOW ARE FRUITS AND SEEDS SCATTERED?}

Individual Project. Examine the fresh or preserved fruits of huckleberry, blackberry, wild strawberry, wild cherry, black haw, wild grape, tomato, and currant. Report how many of the above have seeds with hard coatings. Notice that in most, if not in all, edible fruits the fruit remains green, sour, and inedible until the seeds are ripe. In the state of nature, how might this be of use to a plant?

Adaptations for seed dispersal: fleshy fruits with hard seeds. Plants are fitted to scatter their seeds by special appendages or adaptations either in the fruit or in the seed. Various agents, as the wind, water, birds, and other animals, make it possible for the seeds to be taken away from the parent plant. 
Fleshy fruits, that is, such fruits as contain considerable water when ripe, are eaten by animals and the seeds are passed off undigested. Most wild fleshy fruits have small, hard, indigestible seeds. Birds are responsible for scattering the seeds of many berries and other small fruit. Bears and other berry-eating animals aid in this as well. Some seeds have especial adaptations in the way of spines or projections. Insects use these projections in order to carry them away. Ants plant seeds which they have carried to their nests for food supply. Nuts are sometimes planted by squirrels and blue jays.

Hooks and spines. Some fruits which are dry and have a hard external covering when ripe possess hooks or spines which enable the whole fruit to catch in the coats of animals and are thus carried away from the parent plant. Thus the whole fruit cluster may be carried about and the seeds scattered. In many of the composites, as in the cockleburs and beggar-ticks, the fruits are provided with strong curved projections which bear many smaller hooklike barbs.

Pappus. The dandelion is an example of a plant in which the whole fruit is carried by the wind. The parachute, or pappus, is an outgrowth of the ovary wall. Many other fruits, notably that of the Canadian thistle, are provided with the pappus as a means of getting away from the parent plant. In the milkweed the seeds have developed a silky outgrowth which carries them long distances from the parent plant.

Dehiscent 1 fruits and how they scatter seeds. One of the many methods of scattering seeds is seen in dry fruits.

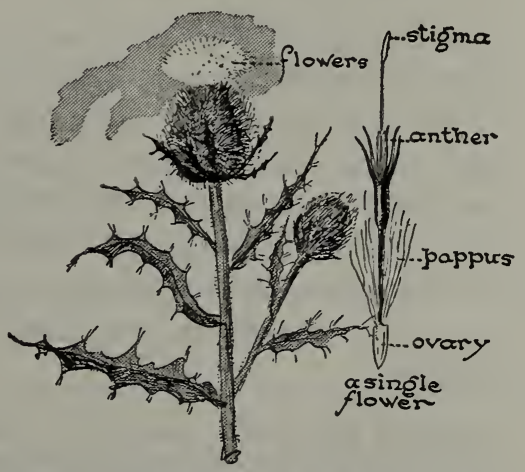

How are the seeds of the Canadian thistle scattered?

These simply split to allow the escape of the seeds. Examples of common fruits that split open, called dehiscent fruits, are seen in the

${ }^{1}$ Dehiscent (dê-hrs'ênt) : opening along a definite line to discharge contents. 
follicle (f́ll' '̌-k'l) of the milkweed, a fruit which splits along the edge of one valve, the pod or legume of the pea and the bean, and the capsule of Jimson weed and the evening primrose. The wild geranium, a capsule with five chambers, splits along the edge of each chamber, snaps back, and throws out the seed for some distance. Jewelweed and witchhazel fruits burst open in a somewhat similar manner.

Winged seeds. The seeds of the pine, held underneath the scales of the cone, are prolonged into wings which aid in their

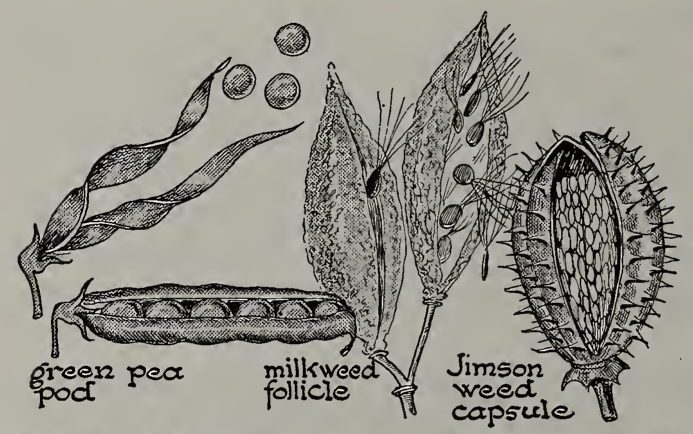

How are these particular fruits fitted for scattering their seeds?

dispersal. The seeds of many of our trees are thus scattered.

Other methods. Sometimes whole plants as the tumbleweeds are carried by the high winds of the fall. Some seeds or fruits (for example, the coconut) may fall into the water and in a few days will be carried to a new place, the fibrous husk providing a boat in which the seed is carried. The seeds of swamp plants collect in the mud along the banks of ponds and streams, and birds which come there to feed carry them away on their feet. The great English naturalist, Charles Darwin, raised eighty-two plants from seeds thus carried by birds. It is probable that most of the vegetation on the newly formed coral islands of the Pacific Ocean may have come from seeds brought to them by birds and by water.

Practical Exercise 3. Name five fruits, other than those mentioned above, that scatter their seeds through the opening of pods. Name five trees that produce winged seeds. Why has the Russian thistle become a pest over such a large area in a relatively short time?

Indehiscent fruits. Dry fruits which do not split open to allow of the escape of their seeds are known as indehiscent fruits. Such are nuts, one-seeded fruits usually with hard outer covering, 
the so-called key fruits of the maple or ash, and many others. Corn, wheat, oats, etc., are indehiscent fruits. A grain is simply a one-seeded fruit in which the wall of the ovary has grown so close to that of the seed that they cannot be separated. Some indehiscent fruits are light and carried by the wind, others may be scattered by animals.

Individual Project. Make a survey of your neighborhood to show at least some examples in every method of dispersal discussed in this unit. Make another classification of ways of dispersal, if you prefer.

The struggle for existence. Those plants which provide best for their young are usually the most successful in life's race. Plants which combine with the ability to scatter many seeds over a wide territory, the additional characteristics of rapid growth, resistance to dangers of extreme cold or heat and to attacks of parasitic enemies, inedibility, and peculiar adaptations to crosspollination or self-pollination, are usually called weeds. They flourish in the sterile soil of the roadside and in the fertile soil of the garden. By means of rapid growth they kill other plants of slower growth by usurping their territory. Slow-growing plants are thus actually exterminated. Many of our common weeds have been introduced from other countries and have, through their numerous adaptations, driven out other plants which stood in their way. Such is the Russian thistle. First introduced from Russia in 1873 in flaxseed, it spread so rapidly that it is now one of the greatest pests in our Northwest. Water cress, introduced in Australia by those who were fond of eating it in England, has become such a pest that it chokes navigable rivers and has to be dredged out frequently.

Practical Exercise 4. Sum up all the ways in which weeds are successful in the struggle for existence.

\section{Self-Testing Exercise}

Seeds of fleshy fruits are scattered by .......(1). Animals scatter seeds that possess $\ldots \ldots \ldots(2)$, or $\ldots \ldots \ldots(3)$. The wind carries the seeds of $\ldots \ldots .(4), \ldots \ldots$ (5) $\ldots \ldots(6)$, and . (7) great distances. Another common agent for dispersing 
seeds is $\ldots . \ldots$ (8). The plants that ......(9) are those that scatter their.......(10) over a wide.......(11), grow.......(12), resist dangers of $\ldots \ldots \ldots(13)$ and $\ldots \ldots \ldots(14)$, and attacks of ........(15).

\section{Summary OUtLINe}

Make an outline, similar to the ones you have used in the previous units. Fill it in for your notebook. Use it to make a summary recitation of the unit. Test your knowledge of the unit by (1) answering and rechecking the survey questions; (2) performing correctly all assigned exercises; (3) checking the answers to the various tests with your teacher and correcting all errors.

\section{Test on Fundamental Concepts}

Make two columns in your notebook, one headed CORRECT and the other INCORRECT. Place the numbers of the statements you think correct and incorrect under their respective columns. Your grade equals correct statements $\times 4$.

I. Weeds are abundant because (1) animals do not eat them; (2) they produce many and hardy seeds ; (3) they have many devices to scatter seeds; (4) birds never eat their seeds; (5) they can live in localities where other plants cannot exist.

II. Weeds do harm because (6) they occupy the places that other plants might have in our gardens; (7) they harbor dangerous parasites; (8) some are poisonous; (9) sheep may eat them; (10) some cause disease, as hay fever.

III. Weeds may be fought by (11) planting large areas to garden crops; (12) burning over the infested areas; (13) plowing them under in the fall; (14) having sheep feed on the infested area ; (15) cutting them in the spring and early summer.

IV. Seeds and fruits are scattered by (16) having fluffy outgrowths which carry them through the air; (17) having hooks or barbs; (18) splitting and letting the seeds out; (19) man; (20) rabbits and chickens.

V. The most successful plants in the struggle for existence are those which (21) are able to scatter their seeds at a distance; (22) have been introduced where they have no natural enemies, as water cress in Australia; (23) grow faster than others which occupy the same area ; $(24)$ are best fitted to endure unfavorable conditions ; (25) produce few seeds. 


\section{Achievement Test}

1. How can you identify 10 common weeds?

2. How can you recognize poison ivy, poison oak, poison sumach?

3. What are the antidotes for these poisons?

4. What are at least ten weed seeds?

5. What are five ways in which a weed scatters seeds? Scatters fruit?

6. What are some fruits that are scattered in different ways?

7. What are the best ways of controlling weeds in your locality?

8. What, if any, weeds in your locality harbor dangerous parasites? If so, what have you done toward exterminating these enemies?

\section{Practical Problems}

1. Make a weed garden, using a pocket germinator, and test which seeds germinate most quickly.

2. Compare the number of seeds produced by some weed with that of some food-producing plant, as wheat. How do they compare?

3. Make a list of all weeds eaten as food; used as medicine.

\section{USEFUL REFERENCES}

Atwood, Civic and Economic Biology. (P. Blakiston's Son \& Co. 1922.)

Downing, Our Living World. (Longmans, Green \& Co. 1924.) Georgia, Manual of Weeds. (The Macmillan Co. 1914.) Hodge, Nature Study and Life. (Ginn \& Co.)

The following pamphlets will be found very useful in helping to identify common weeds :

Farmers Bulletin 86, 531, 660 .

U. S. Dept. of Agric. Bul. 28, Weeds and How to Kill Them.

Bul. 161, Conn. Agric. Station (New Haven).

Bul. 31, 70, Iowa Agric. Exp. Station (Ames).

Bul. 50, 66, Kansas Agric. Station (Manhattan).

Bul. 183, Kentucky Agric. Station (Lexington).

Bul. 267, Michigan Agric. College Exp. Station.

Bul. 62, North Dakota Agric. Station (Fargo).

Bul. 59, Ohio Agric. Station (Wooster).

Bul. 150, South Dakota Agric. Station (Brookings).

Bul. 48, Univ. of Wisc. Agric. Exp. Station (Madison). 


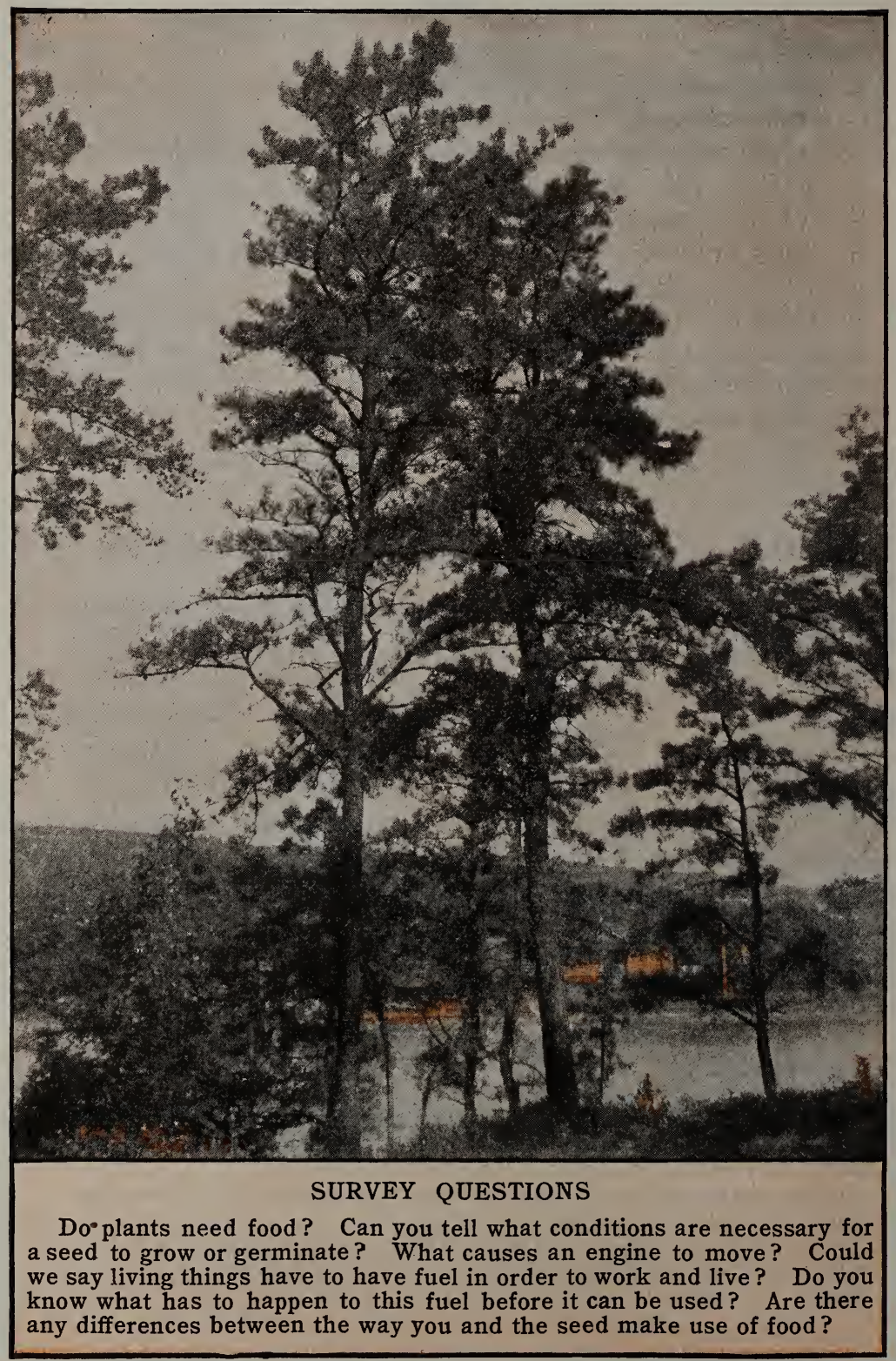

Photo by $L . W$. Brownell 


\section{PART II. GREEN PLANTS MAKE THE FOOD OF THE WORLD}

\section{UNIT V \\ WHY DO SEEDS GERMINATE?}

Preview. We have seen in a previous unit that the pollination of flowers usually results in the growth of a fruit containing seeds from which new plants grow. The purpose of the next few pages is to show how this baby plant, or embryo, grows into an adult. Every boy and girl knows that a dry seed, after lying dormant and apparently dead sometimes for months, will wake up and show signs of life when certain outside conditions are favorable. Evidently some conditions outside the seed start the growth of the little baby plant within the seed coats. There are several things which are absolutely necessary for germination, as this beginning of growth is called. The seed must first be provided with a protective coat which keeps the delicate baby plant within from being harmed. Then it must be able to live for long periods under adverse conditions such as extreme dryness or lack of soil. Many seeds, especially those of weeds and some garden seeds, such as the radish, cabbage, carrot, cauliflower, cucumber, and turnip, may live for as long as ten years before being germinated, but the average age that a seed lives is much less than this. The stories of germinating of wheat found in the Tombs of the Pharaohs may be disbelieved, although recently some lotus seeds, believed to be at least four hundred years old, were taken from a dried lake bed in the Gobi Desert, and were successfully germinated. But the reason that these seeds retained their vitality was because they were protected from decay by the peat bog in which they were embedded. 
Two sets of factors are necessary for the growth of seeds: first, the presence of food substances inside the seed in order to give the baby plant a start in life ; and, secondly, certain stimulating factors outside the seed, such as air, moisture, and warmth. Experiments which you can do yourself and observations you can make in almost any garden show the necessity of these factors very clearly. One value you will get from this unit will be the opportunity you have for determining, by means of certain simple experiments, the factors which control the beginnings of growth in a seed.

It is a trite but true saying that we grow because we use food. The same is true of plants. Certain food substances, the organic nutrients (such as carbohydrates, fats, and proteins), are found in seeds. We eat peas and beans. If we test these seeds, we can show the presence of foodstuffs within them. The pea or bean seedling uses the locked-up energy within the foods in order to break out of the seed coat and force their growing roots and stems through the soil. The little plants also grow in size. This indicates quite clearly that some of the nutrients within the seed are transformed in some mysterious manner into the living material out of which the plant is built. Later we shall be able to make a comparison of the manner in which these nutrients are used by the plant with the way in which we use these same food substances. It will be sufficient to say here that the foods which are really outside of the baby plant must be changed from a solid food substance into a liquid form so that the cells out of which it is formed may absorb the food substances into their own bodies. This process of changing insoluble foods into soluble food substances is called digestion.

\section{PROBLEM I. WHERE ARE BABY PLANTS FOUND?}

Laboratory Exercise. Make a drawing of a bean pod. Mark all the parts of the flower that you can find in it. What is a pod? Now open the pod and examine the seeds. How are they attached? Remove a bean, open it, and find the tiny future stem and leaves of the baby plant between the two "halves" of the bean called the cosyledons. Referring to the next paragraph, draw and label all the parts of the bean seed. 
The bean. If we open a bean pod, we find the seeds lying along one edge of the pod, each one attached to the inner wall at the placenta by a little stalk through which it gets its nourishment. The stalk leaves a scar on the coat of the bean, called the hilum (hï'lüm). The tiny hole near the hilum is the micropyle ( $\mathrm{mi}^{\prime} \mathrm{kro}-$ pil). Turn to the diagram on page 85 , showing the fertilization of an ovule. Find there the little hole through which the pollen tube reached the embryo sac. This small structure, the micropyle, remains and is found in the seed. The thick seed coat, the testa, is readily removed from a soaked bean. The seed then separates into two parts: the cotyledons

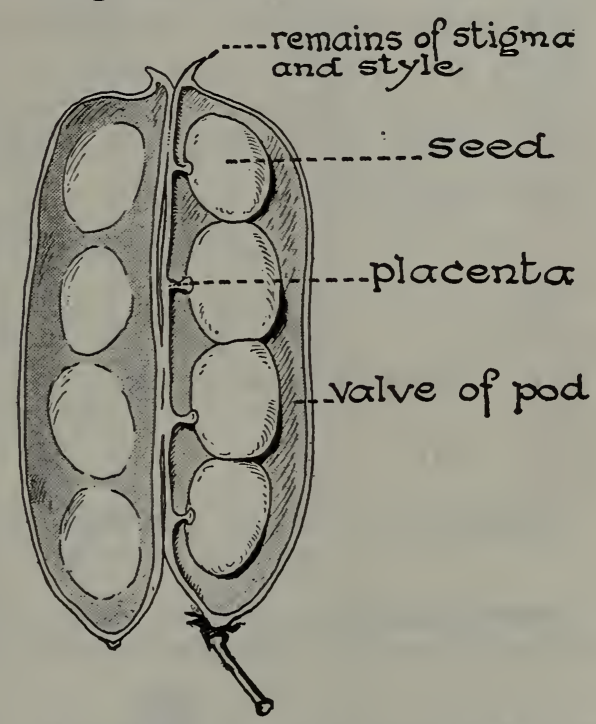

A pod opened to show attachment of seeds. Find the parts of the flowers.

or seed leaves. The rodlike part between the cotyledons is called the hypocotyl (hi'pot-kŏt'il). This will later form the root and part of the stem of the young bean plant. The first true leaves, very tiny structures, are folded together between the cotyledons, and, with the future stem, are known as the plumule (plō'mūl). All the parts of the seed within the seed coats form the embryo or young plant. A bean seed contains, then, a tiny plant protected by a tough coat.

Practical Exercise 1. Using a number of seeds, show to the class the presence of an embryo in each. Does it occupy the same position in each case?

Write in your notebook a good definition of a seed.

Food in the cotyledons. The laboratory work shows us that a seed really contains a baby plant or embryo, with a sufficient supply of food to give it a start in life. The problem now before us is to find out how the embryo of the bean is adapted to grow н. вIO -9 
into an adult plant. Up to this stage of its existence it has had the advantage of food and protection from the parent plant. Now it must begin the battle of life alone. We shall find in all our work with plants and animals that the problem of food supply is one of the most important problems to be solved by the growing organism. Let us see if the embryo is able to get a start in life (which many animals get in the egg) from food provided for it within its own body.

\section{Self-Testing Exercise}

The bean pod contains ........(1) which under favorable conditions will .......(2). The ......(3) is the baby plant within the $\ldots \ldots \ldots(4)$. Its parts are the $\ldots \ldots \ldots(5)$, the $\ldots \ldots .(6)$, and the $\ldots \ldots$ (7). The ...... (8) contain the food supply for the ....... (9).

\section{PROBLEM II. WHAT ARE THE TESTS FOR THE ORGANIC NUTRIENTS FOUND IN SEEDS?}

Demonstration 1. Test for starch. Boil water with some laundry starch in a test tube, then cool it, and add to the mixture two or three

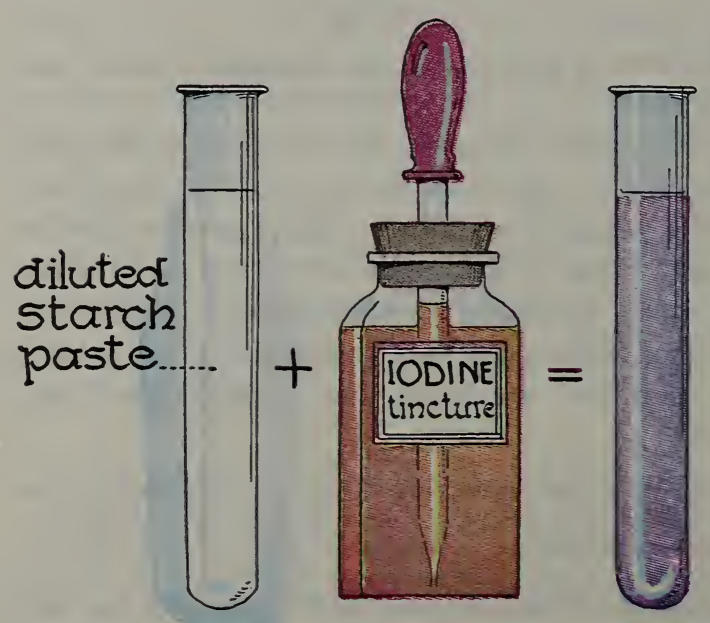
drops of iodine ${ }^{1}$ solution. The mixture in the test tube turns purple or deep blue. It has been learned after many experiments that starch is turned purple or dark blue by iodine. Therefore, iodine solution is used as a test for the presence of starch.

Demonstration 2. Test for oils. If a substance is rubbed on brown paper or is placed on paper and then warmed in an oven, the presence of

${ }^{1}$ Iodine solution is made by simply adding a few crystals of iodine to 95 per cent alcohol; or, better, take by weight 1 gram of iodine crystals, $\frac{2}{3}$ gram of iodide of potassium, and dilute to a dark brown color in weak alcohol ( 35 per cent) or distilled water. 
oil will be shown by a translucent spot on the paper. Since the proportion of oil in beans is small, it is better to try this test with a walnut.

Demonstration 3. Test for protein. Another nutrient present in the bean cotyledon is protein. Several tests are used to detect the presence of this nutrient. The following is one of the best known :

Place in a test tube a bit of hard-boiled white of egg. Pour over it an 80 per cent nitric acid, and heat the tube gently. Note the color that appears - a lemon yellow. If a little ammonium hydroxide is added, the color turns

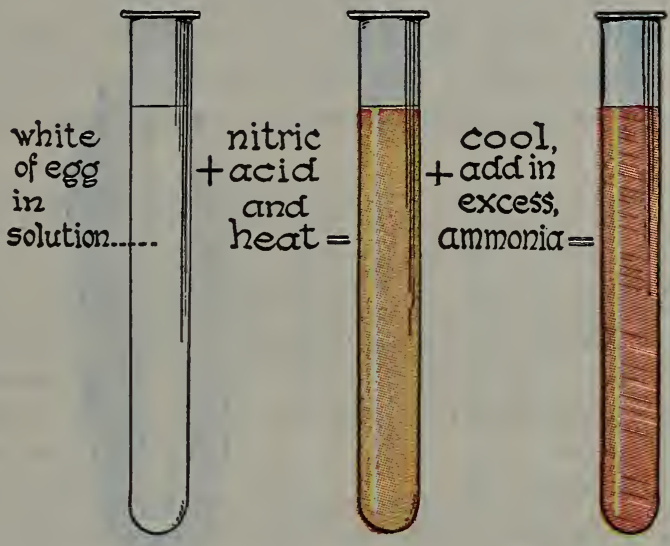
a deep orange.

Practical Exercise 2. Test a number of substances for the presence of starch, fat, and protein. Give your findings in tabular form. What is the value of knowing these tests?

Nutrients in the bean. If we mash up a small piece of a bean cotyledon which has been previously soaked in water, and test it with iodine solution, the characteristic blue-black color appears, showing the presence of starch. If a little of the stained material

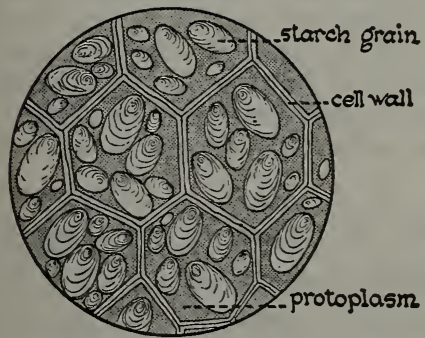

Cells from a potato, under microscope. Which part of the cell turns blue with iodine? tests to contain about 23 per cent of protein, 59 per cent of tests to contain about 23 per cent of protein, 59 per cent of
carbohydrates, and 2 per cent of oils. The young plant within is mounted in water on a glass slide under the compound microscope, we shall find that the starch is in the form of little ovoid bodies called starch grains. The starch grains and other food products are made use of by the embryo.

A test of the cotyledon of a bean with nitric acid and ammonium hydrate shows us the presence of protein. Beans are found by many 
a bean is thus shown to be well supplied with nourishment until it is able to take care of itself. In this respect it is somewhat like a young animal within the egg, such as a bird or fish. All of our cereal foods are made from seeds or grains that contain proteins, carbohydrates, and oils. Seeds also contain water and mineral matter, as can be shown by simple experiments.

\section{Self-Testing Exercise}

....... (1) solution is used to $\ldots \ldots \ldots$ (2) for the presence of starch. If the ....... (3) tested turns dark....... (4) or....... (5), we know that starch is present. Oil is known by the presence of a (6) spot when the ....... (7) is ieated on ....... (8). To test for protein we add ........(9) ......(10) to the substance: if it turns ....... (11) ....... (12), it is an indication that ...... (13) is present. If $\ldots \ldots \ldots$ (14) $\ldots \ldots \ldots$ (15) is then added to the substance and it turns a deep ........(16) color, we may be sure that it is a protein.

\section{PROBLEM III. WHAT FACTORS ARE NECESSARY TO AWAKEN THE EMBRYO WITHIN THE SEED?}

Demonstration 4. To show how much water is needed for the germinating of peas.

Materials. Soaked and dry peas, sawdust, cups.

Method. Place an equal amount of moist sawdust in the bottom of each of two cups. ${ }^{1}$ Put ten soaked peas in each. In a third cup containing dry sawdust put ten dry peas. Keep the seeds in one cup partially covered with water, those in the second slightly moistened, and those in the third dry. Keep the cups covered in a moderately warm place. Examine them daily for four days. Tabulate your results.

Conclusion. Which amount of water seems best for germination? Give your reasons.

\section{How much water does a seed need in order to germinate?} The exact amount of water which is most favorable for the germination of a seed can be determined only by careful experiment.

1 Pupils performing this or any other experiments must remember that the success of an experiment depends upon the accuracy with which it is performed and the exclusion of all factors from the experiment except the one which they are trying to prove. For example, in the experiment, on the effect of different amounts of moisture, all the other factors - temperature, light, food, etc. - must be the same in each of the three cups; the only variable factor being moisture. 
An oversupply of water may prevent growth of seeds almost as effectually as no water at all. In general the amount most favorable for germination is a moderate supply. Seeds rapidly lose their vitality if kept in a very moist atnosphere, especially if the moist air is hot. If seeds are given too much water they drown.

Demonstration 5. To show the best temperature for germinating peas.

Materials. Soaked peas, sawdust, boxes.

Method. Plant twenty soaked peas in each of three boxes containing moist sawdust. Put one box in a place where the temperature is about $150^{\circ} \mathrm{F}$., another where the temperature is about $70^{\circ} \mathrm{F}$., and the third where the temperature is about $40^{\circ} \mathrm{F}$. Give to all the same conditions of air, light, and moisture. Observe them for four days. Tabulate the daily observations.

Conclusion. State what temperature seems best for germinating peas. Give reasons.

What is the best temperature for germinating seeds? Here again our experiment answers the question only for the seed with which we are working. Peas germinate best at one temperature, corn another, wheat still another - or more properly, each variety of a seed has a certain temperature (called its optimum) at which it germinates best. It is this fact that makes possible the earlier germination of some garden seeds.

\section{Demonstration 6. To show that air is necessary for germinating peas.}

Materials. Soaked peas, bottles, sawdust.

Method. Place an equal amount of moist sawdust in the bottom of two bottles. Fill one bottle full of peas and close it securely with a stopper. Put about twenty peas in the bottom of the other bottle. Examine the bottles daily for four days.

Conclusion. In which bottle did germination take place? Why?

Why is air necessary for germination? All living things respire or use oxygen in order to release energy and a seed is no exception. to the general rule. Without an ample supply of oxygen it cannot release from its food supply the energy necessary for its growth. Hence a constant supply of fresh air is an important factor in the germination of seeds. If the seeds are planted in the ground it is necessary for the soil to be sufficiently loose so that air can penetrate it. 


\section{Self-Testing Exercise}

In order for seeds to germinate they need a .......(1) supply of ....... (2), a certain degree of ...... (3), and ....... (4). The amount of $\ldots . \ldots$ (5) required for germination varies with the kind of $\ldots \ldots \ldots$ (6). If too much ....... (7) is used, some seeds will ....... (8) or decay.

\section{PROBLEM IV. WHAT BECOMES OF THE PARTS OF THE EMBRYO DURING ITS GROWTH INTO A YOUNG PLANT?}

Germination. If you plant a number of soaked kidney beans in damp soil or sawdust and at the end of each day remove one, you will be able to obtain a complete record of the growth of the kidney bean. The first signs of germination are the breaking of

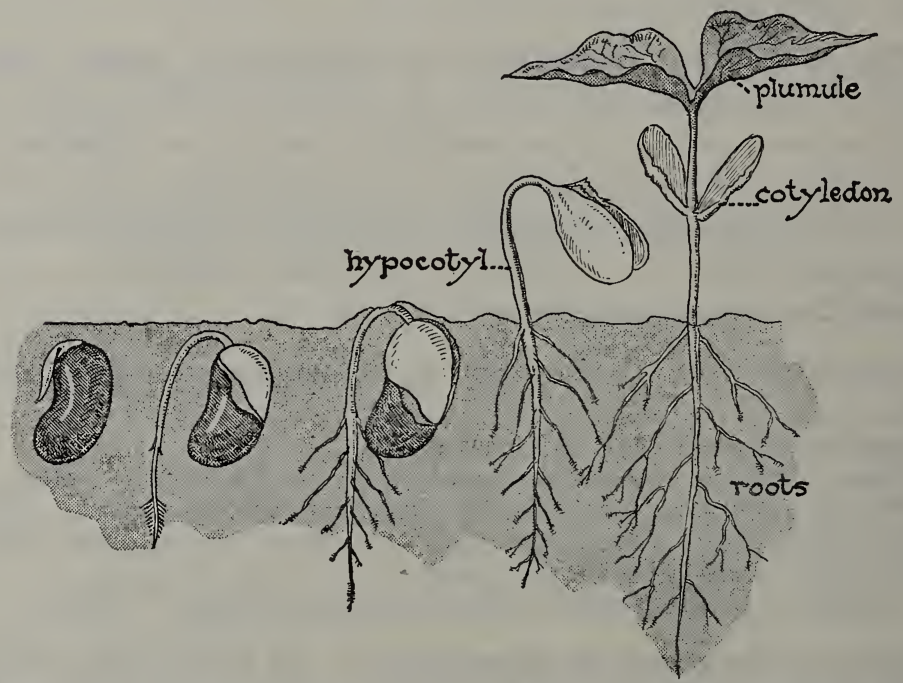

Stages in the growth of a bean. Note the direction of growth in the root. How does the cotyledon get out of the ground? What has happened to the hypocotyl in the right-hand figure?

the testa and the pushing outward of the hypocotyl to form the first root which grows downward. A later stage shows the hypocotyl forming an arch and dragging the bulky cotyledons after it. The stem, as soon as it is released from the ground, straightens up. The cotyledons open, and between them the 
budlike plumule grows upward, forming the first true leaves and all of the stem above the cotyledons. As growth continues, we notice that the cotyledons become smaller and smaller, until their food contents are completely absorbed by the young plant. The young plant now has roots and leaves and is able to care for itself and may be said to have passed through the stages of germination.

Laboratory Exercise. Examine several stages in the growth of the pea or bean. Make drawings for your workbook to illustrate at least three of the stages described below.

Practical Exercise 3. Look up in seed catalogs or gardening books how deep you should plant several different kinds of seeds. Is there any relation between the depth of planting and the size of the seed? If so, explain this.

\section{Self-Testing Exercise}

When a bean seed germinates, the ...... (1) first grows ....... (2). Then it develops an ....... (3) which draws up the .......(4) as it grows upward. Later the ........ (5) develops. During this growth the ....... (6) are used up as ....... (7) by the ....... (8) ....... (9).

\section{PROBLEM V. WHAT MAKES A YOUNG PLANT GROW?}

\section{Demonstration 7. To prove that growing seeds oxidize food.}

Materials. Bottle, rubber stopper, thistle tube, delivery tube, soaked peas, blotting paper, and limewater.

Method. Put some soaked peas in the bottom of a bottle containing some soaked blotting paper. Fit the bottle with a rubber stopper containing a thistle tube and a delivery tube.

Watch for evidences of growth in the bottle. At the end of fortyeight hours, insert the delivery tube in a tube of limewater. Pour water through the thistle tube into the bottle. What happens to the limewater? Why was water poured through the thistle tube?

Conclusions. Remembering what you have learned in your previous experiments, account for what happened. Why did the seeds start to grow? From what source did the seeds get their energy to grow?

Write a brief statement, using proof to show that energy is stored in food and that it can be released and used only by oxidation.

What makes an engine go. If we examine the sawdust or soil in which the seeds are growing, we find it forced up by the growing seeds. Evidently work was done; in other words, energy was 
released by the seeds. A familiar example of release of energy is seen in an engine. Coal is placed in the fire box and lighted, and the lower door of the furnace is opened so as to

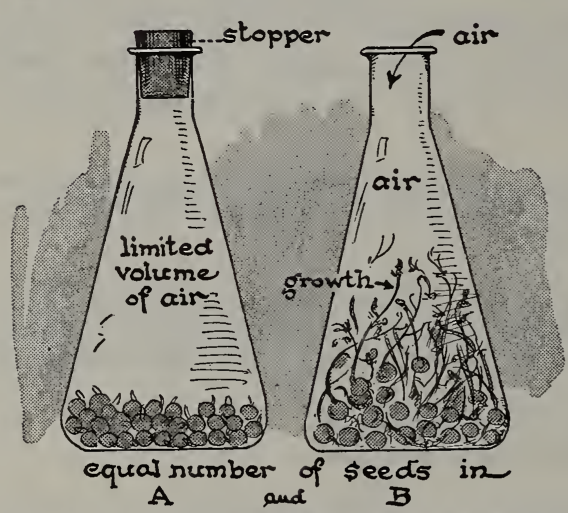

Why is the growth of seeds in flask B greater than that in flask $\mathbf{A}$ ? make a draft of air which will reach the coal. The coal burns, heat is released, causing the water in the boiler to make steam, the engine wheels to turn, and work is accomplished. Let us see what happens from the chemical standpoint.

Coal is formed largely from dead plants, which were long ago pressed into the present hard form of coal. It contains a large amount of the chemical element carbon. We have already observed one of the effects of the oxidation of carbon as proved by the limewater test. Let us now apply this test to the oxidation of food substances in our own bodies.

Demonstration 8. To prove that food materials are oxidized by the human body. Expel air from the lungs through a tube into a bottle of limewater. Note what happens. As a control pass air from the room through limewater. Explain your results.

Oxidation in our bodies. In life the temperature of the body (98.6 $6^{\circ}$ Fahrenheit) is due to oxidation within the cells. Food is also oxidized within the human body to release energy for our daily work. In fact, all living things, both plant and animal, release energy as the result of oxidation of food within their cells.

\section{Self-Testing Exercise}

The presence of .......(1) .......(2) in large amounts in the air surrounding seeds growing in a closed jar indicates that they have ....... (3) food within their bodies. The ....... (4) of ....... (5) in the body releases ....... (6) to do work. When seeds grow they take in ........(7) and give off 


\section{PROBLEM VI. WHERE IS THE FOOD SUPPLY OF DIFFERENT SEEDS?}

Laboratory Exercise. To study the structure and composition of a grain of corn.

Materials. Soak corn grains, some whole and some cut lengthwise at right angles to the flat surface.

Method and Observations. In whole corn grain find a light-colored area on one side. This marks the position of the embryo.

In a grain cut lengthwise at right angles to the flat side find the embryo. Describe its shape, position, and relative size compared with the rest of the corn grain. The area outside of the embryo is known as the endosperm. Place iodine on the surface of the cut corn grain. Describe what happens. Test a grain of corn for protein.

Conclusion. What nutrients are present in the corn? Where are they found?

Endosperm the food supply of corn. We find that the one cotyledon of the corn grain does not serve the same purpose to the young plant as do the two cotyledons of the bean. Although we find a little starch in the corn cotyledon, still it is evident from our tests that the endosperm is the chief source of food supply. The study of a thin section of the corn grain under the compound microscope shows us that the starch grains in the endosperm are large and regular in size. When the embryo has grown a little, an examination shows that the starch grains near the edge of the cotyledon are much smaller and quite irregular, having large holes in them. This means that the starch is being used by the young plant.

Seeds with endosperm. In the

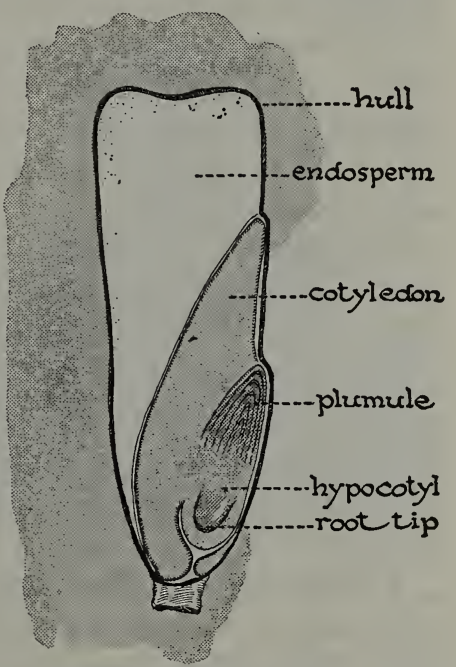

Longitudinal section of a grain of corn. Find the embryo. Is the corn a seed or a fruit? Why?

seeds of the pea and bean we have found that the embryo takes up all the space within the seed coats. There are some plants that have food stored outside of the embryo. Such a plant is the 
castor bean. A section cut vertically through the castor bean discloses a white oily mass directly under the seed coats. This mass is called the endosperm. If it is tested with iodine, it will be

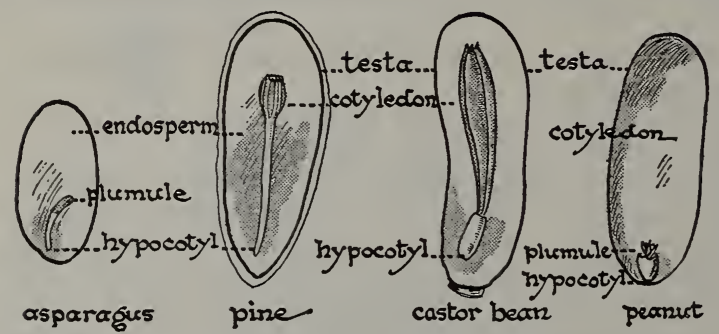

Seeds always contain a food supply which may be either in the cotyledons of the embryo or in an endosperm outside of the embryo.

found to contain starch; oil is also present in considerable quantity. Within the endosperm lies the embryo, a thin, whitish structure.

Monocotyledons, dicotyledons, and polycotyledons. Plants that bear seeds having but a single cotyledon in the embryo are called monocotyledons. Although we find many monocotyledonous plants in this part of the world, the group may be said to be characteristic of the tropics. Sugar cane and many of the large trees, such as the date palm, palmetto, and banana, are examples. Among the common monocotyledons of the north temperate zone are corn, lilies, grasses, grains, and asparagus.

Dicotyledons, or plants having two cotyledons in the seed, are those with which we come in contact most frequently in daily life. Many of our garden vegetables, peas, beans, squashes, melons, etc., all of our great hardwood forest trees, beech, oak, birch, chestnut, and hickory, the shade trees of our city streets, elm, maple and poplar, all of our fruit trees, pears, apples, peaches, and plums, and, in fact, a very large proportion of all plants living in the north temperate zone, are dicotyledons.

A third type of plant, with more than two cotyledons, is the group called the polycotyledons, represented by the pines and their kin. Such plants furnish most of the lumber and shingles used in the construction of frame houses. The soft woods, as the pines, hemlocks, spruces, and other "evergreens," are also of much value in the manufacture of paper. The wood-pulp industry has grown to such proportions as to be a menace to our softwood forests. 


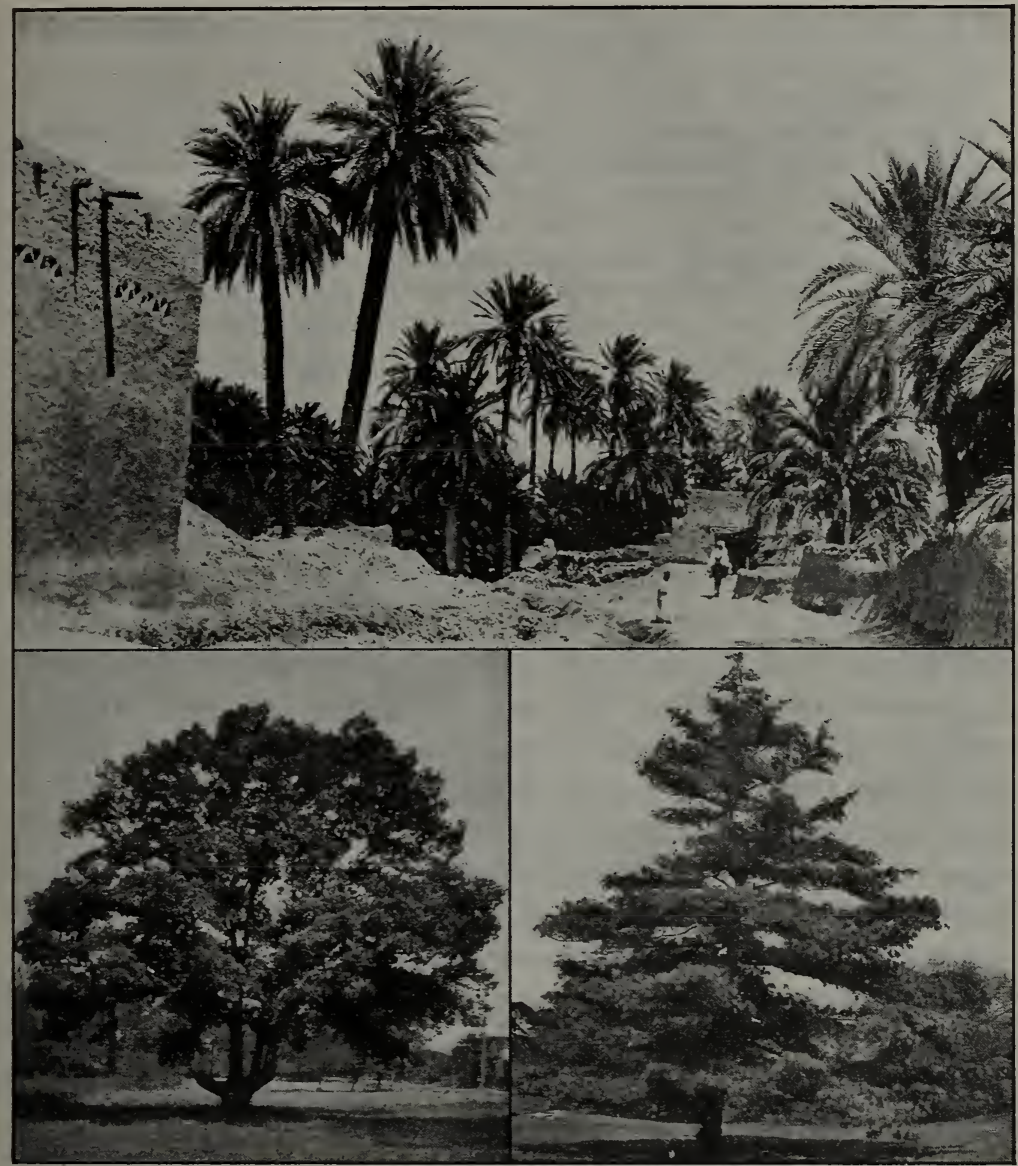

Brooklyn Botanical Garden, Brooklyn, N. Y.

The upper picture shows date palms growing in Algeria; the lower left shows a white oak tree; and the lower right shows a white pine tree. Why are these trees classified as monocotyledons, dicotyledons, and polycotyledons respectively.

\section{Self-Testing Exercise}

Seed plants are divided into three groups : ....... (1), ...... (2), and $\ldots \ldots \ldots(3)$. In the first, the food is stored in the ....... (4), while in the second group it is in the ..... (5). Corn is a ..... (6), while the bean is a $\ldots \ldots$ (7). The pine is an example of a (8). 


\section{PROBLEM VII. HOW DOES THE CORN GRAIN MAKE USE OF STORED FOOD?}

Demonstration 9. How is the endosperm usea ?

Remove the endosperm from some corn grains that have just started to sprout. Place them in moist sawdust side by side with some normal sprouted grains. Give each lot of seedlings the same conditions of water, light, and air.

Watch them carefully for at least two weeks. What differences do you observe in the rates of growth in the two lots of seedlings?

Conclusion. What is the relation of the endosperm to growth?

Changes in the food supply of a seed during germination. We have learned that the chief source of the food supply of the corn grain is the endosperm which contains starch and also some protein in its outer parts. These foods are in an insoluble form. In order that the growing embryo may make use of the stored nutrients they must be changed into a soluble form so that they may be carried out of the endosperm through the cotyledon to the growing parts of the embryo. Starch can easily be changed by the process of digestion into grape sugar or glucose ${ }^{1}$ which is soluble. We know that the germinating corn grain has a sweeter taste than that which is not growing. This is noticed also in sprouting barley or malt. The germinating grain contains grape sugar which has been formed from the starch. This, with protein which has also been digested in the endosperm, passes from cell to cell and thus reaches the growing part of the embryo.

This process of chemical change or digestion cannot take place in dry seeds. Water must be absorbed by the seed, first, in order to allow digestion to take place and, second, to allow the soluble material to dissolve and pass through the cells. This digestion cannot take place without a moderate degree of warmth. For this reason moisture and warmth are necessary for germination.

Test for grape sugar. Just after the test for starch was worked out, a chemist by the name of Fehling prepared a solution which is named in honor of him and which is used as a test for glucose. An American chemist, Dr. Benedict, modified this solution and we can now use either the Fehling or the Benedict solution as a test for glucose.

${ }^{1}$ Grape sugar, or glucose, is a simple kind of sugar found in many plants and is the form in which digested starch is passed on to the plant cells. 


\section{Demonstration 10. To show the test for grape sugar.}

Materials. Glucose, Fehling's or Benedict's solution, ${ }^{1}$ test tubes, Bunsen burner.

Method. Place in a test tube a little glucose and water. Add to it an equal volume of Fehling's solution. Heat the mixture to the boiling point.

If the color of the mixture becomes brick red after heating a short time with Fehling's solution, then grape sugar is present, a precipitate will be formed having a red, yellow, or green color, depending upon the amount of sugar present.

Conclusion. Is Fehling's solution a test for cane sugar? Explain.

Laboratory Exercise. Wash some dry, unsprouted corn grains and test them for grape sugar. Then cut some corn grains that have just begun to germinate, lengthwise, through the embryo, and test for grape sugar. Look for changes in color between the embryo and endosperm.

Using a diagram, fill in with correct colors the changes that took place when germinating corn was tested.

Digestion. The change of starch to grape sugar in the corn is due to a process called digestion. If you chew for a little time a bit of unsweetened cracker - which we know contains starch it will begin to taste sweet, and if the chewed cracker is tested with Fehling's solution, some of the starch will be found to have changed to grape sugar. Here, again, the process of digestion has taken place. Both in the corn and in the mouth, this change is brought about by the action of chemical substances known as digestive ferments, or enzymes (ĕn’zīmz). Such substances have the power

1 Fehling's solution may be made as follows: Add $35 \mathrm{~g}$. of copper sulphate to 500 cc. of water. Solution No. 1.

To $160 \mathrm{~g}$. caustic soda (sodium hydroxide) and $173 \mathrm{~g}$. Rochelle salt, add $500 \mathrm{cc}$. of water. Solution No. 2.

For use mix equal parts of solutions 1 and 2. This may also be obtained from druggists, in tablets.

Benedict's second solution. - Copper sulphate . . . . . . . . $17.3 \mathrm{~g}$. Sodium citrate . . . . . . $173.0 \mathrm{~g}$. Sodium carbonate (anhydrous) . . $100.0 \mathrm{~g}$.

Make up to 1 liter with distilled water.

With the aid of heat dissolve the sodium salts in about $600 \mathrm{cc}$. of water. Pour through filter paper into a glass graduate and make up to $850 \mathrm{cc}$. with distilled water.

Dissolve the copper sulphate in about $100 \mathrm{cc}$. of water, and make up to $150 \mathrm{cc}$. with distilled water. Pour the carbonate citrate solution into a large beaker and add the copper suiphate solution slowly with constant stirring. 
under certain conditions to change insoluble foods - solids into soluble substances. The result is that foods which before

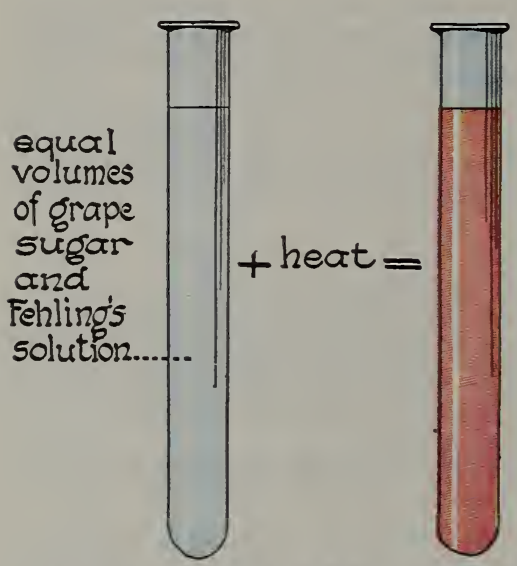

Explain what has happened here. What does it show? digestion would not dissolve in water will dissolve after being digested.

The action of diastase on starch. The enzyme found in the cotyledon of the corn, which changes starch to grape sugar, is called diastase (di' $\dot{a}$-stās). It may be separated from the cotyledon and is prepared by chemists for use in the form of a powder.

Demonstration 11. To show how starch is changed to sugar. To a little starch in half a cup of water add a very little diastase (1 gram) and put the vessel containing the mixture where the temperature will remain nearly constant at about $98^{\circ}$ Fahrenheit. Test part of the contents at the end of half an hour, for starch and for grape sugar. If the rest of the mixture is tested the next morning, it will be found that the starch has been completely changed to grape sugar. Starch and warm water alone under similar conditions will not react to the test for grape sugar.

Digestion has the same purpose in plants and animals. In our own bodies we know that solid foods taken into the mouth are broken up by the teeth and moistened by saliva. If we could follow that food, we should find that eventually it became part of the blood. It was made soluble by digestion, and in a liquid form was absorbed into the blood. Once a part of the body, the food is used either to release energy or to build up the body.

\section{Self-Testing Exercise}

Check correct answers for your workbook.

Digestion is brought about by: (1) heating the food in the body; (2) chewing the food well; (3) enzymes; (4) adding grape sugar to a substance. 
REVIEW SUMMARY

A SUMMARY OF FOOD SUBSTANCES AND THEIR TESTS

\begin{tabular}{|c|c|c|}
\hline NAME & Chemical Composition & Test \\
\hline Starch & $\begin{array}{c}\text { Contains Carbon }(\mathrm{C}) \\
\text { Hydrogen }(\mathrm{H}) \\
\text { Oxygen }(\mathrm{O})\end{array}$ & $\begin{array}{l}\text { Solution of iodine turns it dark } \\
\text { blue. }\end{array}$ \\
\hline Grape sugar & $\begin{array}{c}\text { Contains Carbon }(\mathrm{C}) \\
\text { Hydrogen }(\mathrm{H}) \\
\text { Oxygen }(\mathrm{O})\end{array}$ & $\begin{array}{l}\text { Forms brick-red precipitate } \\
\text { when heated to boiling with } \\
\text { Fehling's solution. } \\
\text { Forms greenish, yellow, or red } \\
\text { precipitate when boiled with } \\
\text { Benedict's solution. }\end{array}$ \\
\hline Fats and oils & $\begin{array}{c}\text { Contain Carbon }(\mathrm{C}) \\
\text { Hydrogen }(\mathrm{H}) \\
\text { Oxygen }(\mathrm{O})\end{array}$ & $\begin{array}{l}\text { Leave a grease spot on paper } \\
\text { after heating. } \\
\text { May be extracted by mashing } \\
\text { up substance with ether. }\end{array}$ \\
\hline \multirow[t]{2}{*}{ Proteins } & \multirow{2}{*}{$\begin{array}{l}\text { Contain Carbon (C) } \\
\text { Hydrogen }(\mathrm{H}) \\
\text { Oxygen }(\mathrm{O}) \\
\text { Nitrogen }(\mathrm{N}) \\
\text { and usually Sulphur (S) } \\
\text { and other elements }\end{array}$} & $\begin{array}{l}\text { Turn yellow when heated with } \\
\text { strong nitric acid, and then } \\
\text { turn orange after addition } \\
\text { of ammonium hydroxide }\end{array}$ \\
\hline & & $\begin{array}{l}\text { Burning test (odor) } \\
\text { Coagulation test (white of egg) }\end{array}$ \\
\hline Mineral matter & $\begin{array}{l}\text { Such elements as Sodium } \\
\text { (Na), Calcium (Ca), } \\
\text { Iron (Fe), and Potas- } \\
\text { sium }(\mathrm{K})\end{array}$ & $\begin{array}{l}\text { Remains as grayish ash after } \\
\text { burning food in hot flame for } \\
\text { long period. }\end{array}$ \\
\hline Water & $\begin{array}{l}\text { Hydrogen }(\mathrm{H}) \\
\text { Oxygen }(\mathrm{O})\end{array}$ & $\begin{array}{l}\text { Passes off from food when } \\
\text { heated, as water vapor, and } \\
\text { can be collected on cold } \\
\text { metal or glass, as drops of } \\
\text { water. }\end{array}$ \\
\hline
\end{tabular}

Digestion is necessary for plants and animals because: (1) it gives them the nutritious part of their food; (2) it breaks food into small particles; (3) it releases energy in foods; (4) it makes substances soluble.

\section{Review Summary}

Test your knowledge of the unit by: (1) Answering and rechecking the survey, questions; (2) performing the assigned exercises; (3) checking with the teacher, your scores on the various tests, and if you do not have a perfect score trying again the parts you missed; and finally, (4) making an outline and filling it in as fully as possible for your notebook. 


\section{Test on Fundamental Concepts}

In a vertical column under the heading CORRECT write numbers of all statements you believe are true. In another column under INCORRECT write numbers of untrue statements. Your grade $=$ right answers $\times 4$.

I. An embryo (1) is found in all seeds; (2) is a young plant; (3) will not be formed unless the flower has been pollinated; (4) in the bean consists of the testa and plumule; (5) is the part of the seed that grows into a young plant.

II. Among the factors necessary for germinating seeds are : (6) food but no water; (7) light; (8) air, water, heat, and food; (9) a temperature of $100^{\circ}$ or over; (10) rich soil and an abundance of water.

III. Organic foods (11) are found in the cotyledons of the bean; (12) are stored in the cotyledon of the corn; (13) contain carbohydrates, fats, and proteins; (14) are necessary for the germination of seeds; (15) can be determined by simple tests.

IV. The food supply of (16) seeds is found within the embryo of seeds having an endosperm; (17) the corn seed is found in the cotyledon; (18) the castor bean is stored in the endosperm; (19) dicotyledenous seeds is always stored in the endosperm; (20) seeds is stored in the form of organic nutrients.

V. Seeds, in order to use the food contained in them must (21) have it in a soluble condition; (22) use it as a solid ; (23) digest it first; (24) change it to such condition as will get into the cells; (25) be exposed to a high temperature.

\section{Achievement Test}

1. How do you make the tests for the different nutrients found in food?

2. What are all the experiments on germination? What factors are necessary to insure germination of seeds?

3. How can you prove that living things burn or oxidize food in order to release energy?

4. How can you make tests to prove that all living things have to digest food before they can use it?

\section{Practical Problems}

1. Prove what organic nutrients are present in a pea, a grain of corn, a lima bean, and a sunflower seed. Tabulate your results.

2. Prove that some seed other than corn digests its food supply before using it for growth. 
3. What conditions outside a seed are necessary to make it grow? What conditions inside the seed?

4. Compare an engine with a plant or an animal. In what ways are they alike?

5. Make diagrams to show how corn grains and bean seeds differ?

6. How could you determine whether light is necessary for the germination of seeds?

\section{USEFUL REFERENCES}

Burlingame and others, General Biology. Chapter IV. (Henry Holt \& Co. 1922.)

Coulter, Barnes, and Cowles, Textbook of Botany, Vol. Two. (American Book Company.)

Eikenberry and Waldron, Educational Biology. (Ginn and Co. 1930.) Ganong, The Teaching Botanist. (The Macmillan Co.)

Holman and Robbins, Textbook of General Botany, pp. 285-308. (John Wiley \& Sons. 1928.)

Hunter, New Laboratory Problems in Civic Biology. Unit VI. (American Book Company.)

Moore and Halligan, Plant Production. (American Book Company.) Trauseau, General Botany. Chapter VI. (World Book Co. 1923.)

Waters, Essentials of the New Agriculture. (Ginn \& Co. 1924.) 


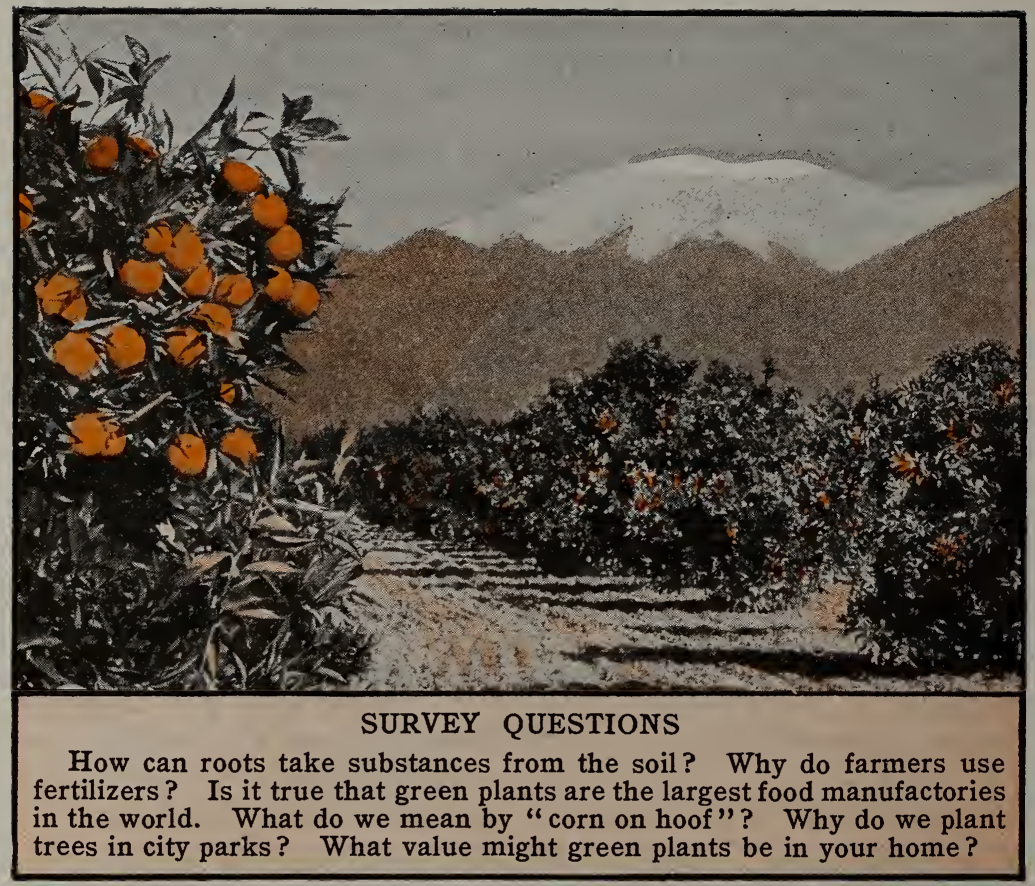

Photo by Wright Pierce

\section{UNIT VI}

\section{GREEN PLANTS AS FOOD MAKERS AND FOOD USERS}

Preview. All of you will agree with the statement that food is probably the most important material in the world. There would be little chance for life on the earth if our food supply was taken away and we had no way of getting a new one. This is exactly what would happen if green plants would disappear from the earth. If you think it out, you can easily prove that all animals are dependent on green plants for food. For example, cows eat grass, and in turn, give man milk and meat. Plants may furnish man with food directly as vegetables, cereals, and fruits. Even the walrus and seal in the arctic regions, which at first sight would 
seemingly be deprived of all plant food, yet live on fish which in turn exist almost entirely on sea weeds and small microscopic plants. Invariably we start with green plants which furnish food for animals.

The green leaves of plants are really solar engines which get power from the sun and which manufacture foods only when the sun gives them this power. In order to make food the plant must have certain raw material on which to work: carbon dioxide from the air, and water and mineral salts from the soil. Another substance must be present in the leaves, a green coloring matter called chlorophyll. This substance seems to be able to use the radiant energy of the sun better than any other living material.

But since the raw material, out of which foods are made, is in the soil, the air, and the water which the plant receives, it is evident that we must account for some way of getting these various substances into the leaf. If one of the seedlings of a bean is placed in sawdust and is given light, air, and distilled water, it will die after the food in the cotyledons is used up. Soil is part of its natural environment and the roots which come in contact with the soil are very important structures. Not only does soil hold water, but this water contains certain dissolved mineral salts which are absolutely necessary for the life of the plant. Distilled water does not contain these mineral salts which come from the soil, consequently the plant will die. You have all read of how plants can be kept alive by feeding them "plant pills." These "plant pills" contain the necessary mineral salts which, when dissolved in water, are absorbed through the roots into the plant. These salts form a very important part of the living matter of which both plants and animals are composed. Hence the plant cannot grow without a small quantity of these materials.

One of our big problems is to discover just how these dissolved mineral substances are taken in by the roots. We say roots absorb them, but how? A good scientist is not content with a statement; he wants proof. To obtain this proof he must use a microscope and then he will see that the lower part of the small roots are covered with tiny outgrowths from the living cells of the root which immensely increase the absorbing surface of the roots. These little projections, called rooi hairs, are the organs by 
means of which soil water, with the dissolved mineral materials, are taken into the root. But again we are met with a problem. Food is manufactured in the leaves of the plant, but all parts of the plant need that food. It is common knowledge that food is stored in seeds, in fruit, in stems such as the asparagus and in the roots such as turnips, radishes, and carrots. How then does the food get from the leaves to the various parts of the plant, and how does the water get from the roots to the leaves themselves where

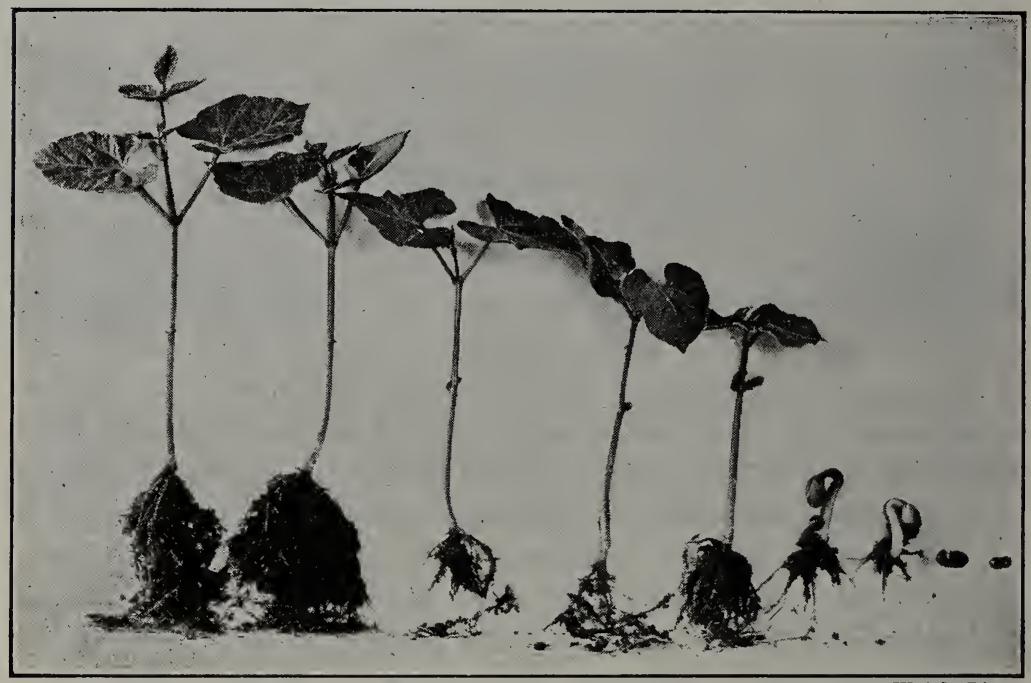

Wright Pierce

In the growth of the bean plant, notice the gradual decrease in size and final disappearance of the cotyledons. How does the plant obtain food for growth after the cotyledons have been used?

it is used in the manufacture of foods? Here again we must call the microscope into play. You are all familiar with the fact that a celery stem is made up of a watery material with long, threadlike fibers in it. If we were to examine one of these threadlike structures under the microscope, we should find that it was made up of a large number of little tubes of various diameters, some large and some small. The larger tubes carry water, some of the smaller ones, food substances. We shall later find that these bundles of tubes, called fibrovascular bundles, are arranged in a 
definite way in the stem; that through these, in the inner bark of a woody stem, food passes down from the leaves, while in the woody stem inside, soil water passes up to the leaves.

Again you might ask the question, how do solid foods pass through such tiny tubes? Not in a solid state, but in the form of dissolved food substances. We shall find that these foods are actually digested or made soluble by means of certain peculiar substances called enzymes which are found in the cells in different parts of the plant. Some of these enzymes seem to have the ability to change solid foods into soluble form, while others change the soluble foods back into insoluble substances. In this way we have starches, proteins, and oils stored in different parts of the plant. It will be the purpose of this unit to explain to us these various processes so that we may really understand how the plant makes food, how it transports it, and how it stores its surplus which is used for the benefit of the animal world, including man himself.

\section{PROBLEM I. WHAT DO PLANTS TAKE FROM THE SOIL?}

Composition of soil. As any one knows, the soil is composed of different substances in different localities. Contrast the black soil of Minnesota or Illinois with the sandy soil of Maine or California, or the red clay of Virginia. If we examine a small mass of garden soil carefully, we find that it is composed of numerous particles of varying size and weight. Between these particles, if the soil is not caked and hard packed, we can find tiny spaces, which are formed and enlarged when the soil is tilled. They allow the air and water to penetrate into the ground. If we examine some soil under the microscope, we find considerable water clinging to the particles, thus forming a delicate film around each one.

Under the microscope, also, most soils are seen to contain particles of different kinds. Some are tiny pieces of rock, like those still being formed where solid rock is exposed to the weather. Rain; cold, and ice, working alternately with heat, chip off pieces of rock. These pieces in time may be worn smaller by the action of winds, running water, and in some places by glaciers. These 
processes of soil making are aided by oxidation. A glance at some crumbling stones will give you an example of this yellow oxide of iron (rust) with which they are covered. So by slow degrees the earth became covered with a coating of what we call inorganic soil. Later, generation after generation of tiny plants and animals which lived in the soil died, and their remains formed the first organic materials of the soil.

We shall later learn more about the bacteria or germs that live in the soil (see Unit VII, Problem III). It is sufficient at this

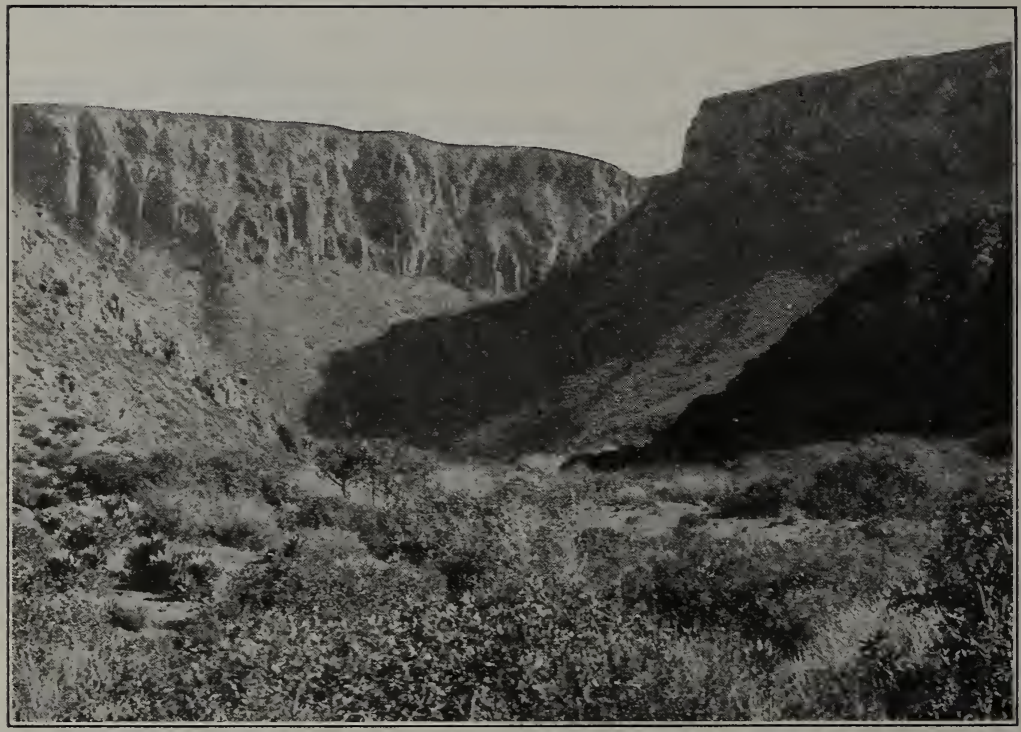

Note the slopes that are gradually being worn down and are forming soil in this canyon. Much desert soil is formed in this way.

time for us to know that due to certain bacteria, dead plants and animals are changed through decay into matter which can be used by living plants. Living things must have nitrogen in order to make living matter. This nitrogen comes partly from the decayed material already in the soil, partly from fertilizers added by man, and partly from fresh nitrogen supplies taken from the air and "fixed" in a usable form by certain bacteria which live in the roots of leguminous plants like the bean or clover. 
Practical Exercise 1. Read some good reference book and report on how soil is formed.

You are all familiar with the difference between so-called rich soil and poor soil. The dark soil contains more dead plant and animal matter, which forms the portion called humus.

Humus contains organic matter. It is easy to prove that black soil contains organic matter, for if equal weights of carefully dried humus and of soil from a sandy road are heated red-hot for some time and then reweighed, the humus will be found to have lost considerably in weight, and the sandy soil to have lost very little. The material left after heating is inorganic material, the organic matter having been burned out.

\section{Demonstration 1. To find out if all kinds of soil hold the same amounts of water.}

Fill funnels of equal size with equal volumes of gravel, sand, barren soil, rich loam, leaf mold, and pulverized leaves - all dry - then pour equal amounts of water on them and measure all that runs through. Which soil holds the most water?

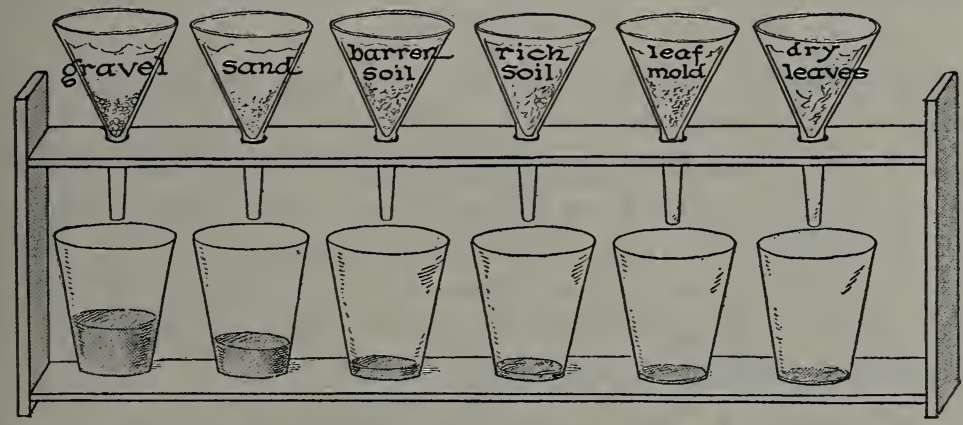

Soil water a solution of mineral salts. Water, as it passes through the soil, gradually dissolves very minute portions of the chemical compounds of which the soil is composed, so that soil water is really a dilute solution of mineral salts.

A plant needs mineral matter to make living matter. Living matter (protoplasm), besides containing the chemical elements carbon, hydrogen, oxygen, and nitrogen, contains very minute proportions of other elements which make up the basis of certain 
minerals. These are calcium, sulphur, iron, potassium, magnesium, phosphorus, sodium, and chlorine.

That plants will not grow well without certain of these mineral substances can be proved by the growth of seedlings in a so-called nutrient solution. If certain ingredients are left out of this solution, the plants placed in it will not develop into adult plants.

Practical Exercise 2. Make a table in which you indicate the relative amount of water that can be held by different kinds of soils.

What kind of soil would you expect to find in a desert? Covering the forest floor? In a river valley?

\section{Self-Testing Exercise}

Humus or .......(1) containing ....... (2) ......(3) will hold .........(4) much better than inorganic soil. When water passes through the .......(5), it takes out certain mineral salts which it holds in .......(6). Such water is called ......(7) water.

\section{PROBLEM II. WHAT FACTORS INFLUENCE THE GROWTH OF ROOTS?}

Root system. Examine the root of a bean seedling grown in sawdust. The long main root is called the primary root. Other smaller roots which grow from the primary root are called secondary, and the roots growing from the latter are called tertiary roots or rootlets. What functions do these roots appear to have? Most of the roots examined take a more or less downward direction. Does gravity act on the growing root? This question may be answered by a simple experiment.

Demonstration 2. To show the effect of gravity on a growing root.

Plant mustard or radish seeds in a pocket garden. A very convenient form of pocket germinator may be made in a few minutes in the following manner: Obtain two cleaned four by five negatives (window glass will do) ; place one flat on the table and on it place half a dozen pieces of colored blotting paper cut slightly smaller than the glass. Now cut four thin strips of wood so as to fit on the glass just outside of the paper. Next moisten the blotter, place on it some well-soaked radish or mustard seeds or grains of barley, and cover it with the other glass. The whole box thus made should be bound together with bicycle tape. Seeds will germinate in this box, and with care may live for two weeks or more. 
Place the pocket garden on one edge, and allow the seeds to germinate until the root has grown to a length of about half an inch. Then turn it at right angles to the first position and allow it to remain for one day undisturbed. Turn it again. In a day or so examine it. Describe your results.

The part of the root near the growing point is the one most sensitive to the change. This experiment indicates that the roots are influenced to grow downward by the force of gravity and that the growing point is most responsive to this stimulus.

Demonstration 3. Does water affect the course taken by roots?

Divide the interior of a shallow wooden box with glass side into two parts by a partition with an opening in it. Fill the box with sawdust. Plant peas and beans in the sawdust on one side of the partition, and water them very slightly, but keep the other side of the box well soaked. After two weeks, take up some of the seedlings and note the
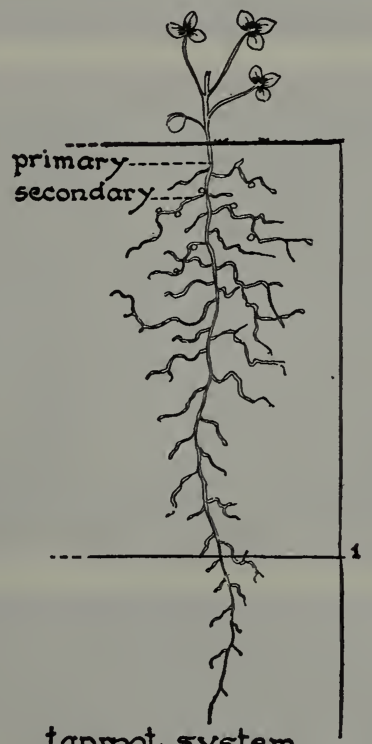

taproot system sweet clover

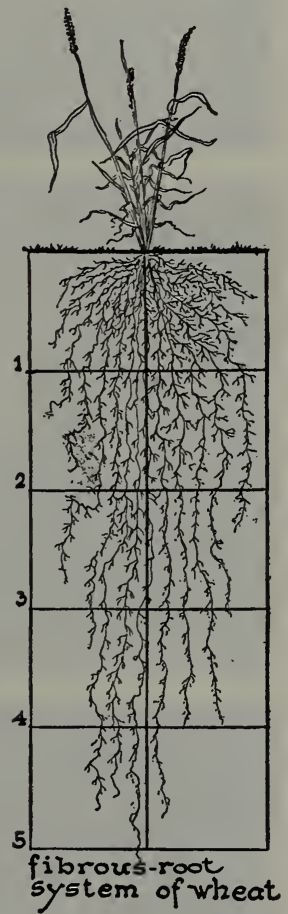

What is the length of the root system as compared with the height of the adult plant in each case? position of the roots.

Water a factor which determines the course taken by roots. Water, as well as the force of gravity, has much to do with the direction taken by roots. If radish seeds germinate on the under side of a moist sponge suspended in the air, their roots will turn against gravity and cling to the wet surface of the sponge. Water is always found below the surface of the ground, but sometimes 

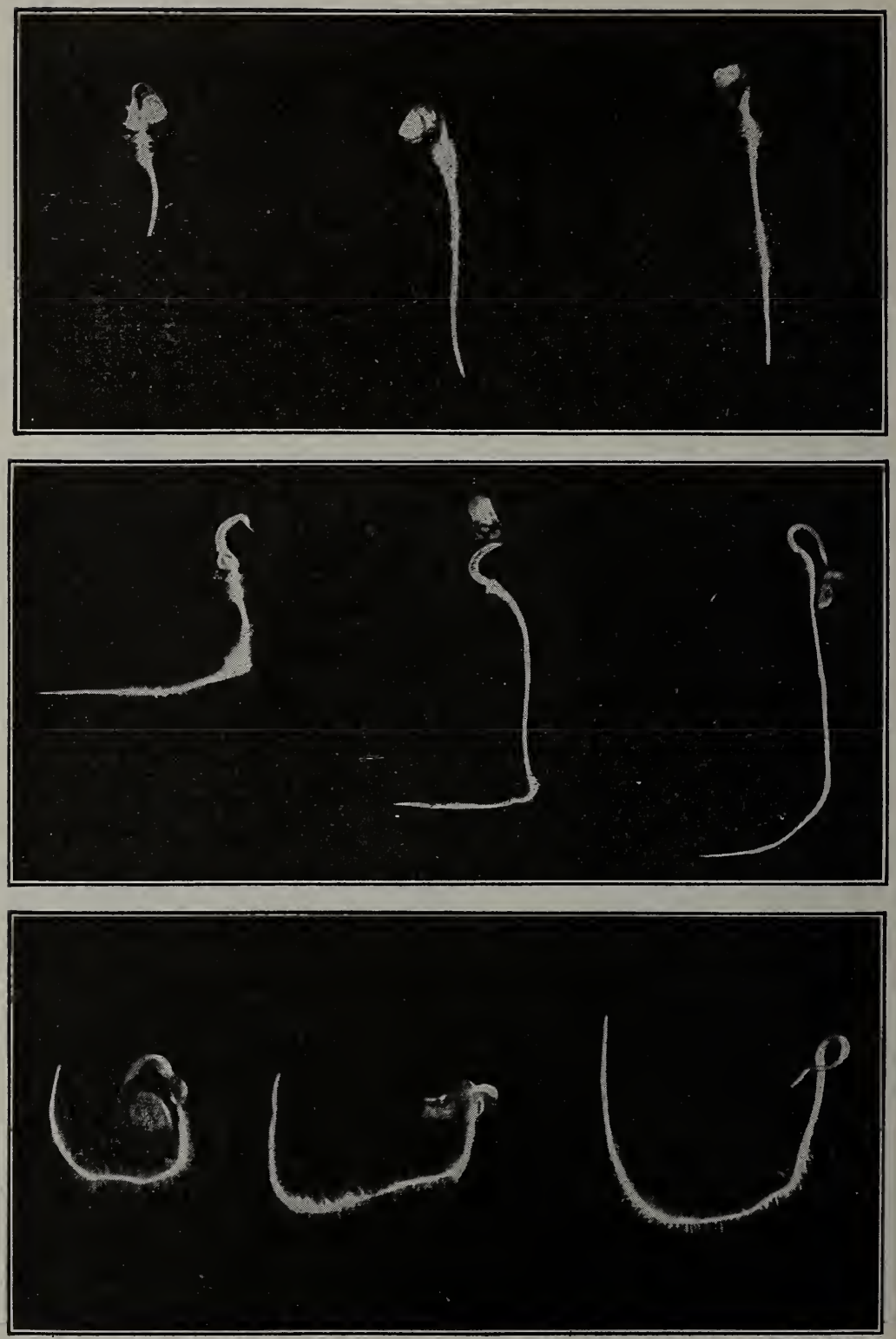

Wright Pierce

A pocket garden. Can you explain why the roots have taken the various positions indicated in the illustrations? 
at a great depth. Most trees and all grasses have a greater area of surface exposed by the roots than by the branches. The roots of alfalfa and sugar beets, in our Western States, often penetrate the soil for a distance of ten to twenty feet below the surface, until they reach that part of the soil which is always moist with underground water.

\section{Self-Testing Exercise}

A root system consists of .......(1), ...... (2), and.......(3) roots. The end of the root is .......(4) to .......(5) and turns toward the center of the .......(6). Roots also respond to . (7) in their environment and will penetrate many ....... (8) into the .......(9) in order to get it. The effect of .......(10) on roots is seen by planting seeds in a ....... (11) garden.

\section{PROBLEM III. HOW DOES THE STRUCTURE OF A ROOT FIT IT FOR ITS WORK?}

Demonstration 4. The finer structure of a root. Use a prepared slide or hand sections of bean roots stained with eosin or iodine and place it under a microscope.

How a root is built. If we study the diagram on page 144 and compare it with what we see under the microscope, we find the root ${ }^{1}$ is made up of cells, the walls of which are rather thin. Over the lower end of the root is a collection of cells, most of which are dead, arranged loosely so as to form a cap over the growing tip. This is evidently an adaptation which protects the young and actively growing cells just under the root cap. In the body of the root a central cylinder of wood can easily be distinguished from the surrounding cortex. It is in the cortex of fleshy roots that foods are stored, as in the carrot or turnip. In a longitudinal section a series of tubelike structures may be found within the central cylinder. These structures are made up of cells which have grown together end to end, the long axis of the cells running the length of the main root. In their development these cells have grown together in such a manner as to lose their small connecting ends, and now form continuous hollow tubes with rather strong walls. Other cells have

${ }^{1}$ Sections of tradescantia roots are excellent for demonstration of these structures. 
developed greatly thickened walls, which give mechanical support to the tubelike cells. Collections of such tubes and supporting woody cells together make up what are known as fibrovascular

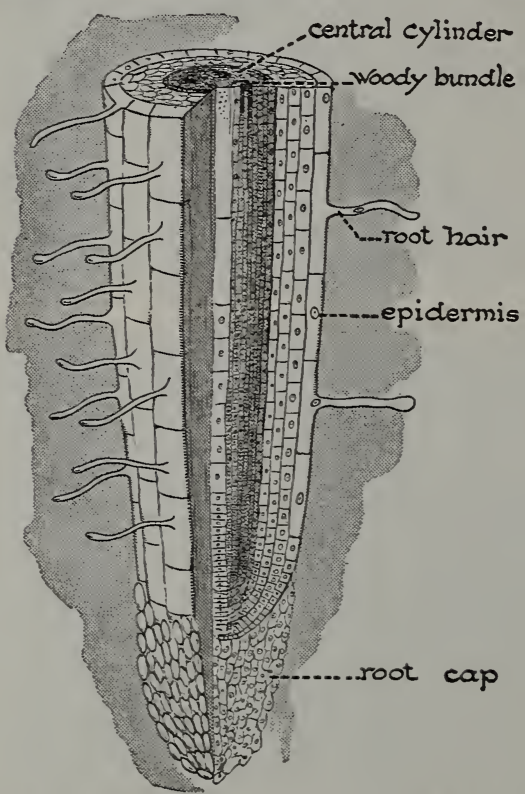

A root, highly magnified. Find and give the functions of the root cap, the woody bundles, and the root hairs.

hairs. Where are they the longest? bundles in the wood. By this system of tubes water is sent quickly from the roots to all parts of the plant body, preventing withering of leaves, and enabling the leaf to use water in food manufacture.

Practical Exercise 3. What would you say was the use to the plant of a carrot root? Of the aërial roots of an ivy plant?

How would you go to work to find out what food substances are stored in a turnip or radish root? Of what value would these substances be to the plant?

Laboratory Exercise. What are root hairs and where are they found?

Grow radish or mustard seeds on blue blotting paper in Syracuse watch glasses, covering each watch glass with a thin glass plate. Describe the structures you see growing from the roots. These are called root Where the most abundant?

Place root hairs of radish or mustard on a glass slide. Mount in a drop of water and cover with a cover slip. Examine with the low power of a microscope. What can you say of the thickness of their walls? Of how many cells does a root hair consist? If the root were covered with these thin-walled, delicate structures, what effect would they have upon the amount of absorbing surface of the root?

Root hairs. Root hairs vary in length according to their position on the root, the longest root hairs being found some distance back from the tip. They are outgrowths of the outer layer of the root, the epidermis, and are of very great importance to the living plant.

A single root hair examined under a compound microscope will be found to be a long, threadlike structure, almost colorless in appearance. The cell wall, which is very flexible and thin, 
is made up of cellulose. Clinging close to the cell wall is the protoplasm of the cell, the outer border forming a very delicate membrane. The interior of the root hair contains many vacuoles, or spaces, filled with a fluid called cell sap. Forming a part of the living protoplasm of the root hair, sometimes in the hairlike prolongation and sometimes in that part of the cell which forms the epidermis, is found a nucleus. The nucleus, the membrane, and the rest of the protoplasm are alive; the cell wall, formed by the living matter in the cell, is dead. The root hair is part of a living plant cell with a membrane and wall so delicate that water and dissolved mineral substan-

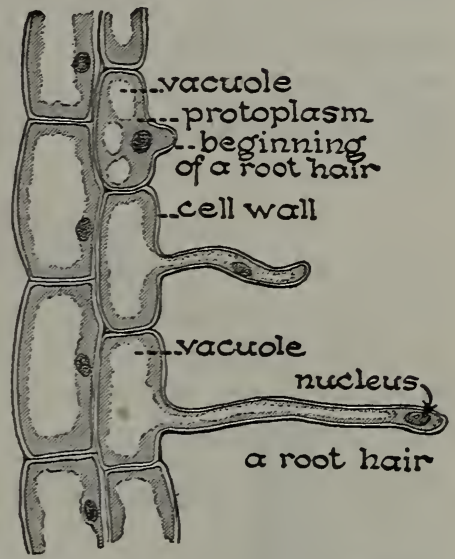

The growth of a root hair. What are root hairs, according to this diagram? ces from the soil can pass through them into the interior of the root.

Functions of the root hairs. If a root containing a fringe of root hairs is washed carefully, it will be found to have tiny particles of soil still clinging to it. Examined under the microscope, these particles of soil seem to be cemented to the sticky

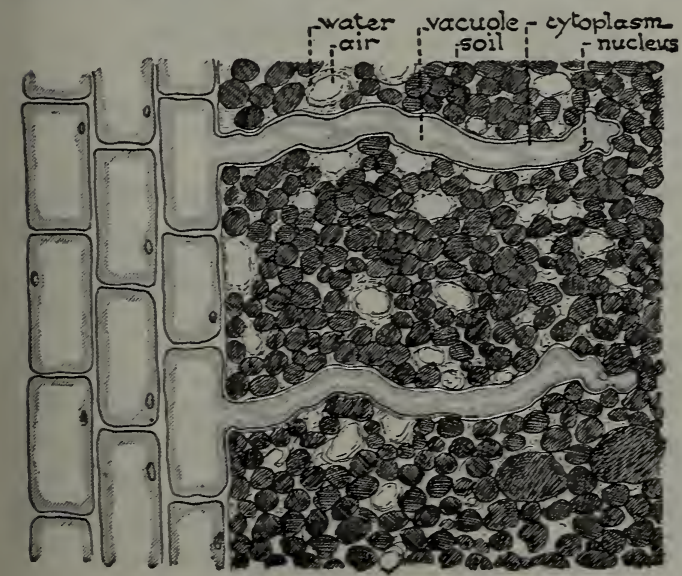

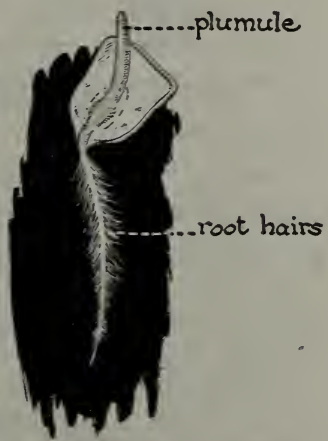

A corn root covered with root hairs which go between the particles of soil to get water and dissolved mineral matter. 
surface of the root hair. The soil contains, besides chemical compounds of various mineral substances, - lime, potash, iron, silica, and many others, - much organic material. Acids of various kinds are present in the soil. They dissolve certain mineral substances in the water which is absorbed by the root hairs. Root hairs also give off small amounts of acid, which assist in dissolving minerals.

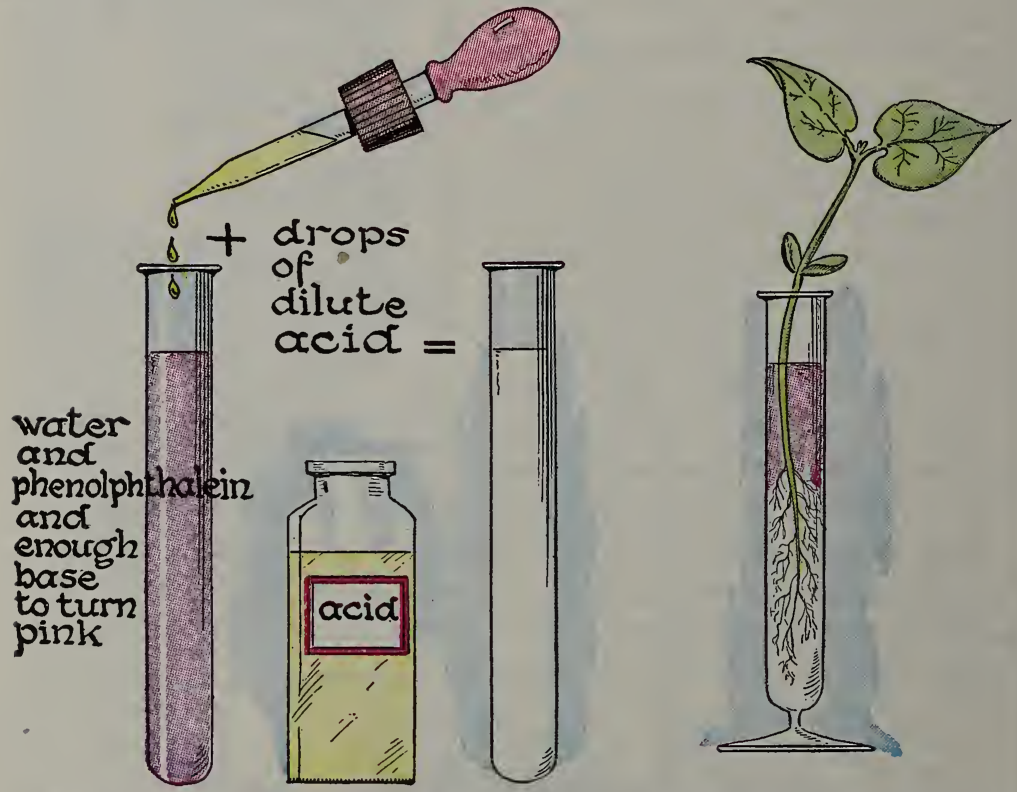

A solution of phenolphthalein will lose its color if an acid is added to it. Explain why the solution of phenolphthalein (on the right) is losing its color.

We say that the delicate root hairs absorb water, and since absorption is a process common to both plants and animal cells we shall study this phenomenon carefully in the next problem.

\section{Self-Testing Exercise}

A root is made up of ....... (1). The outer layer, called the . (2), is prolonged into many ........(3) walled structures

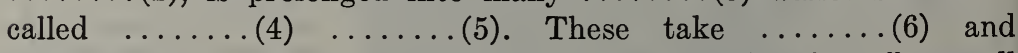
....... (7) .......(8) out of the soil. Root hairs give off a small amount of ....... (9), which aids in .......(10) mineral salts. 


\section{PROBLEM IV. HOW DO ROOT HAIRS TAKE IN WATER}

\section{AND SOIL SALTS?}

Demonstration 5. To show diffusion in gases and liquids.

(a) Open a bottle of carbon bisulphide at one point in the school room. Show, by raising of hands, the time it takes for the odor of the gas to become noticeable in different parts of the room. (b) Place a little powdered eosin in a glass of water. Leave undisturbed for some hours. How long will it be before the entire glass of liquid is colored?

Diffusion. We all know that certain substances, such as the odor of tobacco smoke or the perfumes of flowers, pass rapidly from the point where they are given off and tend to spread in all directions through the air. The odor of the orange blossoms in California is a memory to those who have driven near the orange groves. Substances which will dissolve in liquids will also diffuse through the liquids. In the diffusion of both gases and liquids particles of the substance pass from the place where they are most concentrated to where they are less concentrated, or lacking, the rate of travel being much slower in liquids than in gases.

Imbibition. The passage of water from point to point by capillarity ${ }^{1}$ does not account for soil water getting inside the cell. It has to go through the cellulose wall and the delicate membrane of protoplasm within. The walls of cells, like wood, absorb soil water readily by a process known as imbibition (ı̆m-bě-bǐsh'ŭn) or absorption. This brings the soil water in contact with the cell membrane. Inside the cell membrane is a liquid which would diffuse freely with the soil water if the membrane were removed. But a membrane acts peculiarly toward diffusing substances.

Osmosis. The process by which water with dissolved substances passes through the cell membrane is called osmosis.

Demonstration 6. To show the process of osmosis.

Carefully break away part of the shell of an egg so as to expose the delicate skin or membrane underneath. Thus we have a picture of the relation of the cell membrane (like the egg skin) to the cell wall (like the egg shell). Suspend this egg in a glass of cold water half an hour. What happens?

If we test the water in the glass for protein, the organic substance of which white of egg is composed, we shall find none.

1 Capillarity (kăp-ř-lăr $\left.{ }^{\prime} \mathfrak{1}-t_{1}\right)$ : rise of liquids in a tube. 
Evidently the egg membrane will permit the passage of water but not of protein. Such a membrane is said to be semi-permeable (pûr'më- $\left.\dot{a}-b^{\prime} l\right)$. It is this kind of membrane that surrounds plant and animal cells. It will permit certain substances such as water to pass through it readily in either direction, and it will permit certain substances in solution to pass less readily, while still other substances will not be permitted to pass through at all.

Demonstration 7. Fill the lower end of a thistle tube with a solution of grape sugar and water. Tie tightly over it an animal membrane (as a pig's bladder or skin of frog's leg), and place the tube in water, as shown in the diagram. After a short time observe your apparatus. What has happened? Why? At the end of an hour, test the water in the beaker with Fehling's solution. Explain your result.

If we could see the separate particles, or molecules, of the water and of the solution of water and sugar, they would be found to arrange themselves on each side of the membrane so as to cover it completely. But since the water mole-

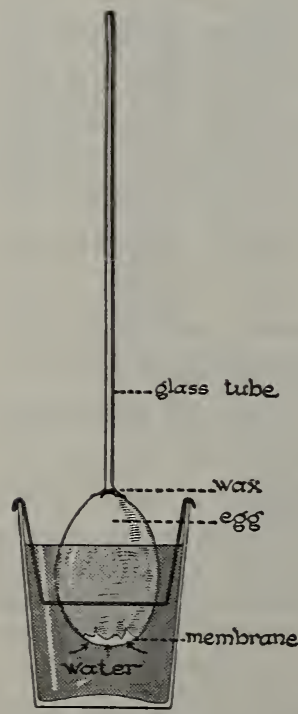

Osmosis in an egg. Explain, with reference to the text, why water will rise in the tube. cules pass easily through the membrane and the sugar molecules do not pass so easily, it will be seen that the inner side of the membrane does not present so much space for the diffusion of water particles as does the other side. Hence the flow of water into the tube is more rapid than the flow out of the tube, and the water gradually rises in the thistle tube. This passage of water through a semipermeable membrane is known as osmosis (ŏs-mō'sǐs). It will be seen that the greater flow of water molecules is always from the point of greater concentration of water to the point of lesser concentration of water. If the solution is completely inclosed in a vessel with rigid walls, the entrance of more water will cause a pressure by the solution within these closed walls and will prevent the entrance of any more water. This is known as 
osmotic pressure. But if the walls of the vessel are less rigid, as in the egg membrane, the osmotic pressure will cause the membrane to swell and distend until it eventually may burst.

Why root hairs absorb water and soil salts. The wall of the root hair readily takes in water and dissolved soil salts by imbibition. The membrane surrounding the protoplasm of every living cell is a semipermeable membrane, which, while allowing water and mineral salts in solution to pass or diffuse toward the inside, will also allow some diffusion outward of the water and soluble materials within the cell. But the inward flow is much greater than the outward flow. As soon as the

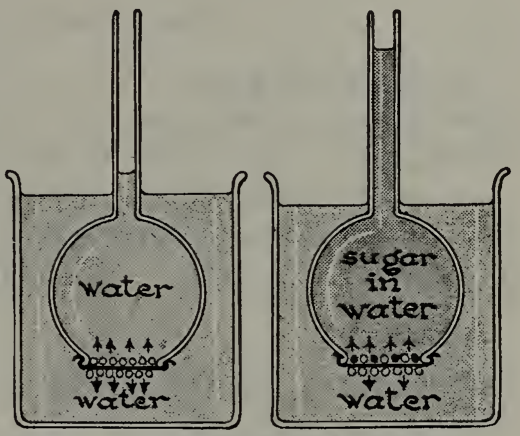

After reading the text, explain what has happened in the right-hand tube and beaker. outer cells have increased their holdings of soil water, an osmosis inward from cell to cell is started because the water tends to flow from the place of its greater concentration to the place of lesser concentration. Mineral salts in solution are carried along with the water so that the needed soil substances are carried along from cell to cell, until they reach the small tubes of the central cylinder. The osmotic pressure in the root hairs is sufficient to cause enough force in these tubes to raise a column of water to a considerable height in the stem. This is known as root pressure.

Physiological importance of diffusion and osmosis. The processes of diffusion and osmosis are of great importance not only to a plant, but also to an animal. Foods are digested in the food tube of an animal; that is, they are changed into a soluble form so that they may pass through the walls of the food tube and become part of the blood. The inner lining of part of the food tube (small intestines) is composed of millions of small fingerlike projections called villi, which look somewhat, in size at least, like root hairs. These villi are (unlike a root hair) made up of many в. BIO -11 
cells, through which liquid food passes into the blood. The process of absorption in animals is not entirely understood, but it takes place largely by diffusion and osmosis. Without these processes we would be unable to use most of the food we eat.

\section{Self-Testing Exercise}

In liquids and gases ........(1) of substances tend to pass from a place where they are more ........(2) to a place of less ........(3) by means of ....... (4). If this takes place through a ....... (5) .......(6), osmosis is said to take place. Substances in the ....... (7) pass with the water through the ....... (8) into the ....... (10) ....... (11).

\section{PROBLEM V. WHAT OTHER PURPOSES DO ROOTS SERVE?}

Besides the purposes of anchorage and water absorption roots have other functions. They absorb oxygen as well as water from the soil into which they reach. The rows of dead trees around a pond that has been raised by damming indicates that one cause of the death of these trees was lack of oxygen. They were actually drowned. The so-called " cypress knees," projections of the roots from cypress trees, which grow in water, are adaptations to obtain oxygen, as they are not found on cypress trees living in dry localities. Food is stored in fleshy roots, like the carrot, turnip, or parsnip. Such stores of food enable the plants that produce seeds every other year (biennials) to get an early start the second year from this stored food. Some plants like the ivy produce roots on the stem, which help it in climbing. Such roots are called adventitious. Another type of air roots is found in tropical plants, such as orchids. These have thickened roots with the special function of absorbing and holding water. Some plants, such as the strawberry, or couch grass, develop new plants by taking root wherever the reclining stem happens to touch the ground. Still another type of root is seen in the dodder, a parasitic plant. The root of this plant pushes its way into the stems of certain plants from which it absorbs its food. 
Practical Exercise 4. Fill out the following:

\begin{tabular}{|l|l|l|l|}
\hline Types of Roots & Functions & Adaptations & Examples \\
\hline & & & \\
\hline & & & \\
\hline
\end{tabular}

\section{Self-Testing Exercise}

Roots act as .......(1) and absorb ...... (2) as well as ....... (3). Some roots store ........(4). Plants may .......(5) by means of .......(6). Many plants produce .......(7) wherever the ....... (8) happens to ........(9) the ground. .......(10) plants absorb food from the ........(11) on which they ........ (12).

\section{PROBLEM VI. WHERE DOES THE GREEN PLANT MANUFACTURE FOOD?}

The primary function of the green leaf is the manufacture of food from the raw materials which are absorbed through the cell walls.

Laboratory Exercise. Examine a leaf of maple or oak. Notice that it consists of two parts : a stem, the petiole, and a broad expandec part, the blade. Note, also, that the petiole leads into a number of branching veins which support the blade. Notice the arrangement of leaves. Can they all receive full sunlight? Estimate the amount of green leaf surface in a plant in the room by multiplying the surface area of one leaf by the number of leaves on the plant. Place in red ink the cut end of a growing shoot from a young tree or shrub. Leave for 24 hours. What happens?

State uses of the veins. Explain how the leaf is fitted to receive light.

The structure of a leaf. In the experiment with the red ink and young shoots we shall find that the fluid has gone into the skeleton or framework of the leaf. Let us examine a simple leaf more carefully. It shows usually (1) a flat, broad blade, which may take almost any conceivable shape; (2) a stalk, or petiole, which spreads out into veins in the blade; (3) stipules, a pair of 
outgrowths from the petiole at its base. In many leaves the stipules fall off early. Some leaves are compound, that is, each of

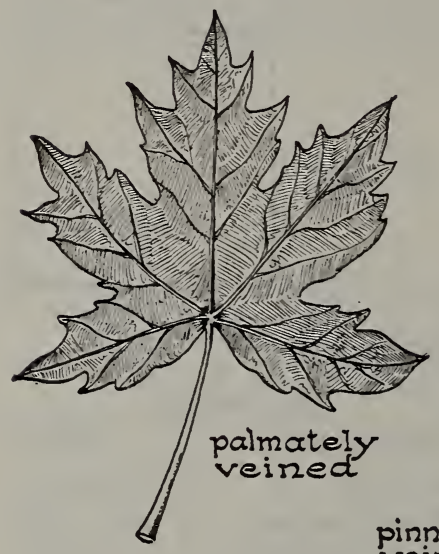

pinnately
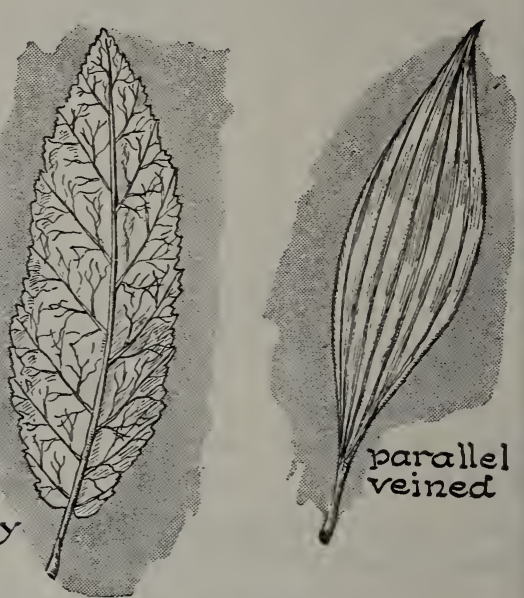

How do these leaves differ? In what ways are they alike?

the little leaflike parts or leaflets is in reality a section of the leaf blade which is so deeply indented that it is cut away to the midrib or central vein, as in the rose leaf shown in the figure below.

The cell structure of a leaf. The

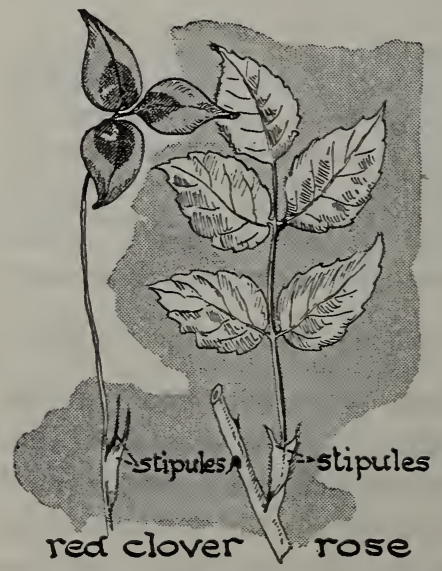

How can you tell that these are compound leaves? outer covering of a leaf, on both the upper and the lower surfaces, is called the epidermis, and is composed of large, irregular cells. The under surface of a leaf seen through a microscope usually shows many tiny oval openings, called stomata (stō'má-t $\dot{a}$, sing. sto'ma). Two cells, kidney-shaped, are found, one on each side of a stoma. These are the guard cells. By a change in the shape and size of these cells, due to absorption of water, the stoma is made larger or smaller.

Study of the leaf in cross section 
shows that the stomata open directly into air chambers which penetrate between and around the loosely arranged cells of spongy tissue composing the under part of the leaf. The position of the stomata varies in different kinds of leaves. Most have stomata only in the under epidermis, but some, as the water lily, have them in the upper epidermis only. Still others have them in both surfaces. The under surface of an oak leaf of ordinary size contains about $2,000,000$ stomata. Under the upper epidermis is a layer of green cells closely packed together (called collectively the palisade layer). These cells are more or less columnar in shape and have tiny green bodies in them. Air can easily pass through the stomata and between the cells of the spongy tissue until it reaches the pali-
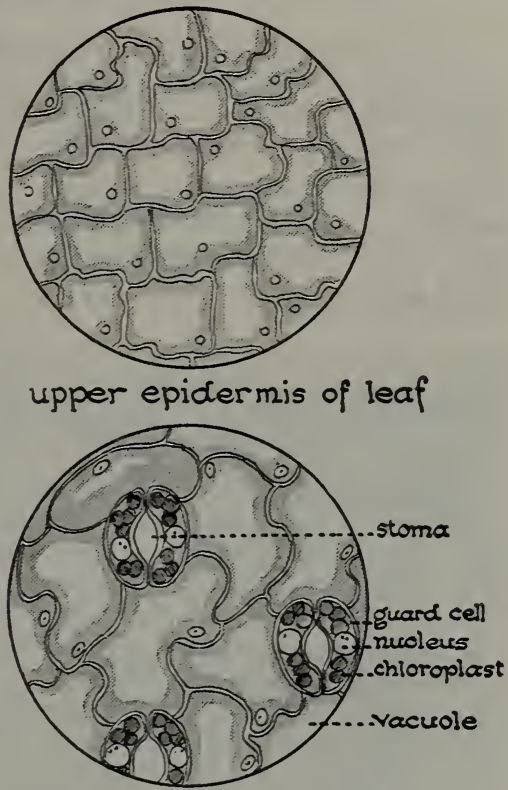

lower epiclermis of leaf

Compare the upper and lower surfaces of the leaf. sade layer. In a section of a leaf cut through a vein, we find the veins to be composed of a number of tubes made up of, and
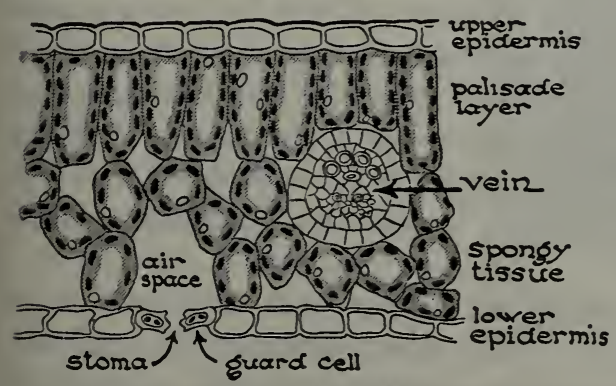

A cross section through a leaf, seen through the compound microscope. State the use of the vein, the stoma, the air spaces, the palisade layer, the epidermis. strengthened by, thickwalled cells. The veins are a continuation of the tubes of the stem which form the framework of the blade of the leaf.

Practical Exercise 5 . Study the opposite diagram carefully and draw one for your workbook that will show all the structures mentioned 
in the text. In this diagram make arrows to show $(a)$ how air gets to the cells, (b) how water gets to the cells, and $(c)$ how food materials made in the palisade layer might get out of the leaf.

\section{Self-Testing Exercise}

A green plant .......(1) food in its ....... (2). The ....... (3) is fitted for its work by being ........(4) and exposing a ....... (5) surface to the $\ldots \ldots \ldots(6)$. It contains many small openings called .......(7), through which .......(8) passes. The size of the $\ldots \ldots$. (9) is controlled by ......(10) ...... (11). A leaf is made up of a ......(12), ......(13), and ......(14).

\section{PROBLEM VII. WHAT RAW MATERIALS AND CONDITIONS ARE NEEDED TO MAKE FOOD?}

\section{Demonstration 8. How does water get into leaves?}

Where is the passageway of water from the roots to the leaves? Place a young growing pea or bean seedling in red ink (eosin) and leave in the sun for a few hours. What happens? What happens after a wilted plant is given water? Why? Place celery stalks in red ink and leave for a few hours in the sunlight. Cut thin sections of the stem. Where does the colored water rise? It is obvious from these experiments that water rises through the minute tubes or ducts in the stems. We will find later in most woody stems that these bundles of tubes are arranged in a very regular way.

What raw materials are needed? If we think back to our work on foods in the last unit, we may remember that organic foods consist of the elements carbon, oxygen, hydrogen, nitrogen, and small amounts of certain elements found in the soil, such as calcium, iron, potassium, and sodium. If the leaf is to manufacture organic food substances, then we must see where these elements might come from. Water is made up of oxygen and hydrogen; carbon dioxide, a gas given off in the breath, is in the air in small quantities, while nitrogen in a usable form is in soil that contains humus. Here then are the raw materials. How do they get into the leaf?

We have just seen that water can get from the roots up through the stem and into the leaves. This water, if it comes from the soil, has dissolved in it mineral matter, including nitrates from which the plant may obtain nitrogen. Carbon dioxide, which is taken 
out of the air, is another of the raw materials. This gas enters the leaf through the stomata and thus comes in contact with the living cells of the leaf which are the manufacturers.

\section{Demonstration 9. To show the effect of light on green leaves.}

Place oxalis or nasturtium plants near a window. After several days, notice the position of the blades of the leaves. Notice also the leaf stalks. Account for the position of the leaves and stems.

Effect of light on plants. Evidently sunlight has something to do with the life of a green plant; for in young plants which have been grown in total darkness, no green color is found in either stems or leaves, the latter often being reduced to mere scales. The stems are long and more or less reclining, as those of a sprouting potato kept in darkness. We can explain the changed condition of the seedling grown in the dark only by assuming that lack of light has some effect on the protoplasm of the seedling and induces the growth of the stem. If seedlings have been growing on a window sill, or where the light comes in from one side, you have doubtless noticed that the stem grows towards the source of light and the leaves tend to arrange themselves so as to receive as much light as possible on their upper surfaces. The illustration here shows very plainly the effect of light on a grow-

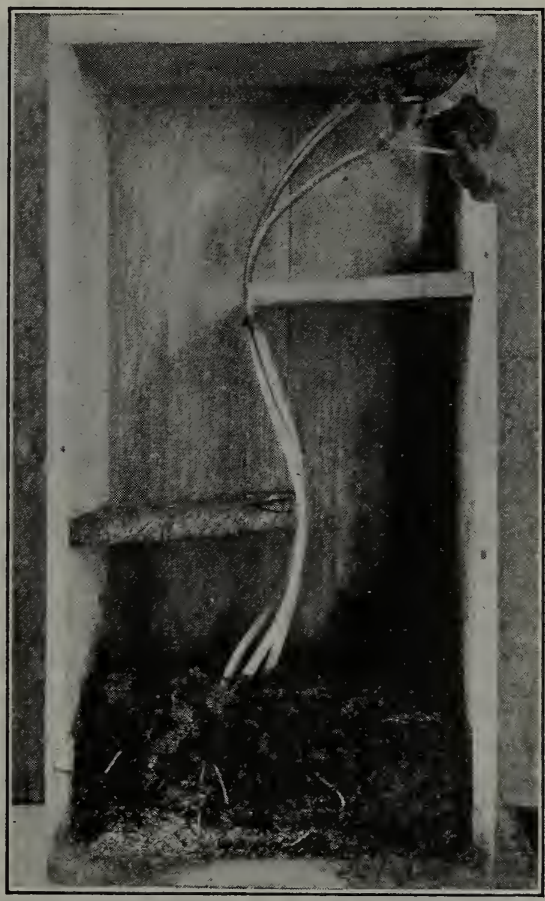

Wright Pierce

Explain why this plant has grown toward the right of the box instead of the left. ing plant. A hole was cut in one end of a box and barriers were erected in the interior of the box so that the seeds planted in the 
sawdust received their light by an indirect course. The young seedling in this case responded to the influence of the stimulus of light so that it grew out finally through the hole in the box into the open air. This growth of the stem to the light is of very great importance to a growing plant, because food making depends largely on the amount of sunlight the leaves receive.

Practical Exercise 6. Why do the leaves of lettuce or cabbage when "headed" turn white?

Effect of light on leaf arrangement. It is a matter of common knowledge that green leaves turn toward the light. Place growing

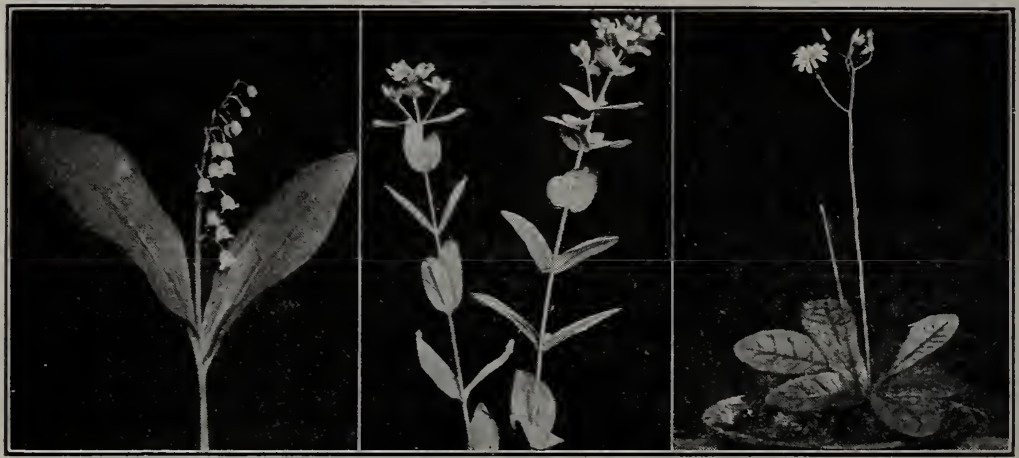

Brooklyn Botanical Garden, N. Y.

Why are the leaves of these plants well arranged for obtaining sunlight? Why do they need a great deal of sunlight?

pea seedlings, oxalis, or any other plants of rapid growth near a window which receives full sunlight. Within a short time the leaves will be found in positions to receive the most sunlight possible. Careful observation of any plants growing outdoors shows us that in almost every case the leaves are so arranged as to get much sunlight. The ivy climbing up a wall, the morningglory, the dandelion, and the burdock, all show different arrangement of leaves, each presenting a large surface to the light. Leaves are often definitely arranged, each fitting in between others so as to present their upper surface to the sun. Such an arrangement is known as a leaf mosaic. Examples of such mosaics are seen on trees having leaves that come out from the branch alternately, first 
on one side and then on the other. In the horse-chestnut, where the leaves come out opposite each other, the older leaves of an upright branch have longer petioles than the younger ones. In the case of the dandelion, a rosette or whorled cluster of leaves is found. Here the leaves are arranged spirally on a very short stem. Leaves with long petioles are nearest the ground while those with shorter petioles alternate with them, filling the space. In the mullein the entire plant forms a cone. The old leaves near the bottom are very large, and the younger ones near the apex are much smaller and come out close to the main stalk. In every case each leaf receives a large amount of light.

Practical Exercise 7. Bring into class as many examples of various leaf arrangement as possible.

The sun a source of energy. We have already learned that green plants are the great food makers for themselves and for animals. We are now ready to learn how green plants make food. We know the sun is the source of most of the energy that is received on this earth in the form of heat and light. Every one knows what "burning glass" will do when it focuses the sun's rays on a piece of paper. Solar engines have not come into any great use as yet, because fuel is cheaper, but some day we undoubtedly shall harness the energy of the sun to do our everyday work. Experiments have shown that as much as 80 per cent of the radiant energy falling on certain green leaves is absorbed. Part of this energy is used by the leaf; but part is changed to heat, raises the temperature of the leaf, and is later lost to the air if the air is cooler than the leaf. Regulation of this temperature is obtained in much the same way as in our own bodies, by evaporation of water. We perspire; the leaf passes off water vapor, largely through the stomata.

Relation of light and air to starch in leaf. We can readily test how light affects the amount of starch found in a leaf. We do this by pinning strips of black cloth, such as alpaca, over portions of several leaves of a growing hydrangea which has previously been placed in a dark room for a few hours, and then putting the plant in direct sunlight for an hour or two. We remove the partly covered leaves, boil them to soften the tissues, and extract the chlorophyll with wood alcohol (because the green color of the chlorophyll 


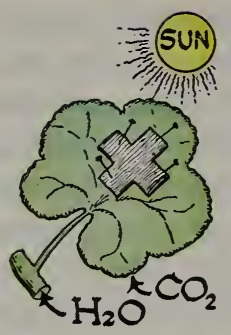

starch made

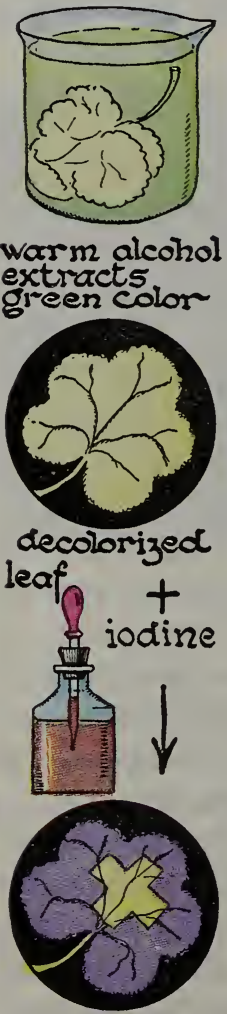

What effect does sunlight have on green leaves? Describe the experiment which will prove this.

interferes with the blue color of the starch test). A test with iodine shows that starch is present only in the portions of the leaves exposed to sunlight. From this we infer that the sun has something to do with the amount of starch found in a leaf.

The necessity of air for making carbohydrates may easily be proved by experiments. For if parts of several leaves on a plant are covered with vaseline, they will be found to contain no starch, while those parts of the leaf without vaseline, but exposed to the sun and air, will contain starch. The part of the air used in carbohydrate-making is carbon dioxide, which is present in the atmosphere in very small amounts.

Air is necessary for the process of making sugar and starch in a leaf, not only because carbon dioxide gas is absorbed but also because the leaf is alive and must have oxygen in order to do its work. It takes this oxygen from the air.

Practical Exercise 8. Explain why some plants do so poorly in the house. Why are trees in cities often so sickly?

Demonstration 10. To show the need of chlorophyll for making carbohydrates.

Place a plant with variegated leaves, as Coleus, in sunlight for an hour or two. Test several leaves with iodine after removing the chlorophyll with methyl alcohol. Do all the leaves show presence of starch? Do all parts of the variegated leaves show starch? Why is chlorophyll necessary?

Demonstration 11. To show the need of carbon dioxide for making carbohydrates.

Place a green plant in a wide-mouth jar which contains carbon dioxide gas. Place the jar in bright sunlight. Place another plant in a jar in which carbon dioxide is removed by means of soda lime (see diagram). After 24 hours test leaves from both plants for starch. Results?

Chlorophyll necessary for making carbohydrates. In the palisade layer of the leaf, we find cells which are almost cylindrical in form. In 
the protoplasm of these cells are found a number of tiny green bodies, the chloroplasts or chlorophyll bodies. If the leaf is placed in wood alcohol, we find that the bodies still remain, but that the color is extracted, going into the alcohol and giving to it a beautiful green color. The chloroplasts are, indeed, simply part of the protoplasm of the cell colored green. These bodies are of the greatest importance directly to plants and indirectly to animals. The chloroplasts, by means of the energy received from the sun, manufacture sugars and then starch out of certain raw materials obtained from the soil and the air. These raw materials are soil water, which is passed up from the roots through the bundles of tubes into the veins of the leaf, and carbon dioxide from the air, which is taken in through the stomata or pores. A plant with variegated leaves, as the tradescantia or "wandering Jew," makes starch

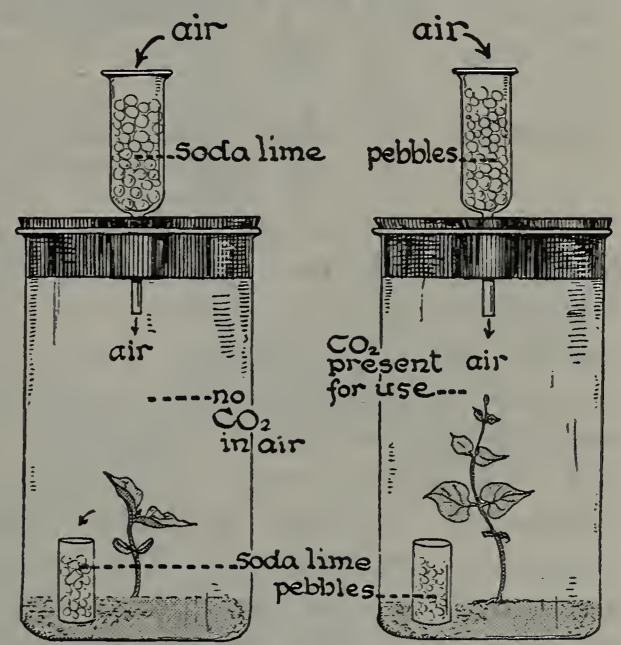

Explain the difference in growth of the two plants.

only in the green part of the leaf, though these raw materials reach all parts of the leaf.

Changes in color in leaves. Green leaves are really solar engines and like all machinery wear out after long usage. It has been estimated that the total working life of a green leaf is about 1500 hours. In the fall we find leaves changing color, and we used to think this was due to the action of frost. Now we think it is due to the breaking down of the green coloring matter in the leaf. This disintegration seems to be an oxidation process. As the chlorophyll disappears from the leaves, the yellow color, which is present in the leaf cells, can now be seen. But other autumn colorations are not yet fully understood. 
Practical Exercise 9. Make a collection of leaves showing as many color changes as possible.

\section{Self-Testing Exercise}

Water rises in the stem of plants through ...... (1) ...... (2).

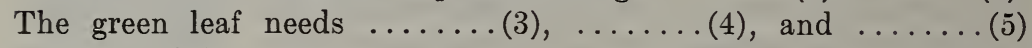
.......(6) in order to manufacture organic food. These materials enter the plants through the .......(7) in the leaves and through the .......(8) in the soil. Plants growing in total darkness are without (11). This material is known as .......(12).

\section{PROBLEM VIII. WHAT ARE THE PRODUCTS AND RESULTS OF FOOD MANUFACTURE?}

Comparison of carbohydrate-making and milling. The manufacture of carbohydrate by the green leaf is not easily understood. The process has been compared to the work of a mill. In this case the mill is the green part of the leaf. The sun furnishes the motive power, the chloroplasts constitute the machinery, and soil water and carbon dioxide are the raw products taken into the mill. The manufactured product is sugar which is later changed into starch. A certain by-product (corresponding to the waste in a mill) is also given out. This by-product is oxygen. To understand the process better, we must refer to the diagram of the leaf (page 161). Here we find that the cells of the green layer of the leaf, under the upper epidermis, perform most of the work. The carbon dioxide is taken in through the stomata and reaches the green cells by way of the intercellular spaces and by diffusion from cell to cell. Water reaches the green cells through the veins. It then passes into the cells and there becomes part of the cell sap. The light of the sun easily penetrates the cells of the palisade layer, giving the energy needed to make the starch. This whole process is a very delicate one, and will take place only when external conditions are favorable. Chlorophyll absorbs light of certain wave lengths, the blue and red rays do most of the work in food manufacture. For example, too much heat or too little heat stops carbohydrate-making in the leaf. The leaf engine works rapidly under favorable conditions and makes sugar in such quantities that 
it clogs up the conducting tubes and slows up the process of food making. But at night the foods are changed into a soluble form, transported to other parts of the plant, and the leaf is ready to begin its wurk again with the shining of the sun. This building

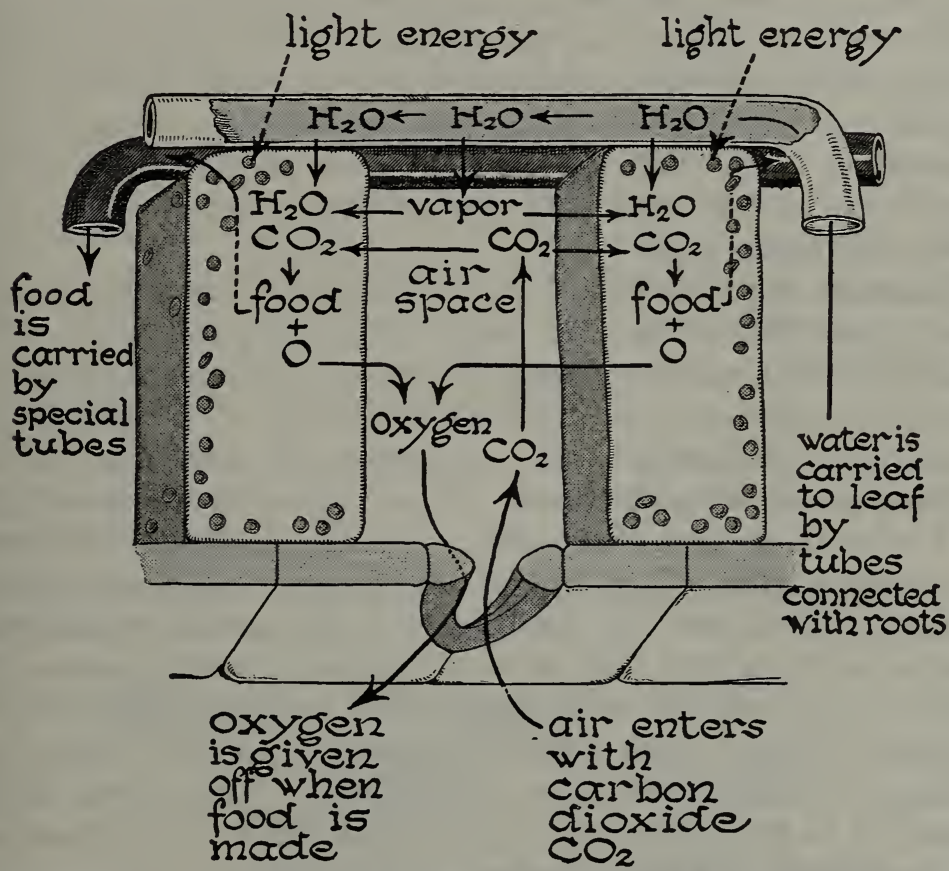

The leaf food factory. Where is the light energy used? How do the raw materials get to the factory? Where do waste products go? Where do the manufactured products go?

up of carbohydrates, with the release of oxygen by the chloroplasts in the presence of sunlight, is called photosynthesis.

Manufacture of fats. Inasmuch as tiny droplets of oil (or fat) are found inside the chlorophyll bodies in the leaf, we believe that fats, too, are made there, probably by a transformation of the starch already manufactured.

Protein-making and its relation to the making of living matter. Protein is a part of the food which is necessary to form protoplasm. It is present in the leaf and is found also in the stem and root. 
Proteins can be manufactured in any of the cells of green plants where starches or sugars and certain salts are found. The presence of light does not seem to be a necessary factor for the process. How they are manufactured is a matter of conjecture. The minerals, nitrates, sulphates, and phosphates in the soil water give nitrogen, sulphur, and phosphorus, and the sugar or starch gives carbon, hydrogen, and oxygen, all of which elements are found in proteins. Proteins are probably not made directly into protoplasm in the leaf, but are transported to other parts of the plant, stored there and used when needed, either to form new cells or to repair waste.

Enzymes and their work. It is a matter of common knowledge that starch food is stored in fruits, seeds, roots, and stems. We also know that starches cannot pass from one part of the plani to another because they are insoluble substances. The particles of which they are formed cannot go through the membranes which surround each cell in the plant. To make possible the circulation of food from one part of the plant to another insoluble foods must be made soluble. This is done by means of substances called enzymes. We have little knowledge of their actual composition, but we do know that they have the power to speed up chemical action in the cells so as to cause certain insoluble substances to become soluble. Each nutrient requires a specific enzyme to change it from an insoluble to a soluble form. This process which seems to go on in almost all plant cells as well in the darkness as in the daylight, is called digestion.

Functions of food. While plants and animals obtain their food in different ways, they probably make it into living substance (assimilate it) in the same manner. Foods serve exactly the same purposes in plants and in animals; they either are used to build living matter or they are burned (oxidized) to furnish energy (power to do work). If you doubt that a plant exerts energy, note how the roots of a tree bore their way through the hardest soil, and how stems or roots of trees often split hard rocks.

Relation of carbohydrate-making to human welfare. Leaves which have been in darkness show starch to be present soon after exposure to light. A corn plant may send almost half an ounce 
of reserve food into the ears in a single day. The formation of fruit and the growth of grain, potatoes, and other food crops show the economic importance of the work of green leaves. Not only do plants make their own food and store it away, but they make food for animals as well; and the food is stored in such a stable form that it can be kept and sent to all parts of the world. Animals, herbivorous and flesh-eating, man himself, all are dependent upon the starch-making processes of the green plant for the ultimate source of their food. When we consider that in 1928 in the United States the total value of all farm crops was about $\$ 12,000,000,000$, and when we realize that these products came from the air and soil through the energy of the sun, we may understand why the study of plant biology is of great importance.

Practical Exercise 10. Make a table in which you list all the food products obtained in your community from green plants.

Water is given off from the leaf. Much more water is taken in by the plant than is used by the plant. This water is given off through the leaves.

Demonstration 12. Take some well-watered potted green plant, as a geranium or hydrangea, cover the pot with sheet rubber, fastening the

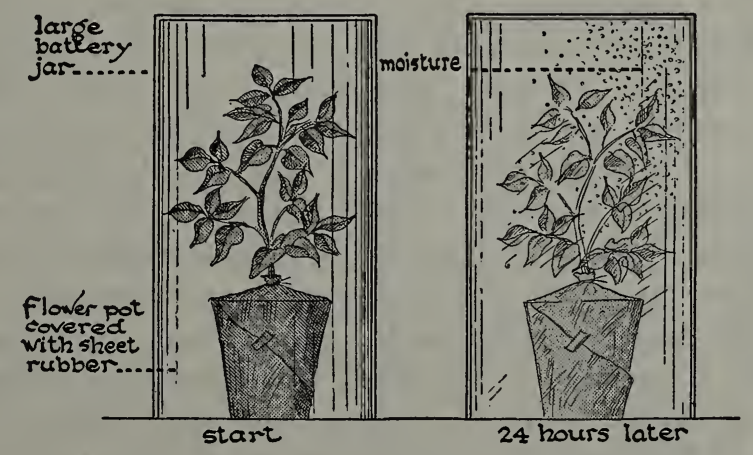

rubber close to the stem of the plant. Next weigh the plant with the pot. Then cover it with a tall bell jar and place the apparatus in the sun. In a short time drops of moisture are seen to gather on the inside of the jar. If after a few hours we weigh the potted plant again, we find it weighs less than before. Obviously the loss comes from the water vapor which has escaped from stem, or leaves, or both. 
Evaporation of water. During the day an enormous amount of water is taken up by the roots and passed out through the leaves in the form of vapor. So rapid is this evaporation, or transpiration, in a small grass plant, that the water evaporated in a day may weigh more than the plant. It is estimated that nearly half a ton of water may be given off into the air during twenty-four hours by a grass plot 25 by 100 feet, the size of the average city lot. It is estimated that a corn plant in the Central West gives off more than forty gallons of water during its lifetime. Nearly 20,000 lbs. of water is given off between June and November by a good-sized birch tree. Fields of wheat are said to give off an amount of water equal to nearly 20 per cent of the total rainfall on their area. The amount of water lost by plants through evaporation is many times more than the amount that goes into making food and living matter.

Factors in transpiration. The amount of water lost from a plant varies greatly under different conditions. The humidity of the air, its temperature, and the temperature of the plant all affect the rate of transpiration. The stomata also tend to close under some conditions, thus helping to prevent evaporation. Certain experiments indicate that the plant probably has some control over the stomata. The stomata are usually closed at night but remain open from shortly after sunrise until late in the afternoon. They begin to close in the middle of the afternoon, and thus decrease the amount of water lost in the latter part of the day. Plants droop or wilt on hot, dry days because they cannot obtain water rapidly enough from the soil to make up for the loss through the leaves. Hairs on the leaf surface, waterproofing of outer cells, a decrease in leaf area, close grouping of leaves, the absence of leaves, as in the cactus, and the turning of leaves edgewise to light are all modifications which help to hold water in the body of the plant.

Green plants give off oxygen in sunlight. In still another way green plants are of direct use to animal life. During the process of sugar-making, oxygen is given off as a by-product. This may easily be proved by the following experiment. 
Demonstration 13. Place any green water plant in a battery jar partly filled with water, ${ }^{1}$ cover the plants with a glass funnel, and invert a test tube full of water over the mouth of the funnel. Place the apparatus in a warm sunny window. Bubbles of gas are seen to rise from the plant. After several hours in the direct sunlight, enough of the gas may be obtained by displacement of the water to prove, by the rapid oxidation of a glowing splinter of wood in the gas, that oxygen is present.

That oxygen is given off as a by-product by green plants is a fact of far-reaching importance. The green covering of the earth gives to animals an element that they must have, while the animals in their turn supply to the plants carbon dioxide, a compound used in food making. Thus a widespread relation of mutual helpfulness exists between plants and animals.

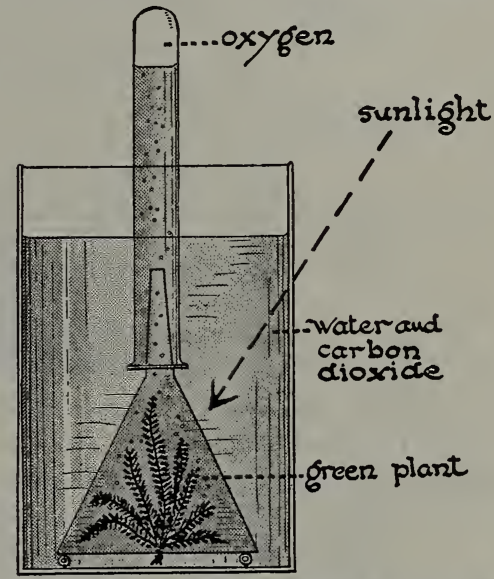

Explain just what is happening here and the conditions necessary to bring it about.

Respiration by leaves. All living things require oxygen. It is by means of the oxidation of food materials within the plant's body that the energy used in growth and movement is released. 4 plant takes in air with its oxygen largely through the stomata of the leaves, to a less extent through the lenticels ${ }^{2}$ in the stem, and through the roots. Thus rapidly growing tissues receive the oxygen necessary for them to perform their work. One of the products of oxidation in the form of carbon dioxide is also passed off through these same organs. It can be shown by experiment that a plant uses up oxygen in the darkness and gives off carbon dioxide; in the light the amount of oxygen given off as a byproduct in the process of carbohydrate-making is much greater than the amount used by the plant in respiration.

${ }_{1}^{1}$ Water contains air in solution, including some carbon dioxide, but the amount may be too small. Immediate success with this experiment will be obtained only if the water has been previously charged with carbon dioxide.

${ }^{2}$ Lenticels (lën'ťr-sěls): lens-shaped spots or warts on the surface of young stems and shoots of peach, apple, and other trees. 
Practical Exercise 11. Fill out the following table on the work of the leaf.

\begin{tabular}{|c|c|c|c|}
\hline Part & Function & What Happens & What Catses It to Happen \\
\hline & & & \\
\hline & & & \\
& & & \\
\hline
\end{tabular}

\section{Self-Testixg Exercise}

Green plants manufacture .......(1), ...... (2), and ...... (3). The manufacture of ........ (4) by green plants in the presence of sunlight is called ........(5). ......(6) is not a necessary factor for protein-making. In order for food to circulate from one part of the plant to another, the .......(7) food must be made ....... (8). This change is caused by .......(9), and is known as $\ldots \ldots$ (10). Food is needed for ........(11) and .......(12). Green plants give off $\ldots \ldots \ldots$ (13) ......(14), ......(15), and ......... (16).

\section{PROBLEM IX. HOW IS FOOD CIRCULATED IN A PLANT?}

The circulation and final uses of food in green plants. We have seen that cells of green plants make food - especially the cells that are in the leaves. But all parts of the bodies of plants grow. Roots, stems, leaves, flowers, and fruits grow. Seeds are storehouses of food. We must now examine the stem of some plant in order to see how food is distributed, stored, and finally used in the various parts of the plant.

The structure and growth of a dicotyledonous or woody stem If we cut a cross section through a young willow or apple stem, we find it shows three distinct regions. The center is occupied by the spongy, soft pith; surrounding this is found the rather tough wood, while the outermost area is bark. More careful study of the bark reveals the presence of three layers - an outer layer, epidermis, a middle green layer, cortex, and an inner fibrous layer. The inner layer is made up largely of tough fiberlike cells known as bast fibers. 
The most important parts of this inner bark, so far as the plant is concerned, are many tubelike structures known as sieve tubes.

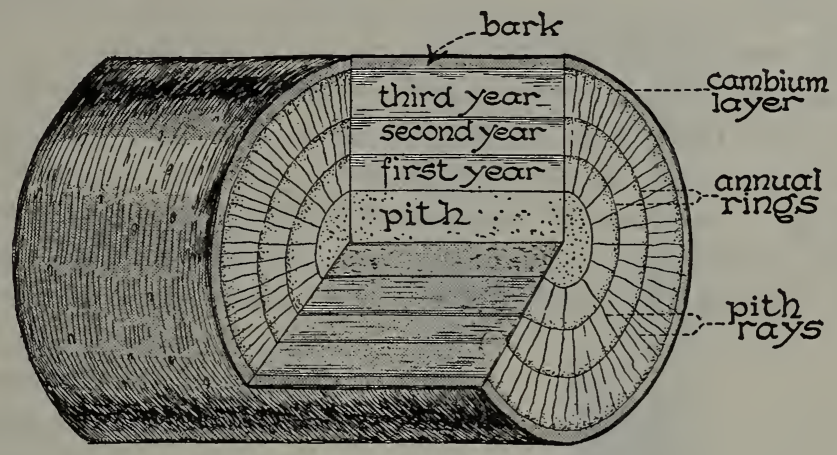

Explain growth in this stem.

These are long rows of living cells, having perforated sievelike ends. Through these cells food materials pass downward from the upper part of the plant, where they are manufactured.

In the wood will be noticed a number of lines called medullary rays, or pith rays, radiating outward from the pith toward the bark. These are thin plates of pith which separate the wood into a number of wedge-shaped masses. The masses of wood contain many elongated cells, which, placed end to end, form thousands of little tubes connecting the leaves with the roots. In addition to these are many thick-walled cells, which give strength to the mass of wood. The bundles of tubes with their surrounding hard-walled cells are the continuation of the bundles of tubes which are found in the root. In sections of wood which have taken several years to grow, we find so-called annual rings. The distance between one ring and the next (see diagram) usually represents the amount of growth in one year. Growth takes place from a

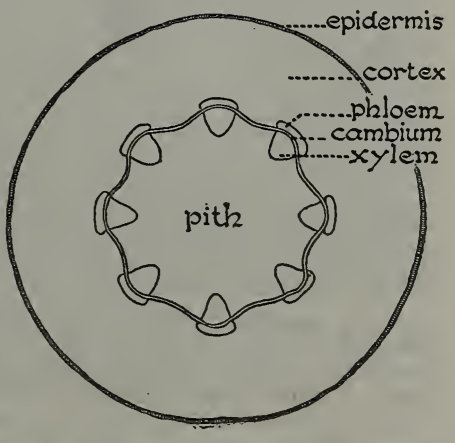

Cross section of a very young dicotyledonous stem, showing arrangement and parts of the bundles and the other tissues. 
layer of actively dividing cells, known as the cambium layer. This layer forms wood cells from its inner surface and bark from its outer surface. Thus new wood is formed as a distinct ring around the old outer wood and new bark inside the old bark.

In a very young dicotyledonous stem before the wood of the bundles has formed an annual ring, these individual fibro-vascular bundles are quite separate, arranged in a circle around the central pith. Each bundle consists of three parts: the outer part, phleom, made up of the bast fibers and sieve tubes, through which liquids pass downwards; the middle part, cambium, or

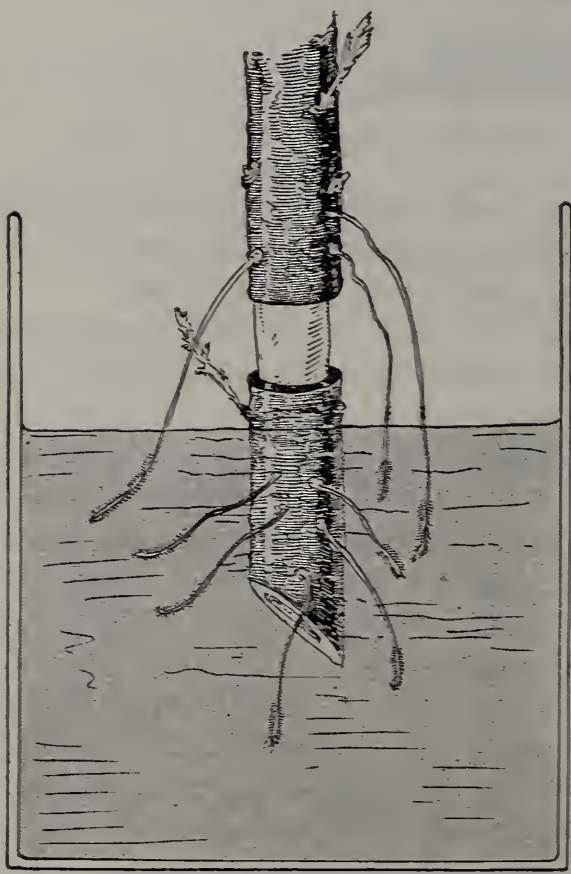

In this experiment the willow twig was girdled by taking off the bark. Can food now reach the part below the ring? Why have roots come out above the ring? Why has a sprout appeared below the ring? growth portion which soon develops also between the bundles and thus forms the cambium layer; and an inner part, xylem, made up of woody fibers and ducts with woody walls through which liquids pass upward through the stem.

Use of the outer bark. The outer bark of a tree is protective. The cells are dead, but the heary moody skeletons prevent the evaporation of fluids from within. The bark also protects the tree from attacks of plants or animals which might harm it. Most trees are provided with a layer of corklike cells. This layer in the cork oak is thick enough to be of commercial importance. There are many lenticels scattered
These can be seen easily in a through the surface of the bark. These can be seen easily in a young stem of apple, beech, or horse-chestnut. 
Demonstration 14. To show that food passes downward in the bark. If a freshly cut willow twig is placed in water, roots develop from that part of the stem which is under water. If the stem then is girdled by removing the bark in a ring just above where the roots are growing, the latter will eventually die, and new roots will appear above the girdled area. The passage of food materials takes place in a downward direction outside the wood in the layer of bark which eontains the bast fibers and sieve tubes.

This experiment with the twig explains why trees die when girdled so as to cut the sieve tubes of the inner bark. Many of the birches of our forests have been killed, as a result of being girdled by thoughtless visitors. In the same way gnawing animals frequently kill fruit trees. To a small extent food substances are conducted in the wood itself, and food passes from the inner bark to the center of the tree by way of the pith rays in which starch is stored.

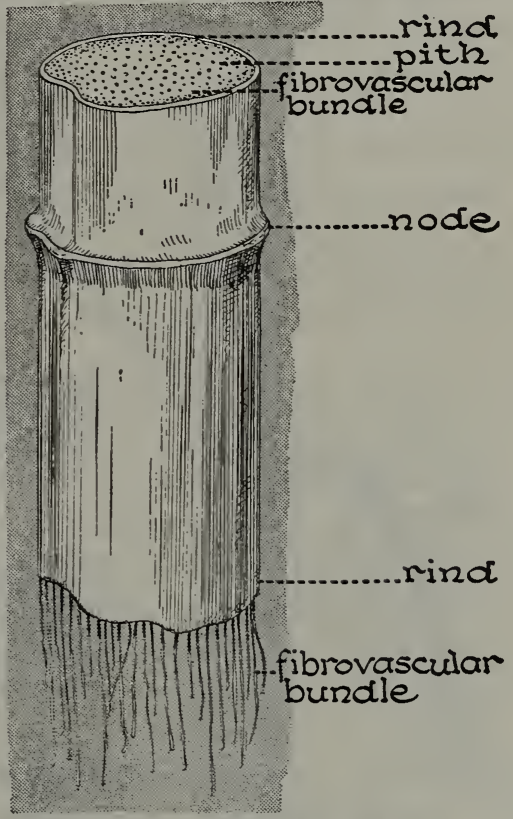

A cornstalk. What are the differences in the arrangement of the fibrovascular bundles here and in a dicotyledonous or vascular stem?

Structure and growth of a monocotyledonous stem. A piece of cornstalk is made up of pith, through which are scattered numerous stringy, tough structures called fibrovascular bundles. The latter are the woody bundles of tubes and fibers which pass through the pith and run into the leaves, where (in young specimens) they may be followed as veins. The outside of the corn stem is formed of large numbers of fibrovascular bundles, which, closely packed together, form a hard, tough outer rind. Thus the woody material on the outside gives mechanical support to an otherwise spongy stem. In a very young stem epidermis is present.

In the monocotyledonous stem the bundles are scattered and the cambium layer is absent. The bundles increase in number as 
the stem grows older. Sieve tubes or phloem are in the outer part and xylem or water-bearing tubes in the inner part of the bundle.

What causes water to rise in a stem. We have already seen that osmosis is responsible for getting water inside the root, and that

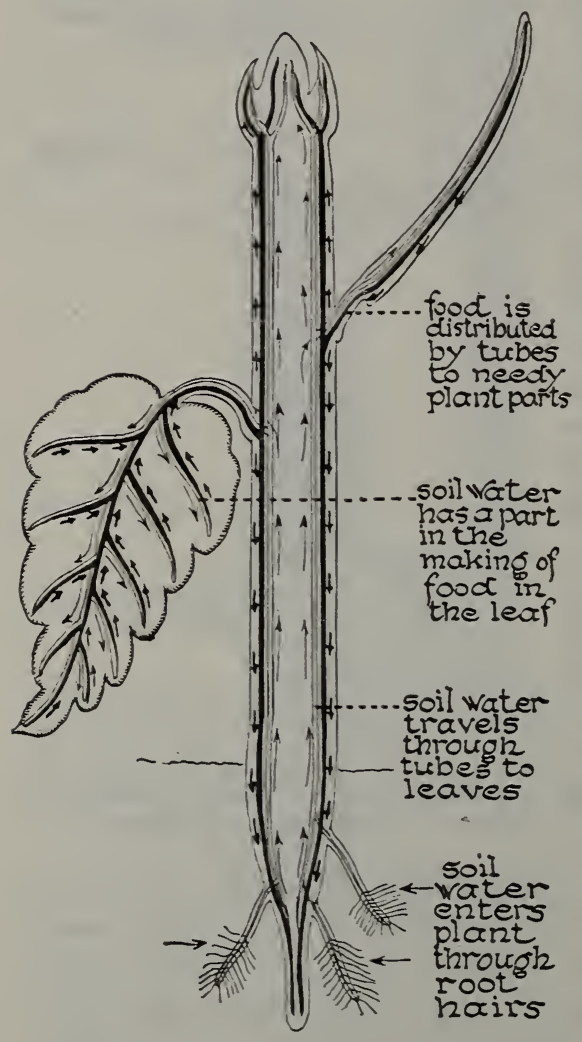

Fluids pass up and down in plants through tubes. Raw materials pass upward into the leaves. The food manufactured in the leaves passes downward to the roots for storage, and to the other parts of the plant which need it.

the pressure exerted by this water (root pressure) is frequently capable of forcing fluids a considerable distance up a living stem sometimes 20 or 30 feet in height. But during most of the year root pressure plays a very unimportant part in this phenomenon. It has been found that in the very tiny tubes, such as we find in wood, the rising column of water is held together by the force of cohesion. A core of water in tubes $\frac{1}{200}$ of an inch in diameter will withstand a pull of over 4600 pounds to the square inch, so it is likely that this force is the strongest factor in raising water in the tubes of tall trees. Also a very large amount of water is evaporated every day, a tree of average size using from 75 to 100 gallons of water daily, most of which passes out through the stomata. This evaporation may cause a pull on the volume of water in the fibrovascular bundles and probably is another important factor in the rise of fluids in stems. 
Digestion and storage of food. Much of the food made in the leaves is stored in the form of starch. But starch, being insoluble, cannot be passed from cell to cell in a plant. In our study of the root hair we found that substances in solution (solutes) will pass from cell to cell by osmosis. In our study of a growing seedling we found that a solid food substance, starch, was digested in the corn grain by an enzyme, thus becoming a diffusible substance which could pass from cell to cell. This process of digestion seemingly may take place in all living cells of the plant, although most of it is done in the leaves. In the bodies of all animals, including man, starchy foods are changed in a similar manner, but by other enzymes, into soluble grape sugar.

The food material may be passed along in a soluble form until it comes to a place where food storage is to take place, and then it can be transformed again by the action of a reversible enzyme into an insoluble form (starch, for example); later, when needed by the plant in growth, it may again be transformed and sent in a soluble form through the stem to the place where it will be used.

In a similar manner, protein seems to be changed and transferred to various parts of the plant. Some forms of protein are soluble and others insoluble in water. White of egg, for example, is slightly soluble, but can be rendered insoluble by heating it so that it coagulates. Insoluble proteins are digested within the plant; how and where is but slightly understood. Soluble proteins pass down the sieve tubes in the bast and then may be stored in the bast or medullary rays of the wood in an insoluble form, or they may pass into the root, fruit, or seeds of a plant, and be stored there. This stored food becomes of immense value to mankind, for it forms not only our cereal, potato, and other crops, but also our fruits of all kinds.

\section{Self-Testing Exercise}

The center of a dicotyledonous stem is the ....... (1). The outer area of bark of a tree gives ........ (2) to the tree. The inner layer is made up of

(4). It contains the ........(5)

(6) through which food materials pass downward to the roots. Growth takes place in the .......(7) forming new ......(8) and 
a new inner layer of .......(9). The breathing holes on the surface of bark are called ........ (10). The main bulk of a monocotyledonous stem is made up of ....... (11), through which....... (12) ....... (13) are scattered. The rise of water in a stem is brought about by the .......(14) of water from the tree and by the $\ldots \ldots \ldots(15)$ of $\ldots \ldots \ldots(16)$. Foods are $\ldots . . .(17)$ and are transported to all parts of the ....... (18).

\section{PROBLEM X. WHY ARE PLANTS MODIFIED?}

Modified stems. We have already seen that the factors of the environment, light, heat, gravity, moisture, air currents, and other
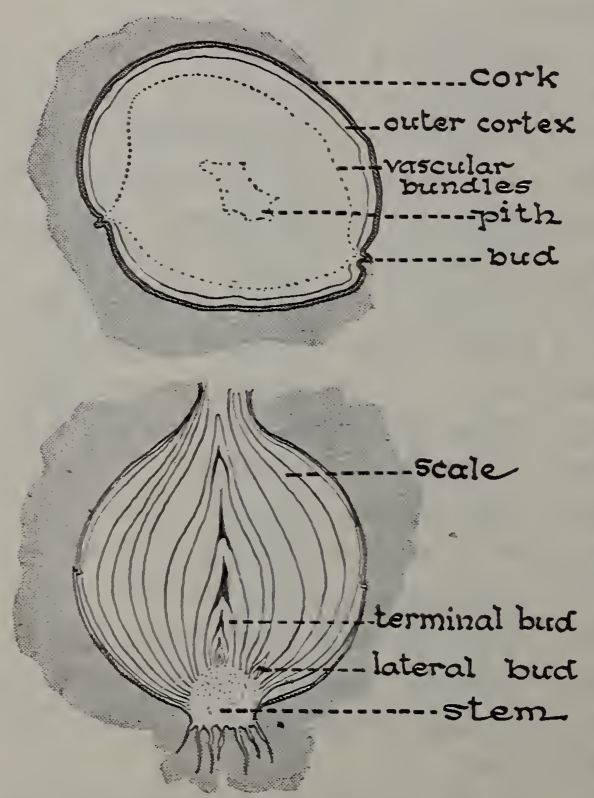

Cross sections of a potato and of an onion. How can you show that these are modified stems? factors act upon the living substance of plants, causing them to react in various ways. The changes which take place usually fit the plant to succeed better in its battle for life. Thus various modifications of stems have been brought about. The potato tuber is simply a much thickened storage stem. The tiny projection growing within the eye is a bud, which may give rise to a branch later. Some stems have come to exist underground because of the protection thus afforded. The pest called couch grass or quick grass has such a stem. Bulbs, like the onion or lily, are examples of stems which have become shortened and covered with thickened leaves, filled with food. Still other stems, like that of the dandelion, have become reduced in length, which prevents them from being broken off by grazing animals. 
Climbing stems, as a result of the stimulation of the sun, twist around a support in a given direction, sometimes revolving with and sometimes against the course of the sun.

We also find stems and leaves modified to become holdfasts as the tendrils found in climbing plants. Thorns, a protection from animals, may be modified parts of leaves or of stems.

Practical Exercise 12. Make a list of the modified stems found in your locality. Show how each modification may be of use to the plant.

\section{Self-Testing Exercise}

A modified stem is one that has probably been changed by the (1) in the ........(2). Modified stems may be in the form of $\ldots \ldots \ldots$ (3) as in the $\ldots \ldots \ldots$ (4). Some stems may be ....... (5), while others may be $\ldots \ldots \ldots$ (6), forming $\ldots \ldots \ldots$ (7).

\section{Review Summary}

Test your knowledge of the unit by (1) rechecking the survey questions; (2) performing all assigned exercises; (3) checking with your teacher all tests and making up all missed parts; (4) making an outline of the unit for your notebook.

\section{Test on Fundamental Concepts}

In a vertical column under the heading CORRECT write numbers of all statements you believe are true. In another column under INCORRECT write numbers of untrue statements. Your grade $=$ number of right answers $\times 2$.

I. Roots (1) grow toward water; (2) are affected by gravity; (3) may take carbon dioxide from the soil; (4) always store food; (5) hold a plant firmly in the ground.

II. A root is able to take in water (6) because it is made of woody tissue; ( 7 ) by means of osmosis ; (8) because it has a root cap covering each tiny root; (9) through minute root hairs; (10) because it gives off an acid.

III. Roots are useful to plants because they (11) may store food; (12) grow against gravity; (13) absorb mineral matter from the soil;

(14) act as anchors; (15) take in oxygen through their stomata.

IV. The process by which food is made by green leaves is known as (16) transpiration; (17) protein-making; (18) nutrition; (19) photosynthesis ; (20) osmosis. 
V. Green plants breathe through (21) lenticels; (22) root hairs; (23) stomata ; (24) guard cells; (25) epidermal cells.

VI. Food in plants is made soluble by (26) water; (27) enzymes; (28) the palisade layer of cells; (29) oxygen; (30) digestion.

VII. A green plant (31) makes sugar; (32) gives off nitrogen; (33) is a solar engine; (34) manufactures proteins and fats by a process known as photosynthesis; (35) gives off oxygen in sunlight.

VIII. Dicotyledonous stems (36) grow from a thin layer called cambium; (37) show annual rings of growth; (38) have a large area of pith and a rind; (39) pass foods downward through the sieve tubes just outside the cambium; (40) contain pith rays.

IX. Monocotyledonous stems (41) have scattered fibrovascular bundles; (42) grow by having these bundles arranged in a ring, growth taking place from the cambium; (43) have a strong rind formed of bundles and epidermis; (44) contain medullary rays; (45) have annual rings.

X. Stems (46) are pathways for food and water; (47) owe their strength to the tough walls of the cells of which they are composed; (48) might be called organs of circulation and support; (49) may be modified into leaves; (50) may be modified into tendrils to help in climbing.

\section{Achievement Test}

1. How can you devise an experiment that would show the amounts of water which various soils can hold?

2. What are root hairs, where are they found, and what do they do?

3. How can you prove that root hairs give off an acid?

4. How can you devise an experiment to illustrate the principle of osmosis?

5. How can you show that the sun affects the direction of growth of a green plant?

6. How can you make a diagram to show the cell structure of a leaf?

7. How can you prove by experiment what factors are necessary for sugar-making in a green plant?

8. What are the chief differences in the structure of monocotyledonous and dicotyledonous stems?

9. How can you prove that water or food passes up and down in a stem? 
10. How can you devise experiments to prove that food in a root has to become soluble before it can pass to another part of the plant?

11. What are the functions of the various parts of a living plant?

\section{Practical Problems}

1. Show why a region well supplied with trees is more likely to have frequent rains than a desert region.

2. Explain fully how you are dependent for your food upon grass.

3. Make a table in your notebook to show how raw food materials get into a green plant, just where each goes, and what becomes of it, what results, and what by-products are passed off. Use colors.

4. Sum up the differences between dicotyledonous and monocotyledonous plants.

\section{Useful ReFERENCES}

Dana, Plants and Their Children. Pp. 99-129. (American Book Company.)

Duggar, Plant Physiology. (The Macmillan Co. 1921.)

Coulter, Barnes, and Cowles, A Textbook of Botany, Vol. I. (American Book Company.)

Gager, General Botany. (P. Blakiston's Son \& Co. 1926.) Hodge, Nature Study and Life, Chapters IX, X, XI. (Ginn \& Co.)

Transeau, General Botany. (World Book Co. 1923.) 


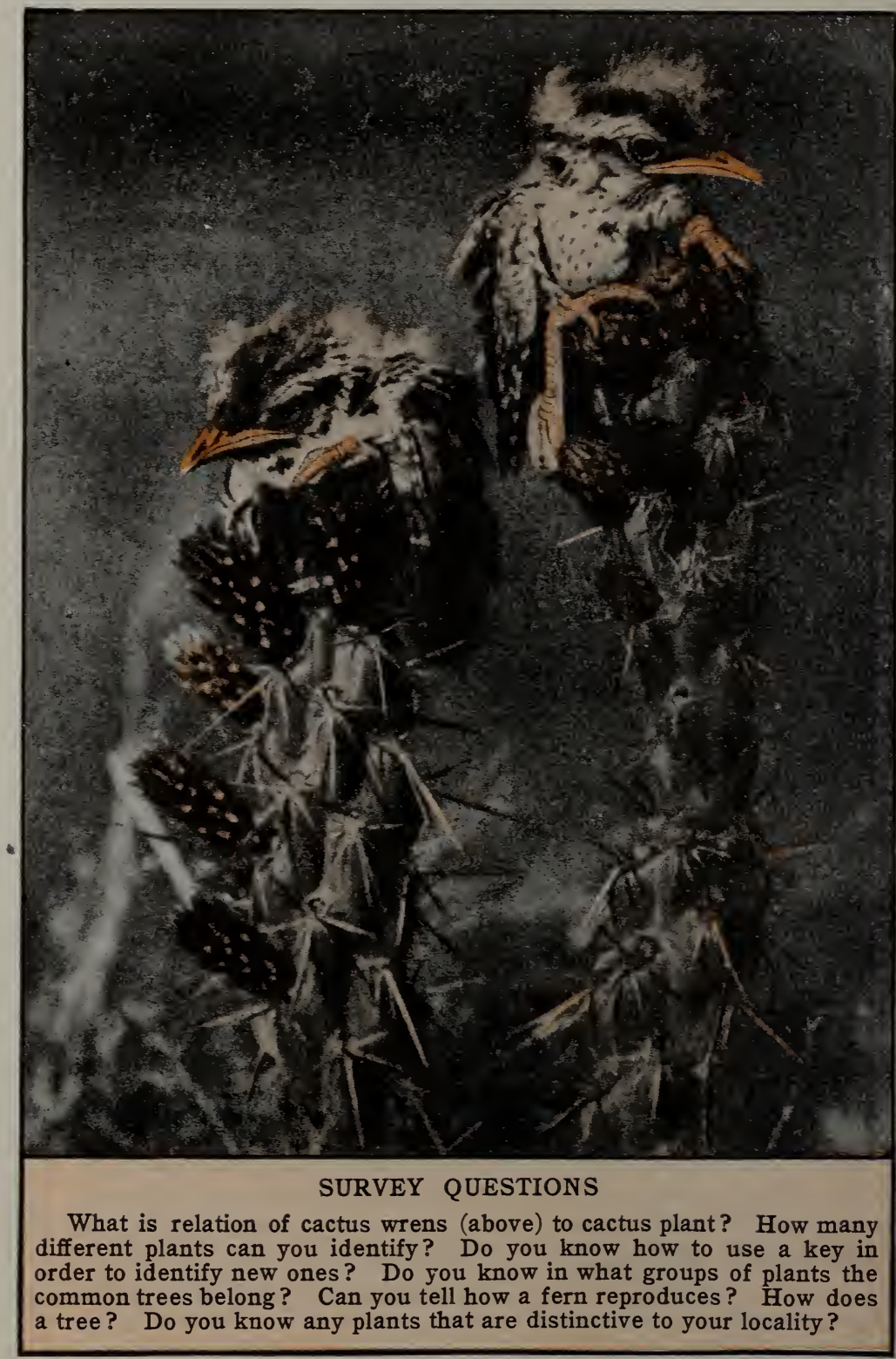




\section{PART III. RELATIONSHIPS AND INTER- RELATIONSHIPS OF LIVING THINGS}

\section{UNIT VII}

\section{THE PLANT WORLD. HOW DOES IT AFFECT MANKIND?}

Preview. Every boy or girl who takes hikes in the open fields, along streams, or on a mountain cannot help noticing tremendous numbers of different plants and animals of which he does not know the names. Every walk I take up a canyon or along a stream brings me in contact with some plants or animals I do not know by name. But I have considerable satisfaction in knowing that if I do see a form new to me I can, in all probability, identify it. If $\mathrm{I}$ take the specimen home to my library and compare it with certain pictures and descriptions that are found in reference books of classification, I may be able to name my specimen. This identification is made possible by biologists who decided that it was necessary to give names to things in order to place them correctly in the plant or animal world and, over a period of years, have worked out appropriate names. At first such names were short descriptions in Latin, which was the universal language of scholars. Then a young Swede named Linnaeus, who lived during the eighteenth century, made up a system of shorter names, which enabled the naturalist more easily to identify and name the specimen. Just as you or I have a family name and a given name, so Linnaeus gave plants and animals two names, the specific and the generic. This means very little until we know that all animals and plants may be placed in groups, of which the members have common characters which distinguish them from all other plants or animals. Such groups we call species (spe'shez). 
A group of different species all of which showed general relationships to one another might be called a genus (jē'nŭs). The specific name corresponds to the given name and the generic to the family name, but the generic name is always placed first as my name is printed, Hunter, George W., in the telephone book.

But what is the use of all this, you ask. One very large division of the study of biology, that of taxonomy or classification, depends upon an understanding of the use of scientific terms used by Linnaeus and his followers. We want to be able to place all plants and animals in the places they belong in the tree of life. To the average boy or girl, who enjoys field trips and who likes to collect specimens, a superficial knowledge of the great groups of plant and animal life is enough. But days and years of hard work may be necessary before the scientist masters enough knowledge to enable him to know how to classify all living things correctly. Fortunately for the layman, our museums, botanical gardens, and zoölogical parks have specimens of various kinds, but in order to get much pleasure out of such a visit he should be able to recognize at least the principal plant and animal groups. The pages that follow are written because every citizen should have some knowledge along these lines.

In addition to the pleasure of knowing the names of plants there is satisfaction in learning something about their life histories, the place they occupy in nature's scale of life, and best of all, we can learn something about the good or harm some of these forms do to mankind.

Look at the enormous damage done to crops each year by parasitic fungi such as molds, mildews, rusts, and other plant diseases. Black stem rust alone costs some of the wheatraising states in a single year almost as much as they put into their state system of public instruction for that year. And yet, paradoxical as it seems to say it, some of these plants add much to man's comfort and control the future of man's expansion on the earth. What would we do without yeast to make our bread rise or give us commercial alcohol? And how much we enjoy the flavor imparted to certain foods by molds.

Man is dependent primarily on the world's crops and the world's crops are dependent upon the amount of raw materials in the 
ground used by plants in food manufacture. Nature's law tells us that food cannot be made without certain raw materials. One of the basic elements needed in protein food manufacture is nitrogen, which is present in the air but is not available for use. One kind of bacteria is able to take it from the air, nature's storehouse, and to fix it in a form usable by green plants. These nitrogenfixing bacteria are among man's best friends.

\section{PROBLEM I. HOW DO WE CLASSIFY PLANTS?}

Laboratory Exercise. Collect a number of common plants in flower at the time you take this work, and see if, by using the information you find later on in this unit, you can identify them. Use all the help you can get, such as simple keys which are found in any good botany or in popular books on identification of flowers.

Plants are placed in groups. If we plant a number of pea seeds so that they will all germinate under the same conditions of soil, temperature, and moisture, the seedlings will differ one from another in a slight degree. But in a general way they will have many characters in common, such as the shape of the leaves, the length of tendrils, and the form of the flower and of the fruit. Moreover, if the seeds from these peas are planted, they in turn will give rise to plants which will closely resemble the parent plants from which the seeds came. Such plants are said to belong to the same species. A species is a small group of plants or animals having certain characteristics in common that make them different from all other plants or animals. Similar species are placed together in a larger group called a genus (plu. genera). For example, many species of peas - the wild peas, beach peas, sweet peas, and many others - are all grouped in one genus called Lathyrus (lăth'î-rŭs) because they have certain structural characteristics in common.

Practical Exercise 1. Give a good definition of a species; of a genus.

Genera of plants or of animals are brought together in still larger or more inclusive groups, the classification being based on general likenesses in structure. Such plant and animal groups are called, as they become successively larger, family, order, class, and phylum. This is called a system of classification. 
Classification of plants. Four great divisions or phyla of the plant kingdom are: the Thallophyta (th $\breve{a}$-lŏf' ${ }^{\prime}$-t $\left.\dot{a}\right)$, known as thallus plants, which do not have roots, stem, or leaves; the Bryophyta

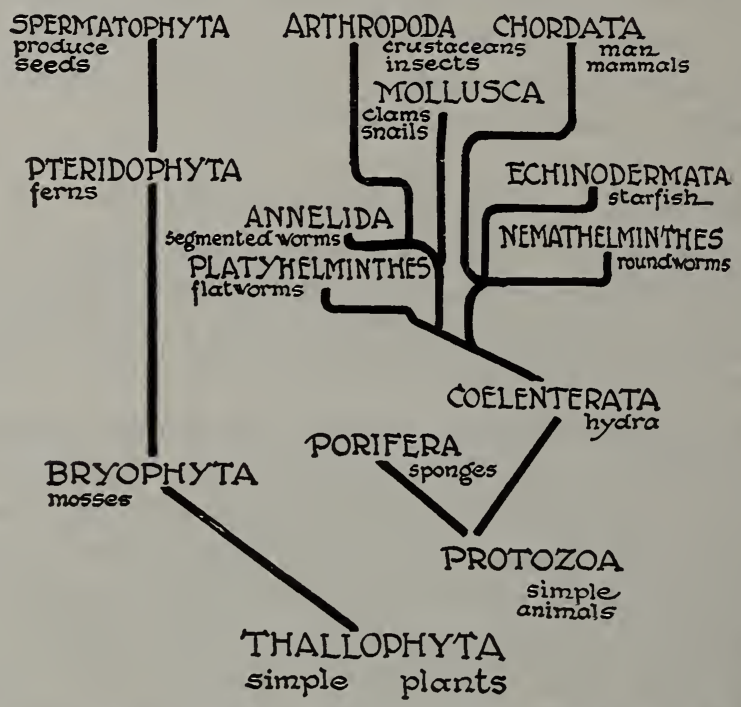

All plants and animals developed from a common ancestor and are classified under the phyla given in the above diagram.

(brī-ŏf' 1 -t $\mathfrak{a}$ ), which include the mosses; the Pteridophyta (tĕr'̂́dŏf'î-ta), which include the ferns; and the Spermatophyta (spur'm $\dot{a}$-tôf' 1 -t $\dot{a})$, which embrace the seed-producing plants.

Practical Exercise 2. Of what use is a system of classification? Write a brief paragraph on this subject.

\section{Self-Testing Exercise}

Plants and animals may be placed in groups based on ........ (1). A group containing individuals which are ........ (2) in ........ (3) and which will ........(4) others of the same kind is called a ....... (5). Species are placed in a .......(6) and more ...... (7) group, which is called a .......(8). These groups in turn are placed in still larger groups, called, as they grow more inclusive, ....... (9), $\ldots \ldots(10), \ldots \ldots$ (11), and $\ldots \ldots$.... (12). 


\section{PROBLEM II. WHAT ARE BACTERIA AND WHERE ARE THEY FOUND?}

The simplest plants, called thallophytes (Lat. thallus, young' branch; Gr. phyton, plant), have many forms. They may be single-celled or many-celled. They may or may not have chlorophyll, but they never possess the organs of root, stem, and leaves found in the higher plants.

The bacteria are probably the smallest and simplest in structure of all the organisms. They are usually classified as thallophytes. They have cell walls but do not have any chlorophyll, and are therefore not able to manufacture their own carbohydrate food.

How bacteria were discovered. As early as 1683 Leeuwenhoek is believed to have seen bacteria with his newly invented microscope. But it was not until 1865 that Louis Pasteur, the famous Frenchman, discovered the relation between bacteria and disease in silkworms. Pasteur had shortly before this proved that bacteria caused fermentation and that when floating germs got into nutrient fluids such fluids would "go bad" and would decay. Pasteur and Robert Koch, one in France, the other in Germany, were the first people to actually apply the idea of pro. tecting animals against disease by inoculating them with injections of a culture of weakened organisms that caused the disease. Pasteur made this application to man in his treatment for the prevention of rabies or hydrophobia.

Demonstration 1. To prepare and sterilize culture media. To a 100 c.c. of hot filtered beef broth add $1 \frac{1}{2}$ grams of the seaweed agaragar. If agar cannot be obtained, use gelatin. Add a little baking soda, if necessary, so that the liquid is faintly alkaline. Boil the mixture and filter through several layers of absorbent cotton into a sterilized Erlenmeyer flask. Close the mouth of flask securely with a plug of cotton and boil flask half an hour in a sterilizer. If the agar mixture is not clear, it should be filtered again.

Pour the hot nutrient agar into Petri dishes which have been sterilized with dry heat for several hours. Keep Petri dishes in a dry place, free from dust until ready to use them.

How we get bacteria for study. To obtain cultures of bacteria for study, it is first necessary to find some material in which they will grow, then to kill all living matter in this food material by 
heating it to the boiling point $\left(212^{\circ}\right.$ Fahrenheit) for half an hour or more (this is one method of sterilization), and finally to protect the culture medium, as this food is called, from other living things that might feed upon it.

Many bacteria thrive in a mixture of beef extract and gelatin or agar-agar, a substance derived from seaweed. This mixture, after sterilization, is poured into flat sterilized dishes with loosefitting covers. These Petri dishes, so called after their inventor, are the traps in which we collect and study bacteria.

Demonstration 2. Making a pure culture of bacteria. Transfer from an infected and incubated culture medium some bacteria on point of a sterile needle to the sterile surface of a Petri dish which contains sterile agar. Watch the growth of the colonies for several days. Are these colonies all alike in appearance?

How we may isolate bacteria of one kind from the other. In order to get bacteria of a given kind to study, it becomes necessary to grow them in what is known as a pure culture. This is done

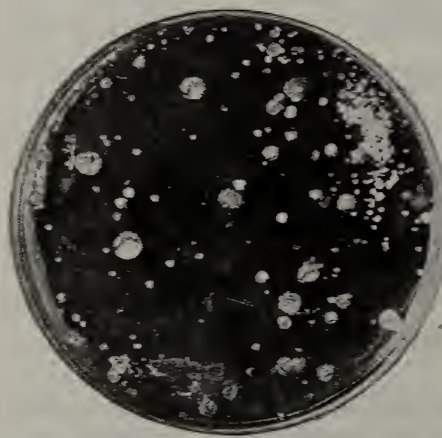

Each spot on this culture medium indicates a colony of bacteria. The different sizes and shapes of the spots show that there might be more than one type of bacteria present. How could you make a pure culture, that is, one containing only one kind of bacteria, if you have a sterilized culture medium and this Petri dish containing colonies of bacteria?

forms of bacteria from entering. When we have succeeded in growing only one kind of bacteria in a given dish, we have a pure culture. some medium such as beef broth or gelatin, or on potato. When the colonies of bacteria appear or the beef broth becomes cloudy, one form may be isolated from the others by the following process. A platinum needle is first passed through a flame to sterilize it. After the needle is cooled it is dipped in a colony containing the kind of bacteria we wish to study. The needle is then quickly drawn across the surface of a dish of sterile culture medium, and the dish is immediately covered to prevent any other

after first growing the bacteria in 
Laboratory Exercise. Observe under a compound microscope the various forms of bacteria seen in Petri dish of agar which has been exposed to the air. Make drawings of these bacteria.

Size and form. In size, bacteria are the most minute plants known. A bacterium of average size is about $\frac{1}{5000}$ of an inch in length, and perhaps $\frac{1}{25000}$ of an inch in diameter. Some species are much larger, others smaller. They are so small that several million are often found in a large drop of impure water or sour milk. Three well-defined forms of bacteria are recognized: a spherical form called a coccus; a rodshaped bacterium, the bacillus; and a spiral form, the spirillum. Some bacteria are capable of movement when living in a fluid. Tiny lashlike threads of protoplasm called flagella project from the body, and by a rapid movement cause locomotion. Bacteria reproduce with almost incredible rapidity. It is estimated that a single bacterium, by a process of division called fission, might, if unchecked, give rise to nearly $17,000,000$ others in twelve hours. Under unfavorable conditions bacteria

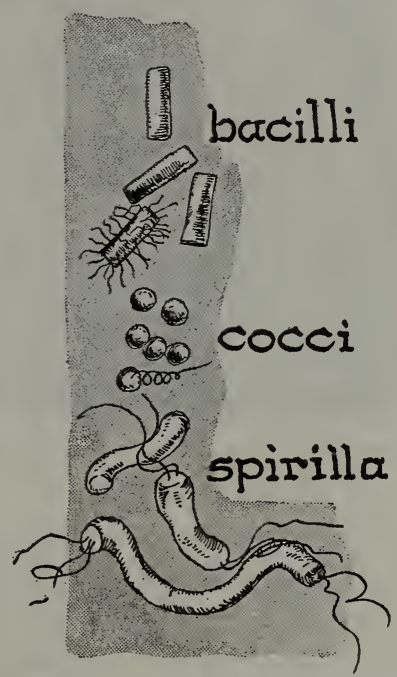

How would you describe the different kinds of bacteria? How do they move about? stop dividing and form rounded bodies called spores. The spore is usually protected by a wall and can withstand very unfavorable conditions of dryness or heat ; even boiling for several minutes will not kill some forms.

Laboratory Exercise. To determine some places where bacteria may be found. Expose a number of Petri dishes containing nutrient agar for 3 minutes each in as many of the following conditions, and as many others, as possible:

(a) to the air of the schoolroom.

(b) in the halls of the school while pupils are passing.

(c) in the halls of the school when pupils are not moving.

(d) at the level of a dirty and much-used city street.

(e) at the level of a well-swept and little-used city street. 
(f) in a city park.

$(g)$ in a factory building.

(h) to dirt from hands.

(i) to contact with scrapings from the interior of the mouth.

(j) to contact with decayed vegetable or meat.

(k) to contact with dirty coin or bill.

(l) to contact with two or three hairs from a pupil's head.

Cover the dishes securely and place them in a warm dark place.

After three to five days, note the conditions of the various plate cultures. Each day count the number of spots (colonies) of bacteria and molds growing on the culture medium. Make a table to show your results.

\begin{tabular}{|c|c|c|c|c|c|c|c|c|}
\hline \multirow{2}{*}{ Petri Dish Exposed } & \multicolumn{8}{|c|}{ Number of CoLonies of Bacteria } \\
\hline & $\begin{array}{l}\text { 1st } \\
\text { Day }\end{array}$ & $\begin{array}{l}\text { 2nd } \\
\text { Day }\end{array}$ & $\begin{array}{l}\text { 3rd } \\
\text { Day }\end{array}$ & $\begin{array}{l}\text { 4th } \\
\text { Day }\end{array}$ & $\begin{array}{l}5 \text { th } \\
\text { Day }\end{array}$ & $\begin{array}{l}\text { 6th } \\
\text { Day }\end{array}$ & $\begin{array}{l}7 \text { th } \\
\text { Day }\end{array}$ & $\begin{array}{l}\text { 8th } \\
\text { Day }\end{array}$ \\
\hline (a) Air of schoolroom & & & & & & & & \\
\hline (b) Busy halls of scho & & & & & & & & \\
\hline (c) Quiet hall of scho & & & & & & & & \\
\hline (d) Busy city street & & & & & & & & \\
\hline (e) Etc. & & & & & & & & \\
\hline
\end{tabular}

Where are bacteria found in abundance? What are the factors in your environment by means of which bacteria may get to your body? Is it true that "bacteria are found anywhere but not everywhere"?

Where bacteria are most numerous. As the result of our studies, we may draw some inferences concerning the presence of bacteria in our own environment. They are evidently present in all air, and in greater quantity in air that is moving than in quiet air. Why? That they stick to particles of dust was proved by exposing a sterile culture dish in a schoolroom. Bacteria are present in great numbers where crowds of people live and move. The air from dusty streets of a populous city contains more bacteria than does the cleaner air of a village street. The air of a city park contains relatively few bacteria when compared with the 
air of a near-by street; the air of the woods or high mountains contains fewer still. Why?

Fluids the favorite home of bacteria. Tap water, standing water, milk, vinegar, wine, cider, all can be proved to contain bacteria by experiments similar to those already suggested. Spring or artesian well water would have very few, if any, bacteria, while the same quantity of river water, if it held any sewage, might contain untold millions of these little organisms.

Individual Project. Determine by experiment whether bacteria will grow without fluids being present. Try dry and moist beans.

Demonstration 3. To determine the foods most favorable for the growth of bacteria.

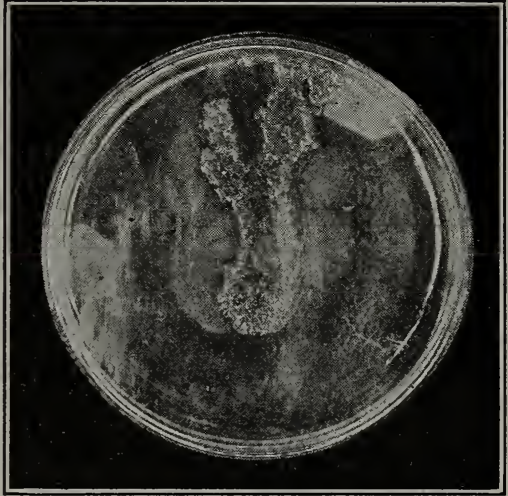

Growth of bacteria in an impure drop of water placed on a sterilized culture medium.

Materials. Raw meat, cooked meat, white of egg, beans, Indian meal flour, cake, sugar, butter, test tubes, and absorbent cotton.

Method. Moisten all of the above food substances. Place small particles of them in test tubes with a little distilled water. Expose all to the air for half an hour. (This can be done during a class period.) Plug the tubes with absorbent cotton and allow to stand for several days.

Note the appearance and odor of the various substances after five days.

In which substances was there rapid growth of bacteria?

Food of bacteria. Bacteria, since they contain no chlorophyll, are unable to make carbohydrate food, but must absorb their foods, ready formed, from decaying organic matter. Some bacteria, however, seem able to build up the protein, which they need for growth, out of absorbed carbohydrates and simple inorganic nitrogenous substances.

What bacteria do to foods. When bacteria feed, they digest the food substances by means of enzymes which they secrete. The food is decomposed and eventually rots. The material left behind after the bacteria have finished their meal is quite different from its original form. It is broken down by the action of the 
bacterial enzymes into gases, fluids, and some solids. It has an offensive odor, and contains poisons which come as a result of the work of the bacteria.

Demonstration 4. To show how light affects the growth of bacteria. Cover with black paper one of two Petri dishes in which bacteria are growing. Place the dishes in a light warm place for a few days. Compare the growth of bacteria in the exposed dish with the growth in the covered dish.

Bacteria and air. We have seen that plants need oxygen in order to perform the work that they do. This is equally true of all animals. But not all bacteria need air to live; in fact, some are killed by the presence of air. Bacteria which live without free oxygen are called anaerobic bacteria. They need oxygen, as do all other living things, but they obtain it by breaking down the foods on which they live, and utilizing the oxygen freed in this process. Those that grow or thrive in the presence of oxygen are called aerobic bacteria.

\section{Self-Testing Exercise}

Bacteria are found almost .......(1). Bacteria can be obtained for study by exposing a ........ (2) medium containing ........(3) to the ...... (4) for a few minutes. Under proper conditions of ........ (5) they grow rapidly. There are three common ........ (6) of bacteria: the ...... (7) form, called coccus, the ....... (8) bacillus, and a ...... (9) form, the spirillum. They prefer ....... (10) to all other food. Many forms are .......(11) by to light. Some forms obtain their .......(13) by breaking down the food substances on which they live.

\section{PROBLEM III. WHAT ARE SOME USEFUL THINGS THAT BACTERIA DO?}

Bacteria cause decay. Imagine a world cluttered up with dead plants, dead animals of all kinds, dead bodies of fish in the waters, insects in the grass, cattle in the fields. Did you ever think what this world would be like if nothing could decay? Bacteria are responsible for decay. These bacteria are most numerous in rich, damp soils containing large amounts of organic material. 
They are useful because they feed upon dead bodies of plants and animals which otherwise would soon cover the surface of the earth to the exclusion of everything else. Bacteria may be considered scavengers. They oxidize organic materials, changing them to compounds that can be absorbed by plants and used in building protoplasm. Without bacteria it would be impossible for life to exist on the earth, for green plants would be unable to get the raw food materials in forms that they could use in making food and living matter.

Relation of bacteria to fermentation. Bacteria continue the process of fermentation begun by the yeasts. In making vinegar the yeasts first make alcohol which the bacteria change to acetic acid. The lactic-acid bacteria, which sour milk by changing the milk sugar to an acid, are useful when they sour the milk for the cheese maker.

Other useful bacteria. Certain bacteria give flavor to cheese and butter, others give flavor to sauerkraut, while still other bacteria aid in the " curing" of tobacco, in the preparation of the dye indigo, in the "retting" or fermentation of certain fibers of plants for the market, as hemp, flax, and ramie, in the rotting of animal matter from the skeletons of sponges, and in the process of tạning hides to make leather.

Relation of bac-

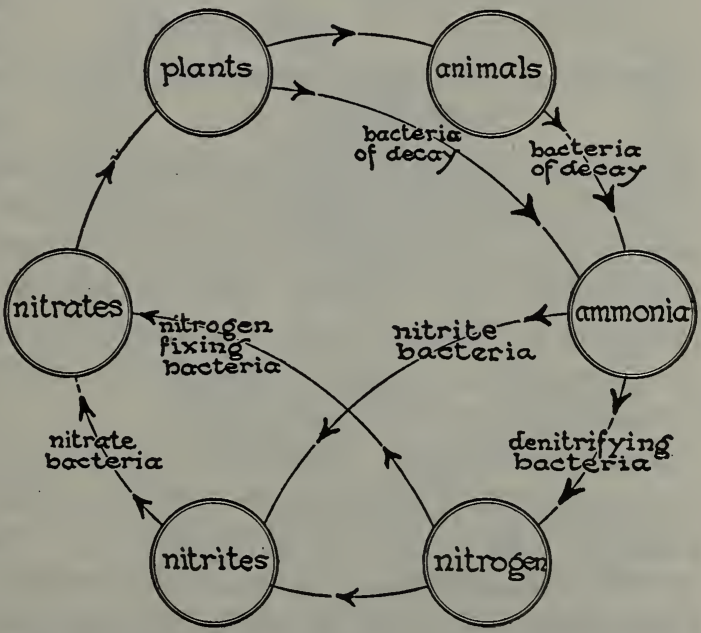

Explain from the text and diagram what is meant by the nitrogen cycle. What is the value of nitrogen-fixing bacteria?

teria to free nitrogen. It has been known since the time of the Romans that the growth of clover, peas, beans, and other legumes 
causes soil to become more favorable for the growth of other plants, but the reason for this has been discovered in late years. On the roots of the plants mentioned are found little nodules

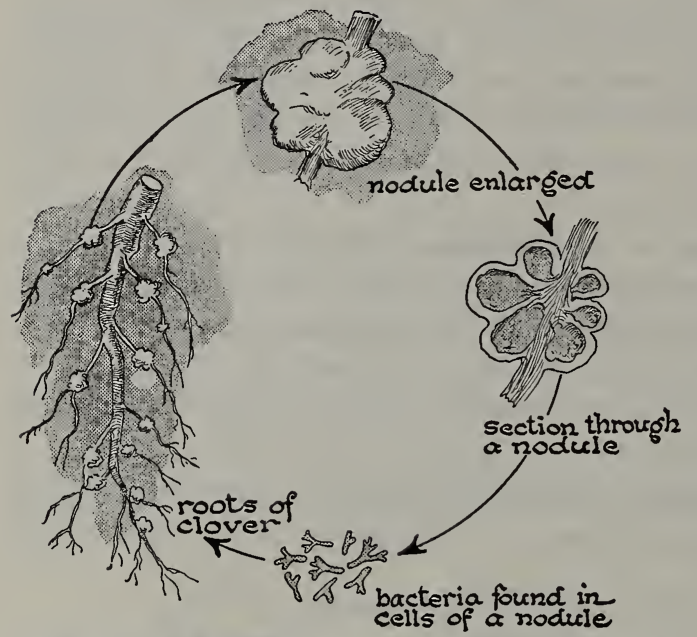

Explain by use of this diagram where the nitrogen-fixing bacteria live. or tubercles; in each nodule exist millions of bacteria, which take nitrogen from the air in the soil and build it into nitrites which are converted by other bacteria into nitrates. In this form it can be used by the plants. Only these bacteria, of all living plants, have the power to take free nitrogen from the air and make it over into a form that can be absorbed by the roots. They live in a symbiotic ${ }^{1}$ relationship with the plants on which they form tubercles, for the legumes provide them with organic food. All the compounds of nitrogen are used over and over again, first by plants, - then as food by animals, eventually returning to the soil again, or in part being released as free nitrogen; but any new supply of usable nitrogen must come by means of these nitrogen-fixing bacteria.

Rotation of crops. The facts mentioned above are made use of by progressive farmers who wish to produce as large crops as possible from a given area of ground. Plants that are hosts for the nitrogen-fixing bacteria are raised early in the season. Later these plants are plowed in and a second crop of a different kind is planted. The latter grows quickly and luxuriantly because of the nitrates left in the soil by the bacteria which lived with the

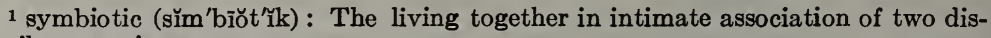
similar organisms. 
first crop. For this reason, clover is often grown on land in which it is proposed to plant corn later, the nitrates left in the soil giving nourishment to the young corn plants. In well-managed farms, different crops are planted in succession in a given field in different years so that one crop may replace some of the elements taken from the soil by the previous crop. This is known as rotation of crops. ${ }^{1}$

Five of the elements necessary to the life of the plant which may be taken out of the soil by constant use are calcium, nitrogen, phosphorus, potassium, and sulphur. Several methods are used by the farmer to prevent the exhaustion of these and other raw food materials from the soil. One method, known as fallowing, is to allow the soil to remain idle until bacteria and oxidation have renewed the chemical materials used by the plants. This is an expensive method if land is high priced. The more common method of enriching soil is by means of fertilizers and materials rich in plant food. Manure is most frequently used, but many artificial fertilizers, most of which contain nitrogen in the form of some nitrate, are used because they can be more easily transported and sold. Such are ground bone, guano (bird manure), nitrate of soda, and many others. Most

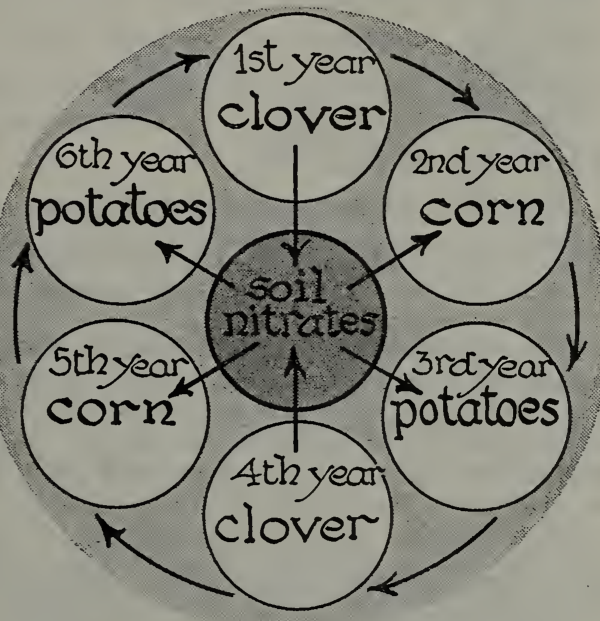

Is this a good plan for rotating crops? Why? fertilizers contain other important raw food materials for plants, especially potash and phosphoric acid. Both of these substances are made soluble by the action of the carbon dioxide in the soil, and in this form they can be taken into the roots.

${ }^{1}$ Crop rotation is not only a process to conserve the fertility of the soil, but also a sanitary measure to prevent infection of the soil. 
Practical Exercise 3. What are the direct values of bacteria to (1) market gardening; (2) fruit raising; (3) manufacturing?

\section{Self-Testing Exercise}

Bacteria which cause .......(1) are useful. More and better crops are made possible through the ........ (2) ....... (3) bacteria. Bacteria are used in the processes of .......(4) fibers of plants, .......(5) of hides, ........(6) tobacco, and giving to some animal products.

\section{PROBLEM IV. WHAT ARE YEASTS AND WHAT DO THEY DO?}

Fermentation. It is of common knowledge that the juice of fresh apples, grapes, and some other fruits, if allowed to stand exposed to the air for a short time, will ferment. That is, the sweet juice will begin to taste sour and to have a peculiar odor, which we recognize as that of alcohol. The fermenting juice appears to be full of bubbles which rise to the surface. If we collect enough of the gas in these bubbles to make a test, we find it is carbon dioxide.

Evidently something changed some part of the apple or grape, namely, the sugar $\left(\mathrm{C}_{6} \mathrm{H}_{12} \mathrm{O}_{6}\right)$, into alcohol $\left(\mathrm{C}_{2} \mathrm{H}_{5} \mathrm{OH}\right)$ and carbon dioxide $\left(\mathrm{CO}_{2}\right)$. This chemical process is known as fermentation.

Home Experiment. To determine the conditions favorable for the growth of yeast. Label three pint fruit jars A, B, and C. Add one fourth of a compressed yeast cake to two cups of water containing two tablespoonfuls of molasses or sugar. Stir the mixture well and divide it into three equal parts and pour into the jars. Place covers on the jars. Put jar A in the ice box on the ice and jar B over the kitchen stove or near a radiator. Heat jar $\mathrm{C}$ by immersing in a pan of boiling water, and then place it next to B. After forty-eight hours, see if bubbles have made their appearance in any of the jars.

Which jars, if any, show bubbles on the surface? Describe the conditions which favor the growth of yeast. Explain how you know that yeast has grown.

Yeast. If a small piece of compressed yeast cake is shaken up with some molasses and water and the mixture allowed to stand overnight in a warm place, fermentation will take place. Examination of a drop of the settlings from the mixture shows that the common compressed yeast cake contains millions of tiny yeast 
plants. In its simplest form a yeast plant is a single cell, ovoid in shape and usually containing one or more vacuoles. The cells reproduce by a process called budding. Under certain conditions spores are found.

An enzyme causes fermentation. It has been proved that if yeast cells are ground up until they are destroyed, the juice filtered from them is able to cause fermentation. Similar experiments have been made with bacteria, showing that enzymes formed within the cells cause fermentation. These enzymes are called zymases.

Commercial yeast. Cultivated yeast is now supplied in compressed or dried yeast cakes. In both cases the yeast plants are mixed with starch and other sub-

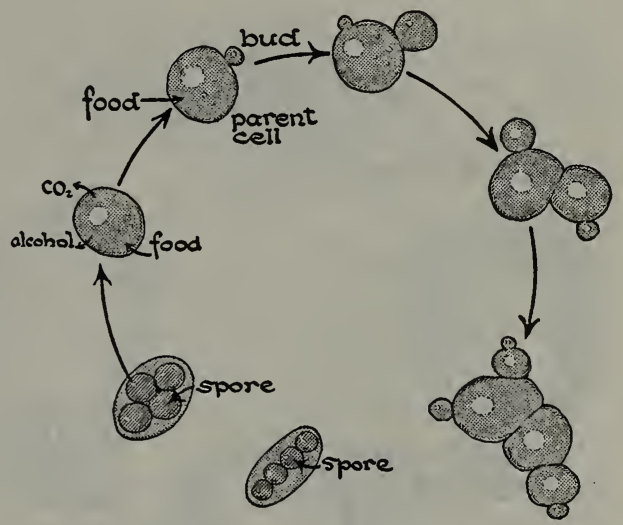

Life history of yeast. Follow the arrows and work out what happens after the germination of the spores. How many spores are produced in the sac or ascus shown at the bottom of the diagram?

stances and pressed into a cake. The compressed yeast cake must be used fresh, as the yeast plants begin to die rapidly after two or three days. The dried yeast cake contains a much smaller number of yeast plants, but is probably more reliable if the yeast cannot be obtained fresh.

Home Experiment. To determine the conditions favorable for the growth of yeast in bread. Make a small amount of dough by mixing flour, sugar, salt, and water in proportions to make a thick paste. Knead with a little yeast which has previously been mixed with water. Now place one lot of dough in the ice box, one at the temperature of the room, and one in a warm place (over $95^{\circ}$ F.). Later bake 'each lot and use in the laboratory.

Which of the three lots has risen the most? Which, after baking, has the best appearance? The best taste? What makes the holes in the bread?

What caused the dough to rise? What are the best conditions for this to take place? Will the mixture rise if no yeast is added? Why? 
Bread making. Most of us are familiar with the process of bread making. The materials used are flour, milk or water, or both, salt, a little sugar to hasten the process of fermentation, or " rising," as it is called, some butter or lard, and yeast.

After the materials are mixed thoroughly the bread is put aside in a warm place (between $70^{\circ}-75^{\circ}$ Fahrenheit) to " rise." If we

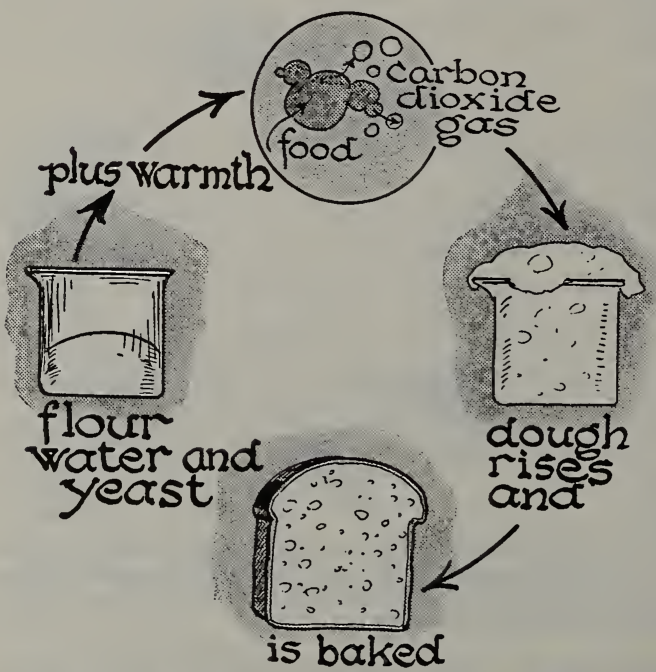

Explain the process by which bread becomes light? examine the dough after a few hours, we find many holes in it, which give the mass a spongy appearance. The yeast plants, owing to favorable conditions, have grown rapidly and made bubbles of carbon dioxide. Alcohol is present, too, but this is evaporated when the dough is baked. The baking cooks the starch of the bread, drives off the carbon dioxide and alcohol, and kills the yeast plants, besides forming a protective crust on the loaf.

Sour bread. In the "rising" of bread, bacteria always do part of the work of fermentation. Certain of these plants form acids after fermentation takes place. The sour taste of the bread is usually due to this cause, and may be prevented by baking the bread before the acids form, by having fresh yeast, good fresh four, and clean vessels with which to work.

Importance of yeasts. Since yeast cells do not contain chlorophyll they cannot make their own food but must get it already made. Their food consists mostly of fruit juices and other sugar solutions. If a fruit syrup is left exposed to the air wild yeast plants will settle on it, and multiply rapidly, causing fermentation. 
They may get into canned substances put up in sugar and cause them to "work," giving them a peculiar flavor. But they can be easily killed by heating to the temperature of boiling. On the other hand, yeast gives us leavened bread.

Many interesting experiments with yeast may be tried as home projects. For excellent suggestions, see Conn's Bacteria, Yeasts, and Molds in the Home, pp. 274-278.

Practical Exercise 4. How may yeasts be useful to man? Where are yeasts found? Give proofs. What products are formed when bread rises? What Decomes of these products? It is said that yeast plants are at once the friends of man and yet make him their slave. Explain what this means.

\section{Self-Testing Exercise}

Yeasts cause ....... (1) by changing ....... (2) into ....... (3) (4) and ........(5). An enzyme called ....... (6) causes fermentation. .......(7) also cause bread to rise, because of the hubbles of ....... (8) ....... (9) formed during their ....... (10) growth when the $\ldots \ldots \ldots$ (11) is put in a .......(12) place.

\section{PROBLEM V. TO LEARN ABOUT SOME DESTRUCTIVE FUNGI}

Most of us are familiar with some fungi, as the edible mushrooms and the so-called "toadstools" found in parks or lawns. We

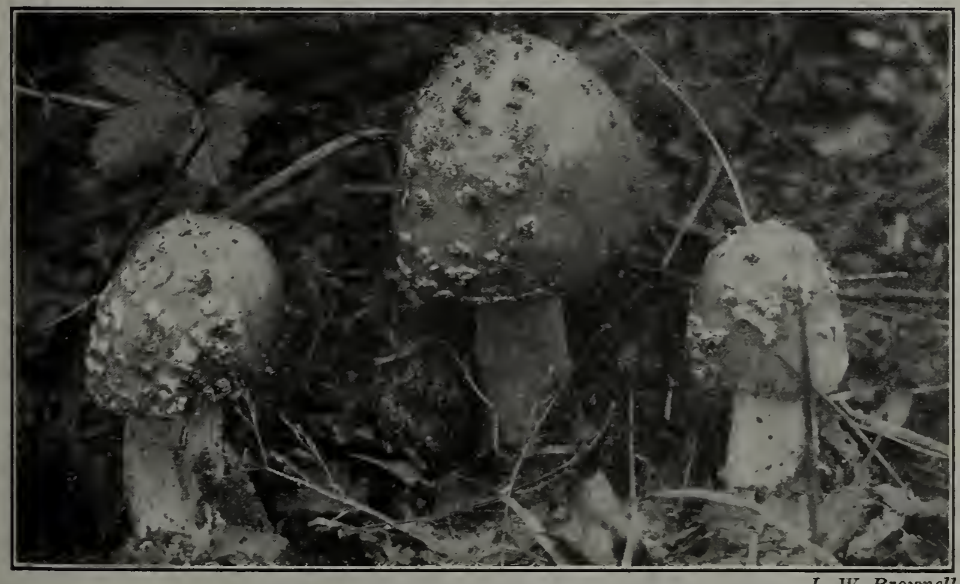

These poisonous toadstools (amanita muscaria) are found during the summer and early autumn along roadsides near trees, in groves, and in woods. 


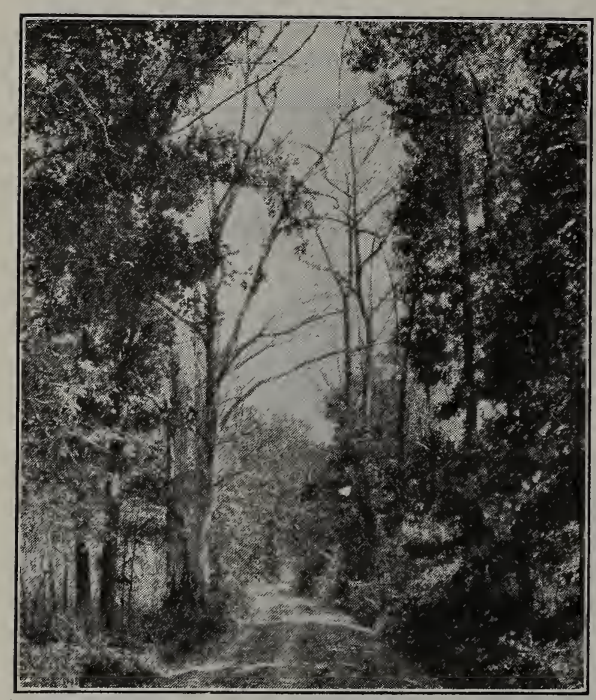

Chestnut blight. The dead trees along this road have been attacked by the parasite.

have already seen something of their characteristics. They are as much dependent upon the green plants for food as are animals. But some of the fungi require dead organic matter for their food. This may be obtained from decayed vegetable or animal material in soil, from the bodies of dead plants and animals, or even from foods prepared for man. Fungi which feed upon non-living organic material are known as saprophytes. Examples are the mushrooms, yeasts, and molds.

Some parasitic fungi. Some fungi prefer living plants or animals for their food and are therefore classed as parasites. An example is the chestnut blight or canker, which has killed chestnut trees by the thousands in the eastern part of the United States. It produces millions of tiny spores, which, blown about by the wind, light on the trees, sprout, and send under the bark thread-like mycelia which absorb the food circulating in the living cells, eventually causing the death of the tree. The chestnut canker, introduced from abroad on chestnuts planted near the city of New York in 1904, within ten years had destroyed practically every chestnut tree in the eastern part of the United States.

Another fungus which does much harm to trees is the shelf or bracket fungus. The shelflike body is in reality the reproductive part of the plant; in its lower surface are formed millions of asexual spores, which, when they fall on a dead or a dying tree trunk, may start a new fungus growth. The true body of the plant, a network of threads, is found under the bark. Once established, it spreads rapidly. There is no remedy except to 
kill the tree and burn it, so as to destroy the spores. Each year many fine trees, sound except for a slight bruise or other injury, are infected and eventually killed by this fungus.

Field Exercise. On a field trip we may see a number of trees which are infected with fungi. Count the number of perfect trees in a given area. Compare it with the number of trees attacked by fungus. Does the fungus appear to be transmitted from one tree to another near

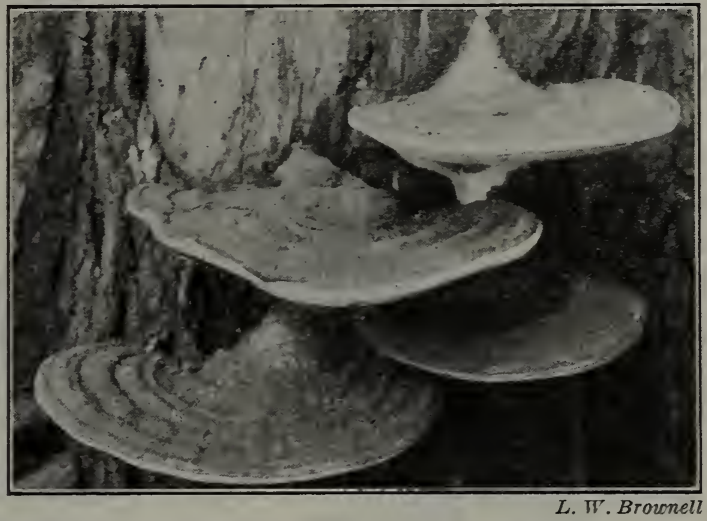

Shelf fungi (Fomes applanatus) as often seen growing on the trunks of trees. They cause enormous losses by causing the timber to decay. at hand? In how many instances can you discover the point where the fungus first attacked the tree? How do the spores leave the spore case? How do they germinate on the tree which they attacked?

Black stem grain rust. Wheat rust is probably the most destructive parasitic fungus. For hundreds of years this rust has been the most dreaded of plant diseases, because it destroys the one harvest upon which the civilized world is most dependent. For a long time past the appearance of rust has been associated with the presence of barberry bushes in the neighborhood of the wheat fields. Although laws were enacted in 1760 in New England to provide for the destruction of barberry bushes near infected wheat fields, nothing was actually known of the relation existing between the rust and the barberry until comparatively recent years. It has now been proved beyond doubt that the wheat rust passes part of its life as a parasite on the common barberry and from there gets to the wheat plant, where it undergoes a complicated life history. The wheat leaf, its nourishment and living matter used as food by the parasite, soon dies, and no grain is produced. 
It is estimated that in the grain-raising states of the Middle West $668,338,000$ bushels of grain have been destroyed by black stem rust in the 13 years from 1915 to 1927 inclusive. This has meant a yearly average loss of almost $\$ 55,000,000$. The only way to prevent this pest is to break the chain of the life cycle by destroying the barberry bushes on which the spores grow in the spring of the year.

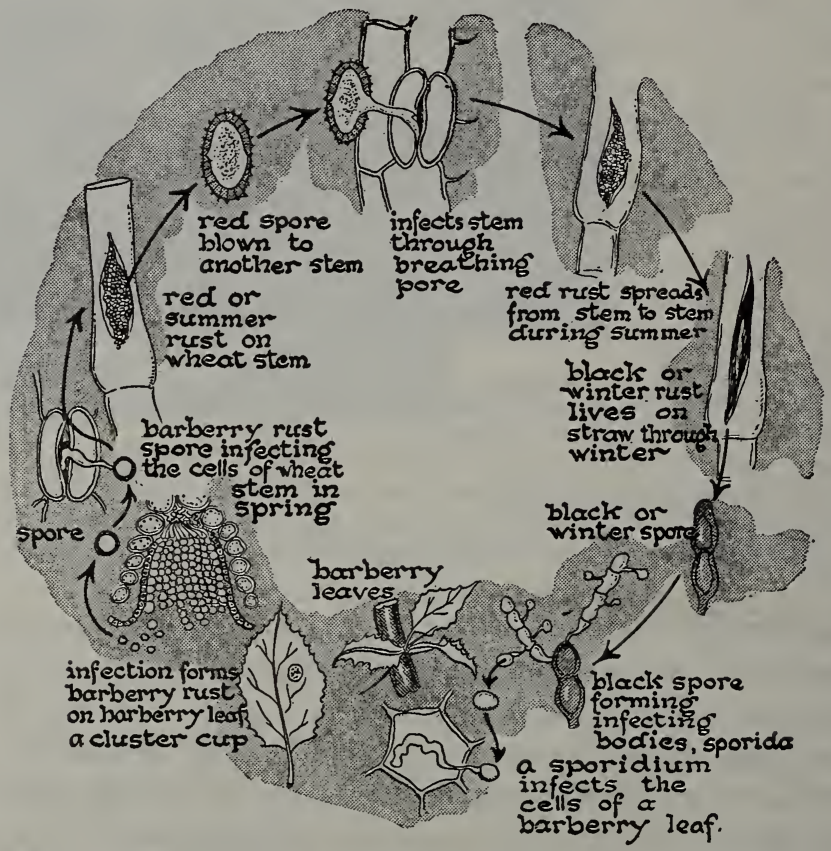

The life history of wheat rust. How would you go to work to exterminate this pest? Explain.

Blister rust. The pine tree blister rust is a recent importation from Europe that threatens our white pine forests. This rust passes one stage on the currant and gooseberry, so that the only way to control it is to remove all currant and gooseberry bushes from the neighborhood of such trees.

Mildews. Another group of fungi that are of considerable economic importance is made up of the sac fungi. Such fungi are commonly called mildews. Some of the most easily obtained 
specimens come from the lilac, rose, or willow. These fungi do not penetrate the host plant to any depth, but cover the leaves of the host with the whitish threads of the mycelium. Hence they may be killed by means of applications of some fungus-killing fluid, as Bordeaux mixture. They obtain their food from the outer layer of cells in the leaf of the host. Among the useful plants preyed upon by this group of fungi are the plum, cherry, and peach trees. The diseases known as black knot and peach curl are caused by these fungi.

Potato wart is another fungus disease which was introduced into this country in 1911 and has now spread over the eastern part of the United States. It attacks the potato tuber, so that the disease may not be noticed until time to harvest the crop. Since its spores may be dormant in soil for several years, the only way to combat the pest is to rotate other crops on the field as well as to destroy all infected tubers.

\section{GRAIN DESTROYED BY STEM RUST IN THIRTEEN YEARS}

1915 to 1927 , Inclusive

\begin{tabular}{|c|c|c|c|c|c|c|c|c|}
\hline State & & & $\begin{array}{l}\text { Whitat } \\
\text { (Bushels) }\end{array}$ & $\begin{array}{c}\text { OATs } \\
\text { (Bushels) }\end{array}$ & $\begin{array}{c}\text { BARLEY } \\
\text { AND } \\
\text { RYE } \\
\text { (Bushels) }\end{array}$ & $\begin{array}{c}\text { Total } \\
\text { ALL } \\
\text { GRAIN } \\
\text { (Bushels) }\end{array}$ & $\begin{array}{c}\text { AVERAGE } \\
\text { ANNUAL } \\
\text { STEM RUST } \\
\text { LOSSES } \\
\text { ALL } \\
\text { GRAINS } \\
\text { (Dollars) }\end{array}$ & $\begin{array}{c}\text { Total } \\
\text { LOSS } 1927 \\
\text { ALL } \\
\text { GRAINs } \\
\text { (Dollars) }\end{array}$ \\
\hline Colorado . & & & $2,469,000$ & 176,000 & 541,000 & $3,186,000$ & 218,000 & Trace \\
\hline Illinois. & & & $4,992,000$ & $50,156,000$ & 353,000 & $55,501,000$ & $2,275,000$ & $\$ 8,707,000$ \\
\hline Indiana & & . & $2,974,000$ & $1,479,000$ & Trace & $4,453,000$ & 481,000 & Trace \\
\hline Iowa. & & . & $4,246,000$ & $33,761,000$ & $2,143,000$ & $40,150,000$ & $1,580,000$ & 729,000 \\
\hline Michigan & & . & $6,487,000$ & $15,831,000$ & 453,000 & $22,771,000$ & $1,409,000$ & 765,000 \\
\hline Minnesota & & . & $86,002,000$ & $50,345,000$ & $3,498,000$ & $139,845,000$ & $11,742,000$ & $18,592,000$ \\
\hline Montana. & & . & $14,863,000$ & 221,000 & Trace & $15,084,000$ & $1,154,000$ & Trace \\
\hline Nebraska & & . & $18,505,000$ & $3,922,000$ & 276,000 & $22,703,000$ & $2,437,000$ & Trace \\
\hline No. Dakota & & & $202,316,000$ & $14,788,000$ & $4,606,000$ & $221,800,000$ & $22,191,000$ & $19,075,000$ \\
\hline Ohio . . & & . & $4,806,000$ & $2,694,000$ & 80,000 & $7,580,000$ & 562,000 & 247,000 \\
\hline So. Dakota . & . & . & $76,209,000$ & $37,574,000$ & $4,170,000$ & $117,953,000$ & $9,385,000$ & $9,297,000$ \\
\hline Wisconsin & & & $4,456,000$ & $10,349,000$ & $2,417,000$ & $17,312,000$ & $1,109,000$ & 375,000 \\
\hline Total . . & . & • & $428,325,000$ & $221,386,000$ & $18,627,000$ & $668,338,000$ & $54,543,000$ & $57,787,000$ \\
\hline
\end{tabular}

These are official estimates of the Plant Disease Survey, Bureau of Plant Industry, United States Department of Agriculture. The money value of the grain destroyed in the thirteenyear period was $\$ 709,081,000$, basing calculations on the farm prices for December 1 of each year and disregarding any effect the reduced production, caused by rust, may have had on the market price. Losses for 1927 are preliminary. 


\section{Self-Testing Exercise}

The ....... (1) are plants which are either parasites or saprophytes, the latter living on ........ (2) ...... (3) matter and the former on ....... (4) plants and animals. The ....... (5) fungi do enormous damage to ........ (6) every year. The black stem wheat rust, which lives on two ......(7), .....(8) and ......(9), does a yearly damage of almost $\$ 55,000,000$. The pine tree ...... (10) ..... (11) is another recent importation from ....... (12). It lives on two hosts: the ......(13) or ......(14), and the ...... (15). To curb the damage from such parasites one of the $\ldots . .$. (16) plants must be destroyed.

\section{PROBLEM VI. WHAT ARE MOLDS? WHAT DO THEY DO?}

Demonstration 5. To determine the conditions favorable for the growth of mold. Place pieces of bread in each of four wide-mouthed bottles or jars. Add a little water, and expose all four bottles to the air of the living room or kitchen for half an hour. Then cover the bottles and plunge one into boiling water for a few moments. Place this and a second jar side by side in a moderately warm room. Place the third jar in the ice box and the fourth in a hot dry place.

Notice day by day any changes that occur in the contents of the jars. In which jar does growth appear first? Do all jars have a like growth of mold at the end of a given period of time?

How does the mold get on the bread? Where does it come from? Why did you add water to the jars? What conditions must you have for the growth of mold? Conversely, how would you keep molds from getting a foothold on foods?

Physiology of the growth of mold. Molds, in order to grow rapidly, need food, darkness, oxygen, moisture, and moderate heat. They obtain their food from the materials on which they live. This they are able to do because they have rhizoids ${ }^{1}$ which give out digestive enzymes which change the starch of the bread to sugar and the protein to a soluble form which can be absorbed by the cells. These absorbed foods are then used to supply energy and make protoplasm. Thus molds act like animals, except that digestion takes place outside of the body.

What can molds live on? Molds feed upon all cakes and breads, upon meat, cheese, and many raw vegetables. They are almost sure to grow upon flour if it is allowed to get damp. Jelly and other foods containing moisture are particularly favorable to the

${ }^{1}$ Rhizoids (ri'zoids) : rootlike filaments or threads. 
growth of molds. Leather, cloth, paper, or even moist wood will give food enough to support their growth. At least one troublesome disease, ringworm, is due to the growth of molds in the skin.

What mold does to foods. Mold usually changes the taste of the material it grows upon, rendering it "musty" and sometimes unfit to eat. Eventually food will be spoiled completely because bacterial decay sets in. Some molds are useful. They give the flavor to Gorgonzola, Roquefort, Camembert, and Brie cheeses. But, on the whole, molds are pests which the housekeeper wishes to get rid of.

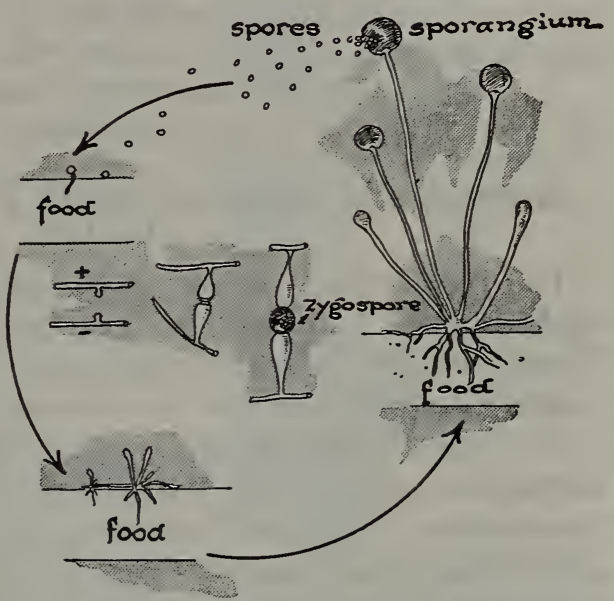

Life history of bread mold. There may be a sexual stage in the life history (shown in center of diagram) in which the formation of a zygospore results. What value might this be to the mold?

How to prevent molds. As we have seen, moisture is favorable for the growth of mold; conversely, dryness is unfavorable. Inasmuch as the spores of mold abound in the air, materials which cannot be kept dry should be covered. Jelly, after it is made, should at once be tightly covered with a thin layer of paraffin or waxed paper, which excludes the air and possible mold spores. To prevent molds from attacking fresh fruit, the surface of the fruit should be kept dry and, if possible, each piece of fruit should be wrapped in paper. Why? Mold spores may be killed in a few minutes with dry heat at $212^{\circ} \mathrm{F}$. Dry dusting or sweeping will raise dust, which usually contains spores of mold and bacteria. Use a dampened broom or dust cloth frequently in the kitchen, if you wish to preserve foods from molds.

Practical Exercise 5. Where may mold spores be found? What must they have in order to grow? On what part of foods do molds grow? How would you prevent mold spores from getting into food? 


\section{Self-Testing Exercise}

Molds grow under favorable conditions of ....... (1), ...... (2), ....... (3), and ....... (4) heat. They spoil many .......(5) and cause ....... (6). Some molds give ....... (7) to cheese. Molds may be kept out of food by keeping the food .......(8) and well ....... (9). Molds send out rootlike threads, .......(10), which give off $\ldots \ldots \ldots$ (11) $\ldots \ldots$. (12) and absorb ....... (13).

\section{PROBLEM VII. WHAT ARE SOME EXAMPLES OF COMMON ALGAE?}

The Fungi which include all the plants which we have so far studied in this unit constitute one large division of thallophytes. We now come to the other main group, the algae. In the classification given below we find three classes of algae.

The Algae. The algae are nearly all water plants, although some few species may be found on tree trunks and rocks which are exposed to moisture. They are a large group of chlorophyll-bearing plants, although in some forms the characteristic green color of chlorophyll is masked by some other coloring matter, usually red and brown. They have many forms, ranging from single cells to filamentous colonies or even long ribbon or rope-like masses many feet in length, as in some seaweeds. Our attention is called to them in an un-

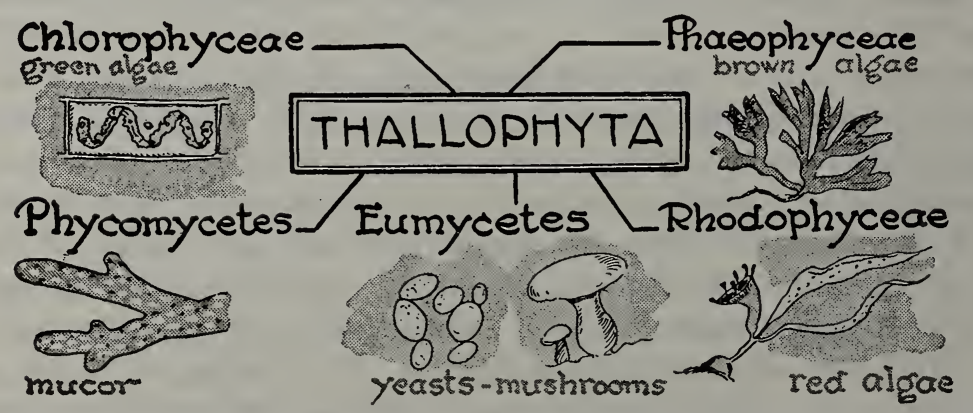

I. The Green algae are of countless forms, unicellular, filamentous, plate-like, and in irregular masses of cells. There are both fresh-water and salt-water forms, and others live on land. The so-called "Red-Snow" is a form living in snow patches. Pleurococcus and vaucheria are also examples. Some 5000 species have been described.

II. The Brown algae are nearly all marine plants. We know them as seaweeds. About 1000 species are known.

III. The Red algae, mostly marine, are our most delicate and beautiful seaweeds. There are about 3000 named species.

IV. The Fungi are without chlorophyll. There are about 75,000 species in all. Many of them are harmful. There are two classes: Phycomycetes, the molds: and Eumycetes, yeasts, mushrooms, and puffballs. Bacteria are usually classed as Fungi. 
pleasant way at times, when, after multiplying very rapidly during the hot summer, they die suddenly in the early fall and leave their remains in our water supply. Much of the unpleasant taste and odor of drinking water comes from this cause.

Some examples of algae. One of the simplest algae is Pleurococcus (plō-rō-kŏk'üs). This little plant consists of a single tiny cell, which by division may give rise to two or more cells which cling together in a mass. The green color on tree trunks, stone houses, etc., is often due to millions of these little plants.

Spirogyra, a pond scum, is known to every boy or girl who has observed a small pond or sluggish stream. It grows as a slimy mass of green threads or filaments. Under the low power

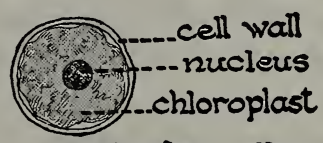

a single cell
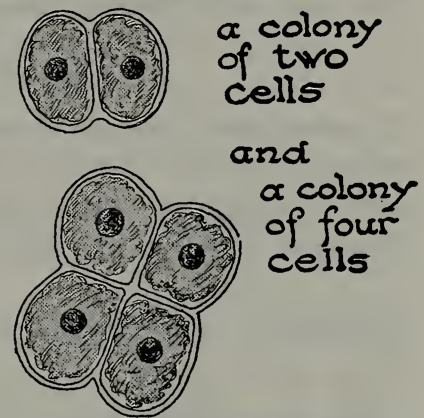

Pleurococcus. Explain how a colony of Pleurococcus might come into ezistence.

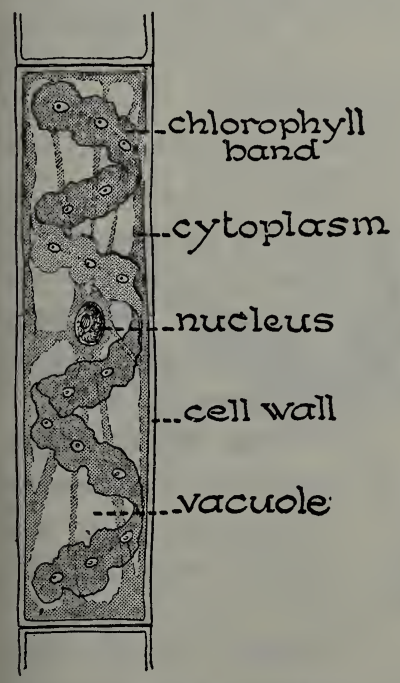

A single cell of Spirogyra. Is the cell flat or round in cross section?

of the microscope, the body is seen to be a filament made up of elongated cylindrical cells, each of which contains a spirally wound band of chlorophyll. Spirogyra may reproduce asexually by division of the cells. It may also reproduce sexually. When this happens, the cells of two adjoining filaments push out portions of their cell walls which meet, forming a bridge. The cell walls in the middle of the bridge dissolve. The protoplasm of the cells thus joined condenses into two tiny spheres, and ultimately the contents of one cell passes through the connecting tube and mingles with the cell of the neighboring filament. This process by which two cells of 
nearly equal size fuse to form a single cell is called conjugation The result of this process of fusion is a thick-walled resting cell which is called a zygospore ( $\mathrm{zi}^{\prime} \mathrm{g}$ ō-spōr). This cell thus formed can withstand considerable extremes of heat, cold, and dryness. After the zygospore is formed, the cell walls break and the zygospore falls to the bottom of the pond. Under favorable conditions, it will germinate and form a new filament.

\section{Self-Testing Exercise}

The simplest green plants are the ..... (1). The ....... (2) of two cells of nearly equal size to form one cell $\mathrm{is}$ called ........ (3). This method of reproduction is characteristic of ....... (4). A ....... (5) is a thick-walled resting cell.

\section{PROBLEM VIII. WHAT IS THE LIFE HISTORY OF A MOSS FLANT?}

The Bryophyta consist of two groups of plants, the liverworts and the mosses. Both are small plants and nearly all forms live

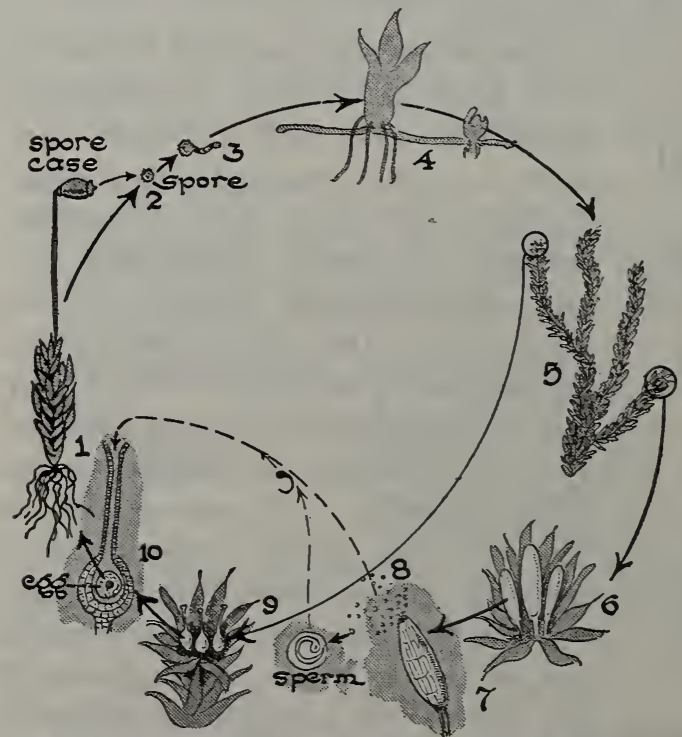

The life history of a moss. Refer to the numbers in your text and work out the stages in the life history. on land. They show a much greater development of tissues than the algae and may be either ihalluslike (liverworts) or have stems with rootlike projections (rhizoids) and very simple leaves, as the mosses.

The Moss Plant. One of the mosses frequently seen and easily recognized is the "pigeon-wheat" moss. A leafy moss plant has rhizoids, an upright stem, and 
green leaves. In the plants which have a stalk and capsule, (1) the stalk grows out of the leafy plant.

Sporophyte. The capsule is the sporangium (2). The stalk and capsule together form the sporophyte (spō'ro-fit) or sporeproducing generation of the moss.

Gametophyte. The spore (3) germinates into a threadlike protonema. The protonema soon develops rhizoids (4), and tiny buds appear which form the adult plants. These may grow only leaves, or they may develop into plants (5) that bear the rosettes of leaves which hold either sperm or egg cells, for these are produced on separate plants. These two kinds of plants form the sexual generation (called the gametophyte) of the moss $(6,7,8$, 9 ). After a sperm has been transferred to the egg cell, fertilization or fusion of these two cells takes place (10). This process results in the growth of the sporophyte which bears the asexual spores. These spores produce a leafy moss plant which bears organs producing eggs and sperms. This life history is known as alternation of generations.

Practical Exercise 6. Why do we call the life history of moss alternation of generations?

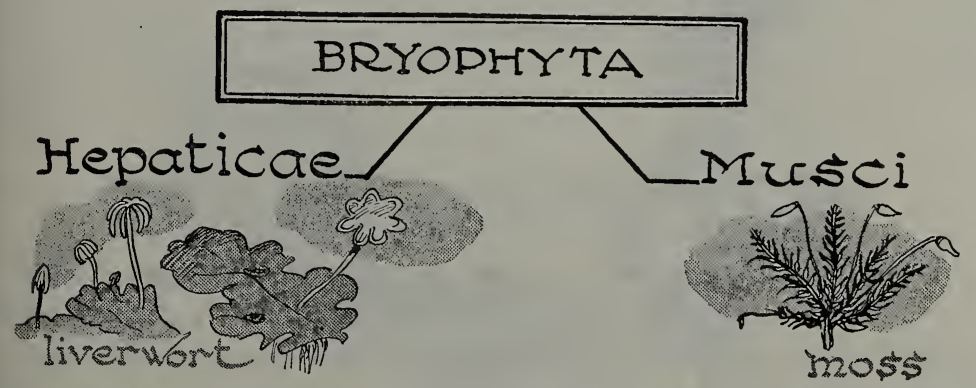

These plants are small and live mostly on land. There are about 16,000 known species.

\section{Self-Testing Exercise}

Bryophytes include ......(1) and .......(2). The mosses show ........(3) of generations in which an .......(4) stage is followed by a $\ldots \ldots$. (5) stage. A spore gives rise to a ....... (6) 
which produces ......(7) and .......(\$). After fertilization an .......(9) grows into a leafy moss plant which produces ........(10) spores.

\section{PROBLEM IX. WHAT IS THE LIFE HISTORY OF A FERN PLANT?}

The pteridophytes are a group which, when the world was younger, played a very important part in the vegetation on the earth. Some coal is made very largely from their bodies. They have true roots, stems, and leaves, but reproduce like the mosses, by forming spores.

Life history of a fern. The common fern begins life as a spore. This germinates into a tiny heart-shaped body called a pro-

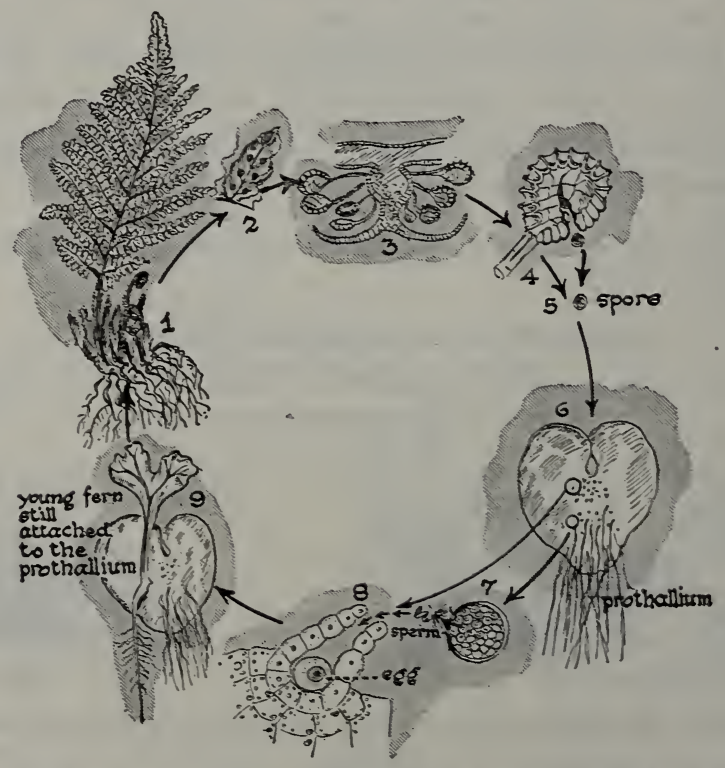

The life history of a fern. (I) Adult plant, (2) a leaflet showing sori or groups of spore cases, (3) a section through a sorus, (4) a spore case opening, (5) a spore which germinates into (6) a prothallium which in turn produces organs containing (7) sperms and (8) eggs. When an egg is fertilized it gives rise to (9) a new fern plant.

thallium which contains sex organs holding sperm and egg cells. This is called the gametophyte generation of the plant because 
it holds the male and female gametes or sex cells. These cells after fertilization produce leafy structures (fronds) which bear the asexual spores. These spores when ripe germinate and the life cycle begins over again, a sexual generation alternating with an asexual generation.

Practical Exercise 7. Compare, by means of labeled diagrams, the life histories of the moss and fern.

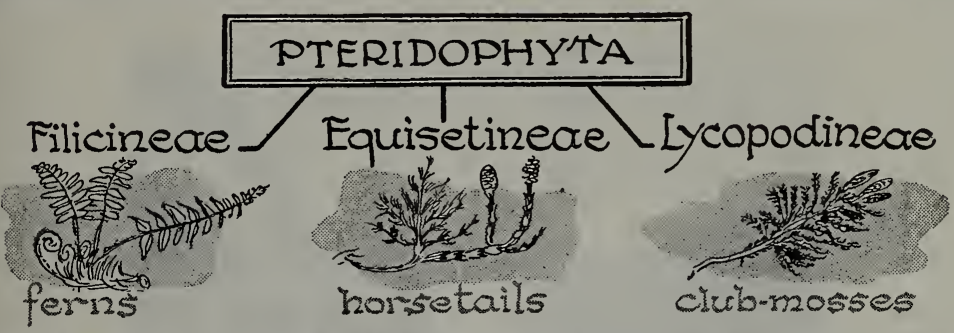

These pteridophytes include three classes : the true ferns, the horsetails, and the club mosses. There are about 8000 known species.

\section{Self-Testing Exercise}

The ....... (1) or ferns have ...... (2) of generations in their life history. In the gametophyte generation, a small ....... (3) structure, called a .......(4), holds the ......(5) and the ......(6) cells. The fertilized egg produces leafy structures which bear .......(7) spores. The pteridophytes include the $\ldots \ldots \ldots$ (8), the $\ldots \ldots \ldots$ (9), and the $\ldots \ldots \ldots(10)$.

\section{PROBLEM X. WHAT ARE SOME EXAMPLES OF SPERMATOPHYTES?}

The spermatophytes (Gr. sperma, seed), or seed-bearing plants, include two groups:

The gymnosperms (Gr. gymnos, naked), or naked-seed plants, are a small group related to the ferns on one side and the flowering plants on the other. Two classes are found: the cycads, of which group the so-called tree ferns are examples, and the conifers or evergreens, as pines, spruces, firs, hemlocks, cypress, and others. There are only about 450 species of gymnosperms. The cycads are practically confined to the tropical regions. They have leaves much like the ferns and their stems are covered with scales. In 
their life history as well as their appearance they show relationship to the ferns. They bear two kinds of reproductive bodies in conelike structures on separate plants.

The conifers are the trees we call evergreens and most of them have needle-like leaves. The evergreens include the sequoias, the largest and oldest trees. The eggs and sperms are borne in pistillate or staminate cones. Seeds are produced in the scales of the

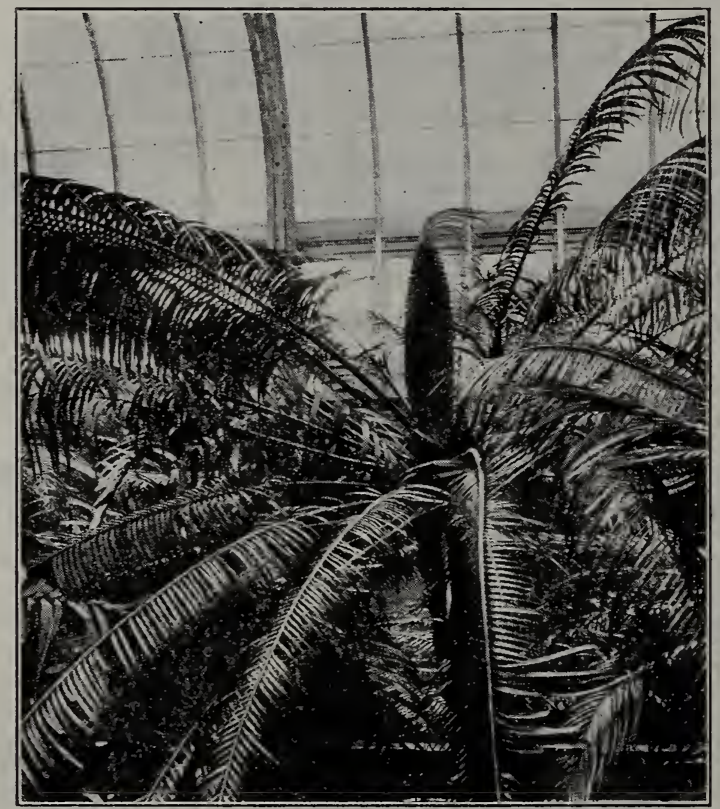

Brooklyn Botanic Gardens, Brooklyn, N.Y.

What are the characteristics of a cycad?

pistillate cones, and when the cone dies, the seeds are released by the curling backwards of the dry scales or sporophylls.

The angiosperms (Gr. angeion, case or vessel), or true flowering plants, of which we already know something, are a very large group, including all of our common grasses and grains, and all trees, shrubs, and plants that bear flowers. There are more than 240,000 known species. They are grouped in two great classes, the monocotyledons and the dicotyledons. 
If we summarize the facts we already know about flowering plants, they are briefly these: Seeds, which are formed in the fruits as the result of pollination and later fertilization, give rise under favorable conditions to young seedlings. The conditions which waken the embryo within the seed to activity and growth are favorable conditions of moisture, temperature, air, and food materials. We have learned that under favorable conditions the young plant grows into an adult and in course of time produces flowers. The flower is really a modified branch which contains the male and female gametophytes of the flowering plant. The female gametophyte is contained within the ovary of the flower and is called the ovule. The male gametophytes are the pollen grains which contain the sperm cells.

Botanists have shown that in the flowering plants or spermatophytes there exists an alternation of generations, as in the mosses and ferns. The pollen grain is believed to be a spore, which develops into the male gametophyte (the pollen tube), while the embryo sac in the ovary of the flower is another spore, within which is found the female gametophyte. Most of the life of the flowering plant is passed evidently in the asexual or sporophyte stage.

\section{SPERMATOPHYTA}

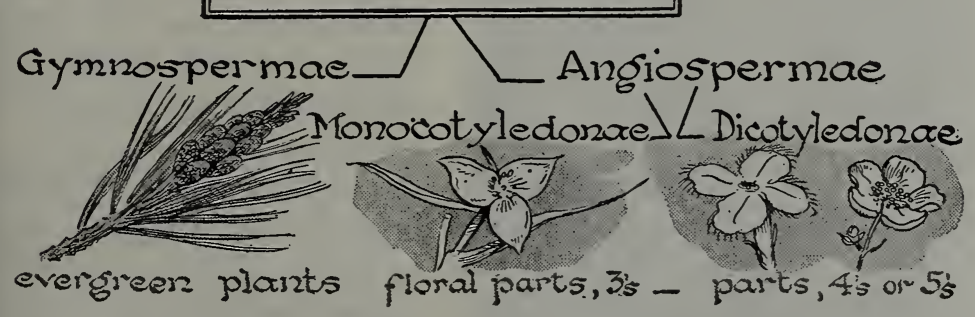

The flowering plants are further divided into monocotyledons and dicotyledons. A brief description of a few of the most important families of these plants is given. These particular ones were selected because they are likely to be seen by the average boy or girl who takes field excursions or hikes. The total number of known species of plants of these groups is more than 240,000 . 


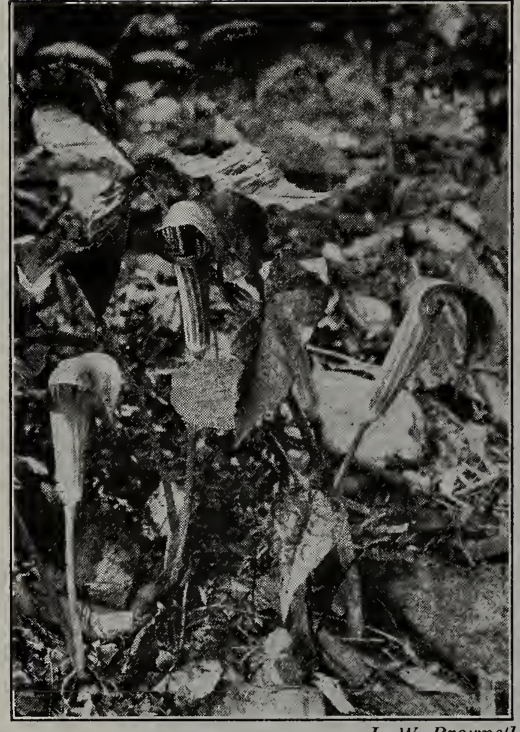

Jack-in-the-Pulpit (arum family).

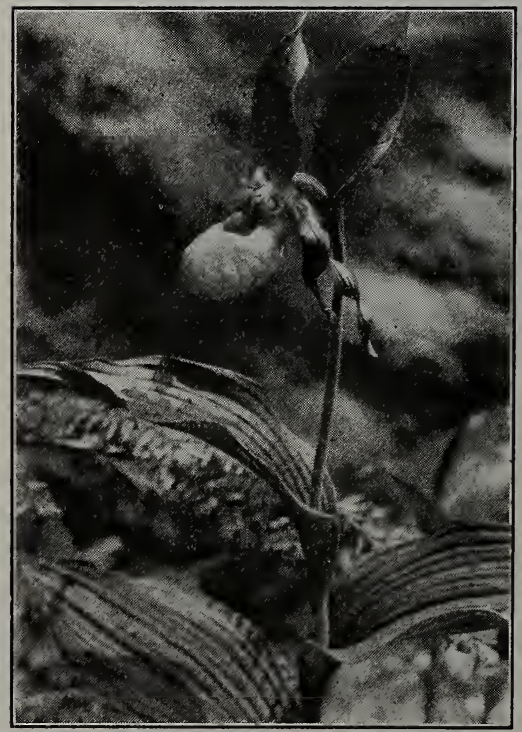

Yellow Lady's Slipper (orchid ramily).
Monocotyledons. The Grass Family. We are all familiar with the narrow parallel-veined leaf of the grasses. The stems are usually round and the flowers are borne in structures called spikelets. The flowers have three stamens and a single pistil, which produces one seed. The one-seeded fruit is called a grain. Examples of grasses are wheat, rye, timothy, wild grasses, sugar cane, and bamboo. The sedges, near relatives of the grasses, have unjointed, triangular stems, while grass stems are always jointed.

The Palm Family. The palm is known from other monocotyledons because it usually has a woody stem. There are about 1200 species of palms in the world. Though mostly inhabitants of the tropics, there are a few species found in the southern part of this country.

The Lily Family. The members of this family are known to most of us. Hyacinths, tulips, lily-of-the-valley, as well as the tiger lily and other lilies, are members of this family. Several food plants, as asparagus and onions, belong in this group. They have the typical liliaceous flower 
with the parts in threes and with a brightly colored and often conspicuous corolla. They have bulbs, rootstalks, etc., which enable them to grow rapidly at the coming of a favorable season. The yucca, well known in our Southwest, is one of this family.

The Arum Family. The members of this family may be told by their peculiar flower cluster, a spikelike structure known as a spadix. In the Jack-in-the-pulpit this is surrounded by a large leaflike structure called the spathe. The calla lily and skunk cabbage are our best-known examples.

The Orchid Family. These plants are noted for their beautiful flowers. In the tropics one member of this group is conspicuous because of its habit of living in trees as an air plant or epiphyte. A few orchids live in secluded places in our north temperate zone, but most have disappeared because of overpicking. Never pick an orchid, if you are lucky enough to find one; photograph it instead.

Dicotyledons. Legume Family. This is one of the bestknown and most easily recog-

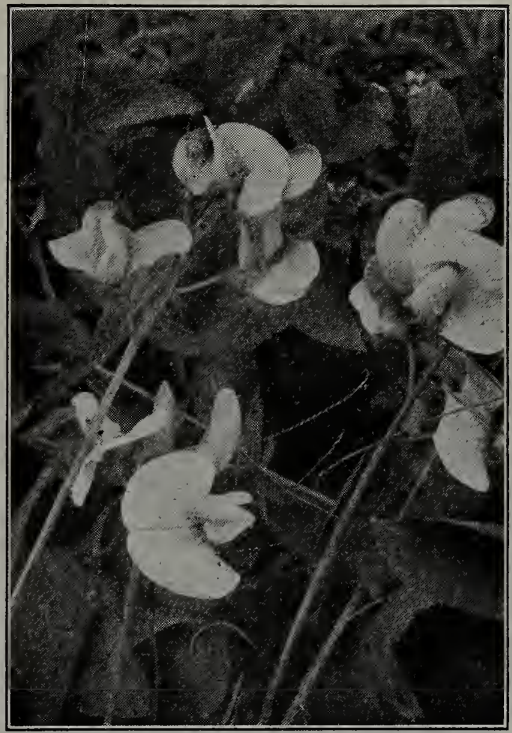

L. W. Brownell

Perennial peas (legume family).

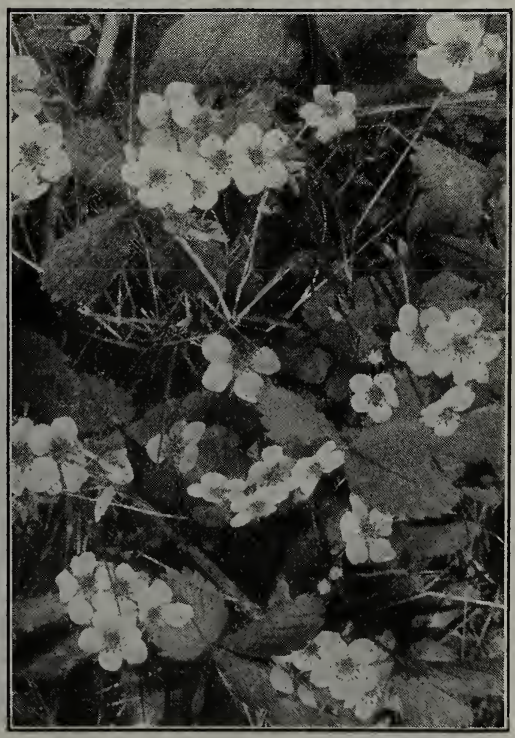

Wild strawberry blossoms (rose family). 


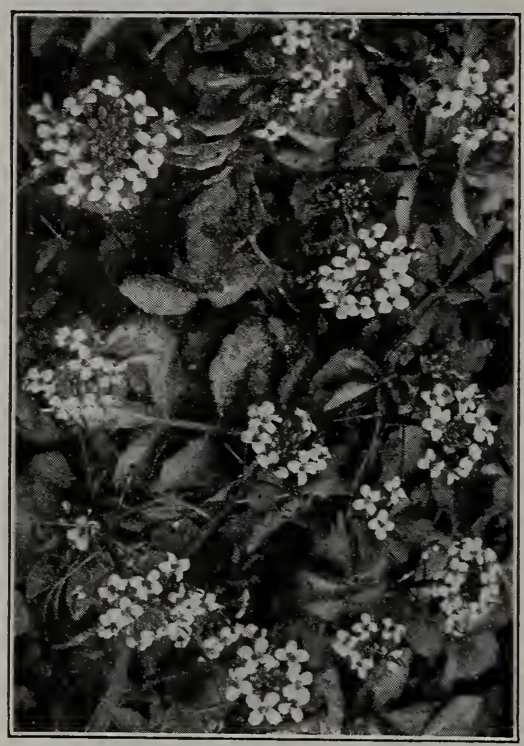

Watercress (mustard family).

nized families of the dicotyledons. The legumes always have irregular flowers, as the sweet pea, and produce fruit which is a pod. Most of the legumes have compound leaves. Examples are: peas, beans, clover, lupines, and peanuts, while locusts and acacias are examples of trees.

The Rose Family can be told by the flower in which the parts come out in fives, the sepals and petals making a cup from which the stamens spring. Roses, and the blossoms of strawberries, blackberries, raspberries, cherries, pears, and apples are examples.

The Buttercup Family is a very large family, which bears solitary and conspicuous flowers in which the calyx and corolla are usually the same color. They have a large and indefinite number of

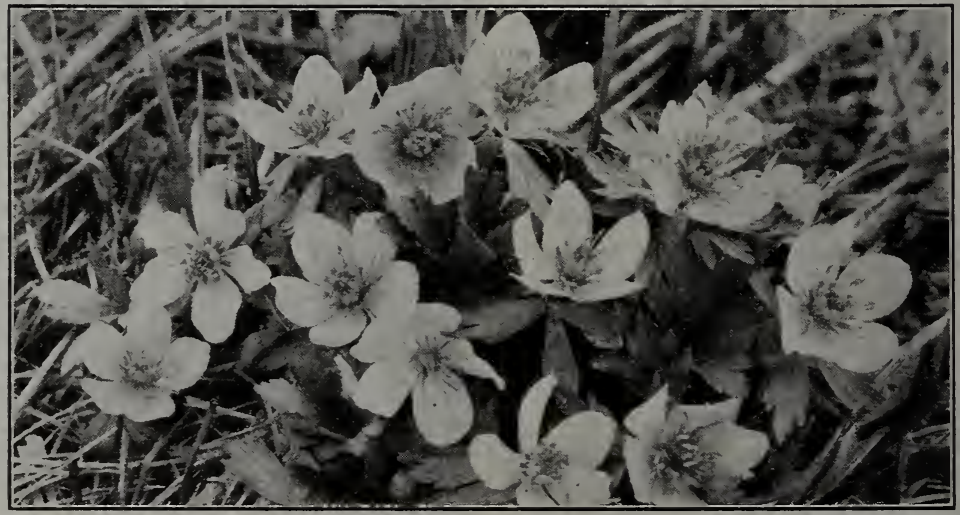

L. W. Brovonell

The Globe flower is a member of the buttercup family. 
stamens and pistils. Examples are : buttercups, anemones, peony, tulip trees, magnolias, and many others.

The Mustard Family has a peculiar flower of four petals and sepals distinct from each other and six stamens. Many of our most troublesome weeds belong to this family, as well as many garden vegetables, cabbage, turnips, radishes, and watercress.

The Mint Family also has a characteristic flower. The corolla is like a tube and has two lips. The pistil has two carpels, but there are five stamens. The plants usually have

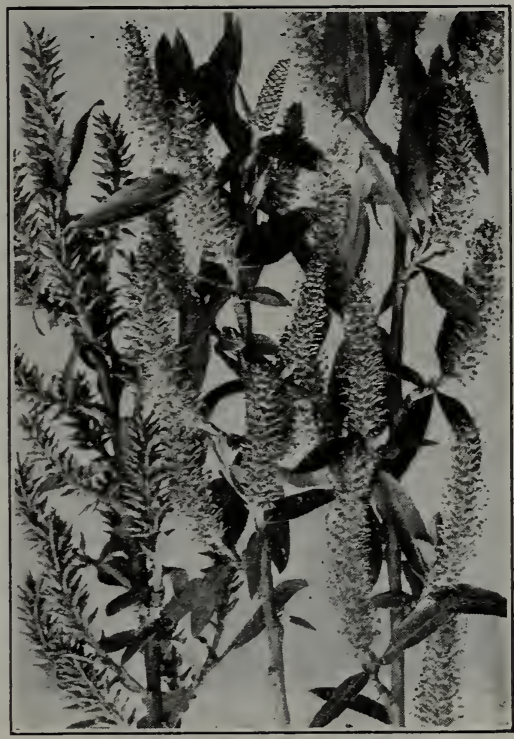

L. W. Brovonet

Blossoms of the crack willow (willow family). a characteristic odor and square stems. Spearmint, lavender, and thyme are members of this family.

The Willow Family is best known by the poplars and willows. These trees have the naked flowers in catkins with separate male

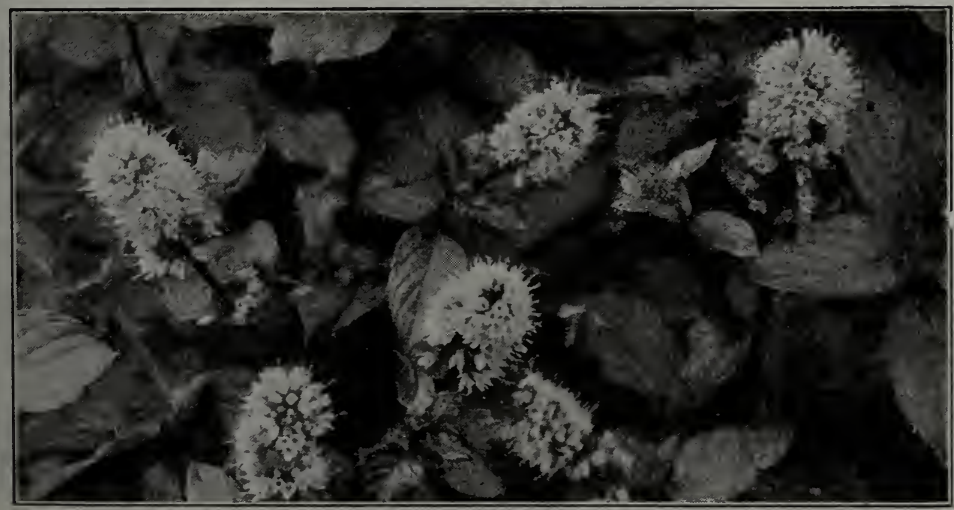

Peppermint is a well-known member of the mint family. 


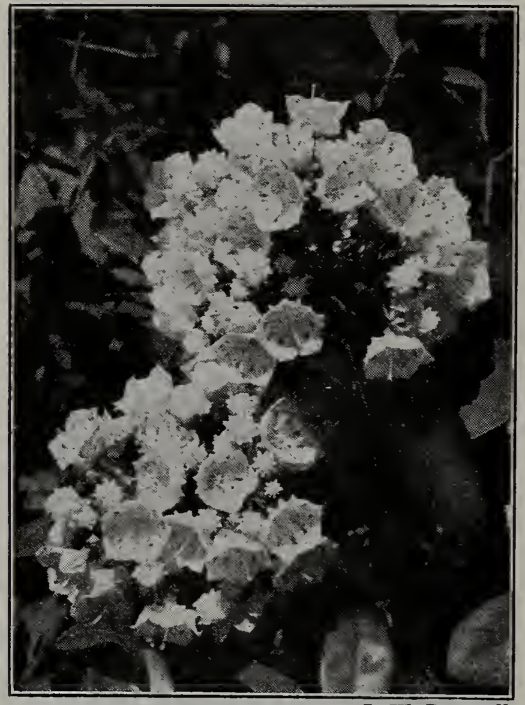

Mountain laurel (heath family).

and female flowers on different individuals.

The Carrot Family can easily be recognized by the umbrellashaped flower cluster. These plants are usually perennial herbs. The leaves are usually deeply indented. Examples are the carrot, fennel, and celery.

The Heath Family can be recognized by the fact that its flowers have a five-parted corolla which is more or less united in a bell and most of the group have simple evergreen leaves. Laurel, blueberries, wintergreen, heather, and rhododendrons are members of this group.

The Composite Family is the largest group of the flowering plants, having over 13,000 species. The flowers are very small and grouped

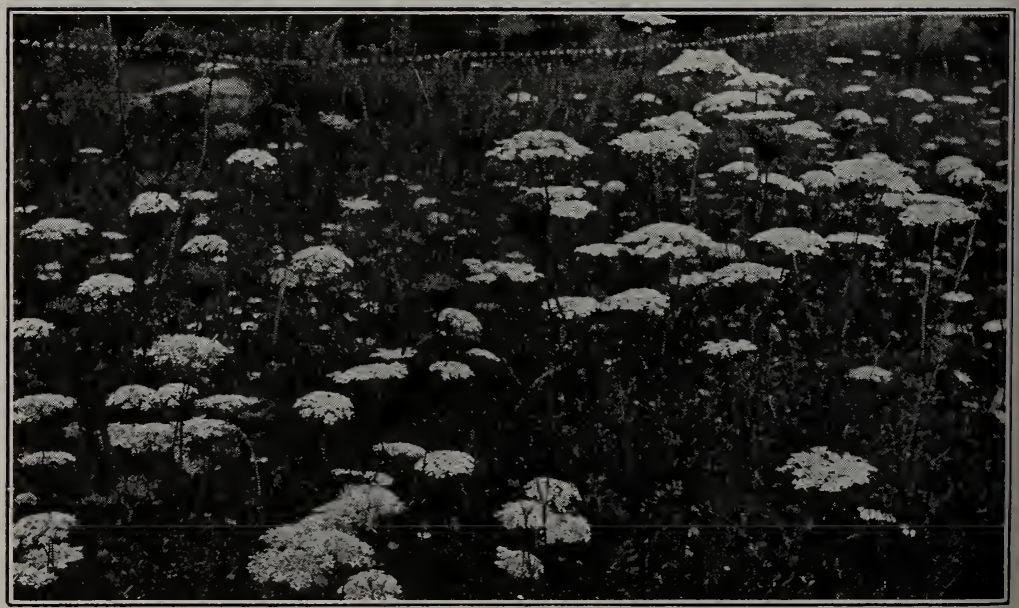

Many fields are infested with wud carrot (carrot family).

L. W. Brownell 
in clusters known as compound heads. They produce numerous seeds. The group includes many of our weeds, such as ragweed, thistles, dandelions, daisies, and cockleburs, and many of our most beautiful garden flowers, as asters, sunflowers, and chrysanthemums.

\section{Self-Testing Exercise}

The seed plants or ........ (1) are divided into two great groups: the .......(2), those producing naked seeds, and the (3), or ........(4) plants, in which the seed is usually inclosed in a........ (5).

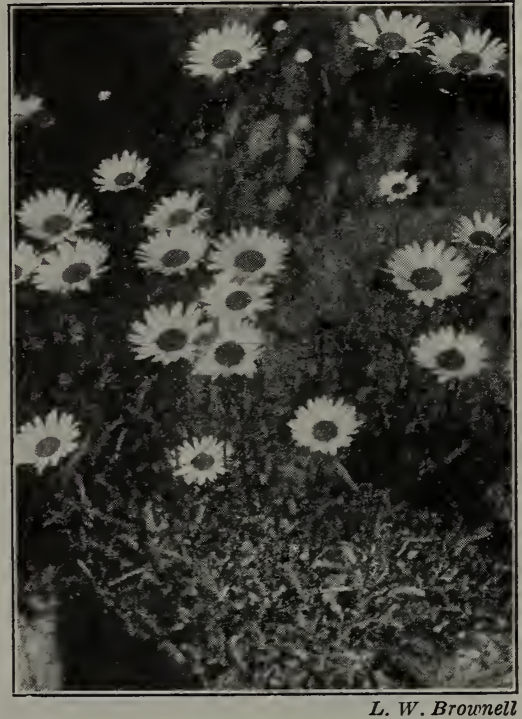

Daisies (composite family).

\section{Review Summary}

Test your knowledge of this unit by: (1) answering and rechecking the survey questions ; $(2)$ performing all assigned exercises and in this case identifying a few common examples of plants; (3) checking up with your teacher on the tests and doing over the parts you missed; and (4) making an outline of the unit for your workbook.

\section{Test on Fundamental Concepts}

In a vertical column under the heading CORRECT write numbers of all statements you believe are true. In another column under INCORRECT write numbers of untrue statements. Your grade $=$ right answers $\times 2$.

I. Living things are classified (1) into groups, the members of which are like one another; (2) into species, genus, order, class, and phylum; (3) because they are then more convenient to study, (4) by placing them in groups which have certain characters in common; (5) as species when they produce others like themselves and their offspring also produce others like their ancestors.

II. Bacteria (6) are small colorless animals; (7) are found in all decaying things ; (8) reproduce rapidly by fission; (9) may form spores and thus live under unfavorable conditions; (10) are often parasites. 
III. Useful bacteria (11) cause decay of dead organic matter; (12) give flavors to foods; (13) cause diseases; (14) take nitrogen from the air; (15) make fertilizers.

IV. Bacteria (16) are killed by sterilization; (17) in milk cause it to sour ; (18) fix the nitrogen in the air ; (19) will grow readily in hot, dry places, provided they have food; (20) may be killed by exposure to sunlight.

V. Fungi (21), such as wheat rust, are responsible for great losses to crops each year ; (22) are able to make their own food; (23) like molds, give flavor to cheese; (24) are more useful than harmful; (25) may be used as foods.

VI. Yeast plants (26) are a kind of fungi ; (27) cause fermentation by means of their growth in fluids ; $(28)$ cause bread to rise because they give off carbon dioxide gas in their growth; (29) produce carbon dioxide and alcohol in food substances; (30) reproduce by a process called budding.

VII. Algae (31) are chlorophyll-bearing plants; (32) cannot make carbohydrate food; (33) have thread-like roots; (34) may reproduce by division of cells; (35) are one source of contamination of our drinking water.

VIII. The main groups of the plant kingdom are (36) the angiosperms, dicotyledons, and algae; (37) algae and fungi; (38) the mosses, lilies, palms, and trees; (39) the thallophytes, bryophytes, pteridophytes, and spermatophytes; (40) phyla.

IX. Alternation of generations (41) occurs when a plant gives rise to other plants just like itself ; (42) is best seen in the algae; (43) in a plant takes piace in two stages, one producing sexual cells, the other asexual spores; (44) occur in the moss and fern, when the life history shows an alternating of the part of the plant bearing asexual spores with that part which bears sexual cells; (45) occur in flowering plants, when the pollen grain and ovules represent the sexual generation, while the seed and the plant that grows from it is the asexual generation.

X. Spermatophytes (46) are seed-producing plants ; (47) are flowering plants only; (48) include both gymnosperms and angiosperms; (49) grow by means of asexual spores; (50) include all of our common flowers, shrubs, and trees. 


\section{Achievement Test}

1. How would you grow bacteria?

2. What is the favorite food of bacteria?

3. What are the factors necessary for bacteria to grow?

4. In what ways are bacteria useful to the farmer?

5. What are at least five parasitic fungi that do harm?

6. How would you prevent mold growth?

7. How can you explain the process of making bread?

8. What examples of all the four large groups of plants have you found in your environment?

9. Where would you find the following plants: red algae, pleurococcus, yeast, puffballs, pigeon-wheat moss, Christmas fern?

10. How many flowers of the families of flowering plants mentioned in this unit have you been able to identify?

\section{Practical Problems}

1. Make a table showing all the ways in which bacteria affect your daily life for good or ill.

2. Make similar tables for both molds and yeasts.

3. Make a collection of your local flowering plants and classify them according to some simple key.

4. Identify all the harmful plants in your locality. To do this get the use of a good manual on weeds or one of the state publications on weeds. The manual published by the University of Iowa is one of the best.

\section{USEFul REFERENCES}

Book of Knowledge. (Grolier Society.)

Broadhurst, Home and Community Hygiene. (J. B. Lippincott Co. 1925.)

Conn, Bacteria, Yeasts.and Molds of the Home. (Ginn \& Co. 1917.)

Downing, Our Living World. (Longmans, Green \& Co. 1924.)

DeKruif, Microbe H unters. (Harcourt, Brace \& Co. 1926.)

Kendall, Civilization and the Microbe. (Houghton, Mifflin. 1923.)

Mathews, Book of Wild Flowers for Young People. (G. P. Putnam's Sons. 1923.)

Parsons, How to Know the Wild Flowers. (Charles Scribner's Sons.) 


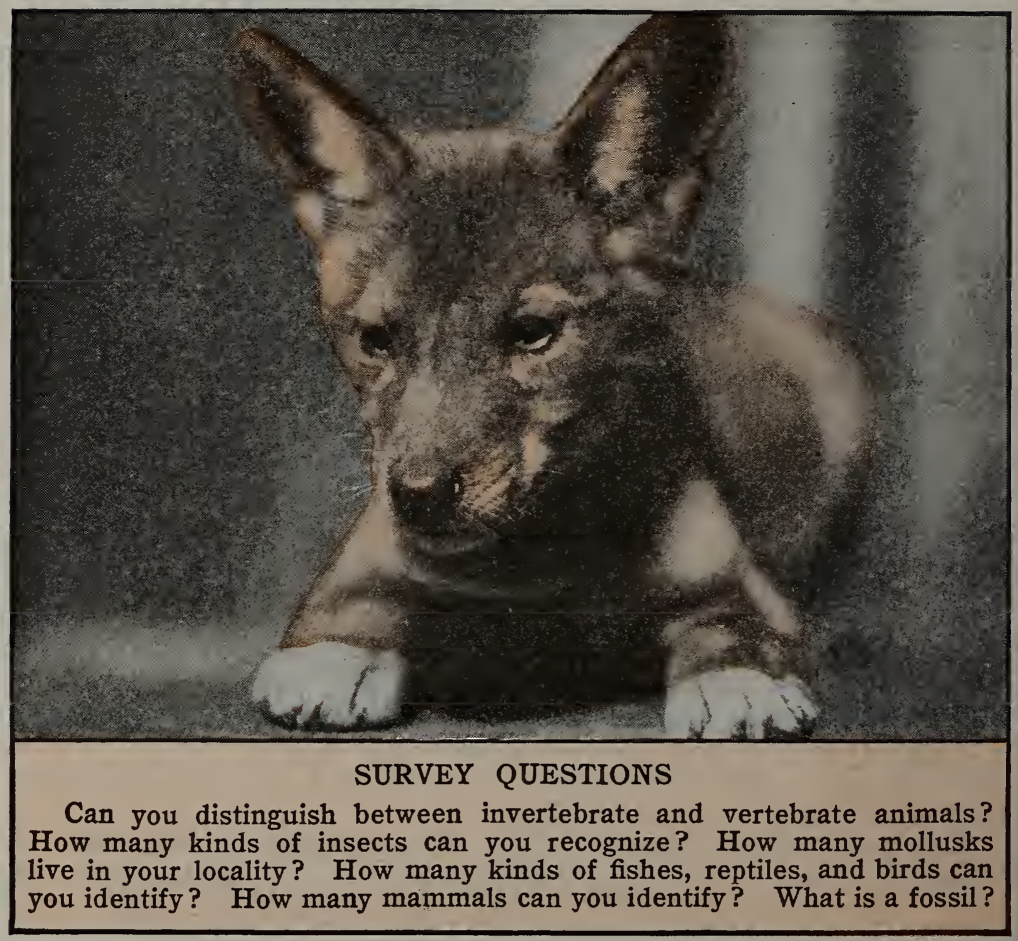

\section{UNIT VIII}

\section{HOW DO WE CLASSIFY ANIMALS?}

Preview. In the classification of animals, as well as of plants, there is one underlying principle which is used to show relationships. Living things which have similar structures or organs in similar parts of their bodies are almost certainly related to each other. Where structures are similar and are found in corresponding positions, they are said to be homologous. For example, the wing of a bat, the wing of a bird, the foreflipper of a dolphin, the foreleg of a dog, and the arm of a man are homologous structures and show that these animals are, in a way, related to one another. On 216 
the other hand, we often find that organs which do not have the same structure or origin are used for similar purposes. Such are the wings of a bird and the wings of a butterfly. Such structures are analogous. Analogy is likeness in function, regardless of origin.

In our study of biology so far we have attempted to get some notion of the various factors which act upon and interact with living things. We have examined a number of forms of plants and have found all grades of complexity from the one-celled plant, Pleurococcus, to the complicated flowering plants of considerable size and with many organs. So in animal life the forms we study will show a constant change, and the change is toward greater complexity of structure and of function. A worm is simpler in structure than an insect, and shows by its sluggish actions that it is not so high in the scale of life as its more lively neighbor.

We are probably aware of the fact that we are better equipped for the battle for life than lower animals, for we are thinking creatures and can change our surroundings if they are unfavorable, while the lower forms of animals are largely controlled by stimuli which come from without, such as temperature, moisture, light, and the presence or absence of food.

There are a great many ways of arranging animals in groups. One way is to put all animals that have no backbones into a large group called the invertebrates as opposed to those which have a vertebral column, the vertebrates.

\section{PROBLEM I. WHAT ARE THE CHARACTERISTICS OF ONE- CELLED ANIMALS?}

Habitat of Protozoa. Protozoa, or one-celled animals, are found in water, seemingly never at any great depth. They appear to be attracted to the surface by light and by the supply of oxygen. Every fresh-water lake swarms with them; the ocean contains countless myriads of many different forms.

Demonstration 1. To show a living amoeba. To obtain amoebas, crush some water plants and let the mass remain undisturbed for a week or so. Living animals will usually be found in the scum that forms. Mount a bit of the scum and observe it under a compound microscope. Describe the amoeba as to shape and size. 
Amoeba. The simplest of all animals is the amoeba, a tiny cell, which changes its shape as it moves about in the water. It has no organs of locomotion, nor of sensation, yet it is aware of the nearness of food. It has no mouth, but takes in food at any point in its body. It is able to change this food into living matter,

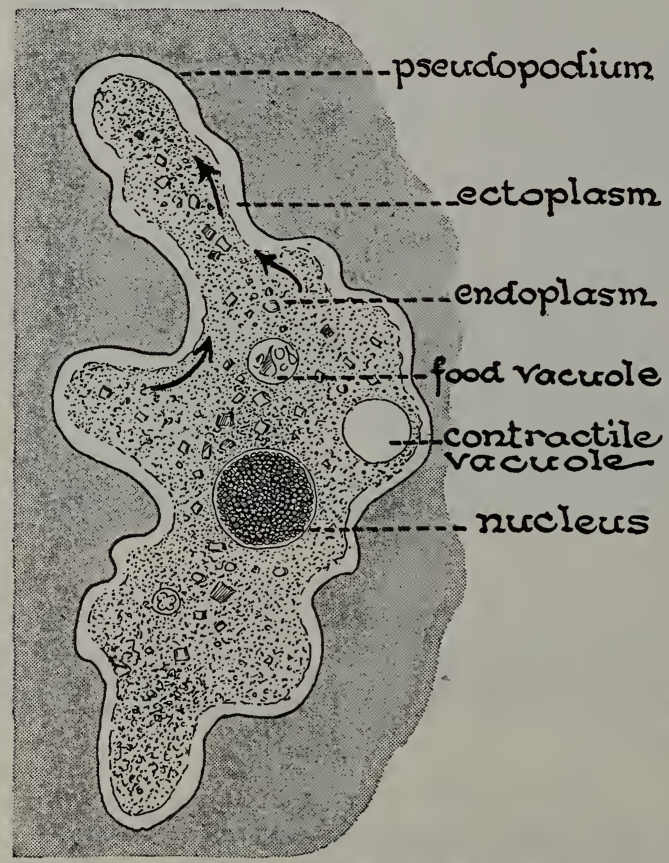

State the use of each part that is labeled. for it grows, and when it reaches a certain size, divides to form two amoebas.

Several theories have been advanced to account for its locomotion: such as the flowing of the protoplasm, a rolling motion of the cell, and most recently the belief that the amoeba moves by a series of body contractions.

Although but a single cell, the amoeba appears to be aware of the existence of food when it is near at hand. Food may be taken into the body at any point, the semifluid protoplasm surrounds and takes in the bit of food, with a little water. Thus a food vacuole is formed. Digestion takes place in the vacuole by means of enzymes. As the food vacuole is circulated by the constant streaming of the protoplasm within the cell, the digested nutrients pass, by osmosis, from the vacuole into the protoplasm. Parts of the food material that cannot be used, such as the shells or outer coverings of tiny plants, are passed out of the food vacuole. Waste products, other than carbon dioxide, resulting from oxidation col- 
lect in the contractile vacuole, which will burst and expel them. The cell absorbs oxygen from the air in the water by diffusion, and passes out carbon dioxide. Thus respiration takes place through every part of the outer covering of the cell.

The amoeba reproduces by splitting into two cells, each of which resembles the parent cell, except that it is of smaller size. When these new cells become the size of the parent amoeba, they each divide. This is a kind of asexual reproduction. When conditions unfavorable for life come, the amoeba, like some one-celled plants, encysts itself within a membranous wall, forming a sporelike structure. Upon return of favorable conditions, the cover disappears and life begins again, as before.

Laboratory Exercise. To learn something of the activities of a onecelled animal, Paramecium. Use material taken from the surface of a hay infusion made by placing a little hay in a beaker of water and letting the material stand for several weeks. Place a drop of the infusion on a slide, cover with a cover glass, and mount it under a compound microscope.

Do the moving structures appear to have any definite shapes? Do they move with any definite end forward? Do they collect in any locality? If so, what influences them to do this?

Heat a needle and introduce it at one side of the cover glass. Is there any movement on the part of a Paramecium?

Notice some of the animals grouped around small masses. Why do you suppose they are there? Notice other animals with reference to the position of air bubbles or to threads of Spirogyra to which they are attached. How do they lie with reference to the air bubble? What might the animal get from the air bubble, if it is to do work? How would a cell covered with a membrane take anything from an air bubble? What might it give in exchange?

Drop a little fountain-pen ink on a slide containing Paramecia. Note the long structures (trichocysts) thrown out by the animal.

Write a paragraph explaining how a Paramecium reacts to the stimuli in its environment. Make drawings to illustrate your conclusion.

The Paramecium. This one-celled animal is elliptical in outline, but somewhat flattened. The rounded (anterior) end of the body usually goes first. As the Paramecium pushes its way between dense substances in the water, the cell body is seen to change its shape as it squeezes through.

The cell body is almost transparent, and consists of semifluid protoplasm bounded by a very delicate membrane, the pellicle, 
through which project numerous delicate threads of protoplasm called cilia (šl' '̂̀- $\dot{a})$.

Imbedded in the pellicle are many defensive structures called trichocysts (trǔk'ö-šst), which are shot out like darts when danger

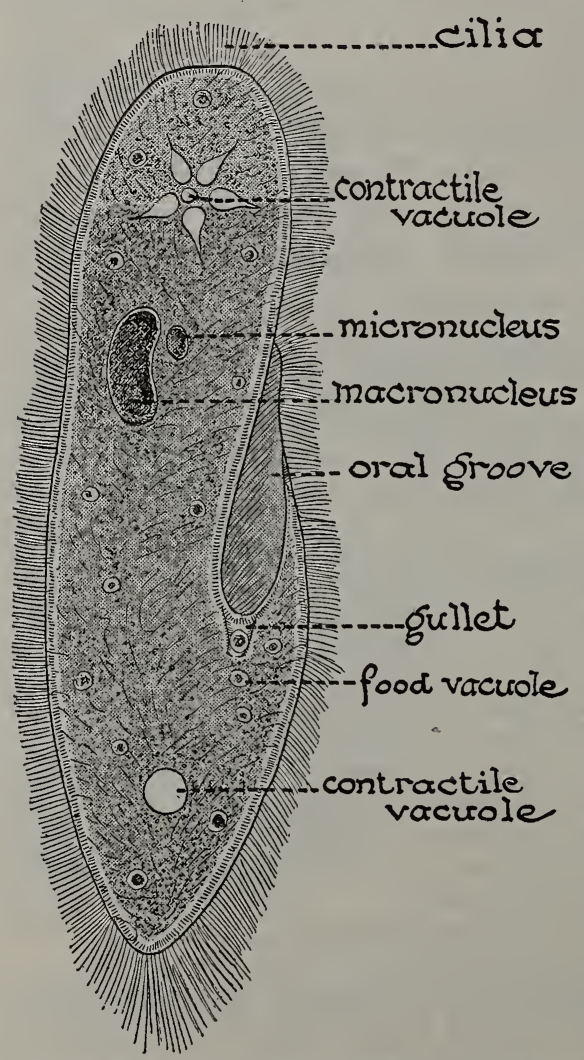

The Paramecium. Which end goes first? Where is the mouth? How does food get inside the cell? How is it circulated? is near. These structures are composed of cytoplasm, are hollow, and secrete a poisonous substance.

The locomotion of the Paramecium is caused by the movement of the cilia. The current of water caused by the cilia carries tiny particles of food into the oral groove on one side of the cell and into a funnel-like opening, the gullet. Once within the cell body, the particles of food materials are gathered within a small area called a food vacuole. Other vacuoles appear to be clear; these are spaces in which food has been digested. One or two larger contractile vacuoles may be found ; their purpose seems to be to pass off liquid waste material from the cell body. This is done by the pulsation of the vacuole, which ultimately bursts, passing the fluid waste to the outside. The cell wall breaks at regular intervals to discharge solid food waste. Since the cell membrane breaks at nearly the same place each time, the opening is called the anal spot. In a cell that has been stained, the nucleus is seen to be a double 
structure, consisting of one large and one small portion, called respectively the macronucleus and the micronucleus.

Sometimes a Paramecium may be found in the act of dividing by the process known as fission. In this process the nucleus first elongates and breaks into two, and the halves go to opposite ends of the cell. The cell elongates, a second gullet appears, and ultimately the cell breaks into two parts, each half provided with a nucleus and a gullet. This is a method of asexual reproduction.

Frequently another type of reproduction may be observed.

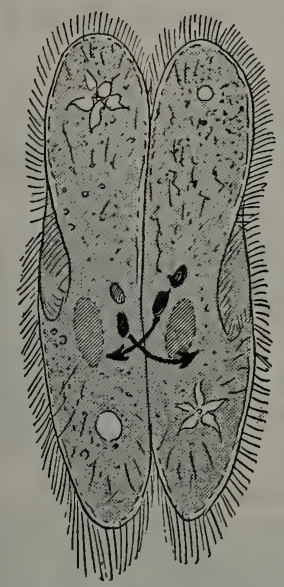

Conjugation in Paramecium. Explain how this takes place.
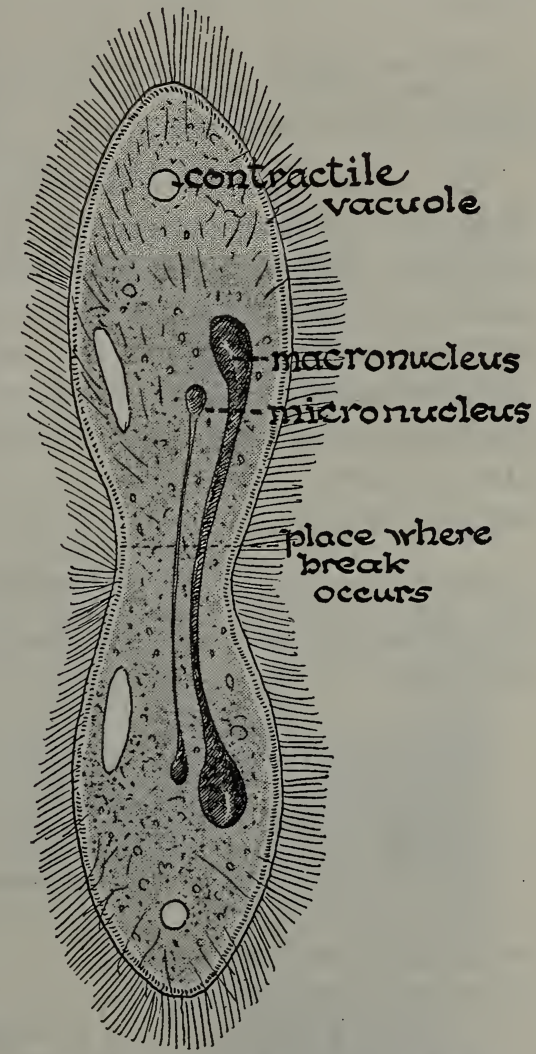

Cell division in Paramecium. What is the process called? Describe exactly what happens.

This is called conjugation, and somewhat resembles conjugation in the simple plants. Two cells of equal size attach themselves rogether as shown in the small diagram. The cell membranes aissolve at the point of contact. Complicated changes take place in the nuclei of the two cells thus united. Finally fragments of the 
material forming the micronuclei of each cell pass over and unite with material forming the nuclei of the opposite cell. After this mutual exchange of nuclear material the cells separate. It is believed that this stage of reproduction, as in the plants, is a sexual stage.

Practical Exercise 1. Compare an amoeba and Paramecium as to size, shape, method of locomotion, method of taking in food, digesting food, excreting waste, and reproducing.

The cell as a unit. In the daily life of a one-celled animal we find the single cell performing all the vital activities which we shall later find that the many-celled animal is able to perform. In the amoeba no definite parts of the cell appear to be set off to perform certain functions; but any part of the cell can take in food, can absorb oxygen, can change the food into protoplasm, and excrete the waste material. The single cell is, in fact, an organism able to carry on the business of living as effectually as a very complex animal.

Practical Exercise 2. Draw a cell and label all its parts. Give the use of each part. How do cells move about? What do we mean by conjugation? Why is the cell called a "unit of structure"? Why is a cell called an organism?

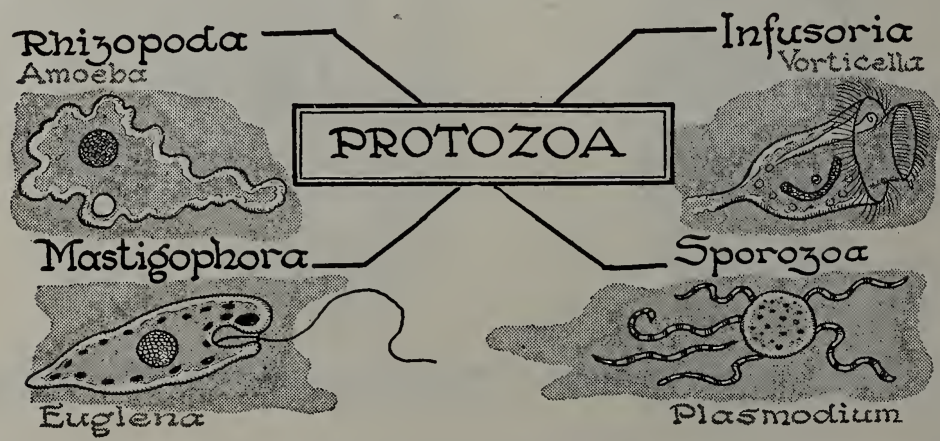

The principal classes of Protozoa, examples of which we may have seen or read about, are -

Class I. Rhizopoda (root-footed). Having no fixed form, with pseudopodia. Either naked as Amoeba or building limy (Foraminifera) or glasslike skeletons (Radiolaria).

Class II. Mastigoph'ora. They move by means of long whiplash threads of protoplasm, called flagella. Examples are Euglena and Monosiga.

Class III. Infuso'ria (in infusions). Usually active ciliated Protozoa. Examples, Paramecium, Vorticella.

Class IV. Sporozo'a (spore animals). Parasitic and usually non-active. Example, Plasmodium malariae. 


\section{Self-Testing Exercise}

Protozoa are ....... (1) composed of one .......(2). Examples are the amoeba, which ........(3) by changing its body form and the Paramecium, which moves by means of ........ (4), tiny threads of ....... (5). These one-celled animals carry on all the ....... (6) of higher animals, including .......(7).

\section{PROBLEM II. WHAT ARE THE CHARACTERISTICS OF SOME SIMPLER INVERTEBRATES?}

Porifera (Lat. porus, pore; ferre, bear) or sponges. The body of a sponge contains many pores through which water bearing food particles enters. They are classified according to the skeletons they possess into limy, glasslike, and horny fiber sponges. The last named are the sponges of commerce. Most sponges live in salt water ; they are never free swimming. There are about 2500 known species.

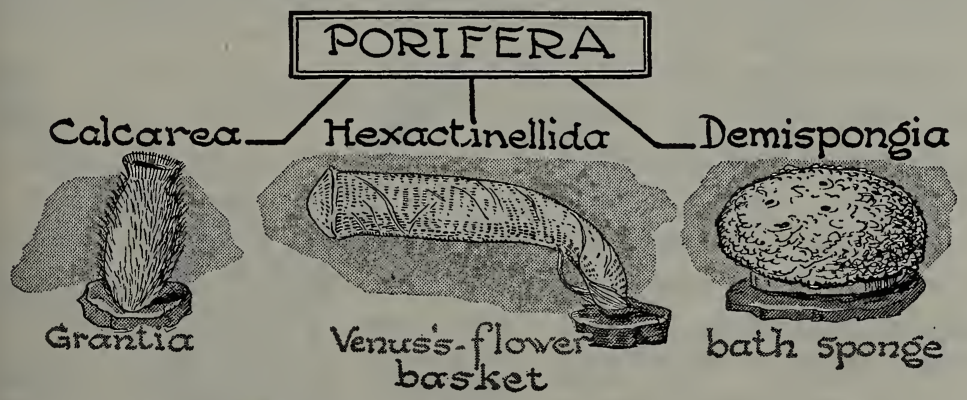

The following is the classification of Porifera :-

Chass I. Calca'rea, having limy spiculesin the body. The Grantia seen along our northeastern coast is an example.

Class II. Hexactinel'lida. Sponges having glasslike spicules, arranged on three axes. Example, Venus's flower basket.

Class III. Demospon'giae. Sponges with glasslike spicules, not arranged on three axes, or with skeleton of horny fiber, the latter type represented by the bath sponge.

The structure of a sponge. The simplest kind of sponge is in the shape of an urn, attached at the lower end. Cut lengthwise, such an animal is seen to be hollow, its body wall pierced with many tiny pores or holes. These pores open into a central cavity, which in turn opens by a large hole, called the osculum (ŏs'kù-lüm) or mouth, into the surrounding water. 
A microscopic examination shows the pores of the sponge to be lined on the inside with cells having collars of living matter sur-

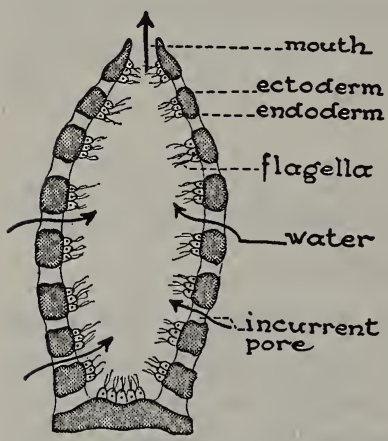

Longitudinal section of a simple sponge. How does this animal get its food? rounding a single long cilium called flagellum (fla-jěl'um). The flagella, lashing in one direction, set up a current of water, bearing food particles, toward the large inner cavity where they are digested. The digested food then passes by osmosis to the other cells of the body. From some of the cells in the jelly-like middle layer of the body lime is secreted to form the spicules, and the reproductive cells, eggs, and sperms occur. The spicules form the skeleton of the sponge.

Practical Exercise 3. Make a diagram of a simple sponge showing how food is taken in and waste given out from the body. How does a sponge breathe?

Coelenterates. The Coelenterates are a large group of animals, practically all of which are found in salt water. They include the beautiful sea anemones, jellyfish, and corals.

The Hydra. This little creature is shaped like a hollow cylinder with a circle of arms or tentacles at the free end. It is found attached to dead leaves, sticks, stones, or water weeds in fresh-water ponds. When disturbed, it contracts into a tiny whitish ball, a little larger than the head of a pin. The outer layer of the

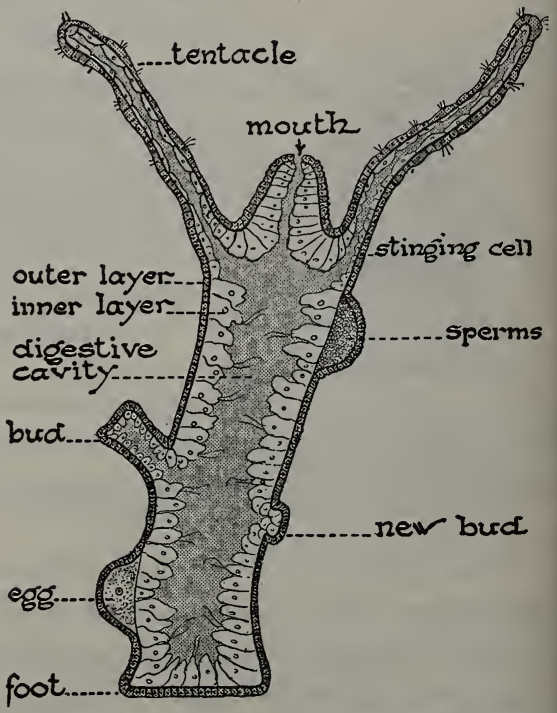

Longitudinal section of Hydra. How does food get into the body? How many layers of cells are found here? 
animal serves for protection as well as movement and sensation, certain cells being fitted for each of those different purposes.

The tentacles are provided with thousands of minute darts or stinging cells, by means of which prey is killed. The tentacles then reach out like arms, grasp the food, bend over with it, and pull it toward the mouth. Certain cells lining the hollow digestive cavity pour out a fluid which digests the food. Other cells with long cilia circulate the food, while still other cells lining the cavity put out pseudopodia, which surround and take in the food particles. The outer layer of the animal does not digest the food, but receives some of it already digested from the inner layer. Oxygen is passed through the body wall, for there are no special organs for respiration.

Reproduction. The Hydra reproduces asex-

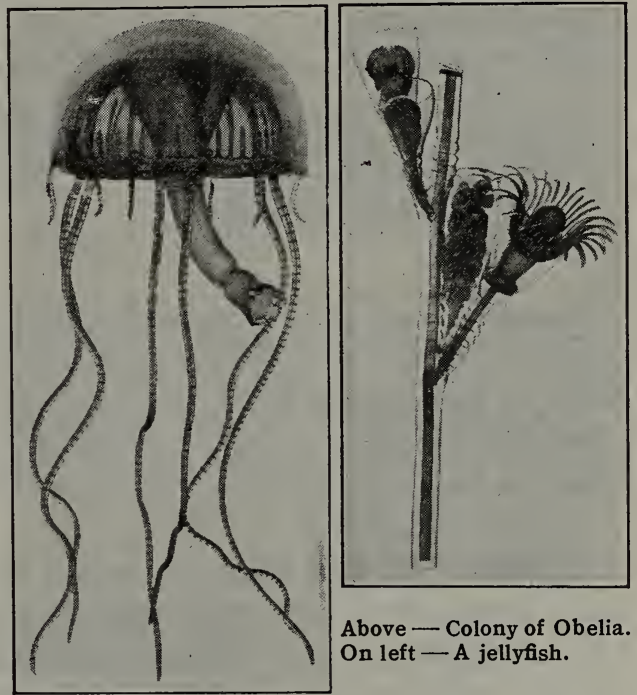

Amer. Mus. of Nat. Hist.

Why are the Obelia and jellyfish classified as coelenterates? In what way are they similar? In what ways are they unlike each other?

ually by budding, as is seen in the diagram. The bud appears on the body as a little knob, the body cavity extending into it. After a short time (usually a few days) the young hydra separates from the old one and begins life alone. This is asexual reproduction.

The Hydra also reproduces by sex cells. The sperms develop in little groups near the free end of the animal, and the egg cells develop near the base. The sperms, when ripe, are set free in the water; one of them unites with an egg, which is usually still attached to the body of the Hydra, and development begins which results in the growth of a new hydra. 
Practical Exercise 4. Study the diagram on page 224 and construct a cross section of the animal. Label all parts shown.

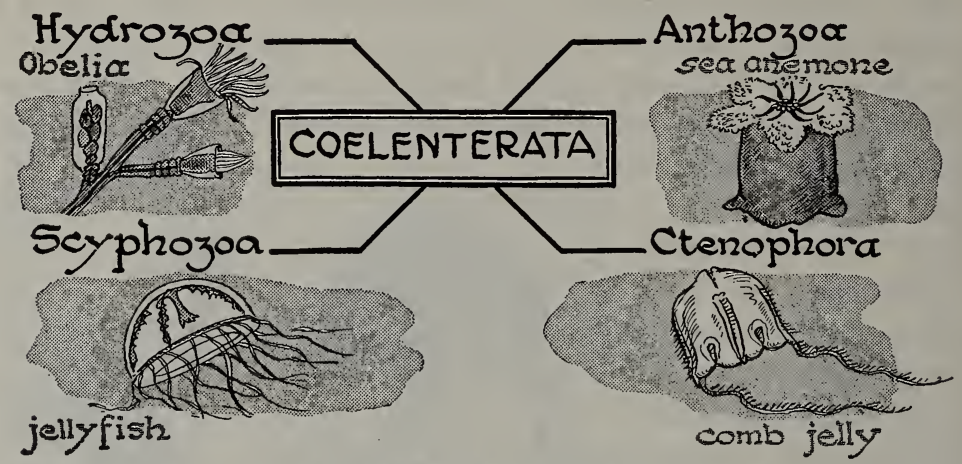

Class I. Hydrozo'a. Simple animals as hydra, or colonial in habit as the hydroids. They produce new individuals by budding, and the eggs and sperms are usually produced in a freeswimming jellyfish, which buds off from the original colony. This is an example of alternation of generations. Examples: Hydra and Obe'lia.

Cuass II. Scyphozo'a. Marine jellyfish, mostly of large size. Example, Aurelia.

Class III. Anthozo'a. Hydralike animals, usually attached, with many tentacles, disposed in circlets in multiples of five. They may be single or colonial. The sea anemones and corals are the best-known examples.

Cisass IV. Ctenophora, or sea walnuts, well known along our eastern coast, are sometimes given as a separate phylum and sometimes as a class of the coelenterates.

Jellyfish. At first sight you would not say a jellyfish was related to the Hydra, but we find that a part of the life of the jellyfish is passed as a colony of hydralike animals which give rise to free-swimming jellyfish as the sexual stage of their life history. This alternation of an asexual generation with that of a sexual generation, which produces the eggs and sperm cells, is seen in many plants and is best shown in this group of animals.

Echinoderms. ${ }^{1}$ These are spiny-skinned animals which live in salt water. They show radial symmetry. There are about 4500 named species.

The starfish. By far the most important enemy of the oyster and other salt-water mollusks ${ }^{2}$ is the starfish. The common starfish, as the name indicates, is shaped like a five-pointed star. A skeleton of lime which is made up of thousands of tiny plates

1 Echinoderm: (è-kīnò̀-dûrm).

${ }^{2}$ Mollusk : popularly called shellfish. Has soft body protected by shell. 
gives shape to the body and arms. Slow movement is effected by means of tiny suckers, called tube feet. The mouth is on the undersurface of the animal, and, when feeding, the stomach is protruded and wrapped around its prey. The body covering of the starfish, as well as that of the sea urchin and others of this group, is spiny; hence the name echinoderm, which means spinyskinned, is given to the group.

Starfish are enormously destructive of young clams and oysters, as is shown by the evidence, collected by Professor A. D. Mead of Brown University. A single starfish was confined in an aquarium with fifty-six young clams. The largest clam was about the length of one arm of the starfish, the smallest about ten millimeters in length. In six days every clam in the aquarium was devoured.

In order to capture and kill mollusks, the starfish wraps itself around the valves of the shell and actually pulls them apart by means of its tube feet, some of which are attached to one valve and some to the other of its victim. The mollusk can withstand

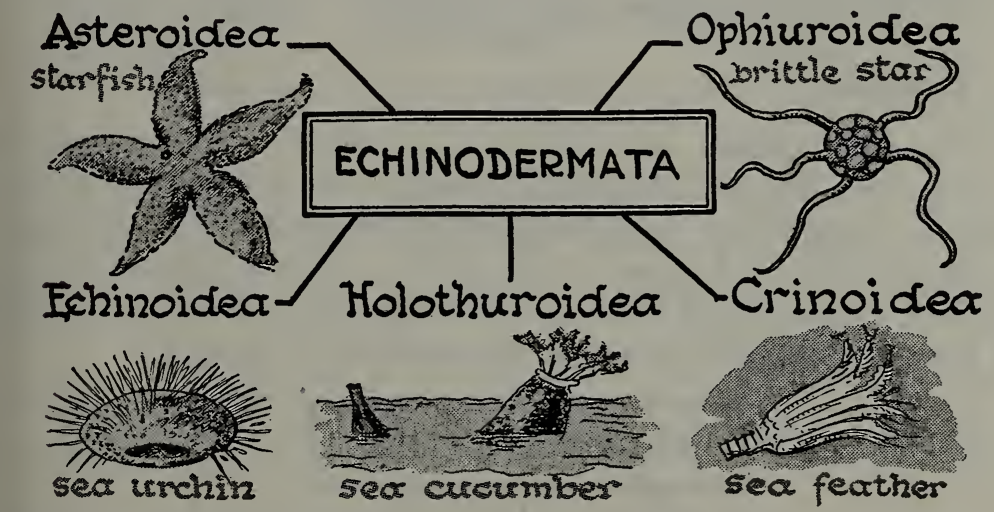

Class I. Asteroi'dea, or starfishes.

CLAss II. Ophiuroi'dea, the brittle stars or snake stars.

Class III. Echinoi'dea, or sea urchins.

Class IV. Holothuroi'dea, including the sea cucumbers.

Cusss V. Crinoi'dea, or stonelike, deep-sea forms, now almost extinct; sea lilies and sea feathers.

a strong pull, but not a long one, and so it eventually gives way. Once the soft part of the mollusk is exposed, the stomach 
of the starfish envelops it and covers it with the secretions of digestive glands, and it is rapidly digested and changed to a fluid.

Hundreds of thousands of dollars' damage is done annually to the oysters in Connecticut alone by the ravages of starfish.

Practical Exercise 5. What echinoderms, if any, exist in your community? What would you consider the chief characteristics of the echinoderms?

Platyhelminthes (Gr. platys, flat; helminthos, worm), or flatworms. These are usually small, ribbon- or leaf-like, and flat. They live in water. Most flatworms are parasitic. The most commonly known ones are the tapeworm and the liver fluke. There are about 5000 known species.

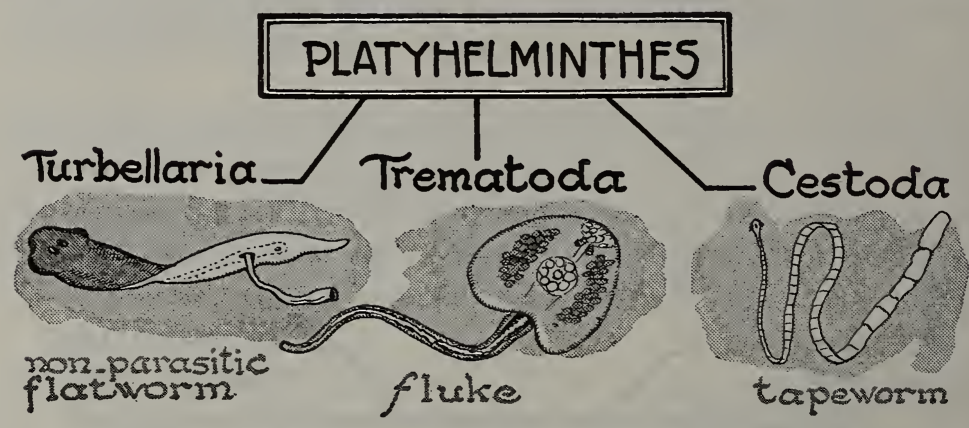

Nemathelminthes (Gr. nematos, a thread), or roundworms. These three-layered, elongated threadlike animals are often parasitic. Vinegar eels, the horsehair worm, the pork worm or trichina, and the dread hookworm are examples. About 15,000 species are known. Examples of these worms will be discussed later in the unit "How Does Man Control His Environment for Health?"

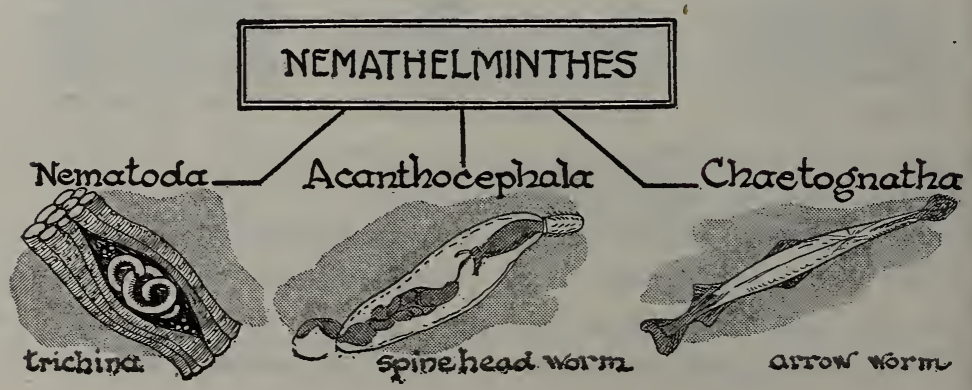


Annulata (Lat. annulus, a ring). The segmented worms are long, jointed creatures composed of body rings or segments. The digestive tract is a tube within a tubelike body. They have no jointed appendages. There are about 4000 known species.

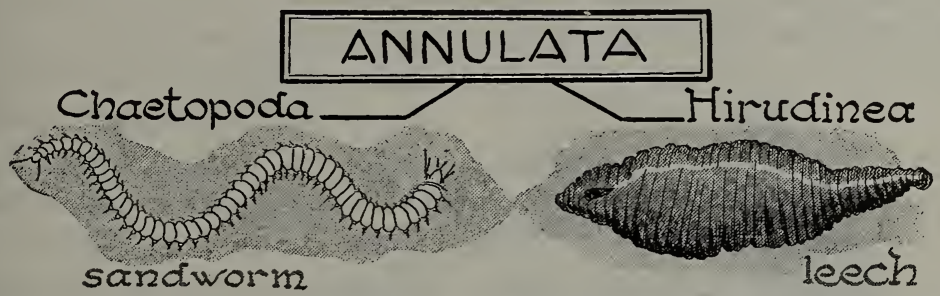

Class I. Chaetop'oda. Many bristles along the sides of the body. Examples are the earthworm or sandworm.

Class II. Hirudin'ea. Without bristles and having suckers at both ends of the body. Examples are the leeches or bloodsuckers.

Laboratory Exercise. Study of a living earthworm. Put several earthworms in shallow tin trays with moist blotting paper in bottom. Have paper wet at one end of tray and dry at the other. At which end of the tray do the worms gather? Wet the paper uniformly and then cover one half of the tray with an opaque object. What happens to the worms? How do earthworms react to light and presence of moisture?

Count the number of rings (segments) in your worm and compare with the estimates of others in the class. What conclusions do you draw?

Watch a worm move. Describe exactly what happens.

Notice the little swelling located about the thirty-first segment from the anterior tip. This is the clitellum and forms a bag in which the eggs are placed when laid. Rub the upper and lower surface of the worms with your fingers. Any differences? Account for this.

Find the mouth and posterior opening of the food tube. Can you find any other structures or openings?

Make a diagram of the first forty and the last five segments of the earthworm.

The earthworm. The common earthworm is familiar to most of us. It has an elongated body made up of segments or rings. It is sensitive to food, to odors, to heat, to light, and to other stimuli. Four rows of tiny, movable bristles called setae are found on all the segments except the first three and the last. Locomotion is accomplished by the thrusting forward of the н. BIO -16 
anterior end ; the setae there are anchored, then a wave of muscular contraction passes down the body, shortening the body by drawing up the posterior end.

How the earthworm digs holes. The earthworm is not provided with hard jaws or teeth. Behind the mouth opening is a part of the food tube called the pharynx. It acts as a suction pump and

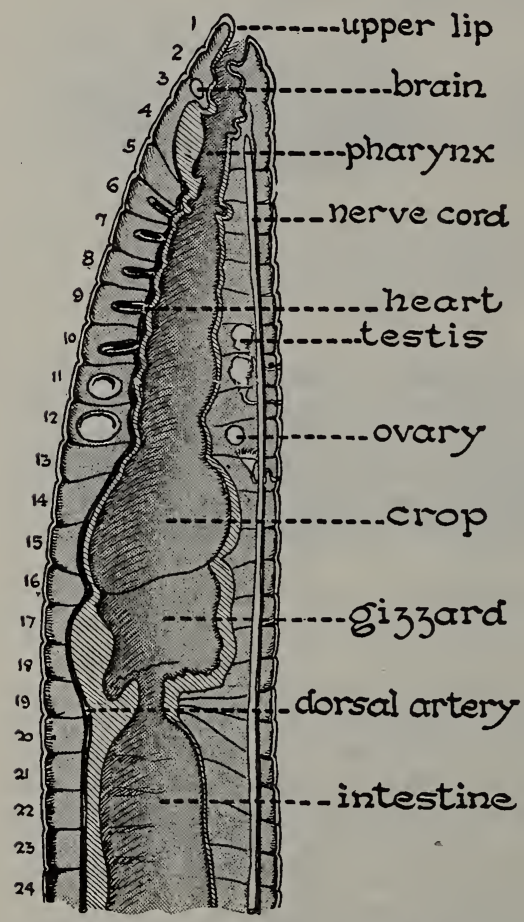

A longitudinal section through an earthworm. In what segments are the hearts, the crop, the gizzard, the brain, the reproductive organs? draws particles of the soil into the food tube. Organic matter in the soil is used as food and the unused soil is passed out of the body and deposited on the surface of the ground, in the form of little piles called worm casts. Charles Darwin calculated that fifty-three thousand worms may be found in an acre of ground and that ten to fourteen tons of soil might pass through their bodies in a single year.

Life processes of the earthworm. The digestive tract of the earthworm is an almost straight tube inside of another tube. The latter is divided by partitions which mark the boundary of each segment. The outer cavity is known as the body cavity, and the inner cavity as the digestive tube. Food is digested within the food tube, passed through the walls of this tube by means of osmosis, and is absorbed by the blood which carries it to various parts of the body. The earthworm has no gills or lungs. The moist skin acts as an organ of respiration, taking in oxygen and giving off carbon dioxide. The nervous system is on the ventral side of the body but forms a ring around the food tube in the 
anterior end of the body with a tiny brain just above the pharynx in the third anterior body segment.

Reproduction. The earthworm has both male and female sex cells present in its body and hence is said to be hermaphroditic (hẽr-măf'ró-dĭt’ík). In order to have the eggs fertilized when they are laid a mutual exchange of sperm cells takes place between two worms, the sperms being placed in four little sacs on the under side of each worm. Later a swollen area called the clitellum (about one third the distance from the anterior end) forms a girdle which, as it passes toward the anterior end of the earthworm, receives from body openings the eggs, the sperms received from the other earthworm, and a nutritive fluid in which the eggs live. The fertilized eggs are then left to

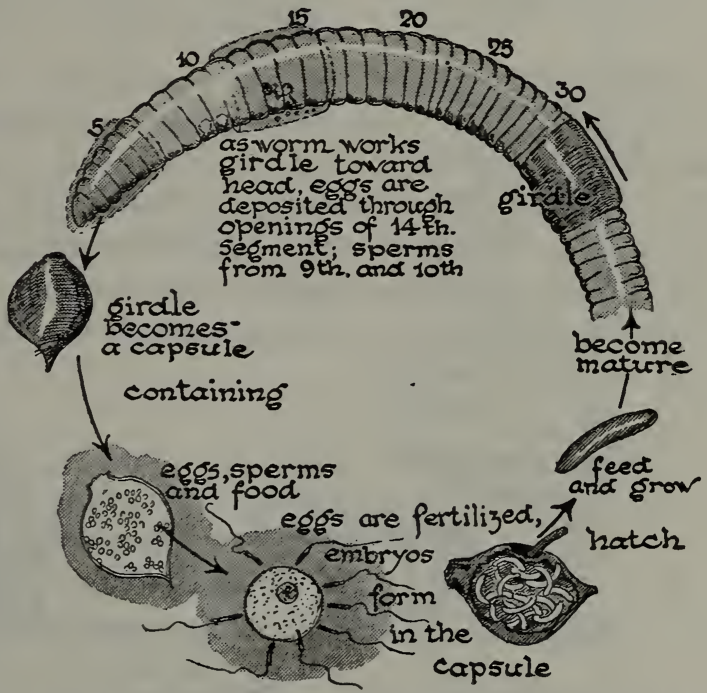

A secretion, given off by the clitellum of the earthworm, hardens, forming a cocoon or girdle which surrounds the body. What is the use of this girdle?

hatch. The bags or cocoons may be found in manure heaps or under stones, in May or June.

Practical Exercise 6. What worms are found in your locality? Are there any useful ones? Any harmful ones? What is the difference between a worm and a caterpillar?

\section{Self-Testing Exercise}

Check the true statements in your workbook.

T. F: 1. Invertebrates have a backbone and an internal skeleton.

T. F. 2. Protozoa are single-celled animals.

T. F. 3. Sponges live only in the ocean. 
T. F. 4. Examples of coelenterates are sea anemones and starfish.

T. F. 5. The Platyhelminthes are the roundworms.

T. F. 6. An example of an annulata is an earthworm.

T. F. 7. The earthworm has a digestive tract inside the body cavity.

T. F. 8. Starfish are echinoderms.

T. F. 9. The Nemathelminthes are the roundworms.

\section{PROBLEM III. WHAT ARE THE CHARACTERISTICS OF THE ARTHROPODS?}

Arthropoda (Gr. arthros, joint; pous, foot). All animals which are jointed, have limy or chitinous exoskeletons, and jointed appendages belong to this phylum, Arthropoda. They live in water, or on land, or in the air. Most of them undergo a metamorphosis. There are about 500,000 known species, more than all the rest of the animal kingdom put together. These animals are similar to the annelids or worms in that their bodies are composed of a number of segments.

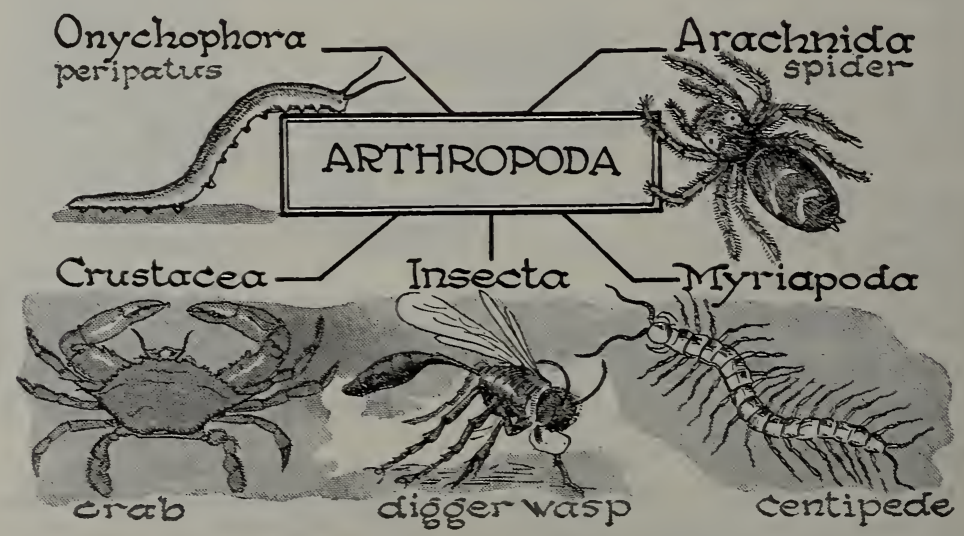

Class I. Onychophora. These are simple wormlike animals. They live on land.

CLAss II. Myriapoda (thousand legs). They have long bodies with many segments and many paired jointed appendages. Centipedes and millepedes are examples.

Chass III. Crustacea. They live mostly in the water and breathe by means of gills. The head and thorax are fused into a hard covering. They have a "crusty" exoskeleton, strengthened with lime. Examples: crabs and lobsters.

CLAss IV. Insecta. The largest of all classes of animals (over 450,000 species). Body segmented; three regions; head, thorax, and abdomen. Three pairs of jointed legs. Usually compound eyes. Breathe through tracheae or air tubes.

Cl.Ass V. Arachnida (a-răk'nì-da). This group has no antennae, four pairs of legs, and a pair of claw-like appendages on each side of the mouth. Head and thorax combined as in crustacea. The spiders, "daddy-long-legs," scorpions, mites, and ticks are in this class. 
The crayfish. Those animals having a limy exoskeleton, living in the water, and breathing by means of gills are called crustaceans. The crayfish is one of the best known representatives of the crustaceans. The body is covered with a hard skeleton, called exoskeleton, composed largely of lime. This forms an unjointed, shieldlike structure, the carapace, over the anterior part of the body, the abdomen being segmented and movable. The coloring of the shell usually resembles that of its natural surroundings and therefore serves as a protection to the animal.

Crayfishes dart backwards through the water with great rapidity, or they move forward by crawling on the bottom. They have five pairs of walking legs attached to the under side of the head-thorax region. These legs are jointed, and the first three pairs bear pincers. The large pincher claws or chelipeds (kē'lǐ-pěd) are used for food-catching and for defense as well as for locomotion.

Under the abdomen, one pair on each segment except the last, are found jointed appendages, made up of three parts called swimmerets. The last pair, together with the last segment of the abdomen, form a powerful tail used in swimming.

How the crayfish gets in touch with its

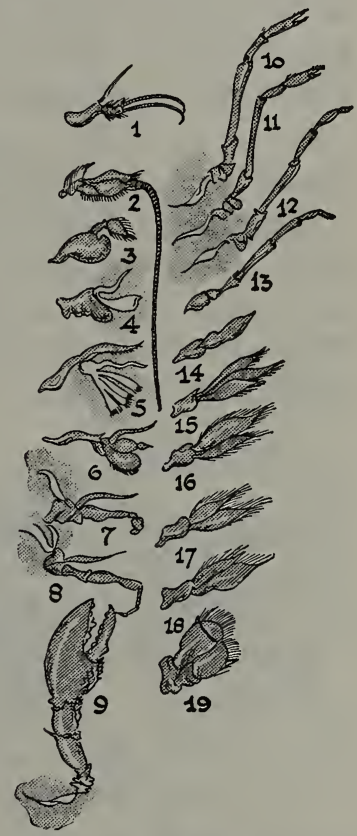

State how the appendages are used by the crayfish. I-5 are appendages found in the head region; 6-r3, on the thorax; and 4 - 19 on the abdomen. surroundings. Two pairs of "feelers," the longer pair called the antennae, the shorter forked pair, the antennules (little antennae), are on the front of the head. The longer feelers appear to be used as organs of touch and smell. The smaller antennules hold at their bases little sacs called balancing organs.

Just above the antennules, projecting on short, movable stalks, are the compound eyes. These eyes are made up of many small structures each of which is a very simple eye. Such an eye 
probably does not have very distinct vision. A crayfish, however, easily distinguishes moving objects and prefers darkness to light, as has been proved by experiment.

Food-getting. The food of the crayfish is obtained with the aid of the pincer claws and shoved toward the mouth. It is pushed on by three pairs of small appendages called foot jaws or maxillipeds, and to some degree by two smaller paired maxillae just under the maxillipeds. Ultimately the food reaches the true jaws, or mandibles, and, after being ground between them, is passed down the gullet into the stomach.

Digestion. Food which has not been ground up previously into pieces small enough for the purpose of digestion is still further masticated by means of three strong projections or teeth called the gastric mill, one placed on the mid-line and two on the side walls of the stomach.

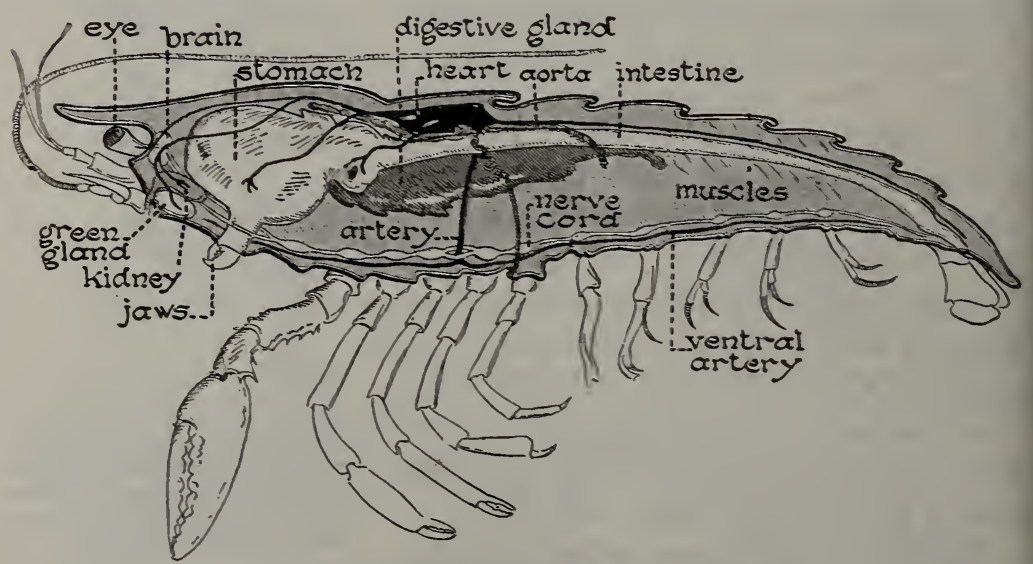

A crayfish, cut lengthwise to show the principal organs.

The stomach is divided into two parts. The entrance to the posterior part is lined with tiny projections which make it act as a strainer for the food passing through. Thus the larger particles of food are kept in the anterior end of the stomach. Opening into the posterior end of the stomach are two large digestive glands, whose juices further prepare the food for absorption by the walls of the stomach and intestine. Once in the blood, 
the fluid food is circulated through the body directly to the tissues which need it.

The gills. The plume-like gills are outside of the body, but are kept moist by being well protected by the overhanging carapace. The blood of the crayfish passes by a series of veins into the long axis of the gill, where the blood vessels divide into very minute tubes, the walls of which are extremely delicate. Oxygen, dissolved in the water, passes into the blood by osmosis, during which process the blood loses some carbon dioxide.

Circulation. The circulation of blood takes place in a system of thin-walled open vessels which allow the blood to come in direct contact with the tissues. The heart lies on the dorsal side of the body, inclosed in a delicate bag (see diagram).

Excretion of wastes. On the basal joint of the antennae are found two projections, in the center of which are tiny holes. These are the openings of the green glands, organs which eliminate the nitrogenous waste from the blood, corresponding to the human kidneys.

Practical Exercise 7. Study the diagram on page 234 and make a diagram of a cross section through a crayfish in the region of the walking legs. Explain how a crayfish might become aware of the presence of food. How might it catch living prey?

Nervous system. The internal nervous system of a crayfish consists of a series of collections of nerve cells called ganglia (găn' glǐ a), connected by means of a nerve cord. Posterior to the gullet, this chain of ganglia is found on the ventral side of the body. At the anterior end it encircles the gullet and forms a brain in the head region. From each of the ganglia, nerves pass off to the sense organs and into the muscles of the body. These nerve fibers are of two sorts, those bearing messages from the outside of the body to the central nervous system (these messages result in sensations), and those which take outgoing messages from the central nervous system, which result in muscular movements.

Life history. The sexes in the crayfish are distinct. The eggs as they pass to the outside of the body of the female are fertilized by the sperm cells. The eggs, which are provided with yolk 
or food material, are glued fast to the swimmerets of the female, where they develop. The young cling to the swimmerets for several weeks after hatching.

North American lobster. In structure the lobster is almost the counterpart of its smaller cousin, the crayfish. It is highly sensitive to changes in temperature, and migrates from deep to shallow water, or vice versa, according to changes in the temperature of the water. The food supply, which is more abundant

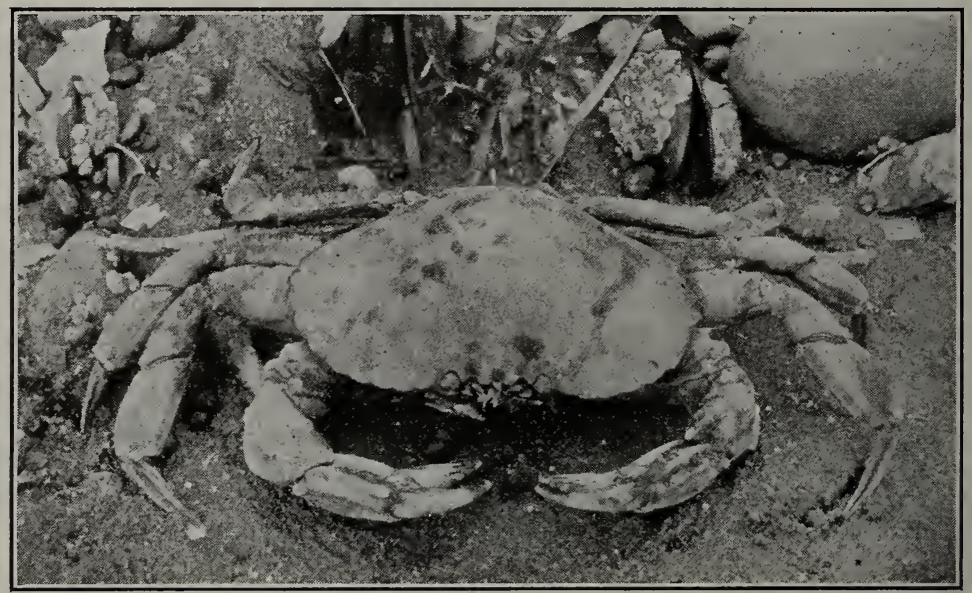

L. W. Brownell

A rock crab. Crabs differ mainly from crayfish in having the abdomen much reduced. Crabs molt, or change their shells, with great frequency when they are young, but rarely after they are fully grown.

near the shore, also aids in determining the habitat of the lobster. As it is the color of the bottom and as it passes much of its time among the weed-covered rocks, it is able to catch living food, even active fishes falling prey to his formidable pincers. It moves around freely at night, usually remaining quiet during the day, especially when in shallow water. It eats some dead food and thus is a scavenger, as is the crayfish.

Several other relatives of the crayfish are the crabs of various species, used for food, on our eastern and western coasts; the shrimps and prawns, thin shelled and small; the fiddler crab, well known to boys and girls of the eastern coast, and the sea-spiders. 
These last-named ones are deep sea crabs and, in some parts of the world, grow to an enormous size.

Insects and Crustaceans. We have already discussed the characteristics of all insects and the distinguishing features of certain orders of insects in Unit III. The bodies of all insects are divided into three distinct regions: head, thorax, and abdomen. Insects have three pairs of legs, breathe through tracheae, usually have two pairs of wings, and undergo a complete or incomplete metamorphosis. They are found everywhere that life can exist.

Insects differ

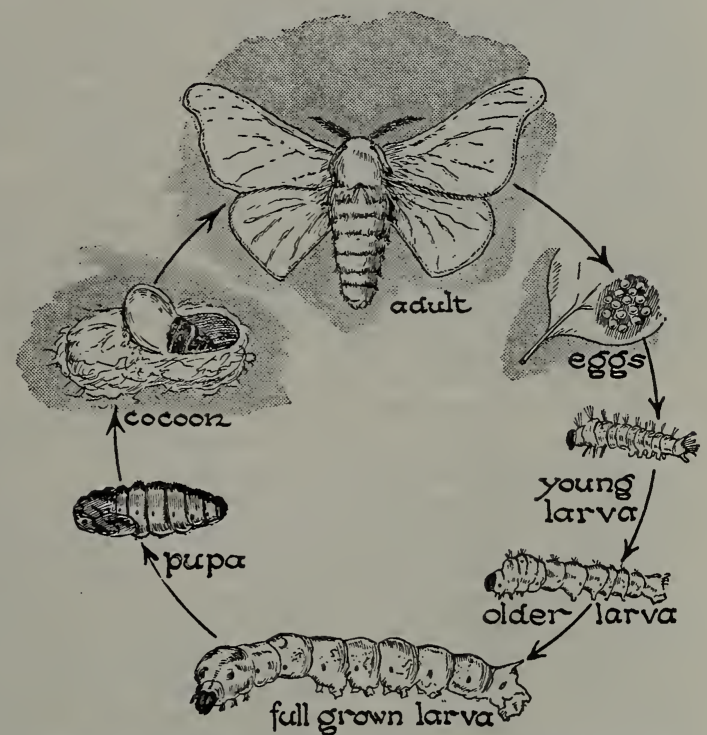

Life history of a moth. Why is the moth classified as an insect? How does it differ from a crustacean?

structurally from crustaceans in having three regions in the body instead of two. The number of legs is always definite in the insects; in the crustaceans the number sometimes varies, but is always more than three pairs. The exoskeleton is composed wholly of chitin ${ }^{1}$ in the insects, but it is sometimes strengthened with lime in the crustaceans. Both groups have compound eyes, but those of the crustacea are stalked and movable. The other sense organs do not differ greatly. The most marked differences are physiological. The crustaceans take oxygen from the water by means of gills, while the insects are air-breathers, using for this purpose air tubes called tracheae. Both insects and crustaceans, because of their exoskeleton, must molt in order to grow.

${ }^{1}$ Chitin (kî̀'tĭn) : a horny substance forming the outer covering of insects. 
There are a number of orders of insects, but examples of the following orders are the ones most commonly found.

Order 1. Coleop'tera (sheath wings). Hard outer wings, forming cover for under wings. Biting mouth parts. Complete metamorphosis. Examples: all beetles and fireflies, etc.

Order 2. Dip'tera (two wings). Insects with two wings, a few with none. Mouth parts fitted for sucking or piercing. Complete metamorphosis. Examples : all flies, mosquitoes, gnats, etc. There are 40,000 described species and it is estimated that there are more than 300,000 as yet undescribed.

Order 3. Ephemer'ida. Insects having complete metamorphosis and biting mouth parts. They have long setae which project from the end of the abdomen. The adult lives only a day or two, lays eggs, and dies. Examples: the mayflies.

Order 4. Hemip'tera (half wings). Sucking mouth parts. Incomplete metamorphosis. Two pairs of wings or none. Examples: chinch bugs and squash bugs.

Order 5. Homop'tera (similar wings). Two pairs of wings alike, sucking mouth parts, incomplete metamorphosis. Examples: cicadas, plant lice, scale insects.

Order 6. Hymenop'tera (membrane wings). Four membranous wings. Mouth parts fitted for biting and sucking. Often long ovipositor modified into sting. Complete metamorphosis. Examples: bees, ants, and wasps, gall and ichneumon flies.

Order 7. Lepidop'tera (scale wings). Four wings, covered with scales. Mouth parts long sucking tube. Complete metamorphosis. Examples: Moths and butterflies.

Order 8. Neurop'tera (veined wings). Four membranous wings with many veins. Biting mouth parts. Complete metamorphosis. Examples: ant lions, dobson flies, etc.

Order 9. Odon'ata. Complete and incomplete metamorphosis. Biting mouth parts. Adults are expert flyers, have large eyes, live mostly in water. Examples: dragon flies and damsel flies.

Order 10. Orthop'tera (straight wings). Four wings, front pair straight and leathery. Biting mouth parts. Incomplete metamorphosis. Examples: grasshoppers, crickets, and cockroaches. Order 11. Siphonap'tera (tube; wingless). Largely parasitic. Sucking mouth parts. Wingless. Complete metamorphosis. Examples: fleas.

Order 12. Trichop'tera (hairy wings) have four hairy wings, rudimentary mouth parts, complete metamorphosis. Examples: caddis flies.

Arachnids (spiders) and myriapods. The body of a spider, like that of the crustaceans, has only two divisions, cephalothorax (head thorax) and abdomen. Spiders have four pairs of walking legs, usually four pairs of simple eyes, and breathe by means of 
lunglike sacs in the abdomen. They have no wings or compound eyes. The silk with which they spin their webs is secreted by means of glands in a liquid form. On exposure to air this fluid hardens and forms a very tough thread which is light and strong.

We are all familiar with the harmless "thousand leggers" found under stones and logs. It is a representative of the group of animals known as the millepedes. These animals have a

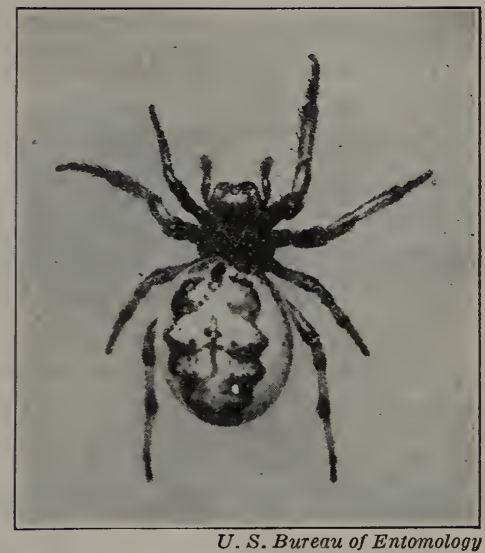

Is a spider an insect? Why?

rounded body divided into two regions, head and trunk, and have two pairs of legs on each body segment. They live in damp places and feed on decaying vegetable matter. They are entirely harmless. The centipedes are long flattened animals with one pair of legs on each segment. Both the millepedes and centipedes are representatives of the class Myriapoda.

Practical Exercise 8. Make four diagrams to show the likenesses and differences between a crustacean, an insect, a myriapod, and a spider. Use books of reference for information. Use colors for different structures, as yellow for exoskeletons, blue for nervous system, red for blood vessel or heart, etc.

Practical Exercise 9. Name all the arthropods you have found living in your environment. Which live in water? On land? In both habitats?

Practical Exercise 10. Study the diagrams of the Arthropods. How many legs has the crab, the centipede, the insect, the spider? Study a real crab and centipede to see how they differ from the insects. From the above study can you make a working definition of an Arthropod? 


\section{Self-Testing Exercise}

Arthropods are animals which have ....... (1) ...... (2) and legs and have a hard ....... (3) ....... (4) made of either .......(5), $\ldots . \ldots$ (6), or both. There are four common .......(7); crustaceans, which live mostly in .......(8) and breathe by means of ....... (9); insects, a ....... (10) group, which has the ....... (11) divided into ....... (12) parts, and has three .......(13) of jointed ....... (14); the myriapods which have .......(15) bodies with .......(16) pairs of .......(17); and the arachnida, spiders, with $\ldots . \ldots$ (18) pairs of legs and no ...... (19), and ...... (20) pairs of simple eyes. The spiders spin ........(21) from silk which they ....... (22) by means of glands.

\section{PROBLEM IV. WHAT ARE THE CHARACTERISTICS OF THE MOLLUSKS?}

Most mollusks have shells composed mostly of lime, either bivalve (two-valved), as the oyster, clam, mussel, and scallop, or univalve (with one valve), as the snail. Usually the univalve shell is spiral in form. Inside the shell, which is formed by a

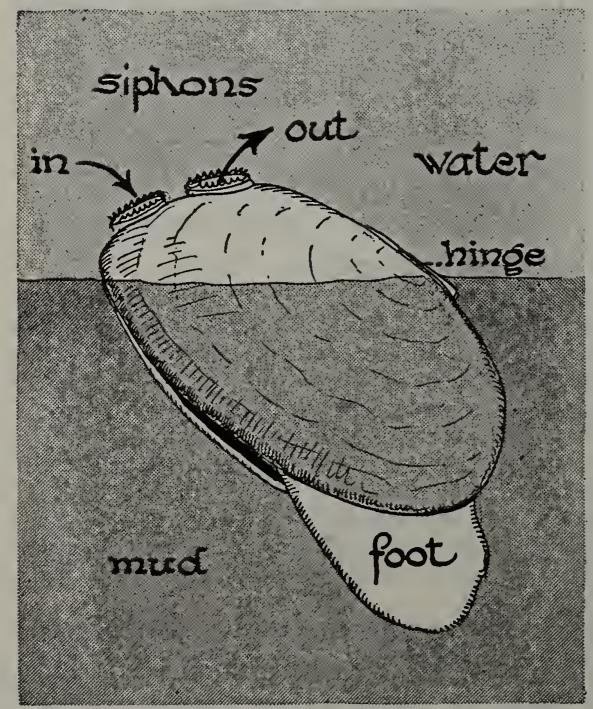

A fresh-water mussel (clam) half buried in the mud. Explain how it moves and how it gets its food. delicate structure called the mantle, is found the soft, unsegmented body, from whence it gets the name mollusk (Latin mollis, soft). Other mollusks, for example the garden slug, have no shell whatever, and one highly specialized form, the squid, has an internal shell.

Pelecypods. Between the mantle and the body of the mollusk is a space, the mantle cavity, in which hang the platelike gills. By means of cilia on the mantle and gills, a constant current of water is 
maintained through the mantle cavity, bearing oxygen to the gills and carbon dioxide away from them. In most mollusks, this current of water passes into and out from the mantle cavity through muscular tubes called siphons.

The food of clams or oysters consists of tiny organisms which are carried in the current of water to .

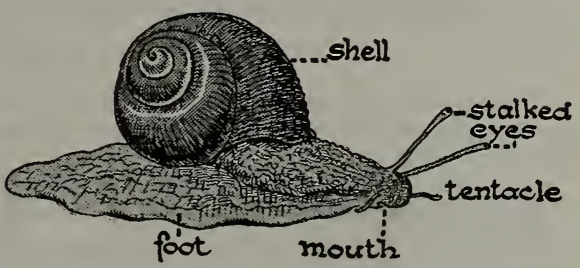

A gastropod (snail). Why is this a mollusk? the mouth of the animal, this water current being maintained in part by the action of cilia on the palps or liplike flaps surrounding the mouth. A single muscular foot enables the clam to move about slowly.

Gastropods. Snails, whelks, slugs, and the like are called gastropods (stomach-footed) because the foot occupies so much space that most of the organs of the body, including the stomach, are covered by it.

Cephalopods. Another class of mollusks are those known as cephalopods (sěf'a-lot-pŏdz). The name means head-footed. As
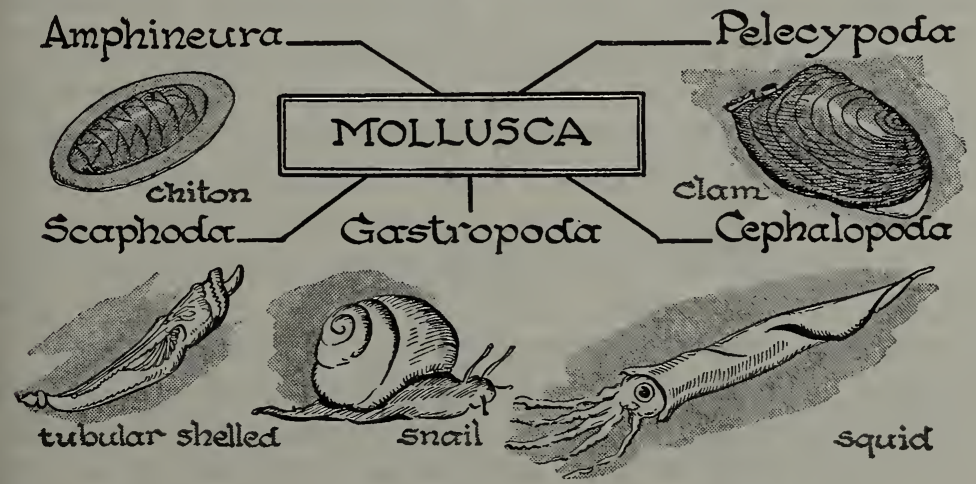

Class 1. Pelecyp'oda (hatchet-footed). Shells of two valves or parts. Clams, oysters, scallops, mussels, etc.

Class II. Cephalop'oda (head-footed). Foot partly surrounds head and bears tentacles or grasping organs. Squid, octopus, outtlefish, etc.

CuAss III. Gastrop'oda (belly-footed). With or without shells, which are usually of one piece and coiled. Snail, whelk, slug.

Cusss IV. Scaphoda. With a tapering tubular shell, with a spadelike foot for burrowing. Tooth shells.

Cusss V. Amphineura. Simple marine mollusks. Protected by a shell of eight arched segments. Chiton. 
the figure of the squid shows, the mouth is surrounded with a circle of tentacles. The shell is internal or lacking.

To this group of animals belong also the octopus, or devilfish; the paper nautilus ; and the pearly nautilus.

Practical Exercise 11. From a study of the diagrams and of the text, make up a good definition of a mollusk. What mollusks are common in your environment?

Mollusca. These animals are soft-bodied animals, often provided with a shell, which is secreted by a part of the body called the mantle. They usually have a single muscular foot on the ventral side. Over 60,000 species are known. There are five classes of mollusks, but only three classes are widely known.

\section{Self-Testing Exercise}

A mollusk is a ....... (1) animal. It usually has a ....... (2) which is ........(3) by the mantle. This ......(4) is either .......(5) as in the oyster, or ......(6) as the snail. Most mollusks, living in the water, take in water through ....... (7) tubes called ........(8). Common examples of mollusks are .......(9), $\ldots \ldots(10)$, and $\ldots \ldots$ (11).

\section{PROBLEM V. WHAT ARE THE CHARACTERISTICS OF FISHES?}

The animals we have studied thus far agree in having any skeleton they may possess on the outside of the body. They are called invertebrates. In higher animals, of which the fish is an example, the skeleton is inside the body. They are called vertebrates. While the exoskeleton of invertebrates is dead material secreted by the body cells the endoskeleton of vertebrates is made up of cartilage and bone, living material, capable of growth and repair. The skeleton of all tertebrates has two main divisions, the axial skeleton, consisting of the skull and vertebral column and the appendicular skeleton, consisting of two pairs of limbs together with the girdles, the bones, by which the limbs are attached to the vertebral column. The vertebral column and skull protect the delicate spinal cord and brain. The limbs support the body and aid locomotion. Vertebrates are segmented but these segments have been highly modified to form the various organs. Vertebrate animals deserve more of our attention than other forms of life because man himself is 
a vertebrate. There are 37,000 known species of vertebrates. These species are divided into five groups or classes: Pisces, or fishes; Amphibia, or amphibians; Reptilia, or reptiles; Aves, or birds; Mammalia, or iThnmals.
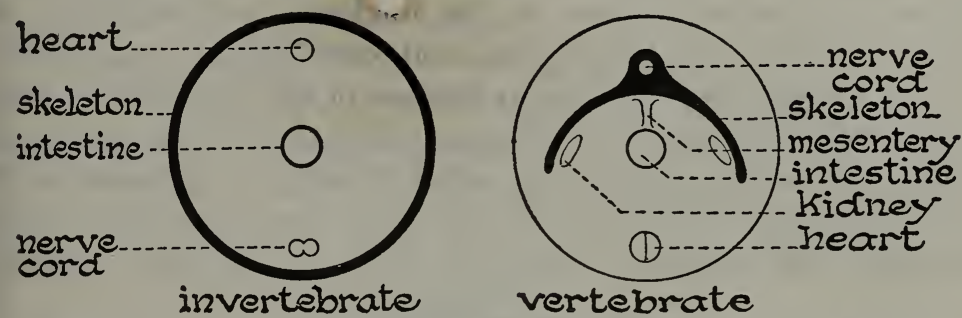

Cross section of an invertebrate and of a vertebrate. In what ways are they similar? In what ways do they differ?

Laboratory Exercise. Adaptations in a fish. How is the body of the fish fitted for life in the water? Mention three different adaptations for swimming. Watch the fish carefully and locate its organs of locomotion. How many single fins are there? How many paired fins?

Try to discover what fins are used in forward motion, in turning, in moving backward. Is the body used in locomotion. How is each particular fin adapted or fitted to do its work?

What structures do you find on the surface of the body? How are these structures placed with reference to each other? Feel the body of the fish. What adaptation for protection exists here? Note the color both above and below. Remembering that many of the enemies of the fish are below him and some above, explain how the animal receives protection from its color. What are the principal adaptations for protection in the fish?

Look at the living fish carefully and observe the movements of the mouth. What is the relation of the movement of the mouth to that of the operculum, the flap which covers the gills? Note position and color of the gills. What gives them this color? Put a few grains of carmine in the water in front of the mouth of the fish. Trace the course of the carmine. Where does it come out? What gas is in the water? How does the fish use this gas? How might this gas come in contact with the gills? Write a paragraph and illustrate with a diagram, showing how 2 fish breathes.

The body. The long, spindle-shaped body, pointed at the anterior end, with its smooth surface, admirably adapts a fish for swimming. Mucus ${ }^{1}$ secreting cells in the skin, and the position

${ }^{1}$ Mucus: a sticky slippery secretion found on the membranes lining various body cavities, as the nose or mouth. 
of the scales, overlapping in a backward direction, are other adaptations for life in water.

The paired fins are called pectoral and pelvic fins because they are attached to the bones forming thailuictoral and pelvic girdles. These fins are homologous to the fcielimbs and hindlimbs of higher animals. The dorsal, anal, and caudal fins are not paired.

A fin is composed of a thin membrane or skin stiffened by long slender spines of bones or cartilage called rays. The caudal fin is light and strong, and, as powerful muscles are attached to it, can push against the water with sufficient force to move the body forward. The flattened, muscular body of the fish, tapering

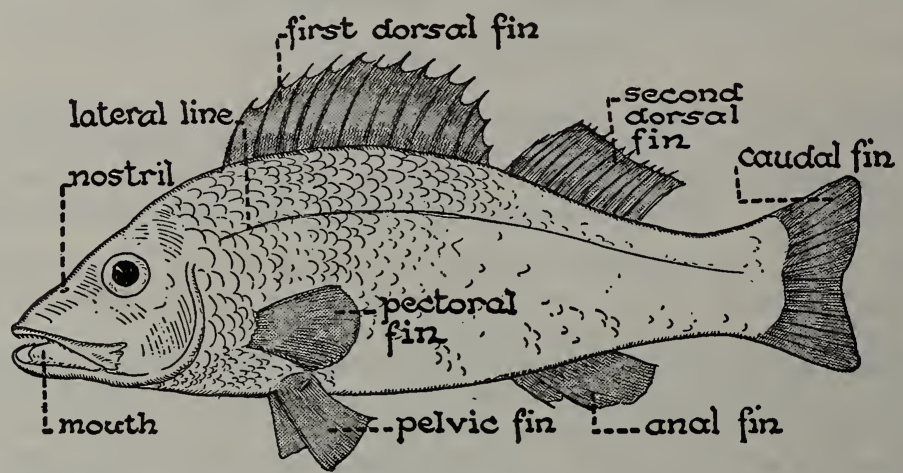

Name all the adaptations you can find in the body of this fish and show how each is an adaptation.

toward the caudal fin, is moved from side to side with an undulating motion which results in the rapid forward movement of the fish. The caudal fin is the principal fin of locomotion. The paired fins are used for turning and balancing.

The sense organs. The eyes, globular in shape, are on each side of the head. They are unprotected by eyelids, but their tough transparent outer covering and their position in the sides of the head afford some protection. A fish becomes aware of the presence of food by smelling it rather than by seeing it. The nostrils, small pits unconnected with the mouth cavity, contain organs for smelling. In the catfish, the barbels, or horns, receive sensations of feeling, smell, and taste. 
Along each side of most fishes is a line of tiny pits, provided with sense organs and connected with the central nervous system. This area, called the lateral line, is believed to be sensitive to mechanical stimuli of certain sorts. The ear of the fish is under the skin and serves partly as a balancing organ.

Breathing. A fish, when swimming quietly and when at rest, seems to be biting even if no food is present. Investigation shows us that under the broad, flat plate, or operculum (ò-pûr'kü-lüm), on each side of the head, lie two pairs of long, feathery structures, gills. The skeleton of the gill, or the gill arch, is composed of

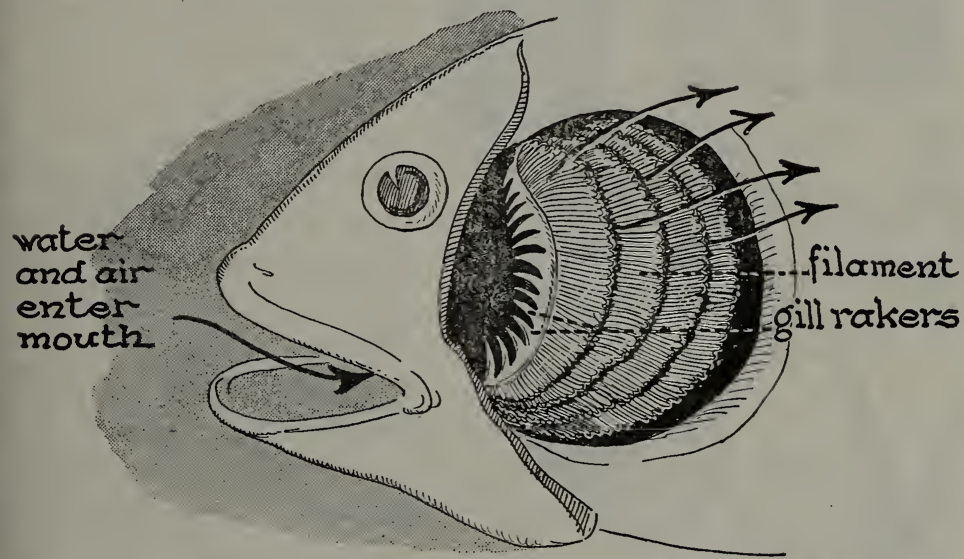

Explain why a fish in an aquarium is continually opening and closing its mouth.

several pieces of bone which are hinged in such a way as to give great flexibility. Covering the bony framework, and extending from it, are numerous delicate gill filaments. These delicate structures are guarded on the inner side by a series of teeth-like structures, the gill rakers. In each of these filaments are two blood vessels; one taking blood to the gills, where it gives up its supply of carbon dioxide, the other vessel taking the blood with its load of oxygen back over the body. A thin membrane separates the blood in the filament from the water bathing the gills. An exchange of gases through the walls of the gill filaments results in a loss of carbon dioxide and a gain of oxygen by the blood. 
Digestive system. The gullet leads directly into a baglike stomach. There are no salivary glands in the fishes. There is, however, a large liver, which appears to be used as a digestive gland. The liver contains

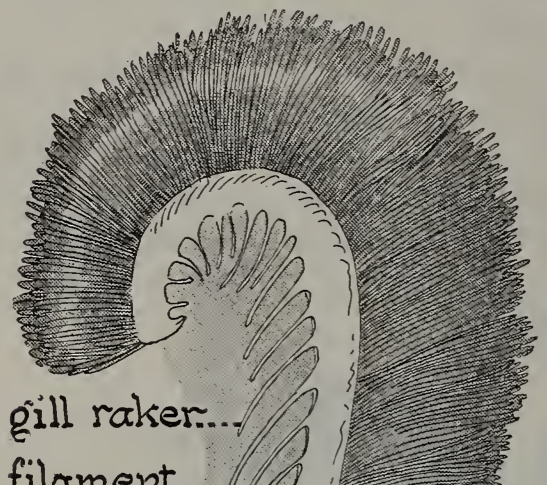
a good deal of oil and therefore is in some fishes, as the cod, of considerable economic importance. Many fishes have outgrowths like a series of pockets from the intestine. These structures, called the pyloric caeca (pĭ-

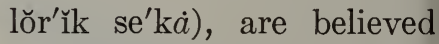
to secrete a digestive fluid. The intestine ends at the vent, or anus, which is usually located on the ventral side of the fish, immediately in front of the anal fin.

Swim bladder. An organ of unusual significance, called the swim bladder, occupies the region just dorsal to the food tube. The size of the swim bladder can be changed by contraction or expansion of its walls. The fish uses this organ to make changes in position so that the water displaced will equal its own weight. In some fishes it is used as a lung.

Explain, by careful study of the diagram, how the blood receives oxygen and how it gets rid of carbon dioxide in the gill.

Circulation of the blood. In fishes the heart is a muscular organ, with two connecting chambers: a thin-walled auricle, or receiving chamber, and a thick-walled, muscular ventricle from which the blood is forced out. The blood is pumped from the 
heart to the gills, where it loses carbon dioxide and receives oxygen; it then passes on to other parts of the body, until it reaches very tiny tubes called capillaries. From the capillaries the blood returns, in veins of gradually increasing diameter, to the heart again. During its course around the body some of the blood passes through the kidneys and is there relieved of its nitrogenous waste. Circulation of blood in the fish is rather slow. Since the temperature of the blood is nearly that of the water in which the fish lives, fishes are called cold-blooded animals.

Nervous system. As in all other vertebrate animals, the nervous system of the fish consists of the brain and spinal cord.

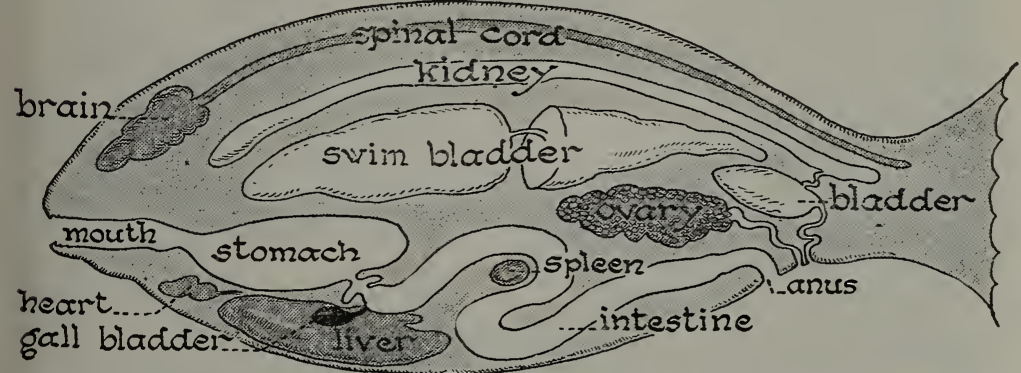

Diagram of a fish cut lengthwise to show the relative position of the internal organs. The veins, arteries, and all smaller organs a e omitted. Where would the gills be with reference to the heart? Why? The swim bladder is attached to the food tube. What is the value of this?

Nerve cells located near the outside of the body send messages to the brain, where they are received as sensations. Cells of the central nervous system, in turn, send out messages which result in the movement of muscles.

The egg-laying habits of the bony fishes (teleosteans). The eggs of most bony fishes are laid in great numbers. The number varies from a few thousand in the trout to many hundreds of thousands in the shad and several millions in the cod. The time of spawning is usually spring or early summer. After the eggs are laid the male usually deposits milt, consisting of millions of sperm cells, in the water just over the eggs. The sperm cells move rapidly through the water to the egg cells, and unite with them, thus bringing about fertilization. Some fishes, as sticklebacks, sunfish, 
toadfish, etc., make nests, but usually the eggs are left to develop by themselves, sometimes attached to some submerged object, but more frequently free in the wator. Some eggs which have a tiny oil drop are buoyed up to the surface, where the heat of the sun

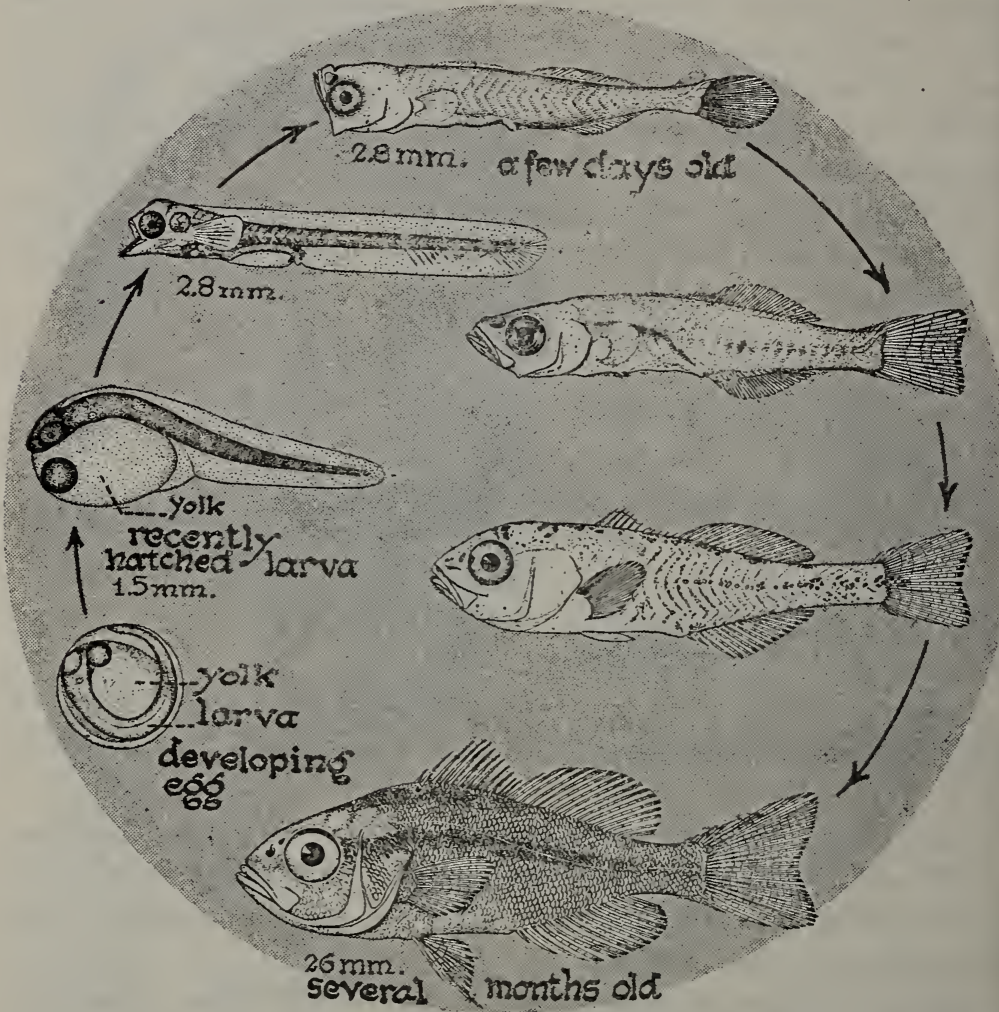

U. S. Bureau of Fisheries

The pigfish or hogfish is a bony fish. It is found from New York to Mexico. The eggs are laid in the early spring, and may hatch within 2 or 3 days. A recently hatched larva is about I.5 millimeters long. A young fish of several months is 26 or more millimeters long.

aids development. Both eggs and developing fish are exposed to many dangers, and are eaten, not only by birds, fish of other species, and other water inhabitants, but also by their own relatives and even parents. Consequently very few of the eggs ever reach maturity. 
Practical Exercise 12. Give a brief definition of a fish that will fit all fishes.

Using the diagram on page 247 , reconstruct a cross section passing through the heart. Use colors for the different organs.

After watching a fish swim make a diagram to illustrate how a fish moves forward in the water.

Fishes. All fishes live in the water. They usually secure oxygen by means of gills. They move by means of appendages called fins. Four of these fins are paired and are homologous to the legs and arms of man. They all possess a vertebral column.

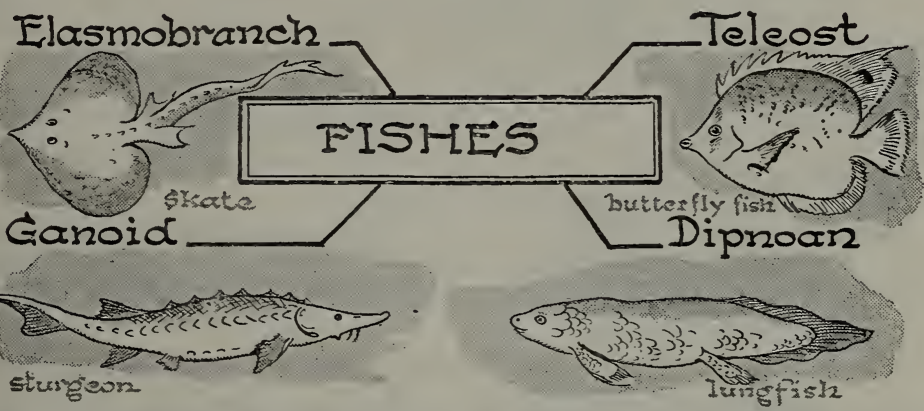

OrDier 1. Elasmobranch. Fishes which have a soft skeleton made of cartilage, and exposed gill slits. Examples: sharks, skates, and rays.

ORDER 2. Ganoid. Fishes which once were very numerous on the earth, but which are now almost extinct. They are protected by platelike seales. Examples: gars, sturgeon, and bowfin.

ORDER 3. Teleostans, or Bony Fishes. They compose 95 per cent of all living fishes. In this group the skeleton is bony, the gills are protected by an operculum, and the eggs are numerous. Most of our common food fishes belong to this class.

ORDER 4. Dipnoan, or Lung Fishes. This is a very small group. In many respects they are more like amphibians than fishes, the swim bladder being used as a lung. They live in tropical Africa, South America, and Australia, inhabiting the rivers and lakes there.

\section{Self-Testing Exercise}

Fishes have a .......(1) made up of irregular-shaped bones. This is called the $\ldots \ldots$. (2) $\ldots \ldots$ (3). In addition there is an exoskeleton which may take the form of .......(4). The fish is adapted for life in the water by the ....... (5) of its body, ...... (6) glands in skin and .......(7) for breathing. The fish has a $\ldots \ldots$ (8) ....... (9), a ...... (10) chambered heart and a welldefined nervous system consisting of a ......(11), ......(12) $\ldots \ldots$..... (13), and .......(14) organs. Many ......(15) are laid but only a ......(16) reach maturity as the ......(17) are exposed to many .......(18) and are eaten by other .......(19) as well as other enemies. 


\section{PROBLEM VI. WHAT ARE THE CHARACTERISTICS OF AMPHIBIANS?}

Laboratory Exercise. Adaptations in a living frog. Examine the skin, note body shape, shape of head, etc., of a frog. What adaptations for its life in the water can you find?

Examine the appendages. How are they adapted for locomotion? Note their position in relation to the long axis of the body. What are the positions of the webbed toes, and of the legs, when at rest and when swimming or jumping.

Compare the position of the eyes of the frog with those of a fish; with your own eyes. In which directions can a frog see? Note the eardrum just back of the eye. What evidence have you that a frog can hear?

Watch a frog catch a fly or other prey and explain how it is done. Examine the mouth of a dead frog. Where is the tongue? How is it attached? How might it be used? Does a frog have teeth? How do you think it eats its food after catching it?

Look for movements of the throat, nose, and abdomen of a quiet frog. Does the frog open its mouth while breathing? Can it breathe under water? Can you describe the process of breathing in a frog?

Sense organs. The frog is well provided with sense organs. The eyes are large, globular, and placed on each side of the head. When the frog goes under water, a delicate fold, called the nictitating membrane (or third eyelid), is drawn over each eye. The vision of a frog is much keener than that of the fish. The external ear, tympanum (tĭm'p $\dot{a}-\mathrm{n} \breve{u m}$ ), is located just behind the eye on the side of the head. Frogs hear sounds and distinguish various calls of their own kind, as is proved by the fact that they recognize the warning notes of their mates when any one is approaching. The inner ear has to do with balancing the body as it does in fishes and other vertebrates. Touch is a well-developed sense. Frogs respond to changes in temperature under water, and go into a dormant state for the winter when the temperature of the air becomes colder than that of the water. Taste and smell are probably not strong sensations in a frog.

Food-getting and digestion. The frog's mouth is large and can be opened very wide. Its sticky tongue is long and flexible. It is attached to the front of the floor of the mouth and can be thrown out with great rapidity to secure living prey. The mouth leads into a short tube, the gullet, which widens into a long stomach. 
The stomach in turn leads into a narrow, much-coiled small intestine, which widens to form the large intestine, the last part of which is the cloaca (Latin, sewer). The kidneys, urinary bladder, and reproductive organs (ovaries or testes) open into the large intestine. Several glands, the gastric glands, the liver, and the pancreas, produce digestive fluids. These digestive fluids by means of enzymes change insoluble food materials into a soluble form which may be absorbed and become part of the blood.

Breathing. The frog takes air into its mouth by lowering the floor of the mouth and drawing air in through the two nostril holes. Then the little valve-like flaps over the holes are closed, the floor of the mouth is raised, and the frog forces the air down into the baglike lungs. When the nos-

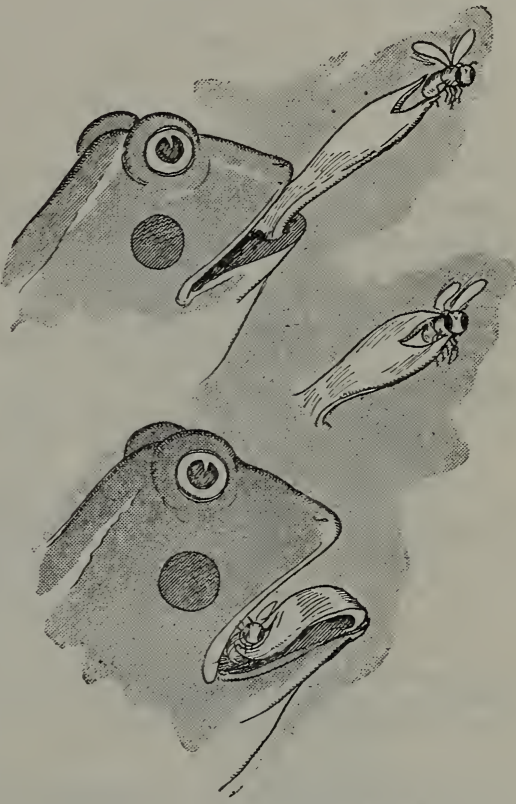

Explain how the frog captures its food. tril flaps are lifted the air is forced back to the mouth by the pressure of the body wall and the contraction of the lungs. Then the mouth floor is raised and the air is forced to the exterior. The lungs contain air spaces surrounded by walls filled with small blood vessels, by means of which oxygen is taken up and carbon dioxide is given off. The skin also is provided with many tiny blood vessels which absorb oxygen and give off carbon dioxide.

Practical Exercise 13. How does a frog breathe during his winter sleep at the bottom of a pond?

Circulation. The frog has a well-developed heart, composed of a thick-walled muscular ventricle and two thin-walled auricles. 
The heart pumps the blood through a system of closed tubes to all parts of the body. Oxidation must take place in the cells of the body wherever work is done. Food in the blood is taken to the

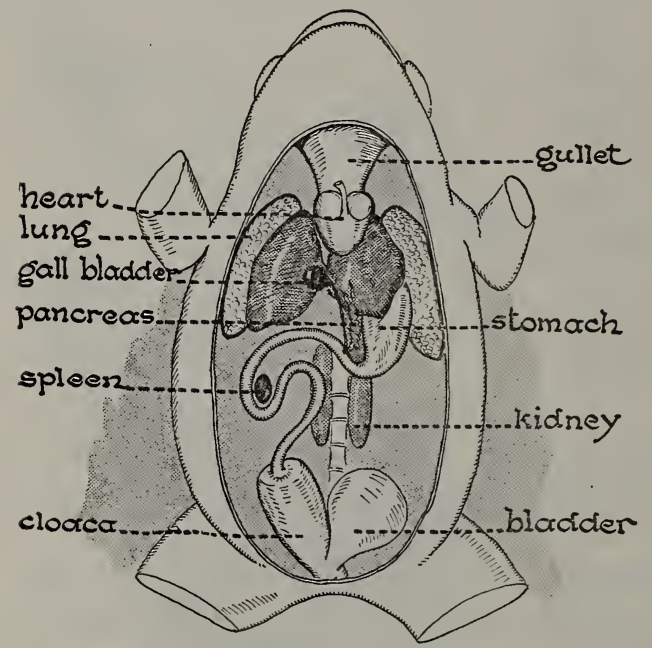

A dissected frog. Seen from the under side. What systems are represented in this figure? What parts are left out of the drawing or are not labeled? muscle cells or other cells of the body and there oxidized. The products of oxidation, chiefly carbon dioxide, and any other organic wastes given off from the tissues must be eliminated from the body. As we know, the carbon dioxide passes off through the lungs and to some extent through the skin of the frog, while the nitrogenous wastes are eliminated by the kidneys.

Nervous system. The frog has a brain and spinal cord and in general its central nervous system resembles that of man.

Reproduction and life history. The eggs of the common frog are laid in shallow water in the early spring. Masses of several hundred, which may be found attached to twigs or other supports under water, are deposited at a single laying. Immediately before leaving the body of the female they receive a protective coating of jellylike material, which swells up after the eggs reach the water. The upper side of the egg is dark, the light-colored side being weighted down with a supply of yolk (food). The eggs are fertilized in the water by sperms which are discharged about the same time as the eggs. The fertilized egg soon divides into many cells and in a week or ten days, if the weather is warm, it develops into a tiny oblong body with a wide tail and indistinct head, which wriggles itself free of the inclosing jelly. This form is known 
as a "tadpole" or "polliwog." At first it is attached to some water weed by means of a suckerlike projection; but in one or two weeks' time, depending upon temperature, it frees itself and becomes a free-swimming tadpole. A mouth is formed at the suckerlike projection, and the tadpole begins to feed upon algae and other tiny water plants. At this time, gills are present on the outside of the body. Later, these gills are replaced by others which grow out under the fold of the skin. Water reaches the gills through the mouth and passes out through a hole on the left side of the body. As the tadpole grows larger, legs appear. The hind legs grow out first. At the same time the tail becomes shorter and shorter. Shortly after the legs appear, the gills are absorbed, and lungs take their place. At this time the young animal may be seen coming to the surface of the water for air.

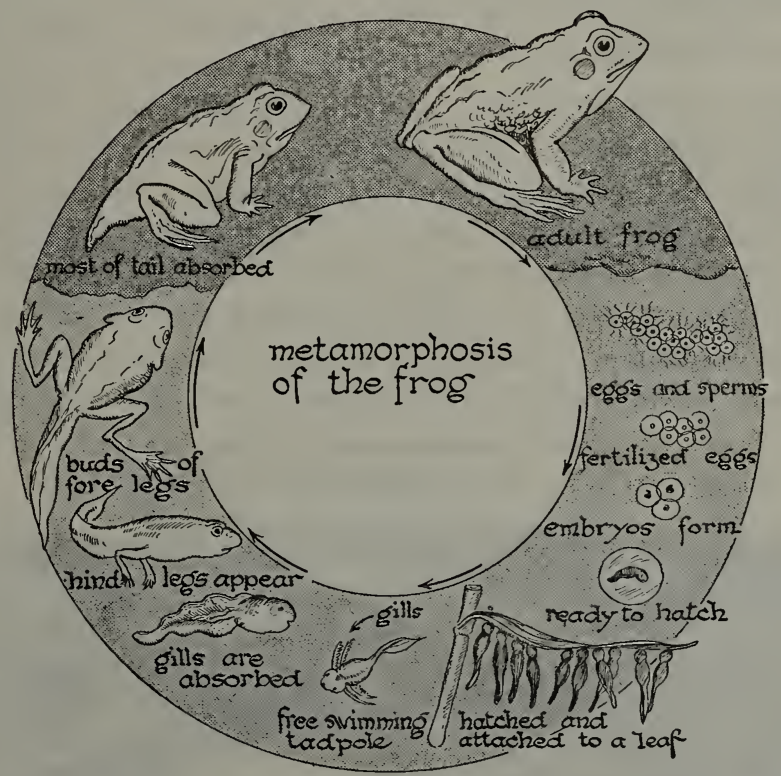

Trace the life history of the frog. How loug does it take for the frog to pass through this metamorphosis? (Use the frog co.nmon to your locality to azswer this question.)

Changes in the diet of the animal also occur; the long, coiled intestine is transformed into a much shorter one. The animal, 
now insectivorous in its diet, becomes provided with tiny teeth and a mobile tongue, instead of the horny jaws used in scraping off algae. After the tail has been completely absorbed and the legs have become full grown, there is no further structural change,

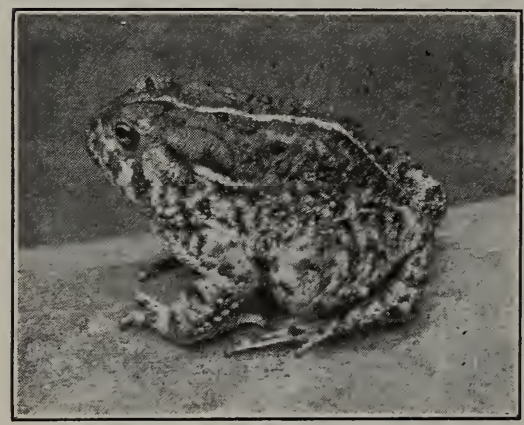

How does a toad differ from a frog? and the metamorphosis is complete.

Practical Exercise 14. Make a series of diagrams to show changes in methods of breathing in the frog, from hatching to adult.

Compare the metamorphosis of a frog with an insect. Can you find four stages in each: egg, larva, pupa, adult?

Toad. One of the nearest relatives of the frog is the common toad. Its ugly appearance has given it a bad name. Toads do not cause warts, and do much good in our gardens by eating harmful insects. Their eggs are laid in strings, and like those of the frog, are deposited in fresh-water ponds. As many as eleven thousand eggs have been laid by a single toad. The egg-laying season of the toad is later than that of the frog. Toad tadpoles differ from those of the frogs, by being darker in color, and having a more slender tail and a relatively larger body.

Other amphibians. The tree frogs or tree toads are familiarly known to us in the early spring as the "peepers " of the swamps. They are among the earliest of the frogs to lay their eggs. During

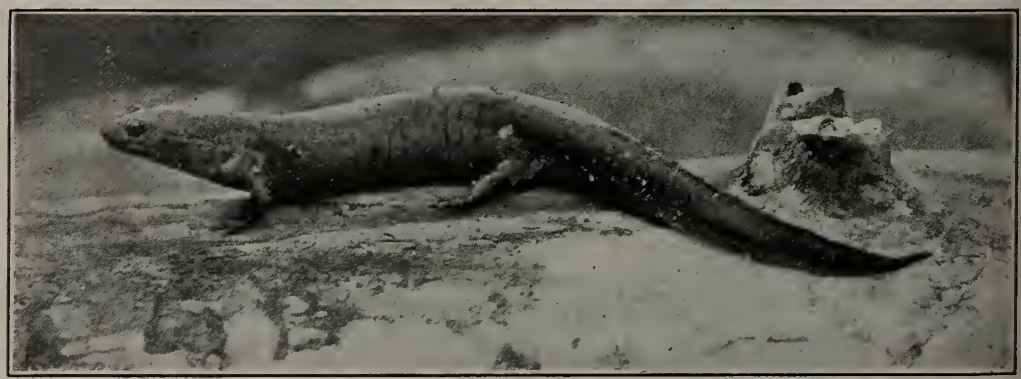

Why is the red salamander an amphibian?

L. W. Brownell 
adult life they spend most of their time on the trunks of trees. Another common amphibian is the newt, a salamander. This smooth-skinned, four-limbed animal, often incorrectly called a lizard, passes its larval life in the water, where it breathes by means of external gills. Later it loses its gills, becomes provided with lungs, and comes out on land, but after two years it goes back to the water again to lay its eggs.

Some salamanders never have lungs, but breathe through the moist skin. Still other amphibians are the mud puppies, sirens or mud eels, and the axolotl.

Practical Exercise 15. Name all the amphibians in your locality. Why is the frog an amphibian? What other animals outside the amphibians could you consider as amphibious animals? frog.

Practical Exercise 16. Compare the life history of a toad with that of a

Amphibia. As the name indicates (amphi, both, and bios, life), members of this group live during their life history both in water and on land. In the earlier stages of their development they take oxygen into the blood by means of gills. When adult, however, they breathe by means of lungs. At all times, but especially during the winter, the skin serves as a breathing organ. The skin is soft and unprotected by bony plates or scales. The heart has three chambers : two auricles and one ventricle. Most amphibians undergo a metamorphosis, or change of form, the young being unlike the adults. About 1500 species are known.

\section{AMPHIBIA}

\section{uroolela}

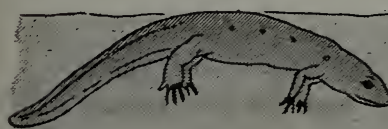

newt

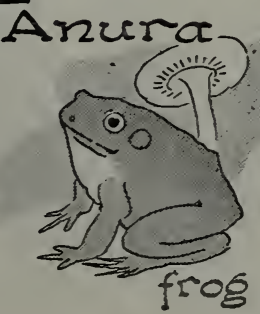

ORDER 1. Urode'la. Amphibia having poorly developed appendages. Tail persistent through life. Examples: mud puppy, newt, salamander.

ORDER 2. Anu'ra. Tail-less Amphibia. which undergo a marked metamorphosis, breathing by gills in larval state, by lungs in adult state. Examples: toad and frog. 


\section{Self-Testing Exercise}

Frogs are adapted to their environment by having ....... (1) feet and a thin skin filled with .......(2) .......(3) by means of which they ....... (4) oxygen. The frog breathes air by means of (5). The short .......(6) leads into a bag-like .......(7) which in turn opens into a much-coiled small .......(8). The heart is.......(9) chambered. .......(10) are laid in water and develop into .......(11) which breathe by ......(12). These are replaced by .......(13). The tadpole feeds on ......(14) $\ldots \ldots \ldots$ (15), but the adult frog eats ....... (16). A relative of the frog is the ....... (17). It lays its eggs in ......(18) in the water while those of the frog are found in .......(19). Toads are of much ....... (20) in gardens where they ...... (21) ...... (22) insects. Other examples of ......(23) are newts and salamanders.

\section{PROBLEM VII. WHAT ARE CHARACTERISTICS OF THE REPTILES?}

Turtles' adaptations for life. The turtles form a group, including both sea and land animals, the latter called tortoises. The body

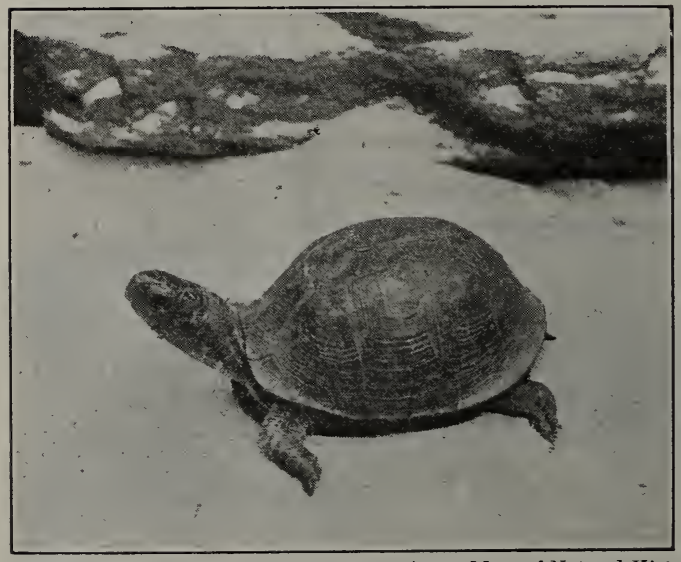

Amer. Mus. of Natural Hist.

How does the three-toed box turtle seem fitted to its environment? is short and broad, and is covered on the upper and lower sides by a bony framework of plates cemented to the true bone underneath. This shell is an adaptation for protection.

The long neck and powerful, horny jaws are factors in procuring food. Turtles have no teeth. Prey is seized and held by the jaws which 
have sharp, chisel-like edges while the claws of the front legs are used to tear the food.

Turtles are very strong for their size. The stout legs carry the animal slowly on land. In some water turtles the front limbs are modified into flippers for swimming. The strong claws are used for digging, especially at the egg-laying season, for some turtles dig holes in sandy beaches in which the eggs are deposited.

Turtles are mostly aquatic in habit. Among the exceptions are the box tortoise and the giant tortoise of the Galapagos Islands. Many of the salt-water turtles are of large size, the leatherback and the green turtle often weighing six hundred to seven hundred pounds each.

Lizards. Lizards may be recognized by their long body with four legs of nearly equal size. The body is covered with scales. The animal never lives in water, is active in habit, and does not undergo a metamorphosis. Lizards are generally harmless creatures, the poisonous Gila monster of New Mexico and Arizona being one exception. Lizards are of economic importance to man because they eat injurious insects. The iguana of Central America and South America, growing to a length of three feet or more, has the distinction of being one of the few edible lizards.

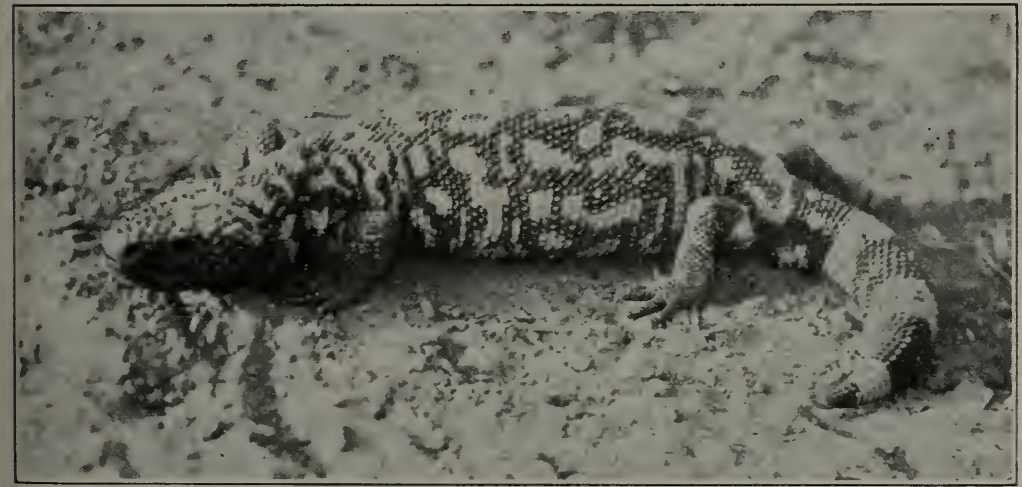

Wright Pierce

The Gila monster is the only poisonous lizard in the United States. It is brilliantly colored in red and black. What may be the value of this coloring? 
Snakes. Probably the most disliked and feared of all common animals are snakes. This feeling, however, is rarely deserved, for, on the whole, our common snakes are beneficial to man, for they live largely on injurious animals, such as rodents, insects, and slugs.

Locomotion. Snakes are almost the only vertebrates without appendages. Although the limbs are absent, the pelvic and pectoral girdles are developed. The very long backbone is made up of a large number of vertebrae. As many as four hundred are

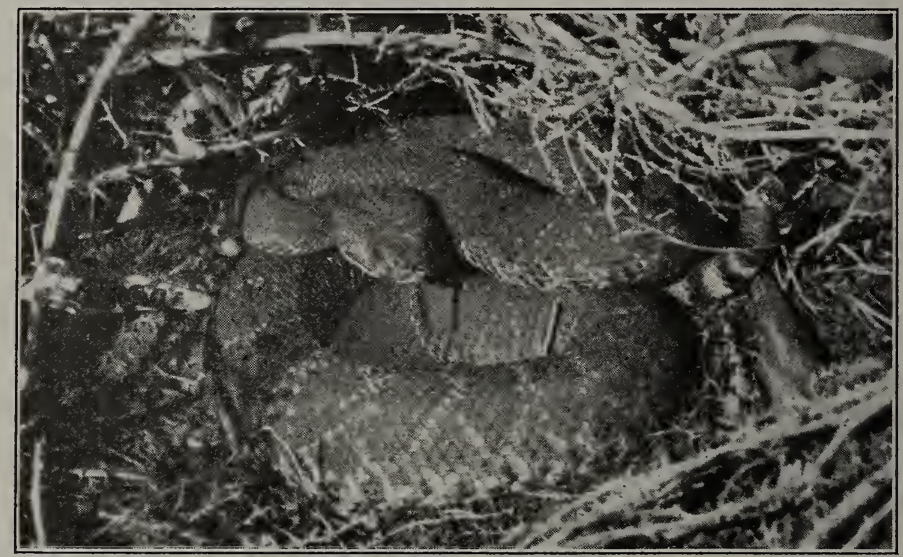

Wright Pierce

The rattlesnake is one of the few poisonous snakes. The snake is coiled, with rattlers buzzing, ready to strike.

found in the boa constrictor. Ribs are attached to all the vertebrae in the region of the body cavity. They progress with a gliding motion caused by pulling and pushing the body along the ground, a leverage being obtained by means of the broad, flat scales, or scutes, on the under side of the body.

Feeding habits. The mouth is a wide, slitlike opening extending nearly around the anterior end of the head, and is therefore capable of wide distention. A snake holds its prey by means of incurved teeth. In the poisonous snakes two of these teeth are hollow or grooved, and serve as a duct for the passage of poison. The poison glands are at the base of the curved fangs in the upper jaw. 
The tongue, an organ of touch and taste, is very long and forked at the end. The food is swallowed whole, and pushed down by rhythmic contractions of the muscles surrounding the gullet. Snakes usually refuse other than living prey.

Alligators and crocodiles. Crocodiles are mostly confined to Asia and Africa, while alligators are natives of North and South America. The chief structural difference between them is that the teeth in alligators are set in long sockets, while those of the crocodiles are not. Both of these lizardlike animals have broad, vertically flattened tails adapted to swimming. Their skins are very tough and are covered with bony scales.

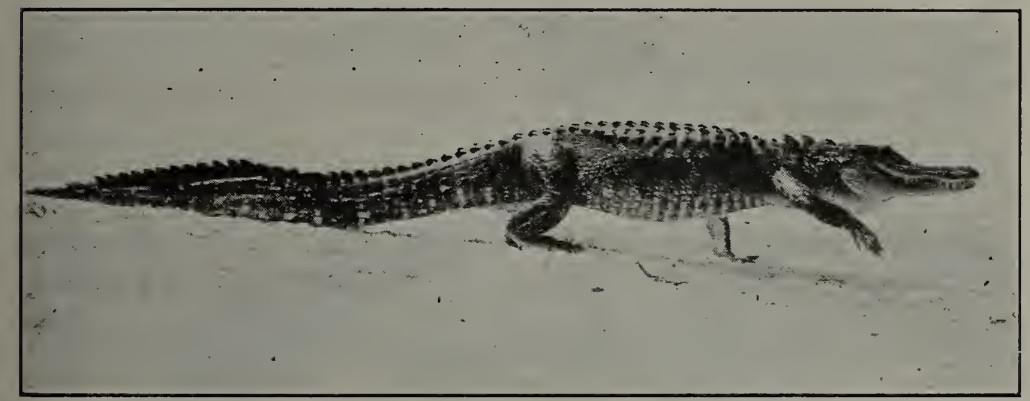

Why is the alligator classified as a reptile?

Amer. Mus. of Nat. Hist.

Practical Exercise 17. Give a good definition of a reptile. What reptiles are common in your locality?

Practical Exercise 18. What is one character by which you can distinguish a reptile from an amphibian? In what part of this country are reptiles most numerous? Why?

Reptiles. These animals are characterized by having scales developed from the skin. In the turtle they have become bony and are connected with the internal skeleton. Reptiles always breathe by means of lungs, differing in this respect from the amphibians and fishes. They have the same temperature as their surroundings and usually hibernate as soon as winter comes. They show their relationship to birds by laying large eggs, incased in a leathery, limy shell. There are about 1500 known species. 

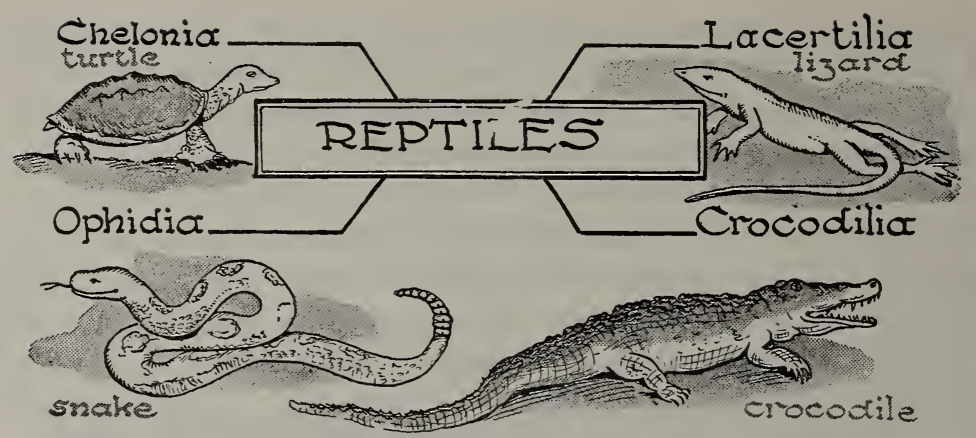

ORDER 1. Chelo'nia (turtles and tortuises). Flattened reptiles with body inclosed in bony case. No teeth or sternum (breastbone). Examples: snappinz turtle, box tortoise.

ORDER 2. Lacertil'ia (lizards). Body covered with scales, usually having two-paired appendages. Examples: fence lizard, horned toad.

ORDER 3. Ophid'ia (snakes). Body elongated, covered with scales. No limbs present. Examples: garter snake, rattlesnake.

ORDER 4. Crocodil'ia. Fresh-water reptiles with elongated body and bony scales on skin. Two-paired limbs. Examples: alligator, crocodile.

\section{Self-Testing Exercise}

Reptiles are animals which have .......(1) or .......(2) plates developed from the ....... (3). They always breathe by means of

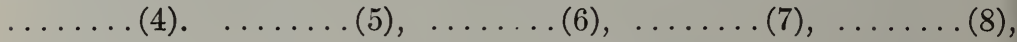
and $\ldots \ldots \ldots(9)$ are examples of reptiles.

\section{PROBLEM VIII. WHAT ARE THE CHARACTERISTICS OF BIRDS?}

Adaptations of birds. Birds are distinguished from all other animals by their covering of feathers and by the modification of the fore limb into a wing for flight. Hollow bones, feathers, and air sacs inside of the body cavity give buoyancy to the body and aid it in staying up in the air. The body is conically-shaped. The tail acts as a rudder. The bill is horny and adapted for securing food. The legs show variations for running, perching, scratching, or swimming.

The wing is a modified arm, with the fingers very much reduced. To the posterior edge of the wing are iastened long quill feathers which overlap and make a broad, stiff surface for pressing against the air. The wing is jointed and moves in flight like a horizontal figure eight. Powerful breast muscles are attached to the wing 
bones and give great strength in movement. The rate of movement of the wing differs greatly in different birds. The wing of a bird is slightly concave on the lower surface when outstretched. Thus on the downward stroke of the wing more resistance is offered to the air. The soaring of birds is probably accomplished by very slight movements of the wings which result in making use of wind currents.

The tail is sometimes used in balancing; its chief function, however, appears to be that of a rudder during flight. Most birds have under the skin of the tail a large oil gland, whence comes the supply of oil that is used in waterproofing the feathers when they preen themselves.

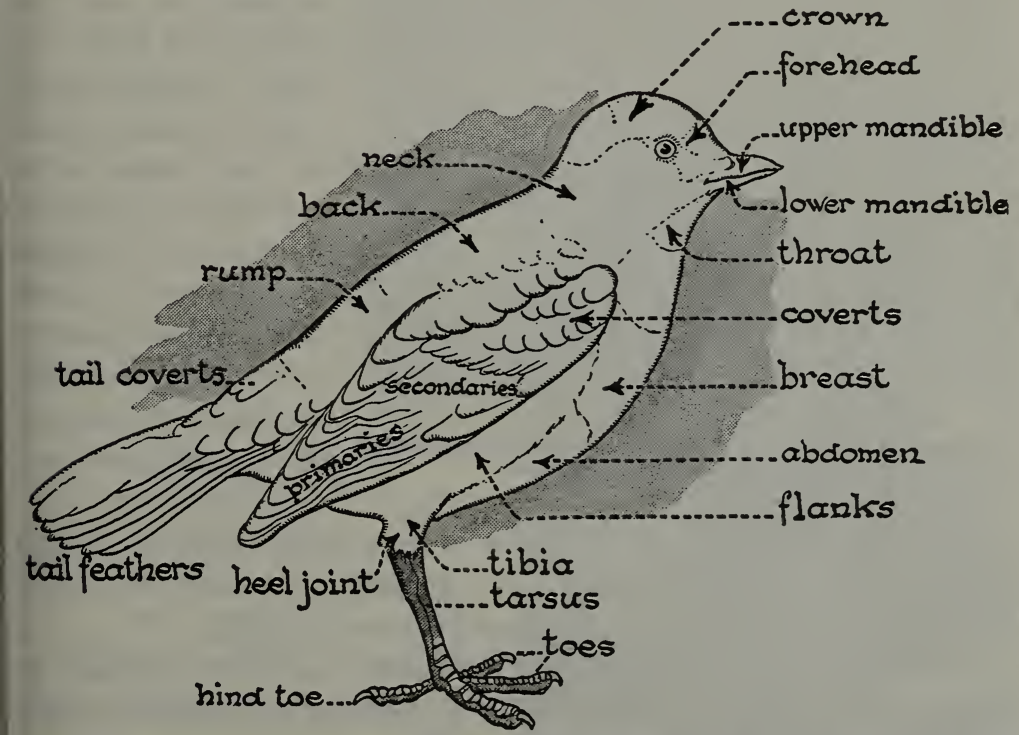

Find and list all the adaptations in this bird. Explain the value of each adaptation named.

Thinly feathered and featherless areas can be found on the body of any bird, although these areas are so well covered by the overlapping feathers that no bare places are to be seen. There are several kinds of feathers on the body of a bird. Soft down feathers make a warm body covering; larger feathers, known as contour H. BIO -18 
feathers, give the rounded contour to the body. In the wings we find quill feathers ; these are adapted for service in flight by having

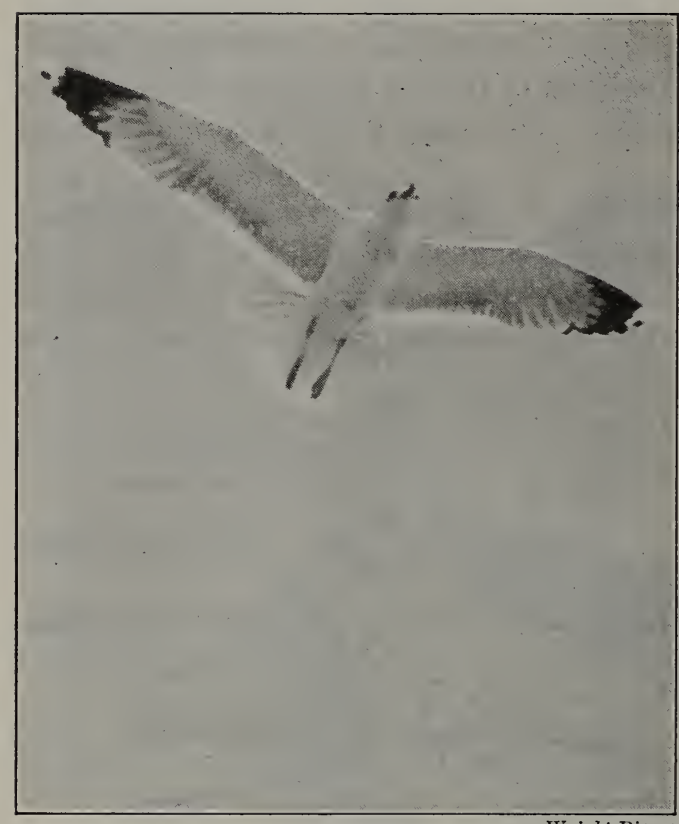

Compare this bird with an airplane. In what ways are they similar, and in what ways different? long hollow shafts, the whole making a light structure and offering considerable resistance to the air. Feathers are developed from the outer layer of the skin, and are formed in almost exactly the same manner as are the scales of a fish or a lizard. Feathers are shed or moulted one or more times during the year, and lost or broken feathers are replaced. Some birds moult twice a year, having different colored feathers in the summer and winter seasons.

Many bones are hollow or have large spongy cavities. Some bones, notably the breastbone, are greatly developed in flying birds for the attachment of the muscles used in flight.

The ankle of a bird is long and reptile-like and, like the foot, is covered with scales. The most extraordinary adaptations are found in the feet of various birds: some for perching, others for swimming, others for scratching, etc. By looking at the feet of a bird we are able to decide almost certainly its habitat, method of life, and perhaps its food.

In the perching birds we find three toes in front and one behind, the hind toe playing an important part in clinging to the perch. The three toes in front curve around the perch, often meeting the 
posterior toe, which is curved also. The tendons of the leg and foot are self-locking. In the flamingoes and other birds, which do not perch, balancing appears to be automatic, for these birds are able to maintain an upright position even when asleep. In swallows, rapid and untiring flyers, the feet are small. In the case of the parrots, where the foot is used for holding food, climbing, and clinging, we find the four-clawed toes arranged two in front and two behind.

The form of the bill shows adaptation to a wonderful degree, varying greatly according to the habits of the bird. A duck has a flat bill for pushing through the mud and straining out the food; a bird of prey has a curved or hooked beak for tearing; the woodpecker has a sharp, straight bill for piercing the bark of trees in search of the insect larvae underneath. Birds do not have teeth. The edge of the bill may appear to be toothed, as in some fish-eating birds; however, the projections are not true teeth. Frequently the tongue has sharp, toothlike edges which serve the same purpose as the curved teeth of the frog or snake.

Respiration. The rate of respiration, of heartbeat, and the body temperature are all higher in the bird than in man. Man breathes sixteen or eighteen times a minute. Birds breathe from twenty to sixty times a minute. The lungs of birds are connected to large air sacs, found in the abdominal cavity of the body, which hold reserve air and

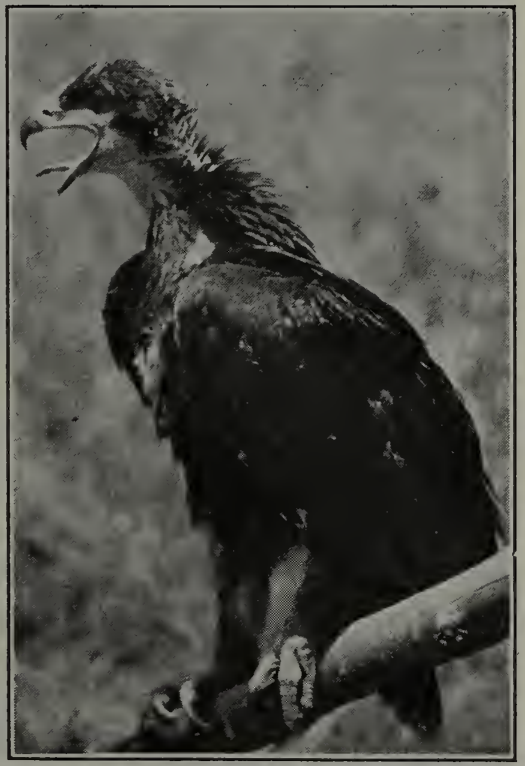

Wright Pierce

What are the adaptations of the Golden eagle? help make the bird lighter. A bird may be compared to a highpressure steam engine. In order to release the energy which it 
uses in flight, a large quantity of fuel which will oxidize quickly must be used. Birds are large eaters, and the digestive tract is fitted to digest the food quickly. As soon as the food is absorbed by the blood, it may be sent rapidly to the places where it is needed, by means of the strong four-chambered heart and large blood vessels.

The high temperature of the bird is a direct result of this rapid oxidation; furthermore, the feathers and the oily skin form an

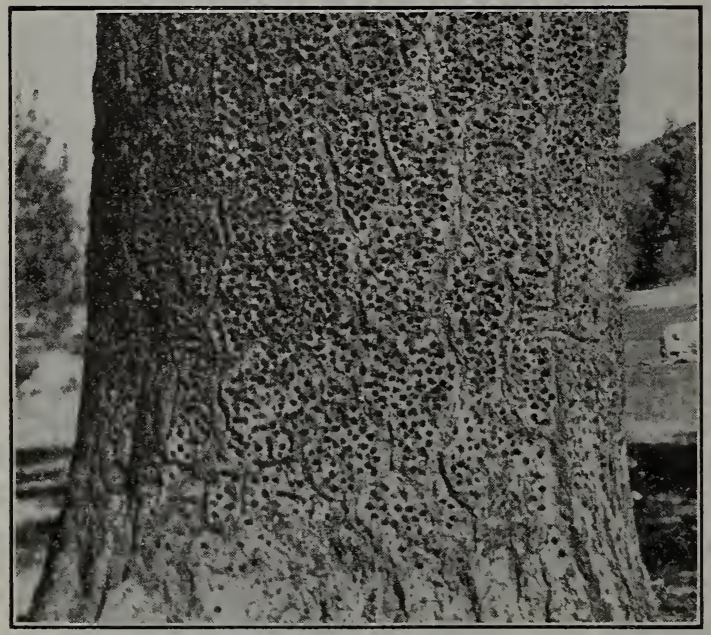

Wright Pierce

The sharp-edged, chisel-like bill of the woodpecker made these holes in the tree. Red-headed woodpeckers also have the unusual habit of storing nuts of various kinds in the crevices and holes they make in the bark of certain trees. insulation which does not readily permit the escape of heat. This insulating cover is of much use to the bird in its flights at high altitudes, where the temperature is often very low.

The nervous system and the senses. The central nervous system of a bird is well developed. Attached to the fairly large brain is the spinal cord which extends the length of the body. From this cord nerves are given off. Sight is probably the best developed of the senses. The keen sight of a hawk is proverbial. Hearing is also well developed in most birds. The sense of smell does not appear to be well developed, and is especially deficient in seed-eating birds.

Nesting habits. Among the most interesting of all instincts shown by birds are those of nest building. Birds incubate their eggs, that is, hatch them, by the heat of their bodies. Hence a nest is needed. The ostrich is an exception; it makes no 

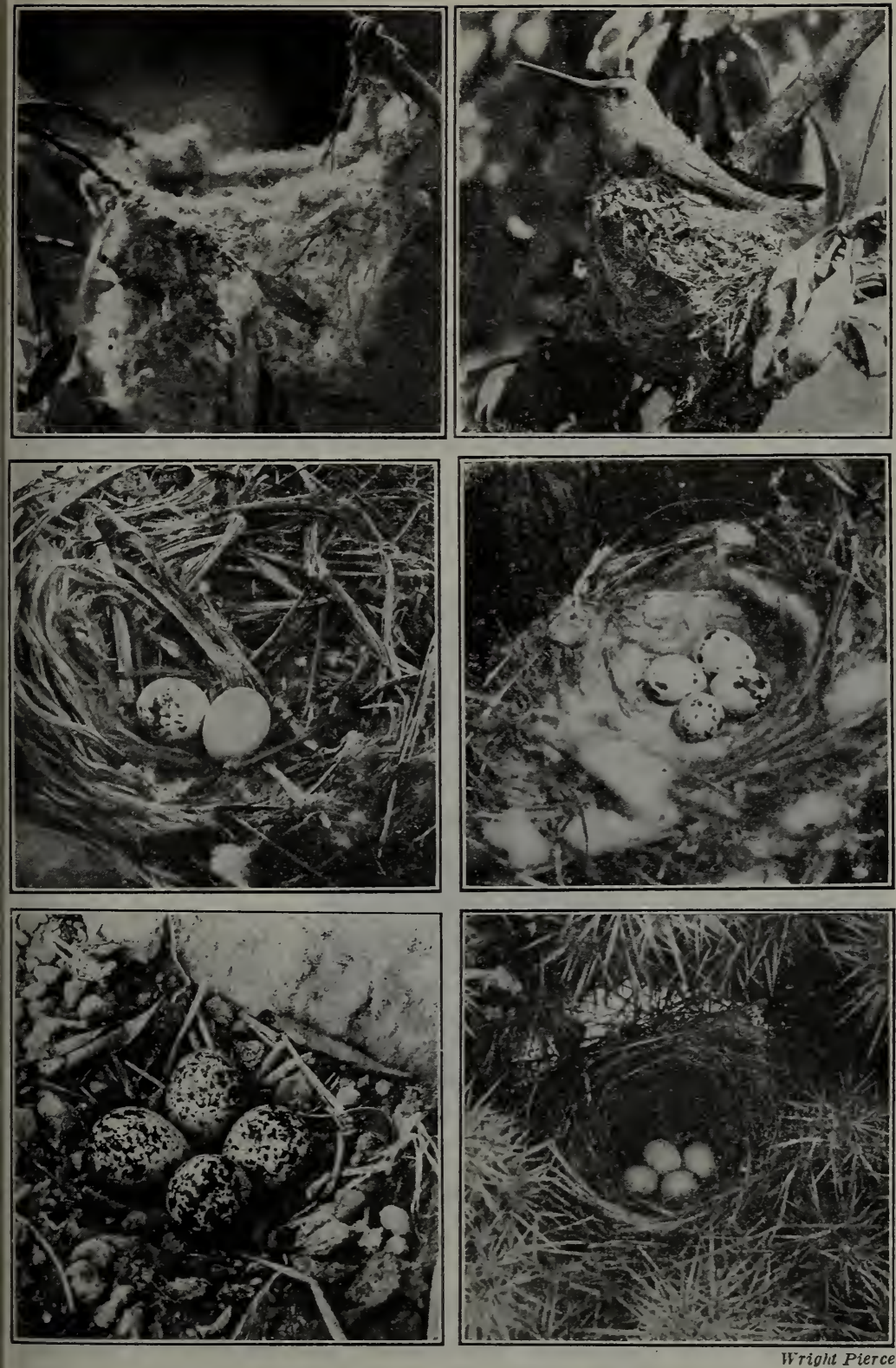

What can you tell about the habits and characteristics of the birds which made these nests? 
nest, but lays its eggs on the ground. Birds immune from the attacks of enemies because of their isolation or their protective coloration (as the gulls and terns) build a rough nest among the rocks or on the beach. The eggs, especially those of the tern, are marked and colored so as to be almost indistinguishable from the rocks or sand on which they rest. Other birds have made their nest a place of refuge as well as a place to hatch the eggs.

Care of the young. After the eggs have been hatched, the young birds in most cases are quite dependent upon the parents for food. Most young birds are prodigious eaters. As a result they grow very rapidly. It has been estimated that a young robin eats two or three times its own weight of food every day. In the case of the pigeons and some other birds, food is swallowed by the mother, partially digested in the crop, and then regurgitated

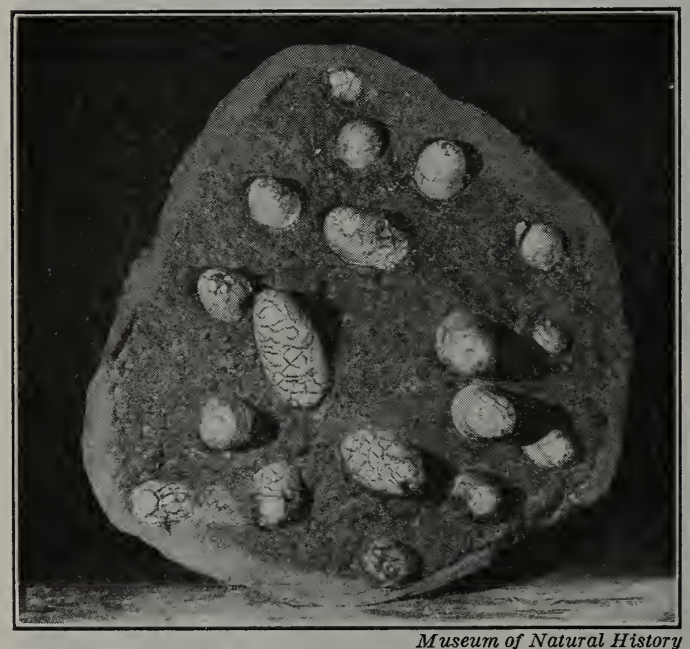

The eggs of a dinosaur, a large land reptile which lived millions of years ago. This nest of eighteen eggs was found in Mongolia. into the mouths of the young nestlings. Relationship of birds and reptiles. The birds afford an interesting example of how the history of past ages of the earth has given a clue to the structural relation which birds bear to other animals. Several years ago, two fossil skeletons were found in Europe of a birdlike creature which had not only wings and feathers, but also teeth and a lizardlike tail. From these fossil remains and certain structures (as scales) and habits (as the egg-laying habits), naturalists have concluded that birds and reptiles in distant times were closely related and that our existing birds probably 
developed from a reptile-like ancestor many ages ago. The recently discovered eggs of the extinct dinosaurs are another link in the chain of relationship.

Practical Exercise 19. Make a comprehensive definition of a bird. What evidences of relationship do you find between reptiles and birds? What particular adaptations would you expect to find in a bird of prey? A swimmer? A wader?

Laboratory Exercise. Using the text as a guide, study a living bird to find: (1) adaptations for flight; (2) for food getting; (3) for protection.

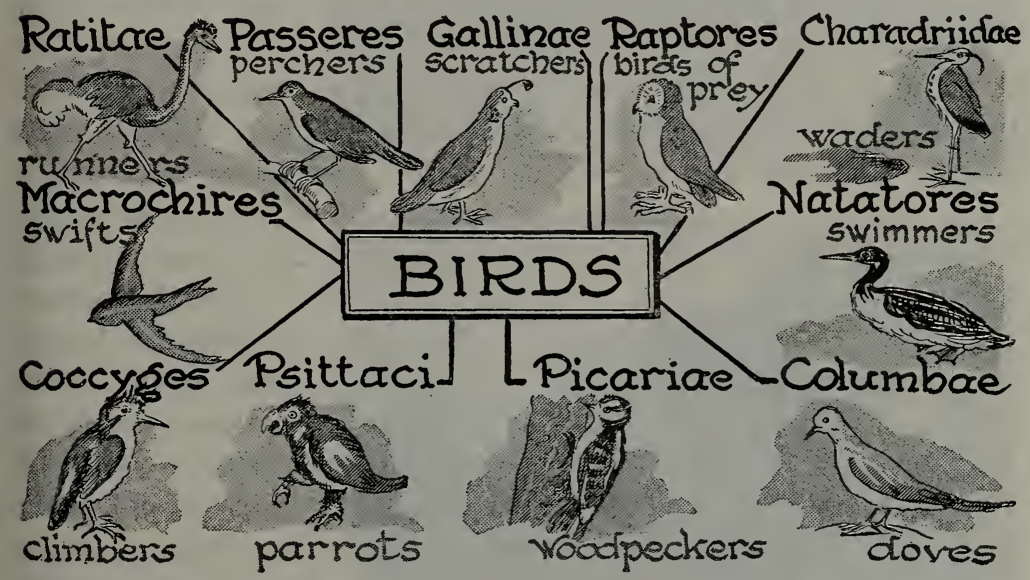

ORder 1. Rati'tae. Running birds with no keeled breastbone. Examples: ostrich, cassowary.

ORDER 2. Pas'seres. Perching birds; having three toes in front, one behind. Over one half of all species of birds are included in this order. Examples: a sparrow, thrush, swallow.

ORDER 3. Galli'nae. Strong legs, feet adapted to scratching. Beak stout. Examples: jungle fowl, grouse, quail, domestic fowl.

ORDER 4. Rapto'res. Birds of prey. Hooked beak. Strong claws. Examples: eagle, hawk, owl.

OrDer 5. Limicolae. An order of the shore birds, wings long, thin, flat, and pointed. Legs usually yery long. Bills are sometimes long. Examples: plover, snipe, sandpiper.

OrDer 6. Longepennes. Drivers and swimmers. Legs short, toes webbed. Examples: gull, duck.

ORDER 7. Colum'bae. Like Gallinae, but with weaker legs. Examples: dove, pigeon.

OrDER 8. Pici. Woodpeckers. Two toes point forward, two backward, and adaptation for climbing. Long, strong bill.

Order 9. Psittaci. Parrots. Hooked beak and fleshy tongue.

ORDER 10. Coccyges. Birds, with powerful beaks, using their feet as a means of progression. Examples: kingfisher, toucan, and cuckoo.

ORDER 11. Macrochires. Birds having long, pointed wings, without scales on metatarsus. Examples: swift, humming bird, and goatsucker.

\section{Self-Testing Exercise}

Birds are characterized by having an ....... (1) covering of . (2) ; ........(3); ........(4) modified for .......(5) in 
.(6) ; ....... (7) bones ; ....... (8) on the legs (which show their .......(9) to the reptiles); ......(10) but no true $\ldots \ldots \ldots(11) ; \ldots \ldots \ldots$ (12) temperature; a ....... (13). They lay $\ldots \ldots$ (14) covered with a ......(15) ...... (16). The $\ldots \ldots .(17)$ in leg and bill show clearly what kind of ...... (18) the bird leads and the ......(19) of ......(20) it uses.

\section{PROBLEM IX. WHAT ARE THE CHARACTERISTICS OF MAMMALS?}

Practical Exercise 20. Make brief descriptions in your workbook of two mammals such as a cat and a horse. How do they differ? How are they similar?

Mammals. Mammals are characterized by being warm blooded, by having a four-chambered heart, a diaphragm, and well-developed lungs. The most characteristic features, however, are that they

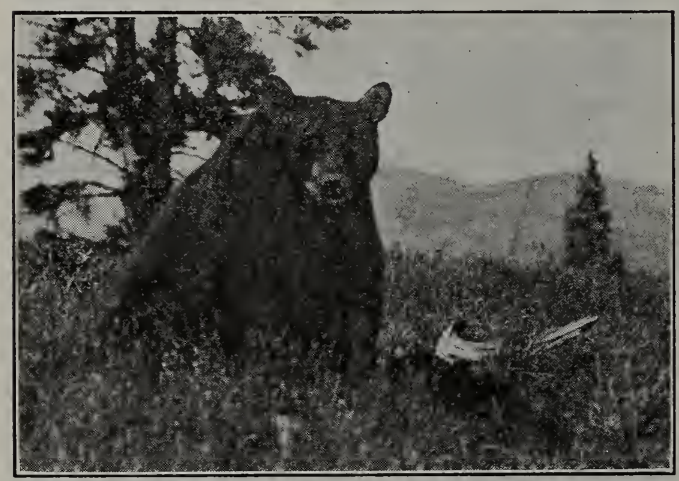

U. S. Bureau of Biological Survey

What kind of food does the black bear eat?

have a hairy covering at some period of their existence and bring forth their young alive. The young are nourished on milk secreted by glands known as the mammary glands; hence the term "mammals." Mammals are considered the highest of vertebrate animals, not only because of their complicated structure, but because of their mental development.

Individual project. Visit a museum and study the skeletons and mounted bodies of a seal and of a whale. Why do we consider these animals mammals rather than fishes or amphibians?

Carnivores. Carnivorous mammals are to a large extent flesh eaters. In a wild state they hunt their prey, which is caught and torn with the aid of well-developed claws and long, sharp canine teeth. 


\section{All flesh-eating} mammals are wandering hunters; many, as the bear and lion, have homes or dens to which they retreat. Some, as bears and raccoons, live part of the time upon berries and fruit.

Rodents. Mammals known as rodents have the teeth so modified that on both upper and lower jaws two prominent teeth, incisors, are used for gnawing. These teeth keep their chisel-like
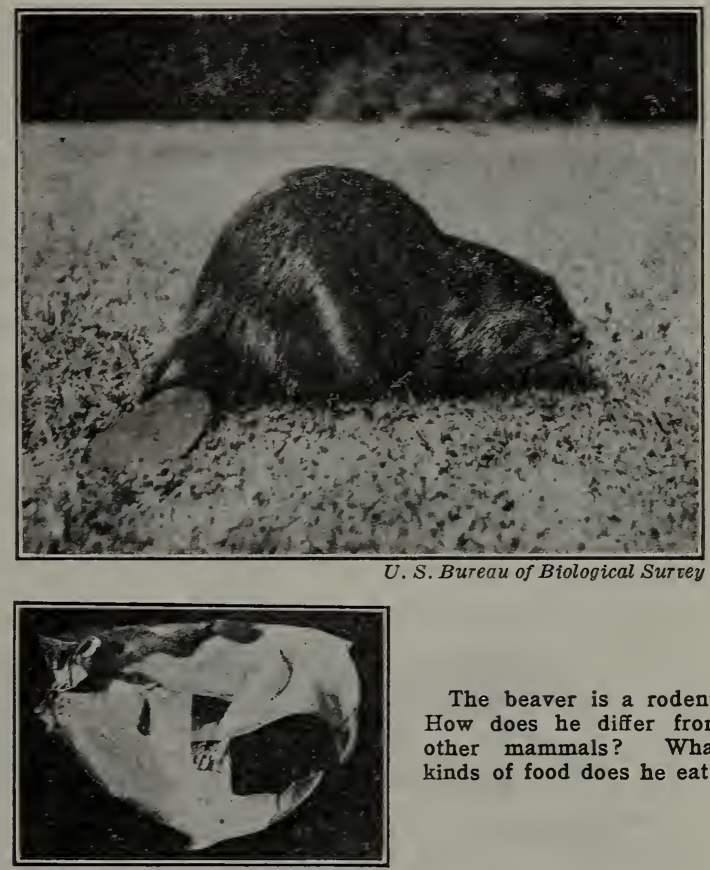

U. S. Bureau of Biological Survey
The beaver is a rodent. How does he differ from other mammals? What kinds of food does he eat?

edges because the back part of the teeth is softer and wears away more rapidly than the front part. The canine or dog teeth are lacking. We are all familiar with the destructive gnawing qualities of one of the commonest of all rodents, the rat.

Ungulates: hoofed mammals. This group includes most of the domesticated animals, as the horse, cow, sheep, and pig. Many of these animals came under the subjugating influence of man and now they form an important part of the world's wealth.

The order of ungulates is a very large one. It is characterized by the fact that the nails have grown down and become thickened as hoofs. In some cases only two (the third and fourth) toes are largely developed. Such animals have a cleft hoof, as the ox, deer, sheep, and pigs. They are the even-toed ungulates. The deer family contains the largest number of species and individuals among our native forms, and in fact the world over. Among them 
are the common Virginia deer of the Eastern states, and the moose and antelope. The bison, or buffalo, is closely related to the deer. Formerly bisons existed in enormous numbers on our Western plains. They are now almost extinct.

Primates. Man is placed in the highest order of mammals, the primates, because he walks upright and the fore appendages (arm) are each provided with hands for grasping. Nails instead of claws are present. The primates have the same characteristics as other mammals, but may be said to be superior to them in having a more highly developed brain and nervous system.

Practical Exercise 21. Name a common example of each order of mammals found in your locality. What are the chief characteristics of the carnivora?

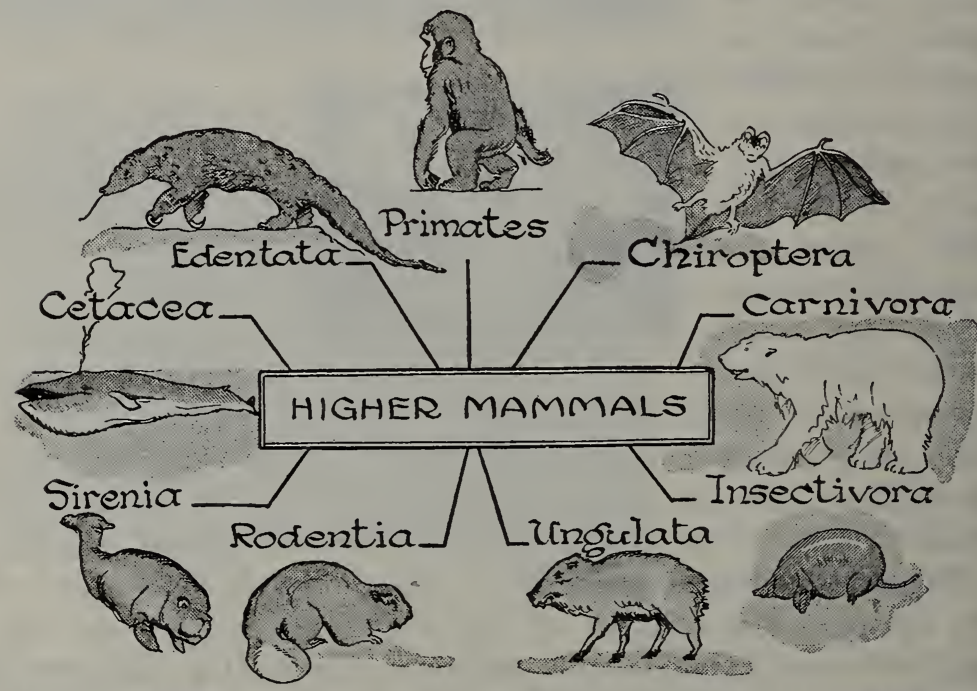

Order 1. Edentata. Toothless or with very simple teeth. Examples: anteater, sloth, armadillo.

Order 2. Cetacea. Adapted to marinelife. Examples: whale, porpoise.

ORDER 3. Sirenia. Fishlike in form; pectoral limbs paddle-like. Examples: manatee, dugong.

Order 4. Rodentia. Incisor teeth chisel-shaped, usually two above and two below. Examples: beaver, rat, porcupine, rabbit, squirrel.

Order 5. Ungulata. Hoofs; teeth adapted for grinding. Examples : (a) odd-toed: horse, rhinoceros, tapir; (b) even-toed: ox, pig, sheep, deer.

ORDER 6. Insectivora. Small, insect-eating, furry or spiny covered; long snout. Example: mole.

ORDER 7. Carnivora. Long canine teeth, sharp and long claws. Examples: dog, cat, lion, bear, seal, and sea lion.

Order 8. Chiroptera. Fore limbs adapted to flight, teeth pointed. Example: bat.

Order 9. Primates. Erect or nearly so, fore appendage provided with hand having nails. Examples: monkey, ape. Anatomically, man is placed with this group of mammals. 
The rodents? The ungulates? Which group is most useful in your locality? Most harmful? Which mernbers should be destroyed? Protected?

\section{Self-Testing Exercise}

Mammals are characterized by having ........ (1) blood, ....... (2) heart, ........(3), and a muscular wall just below these organs called a ......... (4). Mammals have .......(5) on the body and (6) their young. The important orders are the .......(7) or gnawers, the $\ldots \ldots \ldots(8)$ or hoofed animals, the $\ldots \ldots \ldots$ (9), with sharp teeth, and the .......(10), which includes man.

\section{PROBLEM X. WHAT STORY IS TOLD BY THE FOSSILS?}

We have learned that animals may be arranged in groups, beginning with very simple one-celled forms and culminating with man himself. These groups are believed by some scientists to represent, in a way, different stages in the evolution or development of life on the earth.

We know that in the millions of years that life has existed on the earth that there have been many changes. According to presentday evidences, living things at first were very simple in structure, but as time went on more and more complex types appeared.

Many of you have probably had the interesting experience of finding in rocks, not far from the shore, shells or other evidences of life. Sometimes these were simply casts in rock which once held the remains of animals and plants. Infrequently, we find actual preserved specimens, as insects in amber. All these things are called fossils. If we study the geology of the rocks in which fossils are found, we learn that these rocks were once laid down under water in layers, and that the animal or plant remains were caught there, then covered up, and preserved. We also find that the rocks nearer the

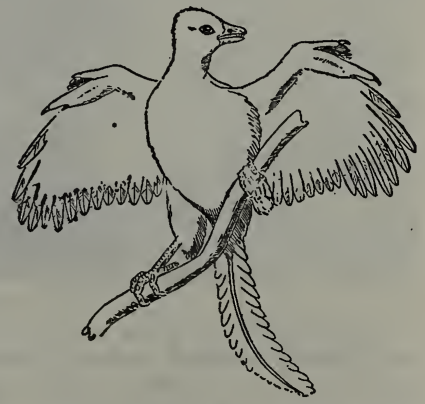

The Archaeopteryx is the earliest known bird. According to fossil skeletons, it was the size of a crow and had teeth. 
surface contain remains of living things that inhabited the earth in fairly recent time, while those deeper in the earth contain fossils of animals and plants that are unlike any that are now living, and are, therefore, thought to have lived millions of years ago. In this way scientists have learned that the earliest forms of life upon the earth were very simple, and that gradually more and more complex forms appeared, as the rocks formed latest in time show the most highly developed forms of plant and animal life.

Some evidences of ancient forms of life. From a study of fossils from various rock formations all over the world the following very interesting facts have been discovered : that the oldest rocks

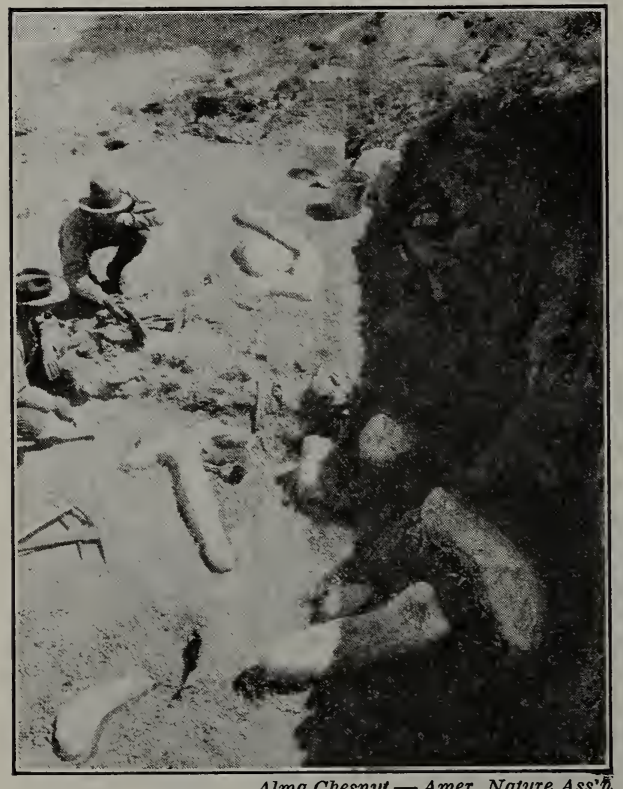

Alma Chesnut - Amer. Nature Ass' $\hbar$

Unearthing the bones of huge animals which at one time lived in Wyoming. These bones are relics of a mighty race that perished in forgotten ages. contain very simple plants and animals, almost all marine; that there came a period in which many kinds of invertebrates lived, at this time land plants appeared; then came the age of fishes, many of which were great armored beasts, long since gone. Still later we have an age of amphibians. During this last period great forests flourished from which our anthracite coal beds were formed. Then came a time when monstrous reptiles roamed over the earth, some of them 60 to 70 feet in length. Later these great animals, dinosaurs, vanished and huge batlike animals and birds appeared. During this time the beginnings of our modern 
mammalian life came into existence. All of these changes have taken tens, or more likely hundreds of millions of years. as we can tell from the thickness of the rock deposits in which the fossils are found.

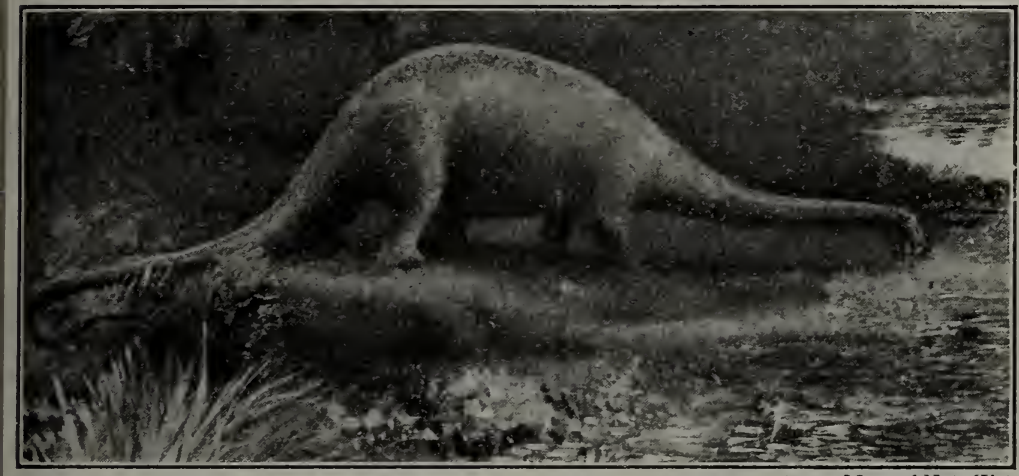

Amer. Mus. of Nat. Hist.

This giant dinosaur, over sixty feet long, lived in Wyoming millions of years ago.

Other evidences of organic evolution. Fvidences of changes in form through past ages have been found in the study of the elephants, which have changed from a trunkless and relatively small animal to the huge elephant of today. The great sabertoothed tiger, which once roamed the fields of California, has given way to the modern type.

In certain of the higher animals we find traces of organs that are no longer used, although they may have been of value to the animals in the past. The appendix in man is small and useless, but in some animals, it is large and performs an important digestive function. The muscles of the ears of human beings are useless, but in lower animals they are of great value in aiding the hearing.

Geologic history of the horse. That developmental changes have taken place in certain types of animals is shown by a study of a series of fossil horse skeletons, which have been reconstructed so that we can pretty certainly tell what ancient horses look like.

The fossils of leg bones show that, ages ago, the remote ancestors of the horse were probably small animals the size of a domestic cat, with five-toed feet. The earliest horse we have knowledge 
of had four toes on the fore and three toes on the hind feet. Thousands of years later there existed a larger horse, the size of a sheep, with three toes on each foot. Through

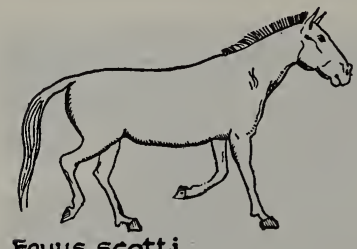

Equus scotti

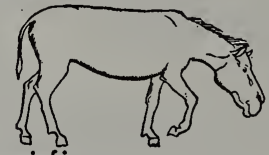

Hippidium
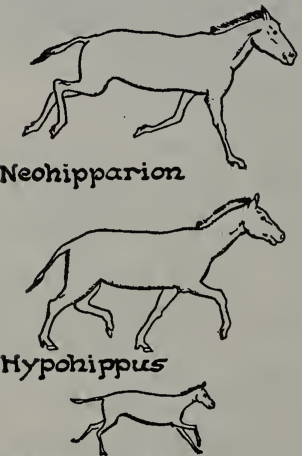

Mesohippus

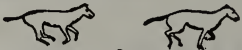

Eohippus Protorohippres

Redrawn from Photo of Amer. Mus. of Nat. Hist.

In what ways has the horse changed through the ages? a series of changes there was eventually produced our present horse, an animal with legs adapted for rapid locomotion, with feet particularly fitted for life in open fields, and with teeth which serve well to seize and grind herbage.

Practical Exercise 22. From outside sources construct a diagram to show the different geologic ages in this country. In what kind of rocks would you look for fossils? Visit a museum and describe some evidences of development seen therein. What examples of change have you seen in the world today? List them.

\section{Self-Testing Exercise}

The ....... (1) forms of ...... (2) on the earth are believed to have been very .......(3), while those that developed .......(4) are more .......(5). $\ldots . \ldots(6)$ or remains of animals and plants ....... (7) in....... (8) tell us the story of ......(9) of life on the earth. Once, ages ago, there existed ........(10) horses having ........ (11) toes on the fore feet. Later, as life on the earth changed, there was a gradual development in these (12) so that today we have horses with ........ (13) toe, and longer legs fitted for more ........(14) locomotion.

\section{PROBLEM XI. WHAT IS MAN'S PLACE IN NATURE?}

There is no doubt that man is young compared to some animals, but he is vastly older than was once believed. Very good evidences in the form of skulls found in the caves of France and the gravel pits of England show that man has lived on the earth tens of 
thousands, probably hundreds of thousands of years, 500,000 to $1,000,000$ years being the latest estimate.

Parts of skeletons found in Java and Europe show a type of man much lower than any savage living today. Arrowheads, of a kind older than any made within the memory of man, have been found among the bones of extinct bisons under the soil of our Western plains. Races of men must have once existed there who have now vanished.

Evidences in the forms of fossil bones and parts of skulls show also that man has been changing during these many centuries. His arms used to be longer, his frame more massive, his jaw and face more ape-like. This does not mean that man has ascended from an ape; it simply shows a gradual development or evolution through many thousands of years from some stock which gave rise to the apes and to man separately. Just as we now have been able artificially to improve plants and animals through scientific breeding, so Mother Nature has, by a hit-and-miss method, improved the breed of man on the earth. How these changes have been brought about is only conjecture, but we do know that there are great differences between the men on the earth today and those

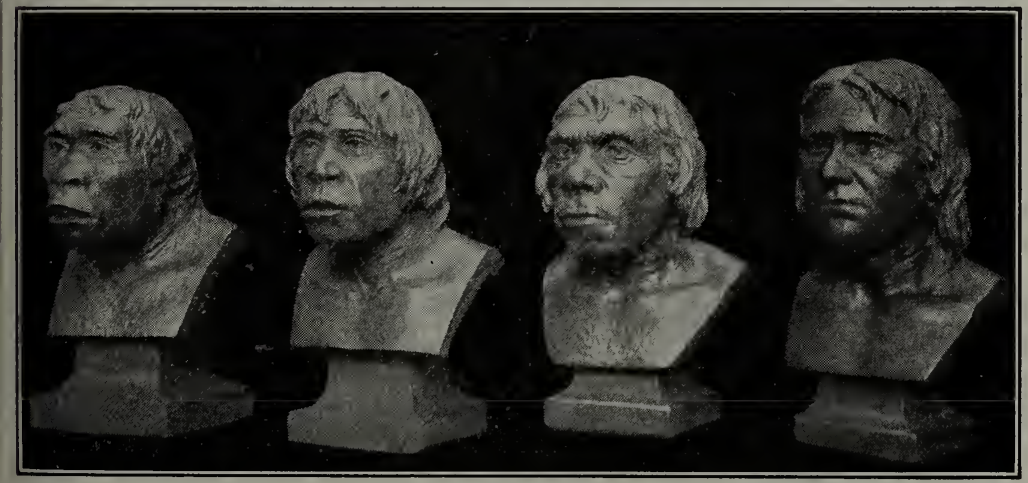

Amer. Mus. of Nat. Hist.

From fossils that have been discovered in many parts of the world, Dr. J. H. McGregor has given us his idea of the probable appearance of prehistoric man in different stages of development.

of yesterday. But there are also as great structural differences between the Bushmen of Africa and the white men of England or 
America as there are between those same Bushmen and some of the early races of man. Undoubtedly there once lived upon the earth races of men who were much lower in their mental organization than are the present inhabitants. If we follow the early history of man upon the earth, we find that at first he must have been little better than one of the higher vertebrates. He was a nomad, wandering from place to place, living upon whatever animals he could kill with his hands and whatever edible plants he found. Gradually, he learned to use weapons to kill his prey, first using rough stone implements for this purpose. As man became more civilized, implements of bronze and of iron were used. About this time the subjugation and domestication of animals began to take place. Man then began to cultivate the fields, and to have a fixed place of abode other than a cave. The beginnings of civilization were long ago, but even today the world is not entirely civilized.

Demonstration. The skeleton of man compared with other mammals. Use skeletons of a fish, frog, bird, dog or cat, and man. If this material is not available in school, visit a museum. Observe the kinds and places of the different bones in body of each skeleton. In what ways do the various skeletons agree? How do they differ?

Why is man a mammal? Although we know that man is separated by a gap from all other animals by the power of speech, we must ask where we are to place him structurally. If we attempt to classify man, we see at once he must be grouped with the vertebrate animals because of his possession of a vertebral column. Evidently, too, he is a mammal, because the young are nourished by milk secreted by the mother and because his body has at least a partial covering of hair. Among the different orders of mammals man most closely resembles anatomically the primates to which the monkeys and apes belong.

If we compare several skeletons of different mammals, we find certain definite likenesses in body plan. In the first place, all vertebrates have the same general parts of the skeleton: the skull, vertebral column, the front and rear appendages, and the bony girdles, pectoral (shoulder) and pelvic (hip), which connect the appendages with the main or axial skeleton. Then, too, they 
all have the same general plan of digestion system, the same kinds of circulatory, respiratory, and excreting systems, although here more variations are evident among the fishes, amphibians, and mammals. Even the nervous system, which seemingly ought to show very great changes in structure, is not as different as one might expect. Moreover, if you compare the skeleton of an ape with that of man, you notice some striking likenesses which set their two skeletons off from those of the other vertebrates. Both show a more or less upright posture ; they both have well-marked fingers and toes; the general shape of the head is similar, the pectoral and pelvic girdles are markedly alike, and a detailed study would show many other similarities. If we follow the same principles for the study of relationships here as we have in other animals, we are forced to the conclusion of a close structural relationship between the apes and man.

\section{Self-Testing Exercise}

Man is a ....... (1) because he has a backbone. Man is a . (2) because he has hair, and the .......(3) are nourished by $\ldots \ldots \ldots$ (4) secreted by the $\ldots \ldots \ldots$ (5) $\ldots \ldots \ldots$ (6). He is a (7) and must be placed anatomically with the $\ldots \ldots \ldots(8)$. This does not mean he is .......(9) from the .......(10), for man has existed in a $\ldots \ldots$. (11) state for $\ldots \ldots \ldots$ (12), perhaps (13) of thousands of years.

\section{Review Summary}

Test your knowledge of the unit by: (1) rechecking the survey questions; (2) performing all the assigned exercises; (3) checking with the teacher your answers on the various tests and trying again the ones you missed; and, finally, (4) making an outline and filling it in as fully as possible for your notebook.

\section{Test on Fundamental Concepts}

In a vertical column under the heading CORRECT write the numbers of all statements you believe are true. In another column under INCORRECT write numbers of untrue statements: Your grade $=$ number of right answers $\times 2$.

I. Classification of living things is based: (1) upon likeness and differences in structure; (2) upon relationships shown by analogies in use of parts; (3) upon relationships shown by homologies in structure; (4) upon the place where they live; (5) on the way in which they grow.

स. ВIค -19 
II. The protozoans (6) always have cilia; (7) are single-celled animals; (8) never live in the water; (9) reproduce by dividing; (10) reproduce by budding.

III. The coelenterates (11) live in the ocean; (12) have baglike bodies with a mouth at one end; (13) are usually fixed and do not move from place to place ; (14) may show an alternation of generations ; (15) include corals, sea anemones, and hydra.

IV. The arthropods (16) have no definite number of legs; (17) always have a limy shell; (18) have an exoskeleton; (19) have jointed legs and jointed body; (20) have compound eyes.

V. Mollusks (21) are soft-bodied animals; (22) always have a shell; (23) usually have a shell; (24) live only on land; (25) include snails, oysters, clams, and squids.

VI. Fishes (26) are the only animals that live in the water; (27) have their limbs modified into fins; (28) breathe by taking oxygen out of water by means of gills ; (29) use the ear as a balancing organ; (30) lay many eggs which are fertilized outside the body.

VII. Amphibians (31) include turtles, snakes, and tortoises; (32) always have moist skin with no scales in it; (33) often undergo a metamorphosis, part of the life being in the water and part on land; (34) always have both lungs and gills at the same time in their life history; (35) include the toads, frogs, and salamanders.

VIII. Reptiles (36) have no teeth; (37) are never poisonous; (38) always have scales on the skin; (39) always breathe by lungs; (40) show their relationship to birds by laying eggs with shells.

IX. Birds (41) show, by scales on their legs, relationship to reptiles; (42) have modified arms or forelegs which are used in flying; (43) always build a nest in which are laid many eggs; (44) have a fourchambered heart; (45) have a skeleton composed of light and hollow bones, with large breastbone to which wing muscles are attached.

X. Mammals (46) are at the top of the evolutionary scale; (47) have a four-chambered heart, a more or less heavy covering of hair, and suckle their young; (48) always stand erect; (49) are found as the most recent fossils ; (50) include man.

\section{Achievement Test}

1. What is the name of at least one animal from each of the phyla of the invertebrates and the vertebrates? 
2. What are the differences between spiders and insects?

3. Where would you look for hydra, crayfish, clams, and toads?

4. How can you distinguish between an amphibian and a reptile?

5. What is the life history of a frog common in your locality?

6. Where and what fossils may be found in your locality?

\section{Practical Problems}

1. Make a collection of all invertebrates that you can find in your community. Classify them and arrange them in evolutionary order.

2. Fill out the following table.

\begin{tabular}{|l|l|l|l|l|l|}
\hline \multicolumn{1}{|c|}{ Strogtures } & Fish & AMphibian & Reptile & Bird & Mammal \\
\hline $\begin{array}{l}\text { Organs of } \\
\text { digestion }\end{array}$ & & & & \\
\hline $\begin{array}{l}\text { Protective } \\
\text { structures }\end{array}$ & & & & & \\
\hline $\begin{array}{l}\text { Locomotion } \\
\text { Organs of } \\
\text { breathing }\end{array}$ & & & & & \\
\hline $\begin{array}{l}\text { Organs of } \\
\text { excretion }\end{array}$ & & & & & \\
\hline $\begin{array}{l}\text { Parts of nervous } \\
\text { system }\end{array}$ & & & & & \\
\hline Sense organs & & & & & \\
\hline
\end{tabular}

\section{Useful Reference Books}

Allen, Birds and Their Attributes. (Marshal Jones Co. 1925.)

Ditmars, Reptile Book. (Doubleday, Doran \& Co.)

Dickerson, Frog Book. (Doubleday, Doran \& Co.)

Hornaday, American Natural History. (Charles Scribner's Sons.)

Jordan and Evermann, American Food and Game Fishes. (Doubleday, Doran \& Co. 1923.)

Lucas, Animals of the Past. (Amer. Mus. of Nat. Hist., N. Y. 1922.) Osborn, Men of the Old Stone Age. (Charles Scribner's Sons. 1919.) Palmer, Field Book of Nature Study. (Comstock Publishing Co. 1927.) Plunkett, Outlines of Modern Biology. (Henry Holt \& Co. 1930.) Reed, Bird Guide. (Doubleday, Doran \& Co. 1925.) 


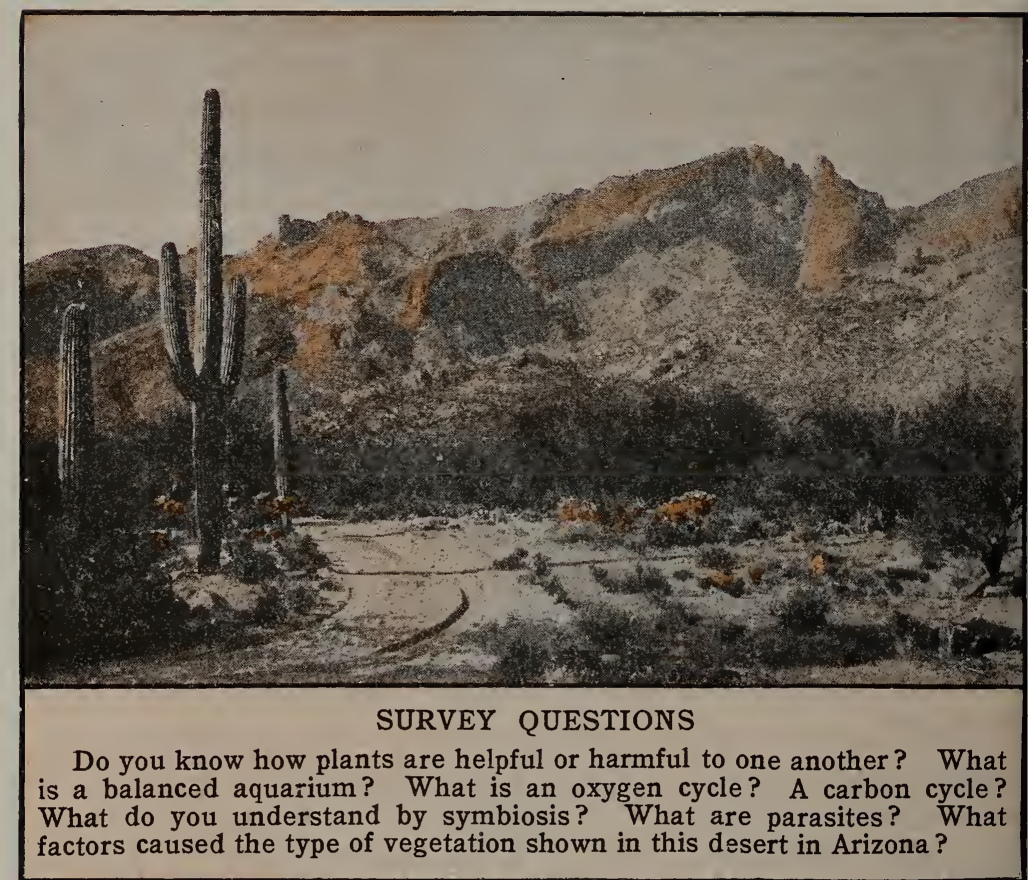

Photo by Frank $M$. Wheat

\section{UNIT IX}

\section{WHAT EFFECTS HAVE THE SURROUNDINGS ON THE LIVES OF PLANTS AND ANIMALS?}

Preview. If bees, in their search for nectar, visited the flowers of an apple tree, they would make possible the development of apples on this tree. This development might be hindered by other insects which prey upon ripening fruit, in which case man may step in, and with a poisonous spray kill the insects and thus save the fruit.

But how did the bees benefit by this visit? They obtained nectar to make into honey, and pollen to make into bee bread for feeding the young. These will in turn replenish the hive the 
following year with more workers, that will make money for man, unless some prowling animal robber gets it first. Charles Darwin saw this interrelationship of plant and animal as a chain of happenings when he pointed out that the size of the clover crop in England depended upon the number of cats in a given region. His friend Huxley immediately went him one better and said the clover crop depended upon the number of old maids. When asked to explain, he gave the following chain of events. Old maids keep cats, cats prey upon mice, mice eat bumblebees and also provide them with places to build their nests, bumblebees pollinate clover, and on this pollination depends the size of the next year's crop. A perfectly logical chain of events!

This unit will explain to us some of these interrelationships between plants and animals and may also show us how man sometimes interrupts or displaces a link in the chain of interrelationships, which results in changing completely the fauna ${ }^{1}$ or flora ${ }^{2}$ of a region. The best example of this perhaps is the case of the man in Australia who wanted a bit of watercress to remind him of the old days in bonny England. Today, the rivers of Australia are choked with this same cress, which, having no enemies and finding conditions favorable, has literally overrun the brooks and rivers.

We cannot fail to see that some animals and plants are fitted to live under conditions totally unsuitable for others. A fish could not live under the same conditions as a lizard, nor would we expect to find seaweeds growing in desert places where cactuses are found. Such things are quite evident, and if we travel in this vast country of ours we shall also find that plants and animals live in more or less different communities, and that there are different climatic zones, in which, because of common needs, certain types of animal or plant life are always found. Such zones can be seen particularly well on a mountainside. Any one who has climbed the Katahdin mountain in Maine, or Mt. Washington in New Hampshire, or any 10,000-foot peak of the Rockies or Sierra Nevada, has had the experience of working his way through forests out into an area of stunted trees and finally out on the bare rocks

: Fauna (fốna $\dot{a})$ : the animals of a given region.

2 Flora $\left(f \bar{l}^{\prime} \mathrm{r} \dot{\alpha}\right)$ : the native plants of a given region. 
above the timber line. We might think that these different regions (life zones) were due entirely to temperature. On the mountainside this is largely true, but we find that all the factors we have already discussed are at work determining the places where living things shall be found. The amount of water present in the soil, the kinds of soils there, the ranges in the temperature, the wind, and many other factors play their parts. One big problem in the geographical distribution of organisms is to find, first, adaptations of organisms for life in various localities, and then the place where a certain kind of living thing has made its start in an area, and finally how life spreads from this area to other areas.

On the whole, nature establishes a balance in life and there is give and take between all living things. That part of biology which deals with the relationships of organisms to each other and to their environments is called ecology.

\section{PROBLEM I. WHAT GENERAL BIOLOGICAL RELATIONS EXIST BETWEEN PLANTS AND ANIMALS?}

Each place where plants and animals are found living together supports a characteristic community of plants and animals. This living together seems to be determined largely by the conditions of the environment in which they are placed. Groups living together in a pond or slow-flowing stream will be quite different from groups living in a rapid mountain stream or in the ocean. The communities of animals and plants living in dry or desert localities would differ to a still greater extent from any of those first mentioned. Only certain animals and plants will live and flourish in an indoor aquarium, but in all such groups the animals and plants living together have certain fundamental relationships to each other and to their surroundings.

Study of a balanced aquarium. Perhaps the best way for us to understand this relation between plants and animals is to study an aquarium in which plants and animals live and in which a balance has been established between the plant life on one side and animal life on the other. Here we see many evidences of the relationship between the environment and the living things in the water. The plants are buoyed up by the water, they do not 
have strong stems, and the leaves are usually divided and present little resistance to the water. The roots are small and are not of much use as an anchor. The fish are obviously adapted for life in the water, as we have already seen. Even the snails have adaptations for their life in the water.

We have learned that green plants, in favorable conditions of sunlight, heat, moisture, and with a supply of raw food materials, give off oxygen as a by-product while manufacturing food in their green cells. We know the necessary raw materials for carbohydrate manufacture are carbon dioxide and water, while nitrogenous material is necessary for the making of proteins within the plant. In previous experiments we have proved that carbon dioxide is given off by living things when oxida-

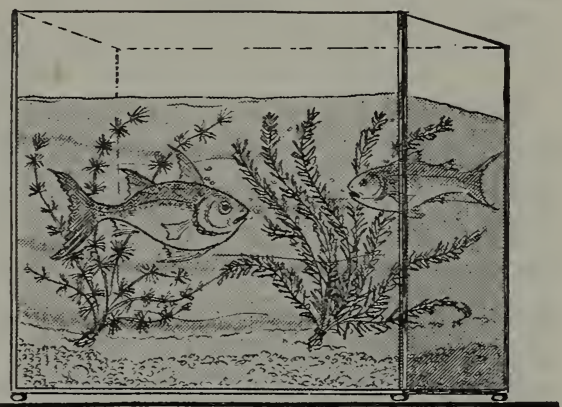

Why will it not be necessary to change the water in this aquarium? tion occurs in the body. The crawling snails and the swimming fish give off carbon dioxide which is dissolved in the water; the plants themselves, at all times, oxidize food within their bodies, and so must pass off some carbon dioxide. The green plants in the daytime use up the carbon dioxide obtained from the various sources and, with the water which they take in, manufacture carbohydrates. While this process is going on, oxygen is given off to the water of the aquarium, and is used by the animals there.

The plants are continually growing, but the snails and fish eat parts of the plants. Thus the plant life gives food to the animals within the aquarium. The animals give off certain nitrogenous wastes. These materials, with other nitrogenous matter from dead animals and parts of the plants, form part of the raw material used for protein manufacture in the plant. This nitrogenous matter is prepared for use by several different kinds of bacteria which break down the dead bodies and change the 
material into soluble nitrates which can be absorbed by the plants. The green plants manufacture food, the animals eat the plants and give off carbon dioxide and nitrogenous waste, from which the plants in turn make more food and living matter. The plants give oxygen to the animals, and the animals give carbon dioxide to the plants. Thus a balance exists between the plants and animals in the aquarium.

Practical Exercise 1. Make a debit and credit balance sheet illustrating the relations existing in a balanced aquarium.

What would be the condition of the balance sheet if the aquarium were put in a dark room? If several extra snails and fish were introduced?

Relations between green plants and animals. What goes on in the aquarium is an example of the relation existing between all green plants and animals. Everywhere in the world green plants are making food which becomes, sooner or later, the food of animals. Man does not feed to a great extent upon leaves, but he eats many roots, stems, fruits, and seeds. When he does not feed directly upon plants, he eats the flesh of plant-eating animals, which in turn feed directly upon plants. And so it is the world over; the plants are the food makers and supply the animals.
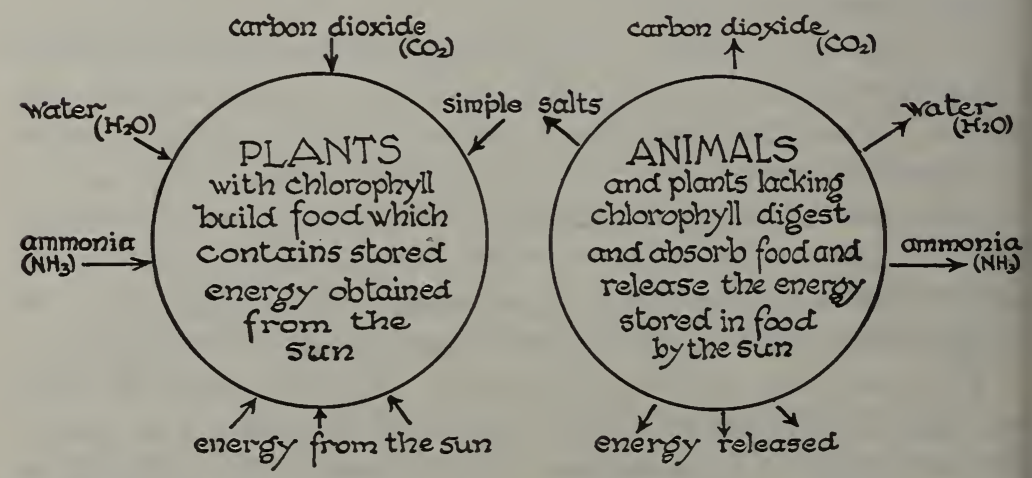

Plants and animals on the earth show the same relation to each other as do the plants and animals in a balanced aquarium. Can you explain, with the aid of the diagram, why this is true?

This is well seen in the distribution of grazing animals in relation to forage crops. Green plants also give to the atmosphere every day a very considerable amount of oxygen, which the animals use. 


\section{Self-Testing Exercise}

..(1) and ........ (2) live together in communities. Such a place is called a ........ (3). A balanced aquarium shows the (4) between animals and plants, the former give ....... (5) (6), and .......(7) wastes to the plants which in turn (8) organic food which the ....... (9) ........ (10). This illustrates the give and take between plants and animals in the (11).

\section{PROBLEM II. WHAT DO WE MEAN BY THE NITROGEN, OXYGEN, AND CARBON CYCLES IN NATURE?}

Nitrogen cycle. The animals supply much of the carbon dioxide that the plant uses in carbohydrate making. They supply some of the nitrogenous matter used by the plants, another part being given the plants from the dead bodies of other plants, and still another part being prepared from the nitrogen of the air through the agency of bacteria which live upon the roots of certain plants. These bacteria are the only organisms that can take nitrogen from the air. Thus, in spite of all the nitrogen in the atmosphere, plants and animals are limited in the amount available. Eaten in protein food by an animal, nitrogen may be given off as nitrogenous waste, get into the soil, and be taken up by a plant through the roots. Eventually the nitrogen forms part of the food supply in the body of the plant, and then may become part of its living matter. When the plant dies, the nitrogen is returned to the soil. Thus the usable nitrogen is kept in circulation. ${ }^{1}$

Practical Exercise 2. Illustrate what is meant by the nitrogen cycle with reference to your own environment.

Make a diagram to show the way the nitrogen cycle works out in life on the earth.

Carbon and oxygen cycles. There are also two other cycles in nature that are easily seen. Oxygen dissolved in the water is taken up by the fish in the aquarium, and is released in the form of an oxide of carbon or carbon dioxide. In this form it is taken

${ }^{1} \mathrm{~A}$ small amount of nitrogen gas is returned to the atmosphere by the action of the decomposing bacteria on the ammonia compounds in the soil. (See figure of nitrogen cycle.) 


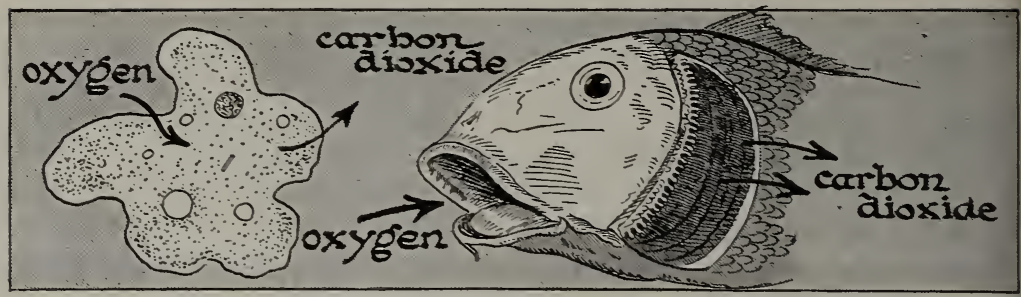

How does the diagram of an amoeba, or head of a fish, or a cross section through the

by green plants in the aquarium and during the starch-making process in the sunlight it is released as a by-product in the form of pure oxygen gas. It is now in the water ready for the fish to use again. This same process is repeated on a large scale wherever we find green plants, sunlight, and animals.

The carbon cycle can also easily be shown. The fish in the aquarium eats some of the green plant, thus getting carbohydrate food which contains the element, carbon. As they swim about releasing energy they oxidize the carbohydrate food in their bodies and thus liberate the carbon in the form of carbon dioxide. This gas is used by the green plant in the suniight to build carbohydrates and the cycle is completed again. Of course, the aquarium shows what goes on in a larger way in the world of living things.

Practical Exercise 3. After carefully studying the text make a diagram in the form of a circle to illustrate the way the carbon cycle exists in nature. Use arrows. Make a second diagram to show the oxygen cycle in nature.

\section{Self:Test Exercise}

The ....... (1) available for plant and animals is ....... (2) over and over again by plants by making ....... (3) ...... (4). Certain .......(5) break down substances containing .......(6) and put it into the ......( 7$)$ as ....... (S) organic material. Then green plants take it up and ....... (9) it into ......(10) food and $\ldots \ldots$. (11) matter. There are ...... (12) and .......(13) cycles in nature. Oxygen is given off by ........(14) plants, is used by $\ldots \ldots$ (15), and breathed out as an .......(16) of carbon. Carbon is given off into the atmosphere by animals as .......(17) .......(18) and is used by .......(19) plants to manufacture $\ldots . \ldots(20)$. In such form it is .......(21) by animals and after 


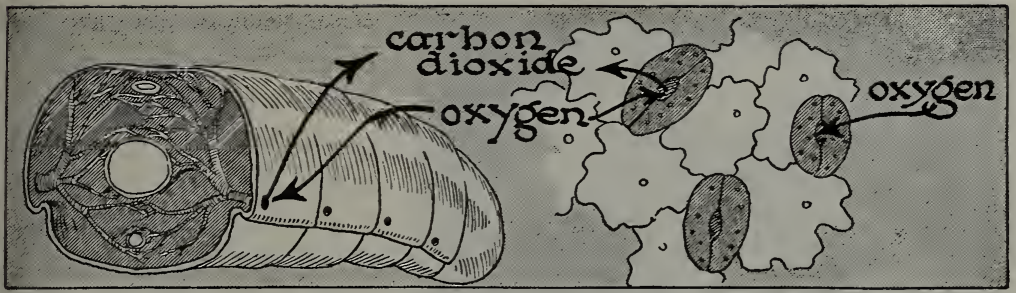

body of an insect, with the lower epidermis of a leaf show that living things breathe?

being .......(22) in the body is passed into the air again as (23) .......(24), thus completing the cycle.

\section{PROBLEM III. WHAT IS SYMBIOSIS AND HOW DOES IT DIFFER FROM PARASITISM?}

Symbiosis. Plants and animals are seen in a general way to be of mutual advantage to each other. Some plants, called lichens, show this mutual partnership in the following interesting way. A lichen is composed of two kinds of plants, one of which at least may live alone, but the two plants have formed a partnership for life, and have divided the duties of such life between them. In most lichens the alga, a green plant, forms starch and nourishes the fungus. The fungus, in turn, produces spores, by means of which new lichens are started in life; moreover, the alga is usually protected by the fungus, which is stronger in structure than the green part of the combination. This process of living together for mutual advantage is called symbiosis (šm-bī-o'šss). Some animals also combine with plants; for example, the hydra with certain of the one-celled algae. Animals also frequently live in this relation to each other, the tiny protozoans living in the digestive tracts of the termites or white ants. These little animals act as digestive cells for the termites, Algae and fungi in a lichen. Explain this making it possible for them to

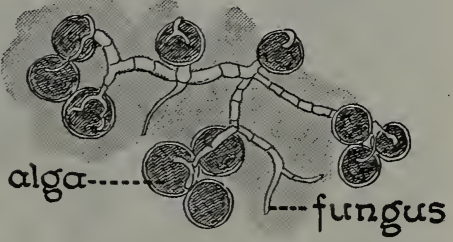
relationship.

digest the wood fibers on which they live. In return these protozoans are protected by their hosts. A somewhat similar situa- 


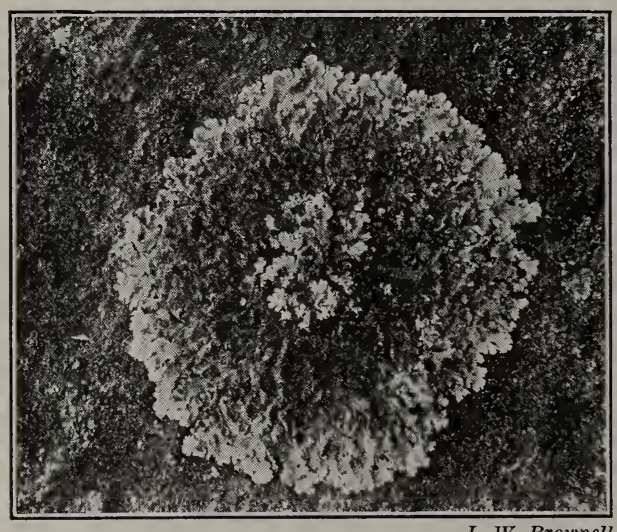

L. W. Brownell

Lichen on a rock. How do lichens differ from other plants?

tion prevails in our own large intestine, where certain types of useful bacteria live. They help keep down the putrefying bacteria while receiving a home and food in return. Other examples are the bacteria which live symbiotically in the roots of certain plants; and the sea anemones which are carried around on the backs of some hermit crabs to places where food is plentiful, and they aid the crab in protecting it from its enemies. In a general way the food relations between green plants and animals may be said to show a symbiotic relationship,

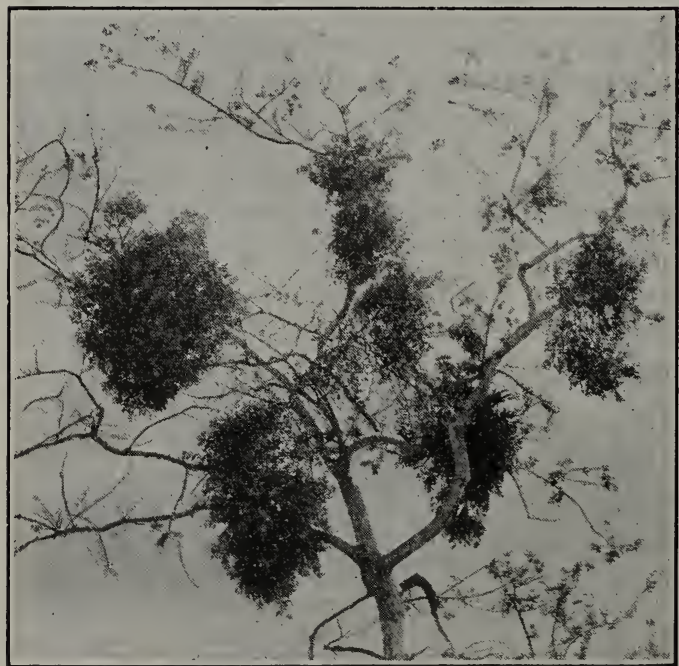

Wright Pierce

Mistletoe on the branches of a sycamore tree. Notice that the branches to the left bear no leaves. They have been killed by the parasite. because the plants could not make food without the wastes from the animals, and the animals could not exist without foods made by green plants.

Parasitism. Not all life is give and take. Some plants and animals live at the expense of others, giving nothing and taking all. Such plants and animals are known as parasites. Examples are seen in the dodder 
and mistletoe among plants, and many insects and worms, among animals. In every case, the parasite lives on another plant or animal known as its host. In some cases, the host is a temporary one, and in others, it is a permanent one, the parasite remaining with it until death. Many plant and animal diseases are caused by parasites, and man has come into the picture to such an extent that he is now engaged in wiping parasitic disease off the face of the earth.

Practical Exercise 4. Give as many examples of symbiosis as you can, using references and museum material. Explain how symbiosis in a large sense exists in the world about you.

\section{Self-Testing Exercise}

Symbiosis is a living

(1) for ....... (2)

(3). It

is a ...... (4), sometimes between ......(5) and ......(6) as in the hydra and algae and sometimes between two plants as in the . (7) and the .......(8); or between two animals as in the (9) ....... (10) and ....... (11) anemone. A ......(12)

lives on another $\ldots \ldots \ldots$ (13) organism known as a $\ldots . . .(14)$, taking food from it but giving .............. (15) in .... Many parasites do ......(17), causing .......(18) or ......(19) of their hosts.

(20) is continually combating ........(21).

\section{PROBLEM IV. HOW DOES MAN DISTURB THE BALANCE OF NATURE?}

Man and the balance of life. Man has come to disturb the balance of life in many ways. He has introduced water to regions and made them support plant and animal life some of which are parasites; he has placed new plants in new localities and had them exterminate the native plants ; and unwittingly he has disturbed the balance which nature had established. He has brought into this country, insects which are doing millions of dollars of damage every year, witness the browntail moth and the gypsy moth in New England, and he is now going to the ends of the earth to find the natural enemies of these imported pests; as is seen in the importation of the ladybird beetle from Australia to feed upon the imported citrus scale insects brought to California from Australia in 1868. He is killing off wolves and coyotes which 


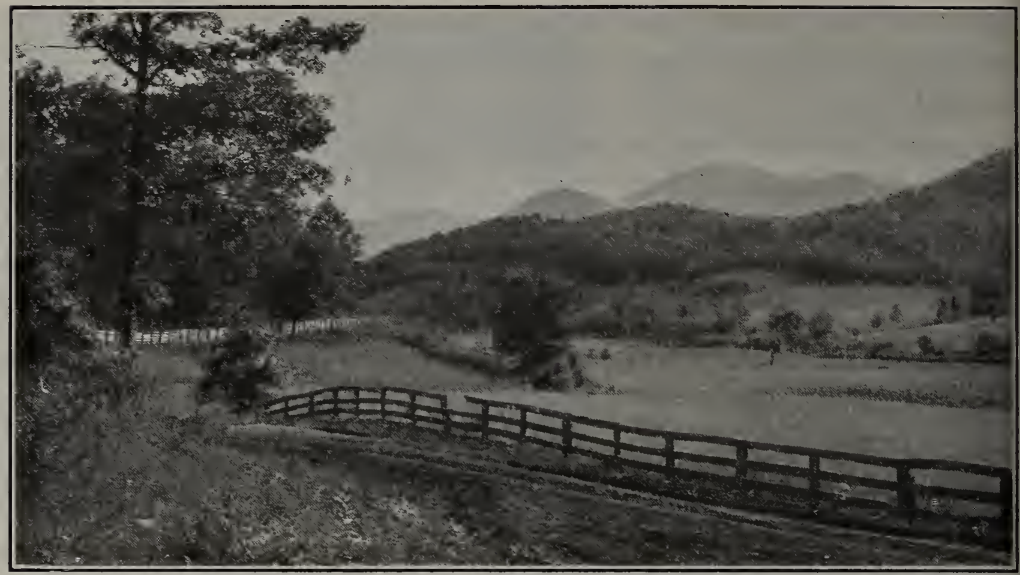

U. S. Forest Sertice

In places where the rainfall is sufficient we may find the ideal combination of farms and forests.

prey upon our deer and he is protecting useful birds which prey upon harmful insects. Man is probably making more changes in life on the earth than any other living factor. But, on the whole, his influence is beneficial, as we will see in the units which follow.

Practical Exercise 5. What is a parasite? Give three examples other than those stated in the text.

Practical Exercise 6. How could a student become a parasite in the school? Explain. How might you become a parasite at home? How can you avoid this?

Practical Exercise 7. Look up the term saprophyte. How does it differ from a parasite? Give examples of each in your environment, if possible.

\section{Self-Testing Exercise}

A ....... (1) exists in ...... (2) between organisms living in a region. Many ....... (3) prey upon others, using them as ........ (4) and thus holding them in check. Man has often ........ (5) this balance by $\ldots \ldots$. (6) new ....... (7) or ...... (8).

PROBLEM V. HOW DO THE FACTORS OF THE ENVIRONMENT AFFECT ECOLOGICAL RELATIONSHIPS?

Ecology is the study of plants and animals in relation to their natural surroundings. Living things can be shown to be affected 


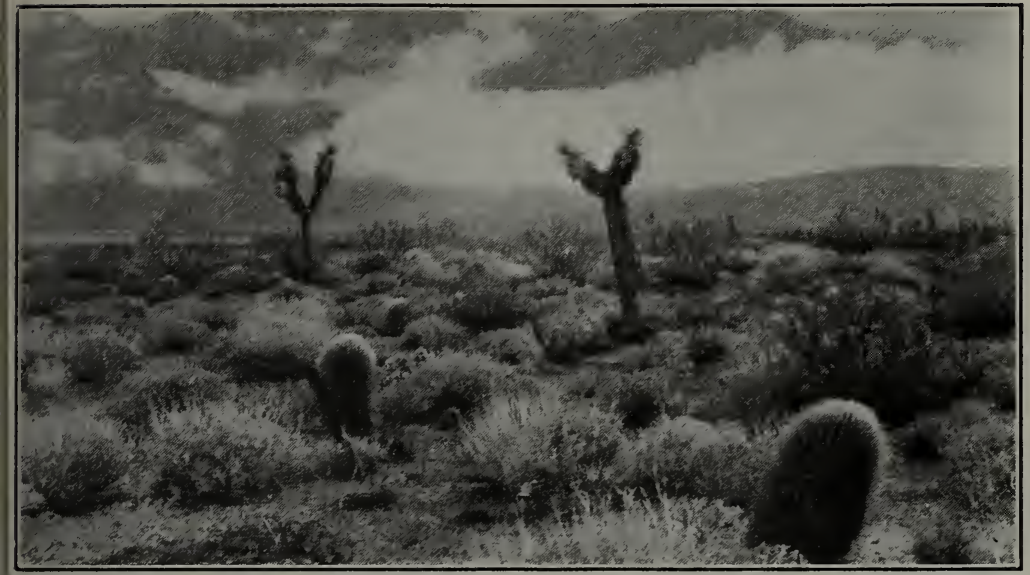

Wright Pierce In a desert, we find that plants are succulent and have spines, bristles, and rigid walls. Why?

by two general sets of factors in their environment, forces and things. These forces are temperature, light, gravity, and, to a lesser extent, such factors as the presence or absence of winds, the presence or absence of electrical storms, and the pressure of the atmosphere.

The things that affect living plants and animals are natural or man-made objects with which they come in contact, such as foods of all kinds and the presence of other living or dead plants and animals in the vicinity.

Temperature. We have already observed the effect of temperature on the growth of seedlings. We know that certain tropical forms of life flourish only in heated areas, and that there are plants, such as the lichens of the frozen tundras of the north, that will grow only in extreme cold. Animal life can equally well be shown to be dependent upon temperature conditions. One of the most striking examples of this was seen in 1882 when fish, abundant in the Gulf Stream, were found dead and dying by the millions in a large area off the eastern coast of the United States. This catastrophe was believed to have been caused by the cold arctic current being shifted by long-continued easterly and northerly winds, the cold water displacing that of the Gulf Stream, thus 


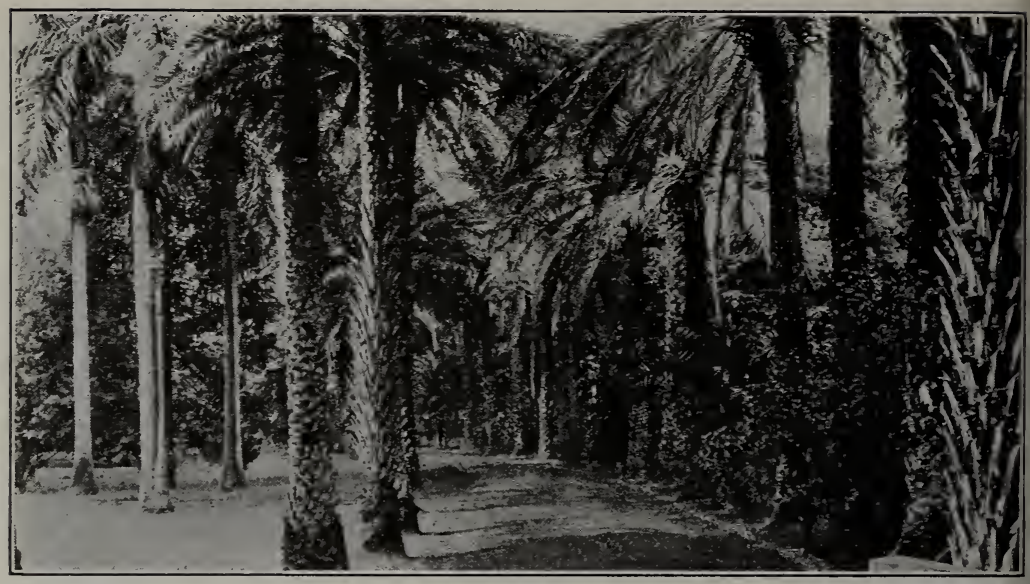

U. S. Forest Service

In the tropics, where heat and rainfall are plentiful, vegetation is abundant. Why is this true?

causing the death of the fish. Fish breeders know how sensitive young fish are to changes of temperature, and any fisherman knows that the trout will go into deep water or will lie in the cool spring holes during hot weather.

We know plants either die or become dormant in winter, while many animals hibernate (become inactive) during the cold weather. But we are not so apt to think of the effect of continuous cold or equally continuous warmth as seen in the arctic regions or in the tropics. The wealth of tropical vegetation and animal life is due in part to the higher temperature. Animals develop faster and go more quickly through their life cycle. In southern California the heat often transforms garden biennials into annuals and the converse is seen in cold countries where annuals may be changed for a time to biennials. High temperature seems to increase the amount of certain pigment in birds and other animals so that they are more highly colored in hot climates.

On the other hand, some fish, as the trout and salmon, are found only in cold water. Dr. H. B. Ward of the University of Illinois says that when salmon ascend a stream to lay their eggs they will invariably take the cooler branch of the river. In ascending the side of a mountain we find different types of animals 


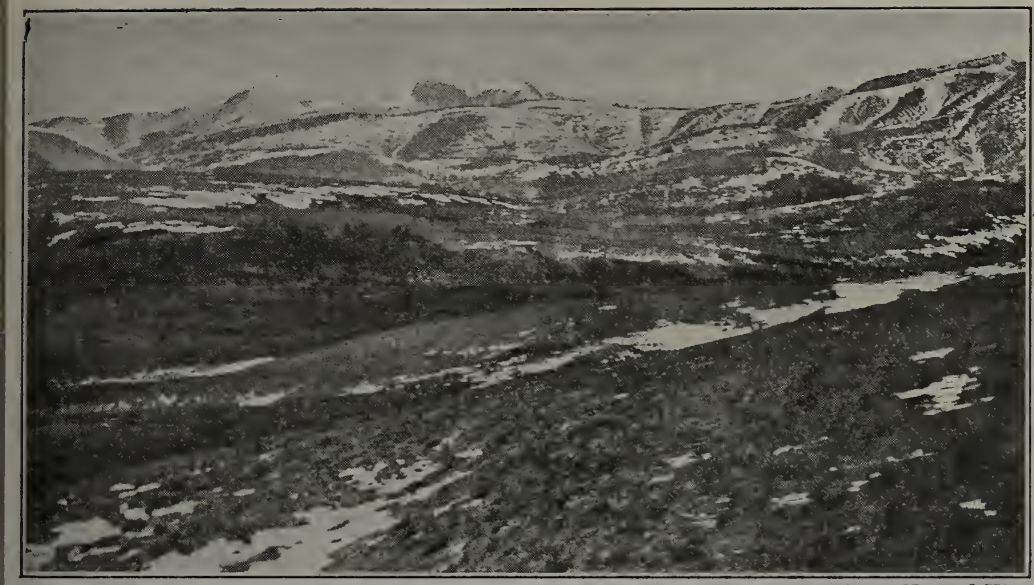

Am. Mus. Natural Hist. Mosses, lichens, and dwarf shrubs are the only vegetation found in the arctic region, (tundra zone).

and plants at different elevations, the determining factor being largely differences in temperature. Animals normally living in the tropics, if brought to this country, may live, but rarely reproduce. In such cases all the environmental factors except that of temperature are the same.

Light. It is easy to pick examples of the effect of light on green plants. For example, we have the turning movements of leaves and stems, the shape and color of plant leaves, and the presence or absence of plants in a given region. But only recently has it been discovered that the flowering of certain plants depends on a lack, rather than an abundance, of sunlight. Such is the chrysanthemum, which flowers when the days become shorter.

Plants and animals are sometimes grouped according to the intensity of light in the environment. Their activity depends upon light, as is seen in the comparative activity of bees on a sunny and on a dark day, or the activity at night of some nocturnal animals, as the owl or coyote. Green plants are tremendously changed if kept in an environment lacking in light. Compare the sprouts of a potato kept in darkness with one grown in the light.

Examples of light affecting animals are many. We know that many animals respond negatively to strong light, as owls, bats, н. В10 -20 
and worms. Many animals that prey on other animals are nocturnal in their habits. On the other hand, most animals can be shown by experiment to respond to light by definite turning movements. The well-known flight of the moth to death in the flame of a candle is an example. Experiments on the tropisms of insects show that a mechanical turning to the source of light is a very general reaction made by all insects.

Gravity. The roots of plants respond positively to gravity by growing toward the center of the earth, while the stems respond negatively by growing away from the center of the earth. If a plant stem which usually grows erect is placed in a horizontal position, it will soon erect itself. This response is readily seen in trees and grasses which have been beaten down by wind and rain.

If boxes containing germinating seeds are fixed on the rim of a horizontally placed wheel which is rotated rapidly, a force stronger than gravity is introduced and the growing stems will tend to grow toward the center of the wheel and the roots will grow toward the circumference.

Water. We need only to look at the luxuriant growth of plants along a stream or irrigation ditch to realize the part water plays in plant life. To anyone who has visited the Imperial Valley of California, where water has made the desert "blossom as the rose," the rôle of water is evident. But an oversupply of water kills plants, as we can see along the shores of any artificial lake where the trees standing in the water are killed. The drying up of lakes has been responsible for the extermination of many fish, just as the bringing of water to new localities may mean new animal life in that locality.

We have seen in the balanced aquarium'some of the adaptations necessary for life there. Plants which live entirely in the water often have slender parts with finely divided leaves. Their roots are apt to be short and stout. The interior of such a plant is made up of spongy tissues which allow the air dissolved in the water to reach all parts of the plant. If the plant has floating leaves, as in the pond lily, the stomata are all in the upper side of the leaf.

Animal life is also restricted to those forms which can easily move, feed, and breathe in water. In the case of insect larvae, as the mosquito, we often find adaptations which enable them to 
get oxygen from the air or, as in other larvae, by gills from the water. Animals living in water are often shaped for living under stones. They are frequently protected from their enemies by having the same color or appearance as the bottom of the sea. They always have devices for catching their food, as evident in the mouth parts of the crayfish, or cilia in unicellular animals which sweep food in a water current. The tiny microscopic animals and plants, called collectively the plankton, which serve as food for other animals, are

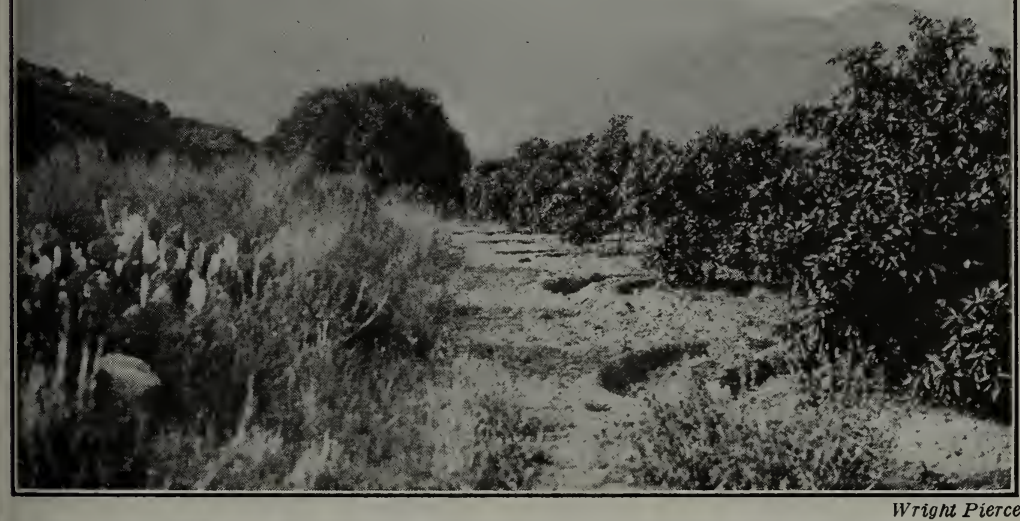

On the left side of the illustration, we see only the type of vegetation that is characteristic of the desert, while on the right, where the land has been well irrigated, a grove of orange trees produces an abundant yield of fruit.

found only in the upper levels of the water, because light penetrates only a few feet and the oxygen supply is deficient at greater depths.

Sunlight heats the water rather uniformly to a depth of 30 to 50 feet in small bodies of water and to a greater depth in the ocean, due to the stirring up of the surface water by wind. Great depths have very low temperatures. Life there is naturally much restricted and few living things are found. There are some fishes living at great ocean depths which are adapted to withstand the great pressure of the tons of water pressing in upon them. However, we know very little about their internal structure because they 
burst when brought to the surface where the pressure is so much less. Few forms of life have adaptations which enable them to get along with the shortage of oxygen at greater depths.

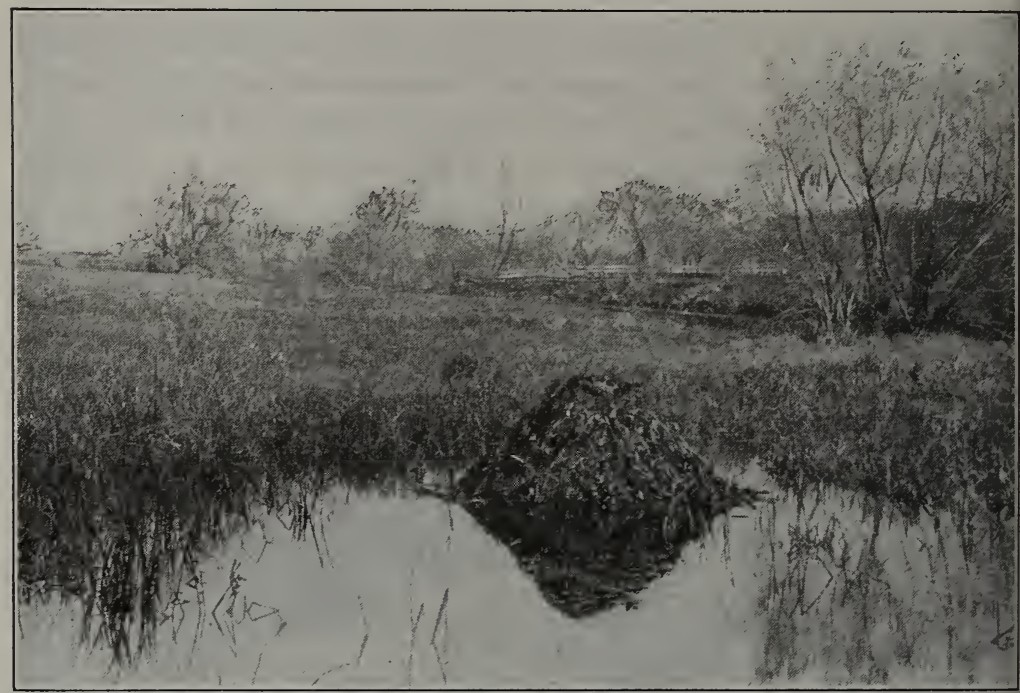

The muskrats make their homes of sticks, mud, and grass in the banks or water of streams, ponds, and lakes. They feed on fresh water clams and lily roots which they get from the bottom of the stream. They usually swim under water, rising oniy now and then to get air.

Plants growing in dry or desert conditions, as cactus, sagebrush, and aloe, show a leaf surface invariably reduced, sometimes in the form of spines, as in the cactus. The stem may be thickened to store water and a covering of hairs or some other material may be present to lessen the loss of moisture by evaporation. If the water or saturated soil, in which the plant lives, contains salts, such as sea salt or the alkali salts of some of our western lakes, plants living there show many characteristics which those in desert conditions show.

Animals living under such conditions are usually few and restricted to those that can burrow to depths so that they may escape the heat, or lizards and snakes which are able to escape the heat by taking shelter under rocks. All forms of animal life found there are able to live on small quantities of water. The desert 
kangaroo rat comes out at night and burrows deep in the sand during the day. One of the ground squirrels avoids the hot sun by running from one bush to another to get shade. Both of these animals die if exposed to the sun for any length of time.

Practical Exercise 8. Make a list of all the plants in your locality that are dependent upon a large supply of water; those which can exist with a very small amount of water.

Soil conditions. Plants grow only in soils to which they are adapted. Some plants, as the blueberry, require acid soils, while others are killed by acid in the soil. The liming of soils is one example of how the farmer keeps the soil in condition for the crops he is growing. The type of soil also affects the animals living in them. Mud, sand, or clay will each contain different species and numbers of plants or animals. Earthworms, for example, are not found living in acid soils.

Food conditions. For both plants and animals food is a factor which determines the presence or absence of life. Mineral matter is so necessary for the growth of plants that manure or artificial fertilizer is employed to fill the need where the element nitrogen is lacking. The presence of animal life in water is often dependent upon the presence of plankton or minute forms of plant and animal life which live near the surface of larger bodies of water. Chemical substances necessary for plants and animals often determine where they will live.

Varying factors. Other factors, such as strong winds, electricity in the atmosphere, the pressure of the air at different altitudes, and the presence of dust or chemical fumes in the atmosphere, may all play decided parts in determining what living things may exist in given localities.

Practical Exercise 9. List all the factors of the environment that affect your daily life and give an example of how each one affects you. How does water affect the life in your community? What effect has temperature on plants in your locality? Do you know any places near your home where unfavorable factors in the environment prevent life? Are such factors forces or things? Explain.

Practical Exercise 10. Make a table naming all the factors of the environment which affect plants and animals and show how each factor affects both plants and animals.

Practical Exercise 11. From reference books, obtain a list of plants and animals adapted to live under conditions lacking water; on alkali plains; in 
salt water; in a fresh-water lake. What adaptations would the plants and animals in the above list show? (Read Jordan and Kellogg, Animal Life, or Kinsey's Introduction to Biology.)

\section{Self-Testing Exercise}

$\ldots \ldots$ (1) $\ldots \ldots$. (2) are affected by the factors of the .......

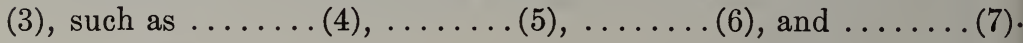
Plants living in water have ....... (8) tissues which hold ....... (9) and are apt to have $\ldots \ldots \ldots(10)$ leaves and $\ldots \ldots \ldots(11)$ roots. Animals living in water show ....... (12) for such life. The ....... (13) of the water is of much importance to the ....... (14) or

(15) living in it. At great depths it is very ........(16). Lack of water results in adaptations in plants for ........(17) ....... (18) such as $\ldots \ldots$ (19) or $\ldots \ldots$ (20) or $\ldots \ldots$ (21) stems. Desert animals can get along without much water, but they ........ (22) in the ground or keep in the .......(23) much of the time. Temperature is a very important .......(24) in determining not only the ...... (25) and ....... (26) found in a given ....... (27) but also how they will .........(28). Animals and plants ... (29) ....... (30) in hot areas, as witness the changing of garden ........(31) into .......(32) in southern California. Many fish, as trout or salmon, are only found in .......(33) water. Some animals can only live in water containing certain ........(34). Plants and animals may be influenced not only by the .........(35) but also by the ........(36) of light.

\section{PROBLEM VI. WHY DO PLANTS AND ANIMALS FORM COMMUNITIES?}

Societies. All of the factors referred to act upon the plants we find living together in a forest, a sunny meadow, along a roadside, or at the edge of a pond. Any one familiar with the country knows that we find certain plants, and only those plants, living together under certain conditions, and, in a similar way, only certain animals will be found to be associated together.

Plants and animals associated under similar conditions, as those of a forest, meadow, or swamp, are said to make up an association or community. If we investigate such an association, we find it to be made up of certain dominant species of plants; that here and 
there definite communities exist, made up of groups of the same kind of plants, while certain animals will be found living on the plants or among them. Evidently conditions of food and shelter are responsible for this close association. We can see that each one of these plant groups in the community evidently came originally from a single individual which flourished under the peculiar conditions of soil, water, light, etc., that were found in this spot. These single plants have evidently given rise to like plants which made up a family group, and thus have populated the locality. This is often seen in a pine grove, or in an

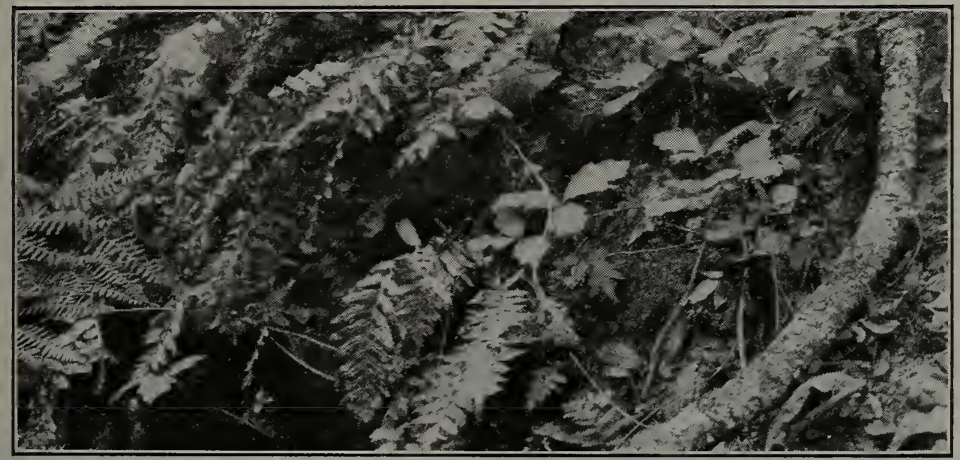

Wright Pierce

A plant society. Can you name the various plants that are living together in this group? What conditions and adaptations make it possible for them to live together in one society?

area covered almost exclusively with ferns. Later, seeds of other plants may be carried there by the wind, birds, or other animals, and we find widely different plants living under similar conditions. They all need the same substances from the air, the water, and the soil. They all need sunlight ; they use the same food. Therefore there must be competition among them, especially between those near to each other. The plants which are strongest and best fitted to get what they need from their surroundings, live; the weaker ones are crowded out and die.

But their lives are not all competition. The dead plants and animals give nitrogenous material to the living ones, from which the latter make living matter; some bacteria provide certain of the green plants with nitrogen; many of the green plants make 
food for other plants lacking chlorophyll, while some algae and fungi actually live together in such a way as to be of mutual benefit to each other. The larger plants may shelter the smaller ones, protecting them from wind and storm, while the trees provide humus which holds the moisture in the ground, giving it off slowly to other plants. Animals scatter seeds far and wide, and man may even start entire colonies in new localities.

Practical Exercise 12. Describe some plant or animal community you have seen. What forms of life are associated together?

Could you have a plant community in the laboratory or school yard? What conditions would you expect to find? What plants living together?

\section{Self-Testing Exercise}

Conditions of ....... (1)

(4) are the chief factors which will live together in
(3) and

(5) what plants and animals all $\ldots \ldots \ldots(8)$ but a mutual give and take. The animals and plants best ........(9) to live under such .......(10) crowd out the ....... (11).

\section{PROBLEM VII. WHAT IS AN ECOLOGICAL SUCCESSION?}

Changes in environment cause changes in life. Changes are always taking place in plant and animal communities. Sometimes these changes are brought about artificially, as when a forest fire sweeps a country or man introduces water by irrigation into a desert region. But alwayŝ there are changes going on, which cause plant and animal associations to change in a given locality and often to move to new localities. Most of these changes are very slow, so that we rarely notice them. Here is an example quoted by Elton: A hole in a beech tree was first used by an owl as a nest; then with the growth of the tree the hole became smaller and was used by starlings. Later it became too small for them to enter, and the hollow was filled by a wasps' nest.

How plants invade new areas. New areas are tenanted by plants in a similar manner. After the burning over of a forest, we find a new generation of plants springing up, often quite unlike the former occupants of the soil. First come the fireweed and 
other light-loving weeds, brought by means of their wind-blown seeds. With these are found patches of berries, the seeds of which were brought by birds or other animals. A little later, quickgrowing trees having seeds easily carried for some distance by the wind, like the aspen, or seeds of ten distributed by birds, as the wild cherry, invade the territory. Eventually we may have the area retenanted by the same kind of inhabitants as formerly, especially if the destruction of the original forest was not complete.

In like manner, on the upper mountain meadows or by the sand dunes of the seashore, wherever plants place their outposts, the advance is made from some thickly inhabited area, and this advance is always aided or hindered by agencies outside of the plant - the wind, the soil, water, or animals. Thus the seeds obtain a foothold in new territory, and new lands are captured, held, and lost again by the plant communities.

How animals get a foothold

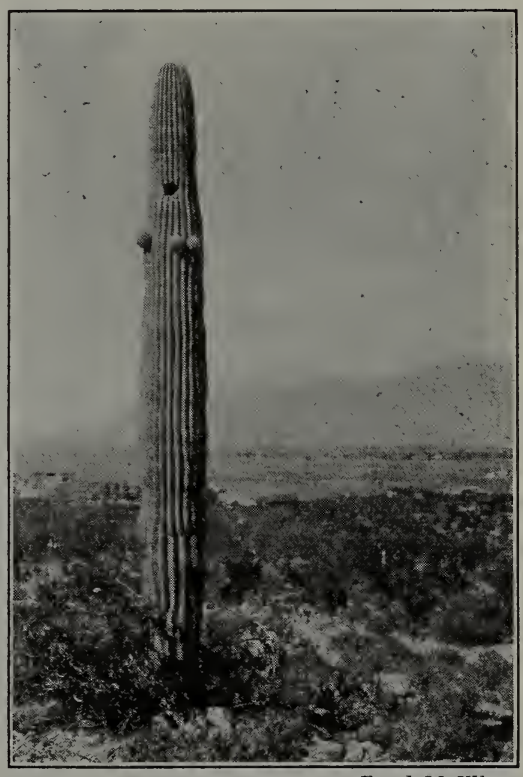

Frank $M$. Wheat

In the giant cactus, woodpeckers drill their nesting holes. In following years, these holes are often used as nests in turn by small owls (elf owls), sparrow hawks, screech owls, fly catchers, and wrens. in new areas. There are many ways in which animals spread over new areas. Transportation to quite distant parts may take place, as when polar bears or seals are carried on ice floes long distances or when insects and other small forms like crustaceans and snails may be carried hundreds of miles by ocean currents. Birds may carry encysted microscopic forms or even the eggs of mollusks or crustaceans in little balls of mud which stick between their toes. Man himself may play a very important part in the distribution of animals in 
new countries. One of the best instances of animals having spread when introduced by man is the case of rabbits in Aus-

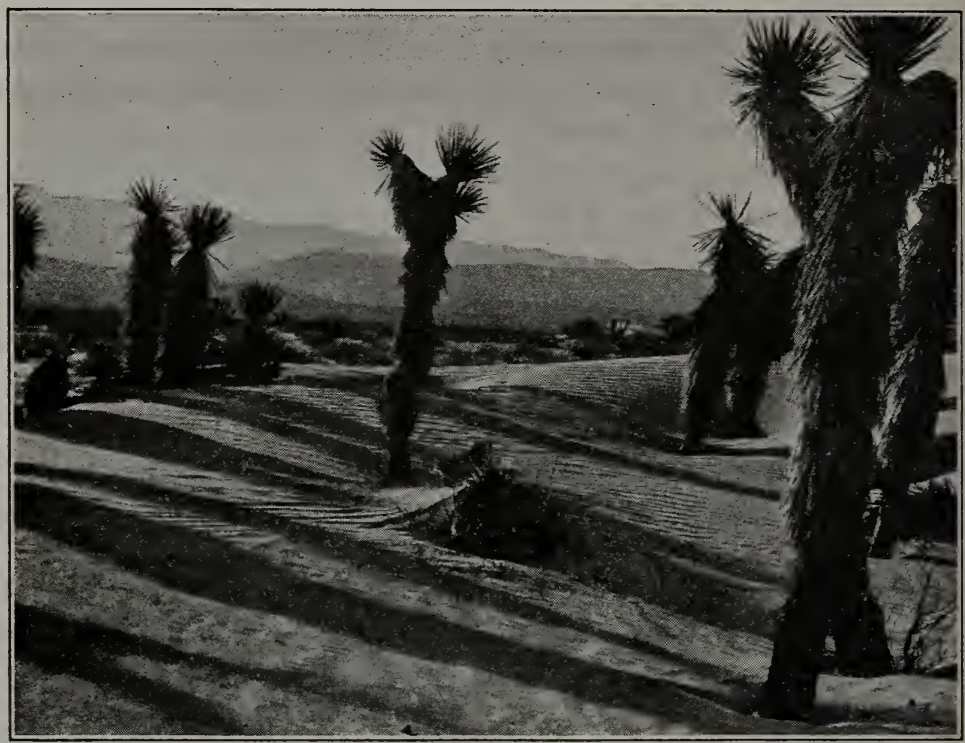

Wright Pierce

If this desert region of southern California should be thoroughly irrigated, what kind of plant society might succeed these Joshua trees?

tralia. They have now become so numerous that they are a serious pest. The English sparrow in America and the English starling in New Zealand are other examples of introductions of animals which have become pests because of lack of enemies to hold them in check.

Practical Exercise 13. Make a list of all the new forms of life introduced by man into your own environment.

Food relations. Animals are confined to certain localities because a food supply is there, and may migrate to new localities when the food supply gives out. Overpopulation with subsequent lack of food brought about great migrations of the house rat across Russia in 1727, which was the beginning of the occupation of all Europe by this species of rat.

Food cycles exist, one animal being dependent upon another 
or on plants and moving away when the food gives out. Such a food chain or cycle would be seen in the warblers which eat insects living in trees, as plant lice and boring beetles. The warblers are in turn preyed upon by hawks. In the same forest there may be mice, whose chief food is acorns, and the mice are eaten by owls. This is another example of a food cycle.

Sometimes we have a sudden invasion of an animal after food, such as the locust. The famous plague of grasshoppers in Utah in early pioneer days was stopped by a similar migration of gulls from the Great Salt Lake which came to feed on the grasshoppers. Thus a balance of life is maintained.

Ecological successions have already been spoken of. When, for example, a lake area dries up, different animals come to occupy the marsh and forest land, taking the place of the water forms of life. Man has played a very large part in attracting new animal forms into regions that he has irrigated or reclaimed for agriculture. Here are an entirely new set of animals which feed upon the introduced plants.

Life succession in a hay infusion. Still another example of an ecological suc-

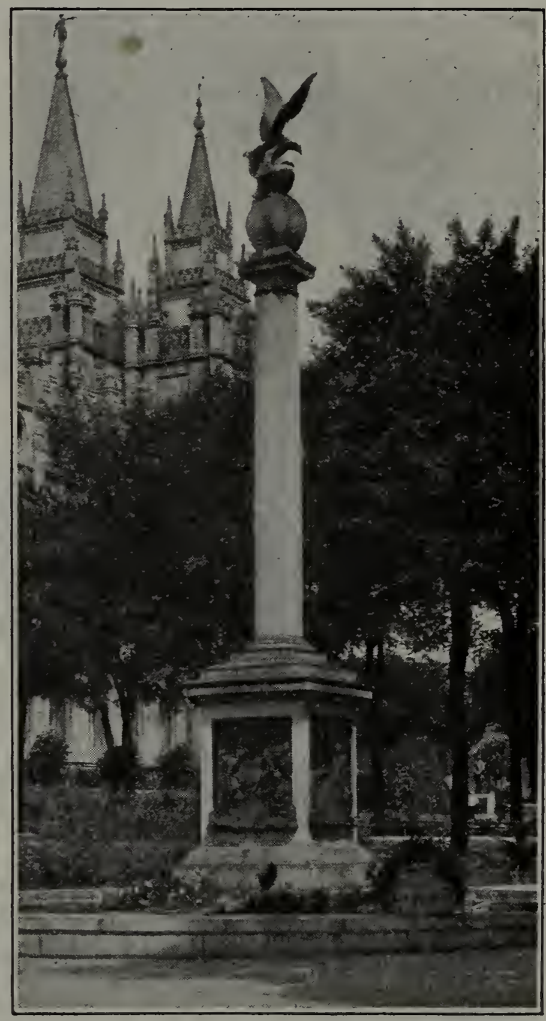

Clifl Bray

The people of Salt Lake City, Utah, erected this monument in commemoration of the service done by the gulls in the destruction of grasshoppers.

cession may be seen in a hay infusion. If we place a wisp of hay or straw in a small glass jar nearly full of water, and leave 
it for a few days in a warm room, certain changes are seen to take place in the contents of the jar; the water after a little while gets cloudy and darker in color, and a scum appears on the surface. If some of this scum is examined under the compound microscope, it will be found to consist almost entirely of bacteria. These bacteria evidently aid in the decay which (as the unpleasant odor from the jar testifies) is taking place. As we have learned, bacteria flourish wherever the food supply is abundant.

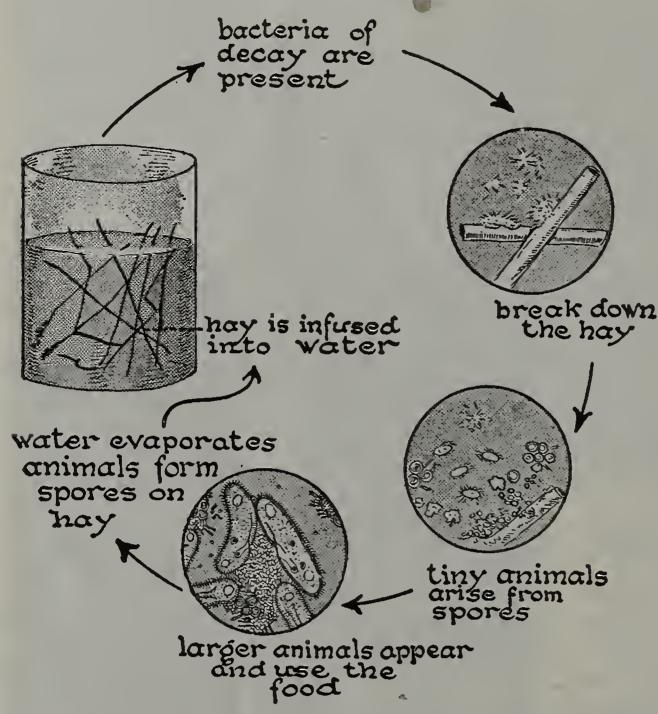

The development of life in a hay infusion. How can you account for the bacteria that attacked the hay?

The bacteria themselves release this food from the hay by causing it to decay. After a few days small one-celled animals appear which multiply with wonderful rapidity. Hay is dried grass, upon which the wind may have scattered some of these little organisms in the dust from dried-up pools. Existing in a dormant state on the hay, they are awakened by the water to active life. In the water, too, there may have been some other living cells, plant and animal.

At first the multiplication of the tiny animals within the hay infusion is extremely rapid; there is food in abundance and near at hand. After a few days more, however, several kinds of onecelled animals may appear, some of which prey upon others. Consequently a struggle for life begins, which becomes more and more intense as the food from the hay is used up. Eventually the end comes for all animals unless some green plants obtain a 
foothold within the jar. If such a thing happens, food will be manufactured within their bodies, a new food supply arises for the animals within the jar, and a balance of life results.

Practical Exercise 14. Look for examples of ecological succession in your laboratory. Any evidences of this? Where?

Visit a burned-over area and note the new plants which come up. How do they differ from the old ones?

Might a garden show examples of ecological succession? Give examples.

\section{Self-Testing Exercise}

.. (1) are always taking place in animal and plant ........(2).

(3) invade areas which have been

(5), or animals ......(6) or shift their

because of lack of .......(8) or other causes. Such a change is called an (10).

\section{PROBLEM VIII. WHAT DO WE MEAN BY GEOGRAPHIC DISTRIBUTION OF LIVING THINGS?}

Range of plants and animals. Plants and animals inhabiting a given territory or area are called the flora or fauna of that range or area. We find out the range of a given form by collecting it in as many places as possible. This kind of work is interesting to boys and girls because they can determine the range of certain plants and animals in their own locality.

The areas in which given species of plants or animals are found may be very limited or very wide. Some trees, for example, the western redwood, have a rather limited range in the extreme northwest while the western yellow pine or the eastern hemlock has a much wider range. Some of these areas were much larger in ancient geological times than they are now. That certain areas have become discontinuous is seen in the distribution of elephants, which once were found over a large part of the earth's surface. Man may reduce or increase the range of an animal, as when he nearly exterminated the buffalo, or introduced a pest such as the orange scale in California or the gypsy moth in Massachusetts or the chestnut canker on Long Island.

Barriers and their effect on plant and animal life. Any one who has seen the Sierra Nevada mountains and knows the difference 


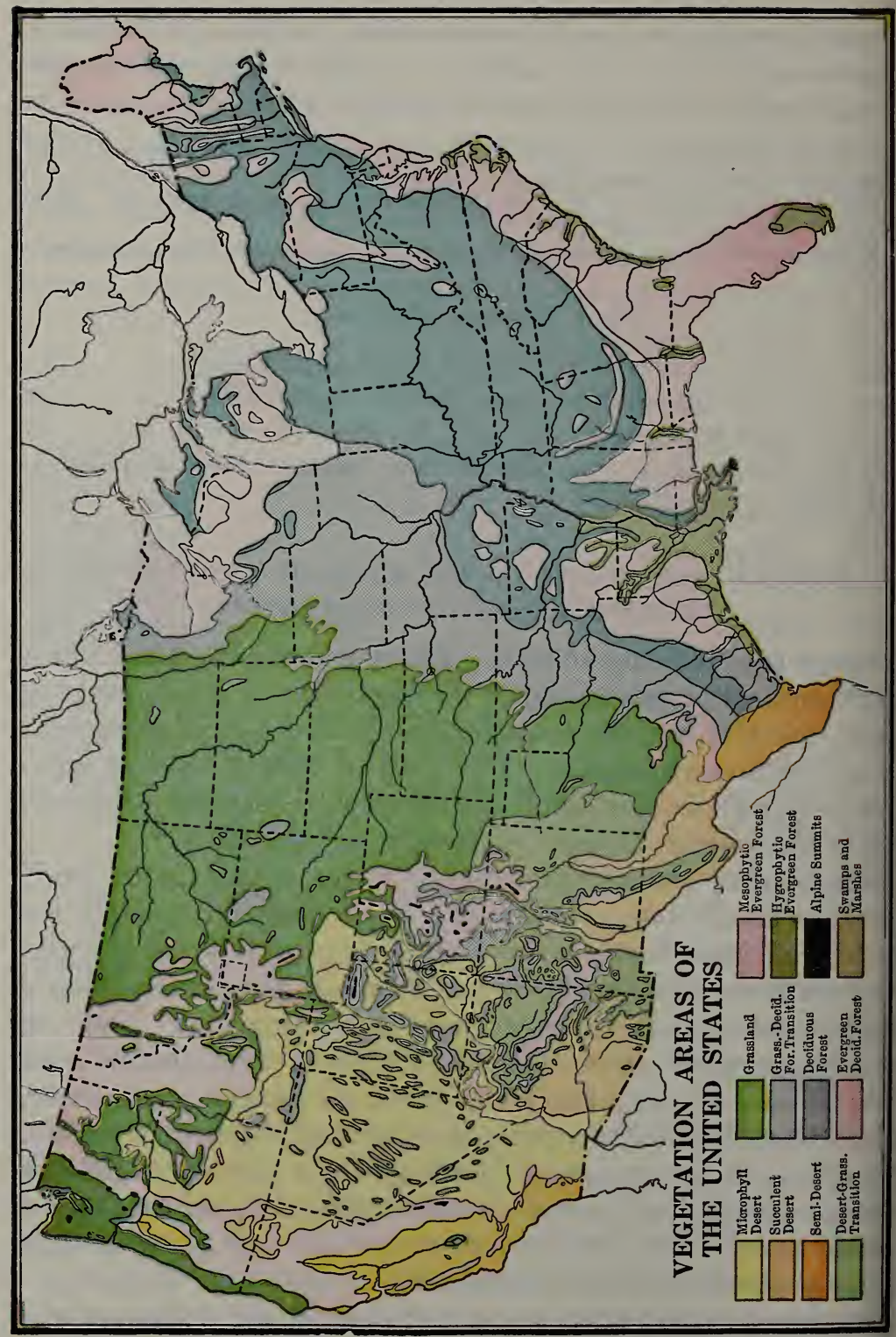


in life on the western and eastern slopes can tell what effect a mountain may have in the distribution of a given kind of plant or animal. Living things on one side of that range are quite different from those on the other. Natural barriers may be mountains, deserts, large bodies of water, and even rivers. Climatic conditions, especially, limit the range of plants, which cannot endure great differences in rainfall, in temperature, humidity, wind, or sudden atmospheric changes. Some plants and animals have special adaptations which enable them to cover large areas, such as parachutes on seeds and the wings of birds. For such plants and animals the geographic range will be greater than for less favored forms.

Life zones. Reference has already been made to the fact that a zonal distribution of plants and animals is easily seen in climbing any high mountain. Any area in which most of the plants or animals belong to single or relatively few groups of

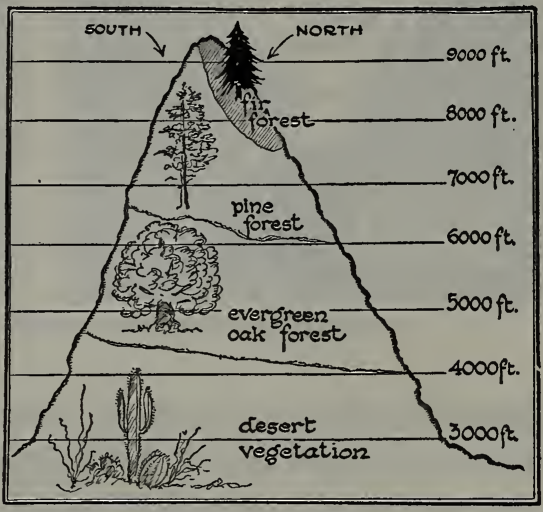

Zonal distribution of plants on a mountain rising from a desert in Arizona. Give cause for different zones. plants and animals is called a life zone. Life zones are often rather sharply marked, but usually show transitional areas between them. A region which has been carefully studied and which shows this zonal distribution in a marked way is the San Francisco mountain region in north Arizona. Here a mountain nearly 13,000 feet in height rises out of a desert plain. This mountain shows successively two types of desert zone, a lower and upper, each with its own desert fauna and flora, cactuses, sagebrush, a few birds, mice, lizards, and snakes. Then a region at between 6000 and 7000 feet of piñon pines and red cedars, inhabited by more birds and a few mammals. Between 7000 and 8200 feet we find forests of Douglas and balsam fir, with such mammals as meadow mice, chipmunks, deer, lynx, and puma. 

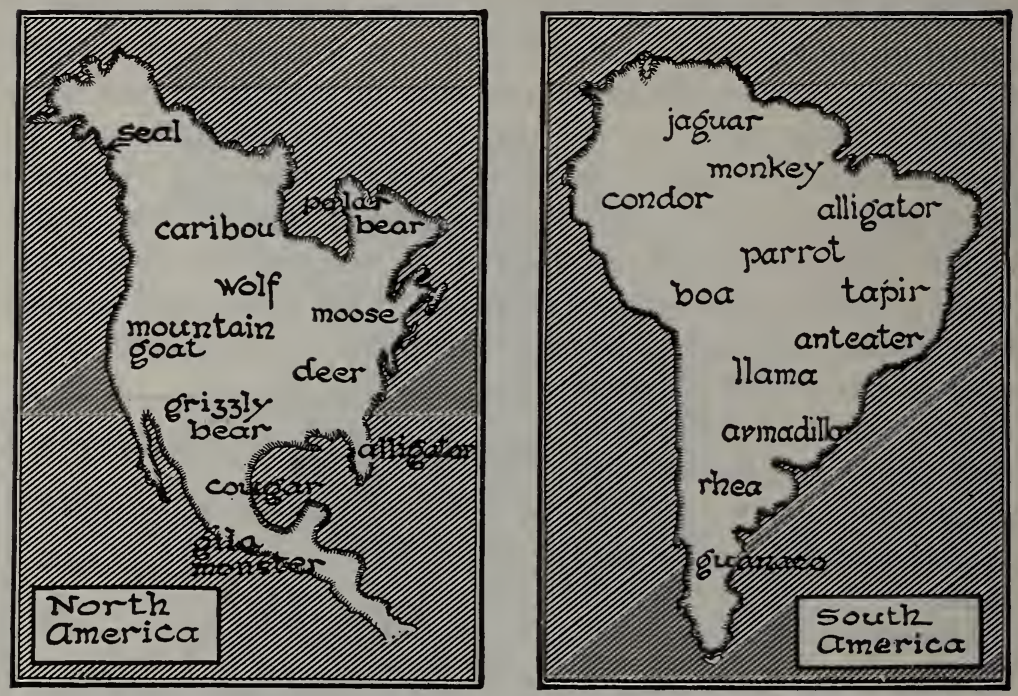

Distribution of animals on the continents. How do you account for the fact Where and why do you

Higher still, between 8200 and 9500 feet, we find a typical Canadian vegetation, timber pine, Douglas and balsam fir and aspens, while the woodchuck, porcupine, rabbit, marten, fox, wolf, and other northern forms are found. From 9500 to 11,500 feet we find a fauna and flora almost like that of northern Canada and called Hudsonia. Stunted spruce and pine exist up to the timber line with a few typical mountain mammals such as the marmot and pika or mountain hare. Above this area lies the rocky Alpine zone, snowclad for one half of the year even in this warm, sunny climate. Lichens on the rocks and a few low herbs are the only plant life visible, while a few insects and an occasional mammal of the Hudsonian zone are the only signs of animal life.

Ecological realms. The facts that the ecologist has found out concerning life zones have been put to practical use by the Biological Survey of the United States Department of Agriculture. A life zone map has been prepared so that the settler going into a new region will know at once the kind of plants and animals best adapted to live there. In addition, the character of the soil, the 

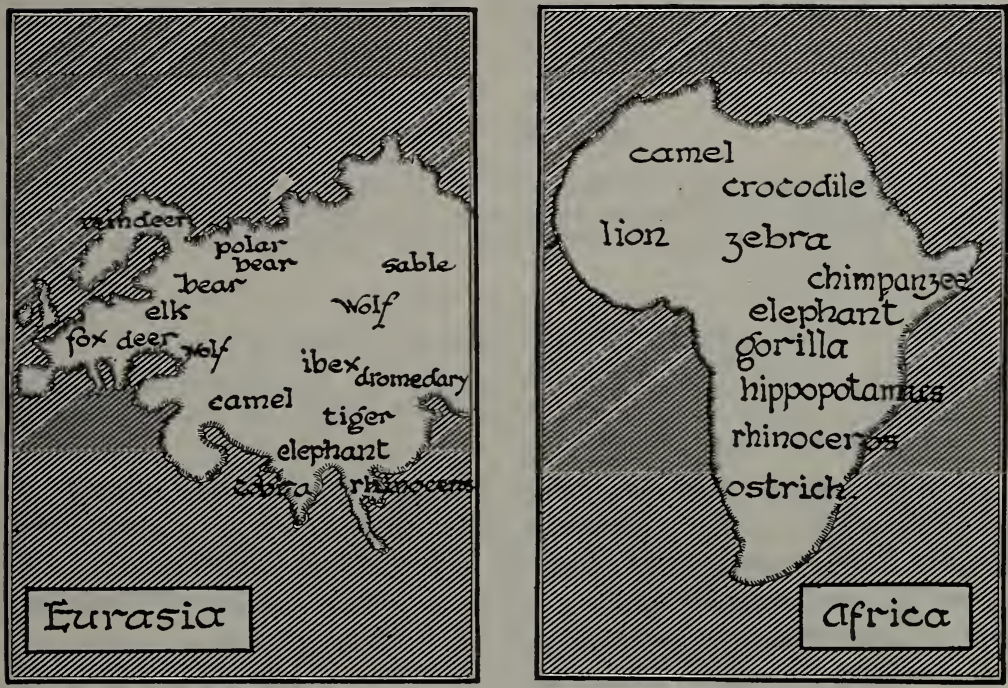

that some of the same animals are found in both North America and Eurasia? find other similarities?

rainfall, temperature range, and lists of the particular cereals, fruits, and vegetables that can grow in the region are made available to the farmer.

Different parts of the world, each with its several life zones, are known as realms or regions. Australia has long been set aside as a distinct realm because its peculiar fauna and flora differ from those in other parts of the earth. North America, South America, the Arctic, the Antarctic, Oriental Africa, Eurasia, and Australia constitute the world realms. Each of these regions has animals and plants peculiar to itself, although resemblances are often found in their inhabitants. The Eurasian fauna and flora resemble closely those of North America. This is thought by geologists to mean that in former times these regions were connected by land.

\section{Self-Testing Exercise}

Areas inhabited by certain .......(1) and .......(2) may be very ....... (3) or very ....... (4). Barriers that affect the range of plants and animals may be ...... (5), ...... (6), and ..... (7). 
A mountain near a desert may show ....... (8) ....... (9). Each of these $\ldots \ldots \ldots$ (10) has .......(11) and .......(12) peculiar to itself.

\section{Review Summary}

Test your knowledge of the unit by: (1) rechecking on all the survey questions; (2) performing all assigned exercises; (3) checking with your teacher all tests and doing over the parts you missed; (4) making an outline of the unit for your notebook.

\section{Test on Fundamental Concepts}

In a vertical column under the heading CORRECT write numbers of all statements you believe are true. In another column under INCORRECT write numbers of untrue statements. Your grade $=$ number of right answers $\times 3 \frac{1}{3}$.

I. The balance of life (1) means that living plants and animals are mutually dependent upon each other; (2) is shown by a poor garden crop in a dry year ; (3) in a certain region is often disturbed by man when he cultivates wild areas; (4) is shown in a balanced aquarium; (5) was disturbed in Australia by the introduction of water cress.

II. The grouping of plants and animals in associations (6) is due to the kind of food available; (7) is called a habitat; (8) differs according to the environment; (9) is seen in a balanced aquarium; (10) is brought about by the ability of certain living things to live together under certain conditions.

III. Plants and animals may be prevented from living in certain localities by (11) too much light; (12) lack of certain salts in the soil ; (13) lack of water; (14) too much water; (15) lack of oxygen.

IV. Symbiosis (16) is the process of living together for mutual advantage ; (17) is a partnership between two living things ; (18) occur when green plants give food to animals and depend upon certain wastes from them in order to make this food; (19) is a bad thing, because it is a one-sided relationship ; $(20)$ is the same as parasitism.

V. Ecological succession (21) occurs when changes in environment cause changes in forms of plants and animals living in a given place; (22) is never brought about by man; (23) is often caused by man; (24) is often caused by immigrations of animals due to lack of food; (25) results in new forms being found in a given locality.

VI. Life zones (26) are found on the sides of a high mountain where life forms characteristic of the tropics to the arctic may be found from the base to the summit; (27) are illustrated by the temperate zone, the torrid zone, etc.; (28) are usually well marked but show 
transitional areas between them; (29) are areas in which most of the plants or animals found belong to single or relatively few animal or plant groups; (30) are not usually sharply marked.

\section{Achievement Test}

1. How many animal or plant societies have you found in your locality?

2. How would you stock an aquarium and keep it balanced?

3. How can you illustrate the nitrogen, carbon, and oxygen cycles?

4. What are all the factors of the environment which affect living things in your own environment?

5. What is the meaning of symbiosis, and can you give examples?

6. Have you any local parasites and how are they controlled?

7. What is the effect of water upon the life in your region?

8. How has man controlled or changed life by use of water?

9. What geographic region do you live in and what are the chief characteristics of its flora and fauna?

\section{Practical Problems}

1. Select some locality near you and try to work out the animal and plant communities there.

2. Make a map for your notebook, showing zonal distribution of plants and animals for your locality.

3. Take an area in your own yard one foot square and list all the living things you can find there.

\section{USEFul REFERENCES}

Coulter, Barnes, and Cowles, Textbook of Botany, Vol. Three. (American Book Company.)

Downing, Our Living World. (Longmans, Green \& Co. 1924.)

Elton, Animal Ecology. (The Macmillan Co. 1927.)

Flattely and Walton, The Biology of the Sea Shore. (The Macmillan Co. 1922.)

Howes, Insect Behavior. (R. C. Badger.)

Jordon and Kellogg, Animal Life. (D. Appleton \& Co.)

Loeb, Forced Movements, Tropisms and Animal Conduct. (J. B. Lippincott Co. 1918.)

Needham, General Biology. (Comstock Publishing Co.)

Pearse, Animal Ecology. (McGraw Hill Co. 1926.)

Schimper, Plant Geography. (Oxford University Press.)

Shull, Principles of Animal Biology. (McGraw Hill Co. 


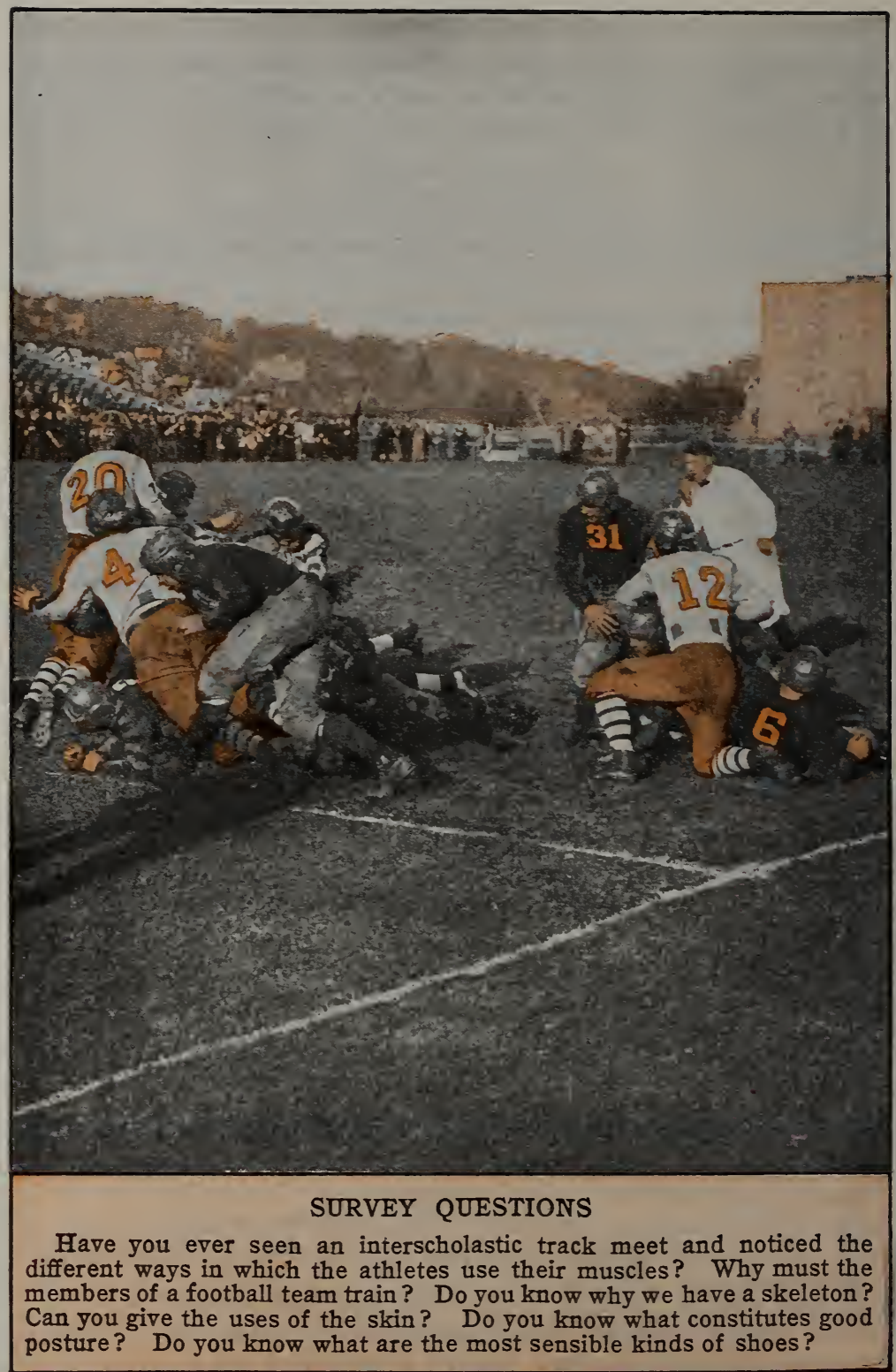

Wide World Photo 


\section{PART IV. THE BIOLOGY OF MAN}

\section{UNIT $\mathrm{X}$}

\section{HOW DOES THE HUMAN MACHINE DO ITS WORK?}

Preview. I suppose every boy and girl who reads these pages has seen an interscholastic track meet and perhaps envied the perfect coördination of every part of the bodies of the men who run hurdles, high jump, or pole vault. Perhaps you have tried some of these feats yourself and have discovered how difficult it is to make the different muscles coördinate at exactly the right time. It is a very wonderful machine, this body of ours, and we cannot help but feel a real reverence for it when we think of the delicate mechanism which, with its numerous adjustments and adaptations, can do work so efficiently. Unlike a man-made machine, the body is self-directed, and with care will far outlast most machines made of iron and steel.

In all animals, and the human organism is no exception, the body has been likened to a machine in that it turns over the latent or potential energy stored up in food into kinetic energy (mechanical work and heat), which is manifested when we perform work. One great difference exists between an engine and the human body. The engine uses fuel unlike the substance out of which it is made. The human body, on the other hand, uses for fuel the same substances as those out of which it is formed; it may, indeed, use part of its own substance for fuel. The human organism does more than purely mechanical work. It is so delicately adjusted to its surroundings that it will react promptly and efficiently to stimuli from without; it is able to utilize its fuel (food) in the most economical manner; it is fitted with machinery for transforming the energy received from food into various kinds of work; it 


\section{HOW DOES THE HUMAN MACHINE DO ITS WORK?}

provides the machine properly with oxygen so that the fuel will be oxidized; and the products of oxidation are carried away, as well as other waste materials which might harm the effectiveness of the machine. Most important of all, the human machine is able to repair itself.

No boy or girl can go into the big game of life and expect to be a helpful member of society with an insufficient knowledge of the human machine. Neglect or lack of proper care of our bodies may defeat some of our life's fondest ambitions. The efficient citizen should be the healthy citizen.

\section{PROBLEM I. WHAT IS THE GENERAL STRUCTURE OF THE HUMAN BODY?}

Laboratory Exercise. The structure of the human body. Use manikin or good chart.

Note the covering of skin. Can you think of any uses for this structure? What general uses would the muscles have? Note their position with reference to the skeleton and the organs of the body cavity. Take off the covering and examine the organs within the body cavity. The thin layer of muscles that separates the heart and lungs from the abdominal cavity is the diaphragm. Use a good text figure to locate the parts of the digestive tract: stomach, small and large intestines, liver, and pancreas. Locate the kidneys, and the tubes (ureters) leading to the bladder and thence outside of the body.

Skin and muscles. If we are thinking of the body as a machine which does work, then it is obvious that, while the skin is partly a protective organ, the muscles are structures by which work is largely accomplished. The diagram (p. 320) shows that they are attached to bones which serve as levers and thus accomplish movement.

Other body structures. In spaces between the muscles are found various other structures - blood vessels, which carry blood to and from the great pumping station, the heart; connective tissue, which holds groups of muscle or other cells together; fat cells, scattered in various parts of the body; various gland cells, which manufacture the enzymes which digest our foods; and the cells of the nervous system, which aid in directing the various parts of the body.

Body cavity. Within the cover of skin, bone, and muscle is a cavity filled with various organs. A thin wall of muscle called 
the diaphragm ( $\mathrm{di}^{\prime} \dot{a}$-frăm) divides the body cavity into two unequal cavities. In the upper one, thoracic cavity, are found the heart, lungs, and esophagus; in the lower, the abdominal cavity, are the stomach, intestines, the liver, the kidneys, and other structures.

Digestion and excretion. The mouth cavity leads into a food tube into which food passes and from which digested or liquid food is absorbed into the blood to be carried to the cells of the various organs which do the work. Emptying into this food tube are various groups of gland cells, which pour digestive fluids over the solid foods, thus aiding in changing them to a soluble form. Solid waste materials are passed out through the posterior end of the food tube, while liquid wastes are eventually excreted by means of the skin and of organs called kidneys.

The nervous system. This complex machine is much more than a mechanical engine. It is self-directed. All its functions are either directly or indirectly under its control. Not only are animals able to receive outside stimuli through certain parts called sense organs, but they react to them, and there is internal coordination and control as well. The complicated machine does its work automatically; the heart beats, the glands secrete, the chest rises and falls without any conscious direction on our part. The nervous system gives sensation, it gives internal control and coördination. In man it does more. It also gives him control over his conscious activities. He is able to make a selection or choice of his daily acts. As such he is a "thinking " animal and has become master of the earth.

Practical Exercise 1. Make in tabular form for your workbook a summary of work done by the different parts of the body.

\section{Self-Testing Exercise}

Check in your workbook the statements that are true.

T. F. 1. The human body is like a machine because it can repair itself.

T. F. $\cdot 2$. Food is oxidized in the human body as is fuel in an engine.

T. F. 3. The skin is an organ of protection but not of excretion.

T. F. 4. The nervous system gives sensation as well as body control.

T. F. 5. Movement is accomplished in the body because muscles are attached to bones which act as levers. 


\section{PROBLEM II. WHAT IS THE STRUCTURE OF THE SKIN?}

\section{Laboratory Exercise. To find out some functions of the skin.}

Hand lens. Ether or alcohol. Large glass jar. Two thermometers. Model or illustration showing section of skin.

Find out whether all parts of the skin of the arm are equally sensitive, by touching various parts of it with the sharp point of a pencil. Cool a large glass jar, and hold the hand and wrist in the jar for a few moments, closing the opening of the jar with a cloth or a towel. What collects on the inner surface of the jar?

What happens when you take violent exercise? Weigh yourself before and after a period of hard work in the gymnasium. Is there any loss in weight? How do you account for it?

Place a few drops of ether or alcohol on the back of your hand and note the evaporation of the liquid. What sensation do you feel while the evaporation takes place?

Study the model or diagram of skin on page 17. Locate the two layers. Find and describe the sweat glands, oil glands, and sense organs. Draw a diagrammatic sketch of the model and label all parts. Write a statement giving the functions of each part.

Conclusions. Is the skin an organ of sensation? What passes off through the skin? What effect on your bodily comfort does this last function have?

The skin. Covering the body is the protective structure called the skin. Under the epidermis, a layer of dead cells, there are delicate sense organs, lying in the dermis or true skin, which give us sensations of touch, pressure, and temperature. The skin aids also in passing wastes out of the body by means of sweat glands, and it plays an important part in equalizing the temperature of the body.

Nails and hair. Nails are outgrowths of the horny layer of the epidermis. A hair is also a growth of the epidermal layer, although it is formed in a deep pit or depression in the dermis; this pit is called the hair follicle.

The glands of the skin. Scattered through the dermis, and usually connected with the hair follicles, are tiny oil-secreting glands, the sebaceous (sè-ba'shus) glands. The secretion of these glands keeps the hair and surface of the skin soft and.pliable. The other glands in the dermis, known as sweat glands, are to be found in profusion, over 2,500,000 being present in the skin of a normal man. These glands excrete certain wastes from the blood in the water they pass off. 
The skin is first of all an organ of protection against man's microscopic foes, the bacteria. But a dirty skin harbors bacteria. Moreover, the skin pores, through which the perspiration and oil pass, are easily clogged with dirt. Frequent washing is necessary if we wish to keep the skin clean. Pride in one's own appearance forbids a dirty skin. Powder or rouge does not clean the skin; it may cover up dirt.

For those who can stand it, a cold

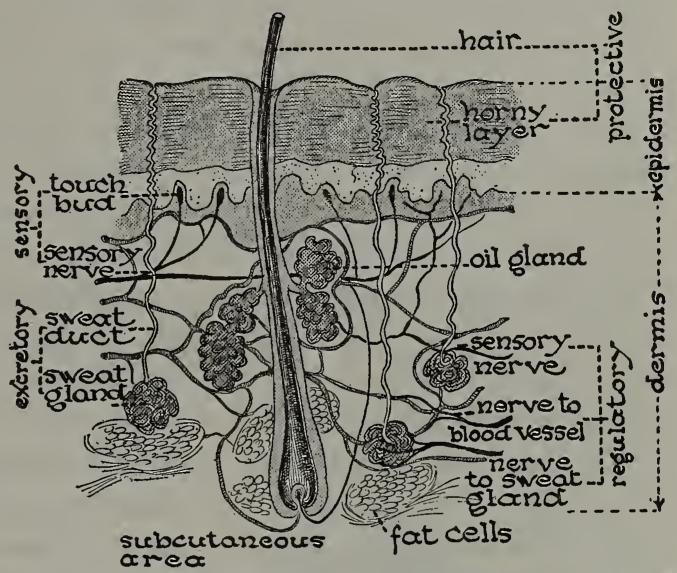

A section through the skin. What are the uses of the various parts? shower or sponge bath should be taken every day with a brisk rubdown afterward, since this exercises the blood vessels of the skin. Soap should be used daily on surfaces exposed to dirt, because it combines with the oil of the skin, thus aiding in the removal of the dirt held there. Exercise in the open air is important to all who desire a good complexion. To have the "glow of health" one must exercise the skin, as well as keep it clean.

Skin infections and their care. We are all aware of the fact that sometimes a scratch or cut becomes infected; bacteria multiply there and cause pus. Pimples are often caused by the infection in the skin pores of rod-shaped bacteria, while boils are usually caused by the infection of the hair follicle with pus-forming baçteria - the streptococci (strĕp-to-kŏk'sī).

Whenever the skin is broken, it is necessary to prevent the entrance and growth of bacteria. This may be done by washing the wound with weak antiseptic solutions such as a three per cent carbolic acid solution, a three per cent lysol solution, or by painting the wounded part with solution of iodine or mercurochrome. These solutions should be applied immediately. A burn or scald should 
be covered at once with a paste of baking soda, with olive oil, or with a mixture of limewater and linseed oil. These tend to lessen the pain by keeping out the air and reducing the inflammation.

The relation of clothing to the skin. Clothes are primarily for protection. They may be classed as either good or bad conductors of heat. Good heat conductors, such as linen or cotton, allow the temperature outside of them to replace that of the layer of air directly around the body, while silk and wool are poor conductors and protect the body from a lower temperature outside. Warmth of clothing is largely dependent on the amount of air held between its fibers. Cool clothes have little air space in the meshes of the cloth, while loosely woven underclothes are warmer because they absorb perspiration rapidly and dry out quickly. Hence they do not feel cold or clammy to the perspiring skin as linen and cotton do. Young people can wear linen or cotton underclothes safely all the year round if they make proper changes in the weight of their outside garments. Older persons, on the other hand, need to wear woolen underclothes in the winter because these keep out cold and absorb perspiration without chilling the skin.

\section{Self-Testing Exercise}

The skin is composed of ........(1) layers, the

(2) and $\ldots \ldots$. (3), the latter is the ....... (4) layer and is largely ........ (5). The skin excretes certain wastes through the .......(6) glands. An open wound may become infected by .......(7) which cause . (8). Boils are an example of an ........ (9) by ....... (10). The skin is a ...... (11) covering consisting of the epidermis, a layer of ...... (12) ...... (13), and the living ....... (14) which contains the $\ldots \ldots \ldots(15)$ and $\ldots \ldots \ldots(16)$ glands, .......(17) $\ldots \ldots$ (18) $\ldots \ldots$. (19), and ...... (20) ...... (21).

\section{PROBLEM III. WHAT IS THE RELATION OF MUSCLES TO BONES?}

Laboratory Exercise. To study the use of the muscles and bones. Frogs preserved in formalin, mounted skeletons of frog, manikin, human skeleton, or good diagram.

Note the "flesh" forming the muscle of the leg. (A muscle is attached to the bone by a tough tendon.)

Holding your leg still, raise the foot up and down. Where do you feel the contraction of the muscle? Referring to the manikin, deter- 
mine how these muscles are attached to the bones? At how many points are they attached?

Explain how movement of the leg results from contraction (shortening) of certain of the muscles. What must occur when some of the muscles contract? (Look at the position of the muscle on the opposite side of the leg.)

Note the shape of your upper arm. 'To what is the rounded surface due? Move it and watch what happens to the muscles. Now examine the skeleton or a diagram to see if you can make out just where the muscles are attached. Why do muscles cause movement? Explain fully. What use, other than movement, have muscles?

Practical Exercise 2. From a study of diagrams and skeletons of a man and of some other mammal, as a cat or a dog, make labeled diagrams for your workbook to show the position of the main parts of the skeleton, vertebral column, skull, shoulder and pelvic girdles, and the appendages.

Bones and muscles. The body is built around a framework of bones. These bones, which are bound together by tough ligaments, fall naturally into two great groups : the bones of the trunk and head, namely, the vertebral column, ribs, breast bone, and skull, which form the axial (ăk'š-ăl) skeleton; and the bones of the appendages (the framework of the arms and legs), which, together with the bones attaching them to the axial skeleton, form the appendicular (ăp-ĕn-dik'tulär) skeleton.

To the bones are attached the muscles of the body. Movement is accomplished by the contraction of muscles, which are attached so as to cause the bones to act as levers. Muscles usually act in pairs : one muscle extends while the other flexes or bends. Bones also protect the nervous system and

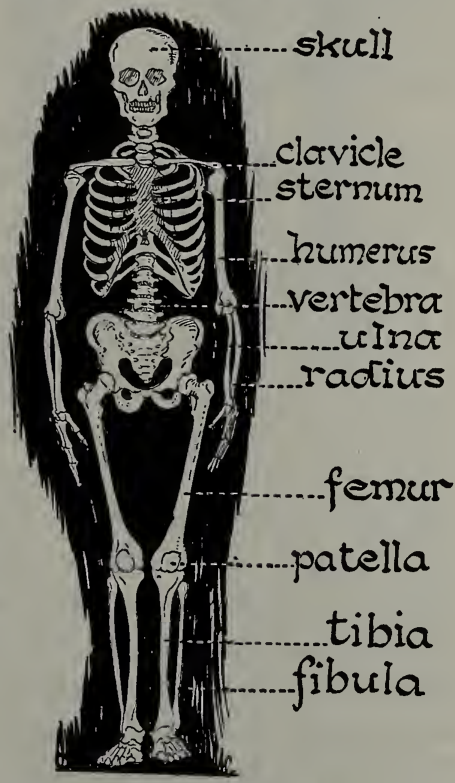

What are the uses of the skeleton? other delicate organs. The bony cranium (krä'nı̆-ŭm), inclosing the brain, is an example of such protection. The internal skeleton also gives form and rigidity to the body. 
Hygiene of muscles and bones. Young people especially need to know how to prevent certain defects which are largely the result

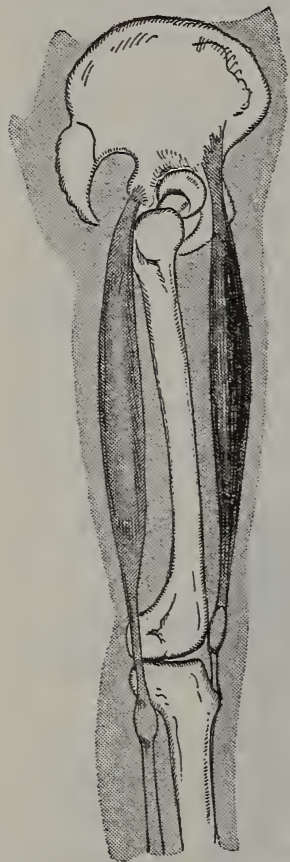

(a)

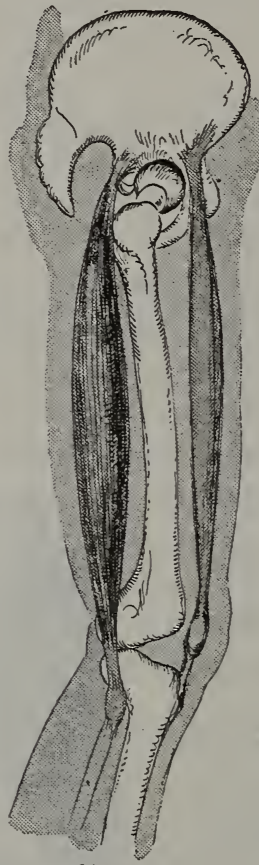

(b) of bad habits of posture. Good posture is a condition of equilibrium of the body which can be maintained for some time, such as standing or sitting erect. Standing erect is a good habit; round shoulders are an indication of a bad habit. The habit of keeping a wrong position of bones and muscles, once formed, is very hard to correct.

Round shoulders are most common among people whose occupation causes them to stoop. A wrong position at one's desk is among the causes. Exercises which strengthen the muscles of the back are helpful in forming the

habit of erect carriage.

Muscles work in pairs - Explain what is happening to the foot in $(b)$.

Slight curvature of the spine either backward or forward is helped most by exercises which tend to straighten the body, such as stretching up with the hands above the head. Lateral curvature of the spine, too often caused by a "hunched-up" position at the school desk, may also be corrected by exercises which tend to lengthen the spinal column. If your posture is not good, study your own defects and find out from an orthopedic specialist just what you should do to correct it. Then go to work to correct it. Remember it takes a long time to overcome results of wrong posture that may have taken years to form. 
Importance of good posture. It is the duty of every girl and boy to have good posture and erect carriage, not only because of the better state of health which comes with it, but also because self-respect demands that we make the best of the gifts that nature has given us. An erect head, straight shoulders, and elastic carriage go far toward making their owner both liked and respected. The person who stands erect and has good posture is usually the one who has good mental poise as well.

Practical Exercise 3. Make an outline of what you would do to correct $(a)$ flat feet, $(b)$ a lateral spine curvature, $(c)$ round shoulders, (d) protruding abdomen.

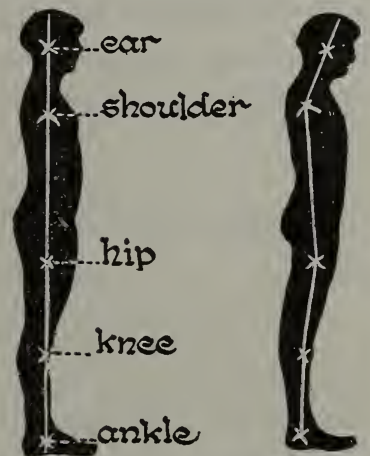

In good posture, the head is directly over the feet. A line dropped from the ear passes through the middle of the shoulder, the hip, knee, and ankle.

\section{Care of the feet. Our health depends} to a large degree upon exercise. Little exercise is possible without the use of the feet. Most of us have known foot discomfort of one sort or another. Let us see how to avoid such difficulties.

Many foot troubles come from either too tight or too loose shoes chafing the foot, thus causing the skin to respond to the irritation by forming callous spots which grow thicker and thicker, developing into corns. But a much more serious effect comes from the use of badly shaped shoes with high heels. If you look at the human skeleton, you will see that the bones of the foot form an arch from the toes to the heel, so that the foot, between the ball and the heel, should touch the ground only slightly. High-heeled shoes throw the weight forward to the ball of the foot, pressing the bones of the arch into unnatural positions and straining the tendons which fasten the muscles to the bones. The foot in a natural position on the ground is also seen to touch along the edges outside, but not in the middle of the foot. This arch is weakened by the use of too narrow and too pointed-toed shoes.

Practical Exercise 4. Make an outline drawing of the sole of your shoe as you stand. Then make an outline of your bare foot as you stand on the first outline. How do the two outlines compare? Are you wearing proper shoes? 


\section{HOW DOES THE HUMAN MACHINE DO ITS WORK?}

Tight shoes, high heels, and "toeing out" all tend to cause strain on the arch and consequently cause flat feet. A severe case produces strain known as a "broken arch," and this condition may produce severe pain or even nervous disorders. An orthopedic specialist should be consulted in such cases.

\section{Self-Testing Exercise}

The body is built around a framework of ........(1). These form a central .......... (2) skeleton and attached portions called collectively the . (3) skeleton. Muscles are attached to ........ (4) which act as ....... (5). Muscles usually act in .......(6) one .......(7) while its opposite is ....... (8). Good posture is necessary for good ........ (9) and can only be obtained by constant .......(10). Posture is a position of ........ (11) of the body. Tight shoes cause ....... (12) on the .........(13) and other foot ....... (14).

\section{REview Summary}

Test your knowledge of the unit by: (1) rechecking all the survey questions; (2) performing all the assigned exercises; (3) checking with your teacher the scores of the various tests and doing over those that you missed; (4) making an outline of the unit for your notebook.

\section{Test on Fundamental Concepts}

In a vertical column under the heading CORRECT write numbers of all statements you believe are true. In another column under INCORRECT write numbers of untrue statements. Your grade $=$ right answers $\times 4$.

I. The body may be compared with a machine because (1) it does work; (2) it is made of organs ; (3) it has a self-directing mechanism; (4) it oxidizes substances to release energy ; (5) it provides for the disposition of its waste products.

II. The skin (6) is of no value as a protection; (7) is a heat-regulating mechanism; (8) protects the body against invasion from germs; (9) can best be kept clean by covering with rouge or powder; (10) contains many pores leading from sweat glands which must be kept open if the skin is to function properly.

III. The skeleton (11) is a framework to which muscles are attached; (12) acts as a protection for the soft parts of the body ; (13) is made largely of lime; (14) gives shape to the body; (15) is entirely external in man. 
IV. Muscles (16) usually work in pairs; (17) are usually attached to bones, which act as levers; (18) never give form to the body; (19) are capable of contraction and relaxation; (20) are only fully developed in people who exercise.

V. Good posture (21) comes as a result of a proper balance or equilibrium of body parts; (22) is the result of round shoulders; (23) is an indication of good mental as well as physical health; $(24)$ is not necessary for health; (25) may be obtained through proper exercise and care of the body.

\section{Achievement Test}

1. What is the general plan of man's body make-up?

2. What would you do in case of a skin infection?

3. What are the functions of each part of the skin?

4. How could you show the ways in which the leg muscles work in walking? In running? In jumping?

5. How would you protect yourself from foot troubles?

\section{Practical Problems}

1. Visit a museum and make a series of diagrams for your workbook to show the relationship of man to the other mammals.

2. Study diagrams and the foot of the human skeleton in order to locate the arches in your foot. Make an impression of the foot on smoked paper and decide if your arches are in good condition. What exercises should you take if they are not? (See the Metropolitan Life Insurance pamphlet, " Foot Health.")

3 . Prove that a given bone acts as a lever for certain muscles in your body.

4. What first aid would you administer for a broken bone in your leg? For a bad scratch made by a rusty nail?

\section{USEFUL REFERENCES}

Hunter, Laboratory Problems in Civic Biology. pp. 93-96 inclusive. (American Book Company.)

Kimber and Gray, Textbcok of Anatomy and Physiology. Chapters IV-VI inclusive. (The Macmillan Co. 1926.) Metropolitan Life Insurance Company, Foot Health.

Walter, Human Skeleton. (The Macmillan Co. 1918.)

Williams, Personal Hygiene Applied. Chapter VI. (W. B. Saunders Co. 1925.) 


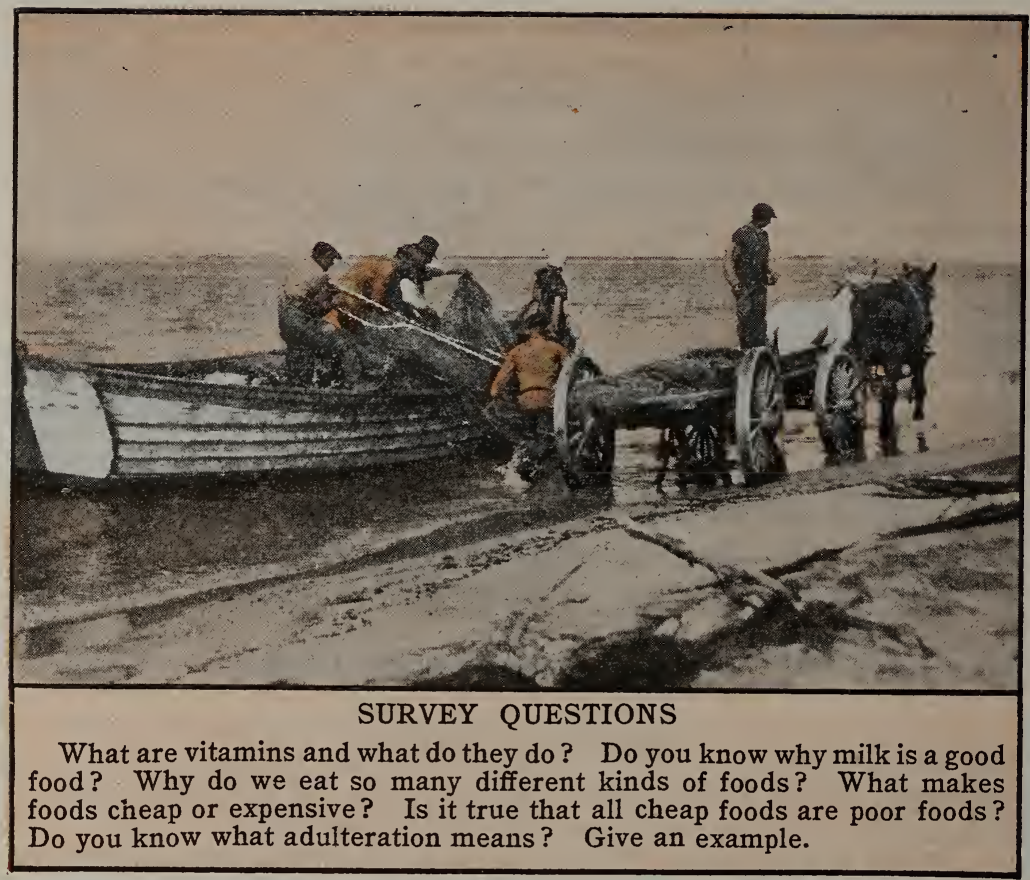

Photo by H. Armstrong Roberts

\section{UNIT XI}

\section{HOW DOES MAN DETERMINE THE VALUES OF FOODS?}

Preview. Anyone reading advertisements in a magazine today cannot help noticing the number of food slogans that the producers of food place before the public. "An apple a day keeps the doctor away," "Take your daily orange juice," "Eat yeast and get your vitamins," "Drink a quart of milk a day," etc. We naturally want to know just how many of these statements are true. The facts concerning what we should eat and why we should eat certain foods are certainly worth knowing.

Every one knows that the human machine needs fuel. A locomotive uses coal, water, and oxygen. A living animal gets 
food, water, and oxygen from its environment. ${ }^{1}$ Both the nonliving and the living machine do the same thing with fuel or food. They oxidize it and make use of the energy thus released. They both receive heat as a direct result of this oxidization or burning. In addition, however, the living organism may use food to repair parts that have broken down or even build new parts. Thus food may be defined as something that can be used by the body of a plant or animal to release energy, or to form material for the growth or repair of that body. However, we must not think of our body as taking the foods and burning them directly, thus providing us with heat and energy to do work. It is a much more complicated process than this might sound. Our digestive organs first have to break down the food materials into such forms that they can be taken into the blood and carried to all parts of the body. The millions of cells of which the body is composed must be given more material which will form new living matter. These cells must also be provided with food material which is oxidized to release energy when muscle cells move, or gland cells secrete, or brain cells work.

Experiments have proved that an animal may be provided with what seems to be the foods necessary to burn and make tissue, and yet it will die. Professor Mendel of Yale and his students have shown that unless animals receive proteins that contain certain so-called amino acids they will die, although their diet is apparently sufficient in quantity and quality. It has been found that in certain proteins there are these amino acids which are used by the animal to build up its tissues. So important are these substances that the Germans have called them "building stones," for without them no growth can take place. Animal proteins appear to have more of these amino acids than do plants. Hence we see the value of a mixed diet which includes both plant and animal foods. Milk appears to have both the necessary amino acids and certain other substances called vitamins of which we shall hear more later. Certain mineral salts, as calcium, iron, sodium, and potassium, are also needed by the body.

1 Animals and some plants get organic food from their environment; but green plants make organic food from materials which they get from their environment.

н. BIO -22 
We live in an age where practical applications of science are found at every turn. It is right that this should be so, for we are more and more surrounded by the things made by science and the things done by science. Foods, which not so many years ago were used directly from the stream or field, are now put through a manufactured process which changes them very greatly. Sometimes the raw plant or animal substances are put into cans and preserved for our use. It is little wonder that as food in these new forms began to be marketed that the unprincipled food handlers began to adulterate or misbrand their foods, thus cheating the purchaser. State government, and later the United States government, began to inspect such foods, and found that nearly half the total number of samples examined were adulterated. The Pure Food and Drugs Act of 1906, with its subsequent requirements, was the result of these investigations. At the present time, due to official examinations and inspection, only a very small amount of adulterated or misbranded food is shipped from one state to another. But materials manufactured and sold in the same state may still be adulterated, since the Pure Food and Drugs Act does not control this situation.

One feature of adulteration that the Pure Food and Drugs Act does not cover in a very satisfactory way is the labeling of patent medicines. While the presence of certain habit-forming drugs and poisons must be shown on the label, there are scores of other deadly poisons that may get into medicines without appearing on the label at all. The labeling of patent medicines is controlled by the Pure Food and Drugs Act; but the purchase of such medicines is in the hands of the American public. Uneducated people will not read labels very carefully, with the result that the patent medicine industry thrives and people throw away several hundred million dollars each year and do what is far worse, damage themselves while they spend their good money.

The worst situation, however, exists with reference to the use of alcoholic beverages. Some of the American people are being extremely unpatriotic, and, incidentally, are taking big chances with " bootleg" liquor. Dr. Louis I. Dublin, in a book entitled "Health and Wealth," points out that in states where the Pro- 
hibition Amendment is not carried out the death rate from alcoholic poisoning has gone above the level of pre-prohibition days, while in states where prohibition is more widely enforced, the death rate is lower than the period before the World War. We should attempt to get at the truth with reference to prohibition and at least show ourselves good citizens by upholding the law whether we believe in it or not.

\section{PROBLEM I. WHAT DO FOODS DO FOR US?}

Practical Exercise 1. Make a list of foods that you have eaten in the last 24 hours. By referring to tables in government bulletins or any good laboratory manual, classify the foods under the following headings.

\begin{tabular}{|c|c|c|c|}
\hline Nutrients & MUCH & Little & None \\
\hline $\begin{array}{l}\text { Carbohydrates } \\
\text { Proteins. . . } \\
\text { Fats . . . . }\end{array}$ & & & . \\
\hline
\end{tabular}

What are the uses of foods? If we use the simile of the human body and the engine, then it is obvious that body heat and the energy we release in our daily work comes from the foods we eat. But unlike an engine, which cannot repair itself if damaged, we not only repair injuries to our bodies but can actually increase in weight. Food then furnishes material for body growth, for repair of waste, for heat, and for work when oxidized in the cells of the body.

The nutrients. Foods contain substances called organic nutrients. These we have already learned are proteins, carbohydrates, and fats or oils. Foods also contain waste. A leg of lamb contains bone and tendons; oysters and clams have shells; potatoes and turnips have skins; and bananas and oranges have outer coverings which cannot be used. All foods have some waste. In addition, they contain various amounts of mineral salts and frequently a large amount of water.

Proteins are nutrients which contain nitrogen in addition to carbon, oxygen, and hydrogen. Foods containing a high proportion of proteins are lean meats, eggs, some nuts, peas, and beans.

Carbohydrates contain carbon, hydrogen, and oxygen, having 
the two latter elements in the proportion found in water. Foods rich in carbohydrates are cereals, breads, cakes, fruits, and jellies. Sugars are pure carbohydrates. Fats and oils contain carbon, hydrogen, and oxygen, but their chemical formula shows a relatively small proportion of oxygen. Examples of foods containing fats are butter, lard, suet, olive oil, and mayonnaise dressing.

The fuel value of food. In various experiments it has been agreed that the energy stored in foods as a source of heat should be stated in heat units called Calories. A Calorie is the amount of heat required to raise the temperature of one kilogram of water one degree Centigrade. This is about equivalent to raising the temperature of one pound of water four degrees Fahrenheit. The fuel value of different foods may be computed by burning a given portion of each food in a calorimeter. It has thus been found that a gram of fat will liberate 9.3 Calories of heat, while a gram of carbohydrate or protein will each liberate only about 4 Calories. The burning value of fat is, therefore, over twice that of carbohydrates or proteins.

Fats and oils have the highest energy value of all foods. But because of their rather indigestible qualities and because one soon tires of an excessive amount of fat, carbohydrates are more used to release energy. Cereals, bread, potatoes, and other starchy vegetables should, for this reason, be a part of our daily diet.

Tissue building and repair of waste. But it is not sufficient for man to " count his Calories." We are made of living matter, protoplasm. Living cells may waste away, and need to be repaired or replaced. New cells must be formed. According to Rose it is estimated that the body of a baby at birth contains about 4000 Calories of burnable material, while that of a full-grown man averages about 70,000 Calories. Where did this growth come from? Evidently, the tissues use food for building purposes.

We have already seen that carbohydrates, fats, and proteins all contain the elements carbon, oxygen, and hydrogen, and that proteins alone contain the element nitrogen. We have learned also that the protoplasm, which forms a large part of the body, is thought to be a very complex compound composed of carpon, hydrogen, oxygen, nitrogen, and ten or more other chemical 
elements. If living matter is to grow, it must have the proper elements for building. And these it can obtain from food. Proteins, although they may be oxidized to release energy, are usually utilized to give the body its nitrogen, from which, in part, living protoplasm is manufactured.

Demonstration 1. Feed two white rats of equal weights for a period on different dietaries, using in one case an incomplete protein (such as gliadin of wheat) and the other with a complete protein (such as in milk) containing the essential amino acids. A striking contrast may be obtained by feeding both with exactly the same foods except that one has a given amount of milk substituted for the same amount of water. Let the class watch the growth of the two animals and report on the final results. Weigh the rats once a week. Keep all conditions except that of food exactly the same for both rats.

Not all proteins are good tissue builders. Recent feeding experiments have shown that not all proteins

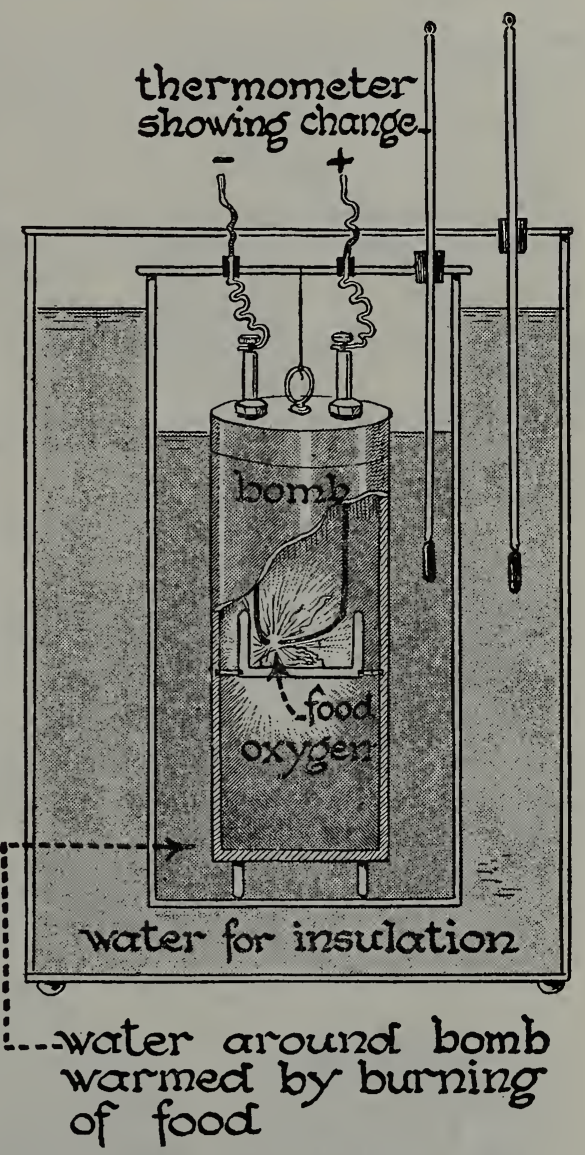

A bomb calorimeter. Explain how it works. are capable of building tissues. It has been found that the complex chemical substance called protein may be broken by the chemist into simpler proteins called amino acids. Some of these amino acids are useful in tissue building, and others are not. If two rats are fed on diets containing different amino acids, one may thrive, while the other wastes away and dies. For example, gelatin is a very poor 
type of protein, because it does not contain all the amino acids necessary for tissue building or tissue repair. On the other hand,

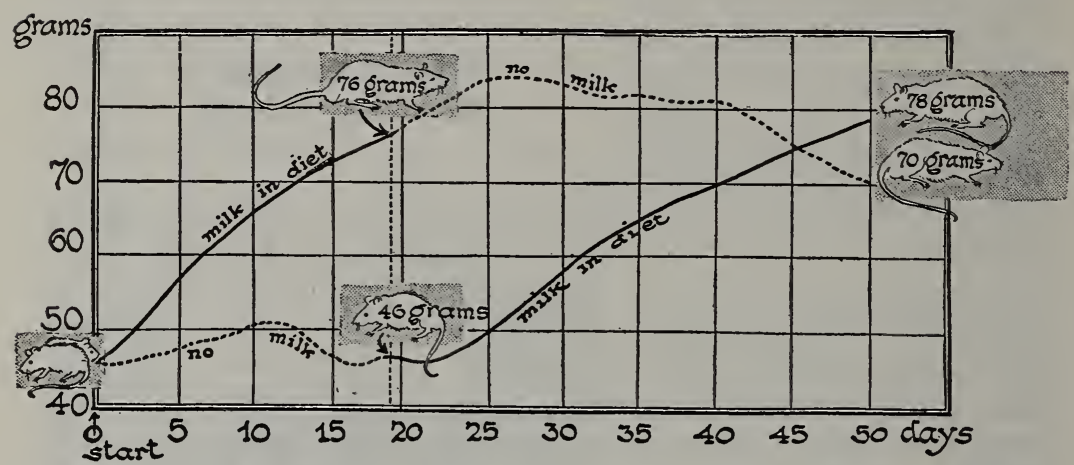

Professor Hopkins showed the value of milk as a good food. Explain his experiment and results as given in the above diagram.

the proteins in milk contain the amino acids necessary for growth. It is estimated that there are eighteen of these amino acids commonly found in proteins, and that all of those essential for growth are found in lean meat, cheese, milk, eggs, and a few grains and nuts. So it happens that probably most of us, without realizing, have used for food the proteins containing all the essential amino acids.

Vitamins. These health-regulating substances must be a part of every diet. We know that they occur in milk and in certain
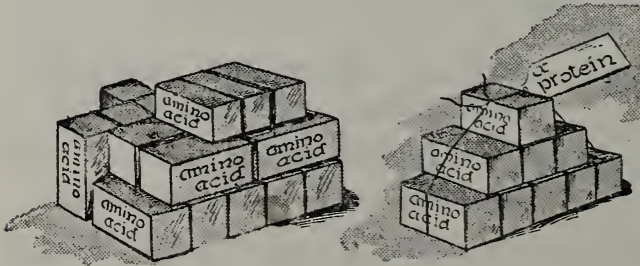

There are eighteen diferent amino acids. Where any number of these are bound up chemically they form a protein. vegetables. We shall learn more about them in the second problem.

The value of water. It has long been known that water and the various mineral salts it contains are essential to life. The human body, by weight, is about two thirds water. Over 80 per cent of the blood is water. Water is absolutely essential in passing off the wastes of the body. Water 
makes up a very large proportion of fresh fruits and vegetables; it is also present in large proportion in milk and eggs, is less abundant in meats, and is lowest in dried foods and nuts. The amount of water in a given food is of ten a decided factor in its cost.

The mineral requirement. Minerals are quite as essential to the body as energy foods and proteins. But it is only recently that scientists have learned how important a part is played by minute quantities of certain mineral substances. For example, the clotting of our blood, without which we should bleed to death from the smallest cut, appears to depend largely on the presence of calcium in the blood. Lack of calcium and phosphorus causes stunted growth, soft bones, and defective teeth, while a lack of iron causes anæmia and other disorders. If one will compute the minerals in the diet served in many homes, which consists so largely of meat, potatoes, and white bread, he will

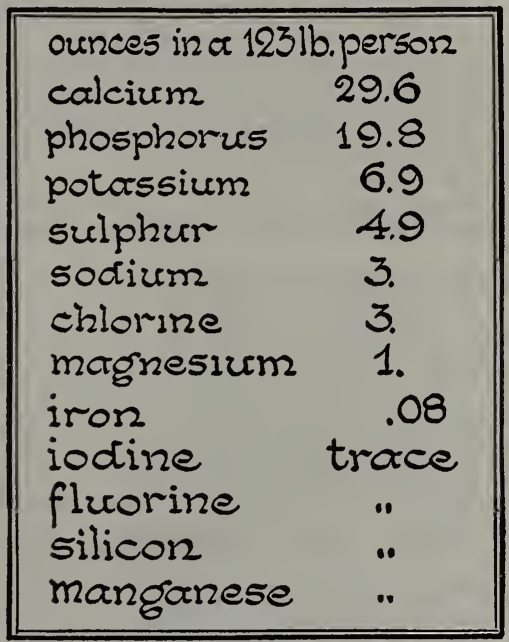

This diagram gives the probable amount of minerals found in the body of a person weighing I23 pounds.

easily see how lacking such foods are in the mineral essentials. Fruits, vegetables, milk, and eggs are the best sources of all these minerals. Meat contains iron, but is so lacking in calcium that a large number of servings would be necessary to furnish the daily calcium requirement. Milk is one of the most important sources of calcium for the body and should be included in the dietary every day. Other minerals are just as essential as these three, but are not so likely to be lacking in the diet.

Some salts, compounds of magnesium, potassium, and phosphorus, aid the body in many of its most important functions. The beating of the heart, the contraction of muscles, and the ability of the nerves to do their work appear to depend on the 


\section{HOW DOES MAN DETERMINE THE VALUE OF FOOD?}

presence of minute quantities of these salts in the body. Thus they act as regulators of bodily activity.

Practical Exercises 2. From the charts given in any laboratory workbook, determine the actual percentage of nutrients in beef, potatoes, oysters, and corn meal. Do all foods have equal nutritive value?

From these charts make a table containing:

(a) Five foods rich in protein (15 per cent or more).

(b) Five foods rich in carbohydrates (50 per cent).

(c) Five foods rich in fat (50 per cent or more).

(d) Five foods having a high fuel value (1500 Calories or more per pound).

(e) Five food substances that are over 50 per cent water. How would water affect the cost of food, providing you had to pay for the water?

$(f)$ Two foods rich in mineral salts.

In your opinion, which of the foods given are the best tissue-building foods? Remember that living matter is made up of carbon, oxygen, hydrogen, nitrogen, sulphur, and a minute amount of mineral salts. Which do you consider the best energy-producing foods? Explain.

Roughage. Certain parts of foods rich in carbohydrates, usually the cellulose walls of plant cells, contain indigestible material which is useful in stimulating the muscles in the large intestine and thus causing the waste matter to be thrown off regularly. This prevents constipation. Bran, whole wheat, fresh fruits, and vegetables provide the best sources of these materials.

Flavors and condiments. Most of us are aware that flavoring materials such as pepper, mustard, and other condiments are not true foods. While flavoring extracts, meat, and vegetable flavors do not have food value, they are of great value in making the food more appetizing and increasing the secretion of gastric juice.

What are the essentials of an adequate food supply? One writer has said that "an adequate food supply should include (1) sufficient organic nutrients in digestible form to yield the needed energy, (2) protein sufficient in amount and appropriate in kind, (3) adequate amounts and proportion of various ash constituents or inorganic foodstuffs, and (4) sufficient of each of essential vitamins." The problems which follow will help us to find out just what this statement means.

\section{Self-Testing Exercise}

A food is anything that furnishes .......(1) and ....... (2) or . (3) up the body. Foods as purchased may contain waste, (4) $\ldots \ldots \ldots$ (5), .......(6), and......(7). The or- 
ganic nutrients are $\ldots \ldots$ (8), ......(9) or .....(10), and .......(11). Proteins contain .......(12)...... (13), the "building stones" of the body. If a protein contains the ........ (14) .......(15) essential for .......(16), it is said to be a ....... (17) protein. .......(18) are essential to a diet because they act as ....... (19) of various bodily ....... (20).

\section{PROBLEM II. WHAT DO VITAMINS DO FOR US?}

Laboratory Exercise. Make a list of all foods which you have eaten within the last 24 hours. Compare your list with the table on pages 336337 to see if you are eating foods that give you the best sources of vitamins $\mathrm{A}, \mathrm{B}, \mathrm{C}$, and D.

Vitamins and their uses. Most wonderful of all our foods are the regulating substances, vitamins. While little is known of their chemical composition, a good deal has been learned of what they do, or, rather, of what effect their absence will cause. These health-regulating substances are known as Vitamins A, B, C, D, $\mathrm{E}$, and $\mathrm{G}$. A glance at the diagram (pagə 334) shows that vitamin $A$, soluble in fats, is found abundantly in milk, egg yolk, cod-liver oil, and butter, and in lesser amounts in certain vegetables. Vitamin $\mathrm{B}$, soluble in water, is found in the outer layers of many cereals and fruit, in milk, and in fresh yeast. Vitamin $\mathrm{C}$ is found in fresh vegetables and in citrus fruits. Vitamin $\mathrm{D}$ is found in cod-liver oil, milk, and coconuts. Vitamin $\mathrm{E}$ is found in meat, lettuce, yellow corn, whole wheat, and milk fat. Vitamin $G$ is found in milk, yeast, and some meats. Vitamins appear to be largely of plant origin and in many cases are destroyed or their value is lessened by heat, although some stand high temperatures, as in canned tomatoes or boiled potatoes.

So much for what they are. Now what do they do? Rats fed on a diet lacking vitamin A are stunted in growth and develop an eye disease called xerophthalmia, which may result in permanent blindness. It has been known for a great many years that if explorers or sailors were deprived of fresh food, they suffered from the disease called scurvy. During the World War more than one war vessel was interned in a neutral port, not because of the guns of enemy ships, but because the crew suffered from this 
dread disease which could only be cured by a supply of fresh vegetables or fruits. This deficiency disease has been found to be caused by a lack of vitamin C. Experiments carried on in the Japanese navy about 1882 showed that beriberi, a serious menace

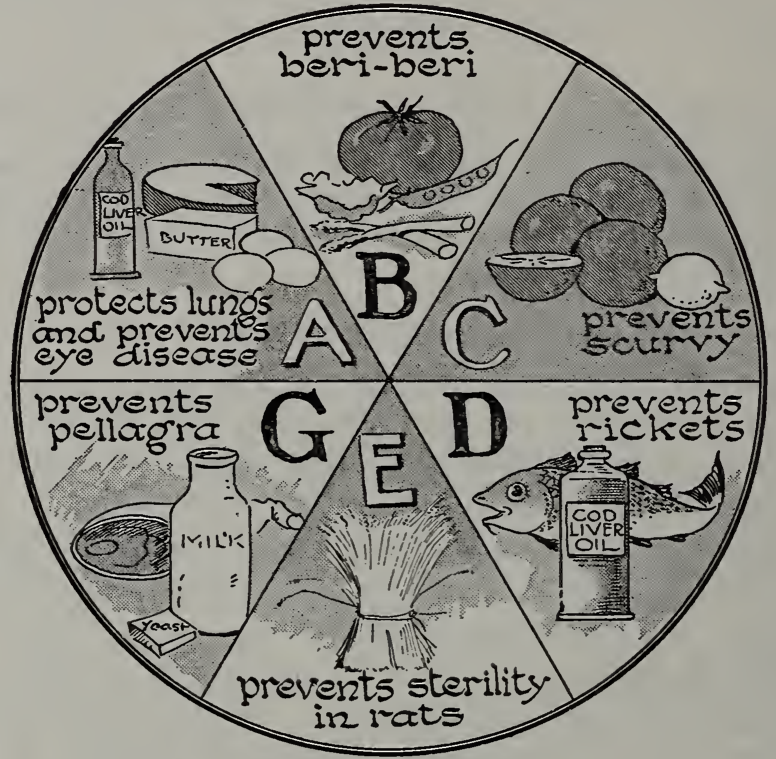

Why are vitamins essential to the diet?

to health among oriental peoples, is caused by a lack of some substance that is not present in the rice and fish which form the major part of their diet, for when milk and vegetables were added to the diet, beriberi disappeared. Later experiments showed that the lack of vitamin B caused beriberi. A lack of vitamin D has been found to be one of the causes of rickets, a disease of children, "characterized by impaired nutrition and alterations in the growing bones." Very interesting is the fact that rickets can be cured by exposing the patient to the direct rays of the sun. The rays that have curative value are the so-called ultra-violet. These rays do not pass through ordinary window glass, but will pass through quartz or "vita glass." More interesting still is the fact that certain foods (such as cottonseed oil which contains no 
vitamin $\mathrm{D}$ ) when treated with ultra-violet rays also have the power to cure rickets. This is thought to be due to the presence in the foods of a substance known as ergosterol, which becomes a powerful antirachitic agent upon oxidation. Ergosterol is also present in our skin, so when we are exposed to the ultra-violet rays of the sun, it is probable that vitamin $\mathrm{D}$ is actually produced in the skin and thus helps in the cure of rickets. Some investigators in the University of California have found that when rats are fed a diet lacking in certain foods, such as wheat germ, which contain vitamin $\mathrm{E}$, they will become sterile and will not produce young. And latest of all is the belief that pellagra, a dread disease in many parts of the South, is a deficiency disease due to lack of a vitamin called G.

\section{Self-Testing Exercise}

Among the best sources of vitamin A are .......(1), .......(2), ....... (3), and........(4) .......(5). Among the best sources of vitamin $B$ are ......(6), ...... (7), and .......(8). Among the best sources of vitamin $C$ are .......(9) .......(10), and ....... (11) $\ldots \ldots \ldots$ (12). The best source of vitamin $D$ is (14). Rickets may be cured by including (16) in the diet. Scurvy is caused by lack of

(18). Beriberi is caused by lack of ........(19)

Lack of vitamin A causes an ........(21) ........ (22).

PROBLEM III. WHAT IS THE RELATION OF WORK, ENVIRONMENT, AGE, SEX, AND DIGESTIBILITY OF FOODS TO DIET?

The relation of work to diet. It has been shown experimentally that a man doing hard, muscular work needs more food than a person doing light work. The exercise gives the individual a hearty appetite; he eats more and needs more of all kinds of food than a man or boy doing light work, for he needs more food for the extra energy release.

The relation of environment to diet. The temperature of the body is maintained at $98.6^{\circ}$ in winter as in summer, but much more heat is lost from the body in cold weather. Hence we need more heat-producing food in winter than in summer. We may 


\begin{tabular}{|c|c|c|c|c|c|c|c|c|c|c|c|c|c|c|}
\hline & & & & & & & & INERAL & & & & TAMIN & & \\
\hline & & $\begin{array}{l}\text { WT. } \\
\text { GRAMS }\end{array}$ & $\begin{array}{l}\text { CALOR- } \\
\text { IES }\end{array}$ & $\begin{array}{c}\text { WT. } \\
\text { FAT } \\
\text { GRAMS }\end{array}$ & \begin{tabular}{|} 
WT. \\
CARBO. \\
GRAMS \\
\end{tabular} & \begin{tabular}{|} 
WT. \\
PROT. \\
GRAMIS
\end{tabular} & $\begin{array}{l}\text { CAL. } \\
\text { CIUM }\end{array}$ & $\begin{array}{c}\text { PHOS } \\
\text { PHOR } \\
\text { US }\end{array}$ & IRON & A & B & c & D & $E$ \\
\hline BEVERAGES & & & & & & & & & & & & & & \\
\hline Cocos & 1 cup & 255 & 240 & 12 & 24 & 9.5 & $x \times x$ & $x \times x$ & $x$ & $x \times x$ & $x x$ & $x$ & & \\
\hline Grape Juice & 1 cup & 199 & 200 & & 50 & & $x$ & $x$ & $x x$ & $x x$ & $x x$ & $x x$ & & \\
\hline $\begin{array}{l}\text { Orange Juice } \\
\text { BREADS }\end{array}$ & 1 cup & 232 & 100 & & 25 & & & & $x$ & $x \times x$ & $x x$ & $x \times x$ & & \\
\hline Coffee cake & $3 \times 3 \times 4^{\prime \prime \prime}$ & 117 & 333 & 12.08 & 48 & 8 & & $x$ & & $x$ & $x$ & & & \\
\hline Muffins, graham & 1 large & 78 & 200 & 3.5 & 35 & 6.5 & $x$ & $x x$ & $x$ & $x$ & $x$ & & & \\
\hline Waffles, plain & $16^{\prime \prime}$ diam. & 26.7 & 100 & 4 & 12.5 & 3.5 & $x$ & $x$ & & $x$ & $\mathrm{x}$ & & & \\
\hline Rolls, French & 1 roll & 36.8 & 100 & 1 & 20 & 3 & & $x$ & & $x$ & $x$ & & & \\
\hline Ham sandwich & 1 slice $2 \times 4 \times x^{\prime \prime} 5^{\prime \prime}$ & 39 & 200 & 14 & 13.7 & 5 & & $x$ & $x$ & & $x$ & & & \\
\hline $\begin{array}{l}\text { Lettuce and tomato } \\
\text { sandwich }\end{array}$ & 1 slice $2 x^{\prime \prime} x^{\prime \prime} 5^{\prime \prime}$ & 59 & 108 & 6 & 11 & 2. & $x$ & $x$ & $x$ & $x x$ & $x$ & & & \\
\hline CAKE & & & & & & & & & & & & & & \\
\hline Gingerbread & $1 " \times 1 \frac{2 \pi}{3} \times 2^{n}$ & 31 & 100 & 2 & 18 & 2 & $x$ & $x$ & $x$ & & $x$ & & & \\
\hline $\begin{array}{l}\text { White } \\
\text { CEREALS }\end{array}$ & $1 \frac{1}{2} \times 2 \times 1^{\prime \prime}$ & 42 & 135 & 5 & 16 & 3 & $x$ & $x$ & & $x$ & & & & \\
\hline Farina $*$ & $3 / 4$ cup & 170 & 100 & .5 & 21 & 3 & & $x$ & & $x$ & $x x$ & & & \\
\hline 0ats, rolled * & 1 cup & 280.5 & 100 & 1.83 & 16.67 & 4.2 & $x$ & $x x$ & $x$ & $x$ & $x x$ & & & $x$ \\
\hline $\begin{array}{l}\text { Wheat, shredded } \\
\text { CRACKERS }\end{array}$ & 1 bis. & 27.4 & 100 & .49 & 20.59 & 3.51 & $x$ & $x x$ & $x$ & $x$ & $x x$ & & & $x$ \\
\hline Saltines & 6 & 23 & 98 & 3 & 15 & 2.4 & & & & & & & & \\
\hline Uneedas & 4 & 28.4 & 105 & 2.3 & 19 & 2.5 & & & & & & & & \\
\hline $\begin{array}{l}\text { FATS } \\
\text { Butter }\end{array}$ & 1 Tbsp. & 13 & 100 & 11 & & .13 & & & & $|x \times x|$ & $x$ & & $x$ & $x$ \\
\hline $\begin{array}{l}\text { Butter } \\
\text { Olive 0il }\end{array}$ & 1 Tbsp. & 11.11 & 100 & 11.11 & & .170 & & & & A^A & & & & $\lambda$ \\
\hline FRUITS & & & & & & & & & & & & & & \\
\hline Apple § & 1 & 212 & 100 & .64 & 23 & .64 & & & $x$ & $x$ & $x$ & $x x$ & & \\
\hline Canteloupe $\S$ & $14 \frac{1}{2}$ diam. & 510 & 100 & & 24 & 1.5 & & & $x x$ & $x x$ & $x x$ & $x$ & & \\
\hline Figs, dried & $1 \frac{1}{2}$ large & 31 & 100 & & 24 & 1.4 & $x$ & & $x x$ & & $x$ & $x$ & & \\
\hline Oranges § & 1 large & 268 & 100 & .3 & 23 & 1.61 & $\mathrm{x}$ & & $x x$ & $x$ & $x x$ & $x \times x$ & & \\
\hline Peaches, fresh $§$ & 3 med. & 290 & 100 & .3 & 23 & 1.5 & $x$ & $x$ & $x$ & & & $x x$ & & \\
\hline $\begin{array}{c}\text { Prunes, stewed } \\
\text { NUTS }\end{array}$ & $2 \& 2 T$. juice & 60 & 100 & & 24 & .5 & $x$ & & $x$ & & $x x$ & & & \\
\hline Brazil nuts & 2 nuts & 15.5 & 100 & 9.5 & 1 & 2.5 & & & & & $x x$ & & & \\
\hline Peanuts, sh'l'd & & & & & & & & & & & & & & \\
\hline $\begin{array}{c}\text { single nuts } \\
\text { PIES }\end{array}$ & $20-24$ & 18.2 & 100 & 7 & 4.5 & 4.69 & $x$ & $x$ & $x$ & $x x$ & $x x$ & & & \\
\hline Apple & $4 \frac{1}{2} / 2 \operatorname{arc}$ & 136 & 300 & 13.8 & 42 & 2.25 & $x$ & & & $x$ & $x$ & & & \\
\hline Custard & $4^{\prime \prime} \mathrm{arc}$ & 118 & 200 & 7.2 & 29.5 & 4.5 & $x$ & $x$ & & $x x$ & $x x$ & & & \\
\hline Lemon meringue & $3^{\prime \prime} \operatorname{arc}$ & 85 & 450 & 13.5 & 76 & 5.8 & & $x$ & & & $x$ & & & \\
\hline Raisin & $41 / 8 \operatorname{arc}$ & 85 & 256 & 9 & 52 & 2.25 & $x$ & $x$ & $x$ & $x$ & $x$ & & & \\
\hline EGGS & & & & & & & & & & & & & & \\
\hline Plain & $1 \frac{1}{3}$ & 67.5 & 100 & 7.09 & & 9.05 & $x$ & $x$ & $\mathrm{x}$ & $x \times x$ & $x \times x$ & $x$ & $x$ & $x$ \\
\hline FISH & & & & & & & & & & & & & & \\
\hline Creamed codfish & $1 / 2$ cup & 60 & 100 & 5 & 5.5 & 8 & $x$ & $x$ & $x$ & $x \times x$ & $x x$ & $x \times x$ & & \\
\hline Mackerel, broiled & $4^{\pi} \times 2 \times 1 \frac{1}{2}$ & 62 & 100 & 5 & & 14 & $x$ & $x$ & $x$ & & & & & \\
\hline Salmon, canned & $1 / 2$ cup & 52 & 100 & 6 & & 11 & $x$ & $x$ & $x$ & $x x$ & $x$ & & & \\
\hline
\end{tabular}




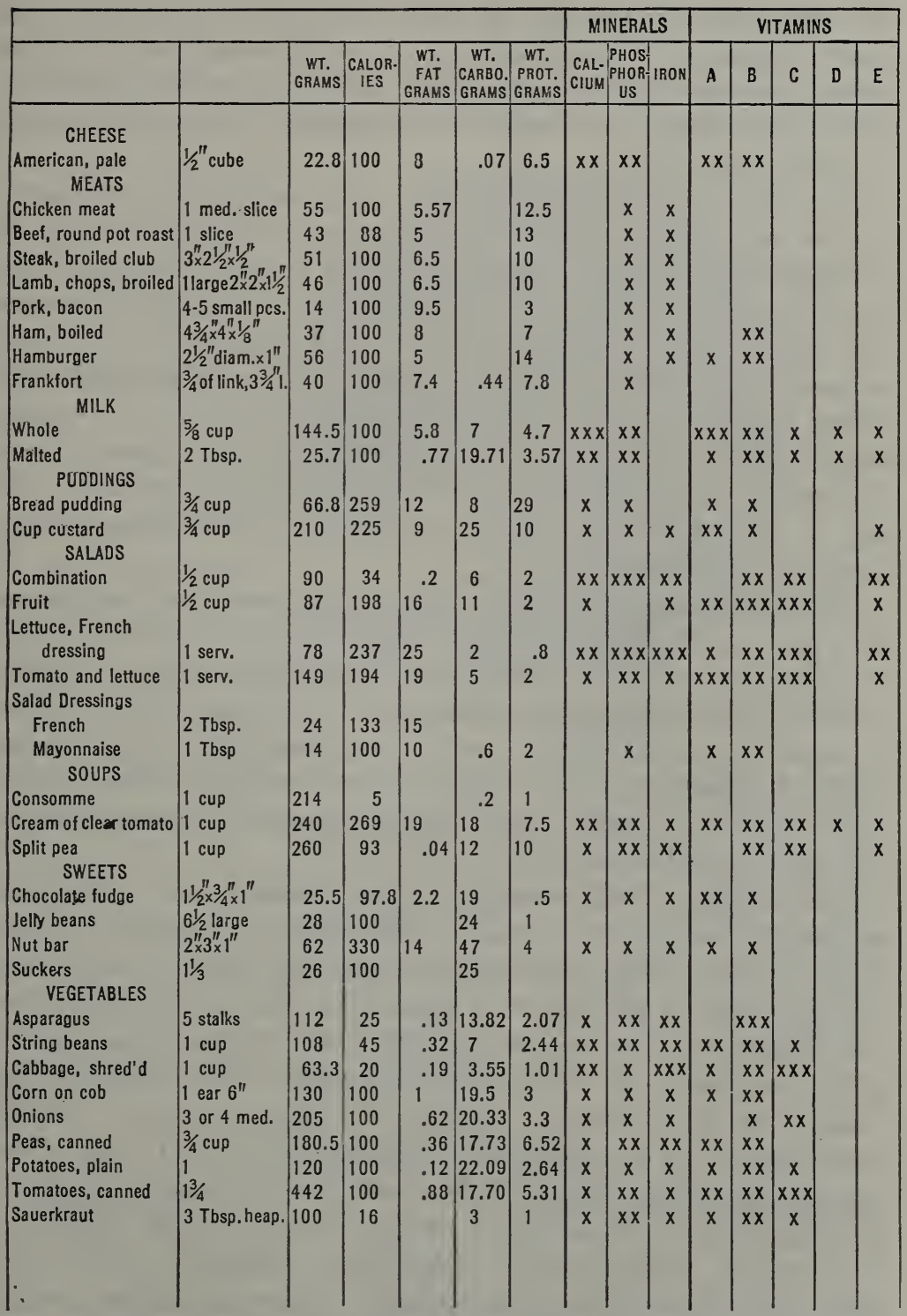

After Tables of Food Values, A.V.Bradley, Santa Barbara State Teachers College, Santa Barbara, Calif. 
use carbohydrates for this purpose, as they are economical and easily digested. The inhabitants of cold countries get their heat-producing foods largely from fats. In tropical countries and in hot weather a considerable amount of fresh fruit should be used in the diet.

The relation of size and age to diet. Age is a factor in determining not only the kind but also the amount of food to be used. Young children require a large proportion of protein in their diet in order to grow. They are also more active than older persons and so use a large amount of food as fuel in proportion to their weight. The body constantly increases in size and weight until young manhood or womanhood, and then its size and weight remain nearly stationary, varying with health or illness. It is evident that adults require food only to repair the waste of cells and to release energy. Elderly people need much less protein than do younger persons.

The relation of sex to diet. As a rule, boys need more food than girls, and men than women. This seems to be due, first, to the more active muscular life of the man, and, second, to a layer of fatty tissue directly under the skin of the woman, which acts as an insulating layer against loss of heat from the body. Larger bodies, because of greater surface, give off more heat than smaller ones. Men are usually larger than are women, - another reason why they require more food.

The relation of digestibility to diet. Food must be digested in order to be used in the body. Animal foods in general can be more completely digested within the body than plant foods. This is largely due to the fact that plant cells have woody walls that the digestive juices cannot dissolve. Heat causes the starch grains to swell and thus break these woody walls. This is one reason for the thorough cooking of vegetable foods. Cereals and legumes are less digestible foods than milk and eggs. The agreement or disagreement of food with an individual is largely a personal matter. Jack Spratt, for example, cannot eat raw tomatoes without suffering from indigestion, while Mrs. Spratt can digest tomatoes but not strawberries. Each individual should learn early in life the foods that disagree with him and leave such 
foods out of his diet, for "what is one man's meat may be another man's poison."

The relation of appetite to diet. Every one likes some things better than others. Through experimentation it has been found that foods which are enjoyed cause a flow of digestive juices, not only in the mouth but also in the stomach. The sight, odor, and taste of food we like actually aid in digestion. "Digestion waits on appetite." If we use common sense in the selection of foods, and take care to avoid foods that we cannot easily digest, we shall

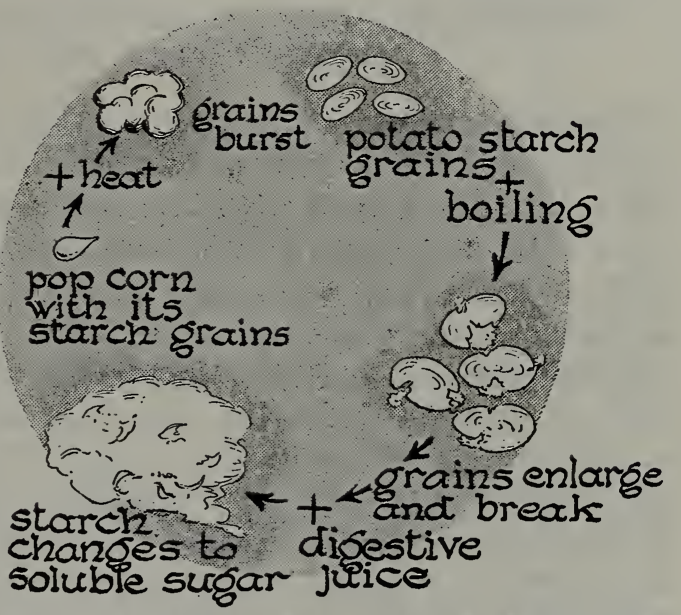

Explain what happens to starch when it is heated? When it is digested?

find that the appetite is often a guide in the selection of foods.

Acidosis and how to prevent it. The body is a very delicate machine. Its parts must be adjusted to a nicety or trouble results. The blood is normally alkaline. If fat is not completely oxidized in the body, the partly oxidized fat remains in the tissues as a fatty acid. This changes the alkalinity of the blood to acidity and trouble immediately follows. This condition, called acidosis or "kotosis," is often benefited by eating fruits and vegetables and avoiding use of meats and fats.

\section{Self-Testing Exercise}

A man needs ....... (1) ....... (2) when he does hard physical work than when he .......(3) a .......(4) life. A .......(5) person needs more food than a .......(6) one, for he has more . (7) to feed. ....... (8) plays a part in the kind as well as the ........ (9) of food needed by the body. What is one man's 
meat is another man's .......(10), so we should learn what we can ........ (11). Acidosis may be combated by a diet in which an excess of $\ldots \ldots \ldots(12)$ and $\ldots \ldots \ldots(13)$ is present.

\section{PROBLEM IV. WHAT IS THE BEST PROPORTION OF NUTRIENTS IN OUR DAILY DIET?}

The nutritive ratio. Inasmuch as all living substance contains nitrogen, it is evident that protein food must form a part of the diet; but protein alone is not a safe choice. If more protein is eaten than the body requires, the liver and kidneys have to work overtime to get rid of the excess of protein, which forms a poisonous waste harmful to the body. We must take foods that will give us, as nearly as possible, the proportion of the different chemical elements as they are contained in protoplasm, as well as an amount necessary to supply energy to the body. It has been found, as a result of studies by Atwater and others, that a man who does moderate muscular work requires nearly one quarter of a pound of protein, the same amount of fat, and a little less than one pound of carbohydrate to provide for the growth, waste, and repair of the body and the energy used up in one day. The proportion of protein in the diet is called the nutritive ratio.

The protein requirement varies with the age and size of a person, but not with the activity. For the child, from 12 to 15 per cent of the total Calories should be protein. Protein is necessary for the building and the repair of the body. Therefore larger amounts are needed during growth. The child requiring 2000 Calories needs from 240 to 300 Calories of protein. Whereas the adult, who has ceased growing, needs but 10 per cent of his total in protein. Therefore with an energy requirement of 2500 he would need about 250 protein Calories. Activity has never been shown to break down the body cells any more than the use of the brain destroys brain cells. Therefore protein does not need to be increased because one is doing muscular work. Milk, meat, and eggs are just as essential for the school teacher as for the man who is doing severe muscular work. 
Atwater, Chittenden, and Voit have worked out tables in which they have given the proportion of the various nutrients

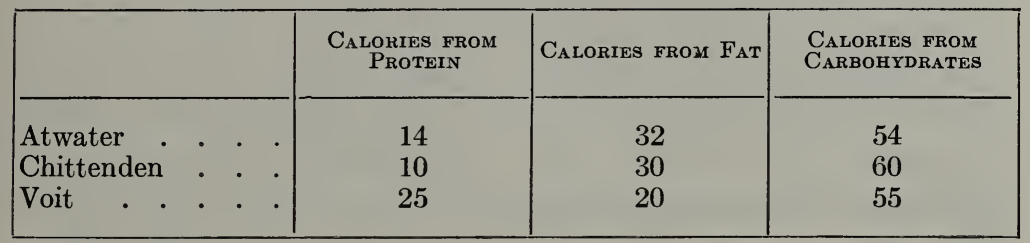

that should be present in every 100 Calories of food. Any of the three standards might be used.

Knowing the proportion of the different nutrients required as well as the foods containing vitamins and minerals, it will be easy for you to determine from tables (such as on pages 336-337) the best combinations of foods for a well-balanced diet.

Workbook Exercises. Foods taken into the body having the proportions of the nutrients given above constitute a balanced ration or diet because they provide the body with the right proportion for tissue building as well as for fuel food.

Compare the life you lead with that of a day laborer. Would your needs be the same?

Compare your life with the life of an Eskimo in the Arctic regions. Would the proportion of the nutrients needed by him be the same as you need? Explain.

Would the same proportion of nutrients be needed for all occupations and in all localities?

Are there any other factors that might cause different proportions of the nutrients needed by individuals?

Would a vegetarian diet contain the protein necessary for the body? How would it compare with a diet containing only meat? Are there any reasons why a wholly vegetable diet is unwise?

Basal metabolism. ${ }^{1}$ The activities of a living plant or animal, which include all the processes that are involved in the building up and breaking down of protoplasm in the body, are known collectively as the metabolic processes (Gr. metabolos, changeable). These changes release heat as a by-product and this heat can be measured in calories. The heat-producing activity of the body during sleep or rest represents the energy which is essential for

${ }^{1}$ Metabolism : mè-tăb'ô-lüz'm. 
carrying on the vital processes and is known as basal metabolism. It is represented in a man of average weight (about 150 pounds) by about 65 Calories an hour.

Method of computing energy requirement. The energy requirement of a person depends primarily upon his age, size, and activity. This requirement is most easily understood if expressed in Calories per pound per day. The following table shows the variation in the energy requirement of the average healthy child due to age.

\begin{tabular}{|r|c|c|c|c|c|c|}
\hline Ages . & 1 & 6 & 10 & 14 & $16-1 \mathrm{~s}$ & 20 \\
Average Wt. & 22 lbs. & 44 lbs. & 66 lbs. & 99 lbs. & $100-150$ lbs. & $120-160$ lbs. \\
Calories per lb. & 45 & 35 & 35 & 33 & $20-33$ & 20 \\
$\begin{array}{r}\text { Total Calories } \\
\text { per day . }\end{array}$ & 1000 & 1550 & 2300 & 3300 & $2600-4400$ & $2400-3200$ \\
\hline
\end{tabular}

The above table shows that the small child needs a much larger amount of food in proportion to his weight than the older child or adult. The larger individual needs a larger amount of food than the smaller person, but if the weight is multiplied by the calories per pound, this factor is taken into account. For example, one fourteen-year-old boy may weigh 100 pounds and another 140 pounds and both be healthy boys, but the larger boy will need a much larger amount of food. The above requirement will vary also with the activity of the child, the less active one will need less food. The difference in the energy requirement of an adult due to the type of activity is shown in the following figures :

\begin{tabular}{|c|c|}
\hline Trpe of Activity & $\begin{array}{l}\text { Average Calories PER } \\
\text { POUND PER HOUR }\end{array}$ \\
\hline $\begin{array}{l}\text { Sleeping or lying awake. } \\
\text { Sitting } \\
\text { Typewriting } \\
\text { Standing } . \\
\text { Walking at moderate rate } \\
\text { Active exercise. }\end{array}$ & $\begin{array}{l}\text { one half } \\
\text { two thirds } \\
\text { nine tenths } \\
\text { three fourths } \\
\text { one and one half } \\
\text { one and three fourths }\end{array}$ \\
\hline
\end{tabular}


Suppose that a man weighing 150 pounds spent his 24-hour day by sleeping 8 hours, sitting 8 hours, typing 2 hours, standing 4 hours, walking 2 hours, he would require 2570 Calories a day.
$150 \times \frac{1}{2} \times 8=600$ sleeping
$150 \times \frac{3}{4} \times 4=450$ standing
$150 \times \frac{2}{3} \times 8=800$ sitting
$150 \times 1 \frac{1}{2} \times 2=450$ walking
$150 \times \frac{9}{10} \times 2=270$ typing

From these two tables one can easily compute his own energy requirement.

\section{Self-Testing Exercise}

The protein requirement .......(1) with the age and .......(2) and not with the .......... A man who does moderate muscular work requires nearly ....... (4) ....... (5) from protein, ....... (6) $\ldots \ldots$ (7) from fat, and ...... (8) ...... (9) from carbohydrate.

\section{PROBLEM V. WHAT IS THE DAILY CALORIE REQUIREMENT?}

Workbook Exercise. Check up your day's total Calories by comparing it with your requirement by body weight and by the tables given on page 342 .

Head your paper: Name......, age......, weight....... lbs.

Daily Calorie needs............

Amount used ..............

Discrepancy................

How does your day's total Calories compare with that given in the table of daily needs of a person of your age, doing the kind of work you did for the day? How can you account for any discrepancy?

Can you suggest any improvement in your diet? Check on the vitamin content of your diet.

Malnutrition. When the body cells do not receive a proper amount of food or the right kinds of food, then a loss in body weight may occur, and we say that person is undernourished, or is suffering from malnutrition. An undernourished person is likely to be susceptible to disease, to tire easily, and to be sensitive to cold and exposure. Frequently, girls having large bones in their skeleton attempt to get thinner, and find all too soon that they have only made themselves ill without much reducing their body weight, which is largely due to these heavy bones. Never take up a " fad" diet without first consulting your own or the school physician. 
Workbook Exercise. What proportion of my daily diet goes into (a) basal metabolism, (b) growth, $(c)$ activity, $(d)$ excretion? Using the diagrams furnished and your own daily diet, check on your age and sex to see the proportion of your daily food that should go
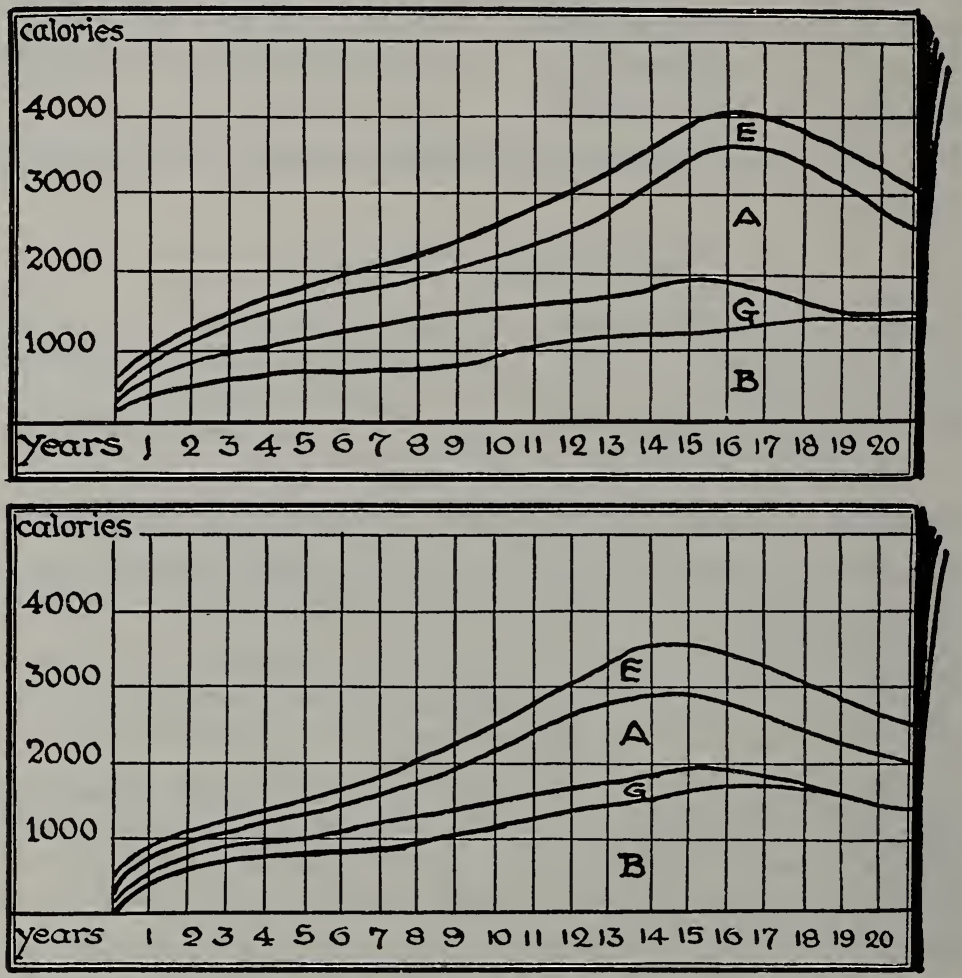

The upper chart is for boys, the lower one for girls. The relative amount of Calories needed for different ages are for (B), space between base line and first graph, basal metabolism (G) growth, (A) activity, and (E) excretion, spaces between graphs (after Holt).

(a) into your basal metabolic needs, (b) into growth of your body, (c) into your daily activity (This, of course, will vary, depending on the kind of work you do out of school), $(d)$ the amount that goes into excretion or body wastes. Remember that your growth calories must come from protein food and that activity should come largely from carbohydrates and fats. Compare carefully to see how near your proportions are to the ideal condition.

Do you eat the correct proportions of nutrients to give your dietetic needs as shown by the charts given above? 


\section{Self-Testing Exercise}

Write the numbers of the correct answers in your workbook.

A person asleep uses, per pound of body weight per hour, (1) one Calorie; (2) $\frac{2}{3}$ Calorie; (3) 10 Calories; (4) $\frac{1}{2}$ Calorie.

Acidosis may be avoided by using (5) orange juice; (6) soda mint tablets; (7) hot water before meals ; (8) red meats in the dietary.

Roughage (9) helps give the body proteins; (10) adds Calories to the dietary; (11) aids in regulating bowel movement.

The protein requirement of the total Calorie requirement of the body is (12) 10 per cent; (13) 25 per cent; (14) 100 per cent; (15) 50 per cent.

\section{PROBLEM VI. HOW CAN THE RELATIVE CHEAPNESS OF FOODS BE DETERMINED?}

Practical Exercise 3. To find the relation of the value of food to its cost in the family dietary. Make a careful record of all purchases of food in your home for one week. Find out what the average weekly cost is by dividing the total cost by the number in your family.

Using the tables on pages 336-337 and your daily calorie requirement, make out a cheap, appetizing but well-balanced menu for one person for a period of one week. Multiply the result by the total number in your family. Compare the total cost thus obtained with that worked out from your home dietary.

Are you living as economically as you might? What inexpensive substitutes might you introduce in place of meat?

The relation of cost of food to diet. It is a mistaken notion that the best foods are always the most expensive. A study of the tables on pages 336 and 337 will show us that fuel and tissuebuilding materials as well as vitamins are present in foods from vegetable sources, as well as in those from animal sources; and the vegetable foods are usually cheaper. The American people are far less economical in their purchase of food than most other nations. A comparison of the daily diets of persons in various occupations in this and other countries shows that as a rule we eat more than is necessary to supply materials for fuel and repair. Another waste of money by Americans is due to the false notion that a large proportion of the daily diet should be meat. Many people think that the most expensive cuts of meat are the most nutritious. The falsity of this idea may be seen by a careful study of the table on page 346 . 


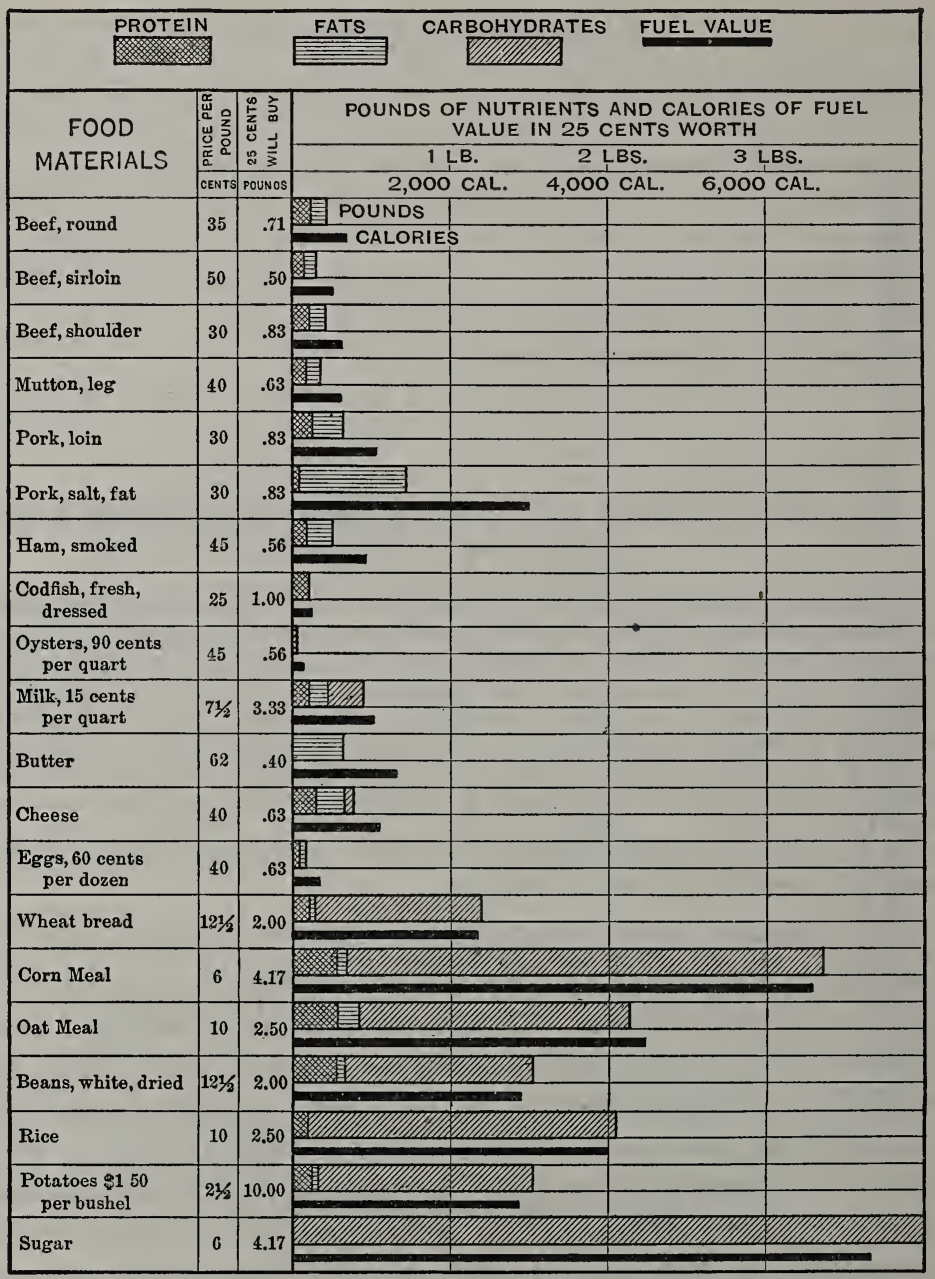

Table showing cost of various foods. Check these prices with present prices in your community.

Preparation of foods. Much loss occurs in the improper cooking of foods. Meats especially, when overdone, lose much of their flavor and are far less digestible than when they are cooked properly. The chief reasons for cooking meats are that 
the muscle fibers may be loosened and softened, in which condition they are digested more easily, and that the bacteria and other parasites in the meat may be killed by the heat. The common method of frying makes foods difficult to digest. A good way to prepare meat, either for stew or soup, is to place the meat, cut in small pieces, in cold water, and allow it to simmer for several hours. Rapid boiling toughens the muscle fibers just as the white of egg becomes solid when heated. Boiling and roasting are excellent methods of cooking meat. In order to prevent the loss of the nutrients in roasting, it is well to baste the meat frequently; thus a crust is formed on the outer surface of the meat, which prevents the escape of the juices from the inside.

Vegetables are cooked in order that the cells containing starch grains may be broken down. This allows the starch to be reached more easily by the digestive fluids. Inasmuch as water may dissolve out nutrients from vegetable tissues, it is best to boil such foods rapidly in a small amount of water. This gives less time for the solvent action to take place. Vegetables should be cooked with the outer skin left on whenever it is possible.

Practical Exercises 4. 1. Why should foods be cooked? Give three reasons.

2. Why is a mixed diet necessary?

3. Name five common errors in selecting foods.

4. Of what use are inorganic nutrients?

5. Of what use are condiments and flavoring substances?

6. Of what use are soups as food?

7. Why do we use fruit in a daily dietary?

8. Is the use of tea or coffee justifiable in a daily diet? Why do people drink them?

9. Why are cheap cuts of meat cheap?

10. Defend the statement, "The average American family wastes enough in the kitchen to support a French family."

Food habits. Habits play a very important part in our life activities. We do not think much about our daily activities, for once having learned the reasons for performing certain acts, those acts become habits. The habit of brushing teeth properly, of the choice of the right kinds and proportions of food, of the avoidance of tea and coffee, - these and other useful acts should become automatic. Some health habits that are worth acquiring are:

(1) Have your meals at regular hours.

(2) Take time to eat and enjoy your meals. 
(3) Chew your food thoroughly before swallowing it.

(4) Do not take an excessive amount of any one food to the exclusion of others. Learn to eat a balanced diet.

(5) Eat plenty of foods containing vitamins.

(6) Avoid too great a proportion of highly flavored or spiced foods.

(7) Avoid greasy or fried food.

(8) Avoid foods that you know do not agree with you.

(9) Avoid foods that you cannot digest easily and properly.

(10) Do not eat when tired. Rest a few minutes before beginning your meal.

(11) Drink plenty of water, at least six glasses a day, preferably between meals.

\section{Self-Testing Exercise}

Foods are cheap if they supply ....... (1) and ....... (2) materials in good quantity for the price paid. ........ (3) foods can be spoiled by ....... (4) cooking. Eating the right kinds of foods in the right way should become a ........ (5).

\section{PROBLEM VII. WHAT IS ADULTERATION?}

Pure Food Law. In 1906 Congress passed a Pure Food and Drugs Act that defined adulteration and remedied to some extent conditions in the preparation of foods that enter into interstate commerce. Before the passage of this act, about half of nearly 2000 samples of food examined in several different states were shown to be adulterated. In Massachusetts, the State Board of Health made examinations of food for adulteration as early as 1883. At that time over 60 per cent of all foods examined were found to be adulterated. Today both adulteration and misbranding of food are forbidden under severe penalties.

Demonstration 2. To study some forms of food adulteration and some means of detecting adulterants.

Put some butter in a spoon and heat it over a lamp. If it is good butter, it will boil quietly, with much foam. Oleomargarine or poor butter will splutter and crackle, with little foam.

Place half a teaspoonful of coffee to be tested on the surface of the cold water in the glass. Leave it for not more than five minutes. 
If the material sinks, leaving a brownish trace in the water as it sinks, it probably contains a large amount of chicory. If it floats for five minutes, it is coffee. What happens to the specimen you tested?

Place half a teaspoonful of mashed canned peas or beans in a beaker containing one teaspoonful of water and 10 drops of hydrochloric acid. Set the beaker in a dish of boiling water. Drop a new iron nail into the mixture. Boil for ten minutes. Stir constantly. If the nail turns green, copper has been used to color the peas.

Put a teaspoonful of milk in a beaker. Add twice the amount of hydrochloric acid to which a drop of ferric chloride has been added. Mix by rotating the beaker gently. Place the beaker in a pan of boiling water and leave for five minutes. If there is a purple or lavender color, formaldehyde was present in the milk.

Adulteration. The substitution of some cheaper substance, the subtraction of some valuable substance from a food, or the addition of poisonous or decomposed substances, with a view to cheating the purchaser, is known as adulteration. Examples of common substitutions in foods are cottonseed oil for olive oil ; apple parings or core for other fruits in jellies ; saccharine, which is several hundred times sweeter than sugar, in candy, ginger ale, and other drinks; glucose or brown sugar for maple sugar; and cereals, which cost less, for meats in sausage.

Other examples of added ingredients which may be harmful to health are arsenic, salicylate acid, borax, and boracic acid.

Still another type of adulteration is seen in the mixing or adding to the substance of colors of dyes. Such artificial coloring is seen in the addition of copper sulphate to give a green color to canned vegetables, annatto to give color to butter, coal-tar dyes of many colors to give coloring to candy, jellies, flavoring extracts, soft drinks, and even meats or sausage.

Examples of the taking away of a valuable part of the food are seen in the abstraction of cocoa butter from chocolate, butter fats from milk, or the essential oils from spices.

Probably the food which has suffered most from adulteration is milk, as water can be added without the average person being the wiser. By means of an inexpensive instrument known as a lactometer, this cheat can easily be detected. Before the Pure Food Law was passed in 1906, milk was frequently treated with 
substances like formalin, a harmful preservative, to keep it sweet for a longer time.

\section{FEDERAL FOOD \& DRUGS ACT}

HERE ARE ITS POWERS AND LIMITATIONS REGARDING THE SALE OF "PATENT MEDICINES"

IT APPLIES ONLY TO PRODUCTS THAT ARE MADE IN ONE STATE AND SOLD IN ANOTHER (INTERSTATE COMMERCE).

IT PROHIBITS "FALSE OR MISLEADING" STATEMENTS IN OR ON THE TRADE PACKAGE ONLY) REGARDING COMPOSITION AND SOURCE OF ORIGIN.

IT PROHIBITS.FALSE AND FRAUDULENT" STATEMENTS IN OR ON THE TRADE PACKAGE ONLY) REGARDING CURATIVE EFFECTS.

IT REQUIRES THE MANUFACTURERS OF NOSTRUMS TO DECLARE (IN OR ON THE TRADE PACKAGE ONLY) THE PRESENCE AND AMOUNT OF ALCOHOL, MORPHINE, OPIUM, COCAINE, HEROIN, EUCAINE, CHLOROFORM, CANNABIS INDICA. CHLORAL HYDRATE AND ACETANILID AND THEIR DERIVATIVES.
IT DOES NOT APPLY TO PRODUCTS THAT ARE SOLD IN THE SAME STATE AS THAT IN WHICH THEY ARE MADE IINTRA STATE COMMERCE).

IT DOES NOT PROHIBIT FALSE OR MISLEADING STATEMENTS IN NEWSPAPER ADVERTISEMENTS, CIRCULARS, WINDOW DISPLAYS, ETC.

IT DOES NOT PROHIBIT ANY KIND OF A LIE REGARDING CURATIVE EFFECTS IF THAT LIE IS TOLD ELSEWHERE THAN IN OR ON THE TRADE PACKAGE

IT DOES NOT REQUIRE "PATENT MEDICINE" MAKERS TO DECLARE EVEN THE PRESENCE OF SUCH DEADLY POISONS AS PRUSSIC ACID, CARBOLIC ACID, ARSENIC, STRYCHNINE - NOR ANY OF SCORES OF OTHER DANGEROUS DRUGS!

American Medical Association

Read this carefully. In what respects is this a good law? What changes would you suggest in it?

\section{Self-Testing Exercise}

Adulteration is the ....... (1) of some ....... (2) substance in a food, the subtraction of some ........ (3) substance from a food or the addition of some ........(4) substance to a food. Saccharine is a substitute for .......(5), chickory for ......(6), and olive oil for ....... (7) $\ldots . .$. (8).

\section{PROBLEM VIII. WHAT IS THE TRUTH ABOUT STIMULANTS AND NARCOTICS?}

Stimulants. We have learned that food is anything that supplies building material or releases energy in the body; but some materials used by man, presumably as food, do not come under this head. Such are tea and coffee. When taken in moder- 
ate quantities, they produce a temporary increase in the vital activities of the person taking them. This stimulation is due to the presence of a drug called caffein which acts upon the nervous system as a whip acts on a tired horse. In moderation, tea and coffee appear to be harmless to most adults. Some people, however, cannot use either, even in small quantities, without ill effects. It is the habit of relying upon the stimulation given by tea or coffee that makes them a danger to man. Cocoa and chocolate, although both contain a stimulant, are in addition good foods, having from 12 per cent to 21 per cent of protein, from 29 per cent to 48 per cent of fat, and over 30 per cent of carbohydrate in their composition.

Demonstration 3. To show the effect of alcohol on white of egg. To some fresh white of egg in a test tube add, drop by drop, 50 per cent alcohol (about the proportion in whiskey). What happens? Remember white of egg is like protoplasm in its chemical makeup. The teacher should explain that this does not happen to the body cells.

Demonstration 4. To show the effect of alcohol on Paramecia. To a grooved slide containing culture of Paramecia add drop by drop some 50 per cent alcohol. What happens at first? What happens later? How do you account for this?

Is alcohol a food? The question of the use of alcohol is still of much interest among physiologists and doctors. Experiments by Professor Atwater in this country and by Durig and Millanby in England confirm the fact that small quantities of alcohol are oxidized in the body and therefore may be used in place of either fat or carbohydrate foods. Raymond Pearl has pointed out that mortality from alcohol is usually amongst the hard drinkers and that there is very little difference in the death rate between the abstainers and the moderate drinkers. But, unfortunately, there are plenty of people who do not know how to control their appetites.

Alcohol a poison. On the other hand, we know that although alcohol may technically be considered as a food, it has a harmful effect on the body tissues which foods do not have. According to Professor Chittenden, one of the great dietary experts of this country, alcohol, ${ }^{1}$ although it is oxidized in the body, has a harmful

1. Alcohol is made up of carbon, oxygen, and hydrogen. It is very easily oxidized, but it cannot, as is shown by the chemical formula, be of use to the body in tissue building, because of its lack of nitrogen. 
effect upon the liver and circulation, because it burns too fast and hence throws into the circulation substances which are harmful to health. This indicates that alcohol is a poison. Furthermore, statistics show conclusively that certain diseases, notably cirrhosis of the liver, are greatly increased by the excessive use of alcohol.

A commonly accepted definition of a poison is : any substance which, when taken into the body, tends to cause the death of the organism or serious detriment to its health. That alcohol may do this is well known by scientists. No one who reads of the increase in the number of deaths from adulterated or "bootleg " liquor can draw any other conclusion than that alcohol is a dangerous substance, especially in the form in which it is illegally sold by "bootleggers." "Home brews" of various kinds often have

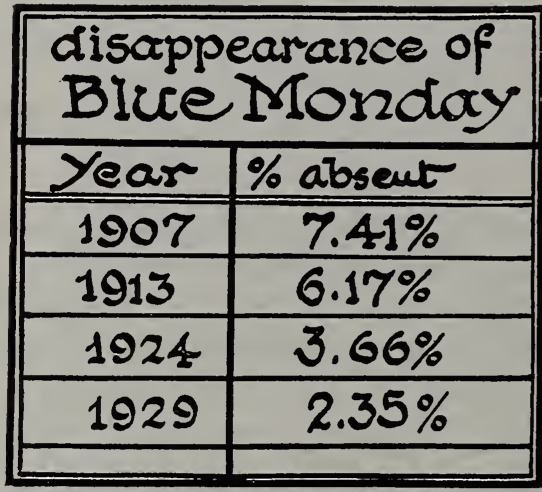

In the last 25 years, a marked decrease in the number absent on Monday is noted in the records of a large manufacturer in the state of Delaware. other poisons formed in them, besides alcohol, and thus are doubly dangerous.

Dangers from alcohol. The annual table of deaths from alcoholism in large American cities, compiled by the Scientific Temperance Federation from data furnished by city health officials, continues to show a smaller number of deaths from this cause than in the pre-prohibition period, although there has been an increase since the first prohibition years. The following figures represent the total deaths from alcoholism in nineteen cities of more than 300,000 population. These cities included in 1920 about $19,000,000$ of the $105,000,000$ people in the United States.

Total Deaths from Alcoholism in Nineteen Large Cities 1916 
The increase in deaths after 1922 is undoubtedly due partly to the dangerous quality of bootleg liquor.

The effect of alcohol on the mortality of offspring. Professor Laitinen, Dr. Stockard, and other experimenters have worked with guinea pigs and white rats to learn if alcohol has any effect upon the birth rate and death rate of the offspring. They found that the death rate is much higher in the animals born from alcoholic parents than in those from non-alcoholic parents. The rate of development of the young is faster in the non-alcoholic animals. In other words, the alcoholic animals were not normal.

Susceptibility to disease increased by alcohol. A good many experiments have been made which prove that alcohol causes

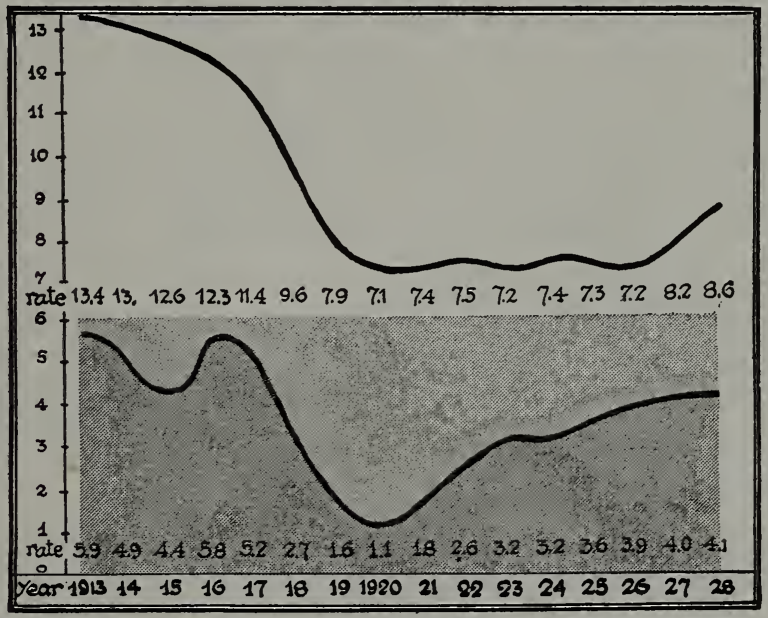

There seems to be a close relation between the death rate per 100,000 from alcoholism (lower graph) and from cirrhosis of the liver, a disease caused by alcohol (upper graph). Since the prohibition amendment went into effect in 1919, there has been a decrease in this disease.

increased susceptibility to disease. Some experiments made by Dr. E. G. Stillman of the Rockefeller Institute show that mice intoxicated with alcohol have much less resistance to pneumonia germs than normal mice.

Death rates in different occupations. Reports from England, where certain occupations give a special temptation to drink, show that if 100 be accepted as an average death rate, the rate 


\section{HOW DOES MAN DETERMINE THE VALUE OF FOOD?}

among brewers is 129, among hotel keepers 160, and among barkeepers 218 . On the other hand, the death rate among clergymen is only 56, for agricultural workers 60 , and in the medical profession 88 .

Project. Try to obtain from your health department statistics which will enable you to get the percentage of people who die from diseases brought about or affected by alcohol. Estimate the number of deaths for the current year. Compare with the number of deaths from the same causes before prohibition. Make your comparison on a proportionate basis.

The use of tobacco. A well-known authority defines a narcotic as a substance "which directly induces sleep, blunts the senses, and, in large amounts, produces complete insensibility." Opium, chloral, and cocaine are examples of narcotics. Tobacco owes its narcotic influence to a strong poison known as nicotine. Its use in killing insect parasites on plants is well known. In experiments with jellyfish and other simply organized animals, the author has found as little as one part of nicotine to one hundred thousand parts of sea water to be sufficient to affect profoundly an animal placed within it. Nicotine in a pure form is so powerful a poison that two or three drops would be sufficient to cause the death of a man by its action upon the nervous system, especially upon the nerves controlling the beating of the heart. It has been demonstrated that tobacco has, too, an important effect on muscular development.

Practical Exercise 5. Why should boys in training stop smoking? Make a list of the harmful results which come from smoking.

\section{Self-Testing Exercise}

Check the correct statements for your workbook:

T. F. 1. Tea, coffee, and alcohol are stimulants.

T. F. 2. Cocoa and chocolate contain no stimulating material.

T. F. 3. Alcohol may be a food as well as a poison.

T. F. 4. A narcotic poison induces sleep by quickening the heart action, thus producing insensibility.

T. F. 5. Opium, chloral, nicotine, and cocaine are examples of narcotics. They are all habit-forming drugs. 


\section{PROBLEM IX. HOW DOES THE PURE FOOD AND DRUGS ACT WORK?}

Project. Make a collection of the labels of patent medicines and classify each under one of the heads in the following paragraphs. Report in class.

Project. Make a collection of free samples of patent medicines and classify under the heads found in the following paragraphs.

Drugs. A certain proportion of people are addicted to the use of drugs found in patent medicines. A glance at the street-car advertisements shows this. As is pointed out by Dr. Arthur J. Cramp of the American Medical Association, the United States patent office requires that in order to patent an article it must be both new and useful. This requirement would automatically prevent the patenting of practically all so-called "patent medicines" because they are usually combinations of drugs that have long been used by the medical profession and frequently given up by reputable physicians in favor of more effective or safer drugs. Patent medicines depend upon secrecy and mystery for their very existence. Hence they are not patented at all, for if they were their formulae would be open. The Pure Food and Drugs Act has at least caused some of the harmful products used in the formula to be placed on the label so that people who buy may know what they are getting.

Bracers. Most of the medicines advertised contain alcohol in greater quantity than beer or wine, and many of them have habitforming drugs in their composition. Not only are many "sarsaparillas" and "bitters" put on the market, but they are often sold to persons who are opposed to alcohol. A dose of one of these medicines usually contains about as much alcohol as the same amount of whisky. Such "bracers," as the American Medical Association have called this type of medicine, are of course habitformers. Any one who begins to take them will soon become dependent upon them.

Heart depressants. Another kind of medicine commonly sold is the poison acetanilid (ăs-ĕt-ăn'̌̌-lĭd), a powerful heart depressant contained, even at the present time, in a good many of the so-called headache powders. Although the Pure Food and Drugs 
Act now requires that the label show a statement of the alcohol, acetanilid, cocaine, opium, and certain other harmful drugs contained in a patent medicine, many people do not read the label, so the danger continues. What is far worse, the use of such drugs often leads to the drug habit. There is danger also from prussic acid, arsenic, and other deadly drugs not covered by the law.

Cure-alls. Perhaps the worst thing about patent medicines is that they rarely cure any one, and they take an immense amount of money from people who can ill afford to spend it. Nearly $\$ 300,000,000$ a year is estimated to be spent for patent medicines alone in this country. Many people, incurably ill with tuberculosis or cancer, make their condition worse through the purchase of cough or cancer cures, which probably contain a habit-forming drug or alcohol. Think how much more good the money thus spent would have done had it been invested in proper foods and good nursing, or in gaining the advice of a reliable physician.

Due to the fact that the present law does not require the publishing of the composition of the medicine on the label, the public is being continually fooled into paying big prices for worthless or even dangerous combinations of drugs. Think of paying $\$ 3.00$ for a few cents' worth of washing soda and salt. Or $\$ .50$ for $\$ .01$ worth of Epsom salt. Yet this is being done every day. To paraphrase a great showman: "There are some people who always want to be fooled." Are any friends of yours in this class?

One of the reasons why people buy patent medicines is because they read the glowing testimonials written by people who say they have been cured by pâtent medicines. Investigation of such letters often shows that they have been written by people who were paid for writing them. There is a regular business in the buying and selling of patent medicine testimonials. Such testimony is worthless, and in cases where the testimonial is written in good faith how do we know that the person who wrote it really did receive the benefits testified to from that particular medicine. Frequently we know he did not because death notices of people who wrote, saying that they have been cured of tuberculosis or kidney trouble by this or that nostrum, have been found in the 
same issue of the paper containing the testimonial which says "I have been cured." The moral is : do not believe the testimonial.

\section{Self-Testing Exercise}

Check the correct statements for your workbook:

T. F. 1. The Pure Food and Drugs Act requires that the trade package declare the presence of all poisonous drugs in a patent medicine.

T. F. 2. The Pure Food and Drugs Act prohibits fake or misleading statements in newspapers and circulars concerning the curative powers of a drug.

T. F. 3. Testimonials are valuable because they prove that persons are cured of disease by patent medicines.

T. F. 4. "Bracers" are valuable because they help people to forget their troubles.

T. F. 5. Some people may be cured by patent medicines.

\section{Review Summary}

Check your knowledge of this unit by: (1) rechecking the survey questions; (2) performing all assigned exercises; (3) checking with your teacher the scores of the various tests and doing over the parts you missed; and finally (4) making an outline for your notebook.

\section{Test on Fundamental Concepts}

In vertical column under the heading CORRECT write numbers of all statements you believe are true. In another column under INCORRECT write numbers of untrue statements. Your grade $=$ right answers $\times 2 \frac{1}{2}$.

I. Foods (1) may contain organic nutrients, salts, vitamins, and water ; (2) are never oxidized in the body; (3) always build tissues; (4) should never be used unless they contain vitamins; (5) are necessary for growth, work, and well being.

II. Proteins (6) are necessary for growth; (7) must contain the amino acids necessary for tissue building if they are to be called complete; (8) may contain several or all eighteen amino acids; (9) in gelatin furnish tissue-building material; (10) in milk contain all the amino acids necessaiy for growth.

III. Foods (11) containing vitamin A promote growth and prevent the eye disease called xerophthalmia ; (12) when taken in the right proportions, form a balanced ration; (13) containing vitamin B prevent loss of sleep; (14) containing vitamin C prevent scurvy; (15) will never contain vitamin D unless they are placed in the sunlight. 
IV. The factors which determine the amount of food one should eat are (16) the kind of work he does; (17) the size of his skeleton; (18) his age; (19) where he lives and the time of year; (20) his appetite.

V. A diet is well balanced (21) when it contains all the vitamins; (22) when 10 to 20 per cent of its Calories are protein; (23) when it has the right proportion of nutrients to make living matter and supply the body with energy for the kind of work we have to do ; $(24)$ when the food is properly cooked; (25) when it contains all the nutrients.

VI. The Pure Food and Drugs Act (26) prevents the use of patent medicines; (27) prevents the use of stimulants; (28) prohibits false or fraudulent statements (on trade packages only) regarding the curative effects of patent medicines; (29) has prevented the use of certain harmful drugs; (30) applies only to the products which are made in one state and sold in another.

VII. Alcohol (31) is a narcotic poison; (32) is a food, because it can be oxidized in the body; (33) is found in many patent medicines; (34) causes greater susceptibility to disease; (35) never hurt anybody.

VIII. Patent medicines (36) are safe to take if you know what they contain; (37) rarely cure and may do much harm; (38) must state on the label the presence of such deadly drugs as arsenic, strychnine, and prussic acid; (39) must state on the label the presence of alcohol, morphine, opium, and cocaine; (40) often have false claims made for them in the newspapers and such statements are lawful.

\section{Achievement Test}

1. What is the difference between a nutrient and a food?

2. Why are some proteins better tissue-building foods than others?

3. How can you make a dietary containing the necessary vitamins?

4. What are "the essentials of an adequate food supply"?

5. What foods are harmful to you?

6. How do you judge a cheap and an expensive food?

7. What are your own calorie needs?

8. How would you make up an individual 100-Calorie dietary giving the correct proportions of carbohydrates, fat, and proteins?

9. What are the strong and weak points of the present Pure Food and Drugs Act?

10. What is an adulterant under the law? 
11. How would you make five tests for the detection of adulterants?

12. What are both sides of the alcohol question?

13. What proof have we that alcohol is a poison?

14. What are the chief types of fakes in the patent medicine game?

\section{Practical Problems}

1. Give examples of ten cheap foods that are good foods. Justify your statement.

2. It is said that an American eats twice as much meat as a Frenchman. Are there any reasons why he should do this?

3 . A boy weighing $125 \mathrm{lbs}$. uses about 150 Calories in slowly walking 3 miles. How many Calories will he use in taking a 10-mile hike? Suppose he should speed up his rate of walking. Would he use more Calories for the same distance?

4. Estimate your own Calorie needs for a hike of 12 miles, walking moderately all the way.

5 . If food costs 5 cents per 100 Calories, would it be cheaper to pay 8 cents for carfare or walk a mile and a half to school?

6. Suppose you were ill and had to use milk as a food. How much milk per day would you have to take to supply your basal metabolism for 24 hours?

7. Make a collection of patent medicine labels to show the various kinds and amounts of alcohol and poisons contained therein. Classify them according to the harm they do; according to the drugs they contain.

\section{Useful References}

Ellis and Macleod, Vital Factors of Foods, Vitamins and Nutrition. (D. Van Nostrand Co. 1915.)

Farmers' Bulletins, 23, 34, 42, 85, 93, 121, 128, 132, 142, 182, 249, 256, 295, 298, 717, 817, 824, 975, 1313, 1383.

Funk, The Vitamines. (Williams \& Wilkins. 1922.)

Harrow, Vitamines. (E. P. Dutton \& Co. 1922.)

Hunter, Laboratory Problems in Civic Biology. (American Book Company.)

Lusk, Science of Nutrition. (W. B. Saunders Co.)

Nostrums and Quackery. American Medical Association, Chicago.

O'Shea, Tobacco and Mental Efficiency. (The Macmillan Co. 1923.)

Sherman, Chemistry of Food and Nutrition. (The Macmillan Co. 1926.) Starling, Hutchinson, Mott, Pearl, The Action of Alcohol on Man. (Longmans Green \& Co. 1923.)

Stiles, Nutritional Physiology. (W. B. Saunders Co. 1924.) 


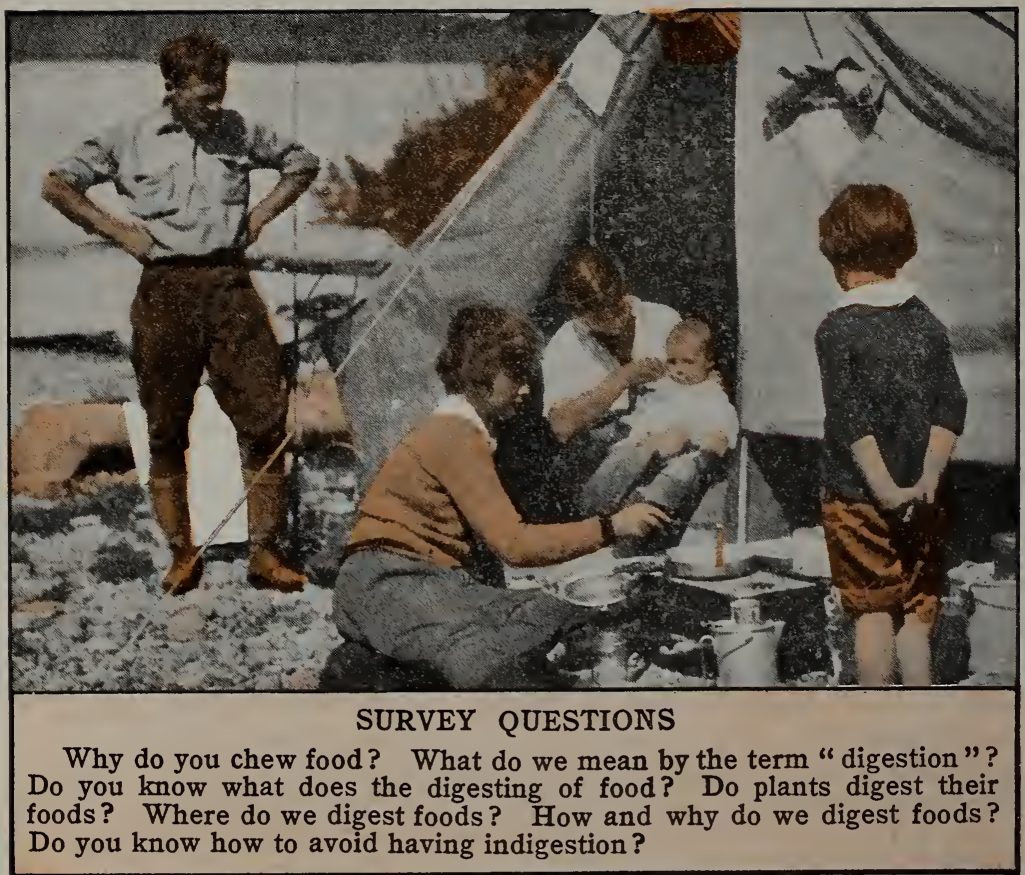

Photo by H. Armstrong Roberts

\section{UNIT XII}

\section{HOW FOOD IS PREPARED FOR BODY USE}

Preview. It seems a far cry from the chemistry laboratory, with its bottles and test tubes, its acids and its bases and all of the complicated formulae that we see in chemistry books, to our own digestive tract. But to the physiologist the human body is a marvelous chemical laboratory which in the complexity of its working makes our science laboratory in school seem very insignificant. We have learned that organic food substances are found in the leaves of plants. This food has to be taken to other parts of the plant in order to be used. Before it can be transported from one part of the plant to another, it has to be made soluble so that it can pass from one cell to another by the process of diffusion through a cell membrane. This change of food from 
an insoluble to a soluble form, you remember, was brought about by agents called enzymes. Several different kinds of enzymes were found in the plant cells, and in those cells digestion took place.

Somewhat the same condition exists in animals. If food is to be of use to man, it must be changed into a soluble form that can pass through the walls of the alimentary canal, or food tube. This process is carried out by the various enzymes which bring about digestion.

In nearly all vertebrate animals, food is taken into the mouth and passed through a food tube, in which it is digested. This tube is composed of different portions, named, respectively, as we pass from the mouth downward, pharynx (făr'ı̌nks), gullet, stomach, small intestine, and large intestine. Attached to this food tube or lying in its walls are structures called glands. It is within the cells of these glands that the enzymes are manufactured which cause digestion to take place.

\section{PROBLEM I. WHAT IS A GLAND AND HOW DOES IT DO ITS WORK?}

In addition to the alimentary canal proper, and connected with it, we find a number of digestive glands. These are the salivary glands of the mouth, the gastric glands of the stomach, the pancreas (păn'krè-ăs) and the liver, both connected with the small intestine by ducts, and the intestinal glands in the walls of the small intestine. Besides these glands which aid directly in digestion, there are several others known as the endocrine (ĕn'dö-krīn) or ductless glands, because they have no ducts or tubes to carry off their contents. These glands give their secretions, which contain substances known as hormones, directly into the blood. We shall study their functions later.

Demonstration 1: A simple gland. (Microscopic preparation.) Under the microscope, notice the structure of a gland in both cross and longitudinal sections. With what is the wall lined? What is the shape of the gland? If work is done by a gland, then it must have food to do this work. Might the material poured out of a gland be manufactured from the food it gets?

What structures would of necessity go to a gland to take food there ? Write a paragraph telling the uses and structure of a gland. 
Structure of glands. In its simplest form a gland may be a collection of cells which, by means of their own activity, manufacture and pour out a substance known as a secretion. The nectar gland of a flower is such a collection of cells. In animals, glands are usually tubular, such as the gastric gland shown on page 371 , or like little sacs, as in the diagram. In all animal glands there is a rich blood supply to and from the secreting cells

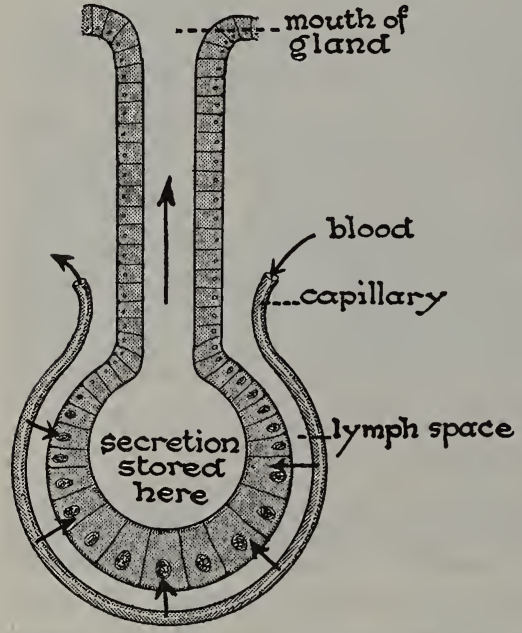

A gland cut lengthwise. Explain how a gland might obtain its secretions.

that line the tubes or sacs, and tiny nerves which control the gland cells and blood supply.

Enzymes and their work. Certain gland cells form secretions containing the chemical activators called enzymes, which we have already learned cause digestion in plants. In animals the enzymes secreted by the cells of the glands and poured out into the food tube act upon insoluble foods so as to change them to a soluble form. They are the product of the activity of the cell, although they are not themselves alive. We do not know much about enzymes themselves, but we can observe what they do. Some enzymes render certain foods soluble, others work in the blood, and still others probably act within the cells of the body as an aid to oxidation, when work is done. Enzymes are very sensitive to changes in temperature and to the degree of acidity or alkalinity of the material in which they act. We shall find that the enzymes from glands in the walls of the mouth will not be active very long in the stomach after the change from the alkaline medium in the mouth to the acid medium in the stomach. Enzymes seem to be able to work indefinitely, provided the surroundings are favorable. A small amount of digestive enzyme, if it had long enough to work, could digest a large amount of food. 


\section{Demonstration 2. To show the use of digestion.}

In one thistle tube place some saliva mixed with starch paste. In a second tube place some paste and water. Fasten membrane covers over the thistle tubes, and wash carefully all starch or other material on outside of tube. Then place the two thistle tubes, large end down, in a beaker containing just enough warm water to cover the membrane on the tubes.

Next test some saliva with Fehling's solution. Is there any grape sugar present?

At the end of the laboratory period test the contents of the beaker with iodine and with Fehling's solution. Was there any starch in the water? Was there any grape sugar? How did it get into the beaker?

Salivary glands. We are all familiar with the substance called saliva which acts as a lubricant in the mouth. Saliva is manufactured in the cells of three pairs of glands which empty into the mouth, and which are called, according to their position, the parotid (beside the ear), the submaxillary (under the jawbone), and the sublingual (under the tongue).

\section{Self-Testing Exercise}

The glands necessary for digestion are the $\ldots \ldots \ldots$ (1) ...... (2), $\ldots \ldots$ (3) $\ldots \ldots$...(4), and ....... (5). They secrete ......(6) that cause digestion of the $\ldots \ldots \ldots(7)$. Starches are changed to . (8) by enzymes in the ....... (9). Glands may be in the form of .......(10) or ......(11). Small ......(12) control the ....... (13) cells and the blood ....... (14) to them.

\section{PROBLEM II. WHAT IS THE STRUCTURE AND WORK OF THE MOUTH CAVITY?}

Laboratory Exercise. Comparison of mouth of a frog and of a man. Compare the open mouth of the frog with the diagram. Do the same studying of your own mouth. Can you find all structures shown in the diagrams?

In man the mouth cavity and the internal surface of the food tube are lined with mucous membrane. The mucus secreted from gland cells in this lining makes a smooth surface so that the food can slip down easily. The roof of the mouth is formed by a plate of bone called the hard palate, in front, and a softer continuation 
to the back, called the soft palate. These separate the nose cavity from that of the mouth. The space back of the soft palate is called the pharynx, or throat cavity. From the pharynx

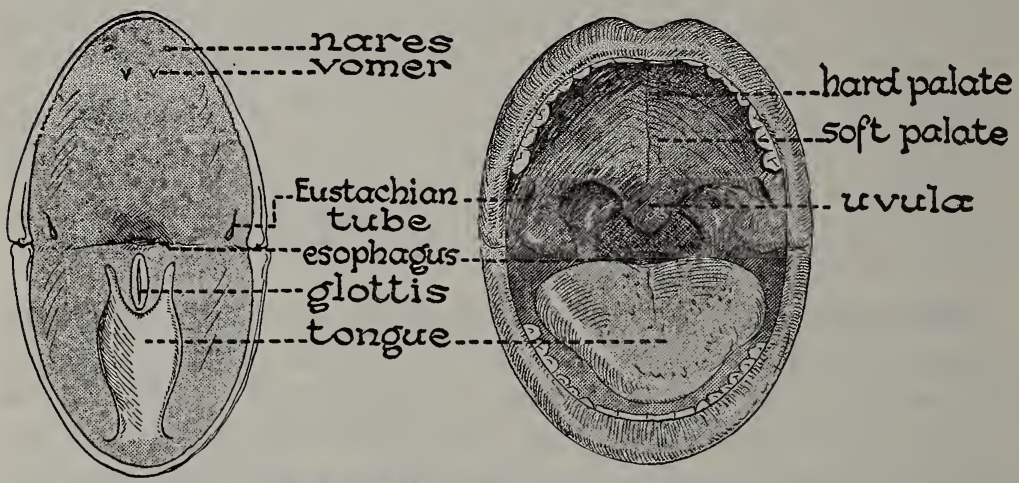

Comparison between the mouth of frog and of man.

lead off the gullet and trachea or windpipe. There are also openings here to the Eustachian tubes and to the nose. The lower part of the mouth cavity is occupied by a muscular tongue. The tongue is used in moving food about in the mouth, and in starting

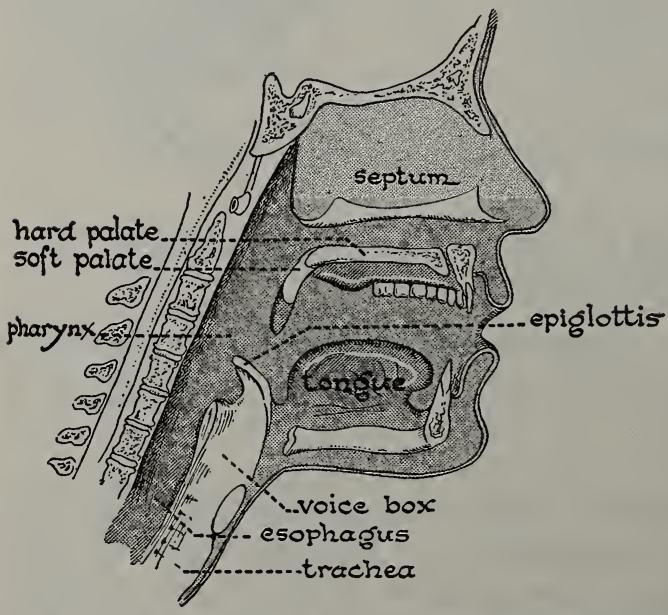

A longitudinal section through the head, showing the throat and its connections. How is the throat connected with the nose? with the stomach? with the lungs? it on its way to the gullet.

Laboratory Exercise. What conditions are favorable or unfavorable for the digestion of starch? Place in test tubes an equal amount of starch paste. In the first tube add water; to a second, saliva; to a third, saliva and a few drops of weak acid; to a fourth tube saliva and a base such as weak sodium hydroxide. Place all these tubes in water of about $99^{\circ} \mathrm{F}$. for 20 minutes. Test the contents of 
each tube with Fehling's solution. In which tube or tubes has digestion taken place?

Take two test tubes, place in each tube an equal amount of starch paste and saliva. Place one tube in warm water, the other in the icebox. Test each for grape sugar after one hour. In which tube do you find sugar? The above experiments show that the enzymes in the saliva under certain conditions change starches to sugars. You will remember that starch in the growing corn grain was changed to grape sugar by an enzyme called diastase. In saliva a similar action is caused by an enzyme called ptyalin ( $\mathrm{t}^{\prime} \dot{a}-$ linn), or salivary amylase; but this enzyme acts only in an alkaline medium at about the temperature of the body.

The teeth. The teeth of man, unlike those of the frog, are used in the mechanical preparation of the food for digestion. Instead of holding prey, they crush, grind, or tear food so that more of its surface may be exposed to the action of the digestive fluids. The first or " milk" teeth of man are only twenty in number, while the second

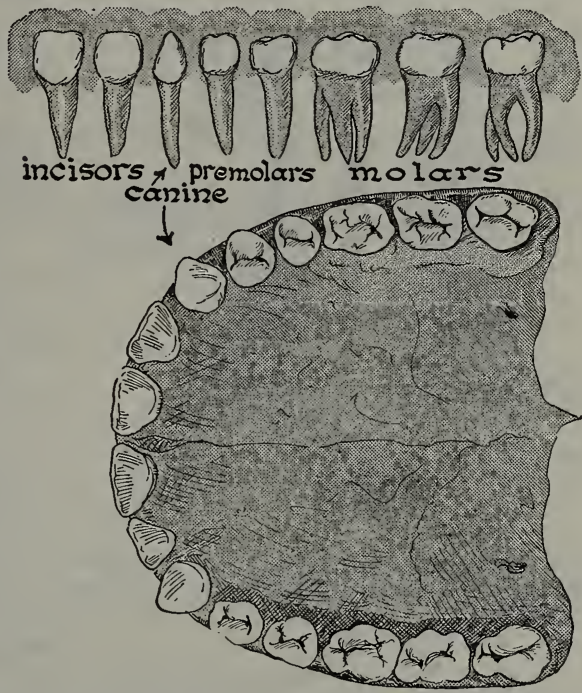

Draw this diagram in your workbook and indicate the four kinds of teeth in their place in the jaw.

or "permanent" set contain thirty-two teeth. These teeth are divided, according to their structure, into four groups; these are the incisors, or cutting teeth; the canines; the premolars; and the flat-top molars, or grinding teeth.

Each tooth, as the figure shows, is composed chiefly of hard bone or dentine. The crown of the tooth is covered with enamel, the hardest substance in the body. In the interior is a pulp cavity, which during the life of the tooth contains nerves and blood vessels which give the tooth its nourishment. The tooth is held in its bony socket in the jaw by cement.

When a tooth dies, bacteria often set up an irritation at its base 
and form a center or focus of infection from which poison gets into the blood. As a result of this, very serious diseases may

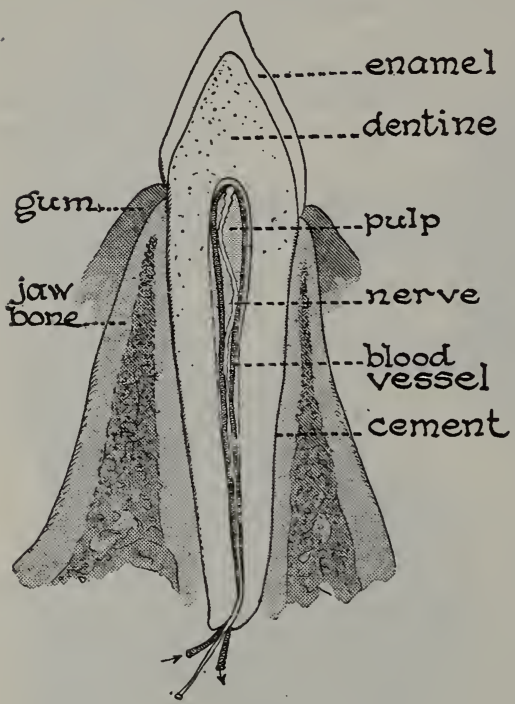

A section through a tooth. Why is a cavity painful? Why is a tooth sometimes so hard to pull?

With a bracket, label each group of teeth. With a cross, mark all the teeth you have lost or that have not grown. Mark all cavities not filled in your teeth by a spot where the cavity exists. If teeth have been filled, mark with appropriate title.

Care of the teeth. Too much emphasis cannot be placed on the proper care of the teeth. They should be carefully brushed each morning and evening. Use a medium stiff brush and work the bristles in a vertical direction away from the gum so as to get between the teeth. After that, a rotating movement over the surface and between the teeth will dislodge any remaining particles of food. Above all, massage the gums with your brush and polish the surface of the teeth both in back and in front, for this helps remove the bacterial film. Dental silk should be used after meals.

It has been found that fruit acids are very beneficial to the teeth. Vinegar diluted to about half strength with water makes an 
excellent dental wash. If one has an acid mouth, a good tooth paste mixed with castile soap may be used to clean the teeth.

The teeth should be cleaned by a reliable dentist at least every six months. In this way deposits which cover the teeth may be removed and decay prevented. If decay once starts, sooner or later the tooth will be lost.

Practical Exercises 3. What are the uses of $(a)$ the incisors, $(b)$ the canines, (c) the premolars, and $(d)$ the molars?

How many teeth are there in the first set of teeth? When do they begin to come, and when do they go?

What makes teeth decay? Why should we clean the teeth night and morning? How should we brush them?

What is a focal infection?. What harm may it do? What harm might come from swallowing fluids which pass through a mouth containing decayed teeth?

How often should one visit the dentist? Why?

\section{Self-Testing Exercise}

Food passes from the ....... (1) into the .......(2) and ....... (3) on its way to the stomach. The enzymes in .......(4) change ....... (5) to sugars. A tooth is composed chiefly of ........ (6). The crown of the tooth is covered with ....... (7). The interior of the tooth is called the .......(8) .......(9). A decayed tooth may be the source of a $\ldots \ldots$ (10) $\ldots \ldots \ldots$ (11). The saliva contains the enzyme, ........(12).

\section{PROBLEM III. WHAT ARE THE PARTS OF THE DIGESTIVE TRACT?}

If we are to understand the work of the parts of the food tube, it is necessary that we know something about their structure. One can learn about the digestive tract through the study of charts or models, but it is much easier to understand if we can see its parts as they would really appear in a living person. This we cannot do, but we have a good substitute in the frog. Let us examine the digestive tract of a frog in order to compare it with man.

Laboratory Exercise. To compare the digestive system of a frog with that of man.

Opened frogs preserved in 4 per cent formalin. Manikin showing. digestive tract. 
Note in the frog the glistening membrane (peritoneum) lining the body cavity. A similar membrane is found in man.

In man, the body cavity or space in which the internal organs rest is divided into two parts by a wall of muscle, the diaphragm, which separates the heart and lungs from the other internal organs. In the frog no muscular diaphragm exists. Numerous blood vessels can be found in the frog, especially in the walls of the food tube, which carry the digested nutrients to other parts of the body.

Notice the large, reddish brown organ covering most of the other organs. This is the liver. Count the lobes or divisions of the liver and compare the position and general structure with the liver of man (use manikin). Lift up the middle lobe of the liver and find the gall bladder, a greenish sac. This contains bile, a secretion from the liver. Now compare with the manikin to see if you can locate where the bile gets into the food tube.

The food tube begins at the mouth, continues as a short, wide gullet into the stomach (just under the liver). Compare these structures in the frog with similar structures in man. The stomach of the frog leads into a long coiled small intestine and thence into a very short large intestine. The large intestine not only excretes the solid wastes of the body, but it is also the reservoir for nitrogenous wastes. It thus differs from a true large intestine and is called a cloaca.

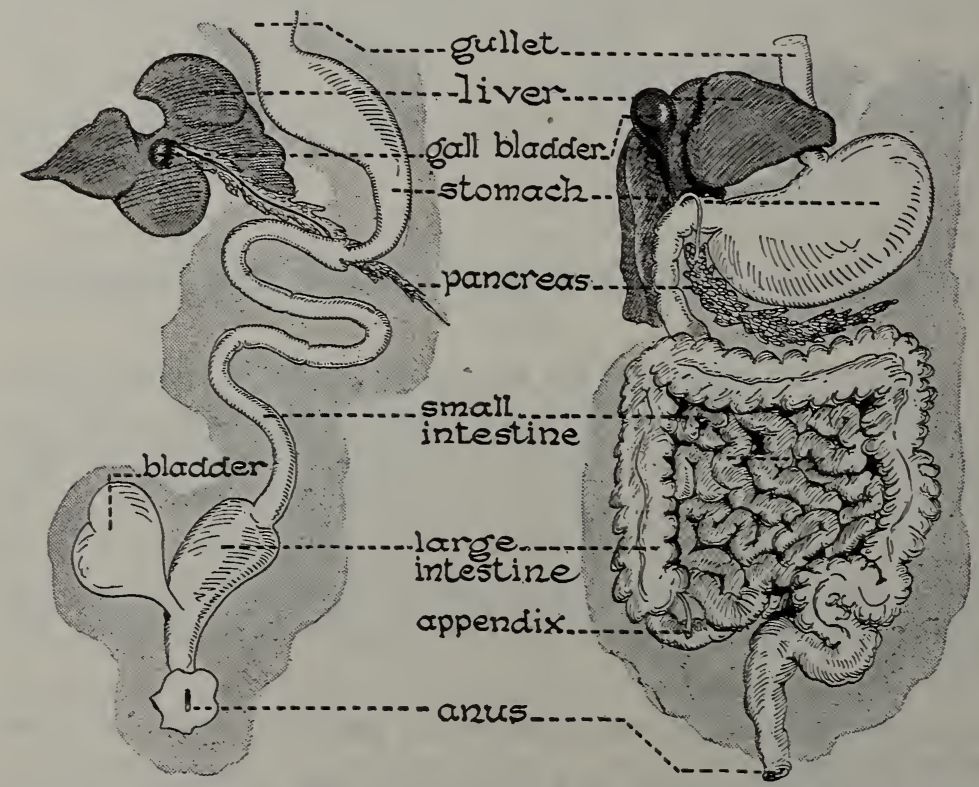

Compare part by part, the digestive tract of the frog with that of man. Are there any structures found in one and not in the other? 
Note that all the organs are held in place by a fold of the body cavity lining called the mesentery. What is its use? A cream-colored body, the pancreas, can be located between the stomach and the first bend in the small intestine.

The digestive tract of man. Comparing the food tube of man and its glands part by part with that of the frog, we find a striking similarity as to parts. The lower part of the digestive tube in the frog is relatively much shorter than that of man, whose small intestine is about 20 feet in length. The large intestine is also relatively shorter. We find that in general the uses of the parts are quite similar in spite of their difference in size and the method of life.

\section{Self-Testing Exercise}

The digestive tract of man consists of a ....... (1), beginning at the ....... (2) and ending at the ....... (3). Ducts from several ....... (4) which aid in digestion empty into it. The parts of the food tube are $\ldots \ldots \ldots(5), \ldots \ldots$. (6),$\ldots \ldots$ (7),$\ldots \ldots$ (8),

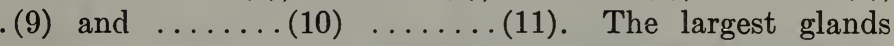
are the .......(12) and ....... (13).

\section{PROBLEM IV. WHAT DIGESTIVE CHANGES TAKE PLACE IN THE STOMACH?}

\section{Demonstration 3. To determine the conditions most favorable for gastric digestion.}

Use five test tubes or beakers and some boiled white of egg. In the first tube put minced white of egg and water; in the second minced white of egg and 0.2 per cent hydrochloric acid; in the third, fourth, and fifth minced white of egg, 0.2 per cent hydrochloric acid, and pepsin.

Keep the first three in a warm place at abotit a temperature of blood heat for several hours. Keep the fourth in an ice box or surrounded by cracked ice. Keep the fifth in boiling water for 15 or 20 minutes, then place it in the warm place with the first, second, and third.

Test the first with biuret test ${ }^{1}$ for the presence of a soluble protein (a peptone). Test the second, third, fourth, and fifth with biuret test and note results.

1 Biuret solution: To the material to be tested add its own bulk of concentrated caustic soda. Then add a drop or two of weak copper sulphate solution. A violet or blue color shows the presence of unchanged protein, a rose pink the presence of peptone. 
What conditions are necessary for the digestion of protein? What is the effect of an extreme heat and cold on the action of hydrochloric acid and pepsin with a protein? Make a table giving all results of the above tests of conditions necessary for the digestion of protein.

Chewing and swallowing. After food has been chewed and mixed with saliva, it is rolled into little balls and pushed by the tongue into such position that the muscles of the throat cavity may seize it and force it downward. Food, in order to reach the gullet from the mouth cavity, must pass over the glottis which is the opening into the trachea. When food is in the process of being swallowed, the upper part of the gullet forms a trapdoor over this opening. When this trapdoor, called the epiglottis, is not closed, and food "goes down the wrong way," we choke, and the food is expelled by coughing.

The esophagus. After food leaves the mouth cavity, it gets beyond our direct control, and the muscles of the gullet, stimulated to activity by the presence of food in the tube, push the food down
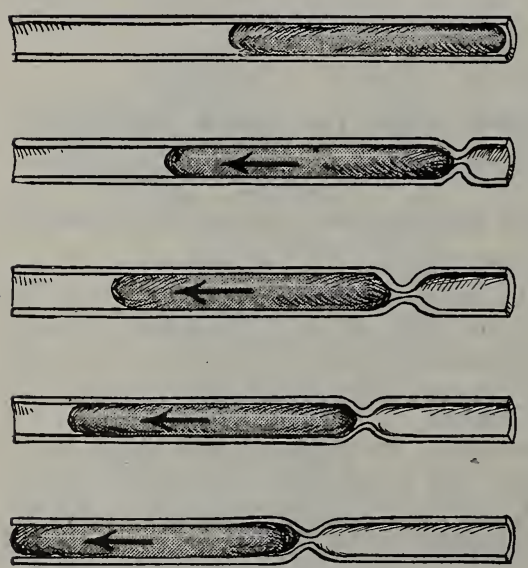

Food passes through the digestive tract by means of a series of successive wavelike movements, which are under the control of the nervous system. The constricted portion is always preceded by an area of relaxation. by a series of slow-moving muscular contractions until it reaches the stomach. These wavelike movements, peristalsis, occur also in the stomach and the small intestine. Peristaltic movement is caused by muscles which are not under voluntary nervous control, although anger, fear, disgust, or other unpleasant emotions may slow them or even stop them entirely.

Stomach of man. The stomach is a pear-shaped organ capable of holding about three pints. Opposite to the gullet, the end which empties into the small intestine is provided with a ring of muscle called the pylorus (p̌̆-lō'rŭs). When this muscle relaxes, it permits the 
passage of food from the stomach. There is also another ring of muscle guarding the entrance to the stomach.

Gastric glands. The folded wall of the stomach is dotted with thousands of tiny pits, the mouths of the gastric glands. The gastric glands are little tubes, the lining of which secretes the gastric juice. When we see or even think of appetizing food, this secretion is given out in considerable quantity. Just as the mouth "waters" at the sight or thought of certain well-liked foods, the gastric glands of the stomach also pour out their secretions under similar stimuli. Gastric juice is slightly acid in its chemical reaction, containing about 0.2 per cent free hydrochloric acid. It also contains two enzymes: one very important, called

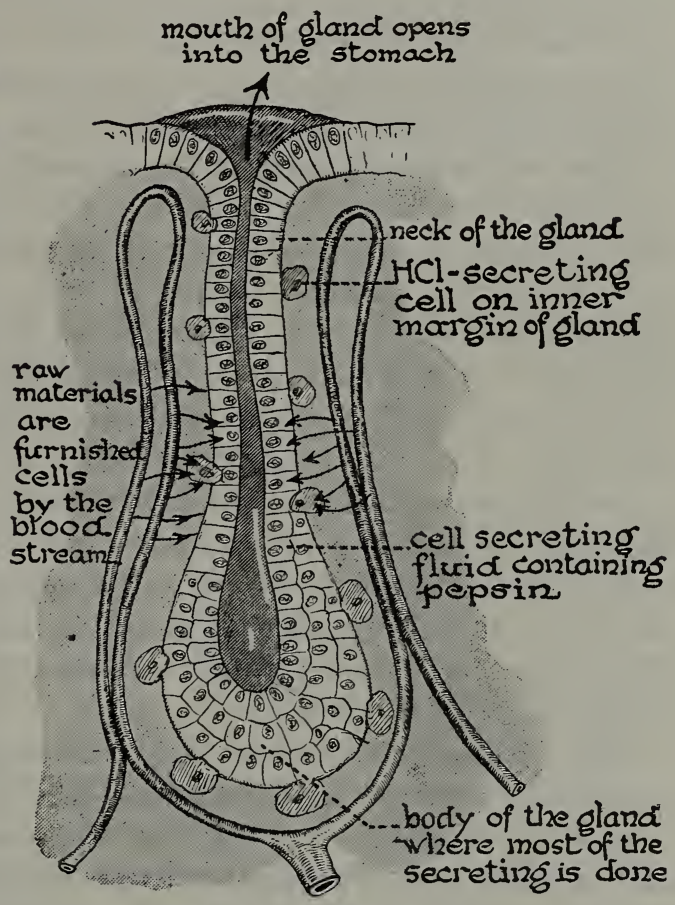

Gastric glands secrete a substance which is changed into pepsin in the presence of acid. The secretion of these glands forms the gastric fluid.

pepsin, and the other, less important, called rennin. Rennin curdles or coagulates a protein found in milk; after the milk is curdled, the pepsin is able to act upon it. "Junket" tablets, which contain rennin, are used sometimes in the preparation of a dessert from milk.

Action of gastric juice. If proteins are treated with artificial gastric juice at the temperature of the body, they will become swollen and then gradually change to substances (peptones) which 
are soluble in water. This is due to the action of the enzyme pepsin.

The hydrochloric acid found in the gastric juice acts upon lime and some other salts taken into the stomach with food, changing them so that they may pass into the blood and eventually form the mineral part of bone or other tissue. This acid also has a decided antiseptic influence in preventing growth of bacteria, some of which cause decay, others of which cause disease.

Experiments on digestion in the stomach. Some very interesting experiments have been made by Professor Cannon of Harvard with reference to the movements of the stomach contents. Cats were fed with a material having in it subnitrate of bismuth, a harmless chemical that is visible under the fluoroscope. It was found that shortly after food reached the stomach, a series of waves began which sent the food toward the pyloric end of the stomach. If the cat was feeling happy and well, these contractions continued regularly, but if the cat was cross or bad tempered, the movements would stop. These experiments were repeated on men, with like results, and show the importance of cheerfulness at meals. Pleasant conversation and a cheerful mind at the table will go far toward making the food taste better and also toward causing it to digest properly.

Other experiments showed that food which was churned into a soft mass was permitted to leave the stomach only when it became thoroughly permeated by the gastric juice. It is the acid in the partly digested food that causes the pyloric ring of muscle to open and allow the food to escape little by little into the small intestine.

\section{Self-Testing Exercise}

The food passes through the ....... (1) and ....... (2) by a series of ....... (3) .......(4). The stomach is a ......(5) organ. The $\ldots \ldots$. (6) ......(7) secrete a ......(8) which empties into the ....... (9). This ...... (10) is slightly ......(11) in chemical reaction, and contains two enzymes, .......(12) and ....... (13). The enzyme .......(14) digests the .......(15) in the stomach. Our digestion is affected by our .......(16). 


\section{PROBLEM V. WHAT WORK IS DONE BY THE PANCREAS?}

Demonstration 4. What is the action of pancreatic juice on starch? Add some artificial pancreatic juice (made by mixing 5 grains of pancreatin and 10 grains of baking soda in 100 c.c. of water) to some dilute starch paste. Keep it at about body temperature for a few hours, then test with Fehling's solution. What occurred when Fehling's solution was added? What was the action of pancreatic juice on starch?

Demonstration 5. What is the effect of pancreatic juice on protein?

Using artificial pancreatic juice instead of a mixture of hydrochloric acid and pepsin, carry out an experiment as described for the test for the third tube in the Demonstration on page 369. Was any of the white of egg digested?

Demonstration 6. What is the effect of pancreatic juice on oils and fats?

Shake up oil and water. What happens? Then add a little alkaline substance, e.g., baking soda. What happens? Now shake up water with artificial pancreatic juice. What happens? What is the effect of pancreatic fluid on oils?

Make a table to show the effect of pancreatic juice on nutrients.

Position and structure of the pancreas. The partly digested food in the small intestine comes in contact almost simultaneously with secretions from the liver, the pancreas, and the intestinal glands. We shall first consider the function of the pancreas. The pancreas is one of the most important digestive glands in the human body. It is a rather diffuse structure, resembling the salivary glands. Its duct (joined with the bile duct from the liver) empties into the small intestine a short distance below the pylorus.

Work done by the pancreas. Starch paste added to artificial pancreatic fluid and kept at blood heat is soon changed to sugar. Proteins, under the same conditions, are broken down into the amino acids. Fats, which so far have been unchanged except to be melted by the heat of the body, are changed by the action of the pancreatic fluid and the bile into substances which can pass through the walls of the food tube. If we test pancreatic fluid, we find it strongly alkaline in its reaction. If two test tubes, one containing olive oil and water, the other olive oil and a weak solution of caustic soda (which has an alkaline reaction), are shaken violently and then allowed to stand, the oil and water will quickly separate, while the oil and solution of caustic soda will 
remain for some time in a milky emulsion. If this emulsion is examined under the microscope, it will be found to be made of

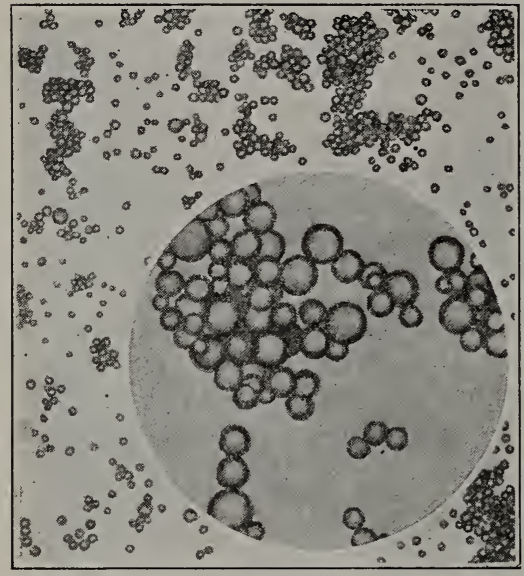

Milk, a form of emulsion, as seen under the microscope. The fat globules appear in groups. The circle shows one group of globules highly magnified. millions of little droplets of fat, floating in the liquid. The presence of the caustic soda helped the forming of the emulsion. Pancreatic fluid emulsifies fats and changes them into fatty acids and soft soaps. Fat in these forms can be absorbed. The above changes are brought about by three enzymes: amylase (ăm'î-lās), which breaks down starches to simpler sugars; trypsin (trĭp'sinn), which, working with other enzymes of the small intestine, breaks protein into amino acids; and lipase (līp'ās), which breaks the fats into fatty acids and glycerin. These fatty acids become soap when mixed with the alkaline material in the intestinal juice.

Conditions in which the pancreas does its work. The secretion of the pancreatic juice is brought about by the action of a hormone called secretin. This substance, which is formed in some of the cells lining the small intestine just below the pylorus, is released into the blood at the time food passes from the stomach through the pylorus. This food is acid, and the acid, on touching the lining of the small intestine, causes the formation of secretin in its walls. This secretin passes into the blood and stimulates the pancreas and liver to release their fluids. This is an example of hormone control.

\section{Self-Testing Exercise}

The pancreatic fluid changes ....... (1) to ...... (2); ....... (3) to

(5), and

(6) into 
.. (8). These changes are caused by the enzymes, ....... (9), (10), and ............ The hormone (12) causes the pancreas to secrete ...... (13) ...... (14), which is ...... (15) in its reaction.

\section{PROBLEM VI. WHAT ARE THE FUNCTIONS OF THE LIVER?}

Liver. The liver is the largest gland in the body. In man, it is found just below the diaphragm, a little to the right side of the body. The liver is not primarily a digestive gland, although it secretes daily about a quart of bile. Bile contains no enzymes, although it may have the power of rendering more active the enzyme in the pancreatic fluid that acts upon fats. Certain substances in the bile aid especially in the absorption of fats. Bile seems to be mostly a waste product from the blood. The color of bile is due to certain waste substances which come from the destruction of worn-out red corpuscles of the blood. This destruction takes place in the liver (and also in the spleen, a large ductless glandlike organ near the stomach). The bile stimulates the peristaltic movements of the intestine, thus preventing extreme constipation. It also has a slight antiseptic effect in the intestine.

\section{The liver a storehouse.} Perhaps the most important function of the liver is the formation and storing of a material called glycogen, or animal starch. The liver is supplied with blood from two sources. Some comes from the heart, but a greater amount comes directly from the walls of the stomach and intestine (see diagram on page 378). The liver normally contains about one fifth of all

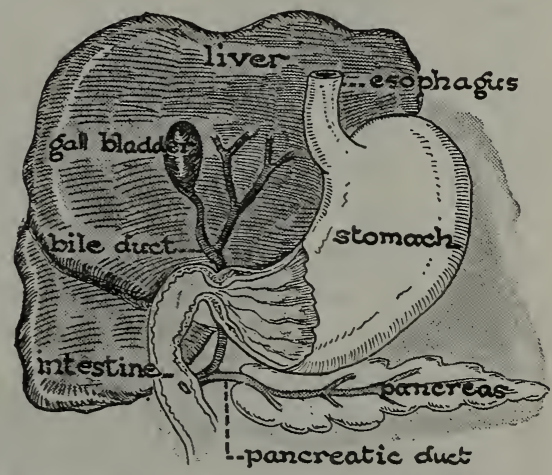

What glandular secretions aid in the digestion of the food in the small intestine? the blood in the body. This blood is very rich in food materials, and from it the cells of the liver take out sugars to form 
glycogen. ${ }^{1}$ Glycogen is stored in the liver until such a time as a food is needed that can be quickly oxidized; then it is changed to sugar and carried off by the blood to the tissue which requires it, and there used for this purpose. Glycogen is also stored in the muscles, where it is oxidized to release energy when the muscles are exercised.

\section{Self-Testing Exercise}

The liver stores ....... (1), which is later changed into ....... (2) when the tissues need it. The bile is secreted by the ........ (3). It is a $\ldots \ldots$ (4) ....... (5) from the blood and it probably $\ldots . \ldots$ (6) in the absorption of ...... (7). The liver contains about $\ldots \ldots$. (8) .......(9) of all the blood in the body. The bile ........(10) the .......(11) movements of the intestine.

\section{PROBLEM VII. HOW ARE FOODS ABSORBED AND HOW DO THEY GET INTO THE BLOOD?}

Laboratory Exercise. How is the surface of the digestive tube increased?

Study the structure of tripe (stomach wall of a ruminant) and the microscopic slide of a cross section of the small intestine. Remember that the chief function of the small intestine is to get food into the blood.

Make a tube of paper having a diameter of one inch. Then try to make a tube having the same diameter but having a fluted wall. Which takes more paper? Which would present more surface? Study the diagram of a villus. How is it fitted to be an absorbing organ?

Structure of the small intestine. The small intestine in man is a slender tube nearly twenty feet in length and about one inch in diameter. As one of the chief functions of the small intestine is that of absorption, we must look for adaptations which increase the absorbing surface of the tube. This end is gained in part by the inner surface of the tube being thrown into transverse folds which not only retard the rapidity with which food passes down the intestine, but also give more absorbing surface.

${ }^{1}$ It is known that glycogen may also be formed in the body from protein, and possibly from fatty foods. 
The villi. But far more important for absorption are millions of little projections which cover the inner surface of the small intestine. So numerous are these projections that the whole surface presents a velvety appearance. Collectively, these structures are called the villi (sing. villus). They form the chief organs of absorption in the intestine, several thousand being distributed over every square inch of surface. By means of the folds and the villi the small intestine is estimated to have an absorbing surface equal to twice that of the surface of the body. Between the villi

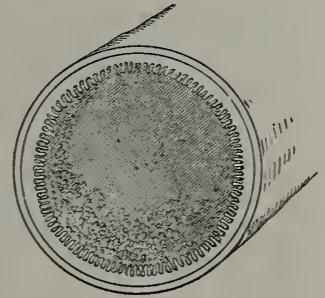

A section through the small intestine. What are the tiny projections. Of what use are they? are found the openings of the intestinal glands which secrete the intestinal juice, which contains at least one hormone and several enzymes with which it assists the pancreatic fluid to do its work.

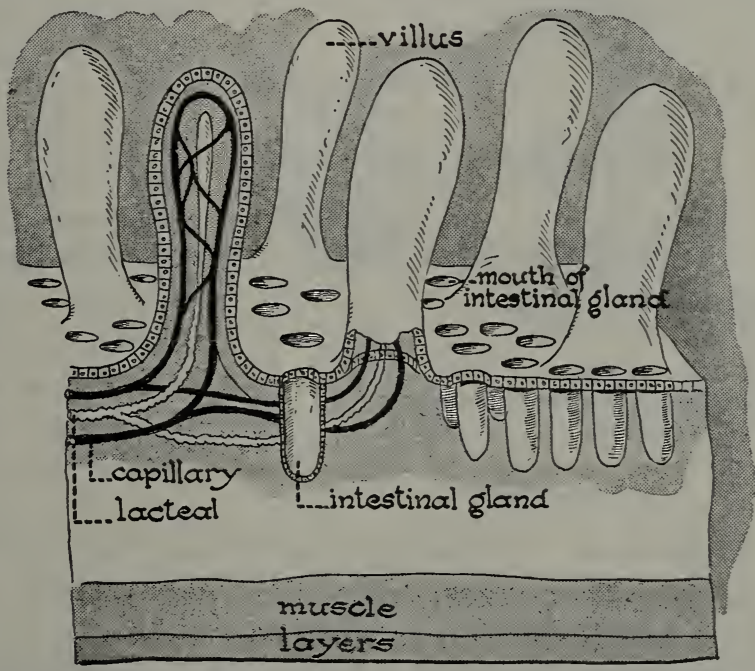

Explain this section through the small intestine, giving the uses of each part.

The internal structure of a villus is best seen in a longitudinal section. We find the outer wall made up of a thin layer of cells, the epithelial layer. These cells absorb the fluid food from within 
the intestine. Underneath these cells lies a network of very fine blood vessels and in the center of the villi are spaces which, because

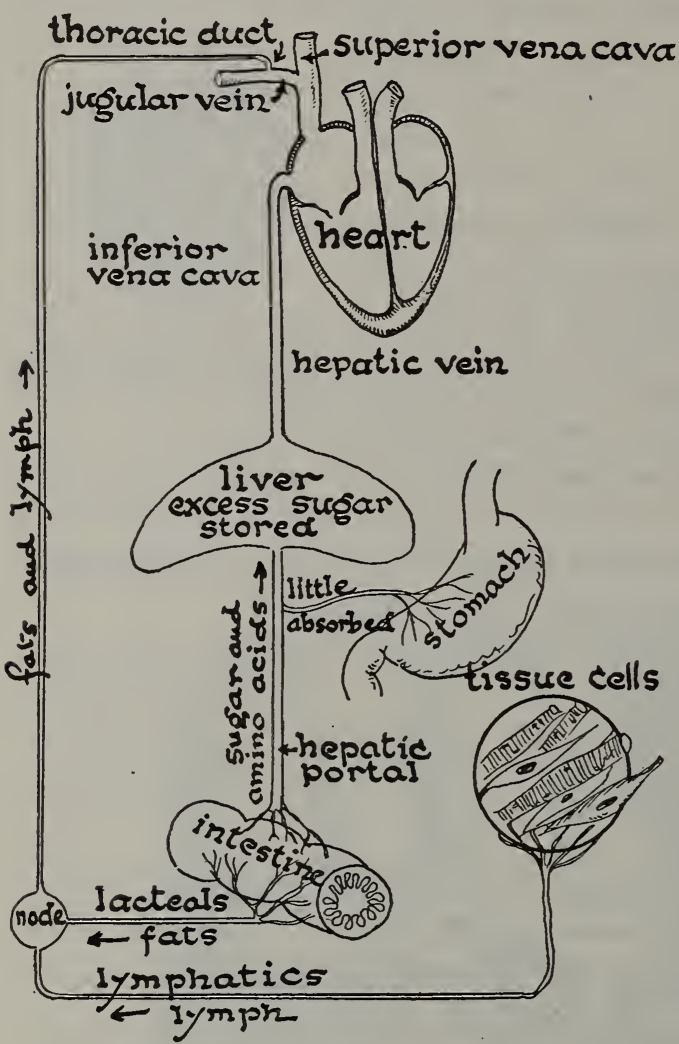

Explain from the diagram and text how the various nutrients reach the blood. of their white appearance after the absorption of fats, have been called lacteals.

Absorption of foods. While diffusion and osmosis are important factors in the passage of food and water through the walls of the intestine, most physiologists agree that the living matter in the cells lining the intestine exerts energy that affects the absorption of the substances that pass into the blood and lacteals. This is proven by the fact that if these cells are injured or poisoned, then absorption follows the laws of

osmosis and diffusion. Ordinarily the cells lining the intestine are like tiny chemical laboratories. Since the object of digestion is to furnish the cells with building material as well as energy foods, it is evident that amino acids, after having been absorbed into the blood, can get into the cells by a similar process. Fats, for example, in the form of fatty acids and glycerol, enter the epithelial cells of the villus and during the process of passing through them are changed back into fat particles. 
This fluid or lymph then passes into the lacteals and other lymphatics and eventually reaches the blood. On the other hand, simple sugars and amino acids pass directly into the blood and reach the blood vessels which carry them to the liver, where, as we have seen, sugar is taken from the blood and stored as glycogen. From the liver, the food within the blood is carried to the heart, pumped to the lungs, returned to the heart, and is pumped to the tissues of the body. A large amount of water and some salts are also absorbed through the walls of the stomach and intestine.

Large intestine. The large intestine has somewhat the same structure as the small intestine, except that it lacks the villi and has a greater diameter. Considerable absorption, however, takes place through its walls as the mass of food and refuse material is slowly pushed along by the peristaltic movements of the muscles within its walls. At the point where the small intestine widens to form the large intestine, a baglike pouch is formed. From one side of this pouch is given off a small tube, usually from one to eight inches long, closed at the lower end. This tube, the rudiment of what is an important part of the food tube in the lower vertebrates, is called the vermiform appendix.

Practical Exercise 4. Summarize the different pathways by which food reaches the heart and general circulation by filling in the following table:

\begin{tabular}{|c|c|c|c|c|}
\hline Foods & Where Absorbed & Form & Adaptations For & Paths to Heart \\
\hline & & & & \\
\hline & & & & \\
\hline & & & & \\
\hline
\end{tabular}

Constipation. In the large intestine live billions of several species of bacteria which, on the whole, may be said to be useful because they break down and decay the indigestible parts of the food we have eaten. But these same bacteria in their life processes make and give off toxins. These substances are easily 
absorbed through the walls of the large intestine, and, when they pass into the blood, cause headaches and sometimes serious trouble. Hence it follows that the intestine should be emptied of this matter as frequently as possible, at least once a day. Constipation is one of the most serious ills the American people have to deal with, and it is largely brought about by the life we lead, with its wrong kinds of food and its lack of exercise, fresh air, and sleep. Fruit with meals, especially at breakfast, plenty of water between meals and before breakfast, and plenty of fresh vegetables and cereals to supply the bulk sufficient to stimulate the muscles of the intestine, all will aid in preventing constipation. Exercise, particularly of the abdominal muscles, and regular times for the elimination of wastes will help to correct this evil.

Hygienic habits of eating. Any habits we may form of chewing our food thoroughly will aid digestion. The smaller the pieces of food the more surface will be presented to the digestive fluids containing the enzymes and the more complete will be the digestion. Undoubtedly much indigestion and other discomfort is due to hurriedly eaten meals with consequent lack of proper chewing of food. It is a good rule to go away from the table feeling a little hungry. Eating too much overtaxes the digestive organs and prevents their working to the best advantage. Still another cause of indigestion is eating when in a fatigued condition. It is always a good plan to rest a short time before eating, especially after any hard manual work. Eating between meals is condemned by physicians because the blood is brought to the digestive organs at a time when it should be more active in other parts of the body. The excessive use of ice cream sodas and cold drinks between meals is bad for this reason and because it dulls appetite for regular meals.

Practical Exercise 5. 1. Tell where each part of a meal of bread and butter, meat, rice pudding, and nuts is digested.

2 . Why should we chew starchy foods well before swallowing?

3 . Why is soup eaten at the beginning of a meal? (Remember it is absorbed rapidly.)

4. Why are partly cooked foods harder to digest than well cooked foods?

5. Name three easily digested foods and tell why they are easy to digest.

6. Name three foods difficult to digest and tell the reasons why.

7. Give, in detail, the digestion of a meal of milk, bread, and apple sauce. 
TABLE OF CHEMICAL DIGESTION

\begin{tabular}{|c|c|c|c|c|c|}
\hline $\begin{array}{l}\text { Place of Di- } \\
\text { GESTION }\end{array}$ & $\begin{array}{l}\text { SECRETION } \\
\text { FORMED }\end{array}$ & $\begin{array}{c}\text { ENZYME } \\
\text { CONTAINED }\end{array}$ & $\begin{array}{c}\text { MEDIUM } \\
\text { REQUIRED }\end{array}$ & $\begin{array}{l}\text { SUbSTANCE } \\
\text { Digested }\end{array}$ & $\begin{array}{c}\text { END PRODUCT } \\
\text { FORMED }\end{array}$ \\
\hline Mouth & Saliva & Ptyalin & Alkaline & Starch & $\begin{array}{c}\text { Grape } \\
\text { sugar }\end{array}$ \\
\hline Stomach & $\begin{array}{l}\text { Gastric } \\
\text { juice }\end{array}$ & $\begin{array}{l}\text { Pepsin } \\
\text { Rennin }\end{array}$ & Acid & $\begin{array}{l}\text { Protein } \\
\begin{array}{c}\text { Casein of } \\
\text { milk }\end{array}\end{array}$ & $\begin{array}{l}\text { Proteoses } \\
\text { and } \\
\text { peptones } \\
\text { Curd }\end{array}$ \\
\hline \multirow{7}{*}{$\begin{array}{c}\text { Small } \\
\text { Intestine }\end{array}$} & \multirow{3}{*}{$\begin{array}{l}\text { Pancreatic } \\
\text { juice }\end{array}$} & Amylase & Alkaline & Starch & Grape \\
\hline & & Trypsin & Alkaline & Proteins & Amino \\
\hline & & Lipase & Alkaline & Fats & $\begin{array}{c}\text { Fatty acid } \\
\text { and } \\
\text { glycerol }\end{array}$ \\
\hline & \multirow[t]{4}{*}{$\begin{array}{l}\text { Intestinal } \\
\text { juice }\end{array}$} & Erepsin & Alkaline & $\begin{array}{l}\text { Proteoses } \\
\text { and pep- } \\
\text { tones from } \\
\text { stomach }\end{array}$ & $\begin{array}{l}\text { Amino } \\
\text { acids }\end{array}$ \\
\hline & & Maltase & Alkaline & $\begin{array}{l}\text { Maltose } \\
\text { (grape } \\
\text { sugar) }\end{array}$ & Glucose \\
\hline & & Sucrase & Alkaline & Cane sugar & Glucose \\
\hline & & Lactase & Alkaline & Milk sugar & Glucose \\
\hline
\end{tabular}

\section{Self-Testing Exercise}

Check the correct statements in your notebook:

T. F. 1. The villi are hollow hairs which suck up digested food.

T. F. 2. A villus absorbs food through the cells covering its surface.

T. F. 3. The large intestine contains many bacteria which cause the decay of the wastes held therein.

T. F. 4. The digestive fluids in the small intestine ultimately change proteins to amino acids in which form they pass into the blood.

T. F. 5. The gastric juice changes sugar to starches.

T. F. 6. The surface of the small intestine is increased by the villi 


\section{HOW FOOD IS PREPARED FOR BODY USE}

\section{Review Summary}

Check your knowledge of the unit by: (1) Answ ring and rechecking the survey questions; (2) performing the assigned exercises; (3) checking with the teacher your scores on the various tests and doing over those that you missed; and finally (4) making an outline of the unit for your notebook.

\section{Tests on Fundamental Concepts}

In a vertical column under the heading CORRECT write numbers of all statements you believe are true. In another column under INCORRECT write numbers of untrue statements. Your grade $=$ number of right answers $\times 4$.

I. The digestive tract of man (1) is a straight.tube extending from the mouth to the anus; (2) is the structure including the glands through which food passes; (3) consists of the diaphragm, blood, and muscles ; (4) may be compared, part by part, with that of the frog; (5) consists of the mouth (including teeth), pharynx, gullet, stomach, and small and large intestines.

II. A gland (6) is a collection of cells which secrete substances which are of use to the body; (7) found in the stomach secretes saliva; (8) found emptying into the small intestine is called the pancreas; (9) does its work by means of enzymes contained in its secretion; (10) of digestion is controlled by the nerves.

III. Digestion (11) is necessary in order to change solid food into a soluble form; (12) is brought about by enzymes; (13) is principally brought about in the large intestine; (14) of fats takes place in the small intestines; (15) of starches takes place chiefly in the stomach.

IV. The teeth (16) are composed chiefly of dentine; (17) are of no value in preparing food for digestion; (18) are divided into four groups on a basis of structure; (19) should be brushed frequently with a gritty powder; (20) if allowed to decay, can make serious trouble through focal infection at the base of the root.

V. Absorption of food (21) is necessary if the cells are to get nourishment; (22) takes place largely in the stomach ; (23) is brought about by the villi ; (24) takes place largely by osmosis through the cells of the villi; (25) is not necessary unless we are growing, for our cells do not need food for other purposes.

\section{Achievement Test}

1. How would you make a comparison of the digestive tract of the frog and of man and what are the parts with the functions of each? 
2. How would you perform an experiment to show how digestion takes place, and what changes it brings about?

3. What are the functions of each group of teeth? Are your teeth in good condition? Have you had them looked over within six months? Do you brush them twice daily in the approved manner?

4. How do you keep from having indigestion?

\section{Practical Problems}

Fill out the following Table :

\begin{tabular}{|c|c|c|c|c|c|c|}
\hline Glands & Location & JUICE & $\begin{array}{l}\text { ENZYMES OR OR } \\
\text { FERMENTS }\end{array}$ & Action of & $\begin{array}{l}\text { RESULT of } \\
\text { ITS ACtION }\end{array}$ & $\begin{array}{l}\text { How TEST } \\
\text { FOR ACTION }\end{array}$ \\
\hline & & & & & & \\
\hline & & & & & & \\
\hline & & & & & & \\
\hline & & & & & & \\
\hline & & & & & & \\
\hline & & & & & & \\
\hline & & & & & & \\
\hline
\end{tabular}

\section{USEFul REFERENCES}

Burton-Opitz, Physiology. (W. B. Saunders Co.)

Harrow, Glands in Health and Disease. (E. P. Dutton \& Co.)

Hunter, Laboratory Problems in Civic Biology. (American Book Company.)

Schafer, The Endocrine Organs. (Longmans, Green \& Co.)

Starling, Principles of Human Physiology. (Lea \& Febiger.)

Wheat and Fitzpatrick, Advanced Biology. (American Book Co.)

Williams, Anatomy and Physiology. (W. B. Saunders Co.) 


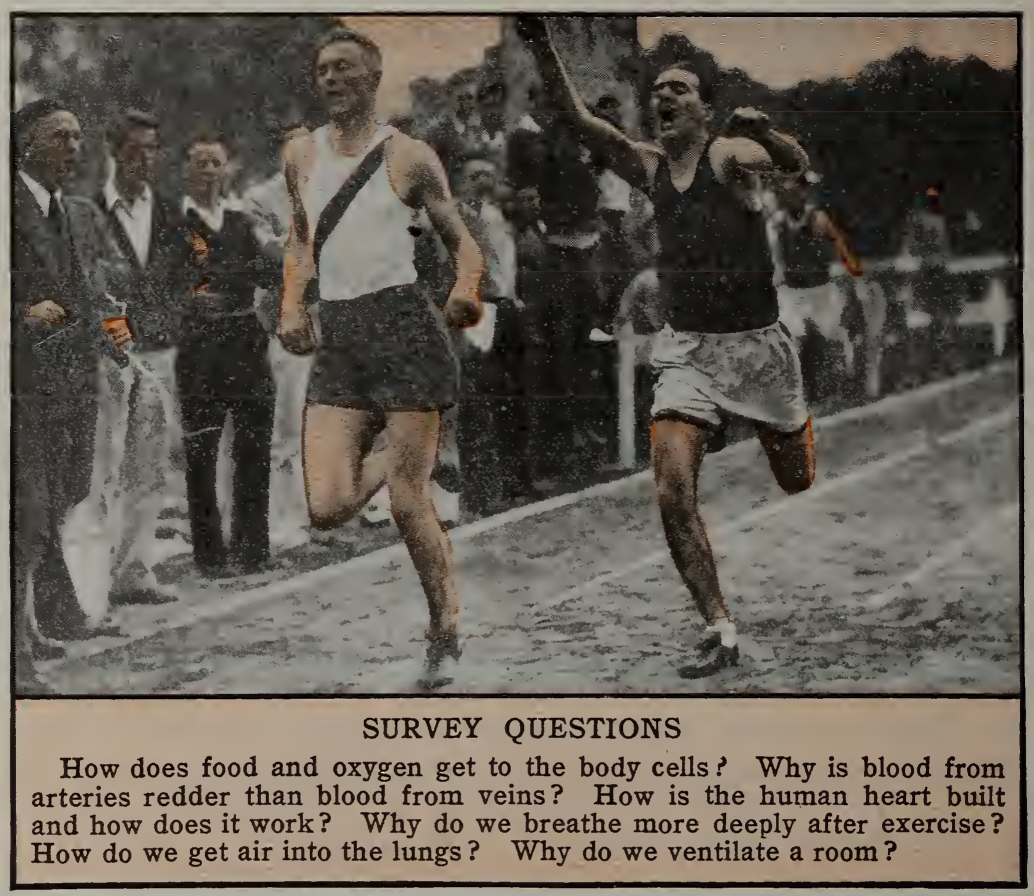

UNIT XIII

\section{HOW ARE FOODS CIRCULATED AND USED IN THE BODY?}

Preview. As we have thought of the digestive system as a chemical laboratory, so we might think of the blood as a moving chemical workshop. Not only is the blood the carrier of food from the food tube to the cells of the body, but it also takes away the waste products from these same cells to those parts of the body that can expel them. It transports oxygen to the cells where oxidation takes place, and carries away the waste products of this oxidation. It conducts heat to all parts of the body, thus keeping the iemperature even. The white corpuscles in the blood act as sanitary police, standing guard at all times to protect the 
body in case of infection. The blood also contains substances, antibodies, which help combat any disease germs entering the body.

The blood circulates through the body by means of a network of tubes and is controlled by the heart. Imagine a pump so built that it is self-regulating, so strong that it works day and night without rest, so powerful that it lifts several tons of weight the height of the body every day, year in and year out. Such is the human heart. Although the two sides of the heart are separate and distinct from each other, yet every drop of blood that passes through the right side of the heart also passes through the left side. It requires from twenty to thirty seconds for the blood to make a complete circuit from the ventricle back again to the starting point. This means that the entire volume of blood in the human body passes through the various organs of the body three or four thousand times a day.

One of the uses of the blood in its capacity as a carrier is to transport certain chemical activating substances known as hormones. There are a good many such substances, the chief of which are manufactured by certain glands known collectively as the endocrines. These structures, of which the thyroid gland is a well-known example, have no ducts or connections with the food tube or other organs. Consequently their secretions can get out only through the medium of the blood stream. The blood distributes the hormones to the body cells, where they cause very great changes to take place through their chemical actions.

Most of us have had the experience of chopping down a tree, of digging a deep hole, or of lifting a heavy rock. In a very short time we notice that we breathe more quickly and deeply, that we get hot and perspire, and that after a time we become fatigued. What does this sequence of events mean? Evidently we can go back to our old analogy of the engine. To do more work we make a hotter fire, to get a hotter fire we increase the amount of oxygen that gets to the fire by regulating the draft. And we know, too, that if we are to keep up the fire, we must remove the ashes and other wastes frequently. A very similar condition exists in the human body. We have learned that plants and animals need oxygen in order to release energy, just as coal is burned to give 
heat to run an engine. As a draft of air is required to make a fire under the boiler, so, in the human body, plenty of oxygen must be given to the tissues so that food may be oxidized there, releasing energy for work and forming the wastes, carbon dioxide, water, and urea (nitrogen product). This oxidation takes place in all the cells of the body, be they portions of a muscle, a gland, or the brain. Here again the blood plays its part, for it carries the oxygen to the cells and takes away the waste products to be excreted either through the skin or the kidneys. The smooth running of this body machine of ours is only continued because of the exchanges of food and wastes made possible by means of this wonderful system of tubes and pumps which makes up the circulatory system.

\section{PROBLEM I. WHAT IS THE COMPOSITION AND WHAT ARE} THE USES OF THE PARTS OF THE BLOOD?

Composition of the blood. We learned in a former unit that the chief function of the digestive organs is to change foods so that they can pass into the blood. The chemical composition of the blood is very complex and varies in different parts of the body. The fluid part is the plasma, which consists of about 90 per cent water and the various organic food substances, digested sugars, fats, amino acids, mineral salts, and numerous other substances, among which are enzymes and hormones. The blood also holds three kinds of bodies: the red corpuscles, the white corpuscles, and the blood platelets.

Laboratory Exercise. To study the corpuscles of the blood. Place a drop of frog's blood on a glass slide. Cover and examine under a compound microscope. What are the color and shape of the corpuscles that are most numerous and most easily seen? What are the other irregular-shaped corpuscles, more transparent and not so easily seen? Are corpuscles cells? Can you prove your statement?

Using a slide containing a drop of your own blood, note that red corpuscles have no nucleus. Are they cells? Do you find colorless corpuscles as well? How do they compare with the red in number? Compare the structure of blood corpuscles in man with those of a frog.

So small and so numerous are the red corpuscles that about five million of them are found in a cubic millimeter of normal blood. 
Their red color is due to an iron-protein combination called haemoglobin. Haemoglobin will combine chemically with oxygen, forming a bright red compound called oxyhaemoglobin. In the parts of the body where oxiration is going on, the haemoglobin gives up its oxygen sup. ply. At the same

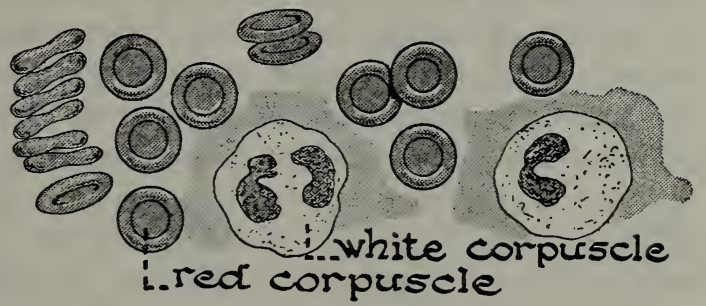

Are the red corpuscles cells? Explain. time the plasma takes up the carbon dioxide which is given off by the cells. The result of this interchange of gases causes a change in the color of the blood from a dull to a bright red.

The colorless corpuscles, of which several kinds are found in the blood, are irregular in outline, as they constantly change their

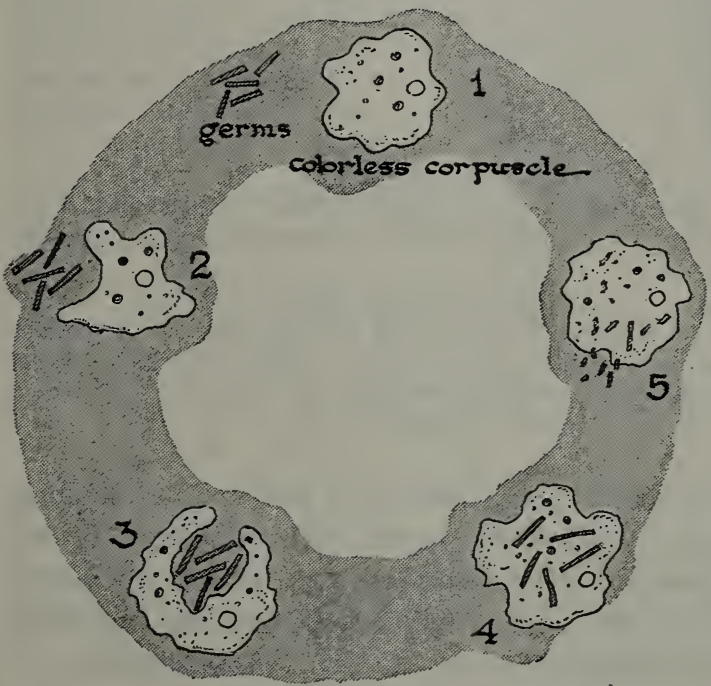

When germs or any foreign organisms enter the body, the colorless corpuscles, phagocytes, accumulate and either ingest the germs directly or with the aid of certain substances, opsonins, destroy them. form. The colorless corpuscles are less numerous than the red, the ratio being about 1 to 700 in a normal person. They increase in number during certain diseases. They have the power of movement, for they are found not only inside but also outside the blood vessels, showing that they have worked their way between the cells that form the walls 


\section{FOODS CIRCULATED AND USED IN THE BODY}

of the blood tubes. Like the amoeba, the colorless corpuscles feed by engulfing their prey. This fact has a very important bearing on the relation of the corpuscles to certain diseases caused by bacteria within the body. If, for example, bacteria get into a wound, colorless corpuscles, called phagocytes (făg' ${ }^{\prime}$-sìt), at once surround the spot and attack the bacteria which cause the inflammation. The blood contains certain antibodies called opsonins (ŏp'sö-ninn), which, when present, enable the corpuscles to engulf and digest the bacteria. If the bacteria are few in number, they are quickly destroyed. If bacteria are present in great quantities, they may prevail and kill the phagocytes. The dead bodies of the phagocytes thus killed and the destroyed tissue help form pus which also contains many dead and living bacteria. When such an infection occurs, we must come to the aid of the colorless corpuscles by washing the wound with an antiseptic.

Laboratory Exercise. What causes blood to clot? Wash your finger thoroughly with soap and water. Holding the finger down, prick it with a sterilized needle. Draw off three drops of blood, placing each drop on a clean microscopic slide. Place the first slide at once on ice. To the second add a drop of 5 per cent sodium oxalate solution. Leave the third drop exposed to the air of the room. At intervals of one minute draw a clean hair through each drop.

Note how long it takes the third drop of blood to clot. Compare this drop with the drop on ice and the drop to which the sodium oxalate was added.

Laboratory Exercise. Let fresh beef blood stand over night. What happens? Whip fresh beef blood briskly with an egg beater. A stringy almost colorless substance will stick to the beater. This, if washed carefully and tested with nitric acid and ammonia, is found to contain a protein substance. It is called fibrin (fín'brun).

In blood within the circulatory system of the body, the fibrin is held in a fluid state called fibrinogen (fî-brǐn'o-jĕn). Blood plasma, then, is made up of a thin liquid, serum, and of fibrinogen which coagulates under certain conditions, entangling the blood corpuscles in a network of fine threads, thus forming the clot.

The clotting of blood is of great physiological importance, for otherwise we might bleed to death even from a small wound. A substance called thrombin is the active agent in changing fibrin- 
ogen to the insoluble fibrin of a clot. This change seems to be due largely to the action of minute bodies in the blood known as blood platelets. Under abnormal conditions these blood platelets break down, releasing some substances which (if the blood has the necessary content of calcium) cause the thrombin to do its work.

Relation of lymph to the blood. The tissues and organs of the body are interlaced by a network of tubes which carry the blood. Outside the blood tubes, in spaces between the tissue cells, is another fluid, much like plasma of the blood. This is the lymph. It is a colorless or yellowish liquid in which some colorless corpuscles, or leucocytes, are found. The lymph bathes all portions of the body not reached by the blood. It acts as the medium of exchange between the blood proper and the cells in the

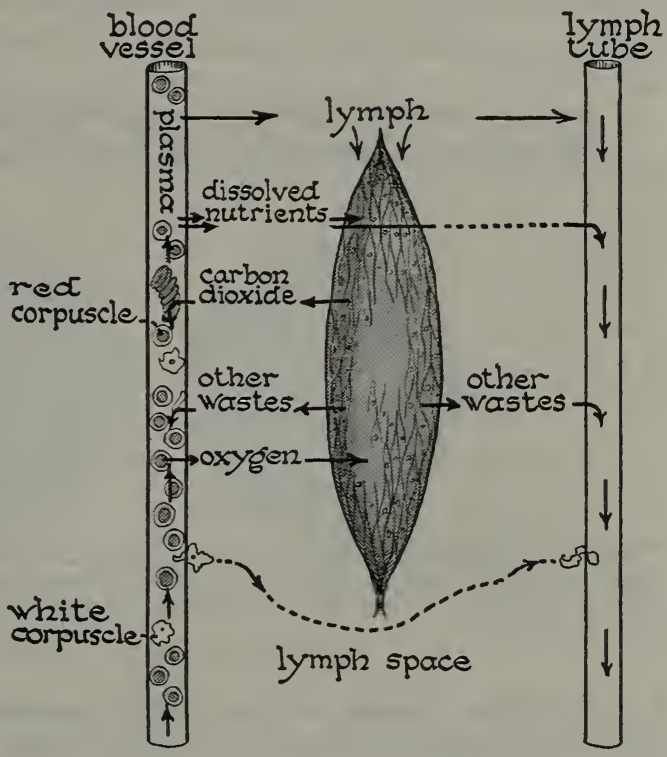
tissues of the body. The relation of cells to the blood. Explain exactly what By means of the happens in the muscle (shown in the center of the diagram) food supply thus

brought, the cells of the body are able to grow, the fluid food being changed to the protoplasm of the cells. By means of the oxygen brought by the red blood corpuscles and passed over through the lymph, oxidation may take place within the cells. Lymph not only gives food to the cells of the body, but also takes away carbon dioxide and other waste materials, which are ultimately passed out of the body by means of the lungs, skin, and kidneys.

$$
\text { н. В1О }-26
$$


Disease-resisting functions of the plasma. It is common knowledge that some of us "take" catching or communicable diseases more easily than others. Some fortunate persons are immune to certain diseases, that is, they do not take them, because certain antibodies are present in their blood. These antibodies act in different ways, but their work is directed against bacteria which get into the body and cause disease. Some antibodies, called lysins, have the power to dissolve bacteria. Others, called agglutinins, cause the bacteria in the blood to clump together in

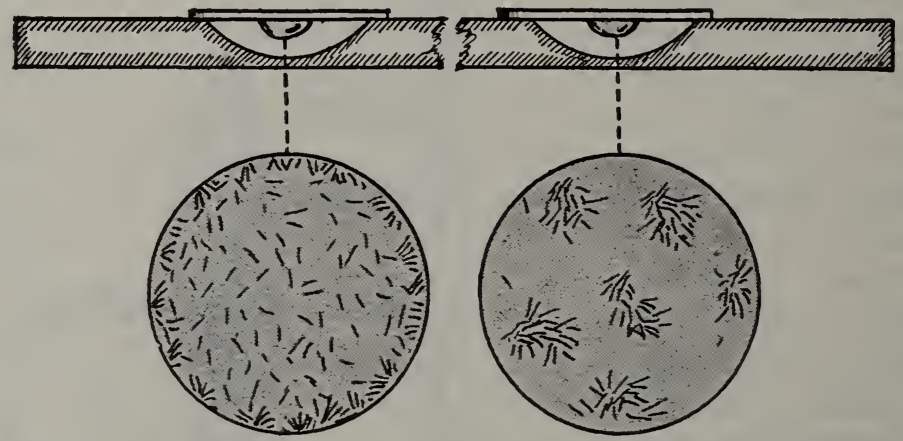

The diagram on the left shows free swimming typhoid bacteria. The diagram on the right shows the bacteria clumped together by agglutinins which are produced by the body cells as a protective measure. The bacteria are stationary and can be more easily destroyed by the white corpuscles.

little inactive masses, so that they are an easy prey for the phagocytes and lysins. We have already heard of the work of the opsonins, another kind of antibody. Agglutinins and certain other antibodies called precipitins, which precipitate the bacteria from solution, have become a great help to physicians in determining whether a person has a given disease. For example, a test known as the Widal (vè-däl') test is now used in all hospitals to determine if a person has typhoid fever. A few drops of blood from the patient is allowed to stand until the serum has separated. 'This is then diluted with a weak salt solution and to this are added some living typhoid bacteria. If the person has typhoid, the bacteria added to his serum will immediately become clumped together or agglutinated, thus showing that his antibodies are 
already formed and at work. This is only one of a number of tests that have been developed in recent years. Just as each disease is caused by a specific kind of organism, producing a specific kind of toxin or poison, so the blood forms specific antibodies to fight each kind of organism or its toxins.

Blood transfusion. It has been found that there are four types of human blood. About 50 per cent of all people have one type. After heavy losses of blood as in an accident or in an operation, and in some illnesses, blood is sometimes injected into a vein of the patient by transfusion from an artery of a donor. Before this operation is performed, it is necessary to make a test to see if the two persons have blood of the same type. This is done by means of the agglutinin test. Red corpuscles of the person who is to give the blood are added to the blood of the patient. If the red corpuscles are agglutinated, then the bloods are of two different types and transfusion cannot be made. Certain lysins called haemolysins may also be present in blood that will dissolve foreign red corpuscles of the volunteer in the blood of the patient. Tests may be made for these haemolysins by adding washed red corpuscles of the volunteer's blood to the serum of the patient's blood. If the corpuscles are dissolved, this blood cannot be used for transfusion.

\section{Self-Testing Exercise}

Blood consists of a fluid part called ........(1) and three kinds of cells : ........ (2) corpuscles, (3) corpuscles and ........ (4)

(5). Red corpuscles take up ........(6) by means of the (7) they contain. There are several kinds of .......(8) corpuscles, all of which are ......(9) in outline and have the power of .......(10). Those called .......(11) feed on bacteria in the blood. Blood clots because of the coagulation of the . (12) it contains. This is brought about through the action of the substance ....... (13). Plasma besides containing ........(14) contains antibodies. Among these are .......(15) , .......(16), and ....... (17). Lymph acts as a medium of exchange between the ........(18) and the .......(19) cells. Blood transfusions can be performed only if persons have blood of the same .......(20). This can be found out by means of (21). 
PROBLEM II. WHAT ARE THE FUNCTIONS OF SOME OF THE ENDOCRINE GLANDS?

The endocrine or ductless glands and their secretions. In addition to all the functions already mentioned, the blood has

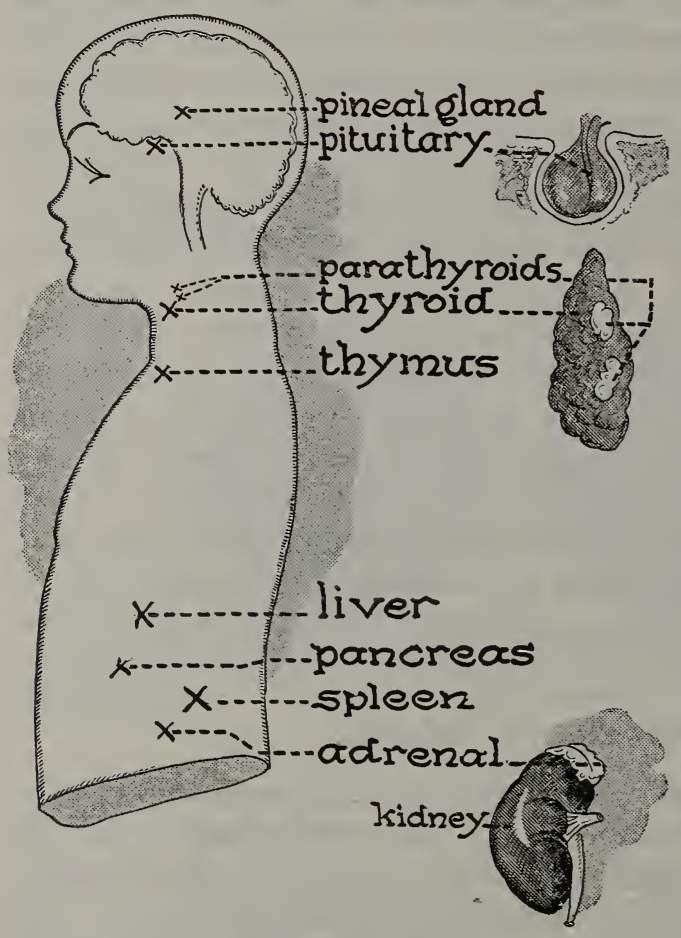

The approximate positions of the endocrine glands are indicated in the diagram.

another very wonderful work. We have already mentioned the hormones (from the Greek word hormon, meaning "to excite"). These chemical activators, produced by the endocrine or ductless glands in various parts of the body, go into the blood stream, and stimulate another organ or organs in the body. The blood is the only means of communication between these glands and the tissues on which their hormones act. Scientists are just beginning to appreciate the tremendous influence on

life of some of these glands, among which are the thyroid and parathyroid, small glands located in the neck; the adrenals (ăd-rē'năl), tiny glands, closely attached to the kidneys; the pituitary body, at the base of the brain; parts of the pancreas; and parts of the egg-producing and sperm-producing organs, the ovaries and testes. The thymus and spleen, although not true glands, are often included with those mentioned above. 
The thyroid. It has been found that undersecretion of the thyroid gland is responsible for the condition known as cretinism, ${ }^{1}$ and that this condition can be improved and frequently completely cured by supplying the patient with thyroid secretion, usually by feeding with thyroid extract. Overactivity of this gland produces exophthalmic ${ }^{2}$ goiter, a condition of extreme nervousness, with loss of weight and other symptoms, such as protruding eyeballs and irregular heart action.

In some parts of the country where the water supply comes from mountain sources many people are troubled with a slight enlargement of the thyroid gland. This trouble comes from a lack of iodine in the water supply. This iodine deficiency in the water can usually be corrected by eating foods rich in iodine, such as sea foods and certain vegetables, or by putting iodine in the drinking water.

The adrenal glands. The adrenal glands produce a secretion, adrenin, which acts upon the muscles and the nervous system. It causes a faster beating of the heart, a heightened blood pressure, and other indications of increased muscular activity. It is indeed the emergency hormone of the body. It is this hormone that enables the sprinter to make his final burst of speed at the tape, or the football player to make a desperate stand when almost exhausted. It explains the " strength of desperation." Adrenin has been prepared in the laboratory and is known commercially as adrenaline (ăd-rē'năl-l̆n). It is used in medicine to contract the blood vessels, hasten the clotting of blood, and to strengthen the heart beat.

The pituitary and thymus glands. The pituitary gland has much to do with body size. Dwarfs appear to lack or have very small pituitary glands, while giants always have abnormally large ones. Dr. Harvey Cushing of the Harvard Medical School, who is an authority on the work of the pituitary body, says: "The Lewis Carroll of today would have Alice nibble from a pituitary mushroom in her left hand and a lutein (a pigment obtained from a

1 Cretinism (krē'tǐn-ǐzm) : idiocy accompanied by physical deformity.

2 Exophthalmic (ek'sŏf-thăl'mı̌k) : pertaining to a disease causing protrusion of eyeballs. 


\section{FOODS CIRCULATED AND USED IN THE BODY}

portion of the ovary) in her right hand and presto! she is any height desired."

The thymus, a little understood structure found near the thyroid gland, gradually disappears as we grow past adolescence.

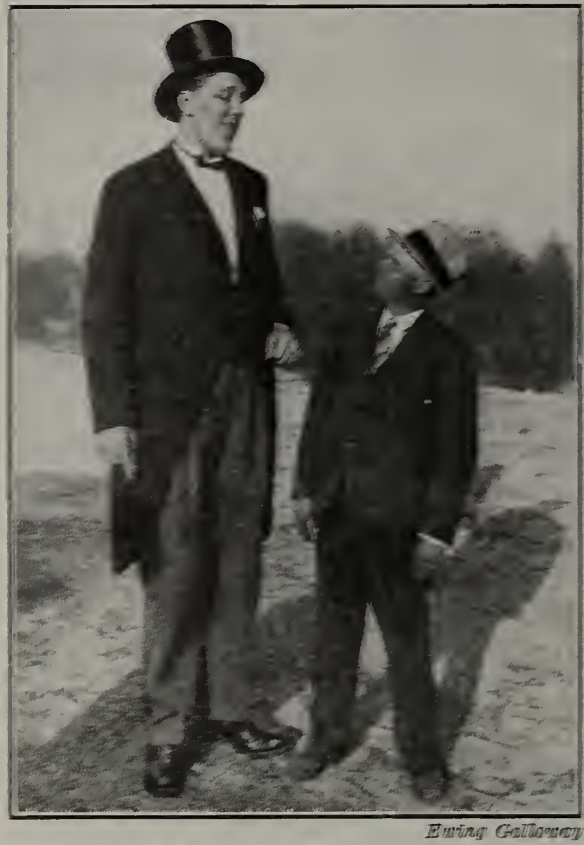

A gian 8 feet $9 t$ inches tall and a normal man 5 feet 6 inches tall. What do scientists consider the cause of tunusually large or small people?
It seems to have some influence on the sex glands and on the lime content of bone.

The reproductive glands. Some part of the ovaries and testes have long been known to control the development of the so-called secondary sex characteristics which give us the difference in appearance between females and males. It is not too much to say that hormones are responsible for many sex characteristics, as experiments with fowls and other animals have proved. But popularstatements on the effect of grafting these glands from other animals in human beings are greatly exaggerated and can be for the most part disbelieved.

The pancreas and liver. It has been known for many years that the pancreas produces another secretion besides that which passes into the digestive tract. But investigators have now discovered that this internal secretion, with its hormone, is produced in groups of cells known as the Islands of Langerhars (lāng'èr-hāns) in the pancreas. If this hormone is not present, then sugar, which normally is stored in the liver as glycogen, is allowed to go directly into the blood, where it soon appears in excessive quantities, 
causing a disease called diabetes (dī- $\dot{a}-\mathrm{be}^{-}$tēz). Work by Dr. Banting and his co-workers of Toronto University has resulted in the production of the substance insulin, which contains the hormone. Now a person whose pancreas has lost the power to regulate the storage of glycogen in the liver may find relief through a proper diet and insulin in prescribed doses.

Practical Exercise 1. Make a report on some one of the endocrine glands. Use Harrow's Glands in Health and Disease or articles from Hygeia.

Practical Exercise 2. Statistics show that diabetes is increasing rapidly in this country in spite of insulin. The reason given is the rich and heary diet. What recommendations would you make for betterment of this condition?

\section{Sflf-Testing Exercise}

Hormones are chemical ........ (1) and are produced by ....... (2) glands. Underdevelopment of the thyroid causes cretinism, overactivity causes $\ldots \ldots \ldots$ (3) $\ldots \ldots$ (t). The produce the emergency hormone. The .......(6) gland seems to regulate body size. The pancreas produces a hormone which regulates the storage of $\ldots \ldots \ldots(7)$ in the liver. If sugar goes directly into the blood, we have ........(\$) and must use ........(9).

\section{PROBLEM III. HOW DOES THE BLOOD CIRCULATE THROUGH THE BODY?}

Circulation of the blood. The blood is the carrying agent of the body. Like a railroad system, it takes materials from one part of the human organism to another. This it does by means of the organs of circulation, - the heart and blood ressels. These blood vessels are of three kinds: the arteries, elastic muscular tubes, which carry blood away from the heart; the reins, thinwalled vessels containing valves which bring the blood back to the heart; and the capillaries, which connect the smallest arteries with the smallest veins. The organs of circulation thus form a system of connected tubes through which the blood flows.

Demonstration 1. What is the structure of the heart? Refer to the diagram of the heart, with the arteries and reins connected with it. Where do the chief arteries lead to and from where do the large veins come? Obtain the heart of a recently killed steer and examine it, noting the four chambers, the valves, and the blood tubes leading to and 


\section{FOODS CIRCULATED AND USED IN THE BODY}

from it. The upper chambers are called the right and left auricles respectively; the lower chambers, the right and left ventricles. Which have the thicker walls? What is probably the use of these walls?

Notice the position of the valves and the direction of their movement. In what direction do arteries lead? Veins?

Do the chambers all connect with one another? Write a paragraph describing the structure of the heart.

The structure of the heart. The heart is a cone-shaped muscular organ about the size of the fist. It is surrounded by a loose

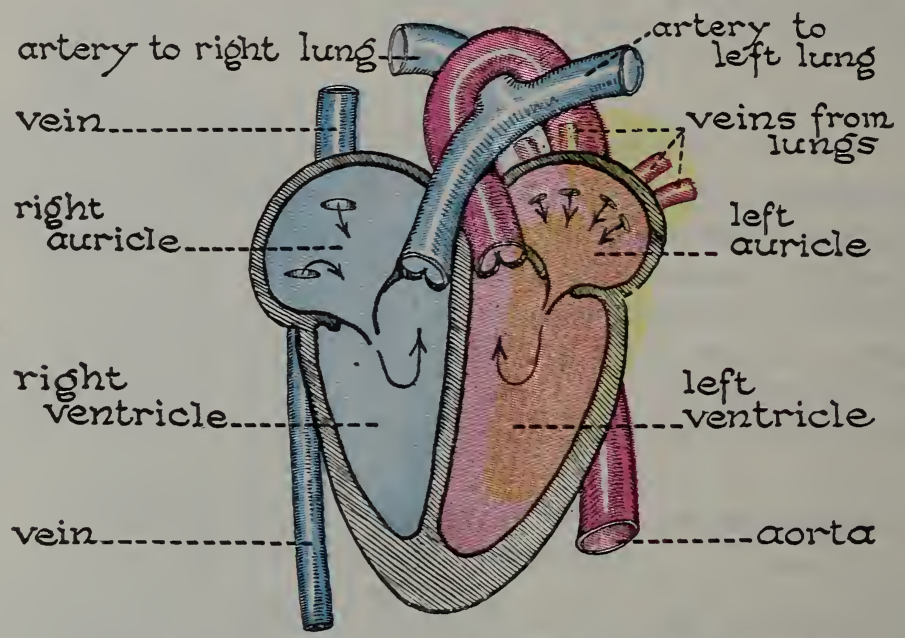

How does the blood get from the left ventricle to the right ventricle?

membranous bag called the pericardium, the inner lining of which secretes a fluid in which the heart lies. If we should cut open the heart of a mammal down the midline, we could divide it into a right and a left side, each of which has within the heart no connection with the other side.

Practical Exercise 3. To make an apparatus that will demonstrate the fact that the heart is a double force pump.

The heart in action. The heart is constructed on the same plan as a force pump, the valves preventing the reflux of blood into the auricles when it is forced out of the ventricles. Blood enters the auricles from the veins because the muscles of that part of the heart relax; this allows the space within the auricles to 
fi!l. Almost immediately the muscles of the ventricles relax, thus allowing blood to pass into the chambers within the ventricles. Then, after a short pause, during which time the muscles of the heart are resting, a wave of muscular contraction begins in the auricles and ends in the ventricles, with a sudden strong contraction which forces the blood out into the arteries. Blood is kept from flowing backward by the valves, which act in the same manner as do the valves in a pump. The blood is thus made to pass into the arteries upon the contraction of the ventricle walls.

Practical Exercise 4. Why is the heart a force pump? Why is the heart said to be double?

The course of the blood in the body. There are two distinct systems of circulation in the body. The pulmonary circulation
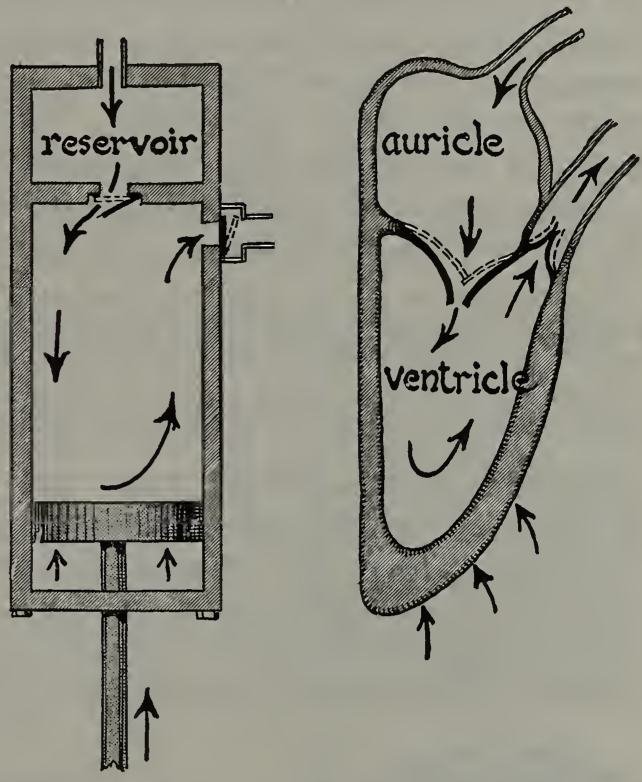

Explain how the heart is a force pump. takes the blood through the right auricle and ventricle, to the lungs, and passes it back to the left auricle. This is a relatively short circulation, in which the blood receives oxygen in the lungs and gives up carbon dioxide. The longer circulation is known as the systemic circulation; in this system, the blood leaves the left ventricle through the great dorsal artery called the aorta. Through ever-branching arteries blood passes to the muscles, the nervous system, kidneys, skin, and other organs of the body. It gives up food and oxygen in these tissues, receives the waste products of oxidation while passing through the microscopic tubes, capillaries, and returns to the right auricle through veins which join 
and increase in size until they form two large vessels known as the venae cavae.

Portal circulation. Some of the blood, on its way to the heart, passes to the walls of the food tube and to its glands. From these parts it is sent with its load of absorbed food to the liver. Here the vein which carries the blood (called the portal vein) breaks up into capillaries around the cells of the liver, which takes out the excess sugar and stores it as glycogen. From the liver, the blood passes directly to the right auricle. The portal circulation connects the stomach and the small intestine with the liver. It is the only part of the circulatory system where the blood passes through two sets of capillaries on its way from auricle to auricle.

Demonstration 2. To show circulation in the web of a frog's foot. Examine under a compound microscope the web of the foot of a living frog. Note the network of tiny blood vessels, capillaries. Those vessels in which the blood moves in spurts are tiny arterioles; the larger vessels in which the blood moves slowly or steadily are veins.

Structure of the arteries, veins, and capillaries. A distinct difference in structure exists between the arteries and the veins in the human body. The arteries, because of the greater strain received from the blood which is pumped from the heart, have thicker muscular walls, and in addition are very elastic. Veins are much thinner-walled than arteries and have small valves which

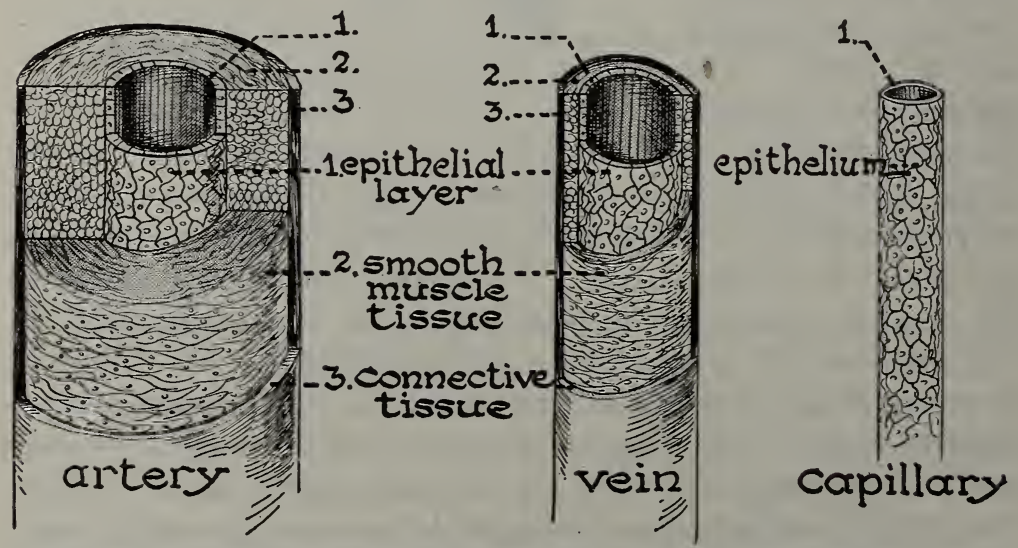

Explain the difference between an artery, a vein, and a capillary. 
open in the direction of the blood flow. Capillaries are a network of very thin-walled vessels through which food, oxygen, and colorless corpuscles pass out to the tissues.

The pulse and blood pressure. The pulse is caused by the contraction of the ventricle which causes a wave of distention to travel along the blood vessel. This pulse can easily be felt in the larger arteries that are near the surface of the body. As the blood is forced from the heart into the arteries it comes under pressure caused by the resistance given to the flow of blood by the small capillaries. Thus a definite blood pressure is caused, which is seen when we cut an artery. Blood pressure can easily be measured by an instrument called the sphygmomanometer.

Practical Exercise 5. Visit a physician and have him explain what happens when he takes your blood pressure, and the significance of what he finds.

Lymph vessels. The lymph is collected from the various tissues of the body by ducts provided, like the veins, with valves. The pressure of the blood within the blood vessels continually forces more plasma into the lymph; thus a slow current is maintained from the lymph spaces into lymph tubes. On its course the lymph passes through many lymph glands, where impurities appear to be removed. The lymph ultimately passes into a large tube, the thoracic (tho-răs' 1 k) duct, and empties into the blood stream in the neck region.
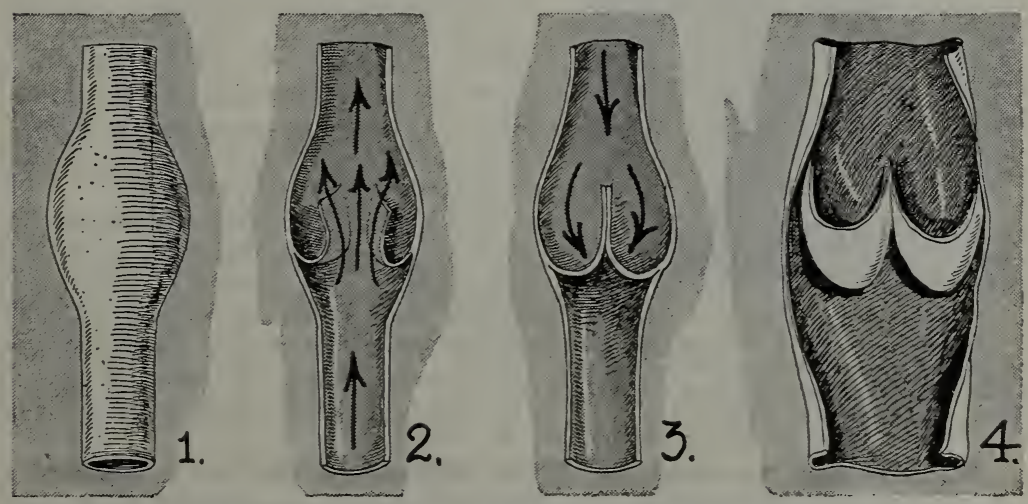

Explain, with reference to your text, why it is that blood flows in one direction in the veins. 
The lacteals. We have already learned that part of the digested food (chiefly sugars, amino acids, salts, and water) is absorbed

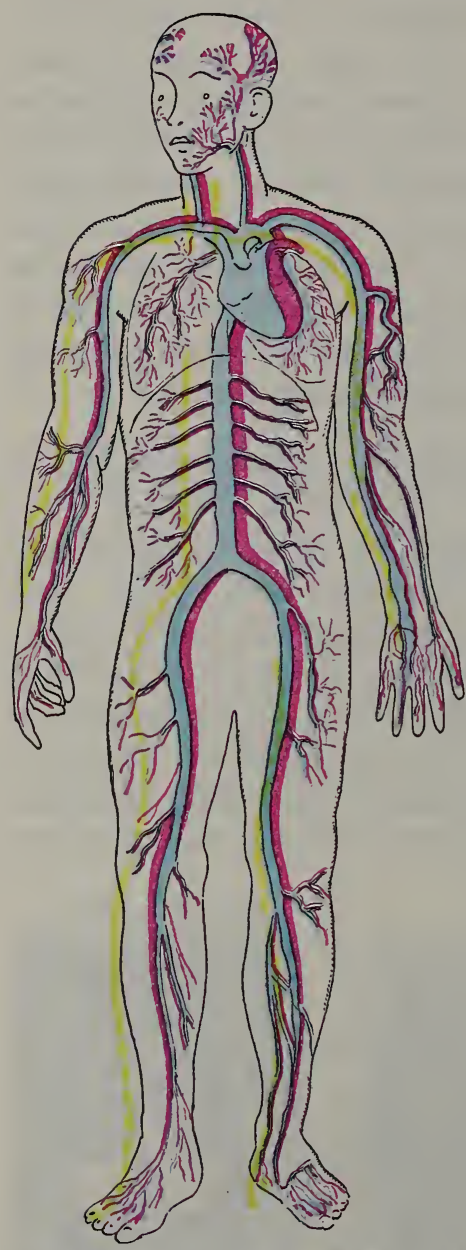

Diagram of the circulatory system. The vessels containing arterial blood are red, those containing venous blood are blue, and the lymphatics are yellow. directly into the blood through the walls of the villi and carried to the liver. Fat, however, is passed into the spaces in the central part of the villus known as the lacteals. This fluid or lymph then passes from the lacteals into other lymphatics, and eventually drains into the blood system by way of the thoracic duct. Shortly after a meal the lacteals are filled with a white fatty substance, but at other times they are filled with a fluid very similar to the lymph in the other lymphatics.

Laboratory Exercise. What is the effect of exercise on the heartbeat?

Place the middle finger of the right hand two inches from the ball of the thumb, to locate the pulse. Count the number of beats per minute. The normal rate in men is seventy-two beats per minute; in women, seventysix. It is higher in children.

Then under the direction of a leader, take a hard setting-up drill for three minutes with the windows open. Count the pulse beats as before and tabulate the result. Note any difference in respiration.

What effect did the exercise have on the rate of the heartbeat? Can you explain the reason?. Can you explain the difference in the rate of respiration? Show in your table the difference between the normal pulse and the one taken after exercising.

The effect of exercise on the circulation. Exercise in moderation is of undoubted value, because it sends more blood to parts 
of the body where increased oxidation is taking place as the result of the exercise. The best forms of exercise are those which give work to as many muscles as possible - walking, out-of-door sports, any exercise that is not violent. Exercise should not be attempted immediately after eating, as this causes a withdrawal of blood from the digestive tract to the muscles of the body. Neither should exercise be continued after becoming tired, as poisons are then formed in the muscles, which cause the feeling we call fatigue. Overdoing in any sport or game is dangerous. Fatigue is a signal to rest. Remember that extra work given to the heart by extreme exercise may injure it, causing possible trouble with the valves. Older people and those who through excessive use of stimulants or tobacco or other causes have developed anteriosclerosis, ${ }^{1}$ hardening of the arteries, need to be especially careful. "A man is as young as his arteries," because the hardening of the wall raises the blood pressure, and if the inelastic artery wall breaks, due to overexercise, death may result through apoplexy.

Treatment of cuts and bruises. Blood which oozes slowly from a cut will usually stop flowing by the natural means of the formation of a clot. A cut or bruise should, however, be washed in a weak solution of lysol or some other antiseptic in order to prevent bacteria from obtaining a foothold on the exposed flesh. If blood gushes from a wound, in distinct pulsations, an artery has been severed. A tight bandage known as a tourniquet (tōr'nĭ-kět)

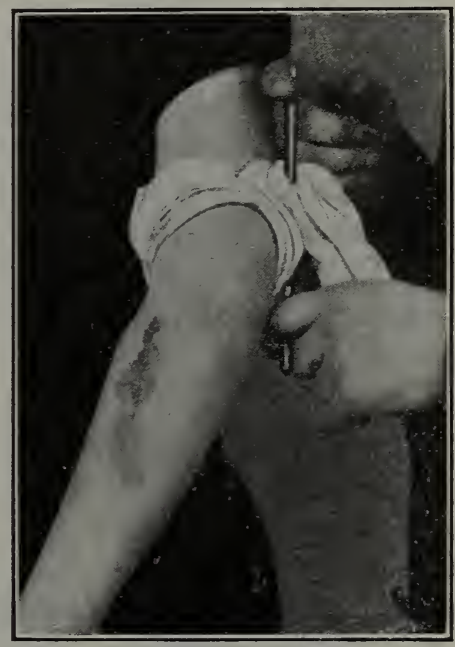

What kind of blood vessel has been cut? must be tied between the cut and the heart. If a vein is cut, the blood flows smoothly. In this case, a tourniquet is applied on the side of the cut away from the heart.

1 Arteriosclerosis : är-tē'rĭ-ö-sklè-rō'sls. 


\section{FOODS CIRCULATED AND USED IN THE BODY}

Laboratory Exercise. What methods should be used to stop the flow of blood in case of an accident? Decide first whether the blood is issuing from an artery or from a vein. How would you know? Then apply a tourniquet made from a stick or ruler and a handkerchief or towel, using a stone or knife to press down on the blood vessel.

Imagine an artery severed in the arm below the elbow and practice applying a tourniquet there. Apply a tourniquet, if the artery cut is above elbow. Does the pulse in the wrist stop when the tourniquet is applied? Explain reason.

Conclusion. How would you make a tourniquet? Describe fully. Where must a tourniquet be placed when an artery is cut? Where when a vein is severed? What is the use of the tourniquet?

The effect of alcohol upon the blood. Alcohol, when taken habitually, causes several very serious effects upon the blood and blood vessels. The bodily resistance against disease which is brought about by the presence of specific antibodies is greatly weakened in those who use alcohol to excess. Drinking also has an injurious effect upon the colorless corpuscles, as it lowers their ability to fight disease germs. Place a drop of alcohol on a slide containing active amoebas, if you wish to see the effect on a similar type of cell. Alcohol acts on the nerve centers controlling the heart and blood vessels. Alcohol may even, in cases of long and severe drinking, cause changes to take place in the walls of the blood vessels which may result in the breaking of the vessel or the formation of a blood clot in the vessel. Such an injury in blood vessels in the brain causes apoplexy and often results in sudden death.

\section{Self-Testing Exercise}

The circulation of the blood is brought about by a heart which acts as a ................ (2). Blood passes out from the heart through ....... (3), then into the tissues by means of the ....... (4), returning to the heart again by way of the ....... (5). There are two important systems of circulation in the body: the ....... (6) to and from the lungs, and the .......(7) which leaves the heart from the .......(8) ventricle and passes out to all the body organs. Arteries are ......(9) and ......(10), capillaries are very $\ldots \ldots$ (11), and veins have ....... (12) walls and have ...... (13) to keep the blood from running backward. The pulse is caused by the gushing of blood from the .......(11), when the walls of the 
. (15) contracts. Blood pressure is caused by the ....... (16) of the tiny $\ldots \ldots \ldots$ (17) against the blood forced from the $\ldots \ldots \ldots$ (18).

\section{PROBLEM IV. WHAT IS RESPIRATION?}

Laboratory Exercise. A comparison of the respiratory tract of a frog and a mammal. Open a frog's mouth and find the slitlike opening (glottis) just back of the tongue. Insert a blowpipe or a glass tube and blow down the short windpipe (trachea) which branches into two divisions leading to the lungs (bronchial tubes). What happens to the lungs?

Examine a section cut through a frog's lung. Is it hollow? Now compare the baglike lungs of the frog with the more complicated lungs of man (see diagram). Do you find the same structures leading to the lungs of man? (Read your text.) Which part of the lungs of man would be elastic? Which part of the frog's? Why?

If blood vessels were found in the walls of these sacs, what gas might be brought in the blood to this point? What gas might be in the air? How might the exchange of these gases take place? Where might it take place?

The organs of respiration in man. We have noted the fact that the lungs are the organs which give oxygen to the blood and take from it carbon dioxide. Air passes through the nostrils into the windpipe. This cartilaginous tube, the top of which may easily be felt

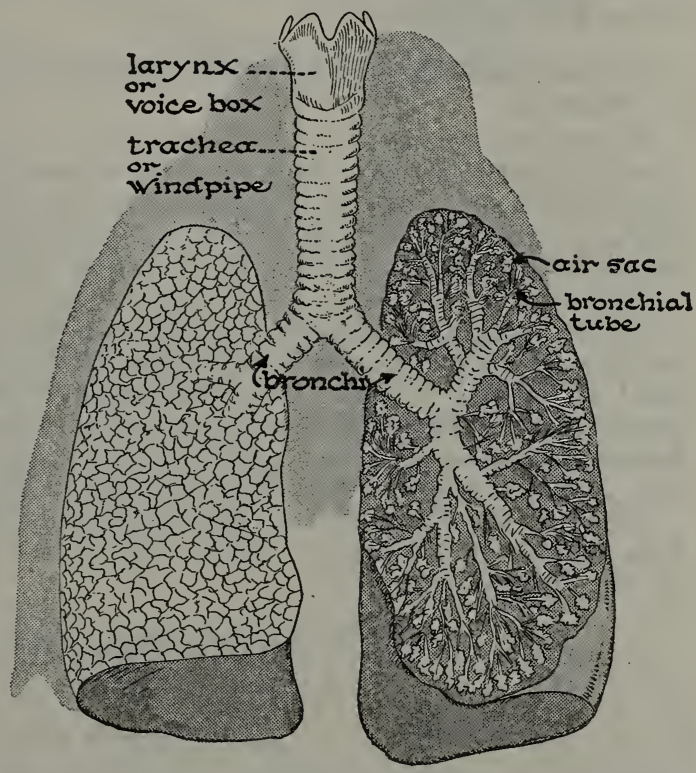

The tissue is cut away from one of the lungs to show the air tubes. Trace the course of air from the nose to the air sacs. as the Adam's apple of the throat, divides into two bronchi (brŏn'kī). The bronchi within the lungs break up into a great number of smaller 


\section{FOODS CIRCULATED AND USED IN THE BODY}

bronchial tubes, which divide somewhat like the small branches of a tree. The bronchial tubes are lined with ciliated cells, the cilia of which are constantly in motion. They lash with a quick stroke toward the outer end of the tube, that is, toward the mouth. Hence any foreign material in the tubes will be raised first by the action of the cilia and then by coughing or " clearing the throat." The bronchial tubes end in very minute air sacs, little pouches having elastic walls, into which air is taken when we inspire, or take a deep breath. In the walls of these pouches are numerous capillaries. Through the very thin walls of the air sacs a diffusion of gases takes place, which results in the blood giving up carbon dioxide and taking up oxygen. As a result of this process the color of the blood becomes a brighter red, due to the combination of the oxygen with the haemoglobin in the red corpuscle.

\section{Demonstration 3. To determine changes that take place in the air in the lungs.}

Breathe on the bulb of a thermometer and record any changes. Breathe gently on any glass or polished metal surface. Note what happens. Take a moderate breath, and force air (tidal air) by means of a glass tube through limewater. Notice what occurs. Force the last part of a deep expiration (reserve air) through limewater. Note result.

Thrust a lighted splinter into a bottle of air. How long does it burn? Now fill a glass jar with expired air by the downward displacement of water. Invert the jar, keeping it covered. Remove the cover, and introduce into the jar a lighted wood splinter. How long does it continue to burn? What does this indicate? Why? (Air loses about one fourth of its oxygen while in the lungs.)

What are the changes that take place in blood in the lungs? What does air gain in the lungs? What does it lose? What is one reason for deep breathing?

Composition of Fresh Air and of Air Expired from the Lungs

\begin{tabular}{|c|c|c|}
\hline Constittents & IN OETDOOR AIR & 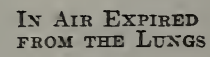 \\
\hline $\begin{array}{l}\text { Oxygen } \\
\text { Carbon dioxide } \\
\text { Nitrogen and other gases. } \\
\text { Water vapor. }\end{array}$ & $\begin{array}{c}20.96 \\
.04 \\
79 . \\
\text { variable }\end{array}$ & $\begin{array}{c}16.4 \\
4.1 \\
79 . \\
.5\end{array}$ \\
\hline
\end{tabular}


As the table shows, there is a loss of nearly 5 per cent of oxygen, and a corresponding gain in carbon dioxide and water vapor, in expired air. There are also some organic waste substances in expired air which are not shown in the table.

Cell respiration. It has been shown, in the case of very simple animals, such as the Paramecium, that when oxidation of food takes place in the cell, energy will result. In man the oxygen taken into the lungs is not used there, but is carried by the blood to all parts of the body where work is done. Cell activity demands food and oxygen.

When oxidation of food takes place

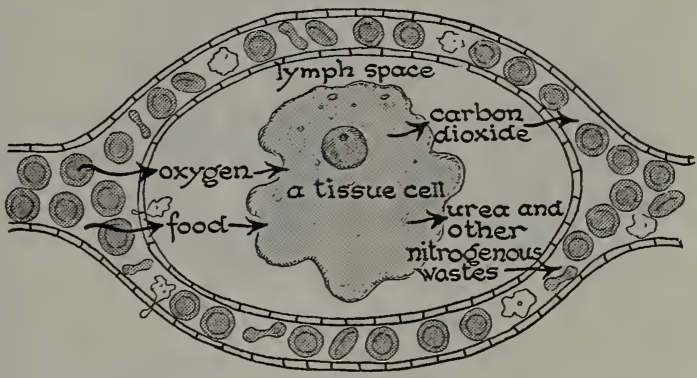

Explain this diagram. in the cell, energy is released for cell work and certain wastes are formed. The waste, carbon dioxide, is given off to the blood when any food containing carbon is burned. When proteins are burned, other wastes containing nitrogen are formed. These must be passed off from the cells, as they are poisons. This is done by the lymph and the blood, which take the waste materials to points where they may be excreted or passed out of the body. Water, another waste product, is excreted by the skin and kidneys.

\section{Self-Testing Exercise}

An ........ (1) of oxygen and ....... (2) ...... (3) takes place in the blood as it passes through the .......(4) ......(5) of the lungs. Air entering the lungs has about .......(6) per cent more ........ (7) than expired air. Respiration takes place in the . (8) of the body. As a result of cell activity after ....... (9) and $\ldots \ldots \ldots(10)$ are taken into the cell.......(11) .......(12), (13) and $\ldots \ldots \ldots$ (14) wastes are given off.

H. BIO -27 


\section{FOODS CIRCULATED AND USED IN THE BODY}

\section{PROBLEM V. WHAT ARE THE MECHANICS OF BREATHING?}

Demonstration 4. To show the mechanics of breathing.

Pass a glass $Y$ tube through a rubber stopper. Fasten two small toy balloons to the branches of the tube. Put the stopper in the small end of a bell jar. Adjust the tube so that the balloons hang free
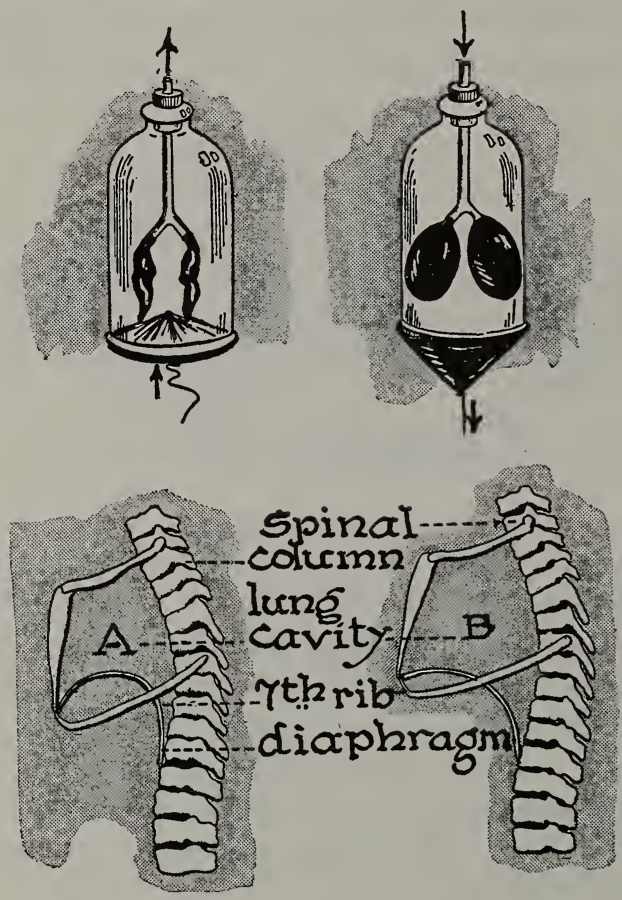

in the jar. Attach a string to the middle of a piece of sheet rubber. Tie the rubber over the large end of the jar.

To what structures in our bodies may the balloons and rubber sheet be compared? Pull down the string gently. What effect does the lowering of the sheet rubber have on the balloon? Why? Push the rubber into the bell jar to form an arch. What happens to the balloons? Why? Explain how this experiment may be compared to breathing?

The pleura. The lungs are inclosed in a thin, elastic, membranous sac, the pleura. This membrane is composed of moist tissue. In breathing, when the

lungs become larger, the smooth, moist surface of the pleura prevents the friction that otherwise would occur between the lung and the walls of the chest.

The mechanics of breathing. In every breath there are two movements, inspiration (taking air in) and expiration (forcing air out). An inspiration is produced by the contraction of muscles between the ribs, together with the contraction of the diaphragm, the muscular wall forming the floor of the chest cavity; this results in pulling the diaphragm down and pulling the ribs upward and outward, thus increasing the space within the chest 
cavity for the air to rush in. Then the diaphragm relaxes and rises and the muscles between the ribs relax. This pressure forces the air out of the lungs, thus producing expiration. During these processes an exchange of oxygen in the air and of carbon dioxide in the blood takes place.

Practical Exercise 6. Explain the difference between breathing and respiration.

Hygienic habits of breathing. Every one ought to accustom himself to inspire slowly and deeply in the open air. A slow expiration should follow. Take care to force all the air out. Breathe through the nose to warm the inspired air before it enters the lungs. Repeat this exercise several times every day. This will prevent certain of the air sacs, otherwise used only infrequently, from becoming hardened and permanently closed. Deep breathing should become a habit with growing girls and boys. It can best be practiced with windows open, after rising in the morning and just before retiring at

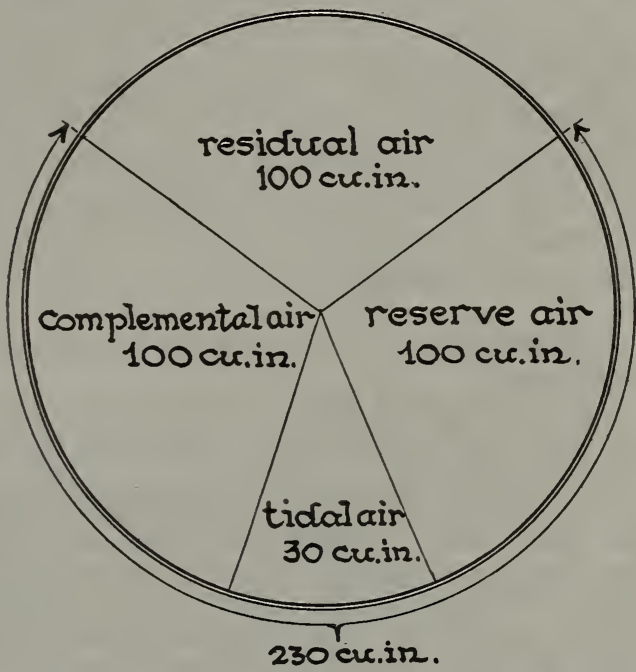

Diagram showing the capacity of the lungs. The tidal air is that taken in an ordinary breath. Complemental air is that taken in a very long breath. In a forced expiration we can expel from 75 to 100 cubic inches of reserve air. What is left in the lungs is residual air. night.

Common diseases of the nose and throat. Catarrh is a disease to which many people with sensitive mucous membrane of the nose and throat are subject. It is indicated by the constant secretion of mucus from this membrane. Chronic catarrh should be attended to by a physician. Often we find children breathing entirely through the mouth because the air passages in the nose 
are closed. If this condition continues for any length of time, the nose and throat should be examined by a physician for adenoids, growths of soft masses of tissue which fill up the nose cavity and prevent normal breathing. Many a child, backward at school, thin and irritable, has been changed to a healthy, normal child, by the removal of adenoids. Sometimes the tonsils, at the back of the mouth cavity, become diseased and enlarged, causing serious throat troubles and sometimes acute rheumatism and heart disease.

Relation to health. We all know that exercise in moderation has a beneficial effect upon the human organism. Exercise, besides training the muscles, increases the activity of the heart and lungs, causing deeper breathing and giving the heart muscles increased work; it liberates heat and carbon dioxide from the tissues where the work is taking place, thus increasing the respiration of the tissues themselves, and aids mechanically in the removal of wastes from tissues. Exercise is of immense importance to the nervous system as a means of rest.

Demonstration 5. To show the prone-pressure method of artificial respiration.

Place the person face downward with his head turned to the side and supported on his arm. Kneel astride him at the bend of his knees and slowly but strongly press down and forward with the hands, keeping the arms straight, immediately over the lower part of the chest carity. Hold this pressure for about three seconds and then swing the weight of the body off suddenly, thus allowing the lungs of the subject to fill with air. After two seconds repeat the pressure as before. Count the seconds as you perform this operation so as to make the total number of respiratory morements twelve to the minute.

Why time these morements twelre to the minute? Why press down on the ribs? What structures play a part when this is done?

Suffocation and artificial respiration. Suffocation results when the supply of oxygen is shut off from the lungs. It may be brought about by an obstruction in the windpipe, by a lack of oxygen in the air, due to inhaling some other gas in quantity, by drowning, or from a severe electric shock. In any one of the above cases, the person's life may be saved by prompt recourse to artificial respiration. The prone-pressure method is considered one of the best. 
Do not give up work if the patient does not at once show signs of recovery. Persons who have been under water for some time have been resuscitated after four to five hours' work. Prompt, regular, and continued effort is the thing that counts.

\section{Self-Testing Exercise}

In breathing there are two movements, ...... (1) and ...... (2). In the first movement the ....... (3) are pulled up and outwards, and the ......(4) is lowered, thus making a larger space within the chest cavity into which .......(5) may pass. .......(6) is a passive movement, the air being forced out by the return of the ....... (7) and ....... (8) to their former positions. We inspire about ....... (9) times a minute. About ....... (10) .......(11) inches of air are taken into the lungs during a "long" breath. To perform artificial respiration by the prone-pressure method we place the patient face .......(12), kneel astride him, and slowly but strongly press $\ldots \ldots$ (13) and ........ (14) just over lower part of the ...... (15) $\ldots \ldots$ (16) at a rate of ......(17) times a minute. Keep this pressure up for . . . . . (18) seconds, release suddenly, rest. . . . . . (19) seconds, and repeat.

\section{PROBLEM VI. WHAT ARE THE REASONS FOR, AND THE BEST METHODS OF VENTILATION?}

\section{Demonstration 6. To show methods of ventilating rooms.}

Make a grooved box $8 \times 10$ inches at base, 8 inches high, with sliding glass door. Place on side and have 4 half-inch holes, two at top and two at bottom, bored in each end and fitted with corks. Place three candles in the box. Light the candles.

With all the corks in place, how long (take exact time) do the candles burn?

Remove the upper corks from both ends. How long do the candles burn?

Remove the lower corks. How long do the candles burn?

Remove the upper and lower cork from one end. How long do the candles burn? Remove the upper corks from one end and the lower ones from the opposite end. How long do the candles burn?

Make cross-section sketches and explain the different trials. Use dotted lines and arrows to represent the course of the air.

What is the best method of ventilating a room? Why should people sleep with windows open? Make a diagram to show how to ventilate a.room. How would you ventilate through a window without making a draft? Can you explain the school system of ventilation? 


\section{FOODS CIRCULATED AND USED IN THE BODY}

Need of ventilation. We have all experienced a certain discomfort in a crowded auditorium or schoolroom after a short time. Some people think that this discomfort is caused by lack of oxygen in the air or by the presence of too much carbon dioxide. But experiments conducted by the New York State Ventilation Commission and in many laboratories have shown that this discomfort comes largely from two sources, the rise in temperature and the increase in humidity in the air. The source of this heat and moisture is largely the bodies of the people who are in the room.

In order to get rid of excess moisture, reduce the heat, and remove the other products of respiration from the air, ventilation is necessary. Ventilation is defined as adequate replacement of used air with fresh air. In addition, air in buildings contains dust, with its load of bacteria, odors of various kinds, and sometimes poisonous gases.

Methods of ventilation. Since 1800 to 3000 cubic feet of air are needed by the average person each hour, various devices for changing the air in rooms are used. In schools, fresh air is often drawn in by fans, washed to remove dust and bacteria, and then forced through ducts into the rooms, the used air in the room passing out through other ducts. But recent studies indicate that much of the expensive equipment of school buildings might be discarded in favor of window ventilation top and bottom with boards placed so as to prevent drafts.

Practical Exercise 7. Make a survey of the temperature conditions in your own school. Take hourly temperature records in several different rooms. Make the report cover at least one week.

A temperature of not more than $68^{\circ} \mathrm{F}$. is most favorable for mental work. It is found that during the winter, when artificial heat is used, the air becomes too dry. Various devices are used to evaporate moisture in a room and raise the humidity content of the air somewhat, but no effective device is in general use for keeping the humidity equal to that of the outside air. Consequently, when we go from a warm, dry room into the cool, outof-door air, the skin becomes chilled and we may take cold. One of the best ways we can keep the air in our rooms moist is to place pans of water on registers or radiators. 
Ventilation of sleeping rooms. Sleeping in badly ventilated rooms is frequently the cause of much discomfort and often of illness. Windows should be open top and bottom, but no direct draft should be allowed.

This ventilation may often be managed with the use of screens.

In cities especially, the night air is purer than day air, because the factories have stopped work, the dust has settled, and fewer people are on the streets. The old myth of "night air"

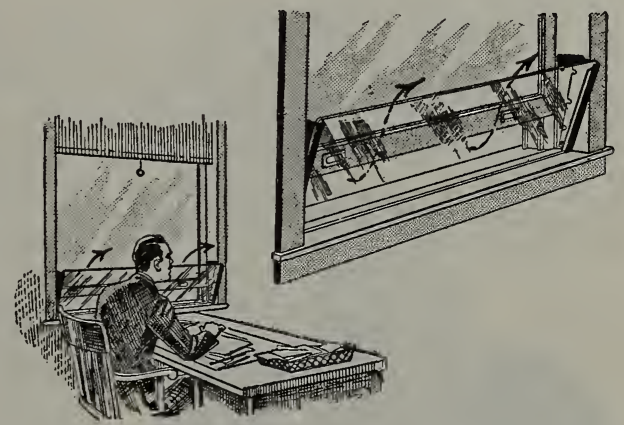
being injurious has long

Is this a good method of window ventilation? Why? since been exploded, and thousands of people of delicate health, especially those who have weak throats or lungs, are regaining health by sleeping out of doors or with the windows wide open. The only essential in sleeping out of doors is that the body be kept warm and the head be protected from strong drafts.

\section{Self-Testing Exercise}

Ventilation is the ....... (1) of ....... (2) air with .......(3) air. From ........(4) to ....... (5) cubic feet of air are needed in a room by every person per hour. Sleeping rooms are best ventilated by opening the window ......(6) and .......(7), but a ........ (8) should be avoided. Ventilate the lungs by ....... (9) (10).

\section{PROBLEM VII. WHAT ARE THE ORGANS OF EXCRETION AND HOW DO THEY FUNCTION?}

Laboratory Exercise. The structure of the kidney. Some idea of the internal structure of the kidney of man may be gained by examination of a sheep's kidney. Get the butcher to leave the mass of fat around the kidney. What is the use of this fat? Notice, after removing the fat, that the kidney appears to be closely wrapped in a thin coat of connestive tissue; this is called the capsule. 


\section{FOODS CIRCULATED AND USED IN THE BODY}

Remove the kidney from this capsule. Notice its color and shape. The depression called the hilum is deeper than the corresponding region in a kidney bean. The hollow tube passing out from this region is called the ureter. Blood vessels also enter and leave the kidney at the hilum.

Cut the kidney lengthwise into halves. Try to find the following regions: (1) the outer or cortical region (note its color); (2) the inner or medullary layer (this layer is provided with little projections, which are the pyramids of Malpighi, so called after their discoverer, Marcello Malpighi, a celebrated Italian physiologist); (3) the cavity or pelvis of the kidney. At the summit of each pyramid is a small opening through which escapes into the pelvis the secretion formed in the little

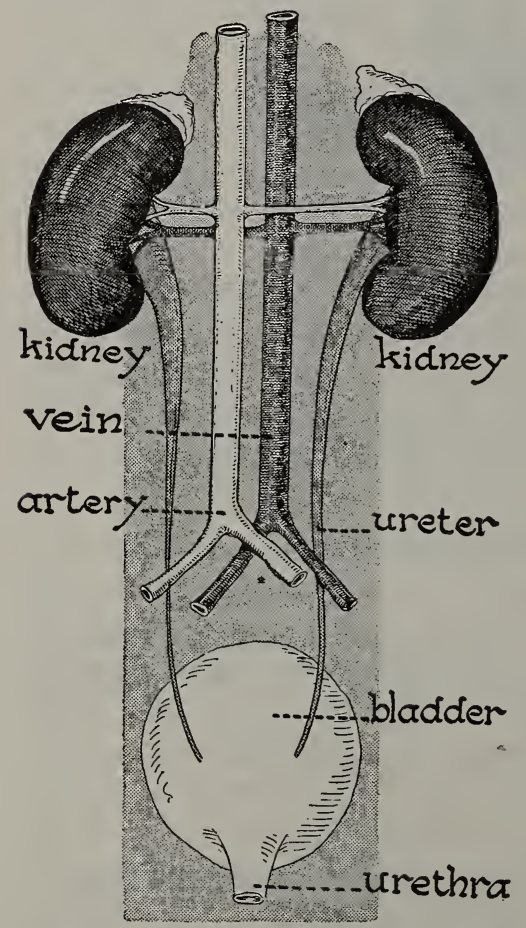

The organs of excretion. Note the blood supply to the kidneys. Of what use is the bladder? tubules, which make up the pyramids, and in which the real work of excretion is performed.

Where is the waste taken from the blood in the kidney? Where does this waste pass out of the body?

Organs of excretion. All the life processes which take place in a living thing result ultimately, not only in the giving off of carbon dioxide, but also in the formation of organic wastes within the body. The retention of the wastes which contain nitrogen is harmful to animals. In man, the skin and kidneys remove these wastes from the body, hence they are called the organs of excretion.

The human kidneys, like those of the sheep, are composed of masses of excretory tubules. The outer end of each of these tubules ultimately opens into the pelvis, the space within the kidney; the inner end forms a tiny closed sac. In each sac, the outer wall of the tube has grown inward and carried with it a very tiny artery. This artery breaks up into a mass of 
capillaries, which, in turn, unite to form a small vein as they leave the little sac. Each of these sacs contains a number of blood vessels, the glomerulus (glö mĕr'oo lŭs).

Wastes given off by the blood in the kidney. In the glomeruli the blood loses by osmosis, through the very thin walls of the capillaries, first, a considerable amount of water (amounting to nearly three pints daily); second, a nitrogenous waste material known as urea; third, salts and other waste organic substances. These waste products pass into the pelvis of the kidney and through ducts, ureters, into the bladder.

The waste products from

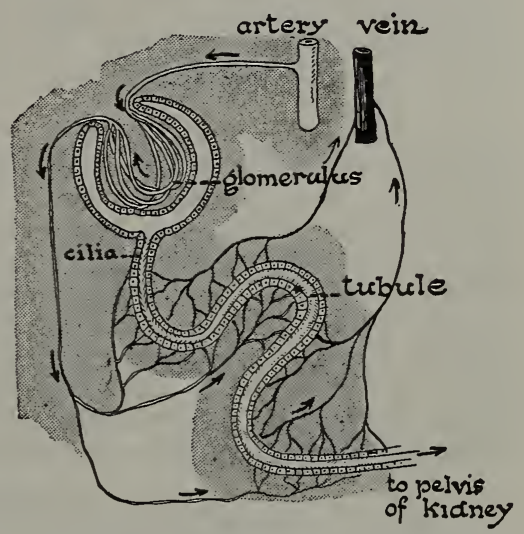

Each kidney is composed of a large number of long tubules. The blood flows through the glomeruli (mass of blood capillaries) and then through the capillaries surrounding the tubules. Wastes from the blood pass through the walls of the blood-vessels (glomeruli) into the tubules, which lead to the bladder. the kidney, together with the water containing them, are known as urine. Urine normally consists of about 96 per cent water and 4 per cent dissolved solids. The total amount of nitrogenous waste leaving the body each day, by means of the kidneys, is about twenty grams. After the blood has gone through the glomeruli of the kidneys it is purer than in any other place in the body, because it has lost much of its nitrogenous waste in them and before going to them it gave up a large part of its carbon dioxide in the lungs. So dependent is the body upon the excretion of its poisonous material that in cases where the kidneys do not do their work properly, death may ensue within a few hours. Since the blood which passes through the kidneys is being continually depleted of water, one should drink plenty of water to make good this loss.

Diet plays a very important part in the care of the kidneys. If we overbalance our diet with too much protein food, we throw increased work on these organs. The nitrogen in proteins cannot 


\section{FOODS CIRCULATED AND USED IN THE BODY}

be oxidized, so, combined with other elements into urea and other wastes, it is eliminated through the kidneys.

Laboratory Exercise. To study the skin as an organ of excretion and of heat control. Examine the diagram of a cross section of skin. Locate the epidermis, dermis, sweat glands, oil glands, nerves, and blood vessels.

Examine the surface of your skin with a hand lens. Where is the epidermis and what structures does it contain? What structures are found in the dermis?

Insert your hand in a clean, dry fruit jar. Wrap a towel over the opening of the jar so as to allow no air to get in between your hand and the sides of the jar. What happens in the jar? What is given off from the hand?

Weigh yourself. Note the weight. Exercise violently for half an hour. Weigh yourself again. Note the weight. Was there any change in weight? How must the change of weight have been brought about? Remember that when oxidation of food or tissue takes

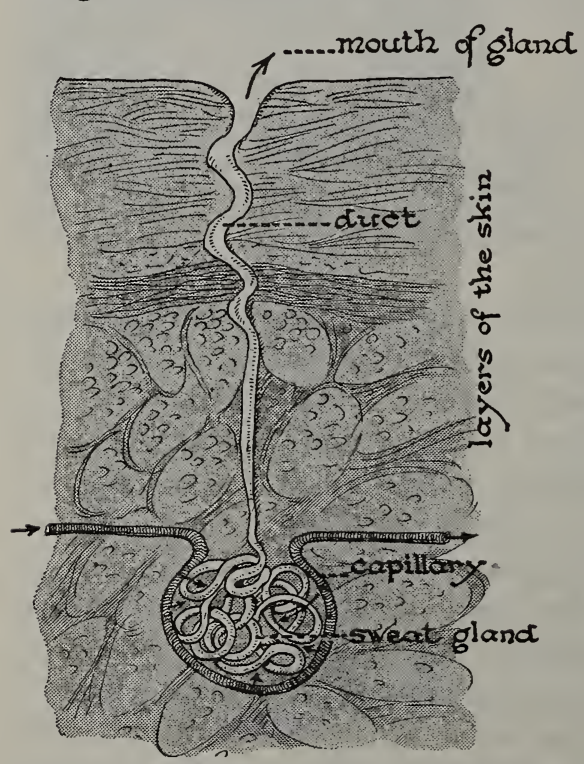

A sweat gland. Explain, with reference to the text, where the water that is given off comes from. The waste materials. place in the body, three products, at least, are formed: heat, organic wastes, and water.

(Food + oxygen $=$ carbon dioxide + water + organic wastes + heat + muscular energy.)

Take the temperature of the body before and after exercise by placing a clinical thermometer in the mouth. Account for any change in temperature.

What three substances are given off from human bodies that might affect the air of a closed room? Are you more comfortable on a hot humid day or on a hot dry day? Explain.

The skin as an organ of excretion. We have already learned that the skin is an organ of protection. Let us now see how it aids in excretion. The glands already studied form the excretion known as perspiration, a watery solution containing little carbon dioxide, 
urea, and some salts (common salt among others). The combined secretions from these glands amount normally to a little over a pint during twenty-four hours. At all times a small amount - of perspiration is given off, but this is evaporated or is absorbed by the underwear. Since this passes off unnoticed, it is called insensible perspiration.

Regulation of the heat of the body. The body temperature of a person engaged in manual labor will be found to be but little higher than the temperature of the same person at rest. The muscles, equal to nearly one half the weight of the body, release about five sixths of their energy as heat. At all times they are giving up some heat. The temperature of the body is largely regulated by the activity of the sweat glands. The blood carries much of the heat, liberated in the various parts of the body by the oxidation of food, to the surface of the body, where it is lost in the evaporation of sweat. In hot weather the blood vessels of the skin are dilated; in cold weather they are made smaller by the action of the nervous system. The blood thus loses water in the skin, and as the water evaporates, we are cooled off. The object of increased perspiration, then, is to remove heat from the body. With a large amount of blood present in the skin, perspiration is increased; with a small amount, it is diminished. Hence, we have in the skin an automatic regulator of body temperature.

Practical Exercise 8. Why is the amount of perspiration noticeably increased in hot weather and after doing hard work?

Colds and fevers. The regulation of blood passing through the blood vessels is under control of the nervous system. If this mechanism is interfered with in any way, as for example through bacterial toxins released in the body, the sweat glands may not do their work, perspiration may be stopped, and the heat from oxidation held within the body. The body temperature goes up, and a fever results.

If the blood vessels in the skin are suddenly cooled when full of blood, they contract and send the blood elsewhere. As a result an increase of blood in the internal organs or a congestion may follow. 


\section{FOODS CIRCULATED AND USED IN THE BODY}

Colds are, in reality, a congestion of membranes lining certain parts of the body, as the nose, throat, windpipe, or lungs, together

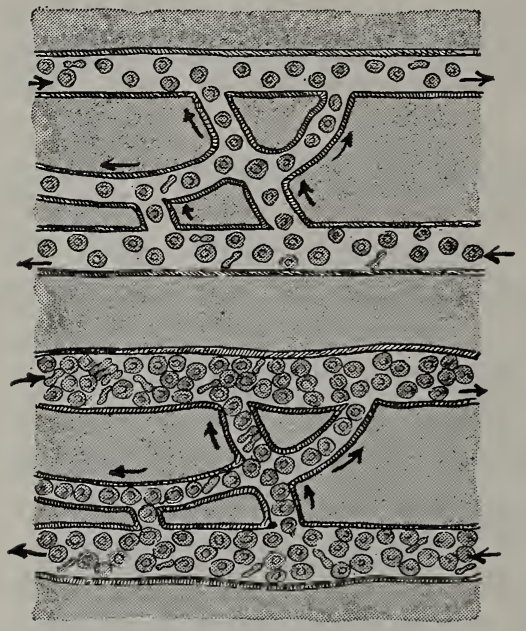

Explain this diagram. What has happened in the lower figure? with a growth of bacteria which were present in the mouth or throat. Some colds are communicable and gain entrance to the body when the resistance is low.

When suffering from a cold. it is therefore important not, to chill the skin, as a full blood supply should be kept in it and thus kept from the seat of the congestion. For this reason hot baths (which bring the blood to the skin), the avoiding of drafts (which chill the skin), and warm clothing are useful factors in the care of colds. Very important also are rest in bed, fresh air, plenty of water to drink, and free bowel movements.

Practical Exercise 9. What is a congestion and how is it caused? How do we "take cold"? Is there more than one kind of cold?

\section{Self-Testing Exercise}

Body temperature is regulated by action of nerves in the ....... (1). They either cause the small blood vessels to ....... (2) or ........ (3), thus placing more or less ....... (4) at the .......(5) of the body where the ...... (6) heat may be ...... (7) by perspiration. The kidneys are organs of $\ldots \ldots \ldots$ (8). . . . . (9) waste is passed out as ......... (10). An oversupply of .......(11) food may make too much work for the kidneys.

\section{Review Summary}

Test your knowledge of the unit by: (1) rechecking the summary questions; (2) performing all the assigned exercises; (3) checking with the teacher on all tests and trying over the parts you missed; (4) and finally making an outline of the unit for your notebook. 


\section{Test of Fundamental Concepts}

In a vertical column under the heading CORRECT write numbers of all statements you believe are true. In another column under INCORRECT write numbers of untrue statements. Your grade $=$ right answers $\times 2$.

I. The blood contains (1) fluid food in its plasma; (2) red and colorless corpuscles ; (3) haemoglobin in its white corpuscles ; (4) enzymes and hormones; (5) a substance called fibrinogen, which acts in causing the blood to clot.

II. Blood is necessary for the body because (6) it acts as a medium of exchange between the body cells and the source of their food supply; (7) it contains regulative substances called vitamins; (8) it acts as a carrier for the chemical activators called hormones; (9) only through the blood is oxygen carried to the cells and carbon dioxide carried away; (10) it carries waste materials away from the cells.

III. Antibodies (11) help to make us immune to diseases caused by bacteria; (12) called lysins can dissolve bacteria; (13) called agglutinins cause bacteria to stick together; (14) are specific and fight specific toxins; (15) are made use of in the Widal Test.

IV. The endocrine glands (16) are the salivary, gastric, and intestinal; (17) are those glands which have no ducts; (18) include the thyroid, parathyroid, thymus, adrenal, the pituitary, and parts of the pancreas, the ovaries, and testes; (19) such as the adrenals may increase body activity: (20) such as the pituitary probably control growth in the body.

V. The blood circulates (21) because it is alive; (22) because the heart acts as a force pump; (23) because arteries and veins are connected by capillaries; (24) through the body cells; (25) to all the cells in the body.

VI. The lungs (26) are the chief organs of excretion in the human body ; (27) are organs for the exchange of oxygen and carbon dioxide; (28) are masses of tiny air sacs, which are thin walled and covered with capillaries; (29) are made larger or smaller during the process of breathing; (30) take in oxygen and give off water, carbon dioxide, some organic wastes, and heat.

VII. Respiration (31) is a process by which oxygen reaches the body cells and carbon dioxide is removed from them; (32) is the same as expiration and inspiration; (33) takes place in body cells; (34) and breathing mean the same thing; (35) is raising and lowering the ribs and diaphragm. 


\section{FOODS CIRCULATED AND USED IN THE BODY}

VIII. Ventilation (36) is necessary in order to raise the temperature of a room; (3i) removes carbon dioxide and renews oxygen; (3S) is necessary because moving air helps to keep a room more comfortable ; (39) removes moisture, heat, carbon dioxide, and other products of respiration and renews the supply of oxygen; $(40)$ is best brought about in sleeping rooms by having the windows open top and bottom.

IX. Body wastes are removed (41) from the cells by the blood which carries the organic wastes to the kidneys; (42) from the kidneys in the form of urea; (43) in a gaseous state; (44) from the body by the kidneys; (45) best by taking cathartics.

$\mathrm{X}$. The skin $(46)$ regulates body heat; $(47)$ furnishes protection against germs; (4S) is an organ of excretion; (49) contains millions of sweat glands under nerrous control; (50) should be kept warm if one has a cold, for this keeps blood from the internal organs and thus prevents congestion.

\section{Achievement Test}

1. What do blood corpuscles look like under the compound microscope?

2. How would you demonstrate the capillary circulation in the web of the frog's foot?

3. How would you make a tourniquet and what would you do in case of an accident where loss of blood occurs?

t. Why is blood transfusion not possible between some people and possible between others?

5. What are the endocrine glands and what is the function of each?

6. How could you make a diagram of circulation of blood in your own body?

7. How can you prove that you oxidize materials (food or tissues) in your own body?

8. How can you demonstrate the prone-pressure method of artificial respiration?

9. How can you demonstrate the best method of rentilating a room and show why it is the best method? Do you practice this in your sleeping room?

10. How could you demonstrate the changes that take place in air in your lungs? 


\section{Practical Problems}

1. Fill out the following table:

WASTES OF THE HUMAN BODY

\begin{tabular}{|l|l|l|l|}
\hline Waste & Where Formed & How Excreted & $\begin{array}{c}\text { Organs Used IN } \\
\text { Process }\end{array}$ \\
\hline & & & \\
\hline & & \\
\hline
\end{tabular}

2. Fill out the table below as completely as you can :

\begin{tabular}{|l|l|l|}
\hline Part of Blood & Substance or Structure & Functions \\
\hline & & \\
\hline & & \\
\hline
\end{tabular}

\section{UsEFul ReFERENCES}

Broadhurst, How We Resist Disease. Chapter V-VII inc. (J.B. Lippincott Co. 1923.)

Burton-Opitz, Textbook of Physiology. (W. B. Saunders Co. 1925.) Fisher and Fisk, How to Live. Chapter IV. (Funk \& Wagnalls Co. 1925.)

Harrow, Glands in Health and Disease. (E. P. Dutton \& Co. 1922.) Hunter, Laboratory Problems in Civic Biology. Pp. 139-152 inc. (American Book Company.)

Kimber and Gray, Textbook of Anatomy and Physiology. Pp. 184298. (The Macmillan Co. 1926.)

Martin, The Human Body, Advanced Courses. (Henry Holt \& Co. 1926.)

Sharp, Fnundation of Health. (Lea \& Febiger. 1924.) 


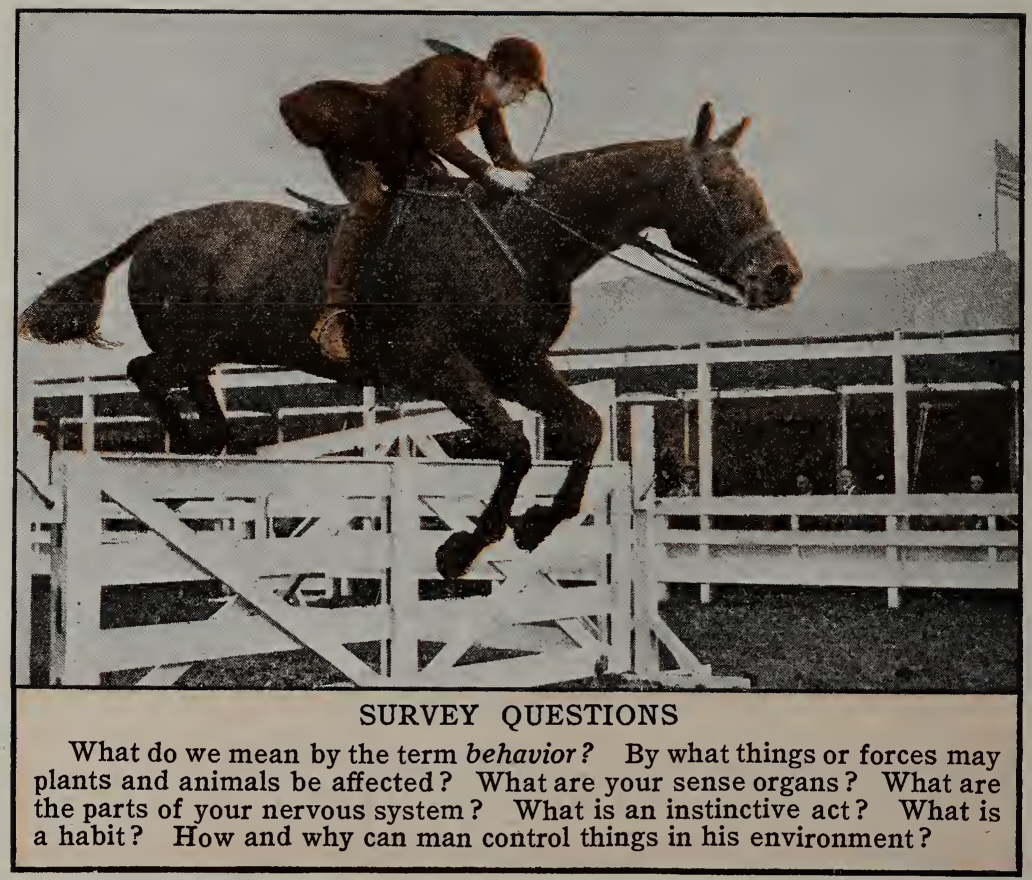

Wide World Photo

\section{UNIT XIV}

\section{HOW HAS MAN BECOME THE CONQUEROR OF THE WORLD?}

Preview. We have seen many instances in which plants and animals respond to stimuli. In our study of plants we found examples of responses to light, gravity, and moisture. These simple responses are called tropisms. But if we are asked to explain why these responses took place, we can only say that protoplasm exhibits the power of irritability by means of which the organism is preserved from injuries and can obtain from its environment the materials needed to carry on its life processes.

The reactions of a dog to the sound of his master's voice or to the odor of a piece of meat seem to be quite a different matter 
from these simple responses. However, biologists and psychologists agree that it is only carrying a little further this matter of response to a stimuli. It is held by some people that most of our everyday actions, of which we do not think, are due to reactions to certain stimuli. Most of the acts which we perform during a day's work are the results of the automatic working of various parts of our body. The heart pumps the blood which circulates its load of food, oxygen, and wastes; the movements of breathing are performed; the kidneys and skin discharge the wastes from the body; and the nerves carry messages to and from the brain. These many complicated acts go on every day within the body and are seemingly undirected, but they are in reality under the control of the autonomic nervous system.

On the other hand, the body may also be influenced by what goes on around it. Our entire day at school may be colored by what happened at the breakfast table. Or suppose we oversleep, eat our breakfast hastily, run to school, reaching there a few minutes late, and therefore are marked tardy. This sequence of events will influence our entire day. The digestive glands in the stomach have not been properly stimulated, due to our hastily eaten breakfast. Certain internal secretions of the glands, poured into the blood when we ran to school and when we were declared late, might arouse our emotions, and cause us to do and say many things for which we would probably be sorry later. All of the actions were really initiated through changes in our environment. The fact that we overslept made breakfast later, our hurry made school seem further away, the closed door gave us a decided jolt and changed the smooth running of our nervous machine. So conditions do modify our life activities.

Most of our activities are habits; that is, we have learned to do them so well that we can now do them without thinking. Habits may be broken, but to do this we must become conscious of them, and earnestly try to break them. Either we shall become slaves to habits or habits will serve us. That is the thing that every person should realize while still in high school. Later, good habits cannot be acquired or bad habits cannot be broken so easily and one will eventually become conquered by his habits.

H. BIO -28 


\section{PROBLEM I. WHAT ARE THE CHIEF RESPONSES OF PLANTS AND ANIMALS?}

Demonstration 1. To show some tropisms in plants and animals.

Grow some bean seedlings in a glass dish which is kept watered at one side only. Grow some bean seedlings in unequal illumination. Examine oxalis or clover at night and in the morning, in order to observe "sleep" movements of leaves. Touch a leaf of a sensitive plant with a pencil.

Place Euglena in a vessel with unequal light illumination.

In the first two cases, note the arrangement of roots against the glass side of the dish. What leaf movements of oxalis and sensitive plant are noticeable? Where in the vessel do you find Euglena most abundant?

What forces act upon plants and animals? How do they affect them?

How plants and animals receive stimuli. In the simplest plant and animal cells which live by themselves there are no

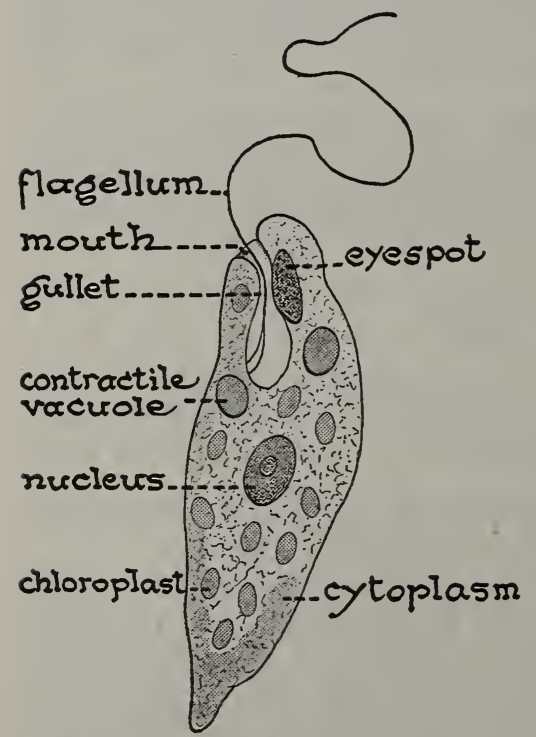

Euglena. Would you call it a plant or an animal? Give your reasons. specialized parts which are especially fitted to receive outside stimuli. The amoeba, for example, is influenced by temperature, food, and other stimuli, but it has no sense organs. Some tiny plant-like animals (or animal-like plants) such as Euglena (ü-glē'nä) have a tiny structure called an eyespot, which seems to be more sensitive to light than other parts of the cell.

The more complex singlecelled animals, as Paramecia, have parts of the cell (cilia) more sensitive to touch than other parts. Animals and, to a lesser degree, plants, as they become more complex in structure, tend to have special parts set aside to receive stimuli. These special parts of complex animals are called sense organs. 
Responses of plants and animals. The responses which plants and animals make to certain definite stimuli are called tropisms. Such responses may be either positive or negative, and appear to be mechanical behaviors. They may be listed as follows:
Phototropism or response to light
Geotropism or response to gravity
Plants Hydrotropism or response to water
and Thigmotropism or response to contact
Animals Chemotropism or response to chemical substances
Thermotropism or response to temperature changes
Galvanotropism or response to electricity

\section{Animals $\{$ Rheotropism or response to water currents \\ Anemotropism or response to air currents}

The response of roots to gravity, the growth of stems toward the source of light, the opening of some flowers in the daytime and others only at night, the climbing of plants by means of tendrils or other organs stimulated by touch, are a few of the many examples which might be mentioned.

Practical Exercise 1. Make a list of all tropisms that you have ever seen plants or animals exhibit.

Some parts of the plant are more sensitive. While a plant as a whole is sensitive to stimuli of different kinds, it is certain that some parts are more sensitive than others. For example, experiments show that in the root an area of not more than one millimeter in length is most sensitive to gravity, as the turning response takes place there. Some tips of stems show a similar sensitiveness, and so do certain parts of growing leaves.

\section{Self-Testing Exercise}

Check in your workbook the correct statements :

T.F. 1. The tip of the root responds most readily to gravity.

T. F. 2. Euglena has an eyespot which is sensitive to light.

T. F. 3. Geotropism is response to the stimulus of gravity.

T. F. 4. Phototropism is response to the stimulus of chemical substances.

T. F. 5. Rheotropism is response to water current. 


\section{MAN BECOMES THE CONQUEROR OF THE WORLD}

T. F. 6. The amoeba has no special organs of sense.

T. F. 7. If touched, the leaves of sensitive plants show thermotropism.

T.F. 8. The responses of simple animals to stimuli are always positive.

\section{PROBLEM II. HOW DO SIMPLE PLANTS AND ANIMALS RESPOND TO STIMULI?}

Demonstration 2. To show the use of the pulvinus to a plant,

Stain a longitudinal section of a bean stem to show the pulvinus. ${ }^{1}$ What might be the use of it? How is it able to do that?

The mechanism of responses in plants. Some of the results of responses are easily seen in plants, but the method by which the responses are brought about is not so easy to see. For example, we say leaves place themselves so as to get as much light as possible.

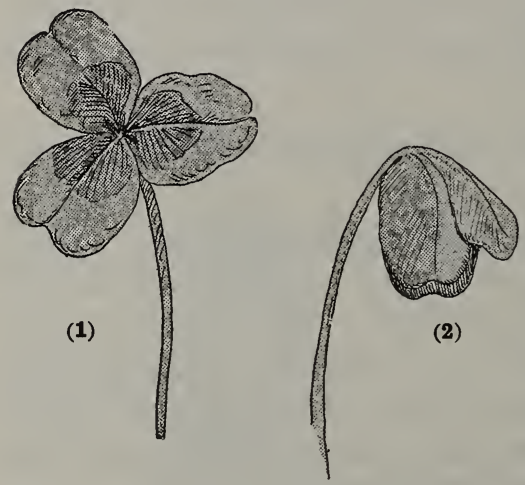

Clover leaf. (1) In the morning. (2) In the evening. Explain the difference.

But this movement is different from that found in animals which have an internal skeleton with muscles attached. The changes in position in parts of plants are often produced by a more rapid growth of the cells on one side of a structure than on the other, this growth having been excited by an external stimulus, such as gravity, water, light, or heat. Such are the curving movements of roots or stems.

The turning of the leaves in a horizontal position is brought about by the more rapid growth of tissues on one side of the leaf stalk than the other.

Changes in the position of leaves are often brought about by special structures at the base of the petiole, as may be seen in the bean plant. These structures, called pulvini ${ }^{1}$ (sing. pulvinus),

1 Pulvinus (pŭl-vi'nǔs) : cushionlike enlargement of petiole at its point of insertion on the stem. 
contain thin-walled cells filled with water, and the position of the leaf probably depends on the relative amount of water in these cells. The more rapid movements of the opening and closing of flower petals ; the changes in position of leaflets of the pea, clover, alfalfa, oxalis, and other plants at night and in the morning; and the relatively rapid response of the leaves of the sensitive plant to outside stimuli are all explained by changes in the water content of the cells in the pulvini, or by rapid and temporary fluctuations in growth on opposite sides of the

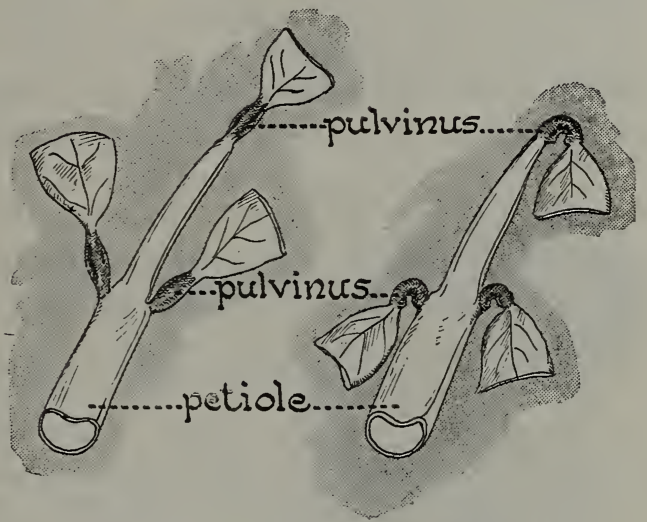

What is the pulvinus? What use is it to a leaf? leaves, or by a combination of both. But other than external stimuli may influence and modify the growth and actions of plants. We know that enzymes play an important part in the storage of food in fruits and seeds, and there seem to be evidences of vitamin and hormone action as well. It is probable that the protoplasm of a plant is under much the same control as is the protoplasm of an animal.

\section{Demonstration 3. To show responses of Paramecium.}

Place a drop of Paramecia culture in a grooved slide. At intervals, heat the water at one end of the slide by introducing a hot needle into it. Note the actions of the Paramecium as the water becomes warmer. Single out one Paramecium and make a diagram showing exactly how it gets away from the heated area. This reaction is known as the " avoiding reaction." How does a Paramecium escape from an unfavorable environment?

Responses of the simplest animals. We have already seen that amoebas and Paramecia seem to respond to the presence of food. Examination of a drop of hay infusion containing Paramecia will show many collected around masses of food, indicating 
that they are attracted by it. In another part of the slide we may find a number of the Paramecia lying close to the edge of an air bubble, with the greatest possible amount of their surface exposed to its surface. These animals are evidently taking in oxygen by diffusion. They are breathing. A careful inspection of the jar containing Paramecia shows thousands of tiny whitish bodies collected near the surface of the jar. Some force or forces keep them close to the surface. Professor Jennings and others have

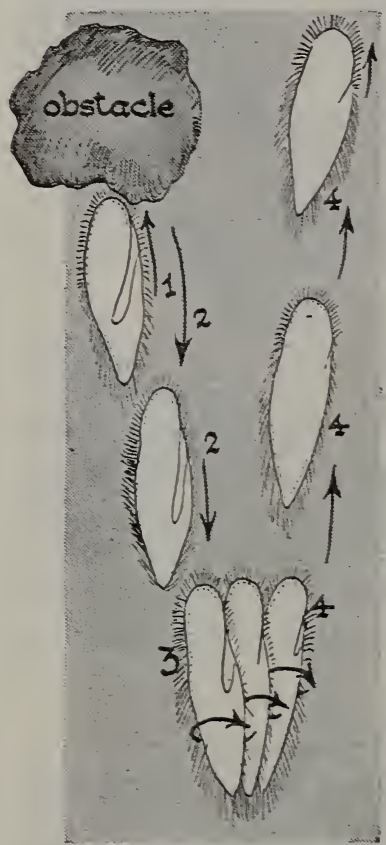

Trial and error method of a Paramecium. Explain what has happened, using the figures as guides. made careful studies of the reactions of Paramecia and other one-celled animals to various stimuli, and have found that in general they react positively toward favorable and negatively toward unfavorable conditions in their environment. For example, if a slide containing Paramecia is heated at one side, the animals will back off from the unfavorable stimulus, then shoot forward until they encounter the heat, then again back off and repeat the operation until they escape from the heated area.

This method of escape from the unfavorable environment is called the method of trial and error. It is an example of the way in which some of the lower organisms react to the unfavorable conditions of their environment. If by such methods they do not escape from harmful conditions, they perish.

Different intensities of light, different kinds of light, the passage of a current of electricity through the water, different chemical substances placed in the water, as well as many other factors, cause very definite responses on the part of these one-celled organisms. The responses in general save the organism from harm, or help it, and thus may be said to be adaptive responses. 


\section{Self-Testing Exercise}

Changes in the .......(1) of leaves are brought about by a structure called the ........(2). Paramecia react.......(3) to a favorable environment and ........(4) to an unfavorable one. Paramecia can be observed to ........ (5) to the presence of ....... $(6), \ldots \ldots \ldots$ (7) and $\ldots \ldots$ (8). If Paramecia cannot escape from ........ (9) conditions, they die. Plants change their positions in response to such stimuli as .......(11), .......(12), ...... (13), and .......(14).

\section{PROBLEM III. WHAT ARE SENSE ORGANS AND WHAT DO THEY DO?}

\section{Demonstration 4. To show types of sensory structure in certain animals.}

Materials. Insects with different types of antennae. Crustaceans with antennae and antennules. Grasshoppers, with wings removed to show tympanic membrane. Model of vertebrate eye and ear. Living crickets, earthworms, crayfish, and living goldfish. Food, such as apple or meat. Weak acetic acid.

Method. Arrange preserved specimens and models so that they may be passed around in class or observed on the demonstration table. Living material should be placed in pans or aquariums where they can be fed, and stimulated with weak acid.

Note the hairs projecting from the antennae and antennules of the insects and crustaceans. They are sensory in nature. Note in the grasshopper the sensory organ, which receives sound. Study the model of the human ear. Does our ear do more than receive sound? Study the model of the human eye. Compare it with a camera.

Observe carefully what happens when food, such as a bit of apple, is placed in a dish containing live crickets or earthworms. Note also what happens when crayfish or goldfish are fed meat. How do they become aware of the presence of food?

Place some cotton soaked in weak acid close to anterior end of an insect, a worm, and a crayfish. What happens?

How do animals become aware of food or harmful substances?

Sense organs and what they do. Most plants do not react quickly to stimuli, because they have no special sense organs. Nor have the one-celled animals any special part of the cell fitted to receive stimuli. But in animals composed of numerous cells, division of labor soon appears, and we have organs fitted to receive light stimuli (eyes), touch stimuli (tactile hairs, etc.), and sound 
stimuli (sensory hairs, tympana of insects, and the ears of higher animals). These end organs or structures at the outside of the animal, when connected by nerves to organs of movement, like muscles, bring about reactions to stimuli which result in obtaining

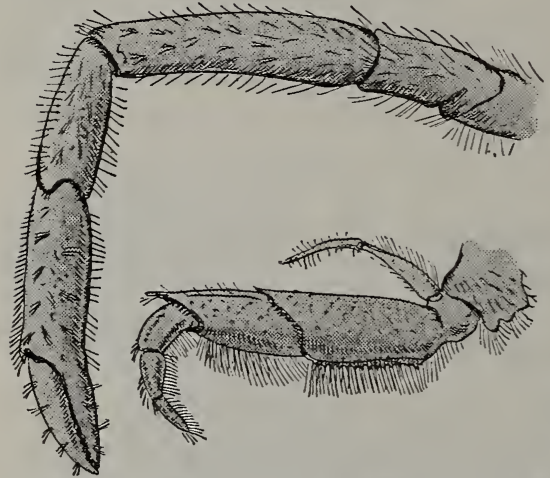

The fine hairs of the appendages of the lobster are organs of touch and they make the animal sensitive to its surroundings. food, in escaping from enemies, and in many other important functions.

Some examples of sense organs. One of the simplest sense organs is a sensory hair which contains nerve cells. These cells have become modified, so that when they are stimulated they send a message inward to another kind of nerve cell in the central part of the body. This cell in turn sends a message which stimulates a muscle to work, and the animal's body is involuntarily moved either away from or toward the source of the stimulus. This type of response is known as a simple reflex.

There are many kinds of sensory structures in the lower animals. The antennae of insects are for feeling and for receiving odors and, in some insects, sound waves. A few insects like the locust have tympanums, or ears. In some animals the "ear" assists in balancing while in other animals the ear is an organ of hearing as well as for balancing. In the shrimp, the "ear" is a tiny pit, the wall of which is lined with sensory hairs. In this pit are small grains of sand or other substances, which move about as the animal changes its position, and thus assist in making the animal aware of its position in space. A German named Kreidl (krī'd'l) showed in an experiment that shrimps, after molting, place small grains of sand in their statocysts (stăt'ö-sǐsts) or balancing pits. He kept the shrimps in an aquarium containing small particles of iron which the shrimps took in place of sand. Using a magnet, Kreidl then found that its pull against gravity affected the shrimps as did the 
force of gravity when sand grains were in the statocysts. This showed that the statocysts are balancing organs.

Light-receiving devices are of various kinds, from the simple eyespot in Euglena or small groups of sensory cells to the complicated compound eye of insects and the camera-like structure of man's eye.

Practical Exercise 2. Fill in the following table, listing the various kinds of sensory structures found in each animal you have studied.

\begin{tabular}{|c|c|c|c|}
\hline ANimal & Structure & Where Found & How Used \\
\hline & & & \\
\hline & & & \\
\hline & & & \\
\hline
\end{tabular}

\section{Self-Testing Exercise}

In higher animals, ....... (1) from special structures carry . . . . . (2) to organs of movement which bring about ....... (3). When an animal .......(4) moves away or toward the ......(5), the response is a .......(6). Light-receiving devices vary from the (7) in ....... (8) to the ....... (9) (10) in man.

\section{PROBLEM IV. HOW IS MAN'S BODY CONTROLLED?}

Laboratory Exercise. The anatomy of the nervous system. In a frog from which the organs of the body cavity have been removed, note the white glistening cords (nerves) which seem to come from under the backbone. Follow the course of some of the larger nerves. To where do they lead? Now turn the frog over and with sharp scissors and a scalpel remove very carefully the bony covering (the skull) from the whitish body (the brain).

How many parts appear to be in the brain? Notice the white elongated hemisphere of the forebrain or cerebrum. ${ }^{1}$ The two anterior projections of the cerebrum are called olfactory lobes. Where do these lobes seem to lead? What do you think, from the name, their use is?

Just back of the cerebrum, find two large lobes, known as optic lobes, which have to do with sight. Look at the chart. Are the eyes connected with the optic lobes? Back of the optic lobe we find the cerebellum ${ }^{2}$ and medulla, ${ }^{3}$ the latter running directly into the spinal cord, from which rise the spinal nerves you have noted.

${ }^{1}$ Cerebrum: sěr'è-brŭm. $\quad{ }^{2}$ Cerebellum : sěr'è-běl'úm. $\quad{ }^{3}$ Medulla : mè-dŭl'à. 
Compare, part by part, the brain of the frog with a model of the brain of man. In what respect is a frog's nervous system like that of man? How does it differ? Write a description, comparing the nervous system of the frog with your own, using charts and models as a guide.

The sense organs of man. We have seen that simpler forms of life perform certain acts because outside forces acting upon them cause them to react. All many-celled animals, including man, are put in touch with their surrcundings by what we call
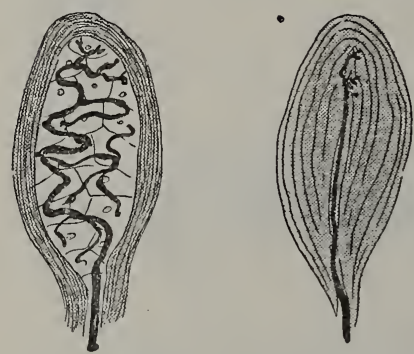

Some parts of the body are more sensitive to certain stimuli than are others. The diagram on the left shows an organ that is concerned in the sensation of touch; the one on the right, concerned in the sensation of pressure. special sense organs. The senses of man, besides those we commonly know as sight, hearing, taste, smell, and touch, are those of temperature, pressure, and pain. It is obvious that such organs, to be of use, must be at the outside of the body. Thus we find eyes and ears in the head, and taste cells in the mouth, cells in the nose for smelling, and others in the skin which are sensitive to heat or cold, pressure or pain.

The nervous system. In the vertebrate animals, including man, the nervous system consists of two divisions. One, including the brain, spinal cord, and nerves, makes up the central nervous system. The other division, called the autonomic nervous system, consists of small collections of nerve cells called ganglia. These ganglia are mostly included in two chains parallel to the spinal cord. This system transmits stimuli from the central nervous system to the heart, glands, and muscles of the internal organs.

Strangely cnovgh, we do not see with our eyes or taste with our taste cells. These organs receive the stimulations which are sent inward by means of a complicated system of greatly elongated cell structures, until the sensory message reaches an inner station, in the central nervous system. We see and hear and smell in our brains.

Neurons. The unit of structure of the nervous tissue is a cell, called a neuron. It is a mass of protoplasm containing a nucleus. 
The body of the nerve cell is usually irregular in shape, and differs from other cells by possessing several delicate, branched, protoplasmic projections called dendrites. One of these processes, the axon, is much longer than the others and ends in a muscle or in a network of endings around another nerve cell. It is not certain that these two nerve cells are actually in contact, but a stimulus is transmitted from one cell to the other by means of this network. Such a communication is called a synapse (š̌-năps's'). The axon forms the pathway over which nervous impulses travel to and from the nerve centers.

A nerve consists of a bundle of tiny axons, bound together by connective tissue. As a nerve ganglion is a center of activity in the nervous system, so a cell body is a center of activity of the neuron and may send an impulse over the thin strand of protoplasm (the axon) prolonged many hundreds of thousands of times the length of the cell body. Some neurons in the human body, although visible only under the compound microscope, give rise to axons several feet in length.

Because some axons originate in organs that receive stimuli and send them to the central nervous system,

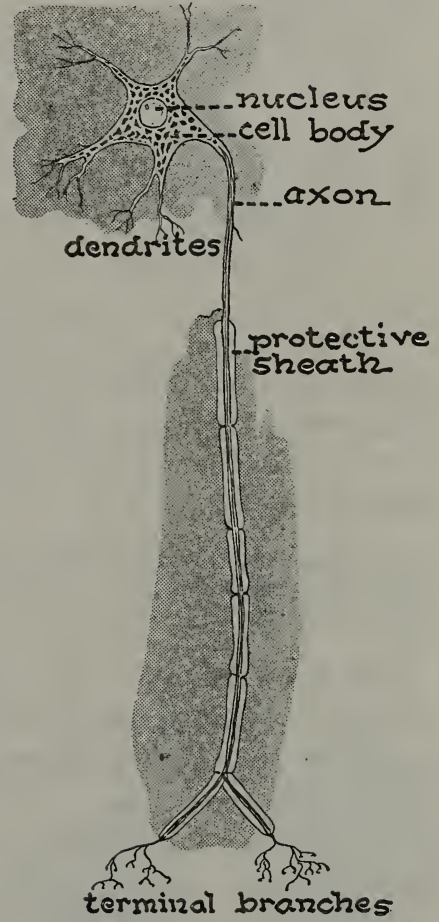

A neuron. Where might such a cell be found? Where might the terminal branches be? they are called sensory axons. Other axons originate in the central nervous system and pass outward, producing movement of muscles. These are called motor axons. The neurons possessing these axons are either sensory or motor neurons. When neurons connect sensory with motor neurons they are called associative neurons.

Reflexes and their place in our lives. We have seen that reflexes play a very important part in the responsive life of simple 
animals. They are equally important in our own lives. The involuntary brushing of a fly from the face, or the attempt to

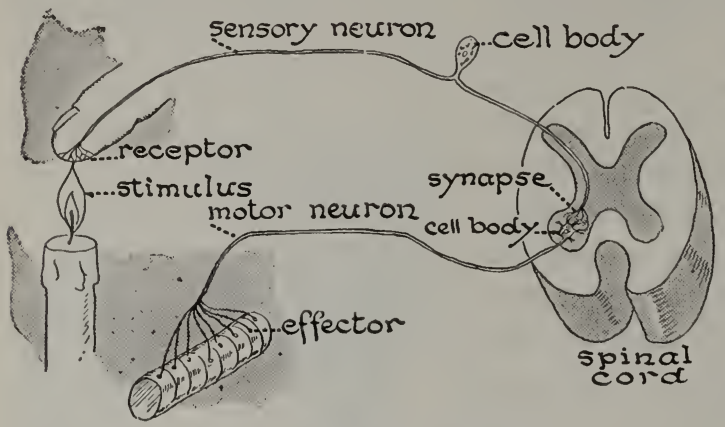

A reflex arc. Explain this diagram. move away from the source of annoyance when tickled with a feather, are examples of reflexes. In a reflex act, a person does not think before acting. The nervous impulse comes from the outside sensory cells to motor cells in the spinal cord, or in the cerebellum, the lower part of the brain. The message is short-circuited back to the surface by motor nerves, without ever having reached the thinking centers.

Practical Exercise 3. Make a list of all the reflex acts that you have made during the past twenty-four hours. Approximately what proportion of your actions are reflexes?

The brain of man. In man, the central nervous system consists of a brain and spinal cord inclosed in a bony case. From the brain, twelve pairs of nerves are given off ; thirty-one pairs more leave the spinal cord. The brain has three divisions. The cerebrum makes up the largest part. In this respect it differs from the cerebrum of the frog and lower vertebrates. It is divided into two lobes, the hemispheres, which are connected with each other by a broad band of nerve fibers. The outer surface of the cerebrum is gray. It shows many convolutions or folds which give a large surface. The cell bodies and synapses of the neurons are found in this part of the cerebrum. Holding the cell bodies and fibers in place is a kind of connective tissue. The inner part (white in color) is composed largely of nerve fibers which pass to other parts of the brain and down into the spinal cord. Below the cerebrum lies a smaller portion of the brain, the cerebellum. The two sides of the cerebellum are connected by a band of nerve 
fibers, the pons, which run around into the lower part of the brain or medulla oblongata. The medulla is the enlarged beginning of the spinal cord, and is made up largely of fibers running longitudinally.

Functions of parts of the central nervous system of the frog. From studies of lower animals scientists have learned about the functions of various parts of the central nervous system in man.

It has been found that if the entire brain of a frog is destroyed or separated from the spinal cord, the frog will continue to live. It will not move or croak, but if acid is placed upon the skin the legs will make movements to push away and to clean off the irritating substance. The spinal cord is thus shown to be a center of defensive movements. If the cerebrum is separated from the rest of the nervous system, the frog seems to act a little differently from the normal animal It jumps when touched, and swims when placed in water. It will croak when stroked, or swallow if food is placed in its mouth. But it manifests neither hunger nor fear, and is in every sense a machine which will perform certain actions after certain stimulations. Its movements are automatic. The cerebellum and medulla then must be the centers of muscular coördination and automatic or involuntary movements. If we

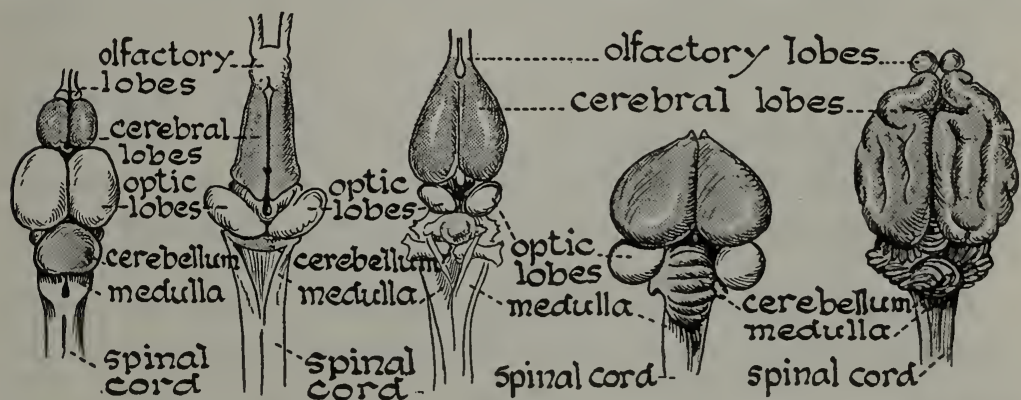

Brains of a perch, frog, alligator, pigeon, and cat. Can you tell, from diagrams, why a cat has more intelligence than a pigeon or a fish?

watch the movements of a frog which has the brain uninjured in any way, we find that it acts spontaneously. It tries to escape when caught. It feels hungry and seeks food. It acts like a normal frog This shows that the cerebrum is the center of all voluntary activities. 
Localization of functions. In a general way, our central nervous system is like that of the frog. The autonomic activi-

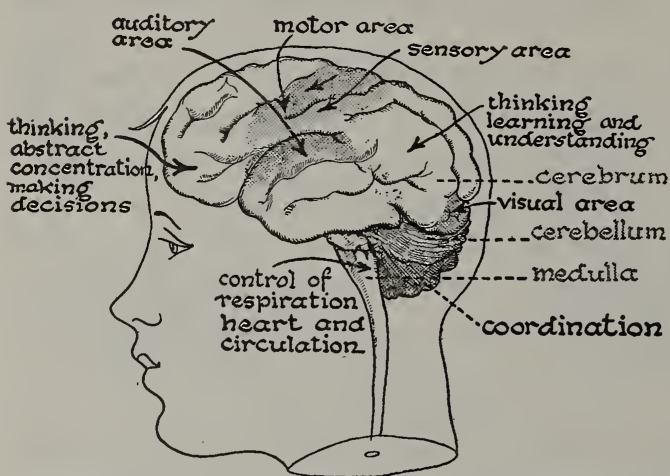

According to the observations of physicians and the experimentations of scientists certain functions are thought to be controlled by different portions of the brain.

ties are largely controlled outside the brain. The cerebellum and spinal cord take care of the habitual reflexes which we learned when growing into childhood. The cerebrum has to do with a large number of conscious activities.

A large part of the area of the outer layer of the cerebrum seems to be given over to some one of the different functions of hearing, sight, touch, and movements of body parts. The movement of the smallest part of the body appears to have its definite localized center in the cerebrum. In addition, certain areas have to do with association and memory; that is, the cells store memories of past acts or things. Those areas have to do with our voluntary actions, for the stored memories are really stored sensory impressions. Voluntary acts, then, are the completion of reflexes. Even reasoning may be explained as the association of concepts, the relation of which is not close. Reasoning is perceiving relationships in seemingly unrelated facts.

Functions of the nervous system of man. There are several types of activities over which the nervous system has control. 'The first are the so-called autonomic activities of the body. The heart beats and we breathe when we are asleep as well as when we are awake. Our glands emit secretions and our kidney cells excrete wastes, all without any consciousness on our part.

A second kind of function is the kind of activity which once was learned but now has become "second nature" or habitual. If we have well-regulated body machines, we get up in the morning, 
automatically wash, clean our teeth, dress, go to the toilet, eat our breakfast, walk to school, and even perform such complicated processes as that of writing, without thinking about or directing the machine. Certain acts which once we learned consciously have become automatic.

Early in our lives we begin to gain a higher control of our body activities. We then make conscious choice; we weigh one course of action against another and decide which is the best course for us to follow - in short, we think. This is the highest type of conscious activity.

Through the sense organs the nervous system keeps us in touch with the outside world.

\section{Self-Testing Exercise}

Check the correct statements in your workbook:

T.F. 1. Man's body is controlled by his brain.

T. F. 2. A neuron is a nerve cell.

T. F. 3. The autonomic nervous system regulates functions which are beyond our control.

T. F. 4. We see and hear in our brain.

T. F. 5. Sensory nerves send outgoing messages.

T. F. 6. Motor nerves send messages toward the central nervous system.

T. F. 7. The human brain consists of convolutions, hemispheres, and thirty-one pairs of nerves.

T. F. 8. There are three types of functions over which the human brain has control: the autonomic, activities such as the beating of the heart, or secreting of glands; the habitual; and those having to do with conscious thought processes.

T. F. 9. The cerebellum controls our conscious activities.

T. F. 10. More of our daily actions are voluntary than habitual.

\section{PROBLEM V. WHAT PART DO THE SENSE ORGANS PLAY} IN THE CONTROL OF THE BODY?

Laboratory Exercise. Blindfold a pupil. Then lightly touch the back of his hand with the two points of the dividers. Begin with them close together and gradually move them apart. Have the blindfolded person tell as soon as he feels the two points separately. 
Experiment further on various parts of the body, and record the results in the form of a table.

\begin{tabular}{|c|c|c|}
\hline & Place Todched & Distance between Points \\
\hline Back of Hand & & \\
\hline Palm of Hand & & \\
\hline Finger Tips . & & \\
\hline Wrist . . . & & \\
\hline Upper Arm . & & \\
\hline Back of Neck & & \\
\hline Back . . . & & \\
\hline
\end{tabular}

Which part of the body seemed most sensitive to touch?

Laboratory Exercise. With a ruler and a pen, draw a square inch on the underside of your wrist. Heat a wire nail until it feels very hot. Now lightly touch all parts of the skin within the square area. Do all parts feel the heat, or only the sense of slight pressure of the nail? Mark with a little cross all spots that are sensitive to heat.

Now cool off the nail by placing it on ice. Wipe it dry and apply while still cold in the same way to the area marked off on the wrist. Do you feel the sensation of cold in all spots? Mark as before, this time using a dot.

Do all parts of the skin feel heat and cold? What does this mean?

Laboratory Exercise. What is the relation between taste and smell ?

Cover your eyes and hold your nose tightly with the fingers. Have another pupil place on your tongue very small pieces of peeled apple, peeled raw potato, peeled raw turnip, and onion. Have the pieces exactly the same taste? Have some one record the results. Are you aware of the different flavors? Are you aware of them with the nostrils open? Try the experiment with a number of other substances, as sugar, vinegar, vanilla, mustard, salt, and spices.

Rub the tongue dry. Place a little sugar on it. In what condition must materials be in order to be tasted?

In tabular form note those substances which are recognized by taste only and those which are recognized by taste and smell. 


\begin{tabular}{|c|c|c|}
\hline & RECogitized by TASTE & RECOGNized by TaSte aNd SMeLI \\
\hline Apple . . . . & & - \\
\hline Onion . . . . & & \\
\hline Potato . . . . & & \\
\hline Turnip . . . . & & \\
\hline Salt . . . . & & \\
\hline Sugar . . . . & - & \\
\hline Mustard . . . & & \\
\hline Vanilla . . . . & & \\
\hline Vinegar . . . . & & \\
\hline
\end{tabular}

What is the relation of taste and smell in distinguishing flavors?

Taste. The surface of the tongue is folded into a number of little projections known as papillae ( $\mathrm{p} \dot{a}$-pill' $\overline{\mathrm{e}})$. In the folds between these projections, near the root of the tongue, are located the organs of taste. These organs are called taste buds.

Each taste bud consists of a collection of spindleshaped neurons, each cell tipped at its outer end with a hairlike projection. These cells send fibers in-

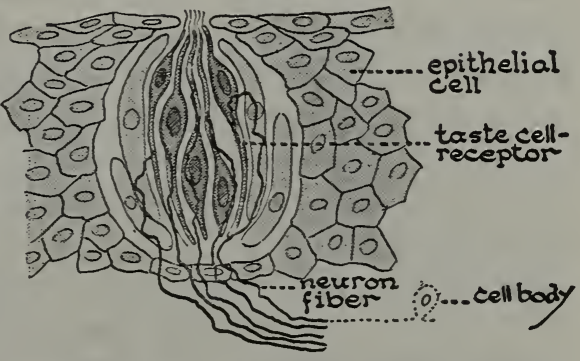

A taste bud. Where is the sensation of taste found? ward to other cells, the fibers from which ultimately reach the brain. The sensory cells are surrounded by a number of protecting cells which are arranged in layers about them. Thus

$$
\text { ㅂ. BIO }-29
$$


the organ in longitudinal section looks somewhat like an onion cut lengthwise.

Four kinds of substances may be distinguished by the sense of taste. These are sweet, sour, bitter, and salt. Certain taste cells located near the back of the tongue are stimulated only by a bitter taste. Sweet substances are perceived by cells near the tip of the tongue, sour substances along the sides, and salt about equally all over the surface. Taste and smell are often confused and many things which we believe we taste are in reality perceived by the sense of smell.

Smell. The sense of smell is located in the membrane lining the upper part of the nose. Here are found a large number of rod-

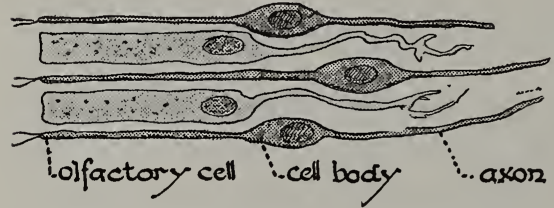

Olfactory cells. Where is the sense of smell located? shaped cells which are connected with the fore brain by means of the olfactory nerve. In order to perceive odors, it is necessary to have them, either as minute particles of solid matter or as gases, diffused in the air. If we wish to smell particularly well, we sniff so as to draw the air higher in the nasal chambers and nearer the olfactory cells.

Hearing. The organ of hearing is the ear. The outer ear consists of a funnel-like organ composed largely of cartilage which is of use in collecting sound waves, and the auditory canal, which is closed at the inner end by a tightly stretched membrane, the tympanic membrane. The function of the tympanic membrane is to receive sound waves or vibrations in the air, which are transmitted, by means of a complicated apparatus found in the middle ear, to the inner ear.

Middle ear. The middle ear is a cavity inclosed by the temporal bone, and separated from the outer ear by the tympanic membrane. A little tube called the Eustachian tube connects the inner ear with the mouth cavity. By allowing air to enter from the mouth the air pressure is equalized on the tympanic membrane. For this reason we open the mouth at the time of a heavy explosion and thus prevent the rupture of the delicate tympanic membrane. 
Placed directly against the tympanic membrane, and connecting it with another membrane which separates the middle from the inner ear, is a chain of three tiny bones, the smallest of the body. They are held in place by very small muscles which are delicately adjusted so as to tighten or relax the membranes guarding the middle and inner ear.

The inner ear. The inner ear is one of the most complicated, as well as one of the most

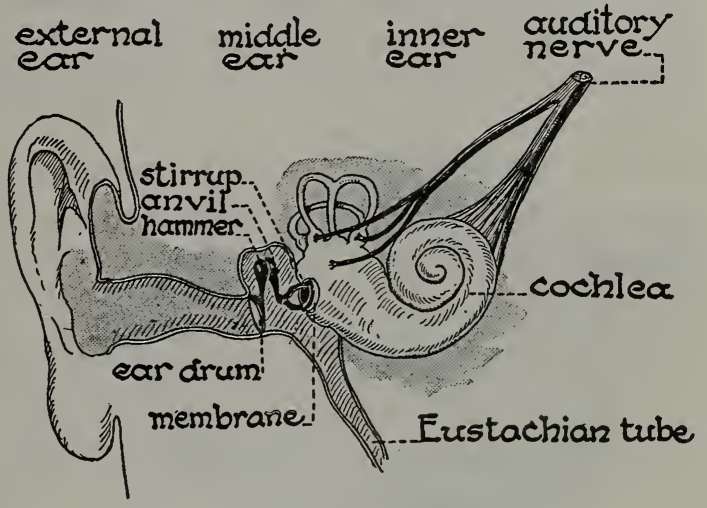

Explain from the diagram, how we hear? delicate, organs of the body. Deep within the temporal bone there are found two parts, one of which is called, collectively, the semicircular canals, the other the cochlea (kǒk'lè- $\dot{a}$ ).

It has been discovered by experimenting with fish, in which the semicircular canal region forms the chief part of the ear, that this region has to do with the equilibrium or balancing of the body.

That part of the ear which receives sound waves is known as the cochlea (Lat., snail shell) because of its shape. This complicated organ is lined with sensory cells provided with cilia, and its cavity is filled with a fluid. It is believed that somewhat as a stone thrown into water causes ripples to emanate from the spot where it strikes, so sound waves are transmitted by means of the fluid filling the cavity to the sensory cells of the cochlea and thence to the brain by means of the auditory nerve.

The character of sound. When vibrations which are received by the ear follow one another at regular intervals, the sound is said to be musical. If the vibrations come irregularly, we call the sound a noise. If the vibrations come slowly, the pitch of the sound is low; if they come rapidly, the pitch is high. The ear 
is able to perceive as low as thirty vibrations per second and as high as almost thirty thousand.

Seeing. The organ of vision, the eye, is almost spherical, and fits into a socket of bone, the orbit. A stalklike structure, the optic nerve, connects the eye with the brain. Free movement is made possible by means of six little muscles which are attached to

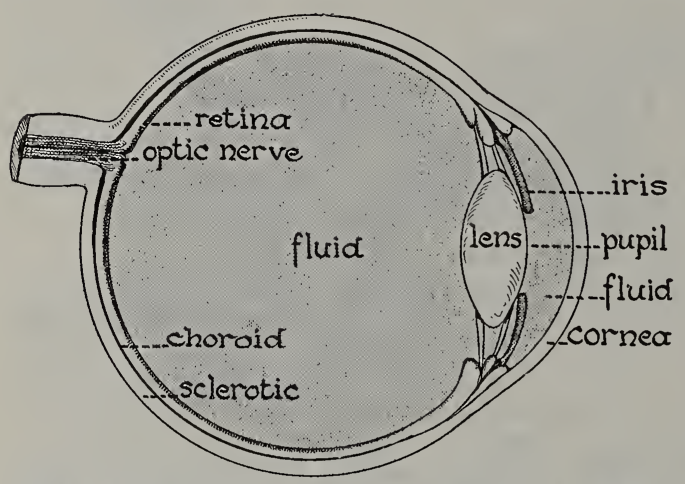

What happens to the eye when we pass from a brightly lighted room into a dark room?

the outer coat of the eyeball, and to the bony wall around the eye.

The wall of the eyeball is made up of three coats. An outer tough white coat of connective tissue is called the sclerotic (sklè-rŏt'ík) coat. In front, where the eye bulges out a little, this outer coat is replaced by a transparent tough layer called the cornea. A second coat, the choroid (kó'roid), is supplied with blood vessels and cells which contain pigments. The iris is part of this coat which we see through the cornea as the colored part of the eye. In the center of the iris is a small circular hole, the pupil. The iris is under the control of muscles, and may be adjusted to varying amounts of light, the hole becoming larger in dim light, and smaller in bright light. The inmost layer of the eye is called the retina (rět'ǐ-nda). This is, perhaps, the most delicate layer in the entire body. Despite the fact that the retina is less than $\frac{1}{80}$ of an inch in thickness, there are several layers of cells in its composition. The optic nerve enters the eye from behind and spreads out over the surface of the retina. Its finest fibers are ultimately connected with numerous elongated cells, which are stimulated by light. The retina is dark purple in color, this color being due to a layer of cells next to the choroid coat. This accounts for the black appearance of the pupil of the eye, when we look through 
it into the darkened space within the eyeball. The retina acts as the sensitized plate in the camera, for on it are received the impressions which are transformed and sent to the brain and result in sensations of sight. The eye, like the camera, has a lens. This lens is formed of transparent, elastic material. It is directly behind the iris and is attached to the choroid coat by means of delicate ligaments. In front of the lens is a small cavity filled with a watery fluid, the aqueous humor, while behind it is the main cavity of the eye, filled with a transparent, almost jelly-like, vitreous humor. The lens itself is elastic. This circumstance permits a ehange of form and, in consequence, a change of focus upon the retina of the lens. By means of this change in form, or accommodation, we are able to see both near and distant objects.

Practical Exercise 4. Make a diagram to show exactly what changes take place in the eye when you look from your book out of the window to focus on something coming down the far end of the street.

\section{Self-Testing Exercise}

There are areas on the skin that are sensitive to $\ldots . \ldots$ (1), (2), and ........ (3). The organs of taste are the ....... (4)

(5). The kinds of substances distinguished by taste are (6), $\ldots \ldots$ (7), $\ldots \ldots \ldots(8)$, and $\ldots \ldots$ (9). The sense of smell is located in the .......(10) lining the ....... (11) part of the nose. The organ of hearing is the ......(12). It is composed of the .......(13), ......(14), and ......(15) (16). The .......(17) receives the sound waves which are transmitted to the ....... (18) by the ...... (19) ...... (20). The eye is covered by three coats ......(21), ......(22), and ....... (23). Impressions of seeing are made on the ....... (24), which are carried to the .......(25) by the .......(26) $\ldots \ldots$ (27). The $\ldots \ldots \ldots(28)$ in form of the lens of eye is called ........ (29).

\section{PROBLEM VI. WHAT BEHAVIORS ARE INSTINCTIVE?}

Demonstration 5. What actions of a newly hatched chick are instinctive?

Place a newly hatched chick on a small tray, with food and water. Place on the tray small, bright-colored, distasteful substances. Watch the chick and make careful record of all its actions. List as many as you can as instinctive. Are instinctive acts always useful? 
Instinctive behavior. In many animals certain important behaviors in life are instinctive, that is, they are performed for the first time without being learned. A wasp lays its eggs in the body of a caterpillar, which it first paralyzes by stinging; the oriole weaves its nest; the swallow builds its nest of mud; the trapdoor spider makes its tunnel in the ground and furnishes it with a door - all these and thousands of other examples might be given. The complicated activities of the pronuba moth (see page 94) can be explained only by instinct, for the moth dies

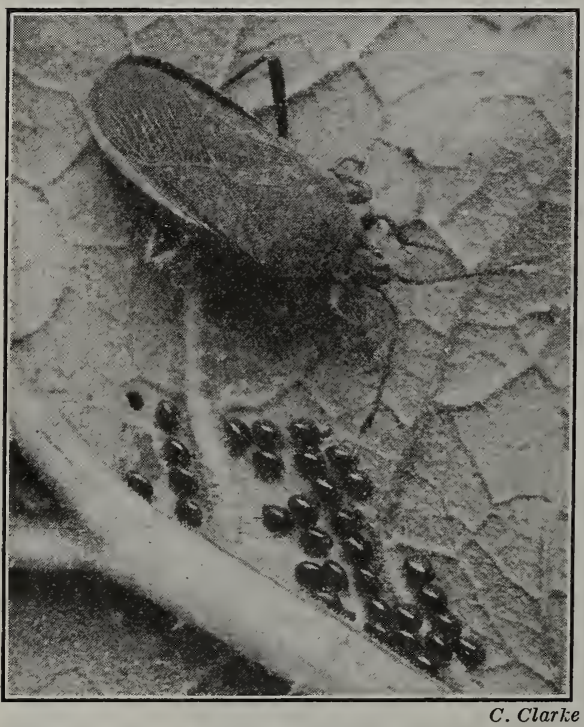

The squash bug fastens her brown shiny eggs with care beside the midrib of the underside of a large squash leaf which the larvæ will feed upon as soon as they hatch. without ever seeing her offspring.

Instincts can best be explained, as workers with insects have shown, as a chain of inborn automatic responses or simple reflexes. For example, an insect's making a nest, stinging the prey, and laying eggs are a series of behaviors, each one depending upon the one before. If we interrupt the sequence, as by removing most of the food supply from the nest, or by giving a fly paper soaked in meat juices, instead of decayed flesh, in which to lay its eggs, the life cycle is ended because the insect cannot modify its actions. As Professor Hodge says, a housefly is about as intelligent as a shot rolling down a board. Once the chain of behaviors is set in motion by some outside stimulus, it continues until the life cycle is completed by egg laying.

Modification of instinctive behavior. Although the French naturalist, Fabre ( $\left.\mathrm{fa}^{\prime} \mathrm{br}^{\prime}\right)$, found that a certain wasp which drags 
its grasshopper prey by one antenna would not touch its prey if both antennae were cut off, yet there are examples of instinctive behaviors being modified for the benefit of the animal. Some insect larvae, if they have consumed all of the plant on which they usually feed, will eat other kinds of leaves and thus save their lives. Fish and frogs can be taught to form new associations, for after many errors they will learn to avoid obstacles placed between them and their food. A dog can be taught to refrain from eating a lump of sugar placed on his nose until a word is spoken, because he has formed new connections which considerably change his natural behavior. Such modified responses, which are caused by new stimuli, are said to be conditioned. The new response made by the dog is conditioned by an association formed by the dog's master.

Practical Exercise 5. Think of some of your pets, as a dog or a bird, and make a list of the instinctive acts performed by this animal. Have you ever tried to condition one of these instinctive responses? Why are instincts important in the lives of animals? Give some examples of household pets that show how instincts may be modified.

\section{Self-Testing Exercise}

Instincts are usually explained as .........(1)

(3). Instinctive acts are often ........(4) in lower animals. When simple ........(5) become.........(6), they are said to be ...... (7). Such a reaction is usually caused by a new or different .......(8). If some animals are not able to ......(9) their ....... (10), they die.

\section{PROBLEM VII. HOW ARE HABITS FORMED?}

Some of our earliest acts or behaviors are instinctive. Babies do not have to be taught to suck; but as they grow older they modify this instinct. They learn to take food from a spoon and to wait for it. Later on they learn, by a series of trials, to stand erect and then to walk. There is a difference between the instinct of sucking and the habits which are learned through repetition when the child is compelled to take other food than its mother's milk. A habit might be called an acquired automatic activity. 


\section{MAN BECOMES THE CONQUEROR OF THE WORLD}

Practical Exercise 6. For every good habit formed there is an opposite bad habit. From the list of good habits named below name the opposite bad habits.

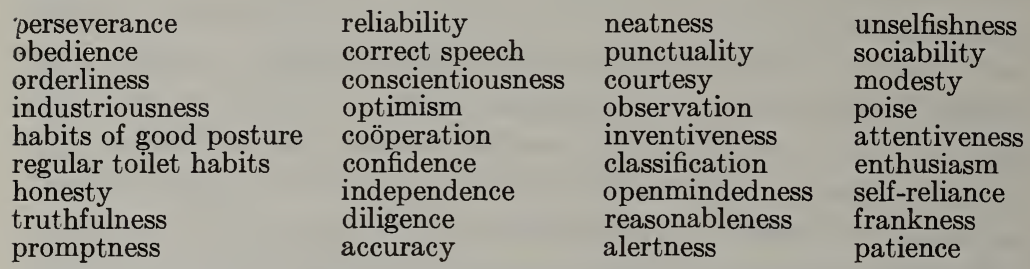
form?

Which of the above-named habits do you have? What habits should you

Habit formation. One object of education is the training of the different areas in the cerebrum to do their work. When we first tried to write, we had to exert conscious effort in order to make the letters. Now the act of forming the letters is done without our thought. By training, the act has become a habit. The actual performance of the action is then taken up by the cerebellum, medulla, and spinal ganglia. Thus the thinking portion of the brain is relieved of this work.

It is surprising how little real thinking we do during a day, for most of our acts are habitual. Habit takes care of our dressing, our bathing, our care of the body organs, our methods of eating. Even our movements in walking and our style of handwriting are matters of habit formation. We are bundles of habits, be they good ones or bad ones.

Different kinds of habits. Habits are of many kinds. They may concern health and well-being, as proper tooth brushing, eating at regular times, maintaining a correct posture, and hundreds of simple things we do automatically. Some concern our dress and our actions in society. We walk, ride, dance, skate, or drive a car without consciously thinking about what we are doing. Our habits of disposition have become a very important part of our lives. We may frequently be sad or be happy, sing or cry, or be kind, or be cross. We may form our habits of thought, too : concentration or scatter-brain methods, ability to think through our problems, or inability to do any real thinking - it all depends upon ourselves. Man has conquered many factors in his environment through 
training his body to do certain things effectively. The most important thing is the control of his nervous system, because it is through the effective use of it that he gets things done. If you will be conqueror in your sphere of life, learn how to control your own thoughts and deeds. In this way you will be prepared to conquer in the bigger field of activity which you will enter later.

Habits must be formed early. We have often heard the saying, "You can't teach an old dog new tricks." This is all too true of habit forming. We exercise our muscles and they grow larger. Not so with our brain cells. We probably all have the same number of neurons, but there is an unlimited number of possible connections between them, which may result in a great many habitual activities. Every time a new act is performed a new connection, synape, is made between two neurons. While the nervous system is young the cells are plastic, and pathways are easily established between cells. These pathways, like a rut in soft mud, become deeper and deeper with use. Habits are, therefore, readily formed at this time. "Practice makes perfect" is a truism, but it illustrates how a habit is formed. Fortunate are the boys and girls of the age who read this book, for they are able to form good habits easily. But a man or woman of middle age has formed habits, and to change them and make new ones is very difficult. The nervous system is no longer plastic.

Practical Exercise 7. What are the best ways of forming good habits? Write a short composition on this for your workbook.

What is the advantage of forming good habits in life? Does habit-forming relieve part of the nervous system from work? Explain fully. Explain the increased effectiveness and power acquired through good habits.

Importance of forming right habits. Among the habits which should be acquired early in life are those of studying properly, of concentrating the mind, of learning self-control, and, above all, of being content. Get the most out of the world about you. Remember that the immediate effect of the study of some subjects in school may not be great, but the cultivation of correct methods of thinking may be of the greatest importance later in life. The men and women who have learned how to concentrate on a problem, how to weigh all evidences with unbiased minds, and then to 
decide on what they believe to be right, are the efficient and happy ones of their generation.

"The hell to be endured hereafter, of which theology tells, is no worse than the hell we make for ourselves in this world by habitually fashioning our characters in the wrong way. Could the young but realize how soon they will become mere walking bundles of habits, they would give more heed to their conduct while in the plastic state. We are spinning our own fates, good or evil, and never to be undone. Every smallest stroke of virtue or of vice leaves its never-so-little scar. The drunken Rip Van Winkle, in Jefferson's play, excuses himself for every fresh dereliction by saying, 'I won't count this time!' Well! he may not count it, and a kind Heaven may not count it; but it is being counted none the less. Down among his nerve cells and fibers the molecules are counting it, registering and storing it up to be used against him when the next temptation comes. Nothing we ever do is, in strict scientific literalness, wiped out. Of course this has its good side as well as its bad one. As we become permanent drunkards by so many separate drinks, so we become saints in the moral, and authorities in the practical and scientific spheres, by so many separate acts and hours of work. Let no youth have any anxiety about the upshot of his education, whatever the line of it may be. If he keep faithfully busy each hour of the working day, he may safely leave the final result to itself. He can with perfect certainty count on waking up some fine morning, to find himself one of the competent ones of his generation, in whatever pursuit he may have singled out." - Willian James, Psychology. (Permission of Henry Holt \& Co.)

Some rules for forming good habits. Professor Horne gives several rules for making good or breaking bad habits. They are: First, act on every opportunity. Think of the good habits you would like to form and then form them. Second, make a strong start. No half-hearted effort ever was successful in forming a habit. Third, allow no exception. You cannot establish the new pathway in the nervous system, if you, like Rip Van Winkle, " don't count this one." Fourth, for the bad habit establish a good one. Most of us know our own faults. Some of us have far too many. Perhaps it is only a little thing such as forgetting some of the numerous conventionalities that make up table manners; it may be something far more important, an uncontrolled emotion or feeling. 
Anyway, there is some opposite helpful habit you can substitute in its place. For example, instead of saying sometimes, "That noise drives me wild," say nothing, but think to yourself, "there's no noise that I can't stand when necessary." Fifth, use effort of will. Habits which are rooted wher young in moral and religious training are those which in later life will do more than any others to steer us straight on the course we would take through life.

Practical Exercise 8. Explain how you would break some specific bad habit by using the rules quoted above:

Make a list of habits of mind that you would like to acquire. How would you go to work to do this?

\section{Self-Testing Exercise}

A habit is an acquired ....... (1) act. Learning to ........ (2) is such an act. Habits are most easily formed when we are ........ (3). "Practice makes perfect" is a good rule in ....... (4) ....... (5). In forming a habit: Act on every .......(6); make a strong . (7); allow no .......(8); replace ....... (9) habits with (10) habits; use your ........(11) of ....... (12).

\section{PROBLEM VIII. WHAT ARE SOME GOOD HEALTH HABITS?}

Health habits for the nervous system. The nerve cells, like all other cells in the body, are continually wasting away and being rebuilt. Oxidation of food material increases when we do mental work. The cells of the brain, like muscle cells, are not only capable of fatigue, but they show this in changes of form and of contents. Food brought to them in the blood, plenty of fresh air, and rest at proper times, are essential in keeping the nervous system in condition. One of the best methods of resting the brain cells is a change of occupation. Tennis, golf, baseball, and other outdoor sports combine muscular exercise with brain activity of a different sort from that of business or school work.

Necessity of sleep. But change of occupation will not rest exhausted neurons. For this, sleep is necessary. Especially is sleep an important factor in the health of the nervous system of growing children. A child needs ten hours of sleep, an adult, eight hours. When a person is sleeping, his brain cells have opportunity to rest and to store food and energy for their working period. 
Sleep is one way in which all the cells in the body, and particularly those of the nervous system, get their rest. The nervous
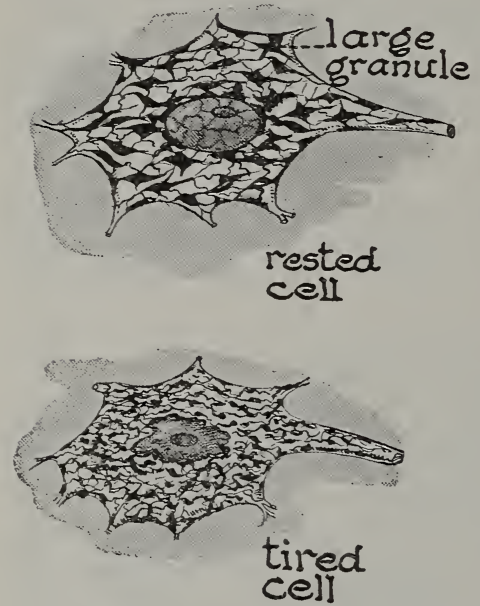

The effect of fatigue on a nerve cell. What has happened to the dark granules characteristic of a normal cell?

system, by far the most delicate and hardest-worked set of tissues in the body, needs rest more than do other tissues, for much of its work of directing the body ends only with sleep or unconsciousness. The afternoon nap, snatched by the brain worker, gives him renewed energy for his evening's work. It is not hard application to a task that wearies the brain; it is continuous work without rest.

Health habits for the sense organs. Overstimulation of any of the sense organs is a bad thing. The ear may be overstimulated by loud noises; the eye by too bright light; the olfactory cells by too heavy odors, the taste cells by too highly seasoned food. The most frequent habits of abuse of the eyes are using them for reading in a dull or flickering light or in too bright a light which makes a glare on the page. We should avoid looking directly into the source of any light.

The eyes are also subject to infection and injury from dust, cinders, flying bits of metal, etc. Certain trades in the past have taken a high toll of eye injuries, although now workers are protected by proper goggles. In case of soreness or irritation place a drop of newly prepared weak solution of argyrol in each eye. This may prevent serious eye trouble.

Many eyes are imperfect because the curvature of the lens is not normal. Such defects are a cause of headaches, and should be remedied by having an oculist prescribe corrective glasses.

Practical Exercise 9. Make two lists --- one of habits practiced by you that are detrimental to health and the other one of habits that promote good health. What can you do to improve your health? Show what habits would result in the protection of your eyes. 


\section{Self-Testing Exercise}

$\ldots \ldots$ (1),$\ldots \ldots$ (2), and ......(3) ......(4) are necessary to keep brain cells healthy. Change of occupation is good for exhausted neurons but ....... (5) is better. The most frequent abuses to the eyes are reading in $a \ldots \ldots .(6) \ldots \ldots .(7) \ldots \ldots .(8)$ or in a ....... (9).

\section{PROBLEM IX. WHAT ARE SOME EFFECTS OF THE DRINK HABIT?}

The drink habit. Although prohibition has made it harder for all people to obtain liquors, many still drink and some seemingly cannot help it. Let us see why.

The first effect of drinking alcoholic liquors is that of exhilaration. After the feeling of exhilaration is gone, for this is a temporary state, the drinker feels depressed and less able to work than before he took the drink. To overcome this feeling, he takes another drink. The result is that before long he finds a habit formed from which he cannot easily change.

The economic effect of alcoholic poisoning. In the struggle for existence, it is evident that the man whose intellect is the quickest and keenest, whose judgment is most sound, is the man who is most likely to succeed. The deadening effect of alcohol upon the nerve centers must place the drinker at a disadvantage.

Dr. Parkes experimented with two gangs of men, selected to be as nearly similar as possible, in mowing. He found that with one gang abstaining from alcoholic drinks and the other not, the abstaining gang could accomplish more. On taking away the alcohol from the one gang and giving it to the other, the same results were obtained. Similar results were obtained by Professor Aschaffenburg of Heidelberg University, who found, experimentally, that men "were able to do 15 per cent less work after taking alcohol." Many other experiments along the same lines have been made. In typewriting, in typesetting, in bricklaying, and in the highest type of mental work, the result is the same. The quality and quantity of work done by men on days when they take alcohol is less than on days when they take no alcohol.

The relation of alcohol to efficiency. We have already seen that neither is work done as well nor is as much accomplished by 
drinkers as by non-drinkers. Some relation of alcohol to efficiency is shown by the chart below, which was made prior to prohibition. During the week the curve of working efficiency is highest on Friday and lowest on Monday. The number of accidents were

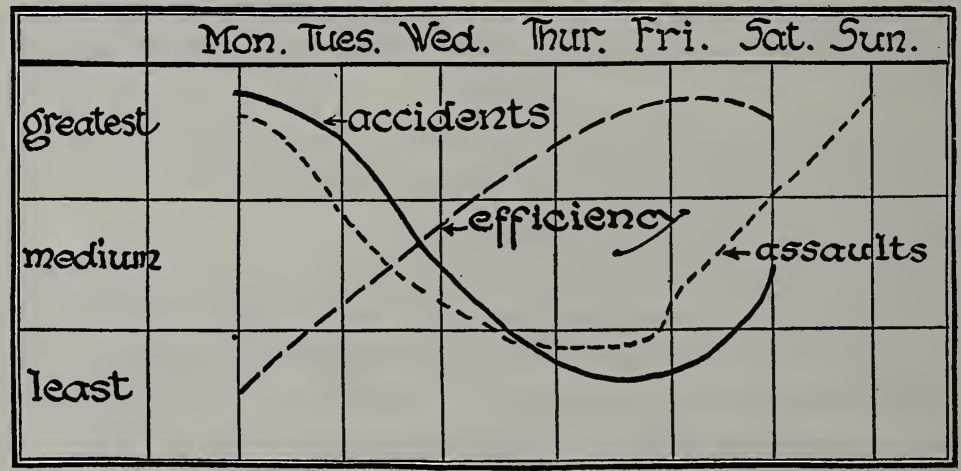

This chart was made prior to prohibition. Can you explain why the above facts were true?

also least on Friday and greatest on Monday. Lastly the assaults were fewest in number on Friday and greatest on Sunday and Monday.

Since the prohibition law went into effect, welfare organizations have reported a great decrease in cases of destitution and dependence caused by drink. Workmen today are saving their wages or investing in radio sets or in automobiles instead of drink. This is one of the greatest arguments in favor of prohibition.

The relation of alcohol to crime. A study, made just before the eighteenth amendment was passed, of more than 2500 habitual users of alcohol, showed that over 66 per cent had committed crime. Of 23,581 criminals questioned, 20,070 said that alcohol had led them to commit crime.

The relation of alcohol to pauperism. Studies of certain families which have long been a heavy burden on the state show that alcohol is at least partly responsible for their condition. Alcohol weakens efficiency and moral courage, and thus leads to begging, pauperism, petty stealing or worse, and ultimately to life in some 
public institution. In Massachusetts, of 3230 inmates of such institutions, 66 per cent were alcoholics.

Practical Exercise 10. Sum up the reasons why alcohol harms a person through its effects on the nervous system.

\section{Self-Testing Exercise}

Alcohol is a ........ (1). There seems to be a direct correlation between drinking and .......(2), and between drinking and . (3). Some experiments show that drinkers are ........(4) $\ldots \ldots(5)$ than non-drinkers. The $\ldots \ldots(6)$ of $\ldots \ldots \ldots(7)$ is
hard to overcome. Alcohol has harmful effects upon the ....... (8) hard to overcome. Alcohol has harmful effects upon the ........ (8) system.

\section{Review Summary}

Check your knowledge of the unit by: (1) rechecking on the survey questions; (2) performing the assigned exercises; (3) checking with your teacher the scores of the various tests and doing over all missed parts; (4) making an outline of the unit for your workbook.

\section{Test on Fundamental Concepts}

In a vertical column under the heading CORRECT write numbers of all statements you believe are true. In another column under INCORRECT write numbers of untrue statements. Your grade $=$ right answers $\times 2 \frac{1}{2}$.

I. Sense organs (1) are never located at the surface of the body; (2) usually consist of cells which are capable of receiving stimuli; (3) in lower animals are usually located in hairs or other structures at the outside of the body ; (4) put animals in touch with their surroundings; (5) are usually more numerous at the anterior end of an animal.

II. A reflex (6) is a structure formed on the outside of animals; (7) is seen in plants when the leaves close up in response to heat or light; (8) is the result of a stimulus and results in movement; (9) is seen when we involuntarily withdraw our finger from a hot object; $(10)$ is the result of a nerve impulse traveling to a nerve center, where it is translated into movement by means of an outgoing nerve impulse.

III. Stimuli (11) travel by means of nerves; (12) are received through sense organs; (13) often are felt as pain, pressure, heat; (14) are of no value to man; (15) are the means by which we are aware of our surroundings. 


\section{MAN BECOMES THE CONQUEROR OF THE WORLD}

IV. We see (16) by means of the retina which receives the light images; (17) in the brain and not in the eye; (18) because the retina transforms the stimulus caused by the light waves and transmits them by the optic nerve to the brain; (19) because our eye is like a camera - the eye becoming deeper or more shallow as we focus; (20) when through a change of shape the lens is focused on an object.

$\mathrm{V}$. The sense organs of man (21) are the nose, tongue, eyes, and skin; (22) are all external; (23) are connected by nerves with the central nervous system; (24) are made up of sensory cells ; (25) are not delicate enough to need protection, and so do not have any.

VI. Instincts (26) are actions that are performed without having first been learned; (27) are behaviors which are useful because they help preserve the race; (28) are acts that are carefully thought out before they are performed; (29) may be modified or conditioned through teaching; (30) serve to avoid dangers.

VII. Habits (31) may be either harmful or useful ; (32) are learned activities; (33) may be mental or physical ; (34) make up a large part of our life activities; (35) cannot easily be learned by young people.

VIII. The following are good rules for forming desirable habits: (36) never use will power; (37) allow no exceptions to occur; (38) never make a strong start; (39) have a real desire to build the habit; (40) act on every opportunity to make the desired reaction.

\section{Achievement Test}

1. How can you demonstrate what a tropism is and how it causes a living thing to react?

2. What are the different stimuli that affect the lives of plants and animals?

3. What is meant by the method of trial and error?

4. How can you demonstrate a reflex act?

5. Locate the parts of your nervous system, and tell the uses of each part.

6. How do we taste, touch, and feel hot or cold objects?

7. How do we hear?

8. How do we see? How can we compare the human eye to a camera?

9. How would you define instinct?

10. What is meant by a "conditioned" reflex? 
11. How can you take the proper steps in forming a good habit or breaking a bad one?

12. Why cannot one "teach an old dog new tricks"?

\section{Practical Problems}

1. Fill out the following table with reference to the sense organs in the human body.

\begin{tabular}{|l|l|l|l|}
\hline Organs & Location & What They Do & How They Do IT \\
\hline & & & \\
\hline & & & \\
\hline
\end{tabular}

2. Show exactly what happens in your nervous system when you touch a hot object in the dark.

3. How would you go to work to eradicate a bad habit?

4. Show that some act of your daily life is a "conditioned reflex."

\section{Useful ReFERENCes}

Dorsey, Why We Behave Like Human Beings. Chap. vi. (Harper \& Bros. 1925.)

Fabre, The Wonders of Instinct. (The Century Co. 1918.)

Horne, Psychological Principles of Education. (The Macmillan Co.)

Hunter, Laboratory Problems in Civic Biology. Pp. 161-168, inc. (American Book Company.)

James, Talk to Teachers on Psychology. (Henry Holt \& Co. 1914.) Jewett, Control of Body and Mind. (Ginn \& Co.)

Loeb, Forced Movements, Tropisms and Animal Conduct. Chap. xviii. (J. B. Lippincott and Co. 1918.)

Watson, Psychology from the Standpoint of a Behaviorist. (J. B. Lippincott and Co. 1924.) 


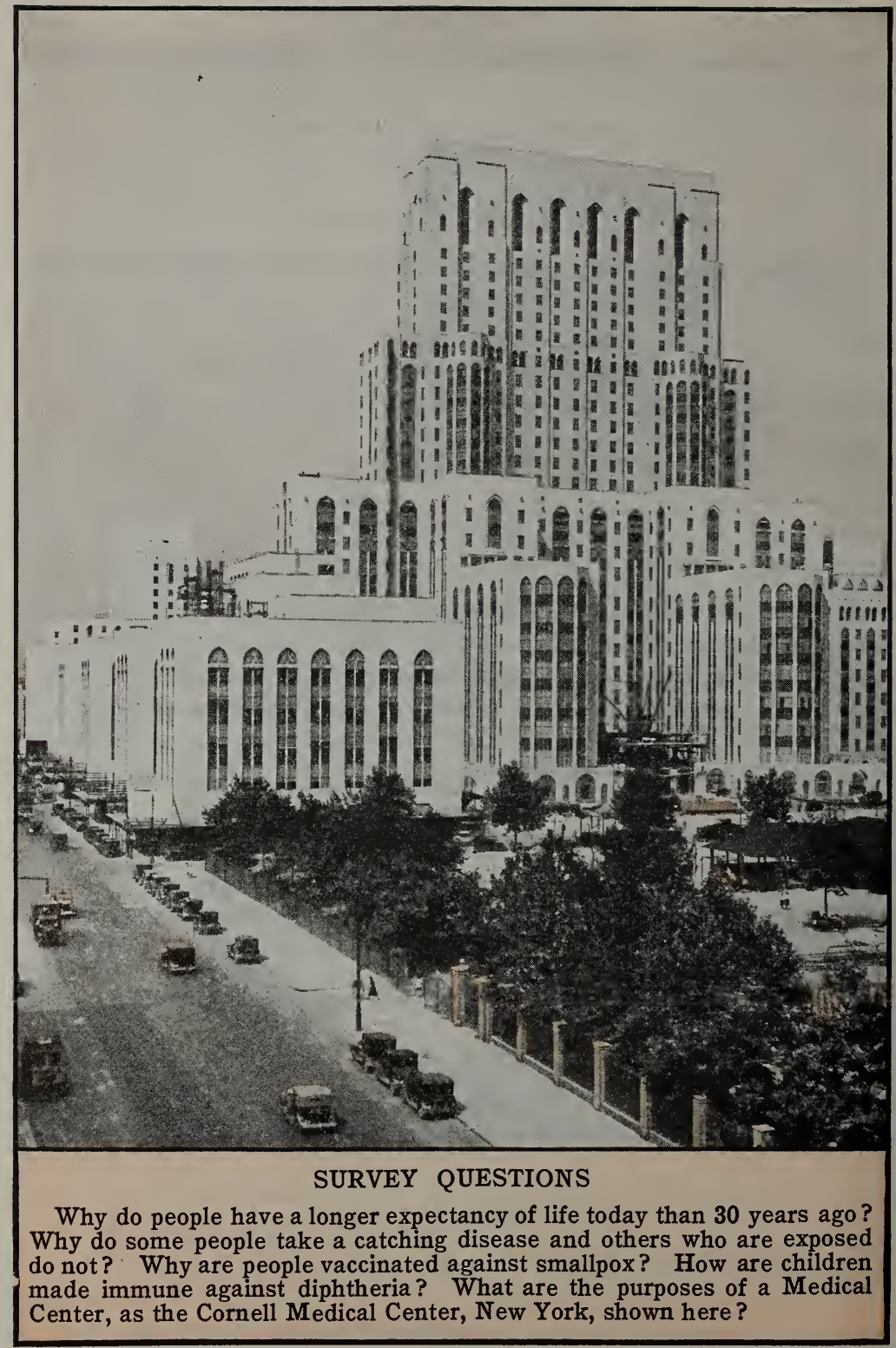

Ewing Galloway 


\section{PART V. MAN'S INTERRELATIONSHIP WITH OTHER LIVING THINGS}

\section{UNIT XV}

\section{HOW DOES MAN CONTROL HIS ENVIRONMENT FOR HEALTH?}

Preview. The body has been likened to an engine, in that each requires fuel and oxygen to work, produces wastes, and must have frequent rest in order to do efficient work. Both the machine and body may eventually wear out. But we do not speak of a sick machine, although we do speak of a sick person. What, then, is health? It is evidently a state in which the human machine runs efficiently. It is a state of well-being, or being well. A person may so abuse his body through lack of sleep, or exercise, or proper food that soon his body will not function properly. $\mathrm{He}$ may poison his body with alcohol or nicotine, and injure some of his internal organs so that he never recovers his former efficiency. He may meet with an accident and be crippled, or he may be attacked by some microscopic foes, bacteria, and suffer from infectious diseases. Diseases caused by these microörganisms cause more than half the common ailments of young people.

We have already learned something concerning the relation of bacteria and other colorless plants to disease. It is the purpose of this unit to show how some animals play a part in the cause and spread of disease. It is obvious that the relation is twofold. Animals may be parasites in man, causing certain diseases, or they may, acting as hosts, carry a parasite for part of their life histories. The malarial parasite and the hookworm are examples of the first type ; the mosquito, which carries the malarial parasite, 
and the flea, which transmits bubonic plague bacilli, are examples of the second type.

It is comparatively recently that we have discovered some of the very definite ways in which these parasites do us harm. I am not an old man, but I can well remember how my father used to keep me in at dusk as he pointed to the mist rising from the lowlands next the river and said, "See the malaria rising there." We did not know, little more than 30 years ago, that a certain kind of mosquito carried the organism that causes malaria and that the only connection between the mist and malaria was that those low-lying marshlands were alive with the mosquitoes which carry the disease organisms within their bodies.

In the control of diseases, prevention is far more important than attempts to cure. Experimentation and experience have taught us that health is closely associated with conditions in man's environment. We have learned to isolate the sick from the well, so that diseases may not be communicated. Many diseases have been partially or entirely controlled through scientific investigation and health education. Immunity or protection against disease may be both natural and acquired. The former is the immunity that one has at birth and stays with one throughout his life. The latter is acquired through the use of antitoxins, weakened living germs, dead germs, or extracts containing poisons made by germs, introduced into the body.

Doubtless it seemed irksome and needless to some of you that during an attack of measles the doctor insisted not only that you should be isolated from the rest of the young people in the family but also that you be kept in a darkened room for several days. Now, measles is not an eye disease and you may have wondered why he did this. If you had been older and wiser, you would have realized that certain parasitic diseases are more feared for the harm they may do the individual in later life than what they do at the time. Doctors could tell you of many cases where measles or scarlet fever have left a trail of weakened body organs which have made people semi-invalids and sent some to early graves. It pays to care for oneself at the time of an illness. 
We also hear a good deal nowadays about the increase in the length of the life span. In every country except India in which vital statistics are available the expectation of life is steadily lengthening. In England, for example, in the decade between 18701880 the average expectancy of life for a child at birth was 42.98 years. In 1922 it was 56.95 years. In Massachusetts, where vital statistics have been kept for a longer period than some other states, in 1855 the expectancy of life was 39.77 years, in 1920 it was 55.25. In the United States (registration area), in 1901, the expectancy of life was 49.24 years, in 1926 it was 57.74 years, and at the present time it is over 58 years. Why is this so? Principally because we are gaining mastery over the diseases caused by bacteria and especially diseases of young children. Dr. Vincent of the Rockefeller Foundation said recently that 80 per cent of the illnesses of man could be avoided if people were willing to obey health laws and live as well as they know how. Then, too, we are learning that health is closely associated with conditions in man's environment and that it pays from every viewpoint to have good sanitation and housing. We are learning to quarantine the sick, so that diseases may not be so easily communicated as in the past. And we have built many and vast "temples of healing" - hospitals and sanitariums, where the sick are brought back to health.

\section{PROBLEM I. HOW MAY WE CONTROL THE GROWTH OF BACTERIA?}

Demonstration 1. To show the effect of temperature on the growth of bacteria.

Number four tubes containing bouillon. Place number one in the ice box, number two in a dark box at a moderate temperature, number three in a box at a hot temperature $\left(120^{\circ} \mathrm{F}\right.$. or over), and boil number four for 15 minutes and then place with number two.

Note in which tube the greatest amount of growth takes place. Note the odor as well as the color of bouillon. Note in which tube the least growth takes place.

Describe the effect of intense heat on bacteria? Would the sand of a desert contain many bacteria? The ice of the polar regions? From this experiment we derive the very important method of fighting bacteria by means of sterilization. Give a definition of sterilization. 
Sterilization. Bacteria grow very slowly, if at all, in the temperature of an ice box, very rapidly from $70^{\circ}$ to $98^{\circ}$, and much less rapidly (or are killed) at a higher temperature. Those bacteria which form spores resist a great deal of heat and may even be

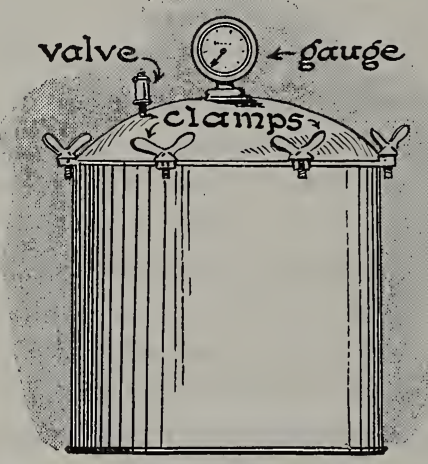

Why an 1 when is a pressure cooker used? boiled for some time without injury. The practical lessons drawn from these facts are many. We boil our drinking water if we are uncertain of its purity; we cook foods that we believe might harbor bacteria, and thus keep them from spoiling. The industry of canning is built upon this method of sterilization.

Canning. Canning is simply a method by which first the bacteria in a substance are killed by heating and then the substance is put into vessels and covered so that no more bacteria can gain entrance. The use of canned goods has completely changed the life of the sailor and the soldier, who in former times used to suffer from various diseases caused by lack of a proper balance of food.

Practical Exercise 1. What is the "cold pack" method of canning? What scientific principles are used in canning?

Cold storage. Man has learned to use cold to keep bacteria from growing in foods. The refrigerator at home and cold storage on a larger scale enable us to keep foods for a more or less long period. If food is frozen, as in cold storage, it might keep without growth of bacteria for years. But frozen foods after thawing are particularly susceptible to the bacteria of decay. For that reason products taken from cold storage must be used as soon as possible.

Demonstration 2. To determine the effect of pasteurization on the keeping quality of milk.

Place half of the milk in a sterilized jar, cover, and leave in a warm place for 24 to 48 hours.

Place the remainder of the milk in another jar, cover, and put it in the double boiler or pasteurizing apparatus. Keep the hot water 
surrounding the jar from $160^{\circ}$ to $180^{\circ} \mathrm{F}$. for about 30 minutes. This is known as pasteurization. Afterwards treat exactly as you did the first jar of milk.

What is the odor of milk in each jar after 24 and 48 hours? What is the taste of the milk in each jar after 24 and 48 hours?

What are found in milk that cause it to sour? How do you know? What is the use of pasteurization?

Pasteurization. Milk is one of the most important food supplies of mankind. It is also one of the most difficult things to get in good condition. This is due in part to the fact that milk is often produced at long distances from the place where it is used and must be brought first from farms to the railroads, then shipped by train, taken to the milk supply depot, bottled, and again taken by delivery wagons to the consumers. During each successive handling and exposure to the air the milk receives more bacteria. When we remember that much of the milk used in San Francisco, St. Louis, Chicago, New York, and other large cities is from twelve to thirty-six hours old before it reaches the consumer, and when we realize that bacteria grow very rapidly in milk, we see the need of finding some way to protect the supply so as to make it safe, particularly for babies and young children. This is done by pasteurization, a method named after the French bacteriologist, Louis Pasteur.

Preservatives. A few substances check the development of bacteria and in this way preserve the food. Preservatives are of two kinds, those harmless to man and those that are poisonous. Of the former, salt and sugar are examples ; of the latter, formaldehyde and possibly benzoic acid.

Sugar. We have noted the use of sugar in canning. Small amounts of sugar are readily attacked by yeasts, molds, and bacteria, but a 40 or 50 per cent solution will effectually prevent such growths. Preserves are fruits boiled in about their own weight of sugar. Condensed milk is preserved partly by the sugar added to it; so are candied fruits.

Salt. Salt has been used for centuries to keep foods. Meats are smoked, dried, and salted; some are put down in strong salt solutions. Fish, especially cod and herring, are dried and salted. The keeping of butter is due to the salt mixed with it. Vinegar 
is another preservative. It, like salt, changes the flavor of materials kept in it and so cannot come into wide use. Spices are also all used as preservatives.

Harmful preservatives. Certain chemicals and drugs, used as preservatives, seem to be on the border line of harmfulness. Such are benzoic acid, borax, and boracic acid. These chemicals may be harmless in small quantities, but unfortunately in canned goods we do not always know the amount used; also, as a rule, food that needs such a preservative is of bad quality in the first place. The Pure Food Law makes it illegal to use any of these preservatives in food (excepting very small amounts of benzoic acid). Food which contains this preservative must be so labeled and should not be given to children or people with weak digestion. Unfortunately, people do not always read the labels, and thus the Pure Food Law is ineffective in its working.

Demonstration 3. To determine the most effective disinfectants. Inoculate test tubes containing bouillon with germs from a Petri dish culture. Number and label the tubes. Expose all tubes, unplugged, to air.

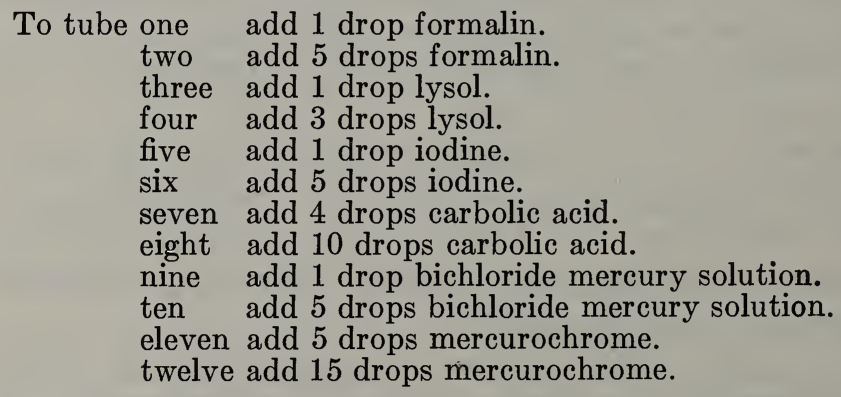

Tabulate daily, for a week or more, the results for the contents of each tube on a table.

Which of the above is the best disinfectant? Why do you answer as you do? (Remember that according to definition an antiseptic may retard the growth of bacteria but will not of necessity kill them; a germicide destroys all bacteria if used properly; while a disinfectant is a solution used to kill disease germs, usually in the excreta of sick people.)

Practical Exercise 2. Using the data from the preceding demonstration, classify the materials used, as antiseptics, germicides, or disinfectants. Give a reason for each. 
Disinfection. Frequently it becomes necessary to destroy bacteria with chemicals. This process is called disinfection. Although sunlight, dry heat, steam, and electricity kill germs, we commonly apply the term "disinfectant" to such substances as iodine, mercurochrome, potassium permanganate, chloride of lime, carbolic acid, formaldehyde, lysol, and bichloride of mercury. Of these, the last named is one of the most powerful as well as the most dangerous disinfectant to use. As it attacks metal, it should not be used in a metal pail or dish. It is commonly put up in tablets which are mixed to form a 1 to 1000 solution. Care must be taken of both the tablets and the solution to avoid a possible accidental poisoning.

Formaldehyde in solution, called formalin, is used as a disinfectant. When vaporized, it sets free an intensely pungent gas. Carbolic acid is an excellent disinfectant although it will not kill spores of bacteria. If used in a solution of about 1 part to 25 of water, it will not burn the skin. It is of particular value in disinfecting skin wounds. Lysol is another excellent disinfectant, because it can be used with soap. Iodine is often used as a skin disinfectant and in open wounds. One of the newest germicides is mercurochrome. It is particularly valuable for wounds and skin bruises in which bacteria might thrive.

\section{Self-Testing Exercise}

(1) kills bacteria. Canning makes use of the principle of $\ldots \ldots \ldots$ (2). Pasteurization of milk is performed best by heating (5) F. Harmless preservatives are ...... (6), ...... (7), (8), and ....... (9). Antiseptics are used to ....... (10) the ......... (11) of ........ (12). Disinfectants are used to...... (13) ....... (14). A germicide ....... (15) all ....... (16).

\section{PROBLEM II. HOW DO BACTERIA CAUSE DISEASE?}

Bacterial diseases. Bacteria cause many diseases in man. They accomplish this by becoming parasites in the human body. Millions upon millions of bacteria exist in the human body at all times - in the mouth, on the teeth, and especially in the lower part of 
the food tube. Some in the food tube are believed to be useful, some harmless, and some harmful; others in the mouth cause decay of the teeth, while a few species may cause disease. Such

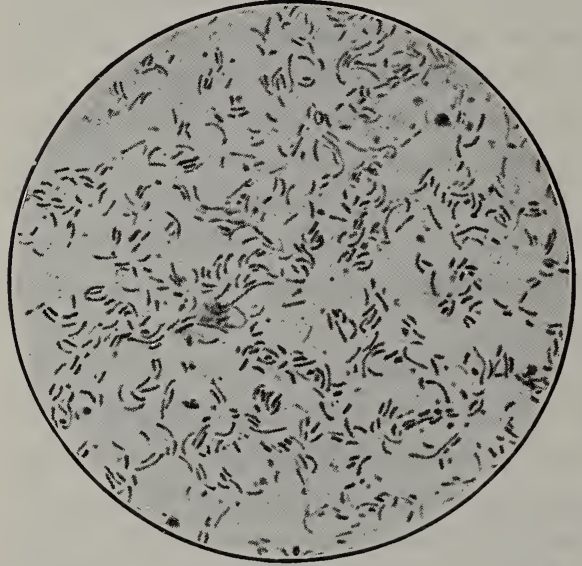

Roy $M$. Allen

A microphotograph of a Petri dish containing a pure culture of bacteria that cause cholera. disease-causing bacteria are called pathogenic.

It is known that bacteria, like other living things, take in food, form organic wastes within their own bodies, and give off some of them. These wastes, called toxins, are poisonous to the host on which the bacteria live, and cause the symptoms of certain diseases. Each species of bacteria forms its own specific toxin, and this has a specific action on the body, causing the symptoms of a specific disease. As bacteria can multiply rapidly in the body, they may become very numerous before the body defenses gain control of the situation. When the bacteria die, as they may in great numbers during the progress of the disease, their bodies break down, and the released protoplasmic constituents, particularly the proteins, separate from each other and split into smaller and smaller molecular groups, as do the proteins when changed to amino acids during digestion. These split proteins, as they are called, are extremely poisonous to the body tissues and act as toxins in the body, causing many of the characteristic symptoms of disease.

Some bacteria break down the body tissues, besides producing toxins. They may destroy the intestinal lining, or destroy the blood corpuscles, or break down tissues in wounds, thus causing specific symptoms of disease.

It was estimated not many years ago that bacterial diseases caused annually almost 50 per cent of the deaths of the human 
race. A very large proportion of these diseases might have been prevented if people were educated sufficiently to take the proper precautions to prevent the spreading of bacteria. Such precautions might' have saved the lives of some 3,000,000 people yearly in Europe and America. Tuberculosis, typhoid fever, bubonic plague, diphtheria, pneumonia, blood poisoning, and a score of other diseases ought not to exist. But within the last decade, due to the sacrifices and discoveries of men in medical science, the control of a number of bacterial diseases has been made possible. It is estimated, for example, that with the coöperation of the people, diphtheria might have been stamped out in New York state by the end of the year 1930. That this has not happened is due certainly to the number of uninformed people who will not or do not know how to coöperate with the medical authorities. A large amount of the present misery of this world might be prevented, and this earth made cleaner, better, and safer, by the coöperation of young people in carrying out and enforcing health regulations.

Practical Exercise 3. Make a table to show all the ways in which bacteria may cause disease and give an example under each heading.

\section{Self-Testing Exercise}

Bacteria cause almost .......(1) ...... (2) ...... (3) of the (4) of the human race. Many of these might have been (5) if people would .......(6) with the medical authorities. Bacteria cause disease either by forming ....... (7), releasing $\ldots \ldots$ (8), or by $\ldots \ldots$ (9) on the ......(10), thus breaking them down.

\section{PROBLEM III. HOW DO WE GET BACTERIAL DISEASES?}

How we get diseases. Bacteria causing infectious diseases enter the body either by the mouth, nose, or other body openings, or through a break in the skin. They may be carried by means of air, food, or water, but are more often transmitted directly from the person who has the disease to a well person. They may be acquired through personal contact, as kissing; in a spray of tiny droplets which are expelled into the air as a person talks; 
by handling or using articles, such as towels, handkerchiefs, cups, or dishes used by sick persons; or by drinking or eating foods which have received some of the germs.

Practical Exercise 4. Make a table to show all the ways in which bacteria gain entrance to the body and name a disease which gets into the body under each heading.

Project. To make a curve showing decrease of tuberculosis in your own state. (Use State Board of Health or Public Health Service Reports for this and following projects.)

Tuberculosis. One of the diseases responsible for the greatest number of deaths, perhaps one tenth of the total on the earth, is tuberculosis. Fisher estimates that tuberculosis has cost this country between $\$ 500,000,000$ and $\$ 1,000,000,000$ a year, by its toll of death, loss of work, maintenance of hospitals, sanitariums, etc. But this disease is slowly but surely being overcome. It is believed that within perhaps fifty years, with the aid of good laws

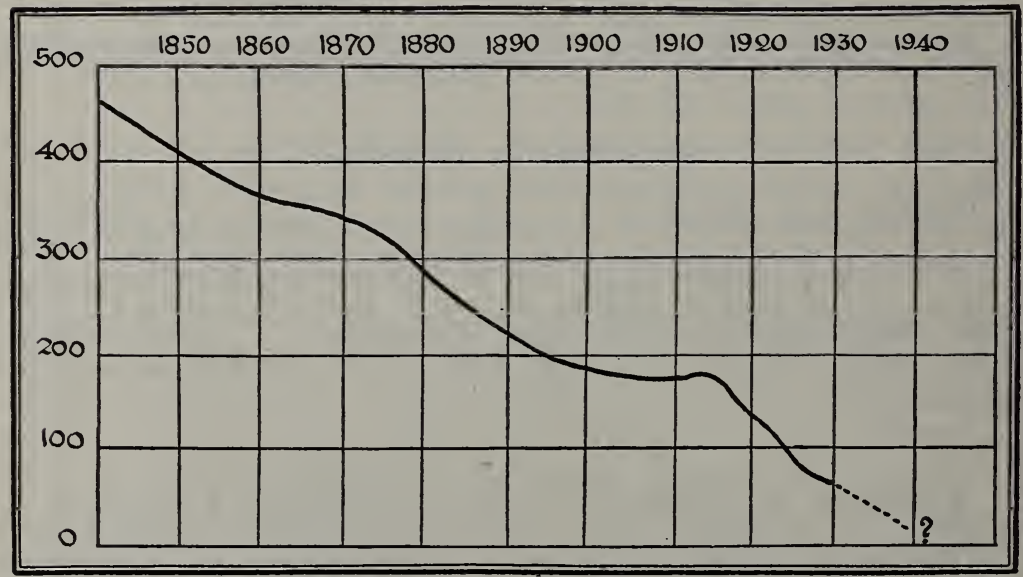

The number of death per 100,000 from tuberculosis has been steadily decreasing each year. If this rate continues there will be very few deaths in 1940 from this disease.

and sanitary living, it might become almost extinct. In 1900 , the death rate in the United States was 195.2 for each 100,000 inhabitants, in 1926 the death rate in the same area was only 84.5 per 100,000. In other words, according to Dr. Louis J. Dublin, there 
are about 130,000 fewer persons dying from tuberculosis each year in the United States than would have died if the tuberculosis death rate for 1900 still held for this area.

Tuberculosis is caused by the growth of bacteria, called the tubercle bacilli, within the lungs or other tissues of the human body. In the lungs they form little tubercles full of germs, which close up the delicate air passages, while in other tissues they may cause hip-joint disease, scrofula, lupus, and other diseases, depending on the part of the body they attack. Tuberculosis may be contracted by taking bacteria from people who have the disease, or by drinking milk from tubercular cows, for the germ that affects cattle causes some of the tuberculosis in children. Dr. William H. Park, a noted authority on bovine (cow) tuberculosis, states that in a large number of cases investigated by him 57 per cent of abdominal tuberculosis in very young children and 47 per cent of such tuberculosis in children under five years of age were of the bovine type. Fortunately, the germs of bovine tuberculosis can be killed by pasteurization of milk of doubtful purity.

Practical Exercise 5. Name some ways in which tuberculosis might be passed from one person to another.

Most of us probably take into our lungs at one time or another bacteria causing tuberculosis. Yet the bacteria seem able to gain a foothold only under certain conditions. It is only when the tissues are in a wornout condition, when we are "run down," as we say, that the parasite may obtain a foothold in the lungs or other organs. The disease may be arrested, and a permanent cure is often brought about, by a life in the open air, the patient living and sleeping out of doors, taking plenty of nourishing food, and very little exercise. The object of this kind of life is to build up the body resistance, so that the germs are rendered incapable of doing harm.

Tuberculosis is a serious disease to combat, because of the conditions which help to cause it. Contrary to common belief, it is not inherited; but unfortunately in families where there are tubercular persons, it is difficult to prevent giving the germs to people living with them, especially if they live in small crowded homes 
with little ventilation. Children of tubercular parents are often handicapped by a weak constitution and are therefore very susceptible to the disease.

Practical Exercise 6. Tuberculosis is said to be a social disease. Explain this statement.

Project. To determine the seasonal variation in the number of cases of diphtheria in your state.

Diphtheria. This disease is caused by bacteria which grow rapidly in the throat and form a false membrane there. But the most serious results come from the toxin, thrown off by the bacteria, which get into the blood and not only cause suffering and fever but also may have very serious after-effects on various body organs. As diphtheria is a throat disease, it may easily be conveyed from one person to another by the droplet method of infection.

Other diseases spread through mouth spray. Influenza, pneumonia, whooping cough, and certain kinds of colds, and many of the so-called children's diseases, are caused by bacteria or other microscopic organisms. Nearly all are spread by the "droplet method" of infection. In our army during the World War, influenza, coupled with pneumonia, was responsible for fourteen times as many deaths as were caused by shells and poison gases. This disease is periodically epidemic, the last bad outbreak previous to this being in 1889 . Influenza is apparently spread largely by human carriers, or people who have a slight attack but are capable of passing the disease on in its most serious form.

Project. Use the report on infectious diseases, United States Public Health Reports, or your State Department of Health bulletin to determine the decrease in typhoid in your state for the past ten years.

Typhoid fever. Typhoid fever, not many years ago, was one of the most common germ diseases in this country and Europe. Today it is one of the less important of the communicable diseases. Typhoid bacilli multiply very rapidly in the intestine and are passed off from the body with the excreta from the food tube. If these bacilli get into the water supply of a town, an epidemic of typhoid will result. In one early epidemic in this country there were 5000 cases of typhoid in a city of only 30,000 inhabitants. 
Chicago and other cities which once obtained their drinking water from lakes polluted with sewage always had a high death rate from typhoid. In the year 1891, the death rate from typhoid was over 170 per 100,000 inhabitants. Today it is less than 3 per 100,000. Olean, New York, had a serious outbreak of 248 cases in the fall of 1928 because one of the shallow wells used by the city became contaminated with sewage from the Allegheny River. It cost the city of Olean $\$ 425,000$ to pay the cost of the care of the cases and to settle the claims made against the city for its carelessness.

Water supplies. By pure water we mean water free from all organic impurities, including disease germs. Water from springs and deep driven wells is the safest water; that from large reservoirs next best; while water that has drainage in it, river water for example, is very unsafe unless properly treated with chemicals.

The water from deep wells or springs, if properly protected, will contain few bacteria. Water taken from shallow, unprotected wells may have from 100 to 20,000 bacteria per cubic centimeter. Water taken from protected streams into which no sewage flows usually has few bacteria (from 50 to 300 bacteria per cubic centimeter), and these are destroyed if exposed to the action of the sun and the constant aëration (mixing with oxygen) which the surface water receives in a large lake or reservoir. But water taken from a river into which the sewage of towns and cities flows may contain many hundreds of thousands of bacteria to the cubic centimeter, and must be filtered and chlorinated before it is fit for use. The water is passed through settling basins and sand filters which remove about 98 per cent of the germs. Final treatment with hypochlorite of lime or liquid chlorine in very small amounts kills most of the remaining bacteria. A few fortunate cities, such as Los Angeles and New York, bring their water supplies from protected areas far up in the mountains.

We have already seen the danger of typhoid fever from unprotected water supplies. Fortunately most large cities now protect their supplies, either by filtration and chlorination or, as in the case of Chicago, by this means plus a drainage canal which carries off the sewage. 
Practical Exercise 7. What methods of protection of water supplies are employed by your community? Visit the city water supply and report on its conditions. Ask your teacher to give you references for Glenn's reports on the water systems of certain cities in this country. Report on some one system and compare it with your own city supply.

Milk and disease. Another source of infection is milk. Frequently epidemics have occurred which were confined to users of milk from a certain dairy. Upon investigation it was found that a case of typhoid had occurred on the farm where the milk came from, that the germs had washed into the well, and that this water was

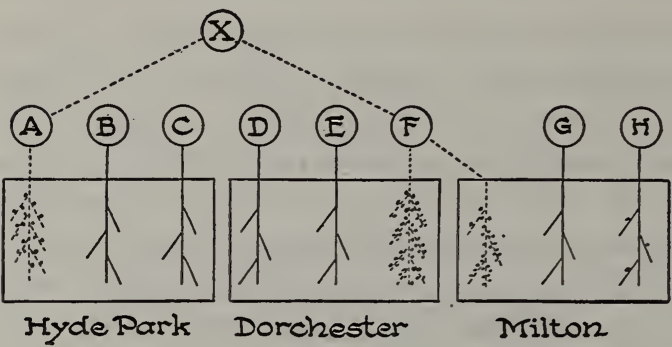

The small dots in the diagram show the number of cases of diphtheria which occurred in three towns, among people who received milk from dairy $X$. What may have been the reason for the cases of diphtheria which occurred in $\mathrm{H}$ of Milton? used to wash the milk cans. Once in the milk, the bacteria multiplied rapidly, so that the milkman gave out cultures of typhoid in his milk bottles.

Most large cities now send inspectors to the farms from which milk is supplied. These men examine and score the health of the cows, the cleanliness of their surroundings, the health of the workers, the care and construction of the utensils, and the methods of handling the milk. Farms that do not attain certain standards of cleanliness are not allowed to have their milk become part of the city supply.

Care of a city milk supply. "Besides caring for milk in its production on the farm, proper transportation facilities must be provided. Some of the milk used in Boston, Chicago, and New York is forty-eight hours old before it reaches the consumer. Milk used in the last-named city is said to come from eight states and from Canada. During shipment it must be kept in refrigerating cars, and during transit to customers it should be iced.

Practical Exercise 8. What regulations are there in your community concerning the farms from which milk is supplied? Concerning the sale of milk?

All but the highest grade milk should be pasteurized. Why? 
Milk should be bottled by machinery, if possible, to insure no personal contact; it should be kept in clean, cool places; and no milk except that which is to be used for cooking should be sold by dipping it directly from cans. Why is this method of dispensing milk likely to contaminate it?

Project. Write or give a report in class on a visit to a dairy.

Project. Investigate the sale of milk in your school and vicinity and report your findings to the class.

Carriers and typhoid. A third and more serious method of spreading typhoid fever comes through "carriers." These are people who have had typhoid fever and who still harbor the living germs in their bodies. Several epidemics of typhoid have been traced to carriers who worked in dairies or on farms which produced milk. The wellknown "Typhoid Mary" through her careless habits gave typhoid to people for whom she cooked.

Still another method of spreading

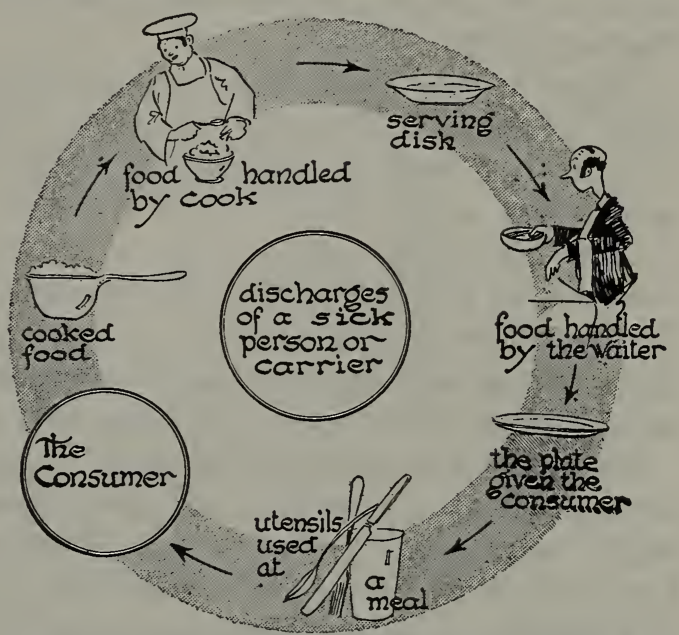

The consumer is in danger of having his food and dishes contaminated by the unclean hands of a worker. A line drawn from the center circle to any of the persons, material, or utensils will mean eventual danger to the consumer.

typhoid is through carelessness in preparation of uncooked vegetables. Several epidemics of typhoid fever have been traced to raw oysters which were "fattened" for the market in water that was contaminated with sewage.

Laboratory Exercise. Plot curves from board of health tables to show the mortality from a certain disease during various seasons of the year.

H. $\mathrm{BIO}-31$ 
Practical Exercise 9. Show how typhoid fever might be eradicated in this country. 'Think back to your general science work and show the different methods by which people can be protected from this disease.

Septic sore throat. This disease is characterized by severe sore throat and fever, and is often followed by heart or kidney trouble. This is another disease carried by milk, and is caused by a streptococcus. The disease is probably given to cows by human beings who may be carriers. The cow may harbor the germ for several weeks and persons drinking unpasteurized milk from such a cow may take the disease. Several severe epidemics have been recorded, in Baltimore, Chicago, Lee, Massachusetts, in 1928, and other cities, but the worst was an outbreak of 2000 cases in Boston, in 1911.

Tetanus. The bacillus causing tetanus is another toxin-forming germ. It lives in dust and dirt and is often found on the skin: It enters the body through cuts or bruises. It seems to thrive best in less oxygen than is found in the air. It is therefore important not to use adhesive tape over wounds until they have been treated with antiseptics. The low death rate from tetanus in the World War was due largely to the fact that wounds were washed with powerful antiseptics and anti-tetanus serum was administered as soon as possible after the wounded were reached.

Other diseases caused by bacteria. A group of bacteria which cause pneumonia, erysipelas, and other common infections besides septic sore throat are the so-called streptococci. Other coccus forms, the staphylococci (stăf-ř-lö-kŏk'sī), are responsible for boils and abscesses. A micrococcus causes one of the pernicious venereal diseases, which produces terrible results. Other forms of micrococci probably cause cerebro-spinal meningitis (měn-ǐn-jî́t tǐs), formerly a fatal disease of the spinal cord but now often treated successfully with serums. Anthrax or splenic fever, Malta fever, whooping cough, bubonic plague, gas gangrene, one form of dysentery, cholera, and many other diseases are definitely associated with specific forms of bacteria. In all of these diseases, contact with the person ill with the disease or, in some cases, with a carrier of the disease, is usually sufficient to cause its spread. 
Practical Exercise 10. Make a table with the following headings and fill out for each disease mentioned in this unit.

\begin{tabular}{|c|c|c|c|}
\hline Disease & Caused by & Method of Transfer & Prevention \\
\hline & & & \\
\hline & & \\
\hline
\end{tabular}

\section{Self-Testing Exercise}

Raw milk is safe if it comes from .......(1) ......(2) cows and has careful .......(3). Infectious diseases are usually transmitted through ............... (4). Bacteria usually enter the body through .......(6) ...... (7) or breaks in the ...... (8). (9) is gradually being conquered by proper treatment. Typhoid may be prevented through protection of ........(10) and $\ldots \ldots \ldots$ (11) supplies, and detection and isolation of ....... (12).

\section{PROBLEM IV. WHY IS QUARANTINE NECESSARY?}

Reasons for quarantine. We all know that when a person has a communicable disease, the doctor, acting under orders of the local board of health, puts the patient and sometimes the entire family under quarantine. Since this often seems needless, especially if one has a mild attack of the disease, we ought to know the reason underlying such action. Communicable diseases become epidemic if they are not controlled. Measles, for example, is a disease easily passed from one person to another. It is especially communicable among children, one of whom may have a very light case but may pass the germs to some one else who will have a severe attack of it. Scarlet fever, colds, and influenza are other diseases which are readily spread and may become epidemic. Since this is true, the reason for the isolation of the patient becomes evident. And every one should be unselfish enough to see this and to coöperate with the health authorities for the common good of the community.

The following table shows important facts about some common diseases. 
MAN CONTROLS HIS ENVIRONMENT FOR HEALTH

\begin{tabular}{|c|c|c|}
\hline Disease & MEANS of Communication & $\begin{array}{r}\text { INCUBATION PERIOD (AP } \\
\text { EARLY SYMP? }\end{array}$ \\
\hline Chicken pox & $\begin{array}{l}\text { Discharges from nose } \\
\text { or throat of a pa- } \\
\text { tient }\end{array}$ & 21 days. Rash. \\
\hline Diphtheria . & $\begin{array}{l}\text { Nose or throat dis- } \\
\text { charges; sometimes } \\
\text { infected milk }\end{array}$ & 2 to 5 days. Begins like a cold. \\
\hline Measles . & $\begin{array}{l}\text { Nose or throat dis- } \\
\text { charges }\end{array}$ & $\begin{array}{l}9 \text { to } 11 \text { days. Begins like a cold. } \\
\text { Reddish spots appear on the } \\
\text { third day. }\end{array}$ \\
\hline German measles & $\begin{array}{l}\text { Nose or throat dis- } \\
\text { charges }\end{array}$ & $\begin{array}{l}\text { Unknown, though longer than } \\
\text { measles. }\end{array}$ \\
\hline Mumps & $\begin{array}{l}\text { Nose or throat dis- } \\
\text { charges }\end{array}$ & $\begin{array}{l}\text { Unknown, probably about } 2 \\
\text { weeks. Pain in salivary glands. }\end{array}$ \\
\hline Infantile paralysis & $\begin{array}{l}\text { Nose, throat, or bowel } \\
\text { discharges of pa- } \\
\text { tient or carrier }\end{array}$ & $\begin{array}{l}\text { Not known. Fever, headache, } \\
\text { vomiting, weakness of one or } \\
\text { more muscle groups. }\end{array}$ \\
\hline Scarlet fever & $\begin{array}{l}\text { Discharges from nose, } \\
\text { mouth, ears. In- } \\
\text { fected milk }\end{array}$ & $\begin{array}{l}2 \text { to } 7 \text { days. Begins like a cold; } \\
\text { in } 24 \text { hours evenly diffused } \\
\text { bright red spots under skin. }\end{array}$ \\
\hline Smallpox · · & $\begin{array}{l}\text { All discharges of a } \\
\text { patient; particles } \\
\text { of skin and scabs }\end{array}$ & $\begin{array}{l}\text { About } 12 \text { days. Fever and back- } \\
\text { ache. Red shotlike pimples on } \\
\text { face and hands, become blisters. }\end{array}$ \\
\hline Septic sore throat & $\begin{array}{l}\text { Discharges from nose } \\
\text { or mouth }\end{array}$ & Varies with resistance. Short. \\
\hline Whooping cough & $\begin{array}{l}\text { Discharges from nose } \\
\text { or mouth }\end{array}$ & $\begin{array}{l}14 \text { days. Cough worse at night. } \\
\text { "Whooping" develops in about } \\
\text { two weeks. }\end{array}$ \\
\hline
\end{tabular}

Incubation period of disease. Quarantine regulations often affect not only the person having the disease, but also all those of the family who were "exposed"; that is, who came in personal contact with the person who has the disease. If, for example, you have measles, the doctor will keep at home the other children in the family who have not had the disease. The period of quarantine for measles lasts in most states fifteen days. Why this precaution?

Consider what we already know of germs. We found it took a certain length of time for colonies of germs to appear in a culture medium after exposure. In the same way it takes a certain amount of time in the case of a disease for the germs to become so abundant in the body that they give off sufficient toxins to 
cause the symptoms of the disease. This period, between the time when the germs enter the body and the time the symptoms of disease appear, is called the incubation period. Since this period

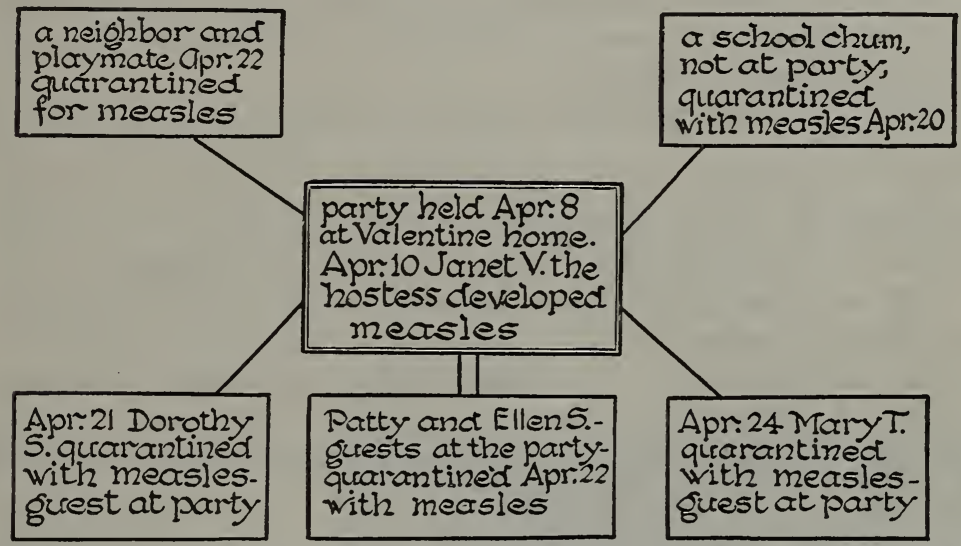

Two days after her party Janet developed measles. Since she was not ill with the disease at the time of the party, how do you account for the other cases which developed?

varies for different diseases, the period of quarantine also varies, as seven days for scarlet fever, fourteen days for whooping cough, twenty-one days for chicken pox. If, after one has been exposed to an infectious disease, no symptoms develop within the time of the recognized incubation period, it is safe to assume that he will not get the disease.

Practical Exercise 11. Study the diagram. How have similar cases worked out in your own school? Diagram them.

Why is it necessary for protection of others to know the incubation period of a disease?

Practical Exercise 12. Why should persons ill with an infectious disease be isolated until they are well? What methods has the Board of Health for warning strangers of the presence of the disease in a home?

What is the reason for quarantine and by what should it be followed to be effective? Why is there a quarantine station at the entrance of San Francisco, Boston, or New York harbor? Why is it of particular value there?

Practical Exercise 13. What do we mean by disinfection? What are the rules of your local Board of Health in regard to disinfection.

What should be done to the body, clothing, and hair of a person who has been ill with an infectious disease before he is allowed to go among well persons again? Why is this necessary?

Can a person have the germs of a disease in the body and still not show symptoms of the disease? How might such a person be a danger to others? 


\section{Self-Testing Exercise}

Check the correct statements for your workbook:

T.F. 1. The incubation period of a disease is the period between the time the germs causing the disease enter the body and the symptoms of the disease appear.

T. F. 2. All communicable diseases have the same length incubation period.

T. F. 3. Children who have been exposed to a catching disease should remain at home during the incubation period.

T.F. 4. Communicable diseases do not become epidemic.

T.F. 5. Quarantine means the isolation of a person who has a communicable disease.

T. F. 6. The length of quarantine differs with different diseases.

T. F. 7. Epidemics cannot be prevented.

T.F. 8. We only catch a disease from people suffering from that disease.

\section{PROBLEM V. WHAT IS IMMUNITY?}

The meaning of immunity. It is a matter of common knowledge that some persons in a family will have a very light attack of a communicable disease, while others may have it severely. Some one else may be exposed again and again to this same disease and not take it, because he is immune to, or able to resist, that particular disease, while those who take it are susceptible to its attack. Immunity against disease may be individual, or it may be racial. Negroes, for example, are very susceptible to measles and tuberculosis, but are less susceptible than white people to malaria, yellow fever, and smallpox. There are also great differences as to the degree of immunity from the same disease in different species of animals. Tuberculosis of the bovine type may occur in children as well as in cattle, hogs, and horses. The human tuberculosis germ attacks only guinea pigs, monkeys, and man. Smallpox and cowpox are probably caused by different types of the same organism. Plague attacks rats, ground squirrels, mice, and guinea pigs, as well as man. A long series of laboratory tests show that most germs that cause illness in man develop ordinarily in man 
only, while a few diseases, like anthrax and glanders, are primarily diseases of certain animals but may attack man.

Immunity may be modified by external conditions. A certain amount of immunity is evidently natural to individuals, races, or species, but there is much variation, as we have seen, even among individuals of the same family. Resistance to disease also is modified by the condition of the individual exposed. Overworked, tired, and "run-down" persons are much more likely to take diseases than those who are in good physical trim. Resistance to disease may also be weakened by the use of drugs and alcohol as shown by the susceptibility of heavy drinkers to pneumonia.

Acquired immunity. It has been a matter of common knowledge for centuries that persons who once have infectious diseases do not usually have them a second time. A Greek historian, describing a visitation of plague in Athens, more than twenty centuries ago, noted that those who had plague and recovered were safe from it thereafter. The Chinese, in order to make their children immune to smallpox, . gave them the disease in a mild form by placing in the nose a little of the pus from one of the

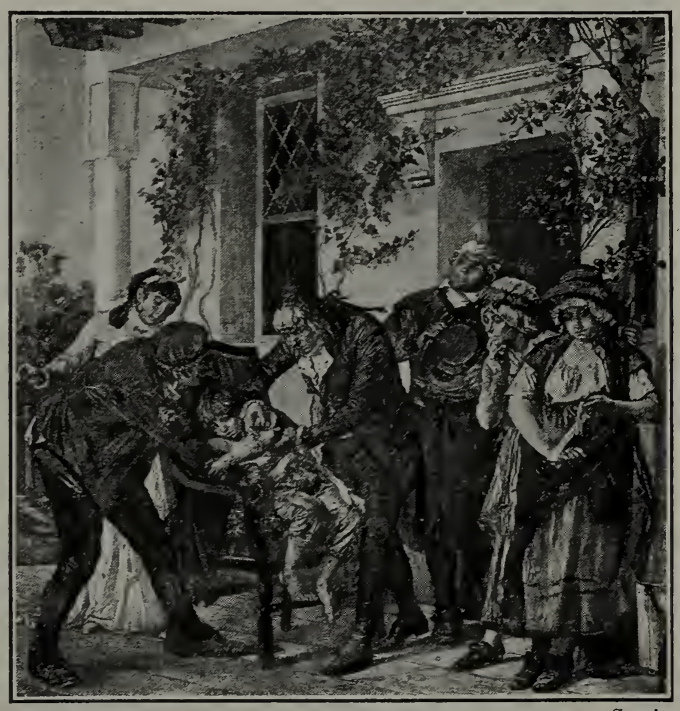

The first vaccination against smallpox by Dr. Jenner. eruptions. It was the chance statement of a dairymaid in England when she said, "I've had cowpox and can't take smallpox," that led Edward Jenner to make his first experiments that have resulted in almost stamping out smallpox through vaccination. And so today when we think of acquired immunity obtained by 
this or that antitoxin or anti-serum or vaccine, we must remember those pioneers, Jenner and Pasteur, who took the first steps in controlling germs, and began the work which may result finally in preventing many diseases.

How the body protects itself. We have already learned that the blood contains small amounts of various protective substances, known collectively as antibodies. These help the cells of the body combat harmful bacteria, the poisons or toxins which the bacteria give out, and the poisonous "split proteins" which are thrown into the blood when these bacteria die. When any protein substance decays, or is only partly digested, it breaks down into simpler substances. Some of these simpler proteins are poisonous and are called ptomaines (tō'mà-1̌nz; Gr. ptoma, dead body). Ptomaine poisoning, while not so common as was once thought, sometimes causes discomfort and even death.

Practical Exercise 14. With the help of a physician, list all the diseases for which immunity has been developed.

Practical Exercise 15. What is immunity? Why are some persons more likely to take a disease than others? Why do some people have a disease more severely than others? Why does travel bring increased likelihood of disease?

\section{Self-Testing Exercise}

Check the correct statements for your workbook:

T.F. 1. A person is immune to a catching disease if, when exposed to it, he does not take it.

T.F. 2. Negroes are much more susceptible to measles and tuberculosis than white people.

T.F. 3. The resistance to a disease is largely determined by a person's physical condition.

T. F. 4. Protective substances, antibodies, in the blood help the body to combat bacteria and their poisons.

T. F. 5. Toxins are useful substances in the blood which help keep us well.

PROBLEM VI. WHAT ARE THE DIFFERENCES BETWEEN ACTIVE AND PASSIVE IMMUNITY?

Active and passive immunity. All toxins, when they enter the human body, cause the body cells to react to the poison. If the 
cells are able to manufacture the protective substances, antibodies, rapidly enough to counteract the work of the bacteria or their poisons, we recover from the disease. In such a case as this, the

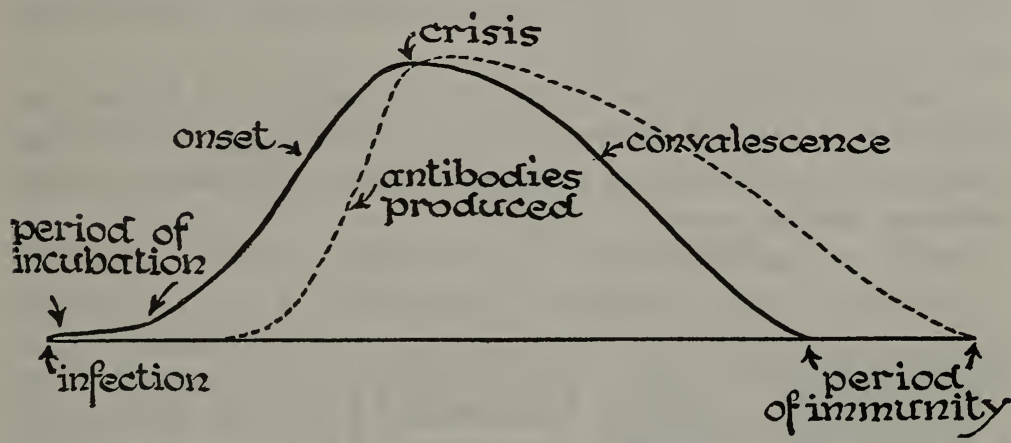

Read your text, study the diagram carefully, and then explain how the body produces an immunity against a specific disease.

body cells do the work in fighting the disease, and the immunity thus acquired is said to be active. In case the body cells themselves do not work, and, instead, an antitoxin is used, which is manufactured outside the body, we have an example of passive immunity. Let us consider the latter case first, as it is easier to understand.

What are antitoxins and how are they used? An example of passive immunity is that obtained by the antitoxin treatment for diphtheria. This treatment, as the name denotes, is a method of neutralizing the toxin given off by the bacteria into the body. It was discovered by a German, Von Behring, that the serum of the blood of an animal immune to diphtheria is capable of neutralizing the poison produced by the diphtheria-causing bacteria. Horses develop large quantities of antitoxin when given the diphtheria toxin in gradually increasing doses.

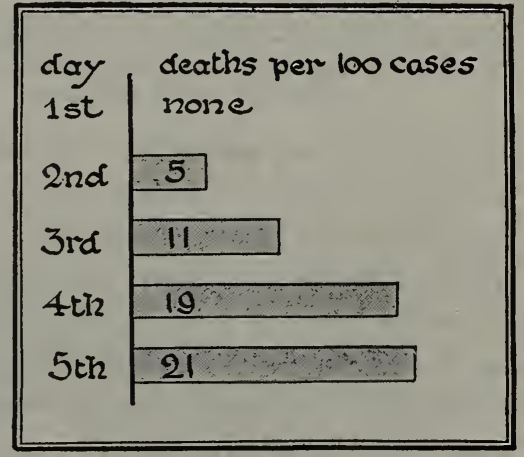

The early use of antitoxin in cases of diphtheria greatly decreases the death rates from this disease. 
The serum of the blood of these horses is then carefully tested and is used to inoculate the patient suffering from or exposed to diphtheria, and thus the disease is checked or prevented altogether. The laboratories of boards of health prepare this antitoxin and supply it fresh for public use.

It has been found from experience in hospitals that deaths from diphtheria are largeiy preventable by the early use of antitoxin. It is therefore advisable, in a suspected case of diphtheria, to have antitoxin used at once.

Schick test and its value. By the Schick test it is possible to determine if a person is immune to diphtheria. A very minute dose

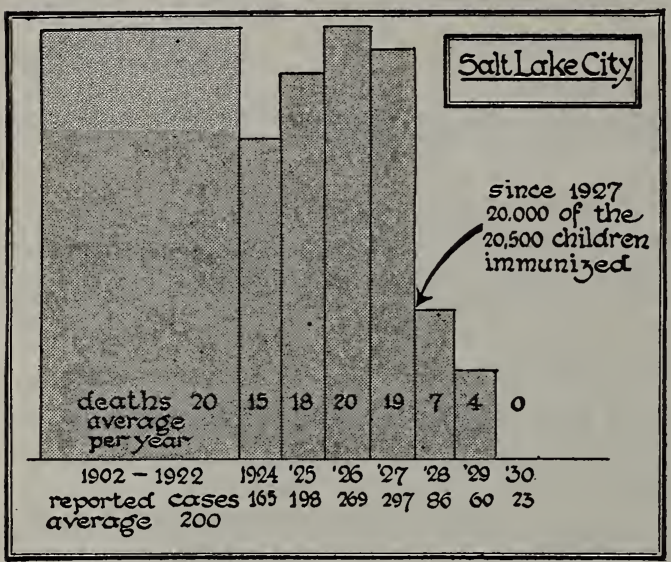

How does this diagram show the value of giving children toxinantitoxin to prevent diphtheria?

of diphtheria toxin is injected under the skin of the forearm. If the person is immune, no reaction takes place, because the blood is provided with antitoxins. But if the person is susceptible, some hours later a slight red spot appears where the toxin was injected. This is a danger signal and shows that the person would take diphtheria if exposed to it. To such a person a treatment, known as the toxin-antitoxin treatment, is given. Small amounts of a mixture of diphtheria toxin and antitoxin are injected into the susceptible person, with the result that he becomes immune by a combination of active and passive immunity. This treatment has been tried with thousands of school children in the city of New York, with the result that the death rate from diphtheria dropped lower than before its use.

The following clipping from a New York paper indicates the progress made in wiping out this dread disease. 
"Quoted as an evidence of the efficacy of inoculation against diphtheria, the statement is made that there were 2226 fewer cases of diphtheria in New York in 1929 than there were in the preceding year. The number of those dying from the disease here last year was 180 less than the number who died of it in 1928 .

"More than 700,000 children received the toxin-antitoxin treatment during the year, making them immune from what not many years ago was a scourge. Approximately 10,000,000 pieces of educational literature, printed in eleven languages, were distributed during the year. The progress made in recent years has warranted the prediction that in five years the disease will be exterminated."

The Dick test and treatment promise to do as much in combating scarlet fever as the Schick test has done in reducing the death rate from diphtheria. In the Dick test a diluted toxin produced by the bacteria which cause scarlet fever is injected into the arm. A redness indicates that the person is susceptible to scarlet fever. Treatment is then given in the form of subsequent doses of toxin which helps the body to produce its own antitoxin and thus build up an active resistance against the disease.

Other antitoxins. Tetanus, commonly called lockjaw, once a much-dreaded infection, has now been almost stamped out through the use of a tetanus antitoxin. During the World War soil-infected wounds were treated with this antitoxin and as a result the death rate from tetanus was much lower than in previous wars. An antitoxin was also used successfully against gas gangrene. Antitoxins are also used for certain types of dysentery and against snake venoms.

Active immunity. Vaccination against smallpox. In 1796 Jenner first proved that inoculation with pus taken from a cow was capable of preventing smallpox. Years later Louis Pasteur proved that inoculation of chickens with an old weakened culture of chicken cholera bacteria caused the chickens to be slightly ill for a short time, but made them immune to chicken cholera. Their body cells were stimulated by the weakened germs to manufacture antibodies which soon got the better of the germs and provided immunity.

So it is with vaccination against smallpox. Smallpox is caused by a filterable virus which means the organisms are too small to 
be seen with the most powerful microscope. The virus used for inoculation probably contains the organisms which cause cowpox, which is a weakened smallpox organism. Therefore when vaccination "takes," the body has been stimulated by the virus to produce its own antibodies. These antibodies make the body actively immune to the disease.

Smallpox has been in the past a great scourge ; 90 out of every 100 persons in Europe used to have it. As late as 1898, in Russia

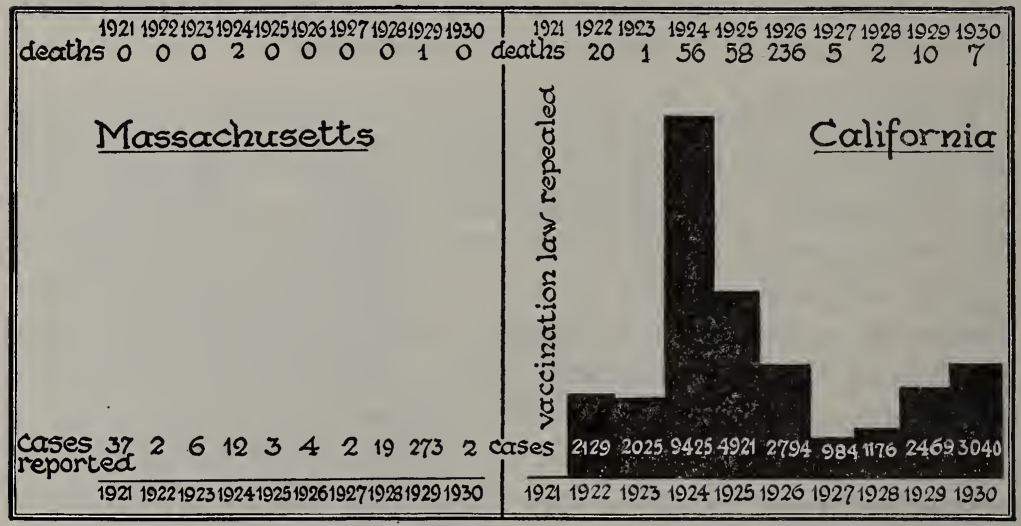

Massachusetts has a law requiring all persons to be vaccinated against smallpox infection. California, at one time, had such a law, but repealed it. Notice the number of cases and deaths from smallpox in California as compared with Massachusetts from 1922 to 1930.

over 50,000 persons lost their lives from this disease in a year. In some places smallpox has been brought under absolute control by vaccination, though in other places, unfortunately, there are outbreaks, due to the fact that some people do not believe in vaccination.

Rabies, or hydrophobia. Rabies ( $\left.\mathrm{rā}^{\prime} \mathrm{bu}-\mathrm{e} \mathrm{z}\right)$ ), which is caused by a filterable virus, is communicated in the saliva from one dog to another by biting. It is also transmitted to man by the bite of an infected animal. The great French bacteriologist, Louis Pasteur, discovered a method of treating this disease which is a success if begun soon after the person has been bitten by the infected animal. Here again the treatment is based upon the inoculation of the patient with a weakened organism which causes 
the body cells to set up a resistance and produce an active immunity.

Vaccination against typhoid. The principle underlying vaccination against typhoid is that of working up an active immunity by introducing into the body large numbers of dead typhoid germs. The presence of the dead bacilli stimulates the blood to make antibodies and thus an active immunity is acquired. This immunity protects the person against the invasion of living germs.

During the Spanish-American War in the army of 107,000 men more than 20,000 were disabled with typhoid. Since 1914, after vaccination against typhoid was introduced, the disease has been almost stamped out in the army, and the death rate for the entire country has been so much reduced that it is now a disease of relatively little importance.

The Widal test, by means of which it is possible to determine at once whether a person has typhoid, has been described on page 390 .

The mechanism of active immunity. Active immunity is thus brought about in a number of different ways: by the introduction of living organisms, by the introduction of attenuated or weakened organisms, by the introduction of dead organisms, and by the introduction of extracts containing the products of bacteria. All of these substances may be called vaccines.

The underlying principle is the same in all cases ; certain cells of the body are roused or activated to form antibodies, and the invading organisms are destroyed and their toxins neutralized. These conditions are brought about through the work of the lysins, precipitins, agglutinins, opsonins, and phagocytes already mentioned in Unit XIII. You should read that unit carefully again in connection with the present unit.

Other vaccines are made and used successfully against boils, another against paratyphoid, and still others for plague and for cholera. When tests show sensitiveness to certain pollens, serums are made from them and a certain amount of immunity from hay fever is thus received. But we are just at the beginning of discoveries along this line and it will no doubt be the work of the physicians and scientists of the future to perfect many more ways of producing immunity against protein poisons and germ disease. 
Practical Exercise 16. Study the diagram on page 480. Show exactly why the changes noted there occurred.

Practical Exercise 17. What is the principle underlying the antitoxin treatment for diphtheria? The Schick test? The Dick test? What is the principle underlying vaccination against smallpox? Against typhoid? Against boils? Explain.

Practical Exercise 18. Make a list of all germ diseases that are now treated by the passive method of immunity; the active method of immunity.

Positive health the goal. In the preceding pages we have seen what science has done in combating disease. But many of these diseases can be avoided simply by keeping in good condition. If we keep our bodies in good physical condition through the use of proper food, exercise, and sleep; if we maintain a calm poise and untroubled mind; if we avoid worry and are cheerful in spite of difficulties; then we have gone far toward keeping well. We now have the knowledge about communicable diseases and how to fight them; let us use this knowledge if it is necessary. But for most of us health is something that can be earned, if we are willing to pay the price. All that we have to do is to treat our bodies in such a way that they will give us the most efficiency, for very few of us have really poor bodily machines to start with.

\section{Self-Testing Exercise}

When poisons enter the body, the cells react by forming $\ldots . . .(1)$. The two kinds of acquired immunities are ....... (2) and $\ldots \ldots \ldots(3)$. In the first, immunity is acquired through the use of ....... (4); and in the second through the use of ...... (5). The Schick test is used to determine whether a person is .......(6) to ....... (7). This disease may be eradicated by the use of .......(8). Diseases that may be stamped out by the use of vaccination are: (9), .......(10), (11), and ........(12).

\section{PROBLEM VII. HOW IS MALARIA CAUSED AND}

\section{TRANSMITTED?}

The cause of malaria. The study of the life history and the habits of the Protozoa has resulted in finding many parasitic forms, and the consequent explanation of some diseases. An amoeba-like parasite, of which at least three species exist, causes 
different types of malaria. This disease, not many years ago, was thought to be caused by bad air. (Hence the name, from Italian mala, bad; aria, air.) But the work of a number of scientists has shown that the disease is carried by a mosquito and is caused by an amoeba-like organism, called Plasmodium malariae. When a female mosquito of the species Anopheles (ä-nŏf' lēz) sucks blood from a person having malaria, this parasite passes with the blood into the stomach of the mosquito. After about twelve days in the mosquito's body, the parasites, having passed through the sexual stages, establish themselves within the salivary glands of the mosquito. If the infected mosquito then bites a person, it passes the parasites into the human blood with its saliva. These parasites enter the corpuscles of the blood, increase in size, and then form spores. The rapid process of spore formation results in the

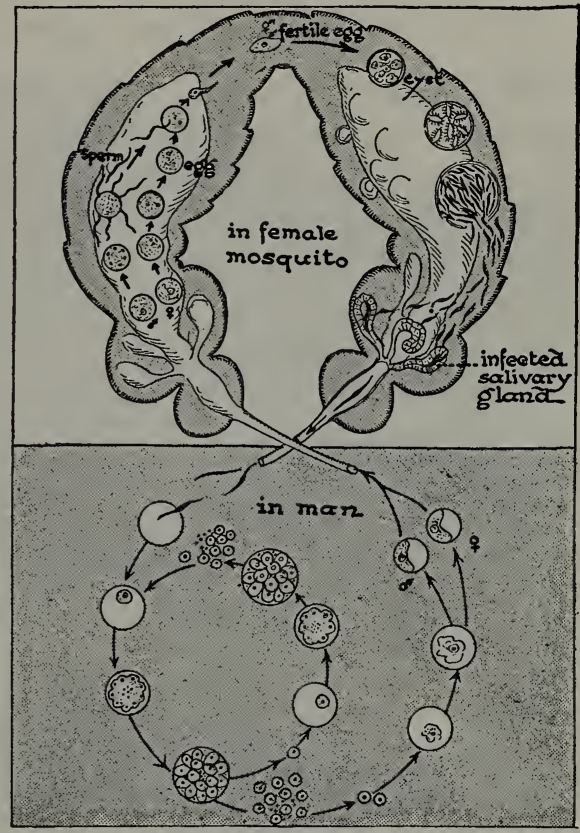

The malarial parasite passes its life cycle from a mosquito, to man, and back again to a mosquito. Trace the life history of the parasite in the above diagram.

breaking down of the blood corpuscles. The spores then escape into the blood stream. The sudden release of the spores and the poisons are thought to cause the chills and the fever so characteristic of malaria. The escaped parasites may enter other blood corpuscles and in forty-eight or more hours, depending on the kind of malaria, repeat the cycle. The spores feed upon the red corpuscles, and destroy half or even four fifths of the normal number. This accounts for the pale, anaemic condition of a person 
who has malaria. The only cure for the disease is frequent doses of quinine. This kills the parasites in the blood.

Workbook Exercise. Using the text and diagram, work out a life cycle of the malarial parasite.

Demonstration 4. To show life history of a mosquito.

Use charts or material in Riker mounts, to show history of any mosquito.

The malarial mosquito. Fortunately for mankind, not all mosquitoes harbor the parasite which causes malaria. The harmless mosquito (Culex) may be usually distinguished from the mosquito which carries malaria (Anopheles) by the position of the body and legs when at rest. Culex lays eggs in tiny rafts of one hundred
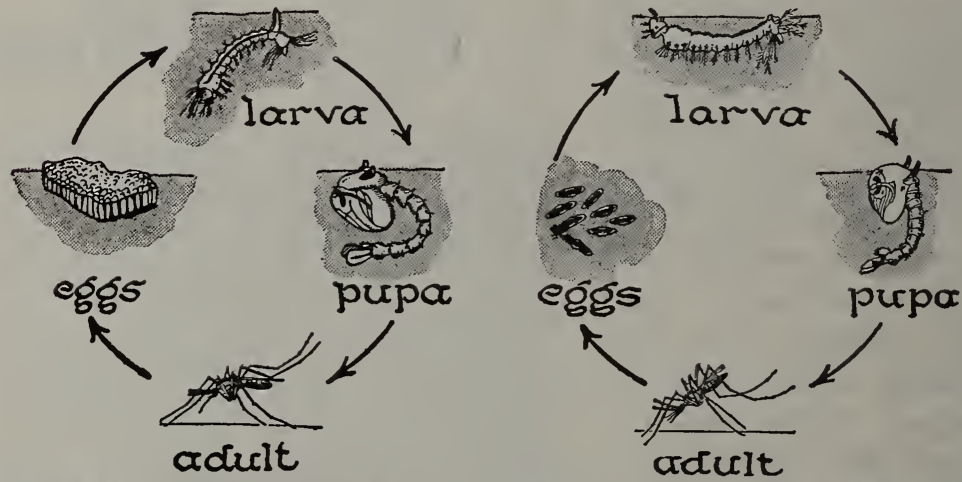

How does the common mosquito, Culex (on left), differ in the various stages of growth from the malarial mosquito, Anopheles (on right)?

or more in standing water; thus the eggs are distinguished from those of Anopheles, which are not in rafts. Rain barrels, gutters, and old cans may breed in a short time enough mosquitoes to annoy a whole neighborhood. The larvae are known as wigglers. They appear to hang on the surface of the water, head down, in order to breathe through a tube at the posterior end of the body. In this stage they may be recognized by their peculiar movement when on their way to the surface to breathe. The pupa, distinguished by a large head and thoracic region, breathes through a pair of tubes' on the thorax. 
Practical Exercise 1). Use the diagram and compare the life histories of the Anopheles and Culex so that you can determine the harmful form at any stage in its life history.

How may mosquitoes be exterminated? The fact that both larvae and pupae take air from the surface of the water makes it possible to kill the mosquito during these stages by pouring oil on the surface of the water where they breed. The introduction of

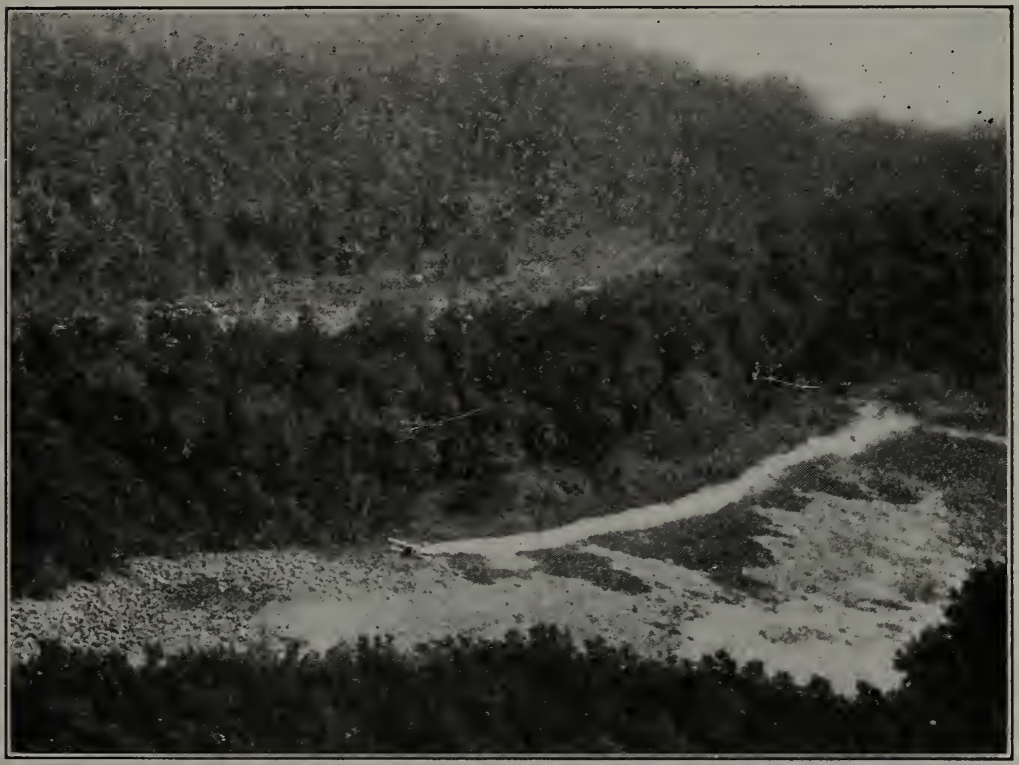

U. S. Department of Agriculture

Dusting with Paris green from an airplane to destroy the malarial mosquito larvae on the surface of water in the swamp and lake.

minnows, goldfish, or other small fish where the mosquitoes breed will do much in freeing a neighborhood from this pest. Draining swamps or low land which holds water after a rain is another method of extermination. Since the beginning of historical times, malaria has been prevalent in regions infested by mosquitoes. The ancient city of Rome was so greatly troubled by periodic outbreaks of malarial fever that a goddess of fever came to be worshiped in order to lessen the severity of what the inhabitants believed to be a divine visitation. At the present time malaria н. В10 -32 


\section{MAN CONTROLS HIS ENVIRONMENT FOR HEALTH}

is being successfully fought and conquered in Italy by the draining of the mosquito-breeding marshes.

The problem of malaria affects nearly $13,000,000$ of the inhabitants of the United States, principally those of the southern states. Mississippi, with over 92 per cent of its population, shows a death rate of over 10 deaths per 100,000 from malaria; Florida with 80 per cent of her population exposed to malaria, and Arkansas, with 75 per cent living in malarial districts, present the most serious problems from a health standpoint. In Arkansas, Mississippi, and other southern states successful fighting of malaria by draining marshes, oiling standing water, and screening houses has greatly reduced the number of malarial patients.

Project. To make a survey of your neighborhood to determine if there are any breeding places for mosquitoes. How can these places be reduced?

Other protozoan diseases. Many other diseases of man are probably caused by parasitic protozoans. Dysentery of one kind is caused by the presence of an amoeba-like animal, Endamoeba, in the digestive tract. These parasites are far more widely spread than was ever thought and many people suffer from the effects of this parasite without knowing what actually causes them to be ill.

Another group of protozoan parasites are called trypanosomes. These are parasitic in insects, fish, reptiles, birds, and mammals in various parts of the world. They cause several diseases of cattle and other domestic animals, being carried to the animal in most cases by flies. One of this family is believed to live in the blood of native African zebras and antelopes. Seemingly it does them no harm, but if one of these parasites is transferred by the dreaded tsetse (tsě'tsĕ) fly to one of the domesticated horses or cattle of that region, the animal dies.

The tsetse fly also carries to the natives of Central Africa a trypanosome which causes the dreaded and incurable sleeping sickness. This disease has killed more than fifty thousand natives yearly, and many Europeans have succumbed to it. Its ravages are largely confined to an area near the large Central African lakes and the upper Nile, for the fly which carries the disease 
lives near water, seldom going more than 150 feet from the banks of streams or lakes. The British government has attempted to control the disease in Uganda by moving all the villages at least two miles from the lakes and rivers. Among other diseases that may be due to protozoans is kala azar, a fever in hot Asiatic countries which is probably carried by the bedbug, and African tick fever, carried by a small insect called the tick. In this country many fatal diseases of cattle, as "tick fever," or Texas cattle fever, are caused by protozoa.

\section{Self-Testing Exercise}

Malaria is caused by a ....... (1) which is carried by the ....... (2) ...... (3). It lives part of its life in the body of the ....... (4) and part in .......(5). When the ......(6) bites a person, it passes the ....... (7) into the ...... (8) with its saliva. Malaria can be eradicated by ....... (9) the .......(10) ......(11) of $\ldots . \ldots$ (12). Other diseases probably caused by protozoans are . (13), ...... (14) .......(15), ...... (16), and ....... (17) $\ldots \ldots$ (18).

PROBLEM VIII. HOW WAS THE CAUSE AND CONTROL OF YELLOW FEVER DISCOVERED?

Yellow fever and mosquitoes. Another disease carried by mosquitoes is yellow fever. In the year 1878 there were 125,000 cases and 12,000 deaths in the United States, mostly in Alabama, Louisiana, and Mississippi. During the French attempt to construct the Panama Canal, the work was at a standstill part of the time because of the ravages of yellow fever. Before the war with Spain, thousands of people were ill in Cuba. But today yellow fever has almost disappeared, both there and in the Canal Zone, through proper control of the fever-carrying mosquito Aëdes.

The knowledge that Aëdes carries the disease-producing agent that causes yellow fever is due to the experiments in 1900 of a commission of United States army officers, headed by Dr. Walter Reed. One of these men, Dr. Jesse Lazear, lost his life in an experiment to prove that yellow fever is transmitted by mosquitoes. 
He allowed himself to be bitten by a mosquito that was known to have bitten a yellow fever patient, contracted the disease, and died a martyr to science. Others, soldiers, volunteered to test further by experiment how the disease was spread, so that in the end the commission was able to prove that Aëdes transmitted yellow fever. The accompanying illustration shows the result of this

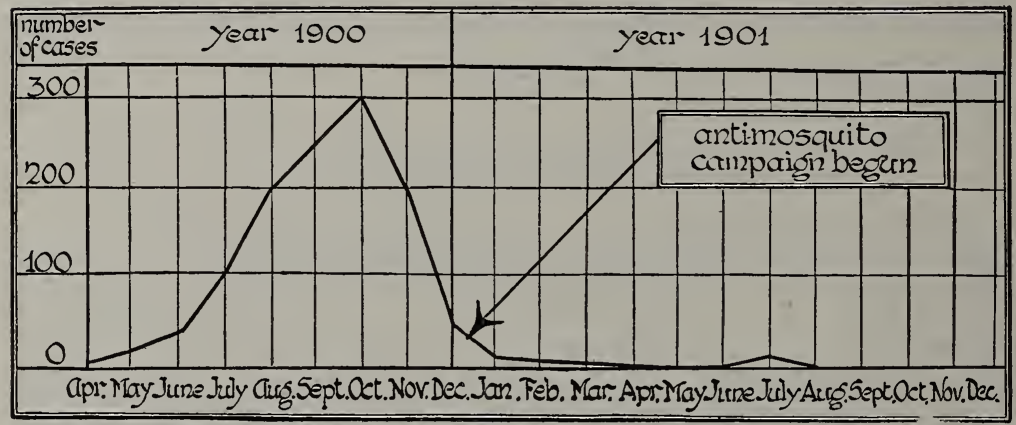

In 1900, experiments were carried on to find the cause of yellow fever. In 1901, it was discovered that the Aëdes mosquito transmitted yellow fever and a campaign against mosquitoes was immediately started. The above chart shows the effect of such a campaign in Havana.

discovery for the city of Havana. For years Havana was considered one of the pest spots of the West Indies. When Americans occupied that city, after the war with Spain, they cleaned up the city, introduced proper sanitation, placed screens in most buildings, and so nearly destroyed the breeding places of the mosquitoes that the city was practically freed of mosquitoes. The result, so far as yellow fever was concerned, was startling, as you can see by reference to the chart.

Practical Exercise 20. Read the Health Heroes Series by Hallock and Turner, and make a report to the class on yellow fever.

\section{Self-Testing Exercise}

A commission headed by Dr. ........ (1) proved that the Aëdes mosquito carries ........(2) ...... (3). This disease was eliminated in Havana by ........(4) the ......(5) .......(6) of mosquitoes, .......(7) the buildings, and introducing .......(8) 


\section{PROBLEM IX. WHAT ARE OTHER DISEASE CARRIERS AND}

\section{WHAT DISEASES DO THEY CARRY?}

Demonstration 5 . Observe the foot of a house fly under a compound microscope. Why it is able to carry bacteria.

Allow a fly to walk across a sterile agar plate. Cover the plate and set it aside in a warm place for several days. Describe the plate.

Demonstration 6. The life history of the typhoid fly.

Expose pieces of raw beef where flies will light on them. After a few hours, cover this meat in glass dishes or small battery jars with screen covers.

Watch the meat. In pieces on which eggs were laid by the flies describe the stages of development as they appear. Do the larvae grow? They are called maggots. State how the pupae differ from the larvae. Watch to see the adults emerge from the pupal case.

How long does a complete life history take? How many generations of flies might develop during a hot summer?

The house fly. We have already learned that mosquitoes of different species carry malaria and yellow fever. Another addition to the black list of disease-carriers is the house or typhoid fly. The development of the house fly is extremely rapid. A female may lay from one hundred to two hundred eggs at one time. These are usually deposited in filth or manure. Dung heaps about stables, outdoor toilets, neglected garbage cans, and fermenting vegetable refuse form the best breeding places for flies. In warm weather, the eggs

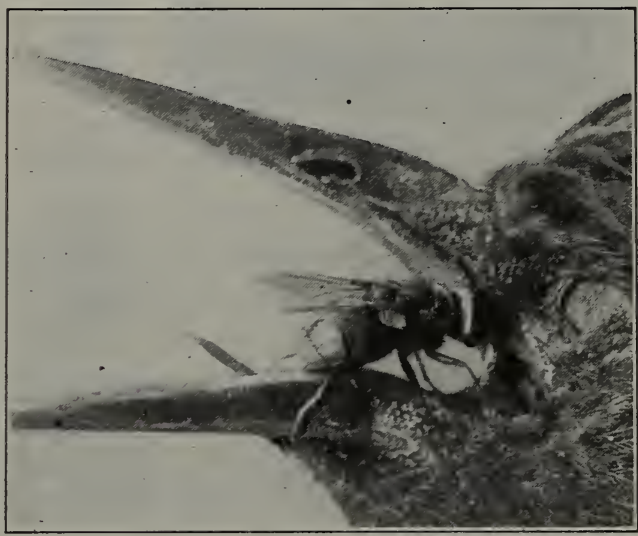

Paul Griswold Howes

A blue-bottle fly depositing eggs in the bill of a dead starling, which will furnish food for the young larvae. hatch a day or so after they are laid and the larvae or maggots crawl out. After about one week of active feeding these wormlike maggots become quiet and go into the pupal stage, whence under favorable conditions they emerge within less than another week as adult flies. The adults breed at once, and in a short summer 
there may be over ten generations of flies. This accounts for the great number of flies in July and August. Fortunately, relatively few flies survive the winter.

The foot of the fly shows a wonderful adaptation for clinging to smooth surfaces. Two or three pads, each of which bears tubelike
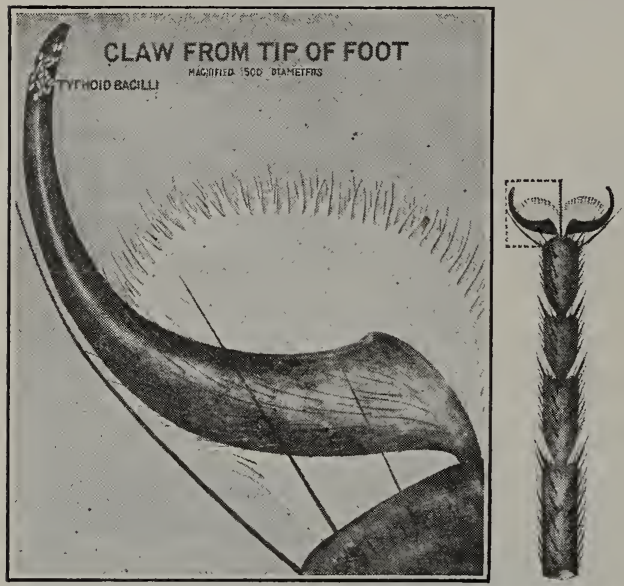

Amer. Mus. of Nat. Hist.

Foot of a house fly. Why is the fly a carrier of diseases? hairs that secrete a sticky fluid, are found on its under surface. It is by this means that the fly is able to walk upside down, and carry filth and bacteria on its feet.

Project. To determine the breeding places of flies in your neighborhood.

The house fly a disease carrier. The common fly is recognized everywhere as a pest. Flies have long been known to spoil food through their filthy habits, and they are blamed for spreading several diseases caused by bacteria. It has been found that a single fly might carry on its feet anywhere from 500 to $6,600,000$ bacteria, the average number being over 1,200,000. Not all of these germs are harmful, but they might easily include those of typhoid fever, tuberculosis, "summer complaint," and possibly other diseases. A pamphlet published by the Merchants' Association in the city of New York shows that the rapid increase of flies during the summer months has a definite correlation with the increase in the number of cases of "summer complaint." Observations in other cities seem to show that the increase in the number of typhoid cases in the early fall is due, in part at least, to the same cause.

Project. If vital statistics of your community are available, work out a correlation between the increase of flies and the increase of certain diseases. 
Cleanliness which destroys the breeding places of flies, the frequent removal and destruction of garbage, rubbish, and manure, the covering of all food when not in use, and especially the careful screening of windows and doors during the breeding season are wise precautions taken to prevent the spread of diseases by flies. Far more important than to "swat the fly" is to remove their breeding places!

Practical Exercise 21. What is the best method for destroying flies in your home? Knowing when and where flies breed, when would be the best time to "swat the fly"? How would this method compare with other ways of extermination?

Other insect disease carriers. Fleas and bedbugs have been added to those insects proved to carry disease to man. Bubonic plague, which is primarily a disease of rats, is transmitted from infected rats and ground squirrels to man by fleas. Fleas are also believed to transmit from rats to rats a form of leprosy found only in these animals. It is thought probable that bedbugs transmit relapsing fevers. Typhus fever is transmitted by body lice.

Animals other than insects that may spread disease. The common brown rat is an example of a mammal, harmful to civilized man, which has followed in his

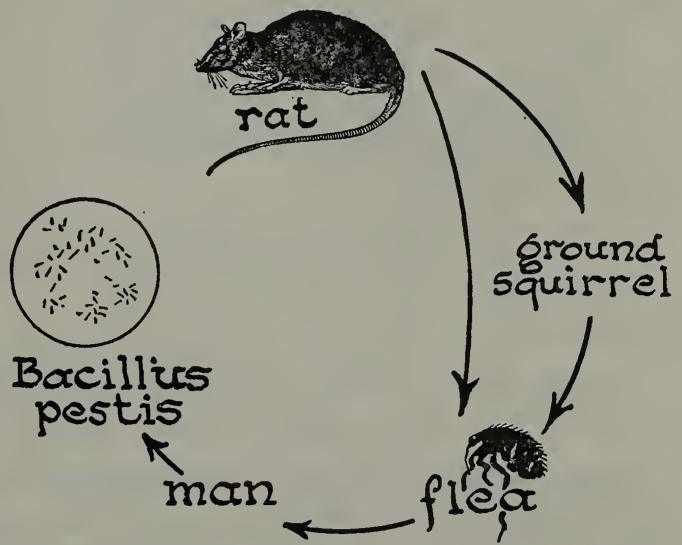
footsteps all over the

world. Starting from China, it spread to eastern Europe, thence to western Europe, and in $\mathbf{1 7 7 5}$ it had arrived in this country. In seventy-five years it reached the Pacific coast and it is now fairly common all over the United States, being one of the most prolific of all mammals. Rats spread bubonic plague, the "Black Death" 
of the Middle Ages, a disease estimated to have killed 25,000,000 people during the fourteenth ceptury. Fleas bite the infected rat and then transmit the disease to man. In 1900 the plague gained entrance on our western coast. It killed more than 100 persons during the next four years, and small outbreaks have occasionally occurred ever since. The ground squirrels of California became infected with the plague, doubtless from the rats which lived in their burrows, so that now the danger of other outbreaks of the plague will be present until all the ground squirrels are exterminated. Over a million rats were killed in fighting the last outbreak of bubonic plague in California and efforts are being made in all large cities to eradicate this pest.

Practical Exercise 22. Look up Farmers Bulletin 896 and report on the best way to exterminate rats.

Project. Make a survey of your neighborhood to determine where rats breed.

\section{Self-Testing Exercise}

The house fly may carry $\ldots \ldots$ (1) and $\ldots \ldots \ldots$ (2) bacteria on its feet. It breeds ........ (3) in ....... (4) ...... (5) during the warm season. Fleas are carriers of $\ldots \ldots$ (6) ......(7), which they get from .......(8) $\ldots \ldots$ (9) and .......(10) ........(11). This disease can be eradicater by exterminating all $\ldots \ldots \ldots(12)$ and $\ldots \ldots$ (13). Body lice transmit .......(14) .........(15).

\section{PROBLEM X. WHAT DISEASES ARE CAUSED BY WORMS AND HOW MAY WE FIGHT THEM?}

Other parasitic animals cause disease. Other animals besides those mentioned have been found to cause illness. Chief among these are certain roundworms and flatworms, which live as parasites not only in man but in many animals and plants. The parasite frequently becomes fastened to its host during adult life and is reduced to a mere bag through which the fluid food prepared by its host is absorbed. Sometimes a complicated life history results from parasitic habits. Such is the life history of the tapeworm and of the liver fluke, a flatworm which kills sheep. 
Cestodes or tapeworms. These parasites infest man and many other vertebrate animals. One tapeworm (Taenia solium) passes through two stages in its life history, the first within a pig, the second within the intestine of man. The developing eggs are passed off with wastes from the intestine of man. The pig, an animal with dirty habits, may take in the tapeworm embryos with its food. These develop within the intestine of the pig, but scon make their way into the muscles or other tissues, where they are known as bladder worms. If man eats undercooked pork containing them, he is likely to become a second host for tapeworms.

Another cornmon tapeworm (Taenia saginata) parasitic on man lives part of its life as an embryo within the muscles of cattie. The adult tapeworm consists of a round headlike part provided with hooks,

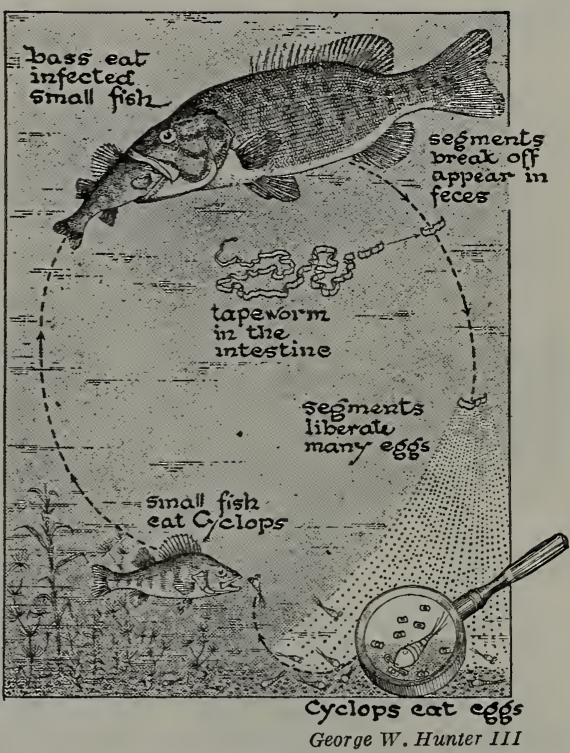

The bass tapeworms infest the small-mouthed black bass. The mature posterior segments of the worm, filled with eggs, break off and pass from the host. The eggs are liberated and settle to the bottom of the stream, where they are eaten by small crustaceans, called cyclops, which in turn are eaten by small fish which form the food of the bass. by means of which it fastens itself to the wall of the intestine. This head now buds off a series of segment-like structures, which are practically bags full of sperms and eggs. These structures, called proglottids, break off from time to time, thus allowing the developing eggs to escape. The proglottids have no separate digestive systems, but the whole body surface, bathed in digested food, absorbs it and thus they are enabled to grow rapidly.

Roundvorms. Still other wormlike creatures called roundworms are of importance to man. Some, as the vinegar eel found in vinegar, or the pinworms parasitic in the lower intestine, partic- 
ularly of children, do little or no harm. The Ascaris, a larger roundworm, sometimes infests children but is rarely dangerous to its host.

The pork worm or trichina (trǐ-kī'na), however, is a parasite which may cause serious injury. It passes through the first

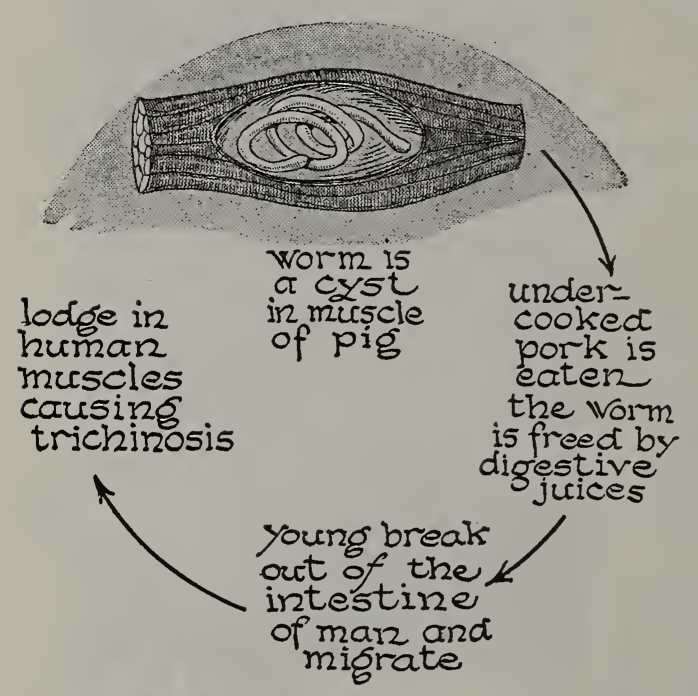

In what way may poorly cooked pork be harmful to man?

part of its existence as a parasite in a pig or other vertebrate (cat, rat, or rabbit); it is enclosed in a tiny sac or cyst, in the muscles of its host. If undercooked pork containing these cysts is eaten by man, the covering is dissolved off by the action of the digestive fluids, and the living trichina becomes free in the intestine of man. Here it reproduces, and the young pass through the intestinal wall into muscles, causing inflammation there and resulting in a painful and often fatal disease known as trichinosis. The government at one time inspected pork for trichina, but since a microscopic examination of meat was necessary and it was impossible to examine all killed hogs in this way, the practice has been discontinued with the result that trichinosis is on the increase. All pork should be well cooked.

Filaria are small roundworms that cause various tropical diseases - the most serious of which is elephantiasis. The parasites possibly enter the body in drinking water and some are probably introduced by the bite of a mosquito.

Practical Exercise 23. Find out from local physicians if there has ever been a case of trichinosis in your community. If so, try to find out why it occurred.

What kind of inspection of meats do you have in your community? 
Demonstration 7. Use a microscopic slide to show hookworm. Why is it called "hookworm"?

The hookworm. The account of the discovery by Dr. C. W. Stiles of the Bureau of Animal Industry, that the laziness and shiftlessness of the "poor whites" of the South is partly due to a parasite called the hookworm, reads like a fairy tale.

The people, largely farmers, become infected with a larval stage of the hookworm, which develops in moist earth. It enters the body usually through a break in the skin of the feet, for adults and children alike, in certain localities where the disease is common, go barefoot to a considerable extent.

A complicated journey from the skin to the intestine now follows. The larvae pass through the veins to the heart, from there to the lungs, where they bore into the air passages, and eventually reach the intestine by way of the throat. One result of the injury to the lungs is that many persons thus infected are subject to tuberculosis. The adult hookworms, once in the food tube, fasten themselves to the walls which they puncture; and then they feed upon the blood of their host. The loss of blood from this cause is not sufficient to account for the blood-

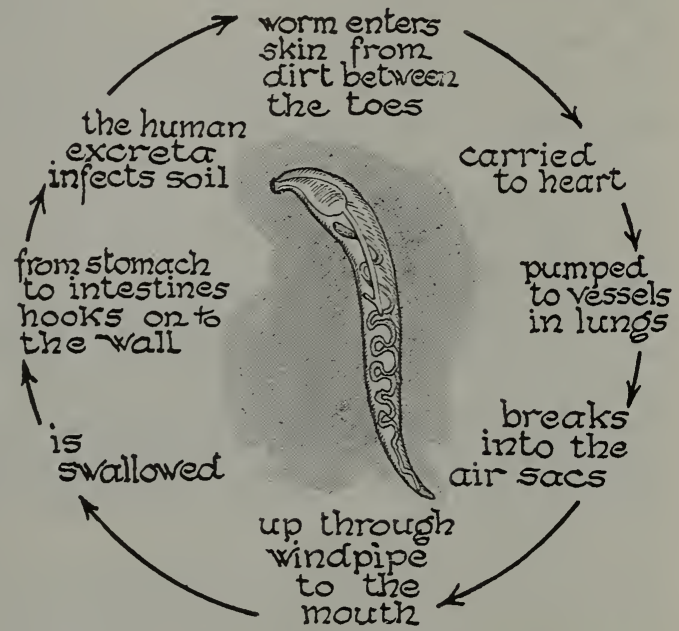

Explain, from the diagram, how one may become infected with hookworm.

lessness of the person infected, but it has been discovered that the hookworm pours out into the wound a poison which prevents the blood from clotting rapidly; hence a considerable loss of blood occurs from the wound after the hookworm has finished its meal and gone to another part of the intestine. 


\section{MAN CONTROLS HIS ENVIRONMENT FOR HEALTH}

The prevention of hookworm lies in sanitary toilets and in proper covering for the feet. The remedy for the disease is very simple: thymol, which weakens the hold of the hookworm, followed by Epsom salts, which helps pass it from the body.

For years a large area in the South undoubtedly has been retarded in its development by this parasite; hundreds of millions of dollars have been wasted and thousands of lives have been needlessly sacrificed. The Rockefeller Foundation has made a study of conditions all over the world and finds that in almost all semitropical countries the hookworm is present and that in some parts of the world almost all the people are infected.

"The hookworm is not a bit spectacular : it doesn't get itself discussed in legislative halls or furiously debated in political campaigns. Modest and unassuming, it does not aspire to such dignity. It is satisfied simply with (1) lowering the working efficiency and the pleasure of living in something like two hundred thousand persons in Georgia and all other Southern states in proportion; with (2) amassing a death rate higher than tuberculosis, pneumonia, or typhoid fever; with (3) stubbornly and quite effectually retarding the agricultural and industrial development of the section; with (4) nullifying the benefit of thousands of dollars spent upon education; with (5) costing the South, in the course of a few decades, several hundred millions of dollars. More serious and closer at hand than the tariff ; . . . making the menace of the boll weevil laughable in comparison - it is preëminently the problem of the South." - Atlanta Constitution.

Practical Exercise 24. Work out a suggested control of hookworm in the United States and report to the class.

Debate the statement from the Atlanta Constitution, using tuberculosis as the opposing disease.

\section{Self-Testing Exercise}

Check the true statements for your workbook:

T. F. 1. One form of tapeworm, parasitic in man, lives as an embryo in the muscles of cattle.

T. F. 2. The tropical disease, elephantiasis, is caused by small roundworms.

T. F. 3. People who live in hookworm-infested districts should never go barefoot. 
T. F. 4. The government examines all pork to see if it has trichina.

T.F. 5. Some tapeworms are given to pigs by man.

T.F. 6. Trichina is a roundworm that causes the disease called trichinosis.

T.F. 7. Hookworms are taken into the body by drinking impure water containing their eggs.

\section{PROBLEM XI. HOW MAY WE IMPROVE CONDITIONS AT HOME?}

The bedroom. Our work in general science has shown us the need of ventilation, especially in our bedrooms. The sleeping porch, so often found in country homes, is one of the most healthful

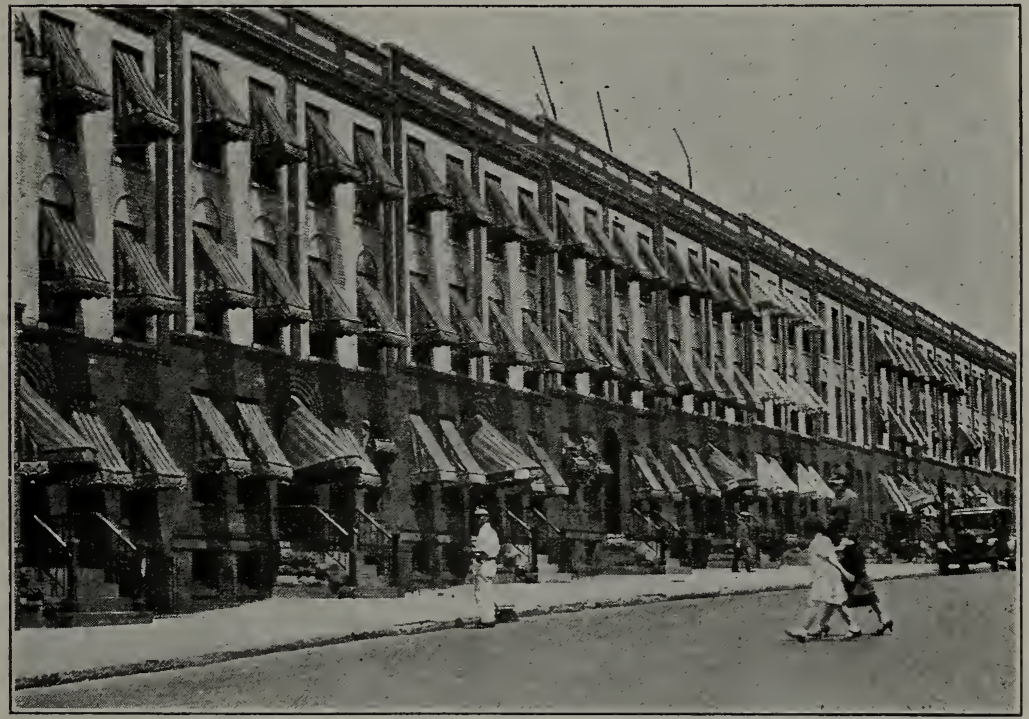

Photo by Douglas - Nesmuth \& Associates

Why are these buildings poor examples of apartment houses?

of modern conveniences. Such a condition as this is manifestly impossible for most people in a crowded city. Until comparatively recent times, many tenement houses were built so that the bedrooms had very little light or air; but now, due to housing laws, wide airshafts and larger windows are required. Laws in some 
cities require that every room in a modern apartment, except the bathroom, must have at least ninety square feet of floor area, that every room must have one outside window, and that at least twenty per cent of a lot (except a corner lot) should not be built upon.

In certain city tenements tuberculosis is believed to have been spread by people occupying rooms in which a previous tenant had tuberculosis. A new tenant should insist on a thorough cleaning of all the rooms and removal of old wall paper before occupancy.

Practical Exercise 25. Why should we have rugs in our bedroom instead of carpets? How would you clean your bedroom? If you use the room for study as well as sleeping, draw a plan for the arrangement of furniture and give reasons for its disposal. Show how you would get the best ventilatior for sleeping.

Sunlight is of great importance to health. Every home should have sunlight for a part of the day at least in its living and sleeping rooms. Sunlight is still the greatest germicide we know.

A student lamp, or shaded incandescent light, should be used for reading, so that the eyes are protected from direct light. Gas is a dangerous servant, because it contains carbon monoxide. It has been estimated that fourteen per cent of the total product of the gas plant leaks into the streets and houses of the cities supplied. This forms an unseen menace to health in cities.

Practical Exercise 26. Contrast indirect- and direct-lighting systems in your home from the standpoint of efficiency and protection of your eyes.

Care of food in the home. Although we can buy many foods in sealed packages, much of our food is exposed to the handling of people who may be careless. Vegetables and meats are too often exposed to dust, dirt, and handling. Raw fruits and vegetables should be carefully washed before being eaten.

In the summer, our houses should be provided with screens. All food should be carefully protected from flies. Dirty dishes, scraps of food, and garbage should be quickly cleaned up and disposed of after a meal.

Carelessness in dishwashing may mean the spreading of disease. Dr. Broadhurst of Teachers College, New York, learned, through a series of tests with several hundred glasses and cups smeared with 
saliva, that when dishes are hand washed and not rinsed all the bacteria are not removed. Some of the bacteria are not destroyed unless boiling hot water is used. At the time of the influenza epidemic during the World War an investigation was made of 66,000 men, half of whom ate from plates which were washed in boiling water, the other half from mess plates which were washed carelessly by the men. The influenza rate was 51 per 1000 among the men who ate from properly washed dishes, and 252 per 1000 among the

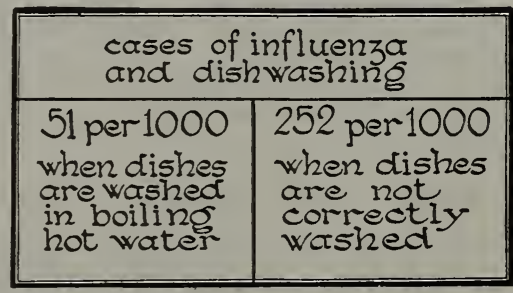

Explain, from text, what this diagram means. men who ate from mess plates. These facts show plainly the need of proper washing of dishes.

Milk at home should receive the best of care. It should be kept on ice and in covered bottles, because it readily takes up the odors of other foods. If we are not certain of its purity or keeping qualities, it should be pasteurized at home. Why? Experiments made with good fresh milk, which at the first observation contained about 30,000 bacteria per cubic centimeter, showed that twentyfour hours later, if kept at the temperature of the average ice box (below $50^{\circ}$ Fahrenheit), there were about the same number of bacteria present; while some of the same milk exposed to a temperature of $68^{\circ}$ Fahrenheit showed 500,000,000 bacteria to the cubic centimeter.

Demonstration 8. To determine the bacterial content of milk of various grades and from different sources.

Put a couple of drops of certified, pasteurized, raw, etc., milk, in separate Petri dishes containing sterile agar. Cover the dishes and put them in a warm dark place (about $90^{\circ} \mathrm{F}$.) for 24 hours. Which dish shows the greatest number of colonies? The greatest number of different colonies? Which is the best kind of milk to use? Why?

Demonstration 9. To determine the bacterial content of distilled water, rain water, tap water, dilute sewage.

Put several drops of the various kinds of water on dishes containing sterile agar. Cover the dishes and put them in a warm dark place for 24 hours. Which dish contains the greatest number of colonies? The greatest number of different colonies? Which is the best water to use for drinking purposes? For cooking? For laundry? Why? 
Practical Exercise 27. What general facts have you learned about refrigeration? What types of refrigerators are most efficient? The most costly to purchase? The most costly to run? What recommendation would you make for the average small family living in the country? In the city?

Practical Exercise 28. What insects are household pests? Which of these damage foods? What would you do to rid a house of ants? Roaches?

Practical Exercise 29. Is cold-storage food as good as fresh food? Give reasons for your answer. Recent tests have shown that the majority of cheap ice boxes do not keep the temperature below $50^{\circ} \mathrm{F}$. Such boxes usually have the ice wrapped in newspapers when it is put in the box. What effect does the paper have on the efficiency of the ice box?

Home water supplies. We have already learned why water which comes from a shallow well or unprotected spring should be carefully tested and protected against pollution. Ice for use in drinking water should be carefully washed, for experiments show that although nearly all bacteria in ice are killed after storage of a few weeks, yet disease germs are often found on the outside of pieces of ice because it is handled by disease carriers or persons of careless personal habits. Water coolers and filters are usually traps for bacteria and are often dangers rather than aids in sanitary living. Moreover, a water cooler in a house is frequently accompanied by a common drinking cup.

Practical Exercise 30. Show what you would do to protect a home water supply of uncertain purity. Make a report to the class.

Disposal of wastes. In country homes where cesspools receive human wastes, great care should be used in locating them, especially if the water supply is from a shallow well. A septic tank costs little more to install and is much safer than the ordinary cesspool. In city houses the disposal of human wastes is provided for by a system of sewers. Garbage should be disposed of each day. The garbage pail should be frequently sterilized by rinsing it with boiling water and plenty of lye or soap. Remember that flies frequent the uncovered garbage pail, and that they fly from it to your food.

Practical Exercise 31. Make a diagram for your workbook to show the method of sewage disposal in your community; in your home.

Find out the method of garbage collection and disposal in your town. Make suggestions for improvement of this service, if needed. 


\section{Self-Testing Exercise}

The best known germicide is .......(1). Some cities require the rooms of all apartments to have ....... (2) ....... (3). Gas leaks are harmful because of the danger of ........ (4) ...... (5). Bacteria on dishes can only be destroyed by ....... (6) ...... (7). Foods should be protected from ........(8). Milk in home should be kept on .......(9) to prevent .......(10) of ......(11). Water supplies should be ......(12) and ......(13) against pollution. A septic tank is ....... (14) than a ....... (15).

\section{PROBLEM XII. HOW MAY WE IMPROVE CONDITIONS AT SCHOOL?}

School surroundings. For forty weeks in the year from five to six hours a day are spent by the average boy or girl in the schoolroom. It is part of our environment and should therefore be considered as worthy of our care. A schoolroom should be not only attractive, but also clean and sanitary. City schools, because of their location, poor janitor service, or the selfishness and carelessness of children who use them, may be very dirty and unsanitary. Bacteria thrive in warm moist places where food is present, and float in the air with particles of dust. Experiments show that there are many more bacteria in the air when pupils are moving about, for then dust, bearing bacteria, is stirred up and circulated through the air. Sweeping and dusting with dry brooms or dusters stirs up the dust, which settles in some other place with its load of bacteria. Professor Hodge tells of an experience in a school in Worcester, Massachusetts. A health brigade was formed among the children, whose duty was to clean the rooms every morning by wiping all exposed surfaces with damp cloths. In a school of 425 pupils not a single case of communicable disease appeared during the entire year. Hundreds of schools have tried experiments similar to this and always with the same result, a pleasanter and cleaner building and better health of pupils.

Pupils should be unselfish in the care of a school building. Papers and scraps dropped by some careless boy or girl make the surroundings unpleasant for hundreds of others. Chalk thrown

$$
\text { в. вIо }-33
$$




\section{MAN CONTROLS HIS ENVIRONMENT FOR HEALTH}

by some mischievous boy and then tramped under foot causes dust particles in the air, which may irritate the lungs of a hundred schoolmates. Colds may be spread by spitting in the halls or on the stairways. Do not be the one to do such an unsportsmanlike act.

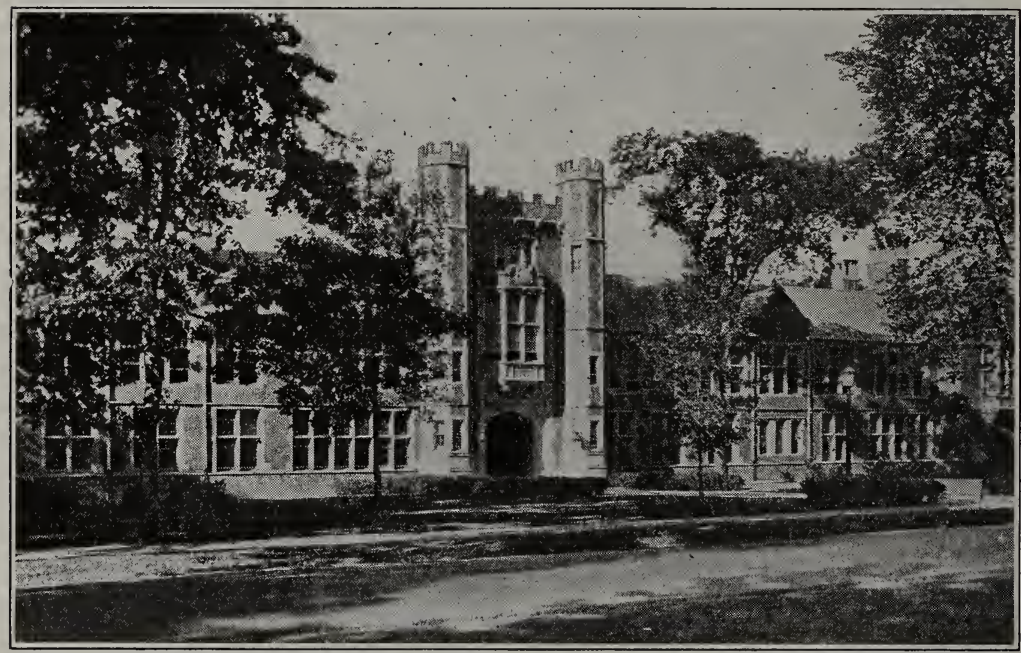

Keystone View Co.

Why might this be considered an ideal high school building?

Project. To form a service squad in your school. Make a report on such school conditions as may be remedied by concerted or individual student action and present it to the class. If conditions warrant it, ask your principal to hold a clean-up week, have a health assembly, or in some other way start public sentiment in the school for better coöperation and a more sanitary school plant.

Demonstration 10. To show the effect of the use of a duster and of a damp cloth upon bacteria in the schoolroom.

Expose a dish of sterile agar for a few minutes in a room which is being dusted with a dry cloth or feather duster. Expose another dish of sterile agar in a room which is being dusted with a damp cloth. Cover the two dishes and keep them in a warm place for 24 hours. What is the result?

Lunch time and lunches. Lunches should be clean, tasty, and well balanced. In most large schools, lunch rooms are part of the equipment and balanced lunches can be obtained at low cost. Do not make a lunch entirely from cold food, when hot can be 
obtained. Do not eat sweets only. Ice cream is a good food, if taken with something else, but be sure of the quality of your ice cream. More than 250 samples of ice cream collected and examined in Washington, D. C., contained from 37,500 to $365,000,000$ bacteria per cubic centimeter. The condition of ice cream depends largely on the sanitary conditions of the place where it was manufactured. Above all, be sure that all the food you eat is clean. Stands on the street, exposed to dust and germs, often have for sale food that is far from fit for human consumption. If you eat your lunch on the street near your school, remember not to scatter refuse. Paper, bits of lunch, and the like, scattered on the streets around your school, show lack of school spirit and lack of civic pride.

Project. Get help from your teacher or the local board of health in testing the purity of ice cream and other foods sold from stands outside the school. Test foods in your own school cafeteria at the same time as a control to see which conditions are better.

\section{Self-Testing Exercise}

Check the correct statements for your workbook:

T. F. 1. Schools are often dusty because of the movement of children through the halls.

T. F. 2. Feather dusters are better than wet cloths because the cloths stain the woodwork.

T. F. 3. Luncheons should be tasty as well as clean and well-balanced.

T. F. 4. Ice cream is always a safe food because freezing kills bacteria.

T. F. 5. If foods are exposed, the sunlight will kill the bacteria.

\section{PROBLEM XIII. HOW MAY WE HELP IMPROVE CONDITIONS IN OUR COMMUNITY?}

Inspection of factories and public buildings. It is the duty of a city to inspect the condition of all public buildings, especially of factories. Certain trades where dirt or poisonous fumes are given off are dangerous to health, hence care for the workers becomes a necessity. In such places the machinery must be protected by hoods or ventilators to carry off the fumes, and the workmen must be provided with dust and fume masks. Often goggles are provided to protect the eyes from dust or bright light. There 


\section{MAN CONTROLS HIS ENVIRONMENT FOR HEALTH}

are other occupations where noise, monotony of work, or too rapid movement causes fatigue and frequently accidents. Workmen in such trades must be protected, and many state laws now provide for proper gas masks, wheel and belt protectors, efficient lighting and

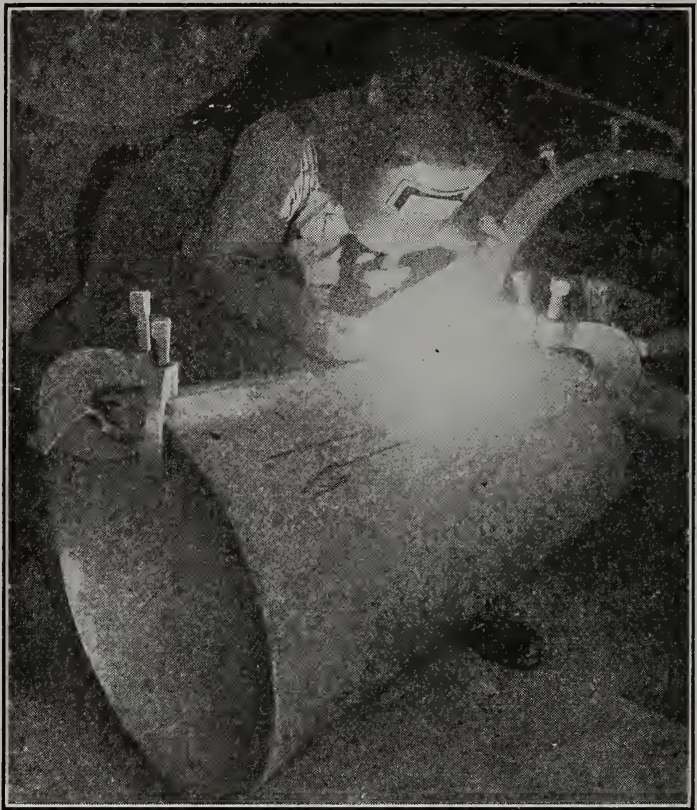

Why is the face of this workman protected with a shield? other devices that protect workmen from the particularhazard to which they are exposed. Factories are inspected as to cleanliness, the amount of air space per person employed, ventilation, toilet facilities, and proper fire protection. Tenement inspection should also be thorough and should aim to provide safe and sanitary homes for workers and their families.

Inspection of food supplies. In all cities certain regulations for the care of public food supplies are necessary. Inspectors are appointed to see that the laws are enforced and that foods are protected for the thousands of people who are to use them. All raw foods on stands should be covered with glass so as to prevent insects or dust laden with bacteria from coming in contact with them. Meats must be inspected for diseases. Inspection of cold-storage plants, of factories where foods are canned, and of bakeries must be and is part of the work of a city in caring for its citizens.

Practical Exercise 32. Visit a factory in your neighborhood and report to the class on all the protection devices you found. Have you any suggestions for improvement? 
Project. Inspect the conditions in your own home block or in the town in which you live. Make a map showing the buildings. Locate all houses, stores, factories, etc. Indicate any cases of communicable disease on the map. Mark all heaps of refuse in the street, all uncovered garbage pails, any street stands or push carts which sell uncovered fruit, and any stores which have an excessive number of flies. Note any other unsanitary conditions and mark them with appropriate symbols.

Sewage disposal. Sewage disposal is an important sanitary problem for every city. Some cities, like New York, pour their sewage directly into rivers which flow into the ocean. Consequently, much of the liquid which bathes the shores of Manhattan Island is dilute sewage. Other cities, like Buffalo or Cleveland, send their sewage into the lakes from which they obtain their supply of drinking water. The city of Chicago has

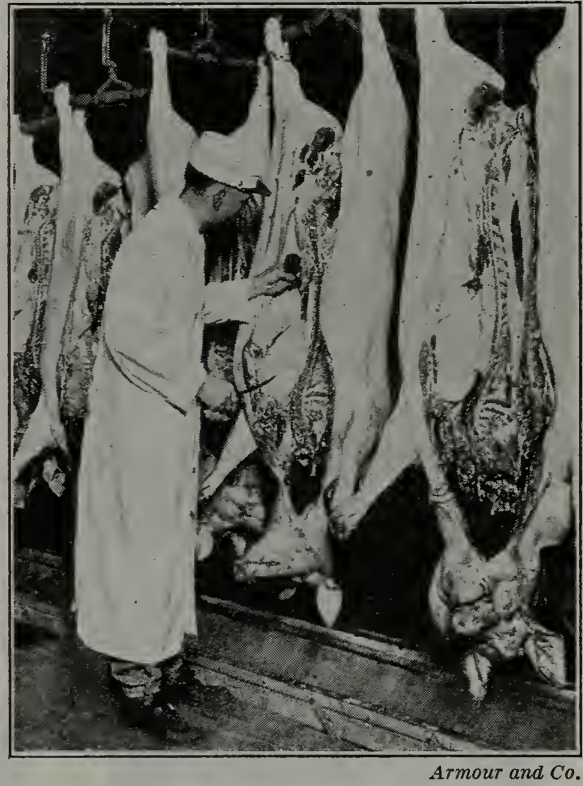

Inspectors are employed by the government to inspect and stamp all meat sent to other states.

built a huge drainage canal which diverts water from Lake Michigan. Through this canal the sewage is diluted and is carried eventually into the Mississippi River by way of the Illinois River. While there is not a noticeable increase in the bacterial content of the Illinois River at the point where it flows into the Mississippi, this drainage canal has done harm in another way. The fish in the upper Illinois River have been driven out or killed by the factory refuse and other wastes which come down the canal. This is only one example of the pollution of rivers by sewage and especially by factory wastes. All over the eastern part of our country rivers have been made open sewers, and now the conservation of our fish, 
as well as the water supply of many of our cities, is becoming a serious problem.

The best way to avoid the pollution of rivers is by proper sewage disposal, even if this method is expensive. Sewers for large cities are planned so that the dilute sewage is carried to a sewage disposal plant, usually situated a short distance outside of the community. Here the solid wastes are screened out, and then the smaller particles are precipitated out. The disposal of the solid material, called sludge, is still a serious problem. In some cities this sludge is dried, treated, and used as fertilizer. The fluid sewage, after the solid matter is taken out, is usually run over filter beds composed of coarse sand. In these filters bacteria oxidize the remaining organic matter of the sewage, so that the liquid which flows off is harmless and odorless. But such water is never used until it is first treated with chemicals, such as chlorine, in order to kill any harmful germs that may be left.

Practical Exercise 33. Report on an up-to-date method of sewage disposal in some city or community. Compare the conditions of this city with those existing in your community.

The work of the department of street cleaning. Another city problem is the disposal of refuse and garbage. The city streets,

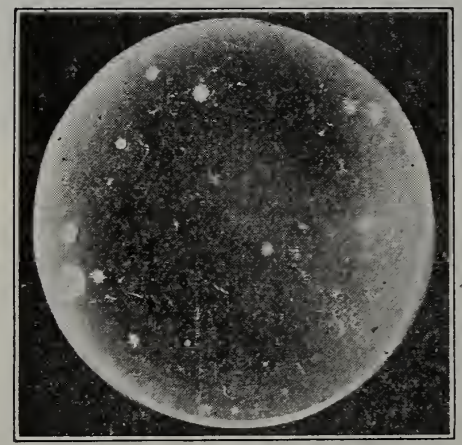

A

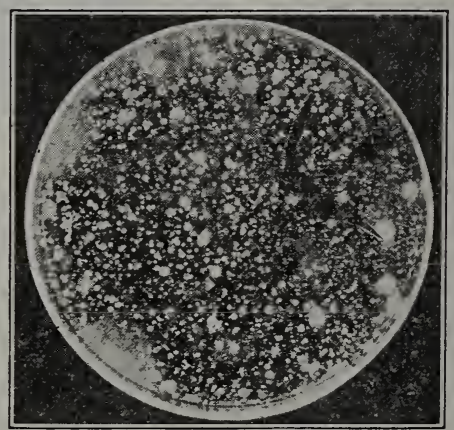

B

Culture A was exposed to the air in a well-cleaned and watered street in a residential section of a city. Culture B was exposed to the air in a crowded street in a business section of the same city. How do you account for the differences and results?

when dirty, contain countless millions of germs which have come from decaying material or from people and animals more or less 
diseased. In most large cities a department of street cleaning not only cares for the removal of dust from the streets, but also has the removal of garbage, ashes, and other waste as a part of its work. The disposal of solid wastes is a tremendous task. In Manhattan, New York, the dry wastes are estimated to be 1,000,000 tons a year in addition to about 175,000 tons of garbage. In some cities, such as Minneapolis, garbage must be wrapped in paper. This aids burning it in the city incinerator. In many cities the garbage is removed in carts, and part of it is burned in huge furnaces. The animal and plant refuse are sometimes cooked in great tanks, the fats extracted from this material, and the solid matter sold for fertilizer. Ashes are used in some places for filling marsh land. Thus the removal of waste matter may pay for itself in a large city.

Practical Exercise 34. Report to the class on the conditions existing in your community with reference to disposal of garbage, ashes, and other wastes. What rules exist? Is the collection of garbage and ashes a city or private function? What is done with reference to street cleaning?

\section{Self-Testing Exercise}

Check the correct statements for your workbook:

T. F. 1. Some occupations, such as trades which have dust or poisonous fumes, are dangerous.

T. F. 2. Food supplies which are not packed in containers do not need to be inspected.

T. F. 3. The government inspects all food so there is no danger to the consumer.

T. F. 4. People could safely drink dilute sewage if it were first filtered and chlorinated.

T. F. 5. Pollution of our streams with sewage not only drives out or kills the fish but makes the polluted stream a menace to health.

T. F. 6. The best method of sewage disposal for large cities is treating it with chemicals.

\section{PROBLEM XIV. WHAT PROTECTIVE HEALTH AGENCIES SHOULD EXIST IN A COMMUNITY?}

Practical Exercise 35. Compare the functions of your local board of health with those listed in the diagram on page 508. How many departments, if any, has it? How large a community does it serve? How many board members are there? Are they paid or volunteer workers? What work do they do? 


\section{MAN CONTROLS HIS ENVIRONMENT FOR HEALTH}

Are there any laboratories? If so, describe them. Do the local health officers concur with all the activities shown on the diagram? To what extent?

Has your locality an efficient board of health? If not, what suggestion can you make for improvement?

Public hygiene. Although it is absolutely necessary for each individual to obey the laws of health in order to keep well, it has become necessary also, especially in large cities, to have a department or board of health to exercise general supervision over the health of the people living in the community. In addition to such a body in cities, supervision over the health of citizens is also exercised by state boards of health. Since 1912 the United States Public Health Service has had general supervision over interstate quarantine and public health. Its valuable reports and reprints are available for schools and should be used in your project and classwork.

The functions of a city board of health. The administration of the board of health of a city includes a number of divisions,

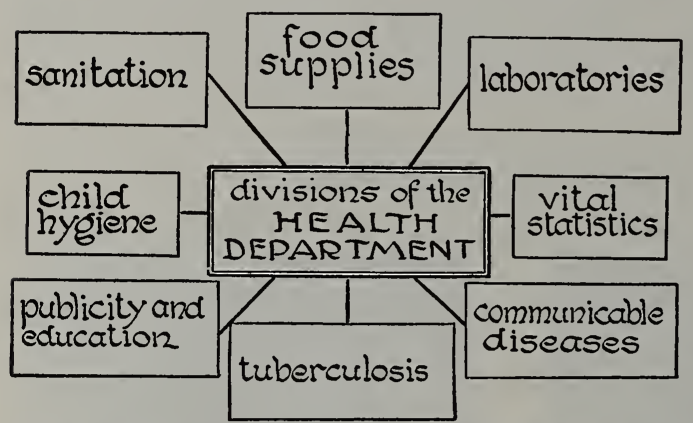

The health departments of various cities; counties, or states have a number of divisions. How many are there in your city and state departments of health?

thority, Dr. C. E. A. Winslow, should supervise the food supplies and sanitation of a city. It should from its laboratories take care of the communicable diseases by means of vaccines and antitoxins. It should have a department of child hygiene and should carry on health campaigns through its department of publicity and education. Finally, it should publish the vital statistics of the community.

The division of communicable diseases. Communicable diseases are chiefly spread through personal contact. It is the duty of a government to prevent a person having such a disease from 
spreading it among his neighbors. This is done by the board of health requiring the quarantine or the isolation of the person

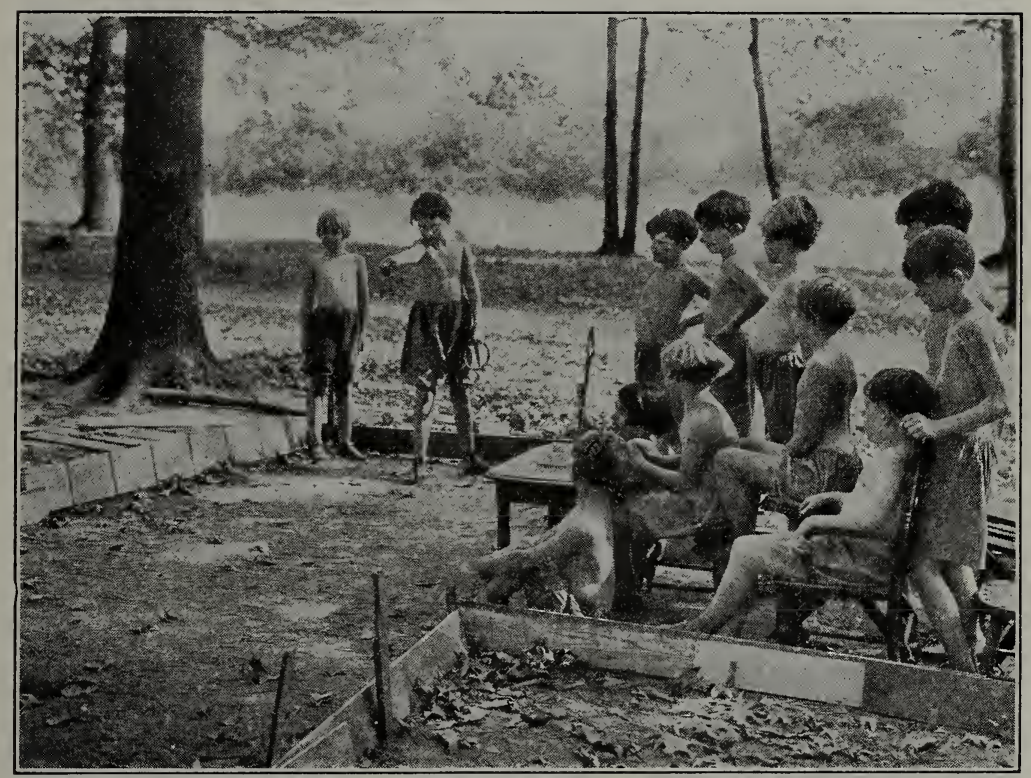

Nat. T. B. Assn.

Some health agencies, schools, and sanitariums provide camps for children who are undernourished or who have been in direct contact with persons suffering from tuberculosis.

having the disease. No one save the doctor and the nurse should enter the room of the person quarantined. After the disease has run its course, the clothing, bedding, etc., in the sick room are disinfected. This is known as terminal disinfection.

Tuberculosis, which not many years ago killed fully one seventh of the people who died from disease in this country, now kills less than one tenth. This decrease has been brought about largely through the treatment of the disease. Since it has been proved that tuberculosis, if treated early enough, is cured by quiet living, good food, and plenty of fresh air and light, we find that numerous sanitariums have come into existence which are supported by private or public means. At these sanitariums the patients live out of doors, and sleep in the open air, and have plenty of nourish- 
ing food and little exercise. Hundreds of sanitariums are now established in various parts of the country and are maintained by taxation as a part of the expenditure of the city, county, and state boards of health. There are many private sanitariums as well, maintained by various benevolent orders. In this way and by laws which require proper air shafts and window ventilation in tenement houses, by laws against spitting in public places, and in other ways, the boards of health in our towns and cities are waging war on tuberculosis.

Work of the division of school and infant hygiene. Besides the division of communicable diseases, the division of sanitation, which regulates the general sanitary conditions of houses and their surroundings, and the division of inspection, which looks after the purity and conditions of sale and delivery of milk and foods, there is another division which most vitally concerns school children. This is the division of school and infant hygiene, which supervises the care of the children of the city.

Adenoids. Many children suffer needlessly from enlarged tonsils and adenoids - growths in the back of the nose and mouth which cut off part of the normal supply of air to the lungs. A child suffering from these growths is usually a " mouth breather." The result to the child may be deafness, chronic running of the nose, nervousness, and lack of power to think. His body cells are starving for oxygen. A very simple operation removes these growths. Coöperation of the children and parents with the doctors or nurses of the board of health will do much in removing this handicap from many young lives.

Eyestrain. Another handicap to a boy or a girl is eyestrain. In a survey, sometime ago, twenty-two per cent of the school children of Massachusetts were found to have defects in vision. Tests for defective eyesight may be made easily at school by competent doctors, and if the weakness is corrected by procuring proper glasses, a handicap on future success will be removed.

Physical examinations. Decayed teeth are another handicap cared for by this division. Free dental clinics have been established in many cities, and if children will do their share in caring for their teeth, the chances of their success in later life will be greatly aided. 
In the schools of Elizabeth, N. J., in 1925 there were nearly 13,000 children examined for physical defects. These were placed in four groups, depending on the condition of physical well-being. Here the group that was in best health showed the best school grades, while those in poorest health had the poorest grades. Boys and girls, if handicapped with poor eyes or teeth, do not have a fair chance in life's competition. In a certain school in New York there were 236 pupils marked " $\mathrm{C}$ " in their school work. These children were examined, and 126 were found to have bad teeth, 54 to have defective vision, and 56 to have other defects, as poor hearing, adenoids, enlarged tonsils, etc. Of these children, 185 were treated for these various difficulties, and 51 did not take treatment. During the following year's work 176 of these pupils improved from " C" to "B" or "A," while 60 did not improve. If defects are such a handicap in school, what will be their effect on the chances of success in life outside?

The department of school hygiene deserves the earnest coöperation of every young citizen, girl or boy. If each of us would honestly help by maintaining quarantine in the case of communicable disease, by observing the rules of the health department, by acting upon reliable advice in case of eyestrain, bad teeth, or adenoids, and most of all by observing the rules of personal hygiene, the community in which we live, a generation hence, would be composed of stronger, more prosperous, and more efficient citizens.

Practical Exercise 36. Make an outline of all the health-protective agencies in your community.

Practical Exercise 37. Tell what is being done in your own school to check on the health of the students. Is there any "follow up" of those who are not well?

\section{Self-Testing Exercise}

Check the correct statements for your workbook:

T.F. 1. The function of the U. S. Public Health Service is to control my city health department.

T. F. 2. Quarantine is a protective measure and should be obeyed.

T.F. 3. Tuberculosis can be controlled entirely through sanitariums.

T. F. 4. Children whose health is poor usually have poor school grades. 


\section{MAN CONTROLS HIS ENVIRONMENT FOR HEALTH}

\section{Review SUmmary}

Test your knowledge of the unit by: (1) rechecking on the survey questions; (2) performing the assigned exercises; (3) checking with your teacher your scores on the various tests and doing over those that you missed ; $(4)$ making an outline of the unit for your work book.

\section{Test on Fundamental Concepts}

In a vertical column under the heading CORRECT write numbers of all statements you believe are true. In another column under INCORRECT write numbers of untrue statements. Your grade $=$ right answers $\times 2$.

I. Quarantine (1) is necessary because it gives the patient a rest; (2) is necessary because by isolating a person sick with a disease we may keep others from having it; (3) is useless except in early stages of disease ; (4) is an unselfish action because it protects others ; (5) should be enforced on all persons who have had contact with a person ill with communicable disease until the incubation period of that disease has been passed.

II. Immunity (6) means that a person can never take a certain disease, no matter if he is exposed to it ; (7) is always specific, that is, against one disease (A person may be immune to smallpox and be susceptible to measles) ; (8) is never restricted to certain races, whites and Negroes being equally susceptible to tuberculosis; (9) is natural to some people but not to others; (10) is not modified by a person's condition.

III. Active immunity (11) is gained by means of antitoxins; (12) takes place when the body helps to fight the disease by making antibodies in the blood; (13) is brought about against smallpox through vaccination; (14) is gained in typhoid through the introduction of dead germs with their toxins; (15) is not possible unless the blood makes antibodies.

IV. Passive immunity (16) occurs when the body fights the disease by making its own antitoxins; (17) is seen in the antitoxin treatment against diphtheria ; (18) is brought about when an antitoxin is formed outside the body and is injected into the body to help fight the disease; (19) is shown by Schick test and Dick test; (20) is not useful, for statistics show it has not reduced the death rate in diphtheria.

V. The way to keep well (21) is to have immunity against all the diseases given at once and get it over with; (22) is to keep the body 
resistance high through sensible living; (23) is to avoid people whom you think have communicable diseases; $(24)$ is to have plenty of nourishing food at regular times, plenty of sleep, and work and play in moderation; (25) is never to worry, and to take proper precautions in case of illness of others.

VI. Animals (26) may cause disease, as the malarial parasite; (27) may cause disease, as the Culex mosquito; (28) may spread disease, as the house fly; (29) may be parasites in two different hosts, needing both to complete their life cycle; (30) are only harmful if they are parasites.

VII. Malaria (31) may be controlled by killing off the Anopheles mosquito; (32) is only known in the tropics; (33) is caused by mosquitoes ; (34) may be cured by taking quinine ; (35) is caused by a protozoan.

VIII. The following animals may act as carriers of human disease : (36) rats ; (37) birds; (38) pigs; (39) flies; (40) fleas.

IX. We may improve conditions in our community (41) by always voting for all public measures without investigating their value because those who make the laws know best; (42) by making sure that our public water supply is protected by chlorination and filtration if the source is not pure; (43) by insisting upon pure milk and regulations that provide for it; (44) by patronizing all stores equally, clean and dirty ones; (45) by coöperation with the health department.

$\mathrm{X}$. The protective health agencies of much value in a community are (46) the city council; (47) the board of aldermen; (48) the board of health; (49) hospitals and sanitariums; (50) the division of school health and hygiene.

\section{Achievement Test}

1. How have you coöperated with the health authorities in the matter of quarantine after exposure to a communicable disease?

2. What is the value of acquired immunity?

3. What is the story of malaria in Microbe Hunters?

4. What is the story of yellow fever in either Microbe Hunters or Health Heroes?

5: How may malaria and yellow fever be controlled?

6. How may we get rid of flies? 


\section{MAN CONTROLS HIS ENVIRONMENT FOR HEALTH}

7. What are all the insects that spread diseases? Suggest a way to control them.

8. Have you made a fly and mosquito survey of your neighborhood? What did you find?

9. Have you made a survey of your home and surroundings and estimated the yearly damage done to them by rats? What is it?

10. What do the reports of the Rockefeller Foundation say about the extent hookworm has been controlled?

11. How do the various unfavorable factors of your environment affect your home and how may you prevent such factors from doing harm?

12. Have you a service squad in your school? What do you do to make its work effective?

13. What facts do you know about sewage and garbage disposal in your community?

14. How is the health department of your community organized and how does it do its work?

\section{Practical Problems}

1. Describe the process of making vaccines. Ask your teacher for references.

2. Suppose your city was threatened with a typhoid epidemic. Outline the probable procedure of the Board of Health and list your part in fighting the epidemic.

3. Suppose your home was made uncomfortable from mosquitoes coming from an unknown source. The rest of the community is not bothered by them. Outline your procedure in ridding your home of these pests.

4. What do you know of the sanitary conditions of your own home? Can you locate sewers, cesspool, or septic tanks, etc.? Do you know if your water supply is tested regularly and is adequately protected? Do you have regular garbage collection? Do you know how garbage is disposed of? How is the food in your home protected? Are you properly screened against insects? How high a score would you and your home make on the following score card?

\section{a. Environment}

Pure air . . . . . . . . . . . . . . . . . . . . 10

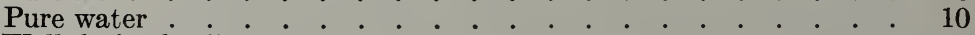

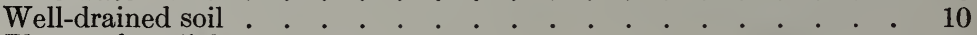

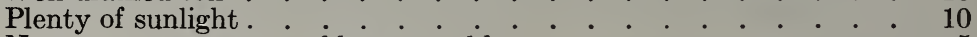

Not too great extreme of heat or cold . . . . . . . . . . . 5

Foods supplied from home garden . . . . . . . . . . . 5

Foods cheap and good . . . . . . . . . . . . 5 
b. Water in my home

Safe supply . . . . . . . . . . . . . . . . 10

Ample supply . . . . . . . . . . . . . . . . . . . 10

All parts of home supplied . . . . . . . . . . . . . . 10

Plumbing in good condition . . . . . . . . . . . . . . 10

Soft water provided . . . . . . . . . . . . . . . . . 10

c. Care of foods in my home

Clean kitchen and utensils . . . . . . . . . . . . . . . . 10

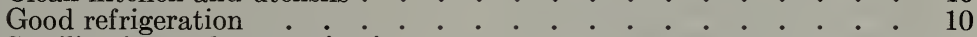

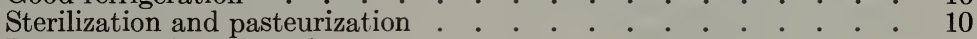

Proper use of preservatives . . . . . . . . . . . . . . 10

Protection from insects, etc. . . . . . . . . . . . . . 10

d. Household pests

No flies . . . . . . . . . . . . . . . . . . 10

No mosquitoes . . . . . . . . . . . . . . . . . . . . 10

No body pests (fleas, bedbugs, head lice) . . . . . . . . 10

No food or cloth pests (roaches, ants, weevils, clothes moths, etc.) 10

No rats or mice . . . . . . . . . . . . . . . . . . 10

e. Removal of wastes

Exposed plumbing . . . . . . . . . . . . . . . . . 10

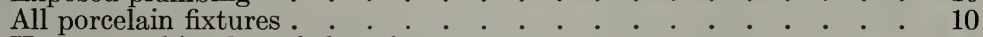

Have a working knowledge of system . . . . . . . . . . . . 10

Sewer connections or septic tank $\quad . \quad$. . . . . . . . . . . . . . 10

Garbage pail properly kept . . . . . . . . . . . . . . 10

f. Personal health habits

Setting-up drill and deep breathing . . . . . . . . . . . . 5

Cool rub or shower every day . . . . . . . . . . . . . . 5

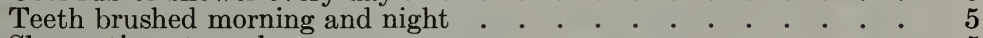

Slow eating at meals . . . . . . . . . . . . . . . . . 5

Food chewed well . . . . . . . . . . . . . . . . . . . 5

No overeating . . . . . . . . . . . . . . . . . . . . 5

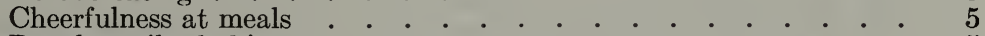

Regular toilet habits . . . . . . . . . . . . . . . . . 5

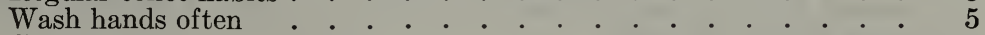

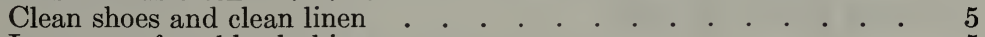

Loose, comfortable clothing . . . . . . . . . . . . . . . 5

Feet warm and dry . . . . . . . . . . . . . . . . . . 5

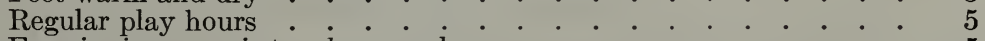

Exercise in open air two hours a day . . . . . . . . . . . 5

Regular work and study hours (at least two hours) . . . . . . 5

Proper lighting for study . . . . . . . . . . . . . . . 5

Bed before 10 P.M.

Sleep in open air or with windows open top and bottom . . . . . 5

No coffee, tea, or cigarettes . . . . . . . . . . . . . . 5

g. Protection against disease

Vaccinated for smallpox

Teeth examined twice a year

All teeth cavities filled

Eyes examined once a year

Glasses used when necessary 
Keep more than five feet distant from those who cough or sneeze $\quad 5$ Take care to use handkerchief if you eough or sneeze...$^{*} \cdot{ }_{5}$ Stay in the house if you have a cold . . . . . . . . . . . 5

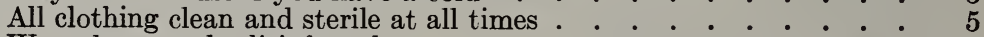
Wounds properly disinfected

$h$. Clothing, bathing, and ventilation

Proper outer clothing

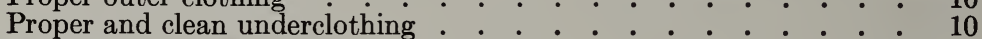

Bathing twice a week at least . . . . . . . . . . . . . . . . 10

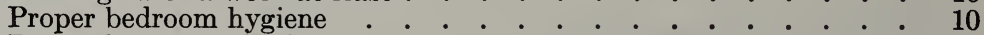

Proper home ventilation . . . . . . . . . . . . . . . 10

$i$. Lighting my home

Sunlight plentiful . . . . . . . . . . . . . . . . . . 10

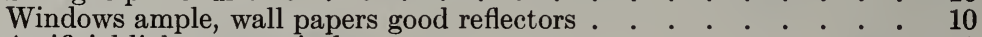

Artificial light economical . . . . . . . . . . . . . . . . . . 10

Proper lighting for all kinds of work

Good systems of lighting used . . . . . . . . . . . . . 10

Total Possible Score . . . . . . . . . . . . . . . $\overline{500}$

5. What do you know about the sanitation of your own community? Its water supplies, milk and food inspection, garbage and ash disposal, sewage disposal? What agencies care for each of the above? What would you do in case of a typhoid outbreak in your city? Septic sore throat? Tuberculosis of children?

6. Is your school adequately ventilated? Is its heating plant, the sanitary condition of its toilets, gymnasium, and the methods of cleaning the best possible?

7. What is the Board of Education doing to protect your health?

8. Do you have a sanitary code in your community? If so, who administers it? What do you know about it? Is there adequate inspection of food supplies? Care of milk? Do you know where the milk you drink comes from and how it is cared for?

9. To what extent in the past have you, as a young citizen, coöperated with the authorities to make your town a more sanitary and safer place to live in?

\section{Useful REFERENCES}

Allen, Civics and Health. (Ginn \& Co.) Andress, Aldinger, Goldberger, Health Essentials. (Ginn \& Co. 1928.) Broadhurst, Home and Community Hygiene. (J. B. Lippincott Co. 1925.)

Broadhurst, How We Resist Diseases. (J. B. Lippincott Co. 1923.) Bulletins and Publications of Committee of One Hundred on National Health.

De Kruif, Microbe Hunters. (Harcourt, Brace \& Co. 1926.)

Farmers' Bulletins: 70, 658, 851.

Hunter, Laboratory Problems in Civic Biology. (American Bools Company.) 
Hygeia. (American Medical Association.)

Jewett, Town and City. (Ginn \& Co.)

Public Health Reprints: 54, 78, 106, 192, 234, 302, 341, 441, 448, 499, $530,680,723,821,827,850$.

Reports of Boards of Health of California, Illinois, New York, Virginia, etc. ; and of the City of New York and other cities.

Richards, Sanitation in Daily Life. (M. Barrows \& Co.)

Richman and Wallach, Good Citizenship. (American Book Company.)

Ritchie, Primer of Sanitation. (World Book Co. 1925.)

School Hygiene. (American School Hygiene Association.)

Sharp, Foundation of Health. (Lea \& Febiger. 1924.)

Tolman, Hygiene for the Worker. (American Book Company.)

Winslow, Healthy Living. (Charles E. Merrill Co. 1920.)

Zinsser, Textbook of Bacteriology. (D. Appleton \& Co. 1927.) 


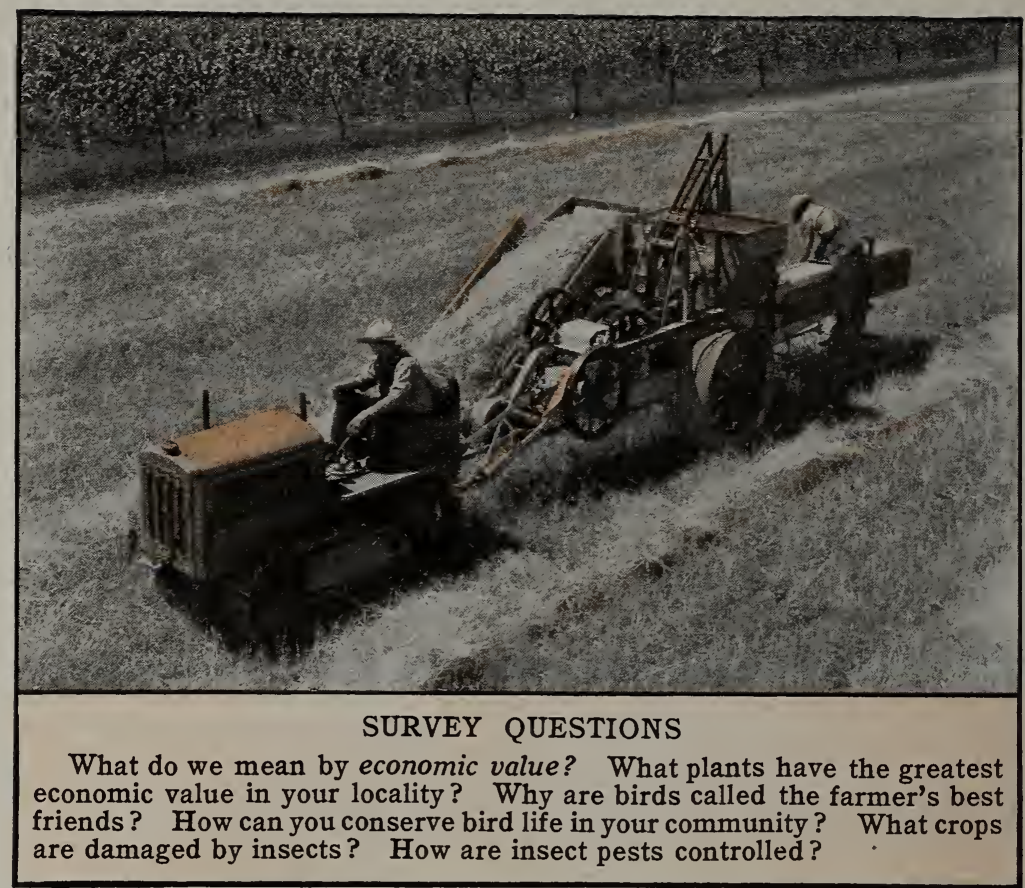

Ewing Galloway

\section{UNIT XVI}

\section{HOW DOES MAN CONTROL HIS ENVIRONMENT FOR WEALTH?}

Preview. To the boy or the girl living in the city green plants seem to have little direct value. Although we see vegetables for sale in stores, and we know that fruits have a money value, we are not likely to realize that the wealth of our nations depends upon growing crops more than it does on manufactories and business houses. The economic or "dollars and cents" value of plants is enormous, and our lives depend on the food which they supply.

Another great source of wealth is the animals man uses for food, as a source of raw material for clothing, furs, dyes, oils, perfumes, 
and many other commodities. But both plants and animals have, in another sense from the above, an economic value. If plants, such as weeds, destroy our crops by taking their place, or if animals, such as coyotes, destroy sheep by killing them, then they are harmful in a "dollars and cents" way.

We have already learned that man plays a very important part in disturbing the balance of life as it exists on the earth. This has been brought about by the increased population and the consequent necessary increase in food and other supplies. Through planting crops which have nitrogen-fixing bacteria associated with them, it has become possible for the earth to supply more crops. By irrigating large areas of practically desert land man has been able to raise large crops of grains, vegetables, and fruits.

Man is also constantly finding new uses for animal products. Fishes, such as the dogfish, which were formerly unmarketable, because they were not thought good to eat, are now an article of food under the name of the grayfish. This is only one instance of how man, as the thinking animal, exploits other forms for his own benefit. More people on the earth means a need for more food. Man has come to realize the way in which he has been wasting the living things which he needs and he is emphasizing methods of conservation as well as the use for food of plants and animals that formerly were not considered as fit for food.

Those of us who live in farming communities are aware of the harm done by many insects and know, too, that our bird friends do a good deal to help make it possible for the farmer to raise his crops. But those of us who do not know the birds as friendly fighters in our behalf should have some evidence along this line. Moreover, all of us ought to know a few common birds so we may be able to recognize them.

Birds not only eat insects but some of them eat weed seeds, thus keeping these pests somewhat more under control. Even the birds which do eat crops make up for this by feeding in part upon insects or harmful rodents.

To understand the value of birds better a few examples of insect damage will be given and, when possible, it will be shown how insects are controlled by the birds which feed upon them. 


\section{PROBLEM I. HOW ARE PLANTS USED AS FOOD?}

Leaves as food. Grazing animals feed almost entirely on tender shoots, leaves, or blades of grass. We can realize the economic value of grass when we consider the fact that for the last ten years the hay crop in this country was worth well over $\$ 1,000,000,000$ a year. And this does not take into account the wild grasses used as forage by numerous grazing animals.

Certain leaves and buds are used as food by man. Lettuce, kale, spinach, and broccoli are examples. A cabbage head is a

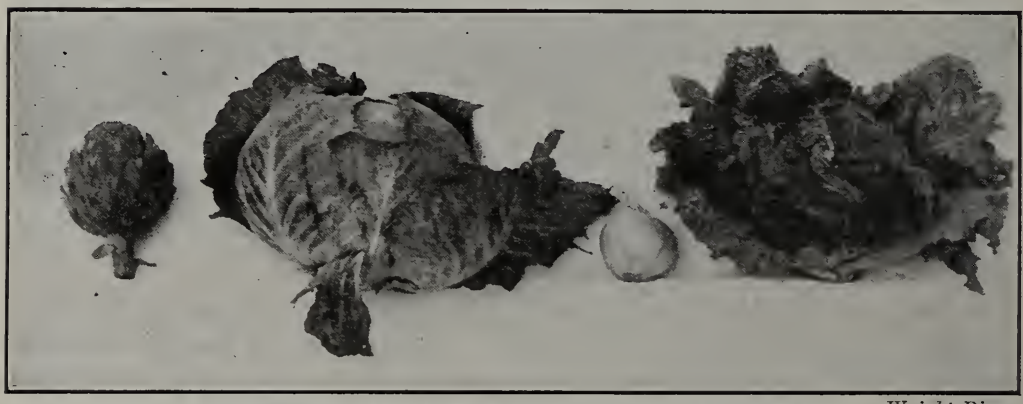

What vegetables are leaves? Do you know any others?

Wright Pierce

large leaf bud. An onion is a compact budlike mass of thickened leaves which contain stored food.

Practical Exercise 1. Make a table of foods to be filled out from material found in this unit and in books of reference. Fill out the first column of this table by placing in it ten leaves used as food by man.

FOOD OF MAN

\begin{tabular}{|c|c|c|c|c|c|}
\hline Leaves & Stems & Roots & Seeds & Flowers & Fruits $:$ \\
\hline & & & & \\
\hline & & & \\
\hline
\end{tabular}

Stems as food. If one were asked to name a stem used as food, he would probably mention either asparagus or celery. Sugar 


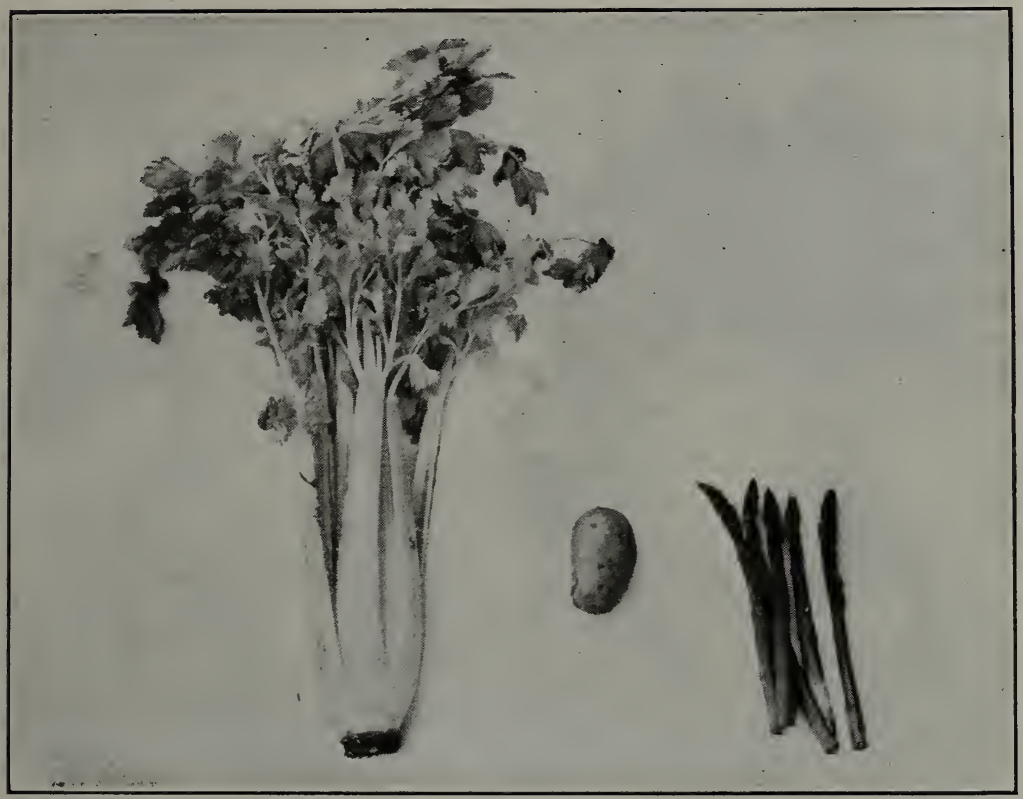

Wright Pierce

Can you name stems, other than those given above, that are used for food?

cane certainly ought to be named also, since over half of the world's supply of sugar comes from this source. Maple sugar is a much used commodity obtained from the sap drawn from the trunks (enlarged stems) of sugar maples. Over 16,000 tons of this sugar is produced every spring. The pithy stem or trunk of the sago palm, grown by the native of the East Indies, is made into a meal or flour. This flour is shipped to all parts of the world and is used for making starch, puddings, and for thickening soups. Another stem, the potato, growing underground, forms one of man's staple articles of diet in this country.

Practical Exercise 2. Fill out a second column in your table with ten different stems used as food.

Roots as food. Roots which store food for plants form an important part of man's vegetable diet. Beets, radishes, carrots, parsnips, sweet potatoes, and many others might be mentioned. 


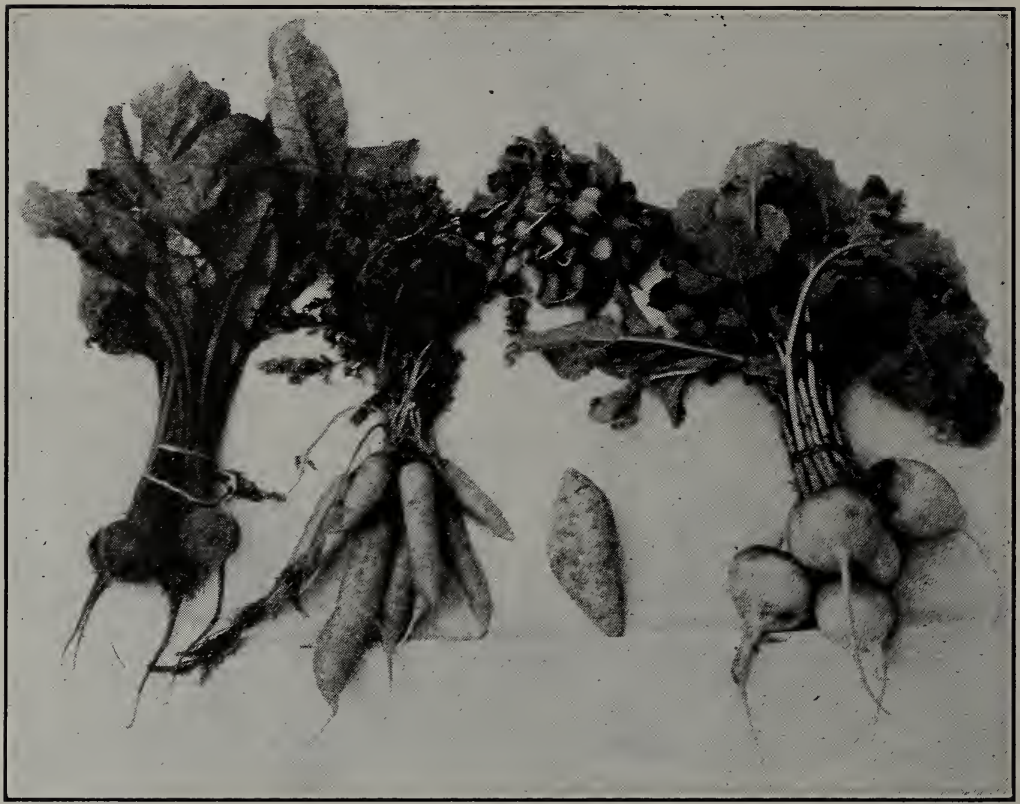

Wright Pierce

Read the table below and tell which of these roots contains the most nutrients.

The following table shows the proportion of nutrients in some of the more common roots :

\begin{tabular}{|c|c|c|c|c|c|}
\hline & WATER & Proteins & $\begin{array}{l}\text { CARBO- } \\
\text { HYDRATES }\end{array}$ & $\mathbf{F}_{\mathbf{A T}}$ & $\begin{array}{l}\text { MINERAL } \\
\text { MATTER }\end{array}$ \\
\hline Carrot . & 89 & 0.5 & 5 & 0.2 & 1.0 \\
\hline Parsnip . & 81 & 1.2 & 8.7 & 1.5 & 1.0 \\
\hline Turnip . . & 92.8 & 0.5 & 4. & 0.1 & 0.8 \\
\hline Sweet potato & 74 & 1.5 & 20.2 & 0.1 & 1.5 \\
\hline Beet . . & 82.2 & 0.4 & 13.4 & 0.1 & 0.9 \\
\hline
\end{tabular}

Practical Exercise 3. Add ten roots to your list of foods. Using the above table, figure out the roots which give you the most food for your money at current prices.

Seeds as foods. Our cereal crops, corn, wheat, oats, etc., have played a very important part in the civilization of man and are now of much importance to him as food products. Bread made 


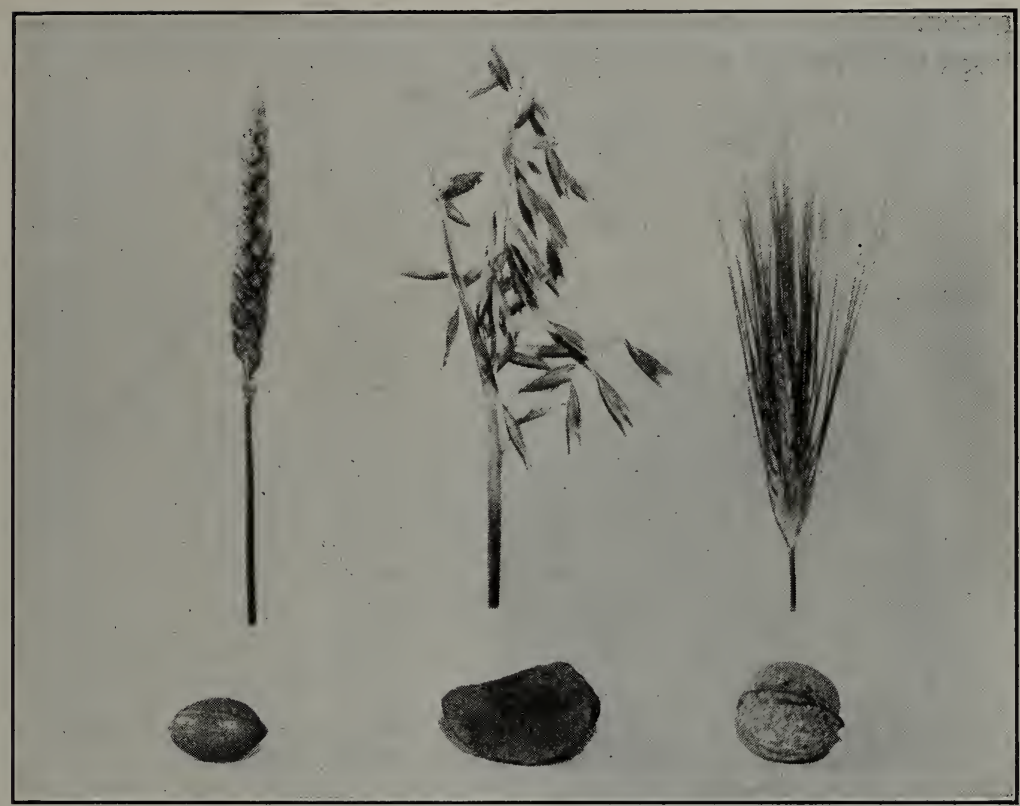

What seeds, other than those given here, do you use for food?

Wright Pierce

from wheat flour is frequently called the "staff of life." Our grains are the cultivated progeny of wild grasses. Domestication of plants and animals marks epochs in the advance of civilization.

The man of the stone age hunted wild beasts for food, and lived like one of them in a cave or wherever he happened to be ; he was a nomad, a wanderer, with no fixed home. He may have discovered that wild roots or grains were good to eat; perhaps he stored some away for future use. Then came the idea of growing things at home instead of digging or gathering the wild fruits from the forest and plain. The tribes which first cultivated the soil made a great step in advance, for they had as a result a fixed place for habitation. The cultivation of grains and cereals gave them a store of food which could be used at times when other food was scarce. The word "cereal" was derived from Ceres, the Roman goddess of agriculture. From earliest times the growing of grain and the progress of civilization have gone hand in hand. As 


\section{MAN CONTROLS HIS ENVIRONMENT FOR WEALTH}

nations have advanced in power, their dependence upon the cereal crops has become greater and greater.

"Maize, Indian corn, has played a most important part in the history of the New World, as regards both the red men and the white men. It could be planted without clearing or ploughing the soil. There was no need of threshing or winnowing. Sown in tilled land,

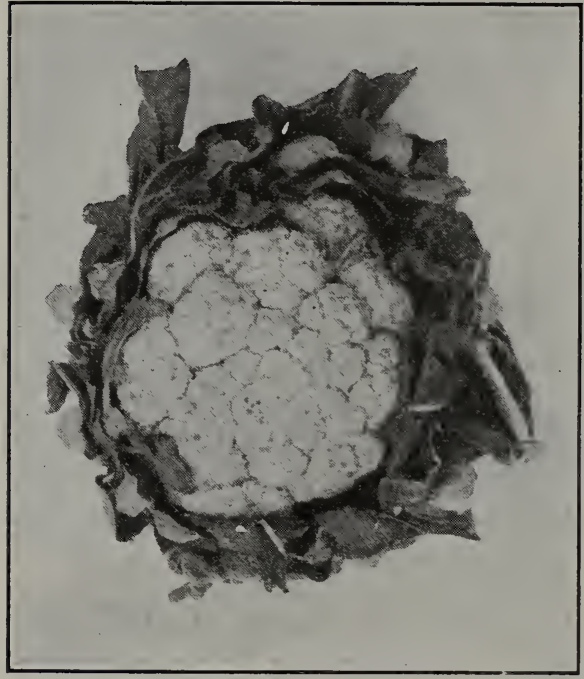

Wright Pierce

What part of the cauliflower is used for food? it yields more than twice as much food per acre as any other kind of grain. This was of incalculable advantage to the English settlers in New England, who would have found it much harder to gain a secure foothold upon the soil if they had had to begin by preparing it for wheat or rye," says John Fiske. (The Discovery of America. Houghton Mifflin Co.)

Today, in spite of the great wealth which comes from our mineral resources, live stock, and manufactured products, a very good index of our country's prosperity is the size of the corn and wheat crop. According to a recent report, the value of farm property in the United States is more than $\$ 57,000,000,000$, a sum greater than that invested in all manufactures in the United States.

Corn. Over 2,000,000,000 bushels of corn were raised in the United States during the year 1929. This figure is so enormous that it has but little meaning to us. Iowa and Illinois are the greatest corn-producing states in this country, each having a yearly record of over $300,000,000$ bushels. The figure on page 525 shows the principal corn-producing areas in the United States.

Indian corn has many uses. It is a valuable food. It has a large proportion of sțarch, from which corn syrup, starch, and 
alcohol are made. Machine oil and soap are made from corn grain. The leaves and stalks make excellent fodder or they can be made into paper and artificial silks. The husks are used in mattresses; the cobs are used for fuel or ground up for meal for live stock; and the pith in the stalk is used as a protective belt placed below the water line of our huge battleships.

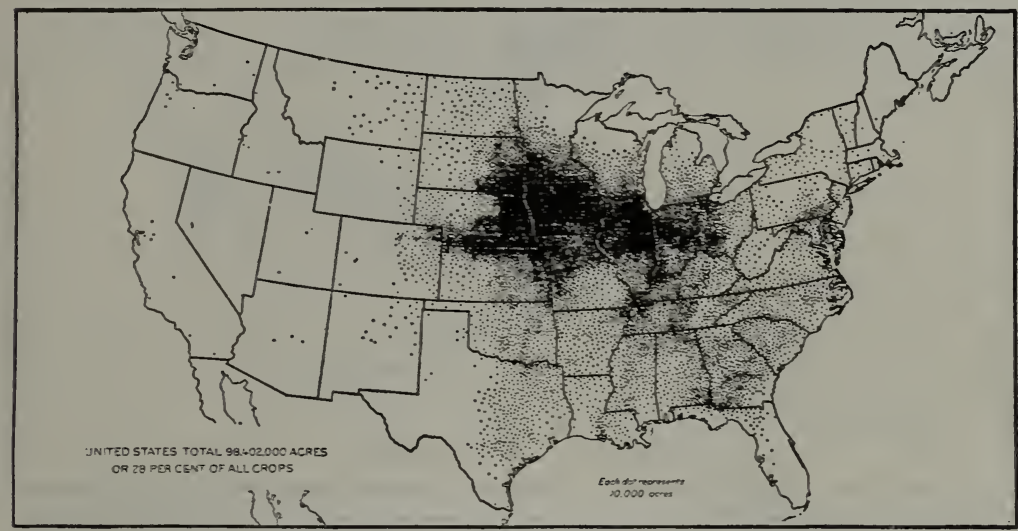

More corn is raised in certain areas of the United States than in other areas. How can you account for this?

Wheat. Wheat is the crop of next greatest importance in this country. Over $800,000,000$ bushels were raised in this country in 1929 , representing a total money value of about $\$ 840,000,000$, although during the World War our farmers received over $\$ 2,000,000,000$ yearly for a crop of less than $1,000,000,000$ bushels. Seventy-two per cent of all the wheat raised comes from the North Central States and the far West. Much of the wheat crop is exported, thus indirectly giving employment to thousands of people on railways and steamships. Wheat is used chiefly for manufacture into flour The germ, or young wheat plant, is sifted out during this process and made into certain breakfast foods. Flour making forms the chief industry of Minneapolis, Minnesota, and of several other large and wealthy cities in this country.

Other grains. Of the other cereal grains raised in this country, oats is the most important crop, more than $1,200,000,000$ bushels 
having been produced in 1929. Barley and rye, grains much like wheat, are produced in smaller quantity. One of the most important grain crops for the world is rice. The fruit of this grasslike plant, after threshing, screening, and milling, forms the principal food of probably one third of the human race.

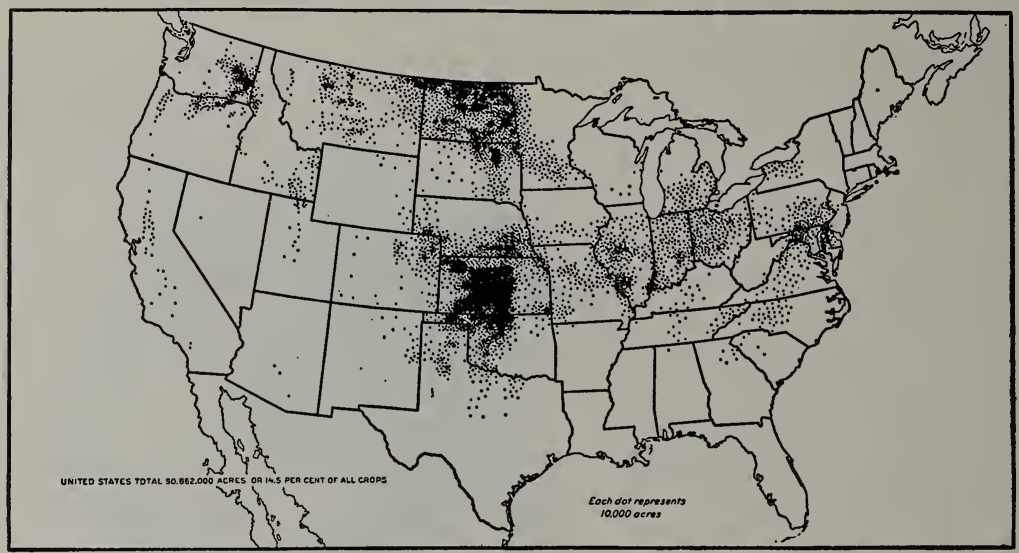

How can you account for the location of these wheat-producing areas in the United States? Why is wheat such an important crop in this country?

Practical Exercise 4. Obtain from government publications or the World Almanac the following facts: (1) amount invested in manufactures for the current year; (2) amount invested in agriculture for the current year; (3) the size and value of the corn crop; and (4) the size and value of the wheat crop.

Practical Exercise 5. What agricultural products are raised in your community? About what proportion of wealth is invested in agriculture as against manufactories? Do they raise any "corn on the hoof" in your community?

Practical Exercise 6. List in your table ten important grains used as foods. Give ten different uses of grains.

Practical Exercise 7. If there is a flour mill in your locality, visit it and report to the class on your trip.

Garden fruits and vegetables. Vegetables have come to play an important part in the diet of man. People are using more vegetables and less meat, and are more healthful and feel better for it. Market-gardening forms the lucrative business of many thousands of people near our great cities and in many of our southern states. Some of the important garden fruits are squash, cucumbers, pumpkins, melons, tomatoes, peppers, strawberries, 


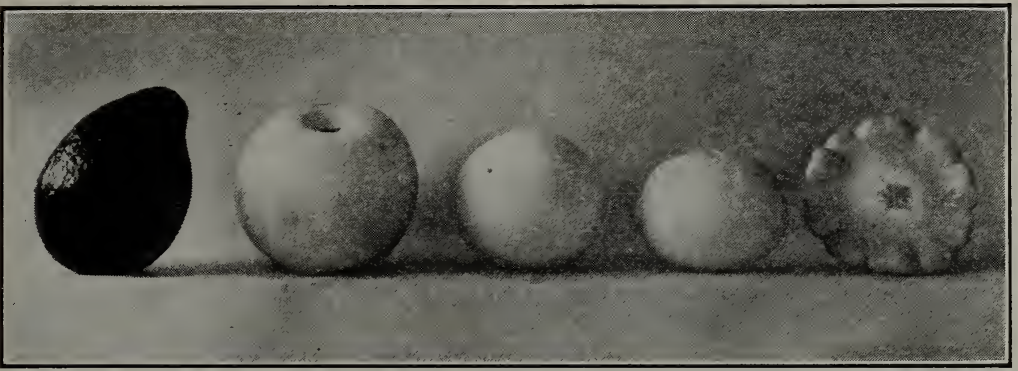

Wright Pierce

Which of the above fruits are raised in your locality? What others are raised there?

raspberries, and blackberries. As many as 1000 carloads of melons were shipped from the Imperial Valley, California, during a single day in 1930. More than $\$ 165,000,000$ worth of fruits are canned or dried each year in addition to what is sold fresh. Beans and peas are important as foods because of their relatively large amount of protein. Canning green corn, peas, beans, asparagus, tomatoes, etc., has become an important industry.

Orchard and other fruits. In the United States an average of nearly 200,000,000 bushels of apples are grown every year. Peaches, pears, plums, apricots, and cherries also are raised in large orchards, especially in California and in Georgia.

The grape crop of the world is commercially valuable, because of the beverage made from the juice and raisins produced from the grapes. The culture of the citrus fruits, lemons, oranges, and grapefruit has increased in recent years because of the discovery

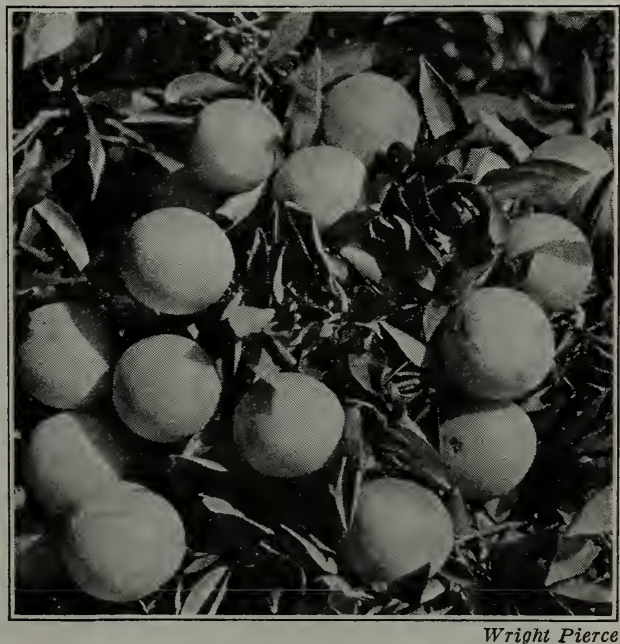

Why are citrus fruits valuable foods? 
of their values as producers of vitamins. Figs, olives, and dates also are grown now in the Southwest; they are staple foods in the Mediterranean countries and are sources of wealth to the people there, as are coconuts, bananas, and many other fruits in tropical countries. Nuts form one of our important articles of food, largely because of the great amount of protein contained in them. Walnut ranches are now very profitable, especially in California.

Beverages and condiments. The coffee and cacao beans and the leaves of the tea plant, products of tropical regions, form the basis of very important beverages of civilized man. Black and red pepper, mustard, allspice, nutmegs, cloves, and vanilla are all products from various fruits and seeds of tropical plants.

Practical Exercise 8. Report to the class on the current value of crops mentioned in this problem. Which crop is most valuable in California, Washington, Florida, Arizona, New York, Michigan? Consult government bulletin and World Almanac for information.

\section{Self-Testing Exercise}

$\ldots \ldots$ (1) $\ldots \ldots$...(2), and ......(3) are examples of leaves used as food $; \ldots \ldots \ldots(4), \ldots \ldots$ (5), and .......(6) are stems used as food. . ....... (7) are the largest crops raised in our country.

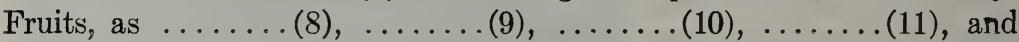
....... (12), are of great importance. .......(13) is the largest cereal crop in the United States, with........(14) a close second.

\section{PROBLEM II. WHAT ARE OTHER ECONOMIC VALUES OF PLANTS?}

Many of our industries would not be in existence were it not for certain plant products which furnish the raw materials. Many cities of the East and South, for example, depend upon cotton to give employment to thousands of factory hands.

Cotton. Of all our native plant products cotton is probably of the most importance. More than twelve million bales of five hundred pounds each are raised annually.

The cotton plant thrives in warm regions. The seeds of the fruit have long filaments attached to them. Bunches of these 
filaments, after treatment or ginning, are easily twisted into threads from which are manufactured cotton cloth, such as muslin, calico, cretonne, and gingham. In addition to the fiber, cottonseed oil, a substitute for olive oil, is made from the seeds, the hulls are used for making artificial silk, rayon, and the refuse makes fodder for cattle.

Other vegetable fibers. Among the other important vegetable fibers are Manila hemp, which comes from the leaf-stalks of a plant of the banana family, and true hemp, which is the bast or woody fiber of a plant cultivated in most warm parts of the earth. These fibers are used for twine or rope. Flax is another im-

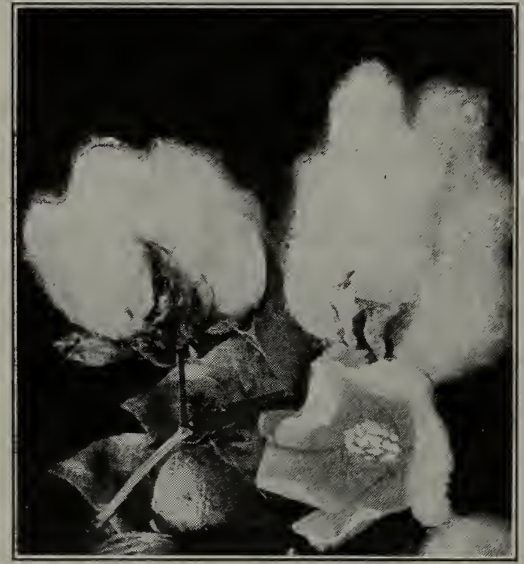

Blossom and bolls of a cotton plant. portant fiber plant, grown largely in Russia, Ireland, Belgium, and other parts of Europe. Flax is becoming a more important crop in this country although it is raised here chiefly for its seeds. Linen cloth is made from the bast fibers of the stem of this herb. Burlap and coarse bags are made from the fiber of the jute plant, raised in India.

Vegetable oils. Some of the same plants which give fiber also produce oil. Cottonseed oil pressed from cotton seeds, linseed oil from the seeds of the flax plant, and coconut oil (the covering of the nut produces a fiber) are examples. One of the important industries of California is olive culture, the fruit being used as a table delicacy, while oil pressed from the fruit is used largely in salad dressings.

Drug-producing plants. Quinine, the specific remedy for malaria, was known by the Indians in South America before the white men came. It is made from the bark of the cinchona tree. South America also furnishes us with cocaine, a habit-forming drug made from the leaves of the coca tree of Peru. Morphine 
and opium come from the poppy. Many of our pleasant oils and flavors, as eucalyptus, wintergreen, and peppermint, come from plants.

Tobacco, although a poisonous plant because of the nicotine it contains, is, nevertheless, one of this country's largest crops. Over $1,200,000,000$ pounds were raised in 1927, having a total value of about $\$ 266,000,000$. Atropine and belladonna, both poisons used as drugs, are from plants related to the tobacco.

Practical Exercises 9. Make a table to show the value of the chief fiber crops in your section of the country during the past year. Get information from your local Chamber of Commerce.

What other crops are of value in your locality and why?

The use of tobacco has greatly increased since the World War. Give three possible reasons why this is so.

\section{Self-Testing Exercise}

Our clothes lines are made from .......(1). Burlap bags are made from ........(2). Linen comes from ........(3). The coca tree gives us ....... (4). ......(5), although a poisonous plant, is one of the largest crops we raise. .......(6) is the most important fiber plant in this country.

\section{PROBLEM III. WHAT IS THE VALUE OF ANIMALS AS FOOD FOR MAN?}

Indirect use of animals as food. Just as plants form the food of animals, so some animals are food for others. Protozoa and many forms of tiny plants, known as plankton, which are swarming near the surface of bodies of fresh and salt water, form the food supply of many forms of life. Many fish live on plankton or on smaller fish which feed on plankton. Some fishes, as the menhaden, the shad, and others, are provided with gill rakers by means of which they strain these minute organisms from the water. Other fishes are bottom feeders, as the blackfish and the sea bass, living almost entirely upon mollusks and crustaceans. Still others are hunters, feeding upon smaller species of fish, or even upon their weaker brothers. Such are the bluefish, the weakfish, the barracuda, and others. The right whale, the largest of all mammals, strains protozoa and other small animals and plants out of the 
water by means of hanging plates of whalebone or baleen, the slender filaments of which form a sieve from the top to the bottom of the mouth.

In a balanced aquarium the plants furnish food for the tiny animals and some of the larger ones, for example, the snails. The smaller animals are eaten by the larger ones. The waste matter given off by the animals and their death and decay furnish the plants with the required nitrogen and other material. Thus we see the aquatic world is a great balanced aquarium. Man disturbs this ecological balance when, as in the Illinois River, he dumps his untreated sewage and factory wastes into the stream near its source. The immediate result has been the destruction of fish life for a distance of about 100 miles. It has been estimated by Professor Forbes that the Illinois River, before it was polluted by the Chicago drainage canal, produced annually over $150,000,000$ pounds of fish food. On the other hand, diluted sewage in a river may be utilized by the bacteria which in turn are used by microscopic animals and these in turn by crustaceans and snails which form the food of fishes.

Practical Exercise 10. Explain how living things in any body of water in your locality indirectly produce food for man.

Direct use of animals as food; lower forms. The forms of life lower than the mollusks are of little use directly as food, although the Chinese are very fond of sea cucumbers (page 227), which are preserved by drying and are called trepang. Sea urchins are eaten in the West Indies, under the name of " sea eggs."

Mollusks as food. The oyster. The oyster industry is very profitable. Hundreds of boats and thousands of men are engaged in dredging for oysters. Three of the most important of our oyster grounds are Long Island Sound, Narragansett Bay, and Chesapeake Bay. The western coast also produces oysters, but they are inferior to those of the eastern coast.

Oysters are never found in muddy water, for they would be quickly smothered by the sediment. They cling to stones or shells or other objects which project a little above the bottom. Here food is abundant and oxygen is obtained from the air in the water surrounding them. Oyster raisers usually throw oyster 
532 MAN CONTROLS HIS ENVIRONMENT FOR WEALTH

shells into the water to provide places of attachment for the young oysters.

In some parts of Europe and of this country where oysters are raised artificially, stakes or brush are sunk in shallow water so that the young oysters, after the free-swimming stage, may find some object to which they can fasten and escape the danger of smothering in the mud on the bottom. After the oysters are a year or two old, they are taken up and transplanted in deeper water

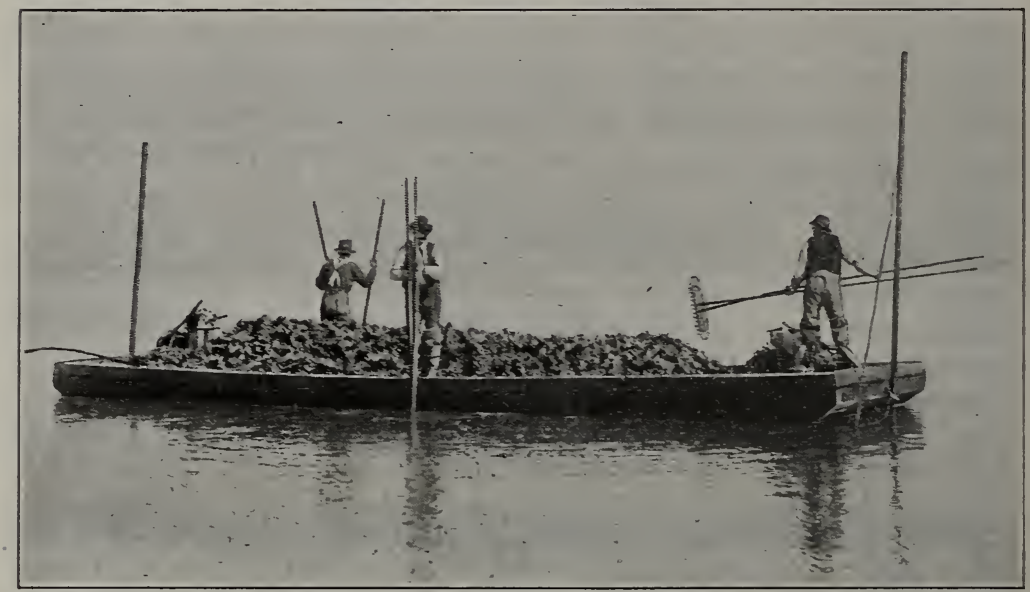

In some places, oysters are gathered by means of long-handled tongs. In other places, dredges are used.

suitable for growth. At the age of three or four years they are ready for the market.

Clams and scallops. Other mollusks used for food are clams and scallops. Two species of the former are known: one as the " round," another as the "long " or "soft-shelled" clam. The former (Venus mercenaria) was called by the Indians " quahog," and is still so called in the Eastern States. The blue area of its shell was used by the Indians to make wampum, or money. The quahog is now extensively used as food. The "long " clam (Mya arenaria) is considered better than the round clam for food by the inhabitants of Massachusetts and Rhode Island. This clam was highly prized as food by the Indians. It has been introduced on 
the Pacific coast and is rapidly coming into favor there. Dredging for scallops, another delicacy of the mollusk family, is an important industry along certain parts of our coasts.

Practical Exercise 11. What mollusks are used for food in your locality? Find out by inquiry in local markets just where each comes from.

If you live where shellfish are produced, make a report to the class on this industry.

Why may raw oysters or clams be a source of disease?

Crustaceans as food. Crustaceans are of considerable value as food. The lobster is highly esteemed as food, but has become scarce as the result of overfishing. Laws have been enacted in most lobster-producing states against overfishing. Egg-carrying

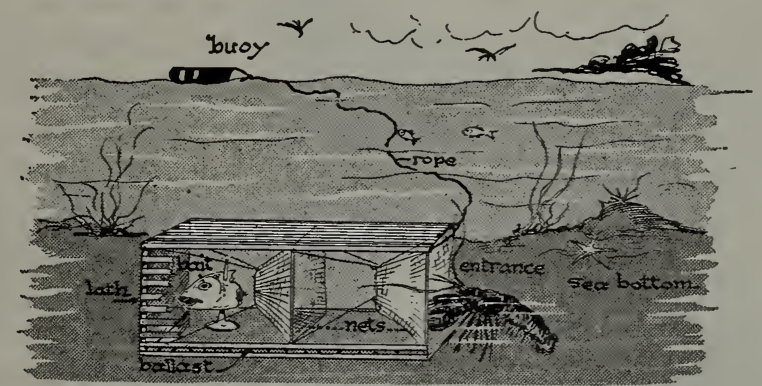

\begin{abstract}
A lobster pot. The lobster crawls forward and swims backward. He crawls through the openings in the nets into the chamber containing the bait, but when he tries to leave by swimming backward he gets caught.
\end{abstract}

lobsters must be returned to the water; all smaller than six to ten and one half inches in length (the law varies in different states) must be put back; and other restrictions are placed upon the taking of these animals, in the hope of saving the race from extinction. The United States Bureau of Fisheries and several eastern states are now hatching out millions of little lobsters each year, keeping them until they are large enough to care for themselves and then liberating them. The spiny lobster of the western coast is also in danger of extinction through overfishing. In consequence a long closed season has been declared, from the first of March to the fifteenth of October of each year. This protects the females during the egg-laying season.
н. $\mathrm{BIO}-35$ 


\section{MAN CONTROLS HIS ENVIRONMENT FOR WEALTH}

Several other common crustaceans used as food by man are near relatives of the crayfish. Among them are the shrimp and the prawn, thin-shelled, active crustaceans common along our coasts. In spite of the fact that they form a large part of the food supply of many marine animals, especially fish, they do not appear to be decreasing in numbers.

Another edible crustacean of considerable economic importance is the blue crab. Crabs are found inhabiting muddy bottoms of salt water inlets; in such localities they are caught in great numbers in nets or traps baited with decaying meat. They are, indeed, among our most valuable sea scavengers, although they are hunters of living prey also. The young crabs differ considerably in form from the adult. They undergo a complete metamorphosis. Immediately after molting or shedding of the outer shell, in order to grow larger, crabs are known as "shedders," or soft-shelled crabs, and are considered a great delicacy. On the western coast a large deep-sea crab is caught which is an excellent article of food.

Practical Exercise 12. List all the crustaceans you know that are found in your locality. Which ones are directly or indirectly used for food?

Practical Exercise 13. Make a report on the lobster industry of the United States. (See Readers Guide or Herrick's The American Lobster, Bul. U. S. Fish Com. 1895.)

Practical Exercise 14. If you have ever caught any kind of crustaceans, describe your methods to the class.

Fish as food. Fish are used as food the world over. The present value of the yearly catch of the world is estimated at over $\$ 1,000,000,000$. From very early times herring were caught by the Norsemen. Fresh-water fish, such as whitefish, perch, pickerel, pike, and the various members of the trout family, are esteemed food and, especially in the Great Lake region, form important fisheries. But by far the most important food fishes are those which are taken in salt water. Here we have two types of fisheries: those where the fishes come up a river to spawn, such as the salmon, sturgeon, or shad, and those where the fishes are taken on their feeding grounds in the open ocean. The eggs of the sturgeon are used in the manufacture of the delicacy known as caviare. Herring are the world's most important catch, though not in this country. The salmon of our western coast are taken to the value 
of over $\$ 45,000,000$ a year. Cod fishing also forms an important industry, over 7000 men being employed and over $\$ 30,000,000$ of codfish being taken each year in this country.

Practical Exercise 15. Make a list of the different fishes found in a local market. Get and record price per pound in a column opposite name of fish. In a third column give approximate distance of local market from source of production. In fourth column give your reasons for price per pound of given fish.

How do fish compare in economic importance with other animals used as food in your locality?

Amphibia and reptiles as food. Frogs live in streams and ponds in all sections of the eastern part of the United States and along the Mississippi valley. They are used to a great extent for food as their large hind legs are esteemed a great delicacy. Certain reptiles, as the iguana, a lizard-like animal, are used as food by people of other nations. Many of the edible salt-water turtles are of large size, the leatherback and the green turtle often weighing six hundred to seven hundred pounds each. The flesh of the green turtle and of the diamond-back

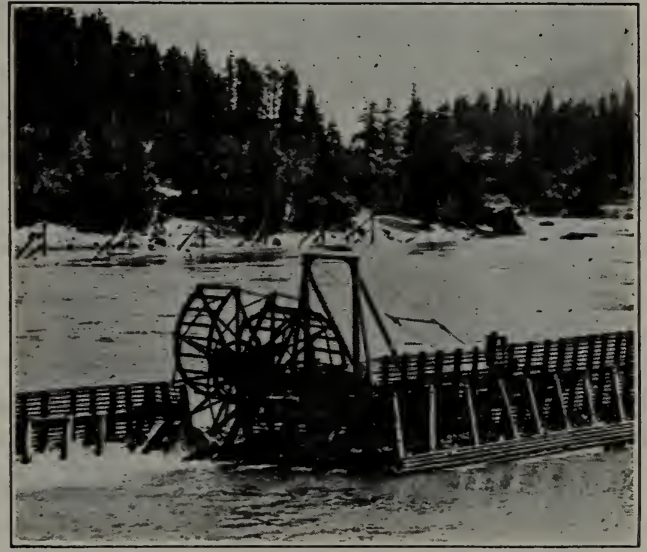

Ewing Galloway

This fishwheel is typical of many found along the Columbia River. Fifteen tons of salmon have been caught by such a wheel in one day. The fish in swimming upstream strike wire nets attached to the rim of the wheel, which in turning raises them in the air and throws them into the boats which are fastened near by.

terrapin, an animal found in the salt marshes along our southeastern coast, is highly esteemed as food. Unfortunately for the preservation of the species, these animals are usually taken during the breeding season when they go to sandy beaches to lay their eggs.

Practical Exercise 16. What amphibia or reptiles in your part of the country are used as food? 
Honey and wax. The honeybee gathers nectar, which she swallows, keeping the fluid in her crop until her return to the hive.

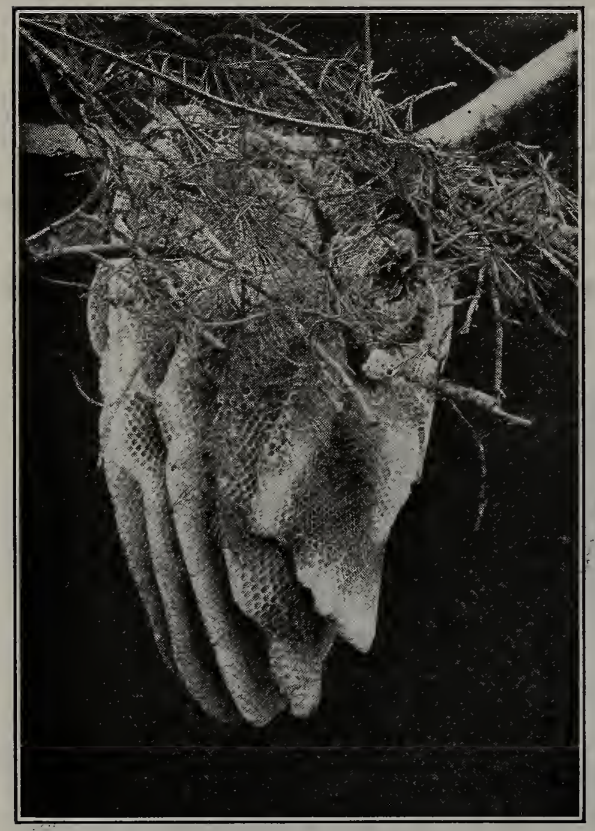

Bee colonies spread by swarming. If hives are not provided for the swarming bees, they will find homes for themselves in hollow places or on trees, as shown above.

Here it is forced out into the cells of the comb. It is now thinner than honey. To thicken it, the bees swarm over the open cells, moving their wings very rapidly, thus evaporating some of the water. A hive of bees may make between 30 and 80 pounds of honey during a season. Over $60,000,000$ pounds of honey is produced in this country every year.

Practical Exercise 17. Report on a trip to an apiary, or on a study of an observation beehive.

Birds as food. Birds, both wild and domesticated, form part of our food supply. But our wild game birds are disappearing so rapidly that we cannot consider them as a source of food. Our domestic fowls, chicken, turkeys, ducks, etc., form an important food supply. Eggs of domesticated fowls are of great importance as food, and egg albumin is used for other purposes, such as clarifying sugars and coating photographic papers.

Practical Exercise 18. Give a report on the different birds in your locality that may be used as food.

Mammals as food. When we consider the amount of wealth invested in cattle and other domesticated mammals bred and used for food in this country, we see the great economic importance of these animals. In 1928 nearly $\$ 3,000,000,000$ worth of meat-pro- 
ducing animals were owned in the United States. The United States, Argentina, and Australia are the greatest producers of cattle. Other products, such as milk, butter, and cheese, are obtained from cows and goats. In this country many hogs are raised for food. Their meat is used fresh, salted, smoked as ham and bacon, and pickled. Sheep, which are raised in great quantities in Australia, Argentina, Russia, Uruguay, and this country, are one of the world's greatest meat supplies. Deer, many game animals, seals, walruses, etc., are available as food for people in certain parts of the earth.

Practical Exercise 19. From the information obtained from your local Chamber of Commerce or other sources, make a report to the class on the value of food mammals in your community.

\section{Self-Testing Exercise}

$\ldots \ldots \ldots$ (1) and $\ldots \ldots \ldots(2)$ are important shellfish used as food. Crustaceans used as food are .......(3), .......(4), and ....... (5). $\ldots \ldots \ldots$ (6) made from the nectar of flowers by the ....... (7) is an important foodstuff. The ...... (8) catch of food fishes is estimated to be over ....... (9). While birds are important as food, ........(10) are by far the most important food producers Most large animals .......(11) upon .......(12) ones. Factory .......(13) may not safely be dumped into .......(14) as they (15) the fish there. The right whale lives upon ........(16) animals which it ....... (17) out of the water by means of hanging plates of .......(18).

\section{PROBLEM IV. WHAT ARE OTHER ECONOMIC VALUES OF ANIMALS?}

Domesticated animals. The domestication of the dog, the cow, the sheep, and especially of the horse, marks epochs in the advance of civilization. Beasts of burden are used the world over: horses almost everywhere ; certain cattle, as the water buffalo, in tropical Malaysia ; and camels, goats, and the llamas in some other countries.

Practical Exercise 20. Obtain from local sources the approximate value of domesticated animals in your locality, and tell why you think your figures are aceurate. 


\section{MAN CONTROLS HIS ENVIRONMENT FOR WEALTH}

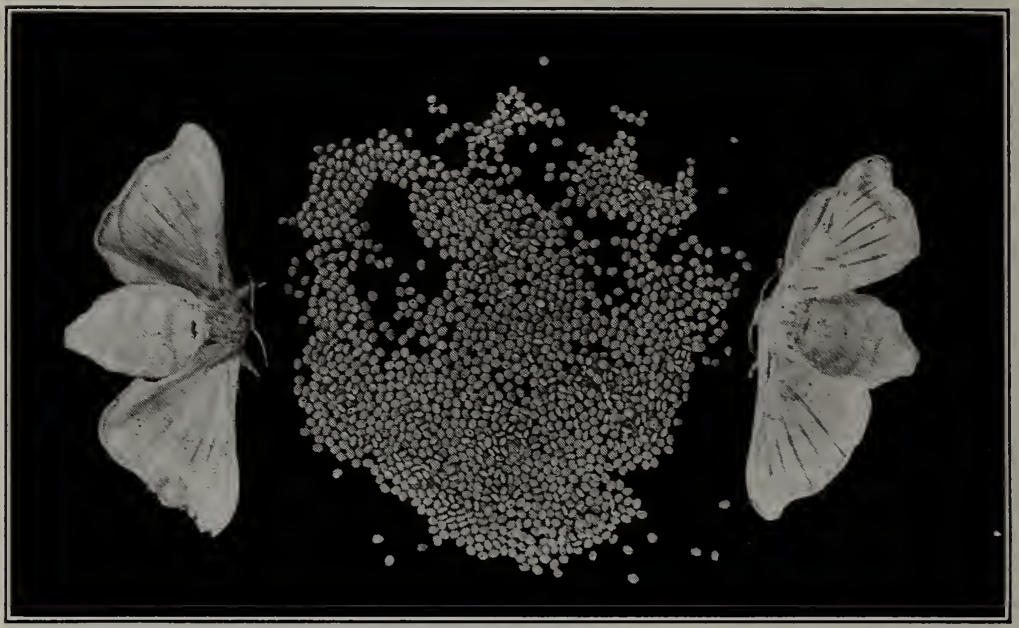

C. Clarke

Two female silkworm moths and some of the eggs they have laid.

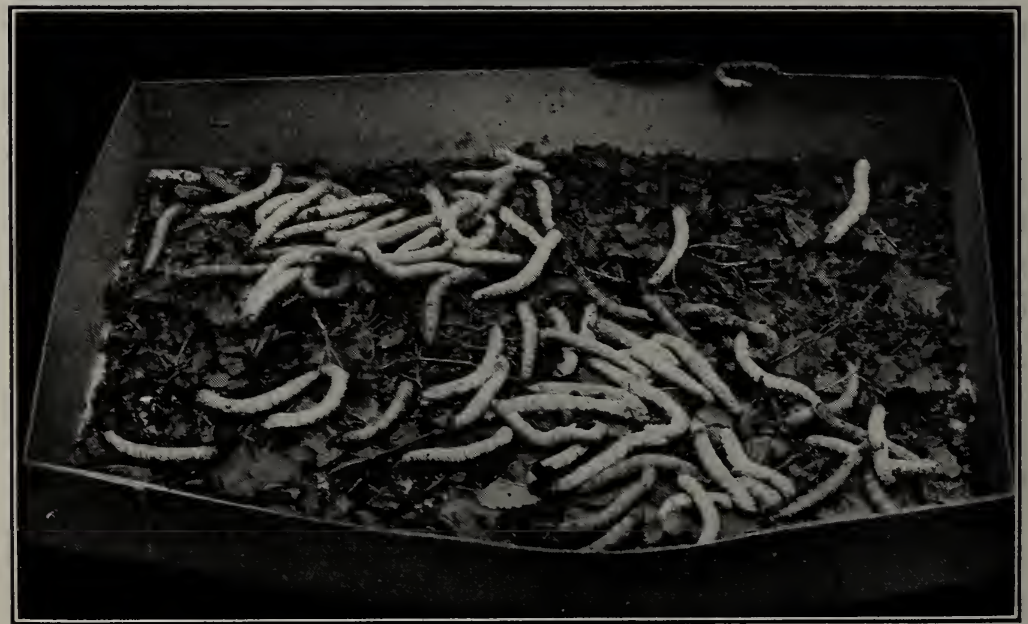

C. Clarke

A tray of well-developed silkworm larvae feeding on mulberry leaves. They rarely leave their box containing food until they are ready to search for a place to spin their cocoons. 


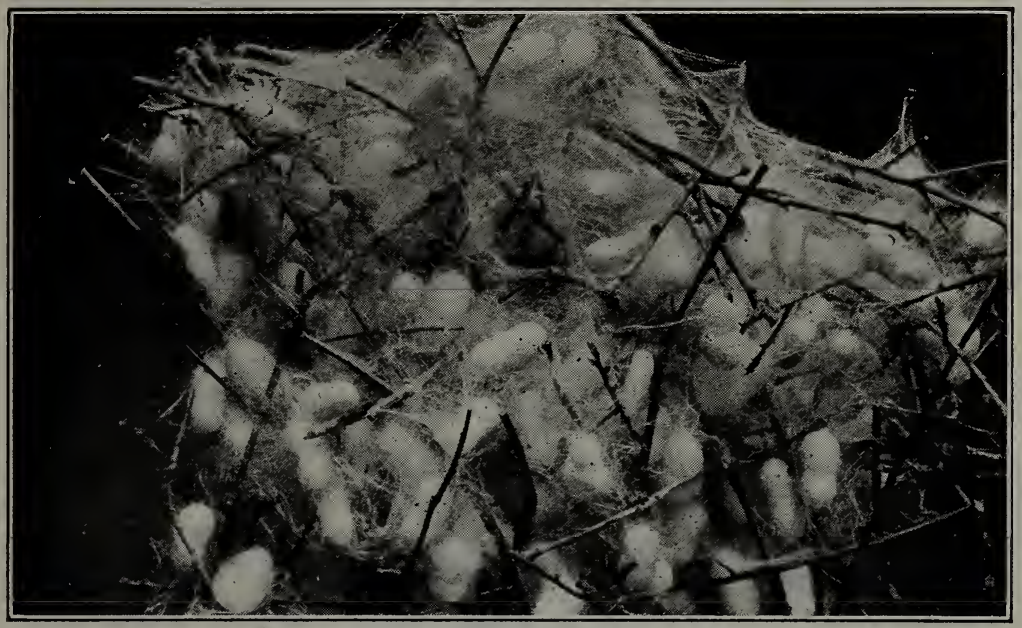

C. Clarke

A mass of silkworm cocoons among the branches of a mulberry tree.

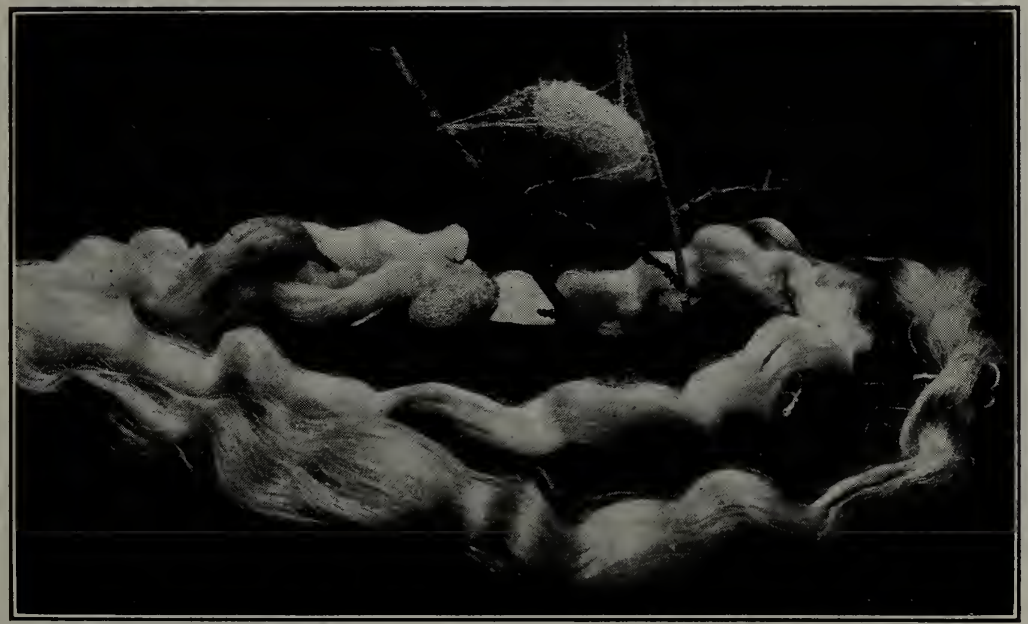

C. Clarke

A raw cocoon and a silken skein that has been made from the raw material. Can you describe the process by which silk thread is made from the silk in the cocoon? 
Uses of animal fibers. Pure silk goods are manufactured from raw silk, which is a fiber produced by the silkworm, the caterpillar of a moth. It lives on mulberry leaves and makes a cocoon from which the silk is obtained. China, Japan, Italy, and France, because of cheap labor, are successful silk-raising countries. But the manufacture of silk goods, from imported raw silk, is still one of our great industries in spite of the production of rayon, one kind of artificial silk produced from wood pulp.

There are in this country more than 1000 woolen mills, with nearly 200,000 wage earners. They produce, yearly, woolen and worsted goods valued at about $\$ 900,000,000$. These mills use both

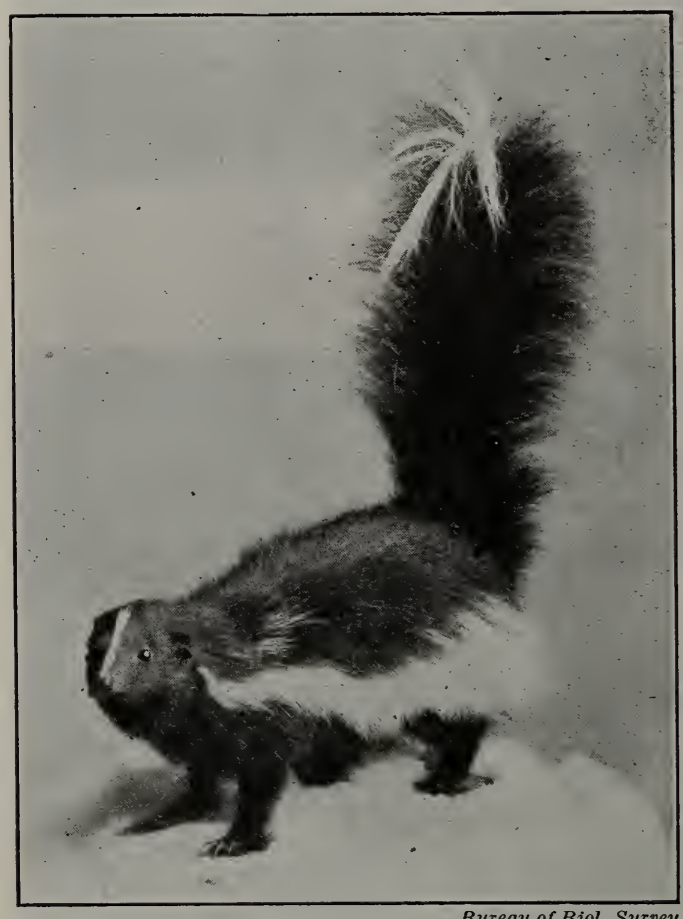

The skunk is now raised for its valuable fur. domestic and imported wool. Nearly $45,000,000$ sheep are raised in this country for their wool.

Goat's hair, especially that of the Angora and of the Cashmere goats, camel's hair, and alpaca are much used in the clothing industries.

Practical Exercise 21. Give a brief report on any of your local industries which use animal fibers.

Furs. The furs of many domesticated and wild animals, especially the carnivores, are of much economic importance. The Alaskan fur seal fisheries, which once amounted to millions of dollars annually, have greatly decreased because of over-killing of the seals. 
Only about 25,000 seals were killed in 1928 . Otters, skunks, sables, weasels, foxes, and minks are of considerable importance as fur producers. Even cats are now used, the fur usually masquerading under some other name. The fur of the beaver, one of the largest of the rodents or gnawing mammals, is now difficult to procure, but fur of considerable value is obtained from the muskrat, squirrel, rabbits, and other rodents. The furs of the rabbit and nutria are used in the manufacture of felt hats. The quills of the porcupine (greatly developed and stiffened hairs) have a slight commercial value for decorative purposes.

Animal oils. Whale oil, obtained from the "blubber" of whales, and formerly used for illumination, is now much used as a lubricating oil. Neat's-foot oil comes from the feet of cattle and is used for lubrication. Tallow from cattle and sheep, and lard from hogs, have so many well-known uses that comment is unnecessary. Cod-liver oil from the codfish is used medically. Much oil is obtained also from the menhaden of the Atlantic coast, which is used in dressing leather and making paints. Menhadens are also used in great quantities for fertilizers.

Hides, horns, hoofs, etc. Leather made from the skins of cattle, horses, sheep, goats, alligators, and snakes is used for shoes, pocketbooks, coats, gloves, and for many purposes. Leather manufacture is one of the great industries of the Eastern states, hundreds of millions of dollars being invested in manufacturing plants. Horns and bones are utilized for making combs, buttons, handles for brushes, etc. Glue is made from the animal matter in bones, horns, and hoofs. Ivory, obtained from the tusks of the elephant, walrus, and other animals, forms a valuable commercial product. It is largely used for knife handles, piano keys, and combs.

Perfumes. The musk deer, musk ox, and muskrat furnish a valuable perfume called musk. Civet cats also give us a somewhat similar perfume. Ambergris, a basis for delicate perfumes, is formed in the intestines of the sperm whale.

Practical Exercise 22. Tabulate the various products, other than meat, that are obtained from animals. In the next column indicate the ones used in your local industries. In the last column show uses of raw products to man. 
Direct use of protozoans. The protozoans have played an important part in rock building. Chalk beds and limestone rocks are made up to a large extent of the tiny skeletons of protozoans called foraminifers. The skeletons of some species are used to make a polishing powder.

Sponges and coral. The sponges of commerce are the skeletons of animals that live attached to the bottom of the sea, and are composed of tough fibers of a material somewhat like that of a cow's horn. This fiber is elastic and has the power to absorb

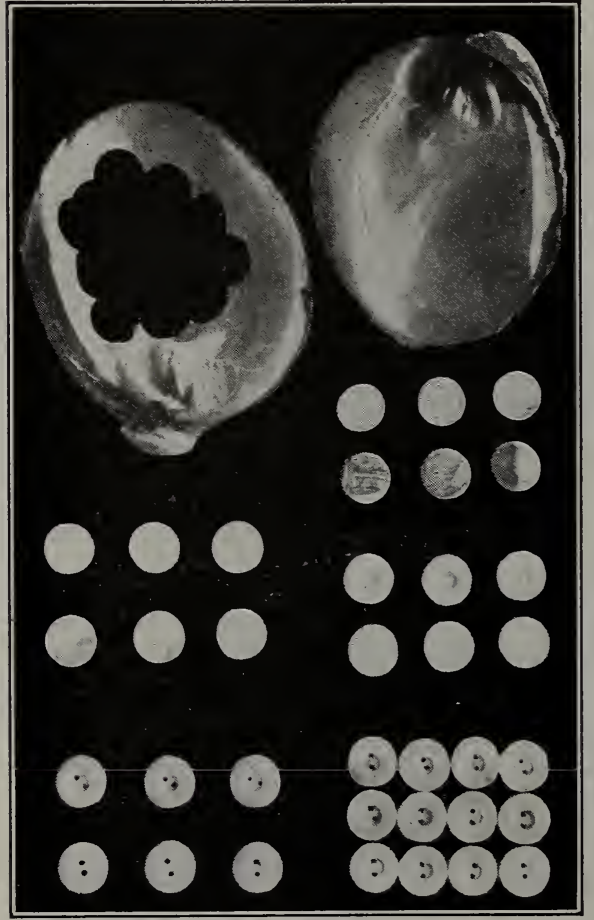

The pearl-like shells of fresh-water mussels are used in button-making. These mussels are extensively cultivated in the United States for this purpose. water. The warm waters of the Mediterranean Sea and the West Indies fur nish most of our sponges. The sponges are pulled up from their resting places on the bottom by means of long-handled rakes operated by men in boats, or they are secured by divers. They are then spread out on the shore in the sun, and the living tissues allowed to decay. Then after treatment consisting of beating, bleaching, and trimming, the bath sponge is ready for the market.

Some forms of coral, the skeleton of marine organisms, are of commercial value. The red or precious coral of the Mediterranean Sea is highly prized for ornamental purposes.

Pearls and mother-of-pearl. Pearls are prized the world over. Most of the finest come from the oysters and clams in the waters 
around Ceylon. It seems likely that the most perfect pearls are due to the growth within the mantle of the clam or oyster of certain parasites which are stages in the development of a flukeworm. The irritation thus set up in the tissue causes motherof-pearl, the substance that lines the interior of the shell, to be deposited around the source of irritation, with the subsequent formation of a pearl.

The pearl-button industry in this country is largely dependent upon the fresh-water mussel, the shells of which are used. This mussel was being so rapidly depleted that the national government has worked out a means for its artificial propagation.

Usefulness of the toad. The toad is of great economic importance to man because of its diet. No

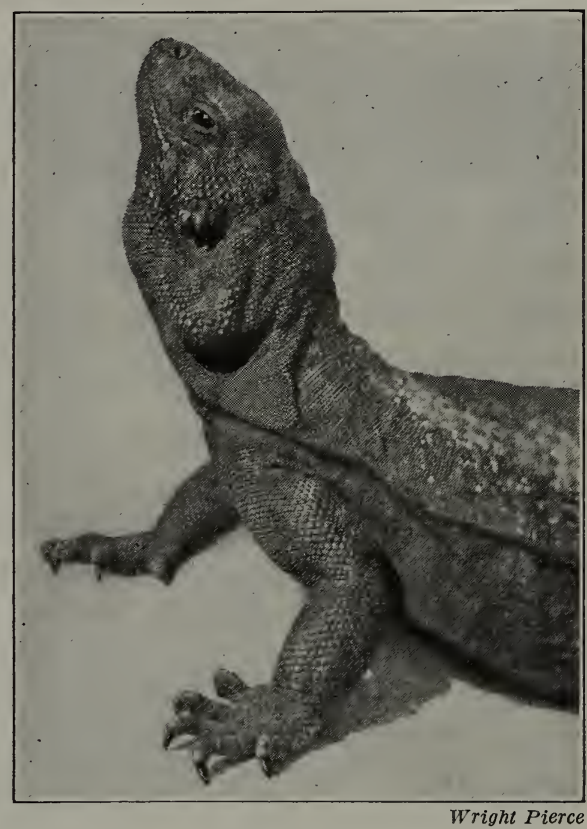

Chuckwalla - a stout-bodied lizard of the deserts of southwestern United States. It feeds on the buds and flowers of plants. Its flesh is used by some people for food. less than eighty-three species of insects, mostly injurious, have been proved to enter into the toad's diet. A toad has been observed to snap up 128 flies in half an hour. Thus it could easily destroy very many insects during a day and do an immense service to the garden during the summer. Toads also feed upon slugs and other garden pests.

Value of snakes. Probably the most disliked and feared of all animals are the snakes. This feeling, however, is rarely deserved, for, on the whole, our common snakes are beneficial to man. The black snake, gopher snake, and milk snake feed largely on injurious rodents (rats, mice, etc.), the green garden snake eats 
injurious insects, and the little DeKay snake feeds partly on slugs. If it were not that the rattlesnake and copperhead are venomous, they also could be said to be useful, for they devour English sparrows, rats, mice, moles, and rabbits.

Practical Exercises 23. Classify the animals mentioned in the preceding sections as to direct or indirect economic importance. Add as much as you can to the list.

Make a list of all the ways in which animals living in your environment help indirectly to make you comfortable.

Food of herbivorous animals. We must not forget that other animals besides insects and birds help to keep down the rapidly growing weeds. Herbivorous animals the world over devour, besides the grass which they eat, untold multitudes of weeds, which, if unchecked, would drive out the useful plants of the pastures, the grasses and grains.

\section{Self-Testing Exercise}

Animals furnish us with $\ldots \ldots$ (1) $\ldots \ldots$ (2), ......(3), and ........(4) for clothing. Animal oils are obtained from the $(5), \ldots \ldots \ldots(6), \ldots \ldots \ldots(7)$, and $\ldots \ldots \ldots(8)$. Ivory is made from the .......(9) of ...... (10); glue from .......(11) and ....... (12); leather from the skins of .......(13), ...... (14), and $\ldots \ldots \ldots(15) ;$ perfumes from .......(16) ......(17); and pearls from ....... (18). Coral is used for ....... (19) ....... (20). Sponges are $\ldots \ldots \ldots(21) \ldots \ldots$ (22). The toad

....... (24). Most snakes are ....... (25) to man.

\section{PROBLEM V. WHAT HARM IS DONE BY ANIMALS?}

Animals destructive to other animals used as food. Directly or indirectly, animals, in their struggle for life, destroy quantities of plants and other animals, that man uses as food. Starfish are enormously destructive to young clams and oysters, as the following evidence, collected by Professor A. D. Mead, of Brown University, shows: A single starfish was confined in an aquarium with fifty-six young clams. The largest clam was about the length of an arm of the starfish, the smallest about ten millimeters in length. In six days every clam in the aquarium had been 
devoured. Hundred of thousands of dollars' damage is done annually to oysters in Connecticut alone by the ravages of starfish. During the breeding season of clams and oysters, the boats dredge up tons of starfish which are thrown on shore to die or to be used as fertilizer.

The liver fluke kills thousands of sheep every year. Tapeworms in cattle and trichina in hogs spoil much valuable food. Roundworms enter the bodies of food fish as parasites and kill large numbers annually. Boring mollusks, such as the whelk, destroy multitudes of other mollusks as food. Parasitic insects abound which kill useful insects, some of which, like the honeybee, produce food. We can hardly estimate the harm done by one-celled parasites and their carriers, the ticks, mites, etc., for they are enormously destructive to cattle.

Fish feed upon crustaceans and mollusks. The dogfish, shark, and other elasmobranchs destroy many lobsters, crabs, and other crustaceans, while many bottom-feeding fish eat mollusks. Fish are cannibals also, eating the eggs and young of their own kind. Salmon eggs are a favorite food of the western trout. Birds eat many fish and much other food. Large numbers of fish are killed by minks, otters, seals, and other fishing mammals. At one time it was estimated that an annual loss of fish equal to $\$ 20,000,000$ was caused by carnivorous animals, such as wolves, coyotes, and others. But this amount is rapidly decreasing.

Practical Exercise 24. Make a table to show the kinds of damage done by the animals common to your locality. Can you estimate the loss in dollars and cents? Get information from local farmers, cattle and sheep raisers, and your Chamber of Commerce.

Rats as pests. David E. Lantz of the Bureau of Biological Survey is authority for the statement that the rat is the most destructive mammal in the world. He estimated the actual money loss from destruction of property by rats each year in this country to be over $\$ 200,000,000$. Rats destroy the timber in houses, they cause fires by gnawing matches, they destroy great quantities of standing grain and stored food, they kill myriads of young chickens and other poultry and untold numbers of young birds. Worst of all, they spread diseases, especially bubonic 


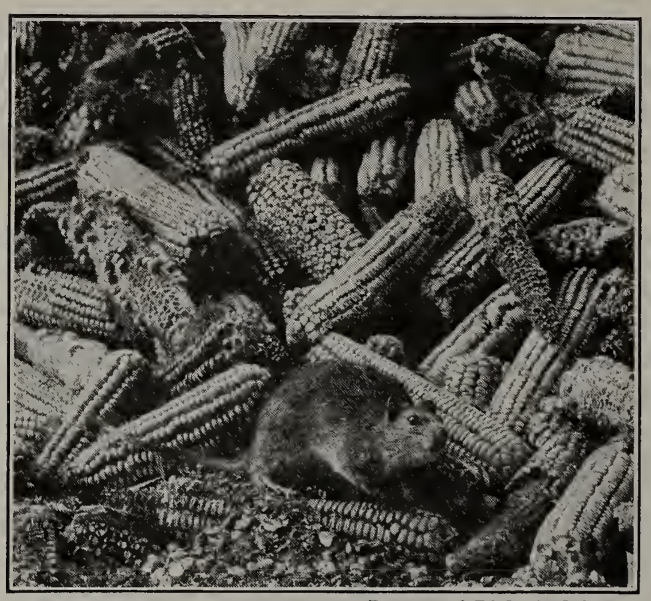

Bureau of Biological Survey

The rat is an enemy of the farmer. Notice the damage that he has done in this corn crib.

plague. The fighting of rats alone, in the epidemics of plague in this country, has cost millions of dollars. They can be and must be exterminated.

Practical Exercise 25. Make a report on methods of control of rats and mice in your community. Consult Lantz, House Rats and Mice, and Farmers Bulletin 896, United States Department of Agriculture.

Cats. Many cats are kept as pets, and many run wild. Cats of both kinds do much injury by killing birds. Forbush, former state Director of Ornithology of the State of Massachusetts, estimated that they killed in New England as many as 1,500,000 birds annually, while Fisher says $3,500,000$ birds is the annual toll for New York State. While this number seems almost impossible to believe, 226 cats under observation in Massachusetts have been known to kill 624 birds in one day. Cats also spread disease germs.

Animals that prey upon man. The toll of death from animals which prey upon or harm man directly is relatively small. Snakes in tropical countries kill many cattle and not a few people. The dreaded cobra of India has a record of over 250,000 persons killed in thirty-five years. The loss of life from snake bites should soon be much reduced, thanks to the manufacture of antitoxin serums made to counteract the venom of poisonous snakes.

Alligators and crocodiles feed not only on fishes, but often attack large animals, as horses and cows, and even man. The crocodiles of the Ganges River in India levy a yearly tribute of many hundred lives from the natives.

Carnivorous animals which are not domesticated, such as lions and tigers, still inflict damage in certain parts of the world, but as 
the tide of civilization advances, their numbers are slowly but surely decreasing, so that as important factors in man's welfare they may be considered almost negligible.

Practical Exercises 26. What harm is done in your locality by any of the above-mentioned animals? How can cats be kept from killing birds? Give all the reasons you can for and against keeping cats. What agencies control the harmful animals in your state?

\section{Self-Testing Exercise}

Many oysters are destroyed annually by .......(1). Rats destroy thousands of dollars' worth of ........(2) for ........(3) every year. Many fishes are killed by .......(4) .......(5), $\ldots \ldots$ (6), and .......(7) ...... (8). Animals that are known to attack men are the $\ldots \ldots \ldots(9), \ldots \ldots$ (10), ...... (11), and (12).

\section{PROBLEM VI. WHAT IS THE ECONOMIC IMPORTANCE OF BIRDS?}

Birds eat insects. The food of birds makes them of great importance to agriculture in our country. A large part of the diet

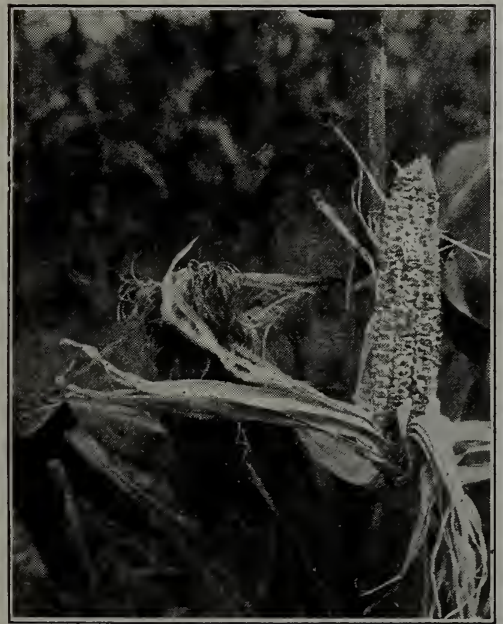

If birds cannot get insects they eat grains. Here is the remains of an ear of corn after a crow has eaten.

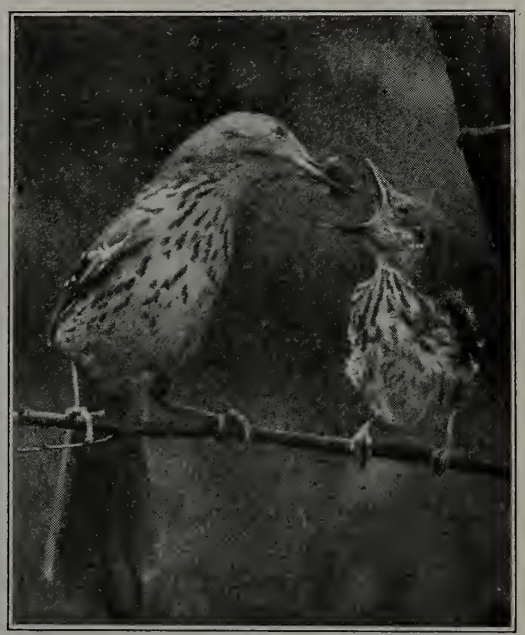

L. W. Brownell

Some birds seem to prefer insects to seeds. Here is a young thrasher receiving a caterpillar. 
of many of our native birds includes insects harmful to vegetation. Investigations undertaken by the United States Department of

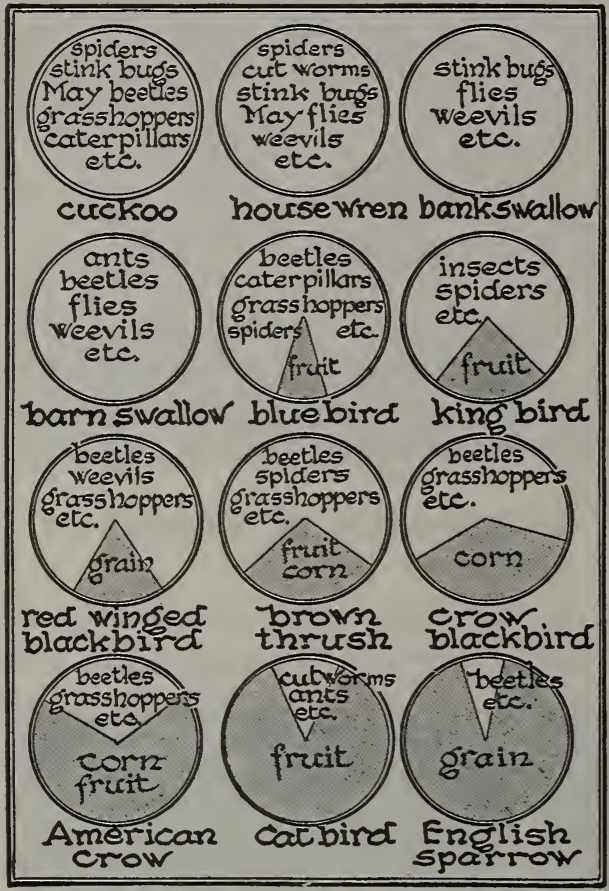

The food of some of our most familiar birds. Which of these birds should be protected?

Agriculture (Division of Biological Survey) show that a surprisingly large number of birds, once believed to harm crops, really perform a service to farmers by killing injurious insects. Even the much maligned crow eats mice and harmful insects as well as grain and fruit. Swallows in the southern states kill the cotton boll weevil, one of our worst insect pests. Our earliest visitor, the bluebird, includes grasshoppers, ants, spiders, weevils, tent caterpillars, army worms, cutworms, and the codling moth in its diet. The robin, whose presence in the cherry tree we resent during the spring and early part of the summer, includes all of the above and several other pests in its diet. It has a 95 per cent insect diet until June, and after that time about 40 per cent of its food is insects. Many birds vary their diet, using the food substances which are most abundant around them. The swifts or swallows eat flies, the cuckoos and blue jays eat hairy caterpillars, which are eaten by few other birds; and much of the winter food of the chickadees consists of eggs of aphids or plant lice. Ants are eaten by many species of birds; beetle larvae are preferred by crows, blackbirds, and robins. A pair of nesting robins were observed to dig out and eat 
from 50 to 70 cutworms and earthworms in one day. Many observations of the feeding of young birds by their parents indicate that birds eat a large amount of food in proportion to their size and consequently destroy vast numbers of injurious insects. Some idea of the amount of food eaten may be had from the data given by Professor Hodge. He says a pair of house wrens, very tiny birds, were observed to feed their five nestlings 230 insects, mostly large cabbage caterpillars, in one day. A young robin three weeks old ate 70 cutworms in one day; a young tanager, 150 cutworms in a day besides other food; and a young phoebe just out of the nest, as many as 200 good-sized grasshoppers in a day.

Without the birds the farmer would have a hopeless fight against insect pests. The effect of killing native birds in great numbers is now well seen in Italy and Japan, where insects have increased and do great damage to crops and trees.

Practical Exercise 27. List the names of all birds that you know. Make a table for your workbook, giving the harm and value to man of each bird.

Birds eat weed seeds. Not only do birds aid man in his battles with destructive insects, but nearly 300 species of birds eat the seeds of weeds also. Our native sparrows (not the English sparrow), the mourning dove, bobwhite, rose-breasted grosbeak, horned lark, crow blackbird, and other birds feed largely upon the seeds of many of our common weeds. An examination of the stomachs of a number of these

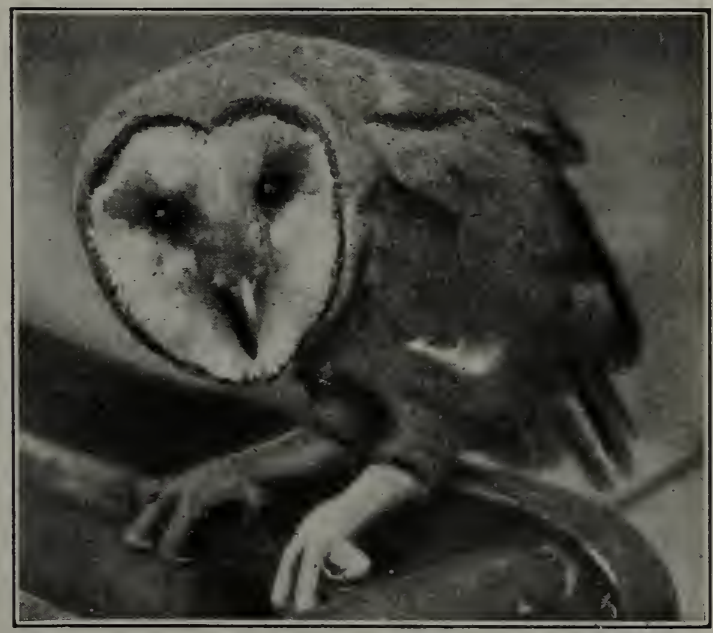

Wright Pierce

What is the economic importance of the owl?

н. вго -36 
birds showed that they had consumed over one hundred kinds of weed seeds. The Biological Survey estimated that the various seed-eating native sparrows saved the farmer the sum of $\$ 89,260,000$ in 1910 . The tree sparrows alone in the state of

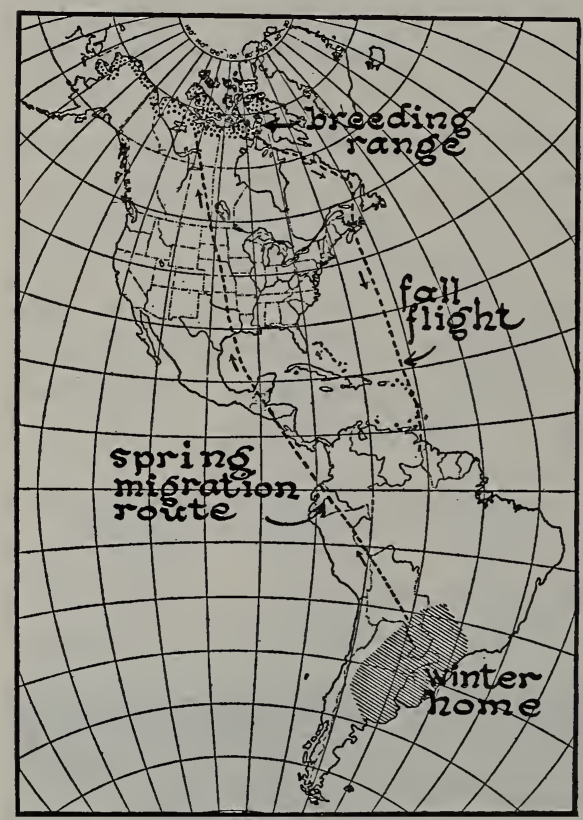

The golden plover spends the summer in the northern part of North America and the winter in the south. Explain why it takes a different route north in the spring from the one it takes south in the fall.

Iowa are estimated to eat 875 tons of weed seeds every winter. Not all birds are seed or insect eaters.

Other foods of birds. Some, as the cormorants, ospreys, gulls, and terns, are active fishers. Near large cities especially, gulls act as scavengers, destroying much floating garbage that otherwise might be washed ashore to become a menace to health. The buzzards of the West and South, and the vultures of India and semi-tropical countries, are of immense value as scavengers. Birds of prey (hawks and owls, eat living mammals, including many harmful rodents, as gophers, field mice, and rats. The Biological Survey has estimated that owls and hawks are worth about $\$ 20$ apiece a year to the farmer because of the field mice they eat.

Geographical distribution and migrations. Most of us are aware that some birds remain in a given region during the whole year, while other birds appear with the approach of spring, and depart southward with the warm weather in the fall of the year. Such birds we call migrants, while those that remain in one place the year round are called residents. For any one locality the migrants fall into three groups: those that arrive in the spring from the 
south and remain until fall are called summer residents; those that come south during the winter for food and to escape the severe cold are called winter residents; and those that remain only a few days or a week in a locality when passing to the north or south are called transients.

In Europe, where the problem of bird migration has been studied carefully, migrations appear to take place along well-defined paths. These paths usually follow the coast very exactly, although in places they may take the line of the coast that existed in former geological times. In this country the Mississippi valley forms one line of migration, while the north Atlantic seacoast forms another route. Just why birds migrate is not fully known. Evidently food shortage in the fall starts them on the path southward, but why they return is not so clear. They seem to have some instinct which brings them back year after year to the same nesting places.

\section{Self-Testing Exercises}

Mark in your workbook the correct statements :

T. F. 1. Few birds are entirely useful.

T. F. 2. No insect pest can be entirely controlled by birds.

T. F. 3. Birds feed on the food that is most abundant at the time.

T. F. 4. Robins do more harm than good, for they eat our cherries.

T. F. 5. Birds of prey are scavengers.

T.F. 6. Most of our migrants, as the finches, warblers, and swallows, feed upon harmful insects.

T. F. 7. Most owls are harmful because they feed upon rodents.

\section{PROBLEM VII. HOW CAN WE RECOGNIZE SOME COMMON BIRDS?}

It has been estimated that during the year there are between 100 and 500 species of birds to be found in localities in various parts of the United States. The desert regions of the Southwest naturally have the fewest, the eastern seaboard states may have 200 to 300 , while there have been about 500 species identified in the northern and central parts of California.

Field Exercise. Make a survey of your neighborhood to find out the number of different birds that are residents or migrants there. 


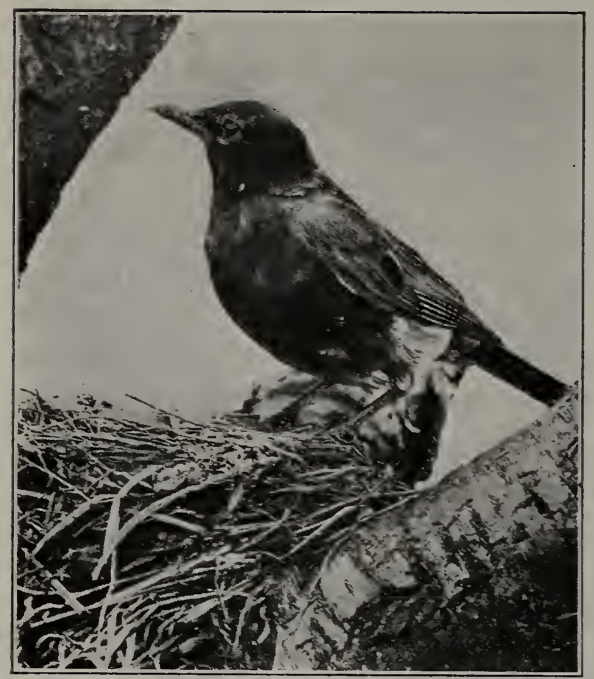

C. Clarke

Of what economic value is the robin?
The following descriptions will help one to recognize a few of our common birds which are of decided economic value or harm. The size, color markings, food, and familiar habits of some of our common birds will be given, with a brief statement of the reason why they are man's friends or enemies.

Robin. A bird known to all of us makes an excellent type for comparison with other lessknown birds. The robin

is nine to ten inches long. The male is brownish gray above, tinged with olive, with brown wings, and black on the head and the tail. The throat is light gray with black spots, and the breast is brownish red. The female is similar but darker in color. The robins live near houses and in orchards and make their nests of grass and mud, in trees or on buildings. The robin is a true thrush, whose pleasing song delights us in early spring. Its economic value is often discussed as it eats much fruit early in the season. Its diet usually consists of about 40 per cent insects, most of which, as ground beetles, caterpillars, plant lice, and cutworms, are harmful. From February to May, in the east, its food is almost entirely insects. The western robin has done damage to olive and other fruit orchards when insect food was scarce, but like its eastern relative, it consumes a large percentage of insects most of the time.

Bluebird. This is one of our earliest migrants. Its cheery note and blue coat are easily recognized. It is six and one half to seven inches in length. The male is bright blue above, and chestnut underneath. The female is duller in color. It nests in 
holes in trees or posts and in bird houses. Its food consists from about 70 to 90 per cent of insects, largely grasshoppers, beetles, spiders, and caterpillars.

Chickadee. This is a small bird, about five and a quarter inches long. It is often an all-year-round resident. The crown of the head and throat are black, the cheeks white, the back gray, and the abdomen usually a dirty white. Its food is about 70 per cent insect and 30

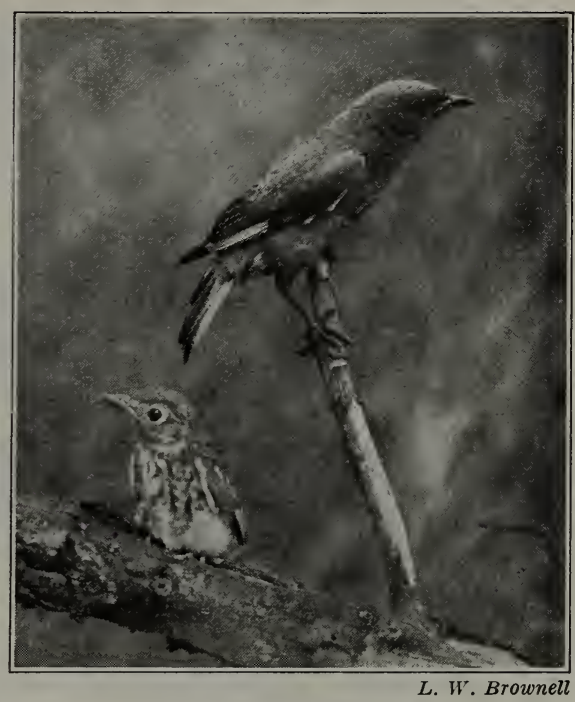

A bluebird and her young.

per cent seeds in the summer. In the winter it devours large quantities of eggs laid by insect pests. One bird was found to have eaten more than 430 eggs of the plant louse in a single day. Professor Sanderson of Cornell University has estimated that they

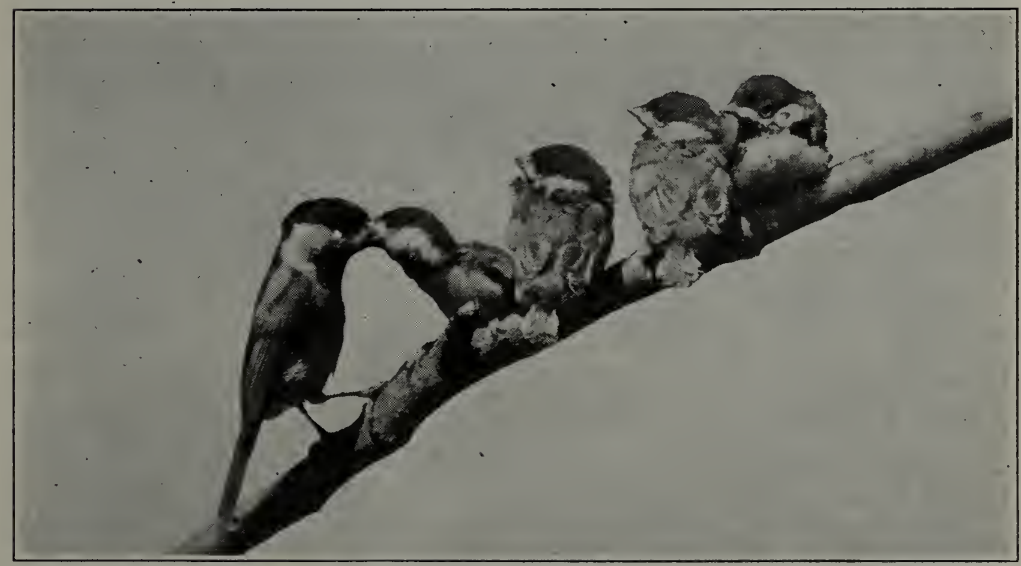

Chickadee serving lunch. 


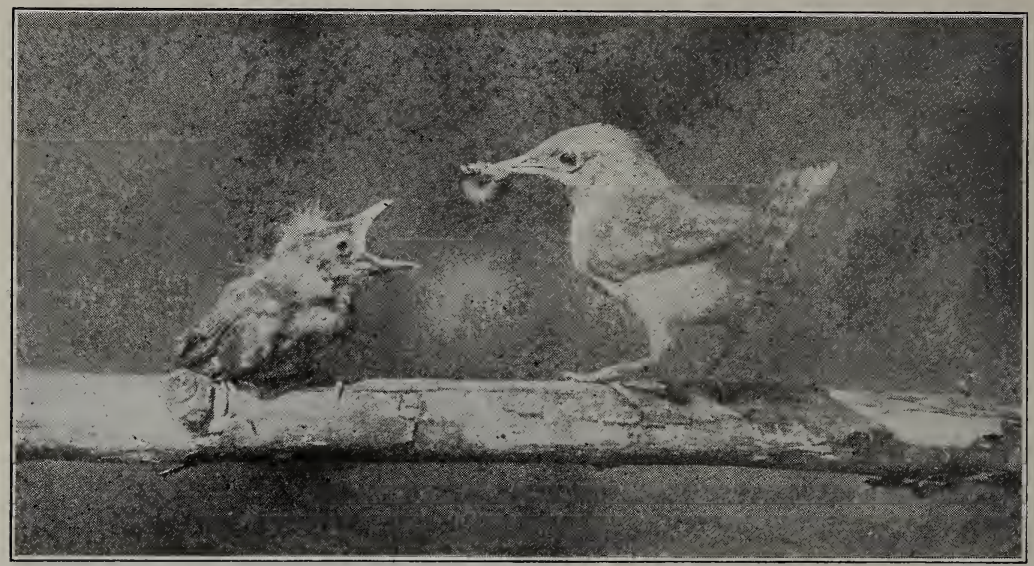

A house wren bringing a caterpillar to her young.

L. W. Brownell

eat over 8,000,000,000 insects in Michigan every year. On that basis what good must they do in the United States? The chickadee is certainly one of man's best bird friends.

House wren. This little migrant nests around our homes. It is a great songster, and is a decided asset to us because of its varied diet of cutworms, spiders, weevils, and May flies. It has a 98 per cent insect diet. One wren was observed to catch 600 insects in one day. Its worst enemies are cats and larger birds. A proper nesting box with a small entrance is one of its best means of protection. The house wren is not quite five inches long. The upper part is brown, the lower grayish brown and white. The wings, flanks, and tail are slightly barred. It can be recognized easily by its small size, coloring, incessant singing or chattering, and by the fact that its tail is frequently held erect when the bird is at rest.

Song sparrow. Another of our earliest visitors is the song sparrow. The male is about six and one half inches long. It is brown above with the head reddish-brown with blackish streaks. A streak of gray runs through the center of the crown, and there is a characteristic brown stripe on the sides of the throat. The breast is streaked with brown on a white ground. Its nest is usually on the ground or in a low bush. It is a friendly bird and is often seen near houses, though it prefers moist areas farther 
away from man. It eats some insects, but like most of the native sparrows it feeds mainly upon weed seeds.

American goláfinch. This bright yellow songster is one of our most attractive birds. It is often called the wild canary. It is about five inches long. The male has a bright yellow body with a black cap, and black and white tail and wings. The female is brownish olive above and yellowish white beneath. The goldfinch eats seeds of weeds, preferring those of the dandelion and thistle, two of our greatest weed pests.

Yellow warbler. A bird often confused with the goldfinch is the yellow warbler. Like all warblers, this is a small bird about five inches in length. Its color is yellow, with breast flecked with reddish brown (it has no black on the head as does the goldfinch). It nests near houses in low trees or bushes. It is of much economic importance because of its preference for the browntail and gypsy moth caterpillars, and other enemies of the forest trees. It also eats cankerworms and insects injurious to crops. We are spending millions of dollars every year to fight these pests, and the warblers, besides being beautiful birds, are helping us in this fight.

Phoebe. Another tireless hunter of insect pests is the phoebe. This bird is a flycatcher, seizing insects on the wing. It builds a

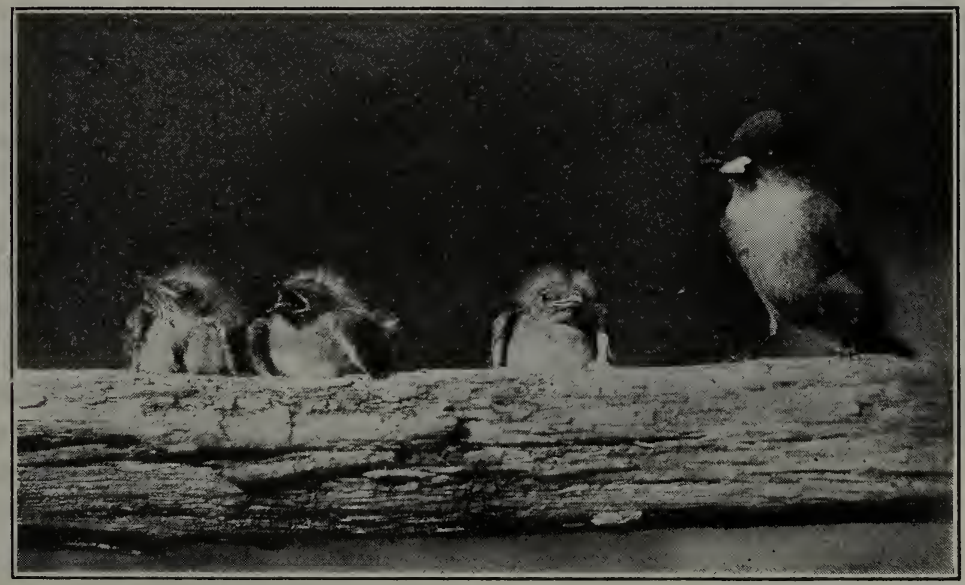

Insects are the preferred food of phoebes.

L. W. Brownell 
nest of mud - often under old bridges, around barns, or sometimes under a barn floor. Its food consists of browntail and gypsy moths, grasshoppers, cankerworms, beetles, flies, and in the South cotton-boll weevils. The phoebe is about seven inches long, dusky olive-brown above, yellowish white underneath, with wings and tail dusky. The head is slightly crested, and the bill and feet are black. It is one of our early visitors.

Barn swallow. Another bird with nesting habits similar to those of the phoebe is the barn swallow, which makes a nest plastered to the rafters of a barn or outbuilding. While most birds decrease in number with the cutting of forests and the building of cities, the barn swallow has increased because it feeds on insects which live on crops in cleared fields. It eats moths of cutworms, codling moths, leaf cutters, and many flies, bugs, and beetles. In the South it is an enemy of the cotton-boll weevil. This swallow is between six and seven inches in length. It is dark steel blue above, with throat and upper breast chestnut; the lower breast

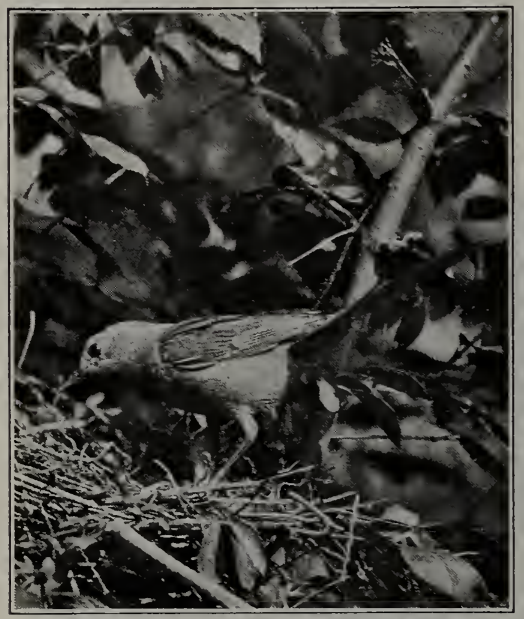

L. W. Brownell

Catbird entering nest. and abdomen buff. The tail is deeply forked, showing white markings when spread.

Catbird. Another bird which nests near houses and prefers the company of man is the catbird. From early May to late October its various calls and songs are the delight of all bird lovers, for it is a great mimic and somewhat of a tease. The catbird, although it eats much fruit, is an insect feeder and gives its young insect food. Like other birds, it eats the food most abundant at the time. Birds taken from a canker-infested orchard made insects 95 per cent of their diet, although normally they eat over 60 per cent fruit. A catbird is about nine inches 
in length, and of a dark grayish color, with the top of head and the tail blackish, with a distinct chestnut patch under the tail.

Downy woodpecker. The woodpeckers are familiar to most boys and girls because of their conspicuous color and their peculiar habits. The male downy woodpecker is six and a half inches long, black and white barred, with a patch of scarlet on the upper side of the neck. It runs quickly up and down the trunks of trees, tapping the wood to locate insect holes. The bill is strong, sharp at the end, and is used as a chisel in boring into wood. The tongue is spearlike, one to one and a half inches long, and is used to pull out the larvae which lurk beneath the bark. On the average about 65 per cent of the food of woodpeckers is insect, largely

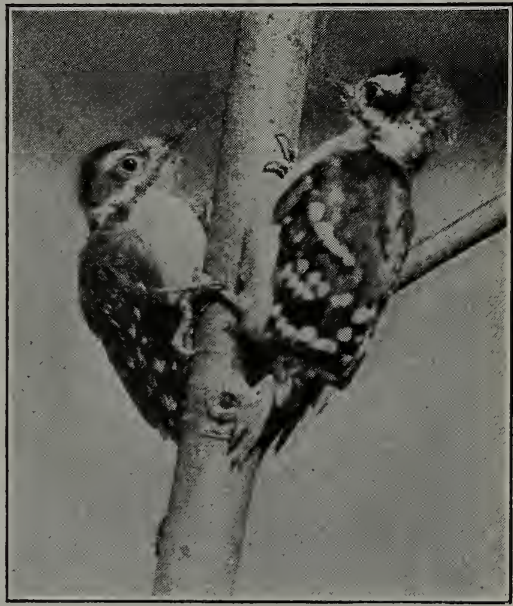

L. W. Brownell

Downy woodpeckers on a tree trunk. maple, birch, apple, and other borers. Woolly aphids, caterpillars, and chrysalids are also its prey. The woodpeckers, called sapsuckers, live up to their name and are said to cause a yearly damage of over $\$ 1,250,000$ to the lumber industry. On the other hand, they destroy large numbers of insects injurious to the same trees.

Flicker. This bird, a woodpecker, is twelve inches long. The male is brown above and golden yellow under the wings and tail, brown spots on breast, a scarlet crescent on back of the neck, and a black crescent on the breast. It has a white rump which is conspicuous in flight and makes an easily recognized mark. The flicker is generally useful, feeding upon plant lice, ants (which make up about 45 per cent of its food), grasshoppers, caterpillars, and weed seeds. Like other woodpeckers, it nests in hollow trees.

Baltimore oriole. This bright-colored and attractive bird is about seven and one half inches long. The male has the upper 
back, wings, and throat black, with the outer tail feathers, breast, and under parts orange. The female is not so brilliantly colored,

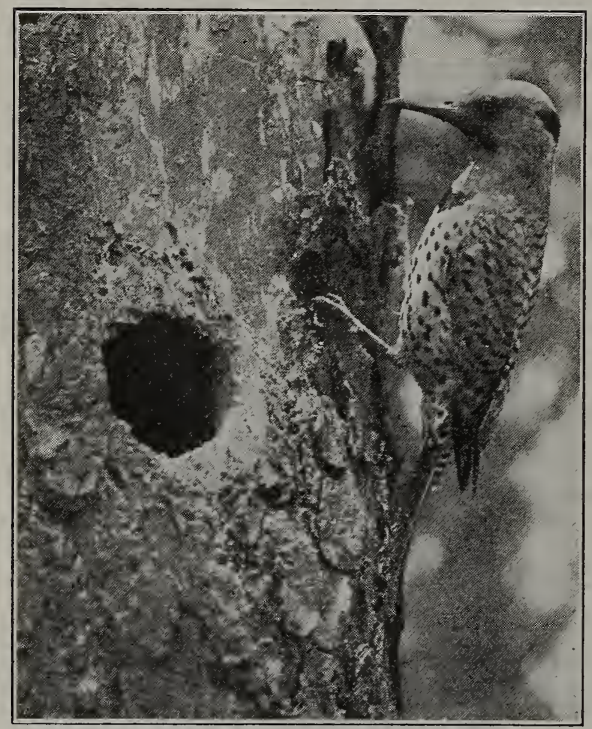

L. W. Brownell

A flicker at its nesting hole. The stiff tail helps to hold the bird in this position. being yellow instead of orange. The hanging nests of the oriole, often woven with bits of string, cloth, and other materials, are a common sight in elm trees near our homes. These birds prefer inhabited areas and, because of their protected nests, are increasing in spite of cats and the English sparrows. They feed largely upon insects. As high as 92 per cent insect diet has been recorded in the summer season. The cankerworm, tussock, browntail, and forest tent caterpillars were found in the stomachs of northern birds, while those examined in the south contained many cottonboll weevils.

Screech owl. This is a small owl and one of the most useful, as it feeds upon field mice and other small destructive rodents as well as upon some moths, caterpillars, and beetles. It is about as large as a quail, about nine and one half inches in length. Its general coloring is gray on the under parts and reddish brown above. The eye is yellow. It usually nests in hollow trees.

Crow. Our common crow, a glossy black bird from sixteen to nineteen inches long, is one of the few birds that may do more harm than good. In the early spring the crow is useful, 80 per cent of its diet being insect larvae, such as wireworms and May beetle larvae. It also eats field mice, but later does much harm in the newly planted corn fields. In parts of the country 
where they are most abundant they cause harm by killing useful birds.

English sparrow. The English sparrow is an example of a bird introduced for the purpose of insect destruction, that has done great harm because of its relation to our native birds. Introduced at Brooklyn in 1850 for the purpose of exterminating the cankerworm, it soon abandoned a diet largely of insects in favor of one of grain and has driven out many of our native insect feeders. Investigations by the Department of Agriculture show that in the country these birds and their young feed to a large extent upon grain, thus showing them to be injurious to agriculture. Dirty and very prolific, they have long since worked their way from the East to the Pacific coast. The English sparrow has become a national pest, and should be exterminated in order to save our native birds.

Birds harmful to man. While there are a few birds that do both harm and good, like the crow, catbird, blue jay, cedar waxwing, and robin, there are others that are bad,

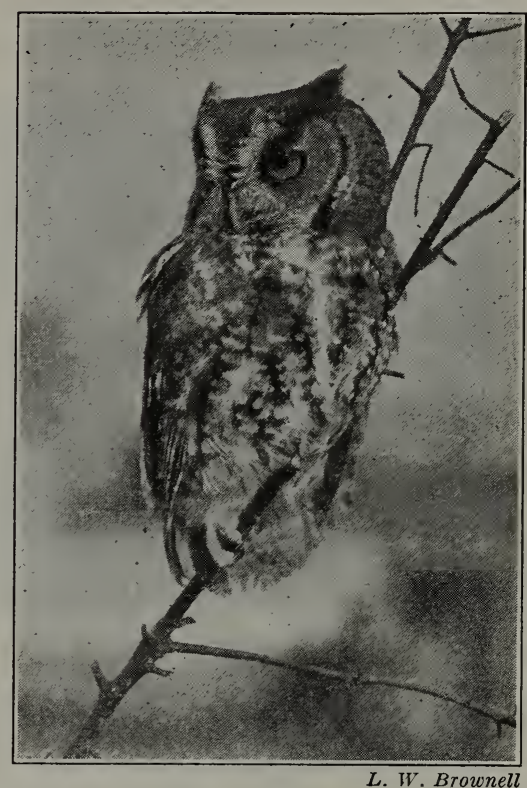

Is the screech owl a beneficial or harmful bird? Why?

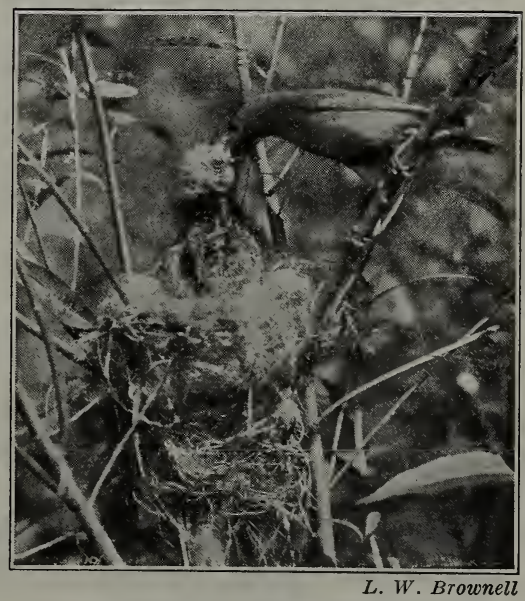

A warbler feeding a young cowbird which is nearly as large as its foster mother. 
and we can find little or no good to say about them. The English sparrow is the greatest bird pest, for reasons given above. The cowbird never builds a nest nor cares for her young. She lays her eggs in the nests of smaller birds, usually warblers, where later the young cowbirds cause the death of the rightful inhabitants of the nest. Cooper's hawk, the sharp-shinned hawk, and the great horned owl kill smaller, beneficial birds.

Practical Exercise 28. Try to find a nest containing eggs and watch the development of the young over a given period. Report your findings to the class.

Practical Exercise 29. Make a table for your workbook in which you name as many local birds as you can. List them as useful, harmful, or harmless, and in a fifth column give evidence for your statements.

Practical Exercise 30. Make a study of the feeding habits of some one bird and report on it.

Practical Exercise 31. What methods of protection of birds do you find in your community? What means have you taken to protect birds that live near your home?

\section{Self-Testing Exercises}

The robin is about

(2) long,

(4) on breast, ....... (5) on wings, and ...... (6) on head.

The chickadee may be recognized by its ......(7). It is about . (8) inches in length, head and throat ........(9), abdomen dirty ........(10). The American goldfinch is .......(11); the bluebird ........(12) in general color. The yellow warbler is about ....... (13) inches long and has no ....... (14) on its ....... (15). The barn swallow is between .......(16) and .......(17) inches long, dark .......(18) .......(19) above, breast and abdomen ....... (20), tail deeply ....... (21). The Baltimore oriole is about (22) inches long . The male oriole is brightly colored with (23), with throat, and upper back .......(24). Owls may eyes.

\section{PROBLEM VIII. WHAT IS THE ECONOMIC IMPORTANCE OF INSECTS?}

Useful insects. We have learned that many insects pollinate Howers; that in many cases insects are preyed upon, and supply an enormous multitude of birds, fishes, and other animals with food. Dr. Forbes of the University of Illinois estimates that many of the smaller fresh-water fishes consumed over fifty per cent insect food, mostly larvae. 
The carrion beetles and many water beetles act as scavengers. The sexton beetles bury dead carcasses of animals. Ants in tropical countries are particularly useful as scavengers. Insects often do a service by eating harmful weeds; thus many harmful plants are kept in check. The "ladybug," orladybird beetle, is the natural enemy of the orange-tree scale. It may often be found also feeding on the plant lice,

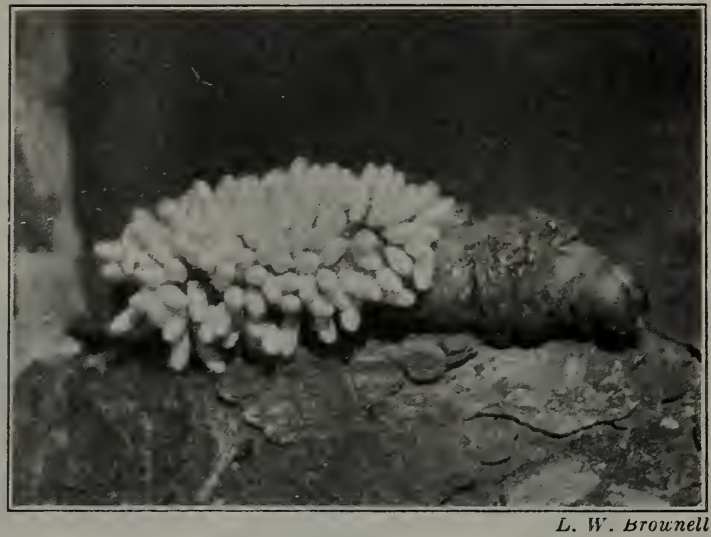

The larvae of the ichneumon fly attach themselves to the body of a caterpillar. They grow by sucking the blood from their host and finaily they spin cocoons. In this illustration cocoons of an ichneumon fly are fastened to a Spingidae larva which feeds upon the leaves and stems of various plants. or aphids.

The ichneumon fly, indirectly, does man considerable good because of its habit of laying its eggs and leaving its young to develop in the bodies of caterpillars which are harmful to vegetation. Some of the ichneumons even bore into trees in order to deposit their eggs in the larvae of wood-boring insects.

Cochineal and lac. Among the many products of insect origin is cochineal, a red coloring matter which consists of the dried bodies of a tiny insect, one of the plant lice which live on the cactus

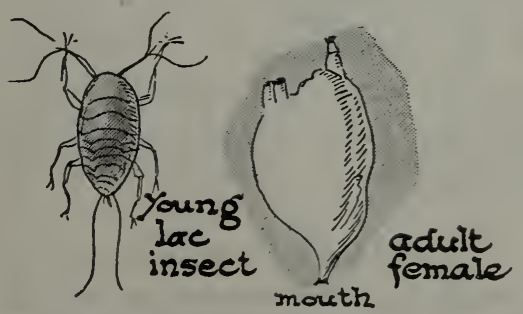

Why is the lac insect useful to man? plants in Mexico and Central America. The lac insect, another one of the plant lice, feeds on the juices of certain trees in India and pours out a substance from its body which after treatment forms shellac.

Gall insects. Oak galls, growths caused by wasp-like 
insects, give us products used in tanning, and in making pyrogallic acid which is much used in developing photographs.

Economic loss from insects. While birds do hold insects in check, the money value of crops, forest trees, stored foods, and other materials destroyed annually by insects is beyond belief. It is estimated that they destroy yearly one tenth of the country's crops, which at the lowest estimate is about $\$ 1,000,000,000$.

Insects which damage garden and other crops. Grasshoppers and the larvae of various moths do considerable harm here,

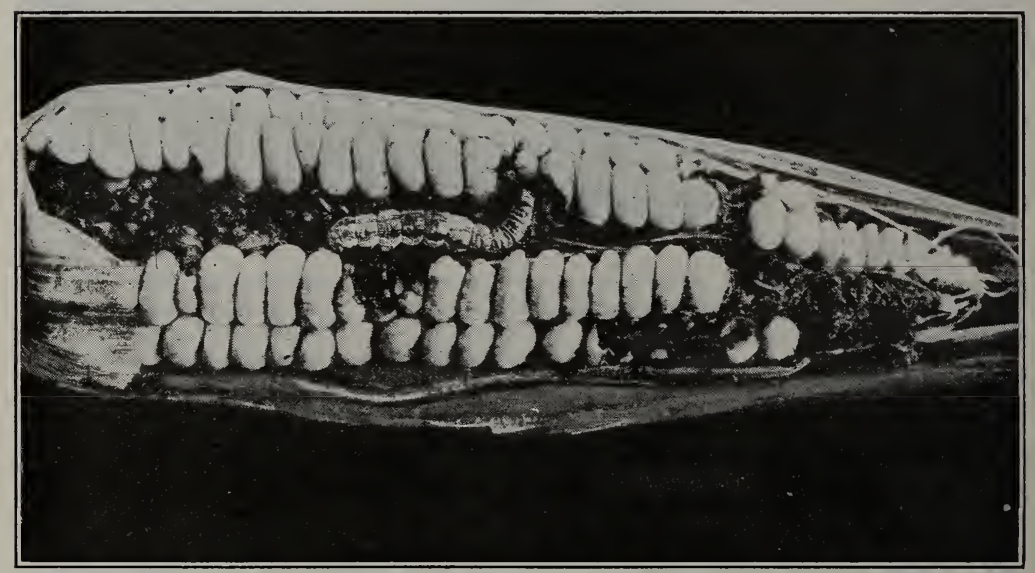

The corn worm does much damage to corn. How does it do this?

especially the "cabbage worm," the cutworm, which eats all kinds of garden truck, and the European corn borer which destroys our corn.

Among the beetles which are found in gardens is the potato beetle which eats the leaves of the potato plant. This beetle formerly lived upon a wild plant of the same family as the potato, and began to infest potato fields when that crop was introduced in Colorado, evidently preferring cultivated forms to wild forms of this family.

The one beetle doing by far the greatest harm in this country is the cotton-boll weevil. Imported from Mexico, since 1892 it has spread over nearly the entire cotton-growing area of the 
South. "Cotton was king" before the days of the Civil War, but now many Southern farmers have been forced to produce other crops in the place of cotton. An example is seen in the decrease of production of the once famous sea island cotton. As late as $1916,117,559$ bales were produced; in 1924 the record gave only 5 bales ginned.

The beetle lays its eggs in the young flower buds and the larvae feed upon the substance within the

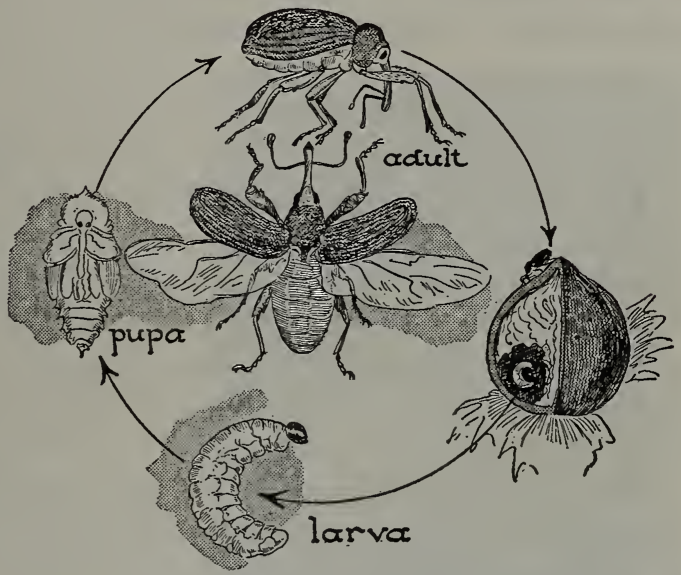

Life history of cotton-boll weevil. At what time during its life does the weevil do the most harm? bud, thus causing it to drop off and, consequently, produce no cotton fiber. Later in the season the beetle lays its eggs in the young fruit or bolls of cotton. These do not drop off, but the bolls become discolored and the cotton is ruined. It is estimated that this pest destroys yearly over one

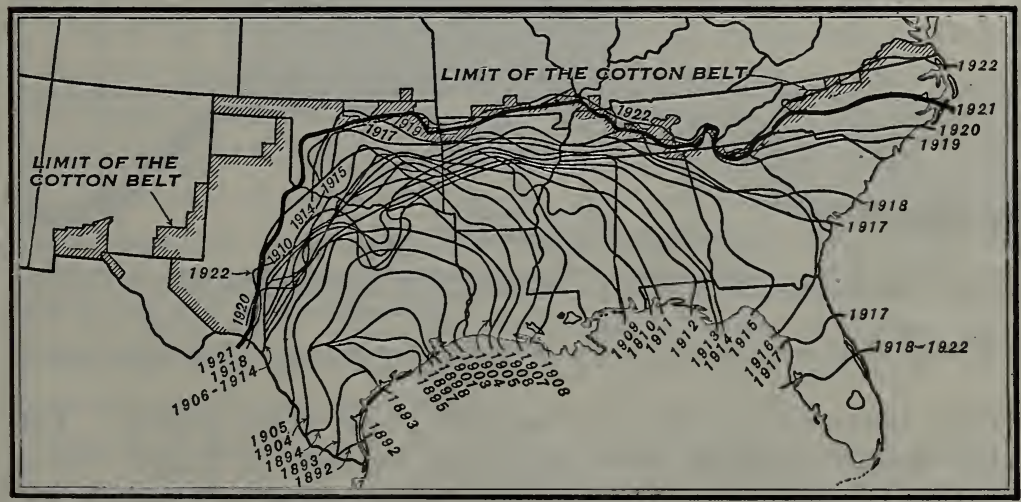

U. S. Dept. of Agriculture

Map showing the spread of the Mexican cotton-boll weevil from 1892 to 1922. 
half of the cotton crop, thus indirectly affecting each one of us through the increased price of cotton. The boll weevil, because of the protection offered by the cotton boll, is very difficult to exterminate. Some weevils are destroyed by birds, millions are killed each winter by cold, insects are introduced to prey on them, and the infected bolls and stalks are burned, but at the present time they are one of the greatest pests the South knows.

The bugs are among our most destructive insects. The most familiar examples of our garden pests are the squash bug; the chinch bug, which, by sucking the juice from the leaves of grain, does yearly damage estimated at $\$ 20,000,000$; and the plant lice, or aphids. The dreaded phylloxera, living on the grape, destroys immense numbers of vines in the vineyards of France, Germany, and California.

The Japanese beetle, in larval form, was introduced into this country from Japan in the soil surrounding the roots of a plant. It was first observed in 1916 in New Jersey and by 1923 it had infested about 2500 square miles in New Jersey and Pennsyl-

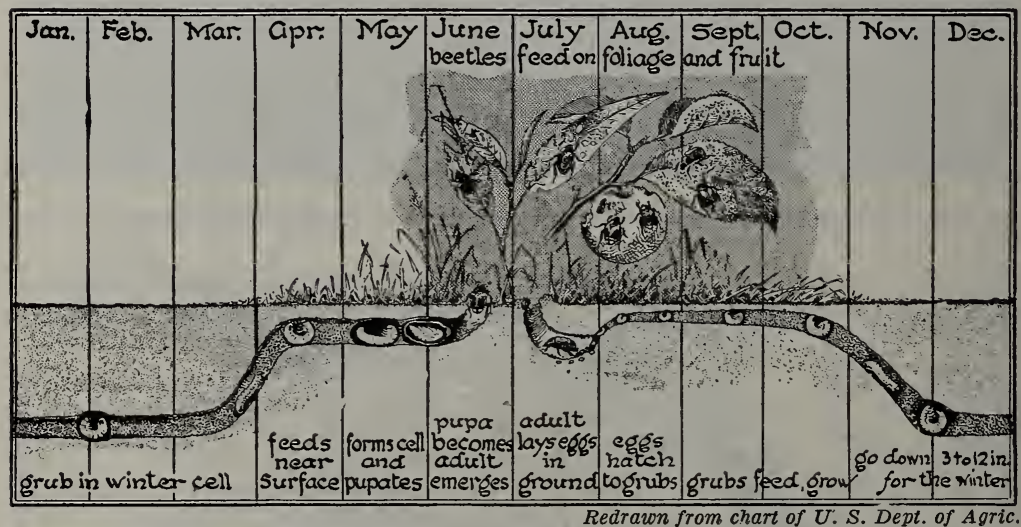

Life history of the Japanese beetle. What is one of the best ways of eradicating this insect?

vania. Since that time it has spread to other states. The adult beetle is about three fourths of an inch in length. It is a bright metallic green with coppery brown wings. It feeds upon the foliage of fruit trees, shade trees, vines, and also attacks the 
early fruits. The larva lives below ground and feeds upon the roots of plants.

Insects which harm fruit and forest trees. Great damage is done to trees by the larvae of moths. Massachusetts has already spent more than $\$ 5,000,000$ in trying to exterminate the accidentally imported gypsy moth. The codling moth, which bores into apples and pears, is estimated to ruin yearly $\$ 3,000,000$ worth of fruit in New York alone, which is only one of the important apple regions of the United States. Probably one of the worst insect pests to the dweller in a large city is the tussock moth, which destroys our shade trees. The caterpillar may easily be recognized by its hairy, tufted body and red

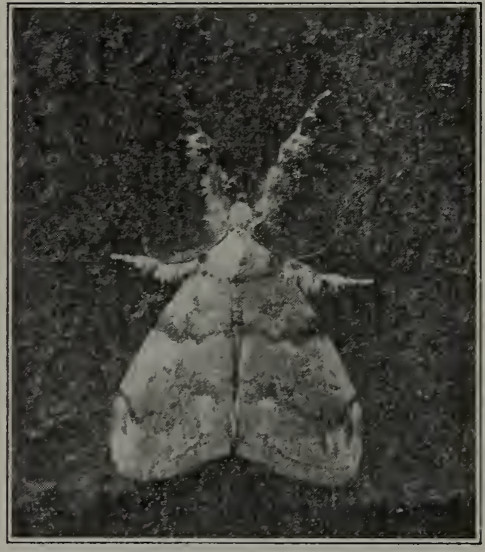

The tussock moth is one of the most destructive of all insects to our shade trees. head. The eggs are laid in what look like masses of foam on the outside of the cocoon attached to the bark of a shade tree. By collecting and burning the egg masses in the autumn, we may save many shade trees the following year.

The larvae of some moths damage trees by boring into the wood of the tree on which they live. Such are the peach, apple, and other fruit-tree borers common in our orchards. Some kinds of beetles produce boring larvae which eat their way into trees and kill thousands of forest and shade trees annually. The hickory borer threatens to kill all the hickory trees in the eastern states.

Among the bugs most destructive to trees are the scale insect and the plant lice. The San José scale, a native of China, was introduced into the fruit groves of California in 1868 and has since spread all over the country.

Insects of the house and storehouse. Weevils are the greatest pests of stored grains, frequently ruining tons of corn, wheat, and other cereals. Cockroaches will eat almost any kind of foodstuffs.

$$
\text { н. віо }-37
$$


The carpet beetle is a recognized foe of the housekeeper; the larvae feed upon all sorts of woolen material. The larvae of the clothes moth do an immense amount of damage, especially to stored clothing. Fleas, lice, and bedbugs are among man's personal foes. Besides being unpleasant, some of them are known to be disease carriers, and as such they should be exterminated.

The Medfly or Mediterranean fruit fly, which, since its appearance in Spain in 1842, has spread to all parts of the world, was discovered in Florida in April, 1929. It was found to breed in all fruits, and also to attack peppers, tomatoes, lima beans, and eggplants. The state of Florida as well as the National Government immediately took steps to eradicate it. No fruit was permitted to go out of the infested areas. All the trees, vines, and other vegetables on which the flies fed were destroyed, and all trees in near-by areas were sprayed at frequent intervals. These methods proved so effective that after November 16, 1930, no flies or infested fruits or vegetables were found. The Federal quarantine on Florida products was then lifted.

Practical Exercise 32. What problems do the farmers in your locality have to meet in insect control? What insect enemies of shade or forest trees are there in your locality? What is being done to control the pests? With the information obtained from your local Chamber of Commerce or other sources try to estimate the money loss caused by insects in one year in your community.

Man's place in the chain of insect life. We have seen that man is frequently directly responsible for the introduction of insect pests. He may be indirectly responsible for them by planting crops on which they can feed, for an increase in easily obtainable food means more insects. Birds and other natural enemies will do much in keeping down the number of insects, but man himself has to do some of the fighting. If the farmers do not plant certain crops, the insects cannot get food and they perish. Naturally farmers do not want to lose their crops, so they have gone to the Bureau of Entomology of the United States Department of Agriculture, the various state experiment stations, and others for help.

Methods of control of insect pests. In general we have three different methods for controlling insect enemies. The first is to learn what their natural enemies are and then introduce these 
enemies so that the balance may be kept in a natural way. An historic case is the introduction of a scale insect from Australia to the California citrus groves in 1868. This insect infested so many orchards that a natural enemy to this scale, the ladybird beetle, was later introduced from Australia. Due to the activity of these beetles the scale insect can be kept in check. But man has made a step further in his control of this pest. He has found that fumigating with hydrocyanic gas will kill the scale insects left on the trees. So we find that artificial methods of control are used in addition to nature's method. Insects may be destroyed by (a) picking (as in the case of the potato beetle) or by (b) contact poisons, which kill by covering up the spiracles of the insect so that it cannot breathe, or by $(c)$ stomach poisons, which are sprayed on the leaves to be eaten by the insects. Man has learned to develop plants that mature faster than the insects do or plant his crops early or late, thus escaping insect damage.

The control of the cotton-boll weevil seems to depend upon early planting so that the crop has an opportunity to ripen before the insects in the boll grow large enough to do harm. Various state and government agencies are at work upon the problem, and ultimately the boll weevil may do more good than harm by bringing about the culture of a type of cotton plant that ripens very early and by forcing the farmers of the South to produce diversified crops, which can be marketed to an advantage if the cotton crop is a failure. Another method is by crop rotation, for in this way insects may be deprived of food plants on which to lay their eggs.

The spread of the Japanese beetle is being fought by the use of sprays, treatment of the soil, and by the importation of insects that lay their eggs in the larvae of adult beetles.

Work of Bureau of Agriculture. Most of these methods of destroying insects have been worked out for the farmer by different bureaus of the Department of Agriculture. The Bureau of Entomology works in harmony with the other divisions of the Department of Agriculture, giving the time of its experts to the problems of controlling insects which, for good or ill, influence man's welfare in this country. The destruction of the malarial mosquito; the destruction of harmful insects by the introduction 


\section{MAN CONTROLS HIS ENVIRONMENT FOR WEALTH}

of their natural enemies, plant or animal ; the improvement of the honeybee; and the introduction of new species of insects to pollinate flowers not native to this country, are some of the problems to which these men have devoted their time.

All the states and territories have, since 1888, established state experiment stations, which work in coöperation with the government in the war upon injurious insects. These stations are often connected with colleges, so that young men who are interested in this science may have opportunity to learn and to help.

Bulletins on insects and their control are published by the various state stations and by the Department of Agriculture. Probably the most useful of these are the Farmers' Bulletins, issued by the Department of Agriculture.

The outline has been made up largely from these sources.

\section{ECONOMIC IMPORTANCE OF INSECTS}

\section{Beneficial Insects}

Silk moth. - Larva spins a cocoon from which silk is made.

Honeybee. - Adult produces honey and pollinates flowers.

Bumblebee. - Adult pollinates red clover and fruit trees.

Ichneumon fly. - Female lays eggs in the bodies of harmful larvae (as the grapevine caterpillar and the tree borers). The developing parasites feed on the hosts and kill them.

Dragon fly. - Adult feeds on mosquitoes.

Ladybird beetle. - Adult feeds on scale insects and aphids.

Gall insect. - The developing larvae cause galls from which ink is made.

\section{Household Pests}

House fly. - Adult carries typhoid, tuberculosis, summer complaint, and other intestinal diseases. To exterminate, it is necessary to prevent breeding and kill overwintering flies.

Mosquito. - Adult carries malaria and yellow fever. May be exterminated by destroying the breeding places.

Body louse. - Adult carries typhus. Insects may be killed by sterilizing infected clothing and by bathing patients in an antiseptic solution.

Flea on rats. - Adult carries bubonic plague. Kill the rats.

Clothes moth. - Larvae eat clothing: wool, fur, etc. They may be controlled by shaking or brushing the clothing, and exposing it to the sun. The use of camphor or naphthaline on clothing which is packed away deters the moth from laying its eggs there.

Buffalo carpet-beetle. - Larva eats carpets. Spray benzine in the cracks in the floor and on the carpet.

Cockroach. - Adults are scavengers and are numerous around sinks and where food is kept. They may be exterminated with poison bait. Cleanliness is necessary.

Garden and Fruit Tree Pests

Potato beetle. - Larva eats leaves of the potato plant. Spray infected plants with arsenate of lead or Paris green. 
Cabbage butterfly. - Larva eats leaves of cabbages and may be destroyed by a spray of arsenate of lead or Paris green.

Hawk moths. - Larva feeds on leaves of grape and tomato vines. Spray.

Rose beetles. - Adults feed on leaves and blossoms of the rose. Spray with a soap solution.

Codling moth. - Larva injures apples and pears. Spray with arsenate of lead at the time petals fall.

San José scale. - Adults suck juices from the leaves and young twigs of fruit trees. Killed by ladybird beetles and by fumigation.

Aphids. - Adult females suck juice from leaves and young twigs. Spray with nicotine sulphate.

Boll worm or corn worm. - Larva lives in the ears of corn.

European corn borer. - Feeds on stalks, roots, and ears of corn plant. Controlled by burning cornstalks in the fall.

\section{Forest and Shade Tree Pests}

Tussock moth. - Larva eats leaves of shade and fruit trees. Destroy egg masses and spray in early spring.

Gypsy moth. - Damage and extermination the same as for tussock moth.

Forest tent caterpillar. - Larva eats leaves of shade and fruit trees. Destroy nests and spray.

\section{Self-Testing Exercise}

Mark in your workbook the correct statements :

T. F. 1. The cotton-boll weevil has done so much harm in the South that that region will never recover economically.

T. F. 2. The tussock moth destroys annually many corn fields.

T. F. 3. Nature usually has a natural check on destructive insects, as in the case of the ladybird beetle and San José scale.

T. F. 4. Larvae which feed upon crops may be killed by fumigation.

\section{Review Summary}

Test your knowledge of the unit by: (1) rechecking on the survey questions; (2) performing all assigned exercises; (3) checking with your teacher the scores of the various tests and trying again those that you missed; (4) making an outline of the unit for your notebook.

\section{Tests on Fundamental Concepts}

In a vertical column under the heading CORRECT write numbers of all statements you believe are true. In another column under INCORRECT write numbers of untrue statements. Your score equals right answers $\times 2 \frac{1}{2}$.

I. Plant foods (1) come from grain, vegetables, sugar cane, and orchards; (2) are valued roughly in the following order: grains, vegetables, orchard fruits, and citrus fruits; (3) are valued at more than animal foods; (4) may come from all parts of a plant 
II. Animal foods (5) come mostly from bivalves; (6) are obtained from animals in every phyla of the animal kingdom; $(7)$ come only from mammals; (8) depend in the long run upon the sun.

III. Animal products are:(9) rayon, flax, cocaine, cottonseed oil, and lumber ; (10) pearls, sponges, piano keys, and tallow ; (11) knife handles, pen holders, buttons, and glue; (12) silk, felt, and shoes.

IV. Examples of animals that are indirectly useful are: (13) snakes; (14) sheep; (15) toads; (16) chickens; (17) house wren.

V. Examples of harmful animals are: (18) starfish; (19) trout; (20) the cobra of India; (21) parasitic worms; (22) screech owl.

VI. Birds should be protected because (23) they feed on fruit and grain; (24) they eat weed seeds; (25) they eat injurious insects; (26) they furnish us with much meat.

VII. Birds (27) that eat weed seeds are useful ; (28) eat fruit only when seeds are scarce ; (29) usually go southward as soon as their young are old enough to fly; (30) always migrate; (31) usually destroy more fruit than insects.

VIII. Insects (32) can only be destroyed by other insects ; (33) such as the ladybird beetle and honeybee are destructive to home gardens ; (34) such as the aphids and gypsy moths destroy the early-ripening fruits; (35) destroy stored grains.

IX. Insects are controlled (36) by birds; (37) by contact and stomach poisons ; (38) by rats and mice ; (39) by picking and burning ; (40) by their breeding places, destroying their eggs and their young.

\section{Achievement Test}

1. What are the cheapest and most nutritious roots, stems, and leaves as food?

2. What cereal crops are of the most importance in your locality?

3. What is your most valuable local fruit crop?

4. Which of your local industries are dependent, directly or indirectly, upon plants?

5. What fish are the cheapest in local markets and why?

6. What "shell fish" are locally obtained and what are they used for?

7. Have you ever kept bees? How much honey do they produce to a hive? 
8. What are ten useful birds in your community? Tell specifically why each is useful.

9. How would you protect five useful birds?

10. What are ten insects that do harm? How does each do harm? How could you get rid of each?

11. What are five useful insects that affect you directly or indirectly?

12. What agencies can you call upon to help in the extermination of harmful insects?

\section{Practical Problems}

1. Make a survey of the plants and animals used in your locality for $(a)$ food, $(b)$ clothing, $(c)$ other uses. List all in order of economic importance.

2. Make a bird house for your yard and report on the birds that inhabit it.

3. Make a bird bath for your yard and keep a list of different bird visitors.

4. Make a list of all insects that trouble your garden and try to find out the birds which prey upon them.

\section{USEFUL REFERENCES}

DePuy, Our Insect Friends and Foes. (Winston Co. 1925.)

Downing, Our Living World. (Longmans, Green \& Co. 1924.)

Farmers' Bulletins, 513, 630, 740, 801, 896, 1294, 1326, 1346, 1353, 1371. U. S. Dept. of Agriculture.

Forbush, Birds of Massachusetts and Other New England States. (Commonwealth of Massachusetts. 1925.)

Henderson, The Practical Value of Birds. (The Macmillan Co. 1927.)

Herrick, Insects Injurious to the Household and Annoying to Man. (The Macmillan Co. 1926.)

Hornaday, The American Natural History. (Charles Scribner's Sons. 1926.)

Jordan and Evermann, American Food and Game Fishes. (Doubleday; Doran \& Co. 1923.)

Sanderson, Insect Pests of Farm, Garden and Orchard. (John Wiley \& Sons. 1921.)

Toothaker, Commercial Raw Materials. Pp. 58-78. (Ginn \& Co. 1927.)

Trafton, Bird Friends. (Houghton Mifflin Co. 1916.) 


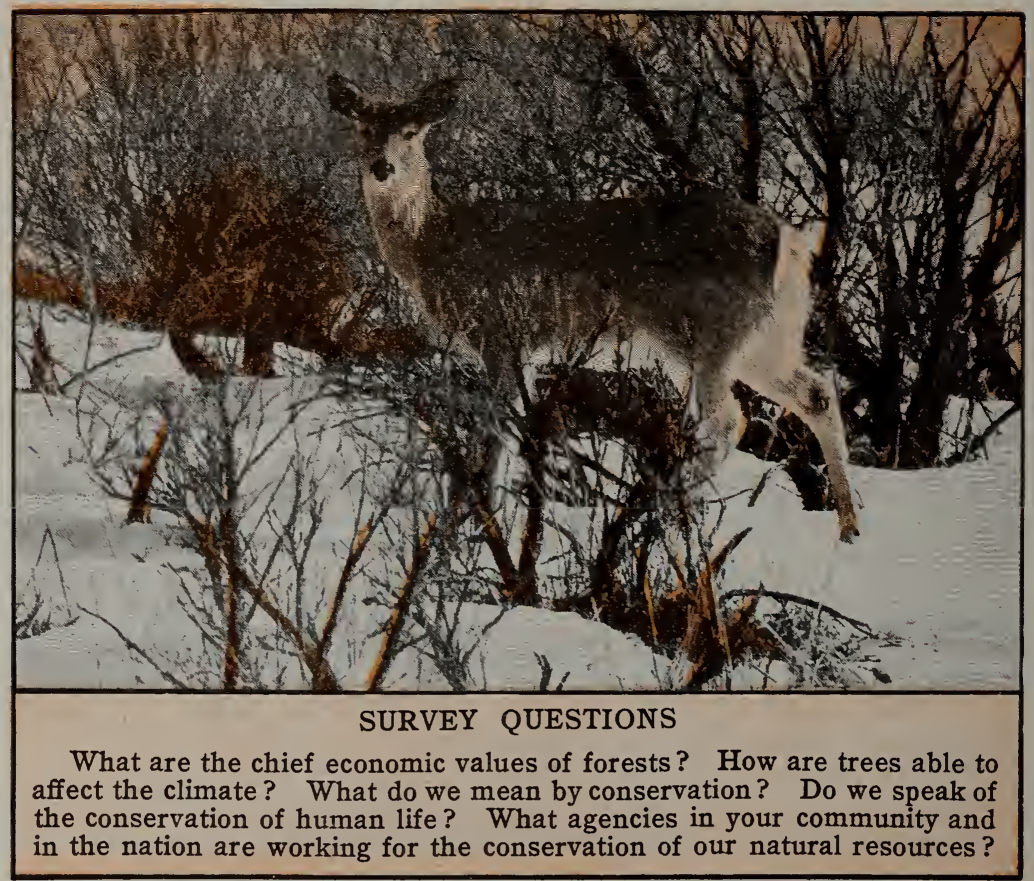

UNIT XVII

\section{HOW DOES MAN CONSERVE HIS NATURAL RESOURCES?}

Preview. No one who has ever read Joyce Kilmer's poem entitled "Trees" can ever forget what a tree meant to him. And no one who has ever hiked through a forest of yellow pine or redwood can forget the majesty of those tree companions. Those of us who have been brought up in New England can never forget our days in the woods or the wonderful elms lining the roadways along which we went to school.

Trees are not only beautiful, but they mean a great deal to man's welfare because they influence the climate, give homes to 
many animals, provide millions of feet of lumber, and help to protect and regulate the water supply of the country. No one who has traveled over the great Southwest can fail to realize the value of forest trees. Great areas of land lie devastated, subject to floods in winter and droughts in summer. Yet these areas, if given water supply, would be capable of producing crops in abundance. Irrigation has proved this in regard to similar areas. Irrigation projects, which now provide homes and employment for thousands of people, besides producing annually great quantities of food supplies, would be impossible were it not for protected forest areas somewhere. Moreover, nearly 800 western communities, with a total population of nearly $3,000,000$, depend for their water supplies upon streams coming from areas protected by national forests. When the earth's surface is covered by trees, the roots prevent soil from being washed away and they hold moisture in the ground. Devastation of immense areas in China and considerable damage by floods in parts of Switzerland, France, and the United States have resulted where the forest covering has been removed. The annual spring "freshets" in the East; the floods in the Ohio and Mississippi valleys; and the damage done by sudden storms along stream beds in the Southwest, are all examples of the great destruction that can be wrought by water which is not controlled by forests at the river sources. It has been estimated that the carrying power of water is increased sixty-four times if its rate of flow is doubled; that is, the transporting power of water varies as the sixth power of its velocity. This accounts for the tremendous destruction produced by a mountain stream in a flood.

Besides holding water in the ground in some localities forests are used as windbreaks and to protect mountain towns against avalanches. In winter they moderate the cold, and in summer reduce the heat and lessen the danger from storms. The nesting of birds in woods protects many valuable plants, which otherwise might be destroyed by insects.

The increasing population has meant the necessity of more food, more and better water supplies, more power to light cities and run machines, and more fuel. The balance of nature has 
necessarily been disturbed by man in his ever increasing demand for food and other supplies. In consequence, he must learn how to conserve the supplies which he now has and which are so necessary to him.

Although in biology we are not directly concerned with methods of conservation which deal with our mines or our fuels, we are indirectly studying the conservation of water supplies when we deal with the problem of the protection of our forests. This unit is also concerned with the conservation of useful plants and animals. There are two general methods to consider : first, how to protect our useful plants and animals; second, how to eliminate harmful ones.

Our personal health is the largest problem of conservation with which we have to deal. The study of present-day statistics shows us the imperative need of the conservation of human health and human life. Communities are doing much more for the health of the people than they did twenty or thirty years ago, but there are still too many careless individuals who do not do all they can to care for themselves properly and who forget the rights of others in a democracy. Conservation means protection or care of the natural gifts that nature has given us.

\section{PROBLEM I. WHAT ARE THE VALUES OF TREES?}

Prevention of erosion by covering of organic soil. Streams unprotected by forests may dig out soil and carry it far from its original source. Results of the carrying-power of streams may be seen in the deltas formed at the mouths of great rivers. The forest prevents the erosion of soil by holding back the water and letting it out gradually. This it does by covering the inorganic soil with humus or decayed organic material which, like a big sponge over the forest floor, holds water through long periods of drought. It is estimated that the forest floor can absorb and hold for some time a rainfall of four or five inches. The roots of the trees, too, help hold the soil in place and prevent erosion.

Regulation of rainfall and water supply. The gradual evaporation of water through the stomata of the leaves cools the atmos- 


\section{PREVENTION OF EROSION BY COVERING SOIL 575}

phere and this tends to precipitate the moisture in the air, causing rains. The rainfall is greater and more regular in forested area.

Regulation of the water supply is most important if the rivers are to be used for water power or navigation. Several cities on the Atlantic coast, such as Savannah, Wilmington, and Philadelphia, owe their importance to their position on navigable rivers supplied with water largely by the Appalachian forests. Should these forests be destroyed, it is possible that the frequent freshets which

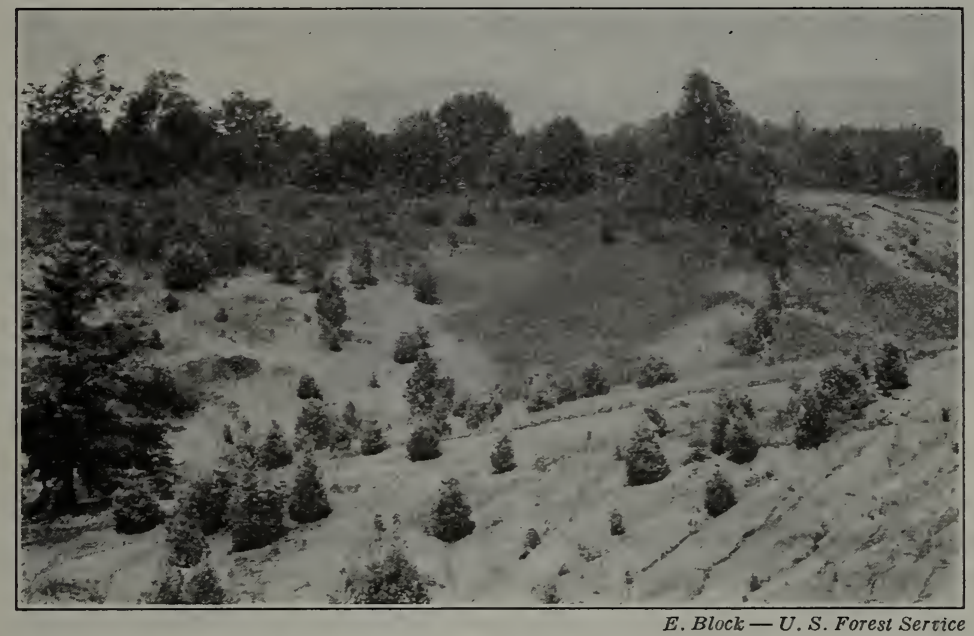

Deep gullies on abandoned hillside land. White pine is slowly restocking this area, but the erosion is still so rapid that it is difficult for the seedlings to secure a foothold.

would follow would so fill the rivers with silt and débris that the ship channels in them, already costing the government millions of dollars a year to keep dredged, would become too shallow for ships. If this should occur, these cities would soon lose their importance.

The story of how this very thing happened to the old Greek city of Poseidonia is graphically told in the following lines:

"It was such a strange, tremendous story, that of the Greek Poseidonia, later the Roman Paestum. Long ago those adventuring mariners from Greece had seized the fertile plain which at that time was covered with forests of great oak and watered by two clear and shining rivers. They drove the Italian natives back into the distant hills, for the white man's 
burden even then included the taking of all the desirable things that were being wasted by incompetent natives, and they brought over colonists whom the philosophers and moralists at home maligned, no doubt, in the same pleasant fashion of our own day. And the colonists cut down the

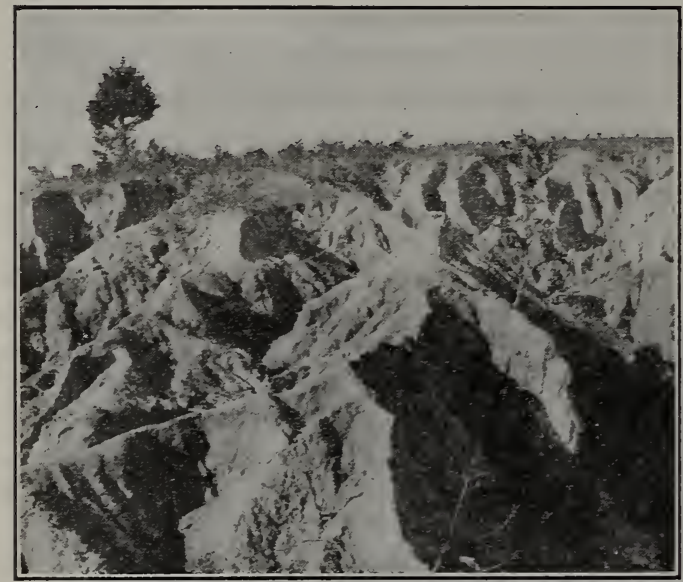

Matlon-U.S. Forest Sertice

Gully farm land badly in need of forestation. oaks, and plowed the land, and built cities, and made harbors, and finally dusted their busy hands and busy souls of the grime of labor and wrought splendid temples in honor of the benign gods who had given them the possessions of the Italians and filled them with power and fatness.

"Every once in so often the natives looked lustfully down from the hills upon this fatness, made an armed snatch at it, were driven back with bloody contumely, and the heaping of riches upon riches went on. And more and more the oaks were cut down - mark that! - for the stories of nations are so inextricably bound up with the stories of trees - until all the plain was cleared and tilled; and then the foothills were denuded, and the wave of destruction crept up the mountain sides, and they, too, were left naked to the sun and the rains.

"At first these rains, sweeping down torrentially, unhindered by the lost forests, only enriched the plain with the long-hoarded sweetness of the trees; but by and by the living rivers grew heavy and thick, vomiting mud into the ever shallowing harbors, and the land soured with the undrained stagnant water. Commerce turned more and more to deeper ports, and mosquitoes began to breed in the brackish soil that was making fast between the city and the sea.

"Who of all those powerful landowners and rich merchants could ever have dreamed that little buzzing insects could sting a great city to death? But they did. Fevers grew more and more prevalent. The malariahaunted population went more and more languidly about their business. 
The natives, hardy and vigorous in the hills, were but feebly repulsed. Carthage demanded tribute, and Rome took it, and changed the city's name from Poseidonia to Paestum. After Rome grew weak, Saracen corsairs came in by sea and grasped the slackly defended riches, and the little winged poisoners of the night struck again and again, until grass grew in the streets, and the wharves crumbled where they stood. Finally, the wretched remnant of a great people wandered away into the more wholesome hills, the marshes rotted in the heat and grew up in coarse reeds where corn and vine had flourished, and the city melted back into the wasted earth." - Elizabeth Bisland and Anne Hoyt, Seekers in Sicily. John Lane Company.

Uses of wood. Even though we have many materials for building and fuel, wood is still the one most used. Practically all buildings use wood some place in their construction. Wood outlasts iron under water, and also is lighter. It is cheap and, with proper care of the forests, the supply is practically inexhaustible. When wood is burned without air, wood alcohol is given off. Partly burned wood is charcoal, the best of which, used in medicine, comes from the willow trees. Much of the soft wood (the coniferous trees, spruce, balsam, hemlock, and pine) and poplars, aspens, with some other species, of our forests are used for making paper pulp. The daily newspapers and cheap books are responsible for inroads on our forests. Since it is not necessary to take the largest trees to make pulp, many young trees of not more than six inches in diam-
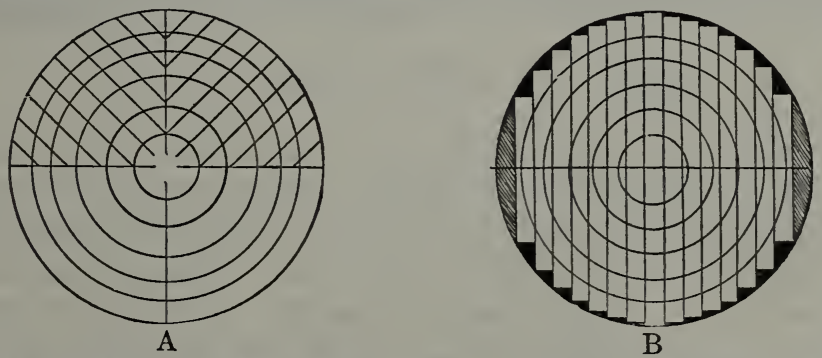

Figure A shows the method used when sawing a $\log$ for trim. Figure B shows the common method of sawing a log. A is known as quarter saw and $B$ as plain saw.

eter are being sacrificed. Of the hundreds of species of trees in our forests, the conifers are probably most sought after for lumber. 


\section{HOW DOES MAN CONSERVE HIS RESOURCES?}

Pine, especially, is probably used more extensively than any other wood. It is used for all heavy construction work, frames of houses, bridges, masts, spars, and timber of ships, floors, railway ties, and many other purposes. Cedar is used for shingles, cabinet work, lead pencils, etc.; hemlock and spruce for heavy timbers. Another use for our lumber, especially odds and ends of all kinds, is in the packing-box industry. Hemlock bark is still

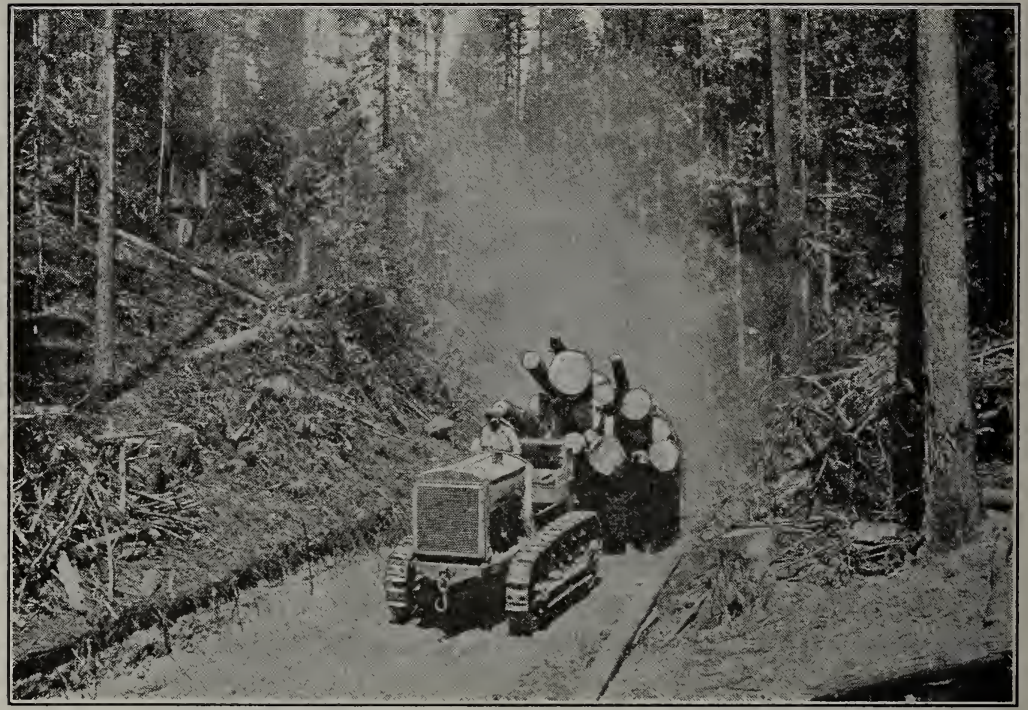

Swan-U.S. Forest Service

Caterpillar truck hauling load of logs to the railroad.

used for tanning. Some of the soft woods, as the poplars, are used for making excelsior used in packing. Wood pulp from the fiber of aspen, basswood, cottonwood, and other trees is chemically treated and used for making artificial silk, rayon. The hard woods, ash, red gum, beech, birch, cherry, chestnut, elm, maple, oak, and walnut, are used largely for the "trim " of our houses, for manufacture of furniture, for spokes of wagon or car wheels and for many other purposes. Our hard wood supply is rapidly becoming exhausted, particularly ash and hickory, and our only remedy is to plant more trees of this kind. 
Practical Exercise 1. List all the various forest products found in your community and give the uses of each.

If there is in your community an industry which uses forest products visit it and give a report of your visit to the class.

Other values of the forest. We have learned that forests regulate the water supply. Much organic soil is formed from decayed trees and other vegetation. The forest gives a refuge for wild animals, particularly game such as deer, elk, and antelope. There are now nearly 12,000,000 acres set aside as refuges for wild birds and game, that they may not become extinct as have some native wild animals. The clear streams of the forest are the homes of many of our best game fishes. And perhaps, best of all, the forest has become the playground for lovers of the out-of-doors in our nation.

\section{Self-Testing Exercise}

Trees protect the soil by preventing .......(1). Land covered with trees can ........ (2) ........ (3) water better than land barren of trees. Paper pulp is obtained largely from ........(4) wood. Evaporation of water through the stomata of the leaves makes the surrounding air ....... (5). Wood pulp is used for making ........

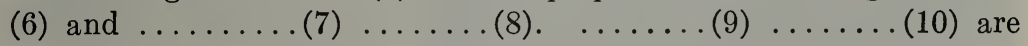
used for the "trim" of our houses.

\section{PROBLEM II. WHY IS THE CONSERVATION OF FORESTS NECESSARY?}

Field Exercise. To study the forest resources of my community. Divide the area to be covered into districts and let each member of the class work over a small area. Count the number and kind of marketable trees, estimate their size or approximate age, etc. Make maps showing these areas, to scale, so that the maps made by the entire class may be put together and an estimate of the entire region may be formed. Since this is an economic project, it will be necessary to get the help of practical lumbermen or field workers.

What are the forest resources of your community? What special tree products give factories employment in your home city.

Good Forestry. The total forest area of the United States today is less than $470,000,000$ acres. More than $80,000,000$ acres have been burned or cut, so that today they are waste land. We have more waste forest land than the combined forest areas of 


\section{0}

HOW DOES MAN CONSERVE HIS RESOURCES?

western Europe. Our present forests are rapidly decreasing, due to the demands of an increasing population, a woeful neglect on the part of the owners of the land, and wastefulness on the part of cutters and users alike.

In some parts of Central Europe, the value of the forests to the country was recognized as early as 1300 A.D., and many towns consequently bought up the surrounding forests. The city of Zurich has owned forests in its vicinity for 600 years and has found them a profitable investment. Europe has long led the way in showing other countries how to care for forests and how to make them pay. In our country we have a Forest Service in the Department of Agriculture which, with numerous state and university

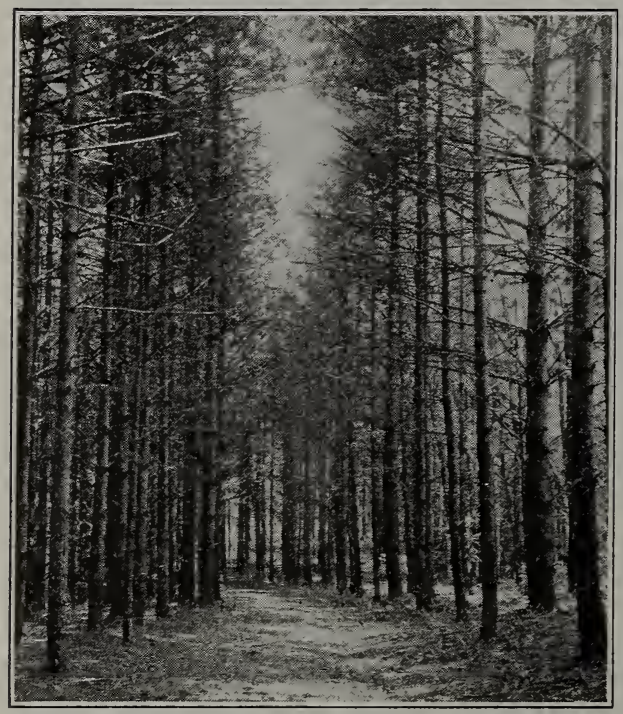

Haasia-U.S. Forest Service

White pine forest. Is this good forestation? Why? Schools of Forestry, is teaching the people of this country the best methods for the preservation of our forests. TheFederal Government has set aside a number of tracts of mountain forest, principally in the western states and Alaska, which are under the control of the $\mathrm{Na}$ tional Forest Service. These National Forest preserves have at the present time an area of about 170,000,000 acres, an area greater than the total area of the New England States, New York, New Jersey, Delaware, Pennsylvania, Maryland, Virginia, and West Virginia. In addition to this there are almost 25,000,000 acres privately owned that are within the National Forest areas. New York has established for the same purposes the Adirondacks, the Catskill Mountain, and other Forest Preserves, with 2,000,000 
acres of timber land; Pennsylvania has preserves of more than $1,250,000$ acres, and many other states have followed their example. Wisconsin, Minnesota, and Michigan have large areas set aside. The total area for all states in 1925 was more than $10,000,000$ acres.

Forest Wastes. Our forests are being cut down at the rate of about 10,000,000 acres a year. But man loses much of this wood by wasteful methods of lumbering. Hundreds of thousands of dollars' worth of lumber is left to rot annually because the lumbermen do not cut the trees close enough to the ground, or because through careless felling of trees many smaller trees are injured. This is particularly true among the large trees in our western

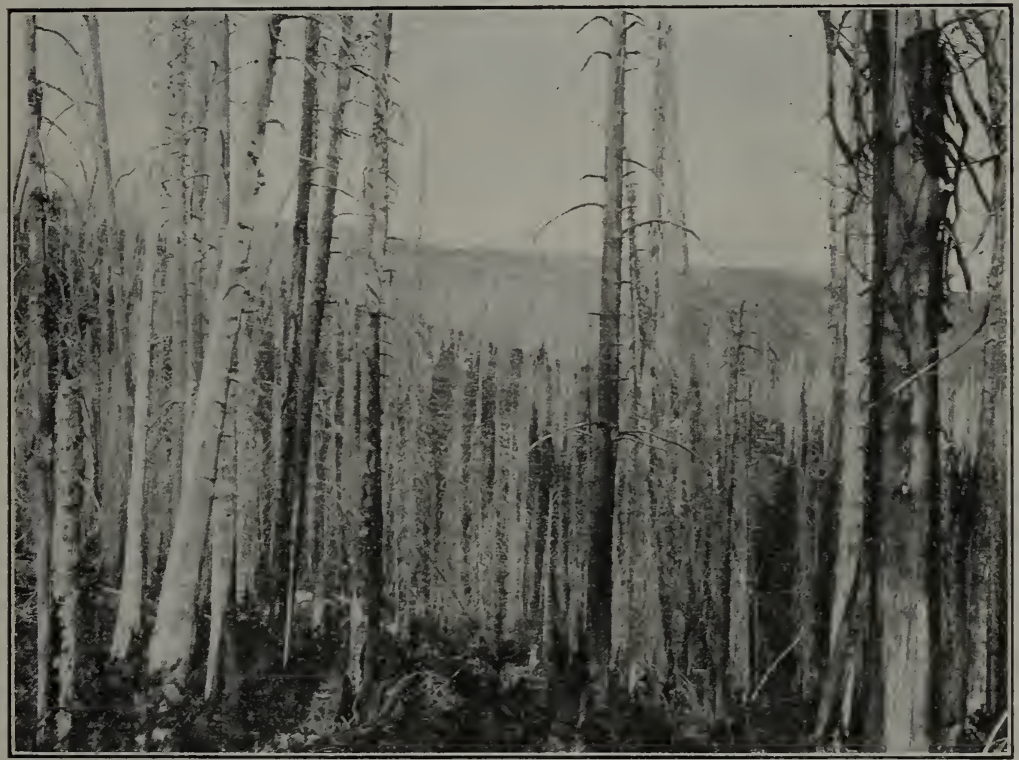

A. Gaskill-U.S. Forest Sertice

A cigarette may have caused this destruction.

forests. There has been great waste also in the lumber mills. In fact, man wastes lumber in every step from the forest to the finished product, and is just beginning to devise methods of preventing these wastes. 


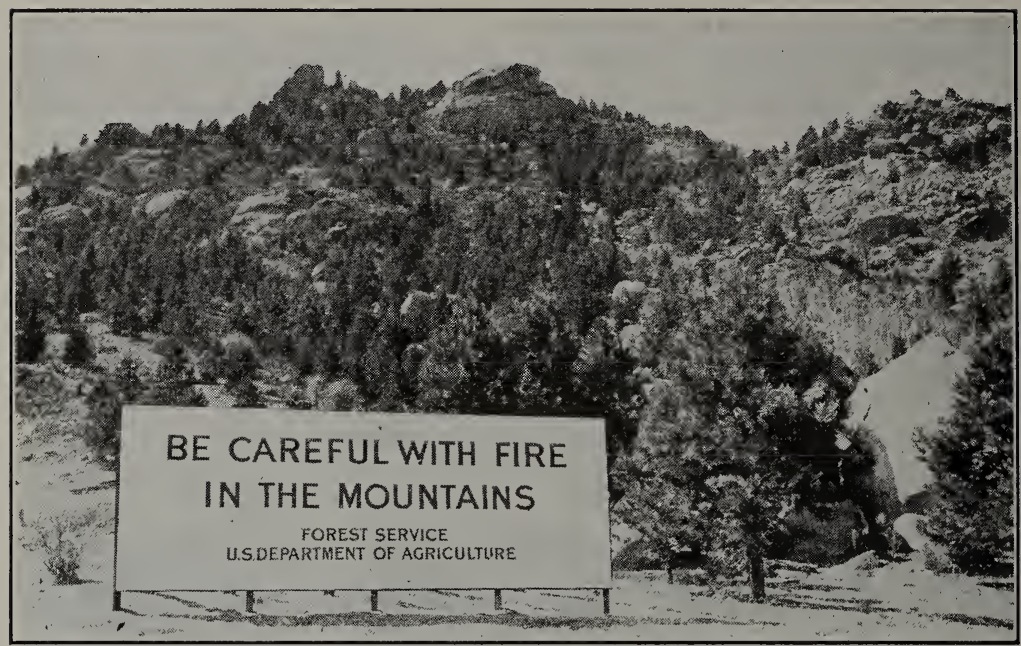

Photo by Hutchinson-U.S. Forest Service Our water supply depends upon our forests. It takes one day to destroy a forest but a hundred years to grow it.

Indirectly, man is responsible for fire, one of the greatest enemies of the forest. Most of the great forest fires of recent years, the losses from which total in the hundreds of millions of dollars, have been due to smokers, to railroads, or to carelessness in making camp fires in the woods. It is estimated that fires have destroyed over 12,000,000 acres of forest and caused a money damage of over $\$ 17,000,000$ in a single year. In the past, great forest fires have devastated Minnesota, Wisconsin, and Michigan with a loss of thousands of lives and hundreds of millions of dollars. In addition to the loss in timber, the fires often burn out the organic matter in the soil (the " duff ") forming the forest floor, thus preventing the growth of new forests for many years to come.

The United States Forest Service and the state forestry departments are constantly on guard against forest fires. Fire lookouts are established at places most favorable for observation of large areas. When a fire starts, notice is sent at once to the forest rangers in that locality so that the fire may be put out before it spreads. State and Federal governments alike do their best to protect our forests. We must do our share in this work by 


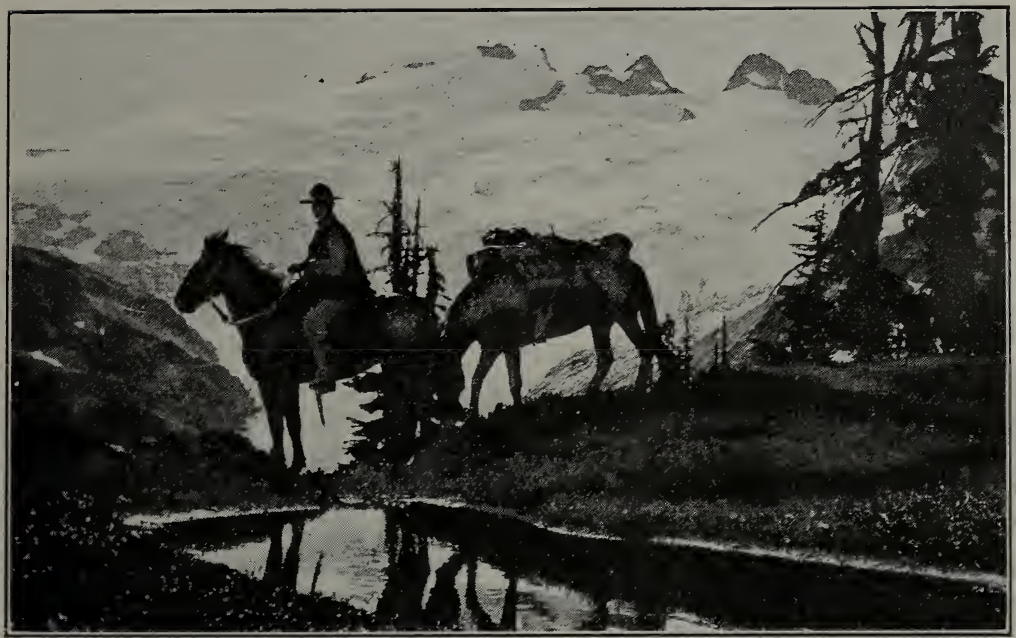

Photo by C. H. Park-U. S. Forest Service

The travels of the forest ranger often carry him through rough and dangerous country and over mountain ranges ten to fourteen thousand feet in altitude.

extinguishing camp fires or bonfires which we may start in the woods.

Other enemies of the forest are numerous fungus plants, insect parasites which bore into the wood or destroy the leaves, and grazing animals. The chestnut blight has killed most of the chestnut trees in the eastern states and has gone as far south as the Carolinas. Our only hope for the chestnut appears to be in finding some trees that are immune to the disease. The Englemann spruce beetle has destroyed millions of feet of lumber in the Rocky Mountains, and the Black Hills beetle has done great damage in South Dakota. Hundreds of other insects, such as the gypsy and browntail moths, are doing very great damage to the trees, especially in the eastern states. Live stock, especially sheep, may do much harm in a forest by eating young shoots and trampling on young trees. Storm, wind, and lightning do damage also, as uprooted trees soon die and make excellent places for fire to start.

Practical Exercise 2. What are the enemies of trees in your community? Can you name them?

How are forest areas protected against fire in your state? Enumerate all the methods of protection. 


\section{HOW DOES MAN CONSERVE HIS RESOURCES?}

Methods of forest conservation. Back of all life on the earth are the food supplies made by the green plants. Back of our water supplies and our rich soil lie our forests. Our forest areas are lessening each year. We already lack hardwoods for trim and furniture and our pulp-wood reserves are dwindling rapidly.

It is evident that we must replant our forests as they are used, plant new areas, make use of waste products from the forests, or we must obtain substitutes for some of the forest products. Formerly, lumber companies burned the sawdust and other waste from the mills; now fuel alcohol and other valuable products are obtained from them. It is estimated that more than 300,000 ,000 gallons of fuel alcohol could be made annually from the wood thus wasted. It is estimated that 20 per cent of the timber now wasted might be used in building. Railroads use 15 per cent of our timber for ties; treatment of these ties with creosote or other chemicals resulted in the annual saving of 1,500,000,000 board feet. Substitutes are being found for wooden boxes, which take a very large amount of cut lumber. And since it is estimated that 25 per cent of a tree in the forest is lost in the cutting and 40 per cent is wasted in the mill, it is evident that less wasteful methods will conserve a large amount of the lumber now lost.

Better management is needed in our forests, especially those under private control. Forests should be kept thinned. Too many trees are almost as bad as too few. They struggle with one another for foothold and light, which only a few can obtain. The cutting of a forest should be considered as a harvest. The oldest trees are the "ripe grain," and the younger trees are to be left to grow to maturity. Several methods of renewing the forest are in use in this country. (1) Trees may be cut down and young ones allowed to sprout from cut stumps. Beech, chestnut, and the redwood of California are among the trees that grow in this way. This is called coppice growth. (2) Areas or strips may be cut out so that seeds from neighboring trees are carried there by the wind to start new growth. (3) Forests may be artificially planted. Two seedlings planted for every tree cut is a rule followed in Europe. (4) The most economical method is to thin a large area 
by cutting the largest trees so as to make room for the younger ones to grow up.

In 1925 it was estimated that we were using up our forest about four times as fast as it was growing, so that we need much more planting if we are to keep our forests at approximately their present area. State forestry stations and the national government are now reforesting cut areas, and many lumber companies have begun to follow their example. Railroads annually are planting thousands of young trees. Farmers have begun to realize that the

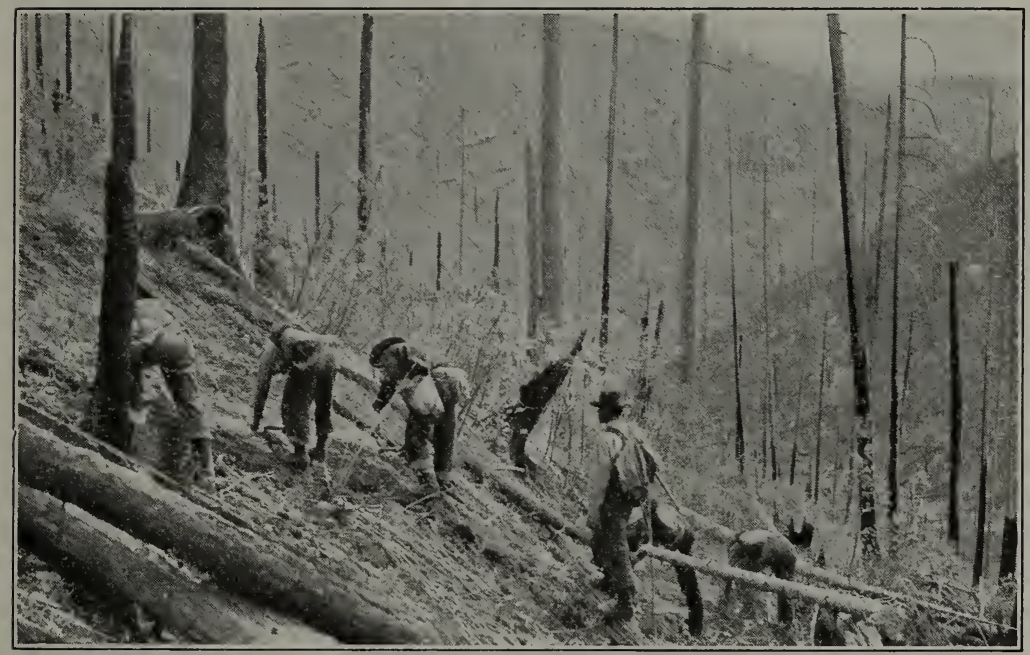

U. S. Forest Service

A planting crew setting out seedlings in burned over forest land.

high price of lumber makes a wood lot often more productive than other areas of similar size on the farm. Forestry is becoming more and more a practical business; hundreds of young men are going out from schools of forestry each year, prepared to help in this work.

Practical Exercise 3. What methods of eliminating waste are found in a modern sawmill? (Look up in Readers' Guide to Periodical Literature.)

Are there any individual examples of the conservation of forest or forest supplies in your community? Be specific.

Project. To make a tree survey. Select a convenient area of your community and map it to scale. Houses, stores, churches, 


\section{HOW DOES MAN CONSERVE HIS RESOURCES?}

schools, and other buildings should be shown. Conventional signs for different kinds of trees may be used and a key attached to the map. Where the tree is not recognized, a reference book should be taken into the field and the tree identified. The list of reference books at the end of the unit will give you some of the best books likely to be found in a school or public library. It would be well to prepare with your report specimens of leaves, buds, twigs, fruits, and flowers, if obtainable. If the survey is made in winter, then winter twigs might be shown.

Practical Exercise 4. Write a paragraph for your workbook on the best methods of reforestation in your locality. If you live in the city, discuss tree protection in streets and parks.

Practical Exercise 5. Get information from any sources you can on the extent and location of national forest preserves within the boundaries of your state. Also the state parks or forest preserves. Make a map of the state and locate all the above. If you have been to a national park or forest preserve. tell about the work of the forest rangers there.

A city's need of trees. The city of Paris, well known as one of the most beautiful of European capitals, spends over $\$ 100,000$ annually in caring for and replacing some of its 90,000 trees. All over the United States municipal governments are beginning to realize what European cities have long known, that trees are of great value to a city. For, besides being beautiful, trees protect the streets and buildings from the direct rays of the sun. The growth of trees along the street and in front of houses increases the value of the property. For these reasons, cities are planting trees and protecting them. Many cities have appointed city foresters who care for the trees in the parks and along the streets. Many municipalities plant trees and tax the property owners who receive benefit thereby, for trees and shrubs have an ornamental value that can be expressed in dollars and cents. Perhaps the most hopeful sign is that people everywhere are beginning to realize the value of our trees and the need for their protection and conservation.

Tree surgery. Another sign of the appreciation of our trees, especially in cities, is found in the work of the tree surgeon. Just as a dentist takes out decayed material from a tooth and protects the tooth by placing within it an antiseptic filling, so tree surgeons take out rotted parts of a living tree, clean it with antiseptic solutions, and fill the cavity with cement or other durable substances. When a large limb is cut off, the cut portion is treated with an 
antiseptic and coated with a waterproof covering. Not infrequently large limbs are wired or in other ways supported so as to relieve stress during storms. Such care often lengthens the life of a tree many years.

Practical Exercise 6. In what southern states are there coniferous forests? In what northern states are such forests found? The supply of hardwoods comes from the deciduous and mixed forests. Where are most of our deciduous forests?
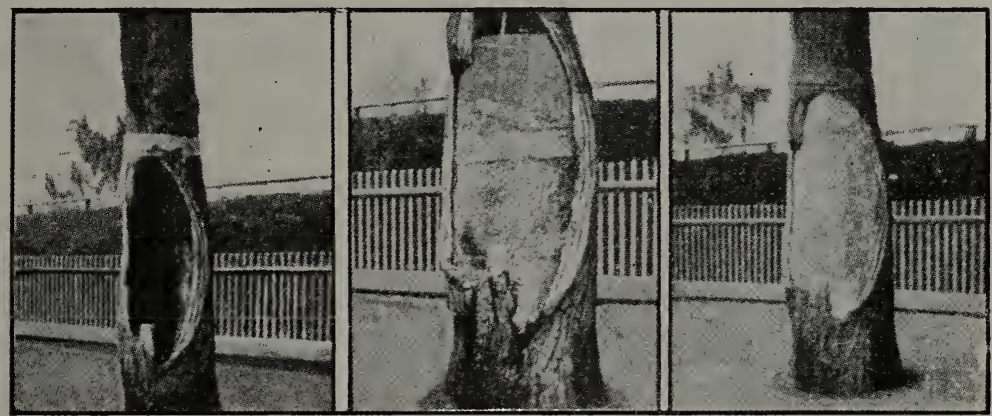

In repairing a tree which is decayed, the affected portions are first cut out. Then the carity is treated with an antiseptic to prevent any further decay, and is filled with cement.

\section{Self-Testing Exercise}

Man is responsible for a .......(1) per cent of the forest fires each year. The chestnut ....... (2) has killed most of the chestnut trees in the ........ (3). We .......(4) trees four times as fast as we .......(5) them. Trees in a city have an ......(6) value. (7) ....... (8) is used to protect trees. Our forests are conserved by .......(9) old areas, .......(10) new areas, ....... (11) unnecessary wastes. .......(12) of cut areas is under the supervision of $\ldots \ldots \ldots(13)$ and $\ldots \ldots$ (14) forestry stations.

\section{PROBLEM III. WHAT IS BEING DONE FOR THE CONSERVA- TION OF FISH AND OTHER AQUATIC ANIMALS?}

The conservation of fresh-water fishes. We have learned that the food supply of many of our fishes depends upon plankton, tiny plants and animals living in the water. In many parts of the United States these little organisms have been exterminated, and the food fish with them, by the pollution of our streams and lakes. 
If crude sewage is discharged into a river untreated, the organic matter absorbs much or all of the dissolved oxygen in the water, which is absolutely essential for plant and animal life. Oil wastes poured out by oil-burning steamers are becoming a nuisance along our shores and are responsible for the death of many food fish. If our fish and other water animals are to be preserved, we must stop the pollution of our national waterways. Dr. Henry B. Ward is authority for the estimate that if rivers now polluted with sewage and factory wastes were clean, they would put $\$ 100,000,000$ a year into the pockets of taxpayers from the sale of marketable fish. In addition to this thousands of persons could enjoy rivers for fishing, boating, and bathing.

Conservation of ocean fishes. We have learned that the relation of fish life to their natural food is an important factor in preserving our supply of fish, especially in inland waters. The balance of life is equally important for fish in the ocean. It is one of the greatest problems of our Bureau of Fisheries to discover the relation of various fishes to their food supplies so as to aid in the conservation of life in our lakes, rivers, and seas.

Migration of fishes. Some fishes change their habitat at different times during the year, moving in vast schools northward in the summer and southward in the winter. In a general way such migrations follow the coast lines. Examples of such migratory fish are the cod, menhaden, herring, and bluefish. The migrations are due to temperature changes, to the quest of food, and to the spawning instinct. Salmon and some other fish pass up rivers to spawn; the eel, on the contrary, leaves the rivers and spawns in the ocean. Some fish migrate to more shallow water in the summer, and to deeper water in the winter; here the reason for the migration is doubtless the change in temperature. All of these habits are studied by the fishermen, who are thus able to catch fish where and when they are most plentiful. The cod and herring fisheries are notable examples.

The spawning habits of fish. The spawning habits of fish are of great importance to us because the fish are caught in vast numbers at the time of migration. Many of our most desirable food fishes, notably the salmon, shad, sturgeon, and smelt, pass up rivers from 
the ocean to deposit their eggs, swimming against strong currents much of the way, some species leaping rapids and falls, in order to deposit their eggs in localities where the conditions of water and food are suitable and the water is shallow enough to allow the sun's rays to warm it sufficiently to cause the eggs to develop. The Chinook salmon of the Pacific Coast, which is used in the western canning industry, travels over a thousand miles up the Columbia and other rivers, to the headwaters where it spawns. The salmon begin to pass up the rivers in early spring, and reach the spawning beds, shallow deposits of gravel in cool mountain streams, before late summer. Here the fish, both males and females, remain until the temperature of the water falls to about $54^{\circ}$ Fahrenheit. The eggs and milt are then deposited, and

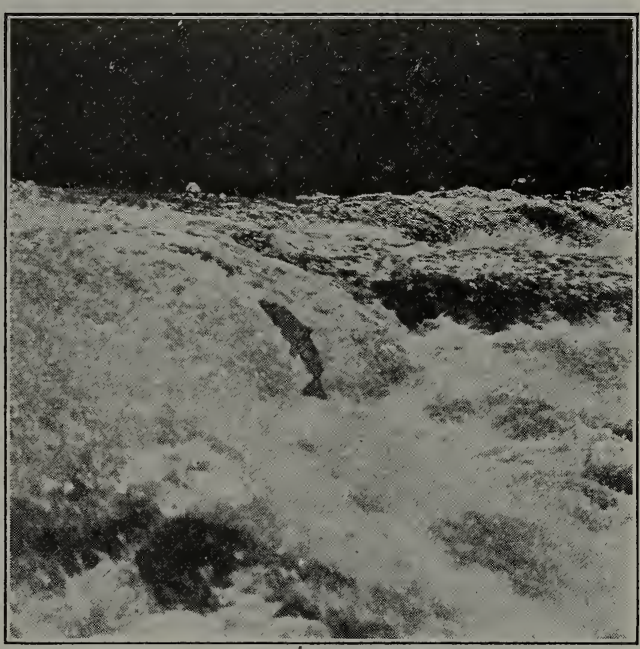

Couirtesy of Field and Stream Magazine A salmon jumping a fall on its way upstream to spawn. the old fish die, leaving the eggs to be hatched out the following spring in the water warmed by the sun.

Need of conservation during spawning season. The shad within recent times have abandoned their breeding places in the Connecticut River and have almost disappeared from other rivers where they breed, partly because they are caught at the breeding season and partly because of the pollution of the rivers in which they breed. The salmon have been exterminated along our eastern coast within the past few decades. Only a few years hence, our western salmon will be extinct if fishing is continued at the present rate. More fish must be allowed to reach their breeding places. 


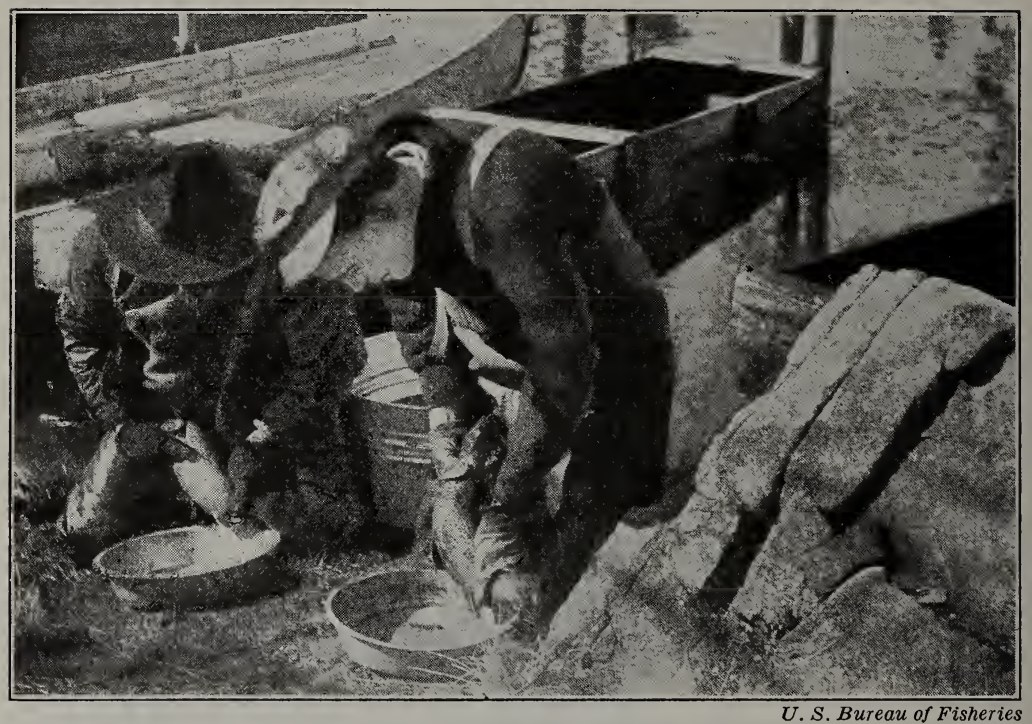

Taking spawn from fish. The fertilized eggs are placed in tanks supplied with running water.

The sturgeon, the eggs of which are used in the manufacture of the delicacy known as caviar, is an example of a fish that is almost extinct in most parts of the world because it was taken at the breeding season. Other food fish taken at such a time are also in danger. Fortunately, the government, through the Bureau of Fisheries, and various states, by wise protective laws and by artificial propagation of fishes, are beginning to turn the tide. Certain days of the week the salmon are allowed to pass up the Columbia River unmolested. Obstructions must be removed which might prevent fish from passing up or down rivers. Closed breeding seasons protect our trout, bass, and other game fish; also the catching of fish under a certain size is prohibited.

Each fisherman should pledge himself, first, to fight against the pollution of streams with factory wastes and sewage; second, to be a real sportsman and obey all laws with reference to limit and size of the catch ; third, never catch fish during their breeding season; and fourth, to moisten the hands before handling undersized fish 


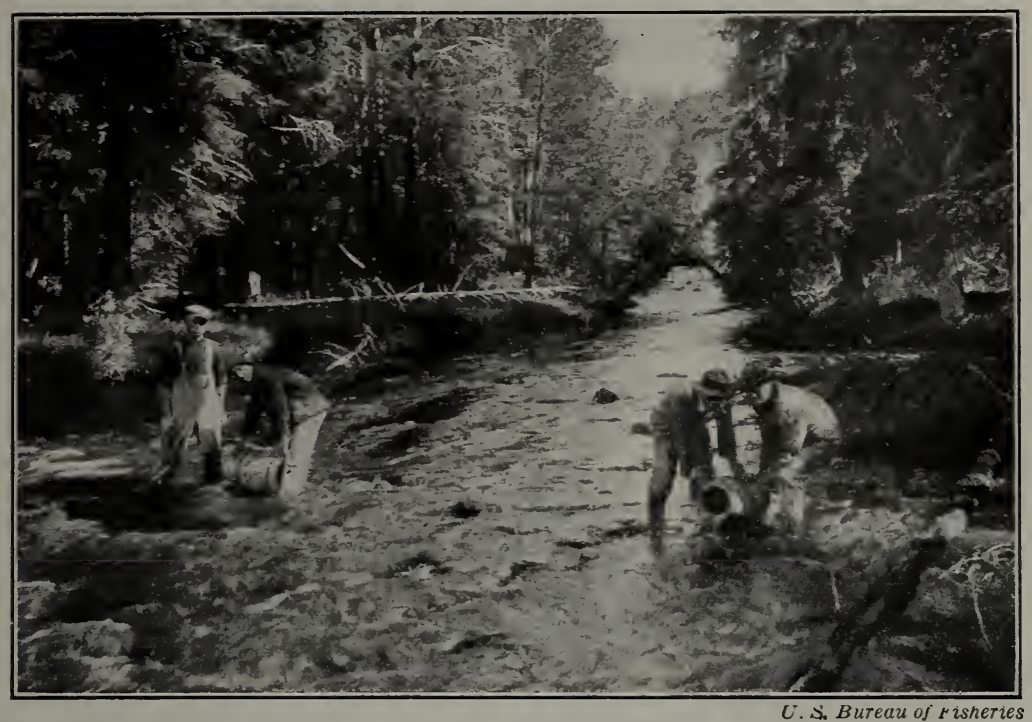

Stocking a stream with young fish which have been grown in a hatchery.

that are to be returned to the water. The use of barbless hooks in fishing in streams containing undersized fish is a sportsmanlike way of allowing the small ones to get off unharmed.

Artificial propagation of fishes. Many fish hatcheries, both government and state, are engaged in artificially fertilizing millions of fish eggs of various species, and protecting the young fry until they are of such size that they can take care of themselves, when they are placed in ponds or streams. For artificial fertilization the ripe eggs from a female are first squeezed out into a pan of water; in a similar manner the milt or sperm cells are obtained, and poured over the eggs. After the eggs are thus fertilized, they are placed in receptacles supplied with running water and left to develop under favorable conditions. Shortly after the egg has segmented (divided into many cells) the embryo may be seen developing on one side of the egg. The rest of the egg is made up of food or yolk, and when the baby fish hatches it has the yolk attached to its ventral surface for some time. Eventually the food is absorbed into the body of the fish. The young fry are kept under 
ideal conditions until they are shipped, sometimes thousands of miles, to their new homes.

It has been found that if trout are kept in breeding ponds until they are 3 or 4 inches long that their chance of survival is very much better than if very young fish are planted.

Practical Exercise 7. What laws does your state have for the protection of fish? Is there a chapter of the Isaak Walton League in your community? If so, what is this organization doing for the conservation of wild life? Is there any work in conservation being done by other organizations?

Practical Exercise 8. Why is stream pollution an important factor in conservation? Why do fish migrations play an important part in their conservation or destruction?

The conservation of shellfish. The problem of conserving shellfish is concerned in part with the extermination of their natural enemies. If we could kill off all starfish and boring mollusks, the oysters and clams would be much more plentiful. But over-fishing is the most important danger. The oysters of Chesapeake Bay were thought inexhaustible until they were almost fished out. Then the state of Maryland discovered that oyster culture was necessary if this great asset was to be preserved.

Oysters pass the first few days of their existence as free-swimming larvae. Then they settle on the bottom, and if they do not find some solid object which raises them above the mud of the bottom, they will die. Oysters are now protected by cultivation. On the bottom, in certain areas of water, are placed bunches of twigs, broken rocks, or old oyster shells to which the young oysters attach themselves. The depth of the water in which oysters grow varies. It may be ten feet or it may be as much as eighty feet. After they have grown to approximately the size of a quarter or half dollar these "seed" oysters are spread over the bottom of the oyster beds. They are usually ready for the market in three or four years.

Clams and scallops have been nearly depleted in some areas, and it has become necessary to conserve the supply by having closed seasons and by transplanting the "soft clam" of the east to the Pacific Coast, where it thrives.

About 1894 it was discovered that the shell of the fresh-water 
" clam" or mussel was valuable in making pearl buttons. The industry became so important that the number of adult clams was rapidly depleted. Today, were it not for the work of Professor Lefevre, Curtis, and others, the freshwater mussel would be practically exterminated. But in studying the life history of the mussel it was found that one stage is passed attached to the gills of certain fish. Now the United States Government raises young mussels to the free-swimming stage, allows the larvae to attach themselves to

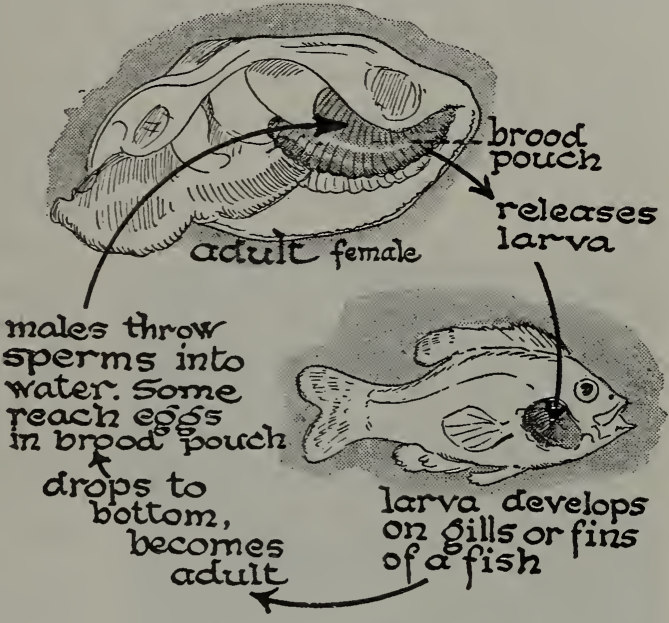

Life history of a fresh-water mussel. the gills of the fish, and then releases the fish which later will deposit the young mussels in localities favorable for their development.

Lobsters are being conserved by taking the fertilized eggs and raising the young in hatcheries until they are large enough to care for themselves.

Practical Exercise 9. What methods are used to conserve shellish in your locality?

\section{Self-Testing Exercise}

Fish should not be caught during the ....... (1) season. Shellfish are killed by .......(2). The freshwater mussel passes its larvae stage attached to the .......(3) of a ......(4). Many fishes spawn in .......(5) ...... (6). ......(7) of our streams costs us millions of dollars a year in marketable fish. The supply of fish would soon be exhausted were it not for ....... (8) ....... (9). Caviar is prepared from the eggs of the ........ (10). 


\section{PROBLEM IV. WHAT IS BEING DONE FOR THE CONSERVATION OF BIRDS?}

We have already learned that birds, with few exceptions, are of very great value to man, through their destruction of weed seeds and of insects harmful to crops. But in spite of this fact, many species of birds have been almost exterminated in this and other countries, and the total number of birds has decreased to an alarming extent. This has been due largely to killing for food and

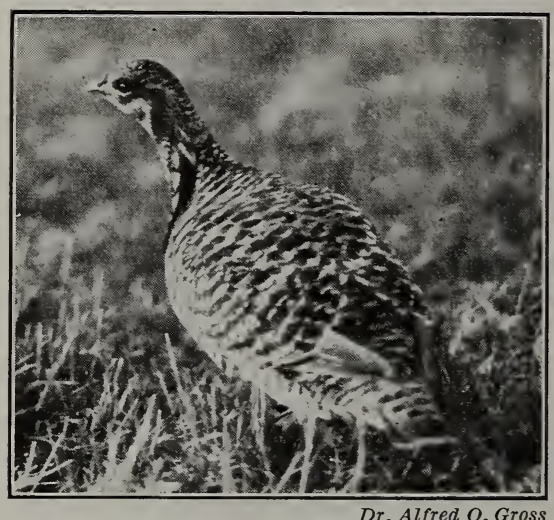

Dr. Alfred O. Gross

In early colonial times the heath hen was very abundant from Maine to the Carolinas. But hunters, disease, and fire have exterminated the entire race except one. This lone survivor is found on Martha's Vineyard Island across the sound from the Marine Biological Laboratory in Massachusetts, and is under the protection of conservation organizations of the state of Massachusetts. "sport," and for plumage. A few decades ago the spraying of trees was unknown; today $\$ 10,000,000$ or more a year is spent for labor and sprays. It is estimated by Dr. Hornaday, of the New York Zoölogical Park, that a yearly toll of $\$ 520$,000,000 now collected by insects might be saved if we had as many birds as formerly.

The American passenger pigeon, once very abundant in the Middle West, is now extinct. Audubon, the greatest of all American bird lovers, gave a graphic account of the migration of a flock of these birds. So numerous were they that when the flock rose in the air, the sun was darkened, and at night the weight of the roosting birds broke down large branches of the trees in which they rested. Today not a single specimen of this pigeon can be found, because they were slaughtered by the hundreds of thousands during the breeding season. As late as 1869 one Michigan town marketed $11,888,000$ pigeons in forty days. The wholesale killing of the snowy egret to furnish ornaments for ladies' headwear is another 
example of the improvidence of our fellow-countrymen. It was killed during its breeding season; and for every egret killed, an entire bird family was blotted out of existence. Prairie chickens are now unknown in many states where they were abundant before 1900 . The same thing will happen to the quail where it is unprotected.

Hawks, owls, shrikes, crows, and jays all play a small part in the destruction of our native birds. The English sparrow has done great harm in driving away useful birds. Squirrels and particularly rats are very destructive of eggs and young birds. Small boys with air guns, and persons who kill for food, are responsible for the death of many birds. But according to Forbush, the house cat is the worst enemy of our feathered friends. He estimated from many observations that the average pet cat kills at least 50 birds a year.

Home conservation methods. Nesting boxes can be easily made and are a great asset for a home. Birds are cheerful and colorful as well as useful neighbors. Wrens are often attracted to boxes having small holes not larger than one and one eighth inches in diameter. The boxes should be placed so that cats cannot get access to them. During the winter birds may be kept around the home by feeding. Suet baskets and nuts put on shelves in trees and inaccessible to cats are the best means of providing food. Bird baths also are means of attracting birds.

Bird migrations in relation to conservation. It has long been known that certain birds breed in the far north and spend the winter in the tropics. The golden plover is a notable example, for it nests in the Arctic and winters in southern South America, making a yearly round trip of more than 16,000 miles, while the arctic tern may make a round trip of 22,000 miles in one year. Wild ducks and geese are examples of game birds that make these pilgrimages each year. The bobolink migrates from the northern part of our country to a tropical part of South America. It is largely due to this migratory instinct that many of our birds have been subject to slaughter by hunters. Many states have laws which allow the killing of small "bags" of ducks and other game birds, but do not sufficiently protect migrating birds. It has been estimated that $5,000,000$ hunters go out every season for birds or 
other animals. Thanks to the treaty of 1916 with Great Britain, more than 500 kinds of migrating birds are protected in this country and Canada from capture, killing, or sale. All over this country, owing to the work of the Audubon Society, of Dr. Hornaday, and of other leaders, we have awakened to the fact that our birds are valuable assets and we have enacted laws prohibiting the killing of game birds during the breeding season, and of most wild birds at any time.

State and government methods of protection. In 1909 the Federal Government framed a law known as the Lacey amendment,

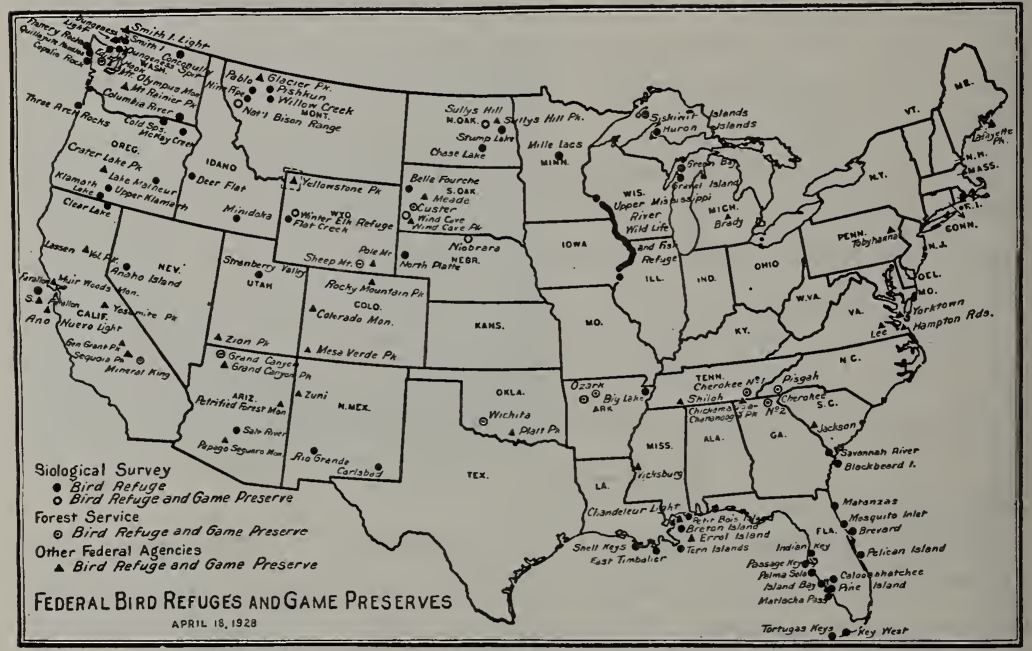

U. S. Bureau of Biol. Surte'

What is your state doing for the protection of birds?

which prohibits shipping of birds from a state where it is illegal to kill them. In the tariff act of 1913 a law went into effect, which protects migratory game birds as well as insect-eating birds, such as robins, orioles, and swallows. Later, the law was amended to forbid the importation for commercial purposes of egret plumes (taken from breeding egrets), or any wild bird skins.

Many states now have protective laws for the birds. New York State has a law which forbids the sale of all game birds, no matter where they were taken. 
Other means of conservation. Several private organizations are at work for the protection of our birds. Most prominent are the Audubon Societies of the various states, all federated under a national organization. Among other things they distribute much interesting literature which can be used in school. The Isaak Walton Leagues are particularly interested in protection of game fish and birds, and the American Ornithologists Union helps through the interest taken by many students and scientific men interested in bird life. Fortunately for the average citizen, some public-spirited people who have money are willing to spend it for the common good. Not only are there many private game preserves in various parts of the country, but also several bird sanctuaries have been established, notably Marsh Island and Avery Island, both in Louisiana. Private game and bird refuges and preserves are estimated to include nearly 800,000 acres in this country and over 150,000 acres in Canada. In addition to this, the United States Government has created a total of nearly sixty bird refuges.

Practical Exercise 10. What are some important factors in the destruction of bird life? Discuss the good and bad points in owning a cat.

Practical Exercise 11. How may we attract birds about our homes?

Practical Exercise 12. What laws in your state protect birds? What societies have organizations in your community for the protection of birds?

Practical Exercise 13. Why are bird migrations important from the standpoint of conservation? Using outside sources, work out the migration routes of at least 5 birds. (Read Wetmore, Migrations of Birds, Harvard University Press.)

\section{Self-Testing Exercise}

Check the correct statements for your workbook:

T. F. 1. Every cat kills, on an average, over 50 birds in a year.

T. F. 2. Passenger pigeons, once very abundant, were shot in such numbers that they have been completely exterminated.

T. F. 3. Some migratory birds make a round trip of over 22,000 miles each year.

T. F. 4. The Federal government has no laws protecting migratory birds.

T. F. 5. Individuals cannot do anything to save bird life.

T. F. 6. The egret is still being killed for its feathers.

T. F. 7. The quail has been exterminated by hunters.

н. ВIо -39 


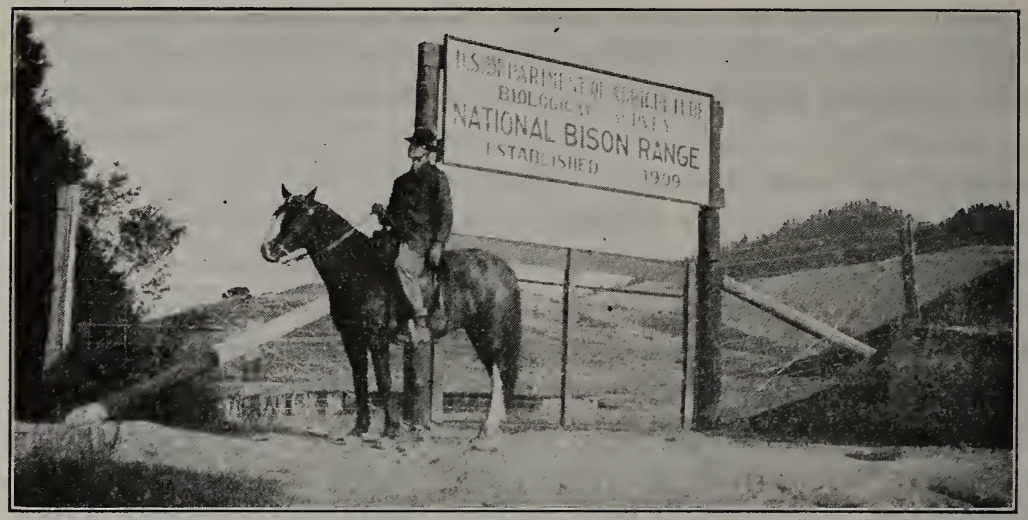

National bison range in Montana.

Bureau of Biol. Survey

\section{PROBLEM V. WHAT IS BEING DONE FOR THE CONSERVATION OF MAMMALS?}

Conservation of mammals. It was not so many years ago that the people of this country thought the vast herds of buffalo that covered the western plains were inexhaustible; but ten years of extensive killing nearly exterminated them. Today a few thousand exist, protected by law. Without doubt, the species would have died out had it not been for the fact that they breed in captivity. The same story may be told of the Alaskan fur seal, almost exterminated a few years ago by overhunting, but now protected by law. One of the two great herds of Alaskan seals, the Pribilof (so called because they went to the Pribilof Islands to breed), was reduced from several million to less than 215,000 animals in 1910 by overhunting. Today, through governmental control of fishing and protection during the breeding season, the herd consists of nearly 600,000 seals. As time goes on and the furs of wild animals become scarcer through overkilling, we find more imperative the need for protection and conservation of many of these wild forms.

Already, breeding of some fur-bearing animals in captivity has been tried with success, and substitutes for wild animal skins are coming more and more into the markets. Black- and silver-fox raising has been tried successfully in many parts of this country 


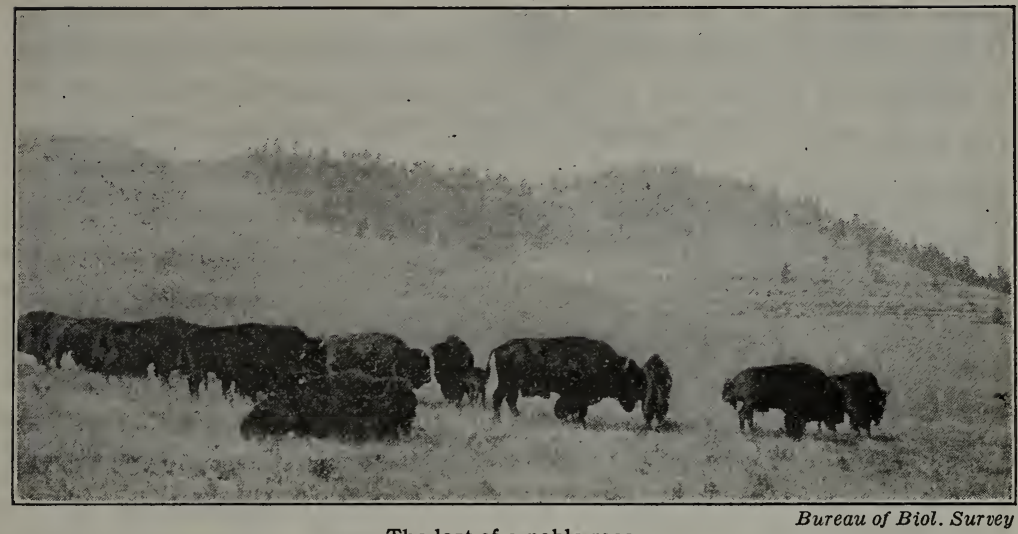

The last of a noble race.

and Canada. Sometimes $\$ 2500$ to $\$ 3000$ is given for a single animal and $\$ 25,000$ has been reported to have been paid for a pair of breeding foxes. Skunks, martens, minks, and other animals are also being bred for the market. At last, partly awake to our duty toward the wild animals of this country, the government has made some wise laws and established a few reservations in our National Parks, so that the future for wild life in this country is safer.

\section{Self-Testing Exercise}

Check the correct statements for your workbook:

T. F. 1. Overhunting has exterminated the buffalo.

T. F. 2. The fur seals are now increasing in numbers because they are protected during the breeding season.

T. F. 3. Raising of fur-bearing animals is a profitable business.

T. F. 4. The need for protecting the seal is becoming more imperative each year.

\section{PROBLEM VI. HOW IS CONSERVATION APPLIED TO MAN?}

We have mentioned in several of the preceding units examples of conservation as applied to human life. The work of communities in giving their inhabitants pure water and milk supplies has resulted 
in the lowering of the death rate in those places; the discoveries of men of science have been applied toward the cure and prevention of disease, as we can see in the reduction of malaria, yellow fever, and hookworm. The splendid work of Dr. Banting of Toronto in

\begin{tabular}{|c|c|}
\hline time & average span of life \\
\hline under-Caesars & 18 years \\
\hline France before 1800 & $28-29$ years \\
\hline 1800 & 32 years \\
\hline 1850 & 37 years \\
\hline 1880 & 40 years \\
\hline 1914 & 46 years \\
\hline 1929 & 57 years \\
\hline 1931 & 58 years \\
\hline 1950 & ? years \\
\hline
\end{tabular}

Can you give several reasons for the increasing average span of life as indicated in the diagram. his discovery of insulin and its application in the treatment and relief of diabetes is another example of work for the conservation of human life.

Health examinations, both individual and those

given in schools and colleges, should aid individuals in keeping in good physical condition. There are a number of agencies which work directly for health conservation.

The health work of the National Government. The United States Public Health Service covers practically all phases of the nation's health. It establishes quarantines against diseases coming from other countries; it assists local communities in maintaining fights against epidemics ; it has established sanitariums and hospitals for care of government employees, soldiers, and sailors. It maintains laboratories for investigation, research, and statistics concerning diseases. It has a department of industrial hygiene which looks after the health of those in the various industries, and in many other ways has general supervision of the nation's health.

State and city supervision of health. Most states now have well-established departments of health which do in general the same work as the United States Public Health Service. For example, New York State, which has an unusually efficient organization, has the following divisions : Child Hygiene, Public Health Education, Tuberculosis and Communicable Diseases, Vital Statistics, Sanitation, Laboratories and Research, Public Health 
Nursing, and Venereal Diseases. It also publishes a weekly bulletin called Health News. Large cities, such as New York, Chicago, and Los Angeles, have health departments organized along the same general lines, for health conservation.

Special health agencies. One of the most important private agencies for health conservation is the Rockefeller Foundation, chartered in 1913 to promote the well-being of mankind throughout the world. It has done notable work since its foundation in eradicating hookworm, yellow fever, and malaria in different parts of the world. It coöperates with other agencies, such as hospitals, schools of hygiene, and universities, and has devoted millions of dollars and, what is far more, the minds and lives of its scientists to the end that the span of human life could be lengthened and man's life on the earth be made safer. It is coöperating with the Health Section of the League of Nations, and in this way is aiding in the eradication of diseases in all countries. It, together with such agencies as the Millbank Memorial Foundation, the National and State Tuberculosis Associations, the National Cardiac Association, the American Society for the Prevention of Cancer, the Eye-Sight Conservation Council, the Nutritional Laboratory of the Carnegie Institute at Boston, the National Health Council, American Red Cross, and the McCormick Institute for Infectious Diseases in Chicago are supported by private or public philanthropy, and are doing much to aid in the splendid work of health conservation.

\section{Self-Testing Exercise}

Check the correct statements for your workbook:

T. F. 1. The periodic health examination is one of the best means of keeping well.

T. F. 2. Every state maintains a health department.

T. F. 3. The law requires every person to have a health examination every year.

T. F. 4. The Rockefeller Institute is interested only in finding the causes of diseases in all parts of the world.

T. F. 5. Sanitation is a form of conservation. 


\section{Review SUMmary}

Test your knowledge of the unit by: (1) rechecking on the survey questions; (2) performing all the assigned exercises; (3) checking with the teacher your answers on the tests and trying again the parts you missed; (4) making an outline of the unit for your workbook.

\section{Test on Fundamental Concepts}

In a vertical column under the heading CORRECT. write numbers of all statements you believe are true. In another column under INCORRECT write numbers of untrue statements. Your score equals right answers $\times 3 \frac{1}{8}$.

I. Trees protect the soil (1) by having a mat of roots which holds water; (2) by shedding leaves which form humus: (3) by shading the ground, thus preventing evaporation of water; (4) by preventing erosion.

II. Wood is used (5) for making this book; (6) for fuel; (7) for making rayon; (8) for making silk.

III. Some of the enemies of the forest are (9) man; (10) fire; (11) weeds; (12) insects.

IV. Some methods of conservation of forests are: (13) thinning the present forest area ; (14) replanting depleted area ; (15) building of National Parks; (16) use of tree surgery.

V. Conservation of animals which form part of our food is seen (17) in the artificial propagation of the fresh-mater mussel; (18) in transplanting clams and oysters from the eastern to the restern coast; (19) in the artificial propagation of salmon; (20) in removing restrictions against catching fishes during their breeding season.

VI. Conservation of birds is seen (21) in the extermination of the passenger pigeon; (22) in keeping of cats; (23) in the establishment of bird sanctuaries; (24) in the passing of laws to protect migratory birds.

VII. Wild mammals are being conserved : (25) by the establishment of national parks and game preserves; (26) by the establishment of breeding farms; (27) by game laws which limit shooting of many animals to certain seasons of the year; (28) by hunting of mountain lions and other predatory animals.

VIII. Conservation is being applied to man (29) through health examinations and follow-up work; (30) partly by means of the U. S. Public Health Service and its supervision; (31) in the reduction of hours of labor with more time for play; (32) through the establish- 
ment of health agencies such as the Rockefeller Foundation, the National Tuberculosis Association, and the National Cardiac Association.

\section{Achievement Test}

1. What are the chief methods of forest protection in your locality?

2. What agencies are at work in your state:

(a) for the conservation of trees?

(b) for the conservation of shellfish and crustaceans?

(c) for the conservation of fish?

(d) for the conservation of bird life?

(e) for the conservation of mammals?

(f) for the conservation of human beings?

3. What is each agency doing in your community?

\section{Practical Problems}

1. Make a table in which you note all the agencies at work to conserve health in your locality and show (1) what each aims to do; (2) the machinery used to accomplish this aim; and (3) the results accomplished.

2. Make a similar table for wealth.

\section{Useful REFERENCES}

Articles in Outdoor America. National Association of Audubon Society publications and Yearbooks of the United States Department of Agriculture.

Farmers' Bulletins: 265, 493, 513, 609, 621, 630, 963, 1208, 1209, 1239, 1241, 1417.

Hornaday, Wild Life Conservation in Theory and Practice. (Yale University Press. 1914.)

Hunter, Laboratory Problems in Civic Biology. Pp. 265-268. (American Book Company.)

Keeler, Our Native Trees. (Charles Scribner's Sons. 1900.)

Mathews, Familiar Trees and Their Leaves. (D. Appleton \& Co.)

Pack, The School Book of Forestry. (The American Tree Association. 1922.)

Pack, Trees as Good Citizens. (American Tree Association. 1922.)

Pinchot, The Training of a Forester. (J. B. Lippincott \& Co. 1917.) Trafton, Bird Friends. (Houghton Mifflin Co. 1916.)

Weed and Dearborn, Birds in Their Relations to Man. (J. B. Lippincott Co. 1924.)

Wetmore, Migrations of Birds. (Harvard University Press. 1926.) 


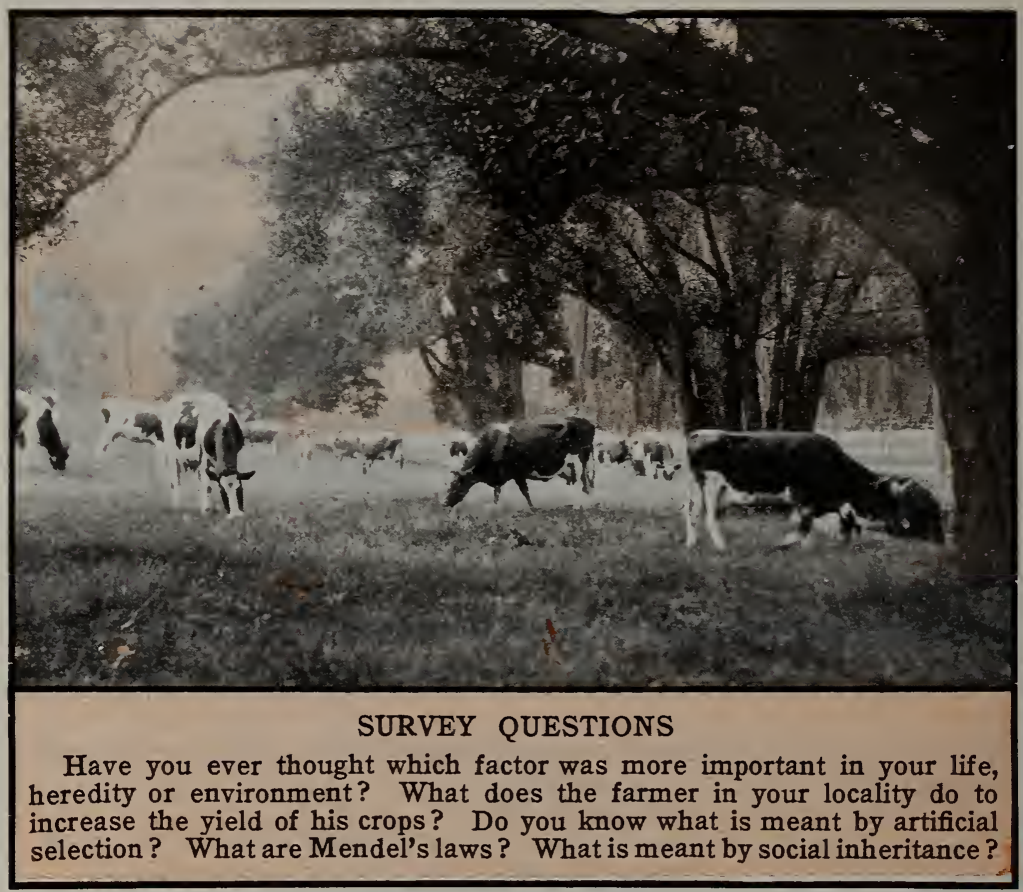

Photo by Eving Galloway

\section{UNIT XVIII}

\section{THE IMPROVEMENT OF LIVING THINGS BY MAN}

Preview. As you look at the boys in your class, you notice that each boy seems to be more or less like every other boy; he has a head, body, arms, and legs, and even in minor ways he resembles each of the other boys in the room. Moreover, if you should ask any particular boy, no doubt he would tell you that he resembled in certain respects his mother or his father. If you should ask his parents whom he resembled, they would say, "We can see traits of his grandfather (or his grandmother) in him."

The law of nature which causes a child to possess characters like either or both of his parents, and like their parents as well, 
is called heredity. If we consider our own individual cases, we shall probably find that we resemble our ancestors not only in physical characters but also in mental qualities. The ability to play the piano well or to paint well may be as much a case of inheritance as the color of one's eyes or the shape of one's nose. We are a complex of physical and mental characters, received from all our ancestors.

But no boy in the class is exactly like any other boy; even brothers are different in appearance and in action. Each one of us tends to be slightly different from his or her parents. Each plant, each animal, varies in a small degree from its immediate ancestors, and it may vary to a great degree. This tendency among plants and animals to be different from their ancestors and from each other is called variation. Heredity and variation are the corner stones on which all the work in the improvement of plants and animals, including man himself, is built.

Charles Darwin was one of the first scientists to suggest how the laws of heredity apply to the development of plants and animals. He knew that although animals and plants are like their ancestors, they also tend to vary. In nature, he believed, the variations which best fit a plant or animal for life in its own environment are the ones which are handed down, because those individuals having variations not fitted for life in that particular environment will die. Thus, said Darwin, since favorable variations survive and reproduce, and, as the descendants of each of these individuals also tend to vary slightly, a new type of plant or animal, fitted for that special place, is gradually formed. Darwin reasoned that if favorable variants are developed in nature, then man, by selecting the variations he wanted, could form new varieties of plants and animals much more quickly than nature. When we compare the improved breeds of dogs with the original wild dog, or cultivated fruits like the apple and peach with their wild ancestors, no one can doubt that man has done much in the way of improving domesticated plants and animals.

Every farmer knows that to produce good results he must first have good seed or good stock. The plants or animals must come from sturdy parents. Then they must have favorable conditions in which to grow, or they will not produce. They must have care. 
On abandoned farms the plants soon tend to revert or go back to wild conditions. And if we are to produce better plants and animals, we must continually select the best products for breeding as well as give them the best possible environment.

Heredity is a much more complicated process than we once thought. Laws of heredity discovered by Gregor Mendel and worked out more recently by a number of scientists have shown that the breeder may be able to get much more exact results than was thought possible a few years ago.

There has been a good deal of discussion among people lately as to the comparative importance of environment and heredity

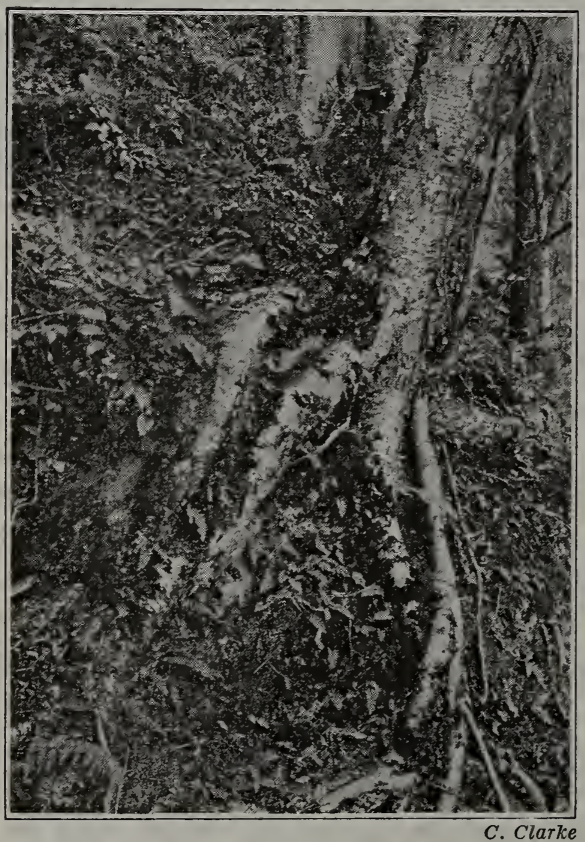

A white birch tree growing on a rock sent long roots over the sides of the rock to the soil lying beside it. How has the environment changed the tree?

and animals. Not only will a plant or animal die if it is deprived of any one environmental factor, but frequently it will be conThe philanthropist says, "Give me an opportunity to improve the conditions of the slum dwellers and I will make happy and healthy individuals out of them." And the breeder of plants or animals says, "I cannot improve my plants or animals unless I give them proper conditions of food and water and air in their surroundings. But even if I give them the best of these conditions, I cannot make a poor animal or plant of poor stock into one having good qualities."

We have learned from observation that environment does play a very big part in the lives of plants

in the lives of people. 
siderably changed or modified if a single factor is modified. Take the case of the potato plant sprouting in the cellar: it is quite a different organism from the one growing in its natural environment. Look at the differences between trees grown near the top of a mountain where they are exposed to the wind and those of the same kind growing on the protected slopes of the same mountain, or notice the differences in the trees growing on the north and on the south sides of a valley. Hundreds of examples might be given to show not only that the environment determines the kind of organisms living there, but also that the plant or animal may be considerably modified or changed through the action of the environment on it.

But it is still somewhat a discussed question as to whether the changes thus brought about will be handed down to the offspring of the plant or animal. We know that seeds from a wind-blown tree if they take root in a protected side of the mountain will grow tall and straight like the others around it. Mice whose tails had been cut off were bred for numerous generations without producing any tailless offspring. Lamarck, the French naturalist, who first noted that the influence of the use or disuse of organs on the organism is very great, followed this statement with another, that the effects of such influences were handed down by heredity to the offspring. Most modern experiments do not uphold Lamarck's views, although there are a few that are believed to show the effect of environment upon the offspring.

We have seen that instinct plays an important part in the lives of animals lower than man. A baby chick just hatched pecks at a bad-tasting caterpillar and receives a sense impression, so that after a few more mistakes of the same kind, it learns that such caterpillars are not good and must be left alone. Man not only learns to profit by experience, as does the chick, but in addition he passes on this knowledge to others. While he cannot hand on this knowledge by heredity, he can teach others, and they in turn can teach their generation. In a similar way the human race has made wonderful progress, the benefits of which we are now enjoying. This great mass of experience, which results in better health, better training, and material things as radios, automobiles, 
and airplanes, is called our social inheritance. Our lives may then be said to be influenced by three factors : training or social inheritance, environment or what we come in contact with, and heredity or what we are. It is self-evident that a handicap such as poor health or lack of education would play an important part in one's success or failure in life. Some men have become great in spite of handicaps, but it was because their heredity was such that they could not be denied success. Great men and great minds have stood out in spite of the most unfavorable environments, witness Abraham Lincoln and William Shakespeare. The list could be

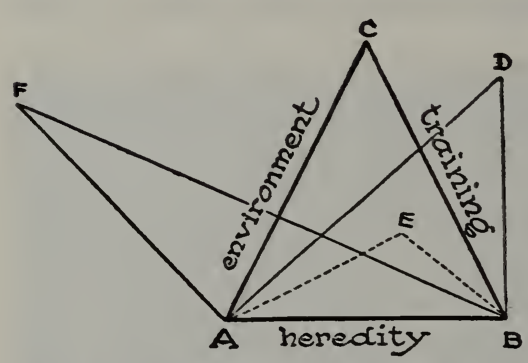

$A B C$ is a triangle representing the three factors which affect a person's life. If one's training and environment are changed and heredity remains the same, a different surface is made possible. multiplied indefinitely. There are other factors at work besides those of environment which produce great men. Sometimes the heredity of such men is easily followed, for certain distinguished families have held a place in the world for a number of generations. The reasons for the sudden emergence from obscurity to greatness, as in the case of Napoleon or Lincoln, is not so easy to understand, but we may be sure that heredity played a very large part.

People today have a chance to live longer than their ancestors because their environment is better. The sanitary conditions are much improved and disease germs are being controlled by providing the race with the best environment possible.

\section{PROBLEM I - HOW MAY ENVIRONMENT AFFECT PLANTS AND ANIMALS?}

Demonstration 1. How may gravity affect growing seedlings?

Grow radish or mustard seeds in a pocket garden placed on edge, until the roots are a half inch long; then turn it on another edge and examine again after 24 hours. Repeat after another 24 hours.

Which part of the root grows down each time the garden is turned? 
What causes roots to turn downward? Compare these plants with plants growing in soil. What other changes have taken place? Might these changes be due to changes in the environment?

Demonstration 2. What substances are necessary for plant growth?

Partly fill five jars, the first with distilled water, the second with nutrient solution ${ }^{1}$ without potassium nitrate; the third with nutrient solution without calcium phosphate; the fourth with nutrient solution without ferric chloride; and the fifth with nutrient solution. Place in the jars corn seedlings with their roots in the liquids. Keep them under observation for two or more weeks. In which jar does the most vigorous growth take place? What has soil environment to do with plants?

\section{Demonstration 3. How may different foods affect an animal?}

Feed two white rats for several weeks upon the same amounts by weight of gluten feed plus water and gluten feed plus milk.

What differences do you notice in the appearance and weight of the rats at the end of this period? Do differences in composition of foods have an effect upon rats?

Plants and their environment. Numberless examples of the effect of the environment upon plants and animals are known to all. Besides those just given, the familiar bleaching of celery or lettuce when the sun is kept from them, the changes in the size and color of plants having little or much exposure to the sun, the effect of lack of water on plants, especially in a country where irrigation is practiced, all these and more are everyday examples.

But the scientist goes even further with his experiments. Bonnier, a French botanist, divided a dandelion plant and planted part of it at a high altitude in the mountains, while the other part was planted in the valley. Two quite different plants resulted. Two lots of corn produced from seeds from the same cob, one lot planted in wide rows and the other crowded, will be astonishingly different. Under certain conditions environment seemingly

${ }^{1}$ A nutrient solution known as Sach's solution may be made as follows:

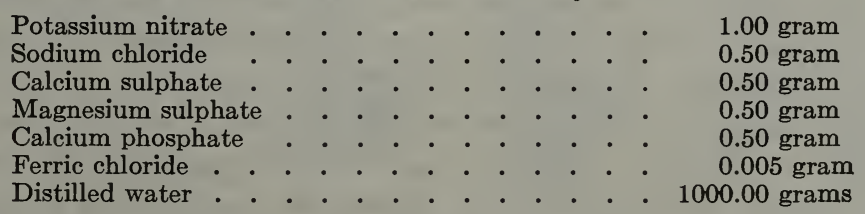

Add the ferric chloride at the time the solution is to be used, by adding a drop or so to the solution in the bottle used for the seedlings. 
affects heredity, at least for a few generations. Professor MacDougal of the Desert Laboratory of the Carnegie Institute

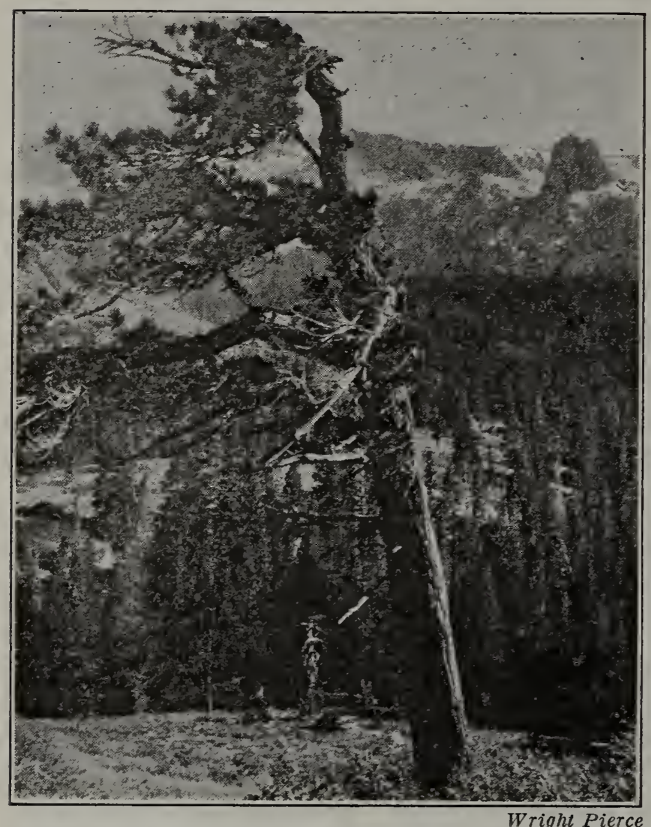

A tree beside a hillside. Notice how the sweeping winds have caused the limbs to grow to one side of the tree. has injected various solutions of salts into the ovaries of several species of plants and has found that the seeds which grew produced plants which differed in the plant leaf and body of the parent plant and these variations persisted through several generations.

Practical Exercise 1. Using one of the books of reference, make as long a list as you can of modifications in plants brought about by changes in the environment.

\section{Animals and their} environment. Professor Tower carried on a series of experiments with the potato beetle and found that in some cases color changes brought about by the beetles living in a changed environment were apparently handed down to the future generations. Dr. Guyer induced eye defects in rabbits, which were handed down to later generations of rabbits. Professor Stockard's experiments in which he subjected guinea pigs to the fumes of alcohol indicate that the young are profoundly affected, many dying, and those which survived were undersized and nervous. These effects were transmitted to the grandchildren. Dr. Hyde reports that eyeless forms of fruit flies appear if the temperature gets above a certain degree, while Dr. Morgan tells of certain. color changes in fruit flies that appear as soon as high humidity becomes a factor in the environment. The developing eggs of 
fish, placed in water containing large amounts of magnesium salts, may produce one-eyed fish. Pressure or other mechanical stimuli may cause the developing eggs of some marine animals to develop into many different sorts of abnormal forms which do not become adults. William Beebe has induced great changes in the colors of birds by keeping them in unusual conditions of humidity. However, the greatest evidence seems to support the fact that plants and animals do not in general hand down the changes brought about by the environment.

Practical Exercise 2. Can you give any examples of how environment has caused changes in animals? Do you see any relation between environment and adaptations? Explain to the class.

Practical Exercise 3. Write a 300-word paragraph on environment as a factor in molding one's life.

\section{Self-Testing Exercise}

Roots grow .......(1) because they are affected by ........ (2). The kinds and amounts of food of an animal or a plant will affect its ........ (3) and ....... (4). Two rows of corn plants from the same ear in different environments will be ....... (5). It has been shown by a few experiments that ........(6) caused by environment may sometimes be ........ (7).

\section{PROBLEM II. HOW DO LIVING THINGS REPRODUCE AND DEVELOP?}

Let us now try to discover why it is that plants and animals tend to hand down unchanged the characteristics that we think of as inheritable. The simplest one-celled plants and animals grow. But since they take in food and oxygen and give off body wastes through their cell membranes and walls, the size of the cell body is limited. This limitation is
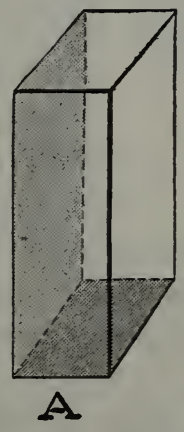

Which has the greater surface area, $A$ or $I$ and 2 ? Why do
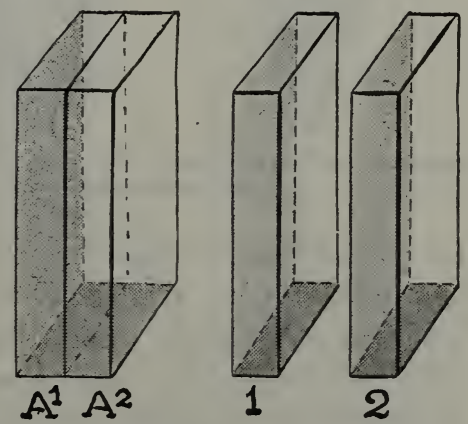
cells divide? 


\section{2}

due to the fact that though the volume grows in proportion to the cube of its diameter, the surface grows according to the square of its diameter. Two bricks cemented together have less surface than two separate bricks. Therefore in order to live, the cell must

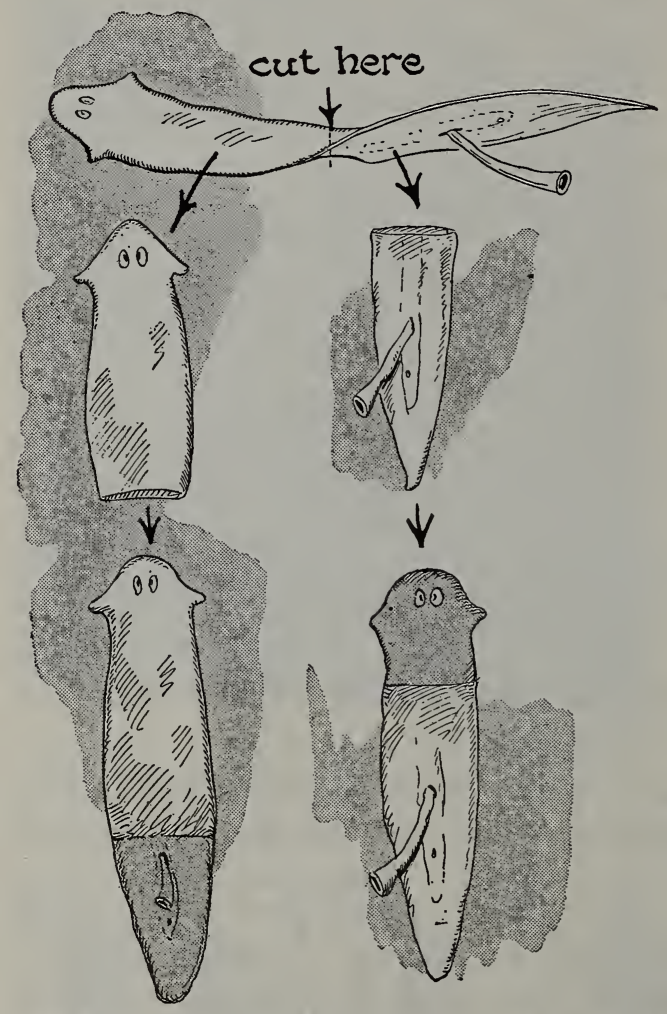

Regeneration of a flatworm. The shaded area shows the newly regenerated parts. get more surface. It does this by cell division. In our study of the amoeba, we saw that a single cell formed two cells by division.

Animals and plants grow larger by a multiplication of the cells. The growth of roots, buds, leaves, and seeds, the development of a kitten, and the shooting up of a boy or a girl at adolescence are examples of rapid cell division.

New plants may be formed by cell division. It is a matter of common knowledge that when a chestnut or a poplar tree is cut down, young shoots come up from around the cut stem. New geranium plants may be grown from "slips" or cuttings from the old plant. Sugar cane and banana plants are reproduced entirely in this way, not from seeds. Grape vines, strawberry plants, and many others take root where the stem comes in contact with the soil. Many grasses, like the couch or quick grass, become pests because they spread with such rapidity from their underground stems. Ferns 
and other plants have underground rootstocks which form new shoots that become new plants. Tubers, as the potato, and bulbs, as the onion or lily, are other examples of growth known as vegetative propagation. Such methods of growth give fixed types of plants and are much used by plant breeders to propagate certain plants which usually cannot reproduce themselves.

Regeneration. In certain animals, lost parts grow again by cell division. A flatworm may be cut into as many as twenty pieces, each one of which will grow into or regenerate a new worm. Earth-

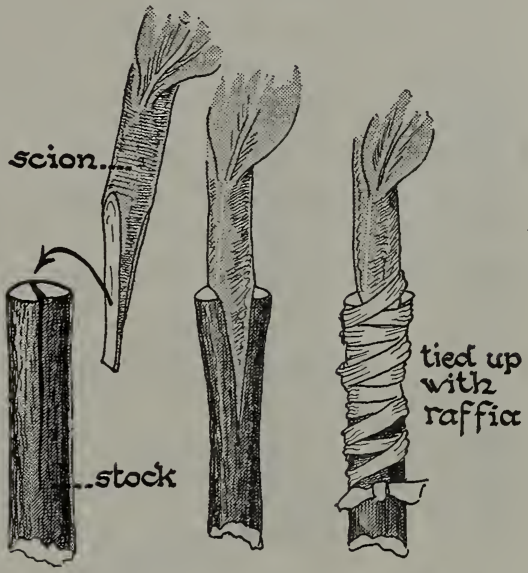

Explain how grafting of fruit tree is done. worms regenerate lost segments and starfish lost rays. Crustaceans regenerate lost antennae or other appendages; it is common for the fiddler crab, when caught by a claw, to detach the claw, in his struggle to escape from his enemies. A new claw

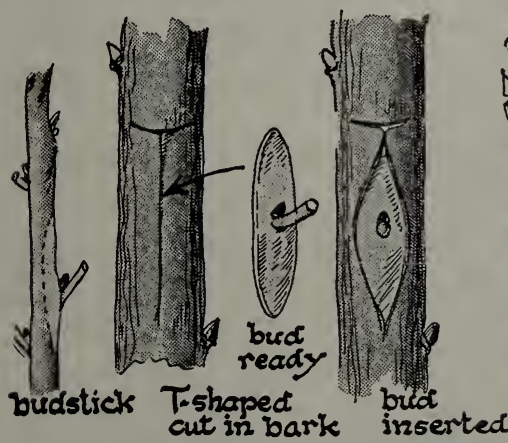

Explain how budding is accomplished.

will grow out later on the stump of the old one. The common swift, a lizard, can throw off its tail to escape being caught; a new tail may later be regenerated.

bua tied in place with raffia

Grafting. A familiar method of reproducing desirable varieties of fruit trees is by grafting. This consists in applying a portion of a tree of the desired variety (called the scion) 
to another tree of a nearly related kind (called the stock). The two parts must be so placed that the cambium surface of the scion comes in contact with the cambium of the tree to which it is applied, thus putting it in direct communication with a supply of food from the tree which is already established. Peach, apricot, apple, and pear trees are often grafted. Another similar method is called budding. A bud of the desired tree is inserted under the bark of the stock. The branches growing from the bud or scion will bear the same variety of fruit as if they had remained on the original tree. Grafting and budding are widely used by plant

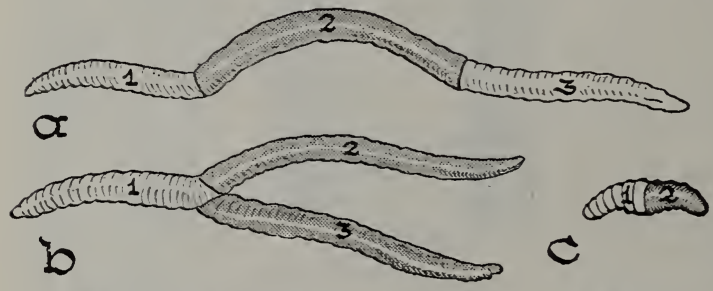

Professor Morgan grafted parts of earthworms and produced (1) a very long worm, (2) a two-tailed worm, (3) a very short worm. breeders to perpetuate desirable kinds of plants.

Grafting is also practiced in animals. Hydra, worms, insects, and frogs all have been used experimentally. Surgeons graft skin after a severe burn, or graft glands in sheep, goats, or other animals and sometimes, but very rarely, in man. In all of these cases the same thing takes place as when we cut ourselves and the wound heals: new tissues are formed by the growth of cells.

Home Project. Make a successful bud or graft and demonstrate it to the class.

Practical Exercise 4. Make a table in which you have as headings all the different ways in which plants or animals are "propagated." Under each heading place examples that you have personally seen.

Practical Exercise 5. Find out from such a magazine as Hygeia all the reliable information you can about gland grafting. Compare this with advertisements on gland grafting taken from newspapers. Do you believe the advertisements? Why?

Practical Exercise 6. List ten useful fruit trees that can be grafted. Consult a fruit grower.

Vegetative propagation and reproduction. When, as in the above examples, a new plant is produced from a portion of a plant, generally used for nutrition, the process is called vegetative propagation or growth. Vegetative propagation is a form of asexual repro- 
duction, since the new organism is îrormed by a cell or cells separating from a single parent. Other examples of this type of reproduction is seen in the reproduction of yeast or mold, which form asexual spores. Such spores under favorable conditions produce new plants.

New living organisms, however, are usually formed by other methods. If two cells, from two plants or animals of different sexes, come together to form a new individual, we call this a case of sexual reproduction. In some plants, like Spirogyra, already studied, a kind of sexual spore is formed by a process we call conjugation.

Two filaments, lying side by side, send out little projections from adjoining cells, which meet, and the contents of the cells in one filament pass over and mix with the cell contents of the other filament. The cells thus formed become resting spores (zygospores) which will develop into new plants. The cells which formed these spores are called gametes.

In the algae we have a step higher in the development of gametes. In the Vaucheria (vô-kē'rü-ä), a branched alga, two structures may be produced from the filament. One contains a large gamete which is called an egg. The other contains small gametes, called sperms, each with two cilia. The sperms when set free appear to be

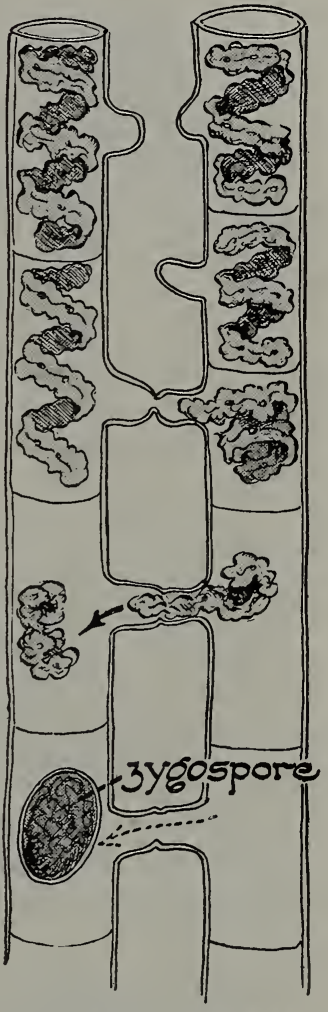

Conjugation in Spirogyra.

Explain the diagram. chemically attracted to the egg cells. If a sperm (male gamete) fuses with an egg (female gamete), it is said to fertilize the egg cell. From the fertilized egg a new plant will eventually grow. This method of development, which is found in all higher plants and animals, is known as sexual reproduction.

We have already learned how sexual reproduction takes place in the flowering plants. The flower holds pollen grains and ovules 
or undeveloped seeds. At an early stage the pollen grain contains but a single cell. A little later, however, three nuclei may be found

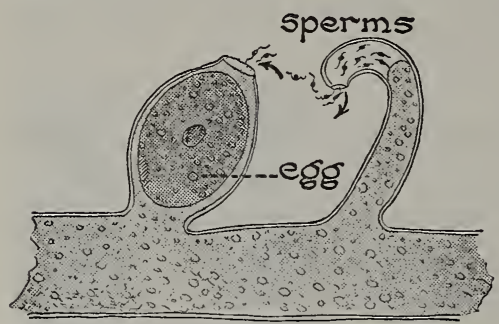

A part of a filament of Vaucheria. Explain how a new plant is formed.

in the protoplasm. Hence we know that at least three cells exist there, two of which are sperm cells or male gametes. We have learned that within the ovary of the flower is an egg cell. It is to this cell that one of the sperm nuclei of the pollen tube grows, ultimately uniting with it. The union of the sperm nucleus with the nucleus of the egg to form a single cell is known as fertilization. This single cell formed by the union of the pollen-tube sperm cell and the egg cell is now called a fertilized egg or zygote and is the beginning of a baby plant, or embryo. The second sperm nucleus unites with another nucleus in the embryo sac and grows into food substances called the endosperm, which in some plants is a very important part of the seed since it supplies the growing embryo with nourishment.

Practical Exercise 7. Make a series of labeled diagrams to illustrate different stages in the development of sexual reproduction in plants. Make a distinction between asexual and sexual reproduction without using the words "sex" or "sex cells."

Field Exercise. During the first warm days in March or April, look for

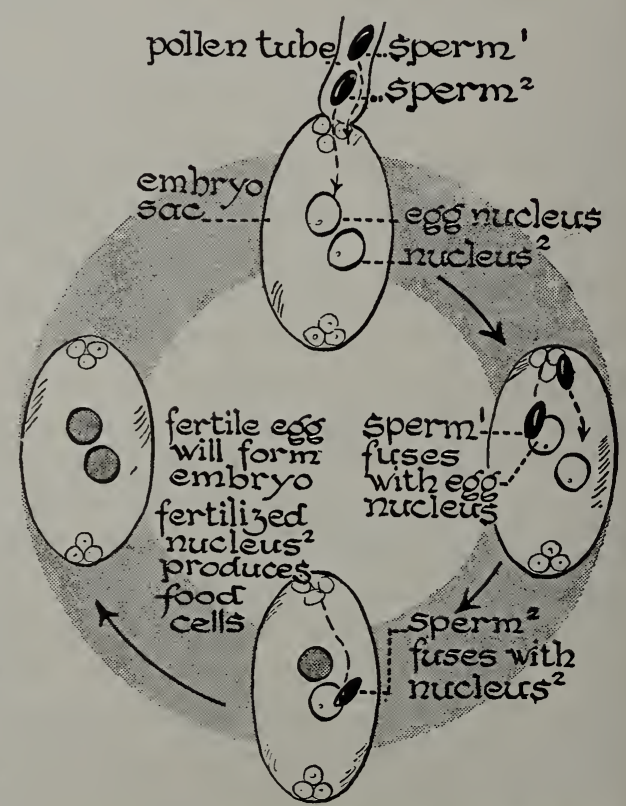

Explain how fertilization takes place in plants. 
gelatinous masses of frogs' eggs attached to sticks or water weeds in shallow ponds. Collect some and keep them in a shallow dish in a window at home until they hatch. Make experiments to learn whether temperature affects the development of the eggs in any way. Place eggs in dishes of water in a warm room, in a cold room, and in the refrigerator. Make observations for several weeks as to the rate of development of each lot of eggs. Also try placing a large number of eggs in one dish, thus cutting down the supply of available oxygen, and in another dish near by, under the same conditions of light and heat, place a few eggs with plenty of water. Do both batches of eggs develop with the same rapidity? In all these experiments be sure to use eggs from the same egg mass, so as to make sure that all are of the same age.

Development of animals. Many-celled animals are formed in much the same way as are many-celled seed plants. A common bath sponge, an earthworm, a fish, or a dog, - each of them begins life as a fertilized egg cell. As in the flowering plant, this cell was formed by the union of two other cells, a tiny (usually motile) cell, the sperm, and a larger one, the egg. After the egg is fertilized by a sperm cell, it splits into two, then into four, then into eight, then into sixteen cells, and so on. As the number of cells increases, a hollow ball of cells

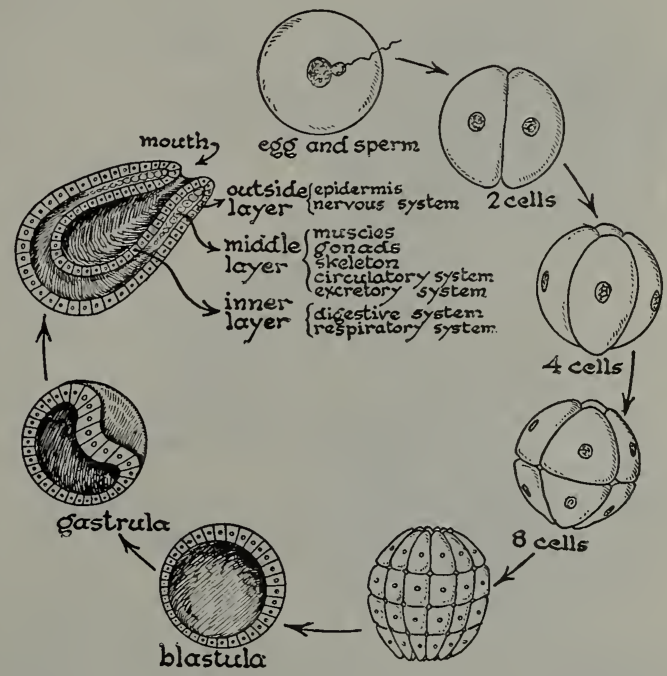

All animals pass through the above stages in the process of their development from an egg.

called the blastula is formed; later this ball sinks in on one side, and a double-walled cup of cells, called a gastrula, results. Practically all animals pass through the above stages in their development from the egg, although these stages are often not plainly seen because of the presence of food material (yolk) in the egg. 


\section{IMPROVEMENT OF LIVING THINGS BY MAN}

In an older stage three layers of cells are noticeable. Those of the outside, developed from the outer layer of the gastrula, are called the ectoderm; this later gives rise to the skin, nervous system, etc. An inner layer, developed from the inner layer of the gastrula, is called the endoderm; this forms the digestive and circulatory systems. A middle layer, called the mesoderm, lying between the ectoderm and the endoderm, gives rise in higher animals, to the muscles, the skeleton, and other internal organs. At a very early stage in development, in some animals the two- or four-cell stage, the so-called sex cells may be found, so that we may say that almost from the beginning the sex cells are set apart from

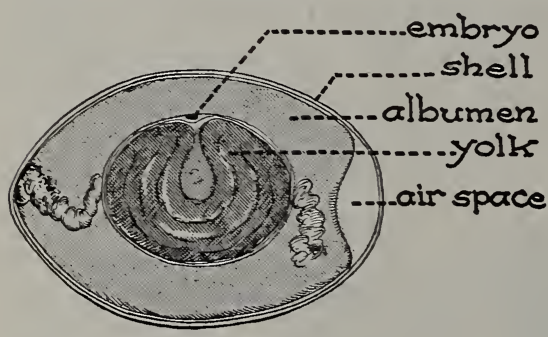
the other cells of the developing organism.

We have already discussed the development of insects, of fishes, and of frogs, and have learned that in every case the fertilization of the egg has resulted in the development of the animal, sometimes through a compli-

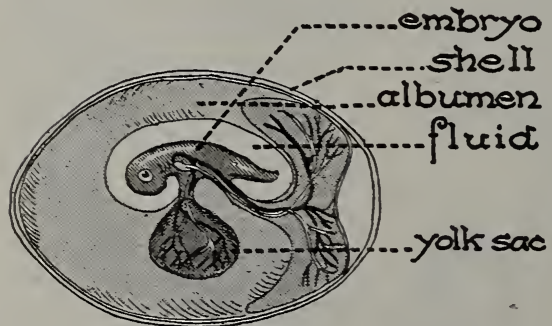

Above, a section through a bird's egg showing tiny embryo connected to the yolk, which is surrounded by albumen.

Below, the egg has been incubated for some days. Various organs have already developed, and can be recognized.

mals the young develop within the mother's body and consequently are protected for a much longer time than those of the lower forms.

Development of birds. The white of the hen's egg is accumulated during the passage of the real egg (which is on the yolk or 
yellow portion) to the outside of the body. Before the egg is laid a shell is secreted over its surface. If the fertilized egg of a hen is broken and carefully examined, on the surface of the yolk will be found a little circular disk. This is the beginning of the growth of an embryo chick. If the development is followed in a series of eggs taken from an incubator at intervals of six hours or less, this spot will be found to increase in size; and later the little embryo will lie on the surface of the yolk. Still later small blood vessels can be seen reaching into the yolk for food, and the tiny heart can be seen beating as early as the second day of incubation. After about three weeks of incubation the little chick hatches and emerges in almost the same form as the adult.

Development of a mammal. In most mammals after fertilization the egg undergoes development within the body of the mother. The blood vessels, instead of connecting the embryo with the yolk as in the chick, are attached to an absorbing organ, known as the placenta. This structure sends branchlike processes into the wall of the uterus (the organ which holds the embryo) and absorbs nourishment and oxy-

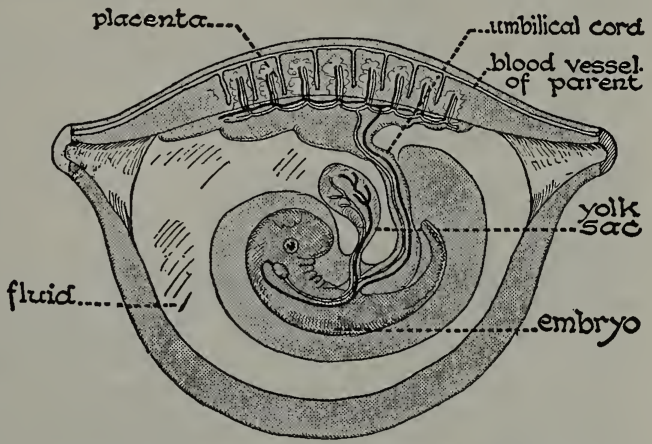

In a mammal, the embryo is attached by the umbilical cord to the placenta of the parent. Fluids surrounding the embryo in the uterus serve to protect it against shock.

gen by diffusion from the blood of the mother. After a length of time, which varies in different species of mammals (from about three weeks in a guinea pig to twenty-two months in an elephant), the young animal leaves the protecting body of the mother, or is born. The young are born, usually, in a helpless condition and are nourished by milk furnished by the mother until they are able to take other food. Higher in the scale of life, fewer eggs are formed, but those few eggs are more carefully protected and cared for by the parents. The chances of becoming adults are much 
greater than are the young of lower animals which produce many eggs but take no care of them.

Practical Exercise 8. Make a series of colored diagrams for your workbook to show stages in development in (1) fish, (2) frog, (3) bird, (4) mammal. Use the same colors in each series to show the same parts. Get help from as many sources as you can.

What would you say were the outstanding differences in development in the groups just mentioned?

\section{Self-Testing Exercises}

Check the correct statements for your workbook.

T.F. 1. Cells grow in size in order to have more food-absorbing surface.

T. F. 2. Starfish and earthworms regenerate lost parts.

T.F. 3. Vegetative propagation means producing new plants from parts of others.

T.F. 4. Grafting and budding are examples of sexual reproduction.

T. F. 5. If we have an arm amputated, we will regenerate another one.

T.F. 6. Sexual reproduction involves the fusion of eggs and sperms.

T. F. 7. An ovule is an egg cell.

T. F. 8. Birds reproduce asexually as well as sexually.

T.F. 9. All animals are produced from eggs and sperms.

T.F. 10. The endoderm is the outer layer of a developing animal.

T.F. 11. The lower the animal the more eggs are produced.

T. F. 12. Mammals' eggs develop within the body of the mother.

\section{PROBLEM III. WHAT ARE THE LAWS OF HEREDITY?}

Heredity and the work of Gregor Mendel. By far the most important discovery for the plant and animal breeder was made by Gregor Mendel, the abbot of a monastery at Brunn, in what is now Czechoslovakia. About 1865, Mendel bred peas in his monastery garden and found that certain characters, such as color of seeds, color of flowers, smooth and wrinkled coats, and other characters, are inheritable. Then he began a long series of experiments in which he crossed or hybridized peas having some of these 
different characters. For example, he crossed tall plants with short ones, and smooth peas with wrinkled ones. The results of these crossings showed that these characters are always transmitted to the next generation as units, not as blendings of the two opposing characters. This was his first great discovery, the inheritance of unit characters.

The law of dominance. But Mendel found, in crossing peas, that the first generation of hybrids ${ }^{1}$ always showed a curious result. One character would appear, while its opposite would seemingly be lost. If, for example, smooth and wrinkled peas were crossed, the

§
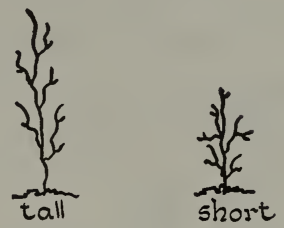

$F 1$
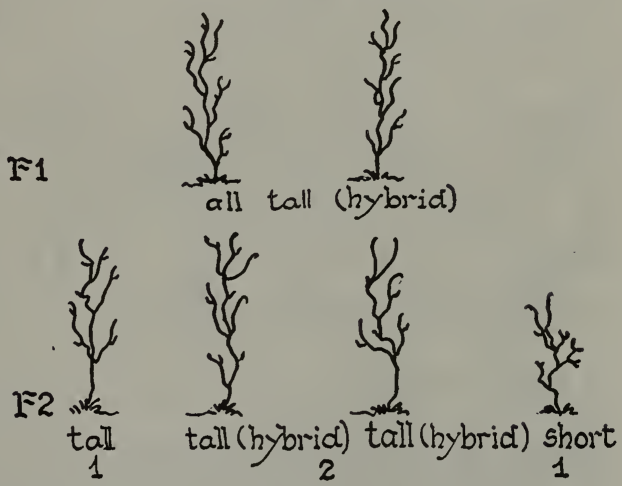

If a tall plant is crossed with a short plant their offspring (the $F_{1}$ generation) will all be tall. If these tall hybrids are then crossed, their offspring (the $F_{2}$ generation) will be in the proportion of one tall, two tall hybrid and one short.

hybrids were all smooth. If tall and short pea plants were bred, the hybrids were all tall, and similar results were obtained with other pairs of characters with which he experimented. This gave rise to the statement that certain unit characters are dominant over others which are called recessive characters.

The law of segregation. But these recessive characters were not really lost. If -some of the hybrid smooth-coated peas are fertilized by others of the same kind and their seeds planted, the next generation (known to breeders as the $\mathrm{F}_{2}$ generation) will include some pea plants bearing smooth peas and some bearing wrinkled peas, in the ratio of $75: 25$. One quarter of all the peas

${ }^{1}$ Hybrid : a plant or animal that contains a pair of widely different unit characters - as smooth and wrinkled skins in peas. 
show the recessive character. If these peas having the recessive character are crossed with each other in another generation, they will produce all wrinkled peas, the recessive character; and such peas, when bred again and again with peas of the same kind, will continue to produce wrinkled peas. The recessive character has been segregated out and is now known as an extracted recessive.

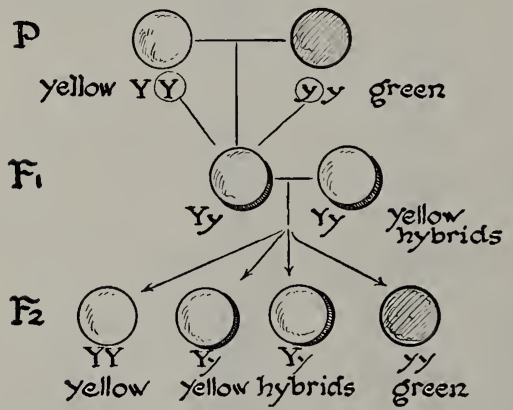

If peas with yellow seed coats are crossed with peas with green seed coats, their offspring will be yellow hybrids. Yellow is dominant to green in color. If these hybrids are cross-pollinated, the $F_{2}$ generation will be 25 per cent yellow, 50 per cent yellow hybrids, and 25 per cent green.

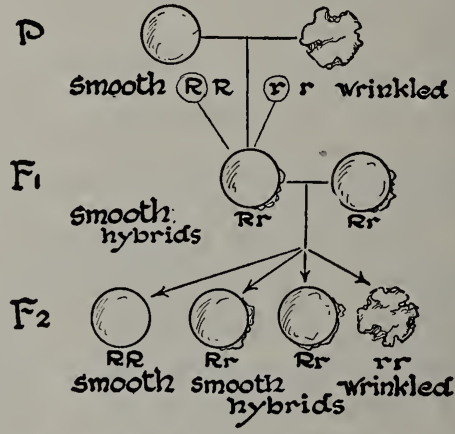

If peas with smooth seed coats are crossed with peas wtih wrinkled seed coats, their offspring will all be smooth-coated hybrids. Smooth is dominant to wrinkled. If these hybrids are then crossed, the $F_{2}$ generation will be 25 per cent smooth, 50 per cent hybrid, and $\mathbf{2 5}$ per cent wrinkled.

This shows Mendel's Law of Segregation. Its importance in plant and animal breeding can readily be seen.

The 75 per cent of $\mathrm{F}_{2}$ peas which are seemingly all smooth-coated are in reality 25 per cent smooth and 50 per cent mixed, that is, having both characters, the recessive hidden by the dominant. If we can separate the pure dominants, they will produce only dominants, while the mixed hybrids will continue to breed dominants and recessives in the ratio of 25 per cent dominant, 50 per cent mixed, and 25 per cent recessives.

In crossing white rats with black ones black is dominant over white, as is seen in the figure on page 624 . But in the $F_{2}$ generation, as in the peas of Mendel's experiments, the recessive color is segregated out. This law of segregation works so that when pure dominants are mated with hybrids there is a segregation of $50 \%$ dominants and $50 \%$ hybrids and when recessives are mated with 
hybrids we have $50 \%$ recessives and $50 \%$ dominants in the next generation. The production of plants or animals having dominant and recessive character is based on the laws of chance. In hybrid peas $\left(F_{1}\right.$, page 622$)$, for example, half the pollen grains would bear germ cells containing the deter- $\mathbf{P}$ miner of "smooth" $(R)$ and half the determiner of " wrinkled" (r), while in the ovule, half would contain the determiner "smooth" and half "wrinkled." Crossing them, we have in the $F_{2}$ generation, the result shown in the diagram.

\section{Dihybrids and} others. Though breeding for one pair of characters is comparatively easy to understand, we often find breeders crossing for two or more pairs of characters. This is purely a
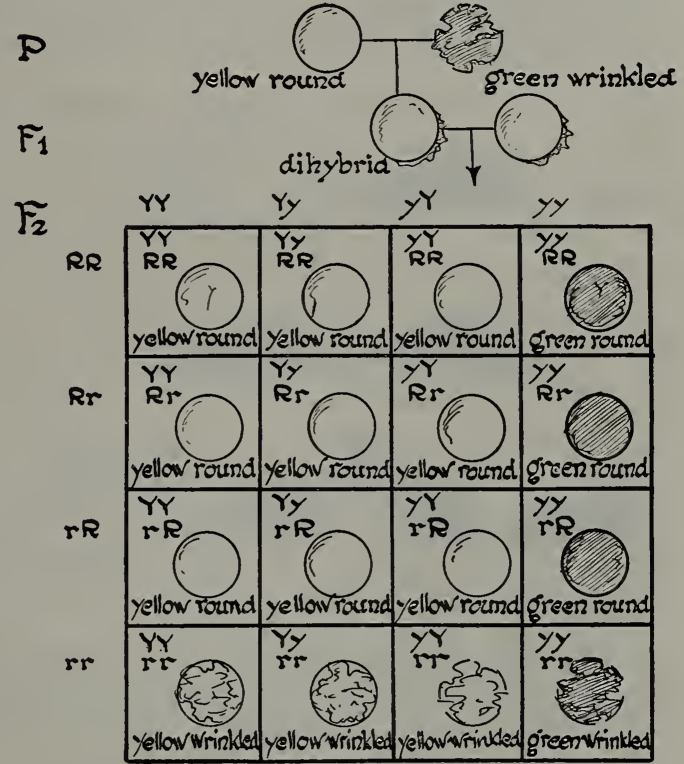

Dihybrids carry two characters. Here one parent is carrying two dominant characters - yellow color and smooth seed coat. The other parent is carrying two recessive characters green color and wrinkled seed coat. In $F_{1}$ generation all four characters are fresent but only the dominant ones show. If these hy orids are crossed. the pro:ortion of the $F_{2}$ generation can be predicted if the characters are arranged as single pairs akove and on the side of a series of squares. The possible combinations of characters are gizen in the squares.

matter of mathematics (on paper) as the diagram on this page shows, but it is too difficult to study in an elementary course in biology. At the present time most of the really worth while work in plant and animal breeding is being done by this method of Mendel. Not only does this enable breeders to fix the unstable hybrid characters, but also it enables them to combine worthwhile characters such as immunity to diseases of various kinds, early ripening, color or size of fruit, and resistance to drought. 
Practical Exercise 9. Make a colored diagram for your workbook to show the following examples of Mendel's laws of dominance and segregation. Work out your diagram to the $F_{3}$ generation: Colored flowers of peas are dominant over white. Green color in pod is dominant over yellow. Gray coat color in mice is dominant over white.

The practical results. Already some progress has been made in the application of Mendel's laws to hybridization. The United
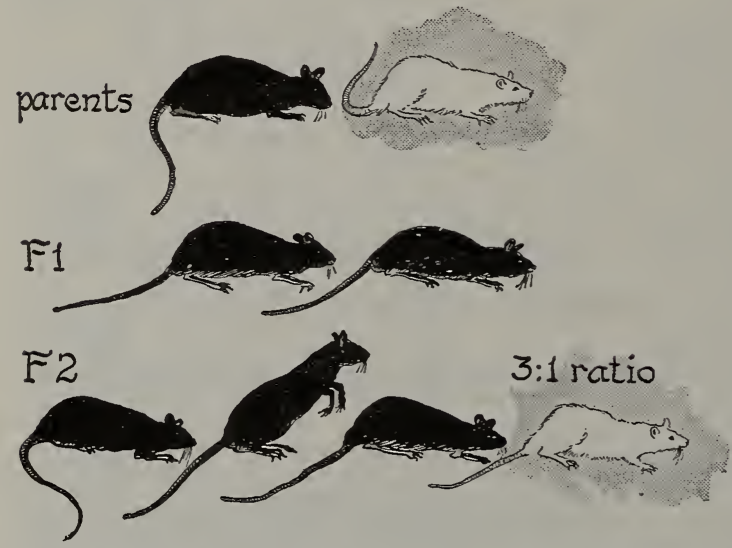

In rats, the black color has been found to be a dominant character, and the white color is a recessive character. If two rats of the second generation $\left(F_{1}\right)$ are mated, why would they probably have one white and three black offspring?

States Department of Agricul$\mathrm{ture}$ is now producing coldresistant fruits and grains in the Alaska experiment station. A hybrid which is a cross between the watermelon and the citron has produced a fruit that will resist "wilt," a serious fungus disease of melons. Rustresisting wheats also have been produced in this country; while in England experiments on wheat have resulted in the production of resistance to disease, "hardness" of grain, and increase in the size of the grain and of the head - all characters which mean greater productiveness. But most of the hybridizing is still done on a hit-or-miss principle, with few permanent results. Luther Burbank, the great hybridizer of California, destroyed tens of thousands of plants in order to get one or two with the characters which he wished to preserve.

Animal breeding. It has been pointed out that the domestication of wild animals - horses, cattle, sheep, goats, and dogs marked great advances in civilization in the history of mankind. As the young of these animals were bred in captivity, the people owning them would undoubtedly pick out the strongest and best 
of the offspring, killing the others for food. Thus man unconsciously aided nature in producing a stronger and a better stock. Later, he began to recognize certain characters that he wished to have in horses, dogs, or cattle, and by slow processes of breeding and of "crossing" or hybridizing one nearly allied form with another, the numerous groups of domesticated animals began to be developed.

Some domesticated animals. Our domesticated dogs are descended from a number of wolf-like forms in various parts of the world. All the present races of cats, on the other hand, seem to be traced back to Egypt. Modern horses are first noted in Europe and Asia, but far older forms flourished on the earth in earlier geologic periods. It is interesting to note that America was the original home of the horse, although at the time of the earliest explorers the horse was unknown here. The wild horse of the Western plains has descended from horses introduced by the Spaniards. The horse, which for some reason disappeared in this country, continued to exist in Europe, and man, emerging from his early savage condition, began to make use of the animal. We know the horse was domesticated in early Biblical times, and that it was one of man's most valued servants. In more recent times, man has begun to change the horse by breeding for certain desired characters. In this manner the various types of horses familiar to us as draft horses, coach horses, hackneys, saddle horses, and trotters have been established and improved.

It is needless to say that all the various domesticated animals have been tremendously changed by breeding since they were brought under the control of civilized man. When we realize there were in 1930 over $13,000,000$ horses, over $57,000,000$ cattle, over $48,000,000$ sheep, and about $52,000,000$ swine on farms in this country, representing a money value of over $\$ 5,000,000,000$, we see how very important a part the domestic animals play in our lives.

Present problems in animal breeding. In spite of the fact that this vast amount of money is represented by our domesticated animals, it could and should be much inore. Crosses in fowls have been obtained that produce as many as 300 eggs from one 
hen in a year; yet the average hen lays less than 100 eggs per year. A few cows of superior breeding in some of the state experiment stations produce as much as 1000 pounds of butter fat each in a year, but the average cow produces little more than 200 pounds a year. A bulletin of the Department of Agriculture says, "Good judges believe that in the entire country one fourth of the cows kept for their milk do not pay for their cost of keeping, and nearly a fourth more fail to yield annual profit." This means that many farmers do not know what their cows are producing. It means that many farmers are poor, through either carelessness or ignorance. The scientific breeding of milk cows would mean millions of dollars in the pockets of the farmer, and an increase in that much-needed commodity, milk. This is only one of the many problems of conservation that will eventually be solved by our animal breeders.

Practical Exercise 10. Make a list of all the kinds of domesticated animals and plants in your locality that are useful to man. Indicate on the list all those that you know have been improved by such factors as: selection, budding, grafting, crossing or hybridizing, use of Mendel's laws, etc. After discussion in class make a revised table for your workbook.

\section{Self-Testing Exercise}

Mendel discovered through experimentation the inheritance of ....... (1) ....... (2). Through breeding, some of these ....... (3) ....... (4) can be .......(5). Most new ......(6) produced by Luther Burbank were .......(7). Certain unit characters are (8) over other characters which are .......(9). If two hybrids are mated, their offspring will be .......(10) per cent recessive and .......(11) per cent dominant in respect to any unit character.

\section{PROBLEM IV. WHAT DETERMINES HEREDITY}

Chromosomes the bearers of heredity. We have learned that a cell contains a nucleus, in which are certain very minute structures known as chromosomes (because they take up color when stained). When cells divide, each chromosome divides by splitting lengthwise, so that equal amounts of each chromosome are thus carried into the new cells formed from the original cell. These chromosomes are believed to be the structures which contain the 
genes or determiners of the qualities which may be passed from parent to offspring; in other words, the qualities that are inheritable.

The germ cells. It has been found that certain cells of the body, the egg and the sperm cells, before uniting usually contain only half as many chromosomes as do the body cells. ${ }^{1}$ In preparing for the process of fertilization, half of these elements have been eliminated by reduction division (diagram, p. 630), so that when the egg cell and the sperm cell are united they will have the same number of chromosomes as the other cells of the body.

We have already learned that in the process of fertilization the nuclei of the sperm and of the egg cell unite, or fuse, to form a new nucleus in the fertilized egg. This fertilized egg will contain an equal number of chromosomes from each parent. Since the inheritable characters are contained ir the chromosomes, both parents will hand down an equal number of characters to their offspring. In this way characters from each parent are handed down to the new individual.

Investigations of heredity have centered, in recent years, on the composition and action of the chromosomes. It has been found that they differ in number according to the species of the animal. In a little worm called Ascaris and in the fruit fly there are only four chromosomes in each body cell; in the mosquito Culex there are six, in the rat sixteen, in the frog twenty-six, in certain crustaceans more than one hundred and fifty, in one spider a hundred and sixty-eight. In some animals, as has been shown, the number differs with sex. Man is believed to have forty-eight. Professor Morgan, of the Institute of Technology, Pasadena, California, has found, as a result of investigations on the fruit fly (drosophila), that each chromosome is actually composed of genes or the inheritable material that represents unit characters, and

${ }^{1}$ This is not quite exact, for it has been found that in some animals at the time when the chromosomes are reduced in number, there is an even number in the female sex cells but an odd number in the male sex cells. When the male cells divide to reduce the number of chromosomes, some sperm cells receive an odd and some an even number of chromosomes. Therefore, after fertilization, some eggs have an even and some an odd number of chromosomes. The fertilized egg cells with the odd number of chromosomes develop into male animals; the cells with the even number of chromosomes become females. The sex-determining chromosome is known as the accessory chromosome and is found in some worms, many insects, myriapods, spiders, and some mammals, including man. 
that some of these characters are linked together in the same sex. This would explain some of the characters common only to male or to female animals.

It is plain that with forty-eight chromosomes, each of which is

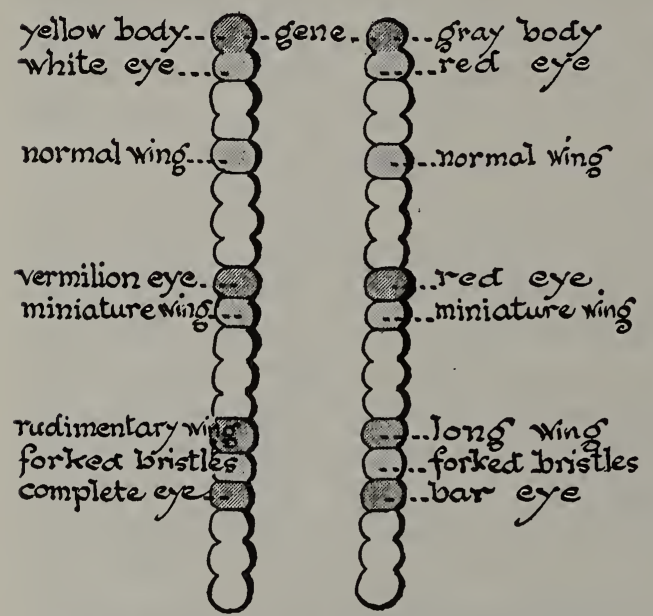

Diagram of chromosomes of the fruit fly, showing that genes for certain characteristics are found in different parts of the chromosomes. probably made up of a large number of genes or determiners, heredity in man is a very complicated matter at best. For a number of unit characters have been found which are inheritable according to Mendel's laws, and undoubtedly others will be added as we learn more about the working of these laws.

But this mechanism of heredity is not as simple as it seems. In the first place the genes are ultra-microscopic. One scientist has said: "If we magnified a hen's egg to the size of the world (which would make atoms rather larger than eggs and electrons barely visible), we could still get a gene into a room and probably on a small table." Moreover, each chromosome probably contains hundreds if not thousands of genes. It is clear then that experiments which will attempt to separate the genes and make new characters appear in the offspring will be extremely difficult, to say the least.

Practical Exercise 11. Make a diagram of a chromosome and place in it genes or determiners for some of the unit characters given on pages $630-631$.

At the time of fertilization of the egg cell the genes or determiners in the sperm cell are added to those in the egg cell and are then handed down as unit characters. Thus a child inherits characters from both parents. 
Here is what Professor H. S. Jennings, geneticist, of Johns Hopkins University says concerning the genes:

"Every pair of human parents contains thousands of pairs of the packets (genes) of chemicals on which development depends. From these a set is drawn almost at random (subject to the condition that one packet is taken from each pair possessed by each parent); this constitutes the heritage of the child. Any pair of parents may thus produce not merely thousands but millions of different combinations, each yielding a child of different characteristics. There is no way of controlling the combinations that shall enter into a child of given parents; there is no prospect that there ever will be. It is, therefore, impossible to predict what kind of offspring will be produced by a given pair of parents - save in a few respects, in cases where the constitution of both packets of a particular pair are known for each parent. If both parents have the corresponding pairs defective in the same mannerlacking, for example, something required for producing a normal mind - then their children will be all defective like the parents; feeble-minded parents will produce feeble-minded children. But if, as may well be the case, the feeble mind is due to defects in different packets in the two parents, then all experimental breeding shows that the two parental stocks may supplement one another, so that the defect will not appear in the offspring. These characteristics that are predictable are extremely few." - From Prometheus by Jennings, published by E. P. Dutton \& Co.

More recently we have found that heredity is complicated by another factor. We have already learned that the hormones play a very important part in regulating life activities and that the overactivity or underactivity of certain glands may produce profound changes in an organism. The under- or overdevelopment of the pituitary gland, for example, causes a dwarf or a giant to result, and other of our ductless (endocrine) glands have almost as startling results. The use of the X-ray in experimental biology has brought about strange results. Professor Müller of the University of Texas has recently produced about 100 new varieties of fruit fly, which breed true, simply by keeping the flies under the $\mathrm{X}$-ray for certain periods of time. We are finding out that our problems of breeding are not as easy to solve as we first hoped.

Practical Exercise 12. Make a report on the action of some one endocrine gland. Get material from Harrow's "Glands in Health and Disease," or use the Readers Guide to find titles of articles on the endocrines.

н. вIO -41 
Offspring are part of their ancestors. If you receive characters from your parents and they received characters from their parents,

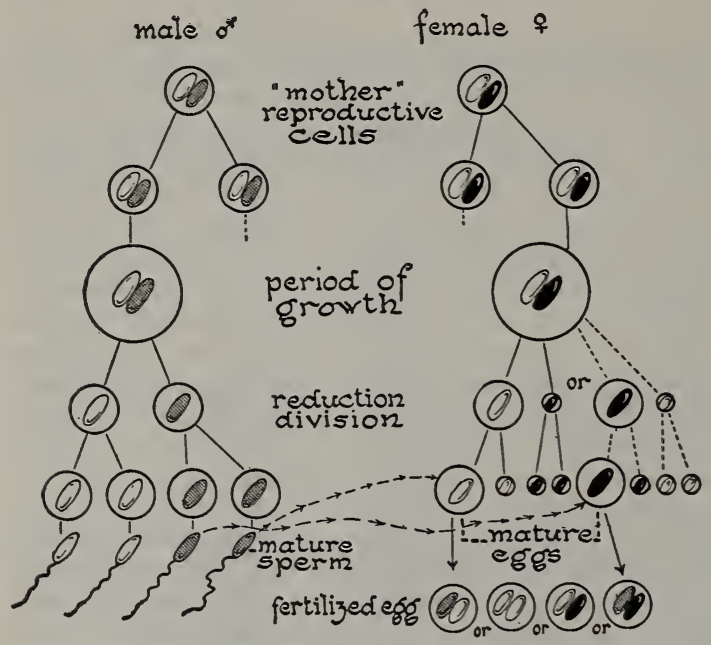

The "mother" reproductive cells divide and one of the resulting cells grows larger. During this period of growth each cell divides in such a way that one half of the chromosomes goes to each of the daughter (or resulting) cells. Each female cell gives rise to one egg and three small cells. The egg has most of the yolk and is generally the only one that will be fertilized. The large male cell divides, and gives rise to four sperms, all the same size, and all of which can function. Each sperm will contain one half the number of chromosomes found in the large cell. One sperm unites with the mature egg in the process of fertilization.

then you must have some of the characters of the grandparents. As a matter of fact each of us does have some traits or lineaments which can be traced back to a grandfather or grandmother. Indeed, as far back as we are able to go, ancestors have contributed something.

Practical Exercise 13. Study the diagram carefully. How can you account for the different combinations in the four fertilized eggs shown at the bottom of the di-

agram? What seems to be the reason for the "reduction" division?
Turn over to the diagram on page 628 . Make a similar diagram for your workbook that will show how a chromosome in an egg and a sperm cell might contain genes.

Characters known to be inheritable. The following table indicates some of the characters in man that have been proved to be inheritable according to the laws of Mendel.

\section{Dominant Character}

Black or brown eye

Pigmented iris

Dark skin

Curly hair

Dark hair

Congenital white lock

Beaded hair

Nervous temperamedt
Recessive Character

Blue or gray eye

No pigment in iris

Light skin

Straight hair

Light hair

Normal hair

Straight hair

Phlegmatic temperament 
Much study has been given to the inheritance of defects and susceptibility to diseases. The following list probably is approximately correct.

\section{Dominant Character}

Two-jointed fingers

Extra digit

Congenital cataract of eye

Abnormally short limbs

Hairless or toothless condition

Spotted hair coat

\section{Recessive Character}

Normal fingers

Normal number of digits

Normal condition of eye

Normal limbs

Normality

Normality

Cases where the defect is recessive to the normal condition are much more difficult to find, but the following examples appear to be well established, according to Guyer :

Dominant Character

Normal pigment

Normal intellect

Normal intellect

Normality

Normality

Normality

Normality

\section{Recessive Character}

Albino skin

Feeble-mindedness

Alcoholism (when based on feeblemindedness)

Susceptibility to cancer

Tendency to asthma or hay fever

Probable susceptibility to tuberculosis

Lack of muscular control

\section{Self-Testing Exercise .}

Chromosomes are the ....... (1) of ....... (2) characters. The fertilized egg contains .......... (3) or ....... (4) from both parents. ....... (5) are definite in number for each species of animal or parent. The triangle of life consists of $\ldots \ldots \ldots(6), \ldots \ldots$ (7), and $\ldots \ldots$ (8). Certain characteristics, such - as .......(9), $\ldots \ldots \ldots$ (10), and ........ (11), appear to be inherited according to Mendel's Laws. Dark skin is a ....... (12) character, light skin a . (13) character. One's heredity may be affected by the $\ldots \ldots \ldots(14)$ from the endocrine glands. The size of giants and
dwarfs appears to be determined by the size of the $\ldots \ldots$ (15) gland.

\section{PROBLEM V. HOW ARE NEW VARIETIES OF PLANTS AND ANIMALS PRODUCED}

Laboratory Exercise. To determine whether there is individual variation in any one measurement of the members of a given class. With a string carefully measure the length of your arm from the finger tips to the elbow. Take measurements on back of hand. 
Verify your figures by having your neighbor take the measurement for you. Do the same thing for him. The instructor will give you an individual number. Hand in your results with your number to one pupil in the class, who will tabulate the figures on the board.

Make a graph showing individual variation in circumference of the wrist in the members of your class. What are your conclusions?

Two types of variations occur. Variations in nature appear to be of two types. If we measure the size of a large number of peas or beans, we find that though most of them are of a certain size,

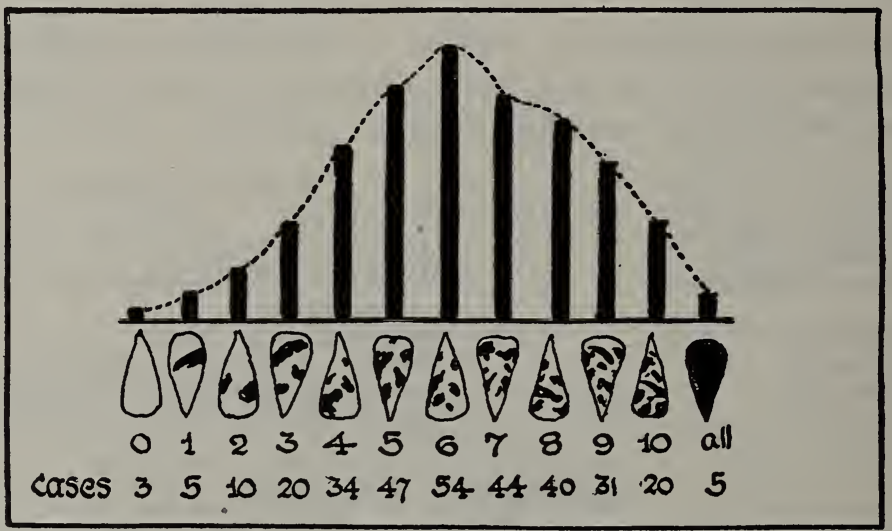

The number of markings on a random 313 sunflower seeds was counted. The result of this experiment is recorded in the diagram.

others will be a little larger or a little smaller, and a very few will be very large or very small. A graph can be made from the results, which shows an even curve, known as Quételet's (ket'laz) Curve. Such variations are, to a large degree, changes brought about as the result of differences in environment upon the plants producing the seed. Such fluctuating variations would not, therefore, influence the heredity of the next generation, as they have no influence upon the sex cells. On the other hand, such variations may be due to certain combinations of chromosomes and as such are inheritable. This makes the problem very difficult for the scientific plant or animal breeder.

Occasionally, however, sudden changes or discontinuous variations occur. Such was the famous ancon ram which suddenly 
appeared in 1791 in Massachusetts. This ram had such short legs that it could not jump fences. Hornless cattle, albinos, and the famous beardless wheat found by Mr. Fultz are examples of such variations. These are called mutants or sports. The term "mutant " has of later years been associated with the Dutch naturalist, Hugo de Vries. Very rarely, as he found, chance mutations appear which breed true. In the evening primrose, for example, he found eight different mutations. This means that new species in nature may arise suddenly, instead of by very slow degrees, as Darwin believed. The reason that such variations as these always breed true is because the germ or sex cells of the animal or plant are affected and thus the variations can be handed down to the next generation. It is easily seen that such variations would be of immense value to breeders, as plants and animals much unlike their parents might be formed and perpetuated. About 1910, a bean mutant appeared in the South which was adapted to life in the cotton belt. As a result, more than 6,000,000 acres of these beans were grown by 1917 . Mutants

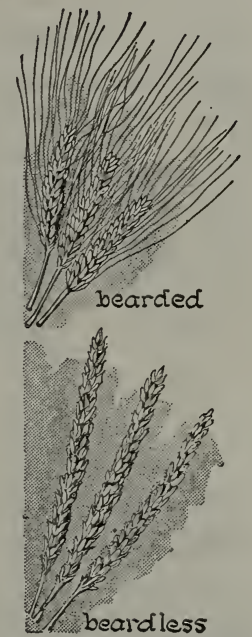

The beardless wheat is a mutant of the bearded wheat. have appeared in tobacco, barley, wheat, oats, tomatoes, and potatoes. One of the important parts of the work of the plant breeder is to discover, isolate, and breed useful mutations.

Practical Exercise 14. Read and report to class something about the life and work of De Vries.

Practical Exercise 15. Make a list, using any source material, of at least ten plants and five animal mutants.

Practical Exercise 16. What type of variation is probably seen in the curve you constructed as the result of your Laboratory study on page 631?

Selective planting. By selective planting we mean choosing the best plants and planting their seeds with a view of improving the yield in some definite ways. In doing this we must not necessarily select the most perfect fruits or grains, but must select seeds from the best plants. Experiments in corn selection at the Uni- 
versity of Illinois have shown that the oil content of the grain, the starch content, the position of the ear on the plant, and other factors could be improved, but no new factor has been produced.

In a government test of corn to increase the yield, ears were chosen from plants that gave a high yield; seed from these ears was planted in rows alternating with seed from equally goodlooking ears from the same kind of corn not selected for its high yield. Note the results with eight pairs of ears.

\begin{tabular}{|l|c|}
\hline \multicolumn{2}{|c|}{ Pounds of Corv Yielded by the Seed of ONe Ear } \\
\hline Field Ears & Ears from High-Yielding Parents \\
\hline $170 \mathrm{lbs}$. & $177.5 \mathrm{lbs}$. \\
139.5 & 180 \\
139 & 199 \\
173 & 197 \\
154 & 172 \\
133 & 176 \\
153.5 & 194 \\
\hline
\end{tabular}

What per cent of increase was there from the selected corn? If the seed from the field-grown corn yielded 42 bushels per acre, what would have been the gain per acre by planting seed from the selected corn? State results both in bushels and in dollars, assuming corn to be worth 50 cents per bushel.

In selecting wheat we might breed for a number of different characters, such as more starch, or more protein in the grain, a larger yield per acre, ability to stand cold or drought, or to resist plant disease. But although selection is the one most important method for bettering production of crops, it is after all a hit-or-miss method, as we do not know whether we are selecting variations that are inheritable. Therefore in order to produce new varieties of plants, another method is used, known as hybridization.

Practical Exercise 17. Suppose you were selecting seed corn from an acre for a large yield. How would you go about making the selection? Would you select from large plants with large ears or plants bearing large kernels of corn? Give reasons.

Hybridization. We have already learned that pollen from one flower may be carried to another of the same species and produce 
seeds. If pollen from one plant is placed on the pistil of another of an allied species or variety, fertilization may take place and new plants will be eventually produced from the seeds. This process is known as hybridizing, and the plants produced by this process known as hybrids. This process is a most painstaking one, if worth-while results are to be obtained. The two plants to be crossed must be selected with great care, they must be carefully protected from possible selfpollination, and the transfer of pollen must be so restricted that no

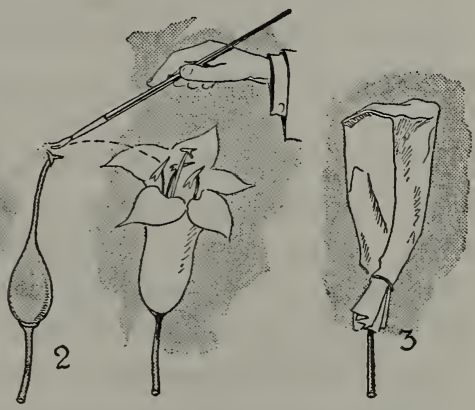

How is artificial pollination accomplished? pollen except the desired kind shall reach the pistil. After the transfer of pollen, the flower must be covered, to prevent any other alien pollen from reaching the pistil.

Hybrids are extremely variable and often are apparently unlike either parent plant. Most hybrids have to be perpetuated by means of some of the methods of vegetative propagation, as they rarely breed true and often do not produce seeds.

Practical Exercise 18. What kind of plants would you select for a hybridizing experiment? Why are all parts of the flower except the pistil cut away in the diagram on page 634? What will happen to the pollen placed on the stigma? Why is the flower covered after artificial pollination?

\section{Self-Testing Exercise}

All plants and animals in nature tend to .......(1). .......(2) tends to make living things like their ancestors. ........(3) variations do not influence herêdity.

(4) variations or ........ (5) produce new kinds of plants that breed true. In selective planting the farmer picks out the

(6) from the ... rather than most perfect ........(9).

produces no new ........(12) in plants. 


\section{PROBLEM VI. HOW DO THE LAWS OF HEREDITY APPLY TO MAN?}

Since our knowledge of heredity has been increased, the demand has become more urgent that we do something to prevent the race from handing down diseases and other defects, by applying to man some of the methods we employ in breeding plants and animals. This is not a new idea. The Greeks in Sparta had it; Sir Thomas More wrote of it in his Utopia; and today it is brought to us as the science of eugenics (ü-jĕn'iks). This word comes from the Greek word eugenes, which means well born. Eugenics is the science of being well born, or born well, healthy and fit in every way. A tendency to cancer, tuberculosis, epileptic fits, or feeblemindedness is a handicap which it is not merely unfair, but criminal, to hand down to posterity.

Two notorious families. Studies have been made on a number of different families in this country, in which mental and moral defects were present in one or both of the parents as far back as it
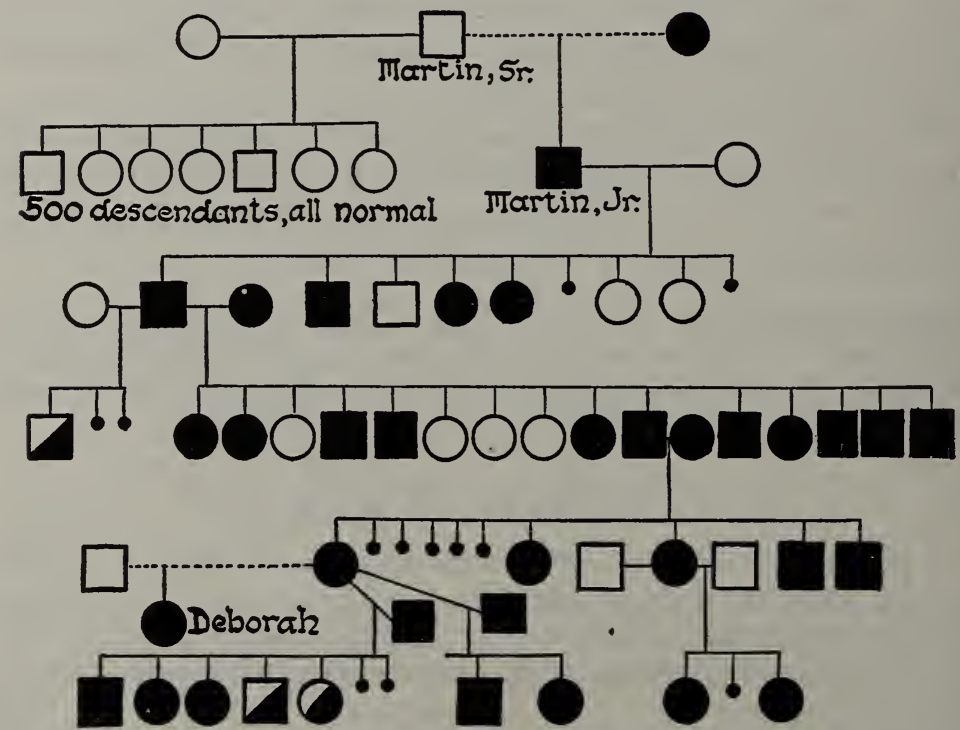

means normal woman; $\square$, normal man; the solid black indicates feeble-mindedness, and the small black circle means died in infancy. A study of the Kallikak family was made by Goddard, who traced back the history from Deborah. 
was possible to trace the family. The "Jukes" family is a notorious example. "Margaret, the mother of criminals, is the first mother in the family of whom we have record." Up to 1915 2094 members of this family had been traced; 1600 were feebleminded or epileptic, 310 were paupers, more than 300 were immoral women, and 140 were criminals. The family has cost the state of New York more than $\$ 2,500,000$, besides immensely lowering the moral tone of the communities in which members of the family live.

Another careful investigation concerned the so-called "Kallikak" family. This notorious family was traced to Martin Kallikak, a young soldier of the War of the Revolution, and a feeble-minded girl, who have had 480 known descendants. Of these 33 were sexually immoral, 24 confirmed drunkards, 3 epileptics, and 143 feeble-minded. The man who started this terrible line of immorality and feeble-mindedness later married a normal Quaker girl. From this couple a line of 496 descendants was traced, and in no instance were there any cases of feeble-mindedness. The evidence and the moral speak for themselves.

Parasitism and its cost to society. Hundreds of families, such as those described, exist today, spreading disease, immorality, and crime in all parts of this country. The cost to society of such families is very great. Just as certain animals or plants become parasitic on other plants or animals, these families have become parasitic on society. They not only do harm to others by corrupting, by stealing, and by spreading disease, but they have to be protected and cared for by the state out of public money. It is estimated that between 25 per cent and 50 per cent of all prisoners in penal institutions are feeble-minded. Largely for them the poorhouse and the asylum exist. They take from society, but they give nothing in return. They are social parasites.

The remedy. One unfortunate fact is that feeble-minded people have little sense of morality, for they do not have a normal mental development. Feeble-mindedness is a very serious problem, for it is estimated that at the lowest figure there are probably 300,000 feeble-minded persons in this country, most of whom are free to breed their kind. The only real remedy seems to be to 
segregate the feeble-minded according to sexes in asylums and to prevent their marriage and the possibilities of perpetuating a low and degenerate race. Remedies of this sort have been tried successfully in Europe and are now meeting with success in various parts of this country.

Traits that are inherited. Eugenics shows us, on the other hand, in a study of families in which brilliant men and women are found, that the descendants have received good. inheritance from their ancestors.

The following, taken from Davenport's Heredity in Relation to Eugenics, illustrates how one family has been famous in American history.

In 1667 Elizabeth Tuttle, " of strong will and of extreme intellectual vigor, married Richard Edwards of Hartford, Conn., a man of high repute and great erudition. From their one son descended another son, Jonathan Edwards, a noted divine and president of Princeton College. Of the descendants of Jonathan Edwards much has been written; a brief catalogue must suffice: Jonathan Edwards, Jr., president of Union College; Timothy Dwight, president of Yale ; Sereno Edwards Dwight, president of Hamilton College; Theodore Dwight Woolsey, for twenty-five years president of Yale College; Sarah, wife of Tapping Reeve, founder of Litchfield Law School, herself no mean lawyer; Daniel Tyler, a general in the Civil War and founder of the iron industries of North Alabama; Timothy Dwight, second, president of Yale University from 1886 to 1898 ; Theodore William Dwight, founder and for thirty-three years warden of Columbia Law School; Henrietta Frances, wife of Eli Whitney, inventor of the cotton gin, who, burning the midnight oil by the side of her ingenious husband, helped him to his enduring fame; Merrill Edwards Gates, president of Amherst College ; Catherine Maria Sedgwick, of graceful pen; Charles Sedgwick Minot, authority on biology and embryology in the Harvard Medical School; Edith Kermit Carew, wife of Theodore Roosevelt; and Winston Churchill, the author of Coniston and other well-known novels."

The daughters of Elizabeth Tuttle had distinguished descendants: Robert Treat Paine, signer of the Declaration of Inde- 
pendence; Chief Justice of the United States Morrison R. Waite; Ulysses S. Grant and Grover Cleveland, presidents of the United States. These and many other prominent men and women can trace back to Elizabeth Tuttle and Richard Edwards the characters which enabled them to occupy the positions of culture and learning they held.

Many other similar cases might be cited. Although we do not know the precise method of inheritance, we do know that musical and literary ability, calculating ability, remarkable memory,

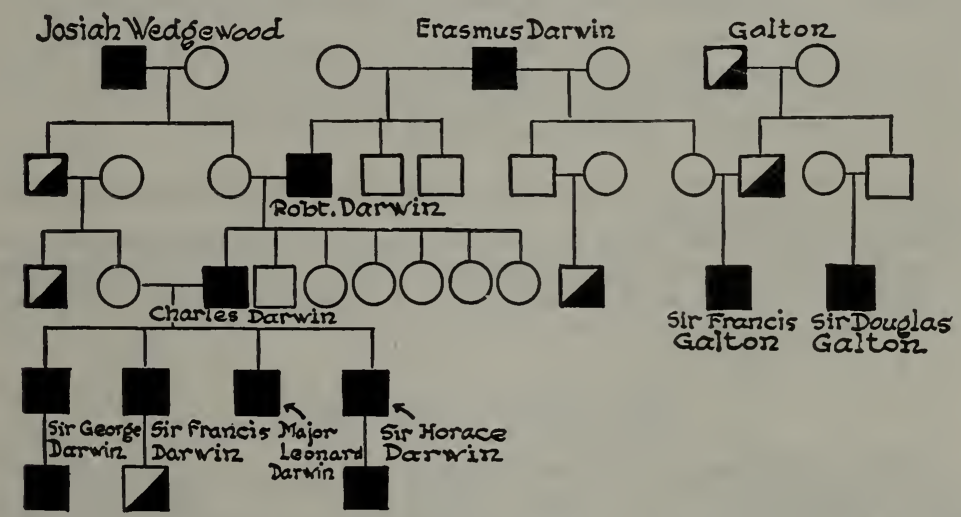

The family tree of Charles Darwin. $\square$, means marked scientific ability; $\square$, very marked scientific ability.

mechanical skill, and many other mental and physical characters are inheritable and "run in families." The Wedgewood family, from which three generations of Darwins have descended, and the Galton family are examples of a scientific inheritance ; the Arnolds, Hallams, and Lowells were prominent in literature; the Balfours were political leaders; the Bach and Mendelssohn families were examples showing inheritance of musical genius. A comparison of fathers' and sons' college records at Oxford University show it is usually " like father, like son " as regards grades. The fathers who did well had sons who did well also. It is said that 26 out of 46 men chosen to the Hall of Fame of New York University had distinguished relatives. Blood does tell. Or rather chromosomes tell the story. 
How to use our knowledge of heredity. Two applications of this knowledge of heredity stand out for us as high school students. One is in the choice of a mate, the other in the choice of a vocation. As to the first, no better advice can be given than the old adage, "Look before you leap." If this advice were followed, there would be fewer unhappy marriages and divorces. Remember that marriage should mean love, respect, and companionship for life. The heredity of a husband or a wife counts for much in making this possible. And, even though you are in high school, it is only fair to yourselves that you should remember the responsibility that marriage brings. You should be parents. Will you choose to have children well born? Or will you send them into the world with an inheritance that will handicap them for life?

Practical Exercise 19. Work out the inheritance of certain traits or peculiarities in your own family.

Practical Exercise 20. Look up the history of one of the families mentioned on page 639 and see what you can find out about their mental inheritance. Use all sources of help, such as Davenport's Heredity in Relation to Eugenics, Walter's Genetics, or Guyer's Being Well Born.

\section{Self-Testing Exercise}

Feeble-mindedness could be stamped out if .......(1) of such persons could be .......(2). Blood or ........(3) count, as is proven by the $\ldots \ldots .(4), \ldots \ldots$ (5), and .......(6) families. Parasitism in ....... (7) is largely caused by the $\ldots \ldots \ldots(8)$ or socially unfit people. The science of being well born and ........ (9) is called ........(10).

\section{Review Summary}

Test your knowledge of the unit by: (1) rechecking on the survey questions; (2) performing all assigned exercises; (3) checking with your teacher on all tests and trying again the ones you missed; (4) making an outline of the unit for your workbook.

\section{Test on Fundamental Concepts}

In vertical column under the heading CORRECT write numbers of all statements you believe are true. In another column under INCORRECT write numbers of untrue statements. Your grade $=$ right answers $\times 2 \frac{1}{2}$.

I. The environment (1) may change the form and traits of a plant or an animal; (2) affects the offspring of plants and animals; 
(3) causes changes in organisms that may be inheritable; (4) causes changes in organisms that are not inheritable.

II. Examples of asexual reproduction are (5) conjugation of spirogyra; (6) budding of yeast; (7) egg laying of fish; (8) grafting of trees.

III. Hereditary qualities are believed to be handed down from one generation to another (9) through the protoplasm of the body cells ; (10) by means of genes found in the chromosomes; (11) unless the environment changes; (12) through the sex cells only.

IV. Variations (13) are changes in structure which may occur in all succeeding generations; (14) are continuous or discontinuous; (15) if continuous, are valuable to plant or animal breeders, as they form new varieties that breed true; (16) cause various types of animals to be developed.

V. Hybridizing (17) consists in crossing two related species; (18) always results in the formation of offspring that breed true; (19) results in the formation of plants which differ from their parents; (20) is a method of breeding.

VI. Genes are (21) believed to contain the determiners of unit characters; (22) found in all body cells; (23) found in the chromosomes; (24) found in both sperm and egg cells.

VII. Mendel's laws of heredity (25) show that certain characteristics are inheritable; (26) are not used by breeders as they are not reliable; (27) show that certain characters are dominant over others; (28) show that unit characters may be segregated out in the ratio of $3: 1$ in the second filial generation.

VIII. Studies of various families show that (29) feeble-mindedness is inherited; (30) artistic ability is inherited; (31) tuberculosis is inherited; (32) persons possessing good characteristics will usually have children with good characteristics.

IX. Observation of the laws of heredity make possible (33) the development of plants that have desirable characters; (34) the improvement of the human race; (35) the gradual elimination of plants or animals that possess undesirable characters; (36) the production of animals that are entirely different from their parents.

X. Mutants (37) breed true; (38) do not breed true; (39) vary largely from their ancestors; $(40)$ are used as starting point for a new species of plants or animals. 


\section{Achievement Test}

1. What scientific proof can you give that environment influences organisms?

2. What are some hereditary qualities? How are hereditary qualities handed down?

3. What is the purpose of reproduction in plants and animals?

4. What are five plant or animal hybrids?

5. How can you work out Mendel's laws with a hybrid? With a di-hybrid?

6. What are the chief problems in plant or animal breeding in your community?

7. What is the mechanism by which inheritable characters from a father or mother are handed down, " even unto the third and fourth generation "?

8. How would you make a diagram of heredity in your own family, going back as far as your parents can remember? Are there any definite examples of heredity which come out in your generation (eye color, hair texture, musical or other ability, etc.)?

9. Explain the meaning and the application of the word "eugenics."

\section{Practical Problems}

1. Could living things improve physically or mentaily if it were not for heredity?

2. Go to a nearby nursery and find out how many of the newer and better plants are raised through hybridization.

3. To what extent do farmers in your locality use selection to improve their crops? Get as many examples as you can.

4. If there is an institution for feeble-minded or criminally insane in your neighborhood, find out how many there are in the institution and how much it costs the state per year to run the institution. What does it cost your father a year in taxes?

5 . What institutions in your state are maintained because of poor heredity?

\section{Useful References}

Atwood, A Civic and Economic Biology. (P. Blakiston's Son \& Co. 1922.)

Babcock and Clausen, Genetics in Relation to Agriculture. (McGrawHill Book Co. 1927.)

Conklin, Heredity and Environment. (Princeton University Press. 1923.) 
Davenport, Heredity in Relation to Eugenics. (Henry Holt \& Co. 1911.)

Downing, The Third and Fourth Generation. (University of Chicago Press. 1918.)

Farmers' Bulletins : 195, 461, 576, 619, 887, 952, 1040, 1167, 1192, 1209, 1263, 1332, 1369.

Goddard, The Kallikak Family. (The Macmillan Co. 1919.)

Guyer, Being Well-Born. (Bobbs-Merrill Co.)

Harrow, Glands in Health and Disease. (E. P. Dutton \& Co. 1922.) Harwood, New Creations in Plant Life. (The Macmillan Co.)

Jennings, Prometheus. (E. P. Dutton \& Co. Inc.)

Jones, Genetics in Plant and Animal Improvement. (John Wiley \& Sons. 1924.)

Journal of Heredity, Numerous Articles. (American Genetic Association, Washington.)

Morgan, Evolution, Genetics and Eugenics. (University of Chicago Press. 1925.)

Shull, Heredity. （McGraw-Hill Co. 1926.)

Walter, Genetics. (The Macmillan Co. 1922.) 


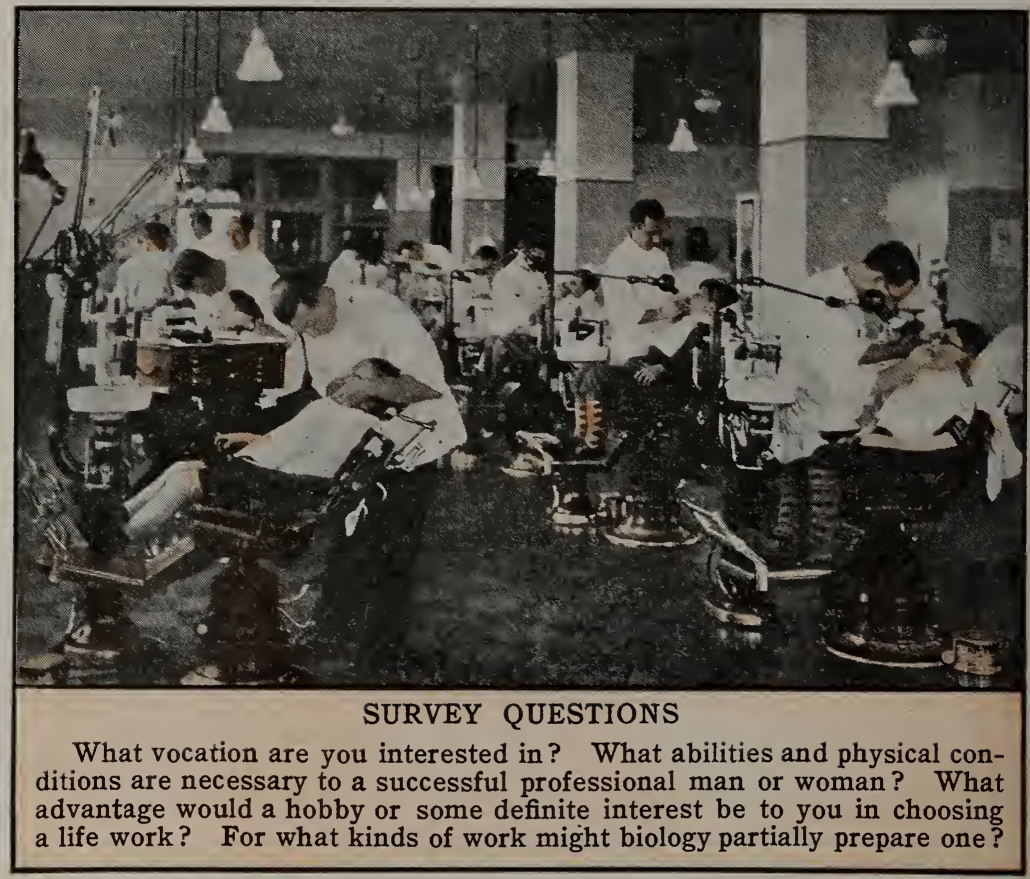

\section{UNIT XIX}

\section{HOW MAY BIOLOGY AID IN MY OWN IMPROVEMENT?}

Preview. High school is the time of life when we dream dreams as well as work and play. And one of the dreams that most of us indulge in sometimes during a study period, sometimes on the way to school, sometimes in the quiet of our own room, is the dream of our future and our life work. Most of us sooner or later will come under the influence of some strong personality, and the leadership of that teacher or friend or parent may have much to do with the forming of our plans for future work. In my own case, it was a professor in college who gave me the inspiration to devote my life to teaching. I have always been happy in my 
choice. But are all people satisfied with their choice? I well remember sitting at dinner with a very wealthy stockbroker once and hearing him say to a distinguished naturalist who was one of the party, "I'd gladly give up all of this wealth to be able to take one trip with you to South America."

Success is one of the greatest assets of life and he who wins it through an interesting life work is most fortunate. It is not easy to determine what we ought to do with our lives; for what we would like to do may not be the thing we ought to do. There are many people who find their work most uncongenial because they are not physically and mentally fitted for their positions. One of the things for you to do now is to begin to think about your future. Make an analysis of your strong and weak points, your likes and dislikes, your abilities and your handicaps. Then you will be able better to determine whether you are fitted for the vocation which you think you would like to make for your life work. Perhaps some of the possibilities that come from your study of biology may interest you. Think it through carefully and then investigate further if you believe you are fitted for the work you have in mind.

The one thing which we should have learned from the preceding units is how to take care of ourselves physically. Not only have we learned certain facts about posture in relation to health, but we have found out certain facts about diet, the values of vitamins, the way to have good digestion and to keep it, as well as many other facts which aid in hygienic living. We have also learned some of the reasons for environmental improvement and care. These are, after all, facts related to health conservation and should be so used by us.

Probably the biggest asset we can have is real knowledge of our own mind and how it works. We can either be slaves or masters of self. It lies with each one of us. For the ability to face life with a smile, to be always cheerful, no matter what the cost, to think straight and clean, to make the most of every opportunity, is something that each of us can acquire. If we do learn this lesson, it will be worth more than all the facts that many books contain.

Another thing we should aim to do is to cultivate a hobby. Learn to like to do some one thing better than others and make H. BIO -42 
that one thing a way of using your leisure time. Some of us like to hike, to collect flowers or rocks or insects. Others of us may enjoy bird study and may make a collection of photographs of birds and their nests. Such a collection is far more interesting, both in the getting and in the keeping, than are the birds or the nests themselves. Others of us enjoy fishing; while others get enjoyment out of gardening, either out-of-doors or in the house. A flower or vegetable garden is a practical kind of hobby and often means extra money for the one who tends to it. In all events, have something to do in your leisure moments.

Another result of this study ought to be a certain amount of interest in the future. We have seen so many instances of fine men devoting their lives to science and the betterment of humanity, that some of us cannot help being stirred by their records. The lives of Pasteur, Reed, Noguchi; Bruce, all have made thrilling stories. It is natural to wonder if there are not some fields that this study of biology has opened our eyes to. That there are fields of work open are obvious; medicine, nursing, teaching, agriculture, forestry, laboratory technology, collecting, natural science, research work, all of these and other vocational possibilities present themselves to us.

\section{PROBLEM I. HOW CAN I CHOOSE A VOCATION?}

The most important problem for most of us is, "What am I going to do after I leave high school? Will it be college and a profession? Or am I better fitted for a trade or business? I cannot afford to be a 'square peg in a round hole.' " Some things are obvious. If one has inherited color blindness, he cannot become a locomotive engineer. The musical profession would be distasteful to one who had no musical sense. Since different vocations demand certain physical and mental traits or characteristics, we must possess those characteristics if we want to succeed along certain lines of work.

Self-analysis necessary. To choose our life work wisely, we must first analyze our abilities and habits, both of which are very important. Do we have good posture? Are we neat in person and dress? Do we dress ouietly and in good taste? Are we 
courteous? Do we know how to use our speaking voice? Do we cultivate smiles instead of ill temper? Do we have good table manners? Impressions made on employers are largely based on an estimate of such habits. Much of our life we control, and the formation of habits of industry, alertness, promptness, thoroughness, orderliness, tolerance, honesty, reliability, and openmindedness will go far in making for success in life.

Abilities. Certain natural abilities, tendencies, and instincts dependent on physical and mental heredity must be considered also in choosing a vocation., Good health is first of all. Certain kinds of work - mining, farming, forestry, stock raising, and many trades - demand a good constitution, if one is to "make good." Persons who become leaders in commercial life must have executive power, system, energy, resourcefulness, and capacity to form sound judgments. Professional life makes demands upon muscles and brain in still another way. Let us examine a few cases to see just what this means.

Abilities needed for the professions. For the ministry high ideals, faith, sympathy, power in thought and in word, capacity for sacrifice, combined with knowledge acquired from books and people, are essentials. For the medical profession, certain skill of hand and eye which aids in making a delicate dissection, nerve, good eyesight, ability to search for causes and to draw conclusions, together with sympathy, tact, and love for the work, are essential to success. For engineering, mathematical and constructive abilities are outstanding, while a lawyer needs high reasoning powers and ability to deal with men. The teacher should be well educated and, in addition, must love boys and girls. Health, tact, good nature, imagination, inventiveness, and enthusiasm are some of the qualities which make the successful teacher.

Abilities needed in commercial life. For all commercial life reliability, promptness, energy, cheerfulness, and high moral character are the basis. Stenographers and clerks need, in addition, special skills which will be increased in practice. If one is to become a manager or a promoter of a business, organizing and executive ability, good judgment, caution, and a knowledge of business affairs are necessary. The business man or woman should 


\section{HOW MAY BIOLOGY AID IN MY IMPROVEMENT?}

know people and have what we call " business sense " for leadership.

Abilities necessary for trades. For the mechanical lines, knowledge of the trade is an essential, with skill of eye and of hand.

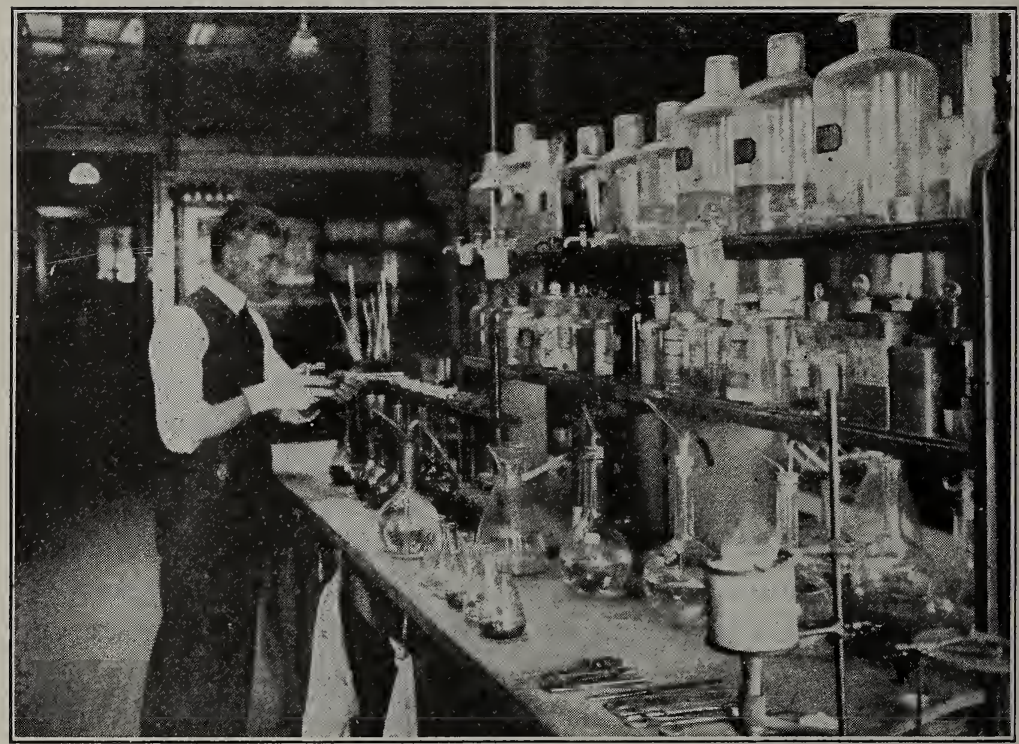

R. L. Nesmith and Associates

A research worker in his laboratory. What qualities does such a man have to possess in order to be successful?

Accuracy and loyalty are essentials, if one is to succeed. For industries of a semi-professional nature, such as illustrating, cartoon drawing, or engraving, the artistic abilities should be cultivated, and imagination, inventiveness, and appreciation of what the public wants should be joined with the purely mechanical abilities which have to do with drawing or color work. ${ }^{1}$

Practical Exercise 1. Make a list of vocations and under each vocation place the qualities you think most essential for success in that field.

Practical Exercise 2. Choose a vocation in which you are interested and list the qualifications necessary to be successful. In the class discussion that follows note the overlapping of qualifications. In what fields might one safely switch his lifework?

${ }^{1}$ For further information as to the conditions necessary to become efficient in any line of work, read Parsons, Choosing a Vocation, Houghton Mifflin Company. 


\section{Self-Testing Exercise}

Before choosing a vocation one should make an ........(1) of his (2) and ........(3). Probably the most important quality that one should possess is ...... (4) ...... (5). Some of the general abilities needed in all vocations are ...... (6), .....(7), $\ldots \ldots \ldots(8), \ldots \ldots \ldots(9)$, and ........ (10). A business man should show .......(11) .......(12); a teacher should have .......(13) and $\ldots . . .(14)$.

\section{PROBLEM II. FOR WHAT VOCATIONS MAY BIOLOGY HELP PREPARE ME?}

Medicine. A great physician once wrote the following to a friend in answer to the question: "Shall my son prepare for medicine?" — "There is nothing on earth greater or more beautiful than man, and the study of mankind is the most difficult and exalted subject of thought and of action. Human development and ambition, human life and ills are all in the highest degree remarkable and touching. But you must bring keen eyes and acute ears; a great gift for observa-

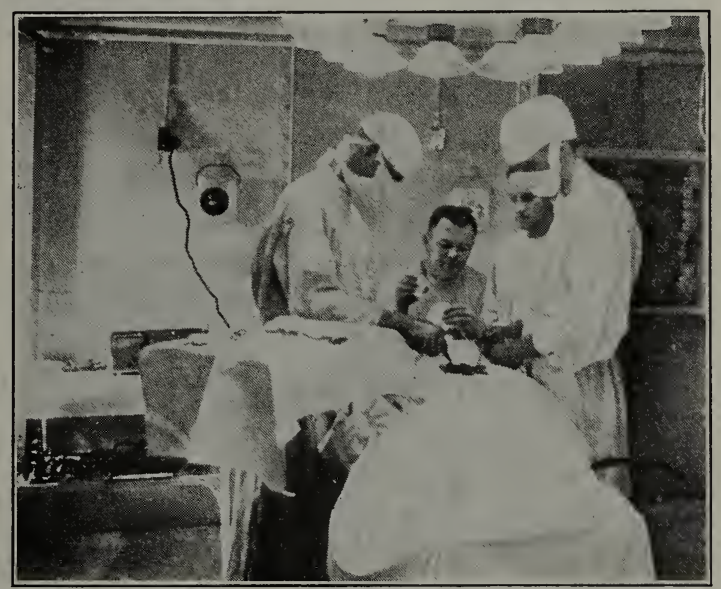

Keystone View Co. Inc.

Physicians must be prepared to work at any place. Here are several doctors, on board a ship, performing an operation.

tion; patience and yet more patience; an iron will strengthened by opposition, but yet a warm and tender heart, comprehending and feeling every sorrow; a reverent spirit and austerity that is superior to sensuality, money, or eminence; adroit fingers and health of body and soul; furthermore a decent appearance, and 
polished demeanor. All of these you must possess if you would not be an incompetent or unhappy physician."

While the life of the physician has its compensations, one must be first of all strong in body and mind if he wishes to follow this path. Eight to ten years of preparation with no financial returns makes the profession impossible for some. And yet if you have the divine fire and know that to be the one profession for your life, do not give it up. There are always ways of borrowing the money, and opportunities are open for him who wants to do the work. It takes many years before one is established, but they are years of unforgettable experiences. And one has the great satisfaction of knowing he is really doing some good in the world. The physician has social position in the world and is often a valued member of his community.

Practical Exercise 3. Note the qualifications you think necessary to become a successful physician, placing them in order of importance. Have you added or subtracted from the list given in the text?

Other health work. Other opportunities in relation to health are research in medicine, the work of the medical missionary, public health work, which is growing rapidly in scope, hospital research, the army and navy and foreign service, nursing, medical inspection of schools, and medical service in corporations.

Dentistry, pharmacy, and nursing are all occupations requiring special training and characteristics. One of the most splendid life occupations for girls who are strong and who have the spirit of service is that of the nurse. Training is obtained in a regular school where, in addition to physiology, anatomy, hygiene, and home economics, the prospective nurse is trained in actual care of the sick. There are many branches of this profession, the most fascinating of which is that of the school nurse or visiting nurse. Social welfare is most important to all and this opportunity is a large one. The nurse must have, in addition to good health, sympathy, tact, understanding of people, and a desire for social service.

Practical Exercise 4. List your qualifications for nursing. How do they compare with those for the physician? Would you change the list for the profession of dentistry? Of pharmacy? 
Teaching. Any one familiar with the growth of education in this country during the last few decades cannot help feeling that here indeed is a vocation that is worth while. Not only is there opportunity to teach a subject in which one is interested, but what is far more, by example and leadership one is able to influence for good many young people. Teaching, however, makes big demands. A college education with specialization in the subject matter of biology, an extra year of training in methods and practice teaching and a lot of time devoted to reading and field work should be the training of the teacher of biology. Salaries are not large but they are sufficient, and one enjoys a certain social place in the community. To be a successful teacher a love for the subject and a love for children are essentials. The teacher must be forever young and see with the eyes of youth. Tact, health, and, above all, a sense of humor, must be part of the native equipment of the teachers of biology. Then an analytical mind, perseverance, a desire to hold to the truth at all costs, are all essential to good teaching in science. Of course, all these are in addition to training and knowledge of subject matter.

Practical Exercise 5. What are the necessary qualifications for the teaching profession? Do all teachers have these qualities? What would you list as the most important outside of good health?

Agriculture. A large percentage of the farmers of this country have no real love for their work and have simply taken it up because the farm was theirs by inheritance or they had other easy reasons for going into the work. But for the young man with a strong body and love for the out-of-doors, what could be a better calling? To become a scientific agriculturist requires a great deal of study, including four years in an agricultural college in the study of the practical applications of the chemistry of soils, of the laws of Mendel in plant or animal breeding, and much else that the modern farmer needs to know to make his business pay. The life of the modern farmer, thanks to automobiles, good roads, and radios, has become much more pleasant and interesting than it was a few years ago. Specialized agriculture, particularly in the fruit farms of the far west, offers most attractive inducements. Experimental animal and plant breeding, although it may be carried on at the 


\section{HOW MAY BIOLOGY AID IN MY IMPROVEMENT?}

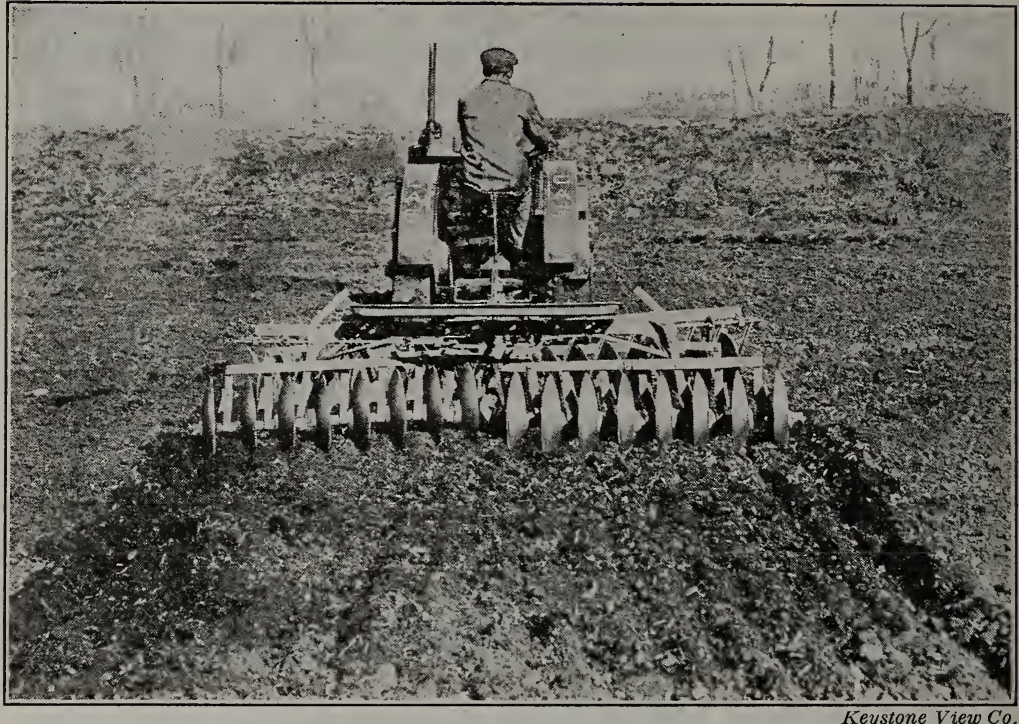

Today farmers depend largely upon machinery to do their work for them. This farmer is using a kerosene tractor to pull a disk harrow.

farm, is usually done at some of the state institutions for the promotion of agriculture.

Practical Exercise 6. What qualifications should a farmer possess? Do you think the average farmer is well fitted for his job? Why?

Forestry. A new and attractive profession has opened up in late years through the need of protection and development of our forests. Schools of forestry in different states train young men to become foresters, either for the government or for private industry. Forest rangers live a life in the open. It is their duty to patrol the forests, to watch for and to fight forest fires, to prevent illegal cutting, to control regular cattle grazing in forest reserves, to replant burnt over areas, and to protect in every way our great national asset, the forests. The lover of the out-of-doors will do well to think seriously of this as a life vocation.

Practical Exercise 7. List the qualifications most essential for the life of a forest ranger.

If possible, visit or tell of a visit to a ranger station. What would be the routine life of a ranger? 
The naturalist or research worker. There are many opportunities for the really able student in research work carried on by some of the government agencies engaged in the conservation of our natural resources. The United States Biological Survey, a division of the Department of Agriculture, has done much to protect and conserve our bird population, and has general supervision over the wild animal life of this country. It is one of the bureaus that employ many field workers. The United States Bureau of Fisheries is interested in the conservation of our national fish, shellfish, and sealing resources. Many fish hatcheries in various parts of the country and various state agencies, such as the New York State Conservation Department, state departments of agriculture, fisheries, and conservation, offer attractive possibilities for research work of a utilitarian sort.

Practical Exercise 8. What do you consider the most outstanding qualifications of a research worker?

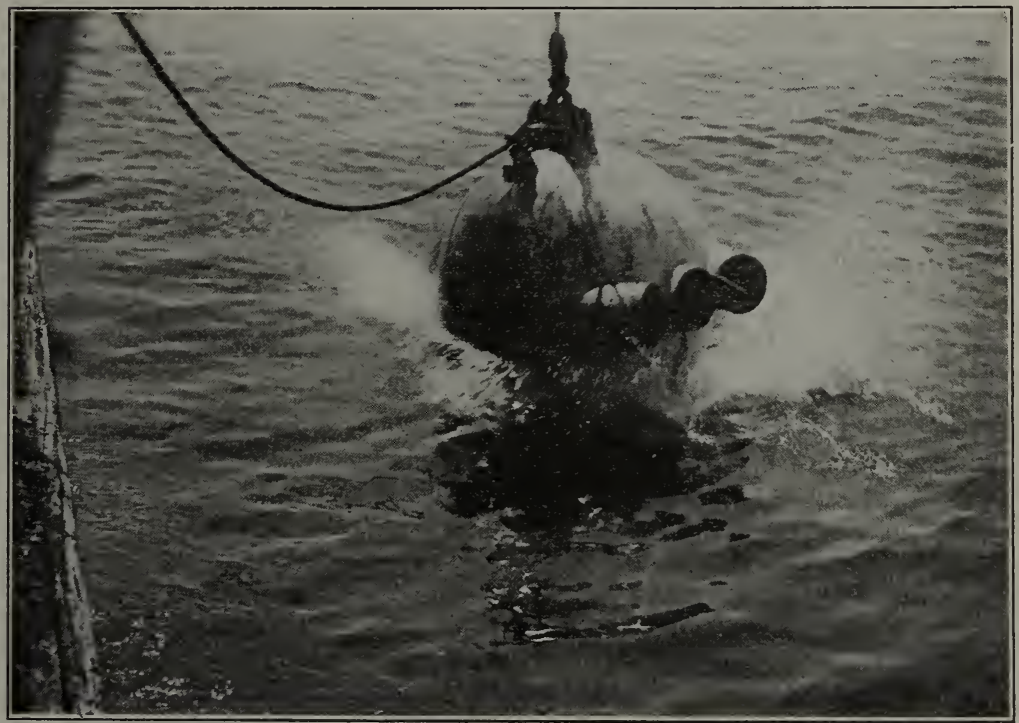

William Beebe

William Beebe has explored the sea and studied the animals and plants there, by means of a large steel sphere (Bathysphere) four and a half feet in diameter. It is equipped wlth a telephone and electric wires and connected to the surface, with a heavy steel cable. 
Since this unit of work is largely for each one's own personal use, a series of test questions is unnecessary. If the unit has started you thinking about your life work and the ways in which you may be able to fit into the niche where you belong, then these pages have served their purpose. It is well, however, to see what standards of attainment we have reached.

\section{Test on Fundamental Concepts}

In a vertical column under the heading CORRECT write numbers of all statements you believe are true. In another column under INCORRECT write numbers of untrue statements. Your grade $=$ right answers $\times 4$.

I. Self-analysis is necessary in choosing a vocation (1) because certain abilities and habits are necessary for success in certain professions; (2) unless a job is already made for us, then we should take it no matter whether we want to do it or not; (3) otherwise we may be a "square peg in a round hole"; (4) so that we may determine whether we are fitted for the work we wish to take up; (5) as well as good health.

II. To be a successful physician (6) one should have a good social position so as to get in with the best people; (7) one must be willing to work hard without adequate pay for at least ten years; $(8)$ it is not necessary to like dissection nor to have good eyesight, as most of the work is done in an office and consists in making prescriptions ; (9) one must have good eyes, a steady hand, a scientific mind, and, above all, a pleasant personality; (10) one must have good health or other qualifications will not matter.

III. Dentistry, public health work, and nursing (11) all require special qualifications, namely, leadership and social position; (12) require training in hygiene, anatomy, and chemistry; (13) require health as a basis for all other qualifications; (14) require such attributes as tact, sympathy, understanding of people, and desire to be of use to others ; (15) are neither lucrative nor interesting and should not be considered as professions.

IV. Teaching (16) is not a worth-while profession as it pays such small salaries; (17) requires health, tact, sense of humor, love of the work, and a love of children; (18) has a high death rate and is therefore classified as a dangerous profession; (19) of biology requires an analytical mind, an ability to seek for the truth, and a love of nature; (20) should not be taken up as a temporary profession because long and careful training is necessary to become a good teacher. 
V. To be successful in agriculture or forestry (21) one must have good health, for much of the work is out-of-doors; (22) one must have training along specialized lines such as plant and animal breeding, tree culture, etc. ; (23) it is not necessary to have any special training except a love for the out-of-doors ; (24) at least four years in a school of agriculture or forestry is desirable; (25) all one needs is tact, optimism, and executive ability.

\section{Achievement Test}

1. What are the chief characteristics necessary to become a successful physician? A dentist? A nurse?

2. What type of mind makes the best teacher? The best research worker?

3. What characteristics would best fit one for agriculture? For forestry?

4. What training would be necessary for each of the above vocations?

\section{USEFUL REFERENCES}

Dorsey, Why We Behave Like Human Beings. (Harper \& Bros. 1925.)

James, Psychology. Briefer Course. (Henry Holt \& Co. 1923.) Parsons, Choosing a Vocation. (Houghton Mifflin Co. 1909.) Spillman, Personality. (Gregg Publishing Co. 1919.) 


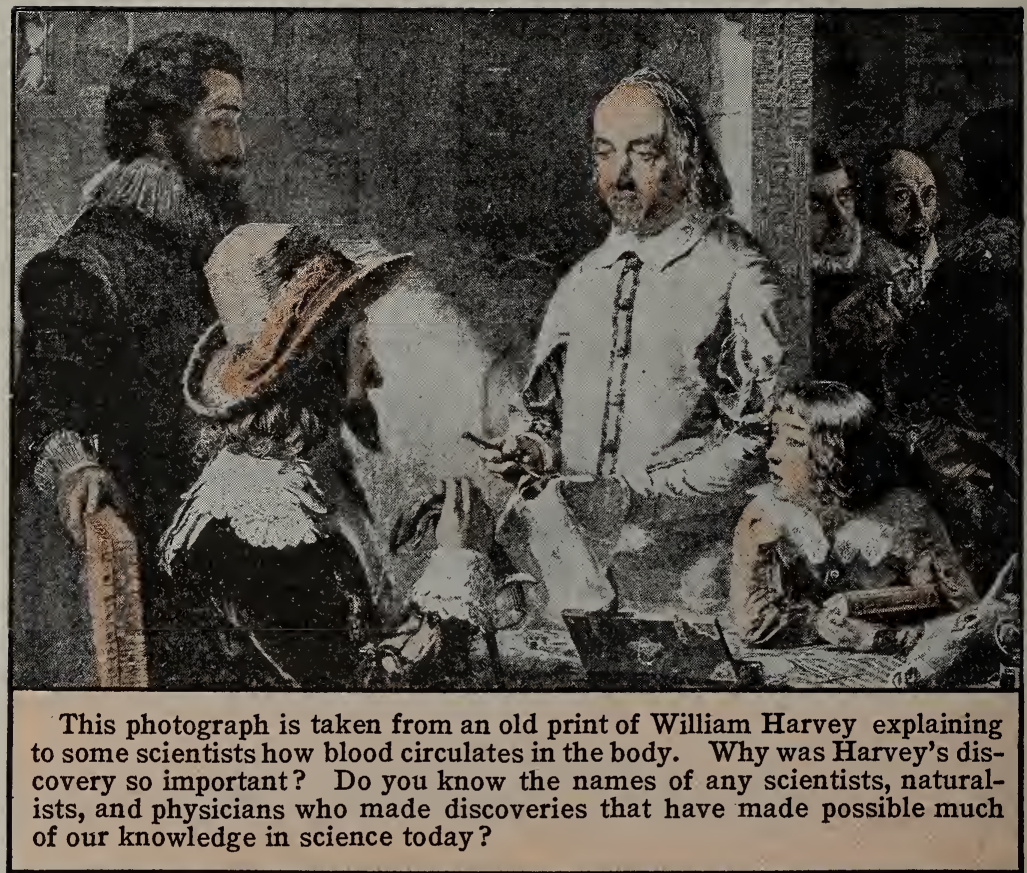

Culver Service

\section{UNIT XX}

\section{WHO ARE SOME OF THE MAKERS OF BIOLOGY?}

Preview. This unit is intended primarily for reference and should be used in connection with the other units of work. When, for example, you are studying about bacteria, read here and elsewhere on the life of Louis Pasteur. Every bird-lover should know something about the life of Audubon. Modern applications of biology to plants and animals are intimately connected with the names of Mendel and Burbank.

If we were to attempt to group the men associated with the study of biology, we should find that in a general way they are connected either with discoveries of a purely scientific nature or 
with the improvement of man's condition by the application of certain scientific discoveries. The first group is necessary in order that the second group may work further on the results. It was necessary for men like Charles Darwin and Gregor Mendel to formulate their theories before Luther Burbank or any of the men now working in the Department of Agriculture could benefit mankind by producing new varieties of plants. The discovery of scientific truths must be made before the men of modern medicine can apply them to the cure or prevention of disease. Since we are most interested in discoveries which touch directly upon human life, the men of whom this chapter treats will be those who, directly or indirectly, have benefited mankind.

\section{PROBLEM I. WHO WERE SOME EARLY WORKERS IN BIOLOGY?}

The discoverers of living matter. The names of a number of men living at different periods are associated with our first knowledge of cells. About the middle of the seventeenth century microscopes came into use. In 1667, an Englishman named Robert Hooke sliced a piece of cork with a razor and looked at it through a lens. He saw that the cork was made up of many tiny boxes or cells. But he saw only the dead cell walls and not the more important living matter. It was not until 1838 that two German friends, Schleiden (shli'den) and Schwann (shvän), working on plants and animals, discovered that both of these forms of life are built up of units called cells and that these cells were composed of living material. Other biologists gave the name protoplasm to all living matter, and a little later Professor Huxley, a famous Englishman, friend and champion of Charles Darwin, called attention to the physical and chemical qualities of protoplasm so that it came to be known as the chemical and physical basis of life.

Life comes from life. Another group of men, after years of patient experimentation, proved the fact that life comes from life. In ancient times it was thought that life arose spontaneously; for example, that fish or frogs grew out of the mud of the river bottoms, and that insects came from dew or the rotting of meat. Redi ( $\left.\mathrm{ra}^{\prime} \mathrm{de}\right)$, an Italian physician, 1629-1694, was the first to show 
by simple experiments that flies laid their eggs in decaying meat, which accounted for the maggots found there. But the controversy frequently raged between those who believed that life arose spontaneously and those who believed that all life came from

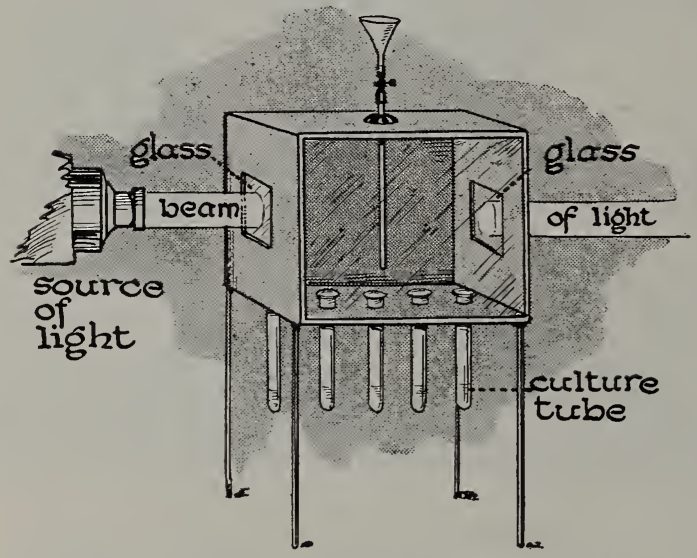

Tyndall used this apparatus to help disprove the theory that bacteria arose spontaneously. He put nutritive fluids in the culture tubes which were enclosed in a box containing air. The sides of the box were sticky so that all dust particles in air were held. A beam of light was used to see if any free particles were floating in the air. The tubes were heated. No organisms appeared in the tubes, as long as they were kept in the dust-free air.

previous life. It was believed that bacteria arose spontaneously in water, even as late as 1876, when Professor Tyndall proved by experiment the contrary to be true.

Physiology. In 1651 William Harvey, physician of Charles I of England, showed that living things came from egg cells. It was much later, however, that the part played by the sperm in fertilizing the egg cell was carefully worked out. It is to Harvey, too, that we owe the discovery of the circulation of the blood. He showed that blood moves in a complete circuit in the body and that the heart pumps it. Up to his time the arteries had been thought to be air tubes, because after death they were, empty of blood. Harvey might be called the father of modern physiology as well as of embryology. The heading of this unit shows an old print of Harvey demonstrating the circulation of blood to a group of scientists.

Van Leeuwenhoek, who lived from 1632 to 1725 , is known as the maker of the improved microscope, although his simple lenses were far from equaling our modern instruments. We also connect his name with the confirmation of Harvey's work on the circulation of the blood, for it was he who first saw the circulation of blood in 
the capillaries. He says in speaking of circulation in a tadpole's tail, that "Thus it appears that an artery and a vein are one and the same vessel, prolonged and extended."

A long list of other names might be added to show how gradually our knowledge of the working of the human body has been increased. At the present time we are far from knowing all the functions of the various parts of the human engine, as is shown by the number of investigators in physiology at the present time. Present-day problems have much to do with the care of the human mechanism and with its surroundings. The solution of these problems will come from the application of hygiene, preventive medicine, and sanitation.

\section{Self-Testing Exercise}

In 1667 Robert Hooke discovered .......(1). .......(2) and ....... (3) independently found that all .......(4) and ....... (5) are made of cells. .......(6) discovered the circulation of the blood. ........ (7) first proved that flies developed from eggs.

\section{PROBLEM II. WHO WERE SOME OF THE CONQUERORS OF DISEASE?}

In the preceding units of this book we have learned something about our bodies and their care. We have found that man is able within limitations to control his environment and make it better. All of the scientific facts that have been of use to man in the control of diseases have been found out by men who have devoted their lives to this work in the hope that their experiments and their sacrifices of time, energy, and sometimes of life itself might make for the betterment of the human race. Such men were Jenner, Lister, Koch, and Pasteur.

Edward Jenner and vaccination. The civilized world owes much to Edward Jenner, the discoverer of the modern method of vaccination. He was born in Berkeley, a little town of Gloucestershire, England, in 1749. As a boy he showed a strong liking for natural history. He studied medicine and also gave much time to the working out of biological problems. As early as 1775 he began 
to associate the disease called cowpox with that of smallpox, and gradually the idea of inoculation to prevent this terrible scourge, which killed or disfigured hundreds of thousands every year in England alone, was worked out and applied. He believed that if the two diseases were similar, a person inoculated with the mild disease (cowpox) would after a slight attack of this disease be immune to the more deadly and loathsome smallpox. It was not until 1796 that his theory was generally accepted, as at first few people would submit to vaccination. War at this time was being waged between France and England, so that the former country, usually quick to appreciate the value of scientific discoveries, was slow to give this method a trial. In spite of much opposition, however, by the year 1802 vaccination was practiced in most of the civilized countries of the world. At the present time the death rate from smallpox in Great Britain, the home of vaccination, is less than .3 to every $1,000,000$ living persons. This shows that the disease is practically wiped out in England. An interesting comparison might be made between these figures and those of France in 1754 before vaccination was practiced. A French physician then stated that " every tenth death was due to smallpox, and one fourth of manhood was either killed by it or crippled and disfigured for life."

Another interesting comparison may be made between Massachusetts and California, two states having nearly equal populations. In Massachusetts vaccination is required by law of all children who attend school ; in California no such law exists and in addition there are a good many people who do not believe in vaccination. During the period between 1921 and 1926 there were 64 cases of smallpox in Massachusetts, a case rate of .3 per 100,000. During the same period there were 26,985 reported cases in California, a case rate of 104.1 per 100,000 and these cases were not centered among the Mexicans or other foreigners, but largely among young people of school age whose parents did not believe in vaccination. Such comparisons speak for themselves. Since some stubborn opposition to vaccination is found even nowadays, Jenner must have had an extremely hard time in his day to have his idea accepted. He had many failures, due to the 
imperfect methods of his time, but he lived long enough to receive many honors and to see vaccination used throughout the civilized world.

Louis Pasteur. The man who, from a biological point of view, has done more than any one other person to benefit mankind directly was Louis Pasteur. Born in 1822, in the mountains near the border of southeastern France, he spent the early part of his life as a normal country boy, fond of fishing and not very partial to study. He inherited from his father, however, a fine character and a grim determination, so that when he became interested in scientific pursuits, he settled down to work with enthusiasm and energy.

At the age of twenty-five he became well known throughout France as a chemist. Shortly

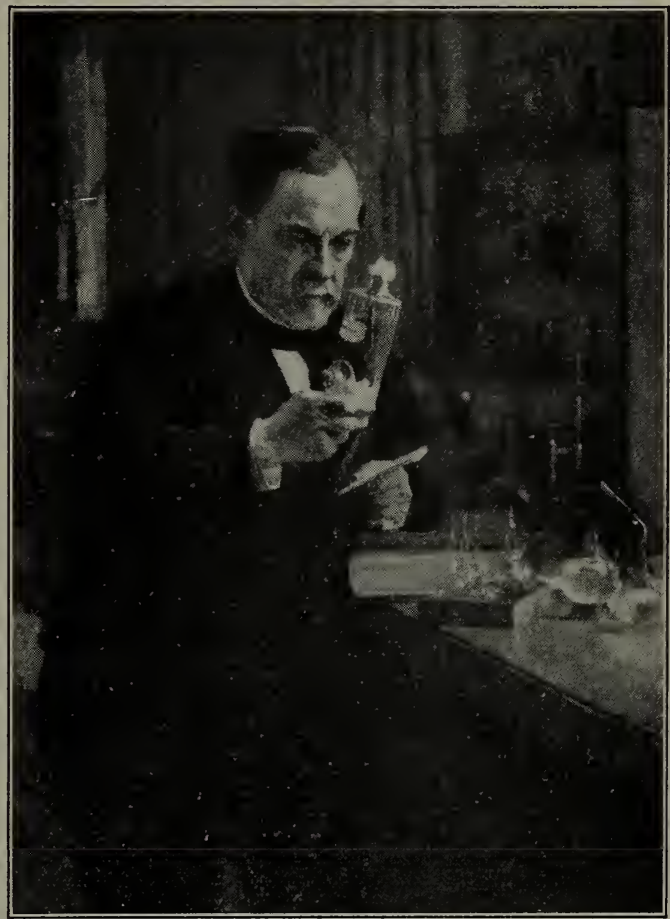

What are some of the discoveries for which Louis Pasteur is noted? after this he became interested in bacteria, and it was in the field of bacteriology that he became most famous. First as professor at Strasbourg, then at Lille, and later as director of scientific studies in the Ecole Normale at Paris, he showed his interest in the application of his discoveries to human welfare.

In 1857 Pasteur showed that bacteria are connected with the process of fermentation, and that it is not a purely chemical н. ВIO -43 
process as had been thought up to that time. This discovery led to very practical ends, for France was a great wine-producing country, and with a knowledge of the cause of fermentation it was possible to check the diseases which had spoiled wine.

In 1865-1868 Pasteur turned his attention to a silkworm disease which threatened to wipe out the silk industry of France and

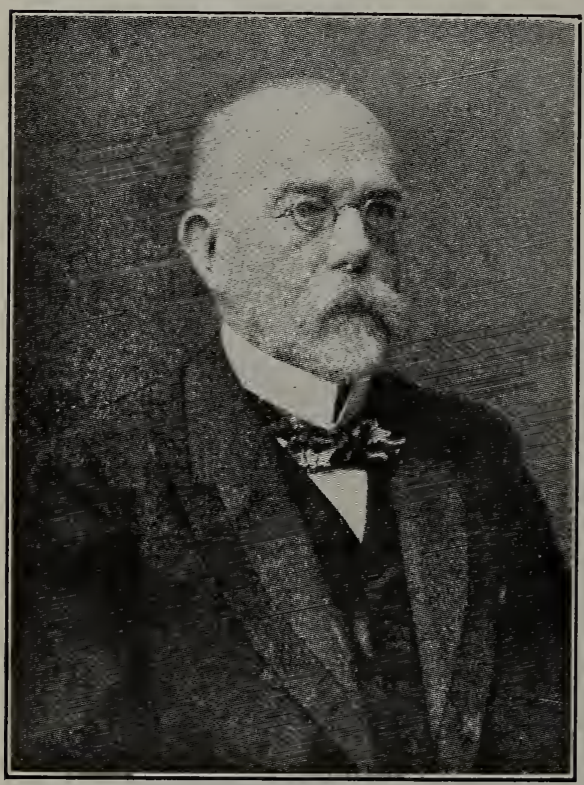

Robert Koch.

Italy. He found that this disease was caused by two tiny organisms, one a protozoan, the other a bacterium. After careful study he made certain recommendations which, when carried out, resulted in the complete conquest of the disease and the saving of millions of dollars to the people of France and Italy.

His greatest service to mankind came later in his life when he applied certain of his discoveries to the treatment of disease in people. First experimenting upon chickens, he proved that a vaccine made from the germs which caused chicken cholera could be reduced to any desired strength. He then inoculated chickens with the vaccine of reduced strength, giving them a mild form of the disease, and found that this made them immune. This discovery, first applied to chicken cholera, laid the foundation for all future work in the uses of serums, vaccines, and antitoxins.

Pasteur is perhaps best known through his study of rabies. The great Pasteur Institute, founded by popular subscriptions from all over the world, has successfully treated many thousands of cases of rabies with a death rate of less than one per cent. But 
more than that, it was the place where Roux (rō), a fellow worker with Pasteur, discovered the antitoxin for diphtheria, which has saved thousands of human lives. There also were established the principles of inoculation against bubonic plague, lockjaw, and other germ diseases.

Pasteur died in 1895 at the age of seventy-three, beloved by his countrymen and honored by the entire world.

Robert Koch. Another name associated with the battle against disease germs is that of Robert Koch (kōk). Born in Germany, in 1843 , he later became a practicing physician, and about 1880 was called to Berlin to become a member of the sanitary commission and professor in the school of medicine. In 1881 he discovered the germ that causes tuberculosis and two years later the germ that causes Asiatic cholera. His later work was directed toward the discovery of a cure for tuberculosis and for other germ diseases. He died in 1910.

Lister and antiseptic treatment of wounds. A fourth great benefactor of mankind was Sir Joseph Lister, an Englishman who lived from 1827 to 1912 .

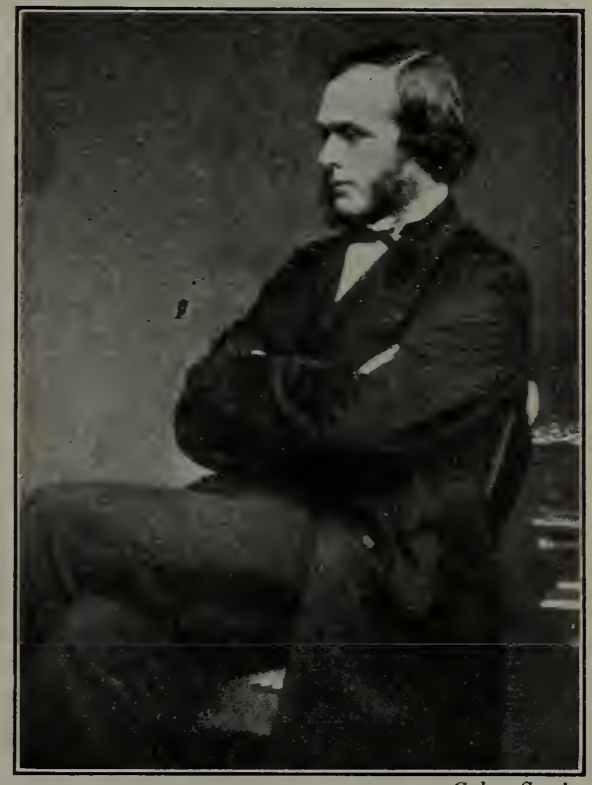

Culver Service

Lord Lister. What has resulted from Lister's discovery of the use of antiseptics?

As a professor of surgery he first used antiseptics in the operating room. By the use of carbolic acid and other antiseptics on the surface of wounds, on instruments, and on the hands and clothing of the operating surgeons, germs were prevented from infecting the wounds. This single discovery has done more to prevent death after operations than any other of recent time. 


\section{WHO ARE SOME OF THE MAKERS OF BIOLOGY?}

Morton and anaesthesia. One can well imagine what a horrible thing an operation was in the early days of surgery when no anaesthetics were used. The first use of ether in surgery was made by Dr. T. G. Morton in the Massachusetts General Hospital

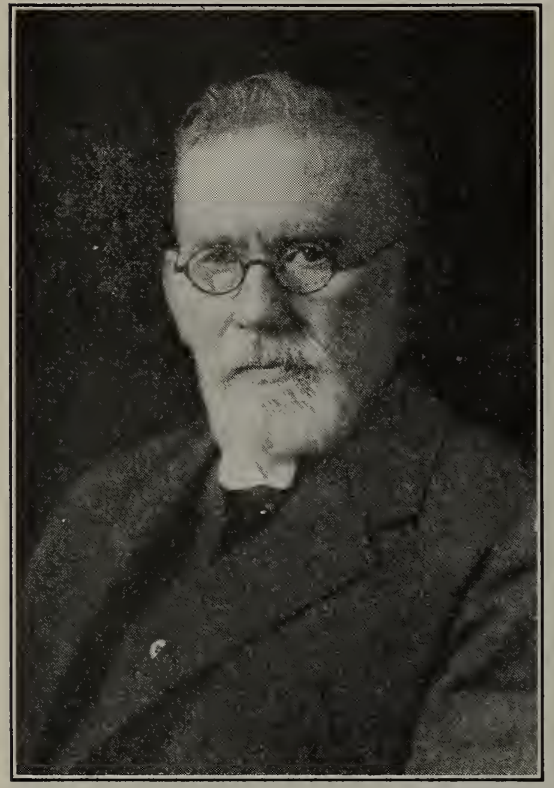

Professor Erhlich. on October 16, 1846. Later chloroform was used, and up to the present time no better agents have been found. The use of anaesthetics was one of the great discoveries in medicine, as they relieve suffering and make operations so much easier and safer.

Modern workers on the blood. At the present time several names stand out among investigators of the blood. Paul Ehrlich (ār'lǐk), a German born in 1854, is justly famous for his work on the blood and its relation to immunity from certain diseases. His able research work has given the world a much better understanding of acquired immunity and has enabled physicians to fight the dread venereal disease, syphilis, with good results.

Another name associated with the blood is that of Elias Metchnikoff, a Russian born in 1845. He first advanced the belief that colorless blood corpuscles, or phagocytes, do service as the sanitary police of the body. He has found that there are several different kinds of colorless corpuscles, each having different work to do. Much of the more modern work done on the blood is founded directly on the discoveries of Metchnikoff.

Other workers. Many other names could be added. Walter Reed, the leader of the fight against yellow fever; Major Ross, who discovered the malarial parasite; Carrel, who was responsible 
for the Carrel-Dakin treatment of wounds during the war; Noguchi, the Japanese who prepared antitoxins against snake venom and who gave his life in May, 1928, in an attempt to conquer yellow fever ; Flexner, for his discoveries in connection with infantile paralysis; and the Dicks, husband and wife, who have worked out a method of treatment for scarlet fever; and many others.

\section{Self-Testing Exercise}

Jenner first used the modern method of ........(1) against (2). This disease has been practically wiped out in states where ........ (3) is (4) by law. Louis Pasteur was the first ........ (5). He laid the foundation for all modernwork in ........

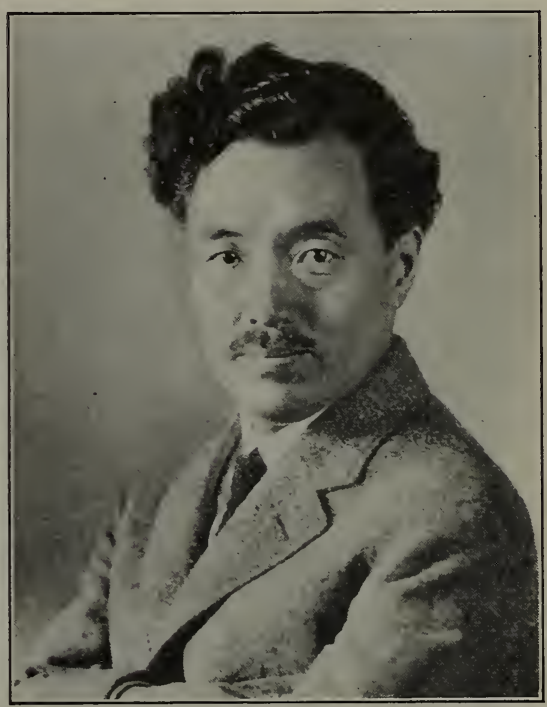

Dr. Hideyo Noguchi.

(6). .......(7), a fellow worker with Pasteur, prepared the . (8) against ....... (9). Lister first used .......(10) in surgery. Koch discovered the ........ (11) which causes tuberculosis.

\section{PROBLEM III. WHAT ARE SOME GREAT NAMES IN THE STUDY OF PROGRESSIVE DEVELOPMENT?}

Charles Darwin. Another important line of biological investigation is the study of the progressive development of life on the earth. The idea of evolution was known to the Greek philosophers and we now call Aristotle the father of the idea of evolution. In the early part of the nineteenth century the name of a French naturalist stands out as he advanced a theory of descent in which the environment played a considerable part. But the name of Darwin is most indelibly associated with modern thought on progressive development. 
Charles Darwin was born on February 12, 1809, a son of wellto-do parents, in the pretty English village of Shrewsbury. As a boy he was very fond of out-of-door life, was a collector of birds' eggs, stamps, coins, shells, and minerals. He was sent to Edinburgh University to study medicine, but the dull lectures, coupled
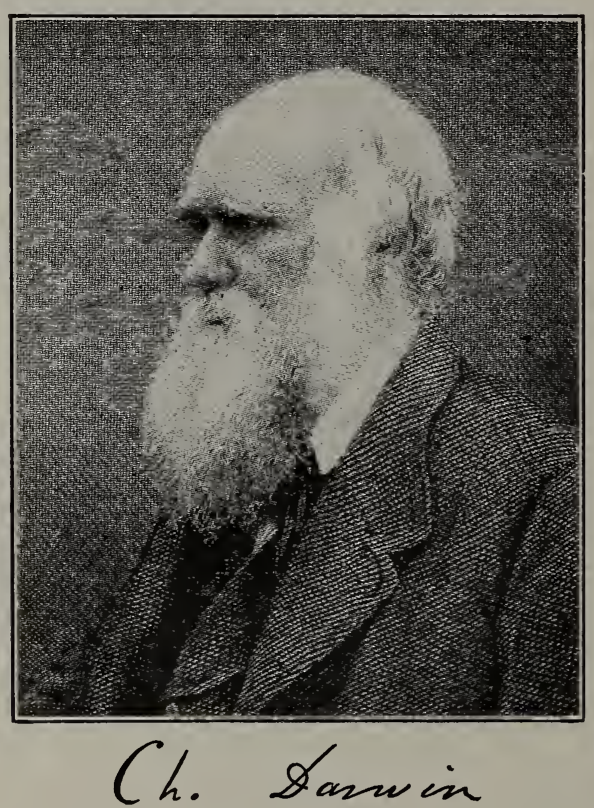

with his intense dislike for operations, made him determine never to become a physician. Instead, he was greatly interested in natural history, and in the proceedings of a student zoölogical society.

In 1828 his father sent him to Cambridge to study for the ministry. His three years at this university were wasted so far as preparation for the ministry was concerned, but they were invaluable in shaping his future. He made the acquaintance I like thes Thotigngh nen much better of one or two professors who were naturalists like himself, and in the $r$ company he spent many happy hours roaming over the countryside collecting beetles and other insects. In 1831 an event occurred which changed his career and helped him to become one of the world's greatest naturalists. He received word through one of his friends that the position of naturalist on the ship Beagle was open for a trip around the world. Darwin applied for the position, was accepted, and shortly after started on an eventful five years' trip around the world. He returned to England a famous naturalist and spent the remainder of his long and busy life writing books 
in which he attempted to account for the changes of form and habits of plants and animals on the earth. His theories established also a foundation upon which plant and animal breeders were able to work. Two of his best known books are Origin of Species and Plants and Animals under Domestication. We have studied about some of his work on pollination (page 56) and his theory of "natural selection" (page 605).

His interpretation of the ways in which all life changes and develops was due not only to his information and experimental evidence, but also to an iron determination and undaunted energy. In spite of almost constant illness brought about by eyestrain, he accomplished more than most well men have done. He died on the 19th of April, 1882, at seventy-four years of age.

Other workers. Associated with Darwin's name we must place also the names of two other co-workers on heredity. Alfred Russel Wallace, an Englishman, who, working independently and at about the same time, reached many conclusions similar to those of Darwin. Thomas Henry Huxley did much to make people understand Darwin's work, as he was a wonderful teacher and lecturer.

In recent years there have been many new facts discovered which make us doubt that Darwin's explanation for some of the phenomena he described may be the best that can be given. But the evidences for the development of plant and animal life are stronger than ever and no thinking scientist can deny this remarkable story which is written in the rocks, and in the relationships of living things as shown in structural and vestigial evidences, in embryological development, and in geographical distribution, all facts that Darwin pointed out after years of study.

\section{Self-Testing Exercise}

(1) is called the father of evolution.

(2) $\ldots \ldots \ldots$

(3) was the founder of the modern theory of progressive development. The foundation for Darwin's life work were laid in a ....... (4) around the .......(5) in the ship .......(6). Alfred Russel (7) worked .......(8) of Darwin, but came to the same (9). 


\section{PROBLEM IV. WHAT ARE SOME GREAT NAMES IN NATURAL HISTORY?}

Linnaeus. ${ }^{1}$ The one name that stands out in the early science of classification of plants is that of Carl von Linne, known to us as Linnaeus. Modern classification of plants (and subsequently of animals) dates from the time of the publication of his great work,
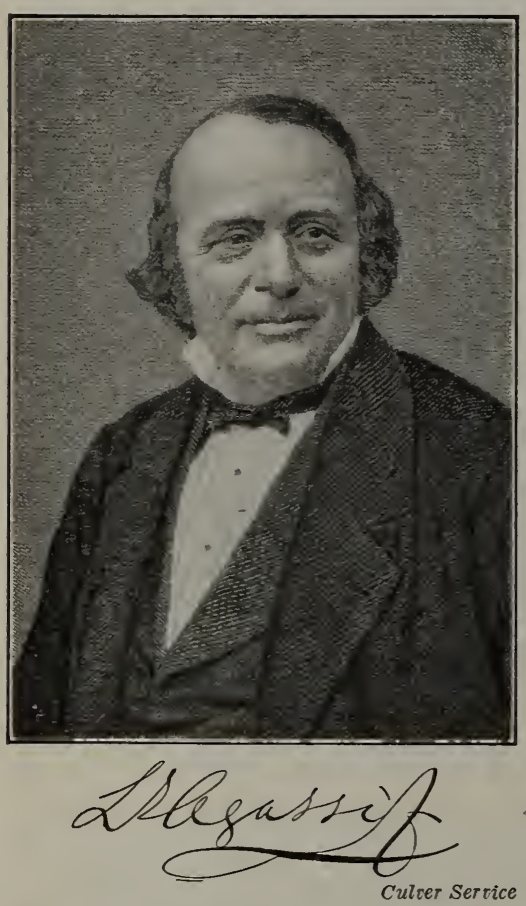
in which all the forms of plants known at that time were described and arranged according to a definite system.

Louis Agassiz. ${ }^{2}$ In this country the names of pioneers in natural history stand out above a host of others. They are Audubon and Agassiz. Louis Agassiz was born in Switzerland in 1807. Coming to this country in 1846 , he soon became one of the bestknown and best-liked professors at Harvard. He founded the great Harvard Museum of Comparative Zoölogy. He was most interested in marine life and he established the first summer school for the study of natural history on the island of Penikese off Cape Cod, Massachusetts, in 1873. This was the beginning from which sprung the world-famous marine laboratory at Woods Hole, Massachusetts, where many of the biologists of this country have had at least a part of their training.

John James Audubon (1785-1851) was French by birth and education. He was educated as a gentleman in a wealthy family, and studied drawing among other subjects. But he always was a 
collector and often returned from rambles in the country loaded down with specimens. Later in life this must have given him the background his genius needed. He lost his money while still a young man, sold his property near Philadelphia, and moved west with his young wife to Louisville, Kentucky. Here he began a life of wandering and careful study of birds which has given to us some of our most valuable information on the bird life of that region west of the Alleghenies. His descriptions of the killing of immense numbers of passenger pigeons and of an Indian swan hunt give us the reasons for the disappearance of these two birds from our country. Audubon is best known for his wonderful work on North American birds, which he illustrated with colored plates drawn by himself. He traveled in all accessible parts of United States and Canada for material. As a result of this work he became famous. He died in comparative comfort at
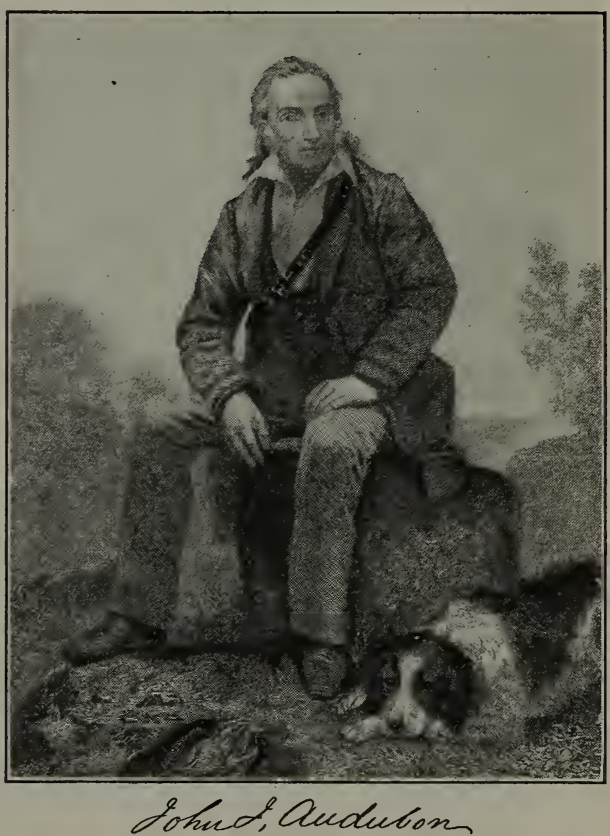

Charles L. Ritzmann his home on the banks of the Hudson in upper Manhattan on January 27, 1851.

\section{Self-Testing Exercise}

Linnaeus made the ....... (1) system of ....... (2).

(3) ........ (4) trained many ....... (5) in this country at the first seashore .......(6) on the island of Penikese. This laboratory later gave rise to the now famous one at ....... (7) ....... (8), (9). Audubon was a great .......(10) and a painter of (11). 


\section{PROBLEM V. WHAT ARE SOME GREAT NAMES CONNECTED WITH PLANT AND ANIMAL BREEDING?}

Weissman. August Weissman, a German, showed that the protoplasm of the germ cells (eggs and sperms) is handed down directly from generation to generation, these cells being different

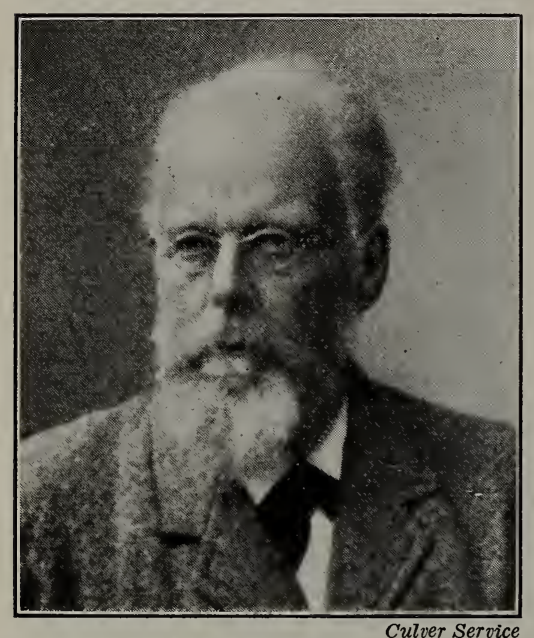

August Weissman.

from the others in the body almost from the beginning of the development of the embryo.

Workers with Chromosomes. In 1883 a German named Boveri discovered that the chromosomes of the egg cell and of the sperm cell are at the time of fertilization just half the number of those of the other cells (see page 627), so that a fertilized egg is really a whole cell made up of two half cells, one from each parent. The chromosomes, we remember, are known to be the bearers of the hereditary qualities handed down from parent to child. Some of the most important work on the chromosomes has been done by Thomas Hunt Morgan, who is now a professor at the California Institute of Technology. He and his students have worked with a little fruit fly, in the chromosomes of which have been isolated the tiny genes which have been found to be the structures which pass on the heredity qualities from parent to offspring.

Mendel. Turning to the practical applications of the scientific work on the method of heredity, the name of Gregor Mendel, an Austrian monk, stands out most prominently. Mendel was born in 1822. He early entered the monastery at Brunn, where he lived until his death in 1884. In 1865, after several years of experimentation, he published the results of his work on inheritance in peas. But his work created no interest at the time and remained unknown until the year 1900, when it became world-famous. The 
application of his methods to plant and animal raising are of the utmost importance in assisting the breeder to develop the qualities he desires and breed for those qualities only.

De Vries. Another name often mentioned with reference to plant breeding is that of Hugo de Vries, the Dutchman who has showed that in some cases new kinds of plants arise by sudden and great variations known as mutations. Professor Morgan has actually produced new species of fruit flies as a result of his careful study of mutants. De Vries's work, with that of scores of other workers in heredity, is paving the way for the practical plant and animal breeders.

Burbank. We must not close without a mention of Luther Burbank, whose work with plant hybrids has won him everlasting recognition as a benefactor of man. He was born in Lancaster, Massachusetts, on March 7, 1849, and he

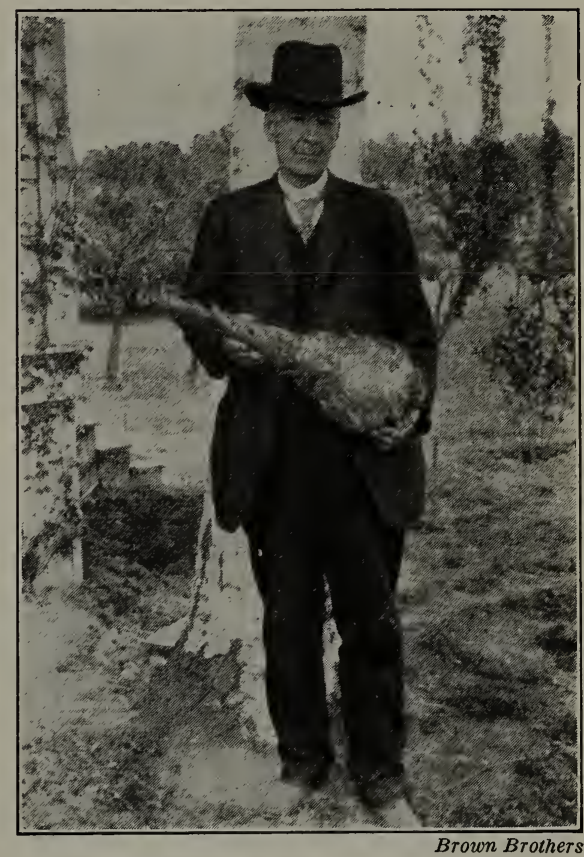

Luther Burbank. Name four improved forms of plants for which he was responsible. died at his home in Santa Rosa, California, on April 11, 1926. As a boy he was interested in the out-of-doors and particularly in plant life. He was known as the Wizard of Santa Rosa because there his experimental farm was located and there he developed most of his new and improved plant forms. The Burbank potato, with its large yield, would alone be a monument, but he followed this with literally hundreds of improved and new forms. He produced a cross between a plum and an apricot, which he called a plumcot. He crossed a small cream-colored berry with a large 


\section{WHO ARE SOME OF THE MAKERS OF BIOLOGY?}

blackberry. Then he selected for breeding the best hybrid berries for several generations, and finally succeeded in obtaining a large white blackberry with a pleasing flavor. By crossing plums which were resistant to cold and frost with plums which had many other desirable qualities, he obtained a large juicy plum with a small stone, and which will grow in practically any conditions of climate and soil. He produced rapid-growing walnuts, and many other new forms of fruits and vegetables. His work was almost entirely hybridizing and he destroyed thousands of plants in order to obtain the ones with exactly the qualities he wished to perpetuate. $\mathrm{He}$ estimated that he raised over 1,000,000 plants every year for breeding purposes. At his death there were over 5000 different forms of plants growing on his experimental farm.

\section{Self-Testing Exercise}

Boveri discovered that the .......(1) and .......(2) before fertilization had just ........(3) the number of chromosomes found in the $\ldots \ldots$ (4) .......(5). Gregor Mendel worked out certain (6) of $\ldots \ldots \ldots(7)$ in $\ldots \ldots \ldots(8)$. These have been (9) today by many plant and animal ........(10). Luther Burbank improved plants largely through ................ (12).

\section{Achievement Test}

1. What are some names of persons, not mentioned in this unit, who are well known in modern biological sciences? In medicine? In public health?

2. How would you classify the names in this unit under the headings given and tell two things for which each person is famous?

3. Why is Mendel's work on heredity considered so important?

\section{USEFUL REFERENCES}

Darwin, Life and Letters of Charles Darwin. (D. Appleton \& Co. 1911.)

De Kruif, Microbe Hunters. (Harcourt, Brace \& Co. 1926.)

Downing, Science in the Service of Health. (Longmans, Green, \& Co. 1930.) 
Gruenberg, Modern Science and People's Health. (Norton \& Co. 1926.)

Hallock and Turner, Health Heroes. Series. (Metropolitan Life Insurance Co.)

Hartzog, Triumphs of Medicine. (Doubleday, Doran \& Co. 1927.)

Harwood, New Creations in Plant Life: (The Macmillan Co.)

Hunter and Whitford, Readings in Science. Pp. 17-41. (The Mac. millan Co. 1931.)

Locy, Biology and Its Makers. (Henry Holt \& Co.)

Locy, Main Currents of Zoology. (Henry Holt \& Co.)

Vallery-Radot, The Life of Pasteur. (Doubleday, Doran \& Co. 1923.) 



\section{GLOSSARY OF IMPORTANT TERMS}

The diacritical marks are those used in the Webster school dictionaries.

Abdomen (ăb dō'mĕn) : the posterior region of the body, behind the thorax, of an insect; the region of the body below the chest in man.

Absorption (ăb sôrp'shŭn): the process of taking up liquid food or other substances through the walls of cells.

Adaptation (ăd'ăp tā'shŭn): fitness for surroundings; fitness to do a certain kind of work; changes which a plant or an animal has undergone that fit it for the conditions in which it lives.

Adenoids (ăd'è noids) : fleshy growths in the back of the nose cavity which clog the air passages.

Adrenaline (ăd rē'năl Ĭn): commercially prepared adrenin, a secretion of the adrenal glands.

Adrenals (ăd rē'năls): two small ductless glands situated just above the kidneys.

Adulterant ( $\dot{a}$ dŭl'tẽr $\breve{n t}): \quad$ a substance put in another to cheapen it ; usually reducing its strength or otherwise injuring it.

Aërobic (ā ẽr ó'bỳk) organisms: bacteria or other organisms which require free oxygen, as opposed to anaërobic organisms (bacteria and some parasitic worms) which do not require free oxygen.

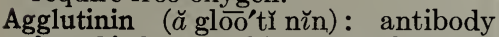
found in blood, which causes bacteria to be clumped together, preparatory to their destruction by the colorless corpuscles.

Albumin (ăl bū'min) : a protein forming an important part of the blood, and found also in many animal and vegetable substances.

Alimentary (ăl'i men't $\dot{a}$ rî) canal: the food tube.

Alternation of generations : the alternating of a sexual with an asexual generation in the life-history of a plant or an animal.

Amino acid (ăm̛̃ nō ăs'ĩd) : a part of a complex protein; one of the simpler substances into which a protein may be broken down in the body.

Analogy ( $\dot{a}$ năl'ó jŭ $)$ likeness in function.

Antenna (ăn tĕn'a) (pl. Antennæ): a jointed feeler on the head of an insect or of a crustacean.

Anterior : nearer the head end (Zoöl.) ; facing outward from the axis (Bot.).

Anther (ăn'thẽr): the part of the stamen which develops and contains pollen.

Antibodies (ăn'tř bŏd'1z): substances found in the blood, which fight against bacteria or toxin which may enter the body.

Antiseptic (ăn'tr̆ sĕp'tı̌k) : a substance which prevents the growth of harmful microörganisms.

Antitoxin (ăn'ty tŏk'sı́n): a substance that neutralizes a toxin or poison produced by invading disease germs.

Anus $\left(\bar{a}^{\prime} n u ̛ s\right)$ : the posterior opening of the food tube.

Aorta $(\bar{a}$ ôr'tà): the large artery leaving the left ventricle of the heart.

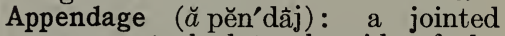
organ attached to the side of the body.

Arachnid ( $\dot{a}$ răk'nı̌d): any of the class of animals including the spiders and scorpions.

Artery (är'tẽr 1$)$ : a tube which conveys blood from the heart.

Aseptic ( $\dot{a}$ sěp'tyłk): free from pusforming bacteria or other harmful organisms.

Asexual ( $\dot{a}$ sĕkk'shù $a ̆ l)$ : having no sex. Assimilation (ă šm' lă'shün): the converting of digested food into living matter. 
Auricle (ốrí k'l): a chamber in the heart which receives blood.

Autonomic nervous system : a part of the nervous system not under control of the will; it is sometimes called the sympathetic nervous system.

Axon (ăk'sŏn): the main elongation of a neuron.

Bacillus (bi sì’ ǔs): a rod-shaped bacterium.

Bacteria (băk tērrǔ $a$ ): microscopic one-celled plants, some of which cause specific diseases.

Bacteriology (băk tē'rr ŏl'ô jǐ) : a study of bacteria.

Bast : tough, fiberlike cells composing the inner layer of bark.

Biennial (bỉ ěn’ř ăl) : a plant which completes its life cycle in two years - producing leaves the first year and fruit and seed the second.

Bile : a fluid secreted by the liver.

Biology (Gr. bios, life ; logos, word or discourse): the study of matter in a living state; the study of plants and animals.

Bivalve: mollusk having shell consisting of two distinct parts or valves connected by a hinge.

Blade : the flat portion of a leaf.

Blastula (blăs'tư lá): a stage in the segmentation of an egg in which the cells form a hollow ball with a wall one layer thick.

Bryophyta (brī of' 1 t $\dot{a}$ ) : the phylum of plants to which the mosses belong.

Bud : an undeveloped branch.

Calorie (kăl'ó rř) : a heat unit, namely, the amount of heat required to raise the temperature of one kilogram of water one degree Centigrade.

Calorimeter (kăl'ô rǐm'è tẽr): a machine for measuring amount of heat in foods.

Cambium (kăm’bř ŭm): the layer between the wood and the inner bark where growth takes place.

Capillaries (kăp'̛ lă rǐz) : minute tubes which connect arteries with veins.

Capillarity (kăp’̂́ lăr'1́ tî) : a phenomenon shown by liquids rising in fine tubes.
Carapace (kăr'a pās): a bony or chitinous case covering an animal's back, as the crayfish.

Carbohydrate (kär'bò hï'drāt) : a class of nutrients composed of carbon, oxygen, and hydrogen, having the oxygen and hydrogen in the same proportion as water.

Carbon: an element found in all organic compounds.

Carbon dioxide: a gas, a product of the oxidation of carbon.

Carnivores (kär'nī vōrs): an order of flesh-eating mammals, including the cats, dogs, bears, etc.

Cell : the structural and physiologicai unit in plant and animal bodies. A small mass of protoplasm in most cases inclosed in a cell membrane and usually containing a nucleus.

Cell membrane: the delicate living covering of a cell.

Cell sap: water, with materials in solution, found in the vacuoles of plant cells.

Cellulose (šl'tû lōs): a dead substance found in the walls of plant cells.

Cephalothorax (sếf' $a$ lô thō'răks): anterior division of body of some animals, consisting of the united head and thorax.

Cerebellum (sěr' è běl'ǔm): part of the brain between the cerebrum and the medulla oblongata.

Cerebrum (sěr'ê brüm): the anterior part of the brain.

Chemical compound: a substance formed by the combination of chemical elements.

Chemical element: a simple substance; one which cannot be broken into simpler substances.

Chitin (kîntin): a hard, nitrogenous substance present in the exo-skeleton of insects.

Chlorophyll (klō'rô fị): the green coloring matter of plants.

Chloroplasts (klōórồ plăsts): small bodies of protoplasm which contain chlorophyll.

Choroid (kón'roid) : the middle coat of the eye.

Chromosome (krō'mō sōm) : a deeply staining body in the nucleus of a 
cell, supposed to carry the determiners of hereditary qualities.

Chrysalis (kris' $a$ liss): the uncovered pupal stage of butterflies.

Cilium (sıl'ı̌ ŭm): a tiny hairlike thread of protoplasm extending from a cell.

Cloaca (klö $\left.\bar{a}^{\prime} k \dot{a}\right)$ : the common cavity into which the digestive, urinary, and reproductive systems open in some kinds of vertebrates.

Coccus (kǒk'ŭs): a spherical-shaped bacterium.

Cocoon (kồ kōn') : a silky covering around a pupa; the egg-case of spiders.

Coelenterata (sè lěn'tẽr à't $\dot{a}$ ): phylum of animals including the corals and jellyfishes.

Coleoptera (kŏl'è ŏp'tẽr $a$ ): the order of insects to which beetles belong.

Communicable disease: a disease that can be passed directly from one person to another.

Compound eye : an eye made up of many simple eyes or ommatidia. Insects have compound eyes.

Conjugation (kŏn'joo gā'shŭn): the temporary union of two sex cells of equal size, with a fusion of nuclei and interchange of nuclear material.

Connective tissue : collections of cells which support and connect other tissues.

Conservation : preserving or protecting.

Contractile vacuole : a small cavity, found in the cytoplasm of many protozoans, which appears and disappears with regularity. It is believed to be an organ of excretion.

Corolla (kó rŏl' $a$ ): the petals of a flower taken together.

Corpuscles (kôr'pŭs'ls): the red and the colorless cells in the blood.

Cortex 'kôr'těks): a fleshy portion of the root, outside the central cylinder; the inner layer of bark.

Cotyledon (kǒt'î lê'dŭn): leaf of an embryo, in a seed.

Cross-pollination : taking pollen from the anther of one flower and placing it on the stigma of another flower.

Crustacea (krŭs tä'shè $a$ ): class of animals including the lobsters, crayfish, and crabs.

Culture: a growth of bacteria or other microörganisms in a prepared nutrient medium.

Cycad (sīkăd): family of tropical gymnosperms.

Cyst (šst): a hard sac or capsule including a one-celled animal in its resting stage.

Cytoplasm (sī'tò plăz'm): the living substance of the cell outside of the nucleus and inside the cell membrane.

Deciduous (dè š̃d'ûu ŭs) : falling off at maturity.

Dehiscent (dè hǔs'ěnt) : opening along a definite line to discharge contents.

Dendrites (děn'drits): delicate protoplasmic branched endings of a neuron.

Dentine (děn'tǐn): material composing the main part of a tooth.

Dermis (dûr'mis): the layer of skin below the epidermis.

Diaphragm (dï' $a$ frăm): the muscular partition between the thorax and the abdomen.

Diastase (dî́ $\dot{a}$ stās): an enzyme formed in plants which changes starch to grape sugar.

Dicotyledon (dī kŏt'î lè'dŭn): a plant that bears seeds having two cotyledons.

Diffusion : the passage of particles of a substance, either gas or liquid, from a point of greater to a point of lesser concentration.

Digestion: the process of preparing food for absorption.

Dihybrid. Mendelian term for a cross between organisms which differ in two pairs of alternative characters.

Diptera (dǐp'tẽr $a)$ : an order of insect having two wings, as the flies.

Disease: a state in which part of the body does not function properly.

Disinfectant (dǔs'ı̂n fěk'tănt): something which kills bacteria.

Dominant: a Mendelian term applied to that unit character which stands out to the exclusion of the other or recessive character. 
Dorsal (dôr'săl) : of or pertaining to the back or top side.

Ductless glands: glands which have no communication with an outer surface, and which manufacture hormones.

Ecology (è kŏl’ò jü) : study of plants and animals in relation to their natural surroundings.

Ectoderm (ěk'tô dûrm): the outer layer of cells in an embryo.

Egg : the female gamete, the ovum.

Embryo (ěm’brī ō): the early stage of a developing plant or animal.

Embryo sac: the structure within the ovule which holds the egg cell.

Emulsion (è mŭl'shŭn): a mixture of liquids which do not dissolve, the particles of one floating as small globules in the other.

Enamel: hardest part of a tooth.

Encyst (en šst') : to become inclosed in an impermeable envelope or cyst.

Endocrine glands (ĕn’dò krīn): ductless glands.

Endoderm (ěn'dò dûrm): the inner layer of cells in an embryo, giving rise to the digestive tract, etc.

Endoskeleton (ěn'dō skěl'è tŭn): a skeleton inside the body as opposed to the outer or exoskeleton.

Endosperm (ĕn'dò spûrm): food stored in the seed outside the embryo.

Energy : work power ; ability to perform work. It may be latent or kinetic.

Environment (ĕn vī'rŭn mĕnt): the surroundings of an organism.

Enzyme (ĕn'zīm): a substance which brings about a chemical action, assisting in digestion.

Epidermis (ěp'î dûr'mǔs) : an outer layer of cells ; the outside skin.

Epiglottis (ĕp'î glŏt'ĩs): a covering over the opening into the trachea.

Erosion (è rō'zhŭn): the wearing away of rocks by water, wind, glaciers, and other agents.

Esophagus (è sŏf' $\dot{a}$ gŭs): muscular tube leading from the pharynx to the stomach; gullet.

Essential organs: the stamens and pistils, parts of a flower which have to do with the production of seeds.

Eugenics (ù jĕñ̂kss): the science which deals with race improvement through heredity.

Eustachian tube (ù stā'ǩ̆ ăn): the canal connecting the tympanic cavity with the pharynx, named for its discoverer, Eustachio, an Italian physician.

Euthenics (ù thĕn'îks): the science which deals with race improvement through betterment of the environment.

Excretion (ĕks krē'shŭn): elimination of waste products from an organism.

Exoskeleton (ěk'sō skĕl'è tŭn): an outside skeleton.

Expiration : process of forcing air out of lungs.

$F_{1}, F_{2}$, etc.: abbreviations indicating the successive generations following crossing or hybridizing.

Fatigue (f $\dot{a}$ têg') : the effect produced by prolonged stimulation on the cells of an organism.

Fats : a class of nutrients composed of much carbon and hydrogen with a little oxygen.

Fermentation (fûr'mĕn tā'shŭn): the chemical transformation of organic substances through the agency of enzymes or ferments, or through the agency of bacteria.

Fertilization (fûr'tǐ lǐ zā'shŭn): the union of an egg cell and a sperm cell.

Fibrinogen (fî brĭn'ó jĕn): a soluble protein substance in the blood plasma.

Fibrovascular bundles : collections of tubular cells, supported by woody cells, which conduct fluids in plants.

Fin: a fold of skin, with skeletal supports, used for swimming.

Fission (fǐsh' ǔn): division of a cell into two cells of equal size.

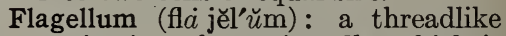
projection of certain cells, which is used for locomotion.

Focus of infection: a center of bacterial infection, often at the base of a tooth, from which toxins reach the blood. 
Fossils : petrified remains or impressions of living things of past ages.

Frond: leaf of a fern.

Fruit: a ripened ovary together with any parts of the flower adhering to it.

Function (fŭnk'shŭn): the normal action of an organ or organs.

Fungi (fŭn'jīi): plants without true roots or stems, containing no chlorophyll and depending upon organic food for their nourishment.

Gamete (găm'ēt): a sex cell.

Gametophyte (g $\dot{a}$ mé$^{\prime}$ tô fït): a stage in the life history of a moss or fern in which sex cells are produced.

Ganglion (găn'glǐ ŏn) (pl. Ganglia) : a group of nerve cells situated outside of the brain or spinal column.

Gastric (găs'trǐk) glands : digestive glands found in the walls of the stomach.

Gastropod (găs'trò pŏd): a mollusk with univalve or no shell.

Gastrula (găs'troo la): a cuplike structure formed by the invagination or turning in of the blastula.

Genes : elements in the chromosomes of the germ cells which carry the hereditary traits.

Genetics (jè nět'ikss): the study of heredity.

Geotropism (jè ŏt'rò pǐz'm) : response to gravity.

Germ cells : eggs or sperm cells.

Germination (jûr'mū nā'shŭn): the beginning of growth in a seed or a pollen grain.

Gill rakers : small spinelike structures attached to gill arches of fish which prevent escape of food.

Gills: breathing organs for use in water.

Gland : an organ which secretes material to be used in or excreted from the body.

Glomeruli (glö měr'oo lī ) : bunches of looped capillaries in the kidneys in which the blood loses its urea.

Glycogen (glī'kô jĕn) : animal starch, found in the liver.

Guard cells : epidermal cells, found on each side of a stoma.

Gullet (gǔl'ět): a muscular canal extending from the pharynx to the stomach ; the esophagus.

Gymnosperm (jîm'nô spûrm): plants having seeds not enclosed in an ovary.

Habit : an acquired reflex act involving no thought.

Hæmoglobin (hē'mồ glō’bı̌n) : red coloring matter of the blood.

Hæmolysin (hê'mō lī’šn): : substance in blood which destroys foreign red corpuscles.

Heliotropism (hē'lY ơt'rō py̌z'm) : response to sunlight.

Hemịptera (hè mîp'tẽr $a$ ) : the order of insects to which the bugs (half wing) belong.

Heredity (hề rĕd’u tru) : transmission of qualities from parent to child.

Hermaphroditic (hẽr măf'rō dǐt'ł́k): having both male and female sex organs.

Hilum (hílŭm): a scar on the testa left where the seed was attached to the pod.

Homology : likeness in structure and position.

Homoptera (hô mŏp'tẽr $a$ ) : the order of insects to which plant lice and scale insects (similar wings) belong.

Hookworm: parasitic worm which "hooks" itself to the wall of the intestine.

Hormones (hôr'mōnz): substances produced by some of the glands of the body, which stimulate certain physiological activities.

Host: an animal or plant furnishing food to a parasite.

Humus (hū'mǔs): vegetable mold, a black or dark colored substance formed by the decay of organic substances in the soil.

Hybrid (hi'brǐd) : the offspring of parents which have specific differences.

Hydrogen (hī'drō jĕn): a gaseous element found in water and many other compounds.

Hygiene (hî̀ jīen): a study of the preservation of health.

Hymenoptera (hī'mĕn ðp'tẽr $a)$ : order of insects to which bees and wasps (membrane wings) belong. 
Hypocotyl (hī'pò kŏt’’il): the part of the developing embryo which forms the root and the lower part of the stem.

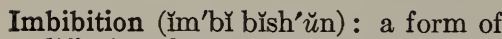
diffusion that results in the swelling of material taking in a fluid.

Immunity (I mū'nǐ tǐ): the successful resistance of an organism to infections from microörganisms.

Imperfect flowers: flowers having only one kind of essential organs, either stamens or pistils.

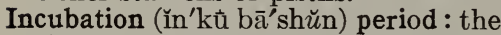
time the germs of a disease enter the body until the symptoms of the disease appear.

Indehiscent (ǐn'dè hřs'ĕnt) : not opening at maturity along a definite line to discharge contents.

Infectious (In fěk'shŭs): caused by disease-producing organisms, or germs.

Inheritance : that which is passed on by heredity.

Insecta : class of insects.

Inspiration : the act of taking air into the lungs.

Instinct (In'střnkt): a tendency to perform an act which is performed for the first time without being learned.

Insulin (ǐn'sú lĭn): a hormone produced in "Islands of Langerhans" in the pancreas; remedy for diabetes.

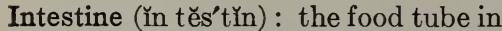
vertebrates from the pyloric end of the stomach to the anus. It is divided into the small and the large intestine.

Invertebrate : an animal not having a backbone.

Iris : the colored portion of the eye, having the pupil in the center.

Kidneys : glands which secrete urine. Kinetic (kínět’’̂k) : energy employed in producing motion.

Lacteal (lăk'tè ăl): lymph vessel in the villi.

Larva (lär'va): a young stage in the development of some forms of ani- mals, which becomes self-sustaining but which does not have the characteristics of the adult.

Latent (lā'tent): lying dormant but capable of development.

Legume (lěg'ūm): plant which bears seeds in pods - pea, bean, and the like; also the fruit or seed of such plants.

Lenticel (lĕn'tř sěl) : a breathing hole in the bark of a tree.

Lepidoptera (lěp'î dŏp'tẽr $a$ ) : order of insects to which moths and butterflies (scale wings) belong.

Leucocyte (lū'kó. sit): a white blood corpuscle which destroys foreign organisms, as bacteria.

Lichen : a composite organism consisting of a fungus and an alga.

Ligament (l'̌g' $\dot{a}$ mĕnt) : a band of connective tissue binding one bone to another.

Lipase (lip $p^{\prime} \bar{s}$ ) : the digestive enzyme that splits fats into fatty acids and glycerol.

Liver (lǐv'êr) : a digestive gland which secretes bile.

Lymph (limf): plasma and colorless corpuscles outside of the blood vessels.

Lysins (lǐ́sìnz) : antibodies which have power to dissolve bacteria in the blood.

Macronucleus (măk'rô nū'klè ŭs) : the large nucleus of a Paramecium, as opposed to the micronucleus, or small nucleus.

Maggot: the larva of an insect.

Mammary (măm'a rř) glands : milk- secreting glands found in mammals. Mandible (măn'dĭ b'l): in insects, a hard cutting jaw.

Mantle: the soft outer fold of skin in mollusks which secretes the outer shell.

Maxilla (măk sul' $\dot{a})$ : an appendage near the mouth of arthropods, modified in insects to form an organ for getting food.

Maxilliped (măk sǐl’1 pěd) : an appendage next to the maxilla in arthropods. Foot jaw.

Medulla oblongata (mè dŭl' $\dot{a}$ øb'lonngāt $\bar{a} \dot{a})$ : the portion of the brain 
between the cerebellum and the spinal cord.

Medullary rays : thin plates of pith which separate the wood of dicotyledonous stems into wedge-shaped masses.

Mesoderm (měs'ò dûrm) : the middle layer of cells in a young animal embryo.

Metabolism (mè tăb'ó lǐz'm) : changes taking place continually in living cells which may result in either building up or breaking down the cells.

Metamorphosis (mět' $a$ môr'fó š̌s): change of form undergone from egg to adult, as in insects.

Micronucleus (mík'krō nū'klè ǔs): the small nucleus in a Paramecium.

Micropyle (mīkrö pĩl): the hole where the pollen tube enters the embryo sac.

Midrib : central vein of a leaf.

Migrant (mï'grănt) : an animal which moves from one place to another and back regularly at stated seasons of the year. Many birds migrate to warmer regions for the winter.

Mimicry (mǐm'1k rǐ): the imitation in form or color of a harmful insect by a harmless one which is protected thereby.

Mitosis : a complex type of cell division, characterized by an equal distribution of chromatic material.

Molecule (mŏl'è kūl): unit of a chemical substance.

Mollusca: the phylum of animals to which the clam belongs.

Monocotyledon (mơn'ồ kŏt'û lē'dŭn): a plant that bears seeds having but one cotyledon.

Monœcious (mö nē'shŭs): having staminate and pistillate flowers on the same plants.

Motor neuron: a neuron, or nerve cell, the branches of which end in an effector (muscle or gland) which brings about activity.

Mucous (mü'kŭs) membrane : a delicate, moist membrance lining all body passages which have an external opening.

Muscle (mǔs"l) : a contractile tissue capable of bringing about movement.

Mutation (mù tā'shŭn): a heritable modification arising from internal causes in an organism.

Mycelium (mī sē'li ŭm): the threadlike body of a mold, or other fungus. The individual threads are called hyphæ.

Myriapoda (mǔr' ă ăp'ó dä): class of animals to which centipedes and millipedes belong.

Narcotic (när kŏt’’k): a substance which blunts the senses and in large quantities causes insensibility.

Nectar (něk'tär) : a sweet fluid secreted by certain groups of cells known as nectar glands in a flower. From this substance bees make honey.

Nemathelminthes (nèm'a thĕl min'thēz): a phylum of animals to which the unsegmented roundworms belong.

Neuron (nū'rǒn) : a nerve cell and its branches.

Nitrate (nítrāt): a soluble salt of nitric acid.

Nitrogen (nī'trồ jĕn) : a gaseous element, found in many organic compounds and forming almost four fifths of the atmosphere.

Nitrogen-fixing bacteria: bacteria which take free nitrogen from the air in the soil and build into nitrites which are later converted into nitrates. These nitrates can be used by the plants.

Nucleus (nū'klè ŭs): the center of activity in the living cell.

Nutrient (nū'trī ěnt): nourishing substance contained in foods.

Nutritive (nū'trǐ tĩv) ratio: the proportion of protein in the diet.

Oils : a class of nutrients composed of much carbon and hydrogen, with a little oxygen.

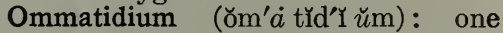
of the elements of a compound eye.

Operculum (ò pûr'kủ lŭm) : a lid or flap covering the gills of fishes.

Opsonin (ơp'sō nIn): a substance in 
the blood which helps colorless corpuscles destroy bacteria.

Organ: each part in an animal or plant which performs some special work.

Organic: pertaining to living things.

Organism: a body which is made up of organs or parts, each of which has a special function; any animal or plant.

Osculum (ŏs'kut lŭm) : the large opening at the end of a sponge.

Osmosis (ŏs mō'šs): diffusion of water through a semi-permeable membrane, the greater flow being toward the lesser concentration of water.

Ovary $\left(\bar{o}^{\prime} \vee a \dot{r} r\right)$ : in a plant, the base of a pistil, containing the orules; in an animal, the egg-forming gland.

Ovipositor (ó'vĭ pǒz'î tẽr): a specialized structure for depositing eggs, found in insects.

Ovule ( $\bar{o}^{\prime}$ vül): a rounded structure in the ovary, which may become a seed.

Oxidation (ŏk'sĭ dā'shŭn): the chemical union of oxygen with some other substance.

Oxygen (ǒk'sī jĕn) : a gaseous element found in the air and in many compounds.

Oxyhæmoglobin (ŏk'sǐ hē'mờ glō'bǐn) : a combination of oxygen with hæmoglobin.

Palate (păl'att): the roof of the mouth. The hard palate is supported by bone; the soft palate is a fold of mucous membrane lying posterior to the hard palate.

Palisade layer: a layer of green cells under the upper epidermis of a leaf.

Palpus (păl'pǔs) or palp: in arthropods, an appendage attached to a mouth part; usually an organ of touch or taste.

Pancreas (păn'krè ăs): a digestive gland. It secretes pancreatic juice.

Pappus (păp'ŭs): a downy or fluffy outgrowth from the ovary wall.

Parasite (păr'a sit): an organism which secures its living directly from another living organism without giving anything in return.
Parathyroids: the four small endocrine glands attached to the thyroid glands.

Pasteurize (pàs'tẽr ĩz) (from Pasteur the scientist): to heat milk to about $140^{\circ}$ Fahrenheit for about $30 \mathrm{~min}$ utes for the purpose of killing bacteria in it.

Pathogenic (păth'o jěn'îk) organisms : bacteria or protozoa which cause disease.

Pectoral girdle : bones which support the anterior pair of appendages in vertebrates.

Pelvic girdle: the bony arch to which the posterior pair of appendages are attached in vertebrates.

Pepsin: the enzyme, in the gastric juice, which begins the digestion of proteins.

Peptones (pěp'tōnz): substance produced by the action of pepsin on proteins.

Perennial (pěr ěn'í ăl) : lasting or continuing more than two years.

Perfect flowers: flowers with both stamens and pistils.

Peristaltic (pěr'í stăl'tǐk): wavelike movements of the muscles of the food tube.

Petal: one of the leaflike parts of the corolla.

Petiola (pět'í ōl): the stalk of a leaf.

Phagocyte (făgo sit): a colorless corpuscle which destroys bacteria.

Pharynx (făr'inks): the part of the alimentary canal between the mouth and the esophagus.

Phloëm (flóĕm): that part of the fibrovascular bundle which contains the sieve tubes.

Photosynthesis (fō'tö sinn'thè sǐs): the process of making starch out of carbon dioxide and water by the aid of sunlight, as is done by a green cell.

Phototropism (fớtŏt'rồ pĭz'm) : reaction to light.

Phylum (fi'lu $\mathrm{um}$ ): a large division of the plant or the animal kingdom. It is composed of classes.

Physiological (fĩúi olŏjij'íkăl) division of labor: performance of different kinds of work by different parts of an organism. 
Physiology (fũz'ĩ ŏl'ó jǐ) : study of the functions of plants and animals.

Pistil : a structure in the flower containing the ovary, in which the seeds are formed.

Pistillate: having pistils but no stamens.

Pith: the soft, spongy tissue in the center of a dicotyledonous stem and between the vascular bundles of a monocotyledonous stem.

Pituitary (pì tū'í tằ rǐ) body : small endocrine gland located in the base of the brain.

Placenta (pla sěn't $\dot{a})$ : absorbing organ which nourishes the embryo.

Plankton (plănk'tŏn): small plants and animals which live near the surface of bodies of water.

Plasma (plăz'ma): the colorless fluid part of blood.

Platyhelminthes (plăt'í hĕl mǐn'thēz): the phylum of animals to which the flatworms belong.

Pleura (ploo'ra): the membrane which covers the lungs and lines the cavity containing them.

Plumule (ploo'mūl): the part of the embryo above the cotyledons which develops into the stem and leaves.

Pollen grain: a small cell in the stamens of a flower which contains the sperm nucleus or male gamete.

Pollination (pŏl'ǐ nā'shŭn): the transfer of pollen from the anther to the stigma. Self-pollination is transfer between parts in the same flower; cross-pollination is transfer between different flowers, or between flowers on different plants.

Polyp (pǒl'ĭp): a simple coelenterate, as a sea anemone or a single coral individual.

Posterior (pǒs tē'rĭ ẽr): nearer the last or tail end of an animal.

Precipitins (prè š̌p'ǐ tǐnz): antibodies or precipitating substances formed in the blood as a reaction to the introduction of certain foreign proteins.

Primary root: the main root of a plant.

Proboscis (prö bŏs'îs) : a slender sucking tube found in insects.
Proglottids : reproductive body segments of a tapeworm.

Proleg: an unjointed abdominal appendage of insect larvæ.

Protective resemblance: the likeness of living organisms in color or form to their immediate surroundings, thus securing protection from attack of enemies.

Proteins (prō'tè ǐnz) : nitrogenous compounds found in the bodies of plants and animals; a class of nutrients composed of nitrogen, carbon, hydrogen, and oxygen, together with other elements in some cases.

Prothallium (prö thăl'ŕ ŭm): the reduced gametophyte of ferns.

Protoplasm (prō'tồ plăz'm): the living substance of plants and animals.

Protozoa (prō'tò zō' $\dot{a}$ ) : a phylum containing one-celled animals.

Pseudopodium (sū'dò pō'dĭ ŭm): a projection of protoplasm used for locomotion in protozoans.

Pteridophyta (těr'î dơf'í ta) : a phylum of plants to which the ferns belong.

Ptomaine (tōmmă inn) : poisonous material probably the result of decomposition of proteins.

Ptyalin ( $\hat{i}^{\prime} \dot{a}$ lin) : an enzyme in the saliva, which changes starchy foods.

Pulmonary (pŭl'mò nă rǐ): pertaining to the lungs.

Pulvinus (pŭl vǐnŭs) : a special motor organ at the base of the petiole of a leaf.

Pupa $\left(p \bar{u}^{\prime} \mathrm{p} \dot{a}\right)$ : the quiescent stage in insect development preceding the adult.

Pylorus (pǏ lō'rŭs) : the opening from the stomach into the intestine.

Quarantine (kwǒr'ăn tēn): isolation of the sick to prevent the spread of communicable disease.

Recessive : a Mendelian term applied to that unit character which is subordinate to another.

Reflex : simplest type of nervous response.

Regeneration (rè jĕn'ẽr $\bar{a}$ 'shŭn): the growing again of a part of an animal which has been lost. 
Reproduction (rē'prò dŭk'shŭn): the process by which organisms produce offspring. In asexual reproduction a new organism is formed by the separation of a cell or cells from a single parent; in sexual reproduction two cells from two plants or two animals of different sexes come together to form a new individual.

Respiration (rěs'pŭ rā'shŭn): taking in oxygen and giving out of products formed by oxidation by living cells.

Resuscitation (rè sŭs'ì tā'shŭn): revival from unconsciousness.

Retina (rět'í na): the coat of the eye in which the optic nerve fibers terminate.

Rhizoid (rî́zoid): one of the rootlike bodies in fungi and some other plants.

Rodents : gnawing mammals.

Root hairs : epidermal cells elongated from the root.

Ruminant (rō'mĭ nănt): an animal that chews a cud.

Saliva ( $\left.s \dot{a} \mathrm{li}^{\prime} \mathrm{v} \dot{a}\right)$ : the secretion of the salivary glands.

Saprophyte (săp'rò fït) : an organism which derives its nourishment from dead organic matter, as a mold or a mushroom.

Sclerotic coat (sklè rŏt'ilk) : the outer coat of the eye.

Scurvy : disease caused by lack of a vitamin.

Secretin (sè krē'tǐn): a hormone which causes the pancreas to give out its digestive fluid.

Secretion (sè krē'shŭn): material formed by the activity of glands.

Seed : a structure formed in a fruit as a result of the fertilization of the egg cell.

Segment: one of a number of serial divisions of an animal's body or of an organ.

Self-pollination: shedding pollen directly on the stigma of the same flower.

Sensory (sěn'sồ rǐ) : having direct connection with any part of the seat of sensation.

Sepal (sē'păl) : a leaflike part of the calyx or outer circle of parts in a flower.

Serum (sē'rŭm): the liquid part of the blood plasma.

Setæ (sē'tē) : bristles used for locomotion in earthworms and other animals.

Sexual (sěk'shù $a l)$ : pertaining to or having sex.

Siphon (sífŏn): a tube through which water may pass into and out from the mantle cavity of a mollusk.

Species (spē'shēz): the smallest group of organisms having characteristics in common that make them different from all other organisms.

Sperm cell: the male sex cell or gamete.

Spermatophyta (spûr'ma tŏf'ú ta): phylum which contains the seedproducing plants.

Spinal cord: a cord of nervous tissue lying in the vertebral column.

Spiracles (spurr $\dot{a}$ k'ls): breathing holes in the abdomen in insects.

Spirillum (spī rı̌l' ŭm) : a spiral form of bacteria.

Spleen (splēn): ductless, glandlike organ near the stomach.

Spongy tissue: a layer of loosely placed cells in the leaf.

Sporangium (spō răn’jŭ ŭm): a sac containing spores.

Spore (spōr): a reproductive cell capable of growing into a mature organism. It may be produced sexually or asexually.

Sporophyte (spō'rō fît): spore-bearing part of a plant.

Stamen (stā'mĕn): an organ of the flower in which pollen is formed.

Staminate: having stamens but no pistils.

Statocyst (stăt'ô š̌st) : semi-organs or balancing pits, formed in crustaceans and some other animals.

Sterilize (stěr'î lĩz): to destroy bacteria and other organisms, usually by heating.

Stigma (stig'ma) : the part of a pistil which receives the pollen grains.

Stimulant (stǐm'ù lănt): a substance which causes temporary activity of nerve or muscle.

Stimulus (stı̆m'û lüs) : an agent which 
causes an organism or some part to react when affected by it.

Stipule (střp'ūl): a leaflike outgrowth at the base of the petiole.

Stoma (stōmma) (pl. Stomata): breathing hole in a leaf.

Stomach (stŭm'ǔk): a sac-like part of the food tube between gullet and intestine.

Streptococci (strěp'tò kǒk'sī): spherical bacteria in the form of chains.

Sweat glands : excretory glands in the skin.

Swimmeret (swrm'ẽr ĕt): one of the paired appendages on the abdomen of crustaceans.

Symbiosis (simm'bī ō'šss) : a condition in which two organisms of different kinds live together in a mutually beneficial partnership.

Synapse (sı̌́năps): point of junction between two neurons.

Tactile corpuscle: sense organ of touch.

Tarsus (tär'sŭs): the ankle bones; also the last region of the leg of an insect.

Taste bud: end organ of taste found on the tongue.

Teeth: limy structures in the mouth of man and other animals, consisting of incisors or cutting teeth; canines, tearing teeth; and molars and premolars, crushing and grinding teeth.

Tendon (tĕn'dŭn): a band of connective tissue attaching muscle to muscle or muscle to bone.

Tentacle (těn't $\dot{a}$ k'l): a flexible organ at the anterior end of an animal used for feeling, grasping, etc.

Testa (těs'ta): the thick outer coat of a seed.

Testes (těs'tĕz): sperm-producing glands.

Thallophyta (thă lof' 1 t $\dot{a}$ ): phylum of plants which do not have roots, stems, or leaves.

Thoracic (thö răs'îk): pertaining to the chest region.

Thorax (thö'răks): the part of the body between the head and the abdomen.
Thyroid (thïroid): large endocrine gland below the pharynx.

Tissue : a collection of cells all more or less alike and having the same function.

Tourniquet (tōr'nǐ kět) : a device for arresting bleeding.

Toxins (tŏk'šnz): poisons produced by bacteria.

Trachea ( $\left.\operatorname{tr} \bar{a}^{\prime} k e \bar{a}\right):$ the windpipe; also a respiratory tube of insects.

Transpiration (trăn'spĭ rā'shŭn): the giving off of water vapor from plants.

Trichina (trǐ kī’na $\dot{a})$ : pork worm, a parasitic roundworm causing the condition called trichinosis.

Tropism (trō'pĭz'm): a definite response of an organism to one of the forces in its environment.

Trypanosome (trǐp'a $\dot{a}$ nồ sōm'): protozoan which causes a disease such as sleeping sickness.

Tympanum (tı̌m'p $\dot{a}$ num $)$ : the eardrum.

Urea ( $\bar{u}^{\prime}$ rè $\left.\dot{a}\right)$ : a nitrogenous waste excreted in the urine.

Vaccination (văk'sū nā'shŭn): inoculation with a vaccine, containing living or dead microörganisms or their toxins, in order to protect the body from disease.

Vaccine (văk'sǐn): a substance made from living or dead organisms, which, when inoculated into the body, protects it against a specific disease.

Vacuole (văk'ù ōl): a space in protoplasm containing air, water, sap, or food material.

Variation (vā'rĭ ā'shŭn): in biology, the occurrence of differences between individuals of the same species.

Vein : a tube which conveys blood to the heart.

Venæ cavæ (vē'nē k $\left.\bar{a}^{\prime} v \bar{e}\right)$ : vessels through which the blood returns to the right auricle of the heart.

Ventilation (věn'tǐ lā'shŭn) : changing of air in a room or building.

Ventral (věn'trăl): the opposite of dorsal. 
Ventricle (věn'trĭk'l): a muscular chamber of the heart, which forces the blood out.

Vermiform appendix (vûr'mĭ fôrm): a narrow tube about four inches long, closed at the outer end, near the beginning of the large intestine of man.

Vertebræ (vûr'tè brē): bones of the vertebral column.

Vertebrate : an animal having a backbone.

Villus (vıl'ús): a minute projection, an absorbing organ of the small intestine.

Vitamins (vì't $\dot{a} \mathrm{~m} \check{n} z)$ : any of the group of constituents in food which are considered necessary to prevent various diseases and to stimulate growth.

Voluntary (vǒl'ún tà rǐ): subject to the will (used with reference to muscles), as opposed to involuntary.

Xylem (zi’lĕm): the inner woody part of a fibrovascular bundle which conducts water up the stem.

Zygospores (zī'gồ spōrs) or Zygotes : spores formed by union of sex cells. 


\section{WEIGHTS, MEASURES, AND TEMPERATURES}

As the metric system of weights and measures and the Centigrade measurement of temperatures are employed in scientific work, the following tables showing the English equivalents of those in most frequent use are given for the convenience of those not already familiar with these standards. The values given are approximate only, but will answer for all practical purposes.

WEIGHT

\begin{tabular}{|c|c|c|}
\hline Kilogram & kg. & $2 \frac{1}{5}$ pounds \\
\hline Gram . & gm. & $\begin{array}{l}15 \frac{1}{2} \text { grains av- } \\
\text { oirdupois. } \\
\frac{1}{28} \text { of an ounce } \\
\text { avoirdupois. }\end{array}$ \\
\hline
\end{tabular}

CAPACITY

\begin{tabular}{|c|c|c|}
\hline Liter . & 1. & $\begin{array}{l}61 \text { cubic inches, } \\
\text { or a little } \\
\text { more than } \\
1 \text { quart, U.S. } \\
\text { measure. }\end{array}$ \\
\hline $\begin{array}{l}\text { Cubic cen- } \\
\text { timeter }\end{array}$ & ce. & $\begin{array}{l}\frac{1}{16} \text { of a cubic } \\
\text { inch. }\end{array}$ \\
\hline
\end{tabular}

Measures of Length

\begin{tabular}{|c|c|c|}
\hline \multicolumn{2}{|c|}{ Metric } & $\begin{array}{c}\text { ENGLISR } \\
\text { EQUIVALENTS }\end{array}$ \\
\hline Kilometer & $\mathrm{km}$. & $\frac{2}{3}$ of a mile. \\
\hline Meter. & $\mathrm{m}$. & 39 inches. \\
\hline Decimeter & $\mathrm{dm}$. & 4 inches. \\
\hline Centimeter . & $\mathrm{cm}$. & $\frac{2}{5}$ of an inch. \\
\hline Millimeter & $\mathrm{mm}$. & $\frac{1}{25}$ of an inch. \\
\hline
\end{tabular}

The next table gives the Fahrenheit equivalent for every tenth degree Centigrade from absolute zero to the boiling point of water. To find the corresponding F. for any degree C., multiply the given C. temperature by nine, divide by five, and add thirty-two. Conversely, to change F. to C. equivalent, subtract thirty-two, multiply by five, and divide by nine.

Cent. Fahr. Cent. Fahr. Cent. Fahr. Cent. Fahr.

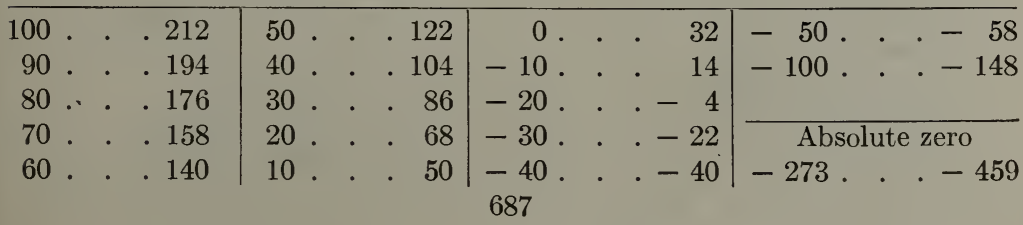




\section{LABORATORY EQUIPMENT}

The following articles comprise a simple equipment for a laboratory class of ten. The equipment for larger classes is proportionately less in price. The following articles may be obtained from any reliable dealer in laboratory supplies : such as

1 platform balance, with rider, weighing to 100 gms., with weights on carrier.

1 bell jar, about $365 \mathrm{~mm}$. high by $165 \mathrm{~mm}$. in diameter.

10 wide mouth bottles, with corks to fit.

$1025 \mathrm{cc}$. dropping bottles for iodine, etc.

25250 cc. glass-stoppered bottles for stock solutions.

100 test tubes, assorted sizes, principally $6^{\prime \prime} \times \frac{3}{4}{ }^{\prime \prime}$.

50 test tubes on base (excellent for demonstrations).

2 graduated cylinders, one to $100 \mathrm{cc}$, , one to $500 \mathrm{cc}$.

1 package filter paper $300 \mathrm{~mm}$. in diameter.

10 flasks, Erlenmeyer form, 500 cc. capacity.

2 glass funnels, one 50 , one $150 \mathrm{~mm}$. in diameter.

30 Petri dishes, $100 \mathrm{~mm}$. in diameter, $10 \mathrm{~mm}$. in depth.

10 feet glass tubing, soft, sizes $2,3,4,5,6$, assorted.

1 aquarium jar, 10 liters capacity.

2 specimen jars, glass tops, of about 1 liter capacity.

10 hand magnifiers, vulcanite or tripod form.

2 compound demonstration microscopes or 1 more expensive compound microscope.

300 insect pins, Klaeger, 3 sizes assorted.

10 feet rubber tubing to fit glass tubing, size $\frac{3}{8}$ inch.

1 chemical thermometer graduated to $100^{\circ} \mathrm{C}$.

15 agate ware or tin trays about $350 \mathrm{~mm}$. long by 100 wide.

1 gal. 95 per cent alcohol. (Do not use denatured alcohol.)

1 set gram weights, $1 \mathrm{mg}$. to $100 \mathrm{~g}$.

1 razor, for cutting sections.

2 books test paper, red and blue.

1 box rubber bands, assorted sizes.

1 support stand with rings.

1 test tube rack.

5 test tube brushes.

10 pairs scissors.

10 pairs forceps.

10 Syracuse watch glasses.

1 steam sterilizer (tin will do).

1 spool fine copper wire.

2 bulb pipettes.

limewater.

$1 \mathrm{oz}$. iodine cryst.

$1 \mathrm{oz}$. potassium iodide.

20 needles in handles.

$6 \mathrm{oz}$. nitric acid.

10 scapels.

12 mason jars, pints.

$6 \mathrm{oz}$. ammonium hydroxide.

12 mason jars, quarts.

$6 \mathrm{oz}$. benzol.

$6 \mathrm{oz}$. chloroform.

1 alcohol lamp.

1 gross slides.

$\frac{1}{2}$ lb. copper sulphate.

$\frac{1}{2} \mathrm{lb}$. sodium hydroxide. 
100 cover slips No. 2.

1 mortar and pestle. $\frac{1}{2}$ lb. rochelle salts.

$6 \mathrm{oz}$. glycerine.

Fehling or Benedict solution.

The following items may be made or obtained locally:

Pocket garden.

Ventilation box.

Foods containing proteins and oils.

Soil: sand, clay, gravel, loam, humus.

Seeds: peas, beans, radish, corn.

Starch, sugar.

The agar or gelatine cultures in Petri dishes may be obtained from the local board of health or from any good druggist. These cultures are not difficult to make, but take a number of hours of consecutive work to prepare.

\section{Preparation of Culture of Protozoa}

If it is impossible to buy cultures of Paramecia for study, they can be prepared in the school laboratory. Fill a sterilized battery jar about half full of water and add a small handful of hay stems cut in short lengths. Keep the jar in a fairly light place. In a few days a scum will form on the surface of the water, in which bacteria will be found. Later protozoans, including Paramecia, will appear. 



\section{INDEX}

Abilities, families of inferior, 637 ; families of superior, $638-639$; needed for commercial life, 647-648; needed for professions, 647 ; needed for trades, 648

Absorption, 147; from large intestine, $377-379$; from small intestine, 379 , 380

Accommodation, of eye, 441

Acidosis, prevention of, 339

Acquired reactions, 443

Active immunity, acquired, 476 -477; mechanism of, 481 ; vaccination against smallpox, 479-480

Activities, acquired automatic, 443; inborn automatic, 442 ; reflex, 428

Adam's apple, 403

Adaptability, of living things, $50-52$

Adaptation, $40-52$; a function of living things, 50-52

Adaptations, for seed dispersal, 108-111 ; of birds, 260-263; of fishes, 243; of frogs, 250 ; of turtles, 256-257

Adaptive responses, meaning of, 426

Adenoids, 408, 510

Adrenal glands, effect of secretion, 393 ; location of, 392

Adrenaline, 393 ; use of, 393

Adrenin, effect on body, 393

Adulteration, of foods, $348-350$

Aëdes, yellow fever mosquito, 487-488

Agassiz, Louis, pioneer in natural history, 668

Age and size, relation of diet to, 338

Agencies, of health, 507-511

Agglutination test, $390-391$

Agglutinins, antibodies, 390

Agriculture, bacteria in, 187-189; profession, 651-652

Air, composition of expired, 404 ; composition of inspired, 404; in lungs, 407; needed by plants for making carbohydrates, 157-158; needed for germination, 121

Air sacs, in lungs, 403

Air tubes, 403-404

Alcohol, and susceptibility to disease, 353; dangers from, 352-353; death rates from, 353-354; economic effect of drinking, 449; effect on blood, 402 ; effect on mortality of offspring, 353 ; relation to crime, 450 ; relation to efficiency, 449-450; relation to pauperism, 450-451

Algae, 200-202; characteristics of, 200201 ; examples of, 201-202
Alimentary canal. See Digestive tract.

Alligators, 259

Alternation of generation, of ferns, 204205 ; of mosses, 203

Amino acids, $329-330$

Amoeba, 217-219; demonstration to show, 217; life processes of, 218-219

Amphibians, 250-255; characteristics of, 255 ; classification of, 255 ; used as food, 535

Amylase, an enzyme, 374

Anaesthesia, Dr. Morton and, 664

Andalusian fowls, heredity in, 622-623

Angiosperms, 207-213; dicotyledons, 209-213 ; monocotyledons, 208-209

Animal breeding, 624-625; present problems in, 625-626

Animals, and plants mutually dependent, 54-96; classification of, 216-277; compared with plants, $43-45$; development of, 617-620; economic value other than food, 537-544; effect of surroundings on, 280-309, 610-611; harmful, 544-547; mechanism of response in, 425-426; one-celled, 217222 ; relation between plants and, $282-$ 284 ; response of, 422,423 ; valuable for food, 530-537

Annual rings, 167

Annulate, characteristics of, 229 ; classification of, 229 ; examples of, 229-231

Anopheles, malarial mosquito, 483-486

Antennae, sensory organs in insects, 58, 64,428

Anther, of flower, 83, 84

Antibodies, 385 ; agglutinins, 390 ; antito zin, 477 ; lysins, 390 ; opsonins, 388 ; precipitins, 390 ; production of, 476-477; work of, $385,390,476$

Antiseptic solutions, 317

Antiseptics, and Lord Lister, 663

Antitoxin, discovery of diphtheria, 663; how used, 477-478; kinds, 478-479; meaning of, 477

Ants, 73, 74-75; how to make nest for, 10

Aorta, 397

Aphids, 77-78; and ants, 74

Appendicular skeleton, 319

Appendix, vermiform, 379

Appetite, relation to diet, 339

Aquarium, balanced, 11-12, 282-284. 286

Arachnida, 232, 238

Arachnids, 238-239

Archaeopteryx, earliest known bird, 271 
Aristotle, on progressive development, 665

Arteries, 395; structure of, 398

Arteriosclerosis, cause of, 401

Arthropoda, 232-242; characteristics of, 232-233; classification of, 232

Artificial propagation, of fishes, 591-592

Artificial respiration, $408-409$

Artificial selection, 605-606, 633-634

Arum family, of flowers, 208, 209

Asexual reproduction, of Paramecium, 221. See Vegetative propagation

Associative axon, 431

Audubon, work on birds, 668-669

Auricles, 396, 397

Autonomic, nervous system, 430 ; functions of, 434

Axial skeleton, 319

Axon, associative, 431; motor, 431; of neuron, 431 ; sensory, 431

Bacillum, form of bacteria, 183

Bacillus pestis, cause of bubonic plague, 491

Bacteria, aerobic, 186 ; anaerobic, 186 ; and air, 186 ; cause of pus, 317 ; control growth of, 457-461; diseases caused by, 463-470; demonstration to show effect of temperature on, 457 ; destruction of white corpuscles, 388 ; effect on food, 185-186; forms of, 183; how cause diseases, 461-463; how discovered, 181; how get for study, 181-182; pure culture of, 182 ; relation to fermentation, 187 ; relation to free nitrogen, 187-188; size of, 183; things done by, 186-189; what are, 181 ; where found, 183-184; where numerous, 184-185; work done by, $1-2,185-189$

Bacterial diseases, 461-463; and milk, 468 ; and water supplies, 467 ; diphtheria, 466; how get, 463-470; immunity to, 474-481; necessity of quarantine in, 471-473; septic sore throat, 470 ; spread through mouth spray, 466 ; tetanus, 470 ; tuberculosis, 464-465 ; typhoid fever, 466467

Bacteriology, definition of, 1

Balance of life, $55-56$

Balance of nature, and man, 288-290

Banting, Dr., work with insulin, 395, 600

Bark, of tree, structure of, 166-167; use of, $167-168$

Barriers, and effect on living things, 305-308

Basal metabolism, meaning of, 341

Bast fibers, 166, 168

Bathysphere, of William Beebe, 653

Bean, growth of plant, 136; laboratory exercise on seed, 117; nutrients in seed, 119-120 ; stages in growth, 122123 ; structure of seed, 117

Beebe, William, 653

Beetle, carrion, 561 ; Japanese, 564-565, 567 ; life history of, 76-77, 563; ladybird, 561 ; potato, 77

Beetles, classification of, 60-61, 238

Biology, activities connected with study of, 7-16; and conservation, 2 ; and self-improvement, 644-654; early workers in, 657-659; economic values of, 2-7; how to study, 6-16; in relation to society, 4 ; makers of, $656-$ 672 ; meaning, 1 ; prepare for vocation, 649-654; reading values of, 3 ; where to study, 4-6; why study, 1-4

Birds, adaptations of, $260-263$; care of young, 266; classification of birds, 267; common, 551-560: bluebird, 552-553 ; catbird, 556-557; chickadee, 553-554; crow, 559 ; downy woodpecker, 557; English sparrow, 559; flicker, 557, 558; goldfinch, 555; oriole, 557-558; phoebe, 555-556 ; robin, 552; screech owl, 558, 559; song sparrow, 554-555; swallow, 556 ; warbler, 555 , 559 ; wren, 554 ; economic importance of, 547-551; food of, 546-549; harmful, 559-560; home methods of conservation of, 594-597; migration of, 595-596; nervous system of, 264 ; nesting habits of, 264, 265, 266 ; relation to reptiles, 266-267; reproduction of, 618-619; respiration of, 263-264; sense organs of, 264 ; state and federal government methods of conservation, 596; used for food, 536 ; work of Audubon on, $668-669$

Blackberry, production of white, 672

Black stem rust, 195-196, 197

Bladder, swim, of fish, 246

Blastula, 617

Blister rust, 196

Blood, cause of clotting, 388-389 ; circulation of, 395-401; circulation in fish, 246-247 ; circulation in frog, 251252 ; composition of, 386 ; corpuscles of, 386-389 ; effect of alcohol on, 402 ; how food gets into, 377-397 ; platelets, 389 ; pressure of, 399 ; relation of lymph to, 389 ; transfusion of, 391

Blood plasma, composition of, 386 ; disease-resisting function of, 390-391

Blood platelets, function of, 389

Blood serum, 388 , chemical composition of, 20-21; compared with sea water, $20-21$

Blood vessels, 395 ; structure of, 398399. See Arteries, Capillaries, and Veins.

Bluebird, 552-553; food of, 548

Body: how body protects itself, 475-476; regulation of heat of, 415 
Bones, relation to muscles, 319-322

Bony-fish, egg-laying habits of, 247-248

Boveri, work on chromosomes, 670

Bracers, in medicines, 355

Bracket fungus, 194-195

Brain, 429 ; localization of functions in, 434 ; parts of, 432 ; structure of, $432-$ 433

Brains, of various vertebrates, 433

Bread making, and yeast, 192-193

Breathing, hygienic habits of, 407 ; mechanics of, 406-407; of fish, 245 ; of frog, 251

Breeding, animal, 624-625; plant and animal, $670-672$; practical results in, 624 ; present problems in, 625-626

Breeding experiments, Mendel's, 620623

Bronchial tubes, 403-404

Bruises, treatment for, 401

Bryophyta, 180; classification of, 203 ; mosses, 202-203

Bubonic plague, cause of, 491

Budding, method of, 613,614 ; of yeast, 191

Bumblebees, 70 ; life history of, 70

Bundles, fibrovascular, 136-137, 144, 168,170

Burbank, Luther, work on plant breeding, 624 ; fruits and vegetables improved by him, 671-672

Bureau of Agriculture, work on insect control, 567-568

Butter-and-eggs, how pollinated, 91

Buttercup family, 210-211

Butterfly, compared with moths, 6869 ; laboratory exercise on, 65 . See Monarch butterfly.

Cactus, 301, 302

Calorie, defined, 328 ; need, 343-344

Calorie requirement, workbook exercises on daily, 343-344

Calories, needed, of various nutrients, 341

Calorimeter, use of, 328,329

Calyx, of flower, 83,84

Cambium layer, 167-168

Canning, and bacteria, 458

Capillaries, 395,396 ; structure of, 398 , 399

Carapace, of crayfish, 233

Carbohydrate-making, compared to milling, $160-161$

Carbohydrates, 30-31; air needed by plants to make, 157; chlorophyll needed by plants to make, 157-158; light'needed by plants to make, 157158

Carbon cycle, 286

Carbon dioxide, demonstration on need of plants for, 158-159; test for, 25

Carnivores, 268-269
Carrell, preparation of Dakin solution by, $664-665$

Carriers, and typhoid, 469

Carrot family, 212

Catbird, 556-557

Cats, harm done by, 546

Cell, as a unit of structure and function, 222 ; body, 627-628; described by Hooke, 38-39; division of, 48, 612613 ; germ, 627 ; guard, 152,153 ; laboratory exercise on plant and animal, 46 ; mitotic division of, 49 ; multiplication of, 48-49; of Elodea, 46 ; respiration of, 405 ; sap, 145 ; sex, 4849,627 ; structure of, 46 ; structure of leaf, 152-153

Centipede, 239

Central nervous system, 430 ; functions of, 434-435

Cephalopods, 241-242

Cerebellum, 429; function, 432,433 , 434 ; position of, 432

Cerebrum, 429; function of, 433,434 ; size in various lower animals, 433; structure of, 432

Character-determiners, in chromosomes, 626-627

Characters, dominant, 621, 630-631; inheritable, 630-631; law of unit, 621 ; recessive, 621, 630-631

Chemical elements, in human body, 24

Chestnut blight, 194

Chewing food, need for, 370

Chickadee, 553-554; food of, 548

Chlorophyll, 135 ; demonstration to show use to plant, 158; needed by plants, 157-159

Chloroplasts, 159 ; function of, 46 ; compared to mill, 160

Chromosomes, bearers of heredity, 626627; behavior in reduction division, 627 , 630 ; functions of, $48-49$; location of genes in fruit fly, 627-628; number in body cells, 627 : number in sex cells, 627-628; workers on, 670671

Cicada, life history of, 77,78

Cilia, of Paramecium, 220

Circulation, demonstration to show in plant, 168-169; effect of exercise on 400-401; in a plant, 166-177; of blood in body, 395-401; portal, 398; pulmonary, 397-398; systemic, 397

Circulatory system, diagram on, 400 ; of fish, 246-247; of frog, 251-252

City supervision, and health, 600-601

Clams, used for food, $532-533$

Classification, devised by Linnaeus, 668 ; of living things, 177-178; of plants, 180

Cloaca, of frog, 368

Clothing, relation to skin, 318

Clover, how pollinated, 92 
Coccus, kind of bacteria, 183

Cochineal, insect origin, 561

Cochlea, function of, 439

Codling moth, 565

Coelenterata, characteristics, 224 ; classification, 226 ; examples of, 224-225

Colds, cause of, 415-416

Cold storage, and bacteria, 458

Coleoptera, 60-61, 238

Color in leaves, cause of change in, 159

Commercial life, abilities needed for, 647-648

Communal life, of insects, 69-75

Communicable diseases, 508-510

Communities, plant and animal, 298-300

Community, improvement of conditions in, 503-507; inspection of food supplies, 504, 505

Composite family, 212-213

Composite flower, pollination of, 92

Compounds, meaning of chemical, 19-21

Conditions, improve community, 503507 ; improve home, 597-600; improve school, 501-503

Conifers, 206

Conjugation, in Spirogyra, 201-202, 615 ; of Paramecium, 221-222

Conqueror, how man has become world, 420-451; of disease, 659-665

Conservation, applied to man, 599601 ; of birds, 594-597; of fish and other aquatic animals, $587-593$; of forests, 581-587; of mammals, 598599 ; of natural resources, 2, 572-601 ; of trees, 574-581

Constipation, 379-380

Contractile vacuole, of amoeba, 219; of Paramecium, 220

Coral, economic value of, 542

Corn, cross section of grain of, 125 ; cross section of stalk of, 169 ; endosperm of, 125; use of food supply during germination, 128; uses of, 524-525

Corn worm, harm done by, 562

Corolla, of flower, 83,84

Corpuscles, red, 387; white, 387-388

Cortex, of stem, 166

Cotton, uses of, 528-529

Cotton-boll weevil, 562-564; control of, 567 ; life history, 563 ; spread of, 563

Cotyledons, bean, 117; food in, 117-118 Cowbird, 559, 560

Crab, fiddler, 236; rock, 236; used for food, 534

Crayfish, antennae, 233; appendages, 233 ; circulatory system of, 235 ; description of, 233 ; digestion of, 234 235 ; eyes, 233-234; excretion of, 235 ; food-getting, 234 ; gills, 235; life history of, 235-236; locomotion of, 233 ; nervous system of, 235 ; skeleton of, 233
Cretinism, cause of, 393

Crocodiles, 259

Crops, damaged by insects, 562-565; rotation of, 188-189

Cross-pollination, 88 ; artificial, 634-635 ; devices to secure, $92-94$; specific examples of, 91-96

Crow, 548, 558-559

Crustaceans, as food, 533-534; compared with insects, 237 ; crab, 534 ; lobster, 533 ; shrimp, 534

Culture medium, for bacteria, 181-182

Cure-alls, medicine, 356-357

Cuts, treatment of, 401

Cycads, 205-206

Cycle, carbon, 286; nitrogen, 285 ; oxygen, 285-286

Cypress knees, 150

Dakin solution, $664-665$

Damsel fly, 79 ; order of, 238

Darwin, Charles, family tree of, 639 ; on natural selection, 605 ; on pollination of flowers, 56 ; on progressive development, 665-667; on variation, 605

Decay, caused by bacteria, 186-187

Dehiscent fruits, scattering seeds by, 109-110

Dendrites, of neuron, 431

Development, of birds, 618-619; of mammals, 619-620; progressive, 665667

de Vries, Hugo, mutants, 633 ; on plant breeding, 671

Diabetes, cause of, 395

Diastase, action on starch, 130

Dick test, 479 ; for scarlet fever, 665

Dicotyledonous stem, circulation of food in, 170-171; cross section of, 167 ; growth of, 167-168; structure of, 166167

Dicotyledons, 126, 127 ; buttercup - family, 210-211; carrot family, 212; composite family, 212-213; heath family, 212; legume family, 209-210; mint family, 211; mustard family, 211 ; rose family, 210 ; willow family, 211-212

Diet, best proposition of nutrients in, $340-343$; relation of appetite to, 339 ; relation of cost of food to, 345-346 ; relation of digestibility to, 338-339; relation of environment to, 335338 ; relation of sex to, 338 ; relation of size and age to, 338; relation of work tc, 335

Diffusion, 147; demonstration showing, 147 ; physiological importance of, 149150

Digestibility, of food, relation to diet, 338-339

Digestion, 129-130; demonstration to 
show use of, 363 ; experiments to show stomach, 372 ; hygiene of, 380 ; in crayfish, $234-235$; in frog, 250251 ; in mouth, $364-365$; in plants, 171-172 ; in small intestine, 373-374; in stomach, 369-372; meaning of, 129 ; purpose of, 130 ; salivary, $364-$ 365 ; table of chemical, 381

Digestive organs, of fish, 246; of frog, 368 ; of man, $368,369-380$

Digestive system, of fish, 246 ; laboratory study of frog's, 367-368; laboratory study of man's, 367-368

Digestive tract, description of man's, 369 ; laboratory study of frog's, 367368 ; laboratory study of man's, $367-368$; parts of, $368-369$

Dihybrid, 623 ; breeding of, 623

Dinosaur, 273; eggs of, 266-267

Diphtheria, antitoxin treatment for, 477-478; cause of, 466 ; prevention of, 478; Schick test of susceptibility to, 478-479; transmission of, 472

Diptera, 59; classified, 238; discussed, $75-76$

Disease, some conquerors of, 659-665

Disease carriers, Aëdes mosquito, 487488; Anopheles mosquito, 483-484; bedbug, 491 ; body louse, 491 ; flea, 491; house fly, 489-491; people, 469

Diseases, carried by insects, 483-484, $487-488,489-491$; caused by protozoans, 482-486; caused by worms, 492-496; how caused by bacteria, 461-463; how get, 463-470; of nose and throat, $407-408$; spread by rats, 491-492. See also Bacterial diseases.

Disinfectant, laboratory problem to show most effective, 460

Disinfection, need of, 461; terminal, 509

Division, cell, cause of, 611-613 ; process of, 48,49

Dodder, 105

Domesticated animals, economic value of, 537

Dominance, Mendel's law of, 621

Dominant characters, 621, 630-631

Dragon flies, 78-79; classification, 238

Drug-producing plants, 529-530

Drugs, in medicine, 355

Duct, thoracic, 399

Ductless glands, 361, 392-395; adrenal, 393 ; location of, 392 ; pancreas, 392 ; parathyroid, 392; pituitary, 393-394; reproductive, $392,394-395$; secretions of, 392 ; thymus, 394 ; thyroid, 393

Dwarfs, probable cause of, 393

Ear, diagram of, 439 ; in fish, 245 ; in frog, 250 ; inner, 439; middle, 438439 ; organ of hearing, 438 ; outer, 438
Earthworm, grafting, 614; laboratory exercise on, 229 ; life process of, 230 231 ; locomotion of, 229-230; reproduction of, 231 ; segments of, 229 ; setae of, 229

Echinodermata, characteristics, 226-228 ; classification, 227

Echinoderms, characteristics, 226 ; classification, 227 ; examples, 226-228

Ecological realms, 308-309

Ecological succession, 300-305

Ecology, 282

Economic importance, of birds, 547-551; of insects, $560-569$

Economic values, of animals, $530-544$; of plants, $520-530$

Ectoderm, development of, 618 ; systems formed from, 617, 618

Edwards, Jonathan, family of, 638-639

Egg, development of fertilized, 617618; in Vaucheria, 615

Egg cell, 617

Elements, found in living things, 29 ; found in the environment, 29 ; meaning of, 19

Elodea, cells of, 46 ; protoplasm of, 47

Embryo, 86; development of bird, 618 ; factor necessary to awaken, 120,121 ; in plant, 616; protection in birds, 618-619; protection in mammals, 619620 ; of bean, 117 ; what becomes of parts during growth, 122-123

Embryo sac, in flower, 85

Emulsion, 374

Endocrine glands, 361; adrenal, 393; location of, 392 ; pancreas, 392, 394 ; pituitary, 393-394 ; reproductive, 392 , 394-395; secretions of, 392 ; thymus, 394 ; thyroid, 392,393

Endoderm, development of, 618; systems formed from, 617, 618

Endosperm, how formed, $€ 16$; of corn, 125 ; of other seeds, $125-126$

Energy, conservation of, 27; forms of, 26 ; kinetic, 313 ; potential, 313 ; sun, source of, 157

Energy requirement, how to compute, $342-343$

Environment, affecting animals, 610611 ; affecting plants, $608-610$; cause of changes, $300-305$; factors affecting ecological relationship, 290-297; how man controls natural, $32-54$; improvement of natural, 33-34; man control for health, 455-511; man control for wealth, 518-569; relation to diet, 335 , 338 ; versus heredity, 606-607

Enzymes, 129, 137; diastase, 130 ; in plants, 162,171 ; work of, 361,362

Ephemerida, order of insects, 238

Epidermis, human body, 316; of leaf, 152,153 ; of root hairs, 144 ; of stem, 166 
Epiglottis, 370

Erhlich, Paul, on immunity, 664

Erosion, prevented by trees, 574

Esophagus, 368,370

Essential organs, of flower, 83

Eugenics, meaning of, 636

Euglena, how receive stimuli, 422

Evaporation, from plants, factors in, 164

Evolution, evidences of, 271-273; of horse, 273-274; workers, 665-667

Examination; physical, 510-511

Excretion, kidneys, 412-414; need of, 45 ; of crayfish, 235 ; organs of, $412-$ 415 ; skin, 414-415

Excretory organs, $412-415$

Exercise, effect on circulation, 400-401

Existence, struggle for, 111

Exophthalmic goiter, 393

Expiration, meaning of, 406 ; process in man, 407

Eye, description of, 440-441

Eyes, of crayfish, 233-234; of fish, 244 ; of insects, 58, 64

Eyespot, of Euglena, 422

Eyestrain, 510

F, meaning of, 621

Factors, affecting life, 608; necessary for germination, 120-121

Families, of inferior ability, 636-637; of superior ability, 638-639

Fatigue, effect on nerve cell, 448

Fats, 31 ; digestion of, 373-374; manufactured in leaf, 161 ; required in diet, 328

Feet, care of, 321-322

Fermentation, and yeast, 190 ; relation of bacteria to, 187

Fern, life history of, 204-205

Fertilization, adaptations of plants for, $91-94,95-96$; in flowers, 84-86, 615616 ; in frog, 252 ; in Vaucheria, 615

Fever, cause of, 415

Fibers, useful vegetable, 529

Fibrinogen, in blood, 388

Fibrovascular bundles, 136-137, 144, $167-168,169$

Fig, pollination of, 94-95

Filament, of flower, 83, 84; of gill of fish, 246; of Spirogyra, 201-202, 615

Filterable virus, $479-480$

Fins, of fish, 244, 246

First aid, for burns and scalds, 316-317 ; for skin wounds, 317

Fish, as food, 534-535; body of, 243244 ; breathing of, 245 ; characteristics of, 242-249 ; circulatory system, 246247 ; classification of, 249 ; digestive system of, 246; egg-laying habits, 247-248; fins, 244 ; gills of, $245-246$; laboratory exercise on, 243 ; lateral line of, 245; nervous system, 247 ; reproduction of, $247-248$; sense organs, 244-245; swim bladder, 246

Fishes, 242-249; artificial propagation of, 591-592; conservation of freshwater, 587-588; conservation of ocean, 588 ; migration of, 588 ; spawning habits of, $588-589$

Fission, of Paramecium, 221 ; process of cell division, 183

Fixation, of nitrogen, by bacteria, 188

Flatworm, regeneration in, 612

Flatworms, Platyhelminthes, 228 ; harmful, 492-493

Flexner, on infantile paralysis, 665

Flicker, 557, 558

Flies, characteristics of, 75-76; classification of various, 59, 238; development of house, 75-76; dragon, 78-79; life history of house, 76

Flowers, artificial pollination of, 634635 ; complete, 84 ; cross-pollination by insects, 91 ; cross-pollination of composite head, 92 ; devices of, to secure pollination, 92-95; essential organs of, 83 ; hybridization of, 634635 ; imperfect, 96 ; laboratory exercise on structure, 83 ; pollinated by wind, 95-96; use to plants, $83-86$

Food, and ecological succession, 302-303 ; animals valuable as, 530-537; care in home, 498-499; definition of, 30 ; digestion in plants, 171-172; digestion in stomach, 369-372; fuel value of, 328 ; functions of, 162 ; how absorbed, 378-379; how man determines value, 324-357; how prepared for body use, 360-381; in cotyledons, 117-118; made by plants, 134-173; need of, 328-329; nutrients in, 30-31 ; plants used as, 520-528; preservation of, 458-460; raw material needed by plants to make, $154-155$; relation of cost to diet, 345-346; response of plants and animals to, 41 ; storage in plants, 171-172

Food conditions, how living things are affected by, 297

Food habits, good, 347-348

Food making, in green cells, and human welfare, 162-163; products of, 160162 ; results, $162-165$

Food nutrients, $30-31,327-328$; 'tests for, 118-119, 131

Foods, determination of relative cheapness of, 345-348; how circulated and used in body, 384-416; inorganic, 31 ; mineral requirement in, 331-332; nutrients in, 30-31, 118-119, 327-328; preparation of, 346-347 ; uses of, 327332

Food substances, tests of, 131

Food supplies, care in home, 498-499: inspection of, 504,505 
Food supply, essentials of an adequate, 332

Food-taking, of plants and animals, 44

Food vacuole, of amoeba, 218; of Paramecium, 220

Forestry, good, 579-581; profession of, 652

Forests, methods of conservation of, $584-585$; need of conservation, 579587 ; wastes in, 581-583

Forest trees, injured by insects, 565

Fossils, story told by, 271-274

Frog, breathing of, 251 ; circulatory system, 251-252; digestion of, 250-251; digestive system, 367-368; digestive tract compared with man, 368 ; foodgetting, 250, 251 ; laboratory study of, 250 ; life history of, 252-254; mouth compared with man's, 363,364 ; reproduction of, 252-254; respiratory tract compared with that of man, 403 ; sense organs, 250

Fruit, definition of, 87-88

Fruit fly, Mediterranean, 566

Fruits, how formed, 86-88; used as food, 526-528

Fruit trees, injured by insects, 565

Fuel value, of foods, 328

Functions, of living things, 36-52

Fungi, characteristics of, 181; destructive, 193-197; kinds of, 181-199

Fungus, shelf, 194-195

Furs, value of, 540-541

Gall insects, value of, 561-562

Gamete, female, 205, 615 ; male, 205, 615

Gametophyte, of fern, 204-205; of moss, 203

Ganglion, 430

Garden fruits, and vegetables, used as food, 526-527

Gardening, 13-14

Gases, in living things, 27-28

Gastric digestion, conditions most favorable for, $369-370$

Gastric glands, 371

Gastric juice, action of, 371-372 ; composition of, 371

Gastropods, 241

Gastrula, 617

Generation. See Alternation of generation

Genes, definition of, 626,627 ; function of, 627 ; location in chromosomes of fruit fly, 627-628

Genus, 178,179

Geographic distribution, of living things, 305-309

Germ cells, 627 ; development of, 630 ; Weissman's study, 670

Germination, factors necessary for, 120121 ; of seeds, 115-130; use of food supply of corn during, 128
Giants, probable cause of, 393

Gills, of crayfish, 233; of fish, 245, 246

Gland, meaning of, 361 ; structure of, 362

Glands, ductless, 361, 392-395; endocrine, 361 , 392-395 ; gastric, 361 , 371 ; intestinal, 377 ; liver, 361 ; location in man, 392 ; lymph, 399 ; of skin, 316-317; oil, 316, 317 ; pancreas, 361 ; salivary, 363 ; sebaceous, 316,317 ; sweat, $316-317,414,415$

Glomerulus, of kidneys, 413

Glottis, 370

Glycogen, 394-395; in liver, 375,376

Goiter, cause of, 393

Goldfinch, American, 555

Grafting, in animals, 614 ; in trees, 613 , 614

Grass family, 208

Grasshopper, 62-65 ; characteristics of, 59 ; diagram of, 62 ; eyes of, 63,64 ; food-taking of, 64-65; laboratory exercise on, 62-63; life history of, 64-65; muscular activity of, 63 ; near relatives of, 65 ; order of insects, 59 , 238 ; sense organs of, 64

Gravity, 294; demonstration on effect on roots, 140-141; effect on plants and animals, 41

Green plants, make food of world, 115173

Growth, of plant, cause of, 123-124

Guard cells, of stomata, 152

Gullet, 364,368

Gulls, at Salt Lake City, 303

Gymnosperms, 205-206

Habit, effect of drink, 449-451

Habits, different kinds of, 444-445; food, 347-348; formation of, 444445; hygienic breathing, 407; importance of forming right, 445-446; meaning of, 443 ; of eating, 380 ; rules for forming, 446-447

Haemoglo bin, 387, 404

Hairs, roots, 135-136

Harvey, William, 656 ; on circulation of blood, 658 ; on germ cells, 658

Hawks, 560

Hay fever, 106

Hay infusion, life in, 303-305

Health, agencies, 507-511, 601; and biology, $1-2$; man control of environment for, 455-511; positive, 482 ; work of department of, 508-511

Health habits, of nervous system, 447448 ; of sense organs, 448

Health work, of national government, 600 ; profession, 650 ; special agencies in, 601; state and city supervision of, 600-601

Hearing, organ of, in man, 438 
Heart, auricles of, 395, 396 ; compared to force pump, 397 ; in action, 396397 ; of fish, 246-247; of frog, 251252 ; structure of, 395-396; ventricles of, 395,396

Heart beat, laboratory study on effect of exercise on, 400

Heart depressants, medicine, 355-356

Heat, necessary for germination, 121 ; regulation of body, 415

Heath family, of flowers, 212

Heath hen, 594

Hemiptera, order of insects, 59, 61, 238

Heredity, 604-605; applied to man, $636-640$; bearers of, $626,627-629$; in Andalusian fowls, 622-623; laws of, 620-624; mechanism, 627-628 ; use of knowledge of, 640 ; versus environment, 606-607; what determines, 626-631

Heredity in Relation to Eugenics, Davenport, 638

Hessian fly, 101, 105-106

Hilum, of bean, 117

Hogfish, life history of, 248

Home, care of food, 498-499; care of water supplies in, 500; disposal of wastes, 500 ; improvement of conditions in, 497-500; ventilation of, 497-498

Homoptera, order of insects, 60, 238

Honey, used for food, 536

Honeybee, classification of, 59,238 ; laboratory study of, 58 ; life of, $70-73$; structure of, 58

Hoofed mammals, 269-270

Hooke, Robert, observed cells, 38-39, 657

Hooks, in seed dispersals, 109

Hookworm, life history of, 495 ; prevention of, 496

Hopkins' experiment, on white rats, 330

Hormones, 361, 392

Horse, geologic history of, 273-274

House fly, carrier of diseases, 489-491; foot of, 490

Human body, structure of, 314-315

Human machine, how it works, 313-322

Human welfare, and food making, 162163

Humus, composition of, 139

Hunter, physician, 14-15

Huxley, 657 ; on Darwin's work, 667

Hybridization, method of breeding, 634635 ; practical results of, 624

Hybrids, meaning of, 621 ; proportion in different generations, 621-623

Hydra, reproduction, of, 225 ; structure of, 224-225 ; tentacles of, 224,225

Hydrophobia, treatment for, 480-481

Hygiene, definition of, 34 ; of muscles and bones, 320 ; public, 508 ; school, 510
Hymenoptera, order of insects, 59,60 . 238

Hypocotyl, of bean, 117

Ichneumon fly, 561

Imbibition, 147

Immunity, acquired, 475-476; active, 476-477; antibodies in, 481; Erhlich's work on, 664; establishing active, 479-481; establishing passive, 477-479; natural, 475; meaning of, 474-475; mechanism of active, 481; modified by certain conditions, 475 ; passive, 476-477

Imperfect flowers, 96

Improved plum, developed by Burbank, 671-672

Improvement, of living things by man, $604-640$

Incubation period, of a disease, $472-473$

Indehiscent fruits, seed scattered by, 110-111

Infections, skin, $317-318$

Inheritance, social, 607-608

Inorganic foods, 23,31

Insect, laboratory exercise on, 58 ; parts of an, 58

Insect control, methods of, 565-569

Insect net, how to make, 7-8

Insects, adaptations for carrying pollen, $72,88-90$; beneficial, 568 ; cage for, 10-11; characteristics of, 237 ; collecting, 8-9; commor forms of, 58-61; compared with crustaceans, 237 ; eaten by birds, 547-549; economic importance of, $560-569$; forest and shade tree pests, 569 ; garden and fruit tree pests, $568-569$; harm done by, 562-566; harm done to trees, 565 ; household pests, 568 ; killing of, 8 ; method of controlling, 566-569; mounting, $9-10$; orders of, 59-61, 238; protective resemblances, 79 , 80-82 ; spreading, 9 ; useful, 560-562 ; why so numerous, $80-82$

Inspection, of food supplies, 504, 505 ; of public buildings, 503-504

Inspiration, meaning of, 406-407

Instinctive behaviors, 441-443; modification of, 442-443

Instincts, 442 ; modification of, 442443

Insulin, in treating diabetes, 395

Interrelations, of plants and animals, 57

Interrelationship, of man and other living things, 455-672

Intestinal glands, 377

Intestine, absorption from large, 379 ; absorption from small, 378-379; relation of constipation to large, $379-380$; structure of large, 379 ; structure of small, 376 ; villi in small, 377-378 
Invertebrates, 217,242 ; annulates, 229230: coelenterates, 224-226 ; echinoderms, 226-228; Nemathelminthes, 228 ; Platyhelminthes, 228 ; Porifera, 223-224 ; simpler, 223-231

Irritability, 420 ; in plants, $423,424-425$; in simplest animals, 424-425

Islands of Langerhans, value of, 394-395

Japanese beetle, control of, 567 ; harm done by, 564-565; life history of, 564

Jellyfish, 225, 226

Jenner, Edward, and vaccination, 475$476,659-661$

Jennings, H. S., on genes, 629

Jimson weed, 106-107

Joshua trees, 302

Juke family, history of, 637

Kallikak family, 636, 637

Kidneys, elimination of wastes through, 413-414; laboratory exercise on structure of, $411-412$; structure of, 412413

Kinetic energy, 313

Koch, Robert, work on germ diseases, 662,663

Laboratory, use of, 14-16

Lac insect, value of, 561

Lacteals, 378, 400

Ladybird beetle, 561 ; value of, 567

Langerhans, Islands of, 394-395

Large intestine, absorption from, 379 ; bacteria in, 379 ; relation to constipation, 379-380

Larva, of butterfly, 66-67

Laws, of heredity, 620-624

Leaf, blade of, 151 ; cell structure of, 152-153; demonstration on transpiration of, 163 ; manufacture of carbohydrates in green, 160-161; manufacture of fats in green, 161 ; manufacture of protein in green, 161-162; petiole of, 151 ; stipules of, 152 ; structure of, 151-152; water given off by, 163

Leaf arrangement, cone, 157 ; effect of light on, 156-157; mosaic, 156; rosette, 156

Lamarck, on effect of environment, 607

Leaves, changes in color, 159 ; compound, 152 ; position of, $21-22,156-$ 157 ; used as food, $520-521$

Leeuwenhoek, improved microscope, 38 , 658-659

Legume family, 209-210

Lenticels, 165,168

Lepidoptera, 59, 68, 238

Lichen, 287 ; on rock, 288

Life span, 600

Life zones, 307-308

Light, effect on animals, 40, 293-294; effect on leaf arrangement, 156-157; effect on plants, $40,155-156,293-294$; needed by green plants for making carbohydrates, 157-158

Light stimuli, received by eyes, 427,429

Lily family, 208-209

Linnaeus, system of classification by, 668

Lipase, an enzyme, 374

Lister, Sir Joseph, work on antiseptics, 663

Liver, 368 ; a gland, 361 ; functions of, $375-376$; storage of glycogen, 376

Living things, development of, $617-620$; effect of chemical substances on, 41, 297; effect of food on, 41,297 ; effect of gravity on, 41, 294; effect of light on, 40, 293-294; effect of temperature on, 41-42, 291-293; effect of water on, $40-41,294-297$; functions of, 36-52; improvement of, $604-640$; in relation to their environment, $19-111$; interrelationship with man, $455-672$; relationships and interrelationships of, 177-309; reproduction of, 611-617

Lizards, 257,543

Lobster, catching, 533 ; conservation of 592-593; North American, 236; sense organs of, 428 ; used for food, 533

Locomotion, of amoeba, 218; of Paramecium, 220

Loeb, work on tropisms, 37

Lungs, 403; air in, 407; changes in air in, 404 ; organs of respiration in man, 403-405; pleura, 406

Lymph, 379 ; relation to blood, 389

Lymphatics, system, 378, 400

Lymph glands, 399

Lymph vessels, 399

Lysins, antibodies, 390

Machine, human, 313-322

Malaria, cause of, $482-484$; how transmitted, 484-486

Malarial mosquito, 484; extermination of, 485-486

Malnutrition, cause of, 343

Mammals, carnivores, 269 ; characteristics of, 268-269; classification of higher, 270 ; conservation of, 598-599 ; development of, 619-620; primates, 271 ; rodents, 269 ; ungulates, 269270 ; used for food, $536-537$

Man, a mammal, 276-277; and balance of nature, 288-290; conservation applied to, 599-601; control of environment for health, 455-511; control of environment for wealth, 518569 ; fossils of ancient, 275-276; how become conqueror of world, 420-451; improvement of living things by, $604-640$; interrelationship with living things, $455-672$; laws of heredity 
Man - Continued

applied to, 636-640; place in nature of, 274-277; sense organs in, 430

Mandibles, of beetles, 61

Material, needed by plant for foodmaking, 154-155

Matter, forms of, 24-25 ; meaning of, 19,23 ;

Medfly, 566

Medicine, profession of, 649-650

Mediterranean fruit fly, 566

Medulla oblongata, 429 ; functions of, 433, 434; location of, 433

Medullary rays, 167

Mendel, Gregor, 670-671; work on heredity, 620-624

Mendel, Professor at Yale, work on proteins, 325

Mesoderm, development of, 618 ; systems formed from, 617,618

Metabolism, basal, meaning of, 341

Metamorphosis, 65; of frog, 253; of monarch butterfly, 66,67 ; of silkworm moth, 538-539

Metchnikoff, theory concerning phagocytes, 664

Micropyle, of bean, 117 ; of ovule, 85

Migrants, 550-551; summer residents, 551 ; transients, 551; winter residents, 551

Migration, of birds, 550-551, 595-596; of fishes, 588

Mildews, fungi, 196-197

Milk, and disease, 468; care of, 468469

Millepede, 239

Milling, compared with making of carbohydrates, 160-161

Mimicry, in insects, 81,82

Min eral matter, in living things, 27

Mineral requirement, of body, 331-332

Mineral salts, in soil, 139 ; needed by plants, 140 ; taken in by root hairs, 149

Mint family, 211

Mistletoe, 288

Mitosis, a form of cell division, 48, 49

Modification, of stems, 172-173

Molds, 198-199; effect on food, 199 ; food of, 198-199; growth of, 198; life history of, 199; prevention of, 199

Mollusca, characteristics of, 242 ; classification of, 241

Mollusks, 226 ; as food, 531-533 ; characteristics of, 240,242 ; classification of, 241 ; examples of, $240-241,242$

Monarch butterfly, life history of, 66-68

Monocotyledons, 126,127 ; arum family, 209 ; grass family, 208; lily family, 208-209; orchid family, 209; palm family, 208

Morgan, Thomas Hunt, work on fruit fly, 627-628, 670
Morton, and anaesthesia, 664

Mosquito, malarial, 484-486; yellow fever, 487-488

Moss, life history of, 202-203

Moth, codling, 565; life history of, 237 ; tussock, 565

Mother-of-pearl, value of, 542,543

Moths, classifications of, 59,238 ; compared with butterflies, 68-69

Motion, characteristic of living things, 43

Motor axon, 431

Mouth cavity, 363-367; structure of, 363-364 ; teeth, 365-366

Mucous membrane, in food tube, 363

Muscles, 314 ; relation to bones, 318322

Mussel, life history of fresh-water, 593

Mustard family, 210, 211

Mutants, examples of occurrence, 632633 ; importance in breeding, 633

Mutations, 671

Mycelia, of fungi, 194

Nails, outgrowths of epidermis, 316

National government, and health, 600

Natural immunity, 475

Naturalist, profession, 653

Naturalists, $668-669$

Natural resources, conservation of, 2, 572-601

Natural selection, theory of Darwin, 605

Nature, man's place in, 274-277

Nemathelminthes, characteristics of, 228 ; classification of, 228 ; harmful, $493-496$

Nerve, description of, 431

Nervous system, autonomic, 430 ; central, 430; functions of, 434-435; good health habits of, 447-448; laboratory exercise on, $429-430$; of birds, 264 ; of crayfish, 235 ; of fish, 247 ; of frog, 252 ; parts of, 429

Neuron, associative, 431; description of, 430-431 ; diagram of, 431 ; motor, 431 ; sensory, 431

Neuroptera, order of insects, 238

Nictitating membrane, in frog, 250

Nitrogen, cycle, 187-188, 285; fixation, 188 ; relation of bacteria to free, $187-$ 188

Nitrogen-fixing bacteria, 187-188

Noguchi, 665

Nose, common diseases of, 407-408

Nucleus, in cells, 46, 48; in root hair, 145

Nutrients, 327-328; best proportion in diet, 340-343; calories needed of various, 341; how and where digested, 381 ; meaning of, 30 ; organic, $30-31$; test for in beans, $119-120$; test for oil, 118-119; test for protein, 119; test for starch, 118

Nutrition, processes of, 44-45 
Nutritive ratio, 340

Nuts, how seeds are scattered, 109

Odonata, order of insects, 79, 238

Oil gland, 316,317

Oils, from animals, 541 ; in foods, 31 ; test for, 118-119; useful vegetable, 529

Olfactory cells, 438

Olfactory lobes, in brain, 429,433

One-celled animals, 217-222 ; amoepa, 217-219; Paramecium, 220-222

Operculum, of fish, 243, 245; of sponge, 223

Opsonins, in blood, 388

Optic lobes, in brain, 429,433

Orchard, and other fruits, $527-528$

Orchid family, of flowers, 208, 209

Organ, meaning of, $43,47-48$

Organic nutrients, $30-31$, in bean, $119-$ 120 ; in seeds, 118-120; tests for, 131

Organism, meaning of, 43,222

Organs, and tissues, 47-48; end, 428; of digestion, 368-369; of excretion, 412-413. See Sense organs.

Oriole, Baltimore, 557-558

Orthoptera, order of insects, 59, 60, 238

Osmosis, 147-148; demonstrations showing, 147, 148, 149; physiological importance of, 149-150

Osmotic pressure, 148-149

Ovary, of flower, 83,84

Ovules, in flowers, 83,84

Oxidation, 25-26; of food, 328, 405, 415 ; in our bodies, 124

Oxygen, 24,25 ; cycle, $285-286$; given off by green plants, 164-165; needed by plant, 121, 158; needed in body, 403-405; properties of, 25 ; test for, 25

Oxyhaemoglobin, 387

Owl, 549 ; screech, 558,559

Oysters, as food, 531-532; mollusk, 240-242

Palate, of man, hard and soft, 363-364

Palisade layer, of leaf, 153

Palm family, 208

Palpi, of beetles, 61

Pancreas, a gland, 361; hormone of, $394-395$; position and structure, 373 , 375 ; secretion of, 374 ; work done by, 373-374

Pancreatic juice, digestion done by, 373 , 374 ; enzymes in, 374

Pappus, in seed dispersal, 109

Paramecium, 219-222 ; cilia, 220 ; conjugation of, 221-222; fusion of, 221 ; response to stimuli, 425-426

Parasites, fungi, 194; mistletoe, 228 ; worms, 228, 492-496

Parasitism, 288-289; social, cause of, 637 ; remedy for, $637-638$
Parathyroid, gland, 392

Passenger pigeon, 594-595, 669

Passive immunity, 476-479

Pasteur, Louis, 1-2; life of, 661-663; on bacteria, 181, 479; work on rabies, 480

Pasteur Institute, 662-663

Pasteurization, and bacteria, 459

Patent medicines, bracers, 355 ; curealls, 356-357 ; drugs, 355 ; heart depressants, 355-356

Pathogenic bacteria, 462

Pearls, how obtained, 542-543

Peas, factors necessary for germination, 120-121; Mendel's experiment on heredity in, $621-622$

Pelecypods, 240-241

Pellagra, deficiency disease, 334,335

Pellicle, in Paramecium, 219-220

Pepsin, in gastric juice, 371

Peptone, form of protein, 371-372

Pericardium, of heart, 396

Peristalsis, 370

Pests, insect, 562-566, 568-569; rats, 545-546

Petals, of flower, 83,84

Petri dish, use of, 182

Phagocytes, function of, $387,388,481$; Metchnikoff's theory concerning, 664

Pharynx, of man, 364

Phloem, 168

Phoebe, 555-556

Photosynthesis, $160-161$

Phototropism, 155-158

Phylum, in classification, 177, 178

Physical examination, 510-511

Pigfish, life history of, 248

Pith, 166 ; rays, 167

Pituitary gland, 392 , 393-394

Placenta, function of, 117 ; of bean, 87 Plankton, 295, 530, 587

Plant, cause of growth, 123-124; cell, 46-47; comparison of animal with, 43 ; growth of bean, 136 ; need of mineral matter, 139-140 ; world, how it affects mankind, 177-213

Plant and animal breeding, 670-672; Burbank, 671-672; de Vries, 671; Mendel, 670-671

Planting, selective, 633-634

Plants and animals mutually dependent, 54-96; classification of, 179-213; compared with animals, 43-45; demonstration to show effect of light on, 155 , 158; drug-producing, 529-530; economic values other than food, 528-530; effect of light on, 155-157; effects of surroundings on, 280-309; factors affecting plants, 39-42; how affected by environment, 290-297; mechanism of response in, 424-425; poisonous, 105-107; production of new varieties, 632-635; raw material 
Plants - Continued

needed by, 154-155; relations between animals and, 282-284 ; reproduction of, $83-85,119,201-202,202-$ $203,204,611-616$; responses of, 422423 ; society of, $298-300$; success in life of seed, 100-111; take food from soil, 137-140; used as food, 520-528; why modified, 172-173

Plasma, blood, 383

Platyhelminthes, 228; classification of, 228

Pleura, 406

Pleurococcus, 201

Plumcot, how produced, 671

Plumule, of bean, 117

Pocket garden, $140-141,142$

Poison ivy, 106

Pollen, 83-84; carried by insects, 8890

Pollen grain, development of, 616 ; germination of, 84,86

Pollination, agents causing, 88-90 ; artificial, 634 ; cross, 56,88

Polycotyledons, 126,127

Pons, position of, 432-433

Porifera, characteristics, 223 ; classification, 223

Portal circulation, 378,398

Posture, 320 ; importance of, 321

Potato beetle, 77, 562

Potential energy, 313

Precipitins, antibodies, 390

Preservatives, and bacteria, 459-460; harmful, 460; salt, 459-460 ; sugar, 459

Pressure, blood, 399; osmotic, 148; root, 149 ; sense of, 430

Primary root, 140

Primates, 270

Proboscis, 59

Products, stored, damaged by insects, 565-566

Professions, abilities needed for, 647 ; agriculture, 651-652; forestry, 652 ; health work, 650; medicine, 649650 ; research worker, 653 ; teaching, 651

Progressive development, 665-667

Pronuba moth, pollination of yucca by, 94

Propagation, artificial, of fishes, 591592 ; vegetative, $612-616$

Protection, of birds, 594-597

Protective resemblance, of insects, 80 , 81

Protein requirement, by body, 340

Proteins, 31 ; amount needed daily, 340 ; digestion in man, $369,371-$ 372,374 ; food rich in, 327 ; made by green plants, 161-162; not all good tissue builders, 329-330; test for, 119 ; use of, $329-330$
Protoplasm, characteristics of, 39 ; discoveries of, 657-659

Protozoa, classification, 222 ; habitat of, 217

Protozoan disease, malaria, 483-486; other, 486-487

Protozoans, direct uses of, 542

Pteridophyta, 180 ; classification of, 205 ; ferns, 204-205

Ptomaines, 476

Ptyalin, an enzyme, 365

Public hygiene, 508

Pulmonary circulation, 397-398

Puise, 399

Pulvinus, use to leaf, 424-425

Pupa, of butterfly, 67

Pure culture, of bacteria, 182

Pure Food and Drugs Act, 326, 348349 ; how does it work, 355-357; requirements of, 350

Pus, cause of, 317

Pylorus valve, of stomach, $370-371$

Quarantine, by board of health, 508509; why necessary, 471-473

Quételet's Curve, 632

Rabies, treatment for, 480-481

Rainfall, affected by trees, $574-577$

Ratio, nutritive, 340

Rats, harm done by, 545-546; spread diseases, 491-492

Reactions, to stimuli, 39-42, 422-426

Realms, ecological, 309-310

Receptacle, of flower, 83, 84

Recessive characters, 621, 630-631; extracted, 622

Red blood corpuscles, 387

Redi, work to show how life begins, 657 658

Reduction division, of germ cells, 627 , 630

Reed, Walter, investigator of yellow fever, 487,664

Reflex, arc, 432; conditioned, 443; importance of, 431-432; meaning of, 428 ; nature of, 432

Regeneration, earthworms, 614 ; of flatworm, 612

Rennin, enzyme in gastric juice, 371

Reproduction, 45 ; by budding, 191 , 614 ; by grafting, $613-614$; cell division, 48, 612-613 ; in Paramecium, 221-222; of birds, $618-619$; of crayfish, 235-236; of earthworm, 231 ; of fern, 204-205; of fish, 247-248; of frog, 252-254; of living things, 611-617; of mammals, 619-620; of molds, 199 ; of mosses, 202-203; of plants, 83-88, 615-616; of Spirogyra, 201-202, 615; regeneration, 612,613 , 614 ; sexual, 615-616; vegetative propagation, 613-614 
Reproductive glands, 394

Reptiles, 256-260; characteristics of, 259 ; classification of, 260 ; relation to birds, 266-267

Research worker, profession, 653

Residents, bird, 551

Resources, conservation of natural, $572-601$

Respiration, artificial, 408-409; cell, 405; comparison of frog with man, 403 ; of birds, 263-264; by leaves, 165 ; need of, 44; organs of, 403404

Responses, adaptive, 426 ; conditioned, 443 ; of living things, 37 ; of plants and animals, 422-426

Rickets, deficiency disease, 334-335

Rind, of corn stem, 170

Ringworm, 199

Robin, 552 ; food of, 548-549

Rodents, 269

Root, structure of, 143-144

Root cap, 143, 144

Root hairs, 22, 135-136; function of, 145-146; how take in water, 147-150; laboratory exercise on, 144 ; structure of, 144-145; why absorb water, 149

Roots, factors influencing growth, 140143 ; influence of gravity, 140-141; influence of water on, 141, 143; purposes of, 150 ; use of, $21,22-23$; used as food, 521-522

Rootlets, 140

Root pressure, 149

Root systems, 140-141

Rose family, 209, 210

Ross, Major, investigator of malarial fever, 664

Rotation, of crops, 188-189

Roughage, needed by body, 332

Round worms, 228, 493-494; harmful, 493-496

Russian thistle, dispersal of seeds of, 102,103

Rust, black stem grain, 195-196, 197 ; pine tree blister, 196

Sac fungi, 196-197

Salamander, an amphibian, 254-255

Saliva, function of, 363

Salivary glands, 363 ; parotid, 363 ; sublingual, 363 ; submaxillary, 363

Salmon, as food, 534-535; spawning habits, 588-589

Salt, as a preservative, $459-460$

Sanitation, definition of, 34

Saprophytes, 194

Scallops, mollusk, 240-241 ; used for food, 533

Scarlet fever, and Dick test, 479

Schick test, $478-479$

Schleiden, on cells, 657

School, improvement of conditions,
501-503; lunch and lunch time, 502-

503; surroundings, 501-502

School hygiene, 510

Schwann, on cells, 657

Scurvy, deficiency disease, 333-334

Sebaceous glands, 316,317

Secondary roots, 140

Secretin, 374

Secretion, of glands, 362

Seed dispersal, dehiscent fruits, 109110 ; indehiscent fruits, $110-111$; of fleshy fruits, 108-109; of hard seeds, 109 ; of weeds, $102-103$

Seed plants, why succeed in life, 100111

Seeds, 84 ; dispersal of weed, 102-103; factors necessary for germination, 120-121; germination of, 115-130; location of food supply on different, 125-126; of weed, eaten by birds, 549-550; produced by weeds, 102 ; used as food, 522-526

Seeing, organ of, $440-441$

Segmented worms, 229-231

Segregation, Mendel's law of, 621-622

Selective planting, 633-634

Self-analysis, in selecting a vocation, 646-647

Self-improvement, biology and, 644-654

Sensation, 43

Sense organs, 422 ; demonstration to show types of, 427 ; function of, 427429,435 ; health habits of, 448 ; of birds, 264 ; of man, 430 ; part played in control of body, 435-441

Sensory neuron, 431

Sepals, of flowers, 83,84

Septic sore throat, 470

Serum, blood, 388

Sewage disposal, in community, 505506

Sex, relation to diet, 338

Sexual reproduction, in flowering plants, 615-616; in Spirogyra, 201-202, 615

Shellfish, conservation of, 592-593; life history of, 593

Sieve tubes, 167,168

Silkworm moth, fibers made by, 540 ; life history of, 538-539

Siphonaptera, an order of insects, 238

Skeleton, human, axial, 319 ; appendicular, 319 ; of crayfish, 233

Skin, 314; clothing and the, 318 ; infections, 317-318; laboratory study of, 414 ; organ of excretion, 414-415; structure of, $316-317$

Sleep, necessity of, 447-448

Small intestine, absorption from, 378379 ; digestion in, 374 ; glands in, 377 ; movement of, 370 ; structure of, 376,377 ; villi in, $377-378$

Smallpox, active immunity, 479-480 ; and vaccination, $475-476$ 
Smell, location of, 438 ; olfactory cells, 938

Snakes, feeding habits of, 258-259 . Iocomotion of, 258 ; value of, 543-544

Social inheritance, $607-608$

Social parasitism, cause of, 637 ; remedy for, 637-638

Societies, plants and animals, 298-300

Society, cost of parasitism to, 637

Soil, composition of, 137-139; conditions of, affect life, 297 ; mineral salts in, 139 ; relation to plants, $137-140$; water held in, 139

Sound, character of, 439-440

Sound stimuli, how received, 427-428, 430

Span of life, 600

Sparrow, English, 559, 560, 595; song, $554-555$

Spawning, habits of fishes, 588-589 ; need of conservation during, 589591

Species, 177, 179

Sperm, 617 ; in Vaucheria, 615

Spermatophyta, 180 ; angiosperms, 206213; classification of, 207 ; examples of, 205-213 ; gymnosperms, 205-206

Spiders, 238-239

Spinal cord, 429 ; function of, 433,434

Spines, in seed dispersal, 109

Spiracles, of insects, 58, 63

Spirillum, kind of bacteria, 183

Spirogyra, 201; conjugation of, 201202,615

Split proteins, 462,476

Sponges, economic value of, 542 ; structure of, 223-224

Spongy tissue, of leaf, 153

Spore, of bacteria, 183

Sporophyte, of moss, 203

Sprengel, on adaptation of flowers, 56

Stamen, of flower, 83, 84

Starch, effect of heat and digestion on, 339 ; test for, 118

Starch-making. See Carbohydrates.

Starfish, discussed, 226-228; harm done by, 544-545

Statocysts, in shrimps, 428-429

Stem, dicotyledonous, 166-169; growth in, 167 ; modified, 172-173; monocotyledonous, $169-170$; rise of water in, 170-171; used as food, 520-521

Sterilization, and bacteria, 458

Stigma, of flower, 83, 84

Stimulants, effect on body, 350-351

Stimuli, how simple animals receive, 422 , 425-426; how simple plants receive, 422, 424-425; light, 427, 429 ; meaning of, 37; Paramecium responds to, 425-426; pressure, 430 ; reaction of living things to, 39-42; sound, 427428,430 ; touch, 427,428

Stomach, digestion of food in, 369-372
Stomata, 152-153

Storage, cold, 458 ; of food, in plants, $171-172$

Stored products, insects harmful to, 565-566

Struggle, for existence, 111

Sturgeon, 534, 590

Style, of flower, 83,84

Succession, ecological, 300-305

Sugar, as a preservative, 459 ; storage in liver, 375-376; test for grape, 128129

Sun, source of energy, 157

Sunlight, necessary for carbohydrate making, 157-158, 160-161

Survey, value of city, 14

Swallow, barn, 556 ; food of, 548

Sweat glands, 316,317 ; function of, 415

Swim bladder, of fish, 246

Swimmerets, of crayfish, 233

Symbiosis, 287-288

Synapse, 431

System, circulatory, 395-401; digestive, 367-369; excretory, 412-415; nervous, 429-435

Systemic circulation, 397

Tadpole, 252-253, 254

Tapeworm, 228, 493; harm done by, 545 ; in bass, 493

Taste, buds, 437 ; location of, $437-438$

Taxonomy, 178

Tea, a stimulant, $350-351$

Teaching, profession of, 651

Teeth, care of, 366-367; effect of decay. $365-366$; kinds, 365 ; number of, 365 ; structure of, 365,366

Teleosteans, bony fish, 247-248

Temperature, 291-293; effect on plants and animals, 41-42

Tentacles, of hydra, 224, 225

Tertiary roots, 140

Testa, seed coat, 117

Tetanus, cause of, 470

Thallophyta, 180 ; bacteria, 181 ; classification of, 200; fungi, 193-197; molds, 198-199; yeasts, 190-193

Thoracic dust, 399

Thorax, of insects, 58, 62, 237

Throat, common diseases of, 407-408; septic sore, 470

Thrombus, in blood, 388-389

Thymus gland, 394

Thyroid gland, 392,393

Tissue building, $328-329$

Tissues, $47-48$

Toad, an amphibian, 254; usefulness of, 543

Toadstools, 193-194

Tobacco, use of, 354

Tonsils, enlarged, 408

Touch, how stimuli received, 427,428 ; organ of, lobster, 428 
Tourniquet, how to use, 401-402

'Toxin, formed by bacteria, 462

Toxin-antitoxin treatment, 478

Trachea, of man, 364 ; of insects, 63

Trades, abilities needed for, 648

Traits, inherited, 638-639

Transfusion, of blood, 391

Transients, bird, 551

Transpiration, factors in, 164

Trees, cause of growth, 31 ; city's need of, 586 ; injured by insects, 565 ; materials found in, 28, 29; position of leaves, 21-22; prevent erosion, 574 ; repair of, $586-587$; skeleton, 21,22 ; uses of wood, 577-578; values of, $574-$ 579

Tree surgery, 586-587

Trial and error, method of response, 425426

Triangle, factors in life, 608

Trichina, 494; harm done by, 545 ; life history of, 494

Trichocysts, of Paramecium, 220

Trichoptera, order of insects, 238

Tropisms, 420, 423; meaning of, 37 ; value of, 42

Trypanosomes, diseases caused by, 486487

Trypsin, an enzyme, 374

Tsetse fly, diseases carried by, 486-487

Tuberculosis, and Koch, 662, 663; care of persons having, $509-510$; cause of, 465-466; effect of, 464-465

Tumbleweed, dispersal of seeds of, 102, 103

Turtle, adaptations of, 256-257

Tussock moth, 565

Tympanum, in frog, 250

Tyndall, John, apparatus and experiment to disprove spontaneous generation, 658

Typhoid fever, carriers of, 469 ; cause of, 467 ; Widal test for, $390-391$

Ungulates, 269-270

Unit characters, 621

Urea, 413

Urine, excreted by kidneys, 413

Useful bacteria, 183-189

Vaccination, against smallpox, 475-476, 479-480; against typhoid fever, 481 ; and Jenner, 659-661 ; to acquire immunity, 475-476

Vacuole, of amoeba, 218-219; of Paramecium, 220

Van Leeuwenhoek, 38, 658-659

Variation, continuous, 632 ; Darwin on, 605 ; discontinuous, $632-633$; meaning of, 605 ; types of, $632-633$

Varieties, production of, new animal, 632-635; new plant, 632-635

Vaucheria, reproduction of, 615,616
Vegetables, used as food, 526-527; uses of fibers of, 529 ; uses of oils of, 529

Vegetation areas, in United States, 306

Vegetative propagation, $612-616$; budding, 614 ; grafting, 613-614 ; regeneration, 612,614

Veins, 395 ; structure of, 398 ; valves of, 399

Venae cavae, 398

Ventilation, methods of, 410 ; need of, 410; of bedroom, 411, 497-498

Ventricles. See Heart.

Vertebrates, 242; groups of, 243

Vessels, blood, 395, 398; lymph, 399

Villi, 377-378; where found, 149-150

Virginia creeper, 106

Virus, filterable, $479-480$

Vitality, of weeds, 103-104

Vitamins, 31,330 ; diseases caused by deficiency of, 334 ; list of foods containing, 336-337; names of, 333; sources of, $333-335,336-337$; use to body, 333-335

Vocation, biology prepared for, 649-654 ; choosing a, 646-648

Wallace, A. R., on progressive development, 667

Warbler, 559 ; yellow, 555

Wasp, 60 ; life history of solitary, 69

Waste disposal, in community, 505-507 ; in home, 500

Water, 294-297; absorbed by root hairs, 149 ; cause of rise in stem, 170171 ; composition of sea, $20-21$; demonstration on electrolysis of, 24-25 ; effect on plants, 39-40; evaporation from plant, 164 ; given off by leaf, 163 ; held by soil, 139 ; in living things, 27 ; necessary for germination, 120-121; value to body, 330-331 ;

Water supplies, and diseases, 467 ; in home, 500 ; regulated by trees, 574577

Wealth, man controls environment for, 518-569

Weeds, eradication of, 108; harmful, 105; methods of protection, 104; place of growth, 105 ; poisonous, 106107; seed dispersal of, 102-103; seeds of, eaten by birds, 549-550; useful, 107; vitality of, 103-104; what are, 101-102

Weissman, August, work on germ cells, 670

Wheat, rust, $101,105,195-196,197$; mutant, 633 ; uses, 525-526

White corpuscles, $387-388$

Widal test, for typhoid fever, 390-391

Willow, girdled twig of, 168 ; family, 211212

Windpipe, of man, 364

Winged seeds, 110 
Wood, of dicotyledonous stem, 166, 167 ; Yeast, 190-193; and bread making, 191uses of, 577-578

Woodpecker, downy, 557

Work, relation to diet, 335

World, how man has become conqueror, 420-451

Worms, 228-231

Wren, house, 554

Xerophthalmia, deficiency disease, 333, 334

Xylem, 167 192; commercial, 191; conditions favorable for growth of, 190 ; importance of, 192-193; life history of, 191

Yellow fever, discovery of cause, 487488; how spread, 487

Yucca, 93; pollination of, 94

Zones, life, 307-308

Zygospore, 615: of Spirogyra, 202

Zygote, how formed, 616

Zymase, an enzyme, 191 
、 


